\title{
LA FLANDRE
}

ETUDE GÉOGRAPHIQUE

DE IAA

\section{PLAINE FLAMANDE \\ EN FRANCE, BELGIQUE ET HOLLANDE}

Thèse prẻsentée à la Faculté des Lettres de l'Université de Lil e

RaOvl BLANCHARD

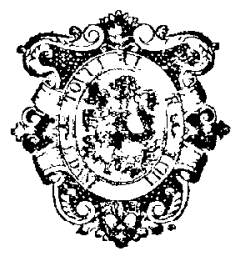

LILLE，

IUPRIMERIE L. DANEL

$1 \overline{906 .}$

Tous dro reserves 
IRIS - LILLIAD - Université Lille 1 


\section{LA FLANDRE}


IRIS - LILLIAD - Université Lille 1 


\section{A Messieurs \\ Paul VIDAL DE LA BLAGHE}

ET

\section{LUGIEN GALLOIS}

MES MATTRES A L'EGOLE NORMAIF SUTF́RTEURE

Hommage respectueux. 
IRIS - LILLIAD - Université Lille 1 


\section{LA FLANDRE}

ÉTUDE GÉOGRAPHIQUE

DE LA

\section{PLAINE FLAMANDE EN FRANCE, BELGIQUE ET HOLLANDE}

Thèse présentée à la Faculté des Lettres de l'Université de Lille

PAR

RAOUL BLANCHARD

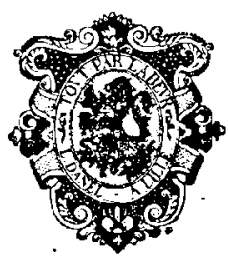

LILLE, IMPRIMERIE L. DANEL.

$1 \overline{906}$.

Tous droits réservês 
IRIS - LILLIAD - Université Lille 1 


\section{AVANT-PROPOS}

L'étude géographique de la plaine flamande n'avait jamais été tentée jusqu'ici; on en restait aux descriptions de Guichardin (XVI ${ }^{e}$ siècle) et de Sanderus (XVII ${ }^{e}$ siècle). Les travaux géographiques de détail étaient rares. L'entreprise était donc considérable. Résoudre toutes les questions de géographie physique et éclaircir tous les problèmes de géographie humaine en̂t exigé une application et des délais excessifs. On s'est donc borné, au cours de la description physique du pays, à indiquer les difficultés et à exposer les solutions provisoires, pour faire porter tout l'effort sur les rapports entre la terre et l'homme. Mais dans cette partie mème du travail, il ne faut pas se dissimuler qu'il reste beaucoup à faire, et qu'en particulier l'étude détaillée des documents d'archives pourra modifier bien des solutions.

Si le travail est imparfait, ce n'est pas cependant que les appuis lui aient manqué. Exécuté à Lille, la bienveillance de M. le Recteur de l'Académie et de l'Université de Lille no s'est pas démentie un instant à son égard. Le Conseil général du département, la Société de Géographie de Lille, la Société des Amis de l'Université, ont bien voulu l'aider de leur's subsides. La Société Dunkerquoise pour l'encouragement des Lettres, des Sciences et des Arts, a assumé les frais de l'impression. Des particuliers ont tenu à contribuer à l'apparition d'un travail 
VIII

qui intéresse leur pays: $\mathrm{M}^{\text {me }}$ Auguste Mahieu, d'Armentières, MM. Félix Coquelle, de Dunkerque, Léonard Danel, AgacheKuhlmann. Ach. Ledieu-Dupaix, de Iille, Albert Deville, de Douai, ont généreusement souscrit en sa faveur.

En remerciant de nouveau ces donateurs, qui ont voulu, par leur bienveillante intervention. marquer plus nettement le caractère régional de l'étude, l'auteur ne saurait oublier les services que lui ont rendus M. Ch. Barrois, membre de l'Institut, el ses amis personnels, MM. Ardaillon, recteur de l'Académie de Besançon, le docteur G. Iuriau, de Dunkerque, Paul Carpentier, avocat à Lille, et Ch. Petit-Dutaillis, professeur à L'Université, qui ont mis à sa disposition toute leur influence et leur activité. Il ne peut non plus négliger d'exprimer sa gratitude, pour la part qu'ils ont prise à l'illustration de son livre, à MM. Parenty, Directeur des Tabacs, à I ille, Cuvellier, à Dunkerque, R. Mancel, à Iille. 
IRIS - LILLIAD - Université Lille 1 


\section{ABRÉVIATIONS BIBLIOGRAPHIQUES}

Act. SS. Belg. - Ghesquière, Acta sanctorum Belgiae.

Act. SS. Boll. - Bollandistes.

Anc. Mem. Ac: Brux. - Anciens mémoires de l'Académie de Bruxelles.

Ann. Ac. Arch. Belg. - Annales de l'Académie d'A rchéologie de Belgique, Anvers.

Ann. C. A. P. Waes. - Annales du Cercle archéologique du pays de Waes.

Ann. Com. fl. Fr. - Annales du Comité flamand de France.

Ann. E. N. - Annales de l'Est et du Nord.

Ann. Géog. - Annales de Géographie.

Ann. P.C. - Annales des Ponts-et-Chaussées.

Ann. S. H. Ypres. - Annales de la Société historique d'Ypres.

Ann. Soc. Arch. Brux. - Annales de la Société d'archéologie de Bruxelles.

Ann. Soc. Em. Br. - Annales de la Société d'Émulation pour l'étude de l'histoire et des antiquités de la Filudre Occidentale, Bruges.

Ann. Soc. Geol. Belg. - Annales de la Société géologique de Belgique, Liège.

Ann. Soc. Géol. N. - Annales de la Société géologique du Nord.

Ann. Soc. mal. Belg. - Annales de la Société malacologique de Belgique.

Ann. Tr. p. Belg. - Annales des Travaux publics de Belgique.

Bull. Ac. R. Belg. - Bulletin de l'Académie royale de Belgique.

Bull. C.C. St. - Bulletin de la Commission centrale de Statistique de Belgique.

Bull. Com. fl. Fr. - Bulletin du Comité flamand de France.

Bull. Comm. H. N. - Bulletin de la Commission historique du Nord, Lille.

Bull. Sc. Hist. Litt. N. - Bulletin scientifique, historique et littéraire du département du Nord.

Bull. Sac. Anthr. Brux. - Bulletin de la Société d'Anthropologie de Bruxelles.

Bull. Soc. belge Géog. - Bnlletin de la Société belge de Géographie, Bruxelles.

Bull. Soc. belge Géol. - Bulletin de la Société belge de Géologie, Paléontologie et Hydrologie.

La Fl. - La Flandre, Revue des monuments, d'histoire et d'antiquitẻ.

Mém. C. Ac. R. Belg. - Mémoires couronnés publiés par I'Académie royale de Belgique.

Mém. Soc. Ac. Boul. - Mémoires de la Société académique de Boulogne-sur-mer.

Mém. Soc. Ant. Mor. - Mémoires de la Société des Antiquaires de la Morinie.

Mém. Soc. Dunk. - Mémoires de la Société Dunkerquoise pour l'avancement des lettres, des sciences et des arts.

Mém. Soc. Sc. Lille. - Mémoires de la Société des sciences de Lille.

Mess. Sc. Hist. - Messager des sciences historiques, Gand.

M. G. SS. - Monumenta Germaniae, Scriptores.

Rev. gén. agr. L. - Revue générale agronomique, Louvain. 


\section{LA \\ PLAINE FLAMANDE}

CHAPITRE I

LA FLANDRE, RÉGION NATURELLE

I. La Flandre d'après l'histoire. - II. Défnition géographique de la Plaine flamande.

I.

LA FLANDRE D'APRÈS L'HISTOIRE.

Extension exagerée du nom de Flandre. - Le nom de Flandre, qui apparaît au VII $^{\ominus}$ siècle ${ }^{1}$ pour désigner un étroit territoire entre Bruges et la mer, a eu une singulière fortune. D'abord restreint aux modestes limites des doyennés de Bruges, Oudenbourg et Aardenburg 2, et distinct du Mempiscus, qui désigne le reste de la Flandre actuelle, il s'étend au IX ${ }^{\circledR}$ siècle à tout le pays situé entre l'Escaut et la mer, franchit le fleuve au XI $\mathrm{XI}^{\mathrm{e}}$ en annexant la partie occidentale du Brabant, gagne vers le Sud et l'Ouest aux dépens des petits pagi d'entre

1 Dans la vie de St Eloi, par St Ouen (Act. SS. Belg., III) : * Flandrenses atque Andoverpenses, Frisiones et Suevi, et barbari quique circa maris littora degentes 》 (p. 231) et: « multum praeterea in Flandris laboravit » (p. 238).

2 Cf: Vanderkindere, Histoire de la formation territoriale des principautés belges au moyen-âge, t. I : la Flandre ( $2^{\circ}$ éd.), pp. 36-37; - Meyer, Commentarii sive Annales rerum Flandricarum (Antverpiae, Steelfius, 1561) : " Flandrensem metropolim ea tempestate (celui de St Eloi) Rodenburgum (Aardenburg) fuisse existimo. Maritimam oram eo tractu Flandras id seculum appellabat...) (p. 5); - a Pagus autem Flandrensis dictus est, quatenus aestus incurrebat marinus ; reliqua pagi erant Mempisci »(p. 6) ; - Quisquis oculatius scrutatur vetustatem facile deprehendit Pagum olim Flandrensem 
Lys et Scarpe, et sa fortune participe à la brillante destinée des comtes de la maison d'Alsace. L'admirable prospérité du comté au moyen-âge, la vitalité qu'il affirme dans la lutte contre les rois, consacrent définitivement la fortune du vocable, et le glorieux nom de Flandre désigne bientôt dans le royaume, aux dépens des termes plus modestes d'Artois et de Hainaut, toutes les riches contrées qui s'étendent au Nord de la Picardie. L'incertitudo des limites naturelles, les innombrables remaniements de frontières qui se succèdent du $\mathrm{XVI}^{\mathrm{e}}$ au XVIII ${ }^{\mathrm{e}}$ siècles augmentent la confusion, que complique encore, au XIX ${ }^{\circ}$ siècle, la création de nouvelles unités administratives ; et de nos jours l'on continue à appeler volontiers les Flandres toute la région française du Nord, l'Artois compris. Cette incertitude et ces erreurs sur l'étendue véritable de la Flandre peuvent faire douter qu'il existe une région naturelle flamande, c'est-ád-dire un pays assez distinct de tous ceux qui l'entourent pour former une unité physique et politique.

Une Flandre ou des Flandres? - La confusion est augmentée encore par l'emploi fréquent du pluriel Flandres. On dit couramment les Flandres pour la Flandre, et dans le monde savant plus que dans le peuple. En usant de ce pluriel peut-être veut-on confusément exprimer que la Flandre n'est qu'une juxtaposition de petites régions sans unité, artificiellement rassemblées par un fragile lien politique ${ }^{1}$. Mais que l'on examine les origines de ce pluriel, et l'on verra que les nombreuses raisons qui ont fait distinguer de loul temps en Flandre plusieurs Flandres ne sont pas d'ordre géographique et n'empêchent pas de considérer le pays flamand comme une région iaturelle. Sans doute le nom même de Flandre, « de Vlaanderen », est un pluriel ${ }^{2}$.

nusquarn ultra aestuaria se extendisse ; quaeque extra aestuaria sunt in Mempisco fuisse sità \$ (p. 11/1). - De même Boretius, Capitulaires $(I$, p. 301) : "In Flandris et in Mempisco (821). - Le Capitulaire de Servais indique qu'à có té du premier comte Baudouin Brasde-F $F_{\ni r}$, il $\mathbf{y}$ avait en 853 d'autres fonctionnaires royaux dans le Mempisc, les pays de Gand et de Courtrai (Vanderkindere, Le Capitulaire de Servais. Gommission Royale d'Histoire de Belgique, $5^{\circ}$ sórie, VII, 1897, pp. 91-138). - Au XI siècle encore, il arrive qu'on distingue les « Flamands 》 des hormes du Mempisc, du Waes, et des autres habilants du comté de Flandre : "Maxime autem in Flandriis ułi cum Menapenses, Wasiacenses et ipsos Flandrenses sanctus Ursmarus convertisset D (Miracula S. Ursmari, M. G. SS. XV, p. 838).

1 G'est ce que dit formellement Michelet: « Ce nom, les Flandres, n'exprime pas un peuple, mais une réunion de pays fort divers, une collection de tribus et de villes. Rien n'est moins homogène s. (Histoire de France, éd. de 1837, 1. III, pp. 45-46).

2 Sur les origines du nom de Flandre, voyez Kern, Revue Celique, II, p. 174; Kurth (G.), La frontière linguistique en Belgique et dans le Nord de la France, (I, pp. 522-523); - Jonckheere (D.), De l'origine du nom de lilandre (Revue Catholique, tome 53,1882 , pp. $535,615,700$; tome 54, 1883, pp. 13, 139);-Vanderkindere, Formation territoriale, (2e éd., I, pp. 35-36 et p. 44);-Gilliodts yan Soveren (L.), Inventaire des 
Pourtant il ne s'agissait guère, à l'origine du nom, de désigner plusieurs régions artificiellement réunies ; rien n'était plus simple que ce petit territoire situé au Nord et à l'Ouest de Bruges, cette étroite marche de défense contre les Normands ; mais le mot était employé au pluriel soit qu’il vînt du latin Planaria et indiquât les vastes terres plates de la région poldérienne, soit plutôt qu'il fût à la fois le nom du pays et celui des habitants et désignât la terre des fugitifs. C'est du flamand, et par habitude, que le pluriel passa à l'équivalent latin, s'étendit au comté tout entier, et fit employer jusqu'au XIII ${ }^{\natural}$ siècle les termes de « Flandriae » et de «Comes Flandriarum ${ }^{1}$. Vinrent ensuite des motifs de distinguer plusieurs Flandres, Iorsque les comtes agrandirent leurs domaines de terres qui appartenaient à l'Empire; et l'on eut à côté du comté proprement dit, placé sous la suzeraineté française, une Flandre impériale, dépendant de l'Empereur, et comprenant les Quatre-Métiers ${ }^{2}$, le pays de Waes, le comté d'Alost et la ville de Grammont. Dans la partie relevant de la France, on ne manquait jamais non plus de faire la différence entre pays de langue française et pays de dialecte germanique, Flandre wallonne et Flandre flamingante. Même la partie flamingante comportait encore deux divisions: d'un côté l'Ost-Flandre, le pays de Crand ; de l'autre le West-quartier ${ }^{3}$; distinction qui correspondait à peu près aux deux grandes circonscriptions ecclésiastiques : à l'Ouest l'évêché de Térouanne s'étendant jusqu'à l'Yser, à l'Est l'évêché de Tournai. Toutes ces distinctions de suzeraineté, de langue, de pouvoirs temporels et spirituels, se compliquèrent encore à partir du XVII ${ }^{\ominus}$ siècle, lorsque la Flandre fut partagée entre trois puissances. Les Hollandais annexèrent le Nord, qui fut dès lors connu sous les noms de Flandre des Etats, ou Flandre zélan-

archives de Bruges (Bruges, 1876, 6 vol.), volume d'Introduction, pp. 245-246 ; - Vercouillie (J.), L'Etymologie de Vlaming et de Vlaanderen (Bull. Ac. R. Belg., Classe Lettres, 1903, pp. 484-491). L'étymologie Planaria, proposée par M. Jonckheere et acceptée par M. Kurth, paraît douteuse; la forme «Vollandèn ", terres de comblement, donnée par M. Gilliodts, semble devoir être écartée. La solution la plus séduisante est celle de Kern, complétée par M. Vercouillie: Ylaanderen vient de Vlame et du suffixe der, qui dans les langues germaniques donne des noms d'agent. Vlaander est donc synonyme de Vlaming, et il a la forme du pluriel comme l'ont des noms de pays qui sont en même temps noms de peuples, tels Polen, Beieren. Vlame est une forme frisonne de Vloome, dérivè du verbe vlieden, et signifie fugitif, exilé : épithète qui s'appliquait bien aux populations frisonnes établies dans la région de Bruges, puisque les pays frisons ne dépassent guère la Zélande au Sud.

1 Cf. Pirenne (HI.), Histoire de Belgique, I, p. 45, note 1.

2 Hulst, Axel, Assenede, Bouchaute et leurs dépendances.

3 Cf. Diegerick (I.), La West-Flandre (Ann. S. H. Ypres, t. I, 1863, pp. 13-32, carle). 
daise; la plus grande partie du comté, restée à l'Espagne, fut la Flandre espagnole, plus tard autrichienne; le Sud devint français. Même dans ce territoire assez restreint de la Flandre française, le pluriel parvint à se glisser encore, car le gouvernement de Louis XIV fit de sa conquête deux petites provinces : la Flandre wallonne au Sud de la Lys, avec Lille, Douai et Orchies; la Flandre maritime ou « du côté de la mer », entre la Lys et la côte. Cette distinction disparue avec la Révolution, une autre naquit dans la Flandre autrichienne, divisée par la République en départements de la Lys et de l'Escaut, dont le gouvernement hollandais fit en 1815 les deux provinces de Flandre Orientale et Occidentale. Ainsi de nos jours encore il existe quatre Flandres : Française, Hollandaise, Orientale et Occidentale ; et c'est de cette division arbitraire, due au hasard des conquêtes, que vient la survivance du pluriel; sans compter la confusion fréquente entre Flandre et pays de langue flamande, qui fait parfois appeler Flandres, ou -région flamande, toutes les provinces germaniques de la Belgique.

L'unité attestée par l'histoire. - Rien n'autorise donc à nier l'unité géographique de la Flandre dans ces distinctions de Flandres impériale, hollandaise, française, wallonne, flamingante, dues à la situation du pays dans une contrée ouverte et riche, facile à l'invasion, au contact de deux idiomes et de deux races refluant sans cesse l'une sur l'autre. L'histoire de Flandre, au contraire, à laquelle ces dénominations pourtant sont dues, semble prouver d'un bout à l'autre l'existence d'une Flandre homogène, durable et puissante. Ces luttes de ville à ville, Gand contre Bruges, Ypres contre Gand, qui ont frappé les historiens et leur ont inspiré des doutes sur l'unité du pays, étaient fatales au moyen-âge entre concurrentes ayant les mêmes besoins et les mêmes intérêts, dès lors jalouses et rivaless; les mêmes phénomènes se retrouvent à la même époque dans les puissantes cités italiennes, et pourtant personne ne nie l'originalité géographique de la Lombardie ou de la Toscane. Quant à la durée, rares sont les provinces françaises qui ont eu si longtemps une existence distincte; pendant huit siècles, du milieu du IX à la fin du XVI $\mathrm{XI}^{\mathrm{e}}$, la Flandre est restée elle-même, et elle n'a commencé d'abdiquer sa personnalité que dans la gloire de donner, en la personne du Gantois CharlesQuint, un maître à l'Europe. Seule en France elle avait acquis dès le XII ${ }^{\circ}$ et retrouvé aux $\mathrm{XIII}^{\mathrm{e}}$ et $\mathrm{XV}^{\mathrm{e}}$ siècles une puissance et une richesse incomparałles. Elle est encore la seule province qui ne se soit jamais laissée enserrer dans les mailles du domaine royal, malgré les tentatives d'un Philippe-Auguste, d'un Philippe le Bel, d'un Louis XI, et qui ait affirmé de siècle en siècle, à Courtrai, Cassel, Roosebeke et Gavere, son autono- 
mie à l'encontre des rois et des comtes dę sang étranger. Sa personnalité s'est révélóe à certaines époques jusque dans une littérature et un art originaux. Il y eut en Flandre au XV $\mathrm{V}^{\mathbf{a}}$ siècle une floraison d'écrivains et d'érudits qui a peut-être contribué largement à lił renaissance de l'humanisme en France, et surtout un art bien flamand, qui exprime la tranquille nature du pays, introduit le réalisme flamand dans la convention des sujets sacrés, élève des monuments adaptés aux goûts et aux besoins des bourgeois de Flandre. Cotte originalité intellectuelle, cette indépendance si farouchement défendue et conservée, cette puissance et cette durée, ce sont là des traits qui semblent l'expression d'un pays homogène, conscient de son unité ; la présence d'une forte individualité historique est au moins une présomption que cet organisme politique s'est développé dans une région naturelle différenciée. S'il est vrai que les régions naturelles «sont celles qui conservent la plus longue durée, dans l'histoire, celles qui sont aptes à atteindre le plus grand développement matériel et la plus grande force $\gg^{1}$, la Flandre est bien une de ces unités privilégiées.

Incertitude des limites historiques. - Il est vrai que si l'histoire atteste qu'il y eut une Flandre, elle ne nous en donne guère les limites. Rien de plus variable que ces frontières politiques du comtẻ. Au $\mathrm{X}^{\mathrm{e}}$ siècle, nous le trouvons étendu du Zwin à la Canche; Arras en est la capitale, et les pays romans y tiennent presque autant de place que les contrées germaniques. Au $\mathrm{XI}^{e}$, le comte Baudouin de Lille annexe les Quatre-Métiers et le pays de Waes, franchit l'Escau tet étend ses domaines jusqu'au delả de la Dendre. La Zélande lui appartient, et le protectorat du Hainaut; Cambrai tombe entre les mains des Flamands. Puis le reflux se dessine; Philippe-Auguste met la main sur l'Artois et refoule la Flandre au delà de Tournai; la Zélande échappe au protectorat, et la Flaudre ne sauve sa liberté en 1302 qu'en abandonnant la partie wallonne à la France. Même l'extrémité occidentale du West-quartier, désagrégée en douaires et apanages, semble se détacher du comté. Cependant l'expansion recommence; la politique des ducs de Bourgogne récupére la Flandre wallonne; Philippe le Bon et Charles le 'Téméraire portent leur frontière bien au delà de la Canche, et l'on bataille deux siècles encore pour la possession de l'Artois. Si les frontières politiques de la Flandre ont été de bonne heure fixées au Nord et à l'Fst, on peut dire que vers le Sud-Ouest le pays n'a jamais eu de limites historiques. L'histoire nous a bien révélé l'énergique vitalité de la petite patrie flamande, qui s'affirme encore aujourd'hui dans les mœur's, les sentiments

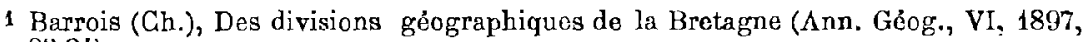
pp. 23-24). 
religieux et les idées politiques des Flamands de France, de Belgique et de Jollande; mais elle n'a pu ni en définir les caractères géographiques, ni en fixer les limites.

\section{II.}

DÉFINITION GÉOGRAPHIQUE DE LA PLAINE FLAMANDE.

Quelle étendue comprend donc cette région flamande, où est née une puissance politique si vigoureuse qu'elle a sonvent débordé hors des limites géographiques du pays? Qu'est-ce que la Flandre, entendue non plus au sens historique de pays soumis a la domination des comtes, mais de Plaine flamande, région naturelle distincte?

Caractères géographiques de la Plaine flamande. - La Flandre, par opposition avec les pays voisins, c'est le pays bas, c'est le pays plat, c'est le pays humide. Pays bas : tandis que le Brabant à l'Est, les plateaux picards et artésiens à l'Ouest se tiennent à des altitudes d'environ 100 mètres, la plaine flamande dans son ensemble reste à la hauteur médiocre de 20 mètres, et la région maritime, étendue tout au long des côtes, est á peine au niveau des hautes mers. Pays plat: la plaine maritime, sauf les dunes de la côte, n'a pas une éminence qui dépasse trois mètres; et si l'intérieur de la Flandre est tout parsemé de monticules, de buttes de sable et d'argile, il n'y a là rien des vallées profondes creusées dans la craie de l'Artois ou dans les sables du Brabant. Pays humide: le sous-sol, et presque toujours le sol, sont imperméables; l'eau qui tombe fréquemment des nuages reste à la surface, s'ćcoule lentement, ou reste à une faible profondeur.

Ces caractères fondamentaux donnent à la région flamande d'autres traits non moins originaux. L'absence de pente, l'imperméabilitẻ du sol, donnent naissance à un réseau très chevelu de cours d'eau, rivières et ruisseaux coulant lentement, tantôt indigents, tantôt gonflés et débordant sur leur vallée plate; la Flandre est le pays de l'eau stagnante, des mares, des marécages, des rivières incertaines de leur pente. L'humidité assure l'existence d'une végétation abondante, plantes arborescentes et herbacées; les prairies naturelles sont nombrouses, les arbres sont partout, alignés autour des champs et pressés derrière les fermes; leurs rangées limitent l'horizon de ces terres plates, qu'on croirait immense. L'abondance de l'eau, amassée en nappes peu profondes, pẹmet à la nombreuse 
population de disséminer ses habitations à travers tout le territoire; la maison isolée est la régle. Pays de plaines basses où les buttes ne font que rendre plus sensible l'horizontalité et la faible altitude du sol ; pays des eaux lentes salies par le sol glaiseux, ou par.l'utilisation industrielle, pays des herbes et des arbres, des maisons innombrables dispersées sur tous les points, telle se présente la Flandre.

Límitos-vers 1'Ouest. - La contrée dont ces traits caractéristiques font une région naturelle ne correspond pas exactement à celle qu'on est accoutamé de prendre pour la Flandre historique; ses limites tantôt dépassent les frontiéres politiques de la Flaudre, et tantôt restent en deçà. Si les données géographiques sont d'accord avec l'histoire pour considérer comme le cceur de la Flandre le pays qui s'étond entre la mer du Nord et la ligne fluviale de l'Aa (Gravelines à Arques), de la Lys (Aire à Menin)', de l'Escaut (Audenarde à Anvers), la plaine flamande dépasse, du côtè de l'Ouest, la frontière politique de la Flandre ; elle déborde au delà de l'Áa et do la Lys sur dos territoires qui faisaient partie de l'Artois.

Les terres basses du Calaisis, triangle dont la côle, l'Aa inférieur et lo haut pays du Boulonnais forment les trois côtés, ne sont que la continuation de la plaine maritime qui longe toute la côte de Flandre depuis l'Escaut jusqu’à Gravelines, et s'étend bien au delá, en Hollande, en Allemagne et en Danemark; mêmes origines géologiques, même sol, mêmes productions ; c'est la continuité complète, car le lit changeant de l'Aa n'a jamais été une limite naturelle, pas mêmo une frontièro linguistique. Détachée de la région flamande et incorporée à l'Artois, cette petite contrée y conservait un caractère particulariste ; elle formait comme trois petites républiques, distinctes du reste de la province, et dont les couturnes dérivaient de celles du Franc de Bruges ; e'était une Flandre en Artois ${ }^{1}$. Au contraire, la limite géographique est particulièrement nette entre le Calaisis et le haut pays qui le domine au Sud: différences de sol, d'altitude, de productions, rien n'y manque. Les hautes croupes rondes de la craie, anx pontes nues parfois couronnées d'arbres, dominent de 100 d 150 mètres les terres à demi noyées du bas pays, et los tourbières viennent se terminer au pied des plateaux secs où se tint lo camp du Drap d'Or '. En haut, l'agriculture est arriórée, le climat rude,

1 Marck, en Calaisis, était chef-sens de Calais; Bourbourg, chef-sens de Marck, et la coutume de Bourbourg dérivait de celle du Franc de Bruges. Cf : Courtois, Lettre sur le Hoop (Bull. Com. Al. Fr., II, pp. 325-330); - Chavanon (F.), Gharte de coutume de Marck (Mém. Soc. Ac. Boul., XIX, 1903, pp. 429452).

2 Voir phot. 1. 
la population clairsemée; en bas, à la faveur d'une température que l'écran des hauteurs rend plus douce ${ }^{1}$, et profitant d'une terre fertile à souhait, on voit régner les cultures savantes, assurant le bien-être a une population nombreuse et dispersée. Nulle part la plaine flamande ne possède des limites aussi précises qu'au long de ce territoire devenu une dépendance politique de l'Artois.

La distinction est encore facile à faire au delà du Calaisis. Du côté flamand, la colline boisée d'Eperlecques, les terres basses des marais de St-Omer, les vertes ondulations argileuses qui bordent la vallée de Neuffossé, s'opposent aux pentes de guérets nus et jaunâtres, aux croupes pelées des hauteurs crayeuses semées des taches blanches des marnières qui se succèdent du côté de l'Artois. La limite géographique du pays s'y confond avec la fronlière historique. Mais celle-ci, lorsqu'elle pénètre dans la vaste dépression alluviale que la Lys et ses affuents ont creusée on débouchant de l'Artois, coupe en deux une région dont les caractères naturels font une partie intégrante de la plaine flamande. La Lys, qui fut souvent entre Aire et Armentières la limite politique de l'Artois et de la Flandre, et qui sépare de nos jours les départements du Nord et du Pas-de-Calais, pouvait à la rigueur former une frontière avec la large bande de prairies basses qui accompagnent son lit, et qu'elle recouvre chaque hiver; mais la partie qu'isolait cette frontiere au Sud de la rivière est bien flamande, avec ses fortes terres brunes, ses innombrables fossés pleins d'eau, ses haies d'ormeaux, et ses maisons éparpillées le long de rues interminables. Au contraire ce « bas-pays $\gg$, comme on dit à Béthune, se distingue aisément des hautes terres qui lo limitent au Sud. Arrivé à Aire, à Lillers, à Béthune, à La Bassée, le long de cette ligne de villes, dont la présence suffirait dójà à indiquer une frontière naturelle, on voit le sol se relever, d'abord en ondulations douces d'argile, bientôt en croupes, plus accusées, de craie, et s'élever en gradins jusqu'aux collines de l'Artois ; les pâtures, les arbres, diminuent, les maisons se groupent en villages. La présence, sur ces premières pentes, de la puissante industrie des houillères, a accentué le contraste avec la région flamande, restée dans cette plaine de la Lys presque exclusivement agricole. Ainsi toute la plaine est bien un coin de Flandre, en dépit de l'opinion exprimée par ses habitants que le pays flamand s'arrête aux coteaux d'Hazebrouck et de Bailleul, parce qu'ils prennent pour une frontière véritable la capricieuse limite des langues, errante de la Lys aux hauteurs, et confondent flamingant et flamand.

1 Voir la carte de la moisson du blé en Flandre, fig. 3. 


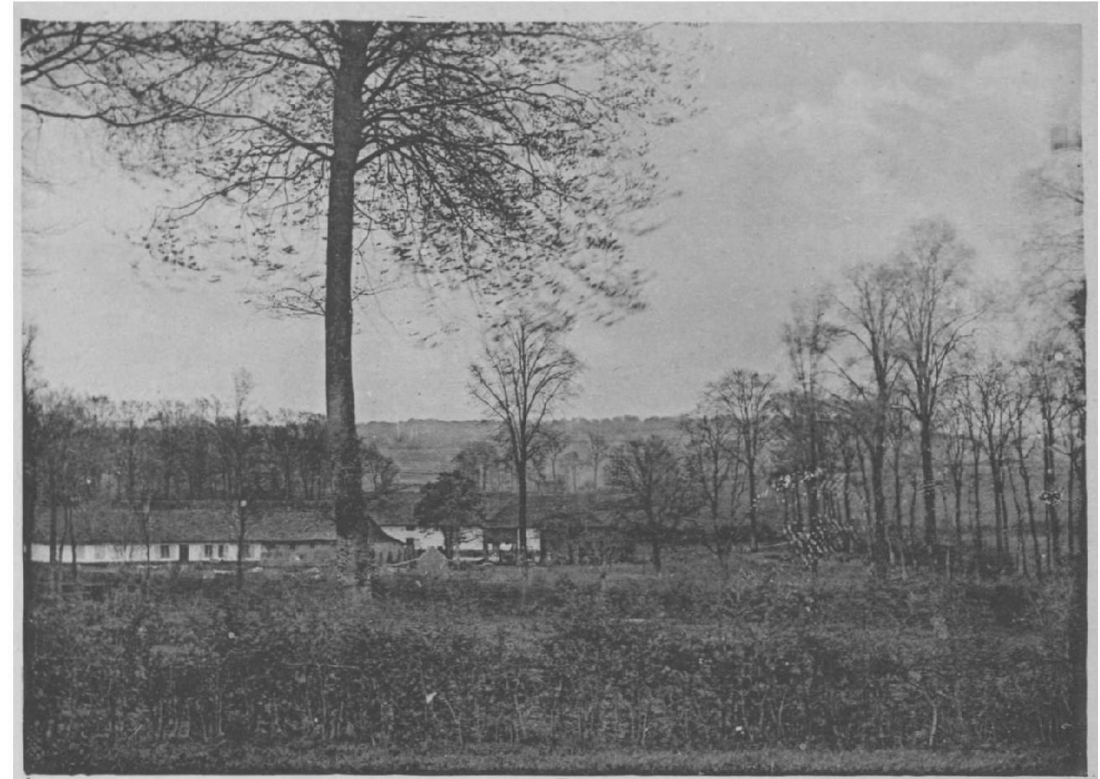

1. - L'Artois vu du bas pays (Landrethun-lès-Ardres).

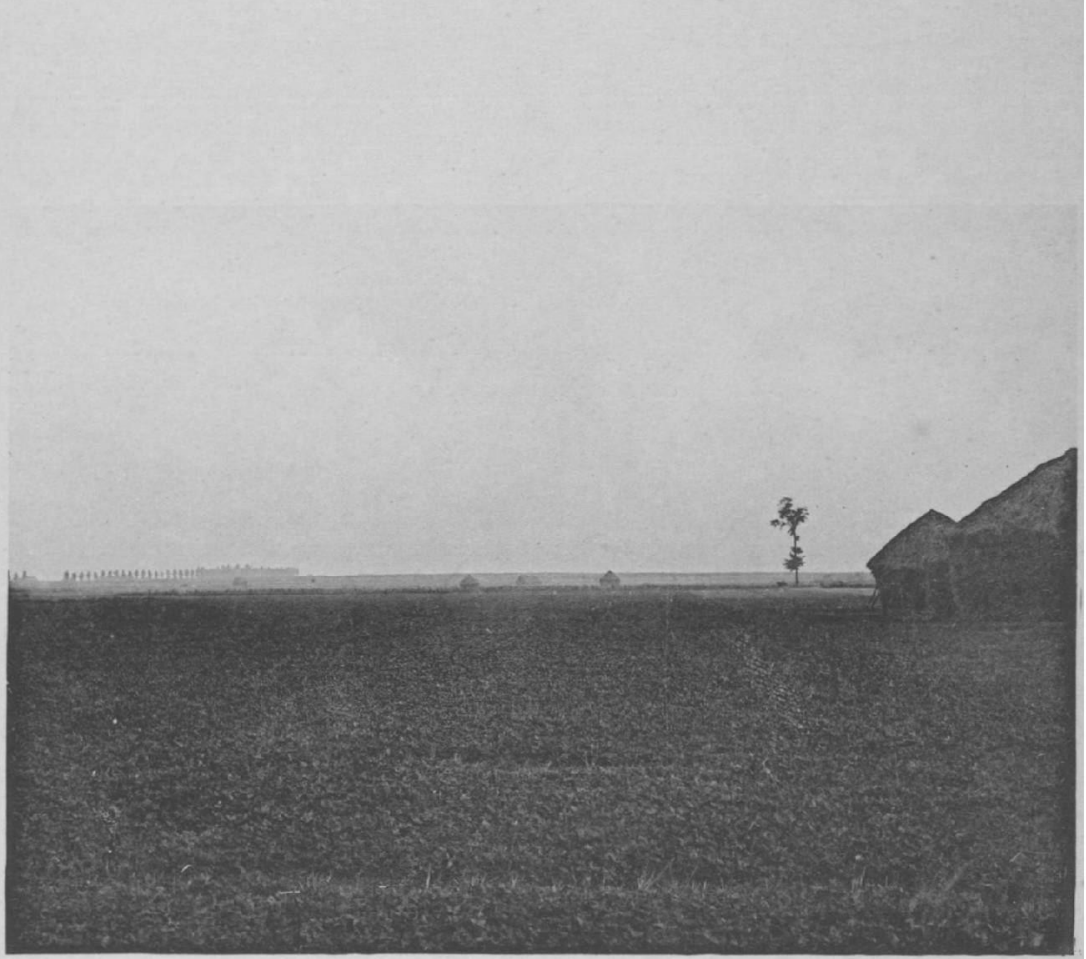

2. - Le plateau crayeux du Mélantois, vu de Lille. 
IRIS - LILLIAD - Université Lille 1 
Limites vers l'Est. - La limite du pays flamand est déjà heauconp plus difficile à ficer vers l'Est. Sans doute l'Escaut, de Termonde à Anvers, peut être considéré comme une frontière. Les régions qu'il sépare sont dissemblables; à gauche le pays do Wáes, avoc son sol do limon sableux, est nne terre d'agriculture riche, à population densc; ‘̀̀ droite les sables de la Campine Anversoise ne portent guère que des bruyères el des forêts auxquelles s'attaquent les défrichements modernes. Le vaste fleuve jaune, large de 500 mètres devant Anvers, était une limite historique en même temps qu'une frontière géographique; l'envahissante domination des comtes ne put jamais le franchir, et nême à partir du XVI $\mathrm{XIècle}^{\mathrm{e}}$ la juridiction du fleuve, jusque-là réservée à la Flandre, fut accaparée par ceux d'Anver's ${ }^{1}$.

Flandre à gauche, Brabant à droite; la petite région de I.ebbeke et Buggenhout, dépendance de la Flandre Orientale sur la rive droite, est encore qualifiée de Brabant par les habitants de la rive gauche. Les difficultés commencent au delà de Termonde, où le pays flamand commence d'envahir la rive droite du fleuve. Ce n'est plus pourtant l'aspect de la vraie Flandre; les accidents de terrain, qui étaient l'exception à l'Ouest de l'Escaut, se multiplient à l'Est; il est facile d'y reconnaître les ruines d'un grand plateau dont l'altitude croît vers le Sud, et que d'innombrables vallons ont si bien entaillé, qu'il n'en reste plus guère qu'un squelette. Tandis que ces débris du plateau aunoncent le Brabant avec leur sol de limon sablonneux ot leurs vastes champs nus et monotones, sans arbres ni maisons, les vallées sont encore la Flandre ; l'argile que cachait la masse sableuse, mise à découvert par l'èrosion, ramène l'humidité et la verdure; on retrouve le long du ruisseau les prairies entourées de peupliers; les villages et les fermes s'espacent le long des vallons, tandis que les bouquets de bois, établis sur les pentes trop glaiseuses, poussent leurs têtes jusqu'au rebord du plateau. A mesure qu'on approche de la Dendre, les vallées se font plus rares, le plateau s'étend, et l'on passe ainsi par une insensible transition au paysage brabançon. Oú fixer une limite dans un pays aussi fuyant, et qu'on pourrait appeler aussi bien Flandre brabançonne que Brabant flamand? Il faut se résoudre à le considérer comme une de ces régions mixtes qui remplacent les frontières dans ces contróes où les différences de climat, de sol et de relief, n'apparaissent qu'insensiblement, et l'étudier avec la Flandre, qui se l'est attribué depuis huit siècles.

1 Duvivier (Ch.), L'Escaut est-il flamand ou brabançon? (Bull. Ac. R. Belg., Classe des Lettres, 1899, pp. 721-768). 
Limites vers le Sud. - Plus incertaine encore est peut-être la frontière du Sud, entre Grammont et La Bassée. A l'Ouest et à l'Est, ce sont surtout les différences de relief qui arrêtent la Flandre au pied des premières pentes crayeuses ou la poussent jusqu'à la vallée de la Dendre, à la rencontre des plateaux sablonneus du Brabant. Vers le Sud, tout relief disparaît; la grande plaine du Nord do la France étend ses monotones ondulations jusqu'au delà de Valenciennes et de Cambrai. De la Lys aux marais de la Sensée, c'est de nouveau un pays mixte, où sélabore lentement la transition de la plaine flamande aux hautes terres du Hainaut et du Cambrésis. Aprés la Lys, c'est jusqu'à la Deûle et la Marcq lo territoiro humide, au sol d'argile, qu'occupaiont les petits pagi de Weppes el de Ferrain; puis le bombement crayeux, rattaché par Carvin au platcau de la Gohelle, et étendu vers l'Est jusque près de Tournai, auquel s'attachent les noms purement historiques de Mélantois et de Carembaut. Derrière, c'est la Pévèle, où un pelit massif d'argile tertiaire, entourè d'une aur'éole sableuse, occupe l'emplacemont d'une dépression de la craie; des bois assez compacts établis sur les sables ou les argiles en jalonnent la périphérie; ils sont particulièrement épais dans le Sud, sur le territoire de l'ancien pagus d'Ostrevant, où la craie qui se rapproche de nouveau de la surface est encore protégéo par uno couche sableuse sur laquelle s'étendenl des forêts. Oủ faut-il s'arrêter daus une région où les contrastos sont si lents à se produire, et où los caractères propres au pays flamand se fondent peu à peu avec cenx des contrées voisines?

Déjà, de Grammonl à Tournai, il faut faire appel à des souvenirs historiques, ressusciter des traits géographiques disparús, pour justifier la limite traditionnelle des plaines Hamandes et des plateaux du Hainaut, qui, par le dédale des collines de Flobecq et de Renaix, atteint l'Escaut vers Avelghem, le suit jusqu'à son coude d'Espierres. C'est la frontière linguistique; c'est aussi la limite administrativo entre Hainaut et Flandre; c'est un des rares points ou la limite du comté n'ait presque jamais varié. Cependant les pays qu'elle sépare ne sont pas très différents ; l'aspect, les cultures sont identiques; ce n'ost que peu d̀ peu que s'opére le passagc aux paysages de plateau agricole qui caractérisentle Hainaut, et où le sol de limon repose sur le calcaire carbonifère qui apparaît dans les vallées, étroites et profondes. C'est que là s'ètendait jadis un obstacle, de chaque côté duquel se terminaient les deux régions: c'étail l'endroit où venait finir la partio occidentale de la grande forêt Charbonnière, considérée par la loi salique comme la frontière du peuple franc, et regardée encore au IX siècle comme une limite naturelle. La 
poussée germanique venue du Nord-Est n'a pas dépassé l'emplac'ement de cette vaste étendue boisée; et c’est ainsi que cette partio des limites du pays flamand, qui peut paraître aujourd'hui la plus artificielle de toutes, a êté jadis celle qui s'imposait le plus ${ }^{1}$.

Plus loin à l'Ouest, de l'Escaut à La Bassée, il est plus facile de retrouver une frontière naturelle au delà de laquelle les traits propres au pays flamand s'atténuent, so raréfient, cédent lo pas à des caractères étrangers. Tandis que la bande de territoire qui s'étend de Lille à la Lys est encore toute flamandè, avec ses hauteurs qui continuent au delà de la rivière la rangée des collines d'Ypres, avec son sol argileux et humide, ses pâtures, ses arbres et ses haies, ses fermes éparses, le paysage change d'aspect dès qu'on atteint le petit plateau crayeux qui s'étend au sud jusque sous la ville de Lille. Tandis que des faubourgs Nord de la ville le pays apparait verdoyant comme un 5ocage, des remparts du front Sud la vue porte sur des champs nus de terre brune, séparant des villages bien groupés, entourés d'arbres comme en Picardie; paysage découvert dont la silhouetle de nombreux moulins à vent accentue encore le vide ${ }^{2}$. Non seulement le sous-sol, mais le sol superficiel different; au Nord c'est un limon d'altération argileux, gras et humide; au Sud le sol ordinaire des grandes plaines de la craie, le limon quaternaire formé d'ergeron recouvert de terre à briques, qui ne paraît pas dépasser Lille ${ }^{3}$. De lá des différences dans la culture ; Ia terre, plus fertile au Sud, était aussi moins soignée. L'intendant Dugué de Bagnols, à la fin du XVII siècle, distinguait nettement dans sa petite province «la partie qui regarde l'Artois, et qui comprend les quartiers de Carembaut, de Mélantois et de Pévèle, au sol sec et marneux», de « la partie qui regarde la Elandre, les quartiers de Ferrain et de Weppes, terrain si gras et si fertile ${ }^{4} . . . »$. Le conventionnel Camus, revenant de Flandre, "s'aperçoit en approchant de Douai que le pays change de mœurs et d'habitudes.... Ce n'est

1 Duvivier (Ch.), La Forêt Gharbonnière (Rev. d'Histoire et d'Archéologie, III, 1862, pp. 1-26) ; - Pirenne, Histoire de Belgique, I, p. 13. - Sur les limites historiques du Tournaisis et de la Flandre, voir d'Herbomez. (A.), Gejographie historique du Tournaisis (Bull. Soc. belge Géog. 16 annèe, 1892, pp. 27-56, 306-333, 386-423).

2 Voir phot. 2.

3 Gosselet (J.), Esquisse géologique du Nord de la France. Age quaternaire (Ann. Soc. géol. Nord, XXX, 1901, pp. 257-335), pp. 290-295.

4 Mémoire de Dugué de Bagnols, intendant de la Flandre wallonne, 1698 (Bull. Comm. H. Nord, X, p. 159). 
plus cette culture flamande qui transforme les champs en jardins ${ }^{1}$. Aujourd'hui, les procédés sont devenus identiques, mais les cultures diffèrent encore. Au Nord, les pâtures favorisées par l'humidilé du sol tiennent le premier rang pour l'importance des produits; au Sud les céréales et les betteraves à sucre sont la grande affaire du paysan.

Cependant au Sud de cette bande crayeuse si différente du vrai pays flamand reparaît en Pévèle l'argile, la roche caractéristique de la Flandre. Au sortir du plaleau sec, le paysage redevient verdoyant; il rappelle les aspects du Nord. Faut-il donc, au delà de la petite zone qui annonce déjà les pays picards, considérer la Pévèle comme une dépendance de la région flamande? Les nuances sont si délicates que l'hésitation est permise. Cependant c'est, plutôt qu'une terre flamande, une petite région à part, qui réunit à ses caractères propres des traits empruntés aux pays voisins. Elle so distingue par son relief, qui en fait un petit massif argileux, d'où descendent de tous côtés des ruisseaux ; par sa ceinture de bois, qui l'isolait du pays d'alentour; par l'infertilité de son sol, ou l'on ne peut guère labourer plus profond que vingt centimètres. Ce ne sont plus les étendues vides de la craie, mais on n'y retrouve pas les pâtures et les haies de la Flandre. Les agriculteurs ont plus de rapports avec leurs voisins du Sud qu'avec ceux du Nord ; leur principal produit, la graine de betleraves, s'adresse plus à la Picardie qu’à la Flandre, où la culturo betteravière est moins développée. Les ouvriers d'industrie sont également sollicités vers Lille et Roubaix, pour lesquelles ils travaillent encore à domicile, et vers le bassin houiller oú des trains les conduisent chaque jour. Evidemment ce n'est plus là le véritable pays flamand, mais une petite région mixte, isolée de la Flandre par la zone crayeuse et par sa bordure de bois, et où la fusion de caractères communs aux contrées voisines et de quelques traits originaux finit par former une petite individualitẻ géographique.

Ainsi c'est vers Lille et Tournai, au longr de la petite zone sèche, et - coïncidence curieuse - sur la ligne qui marque la limite vers le Sud de l'expansion germanique, que s'arrête la vraie région flamande; les deux villes sont à la frontière de la Flandre. Le rôle d'intermédiaires entre les pays du Nord et ceux du Sud domine d'ailleurs toute leur histoire; Lille continue à le tenir; Tournai ful jusqu'au XVI siècle l'avant-garde de la France, et le plus solide point d'appui de la politique française en Flandre; c'est par ses écrivains et ses artistes que les

1 Voyage dans les départements nouvellement réunis.... a la fin de l'an X (Paris, Beaudouin, an XI, 2 vol.), II, p. 168. 
influences romanes pénétraient dans la région germanique. Fragile frontière que celle qu'elles jalonnent; mais il ne faut pas être trop exigeant pour un pays si ouvert et si peu accidenté, où l'on entre si facilement qu'on en oublie qu'il y a une porte. Du moins, au delà des marches qui servent souvent de limites, les différences apparaissent avec netteté; l'homme lo moins averti, en passant de Boulogne à Calais, de Lens à Armentières, de Bruxelles a Gand, s'aperçoit qu'il a changé de pays. Il n'en faut pas plus pour reconnaître une région naturelle; et l'étude des principaux caractères physiques de la Flandre ne fera que fortifier cette impression. 


\title{
CHAPITRE II
}

\author{
LE CLIMAT ${ }^{1}$
}

I. Les éléments du climat. Température. Anomalie de la plaine maritime. Pluie. Vents. - II. Caractères du climat. Influences sur la nature et l'homme. Prétendus changements.

Le climat de la Flandre n'a pas bonne réputation. Ies étrangers qui viennent habiter le pays ne tarissent pas sur les ennuis que leur cause l'atmosphère flamande; les plus modérés estiment que le climat est au moins désagréable; étouffant l'été, aigre l'hiver, changeant et surtout humide en tous temps; il n'y a pas de printemps; le soleil ne se montre qu'à regret, toujours obscurci, et la boue n'a pas eu le temps de sécher que la pluie recommence. Au contraire, l'examen des moyennes donne du climat flamand une idée satisfaisante; la chaleur et le froid sont tempérés, la pluie ne paraît pas tomber en quantités considérables. Il y a là une anomalie à expliquer: on essaiera de le faire pour les deux éléments principanx, pluie et température.

\section{LES ÉLEMMENTS DU CLIMAT}

\section{Température}

L'étude détaillée de la température d'une région est assez difficile, faute de données suffisamment nombreuses. Les pouvoirs publics n'entretiennent qu'un petit nombre de stations, et rares sont les observateurs bénévoles assez zélés et consciencieux pour faire chaque jour des observations thermométriques. Dans la plaine flamande délimitée comme on l'a vu

1 A consulter: Durieux (Ch.), Etude sur le clinat du littoral belge (Ann. Observat. royal Belg., 1900, 25 p., 9 pl.); - Iancaster (A.), La pluie en Belgique, 1er fascicule (Bruxelles, Hayez, 1894, in-8n, 224 p., 1 pl., carte à 1.400.000); - Blanchard (R.), La pluviosité de la plaine du Nord de la France (Ann. Géog. XI, 1902, pp. 203-220, 10 tig., 16 cartes à $1: 1.500 .000,1$ carte à $1: 750.000)$. 
précédemment, on n'a pu trouver quo 9 stations, parmi lesquelles trois donnaient des observations incomplètes. Il a donc fallu dépasser les frontières du pays, et s'adresser, pour pouvoir obtenir quelques termes de comparáison, aux régions voisines ${ }^{1}$. On a réuni ainsi les observations de 13 stations, assez heureusement placées, il est vrai, pour étudier le pays : quatre dans la plaine maritime; trois dans la Flandre de l'intérieur, entre la mer et la Lys : deux dans la région de Lille, trois sur les frontières du pays picard, une en Brabant ${ }^{2}$.

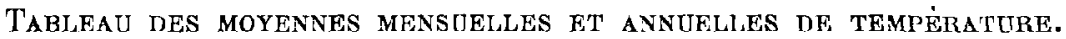

\begin{tabular}{|c|c|c|c|c|c|c|c|c|c|c|c|c|c|c|}
\hline \multirow{2}{*}{ STATIONS } & \multirow{2}{*}{ 窧 } & \multicolumn{12}{|c|}{ MOYENNÉS MENSUWLLES } & \multirow{2}{*}{ 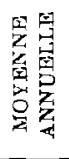 } \\
\hline & & 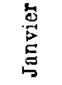 & 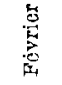 & 象 & 章 & 茪 & $\stackrel{g}{B}$ & $\begin{array}{l}\vec{\Xi} \\
\stackrel{3}{3}\end{array}$ & . & $\begin{array}{l}\text { 离 } \\
\text { 员 }\end{array}$ & 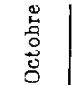 & 党 & 芦 & \\
\hline Arras. & 66 & 1.3 & 3.1 & 5.5 & 9.4 & 12.4 & 16.1 & 17.4 & 17.3 & 14.5 & $9.6^{\circ}$ & 5.8 & 2.9 & 9.6 \\
\hline Dunkerque... & 7 & 3.4 & 4.3 & 6.0 & 8.7 & 11.4 & 14.8 & 17.1 & 17.4 & 15.4 & 11.2 & 7.7 & 1.9 & 10.2 \\
\hline Flessingue. & 4 & 2.4 & 3.3 & 5.5 & 9.2 & 12.3 & 16.1 & 18.0 & 18.0 & 15.9 & 11.3 & 7.3 & 4. & 10.3 \\
\hline Furnes .. & 5 & 2.1 & 3.3 & 5.4 & 8.7 & 11.5 & 15.0 & 16.7 & 16.7 & 14.7 & 10.2 & 6.4 & 3.6 & 9.5 \\
\hline Iseghem. & 15 & $1.6^{\circ}$ & 2.9 & 5.4 & 9.0 & 12.3 & 16.3 & 17.9 & 17.6 & 15.0 & 9.9 & 6.0 & 3.0 & 9.8 \\
\hline Laventie. & 20 & 1.9 & 3.4 & 5.7 & 9.4 & 12.3 & 16.0 & 17.6 & 17.4 & 15.0 & 10.1 & 6.2 & 3.2 & 9.8 \\
\hline Aille... & 25 & 2.0 & 3.0 & 5.3 & 9.3 & 12.3 & 16.2 & 18.1 & 17.5 & 14.8 & 9.6 & 5.6 & 3.0 & 9.7 \\
\hline Maldegem & 6 & 1.6 & 2.9 & 5.4 & 8.9 & 12.1 & 15.7 & 17.4 & 17.4 & 15.0 & 10.1 & 6.1 & 3.0 & 9.6 \\
\hline Ostende (ville) & 5 & 2.4 & 3.3 & 5.3 & 8.5 & 11.5 & $\mathbf{1 5 . 1}$ & 17.0 & 17.1 & 15.3 & 10.7 & 6.7 & 3.9 & 9.7 \\
\hline Le Quesnoy... & 131 & 1.1 & 2.9 & 5.4 & 9.5 & 12.4 & $16 . \overline{5}$ & 18.1 & 17.9 & 15.2 & 10.0 & 6.0 & 2.6 & 9.8 \\
\hline Selzacte. & $\mathbf{b}$ & 1.8 & 3.1 & $5 . \tau$ & 9.4 & 12.7 & 16.4 & 17.7 & 17.7 & 15.3 & 10.4 & 6.3 & 3.2 & 10.0 \\
\hline Uccle.. & 100 & 1.0 & 2.3 & 4.9 & 8.8 & 11.9 & 15.8 & 17.3 & 17.3 & 14.8 & 9.9 & 5.7 & 2.7 & 9.4 \\
\hline Nalenciennes.. & 56 & 1.7 & 3.3 & 5.7 & 9.5 & 12.4 & 16.3 & 17.7 & 17.6 & 14.9 & 9.9 & 6.1 & 3.2 & 9.9 \\
\hline
\end{tabular}

1 Les documents utilis ss pour leétablissement des moyennes sont de provenance diverse : la Commission métẻorologique du Nord a fourni les chiffres des stations de Lille, Valenciennes et Le Quesnoy; lo Bulletin métėorologique de la Station Agronomique d'Arras, Laventie et Arras; les Annales du Bureau Central météorologique, la station de Dunkerque (Service du Port); l'Observatoire royal de Belgique, à Uccle, les stations de Furnes, Isoghem, Maldegem, Ostende, Selzatete, Ucclo; l'Observatoire royal néerlandais, à de Bilt près Utrecht, la station do Flessingue.

\& On n'a pas utilisé les stations de Douai et Gondecourt, relevant de la Commission météorologique du Nord, dont les chiffres élaient manifestement trop forts. La station de Somergem (Flandro Orientale), fonctionnant depuis trop peu de temps, a été également écartée. 
La plupart des stations considérées fonctionnent depuis peu de temps : une ving taine d'années à peine. Cependant on ne pouvait utiliser les résultats des dernières années, la période quinquennale 1901-1905 n’étant pas terminée; on a donc dû se résigner à prendre, pour établir les moyennes, les chiffres de la seule période décennale 1891-1900. C'est peu de dix ans pour établir des chiffres moyens de température; mais il était impossible de faire autrement, les stations de Valenciennes, du Quesnoy et de Selzaete n'ayant commencé à fonctionner qu'en 1890, celle d'Iseghem en 1889, Maldegem et Ostende en 1888, Furnes en 1887. Il a même fallu combler par des interpolations quelques vides dans les chiffres de Maldegem et Laventie. On est arrivé ainsi au tableau précédent, donnant les moyennes mensuelles et annuelles pour la période 1891-1900.

La comparaison de ces chiffres avec ceux que l'on aurait obtenus en utilisant un nombre d'années beaucoup plus grand, est rassurante. A Lille, la moyenne de température annuelle obtenue par les observations s'étendant de 1757 à 1888 est de $9^{\circ}, 9$; pour la période 1891-1900, on trouve $9^{\circ}, 7$. A Uccle, la moyenne des années $1833-1900$ est de $9^{\circ}, 1$, contre $9^{\circ}, 4$. Les différences sont donc faibles, et l'on peut affirmer que les chiffres du tableau précédent donnent une idée à peu près exacte des températures moyennes de la Flandre.

Comme il fallait s'y attendre dans un pays largement ouvert, et parallèle à la mer, où les influences marines peuvent se faire sentir partout, les différences des températures annuelles sont faibles entre les différentes stations. Entre le minimum $9^{\circ}, \dot{4}$, à Uccle, et le maximum $10^{\circ}, 3$, à Flessingue, il n'y a même pas un degr'é. La différence diminue encore lorsqu'on applique à ces chiffres la correction de l'altitude ; en réduisant ces températures annuelles au niveau de la mer, on obtient en effet pour Lccle $9^{\circ}, 9$, pour Arras $10^{\circ}$, pour Valenciennes $10^{\circ}, 2$, pour Le Quesnoy $10^{\circ}, 5$; l'on a, pour toute la Flandre à peu près, la température moyenne de $10^{\circ}$.

Cependant des différences apparaissent entre les moyennes des différents mois. En janvier, Dunkerque a $2^{\circ}, 1$ de plus que Lccle ; en février, $Z^{\circ}$ encore; en mars, $1^{0}, 1$. - En juillet, Lille a $1^{0}, 4$ de plus que Furnes, $1^{0}, 1$ de plus qu'Ostende. En septembre, Flessingue dépasse Arras de $1^{\circ}, 5$; en novembre, Lille est inférieur de $2^{0}, 1$ à Dunkerque ; en décembre, Dunkerque a 20,3 de plus que Le Quesnoy. Ainsi, d'octobre à mars, les stations de la plaine maritime présentent les températures les moins basses; dans la saison chaude, elles sont plus fraîches que les stations de l'intérieur. La température de la plaine maritime paraît donc beaucoup plus égale que celle de l'intérieur; l'amplitude entre les extrêmes des moyennes mensuelles est 
de $14^{\circ}$ à Dunkerque, de $14^{\circ}, 6$ à Furnes; elle est de $16^{\circ}, 3$ à Uccle, de $17^{\circ}$ au Quesnoy.
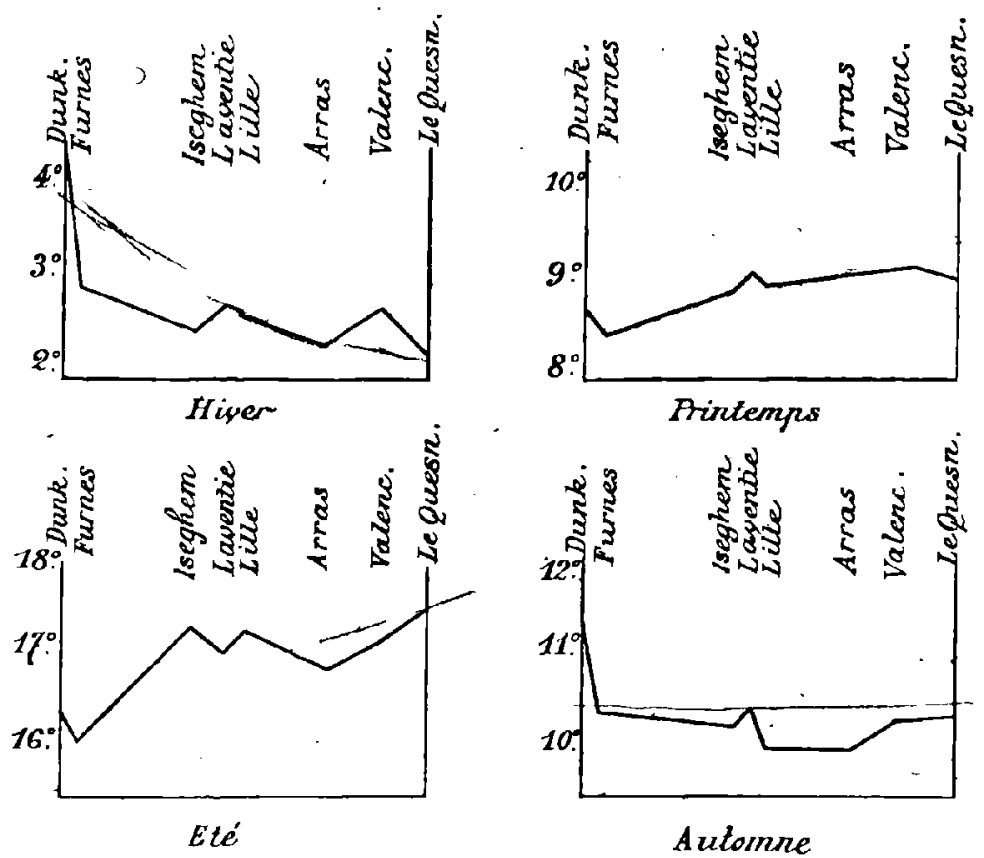

Fia. 1. - Influence de l'éloignement de la mer sur les moyennes saisonnières de température.

TABleaU DES MOYenNES SAISONNIÉRES.

\begin{tabular}{|c|c|c|c|c|}
\hline STATIONS & Hiver & Printemps & Été & Automne \\
\hline 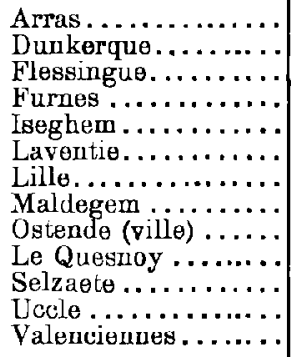 & $\begin{array}{l}2,4 \\
4,2 \\
3,4 \\
3,0 \\
2,5 \\
2,8 \\
2,7 \\
2,5 \\
3,2 \\
2,2 \\
2,7 \\
2,0 \\
2,7\end{array}$ & $\begin{array}{l}9,1 \\
8,7 \\
9,0 \\
8,5 \\
8,9 \\
9,1 \\
9,0 \\
8,8 \\
8,4 \\
9,1 \\
9,3 \\
8,5 \\
9,2\end{array}$ & $\begin{array}{l}16,9 \\
16,4 \\
17,4 \\
16,1 \\
17,3 \\
17,0 \\
17,3 \\
16,8 \\
16,4 \\
17,5 \\
17,3 \\
16,8 \\
17,2\end{array}$ & $\begin{array}{l}10,0 \\
11,4 \\
11,5 \\
10,4 \\
10,3 \\
10,4 \\
10,0 \\
10,4 \\
10,9 \\
10,4 \\
10,7 \\
10,1 \\
10,3\end{array}$ \\
\hline
\end{tabular}


Les différences apparaissent plus nettement encore lorsqu'on établit les moyennes saisonnières : en hiver et en automne, la température de la plaine maritime est sensiblement plus élevêe qu'à l'intérieur : au printemps et en été, le contraire se produit. L'amplitude entre les moyennes saisonnières n'est plus que $12^{\circ}, 2$ à Dunkerque; mais elle atteint encore $15^{\circ}, 3$ au Quesnoy.

Les mêmes différences se retrouvent lorsqu'on examine d'autres éléments de température: le nombre des jours de gelée et de forte chaleur; la variation diurne. Pour 50 jours de gelce à Ostende (moyenne des 10 années 1891-1900), on en a déjà 56 à Furnes, 58 à Iseghem; le nombre s'accroît dans la région sablonneuse : 66 à Maldegem, 67 à Selzaete. Plus loin, en Campine, la station de Turnhout, dont la température moyenne est semblable à celle de la Flandre, donne 73 jours de gelée; Uccle en a 70. Pour les fortes gelées, dépassant $-10^{\circ}$, on obtient les moyennes suivantes : 3,0 à Ostende, 3,6 à Furnes, 1,0 à Iseghem, 5,0 à Maldegem, 6,0 à Selzaete et à Uccle, 6,1 à Turnhout. Il y a donc, dans la plaine sablonneuse du Nord-Est, deux fois plus de fortes gelées qu'au bord de la mer. I.es jours de forte chaleur (au-dessus de $25^{\circ}$ ) sont egalement beaucoup plus rares sur la côte, 8 (?) à Dunkerque, 12 à Ostende, 14 à Furnes; le nombre augmente dès qu'on pénètre dans l'intérieur: 27 à Iseghem, 28 à Maldegem, 31 à Lille, 28 à $\Lambda$ rras, 26 à Lccle, 34 à Laventie ; et il est particulièrement considérable dans la région sablonneuse : 38 à Selzaete et à Turnhout.

La variation thermique diurne est également moins forte sur la côte que dans l'intérieur. Pour $6^{\circ}, 1$ d'amplitude diurne (moyenne annuelle) à Ostende, on a $8^{\circ}, 0$ à Uccle, $9^{\circ}, 1$ à Turnhout, $9^{\circ}, 5$ à la station d'Hechtel (Campine), $10^{\circ}, 4$ à Bastogne, dans l'Ardenne ${ }^{1}$; en Flandre, Iseghem a déjà $8^{\circ}$, et Somergem, dans la région sablonneuse, $8^{\circ}, 9$. Même dans la plaine maritime, il y a une différence entre la côte et la zone des polders. A Furnes, les nuits, en toute saison, sont plus fraîches qu'à Ostende : $8^{\circ}, 2$ contre $9^{\circ}$ au printemps et en eté, $3^{\circ}$ contre $3^{0}, 7$ en automne et en hiver; et les aprèsmidi sont plus chaudes, surtout l'été, que sur le littoral : $16^{\circ}, 7$ contre $16^{\circ}$ d Ostende. Il en résulte une amplitude diurne plus considérable : $7^{\circ}, 5$ à Furnes contre $6^{0}, 4$ à Ostende ${ }^{2}$.

I Ainsi toutés les observations amènent à la même conclusion : si la température moyenne annuelle est á peu près la même pour toute la Flandre, du Nord au Sud, et pour les régions voisines, il y a dans les moyennes

1 Cf. Monographie agricole de la région des Dunes, p. 3.

2 Monographie agricole de la région des Polders, p. 2. 
mensuelles et saisonnières des différences entre la plaine maritime et l'intérieur. Sur la côte particulièrement, l'influence modératrice de la mer adoucit la chaleur de l'été et le froid de l'hiver'; les températures très élevées et trés basses sont rares. Les courbes thermométriques sont plus capricieasesà l'intérieur, surtout dans la région sablonneuse. Là se fait sentir l'ínfluence du sol; cette légère terre sableuse s'échauffe et se refroidit rapidement; elle absorbe facilement la chaleur solaire et subit la nuit, par. le rayonnement, des déperditions thermiques considerables. Cependant le caractère excessif de ce climat de Ia r'égion sablonnouse est moins prononcé que dans la Campine, situóe pourtant sous la même latitude: c'est que la culture intensive de la Flandre a peu à peu amendé et alourdi en quelque sorte le sol du pays, devenu dès lors moins bon conducteur de la chaleur que celui de la Campine. Cependant les gelées blanches sont toujours

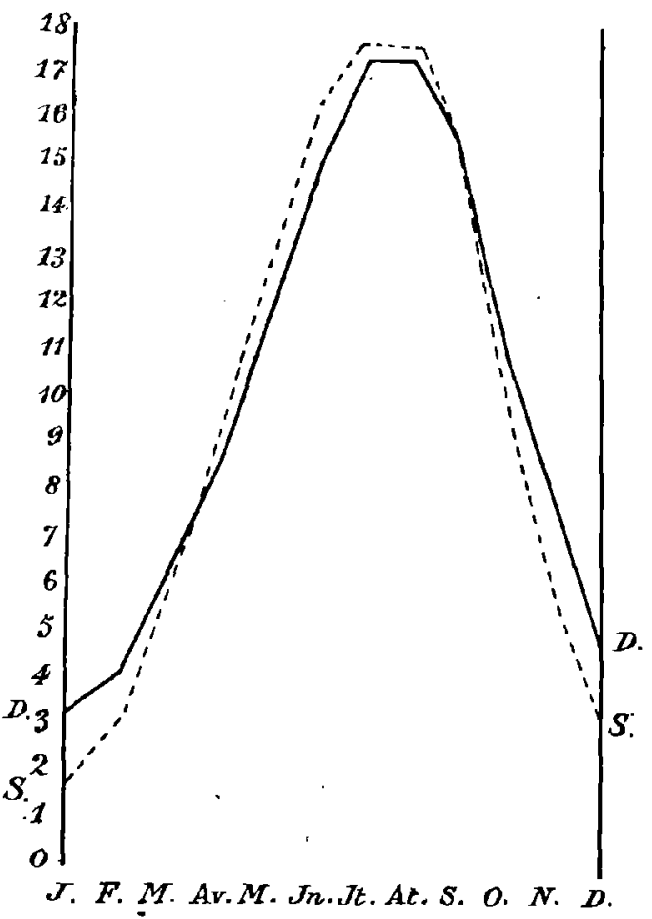

Fig. 2. - Températures moyennes à Dunkerque et à Selzaete. à craindre dans la région sablonneuse, même au milieu de l'été. On en signale dans le mois de juin, en 1887, 1890, 1892, qui causent les plus grands dégâts, détruisant les pommes de terre, les haricots, le sarrasin. D'autres se produisent en septembre. Enfin en août 1887, on en constate à plusieurs reprises à Maldegem ${ }^{4},(3,4,12$ et 13 août).

Il peut paraître intéressant de comparer ces résultats avec ceux que procure l'étude de la végétation; par exemple avec une carte, dressée d'après des renseignements recueillis sur place, et indiquant l'époque moyenne à laquelle on fait la moisson du froment dans les diverses parties

1 Monographio agricole de la région sablonneuse des Flandres, p. 7. 
de la Flandre ^. Cette carte ne saurait prétendre à une précision absolue, et la direction des courbes tracées reste un peu indécise dans ses détails. Mais les traits généraux suffisent à la démonstration. Le plus saillant,

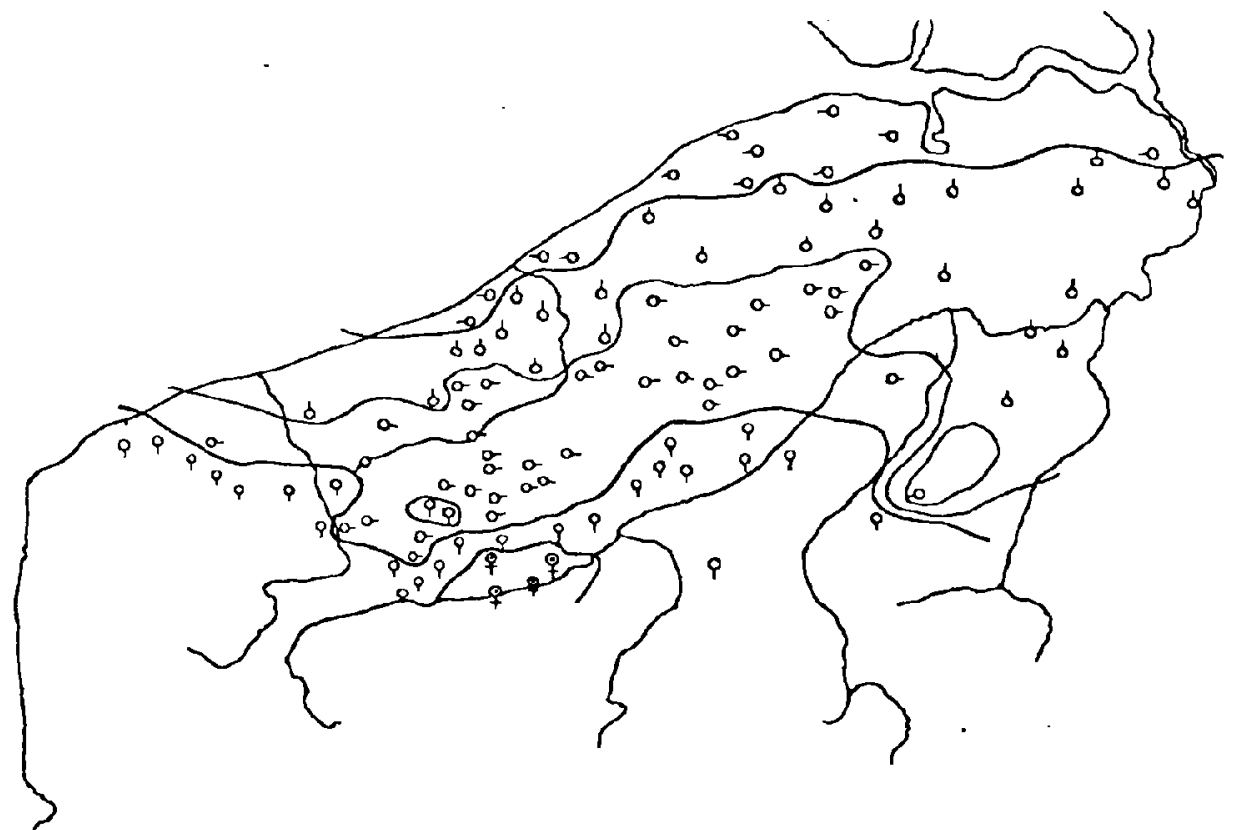

Fig. 3. - La moisson du froment en Flandre.

Localités où la moisson a lieu ordinairement:

$$
\begin{aligned}
& \text { Q Avant le } 5 \text { AoQL } \\
& \text { Q Du tor au } 10 \text { Aoot. } 8 \text { Du } 10 \text { an } 20 \text { Aoûs. } \\
& \text { ○ Du } 15 \text { au } 30 \text { Aoút. }
\end{aligned}
$$

c'est l'inclinaison des courbes vers la mer; la moisson dans la plaine maritime est plus tardive, à latitude égale, que dans l'intérieur ; et cette différence s'accuse surtout vers le Nord. Tandis que les communes sablonneuses de Somergem, Landegem, Nevele, Aeltre, moissonnent le blé du 5 au 15 août, les communes de l'embouchure de l'Yser, Slype, Westende, Coxyde, meme Ghyvelde et la région de Dunkerque ne se mettent à l'œuvre qu'après le 1,5; la différence est d'au moins dix jours. Cela tient à

1 Dans certaines communes de la Flandre Orientale, où le froment n'est presque plus cultivé, on a tourné la difficulté en majorant de 15 jours environ la date de la moisson du seigle; c'est là à peu près l'intervallo qui sẻpare les deux récoltes dans les communes où l'on pratique à la fois la culture de ces deux céréales. 
ce que le printemps et l'été sont moins chauds dans la plaine maritime qu'à l'intérieur, ét particulièrement les mois de mai etjuin, si décisifs pour la végótation en Flandr'e; la différence entre les deux régions est d'environ un degré pour chacun de ces mois.

\section{TEMPÉRATURE EN MAI ET JUIN}

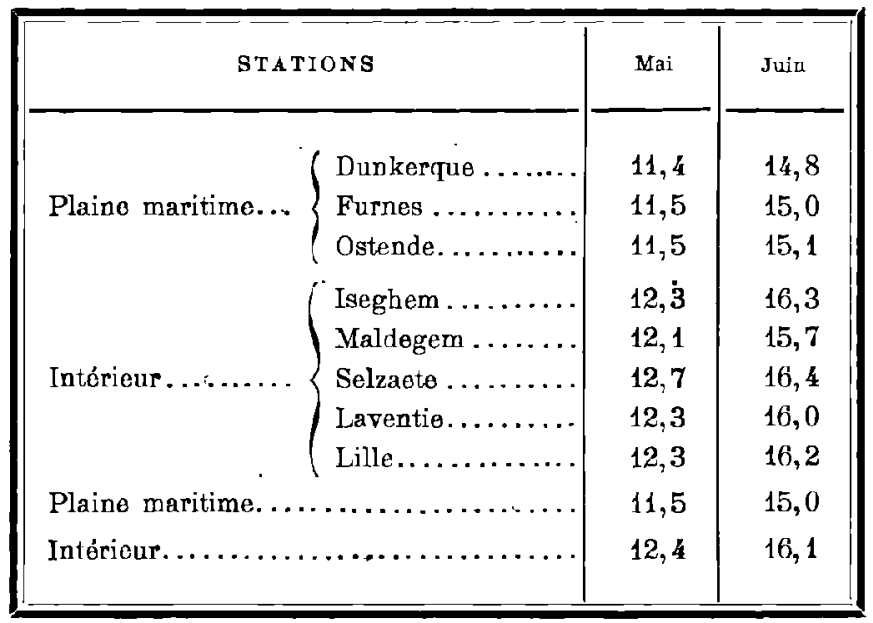

Cependant la carte contient encore d'autres particularités, dues en génóral à l'influence du sol. La plaine de la Lys, Steenwerck, VieuxBerquin, Merville, Fstaires, est en avance sur le reste du pays, grâce à sa latitude et à sa fertile terre franche; l'avance est d'une semaine sur Bailleul. Derrière l'écran de' Cassel, qui les protège des vents frais de la mer, les communes d'Oxelaere et Ste-Marie Cappel rentrent leurs gerbes un peu plus tôt que leurs voisines; au contraire Sercus, Staple, WallonCappel, Ies terres froides à l'Ouest d'Hazebrouck, sont en retard de 10 jours sur Boeseghem, Steenbecque, Morbecque, qui les touchent au Sud et à l'Est. De Watten à Sangatte, la jolie région de Bredenarde, d'Ardres, Guînes, abritée derrière les hauteurs artésiennes et boulonnaises, jouit d'un climat plus doux, et sa moisson est en avanco. Enfin le Sud du pays d'Alost, avec ses fortes terres argileuses et son altitude assez considérable, est en retard sur tout le reste de la Flandre, et on n'y moissonne guère lo blé que dans la $2^{e}$ quinzaine d'août. Mais le trait dominant reste la différence entre la plaine maritime et l'intérieur. Tout le long de la lisière, c'est un retard d'une dizaine de jours entre villages séparés par quelques kilo- 
mètres: entre Oudenbourg et Zandvoorde, entre Moerkerke et Damme, Hondschoote et les Moëres.

Ainsi la Flandre doit à sa forme de grand parallélogramme allongó au bord de la mer du Nord une certaine variété climatique. La température d'ensemble est douce, égale, sans grands écarts ${ }^{1}$; c'est un climat moyen, à peu près semblablo à celui du bassin de Paris, malgré la latitudo plus élevée. Cependant la plaine sableuse du Nord doit à son sol un climat qui se rapproche un peu du type excessif; au contraire dans la plaine maritime et surtout sur la côte l'amplitude moyenno annuelle diminue, et leur climat n'est pas loin d'être régulier, ou maritime.

\section{Anomalie de la plaine maritime}

Ces conclusions, prouvées pourtant par les chiffres, ne laissent pas d'étonner ceux qui connaissent la plaine maritime. Parler de la douceur et de l'agrément de son climat leur semble uno plaisanterie. La vérité, c'est que le temps y est, en toute saison, beaucoup plus frais et plus désagréable que dans l'intérieur. On pouvait s'y attendre pour l'étó; mais l'hiver? Or là-dessus, les habitants sont unanimes, et il suffit de franchir la limite de la Plaine pour s'apercevoir qu'ils ont raison. Climat froid, changeant et humide, déclare-t-on d'un bout à l'autre. Climat froid : on va jusqu'à trouver que la différence avec l'intérieur est encore plus sensible l'hiver : et les habitants de la Plaine sont, sur ce sujet, du meme avis que leurs voisins de l'intérieur. Mème les silos de betteraves sont atteints par la geläe plus facilement que dans le Sud; il faut les recouvrir d'une plus forte epaisseur de terre. La différence de température, d'après un paysan du Furnambacht, est bien de l'épaisseur d'un bon gilet de laine. Sitôt que, la limite franchie, on entre dans la Plaine, on s'aperçoit du changenent : à 500 mètres près, les gens du pays savent où le froid se fait sentir. Entre Hondschoote et les Moëres, c'est au Ringslot; d'Alveringhem à Lampernisse, c'est à Forthem ;

I entre Caprycke et Watervliet, à Bentille. Climat changeant: ce sont les quatre saisons dans la même journée; Ia pluie succède brusquement au beau temps, le vent au calme. L'ouvrier agricole ne va pas aux champs sans emporter avec lui une grosse veste de drap, pour s'en couvrir si le temps

1 Amplitude maxima à Arras (28 années d'observations) : $57^{\circ}, 4$; maximum : $37^{\circ}, 4$, le 15 juillet 1881 ; minimum : - 200,0, le 7 fẻvrior 1895 . - A Lille (147 années d'observations) : $54^{\circ}$; maximum : $35^{\circ}$, atteint 10 fois, dont le 19 juillet 1881 ; tninimum : $-19^{\circ}$, le 3 décembre 1879. 
change: précaution inutile dans l'intérieur. Ie vent saute d'un point cardinal à l'autre; lo vont Nord peut souffler à Coxyde quand les girouettes de Furnes marquent lo Sud, et parfois à 3 ou 4 kilomètres de distance deux moulins sont orientés dans des directions différentes. « En général, dit Tully, le temps est ici très inconstant et sujet à varier dans la même journée du chaud au froid, et du froid au chand; jusque là, que celui qui prend un habit d'été le matin, est souvent contraint d'en endosser un d'hiver avant la fin du jour $\gg 1$. Ces brusques changements contribuent à entretenir les fièvres paludéennes. Enfin climat humide, père des rhumatismes qui affligent les habitants ; la rosée y est abondante; matin et soir', le brouillard monte fréquemment du sol : c'est le moment de se couvrir, surtout quand on vient de l'intérieur. Aussi l'habitant des Polders est-il mieux vêtı, mieux chaussé que le paysan de l'intérieur ; cela prouve qu'il est plus aisé, mais aussi que ce confort lui est nécessaire.

Il y a donc contradiction entre les conclusions à tirer des chiffres et l'impression que ressentent de leur climat les habitants de la plaine maritime. Sans doute l'humidité est pour quelque chose dans cette sensation de froid qu'on y éprouve été comme hiver, et qui s'accorde peu avec les moyepnes thermométriques ; et cette humidité est due au sol, découpé par mille canaux et où l'eau est si près de terre qu'on ne peut guère creuser un trou sans la rencontrer. Mais il $\mathrm{y}$ a aussi un autre élément: la fréquence et la violence du vent. Le vent est chez lui dans la plaine maritime: rien ne l'y arrête. Aussi y règne-t-il en maître; les journées calmes y sont extrêmement rares. Il n'existe malheureusement pas dans les stations du littoral d'observations scientifiques sur la force, les sautes et la fréquence de cet élément; mais il suffit de regarder l'état des arbres pour être éclairé au moins sur la puissance des vents d'Ouest ${ }^{2}$, les plus fréquents et les plus violents de Flandre. En général, le tronc est à peu près vertical dans les denx ou trois premiers mètres, grâce au tuteur qui l'a soutenu; mais ensuite il penche gauchement vers l'Est, avec une inclinaison qui peut atteindre 20 degrés, et les branches, déchiquetées et massacrées, se tendent désespérément dans la même direction, vers l'Orient, comme si olles fuyaient devant un ouragan perpétuel. Ce vent qui tord les arbres rafraîchit aussi l'atmosphère. Toutes les températures semblent plus froides lorsque le vent se fait sentir: or il ne chôme pas dans la plaine maritime, et il,y rend le climat plus rude. Les habitants

1 Tully, Essai sur les maladies de Dunkerque (Dunkerque, do Boubers, 1760, in-180, $26 \%$ p.), p. 13.

2 Nord-Ouest et Sud-Ouest. 
de l'intérieur, du pays boisé, attribuent à la présence de lours arbres la différence do température qui est si sensible entre les deux régions. Il est probable qu'en effot ces épaisses rangées d'arbres arrêtent les vents et protègent contre le froid; c'est pourquoi beaucoup de fermes de la région côtière se couvrent du côté de l'Ouest d'un véritablo rempart do grands arbres; mais s'il y a dans l'intérieur tant de plantations pour protéger du vent, quand la plaine maritime en possède peu, c'est en grande partio parce que la violence des vents, qui empêche la végétation arborescente de se développer près des côtes, s'atténue dans l'intérieur du pays et laisse s'élever les ormes et les chênes 1. En fin de compte c'est donc au régime de ses vents que la zone des polders doit son climat froid et changeant, quand les moyennes de température semblaient lui promettre toutes les douceurs du climat océanique ${ }^{2}$.

\section{Ia Pluie}

C'est à une méprise analogue que mène l'examen des chiffres de pluie tombée en Flandre; et la vue d'une carte des précipitations annuelles ferait croire que la région côtière est un pays oủ règne la sécheresse. Lả encore, il faudra montrer que les chiffres ne représentent pas exactement la réalité ${ }^{3}$.

1. Depuis 50 ans les arbres sont abattus en grandes quantités dans la Flandre intérieure de l'Ouest, ce qui no laisse pas d'exercer quelque influence sur lo climat, au dire des vieux paysans.

2 Aussi les conclusions de la petite étude de M. Durieux sur le climat du littoral belge sant ellos sujettes à caution. Lorsqu'il dit qu'un des principaux caractères de ce climat est une grande modération de la température, que les hivers y sont particulièrement doux et que l'on peut préconiser la côte pour l'installation d'établissements curatifs (pp. 24-25), ce sont des appréciations faites plutôt d'après les statistiques, que d'après la réalité.

3 Les chiffres des 76 stations utilisées représentent la moyenne des 20 années qui s'étendent de 1881 à 1900. 33 stations sont françaises, 38 sont belges, et 5 hollandaises. Les chiffres des stations françaises sont empruntés a Blanchard, Pluviosité, p. 205. Pour les stations belges, les chiffres de 1881 à 1892 sont tirés de Lancaster, La Pluie en Bolgique; M. D. Vanhove, répétiteur à l'Université de Gand, a bien voulu nous communiquer les chiffres des observations faites de 1892 à 1900, non encore publiées, et nous faire profiter des interpolations de détail, portant sur des mois isolés, qu'il avait déjà établies. I es chiffres des cinc stations zẻlandaises ont été fournis par l'Observatoiro néerlandais de de Bilt. Pour suppléer à l'absence de certaines années dans l'établissement des moyennes monsuclles et annuelles, on a eu recours au systéme d'interpolations formulé par M. Angot dans son mémoire sur le régimo dos pluies de la pẻninsule ibérique. (Ann. Bur. central météor., 1893, I, Mém. pp. B. 161-163). 
Tablead Des moyennes mensuelles ET anNuelles de Pluie 1

\begin{tabular}{|c|c|c|c|c|c|c|c|c|c|c|c|c|c|c|}
\hline \multirow{2}{*}{ STATIONS } & \multirow{2}{*}{ 䍖 } & \multicolumn{12}{|c|}{ NOYKNNES MENSUELLES } & \multirow{2}{*}{ 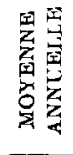 } \\
\hline & & 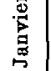 & 离 & 总 & $\overrightarrow{\mathrm{E}}$ & $\sum_{\nu}^{\pi}$ & & 㗼 & 蒙 & 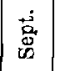 & 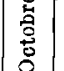 & 宮 & $\dot{\mathscr{g}}$ & \\
\hline Allouagne... & 30 & 46 & 37 & 42 & 33 & 49 & 56 & 66 & 60 & $\theta 1$ & 84 & 63 & 64 & 660 \\
\hline Alost ..... & 20 & 47 & 39 & 47 & 43 & $4 y$ & 68 & 76 & 71 & 65 & 80 & $62 \mid$ & 71 & 712 \\
\hline Anvers. & 7 & 43 & 37 & 38 & 36 & 43 & 63 & 68 & 62 & 64 & 67 & 53 & 61 & 644 \\
\hline Arras. . & 66 & 47 & 38 & 47 & 38 & 49 & 63 & 67 & 59 & 60 & 69 & 61 & 68 & 664 \\
\hline Audenarde.... & 11 & 39 & 38 & 45 & 37 & 48 & 60 & 71 & 52 & 57 & 77 & 61 & 62 & 657 \\
\hline Autryve...$\ldots \ldots$ & 15 & 36 & 29 & 33 & 35 & 47 & 52 & 62 & 55 & 57 & 74 & 52 & 58 & 590 \\
\hline Berchom...... & 12 & 42 & 35 & 42 & 35 & 48 & 60 & 66 & 63 & 58 & 77 & 62 & 63 & 652 \\
\hline Bergues ... & 7 & 44 & 37 & 44 & 35 & 45 & 49 & 60 & 69 & 69 & 95 & 64 & 62 & 673 \\
\hline Boesinghe & 10 & 40 & 33 & 44 & 35 & 48. & 53 & 65 & 72 & 62 & 84 & 56 & $63 \mid$ & 654 \\
\hline Boulogne ..... & 8 & 56 & 50 & 46 & 41 & 44 & 43 & 52 & 59 & 78 & 116 & $\cdot 77$ & 82 & 745 \\
\hline Bouvignies.... & 23 & 41 & 34 & 41 & 35 & 49 & 61 & 63 & 51 & 53 & $|67|$ & 55 & 59 & 609 \\
\hline Breskens & 1 & 34 & 35 & 34 & 30 & 42 & 47 & 65 & 64 & 60 & 80 & 49 & 47 & 590 \\
\hline Bruges P. C... & 5 & 41 & 34 & 44 & 35 & 46 & 58 & 66 & 72 & 66 & 85 & 56 & 58 & 661 \\
\hline Calais .... & 7 & 50 & 46 & 40 & 38 & 43 & 47. & 55 & 67 & $\cdot 78$ & 113 & 74 & 70 & 719 \\
\hline Cassel... & 106 & 53 & 47 & 53 & 45 & 51 & 59 & 70 & $80 \mid$ & 76 & 105 & 75 & 77 & 792 \\
\hline Comines ....... & 15 & 37 & 34 & 37 & 28 & 42 & 50 & 51 & 54 & 53 & $|73|$ & 52 & 53 & 563 \\
\hline Condé............. & 25 & 38 & 33 & 40 & 34 & 48 & 59 & 74 & 56 & 56 & 70 & 54 & 57 & 621 \\
\hline Dacknam ... & 2 & 36 & 31 & 31 & 31 & 4.4 & 58 & 69 & 61 & 61 & $74 \mid$ & 46 & 53 & 597 \\
\hline Deynze...... & 9 & 42 & 37 & 43 & 39 & 50 & 55 & 62 & 75 & 66 & 82 & 58 & 64 & 673 \\
\hline Dixmude.... & 6 & 35 & 29 & 37 & 31 & 45 & 49 & 59 & 67 & 59 & 78 & 52 & 50 & 591 \\
\hline Douai. & 28 & 46 & 40 & 48 & 39 & 53 & 67 & 74 & 61 & 59 & 74 & 63 & 66 & 690 \\
\hline Dunkerque. & 7 & 30 & 29 & 30 & 29 & 37 & 41 & 47 & 59 & 57 & 79 & 52 & 51 & 541 \\
\hline Erquières. & 120 & 59 & 47 & 52 & 45 & 55 & 55 & 77 & 82 & 75 & 106 & 81 & 91 & 824 \\
\hline Espierres & 13 & 37 & 30 & 32 & 31 & 43 & 52 & 57 & 53 & 56 & 70 & 49 & 55 & 565 \\
\hline Fauquembergues... & 90 & $\tau_{1}$ & 57 & 60 & 46 & 52 & 56 & 72 & 81 & 91 & 126 & 94 & 102 & 909 \\
\hline Flessingue ..... & 4 & 30 & 29 & 32 & 30 & 41 & 44 & 55 & 62 & 59 & 72 & 42 & 41 & 545 \\
\hline Frévent..... & 80 & 63 & 50 & 56 & 46 & 54 & 61 & 78 & 75 & 70 & 93 & 80 & 92 & 818 \\
\hline Fruges......... & 122 & 67 & 53 & 53 & 43 & 45 & 51 & 79 & 91 & 99 & 128 & 90 & 100 & 900 \\
\hline Furnes P. C.. & 5 & 40 & 34 & 42 & 34 & 52 & 51 & 61 & 65 & 73 & 90 & 58 & 59 & 659 \\
\hline Gand P. C... & 5 & 48 & 39 & 47 & 39 & 53 & 64 & 76 & 77 & 71 & 32 & 68 & 72 & 746 \\
\hline Gondecourt.... & 30 & 43 & 40 & 48 & 41 & 53 & 62 & 71 & 63 & 63 & 78 & 63 & 64 & 690 \\
\hline Grammont... & 18 & 54 & 45 & 51 & 45 & 52 & 68 & 73 & 26 & 67 & 88 & 65 & $7 k$ & 758 \\
\hline Gris-Nez (sẻmaphore) & 44 & 58 & 533 & 46 & 43 & 47 & 49 & 54 & 64 & 80 & 126 & 89 & $86 \mid$ & 796 \\
\hline Harlebeke... & 10 & 38 & 33 & 36 & 30 & 42 & 53 & 57 & 59 & 52 & 67 & 51 & 52 & 570 \\
\hline Heyst .... & 7 & 31 & 29 & 34 & 29 & 41 & 43 & 52 & 63 & 65 & $70 \mid$ & 49 & 46 & 552 \\
\hline Houthem & 4 & 40 & 36 & 41 & 36 & 51. & 55 & 68 & 72 & 71 & 94 & 61 & 58 & 683 \\
\hline Hucqueliers......... & 150 & 83 & 66 & 68 & 51 & 56 & 59 & 80 & 95 & 109 & 149 & 109 & 117 & 1041 \\
\hline
\end{tabular}

1 P. C. = Ponts-et-Ghanssées. 


\begin{tabular}{|c|c|c|c|c|c|c|c|c|c|c|c|c|c|c|}
\hline \multirow{2}{*}{ STATIONS } & \multirow{2}{*}{$\begin{array}{c}\text { 国 } \\
\stackrel{5}{5} \\
\stackrel{5}{G}\end{array}$} & \multicolumn{12}{|c|}{ MOYENNES MENSUELLES } & \multirow{2}{*}{ 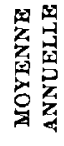 } \\
\hline & & 胥 & 蛋 & 总 & 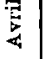 & $\bar{\Xi}$ & $\stackrel{a}{\rightrightarrows}$ & $\stackrel{9}{\Xi}$ & $\vec{z}$ & 苟 & : & 8 & ஜ் & \\
\hline Ijzendijke... & 2 & 45 & 38 & 44 & 35 & 51 & 52 & 70 & 75 & 64 & 88 & 55 & 62 & 679 \\
\hline Iseghem . . . . . . & $1 \overline{0}$ & 49 & 43 & 51 & 39 & 53 & 52 & 65 & 71 & 61 & 80 & 66 & 67 & 697 \\
\hline Knocko..... & 5 & 35 & $\boldsymbol{2 0}$ & 34 & 27 & 41 & 46 & 57 & 68 & 59 & 81 & 53 & 52 & 582 \\
\hline Laventie ... & 20 & 47 & 40 & 46 & 36 & 48 & 55 & 65. & 62 & 64 & 80 & 63 & 65 & 677 \\
\hline Le $\operatorname{Coq} \ldots .$. & 11 & 31 & 27 & 31 & 25 & 39 & 42 & 54 & 60 & 57 & 73 & 48 & 48 & 545 \\
\hline Lille.......... & 25 & 48 & 44 & 47 & 39 & 52 & 58 & 73 & 65 & 66 & 85 & 6.5 & $\tau(0)$ & 711 \\
\hline Magnicourt-s-Canche & 132 & 59 & 49 & 56 & 46 & 55 & 63 & 75 & 68 & 66 & 86 & 72 & 83 & 776 \\
\hline Maldegem .. & 6 & 49 & 40 & 49 & 39 & 50 & 61 & 69 & 81 & 70 & 89 & 62 & 67 & 727 \\
\hline Malinos...... & 11 & 49 & 40 & 46 & 43 & 50 & 64 & 76 & 67 & 69 & 70 & 54 & 62 & 690 \\
\hline Menin....... & 17 & 37 & 35 & 39 & 29 & 47 & 52 & 60 & 61 & 59 & 76 & 53 & 56 & 605 \\
\hline Merville...... & 17 & 40 & 35 & 41 & 33 & 44 & 51 & 60 & 57 & 59 & 80 & 58 & 57 & 614 \\
\hline Messines..... & 60 & 51 & 47 & 53 & 38 & 52 & 54 & 68 & 59 & 68 & 79 & 67 & 71 & 707 \\
\hline Les Moëres... & 1 & 41 & 34 & 38 & 33 & 51 & 50 & 61 & 69 & 71 & 96 & 60 & 58 & 660 \\
\hline Mont des Cats. & 158 & 47 & 30 & 49 & 37 & 51 & 57 & 67 & 71 & 69 & 95 & 67 & 67 & 712 \\
\hline Mouscron.... & 51 & 40 & 38 & 44 & 41 & 51 & 60 & 68 & 61 & 58 & 80 & 61 & 62 & 670 \\
\hline Nicuport... & 6 & 35 & 34 & 36 & 31 & 43 & 42 & 54 & 67 & 65 & 81 & 53 & 55 & 596 \\
\hline Nordpeene.. & 20 & 47 & 40 & 49 & 43 & 55 & 57 & 66 & 73 & 73 & 104 & 70 & 66 & 743 \\
\hline Orchies.. & 35 & 46 & 40 & 47 & 37 & 49 & 62 & 70 & 60 & 62 & 75 & 59 & 63 & 670 \\
\hline Ostende (nouv. phare) & $\$ 3$ & 33 & 24) & 36 & 29 & 38 & 43 & 55 & 57 & 59 & 73 & 51 & 49 & 552 \\
\hline Oye........ & 5 & 49 & 40 & 41 & 39 & 42 & 50 & 57 & 68 & 71 & 108 & 73 & 68 & 705 \\
\hline Péronne.... & 36 & 43 & 38 & 41 & 33 & 45 & 57 & 65 & 55 & 55 & 70 & 58 & 60 & 620 \\
\hline Pollinchove. . & 6 & 33 & 31 & 37 & 31 & 41 & 46 & 56 & 64 & 64 & 83 & 51 & 54 & 591 \\
\hline Pont do Paille.. & 5 & 42 & 31 & 36 & 33 & 50 & 57 & 65 & 77 & 66 & 78 & 55 & 58 & 644 \\
\hline Roodenhuyze . & 4 & 48 & 36 & 41 & 37 & 49 & 60 & 68 & 71 & 64 & 86 & 62 & 69 & 689 \\
\hline Roulers........ & 18 & 42 & 35 & 42 & 36 & 49 & 53 & 67 & 71 & 63 & 82 & 56 & 58 & 655 \\
\hline Rousbrugge ... & 6 & 37 & 35 & 39 & 33 & 45 & 53 & 59 & 65 & 68 & 86 & 57 & 57 & 634 \\
\hline Saint-Amand ... & 25 & 47 & 42 & 50 & 40 & 54 & 62 & 75 & 55 & 54 & 72 & 62 & 67 & 678 \\
\hline Samer......... & 67 & 05 & 56 & 52 & 48 & 50 & 50 & 67 & 83 & 97 & 135 & 94 & 48 & 894 \\
\hline Sint-Kruis .... & 1 & 45 & 38 & 42 & 36 & 48 & 57 & 69 & 79 & 71 & 78 & 54 & 58 & 675 \\
\hline Schipdonck ... & 10 & 42 & 36 & 39 & 33. & 48 & 57 & 65 & 71 & 62 & 80 & 54 & 63 & 649 \\
\hline Selzaete..... & 6 & 46 & 35 & 40 & 35 & 46 & 60 & 74 & 75 & 63 & 81 & 60 & 64 & 679 \\
\hline Semmorzaeke . & 9 & 45 & 33 & 39 & 35 & 44 & 59 & 71 & 69 & 65 & 91 & 60 & 62 & 673 \\
\hline Sluis........ & 2 & 41 & 41 & 41 & 35 & 48 & 53 & 68 & 80 & 67 & 85 & 59 & 60 & 677 \\
\hline Somergem...... & 15 & 50 & 39 & 45 & 37 & 51 & 62 & 66 & 77 & 70 & 85 & 59 & 68 & 711 \\
\hline Steene (France).. & 8 & 46 & 40 & 42 & 32 & 40 & 47 & 54 & 63 & 62 & 89 & 64 & 64 & 644 \\
\hline Steene-Schuur. & 2 & 38 & 32 & 39 & 34 & 50 & 64 & 70 & 76 & 69 & 88 & 56 & 58 & 674 \\
\hline Le Touquet. & 8 & 52 & 53 & 44 & 43 & 56 & 46 & 50 & 65 & 81 & 125 & 87 & 84 & 787 \\
\hline Valhuon .... & 150 & 68 & 56 & 60 & 50 & 56 & 62 & 76 & 75 & 78 & 104 & 86 & 95 & 864 \\
\hline Wormhoudt .... & 17 & 45 & 39 & 44 & 38 & 46 & 53 & 63 & 76 & 77 & 104 & 68 & 66 & 720 \\
\hline
\end{tabular}


Un rapide coup d'œil sur les moyennes annuelles montre d'abord que la quantité de pluie tombée est ordinairement comprise entre 600 et $700 \mathrm{milli}$ mètres. La différence est frappante entre Flandre et Artois. Celui-ci, dont l'altitude dépasse par endroits 200 mètres, et qui est directement exposé au souffle humide des vents d'Ouest, reçoit une quantité d'eau partout supérieure à 750 millimètres. La Flandre, abritée derrière l'Artois, est beaucoup moins arrosée, et ne reçoit qu'en un seul point, la colline do Cassel, une quantité supêrieure à 750 millimètres de pluie.

Cependant de notables dilférences apparaissent également dans la plaine flamande. La ligne des collines, reliees par Watten et Eperlecques aux hauteurs de l'Artois, apparaît jusqu'à l'Est d'Ypres sur la carto pluviométrique avec une somme d'eau tombée supérieure à 700 millimètres. Le pays d'Alost, grâce à son altitude, en reçoit autant. Enfin trois curieux maxima secondaires réclament explication: Gand reçoit 746 millimètres de pluie, Iille 711, la région d'Eecloo 711 et 727. Pour les deux grandes villes, dont l'altitude est cependant assez basse, il semble qu'il faille attribuer cette forte pluviosité aux énormos quantités de poussières que lancent dans l'atmosphère les fumées de leur groupe industriel, poussières dont le rôle est si grand dans la formation de la pluie ${ }^{1}$. Pour le pays d'Eecloo, l'augmentation de la quantité de pluie doit être due à la présence de grands bois. De Somergem à Thourout, par Maldegem et Aeltre, c'est la partie la plus boisée de la Flandre; or les forêts attirent la pluie ". Aussi ce maximum secondaire se prolonge-t-il vraisemblablement vers le SudOuest, dans la direction de Thourout et Thielt.

- Entre les maxima, des minima se creusent dans les vallées. Celle de l'Escaut, entre Condé et Berchem, ne reçoit même pas 650 millimètres ; et à l'abri des hauteurs de Mouscron et Sweveghem, le chiffre des précipitations n'est plus que de 590 millimètres à Autryve, 565 à Ispierres. Mieux abritée, la vallée de la Lys est encore plus sèche. Déjà sur le bord de l'Artois, il ne tombe plus que 660 millimètres d'eau à Allouagne; à Merville, au centre de la plaine, 614. Enfin entre Armentières et Courtrai, où la ligne des collines fait écran devant les vents d'Ouest et Nord-Ouest,

1 Les pluies à Lille ont augmenté avec l'essor industriel de la région. Voici les moyennes annuelles:

$\begin{array}{llll}\text { De } 1811 \text { à } 1840 \ldots \ldots & 651 \text { millimètres } \\ \text { De } 1841 \text { à } 1870 \ldots \ldots & 681 \\ \text { De } 1870 \text { à } 1900 \ldots \ldots & 726 \quad \text { 》 }\end{array}$

Donc, augmentation de 30 millimètres dans la première période, et de 45 dans la deuxième. - Voir: Schmeltz, Observations météorologiques faites à Lille de 1757 à 1888 (Lille, Danel, 1901, in-8 $8^{\circ}, 335$ p.).

* Cf. Blanchard, Pluviosité, pp. 215-216. 
la pluviosité s'abaisse à 565 (Comines) et 570 (Harlebeke). Au contraire à la hauteur de Deynze, où la vallée n'est plus abritée, la quantité se relève à 673 millimétres. La faible pluviosité des vallées n'est done pas due uniquement à l'altilude, mais à leur orientation par rapport à des régions plus élevées, sur lesquelles les nuages pluvieux épuisent leurs réserves d'eau.

Mais le trait le plus caractéristique, c'est le minimum de la plaine maritime, que l'on suit sur la carte de Gravelines à l'Escaut. Même ce n'est pas à la Plaine tout entière que s'étend cette faible pluviosité, mais bien à la région côtière. Là sont les chifres les plus bas de la région: 552 millimètres à Ostende et Heyst, 545 à Flessingue et Le Coq, 541 à Dunkerque. Au contraire la pluie augmente rapidement vers l'intérieur: 660 millimètres aux Moëres, 673 à Bergues, 683 ả Houthem, 659 à Furnes, 661 à Bruges, 677 à Sluis, 679, 675, 674 à Ijzendijke, S. Kruis et SteeneSchuur. Ce sont là des chiffres considérables, étant donné la faible altitude des stations; souvent plus considérables que ceux de l'intérieur. Entre Houthem, à l'altitude 4, et le Mont des Cats, à 158 mètres, la différence des chiffres de pluie n'est que de 29 millimètres. Donc, sur la côte même, la pluie tombée est très faible, tandis qu'à quelques kilomètres de la mer la quantité est plutôt forte. Ce n'est pas cependant que sur la côte la force du vent empêche les gouttes de pluie de tomber dans l'entonnoir des pluviomètres, car le vent est violent aussi dans l'intérieur de la plaine. Il faut s'en tenir à ce fait, qu'à égalité d'altitude, la côte est moins arrosée que l'intérieur : Gris-Nez et Boulogne moins que Samer, Dunkerque moins que Bergues (différence: 132 millimètres); Nieuport moins que Furnes (63 millimètres), Heyst que Bruges (109 millimètres), Knocke que Sluis (95 millimètres), Flessingue qu'ljzendijke (134 millimètres).

Cependant, malgré ces différences formelles, les habitants no paraissent guère s'apercevoir que la pluie tombée sur la côte est beaucoup moins considérable qu'à l'intérieur ; ils sont persuadés qu'à Durkerque comme à Bergues il tombe beaucoup d'eau, et souvent; que c'est lo cas pour tonte la Flandre. Cette impression s'explique par la façon dont ces pluies inégales se répartissent en des quantités à peu près ógales de jours pluvieux. On trouve même à Dunkerque 157 jours pluvieux contre 134 à Bergues. La moyenne peut etre évaluée à 150 jours pour la plupart des stations, encore que ce soit là un genre d'observations où l'appréciation personnelle des observateurs tienne trop de place. En tous cas, la pluie tombe aussi fréquemment sur la côte, où elle donne 541 millimètres, que dans l'intérieur, où elle en fournit 792 ; les averses sont aussi nombreuses, mais elles sont plus fines, moins abondantes. 

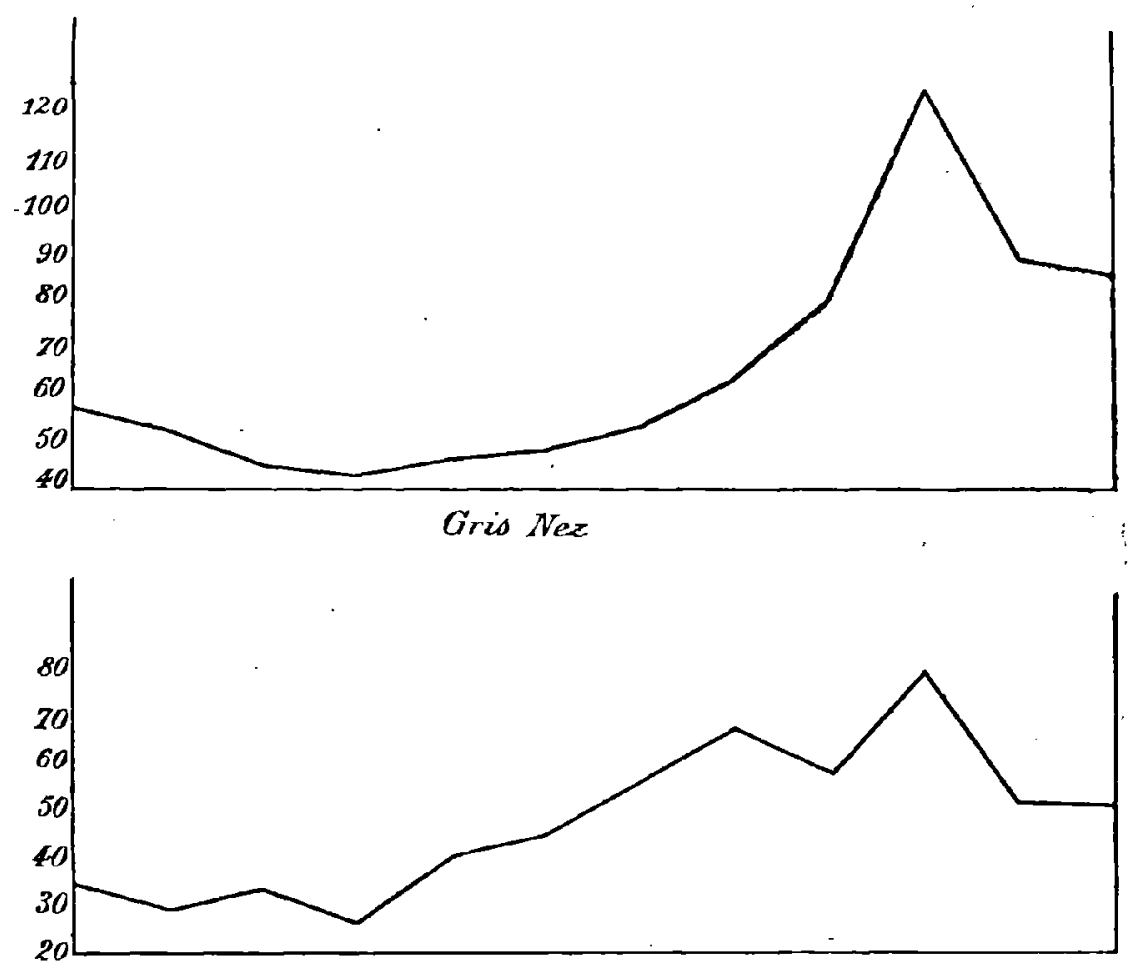

Knocke
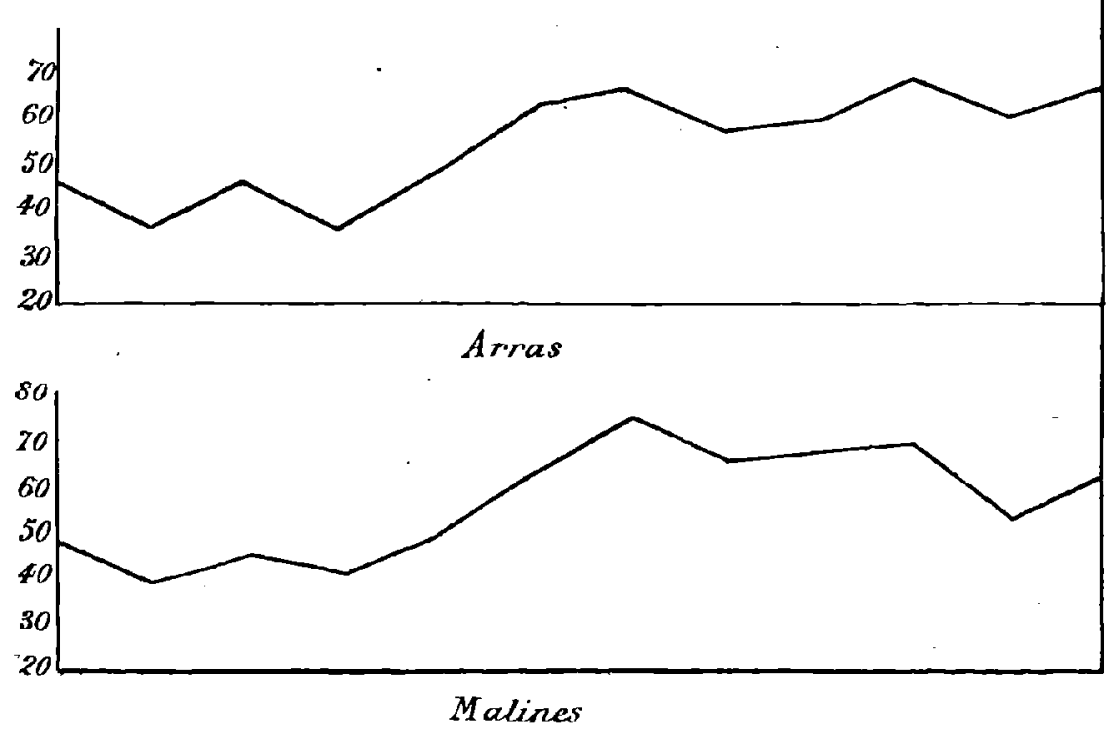

Fia. 4. - Courbes anmuelles de quelques stations pluviométriques. 
Ces pluies se répartissent assez inégalement dans les différents mois : il y a des mois qu'on peut qualifier de secs, d'autres qu'on peut appeler pluvieux : la moyenne de ceux-ci étant parfois trois fois plus considérable que celle de ceux-lá. Cette constatation étonne encore les Flamands, auxquels il semble que la pluie est libéralement distribuée entre tous les mois. En effet pendant les mois secs (printemps), l'eau tombe en giboulées, en petites averses fréquentes ; pendant les mois pluvieux (été et automne), en grosses pliuies d'orage. Aussi le nombre des journées mouillées est-il à pen près le même dans chaque mois, exception faite pour octobre, et c'est ce qui masque les fortes diffèrences qu'on observe entre les quantités d'eau tombée.

C'est au Nord-Ouest que l'amplitude entre les moyennes mensuelles est la plus forte. A Gris-Nez, il n'y a qu'un minimum et un maximum: 43 millimètres en avril, 126 millimètres en octobre, soit 83 millimètres d'amplitude; la courbe se développe régulièrement, sauf une chute brusque de décembre à janvier; c'est un régime de pluies d'automne, assez semblable à celui de Brest (fig. 4). A l'autre bout de la côte flamande (Knocke), la courbe est déjà moins régulière, quoique l'allure générale soit la même; avril et octobre sont toujour's les mois extrêmes, avec une amplitude de á4 millimètres ; mais il existe un second minimum en février, un second maximum en août; ce n'est plus, dans toute son ampleur, le climat maritime de l'Ouest de l'Europe. Dans le Sud, tout s'egalise. A Arras, il y a deux maxima à peu près égaux, 69 en octobre, 67 en juillet, et deux minima : 38 en avril et fóvrier ; l'amplitude est de 31 millimètres. Les pluies d'èté sont déjà presque aussi abondantes que celles d'automne. Enfin à l'Est de la Flandro, les pluies d'été l'emportent ; le maximum est en juillet à Malines (76), contre 70 en octobre; le minimum est en février (40); l'amplitude reste faible (36). C'est déjà ce qui se passe pour les pluies de l'Allemagne occidentale (région rhénane). Aussi la comparaison est-elle intéressante entre la carte des moyennes de juillet et celle des moyennes d'octobre. En juillet, la quantité de pluie augmente régulièrement de la côte vers l'intérieur, de Dunkerque, Boulogne, Heyst $(47,52,52)$ vers Condé, Grammont, Alost (74, 73, 76). En octobre, la quantité va croissant de l'intérieur vers la côte occidentale, d'Anvers (67), Conde (70), Arras (69), vers Calais (113), Gris-Nez (126). Ainsi le régime des pluies, dans le Nord-Ouest de la Flandre, est déjà océanique; dans l'Est, il tend à être continental ${ }^{1}$.

1 On n'a pas dressé de moyennes ni de cartes saisonnières: une saison pluviomètrique, en Flandre, n'est qu'une entité : comment comparer, en hiver, décembre à 
En résumé, les pluies dominantes en Flandre sont celles d'automne et d'été, les premieres surtout dans l'Ouest; les minima se produisent en hiver et au printemps. De cette répartition résultent parfois des inconvénients pour la culture. Dans les cantons très argileux, les pluies d'automne empêchent parfois les labours et les semailles, les champs étant impraticables. Les pluies d'été nuisent peu; en général elles sont brusques, rapides, et leur effet est faible; elles imprègnent peu le sol. C'est encore aux fortes pluies d'automne que sont dues les crues annuelles des cours d'eau et les inondations. Dans un mois humide comme octobre, qu'une longue et forte pluie survienne lorsque ce sol imperméable est déjà saturé d'èu, tout glissera à la surface et ira grossir d'un flot de crue les rivières; de là des débordements soudains qui peuvent être dangereux.

\section{Les vents.}

Cette inégale répartition de la pluie dans les différents mois est due aux changements, d'ailleurs peu importants, qui se produisent dans la répartition des vents dominants ${ }^{1}$. Pour l'ensemble de l'année, les vents d'Ouest l'emportent de beaucoup sur les autres, comme il fallait s'y attendre: vents du S.-W. à Ostende, Furnes, Iseghem, Maldegem, Uccle, Turnhout, vents d'W. à Selzaete, vents du N.-W. à Arras ${ }^{2}$. En janvier, la répartition est à peu près identique à celle de l'année moyenne; à peine le vent d'E. gagne-t-il quelques unités à Selzaete, le vení S.-E. à Arras. De même, la répartition des pluies en janvier est à peu près la même que celle de l'année. La sécheresse du printemps s'explique par la direction

fëvrier (différence à Iille, 36 millimètres); en automne, octobre et novembre (différence à Lille, 20 millimètres)? On a donc établi seulement 4 cartes de moyennes mensuelles, celles do janvier, avril, juillet, octobre, qui représentent assez bien les faibles précipitations d'hiver et printemps, les fortes pluies d'automne et été (voir les cartes à la fin du volume).

1 Les observations sur les vents ont été recueillies dans l'Annuaire météorologique de l'Observatoire royal de Bulgique pour les sept stations belges; pour Arras, dans le Bulletin de la Station agronomique du Pas-de-Calais. Les moyennes ont été établies d'après les chiffres des dix années 1891-1900.

2 La prédominance du vont du N.-W. à Arras, presque en toute saison, semble s'expliquer par la situation topographique de la ville, établie dans un fond que protègent des vents d'W. les hauteurs de Warlus et de Tilloy, tandis que la vallée de la Scarpe ouvre une route aux vents du N.-W. De même les hauteurs de Souchez forment écran contre les vents du $\mathbf{N}$., qui y sont plus rares que partout ailleurs. 
des vents en avril ; les vents du N. et du N.-E. prennent l'avantage ${ }^{1}$; ils deviennent les vents dominants. En juillet, les vents secs, N. et N.-E., figurent encore honorablement dans la région côtière et ses abords, à Ostende, Furnes, Maldegem; mais ils n'ont plus aucune importance dans l'intérieur, et surtout à Arras et Uccle, où le N.-W. d'un côté, le S.-W. de l'autre, prennent toute la place ; ainsi s'explique qu'en juillet la quantité de pluie diminue de l'intérieur vers la côte. Au contraire en octobre les vents humides prennent partout une grande avance: S. et S.-W. à Ostende, Furnes, Iseghem, Turnhout, W. à Selzaete, S. à Maldegem : cependant à Arras et à Uccle, le vent sec du S.-E. garde une certaine importance, ce qui empêche les pluies de ces stations d'ètre aussi abondantes que celles de la région côtière. Ainsi les vents secs de la région E. peuvent par moments atténuer les effets des vents humides de l'W.; mais cenx-ci restent largement prédominants, et peuvent souffler des mois entiers : à Arras, en juillet 1891, le vent du N.-W. resta le plus fort pendant 26 jours, amenant 8 orages, donnant 20 jours de pluie et 105 millimètres d'eau (moyenne 67), dont $45 \mathrm{~m} / \mathrm{m}$ dans une seule journée. C'est d'ailleurs cette fréquence des vents d'W. qui amène dans l'intérieur de la Flandre les orages qui y éclatent si souvent, en plus grand nombre que dans le reste de la Belgique, et jusque dans l'arrière-saison (20 à 30 jours de tonnerre par an). Parfois l'orage s'y accompagne de tourbillons, véritables petites trombes, assez fortes pour renverser les meules de lin ou de paille et pour déraciner les arbres, dans l'étendue restreinte où elles se produisent. Une ferme fut ainsi renversée près de Maldegem le 13 juillet 1884, et un moulin à vent à Ronsele le 16 avril 1887. Ce sont là des sinistres exceptionnels; en général les branches cassées, les gerbes dispersées, les tuiles enlevées, témoignent seules de la force de ces météores ${ }^{2}$. Ces orages sont beaucoup plus rares dans la plaine maritime; en revanche les tempêtes y sont d'une rare violence, et toujours causées par les vents d'W., daus les derniers mois de l'année. En 1136, le vent jette à bas 60 pieds de rempart à St-Omer ${ }^{3}$; en 1143 et 1149 , la tempête enlève les arbres et les toits,

1 a Les vents d'Est. ... règnent ordinairement dans la Flandre pendant les premiers mois de l'annẻe. Ils purifient l'air par leur sécheresse, lui remettent son élasticité, et causent do fortes gelées.... Ces gelées, quand elles arrivent dans la saison convenable, font un bien inexprimable aux habitants et à la terre; les maladies ordinaires disparaissent, la vermine est détruite ». Abbé Mann, Mémoire contenant le précis do l'histoire naturelle des Pays-Bas maritimes. (Anc. Mćm. Ac. Brux., t. IV, p. 137).

2 Monographie agricole de la région sablonneuse des Flandres, p. 14.

3 Meyer, Annales, ad annum. 
foudroie hommes et bêtes ${ }^{1}$. En 1406, nouveau sinistre ${ }^{2}$; en 1517 l'inondation suit l'ouragan ${ }^{3}$; les deux catastrophes se produisent à la fin de décembre. On remarque que novembre est particulièrement dangereux : c'est le mois des grandes inondations marines, causées par le vent de N.-W., le plus violent et le plus redoutable de tous ; c'est lui qui démolit les constructions, fauche les arbres, lance les flots à l'assaut des digues ${ }^{5}$.

Mais qu'on n'oublie pas que le vent est essentiellement variable en Flandre. Dans la même journée, il n'est pas rare que la girouette regarde successivement de tous les côtés de l'horizon. C'est un caractère commun à toute l'Europe occidentale; mais il est rarement aussi développé qu'en Flandre, particulièrement dans la plaine maritime. Et c'est cette variabilité qui raméne de l'uniformité dans le climat tlamand. Pas d'extrêmes : ni extrêmes de température, grâce aux vents marins qui continuent de souffler en toute saison, presque en toute journée; ni extrêmes de sécheresse puisque les souffles humides de l'W. contrarient l'action desséchante des vents d'E. Et c'est cette uniformité qui fait le dèsespoir des étrangers: les beaux jours sont rares, et l'on n'est jamais sûr du temps. On peut presque dire qu'en Flandre le temps est uniformément changeant.

II.

\section{LES GARAGTÈRES DU GLIMAT.}

Chaque mois du climat flamand est ainsi enveloppé de cette grisaille, de cette uniformité de ton qui atténue ses caractères propres. Janvier, pour le vieux calendrier flamand ${ }^{6}$, e'est le Sneeuw-maand, le mois de neige; mais voilà neuf ans qu'il n'est guère tombé de neige; en revanche il y

\footnotetext{
1 Meyer, Annales, ad annum.

2 Ibid.

3 Ghronicon monasterii Evershamensis, conscriptum per Gerardum de Meestere. (Bruges, Soc. d'Em., 1852, p. 28).

4 Sur 40 observations de tempêtes faites à Calais, 13 étaient dues au vent du N.-W., 13 au vent d'W., 6 au N.-E., 4 au N., 2 à l'E., 1 au S.-W., 1 au S.; le S.-E. n'en avait produit aucune. (Cf. Aron, le Port de Calais, dans : Ports maritimes de la France, publication du Ministère des Travaux publics, t. I, Paris, 1874, gr. in-80 ; pp. 197-198).

- Meyer, Annales, édition de 1561, pp. 163 et 270.

6 Cf. Werner de Haerne, Quelques notes sur l'ancien calendrier flamand. (Mess. Sc. Hist., tome 58, 1890, pp. 1800-192).
} 
pleut, et beaucoup : 53 millimètres à Cassel, 50 à Calais et Somergom, 51 à Messines, 54 à Grammont: parfois plus de 100 millimètres; et la température aussi varie, mais descend rarement au-dessous de zéro: $-1^{0}$ à Lille en 1893, + $5^{\circ 2}$ en 1900. Février, mars, avril, sont les mois secs; avril reçoit les quantités d'eau les plus faibles do toute l'annéo; mars est le mois des vents qui sèchent la terre, I)oore-maand, Wind-maand ; c'est le moment de semer dans la région sablonneuse, où les plantes mûrissent vite, sauf quand la pluie est trop abondante, comme en 1901. Mai et juin sont déconcertants: la tempórature peut y descendre à $0^{\circ}$, et monter jusqu’à $30^{\circ}$; la pluie varier de $7 \mathrm{~m} / \mathrm{m} 7$ (mai 1896) à 127 m/m 5 (mai 1898) ${ }^{1}$. Juillet, mois chaud, est rarement sec; il y tombe des quantités d'eau considérables, et la chaleur reste lourde, humide; quoiqu'elle dépasse rarement $30^{\circ}$, elle est peut-être plus difficile à supporter que celle du midi. Au mois où l'on fait les foins (Hooeij-maand) succède celui où l'on moissonne le blé (Ougst-maand); mais moisson en Flandre ne signifie pas sécheresse, et août, aussi chaud que juillet, est à peu prẻs aussi humide. Les quinze premiers jour's de septembre sont peut-être les plus agréables du climat flamand; mais bientôt les grandes pluies d'automne se produisent, el octobre est uniformément tiède et humide. Aussi novembre est-il bien le mois de boue (IIore-maand) ; mais il est aussi le Nevel-maand, le mois du brouillard, ce brouillard qui couvre la Flandre des journées entières; do même en décembre qui est assez doux, rarement froid, puisque la température peut encore atteindre une moyenne de $7^{\circ}, 7$ (Dunkerque, 1898), avec des journées de $13^{\circ}, 0$ (18 décembre 1898), et reçoit des quantités de pluie élevées, 70 millimètres à Lille, 72 à Gand, 77 à Cassel.

\section{Influence sur la nature et l'homme.}

Dans l'ensemble un pareil climat est favorable à la culture. T'empéré, un peu uniforme, il favorise l'éclosion et la croissance des végétaux; la pluie, suffisamment abondante et répartie sur un grand nombre de jours, est précieuse pour les sols sablonneux du Nord, particulièrement avides d'eau, et pour les terres argileuses, qui se fendent à la sécheresse. Le climat corrige donc un peu les gros défauts du sol flamand; il a contribué à faire de ces terres souvent ingrates de riches terroirs agricoles. Mais il n'est pas séduisant. La pluie bénie par le paysan est désagréable au

1 Station des Moëres. 
citadin qui patauge dans une boue continuelle, due antant a l'humidité de l'atmosphère qu'd̀ la nature gluante du sol. La nébulosité est forte : 6,0 à Furnes, 6,2 à Ostende (ville), 6,5 à Maldegem, 6,8 à Iseghem et Selzaete ; certains mois sont presque complètement privés de soleil, surtout ceux d'hiver; Janvier 1896 à Arras a 26 jours complètements couverts, et le soleil n'éclaire en tout que pendant 16 heures ; Novembre 1892 a 22 jours entièrement gris, Décembre 1889 et 1895, 19 jours ${ }^{1}$. «Un pâle soleil amical sourit doucement, se cache, et tout caché qu'il est, attiédit l'air », note Taine en parcourant la Flandre ${ }^{2}$. Souvent le brouillard se met de la partie; matin et soir il se lève des terres basses; dans les mois d'automne et d'hiver il couvre tout le pays. Ostende en a, en moyenne, 78 jours par an; Iseghem 70, Maldegem 67. Même par les temps clairs, il est rare qu'on voie quelque chose au loin, en Flandre. Les objets s'estompent d'une brume bleue, qui n'est pas sans charme. L'horizon est vaste, mais presque toujours indistinct. Enfin l'humidité règne d'un bout à l'autre de l'année : c'est la note dominante du climat flamand. Elle se révẻle par la vigueur de la végétation, les prairies à l'herbe drue, les moissons fortes en paille, les arbres florissants. Ouvriers infatigables, tous ces végétaux travaillent à assainir l'air et la terre, à absorber l'humidité ${ }^{3}$; et pourtant ils n'y suffisent pas ; elle reste assez abondante pour être désagréable ; une humidité tiède, mère des moisissures et des végétations cryptogamiques. Elle poursuit l'homme jusque chez lui, s'attaque à ses vêtements, à ses meubles. L'homme se défend, frotte, nettoie, arrose. L'humidité a fait la propreté flamande, célèbre dans la France entière. On Iave a grande eau, on inonde la maison chaque semaine. C'est pour le dimanche que la maison doit etre propre; on y travaille done le samedi, el on finit par s'y mettre le

1 Il est rare que la nébulosité mensuelle descende au-dessous de 4. A Arras, les minima furent atteints (pour la période 1884-1902) en avril 1893, ou Ia nébulosité fut de 1,57 seulement, 20 jours ayant été complètement découverts; le vent resta 19 jours au S.-E. ; le nombre d'heures de soleil s'éleva à 275 , au lieu de 155 (chiffro moyen). Juillot 1900 compto 308 heures de soleil ; la nébulosité était do 3,16 ; le vent variable (13 jours au N.-W.).

2 Taine, Notes de voyage en Belgique et en Hollande. (Revue de Paris, 1895, t. III, p. 687).

3 « Ce qu'on doit compter pour beaucoup dans ce pays co sont les vapcurs lumides ou brouillards qui se répandent presquo continuellemont des marais ou bas-fonds. Cette humidité serait pout-être très pernicieuse aux habitants, si elle n'était absorbée continuellement par les plantes et les bleds qui y croissent abondammeni. C"est peut-être cette humidité qui fait que ces pays paraissent plus tempérés qu'ils ne devraient être, selon leur position ". Guettard et Monnet, Atlas et description minéralogique de la France. $1^{\text {ro }}$ partie (Paris, Didot, 1780), p. 48. 
jour précédent; dès le vendredi, la ménagère flamande commence son grand nettoyage. Boucher de Perthes, visitant Lille en 1856, trouvait que la ville sentait le savon noir. Le résultat paraît mince dans les grandes villes industrielles, emplies de fumée, de poussière et de boue; mais les villes un peu assoupies, Ypres, St-Omer, Furnes, Bailleul et même Courtrai, Bruges, une partie de Gand sont réellement propres, nettes; elles qnt même l'air un peu froid, trop bien tenu. De même les campagnes flamandes sont généralement irréprochables; meubles frottés, dallage brillant, tout bien en ordre. Souvent la maison ne paye pas de mine, c'est une vieille ferme en torchis, murs déjetés, toit de chaume, et l'intérieur est attrayant, avec ses ustensiles reluisants, son grand poële astiqué, ses meubles cirés, et la petite collection d'objets de piété aux couleurs claires. C'est que le climat désagróable force le Flamand à vivre beaucoup chez lui. Aussi cherche-t-il à se créer un intérieur qui soit gai, clair, et lui tienne lieu du monde extérieur que la pluie, le brouillard et la boue, rendent déplaisant. De lả les nombreuses et hautes fenêtres dont s'ornent les vieux manoirs ruraux, et toutes les maisons des villes; elles tiennent toute la rangée de la façade, et n'ont pas de contrevents, comme si on craignait d'empêcher un peu de jour d'entrer; de lá aussi les larges baies qui remplacent les fenêtres dans les demeures modernes, et laissent pónótror á flots une douce lumière tamisée dans la dentelle des rideaux. Mais si l'on désire que la lumière pénètre le plus largement possible, l'entrée de l'air brumeux, humide, souvent agitê par les vents d'Ouest, est chichement mesurée; toutes ces fenêtres sont divisées en deux parties, dont la seconde seulement peut s'ouvrir : et c'est sonvent la plus petite. C'est encore à la lutte contre un climat brumeux qu'est due la véranda, cette pièce vitrée si caractéristique de la maison lilloise, où l'on a résolu le problème de voir clair, de vivre hors de la maison un peu sombre, d'être à l'exterieur tout en restant confortablement enfermé. Pour assurer à la pluie fréquente un ecoulement rapide les grands toits s'allongent, interminables, faits de petites tuiles rouges, qui donnent un aspect de gaiete si inattendu aux vieilles villes flamandes vues de leur beffroi, comme Bruges ou Bergues.

Ce climat déplaisant est-il malsain? Les ótrangers l'affirment, et déclarent qu'ils en ont fait l'épreuve. Cependant la population ne paraît guère s'en apercevoir. Cette humidité si redoutée donne peut-être une proportion de rhumatismes plus considérable qu'ailleurs; c'est là son principal méfait. Si la mortalité est très considérable en Flandre, cela ne tient guère au climat: c'est que la Flandre est un pays paurre à natalité trop forte; c'est que sa population, qui a des habitudes invétérées de propreté, se croit par là dispensée de pratiquer l'hygiène: enfin que les 
grandes villes industrielles sont encore mal assainies, malgré de très grands efforts, et assez insalubres. Mais le climat n'y est pour rien; et c'est dans la plaine maritime, la région la plus humide, et où le climat est le plus désagréable, que l'on se porte peut-être le mieux. C'est qu'elle est plus aisée que le reste de la Flandre, et son exemple montre que le fléau du pays n'est pas son brouillard ou sa pluie, mais la pauvreté el l'ignorance.

D'ailleurs le climat flamand est-il bien différent des climats voisins, hollandais, picard? La température est à peu prés la même, la quantité de pluie sensiblement égale; les jours pluvieux aussi nombreux ${ }^{1}$. Si la Picardie est moins humide, à cause de son sol perméable, la Hollande l'est encore plus, en raison de sa faible altitude et de l'imperméabilité de ses polders. Cependant le climat hollandais n'éveille que des idées agréables et des souvenirs d'art, évoque l'image des tableaux do Ruysdael et de Potter. Il a manqué au climat flamand d'être réhabilité par un grand peintre; il reste gris et triste, et n'est agréable que lorsque cela ne l'empêche pas d'être utile.

\section{Prétendus changements du climat.}

On prêtend qu'il n'en a pas toujours été ainsi. La Flandre aurait connu les ardeurs du soleil, et les sécheresses qui font mûrir la vigne délicate. Il aurait fait jadis plus chaud en Flandre qu'aujourd'hui, puisqu'on a vendangé sur les bords de la Lys et de la Deûle. Il est vrai qu'il y eut jadis dans le pays des vignobles en exploitation, et qu'on buvait du vin de Flandre. Même la vigne ne fut pas introduite artificiellement dans le pays au XI' siècle par le comte Baudouin V, comme le disent les chroniqueurs ${ }^{2}$; son existence y est signalée bien avant, et au $\Gamma \mathrm{X}^{\circ}$ siècle Eginhard parle longuement du vignoble planté sous l'abbaye de St-Pierre ${ }^{3}$, à Gand. Près de Lille en 812, les missi de Charlemagne déclarent avoir trouvé dans le fisc d'Annapes et de Gruson une vigne d'un arpent; en 1235, il est question de la reconstitution d'une vigne à Moncheaux en Pévèle; en 1265 et 1296 , les chartes parlent de vignobles situés à Lille même, derrière

1 Sur le climat de la plaine picarde, voir : Demangeon ( $\Lambda$.), La Picardie et les régions voisines (Paris, Colin, 1905, in-8`, 496 p.), .pp. 85-110.

M. G. SS. XV, p. 854 .

3 Van Lokeren, Chartes et documents de l'abbaye de St-Pierre au mont Blandin à Gand (Gand, 1871, 2 vol. in $\left.-4^{\circ}\right)$, I. p. 17. 
l'église St-Maurice; en 1536, on constate l'existence des plantations de Wattrelos près Roubaix ${ }^{1}$; des noms de fiefs rappellent le souvenir de vignes à Roubaix, Bondues, Erquinghem, Linselles, Prémesques, Wattrelos, Hem, Tourcoing. En Artois, les vignes du Mont-St-Eloi fournissaient en 1208 assez de vin pour suffire aux deux repas des moines". D'autres clos sont signalés au XIII ${ }^{\theta}$ siècle dans la plaine maritime, à Bulscamp et Wulpen ${ }^{3}$; dans les biens de l'abbaye d'Eename (Fl.-Orientale); au $\mathrm{XIV}^{\mathrm{e}}$ siècle à Bousbecque, sur la pente Sud de la colline du Colbras ${ }^{3}$; au $\mathrm{XV}$ e siècle à Gand, où les plantations d'Eginhard s'étaient développées, et sont indiquées en 1406, 1414, 1452, etc. ${ }^{\circ}$. Enfin des noms de lieux-dits rappellent la présence de la vigne un peu par toute la Flandre, d'Anvers à la frontière française ${ }^{7}$. Or les vignobles sont disparus aujourd'hui. Déjà au XVIII siècle, on n'en trouve guère en Picardie au delà de Montdidier $^{8}$; au inilieu du XIX ${ }^{\circ}$ siècle, on n'en rencontre plus autour de Laon. On a conclu de cette disparition progressive que le climat avait changé, devenant plus froid ou plus humide, faisant reculer doucement la vigne vers le Sud, vers la Champagne ou les coteaux parisiens.

Cependant les vignobles de Flandre ont pu mourir sous d'autres coups. Ils portaient en eux-mêmes les causes de leur décadence ; l'âpreté de leurs produits suscitait la concurrence étrangère. De bonne heure les vins du Poitou et du Bordelais les chassèrent de la tahle des honnêtes gens; les

1 Gf. Leuridan (Th.), Statistique féodale du département du Nord; la chatellenie de Lille (Bull. Comm. H. N., XXI, pp. 177-178); - Hautcour (E.), Cartulaire de St-Pierre de Lille, I, pp. 227-228; Histoire de l'église collégiale et du chapitre de St-Pierre do Lille, I, p. 242 ; - Roisin (Jean), Franchises, lois et coutumes de la ville de Lille (édition Brun-Lavainne, Lille, 1842, in-4\% ${ }^{\circ}$ ), p. 339.

2 Recherches sur l'abbaye de Mont-St-Eloi. (Mém. Soc. Ant. Mor., V, p. 216).

3 Van de Putte et Carton, Chronicon et cartularium abbatiae S. Nicolai Furnensis, 1120-1354 (Bruges, Soc. Em., 1849, in-4\% , p. 75 .

+ Piot (Ch.), Cartulaire de l'abbaye d'Eename: 1069-1525. (Bruges, 1881, in-4º), p. 232.

3 Dalle (J.), Histoire de Bousbecquo (Wervicq, 1880), p. 114.

6 Van der Haeghen (F.), La culture de la vigne à Gand. (Mess. Sc. Hist., t. 54, 1886, pp. 133-137).

7 A Alost, Basel, Beveren-lės-Roulers, Bruges, Calloo, Cruybeke, Dickelvenne, Haringhe, Hooglede, Langemarck, Lebbeke, Rupelmonde, St-Paul, Sinai, Steenhuyzen, Wachtebeke, Wetteren, Wevelghem, Wondelgem. - Cf. Halkin (J.), Etude historique sur la culture de la vigne en Belgique (Soc. d'art et d'hist. du diocèse de Liège, t. IX, 1895, pp. 1-146), pp. 66-69.

* Calonne (A. de), La vie agricole sous l'ancien régime dans lo Nord de la France, . p. 100. 
comptes d'archives sont pleins de cette invasion; et l'importation des vins fut un des articles les plus considérables du trafic des ports. Plus tard les ducs de Bourgogne favorisèrent les crus de leur pays. La résistance était difficile : en 1590, on remarque que les vignobles rapportaient moitié moins que les terres á blé ${ }^{1}$. Aussi dès cette époque l'issue de la lutte n'était plus douteuse. On a fait l'ingénieuse remarque qu'au moyen-âge les vins, mêlẻs de miel, de cannelle et de coriandre, pouvaient impunément être rudes, tandis qu'on exigra des vins de bonne qualité lorsque la mode eut délaissé l'hypocras pour le vin pur ${ }^{2}$ : dès ce jour, les vins de Flandre étaient condamnés. On peut ajouter que la disparition des vignobles n'a pas été aussi complète qu'on le pense, puisqu'au début du XIX ${ }^{\circ}$ siècle la côte du Muziek herg,dans les collines de Renaix, fournissait encore, année moyenne, 29 tonneaux de vin ${ }^{3}$, et qu'on trouve aujourd'hui, jusque dans la Flandre zélandaise, des treilles sur lesquelles on peut manger du raisin à la fin de septembre.

Ainsi la disparition des clos de la Lys ou de l'Escaut ne prouve pas que lo climat flamand soit devenu plus frais depuis dix siècles. Et ce serait d'autant plus surprenant que d'autres auteurs prétendent qu'il est plus chaud; d'aprés Schayes, la différence serait de 5 à $6^{\circ}$, et la Flandre de Cossar aurait joui d'une température semblable à celle de la Norvège . La présence d’une immense étendue boisée qui aurait recouvert tout le pays serait la cause de ce climat anormal. Cependant les végétaux trouvés dans la tourbe de la plaine maritime, c'est-à-dire sur le sol que foulèrent les Romains, sont exactement les mêmes que les essences qui croissent aujourd'hui dans la Flandre; et e'est là une preuve sérieuse que le climat n'a pas changé. On verra d'ailleurs que les forêts n'ont jamais été aussi denses que le prétendent les anciens auteurs; quant à s’appuyer, pour caractériser le climat flamand, sur les descriptions laissées par les écrivains grecs et romains, Méridionaux habitués au soleil et à la sécheresse, autant vaudrait prendre sur la question l'avis d'un Arabe de Biskra ". Mais au

1 Laveleye (de), Essai sur l'Economie rurale de la Belgique (Bruxelles, Lacroix, 1863), p. 276.

2 Dalle (J.), Hist. de Bousbecque, p. 114.

3 Delvaux (E.), Notice explicative de la feuille de Flobecq. (Bull. Suc. Anthr. Brux., VIII, 188889, p. 34).

- Schayes, La Belgique et les Pays-Bas avant et pendant la domination romaine (t. II, pp. 230-231).

3 " Chez eux, dit Strabon des Ménapiens et Morins, le eiel est plutôt pluvieux que neigeux; dans les beaux jours le brouillard tient assez longtemps pour ne laisser voir le soleil que 3 ou 4 heures par jour, aux alentours de midi ». (Strabon, IV, 5, 3). 
milieu de ces contradictions, d'autres témoins, des chroniqueurs, nous ont laissé non pas leur impression générale: - hommes du pays, ils ne songeaient pas à en apprécier le climat - ; mais une sorte de bulletin des phénomènes météorologiques qui les ont frappés. Et comme ces exceptions sont à peu près celles que nos savants enregistrent aujourd'hui, on peut en conclure que le climat ordinaire était le même que le nôtre. Il y eut des hivers longs et rigoureux, celui do 1110 où la neige resta interminablement sur le sol ${ }^{1}$; celui de 1125 , qui gela les récoltes ${ }^{2}$; ceux de 1150 et 1205 , où la gelée dura sans interruption de décembre à mars, et de février à avril ${ }^{3}$, et qui ressemblent singulièrement à ceux de 1894-95 foù la gelée fut à peu près continuelle du $1^{\text {er }}$ janvier au 15 mars), et de 1890-91 (gelée du 25 novembre au $1^{\text {er }}$ mars). De même en 1464, où la température reste au-dessous de zéro entre le 10 décembre et le 15 février ${ }^{4}$. La liste des dates où l'Escaut est pris devant Anvers, nous montre que le nombre des hivers rigoureux, du XVe siècle à nos jours, est à peu près le même par siècle ${ }^{3}$. En revanche on nous signale des années chaudes et secches, favorables à la vigne: 1351 , qui brûle les moissons ${ }^{6}$; 1452 , où il n'y a que quelques jours de pluie pendant les 3 mois d'été : on y voit la main de Dieu s'appesantissant sur les Gantois 7 ; 1458, où la sécheresse dure d'avril au milieu d'octobre, temps précieux pour la vigne, remarque le chroniqueur ${ }^{8}$. Si l'on s'étonnait de celte chaleur sèche, c'est qu'elle n'était pas plus habituelle qu'aujourd'hui. En revanche, on se plaint sans cesse de la pluie. En ، 820, les moissons pourrissent sur pied, en 1093, la Flandre est noyée d'octobre à avril ${ }^{9}$; en 1174 , de juillet à décembre ${ }^{10}$. Mêmes calamités en 1275, 1315; en 1407 Bruges est inondée par des pluies formidables de décembre ${ }^{11}$; l'hiver de 1467 , l'eau tombe 7 semaines de suite ${ }^{12}$.

1 Annales Formoselenses, (M. G. SS. V, p. 36).

2 Meyer, Annales, ad annum.

3 Annales S. Petri Blandinienses (éd. Van de Putte), pp. 15 et 17.

4 Meyor, Annales, ad annum.

5 On trouvera cotte liste dans Yan den Bogaerde (A.), Het distrikt van Sint-Nikolaas, voorheen land van Waes (S. Nik., Dorey, 1825, 3 d. in-80), I, pp. 5860 ; et dans Torfs (L.), Fastes des calamités publiques (Tournai, Casterman, 1859-1862), II, pp. 3-111.

6 Meyer, ad ann.

7 Ibid.

8 Ibid.

I Ibid.

10 Annales S. Petri Blandinienses (éd. Van de Putte), p. 16

11 Meyer, ibid.

12 Chronicon monasterii Evershamensis, p. 25. 
Plus près de nous, dans la $2^{\circ}$ moitié du XVIII ${ }^{\bullet}$ siècle, il ne so passe guère 3 ans de suite sans quo le clergó de Bergues n'adresse des prières pour la cessation de la pluíe; en 1767, pendant tout l'été il n'y eut pas plus de 3 jours d'accalmie de suite; en 1768 la pluie est continuelle du milieu d'août à la fin de décembre; en 1770 le temps a été si affreux qu'on n'a pas pu cultiver les champs au printemps ${ }^{1}$.

De cette liste monotone d'intempéries qui ont gelé, desséché, noyé le sol de la Flandre, se dégage l'impression que rien n'a changé sous le pâle soleil de ce pays. Ies mêmes vạpeurs humides et puantes que décrit tristement le confident de Philippe-Auguste s'élèvent encore des marais de la Deûle ${ }^{2}$. Les petites pluies, «incessantes en ce Nord, oủ sans trêve les nuages s'effilochent en bruines ", sont tombées sur la vigne d'Eginhard à Gand comme elles tombent aujourd'hui sur les seigles de la Flandre orientale. Philippe-Auguste enlisé avec son armée dans la boue argileuse de Steenvoorde, Harold, futur roi saxon, chassant les oiseaux de marais dans les moeres de la plaine maritime, ont connu le même ciel gris, les mêmes pluies longues et lentes qui étonnaient les anciens, et rendent encore le climat flamand si mélancolique pour l'étranger. Il n'a pas changé depuis le début de la période historique; c'est toujour's le même climat moyen, où se neutralisent les influences maritimes et continentales. Largement ouverte aux souffles de la mer, bordée d'une longue étendue de côtes, la Flandre n'en tient pas moins fortement au continent; en elle se fondent les caractères climatiques de la France du Nord, de l'Angleterre, et de l'Allemagne rhẻnane; pour le climat comme pour la civilisation, elle est un carrefour de l'Europe occidentale.

1 Pruvost (A.), Chronique et Cartulaire de l'abhaye de Bergues St-Winoe (Bruges, Soc. d'Em., 1875-78, 2 vol. in-8 $\left.{ }^{\circ}\right)$, II, pp. 766-771. - Il ne semble pas que depuis une cinquantaine d'années la pluie ait dininué en Flandre, car on ne s'y plaint pas de diminutions sensibles dans le débit des nappes aquifères, comme dans cortaines rógions crayeuses, et on ne signale nulle part que des sources aient disparu.

2 Philippide de Guillaume le Breton, M. G. SS. XXVI, p. 352, v. 672-679. 


\section{CHAPITRE III}

\section{LE SOL}

I. Histoire géologique. La dépression flamande. Primaire et Crétacé. Landénien. Yprésien-Paniselien et Parisien. Oligocène, Miocène, Pliocène. Erosion quaternaire. - II. Le sol actuel. Imperméabilité : les nappes aquifères. Le sol quaternaire.

Le climat de la Flandre, par son uniformité, sa ressemblance avec celui des régions voisines, n'est pas un de ces traits essentiels qui permettent de caractériser une région. Même certains de ses détails les plus particuliers sont dus à des différences dans la nature du sol. C'est donc à celui-ci qu'il faut en venir pour bien comprendre la Flandre et $\mathbf{y}$ distinguer une certaine variété de caractères.

I.

\section{HISTOIRE GÉOLOGIQUE}

\section{La Dépression flamande}

La Flandre fait partie d'un bassin, symétrique de la région parisienne, et qui s'ètend de l'Ardenne au Sud-Ouest de l'Angleterre, d'où les noms de bassin de Bruxelles ou bassin anglo-flamand. Entre les deux dépressions s'allonge un bombement crayeux, profondément entamé par l'érosion dans le Weald et le Boulomais, moins endommagé mesure qu'on descend vers le Sud; c'est l'axe de l'Artois. Il ne s'agit pas là d'un grand anticlinal très simple reliant le Boulonnais a l'Ardenne, car on a pu y observer plusieurs plis, en particulier un synclinal Est-Ouest qui sépare le Boulonnais du

1 Consulter : Gosselet (J.), Esquisse géologique du Nord de la France et des Contrées voisines. Lille, aux archives de la Soc. Géol. du Nord. Terrains primaires, secondaires et tertiaires (1880-83), 3 fasc. in- $8^{\circ}$ texte, 342 p.; 3 fasc. in- $8^{\circ}$ planches ; Terrain quaternaire : Ann. Soc. gẻol. N. XXX, (1901), pp. 257-335, 4 pl. ; - De Lapparent (A.), Traitẻ de Géologie, $4^{\circ}$ édition (1900, fascicule III), pp. 1405-1642;-Mourlon (M.), Géologie de la Belgique. Paris, Savy (1880-81), 2 vol. in-80, $317+392$ pp.; - Légende de la Garte géologique de Belgique au $1: 40.000$, dressée par ordre du Gouvernement; édition de 1900. Bull. Soc. belge Géol., XIV, (1900), Traductions et reproductions, pp. 21-42. 
véritable anticlinal de l'Artois ${ }^{\mathbf{1}}$; mais peu importe puisque l'ensemble forme une ligne de faîte très appróciable entre les dépressions flamande et parisienne. Les différences sont notables entre les deux bassins. Tandis qu'au Sud la pente des couches est douce, et que la craie affleure presque jusqu'au centre du bassin de Paris, la plongée est brusque vers le Nord, accentuée par une faille, et la craie disparaît aussitốt sous une formidable épaisseur de terrains tertiaires ${ }^{2}$. Grâce à cette circonstance, le bassin anglo-flamand possède, bien plus que le bassin parisien, le caractère d'une profonde dépression.

Cette dépression s'est produite à une date relativement récente. Pendant toute la période jurassique, les rôles étaient intervertis, la Flandre émergée, l'Artois affaissé sous la mer; la limite du continent ardennaisflamand passe à l'Ouest de Calais et de St-Omer. Pas d'affaissement non plus à l'époque crétacée, où Flandre et Artois sont également recouverts ; de même pendant le landénien-thanétien, où la mer du bassin de P'aris rejoint celle du bassin de Bruxelles. Cependant le plissement artésien se formait lentement. Divers mouvements datent de l'époque crélacée, et se sont continués insensiblement pendant l'éocène inférieur, jusqu'au lackénien (division du Lutétien). C'ost alors que se produit la phase principale du relévement, dont l'amplitude a été de 100 mètres au moins par rapport à Bruxelles; relèvement qui atteint son maximum à la fin de l'époque éocène ${ }^{3}$.

\section{Primaire et Crétacé}

Depuis lors, la Flandre constitue donc un vaste creux, enfoncé entre les bombements de l'Artois et dı Brabant, un trou profond comblé par les couches crétacées et tertiaires. Au fond du trou, les terrains primaires,

1 Cf : Parent (H.), Etude sur la craie à Micraster dı Boulonnais et sur les plissements de la craie dans cette région. (Ann. Soc. géol. N., XX, 1892, pp. 304-332, carte, pl. V);-Gosselet (J.), Les collines de l'Artois. (XIIIe Congrès national de Géographie, Lille, 1892, 7 p.).

2 Sur cette allure du crétacé et du primaire, voir Parent (Op. cit.).

3 Cf: Ch. Barrois, Recherches sur le terrain crétacé supérieur de l'Angleterre et de l'lrlande (Mémoires Soc. géol. N., t. I), p. 179; - Ch. Barrois, L'Eocène supérieur des Flandres. (Anu. Soc. géol. N., III, 1875-76, pp. 84-87) ; - Parent (H.), Notes supplémentaires sur les plis du Nord de l'Artois. (Ann. Soc. géol. N., XXI, 1893, pp. $43-106)$. 
atteints par d'assez nombreux sondages jusqu'au Nord de la Flandre ${ }^{1}$. Leur allure en profondeur est à peu près régulière; les courbes d'altitude se suecèdent, dans l'ensemble, à des distances à peu près équivalontes,

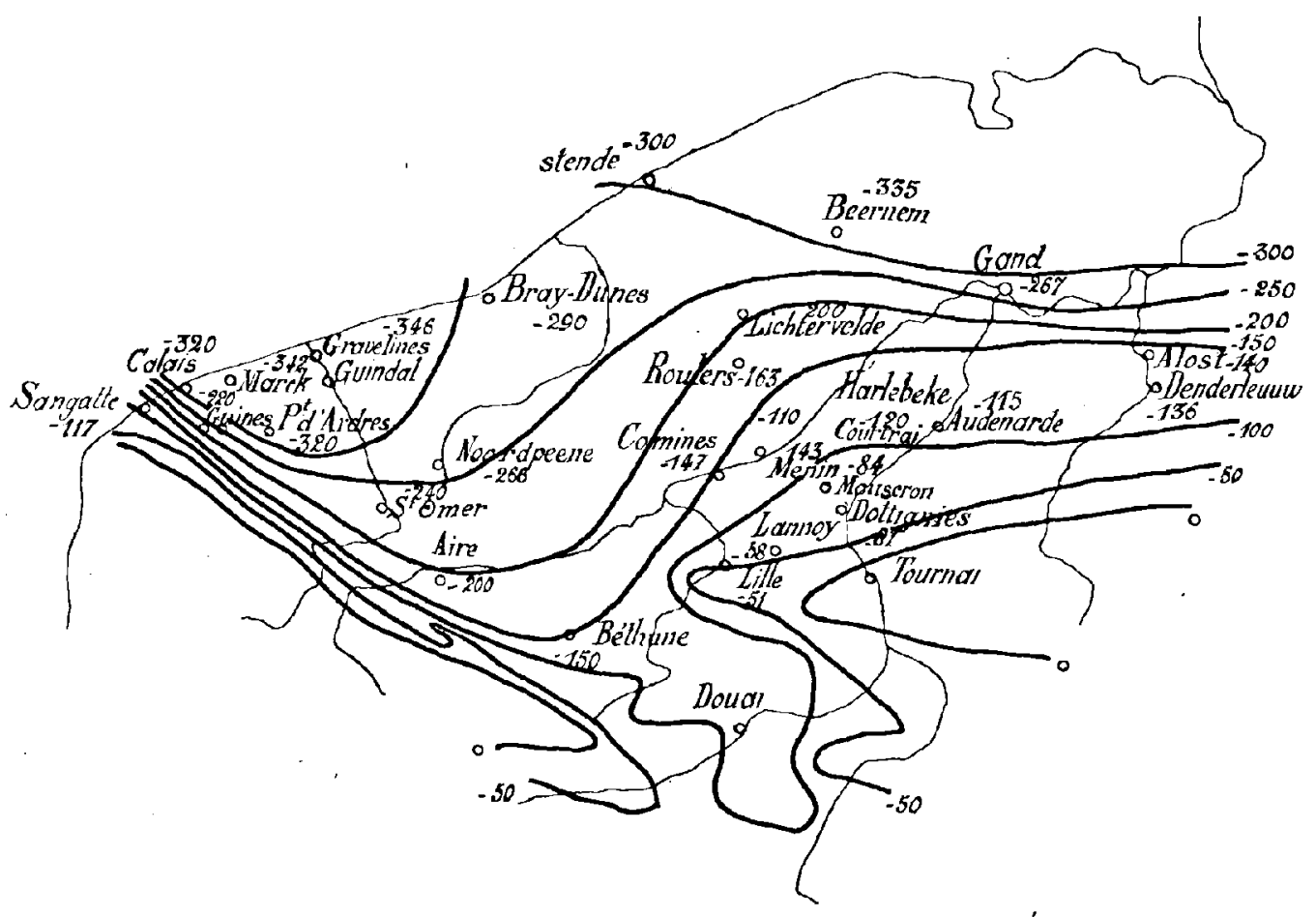

FIg. 5. - Altitude de la surface du Primaire sous la Flandre,

Échelle de $1: 1.500 .000$

d'après M. Gosselet, (Terrains Secondaires, pl. XII B.), et quelques sondages récents.

plongeant dans la direction du Nord en s'éloignant des bombements de l'Artois et de Tournai. La seule particularité, avec la dépression de Douai qui n'intéresse qu’à-demi la Flandre, c'est la brusque déclivité qui se produit du Boulonnais au Calaisis, faisant tomber l'altitude du primaire de +80 mètres vers Marquise à - 320 mètres à Calais, et - 346 mètres

1 Sur l'allure des torrains primaires en Flandre, cf. Forir (H.), Le relief des formations primaires dans la basse et la moyenne Belgique et dans le Nord de la France, et les conséquences que l'on pent en déduire. (Ann. Soc. géol. Relg., XXVI 1898-99, Ḿdm., pp. 130-155; 1 carte à $1: 500.000)$. 
à Gravelines. C'est sur ce flanc Nord du pli primaire du Boulonnais que l'affaissement a êté le plus considérable de toute la Flandre ${ }^{1}$.

Au-dessus du primaire, le crétacé, sauf dans le Sud du pays d'Alost, où les couches tertiaires reposent immédiatement sur le Silurien ${ }^{2}$. Partout

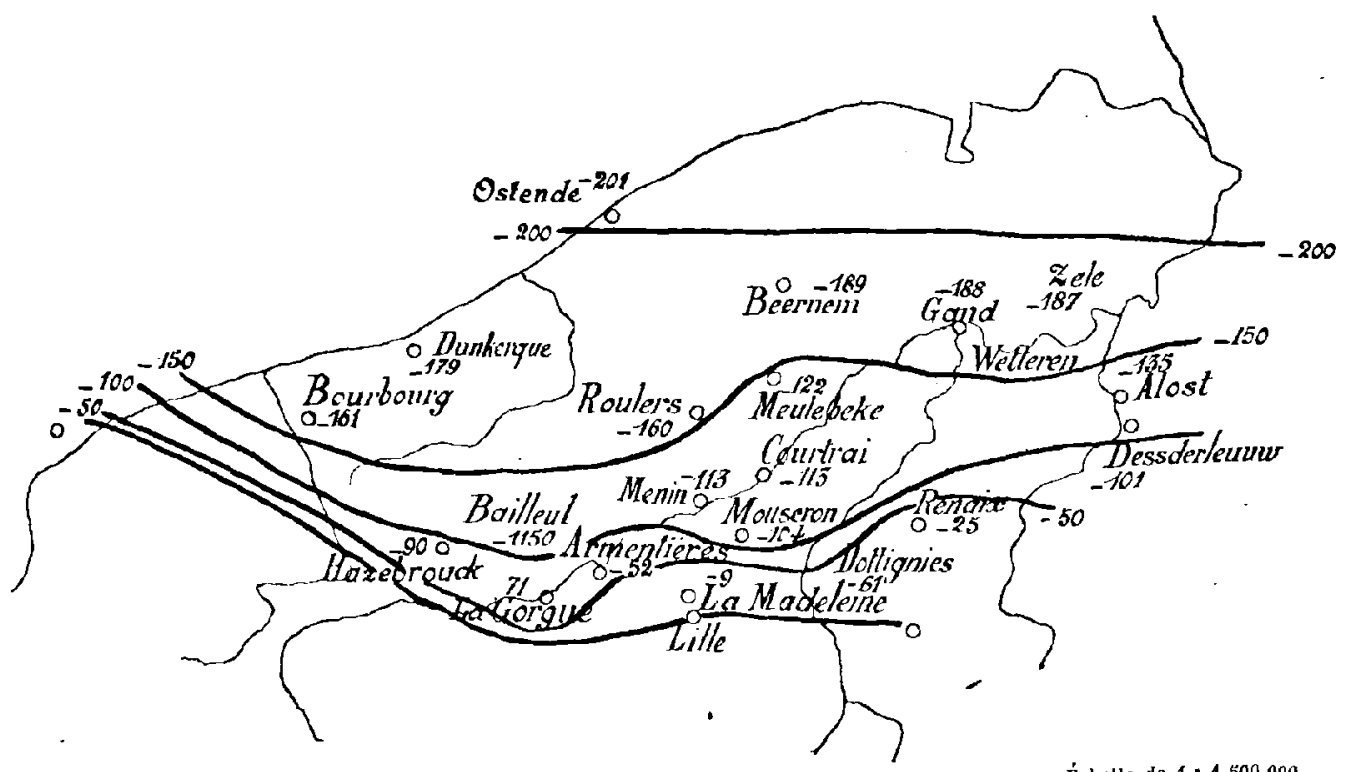

Échelle de $1: 1.500 .000$

Frg. 6. - Altitude de la surface du Crétacé sons la Fliandre, d'après quelques sondages.

ailleurs, le crétacé, sous forme de craie blanche sénonienne et de marnes grises turoniennes, se présente sous des épaisseurs variables: 80 mètres à

1 On a pu espérer ur moment, lors des premiers sondages heureux en Campine pour la recherche de la houille, que les couches houilleres se prolongeaient sous la ville d'Anvers et dans la Flandre arientale. Cette attente semble déçue depuis que les sondages opérés à Kessel et à Santhoven, jusqu'à 12 kilomètres à l'Est d'Anvers, ont montré que l'épaisseur des morts terrains augmentait de ce côté, et que le houiller se dirigerait plutôt vers le Nord-Onest. Quant à l"altitude du primaire, on peut croire qu'elle continue à s'abaisser régulièrement vers le Nord de la Flandre, si l'on s'en rapporte a l'allure qu“il affecte dans la province d'Anvers. - Cf: Kersten (J.), Ie Bassin houiller de la Campine [Bull. Soc. belge Géol., XVII (1903), Mémoires, pp. 35-45, 2 cartes (pl. I et II) à $1: 320.000]$; - Harzé (W.), Considérations géométriques sur le Houiller du Nord de la Belgique (Bull. Soc, belge Géol., XVII, 1903, Pr.Verbaux, pp. 5f8-576).

2 Cf. Rutot (A.), Note sur le sous-sol des villes de Grammont et de Ninove. (Ann. Soc. géol. Belg., XIII, 1886, Bull., pp. CII-CIII). 
Ostende, $13^{\mathrm{m}}, 70$ à Roulers, $22^{\mathrm{m}}, 50$ à Menin, 10 mètres à Courtrai, 15 mètres à Gand, 6 mètres à Alost, 7 mètres à Renaix ${ }^{1}$. 19 mètres à Mouscron ${ }^{2}$, avec forte augmentation ver's l'Ouest: plus de 120 mètres à Hazebrouck ${ }^{3}$. Quant à l'allure de la surface des couches crétacées, elle est plus régulière encore que celle du primaire: la descente s'opère posément vers le Nord, de Iille vers Ostende, et l'on peut remarquer que le bassin crétacé correspond exactement à la région flamande délimitée précédemment.

C'est dans ce bassin que sont venus s'accumuler les dépôts tertiaires, qui forment le vrai sol de la Flandre et lui donnent son originalité. Craie et Flandre sont deux termes contradictoires : où paraît la craie, la Flandre s'arrête. Elle ignore les lointaines couches enterrées sous 100 ou 200 mètres de sables et d'argiles, et qui ne peuvent même pas lui fournir les eaux pures qu'elle est allée parfois y chercher. Au contraire les sédiments tertiaires de tout age, du paléocène au pliocène, réussissent à apparaître à la surface du sol, avant de plonger à leur tour dans les grandes profondeurs du Nord, oủ disparaîl leur trace.

\section{Le Landénien}

Cependant le bassin n'était pas encore formé au moment où les premiéres mers tertiaires apparurent sur le continent crétacé, et les limites de leur extension dépassérent lárgement colles de la région angloflamande. La mer landénienne étale jusqu'en Normandie ses sables argileux, qui passent parfois au tuffeau ou au grès; en Flandre et aux alentours la formation recouvre encore 15 à 20 métres d'argile plastique (argile de Louvil), deposée dans les bas-fonds de la craie. Au-dessus des sables à tuffeau, et s'en distinguant si peu qu'il est difficile de trouver la limite, se sont déposés les sables verts dits d'Ostricourt, épais de 10 à 25 mètres, qu'on retrouve sous forme de sables et de grès jusqu'au Sud de la Picardie. Toutes ces couches à leur tour sont à peu près disparues de la surface.

A mesure que le bassin anglo-flamand s'enfonçait, de nouvelles formations venaient recouvrir d'un épais manteau les dépôts landéniens, de sorte que ceux-ci n’apparaissent plus qu'en débris sur les pentes de l'Artois,

1 Pour ces ćpaisseurs, of : Van Ertborn (O.), Le projet Lambert pour l'alimentation en eau de la ville d'Anvers. (Ann. Soc. géol. Belg., XXVI, 1899, Mém., pp. 47-58).

2 Rutot (A.), Le pujta artésien de la gare de Mouscron. (Bull. Soc. belge Géol., XVIII, 1904, Pr.-Verb., pp. 10-12).

Cayeux (A.), Le forage de la ville d'Hazebrouck. (Ann. Soc. géol. N., XVII, 1890, pp. $272-283)$. 
et le.long de la lisière méridionale de la dépression, où l'érosion les a débarrassés de leur revêtement d'argile yprésienne. Mais on les retrouve partout sous la Flandre, plongeant vers le Nord avec la même allure que les courbes de la surface crètacée. L'épaisseur de ces couches souterraines est remarquablement égale : un peu plus forte vers le S. et l'W. (42 mètres à Ia Gorgue et Armentières, 44 mètres à Hazebrouck, 55 mètres à Bourbourg et Dunkerque, 57 mètres a Bailleul), elle atteint encore 30 mètres à Alost, 33 mètres à Gand, 37 mètres à Wetteren et Zele,

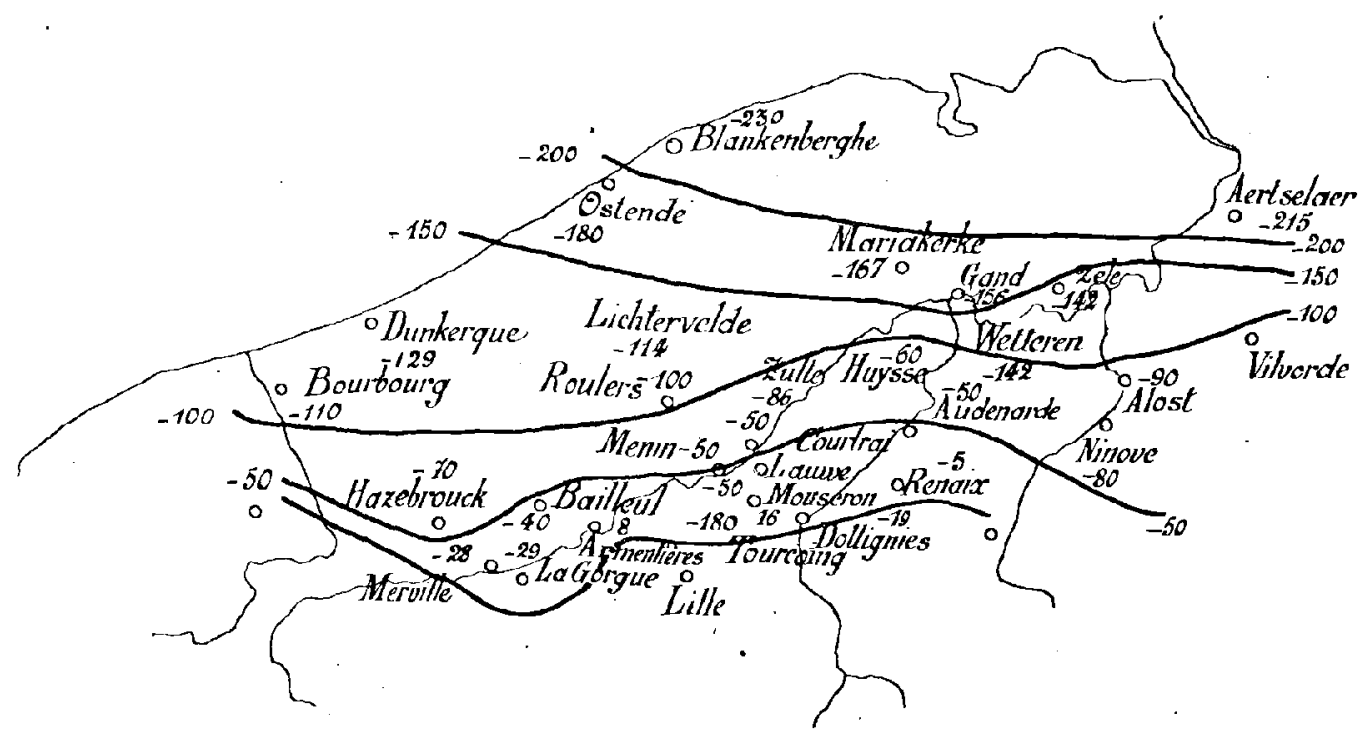

Échelle de $1: 1.500 .000$

Fig. 7. - Altitude de la surface du Landénien sous la Flandre, d'après M. Gosselet (Esquisse, Terrains Tertiaires, pl. XI A.) et quelques sondages récents.

38 mètres à Lichtervelde è à Ostende ${ }^{1}$. Jusque dans ces forages du Nord, le landénien supérienr est représenté par ces fins sables verts d'Ostricourt, dont l'argile de Louvil sous-jacente fait un des niveaux aquiféres les plus

1 Voir pour les forages de : La Gorgue: Ann. Soc. géol. N., I (1870-74), p. 33 ; Armentieres: Ibid. XIV,(1887), p. 181 ;- Hazebrouck: Ibid. XVII, (1890), pp. 272-283;Hourbourg, Dunkerque, Bailleul : Lhid. IX, (1882), pp. 71-76; - Alost : Ibid. X, (1883), p. 188; - Gand, Wetteren, Zele : feuilles Gand-Melle et Wetteren-Zele de la Carte géologique de Belgique à 1 : 40.000; - Lichtervelde et Ostende : Rutot (A.), Note sur quelques points nouveaux de la géologie des Flandres (Bull. Soc. belge Géol., IX, 1895, Mém., pp. 289-319); - Dottignies: Rutot (A.), Le puits artésien de Dottignies (13ull. Soc. belge Géol., III, 1889, Pr.-V., pp. 18-19). 
abondants de la Flandre. Même au delà d'Ostende l'eau landérienne, infiltrée aux lointains affleurements de Tournai ou de St-Omer, jaillit encore au-dessus du sol de la plaine maritime, lorsqu'on perce la tenace argile bleuâtre qui emprisonne sous son énorme masse la nappe des sables verts.

\section{Yprésien-Paniselien et Parisien.}

A la mer landénienne succède dans le bassin de Paris un régime de lagunes (Sparnacien), dont la présence est douteuse en Flandre ${ }^{1}$. En tous. cas, à l'époque yprésienne, la mer s'établit pour longtemps dans le bassin anglo-flamand et $\mathrm{y}$ dépose lentement d'épaisses couches de sables et d’argiles. Rien de plus uniforme, au centre de la Flandre, que cette centaine de mètres d'argile plastique bleuâtre, à peu près dépourvue de fossiles, et à peine entrecoupée de petites lentilles sableuses. C'est un bloc indivisible où le géologue peine à distinguer plusieurs niveaux. Les différences n'apparaissent guère qu'aux bords du bassin. L'Yprésien devient plus sableux au Sud-Est; la zone moyenne y est formée des sables verdâtres de Mons-en-Pévèle, que l'on retrouve, déjà plus argileux, au mont de la Trinité ; l'assise supérieure présente même, dans les monts de Renaix, des psammites grisâtres el jusqu'à un vóritable calcaire nummulitique 2. Mais sitôt que des collines on se dirige vers le Nord-Ouest, on voit le facies sablcux disparaitre, et toule la masse redevenir argileuse.

Dans la partie orientale, au-desśus de l'Yprésien typique s'étendent des couches un peu différentes, argiles sableuses et sables, dont on a fait en Belgique un étage distinct, le Paniselien. Peu importe d'ailleurs, car l'Yprésien passe au Paniselien par des transitions assez insensibles pour qu'on puisse considérer en bloc les deux étages. En effet les sables fins, assez argileux, qui forment duns l'Est de la Flandre le terme supérieur de l'Yprésien, n'offrent guère de différence avec les alternances de sable et d'argile paniseliens qui les surmontent. I e passage se fail ainsi peu à peu des profondeurs de l'argile plastique à la couche arénacée, parfois agglo-

1 Cf: Van Ertborn (O.), Rectifications stratigraphiques dans l'Éocène belge. (Bull. Soc. belge Géol., XVII, 1903, Mém., pp. 103-118); - Rutot (A.), Compte rendu des excursions de la session extraordinaire de la Soc. belge de Géologie dans le Hainaut et aux environs de Bruxelles (Bull. Soc. belge Géol., XVII, 1903, Mém., pp. 383-499).

2 Cf. Delvaux (E.), Notice explicative du levé géologique de la planchette de Renaix, pp. $4-9$. 
mérée en grès (sables d'Aeltre), que des fossiles caractéristiques indiquent claireìnent comme la partie supérieure de la série tout entière ${ }^{1}$.

L'épaisseur de l'Yprésien-Paniselien est considérable. Ce sont ces sédiments et surtout l'argile plastique, qui remplissent jusqu'aux bords la profonde cavité dont les couches crétacées et landéniennes garnissent seulemont le fond. I'abord mince sur la tranche Ouest, oủ le dépôt a été moins abondant et où l'érosion en a fortement réduit l'épaisseur, la couche d'argile augmente rapidement vers le Nord-Est. De quelques mètres à Arques, où on l'aperçoit surmontant les sables d'Ostricourt, de 5 mètres à La Madeleine-lès-Iille et do 9 mètres à Marquette, elle atteint déjà 39 mètres à La Gorgue, 55 mètres à Hazebrouck, 98 mètres à Bailleul, une centaine de mètres sous Bourbourg et Dunkerque. Du Sud au Nord, l'épaisseur augmente régulièrement; le profond bassin en est presque comblé: 50 mètres à Mouscron, 80 mètres à Zulte, 109 mètres à Roulers, 131 à Lichtervelde, 136 à Ostende, 177 à Blankenberghe ${ }^{2}$. Et il ne s'agit là que de l'argile plastique, proprement yprésienne ${ }^{3}$. L'épaisseur est telle que malgré la pente réguliêre du bassin vers le Nord, la puissante assise se maintient à la surface du sol jusqu’à la hanteur de Dixmude, Roulers, Audenarde, où elle cornmence seuloment à disparaître sous les sables. Mais toute cachée qu'elle est, elle ne cesse pas de faire sentir son influence; elle arrête de sa masse bleuâtre la descente des eaux dans le sol, maintient I'humidité à la surface, en même temps qu'elle comprime les eaux landéniennes dans leur élan pour remonter au jour. Enorme et compacte, elle est le trait caractéristique du sol flamand.

1 Dans la partie belge, le Paniselien comprend en général un lit d'argile grise schistoide, et des sables glauconifères plus ou moins argileux, avec ou sans grès. A Cassel, il forme une couche de sables gris glauconifères, surmontée d'une marne sableuse a Turritelles qui correspond aux sables d'Aeltre.

$\approx$ Pour ces chiffres, voir les réfẻrences indiquées page 47 , note 1 , ot on plus : pour Arques : Ann. Soc. géol. N., XX (1892), p. 335; - La Madeleine: ibid., III, (1875-76), P. 152 ; - Marquette : ibid., XVII, (1890) p. 150 ; - Mouscron : Bull. Soc. belge Géol., XVIII (1904), Hr.-Y.. p. 12; -Zulte: ibid., V, (1891), Pr.-V., p. 12;-Roulers : ibid., IX (1895), Mém., pp. 289-319; - Blankenberghe : ibid., II (1888), Mém., pp. 260-270, et IX, (1895), Mém., pp. 206-297.

3 L'épaisseur du Paniselien proprement dit varie en général de 20 à 30 mètres: 18 mètres à Bruges, $20^{\circ}{ }_{2}, 9$ et $23^{\mathrm{m}}, \check{\partial}$ à Mariakerke-lès-Gand, $21^{\mathrm{m}}, 5$ et 24 mètres $\mathrm{z}$ Gand, 27x,8 à Zele, 33 mètres au Bisschopveld, près Beernem. (Carte géologique au 1 : 40.000, feuilles Bruges-Moerkerke, Gand-Melle, Wetteren-Zele, Lophem-Oedelem). - M. Rutot lui attribue seulement 13 mètres au Mont de l'Hotond (Sur un sondage effectué par M. Moulan au Mont de l'Hotond: Bull. Soc. belge Géol., III, 1889, Pr.-V., pp. 16-18). 
La mer recommence après le Paniselien son mouvement de va et vient sur ce sol qu'elle ne peut se décider à abandonner ou à garder pour elle. Cependant il y a quelque chose de changé. La mer yprésienne communiquait encore avec le bassin de Paris ${ }^{1}$; cette issue vers le Sud va se fermer pendant l'époque parisienne (lutétienne). La mer bruxellienne parvient enciore à pousser ses sables jusqu'au delá de St-Quentin, et à travers toute la Belgique. Après elle, le soulèvement de l'axe de l'Artois barre définitivement le passage vers le Sud, et la mer se trouve enfermée dans le bassin de Flandre. Elle y dépose la mince couche des sables laekeniens (1 mètre à Cassel, 5 mètres à Bruxelles), puis les sables et grès de Lede et de Wemmel, à peine plus épais (4 mètres à Gand), enfin l'argile glauconifère asschienne, parfois assez sableuse (quelques mètres à Gand). C'est par ces faibles dépôts plus sableux qu'argileux que se termine l'Focène flamand; sur les puissantes assises yprésiennes à peine immergées erre une mer sans profondeur, prête à abandonner le territoire, et qui disparaît peut-être en effet pendant la fin de l'époque éocéne².

\section{Oligocène, Miocène, Pliocène.}

A l'époque oligocéne, les invasions marines se font dans une direction nouvelle. La mer, qui venait anparavant du Nord, envahit la Belgique par le Nord-Est, parallèlement à l'axe de l'Artois. Il en résulte que la pente des couches oligocènes, miocènes et pliocénes est dirigée désormais dans ce sens, tandis que les sédiments éocènes plongeaient vers le Nord. C'est comme un bassin secondaire qui se creuse dans la grande dépression anglo-flamande, avec son centre vers Anvers et la Hollande. Ainsi

1 Cf. Leriche (M.), Sur les relations des mers des bassins parisien et belge à l'époque yprẻsienne (Ann. Soc. géol. N., XXXII, 1903, pp. 120-124).

I es sédiments éocènes du Nord de la Flaudre, disparus sous les accumulations de dépôts pliocènes et quaternaires, se retrouvent à des profondeurs qui augmentent rapidement vers le Nord. $\Lambda$ Eccloo, l'Asschien, épais de $7^{m}, 45$ est a la cote -14 , le Wemmelien, à la coto - 21, le Ledien à la cote - 25 (Rutat, Noto sur quelques points nouveaux, p. 319). A Watervliet, l'Asschion se trouve a la cote - 26; an Hoogkasteel, près Watervliet, environ à la cote - 36; l'épaisseur en est déjà de 32 mètres (Feuillo Watervliet de la carte géologique). A Terneuzen on trouve l'Ásschien à la cote - 86 environ, avec la forte épaisseur de $42^{\mathrm{m}}, 30$; le Laekenien à la cote - 128 (De Brouwer, Le puits artésien des aciéries de 'Terneuzen. Bull. Soc. belge Géol., XVII, 1903, C.-Rendus, pp. 37-44). Au delà vers le Nord, on n'a plus rencontré, jusqu'à plus de 200 mètres, que les dépôts oligocènes (Lorié, Sondages en Zẻlande et en Brabant. Bull. Soc. belge Gẻol., XVII, 1903, Mém., pp. 203-259). 
s'orientent les sables et argile sableuse du Tongrien inférieur, apportés par une mer qui s’avançait vers Bruges, Gand et Alost. Une nouvelle transgression marine, celle du Rupélien, ne dépasse pas Termonde; mais cette fois elle dépose une épaisseur de sédiments qui rappelle celle des couches yprésiennes : c'est une argile plastique qui porte le nom d'argile de Boom, et repose sur quelques mètres de sable gris; l'ensemble atteint 60 mètres sur les bords du Rupel 1 .

De nouveau la région flamande est asséchée. La mer semble renoncer à l'occuper; ses transgressions se font de plus en plus restreintes. A la fin du Miocène, la mer boldérienne tente un retour offensif qui ne dépasse pas le pays de Waes, et $\mathbf{y}$ dẻpose une faible couche de sables glauconifères verdâtres, dont l'épaisseur atteint rarement un mètre. Et c'est juste à ce moment, où la Flandre peut paraître définitivement émergée, que se produit la grande-invasion pliocène. La mer diestienne (Plạisancien) s’avance vers le Sud-Ouest, ravinant profondément les dépôts miocènes, oligocènes et éocènes, comblant les vallèes creusées pendant les émersions, et accumulant sur toute la surface recouverte son conglomérat de cailloux de silex, ses sables vert noirâtre, glauconifères, devenus rougeâtres par la transformation de la glauconie en limonite, et qui ont formé çà et là des bancs irréguliers de grès ferrugineux.

Ces sédiments caractéristiques ne se rencontrent plus aujourd'hui dans le Sud de la Flandre qu'à l'état de témoins très endommagés, aux Noires Mottes près de Calais, au mont de Watten, sur les collines des environs de Cassel, dans les monts de Renaix ; on en signale des restes à Hem, au mont d'Halluin, au mont de là Trinité, et jusqu'à Mons-en-Pévèle ? Il semble permis de prolonger encore les limites de leur extension. Comme on l'a fait remarquer récemment ${ }^{3}$, c'est seulement sur la craie et l'argile à silex, c'est-à-dire sur l'axe de l'Artois, que la mer diestienne a pu aller chercher les galets de son conglomérat de base. Puis le relèvement considérable présenté dans l'Ouest de la Flandre par le Diestien, qui

1 A Goes, le Rupelien šétendrait do la cote - 93 mètres à la cote - 2ُ0 mètres (sous l'Amsterdamsch-Peil, niveau moyen de la mer à Amstordam), d'après J. Lorié (Sondages en Zélande et en Brabant, pp. 206-210), soit une épaisseur de 127 mètres.

2 Gosselet (J.), Esquisse, p. 340. - Cf, sur la limite de la mer diestienne: Van den Broeck (E.), Note sur un nouveau gisement de la Terebratula grandis avec une carte de l'extension primitive des dépôts pliocènes marins en Belgique (Bull. Soc. belge Géol., I, 1887, Mém., pp. 49-59).

3 Cornet (J.), Etudes sur l'évolution des rivières belges (Ann. Soc. géol. Belg., t. XXXI, 1904, Mém.; - Gf. pp. 403-410). 
passe de la cote 0 à Anvers à l'altitude de 160 mètres à Cassel, a dû se continuer au delá des collines actuelles, et l'ancien rivage se trouve ainsi amené jusqu'à la crête de l'Artois, d'ailleurs beaucoup moins abaissée à cette époque qu'aujourd'hui. Il est donc infiniment vraisemblable que la mer du pliocène diestien s'est étendue vers l'Ouest jusqu'à l'Artois, qui la séparait du bassin parisien, et que la Flandre entière a été recouverte de ses sédiments.

Tandis que les sables diestiens se trouvent à Cassol à partir de la cote 143 mètres, au mont de la Trinité à 145 métres, la base de l'étage, d̀ Gand, n'est déjà plus qu'à 30 mètres; à Anvers, les sables se trouvent à peu près au niveau de la mer; à Goes (Zuid-Beveland), la base est déjà à -93 mètres ; à Gorkum, un sondage de 178 mètres sous le niveau de la mer n'a même pas atteint le sommet de l'étage, pourtant épais de $\mathbf{1 0}$ mètres environ à Goes ; à Utrecht, la sonde n'a pénétré qu'à - 268 mètres dans les sables de Diest, et n'en était pas encore sortie à 365 mètres, profondeur à laquelle on a arrêté le forage; aussi à Amsterdam, par 335 metres au-dessous du niveau de la mer, n'avait-on même pas atteint les couches supérieures au Diestien ${ }^{1}$. Un formidable mouvement de bascule s'est donc produit depuis l'époque pliocène, qui a élevé la Flandre et abaissé la Hollande, la région d'Anvers formant l'axe. Ce mouvement ne s'est pas produit tout d'une pièce, mais par oscillations nombreuses. Après la régression marine qui suit le dépôt des sables de Diest, la mer reparaît timidement dans la Campine et sur le sol de la Flandre, pour déposer une couche de sables jaunâtres dont la situation a fail donner à l'étage le nom de Scaldisien; et l'on a encore distingué à la partie supérieure du Scaldisien un étage Poederlien, caractérisé par la présence d'un fossile spécial (Corbula striata). Tous deux d'ailleurs beaucoup moins intéressants par les minces sédiments qui les représentent (sable sur sable, dans un coin où toutes les couches antérieures étaient déjà sableuses), que parco qu'ils sont les témoins de la dernière invasion marine en Flandre pendant l'ère tertiaire.

Cependant l'époque pliocène n'était pas terminée. La mor, qui avait quitté le sol belge, se retirait lentement, et séjournait Iongtemps en Zèlande, à proximitẻ. C'est l'époque de l'Amstelien, qu'on trouve à Goes à - 29 mètres, surmontant le Poederlien-Scaldisien, et dont l'épaisseur (et

1 Cf. Loriẻ (J.), Contributions à la Géologie des Pays-Bas, fasc. I : Résultats géologiques et paléontologiques des forages de puits à Ltrecht, Goes ot Gorkum (Archives du musée Teyler, série II, vol. II, 1885, $3^{e}$ partie, pp. 239-240); - Idem, Contributions, fasc. X : Sondages en Zélande et en Brabant, p. 243 ; - Harmer, Lo tertiaire supéricur du bassin anglo-bolgo (Ann. Soc. belge Géol., X, 1896, Mém., p. 323). 


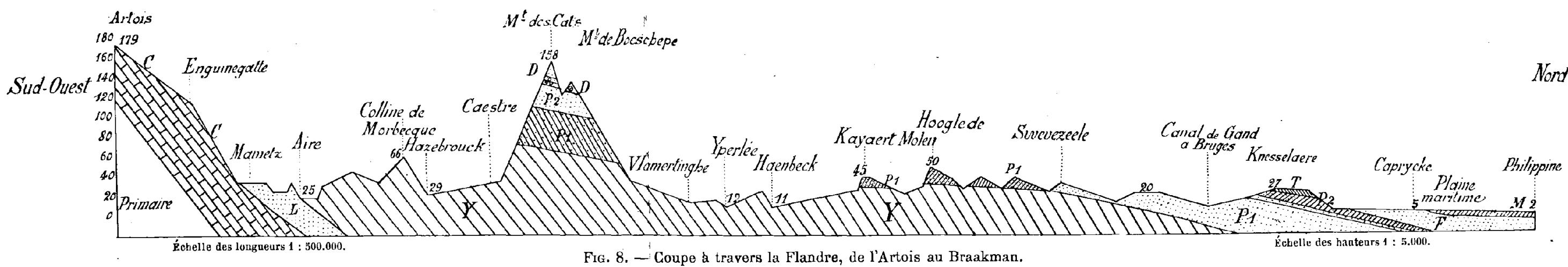

Fig. 8. - Coupe à travers la Flandre, de l'Artois au Braakman.

\begin{tabular}{|c|c|c|}
\hline $\begin{array}{l}\text { L Landénien : sables et argiles. } \\
\text { Y Yprésien : argiles et arbles. }\end{array}$ & $\begin{array}{l}\text { P1 Paniselien : argiles at sables. } \\
\text { H2 Yarisien : sables et argiles. } \\
\text { T Tongrien : argile et sablo. }\end{array}$ & $\begin{array}{l}\text { D Diestion : sable at grès. } \\
\text { F Flandrien : sable. } \\
\text { M Terrain moderne : argile et sable. }\end{array}$ \\
\hline
\end{tabular}

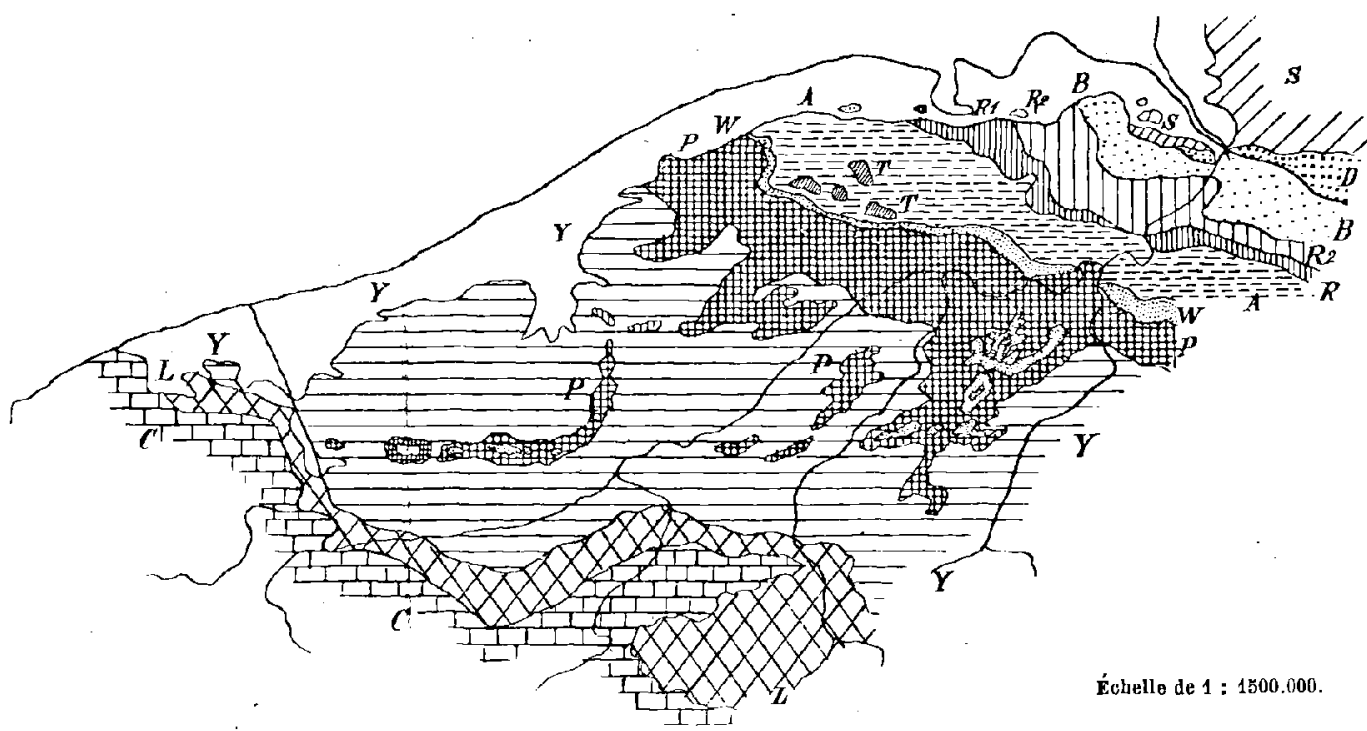

Fig. 9. - Carte géologique de la Flandre d’après la carte géologique de la Belgique là $1: 500.000$ de G. Dewalque (2॰ éd., 1903).

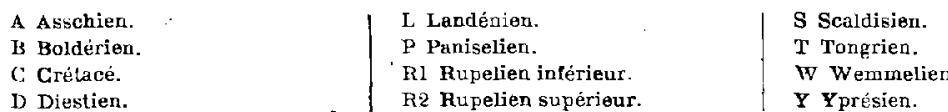

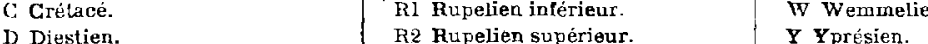


IRIS - LILLIAD - Université Lille 1 
la profondeur) vont sans cesse croissant vers le Nord ${ }^{1}$. Puis la mer quitte la Hollande ello-même, recule sans cesse vers le Nord, et dépose sur la côte anglaise les dépôts pliocènes supérieurs du Norfolk; il y a donc lacune, en Flandre comme en Hollande, entre le sommet du pliocéne et la base des couches quaternaires.

\section{Erosion quaternaire.}

Que deviennent, pendant cette longue période d'émersion, qui se continue fort avant dans l'êre quaternaire et peut-être jusqu'à nos jours, les sédiments assez peu cohérents déposés sur le sol flamand par les dernières mers tertiaires? Sur la pente rapide que formait, entre l'Arlois et lo rivage amstélien, le fonds émergé de la mer diestienne, l'érosion se mettait aussitôt au travail, faisant ruisseler vers le Nord-kst les eaux chargées de débris qui allaient combler les dernières mers pliocènes. A mesure que le rivage reculait, l'érosion devenait plus active, puisque le niveau de base des cours d'eau se déplaçait vers l'aval et que la hauteur du pays émergé s'accroissait. Cette activité atteignit donc son paroxysme à la fin du pliocène, lorsque la mer était reléguée au delà du Norfolk, et dut se continuer pendant les premières périodes du quaternaire. Peut-être un régime de fortes pluies, contemporaines de la première extension glaciaire, vint-il ajouter ses effets à ceux du recul de la mer.

Sur les sables poederliens, scaldisiens et diestiens, cette puissante érosion dut faire de rapides et profonds ravages. Dans le Nord-Est elle ne tarda pas à atteindre, sous les sables pliocènes, les couches boldériennes, à les dénuder à leur tour, et à percer jusqu'à l'argile rupélienne, qui résista mieux. Vers le Nord, le Tongrien, que le Rupelien ne protégeait pas ${ }^{2}$, fut bientôt attaqué et mis en lambeaux, découvrant les séries éocènes, qui furent largement entamées. Mais c'est surtout à l'Ouest que les ravages étaient considérables et que les sables et argiles semblaient fondre dans les eaux. De ce côté, la pente plus lorte rendait plus efficace l'action mécanique des eaux courantes ; l'émersion était plus ancienne, datant du premier recul de la mer diestienne; cornmencée plus tôt, l'érosion était on même temps plus active. Déjả pendant les longues années du Miocène et de l'Oligocène, les couches de l'Eocène avaient dû être fortement endommagées; mais les. sédiments diestiens s'étaient

1 Mêmes références qu'à la page prẻcédente.

2 La transgression marine du Rupelien s'ètendit moins loin vers l'W. que la mer Tongrienne. 
tout relief disparaît. D'Arseele à Dixmude, la rangée n'a guère qu'une quarantaine de kilomètres : peu de chose à côté des collines du Sud, dont l'alignement s'étend à travers toute la Flandre. Mais les formes aussi sont différentes; les pentes sont douces; tandis que le socle est presque aussi large que celui des collines du Sud, l'altitude des sommets est trois fois moindre. La déclivité est un peu plus prononcée vers le Sud, c'est-à-dire vers la vallée de la Mandel, que vers le Yord. De méme pour le petit massif de collines de Wynendaele, séparé de celui d'Hooglede par la dépression de l'Handzaeme; la longueur n'en est guère que de 13 kilomètres, l'altitude maxima de 51 mètres; lui aussi descend vers le Nord-Est en pente douce, tandis qu'il se termine vers le Sud par un petit abrupt.

Le relief de la quatrième rangée de hauteurs est encore plus insignifiant. Ce ne sont plus des collines, mais une ondulation douce, en grande partie boisée. De 7-8 mètres dans les champs du Beverhoutsveld, à l'Est de Bruges, le sol s'élève à 25 mètr'es près d'Oedelem, et reste à une hauteur moyenne de 20 mètres jusqu'à Somergem; quelques buttes alleignent 29 mètres. Partout ailleurs, il serait ridicule de s'occuper de pareilles montagnes; mais au milieu de cette région dont l'altitude moyenne est de 10 mètres, une élévation de 19 mètres paraît notable, surtout lorsque le sol y diffère de celui de la plaine; au milieu de l'étendue sableuse, ces hauteurs portent des plaques d'argile asschienne et tongrienne, sur

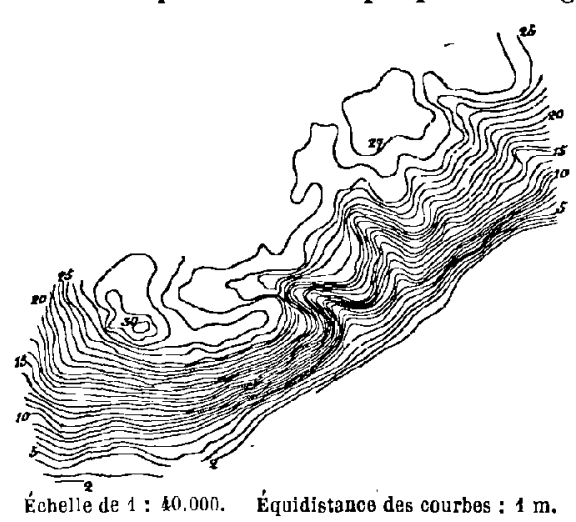

Fia. 14. - Rebord du pays de Waes a Thielrode (falaise rupelienne). lesquelles il ne pousse guère que des bois. Avec d'aussi faibles altitudes, il ne peut guèro être question de pente plus prononcée au Sud qu'au Nord; pourtant l'on peut remarquer que la limite des collines, à peu près rectiligne vers le Sud, s'allonge du côté Nord dans la direction d'Adegem; la forme générale est donc la même que dans les groupes précédents.

Cette forme, on la retrouve, particulièrement nette, dans la dernière rangée de hauteurs. La Durme, dans son cours inférieur, et à sa suite l'Escaut, de Thielrode à Rupelmonde, sont bordés à gauche par un coteau au relief accusé, d'une altitude très égale : 30 à 35 mètres à l'Ouest, (vers Waesmunster), 25 à 30 mètres à l'Est. Le point culminant atteint 35 mètres. Au-dessus de la basse vallée dont les prairies sont à la cote 2 mètres, 
le coteau, rapidement dressé, a quelque allure ; il ferait penser parfois à certains rebords de la vallée de la Loire, ver's Blois. Ce qui augmente la ressemblance, c'est que la falaise est bien un rebord, et que derrière on trouve une plaine descendant vers le Nord d'une pente insensible: 18 mètres à St-Nicolas, 5 mètres à St-Gilles; 25 métres de pente pour 12 kilomètres. Le pays de Waes forme donc bien un plateau qui s'abaisse dans le sens de l'inclinaison des couches, et dont le bord Sud se relève en forme d'abrupt au-dessus de la dépression de l'Escaut-Durme.

En dehors de ces alignements de collines, il reste peu de chose. Dans la Flandre française s'étendent, au Nord de Watten, du Balemberg et de Cassel, quelques ondulations pittoresques, dont la hauteur varie de 40 a 60 Inèlres ; orientées vers le N.-E., par Bollezeele, Zeggers-Cappel, d'une part, par Winnezeele et Poperinghe de l'autre (62 mètres près de l'Abeele), elles représentent bien, par leur allure, ot leur direction, des débris très endommagés de l'ancien plateau, abrités derrière les collines. Il semble qu'il en soit de même pour la ligne de hauteurs qui joint, à l'Est d'Ypres, les collines du Sud à l'alignement Dixmude-Hooglede. Elles se relient vers Wytschaete, par des altitudes d'environ 5j mètres, aux massifs interrompus par la vallée de la Lys, et se dirigent vers le Nord-Est ; la hauteur passe de 64 mètres vers Gheluwelt à 50 mètres (Becelaere), 56 mètres (Zonnebeke), 55 mètres (Passchendaele), 49 metres (West-Rousebeke), et rejoint par 40 mètres environ, à Sladen, les collines venues de Dixmude. Donc encore une légère pente vers le Nord. On a presque toujours été tentẻ de considérer ces collines comme le prolongement du massif de Kemmel, et de faire de l'ensemble un vaste demi-cercle de hauteurs, entourant de Steenvoorde à Dixmude un large amphithêatre-au fond duquel est assise la ville d'Ypres. On a vu qu'il y a bien plutôt là au Nord et au Sud deux alignements paralléles; quant à la chaîne de jonction, sa pente vers le Nord, son orientation, la font ressembler aux collines d'Anseghem; comme elles, elle doit représenter un fragment du plateau, plus endommagé que le fragment d'entre Escaut et Lys, mais mieux conservé que les collines de Poperinghe et de Bollezeele. Ces hauteurs d'Anseghem, d'Ypres, de Poperinghe et de Bollezeele représentent donc, en dépit des dénudations qui les ont mutilées et séparées parfois des massifs voisins, la pente douce vers le Nord des grandes collines Watten-Renaix. Elles sont au mont Cassel, au massif de Bailleul, aux collines de Mouscron, ce que le plateau d'entre Escaut et Dendre est aux monts de Renaix. Par là cet alignement méridional, malgré ses dimensions plus considérables, ressemble aux autres rangées de collines, qui ont toutes leur plus faible pente dirigée vers le Nord. Il est facile d'en conclure que toutes les collines 
flamandes ne sont que les rebords méridionaux de fragments plus ou moins intacts, el généralement très endommagés, du grand plan incliné d'autrefois.

\section{Hypothese des Cuestas.}

Cette constatation est très importante pour l'explication du relief de la Flandre. Elle permet d'éliminer les vieilles hypothèses qui attribuaient à des phénomènes éruptifs ou à d'autres causes profondes la formation des collines ${ }^{1}$. Le parallélisme des lignes de faite, la présence uniforme de pentes douces vers le Nord, raides vers le Sud, et surtout la comparaison des superpositions stratigraphiques montrent clairement: d'abord qu'il n'y a là que des têmoins dus à l'érosion; ensuite que les collines tlamandes sont l'équivalent imparfait des crêtes concentriques du bassin de Paris. Ce dernier point a été démontré récemment à propos de la rangée des collines méridionales ${ }^{2}$; cette ligne de faîte, toute tronçonnée et irrégulière qu'elle est, paraît bien une de ces cuestas dont la formule a été donnée par M. Morris Davis. L'origine d'une cuesta est due à la présence, dans une plaine pou inclinće, d'affleurements successifs de couches cohérentes plongeant dans la mème direction; la tranche de ces couches mises à nu par l'érosion forme autant de crêtes, tandis que sur le plat s'établissent des déprossions qui s'étendent jusqu'au pied de la tranche suivante. Chaque cuesta doit donc être précédée d'une dépression. Ces caractères, si nets dans le bassin de Paris, sont réalisés dans chacune des lignes de faîte flamandes, mais d'une façon très imparfaite à cause du peu de cohérence des couches et de leur caractère uniforme; on a vu que les roches les plus dures de la Flandre sont des argiles.

La première rangée (collines du Sud), c'est celle de l'argile yprésienne, suffisamment compacte pour rester en saillie au-dessus de la plaine, formant un socle puissant élevé jusque vers 100 mètres à l'Ouest et sur lequel sont restées perchées les formations plus récentes enlevées ailleurs. Devant ce socle s'étend une série de dépressions: marais de St-Omer, vallée de Neuffossé, plaine de la Lys, vallées de la Marque et de

\footnotetext{
1 Exposẻ de ces anciennes théories dans le livre de M. Cornet, Etudes sur l'évolution des rivières belges, pp. 463-467.

2 Cornet (J.), Etudes sur l'évolution, et particulièrement les pages 454 à 467 , reprises dans un article intitulé: "Sur la signification morphologique des collines de Flandre »(Bull. Soc. belge Géol., XVIII, 1904, Mém., pp. 115-12/).
} 
la Rhosnes, tandis que les petits vallons de la Peene, de la Douve, de l'Espierres, serrent de près le pied des hauteurs. Au Nord des collines, c'est bien le plat de l'Yprésien qui alfteure jusqu'à la deuxième ligne de coteanx, sanf anx endroits où les témoins paniseliens des hauteurs de Poperinghe et de West-Rooscbeke masquent de leurs collines sableuses le sol d'argile.

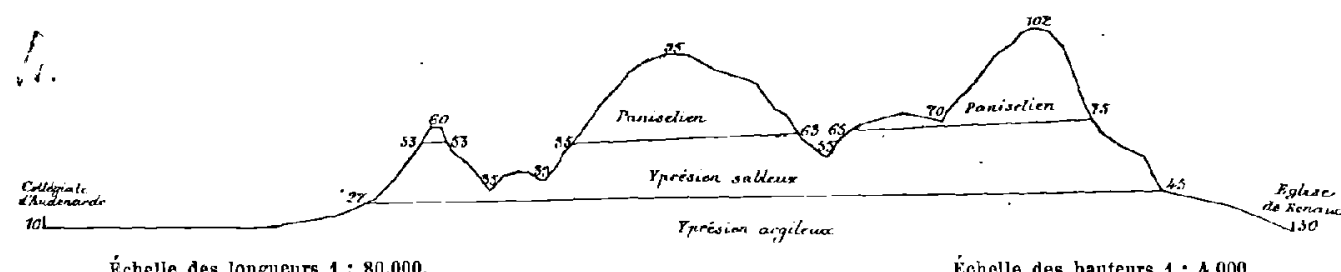

Frg. 15. - Profil des collines de Renaix entre Renaix et Audenarde.

Plongement des couches vers le Nord; pente douce vers le Nord, raide vers le Sud.

La seconde rangée est surtout paniselienne. A Staden, Ilooglede, Eeghem, Coolscamp, Thielt, Aerseelo, c'est l'argilite sableuse avec grès argileux (Plc de la carte géologique belge) qui est restée en saillie audessus de l'Yprósien supérieur, et domine la dépression de la Mandel. Les mêmes argiles sableuses et gréseuses ont donnẻ le relief de la colline de Wynendaele, prëcédée de la basse vallée de l'Handzaeme. Au delà, le Paniselien s'abaisse lentement jusqu'à la dépression ó coule le canal de Bruges à Gand : dépression d'une altitude si égale (envi-

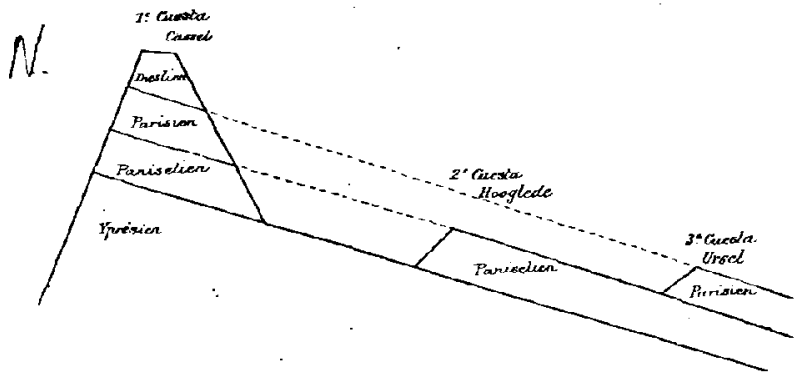

Frg. 16. - Allure théorique des collines de Flandre. ron 10 mètres) que la voie d'eau, entre les denx villes, n'a pas une écluse. Les hauteurs qui suivent sont formées cotte fois de sédiments parisiens (Lutétiens); c'est l'argile d'Assche, surmontant les sables de Wemmel, qui est en saillie, recouverte çà et là d'argile tongrienne. Fnfin le rebord du pays de Waes est constitué par la masse de l'argile rupelienne, beaucoup plizs résistante que les sables qu'elle surmonte (sables rupeliens) ou qui la recouvrent (boldériens et pliocènes); de là la falaise qu'elle constitue, avec la vallée de l'Escaut en bas. 
Quant aux agents d'èrosion qui ont débarrassé le pays de son manteau pliocène, mis à nu les tranches des couches cohérentes qui devaient former les crêtes, et permis ainsi aux cuestas de s'élever modestement audessus de la plaine flamande, on les retrouve dans les dépressions au pied des collines. Ce sont les cours d'eau subséquents, affluents des grands troncs conséquents qui coulent dans le sens général de l'inclinaison des couches, c'est-à-dire perpendiculairement aux zones d'affleurement. Ce sont, pour la première ligne des collines, les ruisseaux qui coulent à leur pied, Peene, Douve, Espierres, Rhosnes, affluents subséquents des fleuves conséquents, Yser, Lys, Escaut ${ }^{1}$; la Mandel et l'Handzaeme, affluents subséquents de l'Yser et de la Lys, ont eu le méme rôle dans la formation des hauteurs de seconde et troisième ligne; les ruisseaux que remplace le canal de Bruges à Gand, pour la quatrième; la Durme-Escaut, pour la derniere. Quant aux troncs conséquents, au lieu de traverser les crêtes par un déflé comme le font les riviéres du bassin de Paris, ils ont si largement entaille la faible ligne des collines, qu'ils en ont fait disparaître une bonne partie: il y a loin de la vallée de la Lys vers Comines au défilè de la Marne à Epernay: pourtant le phénomène est bien le même.

Ainsi s'expliquent la formation des collines, et leur alignement, leur parallélisme. Il peut sembler étrange cepentant que certaines de ces hauteurs, ces cuestas des restes du plateau flamand, ne soient pas orientées perpendiculairement aux cours d'eau conséquents, c'est-à-dire N.W.-S.E., mais obliquement, E.-W. L'observation est vraie surtout pour les deux premières lignes. C'est que les hauteurs qui les composent, formées de sédiments éocènes, représentent la tranche des couches éocènes, tranche de l'Yprésien, tranche du P'aniselien; ces assises plongeant vers le N., et non vers le N.-E., leur tranche ne peut êtro orientée que W.-E. ; et c'est ce qui fait dire à l'auteur do la théorie sur la signification morphologique des collines que l'orientation de la cuesta du Sud, régie par le sens de l'inclinaison de l'Eocène, doit être Est-Ouest 2.

Le relief confus et médiocre de la Flandre s'explique ainsi. Les assises du plateau pliocène ont opposé une résistance inégale á l'érosion; les tranches des couches argileuses se sont mieux tenues, et sont restées en saillie; il en est résulté une série de crêtes concentriques : faibles murailles d'ailleur's, éventrées, arasées, tronçonnées, reconnaissables pourtant; derrière elles, des débris de plateau ont conservé leur allure primitive,

1 Cornet, Etudes Evolution, pp. 460-461.

I Ibid., p. 463. 


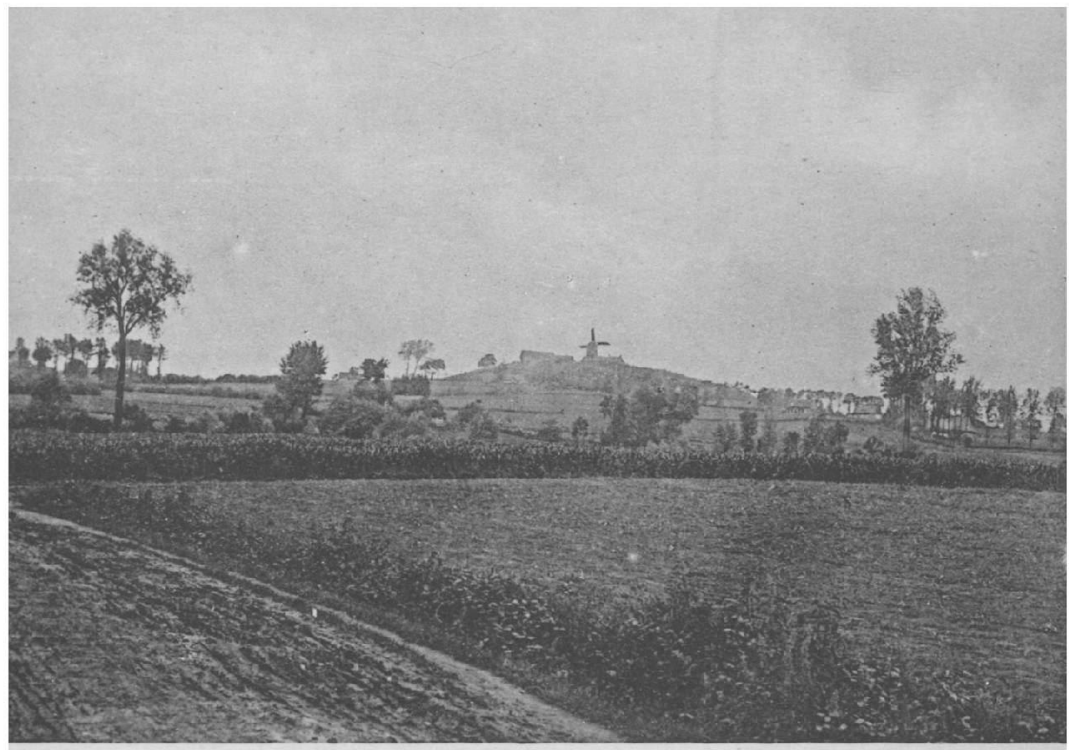

5. - Une colline flamande : le Mont-Aigu, près Locre.

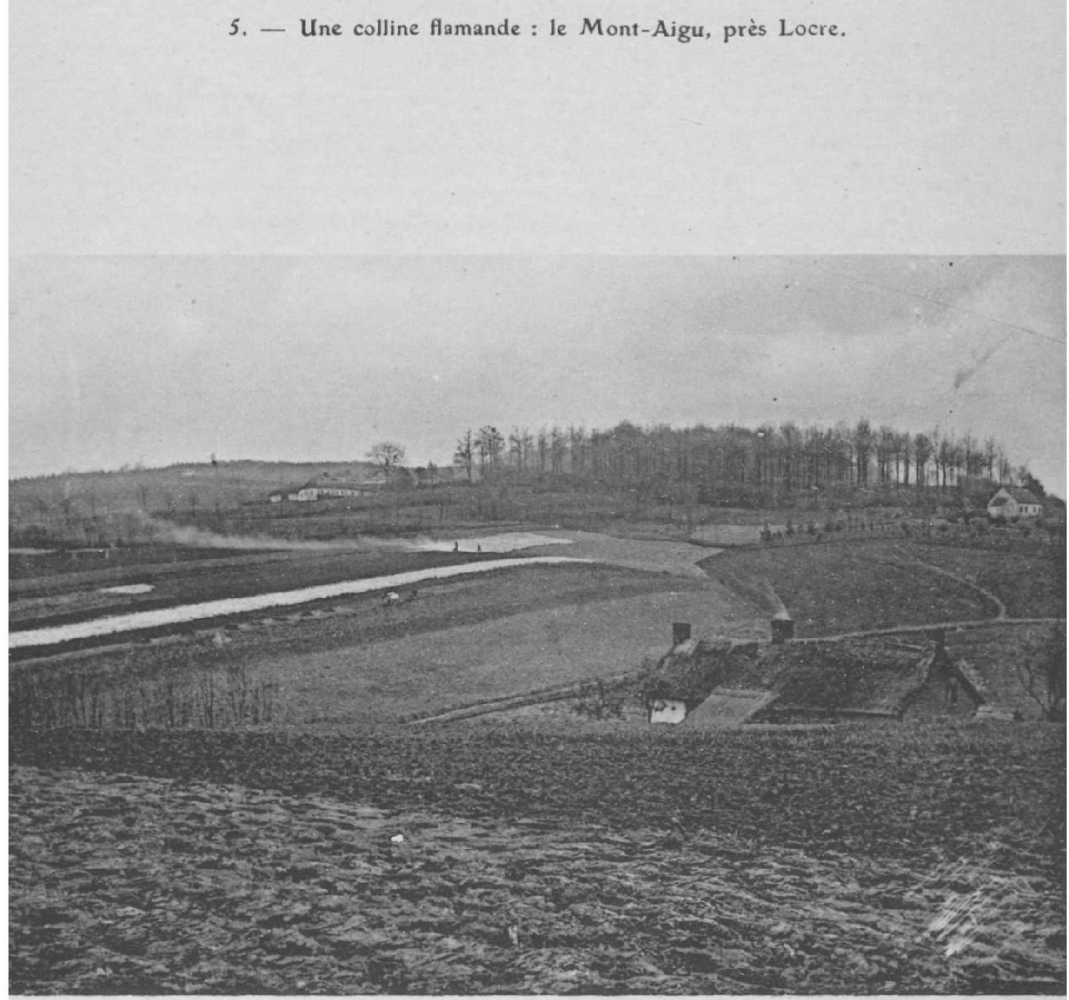

6. - Une colline flamande: le Muziek-Berg, près Renaix. 
IRIS - LILLIAD - Université Lille 1 
tandis que l'érosion a largement déblaye devant elles. On a vu que plus on avance vers l'Ouest, moins le relief a ressisté; le plateau est encore reconnaissable à droite de l'Escaut; il est à l'état de collines à gauche du fleuve; il se réduit au delà de la Lys à quelques lignes de hauteurs, et à des ondulations aprés l'Yser. L'érosion a donc été plus active à l'Ouest, malgré le peu d'importance des cours d'eau qui y coulent aujourd'hui, Yser, Waerdamme; on en a conclu qu'il aurait existé de ce côté à la fin du pliocéne un grand cours d'eau sur l'emplacement actuel de la côte, dont le rôle dans la dénudation du pays aurait été plus important encore que celui de l'Escaut et de la Lys ${ }^{4}$.

\section{Rôle des Collines}

La ressemblance thẻorique constatée entre les hauteurs flamandes et les crêtes du bassin de Paris ne doit pas abuser. Quelle qu'ait été l'origine du relief de la Flandre, il reste très médiocre, et à peu près sans influence sur les phénnmènes géographiques. Quelques centimètres de pluie et quelques orages de plus sur les collines, c'est là toute la perturbation qu'il prodnit dans le climat. Les fleuves étendent leur vallée au travers des chaînes sans daigner la rétrécir. Les roules ne se détournent pas à l'approche dess monts et n'essaient pas de les éviter: voies romaines, routes des intendants, et chemins du XIX ${ }^{e}$ siècle montent do tous côtés à Cassel ; on y a fail passer la grande chaussẻe de Dunkerque à Iille. Les chemins de fer les traversent comme sans, y prendre garde; quelques tranchées suffisent, et les seuls monts de Renaix ont eu leş honrleurs d'un tunnel. Les canaux eux-mêmes enjambent les chaînes: celui de Bossuyt à Courtrai traverse les collines du Sud à Sweveghem; celui d'Ypres à la Lys est en construction à travers les hauteurs d'Hollebeke; on projette depuis longtemps d'en faire passer un à travers les coteaux de Staden, do la Mandel à l'Handzaeme. Jamais les hauteurs n'ont rien séparé en Flandre: sol, productions, langue, mours, sout identiques de chaque côto de Cassel ou de Kemmel, et si le flamand s'arrête aux collines de Renaix, c'est que la Forêt Charbonnière lui fixa jadis cetle limite.

Seul le petit massif de Bailleul, de Kemmel au Mont des Cats, était assez large et continu pour former une petite région à part: les habitants disent

1 Cette hypothèse de M. Cornet (Etudes Evolution, pp. 129-431) est corroborée par une hypothèse semblable à laquelle M. Rutot est arrivé par d'autres moyens (Origines du Quaternaire, pp. 54-56). 
« de Bergkant ». La raideur des flancs sableux, la présence de bois épais, disparus en grande partie depuis une soixantaine d'années, en faisaient un coin d'accès plus difficile, oủ se réfugiaient les mécontents et les vaincus. Ce sont peut-être lả les « forêts épaisses des hauteurs » où les Ménapiens, d'après Dion Cassius, avaient caché leurs biens les plus précieux ${ }^{1}$; ce fut en tous cas au pied des monts que se produisirent les premieres manifestations protestantes, et le premier prêche se fit le 12 juin 1562 dans le cimelière de Boeschèpe; c'est sur le mont Kemmel que se réunissent le $1_{\text {er }}^{\text {eoût }} 1566$ les « gueux des bois » avant de marcher sur Nieuport 2 . De nos jours, ce sont les indigents des communes voisines qui sont fixés sur les monts, où le sol est pauvre et se loue bon marche; et ces habitants des hauteurs ont chez ceux de la plaine la réputation d'individus douteux, pillards, venant voler la nuit dans les fermes d'en bas.

Malgré leur médiocrité, ces minuscules montagnes sont populaires en rlandre. Des auteurs graves les comparent sans sourire aux Alpes. Le pittoresque de leurs pentes boisées, d'où coulent des ruisseaux, l'étendue du panorama visible du sommet, attirent les foules. L'homme s'y est fixẻ de tout temprs, lorsqu'il y trouvait, à peu de profondeur, une nappe aquifère retenue par une couche d'argile: commode refuge pour le préhistorique, oppidum naturel pour le Belge et le Romain, bourgade commerçante et marché agricole d'aujourd'hui, c'est le cas de Cassel, d'Hooglede, de Thielt et de bien d'autres. Le grand fabricant d'Armentières, de Roubaix ou de Lille est aussi fier de sa villa de l'Enclus ou de Kemmel que le Genevois de sa maison du Salève. L'habitant des plaines basses de Bergues et de Bourbourg regarde avec intérêt le profil grêle de la montagne, et écoute volontiers les légendes qui courent surson origine. Dans cette terre prosaïque, la colline représente modestement l'élément pittoresque, romantique.

II.

\section{LES FORMES DU TERRAIN.}

L'étude détaillée des formes du terrain ne présente guére, de son côté, qu'un intérêt théorique. Il y a en Flandre trop peu de variêtés de roches, et ces roches elles-mêmes no sont pas assez cohérentes, pour pouvoir

1 Dion Cassius, I, 39, 44.

2 Wynekius, Gueusianismus Flandriae Occidentalis, édition Van de P'utte (Bruges, Soc. d'Em., 1841, in $-4^{0}, 107$ p.), pp. 220. 
donner autre chose que des formes assez simples. Il est bien rare que ces formes aient quelque importance pour l'agriculture: tout au plus peut-on remarquer que sur les Hancs raides les pâtures dominent. Mais la culture s'y établit aussi en s'aidant de rideaux ${ }^{1}$, comme en Picardie, si bien qu'elle ne connaît guère de régions qui lui soient interdites. D'ailleurs les fortes pentes sont rares. Le versant Sud du mont Noir atteint par endroits une déclivité de 45 degrés ; certaines pentes du flanc Nord de Cassel, à peu près autant; ce sont là des cas exceptionnels, môme dans les monts. Sur le versant Sud de Cassel, les plus grandes pentes ne dépassent pas 15 degrés ${ }^{2}$. Hors des monts, les pentes sont bien plus insignifiantes encore, et l'on peut dire sans exagération que les dèclivités les plus fortes en Flandre sont celles des digues qui défendent le pays contre la nier.

Cette rareté des pentes raides s'explique par la nature des sédiments flamands. Les sables et argiles, qui constituent le sol du pays tout entier, sont généralement peu susceptibles de donner des reliefs aux pentes raides. Il y a cependant d'intéressantes différences à noter entre les formes des sables et les formes des argiles; mais il faut toujours se garder de.donner aux termes un sens absolu; les pentes des argiles, en Flandre, ne sont raides que par rapport á celles des sables.

\section{Les Sables.}

Les sables présentent les formes les plus plates, les contours les plus effacés. Ce sont eux qui donnent aux sommets des collines d'altitude moyenne, situées au centre de la Flandre, cet aspect caractéristique de plateaux à peine ondulés qu'on retrouve partout. I es flancs argileux des collines peuvent être plus ou moins escarpés: si la partie supérieure est sableuse, le sommet est plat. C'est le cas des hauteurs qui s'ètendent de Gheluvelt à Staden, oú les sables paniseliens ( $P l d$. de la carte belge) forment le sommet; de la colline de Wynendaele, vrai platean de sable avec un rebord argileux; des hauteurs d'Anseghem, où la pente diminue notablement dans les sables glauconifères du sommet, dés qu'on s'est élevé au-dessus de l'argilite paniselienne. De même pour la colline d'Edelaere, et pour beancoup de hauteurs du pays d'Alost. Il n'y a guère d'exception

1 Le pays d'Alost, partie la plis accirlentée de Ia Flandre, en offre d'assez nombreux exomples. Voir en particulier le Sud de la feuille Sottegem à $1: 20.000 ;$ la région des hauteurs dans la feuille Renaix à $1: 20.000$.

2 Chiffres pris dans Meugy, Essai de géologie pratique de la Flandre française (Mém. Soc. Sc. I ille, 1852, pp. 43 et 59). 
que lorsque le sable est aggloméré en couches de grès assez puissantes: c'est le cas du Diestien des hautes collines, dont les formes restent raides jusqu'au plateau qui les surmonte. Enfin le sable meuble peut former des

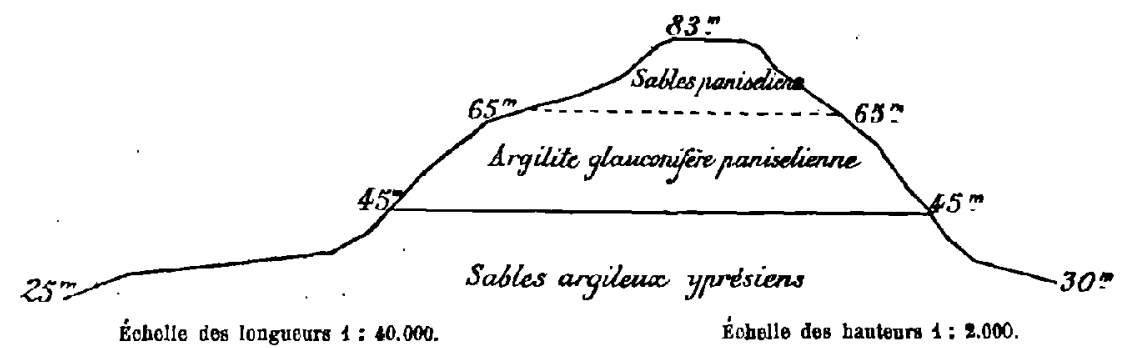

Fig. 17. - Profil et coupe des hauteurs d'Anseghem. Différences de pente dans les sables et les argiles.

éminences à flancs raides lorsque le vont l'accumule en petites dunes; c'est de dunes intérieures qu'il s'agit ici, et non pas de celles qui bordent une partie de la côte; on en trouve d'intéressants exemples soit au SudOuest de Maldegem, soit entre Lokeren et Waesmunster, soit à Deurle, sur les bords de la Lys, où ces monticules forment comme de grosses fourmilières, hautes d'environ 10 mètres, toutes plantées do sapins.

Le cas est déjả diffêrent lorsque les sables sont surmontés d'une couche d'argile. Sans doute, si les couches sableuses sont peu épaisses et si une autre couche argileuse leur sert de support, il peut leur arriver ce qui s'est produit dans les collines d'Ursel : là le sable base du Tongricn et le sable d'émersion asschien, faibles lits enserrés entre l'argile d'Assche et l'argile tongrienne, se sont écoulés latéralement, entraînés par l'eau de la nappe aquifére retenne entre les deux couches imperméables; ce foiroment du sable intermédiaire a fait glisser l'argile tongrienne jusque sur l'argile asschienne ${ }^{1}$, supprimant complètement tout relief qui serait dû au sable. Au contraire, quand les couches sableuses sont épaisses, l'argile qui les recouvre joue le rôle de manteau protecteur, de parapluie ${ }^{2}$, à l'abri duquel les sables peuvent conserver des pentes raides, prolongement des pentes argileuses qui les surmontent. C'est ce qui se produit généralement dans les collines du Sud, où d'assez fortes épaisseurs de sables parisiens sont comprises entre l'argile d'Assche au-dessus et l'argilite paniselienne au-dessous; oú l'yprésien sableux est protégé par les argiles du Paniselien. Un « mont

1 Cf. Rutot, Note sur quelques points nouveaux do la géologie des Flandres.

- Gosselet, Géog. physique, p. 42. 
de Flandre » comprend d'abord un vaste socle d'argile plastique, d'une faible inclinaison générale, mais entaille de petits ravins assez profonds. Au-dessus s'étendent, en pentes douces, les sables fins du sommet de

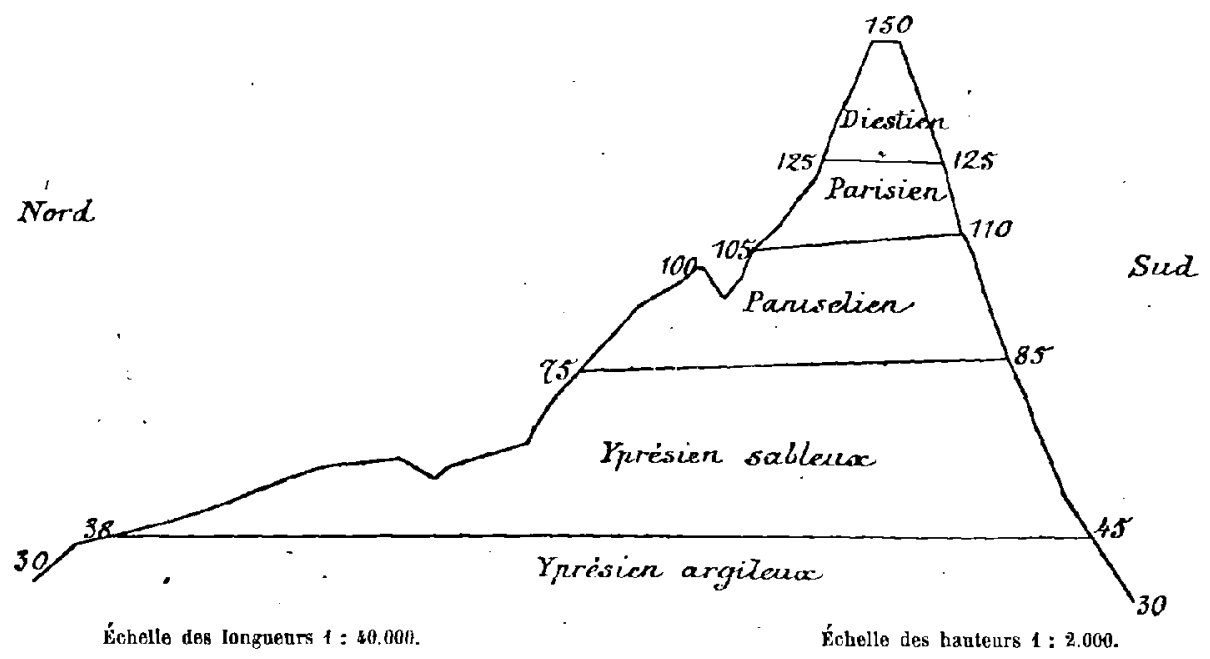

FIG. 18. - Profil Nord-Sud et coupe du mont de l'Hotond. Diffẻrences de pente dans les sables ot les argiles. Pente gúnérale plus douce au Nord, plus raide au Sud.

l'Ypresien, dont l'allure devient plus raide à la partie supérieure, que protège l'argile paniselienne. Au-dossus de la pente prononcée due á cette derniére couche, le profil s'adoucit de nouveau légèrement dans les sables parisiens, pour redevenir raide avec l'argile asschienne et le Iliestien. Le flanc Nord du mont de l'Hotond offre un bon exemple de cette superposition de pentes; on en retronvo d'autres au mont Vidaigne, au monl Rouge, au mont Aigu. Cette succession de pentes tour à tour plus raides et plus douces contribue à rendre facile la montée; elle a aidé l'établissement de l'homme sur les collines.

\section{Les Argiles.}

En rẻsumé, les couches sableuses ne donnent un profil accentue que par la présence d'un rexêtement d'argile, qui les empêche de se fondre sous l'effort de l'érosion. Les argiles sont les seules roches flamandes capables de donner par elles-mêmes des formes de relief appréciables. Grâce à leur imperméabilité et ả Ieur ténacité, elles résistent bien à l'érosion et sont capables de former parfois de petits abrupts, qui contrastent avec les 
ondulations molles des sables. Ce phénomène s'observe fréquemment dans les collines paniseliennes. Au-dessus du socle en pente douce des hauteurs d'Anseghem, formé des sables yprésiens argileux, on voit s'élever la pente plus raide de l'argilite glauconifere paniselienne, qui s'adoucit en arrivant aux sables de la partie supérieure (fig. 17). Même phénomène à Hooglede, où le relief est aussi donnè par l'argilite paniselienne s'élevant au-dessus du sable yprésien ; au Poelberg, où l'argilite se dresse en un petit massif raide au-dessus des sables glauconifères. Dans le pays d'Alost, les argiles asschienne et tongrienne peuvent former, au-dessus des sables lediens, laekeniens et paniseliens, de petits massifs dont les flancs sont assez raides pour que la pente soit sensible même du côté du Nord, contrairement à ce qui se passe dans cette région, où tous les abrupts font face au Sud ou à l'Ouest. Un autre exemple est fourni par la falaise de l'argile rupelienne,

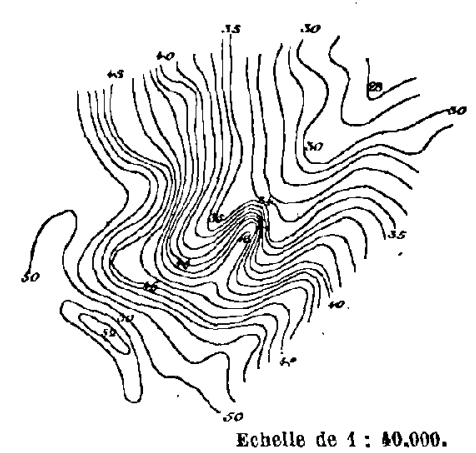

Fig. 19. - Glissement d'argile paniselienne, au Sud de West-Roosebeke (feuille Roulers a 1 : 10.000). s'elevant au-dessus des sables rupeliens, et dont les flancs sont avivés encore par les carrières que les briqueteries $y$ ont pratiquées ${ }^{1}$. Bien entendu, tous ces abrupts, falaises, pentes raides, parầtraient presque hor'izontaux à côté d'un rebord de massif calcaire; mais en Flandre, ce sont de vrais reliefs, des reliefs sérieux, qui s'imposent à l'attention.

Les versants argileux présentent encore quelques autres phénoménes intéressants. Sous l'influence de la dessiccation, des fentes, des crevasses profondes se forment dans la masse; les eaux pluviales s'y introduisent, délayent l'argile, et finissent par provoquer le glissement de la partie supérieure, parfois des éboutements considérables de matériaux qui vont recouvrir au loin les formations sous-jacentes ${ }^{2}$. De là l'aspect irrégulier des versants argileux, semés de protubérances et de creux, indices de glissement. On en trouve en Flandre d'assez nombreux exemples, qui contribuent à rendre plus iucertain l'aspect du relief. Dans l'Ouest, ils se trouvent sur les pentes d'argile yprésienne; brusquement on voit une protubérance s'avancer jusque dans le thalweg, rompant l'alignement des courbes de niveau; ailleur's c'est une apophyse qui descend juste au milieu

1 Voir fig. 13, p. 68.

2 G. La Noé et Margerie, Les Formes du terrain, p. 27. 
d'une vallée, à l'endroit où la profondeur devrait être la plus considérable. On a vu que l'argile tongrienne des collines d'Ursel peut glisser sur largile asschienne, et descendre ainsi de quelques mètres. Mais c'est encore l'argile paniselienne qui se déplace le plus facilement, à cause de sa situation sur les collines, où les pentes sont plus fortes. L'argilite sableuse glauconifère est, de toutes les roches flamandes, celle qui s'éboule le plus

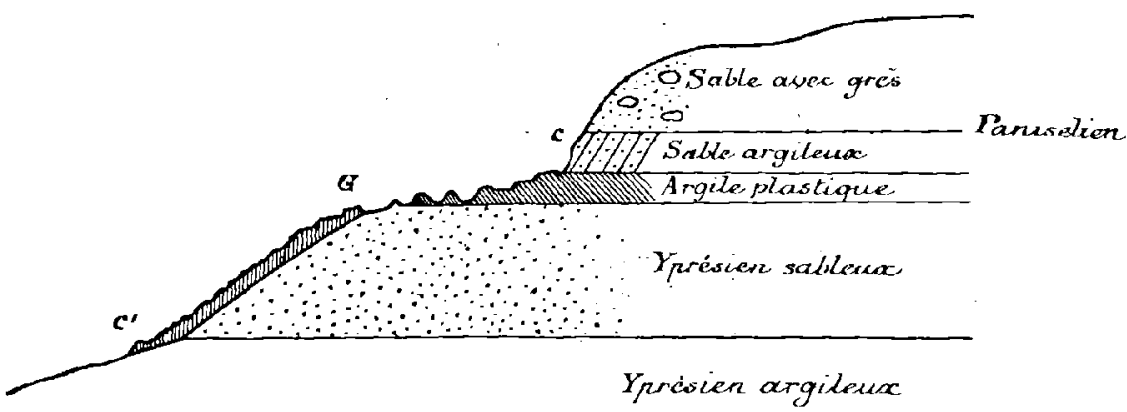

FIG. 20). - Glissement de février 1904 au Waienberg, d'après M. F. Halet. C G Partie éboulée.

G $C^{\prime}$ Nouvel emplacement de la partío éboulée.

souvent: les collines de Renaix en présentent de nombreux exemples. En 1843, après un hiver très pluvieux, une maison sur le versant Ouest du mont de l'Enclus serait descendue avec son jardin et ses arbres en fleurs; elle aurait ainsi parcoura 600 mètres, en traçant un profond sillon dans l'argilite ${ }^{1}$. I.es faits

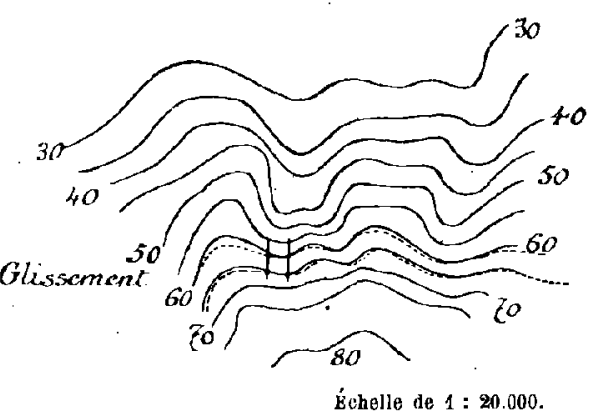

Frg. 20:- Emplacement du glissement. unt pent-être été grossis; mais M. Delvaux déclare avoir vu le versant Nord de la colline de Wayenberghe, à l'Est de Renaix, descendre avec tous ses arbres, ensevelissant les champs et le bois qui se trouvaient en contre-bas, et retardant de 6 mois l'inauguration de la voie ferrée de Renaix à Ellezelles ${ }^{2}$. La colline d'Edelaere, qui domine Audenarde,

1 Delvaux, Texte explicatif de la planchette d'Avelghem.

2 Delvaux, Notice explicative de la feuille de Flobecq (Bull. Soc. Anthr. Brux., V1I, 1888-89, p. 41, note). 
est constamment menacée de glissements qui vont couper la route de Grammont et descendent jusqu'à l'Escaut: en bas, ce sont de vastes coulèes d'argile yprésienne; au-dessus, des paquets d'argilite paniselienne; aussi cette montagne a-t-elle une réputation historique de mobilité. Très récemment, à la fin de février 1904, une prairie est descendue sur le flanc Nord de la colline de Waienberg, près de Sulsique; cette fois c'est le sable argileux paniselien qui a glissé sur l'argile plastique base du système, et est allé recouvrir, plus bas, lé sable yprésien ${ }^{1}$. Aussi se met-on a planter d'essences à racines pivotantes les pentes raides susceptibles de glisser en contre-bas. Jans toute cette région des collines de Renaix, les glissements ont été si fréquents qu'il n'est pas rare de voir des sables wemmeliens et diestiens reposer directement sur l'Yprésien 2.

L'argile produit encore une autre forme curieuse; c'est la tête de valton

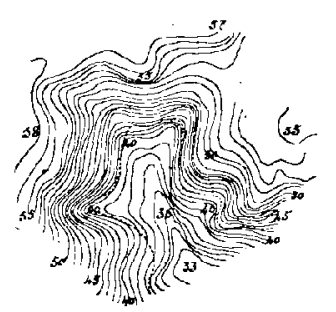

Échelle do $1: 40.000$.

FIG. 21. - Tête de vallon

à flancs raides et fond plat (Source du Krommebeek, feuille Ypres à 1: 40.000 ).

..... Limile de l'Y présien sebleux et du Paniselien argileux.

à flancs raides, ou plutôt le petit cirque par lequel se termine une vallée. Ces cirques ne se trouvent guère que dans les régions à la fois assez élevées et assez proches de dépressions, pour que les ruisseaux soient obligés d'approfondir considérablement leur lit, étant donné la proximité d'un niveau de base d'une très faible altitude. Or, lorsqu'après avoir entaillé la couche argileuse, l'érosion atteint un sol plus meuble; lorsque par exemple, sous l'argilite panisclienne elle arrive au sable yprésien, le creusement devient beaucoup plus facile; le vallon s'élargit par la base, dans la couche tendre, faisant ébouler et reculer les flanes plus raides de l'argile. On obtient ainsi une têtede vallon au fond large et plat, aux pentes raides. C'est ainsi que se sont formés un certain nombre de petits cirques dans les hauteurs d'Ypres, à proximité des vallées de la Lys et de l'Yperlée (11 mètres d'altitude à Menin, 18 mètres à Ypres); d'autres sur les flancs des collines de Renaix, au bas desquelles la vallée de l'Escaut descend à 11 mètres, et dans l'Ouest du pays d'Alost, à la faveur du niveau de base de la vallée de la Dendre (14 mètres à Ninove).

Ailleurs, le contraire se produit, lorsque la couche tendre est superposée

1 C. Halet (F.), Ln glissement de terrain aux environs de Renaix (Bull. Soc. belge Géol., XVIII, 1904, Pr.-V., pp. 161-163).

Delvaux, Planchette d'Avelghem. 


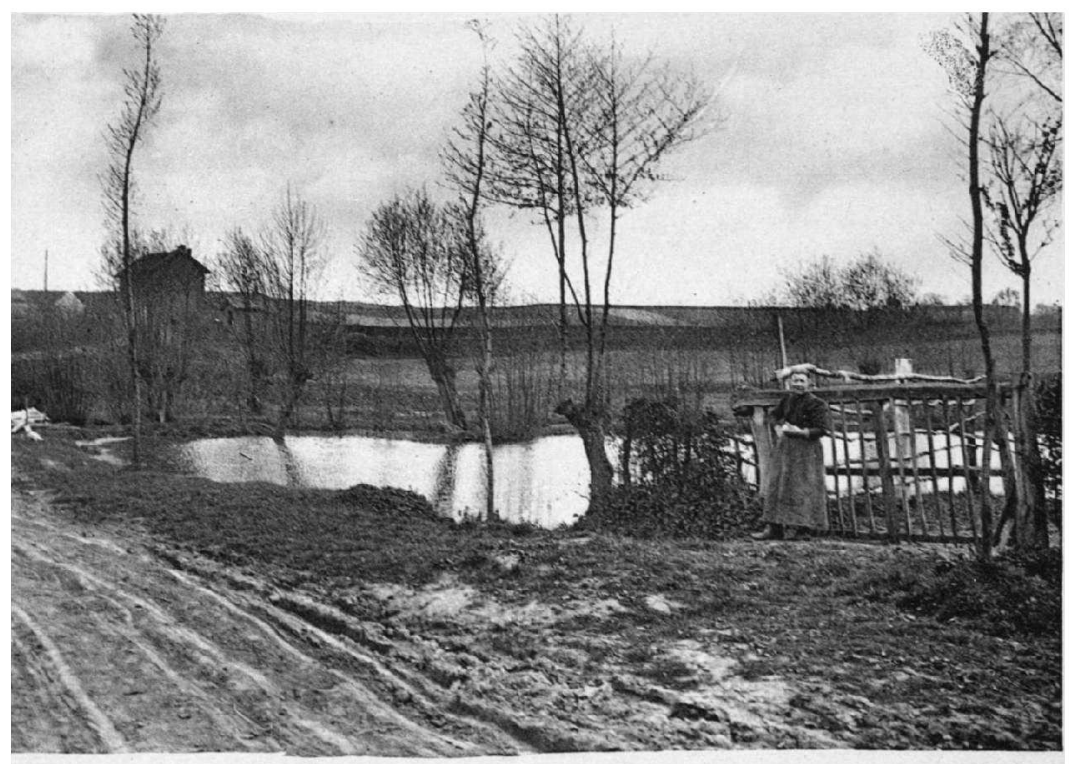

7. - Rebord Est de la Vallée du Molenbeck, à Moortzeele.

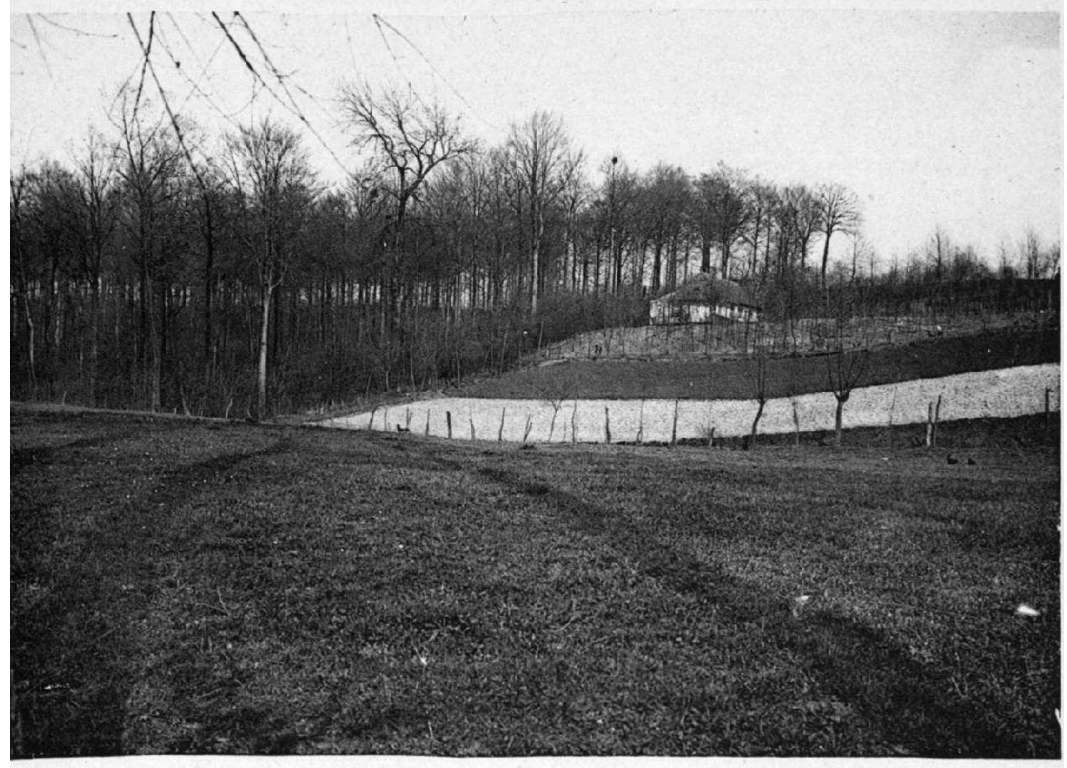

8. - Tête de ravin en entonnoir, boisé (Collines de Renaix). 
IRIS - LILLIAD - Université Lille 1 
à la couche dure. Les eaux, crensant leur lit dans la partie meuble, la ravinent largement el établissent un profil de pentes adoucies et régulières. Mais lorsque vers l'aval le ruisseau, s'enfonçant à l'approche du niveau de base pour atteindre son profil d'équilibre, pénètre dans la couche dure, le ravin se rétrécit, s'approfondit, et l'ensemble prend la forme d'un entonnoir dont la pente deviendrait plus raide vers le fond. Les exemples en sont nombreux sur le flanc Nord des collines de Renaix, où l'argile base et l'argilite glauconifère du Paniselien peuvent atteindre une épaisseur

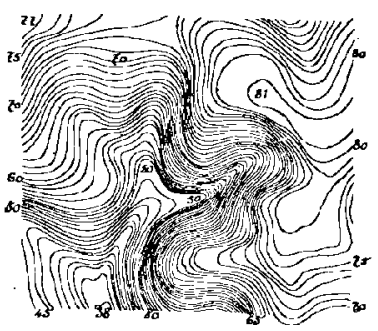

Écluelle de 1 : 40.000.

FIG. 22. - Tête do vallon à flancs raides et fond plat, dans l'ar-gilite paniselienne ( St-Antelinkx, feuille Grammont a $1:$ : 0.000$)$. de 30-40 mètres, surmontée de 10 à 15 mètres de sables glauconifères. Les entonnoirs ouverts dans les sables se rétrócissent rapidement à l'entrée dans l'argilite, et deviennent un ravin otroit et profond qui ne s'élargit qu'an contact des sables yprésiens. Presque tous les vallons de ce flanc Nord présentent cette forme, typique dans la vallée de l'Ingelbeek.

Mais si l'on quilte la région des collines, la Flandre du Sud-Ouest, où les brusques changements d'altitude et les différences de roches produisent ces formes pittoresques, les sols argileux ne sont guère plus accidentés que ceux des cantons sablonneux. C'est une suite d'ondulations douces, un paysage calme, a ux contours lents et arrondis ; une plaine qui est loin d'être parfaitement horizontale, mais où les déclivités sont rarement brusques. D'ailleurs à l'Est d'Ypres, le limon sableux et le sable occupent presque tonte la surface, remplissent tous les creux, noient

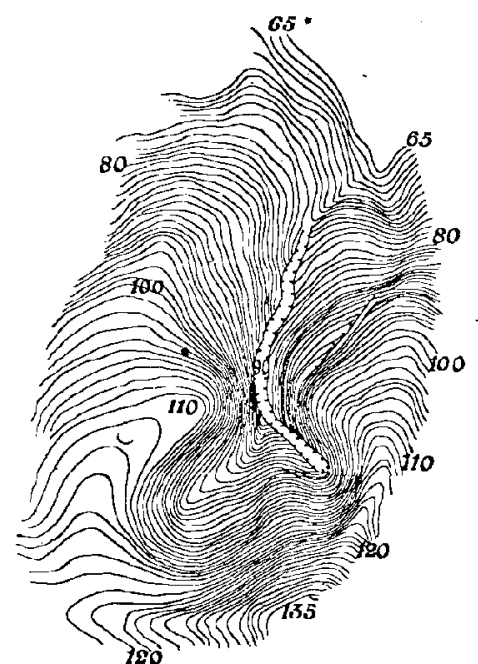

Écholle de $1: 20.000$.

FIG. $233^{\circ}$ - Tête de vallon en entonnoir dans les sables glauconifëres et l'argilite paniseliens (Source. de 1 Ingelbeek, feuille Renaix de la carte topographique belge à $1: 20.000)$.

toutes les éminences. Do là jusqu'à Anvers, c'est la Flandre plate, avec ses horizons qui seraient immenses, si les rangées d'arbres ne masquaient de leurs lignes monotones la monotonie plus grande encore de la vaste plaine. 
Tel est ce relief flamand, très modeste assurément, et qui ne mérite ni l'enthousiasme de quelques patriotes locaux, ni les railleries de ceux qui n'ont pas vu les pentes boisées du mont Noir ou les ravins verdoyants du pays d'Alost. Modeste, il devait l'être, dans un pays naturellement bas, affaissé, longtemps disputé entre la terre et la mer; oú le sol n'est composé quo de matériaux grossiers ou peu cohérents; oủ les infuences tectoniques n'ont produit ni rajeuni les formes, si bien que toutes les protubérances ne sont que les débris échappés à l'érosion. 


\section{CHAPITRE V}

\section{LES COURS D'EAU ${ }^{1}$}

I. Hydrographie. Hypothèses sur l'origine des cours d'cau. Cours d'eau conséquents et subséquents. Les rivières au Nord de Gand. - II. Hydrologie. Éléments du régime. Crues régulières et inondations. Travaux de régularisation. Livières à marée.

I.

\section{HYDROGRAPHIE.}

Les agents de ce vaste travail d'érosion, capable de faire disparaître dans l'Ouest de la Flandre une épaisseur de presque 200 mètres d'assises tertiaires ${ }^{2}$, sont les modestes cours d'eau qui parcourent lentement la plaine flamande. La plupart arrivent en Flandre tout formés. L'Aa el la Lys débouchent à Arques et Aire de pittoresques vallées parallèles, enfoncées dans l'Artois. L'Escaut, descendu sans hâte des croupes

1 Consulter: Van Overloop (F.), Les origines du bassin supéricur de l'Esciut (Bruxolles, Hayez, 1889, in-8o, 48 p., 1 pl., 2 cartes); - I,rs origines du bassin de l'Fscaut (Annexe du Bull. Soc. belge Géul., III, 1889, 92 p., 1 pl., 2 cartes) ; - L.orié (J.), Contributions à la Géologio des Pays-Bas, fasc. VII : Les métamorphoses de l'Escaute de la Meuse (Bull. Soc. belge Géol., IX, 1895, pp. 50-77, 2 cartes) ; - Gosselet (J.), Geographie physique du Nord do la France et de la Belgique: Brabant et Pays de Waes (pp. 103-108); - Rutot (A.), Le régine fluvial de la Belgique aux temps quaternaires (Mouvement géographique, 1897, $n^{\circ} 4$ ) ; - Le cours de l'Escaut á travers les âges géologiques (Ibid., $n^{\text {os }} 15,17,18$ ); - Les origines du Quateruaire de la Belgique (Bull. Soc. belge Gẻol., XI, 1897, Mém., pp. 1-140, carte à 1: 400.000); Cornet (J.), Etudes sur l'évolution des Rivières belges (Aun. Soc. géol. Belg., XXXI, 1904, Mém., pp. 261-500); - Bertin, Navigation interieure de la France, Notice sur les voies navigables du Nord et du Pas-de-Cialais (Lille, Danel, 1879 ; in-4 ${ }^{\circ}, 132$ p., 1 carte); - La Rivière, Navigation intérieure de la France, Notice sur les voies navigables du Nord et du Pas-de-Calais (Arras, Repessé-Crespel, 1000; in- $\mathbf{4}^{\circ}$, XVI + 160 p., 2 cartes, 5 grapliques); - Ministere des Travaux publics. Direction des travaux hydrauliques. Voies navigables de la Belgique. Recueil de renseignements (Bruxelles, Weissenbruch, 1880 , in $-8^{\circ}, 2$ vol., 348 et 392 p.).

2 Altitude de l'Ypresien sous Dunkerque : - 29 mètres ; sommet du Diestien à Cassel, au moins 170 mètres. 
crayeuses du Cambrésis, s'attarde en détours; dirigé vers le N.-E. jusqu’à Condé, il rebrousse au N.-W., vers la Flandre, qu'il atteint après Tournai. Mais aussitôt arrivẻ dans ce pays le fleuve reprend vers le N.-E. un cours paralléle à celui de la Lys : et les deux rivières se rapprochent insensiblement jusqu'à se confondre à Gand. Là, nouveau changement ; la direction générale, en dépit d'immenses méandres, reste W.-E. jusqu'à Termonde. C'est le confluent de la Dendre, et le fleuve y adopte encore une fois la direction N.-E., que cet affluent a fidèlement suivie depuis son origine. Aussí l'Escaut, de Termonde à Anvers, semble-t-il la continuation de la Iendre. Dernier épisode: le coude de Condé se reproduit à Anvers, et le fleuve gagne la mer vers le N.-W.

De son côté l'Aa adopte, après Arques, la même direction N.-W.; le petit fleuve de l'Yser quitte à Dixmude une direction N.-E. pour tourner du même côté. Même observation pour la Deûle à Lille. Le phénomène est donc général. I es principales rivières flamandes ont un cours parallèle, dirigé soit ver's le N.-E., soit vers le N.-W. ; et cette dernière direction s'impose principalement dans la partie basse de leur cours. Ainsi, an lieu de descendre directement vers la mer flamande, tous ces cours d'eau commencent par s'en écarter; par endroits, ils lui tournent le dos. C'est vers le N.-E., c'est presque vers le continent, que leurs eaux semblent sollicitées de descendre. Singulière anomalie pour un pays où le sol présente si peu d'obstacles.

Quant aux affluents de ces rivières, ils sont, soit perpendiculaires, soit légèrement obliques aux troncs principaux. C'est lo cas de la becque de Steenwerck, de la Douve, de la Mandel, du Poucquesbeek pour la Lys; de l'Espierres, de la Rhosnes, du Marckebeek, de la Zwalm pour l'Escaut; de la Dendre de Leuze, de la Marcq, de la Sille, pour la Dendre. Done nouveau parallélisme, aussi constant que celui des troncs principaux. Ce sont là des faits d'autant plus remarquables qu'ils se reproduisent à propos de toutes les rivières belges au Nord de la Sambre-Meuse. La Senne, la Dyle, la Gette se dirigent également vers le N.-E., jusqu'au point où elles se détournent vers le N.-W. pour former le Rupel qui vient rejoindre l'Escaut entre Termonde et Anvers.

L'origine de ces directions des rivières flamandes est une question délicate. Si « les considérations morphologiques, dans les problèmes d'histoire des vallées, ne pouvent rien prouver ${ }^{1}{ }^{1}$, même dans les pays de montagnes, que sera-ce pour la Flandre, avec son miserable reliof? II

1 De Martonne (E.), Problèmes de l'histoire des vallées (Ann. Géog., VII, 1898, p. 389). 
ne faudra demander à la morphologie que des indications générales. Même l'étude géologiqne des dépôts fluviatiles est singulièrement difficile. Les vallées sont si larges et leurs flanes si aplatis que les terrasses se distinguent malaisément; les matériaux se ressemblent tant qu'on peut bien prendre des alluvions de fleuves pour des roches en place. Aussi la question est-elle encore à l'étude; et bien qu'un grand pas ait été fait récemment, la plupart des détails restent obscurs.

\section{Hypothéses sur l'origine des Cours d'eau.}

La première hypothèse qui venait à l'esprit était celle d'une origine tectonique. Elle ponvait être permise tant qu'on n'avait sur le sous-sol que des données incomplétes. Le parallélisme remarquable de toutes les rivières du bassin de l'Escaut était dû à une série de failles, alignées S.-W. N.-E., et parallèles elles-mêmes à la direction de la côte. Guidés par ces dénivellations, les cours d'eau, évitant la côte, descendaient forcément vers Anvers. Formulée par Dumont à propos des vallẻes de la Hesbaye, qui laissent affleurer sur leur bord occidental le limon disparu de leur flanc oriental ${ }^{1}$, la théorie fut nettement énoncèe par d'Omalius d'Halloy et Honzeau 2. Restait à démontrer l'existence des failles autrement que par le parallélisme des rivières. Pour cela, des constatations géologiques nombreuses étaient nécessaires. Commencées depuis 1870, elles semblèrent d'abord prouver la réalité du phénomène. L'absence des sédiments paniseliens à l'Fst de la vallée de la Senne, des sédiments bruxelliens à l'Ouest, paraissait de nature à faire admettre la présence d'une faille qui suivait cette vallée de la Senne, et se serait produite à la fin de l'époque paniselienne. Les résultats des forages de Gand et de Mariakerke-les-Gand firent conclure de même en 1887 à l'existence d'une faille au droit du cours de l'Escaut, faille qui aurait probablement suivi la direction générale de la vallée de l'Escaut au Sud de Gand ". Mais l'hypothèse de la faille de la Senne est combattue par ceux-là même qui l'avaient formulée avant 1880, car il a été reconnu que le Bruxellien n'est pas complétement absent

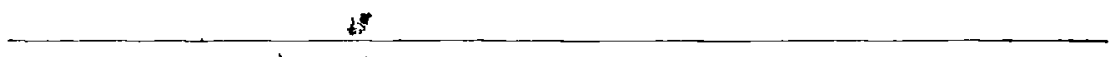

1 Le limon a été entraîné, sur le bord oriental des vallées, par les pluies dues aux vents d'Ouest.

z D'Omalius d'Halloy, Coup d'ceil sur la géologie de la Belgique (1842), pp. 114-115. Houzeau (J.-C.), Essai d'une géographie physique de la Belgique (1854), pp. 127-128.

3 Gf. Rutot (A.), Détermination de l'allure souterraine des couches forinant le soussol des Flandres entre Bruxelles et Ostende (Bıll. Soc. belge Géol., I, 1887, Mém., pp. 3-19). 
de la rive occidentale de la Senne ${ }^{1}$; enfin de nouveaux sondages à Gand ont montré sans contestation possible qu'il n'existait pas de faille à cet endroit 2 . Rien ne permet donc de croire que la direction des rivières de la Basse-Belgique soit due à des accidents tectoniques.

A cette conception un peu métaphysique de failles dont on ne pouvait vérifier l'existence succédèrent d'autres tentatives d'explication, appuyées sur des considérations morphologiques. De l'étude du relief actuel, M. Van Overloop déduisit les transformations de l'Escaut. L'allure des courbes de niveau, suivies sur la carte belge à 1:20.000, lui permit d'établir la prósence d'une série de dépressions par où il supposait que l'Escaut était successivement passé. Représenté par une énorme nappe d'eaux sauvages, large de quelques dizaines de kilomètres, le fleuve se serait dirigé d'abord du Vermandois vers Namur, en occupant à peu près le cour's actuel de la Sambre ${ }^{3}$. Mais un soulévement du sol intervient au S.-E., qui affecte L'Ardenne, et refoule l'immense courant vers l'Ouest: " l'évolution des eaux figure un véritable mouvement d'éventail, ayant pour centre fixe le massif d'origine de l'Escaut $\gg$; et dans la dépression que les eaux viennent de quilter' s'établit un cours d'eau indépendant, la Sambre. Cependant le déplacement ver's l'Ouest continue, le soulèvement gagne de ce côté, refoulant les eaux; de la vaste nappe émergent des îlots, qui s'élèvent peu à peu au-dessus des flots, s’agrandissent, se rejoignent, et finissent par constituer une nouvelle rive; c'est alors qu'apparaît le Mont Panisel, « qui débute à cette époque comme modeste îlot et dont le plateau supérieur porte la cote 107 comme une date de naissance ${ }^{5}$. Les eaux se sont concentrées à l'Ouest du nouveau rivage; dans la vallée abandonnée coule la Senne; le stade Senne du grand courant fluvial est terminé. C'est le tour du stade Dendre; le fleuve se dirige de Quiévrain vers Baudour, puis de Condé vers Belceil, le cours actuel de la Dendre formant l'axe de la vallée. Mais le stade Dendre a le sort du stade Senne, les passes de Baudour et de Belœil se bouchent, et

1 Gf. Rntot (A.), Sur l'absence de faille dans la vallée de la Senire (Bull. Soc. belge Gẻol., XVIII, 1(N)', Pr.-V., pp. 178-179).

2 Coune (C.), Note sur le forage d'un puits artésien pour la distribution d'eau de Gand (Ann. Assoc. Ingén. Gand, XX, 1896-97, p. 70); - Vanhove (D.), Note sur le nouveau puits artésien de l'usine Lousbergs, à Gand (Bull. Soc. belge Géol., XV,1901, Pr.-V., p. 63).

3 Van Overloop, Origines du bassin de l'Escaut, p. 30.

- Ibid., p. 30.

s Ibid., p. 24. 
l'Escaut, qui s'est rejeté d'abord sur la vallée de la Rhosnes, finit par se cantonner dans sa vallée actuelle, et n'en bouge plus. Ia rive gauche peut. naître. Jusque là, on n'avait suivi les déplacements du fleuve qu’à la marche ininterrompue de sa rive droite vers l'Ouest; de la rive gauche il n'étail pas question, arasée qu'elle élait par' les eaux dans leur mouvement latéral. Désormais, le fleuve étant fixé, la rive gauche s'établit définitivement, s'allonge d'îlots, se rapproche de la rive droite, et l'Escaut prend peu à peu son aspect actuel.

Il y aurait bien des chicanes de détail à faire à la théorie de M. Van Overloop. Pourquoi la Meuse, bien plus puissante que I'Escaut, n'a-t-elle pas été refoulée comme lui vers l'Ouest, et ne l'a-t-elle pas poursuivi dans les dépressions de la Sambre, de la Senne et de la Iendre? Pourquoi la Lys n'a-tello pas eu une histoire analogue à celle du fleuve? $\Lambda$ u lieu de se déplacer vers l'ouest, elle a ramené vers l'Est ses eaux qui d'abord gagnaient la mer du Nord par les passes de Staden, puis de Wynghene ${ }^{1}$. Comment expliquer l'inopportune présence des collines de Renaix, qui ont si victorieusement résisté á l'arasement des rives gauches? Mais les objections d'ensemble suffisent. Jamais I'Escaut pliocène ou quaternaire n’a pu avoir la largeur que Iui prodiguent les tracés de M. Van Overloop; où aurait-il pris les quantités d'eau que suppose un lit pareil ? Est-ce sur ce «massif central » ${ }^{2}$ d'où descend le fleuve d'aujourd'hui, avec son altitude moyenne de 120 mètres? Comment croire qu'un fleuve dont le débit aurait été supérieur à celui des plus puissants cours d'eau du globe ${ }^{3}$, eût pu recovoir tant d'eau d'une région aussi restreinte que lo bassin supérieur de l'Escaut? Mais surtout ce déplacement latêral d'un fleuve á travers tout le territoire belge est singulier. Sans parler de ces soulévements de toute une région qui ne sont démontrés que parce qu'on a besoin d'eux, le mouvement de ce fleuve, roulant ses eaux vers le Nord et poussé en même temps vers l'Ouest, paraît un phénomène invraisemblable. Nul autre exemple dans le monde. Le Hoang-Io déplaçant son cour's infèrieur est un cas bien different, celui d'un fleuve en crue qui reprend, dans une plaine alluviale, un ancien cours abandonné. En France la Garonne; qu'on dit poussée contre sa rive droite, est loin de la faire disparaître; au contraire elle en avive la pente, qui se dresse en escarpements au-dessus

1 Origines Escaut, pp. $76-78$.

2 Ibid., p. 32.

3 M. Cornet calcule qu'un fleuve semblable aurait eu un débit de 125.000 mètres cubes par seconde, soit la somme des débits du Congo ot du Mississipi (Etudes évolution, p. 275, note 2 ). 
du fleuve. Rien de commun avec celte rive gauche fantôme de l'Escaut, qu'on ne voit jamais, et qui devait exister pourtant; que le fleuve dévore mystérieusement dans sa retraite vers l'Ouest, sans qu'elle puisse l'arrêter. Et ce bizarre déplacemenl, qui n'affecte que l'Escaut, et ne fait émigrer ni la Lys ni la Meuse, se produit toujours vers l'Ouest, quoique la pente des couches fût dirigée vers le Nord. L'Artois ne se serait done pas soulevé, en dépit de la présence des sédiments diestiens a 170 mètres à Cassel ?

\section{Cours d'eau conséquents et subséquents.}

C'est en s'inspirant, comme M. Van Overloop, de la morphologie du territoire flamand, mais en complétant cette étude par des considérations géologiques, que l'on esl arrivé récemment a émettre sur la question une hypothèse très plausible ${ }^{1}$. M. Cornet rappelle d'abord que c'est du retrait de la mer diestienne que date la formation du réseau hydrographique actuel. Or il est difficile de nier que la mer diestienne ne se soit étendue sur tout le bassin des rivières flamandes. C'est donc bien sur la surface toute neuve, peut-on dire, ahandomée par la mer diestienne en retraite, que s'est installe le drainage de Ia Flandre.

La plaine côtière diestienne ne tarda pas à s'incliner fortement. Un mouvement de bascule, réel celui-là, et attesté par des données géologiques et paléontologiques incontestables, se produisit autour d'un axe situé à la hauteur d'Anvers: l'Artois s'éleva, la Hollande s'affaissa. Sur le plan incliné ainsi formé ruisselèrent les eaux pluviales, coulant de la partie haute ver's la dépression, du S.-W. vers le N.-E.; c'est le drainage conséquent qui s’établit. Cotte direction, on l'a vu, est encore celle de nombreuses rivières ${ }^{2}$; les cours d'eau orientés ainsi sont done les artères conséquentes du réseau.

Copendant les eaux se réunirent pour s’écouler, en quelques branches maîtresses: Lys, Escaut d'Audenarde, Dendre, Senne, etc.; branches situées à des distances à peu près équivalentes. D'où vient cette particularité ? Faut-il croire que les rivières se sont dès l'abord établies dans des dépressions tertiaires faiblement accusẻes? M. Crosselet « admet que c'est

1 Gornet (J.), Etudes sur l'Evolution des Rivières belges. - Une partie du travail a été reproduite à part sous le titre: «Lorientation des vallées dans le bassin de l'Escaut ". Bruxelles, Vanderauwera, 190\%, in-8 13 p.

2 Cotte disposition a été parfaitement indiquẻe par M. Gosselet (Esquisse, Quaternaire, p. 259). 
la courbure des couches tertiaires qui a déterminé l'emplacement des vallées actuelles de la Scarpe et de la Deûle aux environs de Douai »; et d'autre part ces synclinaux tertiaires remplissent un leger vallon de la surface de la craie ${ }^{1}$. Peut-être en est-il de même en Flandre; mais ce détail ne pourra être éclairci que par la construction de coupes géologiques perpendiculaires aux trones conséquents ${ }^{2}$.

Une fois que les cours d'eau conséquents sont formés, des affluents leur arrivent: ce sont les rivières subséquentes, à peu près perpendiculaires aux troncs principaux. Le bassin de ces affuents subséquents est asymétrique, étendu au Sud, restreint au Nord. C'est que la partie Sud correspond à peu près au plat dẹs couches tertiaires, lentement inclinẻes vers le Nord, et la partie Nord à la tranche; celle-ci est donc moins large et plus inclince ${ }^{3}$. Parfois des affluents de rivières subséquentes sont en prolongement les uns des autres, et l'on peut alors supposer que ce sont des restes d'ancions cours d'cau conséquents, capturés par les affluents subséquents. Tel serait lo cas de certains ruisseaux du bassin de la Dendre; tel celui du Gaverbeek, affluent de droite de la Lys. Enfin l'on remarque que beaucoup d'affluents subséquents ne sont pas rigoureusement perpendiculaires aux rivières conséquentes; ils forment, à leur rencontre avec elles, des angles plus ou moins aigus. M. Cornet en donno une très ingónieuse explication. Ces affluents sont nés lorsque le pliocène était déjà enlevé, et que les couches éocènes avaient été ramenées au jour ; coulant sur l'éocène, ces cours d'eau se sont conformés à la pente de ses assises, qui est dirigée ver's le Nord, tandis que la pente du pliocène est à peu près N.-E. Aussi ces alfluents plus récents sont-ils E.-W.; de là l'angle aigu qu'ils font avec les rivières conséquentes, qui continuent à couler suivant l'ancienme pente du pliocéne disparu, et sont en quelque sorte «surimposées» aux couches éocènes, dans lesquelles lour lit est aujourd'hui frayé ". Cependant une réserve s’impose. Ces rivières subséquentes obliques se trouvent être en effet les affuents les plus importauts des trones conséquents: Douve, Mandel pour la Lys, Rhosnes, Marckebeek, Zwalm pour l'Escaut, Ancre, Marcq, Bellebeek pour la Dendre. Faut-il admettre que les plus importants des cours d'eau subséquents soient ainsi les plus récents?

1 Gosselet (J.), Coupe du Canal de Dérivation autour de Douai (Ann. Soc. gẻol. N., XXXII, 1904, pp. 88-89).

2 Etudes évolution, p. 454 .

3 Ibid, p. 457.

4 Ibid., pp. $458-459$. 
Cette explication de la direction des rivières flamandes a le mérite d'être simple, claire, et de s'accorder avec ce qu'on sait de la géologie du pays. M. Rutot, dans son travail sur le creusement de la vallée de la Lys, apporte une preuve nouvelle: la Lys est bien un cours d'eau conséquent, qui est descendu sur place en laissant des terrasses qui marquent les ćlapes du creusement ${ }^{1}$. En France, il est facile de trouver d'autres faits qui viennent appuyer la théorie de M. Cornet: l'ancienne rivière Scarpe d'Arras-Sensée, séparée aujourd'hui en 2 tronçons, était un affluent subséquent oblique de l'Escaut; de même pour la Scarpe de LouaiSt-Amand, qui rejoignait jadis le fleuve vers Condé par une dépression

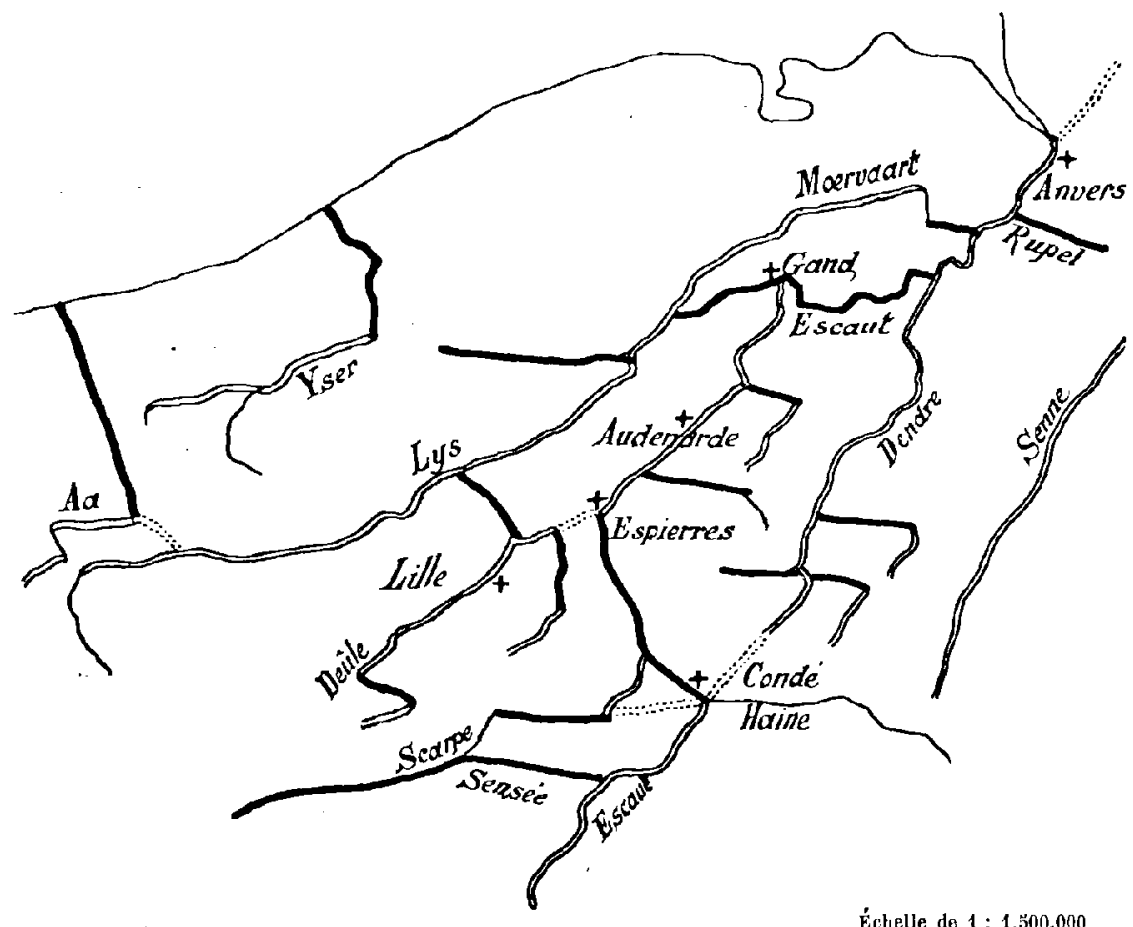

Échelle de $1: 1.500 .000$

FIG. 2\%. - Direction des cour's d'eau flamands.

$\begin{array}{ll}= & \text { Direction conséquente. } \\ = & \text { Direction subséqueute. } \\ \text { Anciens cours possibles ou probabies. }\end{array}$

1 Rutot (A.), Note sur la découverte d'importants gisements de silex taillés dans les collines de la Flandre Occidentale. (Coupe de la vallée de la Lys, page 9) ; - Idem, Greusement de la vallée de la Lys (Bull. Soc. belge Géol., XIII, 1899, Pr.-V., pp. 91-101). 
trés nettement indiquée encore à travers la forêt de Raismes ${ }^{1}$. Nul doute que d'autres observations ne viennent encore prouver l'exactitude de la theorie.

Cependant la théorie générale une fois admise il reste bien des délails à expliquer. Ies cours d'eau de la région côtière, Hem, Aa, Yser, Wacrdamme, ont un cours supérieur conséquent à l'ancien rivage diestien. Brusquement, arrivés au bord de la plaine maritime, ils tournent au Nord, même au N.-N.-W., vers la mer. I'où vient ce changement soudain ?' C'est ici le lien de rappeler qu'un grand cours d'eau a dû exister jadis sur l'emplacement actuel de la côte. M. Rutot en a le premier soupçonné l'existence ${ }^{2}$ : découvrant sur la plage, après des tempetes, des fragments de grès paniseliens avec fossiles, il en conclut qu'un peu au large de la côte les sédiments quaternaires (sables flandriens) ne surmontaient plus le Paniselien. Ainsi les sables flandriens seraient amoncelés dans une dépression qui comprend la plaine maritime et une petite fr'ange seulement de la mer du Nord; cette dépression serait une ancienne vallée fluviale (conséquente à la mer pliocène), dans laquolle la mer flandrienne aurait pénétrè. M. Cornet voit dans ce fleuve disparu l'agent de l'énorme dénudation qu'ont subie les couches tertiaires de la Flandre occidentale ${ }^{3}$. L'existence de ce fleuve admise, plusieurs hypothèses s'offrent pour expliquer la direction actuelle des rivières de la plaine maritime. On peut se demander si elles n'ont pas été (comme l'Escaut inférieur) capturées par l'invasion marine du $V^{e}$ sićcle; ou plutôt si leur cours inférieur' ne date pas du recul de la mer quaternaire, abandonnant la plaine maritime au début de l'époque historique. Une hypothèse plus complète encore se présente. Les cours supérieur's de ces rivières seraient des fragments de cours d'eau conséquents, capturés par des affluents subséquents du grand fleuve de la côte. D'où la direction Sud-Nord de leur cours infèrieur. La mer flandrienne pénétrant dans la vallée du fleuve, serail remontée dans celle de ses affluents, et y aurait déposé ses sédiments; d'où la forme de golfes que présente aujourd'hui la plaine maritime au débouché de la Ilem, de l'Aa et de l'Yser : ces golfes étant d'anciennes vallées submergées, puis á demi comblées de sables flandriens. Après le départ de la mer, les rivières auraient établi sur la plaine exondée un cours conséquent

1 Indication due à M. Maurice Leriche.

2 Rutot, Origines, pp. 53-56.

3 Etudes évolution, pp. $430-431$. 
au nouveau rivage; et les mêmes phénomènes se seraient reproduits avec l'invasion marine du IV' siècle ${ }^{1}$.

I'autre part, des phénomènes de capture sont probablement intervenus à l'intérieur de la Flandre pour modifier le reseau primitif ; les changements de niveau de base qui se sont produits depuis le départ de la mer diestienne ayant donné aux lentes rivières d'aujourd'hui une activité de fleuves travailleurs. Rien qu’à l'époque moderne on a pu constater des phases torrentielles dans le régime de rivières qui sont des modèles de calme. Vers le $I I I^{\mathrm{E}}-I V^{\mathrm{B}}$ siècle de notre ère, la Deûle a roulé des galets do craie assez volumineux, déposès dans un banc de sable verdâtre avec des fragments de meules et de luiles romaines; et elle a en une autre forte crue au XIII ${ }^{e}$ siècle ${ }^{2}$. Ainsi des rivières aussi lentes et faibles que la Deûle ont pu, à diverses reprises, avoir assez de force pour cremser leur lit, reculer leur lête et capturer des systèmes hydrographiques voisins. En tenant compte de la prudence avec laquelle il faut étudier des phénomènes qui ont laissé si peu de traces, on pourrait peut-ètre supposer que la Ieûle actuelle, jusqu’a Lille, se continuait jadis vers Espierres, où l'Escaut d'Audenarde semble être son prolongement. De même il est permis de voir, dans le tronçon de l'Escaut qui va de Condé à Espierres, un ancien alfluent subséquent de la rivière d'Audenarde, qui a capturé l'Escaut supérieur. Jusqu'alors, celui-ci s'écoulait probablement droit au Nord, par la dépression de Blaton où passe maintenant lo canal d'Ath; et la Dendre était le prolongement direct du fleuve de Cambrai et de Valenciennes. C'est un peu le «stade Dendre» de M. Van Overloop, mais le fleuve reconstitué n'a rien de l'immense nappo que l'on présentait nagnère, et ses transformations s'expliquent par des phénomènes vraisemblables; l'hypothèse est au moins possible.

\section{Ies rivières au Nord de Gand.}

Oủ les difficultés deviennent particulièrement nombreuses, c'est lorsqu'il s'agit d'expliquer le conrs de l'Escaut et de ses affluents conséquents audulà du parallèle de Gand. A première vue, le phénomène paraît assez

1 Sur le cas de l'Aa, jadis affuent de la Lys à Aire, et capturé par une rivière venant de la Plaine maritime, voir Briquet (A.), Quelques phénomènes de capturo dans le bassin de l'Aa (Ann. Soc. géol. N., XXXIV, 1905, pp. 111-120, pl. V).

2 C. Ladrière (J.), Les anciennes rivières (Ann. Soc. géol. N., VIII, 1880-81, pp. 11-17); - Gosselet, Esquisse, Quaternaire, pp. 324-326. 
simple. Un cours d'eau central, dans l'espèce la Dendre, a capturé par l'intermédiaire d'affluents subséquents, les trones conséquents voisins: l'Escaut de Wetteren lui a amené les eaux de l'Escaut d'Audenarde et de la Lys; le Rupel, celles de la Senne, de la Ilyle, de la Gette. Rien de.moins compliqué; et la réunion des eaux du bassin vers Anvers s'expliquerait ainsi facilemenl. Mais a Anvers il n'existe pour ainsi dire pas de sédiments quaternaires dans la vallée du fleuve; les alluvions modernes reposent sur des conches tertiaires ${ }^{1}$. D'autre part l'allure rectiligne de la limite Sud du Scaldisien dans la région d'Anvers montre que le fleuve n'existait pas pendant la période correspondant au dépôt de cette couche ${ }^{2}$. Le cours par Anver's daterait donc seulement de l'époque moderne. Pourtant des recherches faites sur le terrain semblent indiquer qu'à la fin de la période quaternaire le flouve gagnait la Meuse par Bréda, la trace de son passage existant encoro dans les tourbières au Sud de cette ville ${ }^{3}$; et cette interprétation a l'avantage d'être en harmonie avec la direction générale des cours d'eau flamands.

A l'époque moderne au moins, il est à peu près certain que le fleuve ócoulait ses eaux par Anvers. An dela, il serpentait sur la plaine de sables flandriens, déposés par la mer quaternaire en retraite; et par l'Eendracht, qui sépare aujourd'hni Tholen du continent, il allait rejoindre la Mense ". N'étant pas gonflé par la marée, cétait un fleuve modeste, coulant au milieu des marécages tourbeux où un nouvean sol s'élaborait au-dessus des sables flandriens. C'est alors que le vit César, qui indique qu'il se jette dans la Meuse ${ }^{5}$. Quatre siécles plus tard, la mer reparaissait sur la plaine déjà toute couverte do tourbe; clle arrivait jusqu'à l'Escaut et pénétrait dans sa vallée jusqu'au delà d'Anvers. Quand elle perdit du terrain, et qu'une partie de la plaine émergea de nouveau, des criques profondes s'étaient formées, et e'est par ces bras de mer que s'écoula désormais le modeste apport de l'Escaut. Rien de commun entre ces deux larges golfes marins et le fleuve qui vient leur apporter ses eaux; cependant on s'habitua à considérer les deux bras comme les branches

1 Van den Broeck (E.), Présentation du travail de M. Van Overloop (Bull. Soc. belge Géol., III, 1889, Pr.-V., pp. 193-194).

2 Van Ertborn (O.), Texte explicatif du levé géologique de la planchette d'Anvers, p. 3.

3 Lorié (J.), laes mótamorphoses de l'Escaut et de la Meuse (Bull. Soc. belge Gíol., IX, 1895, Mém., pp. $5-77$ ).

4 Ibid., p. 58.

5 César, de Bello Gallico, VI, 33, 3. 
d'un delta, et à les appeler Escaut oriental et occidental. En réalité c'est au Doel, en aval d'Anvers, que se termine le véritable cours du fleuve; c'est là qu'il rejoint le bras de mer de l'Escaut occidental.

Cependant le détour qu'accomplit l'Escaut, après Gand, pour aller rejoindre la mer, reste un objet d'étonnement pour tous ceux qui consultent une carte de Flandre. De Gand à l'ancienne extrémité de la crique du Braakman, étendue il n'y a que 120 ans jusqu'au Sud de Sas-deCrand, il n'y a guère que 18 kilomètres, et le canal de Terneuzen entre Gand et le Sas n'a pas besoin d'une seule écluse; sur ce parcours, l'altitude moyenne ne dépasse pas 8 mètres. D'autre part les profondes criques qui traversaient la plaine maritime, le $Z$ win disparu au $\mathrm{XIX}^{\mathrm{e}}$ siècle, le Braakman qui existe encore, ressemblaiont trop à d'ancions estuaires pour qu'on ne fut pas tenté d'en faire des embouchures oblitérées de la Iys et de l'Escaut. Ia présence, au Nord de Gand, de la bizarre vallée de Ia Caele, semblait une autre preuve de l'ancienne direction des cours d'eau: se détachant vers Deynze de la Lys, la Caele s'oriente vers le N.-E. ; la dépression marécageuse où elle coule, bien lentement, est empruntée successivement par les canaux de Schipdonck et de Bruges. Passant au Nord de Gand, la Caele vient se confondre avec le canal de Terneuzen ; mais un peu plus loin, à Roodenhuyze, sa vallée s'écarte du canal et s'incline peu à peu vers l'Est. La rivière a changé de nom : c'est le Moervaart; la vallèe s'est élargie jusqu’à dépasser 2 kilomètres; elle est digne d'un fleuve. Le Moervaart longe la rive Nord; un autre bras, la Zuidleede, recueille les eaux du Sud; entre les deux courants s'étendent des prairies marécageuses, coupées de nombreux fossés. La plaine du Moervaart se termine à l'Est en cul-de-sac vers Stekene; Moervaart et Zuidlecde se réunissent, tournent au Sud, prennent le nom de Durme, ot la nouvelle rivière gagne l'Escaut en contournant le rebord du pays de Waes.

Ia présence de cette rivière Caele-Moervaart-Durme, le peu de distance qui sẻpare Gand du Sas, l'altitude si faible do la région intermédiaire, devaient done faire naître l'hypothèse que la I.ys et l'Escaut avaient jadis gagné la mer droit au Nord. La direction de la vallée Caele-Moervaart, sa largeur, les alluvions qui en forment le sol, rendent en effet plausible l'hypothèse qu'une partie des eaux de la Lys aient emprunté jadis ce chemin, prolongement de la vallée supérieure ${ }^{1}$. Mais on a fait

1 Cf. sur la vallée du Moervaart, la description donnée par M. Van Overloop dans : Les silex de la station préhistorique de Mendonck (Buil. Soc. Anthr. Brux., III, 18841885 , p. 334). 
bien d'autres suppositions. On a affirmé que la Lys débouchait dans le $Z$ win, en passant sur les emplacements actuels des canaux de Bruges ou de Schipdonck. Or, rien dans le sol ni dans le relief entre Deynze et I3ruges ne rappelle des alluvions récentes ou une vallee. D'autre part trois consciencicuses études ont été écrites pour prouver que - l'Escaut et la Lys, à l'époque historique, se jetaient encore dans le Braakman et les criques voisines ${ }^{1}$. Pour les uns, l'Escaut empruntait la vallee du Moervaart, et se partageait en deux bras, dont l'un, par Stekene, gagnait Hulst, Axel et le Braakman, et dont l'autre continuait par la Durmo; c'est assez longtemps après Charlemagne que la première passe aurait disparu, comblée par le sable campinien que le vent y aurait amené ${ }^{2}$. Cette date si récente, après Charlemagne, peut surprendre: mais c'est justement la qu'est lè secret de cette theorie; beaucoup d'historiens, étonnés que le pays de Waes et les Quatre-Métiers tissent partie de l'Kimpire, ont pensé que l'Escaut, limite de la Flandre et de l'Empire de Tournai à Gand, avait dû continuer à former la frontière an delà de Gand, jusqu'à la mer ; le fleuve plus tard s'était détourné, mais la limite restait, témoin de son ancien cours. La raison n'était pas suffisante; une limite n'est pas nécessairement rivée à un fleuve, surtout lorsque ce fleuve est un très modeste cours d'eau. Aussi l'auteur de la troisième étude ne s'y est-il pas arrêté. Pour lui le Moervaart-Durme est le prolongement de la Lys ${ }^{3}$, qui jusqu'au XIII' siècle se jetait dans le Hont (Escaut Occidental) par un véritable delta, tandis que l'Escaut, relié à la Lys dans la ville de Gand par des bras d'une importance secondaire, continuait sa route par Wetteren, Termonde et Anvers. Le delta de cette Durme-Lys comprenait 7 ou. 8 bras. Le premier quittait la vallée principale à Langerbrugge, se subdivisait après Cluysen en deux ramifications, l'une allant au Hont par Bouchaute, l'autre par Ertvelde et Assenede ". Lne autre branche suivait, depuis Roodenhuyze, l'em-

1 David, Recherches sur le cours primitif de l'Escaut (Bull. Ac. R. Belg., $1^{\text {ro }}$ série, t. XVI, 1849, $1^{\text {re }}$ partie, pp. 257-282, et $1^{\text {re }}$ série, t. XIX, 1852, $1^{\text {re }}$ partie, pp. 649-679); - Verstraete (E.-J.), Nonvelles études sur le cours primitif de l'Escaut en aval de Gand (Bull. Soc. belge Géog., II, 1878, pp. 313-333); - Van Werveke (A.-K.), Etude sur le cours de l'kscant et de la Lys-Durme au moyen-âge (Bull. Soe. belge Gég., XVI, 1892, pp. 453-485, 588-511, 2 cartes à $1: 240.000$ et $1: 30.000$ ).

2 Verstraete, p. 328.

3 Nombreux textes pour prouver que, depuis Gand jusqu'au Moervaart, le cours d'eau prolongement de la Lys est désigné plusieurs fois sous le nom de Durme (Van Wervoke, pp. 163-466).

- Van Werveke, pp. 467-470. 
placement actuel du canal de Terneuzen jusqu'au delà de Selzaete; la I angeleede, de Wachtebeke au Canisvliet, était une autre issue. Le bras le plus important du delta quittait le Moervaart à Calve, passait par Overslag et suivait les criques des Polders par Axel jusqu'à Othene, hameau à l'Est de 'Terneuzen; il était encore important en $1547^{1}$. Le bras Haringsleede suivait à l'Est, et le dernier était le canal de Stekene, qui rejoignait Hulst et le Hellegat. Le travail est appuyé sur de nombreux texles, qu'il faudrail discuter pied à pied, sans arriver d'ailleurs à un résultat très net, car on pourrait toujours équivoquer sur le sens des termes désignant les « cours d'eau »; signifient-ils rivière naturelle ou canal ? En tous cas on peut fort bien penser, à voir ces bras du prétendu delta, que c'étaient de trés anciens fossés assurant l'écoulement des eaux pluviales vers les Polders ou le Moervaart. C'est dans ce but, par exemple, qu'on élablit en 1315 le canal de Stekene à Hulst ${ }^{2}$; ce creusement de canaux d'assèchement était nécessaire sur ce sol plat, à peu près imperméable. I' autre part rien n'indique que le pays qui sépare Gand des Polders fut un delta, c'est-à-dire une plaine a pente insensible, lentement formée des apports de la rivière, et sur laquelle celle-ci se divisait capricieusement en plusieurs bras. Le sol est uniquement formé de sable, parfois assez grossier et meuble, bien différent des alluvions argileuses de la vallée de la Lys ; de même qu'aucune trace d'alluvions marines récentes ne s'observe le long des fossés qui seraient les anciennes branches du delta. Ainsi pas de traces de l'action marine: et cependant la marée aurait dû remonter dans ces bras au moins jusqu'au Moervaart; pas de traces d'alluvions fluviatiles, siuf dans la vallée, parallèle à la côte, de la Caele et du Moervaart. Cette ingénieuse hypothèse, due à une étude soignée des cartes et des textes, ne se vérifie donc pas sur le terrain. En conclusion, si la Lys et l'Escaut ont pu couler au Nord de Gand à l'èpoque quaternaire, ils n'ont pas laissé trace d'une pareille direction à l'époque moderne. Les contemporains de Charlemagne u'ont pas vu les eaux «blondes » de l'Escaut et de la Lys se ramifier dans la plaine sableuse de Selzacte; l'étroite branche de Wetteren suffisait déjà à mener à la mer le débit des deux rivières. Ia vue de l'Escaut et de la Lys d'aujourd'hui, dont l'homme pourtant soutient le niveau par des barrages, approfondit le lit et concentre les eaux dans un seul bras, doit faire réfléchir cenx qui rêvent pour ces gros canaux une histoire glorieuse et compliquée.

1 Van Werveke, pp. $470-480$.

2 Van de Putle, Cronica et Cartularium monasterii de Dunis, Charte de Roluert de Béthune, no 1544, p. 695 . 
II.

HYDROLOGIE.

Rien n'est moins imposant que ces rivières tlamandes. De loin, quand on découvre d'une hauteur la large vallée, toute verte avec des lignes de peupliers inclinés, et des files de toits rouges le long des versants, on s'allend à une manière de fleuve. Un étonnement vient déjà de ne pas apercevoir la rivière, enfouic souvent derrière une petite digue. Mais la désillusion est complète quand, à travers les prairies, on alteint enfin le cours d'eau. Même pour ceux qui les connaissènt, il y a toujours un peu de surprise à les voir si minces. L'ampleur do la vallée promettait un fleuve: on trouve un canal. Aux temps Iointains de leur indépendance, lorsque l'habitant de la Flandre avait autre chose à faire qu’à essayer de régulariser leur lit, les cours d'eau avaient peut-être plus d'allure; ils s'attardaient dans la vallée plate, se compliquaient de bras morts et de marécages tourbeux; leur's eaux largement ótalées pouvaient faire illusion sur leur faible volume. Depuis l'homme s'en est emparé ; il les a enfermés derrière des diguettes, sẻparés de leur vallée par des vannes cadenassées; des barrages les découpent en sections égales, el ils ne peuvent passer que lorsqu'on leur ouvre les portes. Ils ont l'air de bons esclaves créés pour se rendre utiles, pour transporter docilement les fardeaux d'un pays riche. Ouvriers salis par le travail, peu soucieux d'être agréables à la vue, ils ne sont pas là pour embellir le paysage, mais pour servir à quelque chose. Ils ont tous au même degré l'air soumis et pacifique; l'aftuent, soutenu par ses écluses, est juste aussi imposant que le fleuve. La Deûle à St-André fait autant d'eflet que la Lys à Deynze ou que l'Escaut à Gavere; elle est seulement plus noire.

Cependant cos rivières bonasses ont leurs caprices. Ces travailleurs soumis ont leurs défauts; leur histoire contient beaucoup de mauvaises páges. Les chroniqueur's ne laissent guère passer d'années sans la mention monotone d'inondations : tantôt la mer, et tantôt les fleuves. La dernière en date est de 1894 ; c'est la grande crue de la Iys. Il faut done que les éléments du régime soient défectueux. En. effet, si les pluies se répartissent sur un grand nombre de jour's chaque année, et sont assez régulières, en revanche l'imperméabilitó générale du sol et le dêfaut de pente condamnent la Flandre à être perpétuellement menacée d'inondations: Heuves, riviëres, ruisseaux, il n'en est guère qui ne débordent chaque année. 


\section{Éléments du régime.}

D'un bout à l'autre du pays, le sol de la Flandre peut être considért comme imperméable. La plaine maritime, avec son tapis d'argile grise qui la recouvre presque tout entière, ne laisse guère filtrer en profondeur ce qui tombe à la surface. Dans l'intérieur, la présence de l'argile yprésienne, à l'Ouest, suffit á arrêter la descente des eaux. Pourtant l'argile affleure rarement à la surface. Mais le limon argileux qui couvre le sol est ${ }^{\circ}$ assez difficilement perméable, et il n'est pas rare, l'hiver, de voir de larges flaques d'eau dans les champs. Cette couche limoneuse est d'ailleurs vite saturée, car il existe, au contact du limon et de l'argile, une nappe permanente à laquelle s'alimentent les puits; on la trouve parfois à 1 mètre de profondeur, et elle s'enfonce rarement au-dessous de 5 mètres. De mème dans la plaine de la Lys, où le limon argileux, jaune, peu perméable, qui retient une bonne partie des eaux superficielles, est superposé à l'abondante nappe qui règne dans les sables verdâtres au-dessus de l'argile yprésienne. Enfin quand l'argile affleure dans les Pacauts et les Clyttes, l'imperméabilitẻ est complète.

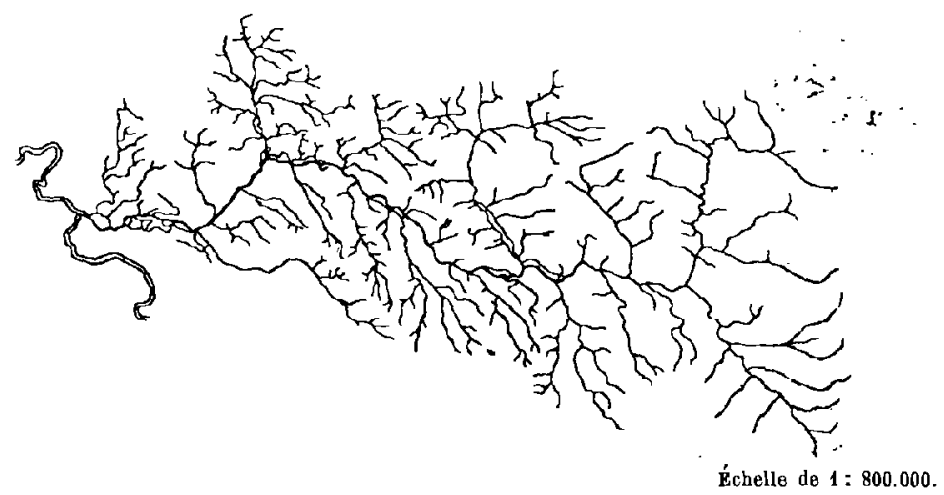

FIG. 25. - Fxemple de chevelu. Le bassin de la Dendre.

On pourrait croire qu'à mesure qu'on s'avance, vers l'Est, on trouve une terre plus sèche; que le sable qui forme la surface est plus perméable. Or la différence est assez faible. Il n'y a qu'à voir combien le nom de « pays sec » est rare en Flandre; à peine deux ou trois hameaux « Droogelandt », ct encore l'un d'eux est situé dans l'Ouest, sur territoire français. En effet le sable yprésien, sillonné de linéoles argileuses, n'est presque pas perméable; le sable quatexnaire (flandrien) est assez souvent limuneux, ou 


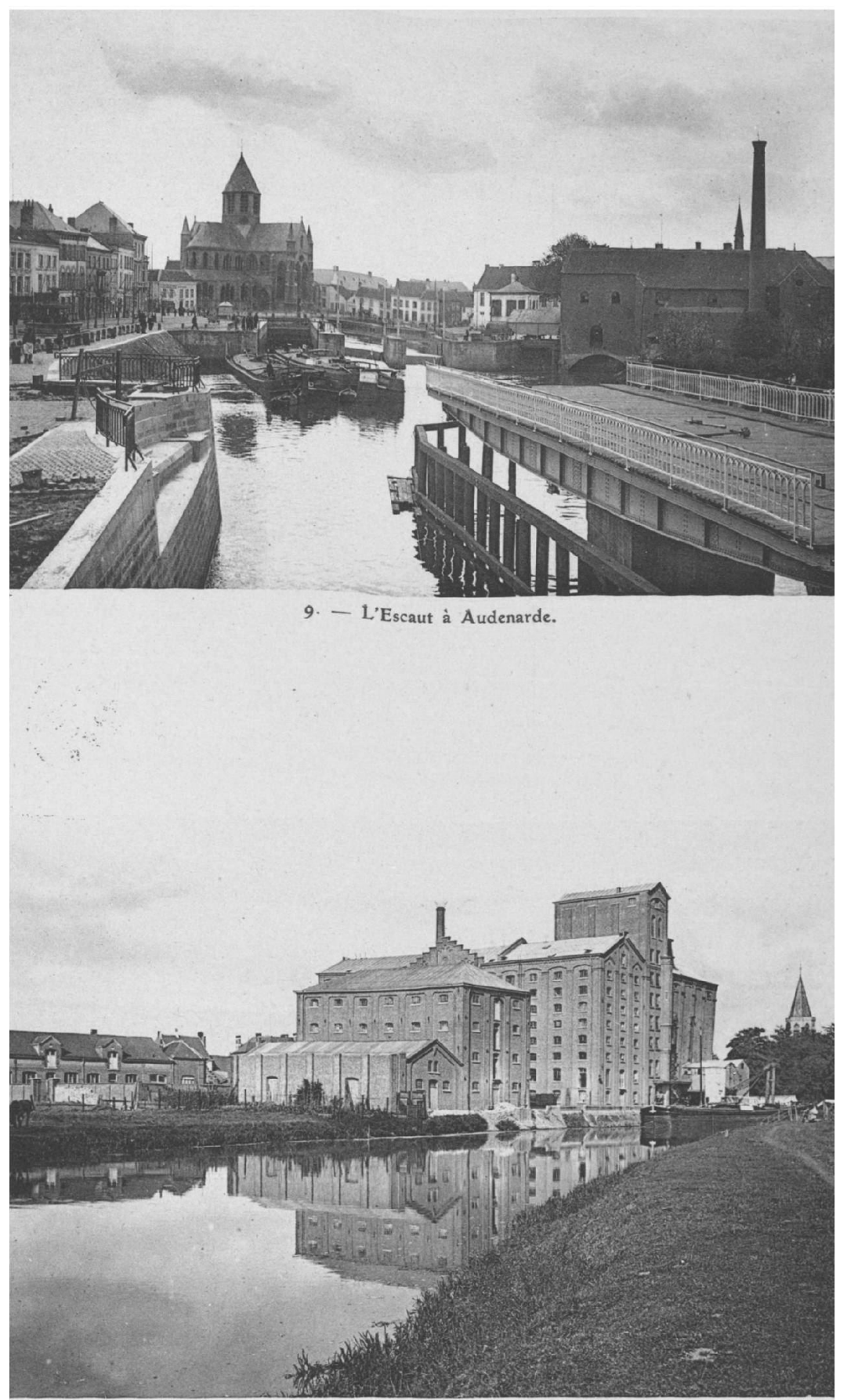

10. - La Lys à Deynze (Moulins de Petegem). 
IRIS - LILLIAD - Université Lille 1 
argileux, à une faiblo profondeur. Même dans l'extrême Nord, où le sable atteint une epaisseur considérable ( 22 mètres à Eecloo), l'eau se trouve loujours à une fáble profondeur, retenue par des linéoles imperméables. Nulle part le sable n'est assez pur' ni assez meuble pour se laisser pénétrer; partout à une faible profondeur s'étend la mince couche imperméable qui empêche l'eau de descendre. Quand ce n'est pas l'argile, c'est la roche, "Rots », tuf brunâtre, oi le sable est aggloméré par un ciment siliceux. Enfin dans le pays de Waes c'est l'argile rupelienne qui, enfouie d'un ou 2 mètres sous le limon sablenx, force les eaux à s'écouler presque immédiatement sur le sol.

Cette imperméabilité de toute la Flandre, et les faibles différences d'altitude, empêchent qu'on y trouve beaucoup de sources. Seule, la région des collines et le pays d'Alost en possèdent, minces filets d'eau, parfois taris dans les étés secs, et qui ne jouent qu'un faible rôle dans l'économie rurale du pays, ou dans le régime des cours d'eau. Dans les collines de Thielt, on ne trouve sur les flanes que de faibles suintements; cependant chaque hauteur paniselienne contient plusieurs nappes, une dans le sable argileux supérieur, une autre au-dessus de l'argile schistoìde; celle-ci est la plus considérable, et sa présence explique que les lieux habités des collines paniseliennes ne sont pas établis tout au sommet, mais déjà sur un flanc (le flanc Sud en général) pour être à portée de cette deuxième nappe. Dans la colline de Wyuendaele, la principale nappe est aussi celle de l'argile base du Paniselien, dont les suintements forment des ruisseaux clairs qui coulent rapidement vers le Nord ; c'est là qu'on projetle parfois de venir chercher de l'eau potable pour Ostende. Dans les collines du Sud, les nappes sont parfois nombreuses; la plus importante, celle qui fournit le plus de sources, c'est celle qui est retenue par l'argilite paniselienne. Là s'alimentent la plupart des ruisseaux des collines de Renaix, des hauteurs d'Anseghem, des collines de Bailleul et de Cassel. A Cassel même, l'argile asschienne retient, dans la partie inférieure des sables diestiens, une nappe aquifère qui a permis à l'homme de vivre sur la colline; et c'est pour se rapprocher de cette nappe et de ses fontaines que la ville de Cassel s'est bâtie, comme Hooglede, sur la pente Sud de la butte. Mais c'est surtout dans le pays d'Alost que les eaux sourdent aux flancs des vallées; l'érosion y a entaillé dans le plateau des rainures nombreuses, qui coupent les couches et les nappes aquifères; de là

1 Van Mierlo (C. J.), Distribution d'eau potable à Ostende. (Bull. Soc. belge Géol., II, 1888, Mém., pp. 249-259, pl. VI). 
plusieurs lignes de sources, aux points d'affleurement de l'argile asschienne, de l'argilite paniselienne, du sable argileux yprésien. Souvent en descendant dans un ravin, on entend.le bruissement de l'eau courante; sensation rare en Flandre. Gràce à la constance de la plupart de ces sources, bien des vallóes possèdent un moulin à cau: et c'est encore là un spectacle qu'on n'a guère en Flandre, sauf le long de quelques grands cours d'eau ${ }^{1}$.

Mais toutes ces sources sont peu de chose. La plupart sont trop faibles pour être utiles; aussi ne trouve-t-on pas en Flandre la vénération qui s'attache aux fontaines en d'autres contrées. Les pèlerinages à une source y sont rares. Il y a trop d'eau dans le sol, la terre en est trop imprégnée pour qu'on s'occupe beaucoup du mince filet qui sort sans bruit de la colline. Leur influence sur le régime des cours d'eau est nulle; si les ruisseaux de la région des collines y gagnent d'avoir de l'eau tout l'été, ils n'en sont pas moins sujets aux crues. Le moindre orage les fait déborder, sitôt la pluie tombée, car la pente concentre rapidement dans leur lit les eaux des versants.

La pente des rivières flamandes est paradoxale: toujours trop forte ou trop faible. Surtout, pour la plupart d'entre elles, il se produit un changement trop brusque entre la forte déclivité du cours supérieur et la pente presque nulle des cours moyen et inférieur, où la rivière, vieillie et fatiguée, se traine à travers la plaine, s'allonge en méandres compliqués, en boucles presque fermées. Tel est le cas de la I ys et de l'Aa qui, nées toutes deux vers 120 métres d'altitude, présentent dans leur cours supérieur une pente moyenne de 2 mètres par kilomètre ; brusquement celle de la Lys à l'arrivée en plaine passe à $0^{\mathrm{n}}, 28$, puis bientôt à $0^{\mathrm{m}}, 07$ par kilomètre; celle de l'Aa est moins forte encore, à peine $0^{\mathrm{m}}, 06$ par kilomètre entre St-Omer et Gravelines. Il en est de même pour les ruisseaux qui descendent des collines; nés vers 100 mètres d'altitude, il ne leur faut pas 10. kilomètres pour avoir atteint la cote 30 . De la une descente brusque des eaux, qui ne peuvent s'écouler rapidement en aval, faute de pente. L'inondation est fatale. Mais le même danger existe pour les cours d'eau qui ont tout leur cour's en plaine. En cas de forte pluie, les eaux que ne peut absorber le sol imperméable encombrent les dépressions; tous les ravins s'emplissent, sans que l'eau puisse s'écouler assez vite. Le moindre ruisseau de Flandre a ses inondations annuelles, comme la Lys.

1 Il existe encore en Flandre une ligne de sources : celle que l'on trouve le long de la ligne des dunes. Il en sera question dans l'étude de la région côtière. 
Ainsi, il sulfit que la régularité des pluies soit un instant interrompue, et qu'il tombe pendant ' 2 ou 3 jours de l'eau en quantités un peu fortes, pour que tous les cours d'eau flamands entrent en crue. Or il y a une époque de l'année où les pluies sont abondantes en Flandre: c'est la période de fin-septembre à fin-décembre. C'est le moment où chaque année les rivières déborderont.

\section{Crues régulières et inondations.}

Les moindres fossés sont capables de déborder l'hiver.' La plupart des ruisseaux qui n'ont pas d'eau les 3/4 de l'année, ne laissent pas de faire des dẻgâts aux pluies. Ce qui est plus grave, c'est qu'ils peuvent devenir dangereux même l'été, à la suite de violentes averses. Tel le Krombeek de Beveren-lès-Roulers, auquel un jour de pluie suffit pour inonder les parties basses du village. De même l'Handzaeme de Cortemarck, débordée deux fois au printemps de 1904 dans les prairies; de même le Henlebeek de Gulleghem, et les ruisseaux de Nazareth, et la Waerdamme, et bien d'autres. Le Pouquesbeek, ce ruisseau de 25 kilomètres environ, qui déborde encore chaque année, et monte jusqu'a la chaussée du bourg de Nevele, causait naguère tant de dégâts que de 1872 à 1877 les conseils communaux de sa vallée ne cessèrent d'assiéger les autorités provinciales de réclamations pour qu'on prît des mesures contre les débordements ${ }^{1}$. Ce sont là les méfaits des ruisseaux de plaine; les «becques » des collines sont plus irrégulières encore. L'insignifiant Roozebeek de Hollebeke déborde 5 ou 6 fois en 1903, couvrant d'un mètre d'eau la route de Wytschaete; la Douve à Messines s'élargit à 30 mètres dans la crue de 1894; le Warandebeck de Waton en 2 heures monte jusqu'à la place; ḋ Steenvoorde le bourg est inondé par l'Eybecque en octobre 1894 ; à Poperinghe, le Caual envahit parfois la partie basse de la ville. L'Yser est le type de ces petites rivières flamandes, qui recueillent les eaux des collines. Dans la partie supérieure, la pente est assez rapide, surtout sur son affluent la Peene qui, née de sources situćes à 100 mètres environ, sur le flanc Sud de Cassel, est déjà descendue à 20 mètres au pont d'Arneke, àprès 14 kilométres de cour's ( $\check{\partial}^{\mathrm{m}}, 70$ par kilomètre) ; au contraire le cours inférieur, de la frontière à Nieuport, est à peu près sans pente, ef les écluses ne laissent couler l'eau dans la mer qu'à marée basse. De là des

1 Moniteur belge, 1877. - Séance du Conseil Provincial de la Flandre Orientale, 3 juillet 1877 ; pp. $200 \%-2010$. 
crues, d'autant plus fortes que la région des collines reçoit plus d'eau que le reste de la plaine. Le 30 décembre 1880, la rivière endommage le pont d'Esquelbecq, inonde les terres de Bollezcele, Zeggers-Cappel ${ }^{1}$. En 1882, l'Yser déborde 14 fois. La cote moyenne des eaux à Bambecque est de $1^{\mathrm{m}}, 43$ : or la rivière est descendue jusqu'à $0^{\mathrm{m}}, 84$ (juin 1884), et est montée à $4^{\mathrm{m}}, \mathbf{1 1}$ (31 octobre 1894) ${ }^{2}$. On a dû, à certains endroits, endiguer l'Yser, reconstruire et rehausser les ponts dont les dimensions surprennent, lorsqu'on voit couler la mince rivière, jaunic par l'argile qu'clle arrache à ses rives dans les parties concaves des innombrables boucles qu'elle décrit au milieu des prairies et des saules. Il n'y a qu'un moyen d'éviter ces inondations, qui peuvent causer beaucoup de dommages lorsqu'elles se produisent l'été : c'est de curer les ruisseaux. Innombrables sont les arrêtés des autorités communales à ce sujet; et la coutume du pays d'Alost, où la pente rend les inondations particulièrement fréquentes, est pleine de prescriptions á ce sujet; des inspections sont ordonnées pour s'assurer de l'état des cours d'eau, et des amendes infligées aux propriétaires négligents ${ }^{3}$.

Les grandes rivières ne sont pas en reste avoc les petites; il n'y a pas d'hiver oủ elles ne dépassent leurs rives basses pour se répandre dans la vallée, qui est ainsi leur véritable lit majeur. La persistance de ces crues hivernales a fini par devenir un bienfait. Les riverains voient monter sans déplaisir les eaux jaunes, gonflées par les pluies de l'automne, chargées d'alluvions (blond.water) ", qui viennent déposer leur limon dans les prairies. Ce limon, légèrement sableux dans la zone qui borde le fleuve jusqu'à 50 mètres environ, est constitué dans le reste de la vallée par une couche très fine, gris-jaunâtre, qui est une terre à briques très estimée. Aussi les vallées de l'Escaut et de la Lys, en amont de Gand, sont-elles activement exploitẻes pour des briqueteries. Le colmatage est si intense qu'entre Gand et Syngem, sur l'Escaut, la couche limoneuse utilisée pour la fabrication des briques peut être remise en exploitation de 30 en 30 ans:

1 Mémorial de Lille, 3) décembre 1880.

2 Service hydrométrique et d'annonce des crues (département du Nord). Bassin de I'Yser. Compte-rendu annuel, année 1902 . (Manuscrit).

3 De limburg-Stirun.- Coutumes des Pays et Comte de Flandre. Quartier de Gand, t. III : Coutumes des deux villes et pays d'Alost. (Bruxelles, 1 vol. in-4ㅁ, 1890). Voir en particulier le chapitre " Van uutloken endo waterleeden ", pp. 3861-391.

4 Cf: Comte de Kerckhove d'Exaerde, Quelques mots sur les inondations des Flandres, leurs causes et les moyens de les faire cesser. (Gand, Van Ryckegem, 1842 , in $-8^{\circ}, 50$ p.). 
or cette couche a $0^{\mathrm{m}}, 60$ environ d'epaisseur ${ }^{1}$. En amont, vers Audenarde, M. Dolvaux estimait l'épaisseur moyenne du dépôt annuel à huit dixièmes de millimètre ${ }^{2}$. Cet alluvionnement intense est même devenu inquiẻtant; le lit du fleuve s'exhausse, ol ses rives sont plus b́levées que les prairies de la vallée; la zone voisine des bords participe á l'exhaussement, jusqu'à être de 1 mètre à $1^{\mathrm{m}}, 60$ en contre haut du reste de la surface alluviale ${ }^{3}$. Il devenait ainsi très difficile d'évacuer les eaux d'inondation concentrées dans les parties basses, ou Cuves. Or, si l'inondation hivernale est un bienfait pour les prairies qu'elle fertilise et pour les briqueteries dont elle augmente la couche exploitable, c'est à condition que les eaux auront disparu avant le $1^{\mathrm{er}}$ mai pour permettre la croissance de l'herbe. Il a fallu

- pour opérer à temps le dessèchement créer tout un système de rigoles circulant à travers les prairies. Chaque rigole s'embranche sur la rivière dans le bief supérieur à celui de la section à drainer, et aboutit en aval à un bief assez bas pour assurer l'asséchement; selon que la vallée est plus large à droite où à gauche, on les voit traverser par un siphon le fleuve ou les autres rigoles. Ainsi les utiles crues d'hiver sont régularisées; par les rigoles on inonde ou on asséche les prairies à volonté ; on peut assurer l'inondation de la vallée même lorsque la crue est trop faible.

Si les crues d'hiver sont bien accueillies, il n'en est pas de même des crues d'été, qui font aux prairies et aux cultures le plus grand tort; or il s'en produit quelquefois à cette saison: telles la crue de juillet 1879 sur l'Escaut, celle de septembre 1860 qui causa une perte de 550.000 francs aux propriétaires du lin qu'on était occupé à rouir dans la Lys 4 . Il se priduit enfin on toute saison, mais surtout l'hiver, de véritables inondations qui dépassent les limites de la vallée et atteignent les habitations. Leur gravité varie d'ailleurs avec les rivières; celles de la Dendre et de l'Escaut sont les moins dangereuses ; l'Aa, et surtout la Lys, en produisent de plus redoutables.

La I)endre est peutêtre la moins capricieuse des rivières flamandes. La pente en est assez régulière, ni trop forte d'abord, ni trop faible ensuite : les deux branches qui la forment naissent à des altitudes d'environ 65 et

\footnotetext{
1 Grenier (L.), Influence des travaux de régularisation effectués à l'kscaut sur lé régime do ce fleuve. (Extrait des Travaux du VIIle Congrès International de Navigation, Paris, 190(0). Paris, Lahure, 1900, br. 21 p., 3 pl. - Voir p. 2.

2 Delvaux (E.), Les alluvions de l'Gscaut et les tourbières aux environs d'Audenarde. (Ann. Soc. géol. Belg., XII, 1885, Mèm., pp. 140-170). - Cf. p. 144.

3 Ibid., p. 143.

- Dalle (J.), Archives de l'agriculture du Nord de la France, 2e série, t. IV, (1860), pp. 543-549.
} 
70 mètres ; à $A$ th, où la rivière se constitue, elle est encore à 30 métres. D' $\Lambda$ th à Grammont, la pente est de $0^{\mathrm{m}}, 56$ par kilomètre; de Grammont à Alost, elle est, de bief en bief, de $0^{\mathrm{m}}, 28,0^{\mathrm{m}}, 23,0^{\mathrm{m}}, 25$ et $0^{\mathrm{m}}, 24$ par kilomètre; d'Alost à Tormonde, les redressements opérós au XIX ${ }^{\bullet}$ siécle l'ont fait remonter $\dot{a} 0^{\mathrm{m}}, 31$. Ainsi la pente est partout convenable, et presque constante. L'écoulement se fait donc avec une certaine facilité, d'autant que le lit majeur est assez vaste pour emmagasiner le volume des crues. Les plus grands dangers etaient pour la ville et la région de Termonde; lorsqu'une crue coïncidait avec une grande marée de l'Escaut, il devenait impossible d'évacuer les eaux surabondantes de la rivière, et une bonne partie de la ville, les quais de la Dendre, la grand'place, la rue de l'Escaut étaient inondès. L'événement se produisait . au moins une fois par an, et on y était si bien habitué que chaque habitant des rues menacées possédait chez lui tout un attirail de défense: des planches qui s'adaptaient à la porte, et de la terre glaise pour rendre les joints ótanches; aussitôt que d'Ostende le service du port avait télégraphié l'approche d'une grande marée, la ville se préparait à la résistance. Le danger a disparu depuis qu'en 1896 on a relevé les quais de la Dendre, et depuis il ne s'est produit qu'une inondation, causée en 1902 par une marée extraordinaire.

L'Escaut est déjà moins régulier que la Dendre, au moins dans la partie belge, oú son défaut de pente lui a valu de nombreuses inondations. En France, la pente des 50 derniers kilomètres, de Bouchain à la frontière, est encore de $0^{\mathrm{m}}, 36$ environ par kilomètre ; en Belgique, la pente d'ensemble, de la frontière à Gand, n'est que de $0^{\mathrm{m}}, 11$, malgré les travaux de redressement qui ont réduit la longueur du fleuve de 114 à 87 kilomètres. Jusqu'en 1872, la pente totale était de $0,{ }^{\mathrm{m}} 09$ par kilomètre, et de $0,{ }^{\mathrm{m}}(08$ senlement entre Audenarde et Gand. Le fleuve décrivait lans sa vallée de longues houcles, qu'il avait tendance à allonger encore : ainsi a Escanaffles, à la limite des provinces de Flandre Orientale et de Hainaut, une boucle était en formation, qui avait entamé la rive droite de $4^{\mathrm{m}}, 50$ en 1881 ; en 20 ans on avait dû reculer 3 fois le chemin de terre qui longeait le fleuve, et le dẻplacement du lit peut être évalué pour cette période à 62 métres ${ }^{1}$. C'est à ces sinuosités où s'attardaient les eaux qu'étaient dues les inondations du fleuve, comme celle de $1808-1809$ qui persista 13 semaines ${ }^{2}$. Ce fut pire

\footnotetext{
p. 39 .

2 Coppens, Mémoire pour prévenir les inondations. (Gand, Fernand, 1810, 24 p.) - C. p. 2.
} 
encore après 1840 ; les travaux exécutés en France, de 1835 à 1839, sur la Scarpe et l'Escaut, redressements du lit, approfondissement, amenérent beaucoup plus rapidement les eaux de crues dans la partie belge. Les inondations se suivirent crue de 1811 , crue de 1845 , où 78 rues de Gand sont envahies par les eaux, el les communications dans plusieurs quartiers de la ville complètement interrompues ${ }^{1}$. Quelques travaux furent entrepris; mais ils élaient insuffisants, comme le montra la crue de décembre 1872, qui mit sous l'eau tous les quartiers ouvriers de Gand, noya et arrèta la plupart des usines, et ne cessa complètement qu'à la mi-janvier ${ }^{2}$; les cuves de la vallée faisaient office de réservoirs, et rendaient très lent l'abaissement du plan d'eau. Le débit fut considérable: au lieu des $96^{\mathrm{m}}, 58 \mathrm{par}$ seconde atteints par la crue de 1841 , celle de 1872 alla jusqu'à fournir $172^{\mathrm{m} 3}$ a Gand ${ }^{3}$, dix fois plus que le débit moyen du fleuve. 1)'autres crues survinrent, juillet 1879, décombre 1880, mai 1881, qui demontrèrent l'urgencè absolue des travaux à effectuer; travaux dont les résultats ont été excellents, puisque les crues du 8 décembre 1885, du 22 février 1897 et du 26 février 1900 n'ont en à aucun degré le caractère désastreux des précédentes, et qu'on peut considérer aujourd'hui la ville de Gand comme à l'abri d'inondations aussi fortes que celle de $1872^{\star 2}$. Ainsi l'Escaut, ce paisible Escaut dont on parle toujours comme d'un grand fossé, a eu ses inondations; il est vrai qu'elles sont dues non à son impétuosité, mais à sa lenteur. Il a fallu néanmoins exécuter à trois reprises d'importants travaux pour qu'il devînt une rivière vraiment navigable et ne causât plus de dégâts à ses riverains.

L'Aa ${ }^{5}$ et la Lys sont cependant moins pacifiques encore que l'Escaut, la Lys surtout, qui est la vraie rivière flamande, el par sa direction, et par son régime. Ses crues sont les plus dangereuses de toutes. Cela tient à la déclivité de son cours supérieur (2 mètres par kilom. jusqu’à Aire), et aussi à l’imperméabilitẻ des terrains qu'elle traverse. La rivière naît dans les marnes à Inoceramus labiratus, et coule jusqu'à Aire entre deux collines de marnes imperméables (Cénomanien et Turonien inférieur); de là un

1 De Denterghem (Prosper), Lettre adressée à MM. les Membres de la Chambre des Représentants et du Sénat à propos des inondations de l'Escaut et de la Lys. (Bruxelles, Devroye, 1846, in-8o, 24 p.).

Mess. Sc. hist., année 1873, pp. 119-120.

3 Grenier, Influence des travaux, p. 8.

Ibid., pp. 20-21.

5 L'Aa flamand, d'Arques à Gravelines, coule tout entier dans la plaine maritime ou ses dépendances, les marais de St-Omer; son régimé est done étudiẻ au chapitre XI, L'Eau dans la Plaine maritime. 
ruissellement intense, plus considérable que celui de la vallée de l'Aa, taillee presque tout au long dans la craie sénonienne ${ }^{1}$. Les masses d'eau tombées sur le bassin supérieur arrivent done rapidement à Aire; or les pluies sont fortes dans la région $(900)$ millimètres, moyenne annuelle, à Fruges); et surtout les précipitations de l'automne sont particulièrement abondantes: 99 millimètres en septembre, 128 en octobre, 90 en novembre, 100 en décembre: 417 millimétres pour ces 4 mois. C'est donc un flot considérable qui descend l'hiver sur Aire, et qui s’épanche dans la plaine, faute de pente. Ces crues hivernales deviennent vite des inondations. L'histoire en est longue. C'est la plaine de la Lys, de Merville à Armentières, qui souffre le plus. Les affluents de droite de la rivière, Clarence et Lawe, augmentent encore l'afflux d'eau ; descendant rapidement des hauteurs de l'Artois, nourries des mêmes pluies que la Lys, elles ont leurs inondations, qui se joignent à celle de la riviere. Armentières est particulièrement frappée. Les archives communales de la ville attestent, de 1339 au XVIII ${ }^{\mathrm{e}}$ siècle, la continuité et l'importance de ces désastres ${ }^{2}$. Une enquête du X VIII' siècle signale les dégâts causés par ces inondations fréquentes, qui couvrent et submergent deux lieues et demie de distance des deux côtés de la rivière, empêchent la culture des terres, et obligent les habitants d'abandonner leurs domiciles ${ }^{3}$. On indique des sinistres presque chaque année: 1761,1762 ; en mars 1769, on constate que depuis août 1'768, la Lys a débordẻ cinq fois, et qu'à cette date les chemins sont recouverts de 3 pieds d'eau ; on ne peut faire les mars, et les semailles d'automne sont perdues * En 1784, l'inondation est si forte a St-Venant, Merville, LaGorgue, que le roi accorde 3 millions pour procurer les denrées de première nécessité, remplacer les bestiaux ot outils, et rétablir les habitations détruites ${ }^{5}$. Les travaux de redressement et d'approfondissement accomplis de 1775 a 1782 font diminuer le nombre des crues, mais non leur intensité. Ils eurent même un effet fâchoux pour la Lys bolge, où l'eau arriva dès lors avec plus de rapidité. Là, la pente est remarquablement faible: $0^{\mathrm{m}}, 07 \mathrm{par}$ kilomètre de Merville a Gand ; des courbes à vaste rayon se succèdent, allongeant lo lit. Aussi les crues de l'Escaut semblent peu

1 Cf. Purent, Notes supplémentaires sur les plis du Nord de l'Artois (Ann. Soc. géol. N., XXI, 1893, pp. 93-10ti).

z Département du Nord. Ville d'Armentières. Inventaire sommuire des archives communales antérieures à 1790. Lille, Lefobvre-Ducroca, 1877, in-4., - Voir série DD.

3 Archives Pas-de-Calais, C. 583, pièce 162.

4 Ibid., C. 584, pièce 1. Rapport du Subdéléguẻ d'Airc-sur-Lys.

s Arch. Nord, Flandre wallonne, C. 1. Lettre du baron de Breteuil. 
de chose à côtó de celles de la Lys; el déjà Meyer remarque qu'en octobre 1423 , Lors de la terrible crue qui ravage la vallée, la Lys refoule l'Escaut au confuent, et le fait refluer vers l'amont ${ }^{1}$. La situation se fit plus grave encore après les nouveaux travaux exécutés en France de 1825 à 1826. la I.ys devenait pour toute la Flandre un véritable fléaul. Icorsqu'elle débordait, non seulement elle ravageait sa vallée, et la ville de Gand, mais elle causait l'inondation de la vallée de l'Escaut, dont elle faisait rether les eaux vers l'amont; elle faisait monter, et parfois déborder, le canal de (xand à Bruges, qu'elle alimente; elle inondait la vallée de la Caele, son ancien lit vers le Nord-Est. Enfin elle empêchait d'évacuer' ver's Gand le trop-plein de la Lieve, canal creusé entre Iamme et Gand ; et dès lors los eaux do la haute Lieve, dont l'écoulement était arrêté vers le Sud, sortaient de leur lit élroit, gagnaient à travers les terres la basse Lieve qu'on essayait de leur interdire par le barrage de Balgerhoecke, noyant les communes d'Adegem, Oostwinkel,- Eecloo, Waerschoot, Middelburg, Lapscheure, Moerkerke; le dommage s'ètendait jusqu'à la plaine maritime, dans des communes que 30 kilomètres séparaient de la Lys ${ }^{2}$. L'inondation de 18 ó fut si violento que les travaux d'amélioration furent décrétés en 1846. Cependant l'œuvre accomplie, qui consistait á dériver vers lo Nord, par un canal spécial, une partie des eaux de la Lys, ne sulfisait pas encore á faire disparaîlre les grandes crues: témoin l'inondation de 1894, particulièrement typique. Octobre 1894 avait été très humide, et lorsque le sol étail déjà saturé d'eau el complètement imperméable, des pluies torrentielles survinrent: les 29 et 30 octobre, il lomba à Fruges 94 millimètres d'eau, à Merville 101 millimètres, à Laventie 105 millimètres, à Lille 94, à Comines et Menin 76, à Harlebeke 53. Une énorme masse d'eau descendit dans le lit de la rivière, dont la section

\footnotetext{
1 Meyer, Annales, ad anmum.

2 Cf. Kerckhove d'Wxaerde, Quelques mots, ete; - Rapport sur le cours de l'Escaut et de ses affuents, ainsi que sur les inondations extraordinaires causées par cette rivière (Bruxelles, I)ubois, $18 / 3$, in- $4^{\circ}, 140$ p.). Ces curieuses inondations d'un pays ou ne passe aucune rivière étaient désastreuses par leur fréquence; certaines terres en étaient irrémédiablement gâtées. En 1841, les habitants de Middelburg, Lapscheure, Moerkerke, se trouvent deux mois (octobre-novembre) dans un vaste lac. Des contestations se produisent: en 1829, le bourgmestre d'Eecloo, voyant la haute Lieve déborder, court au barrage de Balgerhoecke, fait ouvrir de foree les poutrelles qui empêchent l'eau de descendre dans la basse Lieve, et place un garde-champêtre qui veille deux jours et deux nuits pour empêcher la fermeture du barrage. Tous les bords de la basse Lieve furent inondés à leur tour. Lianecdote montre l'importanco d'une dénivellation de quelques mètres dans un pays si plat. On en trouvera d'autres exemples dans la plaine maritime,
} 
n'est que de 27 mètres carrés jusqu'à Estaires ; en deux jours la surélévation fut de $2^{\mathrm{m}}, 22$ à St-Venant, de $3^{\mathrm{m}}, 49$ à Merville, de $3^{\mathrm{m}}, 78$ a Comines, où la rivière, du 30 au 31 , monta de $1^{\mathrm{m}}, 30^{1}$. Les crues de 1872 et de 1880 étaient largement dépassées; à Merville il y avait $1^{\mathrm{m}}, 40$ d'eau dans les rues; à Courtrai les quartiers bas furent inondés, le chômage s'étendit à plusieurs usines. Des fermes furent envahies, les récoltes avariées ou détruites, les lins qui séchaient sur les prairies furent endommagés, les ballons do rouissage emportés par le courant ". Dans le Bas-Escaut même, l'amplitude de la marée fut annulée complètement à Gentbrugge ; elle fut réduite à $0^{\mathrm{m}}, 70$ à Wotteren.

A près ce récit de leurs méfaits, les rivières flamandes ne paraissent déjà plus des serviteurs irréprochables, dociles à tous les désir's do l'homme. Il faut avouer qu'elles ont encore d'autres défauts. La lenteur du courant, due à l'absence de pente, provoque la formation d'atterrissements, de hautsfonds. Ia liys, aux eaux chargées d'alluvions arrachées à son cours supérieur, en était particulièrement encombrée, surtout dans la partie belge, où les vases se déposaient dans les remous qu'oceasionnaient les sinuosités: on citait jadis le « plat» d'Oyghem, où la profondeur était réduite à $0^{\mathrm{m}}, 80$ en basses eaux; le plat de Wacken, long de 260 mètres, où les bateliers étaient obligés pour passer de prendre des allèges, à moins de forte crue; le plat de Vive-St-Eloi, de 400 metres do long ${ }^{3}$. Les péniches ne pouvaient guère circuler sans risquer des avaries; aussi évitaient-elles autant que possible la Lys. Fnfin la pénurie d'eau se faisait souvent sentir pendant l'été. Dans cette région imperméable, où les cours d'eau ne sont pas soutenus par des sources, le débit de la rivière devient dérisoire en saison sèche: c'est la contrepartie des crues d'hiver. L'Escaut descend $\dot{a} 5^{\mathrm{mi}}$ à Gand; la Iys en étiage roule 900 litres par seconde à Lire, $2^{\text {nn3 } 3}$ après I.a Gorgue, $5^{\mathrm{m} 3}$ après le confluent de la Deûle. Son affluent la Lawe s'abaisse à 200 litres à Béthune. L'Aa, qui a dû atteindre $100^{\mathrm{m} a}$ à Gravelines dans la crue de 1894, tombe à 1.800 litres aux plus bas étiages; la proportion est de 1 à 56 . Enfin la Deủle, si heureusemont dirigée pour faire communiquer la Lys avec la Scarpe, la Flandre avec l'Artois et la

1 Navigation intérieure $(1900)$, p. 105).

2 Rapport de la Commission instituée à la suite des inondations survenues dans la vallée de la haute Lys aux mois d'octobre et do novembre 1894 (Bruxelles, Goemaere, 1898, in-8o, 28 p. ; 1 diagr., 1 carte à $1: 40.000$ ).

3 De Rive (B.-L.), Précis historique et statistique des canaux et rivières navigables de la Belgique et d"une partie de la France. (Bruxelles, 1835, in-8). - Cf. pp. 116117. 
France, n'avait guère en été, avant l'adduction des eaux de la Scarpe, plus de 1.000 litres par seconde. Des travaux considérables et multiples étaient donc nécessaires.

\section{Travaux de régularisation.}

On se préoccupa d'abord d'assurer aux rivières la quantité d'eau nécessaire à la navigation. Pour cola, il n'y avait qu'un moyen: retenir l'eau derrière des barrages. Dès les XII ${ }^{\mathrm{e}}$ et XIII' siècles, il est question des «portes d'eau » de Deûlémọnt ${ }^{1}$; la Dê̂le n’avait-elle pas particulièrement besoin de ce secours? D'autres écluses sont établies en 1212 à Marquette, Wambrechies et Quesnoy-sur-Deûle; en 1236 a Menin et Harlebeke ${ }^{2}$. En 1285, on en construit sur la Dendre ${ }^{3}$; et bientôt après sur l'Escaut. On continue d'en élever aux XVII et XVIII siécles. Cependant le nombre en était encore insuffisant. Pour suppléer à la pénurie du débit, la navigation se faisait par bonds d'eau; deux fois par semaine seulement on livrait passage à la masse liquide amoncelée derrière les barrages, et le flot emportait la rame de bateaux de bief en bief. Les quantités retenues en amont des barrages étaient si considérables qu'elles noyaient les prairies, et empêchaient lour dessèchement. On augmenta donc au XIX siecle le nombre des barrages sur la Lys, l'Escaut et la Dendre, pour pouvoir supprimer le système des bonds d'eau et assurer la navigation d'une manière permanente, à la remonte comme à la descente. C'est ainsi que la Lys, d'Aire à Gand, voit sa chute de 16 métres répartie entre 12 biefs ; que les 12 mètres de chute du Haut-Escaut belge sont rachetés par 8 barrages et écluses, et les 25 mètres de la Dendre par 14 bietis. Pour la Deûle, il ne suffisait pas d'établir, pour compenser les $10^{\mathrm{m}}, 50$ de pente, 8 écluses entre Fort-de-Scarpe et Deûlémont; il fallait surtout amener de l'ean. Vauban, désirenx d'augmenter lo débit pour pouvoir tendre l'inondation autour de Lille, fil joindre a la Scarpe, par un canal entre Douai et Courrières, la haute Deûle ou Souchez; le volume de la Deûle s'accrut ainsi des eaux de l'Escrébieux et de la saignée faite à la

4 Diegerick (J.-L.-A.), Inventaire analytique et chronologique des chartes et documents appartenant aux archives de l'abbaye de Messines. (Bruges, Soc. d'Em., 1876, in $\left.-1^{\circ}\right)$.

2 Flimmernont (J.), Lille et le Nord au moyen-âge (Lille, 1888, in-80), p. 285.

3 Wolters (G.), Recueil des lois, arrêtés, règlements, etc, concernantl'administration des eaux et polders de la Flandre orientale (Gand, Hoste, 2 vol. in- $8^{\circ}$ ), tome I ( $3 \mathrm{e}$ éd., 1874), p. 1234. 
Scarpe par la rigole des Pestiférés; les eaux moyennes s'élevèrent à 2.600 litres à Lille. En 1825, on abaissa le plan d'eau du canal, et l'eau de la Scarpe put descendre librement sur Lille; le débit se trouva porlé à 3.800 litres, et après le relèvement du niveau de la Scarpe opéré en 1849, il put arriver en moyenne 5 mètres cubes par seconde. Suffisant pour assurer la navigation, co débit ne l'était pas pour assainir la ville do Lille. On chercha plus loin. Les travaux de suppression du faîte de partage, exécutés depuis 1901 sur le canal de la Sensée pour rendre la navigation plus rapide, donnèrent l'augmentation souhaitée; l'eau de l'Escaut, par la Sensée, la Scarpe et la haute Dê̂le, peut maintenant descendre vers Lille. Mais le Haut-Escaut lui-même est alimenté indirectement par l'Oise, car c'est la rigole souterraine de l'Oise qui amène de l'eau à l'Escaut supérieur par le canal de St-Quentin. Ainsi l'eau de l'Oise elle-même vient contribuer à l'augmentation du débit de la Deûle, et on peut prévoir le moment où le futur canal du Nord-Est amènera à son tour le tribut de la Sambre, toutes les eaux du département contribuant ainsi à assainir les canaux bououx de son chef-licu ${ }^{1}$.

Fn même temps qu'on régularisait le débit par la construction de barrages et d'écluses, on se préoccupait d'organiser au mieux possible la distribution des crues d'hiver. Le point capital était d'assurer l'évacuation des eaux avant la fin du printemps; pour cela on creuse des rigoles, et on veille à leur entretien ; une ordonnance de l'empereur Charles VI (1740) prescrit le nettoyage des canaux d'irrigation, le faucardement des herbes trois fois par an, pour éviter les dommages causés aux prairies de l'Escaut ${ }^{2}$; et le préfet del'Escaut, d'Houdetot, reprend cet arrêté en août 1812 ${ }^{3}$. Sur la

Cf. Bertin, Navigation intérieure, pp. 57-58.

Il est intéressant de voir le cliemin que parcourt ensuite cette eau amenée de si loin dans la Deûle. Une partie s'écoule dans le canal d'Airo à La Bassée, dont le bief supérieur communique librement avec la Ien̂le: elle arrive ainsi à la hys, et au canal de Neuffossé. Celui-ci supplée, en été, à la pénurio de l'Aa, et l'eau de la Deûle peut ainsi descendre dans l'Aa, le canal de Bourbourg, et arriverjusqüä Dunkerque. Liautre partie tombe dans la Lys noyenne à Deûlémont et descend vers Gand. Là, elle contribue à l'alimentation du canal de Gand à Bruges. Celui-ci à son tour déverse ses eaux dans le canal d'Ostende. Le canal d'Ostende, plus élevé que celui de Plasscbendaele, lui fournit son trop plein, et l'on arrive ainsi à Nieuport. Là il se trouve que le canal de Plasschendaele est la plus élevée des artères qui aboutissent à cette ville; par suite il est appelé parfois à donner un peu d'eau au canal de Furnes. Et l'on revient ainsi à Dunkerque. Par deux chemins éloignés, l'eau de l'Oise finit donc par arriver à Dunkerque, après un voyago bizarre. C'est là un curieux exemple de la circulation do l'eau en Flandre.

2 Wolters, Recueil de lois, I, pp. 236-244.

3 Ibid. I, p. 594. 
Lys française, deux rigoles continues sont organisées en se servant des anciens bras, de 1850 a 1861 . Le même travail est fait sur l'Escaut après l'inondation de 1872. Désormais, l'évacuation des eaux des prairies se fait à volonté.

Fnfin on songea à empêcher les inondations. Jusqu'an XIX ${ }^{\mathbf{p}}$. siècle, on ne s'était guère préoccupé que de protéger, par des digues, ou en détournant le cours de la rivière, telle ou telle localité ${ }^{1}$. Maintenant on essaie de s'en prendre à la cause même du mal. Les riverains se groupent en associations de défense, et forment des Wateringues auxquelles est confié l'entretien des digues; il s'en constitue tout le long de la Dendre, 'de l'Escaut et de la Lys (1838-1817) 2. Les ingénieurs, s'apercevant que le défaut de pente est la cause principale des inondations, cherchent des moyens de faire ècouler l'eau plus vite. L'ingénieur Wolters propose en 1843 d'établir sur le Bas-Escaut à T'ermonde un barrage contre les marées ; le remplissage du réservoir ainsi formé en amont du barrage aurait augmenté de moitié, suivant ses calculs, la décharge des eaux en aval de Gand ". Mais il était dangereux de toucher au régime d'un fleuve à marée; et l'on s'aperçut bientôt que le mieux était de suivre l'exemple des ingénieurs français, qui avaient amélioré le régime de la Scarpe et de la haute Lys en redressant le cours et en supprimant les courbes. Le procédé présentait lo double avantage de raccourcir la distance que les eaux devaient parcourir et d'augmenter la pente. On avait déjà essayé au XVIII ${ }^{\mathrm{e}}$ siecle: en 1752, on proposait, comme remède aux inondations de l'Escaut, plusieurs coupures, à Gand, à Melle; en 1754 et 1756, d Seevergem, à Heurne ${ }^{4}$. A partir de 1847, on en proposa et en exécuta de nombreuses sur l'Escaut et la Dendre ; on pratiqua de nouveaux redressements après la grande crue de 1872, si bien que le Haut-Escaut belge fut réduit de 111 à 87 kilomètres, soit 24 kilomètres en moins. Depuis 1880, les inondations ne se sont plus reproduites sur l'Escaut; et la partie la plus

1 En 1276, la comtesse Marguerite redresse à Meirelbeke le cours de l'Escaut pour mettre à l'abri des inondations son manoir d'Ottersam. Gf. Van Lokeren, Chartes ot documents de l'abbaye de St-Pierre au mont Blandin, à Gand (Gand, 1871, 2 vol. in-4 $\left.{ }^{\circ}\right)$, I, p. $383, n^{\circ} 871$.

2 C.f. Schramme (J.); Des Wateringues (Bruges, Maertens, 1899, in-80, 200 p.). Jétails de l'organisation des wateringues fluviales, pp. 47-50. Liste des wateringues de l'Escaut, de la Dendre et de la Lys, pp. 148-166.

3 Wolters, Mémoire sur les marées, et sur le noyen de diminuer les inondations de l'Escaut, de la Lys et de la Durme (Bruxelles, Devroye, 1844, in-40, 110 p., 3 pl.), pp. 23-28.

4 Wolters, Recueil de lois, I, pp. 264, 282, 286, 
menacée de la vallée, entre Audenarde et Gand, est restée indemne. A claque crue nouvelle, on constate que l'amplitude tend à diminuer vers l'aval. Les crues de 1897 et de 1900, égales ou supérieures à la crue de

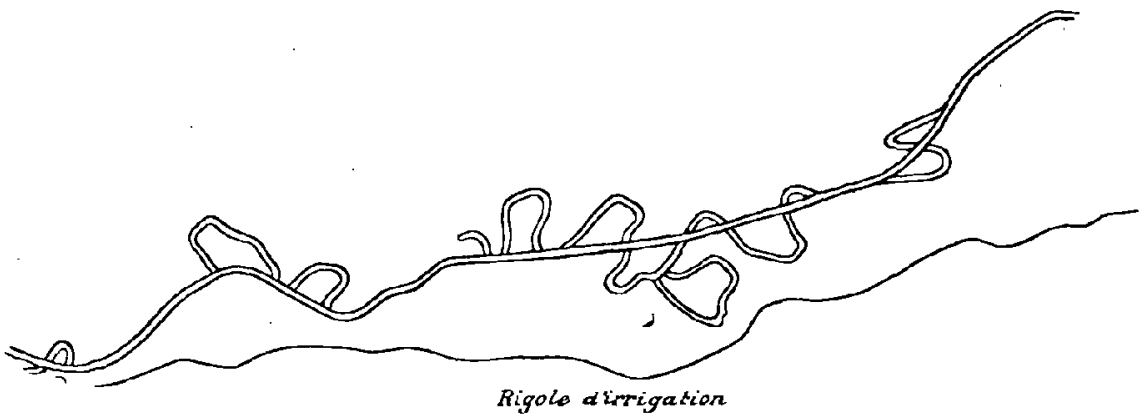

Échelle de 1: วั0.000.

Fra. 26. - L'Escaut de Molsen à Zwynaerde. Anciennes boucles et rectifications.

1885 aux écluses de Berchem et d'Audenarde, Iui furent notablement inférieures, (surtout celle de 1900), à Syngem et à Semmerzaeke. Gand peut se considérer aujourd'hui comme à l'abri des inondations de l'Escaut ${ }^{1}$.

Sur la Lys belge, le mal était si grand qu'on avait eru devoir recourir à des moyens plus puissants. Les ingénieurs français avaient, de 1775 à 1782, redressé la rivière; en 1825 et 1826, on avait curé lo lit, fait disparaître les plats. Le résultat avait été désastreux pour la partie belge, où les eaux arrivaient plus rapidement. Désespérant de jamais pouvoir écouler par le Bas-Escaut les masses liquides qui descendaient de la France, on songea à leur créer une voie spéciale à travers la Flandre. Cette voie avait existé jadis; avant la reconstruction du canal de Terneuzen, la Lys avait un débouché d'inondation par la Vieille-Caele, le Moervaart et la Durme. Comme le flot de marée dans la Durme empèchait l'écoulement régulier des crues, le gouvernement de Marie-Thérèse fit mêrne approfondir en 1775 le passage de la Langeleede, qui, par l'écluse de Wachtebeke, donnait aux eaux de la Lys une issue directe dans le bras de mer, aujourd'hui disparu, du Canisvliet ${ }^{2}$. Lorsque le canal de 'Temeuzen eut été achevé (1828), harrant l'ancienne vallée de la Caele et empêchant l'écoulement vers le Moervaart du trop plein de la Lys, il fallut aviser. On en revint à l'idée d'un canal de dérivation qui traverserait toute la

1 Grenier, Influence des travaux, pp. 20-21.

2 Vifquain (J.B.), Des voies navigables en Belgique (Bruxelles, Devroye, 1842, in $-4^{\circ}, 494$ p.) p. 82 . 
Flandre, de la Lys à la mer du Nord, vers Heyst. Déjà en 1788 l'ingénieur Mathieu proposait de doubler le canal de Gand à Bruges et Ostende par un canal parallèle qui servirait uniquement à la décharge ${ }^{1}$. On préfóra établir le tracé par Somergem, Eecloo, Maldegem, une région où l'ancien canal de la Lieve était devenu plus nuisible qu'utile. Comme il fallait avaut tout preserver Gand, on plaça le point de départ assez loin en arnont, a Deynze. Le 18 juillet 18i6, une loi autorisait l'ouverture du canal entre Deynze et Schipdonck, point de rencontre du canal de Gand à Bruges; le 20 décembre 1851, on décrétait la continuation entre Schipdonck et la mer du Nord. Cette nouvelle voie d'eau devait offrir des avantages multiples: empecher les inondations de la Lys en assurant l'écoulement rapide de ses eaux; assurer la navigation jusqu'en aval d'Eecloo, a u barrage de Balgerhoecke; soulager le pays d'Eecloo des débordements de la Lys; débarrasser la rivière des eaux infectées par le rouissage du lin ${ }^{2}$. C'est un spectacle curieux, dans son bief inférieur, que celui de ce fleuve solitaire, enfermé entre de hautes berges couronnées de quatre rangées d'arbres magnifiques, et roulant avec rapidité des eaux noires, moirées de taches luisantes. Lne odeur abominable s'en dégage. "Cela vient do la France », disent les habitants ${ }^{3}$.

Cependant le canal de Schipdonck ne fut pas la panacée qui devait guérir tous les manx de la vallée. Les inondations continuèrent en amont de Deynze; il fallut donc poursuivre les améliorations. En France, on continua à redresser le lit (dérivation d'A rmentières), à l'élargir et à l'approfondir ${ }^{*}(1873,1883-87)$. En Belgique, il fallut bien se décider à en faire autant. L'inondation de 1894 démontra l'urgence des travaux. La Commission réunio pour aviser aux mesures à prendre écarta le projet d'une nouvelle dérivation de Menin à la mer, et celui d'un bras d'évacuation parallèle à la rivière, qui anrail fait à l'industrie du rouissage un tort considérable; elle décida qu'il fallait avant tout opérer des rectifications

1 Rapport sur le cours de l'Escaut et de ses affluents (1843), p. 111.

2 Le canal de la Dérivation, appelé aussi canal de Schipdonck, a deux biefs, celui de Deynze à Balgerhoecke, celui de Balgerhoecke à la mer; le 1or seul eommunique avec le reste du réseau navigahlo. Le canal peut être mis en communication avecle canal de Bruges à Gand; mais lorsqu'on veut éviter d'introduire dans celui-ci les eaux de rouissage ou le trop plein des crues, on fait passer le canal de Schipdonck sous l'autre par un siphon. Un autre siphon assure le passage sous le canal de Damme.

3 En réalité, l'infection de ces eaux est due surtout au rouissage du lin, industrie extrêmement active tout le long de la Loys, de Menin à Deynze. La part de la France est représentée par l'apport de la Deûle, chargée des résidus de Lille.

+ La Rivière, Navigation intérieure, p. 97. 
do courbes '. Le travail est en cours d'exécution : ainsi disparaîtront, entre Vive-St-Eloi et Grammene, les fameux Krommewaters, avec leurs hauts-fonds et lourbillons ; la rivière en sera raccourcie de 7.100 mètres. On doit se mettre ensuite à la Lys moyenne, de Houplines à Menin, où cinq rectifications sont prévues.

Ainsi s'étend à la Lys le système qui a si bien réussi à l'Escaut. Peu à peu disparaît l'aspect des anciens cours d'eau flamands, traçant leurs longues courbes à travers les prairies. La rivière qu'on voit aujourd'hui rectiligne, d'une largeur partoul égale entre les doux berges réglementairement inclinees, c'est le plus souvent un bras artificiel, qui relie par le plus court chemin les racines des grandes courbes. La véritable, l'ancienne rivière, dort an loin dans les prairies, désormais fermée au courant, encombrée do roseaux : le colmatage est rapide, le vieux bras se comble et disparaît. S'il survit, c'est pour devenir un vivier. Le nouveau cours est banal; l'ancienne riviére était plus pittoresque, avec ses replis imprévus. Et surtout, ce qui fait tort aux rivières actuelles, c'est l'aspect repoussant de leurs eaux. La Lys n'est déjà pas séduisante après la traversée du groupe industriel Armentières-Houplines; plus loin elle reçoit la Deûle, que son passage dans Lille transforme en véritable égout. Puis de Menin à Deynze, le rouissage du lin achève de salir et d'empoisonner la rivière. L'Escaut, deja trouble à Tourvai, est abominablement souille par l'Espierres, ruisseau qui lui apporte les eaux industrielles de Roubaix, Tourcoing, Mouscron et Wattrelos; plus loin la Rhosnes lui amèno les dechets de Renaix ; la rivière, vers Avelghem, est lamentable : liquide epais, noir et puant, avec des bulles qui viennent crever à la surface. Ce sont des egouts à ciel ouvert qui traversent ainsi la Flandre: et dans ce pays oủ l'absence de relief a permis l'extension du réseau navigable, les répercussions sont lointaines. Bruges même est incommodée par les eaux de la Lys, qui alimentent le canal de Gand à Ostende ${ }^{z}$.

\section{Rivières à marée.}

Il faut faire une place à part aux rivières à marée, le Bas-Escaut, de Gand à Anvers, et la Durme. La marée s'étend, lorsque les eaux supé-

\footnotetext{
1 Rapport de la Commission de 1895, pp. 15-28.

2 La solution semble devoir se trouver dans des procédés économiques d'épuration des eaux industrielles. Cf. les expériences di docteur Calmette, de I.ille, relatées dans Gosselet (J.), L'alimentation en eau de la ville de lille (Lille, Danel, 1904 br., 19 p.), p. 11.
} 
rieures sont basses, jusqu'à l'échuse de la Pêcherie, à Gand, à 92 kilomètres d'Anvers, à 184 de Flessingue "; dans les hautes eaux, elle ne dépasse guère Wetteren. Dans la Durme, elle remonte aux basses eaux jusqu’à Moerbeke, à 59 kilornètres d'Anvers, et aux hautes eaux vers le confiuent du Moervaart et de la Zuidleede. La vitesse de translation est plus forte dans l'Escaut que dans la Durme, dont les innombrables sinuosités arrêtent le courant. Quant à l'amplitude moyenne de la marée, M. Wolter's l'évaluait à $4^{\mathrm{m}}, 06$ à Anvers, $2^{\mathrm{m}}, 63$ à Termonde, $1^{\mathrm{m}}, 38$ à Wetteren, $3^{\mathrm{m}}, \mathrm{j} 8$ à Hamme, $1^{\mathrm{m}}, 63$ à Lokeren; elle devient très faiblo en amont de Termonde à cause du rétrécissement du lit, ò̀ les eaux supérieures remplissent immédiatement une partie de la capacité abandonnée par la marée descerrdante ${ }^{2}$.

Etant donné Je faible volume d'eau qu'apportent à Gand le Haut-Escaut et la Lys saignée par les canaux de Bruges, de Terneuzen et de Schipdonck, c'est la marée qui fait le Bas-Escaut. La disproportion est énorme entre son apport et celui des eaux supérieures. Alphonse Belpaire évaluait la part de la marée à 533 millions de mètres cubes en 6 heures, celle de la rivière à 4,5 millions; le rapport est de 118 à $1^{3}$. M. Petit a calculé les volumes d'eau passant par le fleuve en des points précis. A Termonde, il a trouvé qu'il était passé à un flot moyen, 3.529.521 mètres cubes, et au jusant 3.863.065: la différence, qui donne lo débit du fleuve pendant le jusant (7 h. 30), est de 333.542 mètres cubes. Tel serait, à Termonde, l'apport des eaux supérieures; ce n'est pas la $10^{\mathrm{e}}$ partie de celui de la marée . A Lillo, un peu en aval d'Anvers, ses calculs lui donnaient 92.115.005 métres cubes pénétrant dans le fleuve avec le flót, contre 12.842.129 mètres cubes de débit de l'Escaut: la marée était presque 8 lois plus considérable que l'apport du fleuve ${ }^{5}$. D'ailleurs, ce n'est pas l'eau de mer qui pénétre ainsi dans lo fleuve á chaque marée; ce sont les

1 Cf. Wolters, Mémoire sur les marées, p. 11. Ces chiffres, donnés en 1844, sont devenus trop forts, à cause des redressements qu'on a opérés et qu'on opère encore en 190/-1905 sur le Bas-Escaut, de Gand à Termonde.

2 Mémoire sur les marées, pp. 11-22.

3 Belpaire (Alph.), Etude sur la plaine maritime depuis Boulogne jusqu'au Danemark (Anvers, Schotmans, 1855, in-8 , $242+26$ p., carte), p. 173.

- Ietit, Etude sur les courants de l'Escaut et de la Durme (Ann. Tr. p. Belg., tome 40,1883, pp. 259-390, 1 pl.) - Gf. pp. $271-278$.

5 Etude sur les courants, p. 354. - Ces chiffres semblent sujets à caution. Le débit du fleuve serait á Lillo de 559 mètres cubes environ par seconde, ce qui semble énorme, malgré l'apport du Rupel. Etant donné ce que fourait l'Escaut à Gand, le chiffre devrait ôtre 4 ou 5 fois moins considérable. 
eaux douces dejà rejetées par l'Escaut, et qui ne s'écoulent que très lentement a la mer, sans cesse repoussées par le flux. Un floltour lancé à T'ermonde mit 7 jours, 10 heures, 10 minutes a atteindre Lillo, soit une distanco de 60.234 métres '. L'eau do mer ne dépasse guère Anvers, et le fleuve n'y contient de l'eau saumâtre qu'à marée haute; la densitó y est alors de 1002. A l'embouchure du Rupel l'eau reste douce méme à marée haute. Même à Bath, sur l'Escaut maritime, la densité n'est encore que de 1007 à marée basse, contre 1020 devant Flessingue ?

Malgré l'apport de la marée, le Bas-Escaut est encore un fleuve médiocre entro Gand et Termonde, même entre Termonde et Rupelmonde. La profondeur est insuffisante; elle atteint en certains endroits $5^{\mathbf{m}}, 20$, mais ailleurs le tirant d'eau n'est que de $1^{\mathrm{m}}, 90^{3}$. Les courbes étaient immouses sur cetle partie du fleuve. La section n'ètant pas assez large, et la pente trop faible, les inondations se produisaient comme sur lo Haut-Escaut. M. Petit pense qu'on a trop pris aux eaux supérieures, à l'Escaut pour alimenter los canaux de l'Espierres et de Bossuyt, à la Lys pour la Dérivation, le canal de I3ruges, le canal de T'erneuzen. Aussi le débit est insuffisant; il s'ensuit que le jusant ne dure pas assez longtemps, et n'a pas assez de force pour nettoyer le fleuve. De là les bancs qui l'obstruent de Termonde à Tamise. Il a donc fallu exécuter les mêmes travaux qu'en amont: dragages, et surtout redressements du cours. Ainsi sont disparues les gigantesques courbes de Destelbergen, de Calcken, d'Overmeire, dont les restes se devinent au milieu des prairies; on en a transformé les tronçons en routoirs. On continue à supprimer les petites courbes, d Melle, à Wetteren. On a exhaussé les digues, pour régulariser l'emploi des crues d'hiver; de décembre à février, les associations de wateringues laissent pénétrer et séjourner l'eau dans les prairies ; et souvent, après la fenaison, on raméne l'eau dans les bras morts pour y faire le rouissage du lin.

Après Rupelmonde, les dangers d'inondations persistent. Aux fortes marées coüncidant avec des crues du fleuve, les terres basses, malgré les digues, risquent d'être englouties. De 1800 à 1840 , une dizaine de marées se sont élevées à $6^{m}, 10 \dot{a}$ Anvers ${ }^{k}$; dans ce cas les digues peuvent céder. En 1880, le polder de Cruybeke fut inondé pendant 5 jours; en avril 1903

1 De Mey (P.), Etude sur l'amélioration et l'entretien des ports en plage de sable et

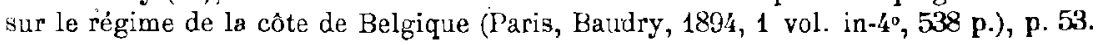

2 Ibid., p. 53.

3 Dehem (A.), Etudo sur le matériel de la navigation intérieure circulant en Belgique (Ann. Tr. p. Belg., 1901, $4^{\circ}$ fascicule; 158 p., 5 pl.), p. 145.

- Wolters, Mémoire sur les marées, p. 15. 
et en mai 1904, l'eau monta jusqu'au sommet de la digue. Sur la Durme, le danger est dû à des endiguements mal conçus, qui restreignent trop le lit de la rivière; il arrive par suite qu'aux époques de grande pluie la Durme trop resserrée ne peut pas évacuer en un jusant tout l'apport des eaux supérieures; d'où une accumulation dangereuse an moment de la haute marée suivante ${ }^{1}$. Aussi les riverains sont-ils constitués depuis longtemps en associations de Wateringues, pour defendre leurs prairies. Ces Wateringues veillent à l'entretien des digues, répartissent les eaux de crues dans les prés. Ie règlement d'organisation de la wateringue Thielrodobroeck date du 7 mai 1555 ; colui du Baselbroeck, du 26 mars $1587^{2}$.

Dangereux aux polders du voisinage, en revanche le fleuve est bon pour la navigation. De Rupelmonde a Anvers, le tir'ant d'eau atteint de $4^{\mathrm{m}}, 20$ à $8^{\mathrm{m}}, 40$; d'Anvers à Lillo, de $5^{\mathrm{m}}, 40$ à $9^{\mathrm{m}}, 50^{3}$. L'afflux de la Durme et surtout du Rupel lui ont donné la force érosive que ne peut lui fournir l'Escaut appauvri de Gand. Il est vrai que depuis Termonde, le fleuve n'est plus qu'à moitié flamand. 'Transformé par l'appoint du Rupel, ce n'est plus le véritable Escaut. Les ports sont sur la rive droite, du côté brabançon. Enfin, après le Doel, le vaste courant, large de 1.200 mètres, n'a plus ácun rapport avec lo modeste fleuve de Gand; ce n'est plus l'Escaut, c'est le bras de mer du Hont.

Ainsi les fleuves flamands portent tout au Iong de leur cours les traces de l'influence de l'homme. Depuis le premier barrage, qui retient leurs eaux naissantes, jusqu'aux hautes digues entre lesquelles ils débouchent dans l'estuaire, ils sont dirigés, réglés, asservis. Leur état actuel est le résultat d'une longue suite d'efforts qui a corrigé leurs défauts primitifs. Depuis dix siécles on les améliore. On a cherché d'abord à rendre la navigation aisée, et l'on a patiemment construit écluses el barrages. Puis on s'est occupé de régulariser les effets des crues hivernales. Enfin c'est au $\mathrm{XIX}^{\mathrm{B}}$ siècle seulement qu'on a essayé sérieusement de prévenir les inondations. Lhomme est allé d'abord à son profit: il a songé ensuite à sa sécurité. I e résultat semble satisfaisant. Les grandes crues sont de plus en plus rares; l'Escaut n'en a pas eu depuis 1872, la Lys depuis 1894. La navigation est assurée; et grâce aux dépressions qui séparent les lignes de collines, on a pu établir entre les rivières des canaux qui complètent le

1 Petit, Etude sur les courants, pp. 366-367.

2 Moniteur Belge, 1877 (Séance du Conseil provincial de la Flandre orientale, 3 juillet 1877), p. 2007 .

3 Dehem, Etude matériel, p. 145. 
système des voies d'eau. L'ouuvre a été considérable, mais le résultat en valait la peine; ce sont les cours d'eau qui ont fait la Flandre. C'est le long des vallées qu'a marché la civilisation, et que s'est fait le peuplement du pays. Les rivières lui ont assuré de honne heure cette activité commerciale qui a fait de ce pays au sol pauvre une des régions les plus peuplées de l'Europe. Rien ne semblait spécialement y attirer l'homme; le climat était humide, le sol souvent ingrat, trop sableux ou trop compact. Mais on y passait facilement; pas de montagnes, juste des buttes pour se défendre; et surtout des rivières partout, lentes, faites pour le trafic; la Flandre en devint un des pays les plus fréquentés de l'Europe. Il y a peu de contrées où le réseau navigable, rivières et canaux, pénètre si avant dans les terres, et soit si intimement lié au sol; c'est un véritable système circulatoire, qui assure les relations entre les parties de l'organisme flamand. 


\section{GHAPITRE VI}

\section{DIVISIONS DE LA FLANDRE : LES VARIETtES RÉGIONALES ${ }^{1}$}

Les noms de pays. Distinction essentielle: Plaine maritime et Intérieur.

L'étude des phẻnomènes actuels a montré que dans la plaine flamande, une par sa situation, son histoire, sa vie physique etéconomique, il existait des variẻtés régionales. La température, la pluie tombée, l'lumidité, changent de la plaine maritime à l'intérieur. Ces différences sont dues à la situation par rapport à la mer ; elles dépendent aussi du sol et du relief : ici une plaine basse et presque horizontale, forcément humide puisque son niveau est inférieur à colui des hantes mers ; là un sol sablonneux et léger, avec de légères éminences argileuses, prompt à absorber la chaleur et à la perdre par rayomement; plus loin des terres recouvertos d'un limon peu perméable, plus élevées et plus ravinées, barrées d'une ligne de collines de sable; ailleurs un plateau cntaillé de valléos profondes, et qui doit à son altitude de recevoir un peu plus d'eau que le reste de la plaine flamande. Ces variótés de sol et de rolief appellent dos diffórences hydrographiques; le réseau des ruisseaux qui descendent rapidement du plateau alostois, ne ressemble pas au lacis de canaux immobiles qui s'étend sur la plaine maritime, ni aux calmes rivières et aux fossés indigents de la région intermédiaire. Il se dócouvre ainsi dans cette plaine flamande, en apparence uniforme et platement semblable à elle-même dans tous ses aspects, une variété de caractères inattendue; des rógions dont les cultures, l'industrie, les mours, les intérêts diffèrent aussi bien que leur tempèrature, leur sol ou leurs cours d'eau. Ce sont là plus que des nuances; il s'agit de pays distincts, connus du peuple, auxquels il a donné des noms, et dont il s'explique les différences.

1 A consulter: Piot (G.). Les pagi de la Belgique et leurs subdivisions pendant le moyen-âge (Mèm. C. A. R. Belg., in- $\mathfrak{k}^{\circ}$, t. XXXIX, 1874); - Leuridan (Th.), Statistique féodale du département du Nord. Première partie: La Châtellenie de Lille (Bull. Comm. H. N., XI, p. 45, XII p. 169, XIII p. 73). 


\section{Les Noms de Pays.}

Cependant cos régions qui portent un nom, possèdent un état-civil, ne sont pas aussi nombreuses qu'on se l'imaginerait d'après la carte de France à l'échelle de $1: 500.000^{1}$. Cette carte indique en effet un Pays de Bredenarde étendu entre les hauteurs do Licques et Audruick, sur le flanc Sud du Calaisis ; une grande région du Franconat, d'Ostende à Eecloo par Bruges; un Pays de Kadzand ot un Pays d'Axel, qui occupent toute Ia Flandre zélandaise, avec le Braakman entre eux; un Bulscampvelt couvrant les bois de Thourout et Wynghene, auquel un Altervelt fait suite dans la direction de Gand; un Pays de Waes qui se déroule de Maldegem à Anvers, sur tout le pays sableux du Nord. Autour de Lille, le Ferrain va de la Deûle à la frontière, avec Roubaix et Tourcoing; le Weppes sépare Lille de la plaine de la Lys, tandis que sur les plateaux crayeux qui recèlent l'avant-garde des couches houillères s'étendent le Mélantois et le Carembault. Pour être complet, il faut ajouter à ces noms celui de l'Alleu, qui désigne un petit canton de la plaine de la Lys, vers Laventie, et celui du Meetjesland, enserré entre Franconat et pays de Waes, dans le triangle Eecloo, Somergem, Waerschoot.

C'est là beaucoup de noms et beaucoup de pays. La plupart sont de vieux termes historiques, d'origine féodale ou ecclésiastique, qui ne correspondaient pas pour la plupart à une unité géographique, et qu'on a repris au XIX ${ }^{\mathrm{e}}$ siècle pour les plaquer sur des divisions d'ordre géologique ${ }^{2}$. C"est là un emploi un peu artificiel, car le peuple ne connaît pas ces noms, et les circonscriptions auxquelles on les applique ne correspondent plus exactement aux vieux Pagi pour lesquels ils étaient crés. Déjà l'on peut trouver abusif le nouvel emploi des termes Ferrain et Weppes, pour distinguer deux cantons dont les differences sont assez faibles, le premier plus ondulé, le second très plat. Le pays de l'Alleu n'est qu'un coin de la plaine de la Lys; et le souvenir de la domination qu'y exerçait l'abbaye de St-Waast ne suffit pas à sauver de loubli le nom géographique de cet ancien alleu. Le Franconat, ou plutôt Franc de Bruges (het Vrije) était une ancienne circonscription politique de la Flandre, à cheval sur

1 Voir la carte à la fin du volume.

2 C'est ainsi que M. Gosselet a ressuscité les termes de Ferrain, Weppes, Mélantois, Carembaull, et leur a donné une signification géologique; les habitanta ignorent ces noms, qu'on retrouve seulement accolés à ceux des communes qui avaient besoin d'une dénomination pour empêcher des confusions: Neuville-en-Ferrain s'oppose à Neuvillesur-Escaut; Sainghin-en-Weppes, à Sainghin-en-Mẻlantois. 
la plaine maritime et l'intérieur ; ce terme n'a jamais eu une valeur géographique, et a lo tort d'être complètement tombé dans l'oubli. Les pays de Kadzand et d'Axel désignent les deux arrondissements de la Flandre zelandaise, sans plus. Bulscamprelt et Altervelt existent, mais on a fait de ces termes un emploi singulièrement étendu: car l'un désigne réellement une ancienne bruyère, aujourd'hui boisée, dans la commune d'Oostcamp, et l'autre n'est qu'un lieu-dit de la commune d'Aeltre.

Les autres noms expriment peut-être plus de réalité, quoiqu'on ait beaucoup trop agrandi la petite région dont ils indiquent l'existence et l'originalité. On a toujours appelé Bredenarde le platean argileux, plus élevé que la plaine maritime qui l'ensorre presque partout, et qui comprend les quatre communes de Zutkerque, Nortkerque, Audruick et Polincove : un coin de Flandre intérieure égaré entre les pentes de l'Artois et la Plaine; ce terme historique s'appliquait donc à un petit territoire différent de ceux qui l'entourent. Mais il faut bien se garder de pousser la Brodenardo au Sud d'Ardres jusque sur les pentes de la forêt de Licques. Le Meetjesland est plus incertain, un peu en l'air. A Eecloo, Waerschoot, Somergem, tout le monde en parle, les habitants s'intitulent Meetjeslanders, les journaux en entretiennent leurs lecteurs. Mais hors de ce petit cercle, on entre dans le vague ; à Bellem, les Meetjeslanders sont ceux qui habitent au Nord du canal de Gand; a Evergem on en parle sans trop savoir ce que c'est; à Knesselaere, Nevele, Lootenhulle, Iandegem, Caprycke, on convient que ce nom n'est guère connu que des gens cultivés. Si le Meetjesland a une signification géographique, il désigncrait done Ia partie de la plaine sableuse qui se trouve a l'Est des collines d'Ursol; mais rien ne distingue ce pays des cantons voisins ; aussi est-il à craindre quo le Metjesland ne soit un vieux nom ou sobriquet historique égaré dans la géographie ${ }^{1}$.

Le pays de Waes a beancoup plus d'originalite. Non pas qu'il faille l'étendre aussi loin vers l'W. que le fait la carte à 1: 500.000 ; jamais Caprycke, Ertvelde, Selzaete n'en ont fait partie. La circonscription historique qui portait ce nom s'arrêtait à l'Éscaut, à la Durme, et à la frontière hollandaise actuelle 2. Géographiquement, le Waes est plus restreint encore: c'est le pays du limon sableux qui surmonte l'argile rupelienne. Au milieu d'un pays de sable, ce limon forme une terre plus fertile, qui fait

1 M. Gosselet fait du Mentjesland la continuation dir pays de Waes, colui-ci s'étendant de Gand à Anvers, celui-là de Gand à Bruges. (Geographie physique, pp. 109-110).

2 Cf. Vau den Bogaerde, Het distrikt van St-Nikolaas, vorheen land van Waes. (S. Nikolaas, Dorey, $1825,3 \mathrm{~d}$., in $-8^{\circ}$ ). 
du pays de Waes la région la mieux cultivée qui soit ; c'est le jardin de la Flandre. Ce limon s'etend jusqu'à Waesmunster, Belcele, Stekene; comme ce n'était pas lá une f́rontière, on a reculé les limites jusqu'à la Durme,.grossie par le flot de marée. Mais les communes situées au delà n'en ont jamais fait partie: Zele, Loochristy, n'ignorent pas qu'ils sont en dehors, que le pays de Waes s'arrête à Lokeren ; les habitants conviennent que leur région, entre la Durme et Gand, n'a pas de nom ; et ils paraissent en prendre aisément leur parti.

\section{Plaine Maritime et Intérieur.}

Mais il y a d'autres noms que ceux dont parlent les cartes. Le peuple qui ignore le Franconat et le Bulscampvelt, qui se soucio peu du Meetjesland ou de la Bredenarde, a toujours fait la distinction, en Flandre, entre deux grandes variétés régionales, la plaine maritime et l'intérieur. C'est là que s'accumulent vraiment les différences physiques, économiques, ethnographiques mème. Aussi pour exprimer ce qu'il y a de tranché entre les deux régions existe-t-il des formes nombreuses, populaires, qui sont de vrais noms de pays, car ils n'ont pas d'ancêtres historiques et designent des phénomènes naturels. A l'Ouest, ce qui frappe, c'est la différence entre les croupes élevées de la craie et les étendues plates du Calaisis : d'un côté c'est donc le Haut-Pays, appelé parfois les Côtes ; de l'autre le PaysBas, la Bassure. Plus loin, après l'Aa, les hauteurs s'éloignent de la lisière des deux régions; le relief de l'intérieur n'est guère plus puissant que celui de la plaine; mais ce qui saute aux yeux c'est que la plaine n'a pas d'arbres, et que l'intérieur en foisonne; l'une est donc le pays découvert (Bloote, Blooteland), l'autre la région boisée (Houtland). Après Ghistelles, et jusqu'au delà de Bruges, la distinction se fait plus simplement encore entre le Noorden et le Zuyden, habilés par les Noordenaars et.les Zuyderlingen; la différence est si nette entre les deux régions qu'on n'a pas besoin d'une désignation plus précise. Au delà le terme Houtland reparaît et se maintient jusqu'à la hauteur du pays de Waes, tandis que la plaine prend le nom de Polders, ou Polderland; c'est la terre des Polders, terme qui a une signification précise puisque toute la Flandre zélandaise est en effet composée de polders arrachés depuis quelques siècles seulement à la mer. Enfin dans le pays de Waes on appelle terres hautes (Hoogland, ou ten hoogen) l'intérieur, qui monte en pente douce jusqu'à l'altitude de 30 mètres, tandis qu'on continue à qualifier de poldors les terres basses qui s'êtendent jusqu’à Anvers. 
Ce sont lá de vrais noms géographiques. Les habitants rendent la distinction plus nette encore par les épithètes, les sobriquets qu'ils se renvoient d'une région à l'autre. L'homme de la Plaine, enrichi par la fertilité du sol, aisé et cossu, se moque du paysan de l'intérieur que le travail courbe sur un sol ingrat : Houtlander est un terme méprisant; ces gons de l'intérieur no sont-ils pas d'un siècle en arrière? Co sont de pauvres sires; on les bafoue du nom bizarre d'Houtlandsche prüm (prune du Houtland). Le Houtlander riposte en se moquant des gros défauts du Blootenaar, son amour d'une bonne table, du confortable, sa morgue, son peu de sociabilité ; dans l'Ouest les gens du pays haut traitent de gris dos ceux de la Bassure; par là ils entendent des orgueilleux, des parvenus. A l'Fst on considère comme pointilleux, rigides et désagréables les Hollandais des Polders, qui traitent les Flamands de l'intérieur de fanatiques arriérés, et d'ignorants. Il n'est pas un fonctionnaire, instituteur, prêtre, passant d'une région à l'autre, qui ne s'aperçoive rapidement qu'il est dans un autre pays, et que le climat est aussi différent que les gens : coux de la plaine froids comme le vent qui souffle sans cesse sur lour pays, ceux de l'intérieur plus démonstratifs, de tempérament plus vif, comme rẻchauffés par la tiẻdeur de leur atmosphère ${ }^{1}$.

C'est là la distinction profonde en Flandre, le pays bas au long de la côte, et lo pays boisé derrière; pays de Waes, Bredenarde, ne sont que des détails dans cot ensemble. Plaine maritime, Flandre intérieure, sont les deux grandes divisions du pays. Cependant, vers le Sud, des nuances nouvelles s'observent; on sent la transition avec les pays voisins. Ia plaine de la Lys tourne le dos á la Flandre, elle regarde déjà un peu vers le Sud, vers le bassin houiller et la région lilloise. Le puissant foyer industriel de Lille-Roubaix esl également un peu a part ; la frontiòre l'isole du Nord et le rapproche du Sud, en dépit des affinités physiques. Le pays d'Alost sert de transition entre les plateaux brabançons et les plaines de Flandre. Ainsi la Flandre est bordée au Sud de régions mixtes, où se mónage le passage de la nature flamande a la Picardie, au Hainaul, au Brabant. Ce sont là des distinctions dont il faudra tenir compte dans l'étude de la Flandre intérieure.

1 a Sans transition, écrit un médecin de Dixmude qui connaît bien le pays, de la plàine à lintérieur tout change inopinément d'aspect: terrain, coutumes, mœurs, température, climat, tout varie. On dirait un autre peuple, un autre pays ». (Woets, Topographie médicale de l'arrondissement administratif de Dixmude. - Ann. de la Soc. médico-chirurgicale de Bruges, 1847, p. 43). 


\section{CHAPITRE VII}

\section{RÉGIME DE LA MER FLAMANDE ${ }^{1}$}

La mer flamande. Régime des marées: le gain de flot. Formation des banes.

De Sangatte à Anvers, sur une largeur d'une douzaine do kilomètres lo long de la côte, la Flandre présente l'aspect d'une plaine basse, au sol gris ou noirâtre, coupée d'innombrables fossés ou canaux, plantée de rares arbres tordus; du côtè de la terre, l'horizon semble infini, jusqu'aux arbres du Houtland aperçus dans les brumes bleuâtres; vers la mer, l'œil s'arrêto sur une rangée de dunes blanches irrégulières, ou sur le profil vert d'une digue. C'est la plaine maritime.

Cet aspect n'est pas particulier à la Flandre. Il y a plusieurs petits paysbas semblables sur les côtes de France: marais poitevin, marais breton, marais de Dol, bas-champs de Picardie. Mais ce type de région paraît surtout développé le long de la mer du Nord; la Zélande continue la plaine maritime flamande, et sans interruption se succèdent les polders hollandais, la Frise, occidentale et orientale, les Marschen de l'Elbe, les Dittmarschen du Holstein, el ainsi de suite jusqu'en Danemark, au cap Blaavands Huk. En face, sur la còte anglaise, la plaine basse des Fen, autour du golfe de Wash, fait pendant aux polders germaniques. Tous ces

1 I'rincipaux travaux à consulter: Keller (F.A.E.), Exposé du régime des courants observés depuis le XVIo siècle jusqu'à nos jours dans la Manche et la mer d'Allemagno (Paris, Didot, 1850, in-8 $8^{\circ} 175$ p.): - Stessels (A.), Des courants de marée sur le littoral de la Belgique (Ann. Tr. P. Belg., XXV, 1867,pp. 27-44); - Plocq (A.). Ftude des courants ot de la marche des alluvions aux abords du détroit de Douvres et du Pas-de-Calais, sur les côtes de France et d'Angleterre (Ann. P.-C., 40 série, $3^{\circ}$ annẻe, 1863, pp. 103-17\%, 7 pl.); - De Moy (P.), Etude sur l'amélioration et l'entretien des ports en plago de sable et sur le régime do la côto do Belgique (Parisis Raudry, 1894, 1 vol. texte in $4^{\circ}, 538$ p., 1 vol. atlas gr. in $4^{\circ}, 42$ pl.); - Van Mierlo (C.-J.), L.a carto lithologique de la partie méridionale de la mer du Nord (Bull. Soc. belgo Géol., XIII, 1899, [janvier 1901], Mém. pp. 219-265, carte); - Van Mierlo et Spysschaert, Carto générale de la partio méridionale de la mer du Nord, dressée d'après les sondages les plus récents; publiée par la Soc. belge de Géologie (Bruxelles, lamertin, 1897); - Gilson (G.), Exploration de la mer sur les cótes de la Belgique en 1899 (Mẻm. Musée Hist. Nat. Belgique, I, 1900). 
pays bas ont le mềme aspoct généraI, la même horizontalité parfaite du sol; les arbres penvent y être plus ou mains nombreux, suivant la distance à la mer: mais l'humidite est partout forte, les canaux nombreux; c'est toujours un pays à demi aquatique. La couleur du sol gris, semblable à cello des vases marines, la présence de coquillages identiques à ceux que contient encore la mer voisine, l'altitude surtout, avertissent que ces plaines sont un fond de mer exondé. Mêmo la mer semble prête à réoccuper un territoire qu'elle paraît n'avoir abandonnẻ que provisoirement; le pays bas est presque partout inférieur au niveau des hautes mers. Dans des marées extraordinaires comme celle du 31 janvier 1877, il resterait dans la plaine maritimo de Flandre une bien faible étendue émergéc, sans la protection des digues et des dunes. Il s'agit donc bien d'une plateforme marine à peine hors des eaux, due à la mer, et qu'il faut à grand' peine protéger contre elle. Aussi peut-il paraître utile, avant d'en commencer l'étudo, d'examiner le régine de cette mer qui l'a formée.

\section{La mer flamande.}

Co n'est pas d'une étudo de la mor du Nord qu'il s'agit. Celle-ci ust vaste, et la Flandre n'en borde qu'une bien petite étenduo. Comparéo à la véritable mer du Nord, celle qui s'élend du Jutland à l'embouchure de la Tyne, la partie qui intéresse la Flandre est singulièrement restreinte: c'est un * canal * au même titre que la Manche, à peine plus large qu'elle; presque un cul-de-sac assez ètroit, s'entr'ouvrant de biais par la fissure du Pas-de-Calais. C'est là une partie très distincte de la mer du Nord, une mer famande, comme il y a une mer allemande entre la Frise et lo Schleswig. Les pêcheurs du littoral n'appellent Nordzee que la grande mer, au delá de la Hollande, colle du Logger-Bank; au Sud du $53^{\mathrm{e}}$ et surtout du 52 degré de latitude Nord, c'est la région des bancs de Flandre (Flemish Banks, Vlaemsche hanken) ${ }^{1}$. C'est cette partio seule qui intéresse la côte et la plaine flamandes, car ses conditions physiques sont différentes de celles qu'on trouve dans la Nordzee proprement dite: là à cause de l'influence de la Manche toute proche, ici parce que les flots de l'Atlantique pénètrent librement par la large ouverture du Nord.

Or, comme la Manche, et plus encore que la Manche, la mer flamande est sans profondeur. En dehors des fonds de plus de 50 mètres qui s'éche-

1 Gilson, p. 61. 
lonnent dans le détroit (61 métres entre Wissant et Dourres), il faut aller loin de la côte de Flandre, jusqu'au delà do la rangée des grands bancs, pour que la sonde accuse plus de $\mathbf{4 0}$ mètres, et l'on n'atteint de nouveau 50 mètres qu'auprès des bancs anglais du Galloper. A côté de ces maxima on trouve des profondeurs extrêmement faibles : $7^{\text {m }}, 20$ sur le banc $\mathrm{du}$ Noord-Hinder, $5^{\mathrm{m}}, 20$ sur lo Sandettie, situés au beau milieu du canal: plus près des côtes, on arrive d $1^{\mathrm{m}}, 50,1^{\mathrm{m}}, 10,0^{\mathrm{m}}, 50$ (Goodwin Sands), et même à des plateaux découverts à marée basse, le Braeck de Dunkerque, le North-Goodwin. Ainsi cette mer étroite est \& peine recouverte d'eau. Si la plaine maritime n'est qu'une plate-forme marine à peine exondée, la mer flamande est un socle continental faiblement inondé. Terre et mer s'emmêlent, se pénètrent réciproquement. On a $v u$, dans l'histoire du sol flamand, qu'il en avait toujours été ainsi. Dans cette lutte entro les deux éléments qui se le disputaient, aucun n'a été assez fort pour vaincre définitivement.

C'est de l'èpoque quaternaire que datent les dernières batailles rangées. Après des fortunes diverses, la terre l'avait emporté pendant le quaternaire moyen, et la Flandre se joignait a l'Angleterre. Mais à l'époque flandrienne (quaternaire supérieur), la mer traverse de nouveau le Pas-deCalais, et s'y est maintenue depuis. C'est d'alors que date la mer flamande. L'évènement n'alla pas sans quelque violence. En effet, la marée, beaucoup plus forte dans la Manche que dans la mer du Nord à l'époque actuelle $\left(8^{\mathrm{m}}, 55\right.$ à Dieppe, $7^{\mathrm{m}}, 86$ à Boulogne, contre $5^{\mathrm{m}}, 45$ à Dunkerque, $4^{\mathrm{m}}, 60$ à Ostende, $4^{\mathrm{m}}, 20$ à Flessingue) ${ }^{1}$ devait être bien plus considérable encore lorsque la Manche n'était qu'un cul-de-sac, où le flot venait s'accumuler comme il le fait aujourd'hui dans le golfe de Saint-Malo ou la baie de Fundy ${ }^{2}$. Tandis que ce formidable bélier battait l'isthme, la mer qui avait peu à peu envahi la plaine du quaternaire moyen en Flandre devait avoir des flux et reflux insignifiants; de nos jours on voit la marée propre d la mer du Nord diminuer de l'Ecosse jusqu'à la ligne joignant Yurmouth au Texel, ou vient la renforcer l'onde de la Manche; on peut donc supposer qu'à l'époque oủ le détroit n'était pas encore ouvert, l'amplitude de la marée restait faible au fond du golfe: peut-êtro 2 mètres, pout-être moins. Mais lorsque l'isthme céda sous les coups du flot de la Manche, une véritable catastrophe dut se produire ; la maréo venue de l'Ouest dut préci-

1 De Mey, Ports en plage, p. 27.

2 M. Van Mierlo l'estime à environ 20 mètres. - Cf: Van Mierlo (C.-J.), Les marées à la fin de l'époque quaternaire sur les côtes do Belgique. (Bull. Soc. belge Géol., XI, 1897, Mém., pp. 273-283). 
piter par l'ouverture des torrents d'eau, qui noyèrent le pays, élevèrent le niveau de la mer du Nord et finirent par donner les marées actuelles.

\section{Régime des marées : le gain de flot.}

Or, c'est encore du système de marées de la Manche que dépend celui de la mer de Flandre; c'est l'onde marée venant de la Manche qui pénétre dans la mer flamande en suivant les côtes de Belgique et de Hollande jusque vers le Texel, tandis que sur les côtes anglaises c'est l'onde de la mer du Nord qui produit le flux et le reflux, jusque vers l'embouchure de la Tamise. Il en résulte que les mouvements du flux et du refiux sont différents sur la côte flamande et sur la côte anglaise. Le long de la côte belge, le courant au dèbut du flot porte au Sud-Est, vers la côte, et incline peu à peu vers l'Est; à l'heure de la haute mer, lorsque le flot atteint sa plus grande vitesse, il est presque paralléle à la côte. Le renversement commence au jusant, le reflux portant d'abord vers le Nord, et s'inclinant lentement vers l'Ouest ; lors de sa plus grande vitesse, lo jusant court à l'W.-S.-W., jusqu'au moment où, au retour du flot, il va tourner au Sud, vers la côte. C'est un mouvement giratoire inverse, c'est-à-dir'e contraire à la marche des aiguilles d'une montre, tandis que sur la còte anglaise la marée décrit un mouvement giratoire direct.

Ainsi les flots de la mer flamande subissent deux fois chaque jour un mouvement de va-et-vient, qui, au moment des plus grandes vitesses, les porte vers l'Est, puis vers l'Ouest. Le déplacement vers l'Ouest dure plus longtemps, car lorsque le vent n'intervient pas, le courant de jusant persiste en moyenne 1 heure, même 1 heure et demie de plus que le courant de flot. En revanche la force du flot est plus considérable, parce que sa vitesse est plus grande; sur le litloral français, elle est de $2^{\mathrm{m}}, 15$ par seconde devant Calais, de $1^{\mathrm{m}}, 80$ dans la rade de Dunkerque (marées moyennes de vive eau); plus loin elle est de $1^{\mathrm{m}}, 30$ dans la rade de Nieuport, de $1^{\mathrm{m}}, 20$ dans la grande rade d'Ostende, de $1^{\mathrm{m}}, 50$ au large de Knocke; celle du jusant dans les mêmes conditions est de $2^{\mathrm{m}}, 05$ devant Calais, de $1^{\mathrm{m}}, 50$ vers Dunkerque, de $1^{\mathrm{m}}, 10$ à Nieuport, $0^{\mathrm{m}}, 95$ à Ostende, $1^{\mathrm{m}}, 45$ vers Knocke ${ }^{1}$. Ainsi le flot est plus fort, mais le jusant dure plus longtemps, et il serait difficile à priori de dire lequel des deux courants l'emporte, de quel côté se trouvent transportées les alluvions que charrie la mer.

\footnotetext{
1 De Mey, Ports en plage, pp. 28 et 33.
} 
Cependant il existe des prouves nombreuses qu'il y a gain de Hot, c'esta-dire que les objets abandonnés à la mer sont transportés vers l'Est. Les bouées de Dunkerque dont les chaînes so sont rompues sont toujours retrouvées sur la côte belge. Les fucus trouvés entre les bancs de Flandre, et qui viennent des côtes bretonnes, fournissont la même indication ${ }^{1}$. Enfin une expérience scientifique a prouvé cette prédominance du flot: sur 100 flotteurs immorgés le 2 mai 1899 au bateau-feu du West-Hinder, 5 seulement ont été retrouvés, du 6 au 15, à l'W. du point do depart, tandis que 49 autres ont été recueillis à partir de juin sur les côtes de IIollande, dont 33 à la fois, entro Ymuiden et Schiermonnikoog, du $1^{\text {or }}$ au 15 septembre 2 . Or les vents avaient été plutôt défavorables, puisque du 2 mai au $1^{\text {er }}$ septembre 1899 , ils avaient fourni 108 unités favorables au courant de flot contre 251 contraires. Ils ont sans doute leur influence, puisque ce sont des souffles du N.-E. qui dans les premiers jouls de mai portèrent 5 flotteurs à l'W. du bateau-feu, et que ce sont les bourrasques d'équinoxe W.-S.-W. qui ont jeté à la côte 33 flotteurs du $1^{\text {er }}$ au 15 septembre ; cependant le courant de flot est puissant par lui-même, puisqu'il a conduit vers le N.-E. la grande majorité des flotteurs malgró des vents contraires: 76 unités de vents N.-E. du 20 mai au 19 juillet, 52 unités de vents N.-N.-W. du 3 au 27 juillet, enfin pour l'ensemble 143 unités de plus au N.-E. qu'au S.-W.: M. Gilson conclut que la force qui a fait cheminer les flotteurs Iui parait être la résultante d'une influence éolienne et d'une influence neptunienne, la dernière étant la plus efficace.

Cette constatation déroute un peu, car on s'était habitué à prendre pour cause du gain de flot la prédominance bien constatée des vents d'Ouest. Il est certain que ceux-ci ont sur la marée une influence considérable; dans certaines marées, fussent-elles de morte eau, accompagnées de violents vents d'Ouest, le flot duro presque constamment dans les ports flamands, mollit à peine à l'heure du jusant, et reprend ensuite avec plus de force ${ }^{3}$. Cependant il est probable que la force du courant de flot n'a pas été justement appréciée jusqu'ici, et que c'est à elle qu'est due une bonne partie du gain constaté par l'expérience, et par les remarques des marins.

Ce gain de flot doit naturelloment transporter vers l'Est les matériaux tenus en suspension par les eaux de la mer flamande. Celle-ci est fortement chargée d'alluvions; sa couleur jaune en prévient : on a pu recueillir

1 Plocq, Étude courants, pp. 138-140.

2 Cf. Gilson, pp. 67-80. - Deux flotteurs parvinront aussi sur la cote du Schloswig.

3 De Mey, Ports en plage, p. 88. 
3 centimètres cubes de sable dans 6 litres de ces eaux troubles ${ }^{1}$. La présence de ces grandes quantités de matériaux provient sans doute du peu de profondeur de la mer, où les vagues de fond agitent les sables des bancs; elle est due aussi à l'apport de la Manche. Ce sont les falaises du pays de Caux, du Boulonnais, du Gris-Nez et du Blanc-Nez, qui fournissent les matériaux entassós dans la mer du Nord. Les alluvions transportées par les fleuves sont en faible quantité, car les fleuves flamands, dont la pente est presque nulledans la dernière partie de leur cours, amènent à la mer des eaux à peu près décintécs, et où ne se trouvent guère que les matières ténues. L'Escaut, par exemple, si trouble à Wetteren, à Termondo et à Anvers, se clarifie vers l'aval; ses eaux sont déjá moins sales à Bath, et presque limpides à Terneuzen; si elles redeviennent troubles à Flessingue, ce n'est pas, en toul cas, par l'apport de vases fluviatiles ${ }^{2}$. Donc, étant donné la présence du gain de flot, et l'apport des fleuves étant insignifiant, c'est bien de la Manche que vionnent les alluvions de la mer flamande.D`ailleurs, la nature de cesélémentsvarie á mesure qu'on va du Pas-de-Calais vers le Nord-Est. Ce sont d'abord des galets, semblables à ceux qui encombrent les ports français de Normandie. A la hauteur de Dunkerque, les galets se font tout petits : c'est plutôt du gravier; et ce gravier n'est plus que du gros sable au large de Nieuport; c'est du sable fin qu'on tronve à Ostende, et vers Wenduyne déjà du sable vasard ${ }^{3}$. En dépit de la violence des courants, il se forme même des vases, qui se déposent dans les criques sous-marines fermées, comme le fond de la petite rade d'Ostende, ou l'ancionne anso du $Z$ win ; olles s'accroissent avec une grande rapidité; ce qui restait du Zwin après l'endiguement de 1872 étail comblé 20 ans plus tard, et on pouvait le franchir à marée basse . Ces vases, produit de la désagrégation des côtes calcaires, de la dissolution des coquilles, de l'attaque par les courants de couches argileuses affleurant sous les eaux, contiennent parfois jusqu'à $28 \%$ de carbonate de chaux, d'où lour fertilité quand elles sont émergées; leur couleur est grise au-dessus, noirâtre au-dessous, par l'oxydation que produit l'oxygène de l'eau de mer ${ }^{5}$. C'est cette vase quì devient l'argile des polders, celle qui forme la plus grande partie du sol de la plaine maritime.

1 Jonglez de Ligne, La Rade de Dunkerque. (Extrait de la Revue maritime et coloniale, 1864 ; Paris, Challamel, 1864, br. in $-80,20$ p., 1 carte), p. 12.

2 Van Mierlo, Carte lithologique, p. 225.

3 Ibid., pp. 227-228.

4 Ibid., pp. 223-224.

5 Gilson, PP. 36-59. 


\section{Formation des bancs.}

C'est avec ces matériaux amenès de l'Ouest que les marées ont édifié les bancs de Flandre. Resserré dans le couloir du Pas-de-Calais, le courant y halaie avec force les matériaux ; mais lorsque la passe s'élargit, et que l'onde marée de la mer du Nord vient contrarier la marche du flot sorti de la Manche, lo courant diverge, sa violence diminue, et il dépose les matériaux qu'il tenait en suspension. Ce dépôt est particulièrement abondant à la hauteur de Dunkerque, où les courants pourtant conservent assez de force pour labourer les alluvions qu'ils apportent et y tracer do profonds sillons. A mesure qu'on s'avance vers l'Est, ce systeme de bancs est moins serré, moins varié; ils deviennent plus larges, et moins nombreux, les dépôts sont plus fins, plus également répartis. Il en est de même sur la côte anglaise où les bancs présentent presque tous des formes aplaties, dues probablement a la rencontre des deux marées du Nord et du Sud ${ }^{1}$.

Les bancs de la mer flamande ne commencent donc qu'd l'endroit où la force du courant, qui atteint $2^{\mathrm{m}}, 15$ par seconde dans les marées moyennes de vive eau, commence à s'apaiser. Du Gris-Nez à Calais, le banc à la Ligne et les Ridens, abrités derrière le promontoire crayeux, n'ont pas grande importance. Au contraire, à la hauteur de Gravelines, les longues arêtes de sable apparaissent simultanement dans toute l'étendue de la mer ; c'est un véritable éventail, qui diverge daus tous les sens. Ce sont d'abord les Goodwin-Sands anglais, á forme aplatie, dont le sommet apparaît à marée basse; puis le South Falls, très long et étroit, à talus raides, où on ne sonde guère moins de 7 a 8 mètres d'eau ${ }^{2}$. L'on tombe ensuite à 40 mètres, entre le Falls et le Sandettie, orienté vers le N.-E., et où l'on touche le fond sur un petit plateau à $5^{\mathrm{m}}, 20$ et $5^{\mathrm{m}}, 40$. Troisiéme fosse de 27 à 36 mètres et banc du Ruytingen, avec 5 à 8 mòtres d'eau en moyenne, sauf quelques parties élevées où l'on ne sonde plús guère que 3 mètres; heureusement ce banc est traversé par plusieurs dépressions de 15 à 30 mètres, précieuses aux navires du Nord qui gagnent la côte de Gravelines. Nouvelle fosse, et série des bancs du Dyck (occidental, oriental), et Cliff d'Islande, hauts-fonds dangereux à cause de lour peu de profondeur (8 à 1 mètres) et de la raideur des talus, sur lesquels se brisent

1 Plocq, Courants, p. 133.

2 Tous ces chiffres de profondeur sont donnés pour Irarée basse. 


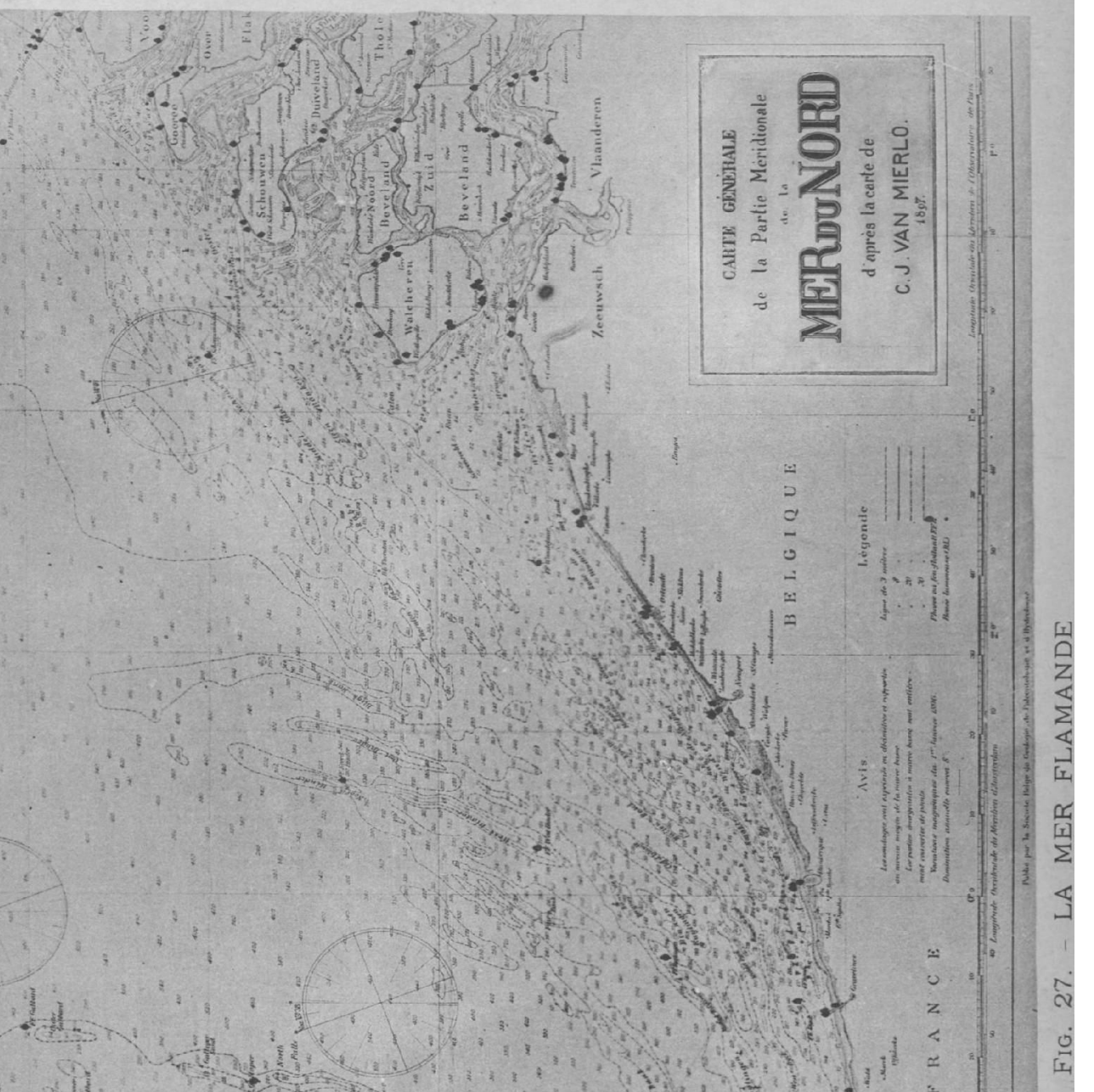

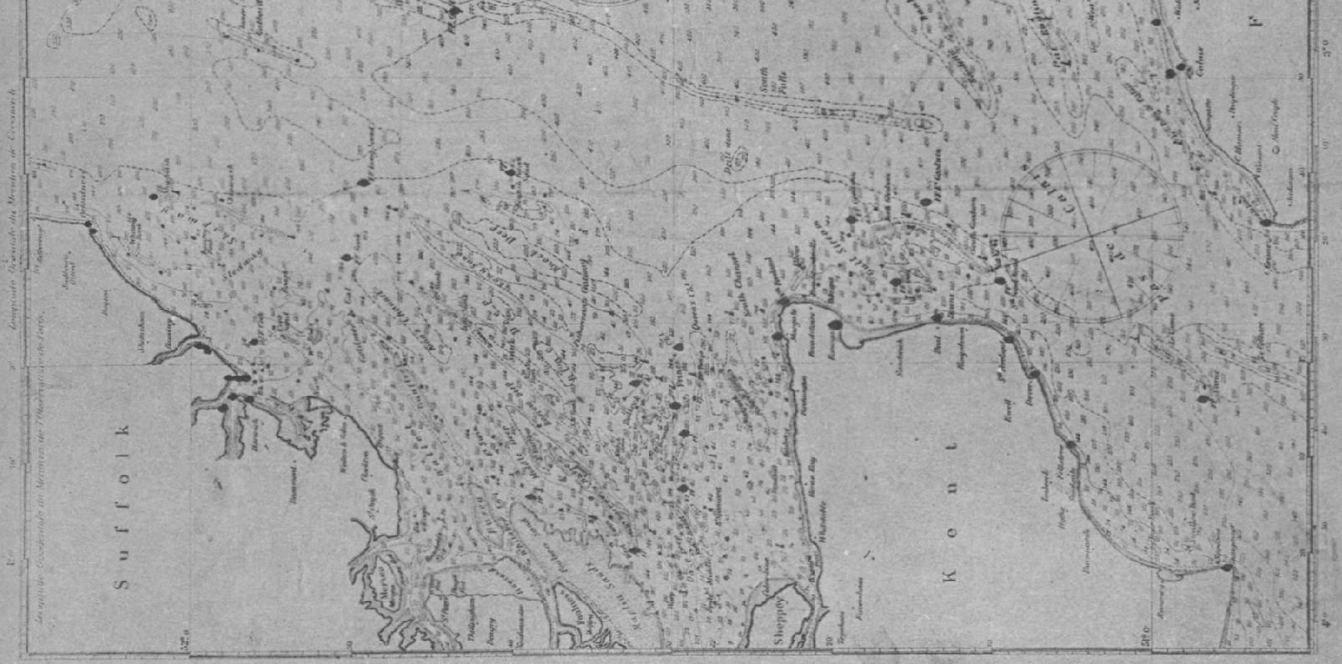


IRIS - LILLIAD - Université Lille 1 
violemment les flots poussés par les vents du N.-W.. Le Binnen et le Buiten-Ratel succèdent aux Dyck; puis vient le Breedt, très large devant Dunkerque, avec des fonds de 1 mètre. Lo Smal-Bank, situé derrière, r'est guère plus profond: à marée basse il n'a que de 1 à 7 mètres d'eau. Enfin vient la longue ligne des bancs qui bordent la côte, Snouw, Braeck, Hills, Traepegeer, dont certaines parties affleurent à marée basse, particulièrement le Braeck devant Dunkerque; ils se relient par des fonds insignifiants de 6 à 7 mètres, dont l'un constitue la passe de

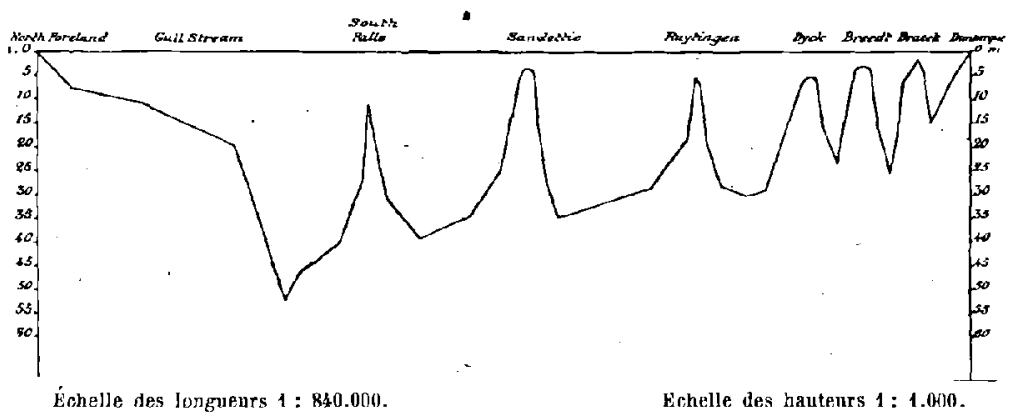

Fig. 28. - Profil du fond de la mer flamande entre North-Foreland et Dunkerque.

Zuydcoote, une des issues de la rade de Dunkerque. Du loyck à la dernière ligne, les bancs continuent à être séparés par des fosses profondes, interrompues çà et là par des apophyses projetées d'un banc à l'autre: entre le Dyck occidental et le Binnen-Ratel, un plateau de 6 à 9 mètres; du Ratel au Breedt, un haut-fond de 6 à 7 mètres; du Breedt au Smalbank, du Smalbank au Hills, d'autres plạteaux do 4 à 5 métres. Enfin le Traepegeer va se relier à la côte à l'Ouest de Nieuport, par 5 métres de fond environ.

C'est donc une série de 9 l'angẻes de bancs et de fosses qui se développe on éventail de Dunkerque à la côte anglaise; la mer flamande à cet endroit ressemble à un champ labouré, aux gigantesques sillons. C'est surtout le long de la côte française, où l'action de la maréo venant de la Manche est seule à se faire sentir, que le spectacle est curieux : 6 ligues de bancs y sont pressées les unes contre les autres, comme des murs séparés par des ruelles, le tout sur une largeur d'environ 20 kilomètres. Car ces bancs sont généralement très accores, surtont du côté de la côte. Cette particularité s'explique : à la fin du jusant et au début du Hot, le courant porte au S.-E., vers la côte, et tend à transporter les particules sableuses dans cette direction, par dessus les bancs; aussi ceux-ci 
pronnent-ils une pente douce du còté du Nord, d'où leur viennent des dépôts, et restent accores vers le Sud ${ }^{1}$. Le Sandettie, le Ruytingen, le Dyck, le Braeck, présentent cet aspect. Puis le flot tourne vers l'Est, creusant les fosses entre les bancs, sans déranger l'équilibre établi entre les deux flancs de chaque crête.

Les bancs allongés devant Dunkerque sont proprement los bancs de Flandre; et les plateaux que l'on trouve encore au large de la côte belge ont déjà un autre aspect. Le courant est moins fort : ils sont plus larges, moins élevés, moins réguliers. Le Fairy Bank, avec $7^{\mathrm{m}}, 30$ d'eau sur sa partie la plus haute, prolonge le Sandettie ; le West-Hinder, l'Oost-Hinder et le Noord-Ilinder ont des fonds de 7 à 5 mètres, mais des passes de 20 à 35 mètres les séparent, et rondent possible la navigation. La plus faible profondeur sur le Bligh est do 9 mètres; sur le Thornton, 10 métres, sauf un petit plateau avec 4 mètres. Lnfin le Kwintebank, avec 5 à 7 mètres de fond, prolonge le Smal-Bank; les bancs de Nieuport, de Middelkerke, d'Ostende et de Wenduyne, avec des profondeurs variant de 4 à 8 mètres, s'alignent parallèlement à la còte d'Ostende ; plus près encore, le Stroombank vient se souder à la plage à l'Oucst de Wenduyne. Eutre ces derniers banes les passes sont moins profondes, et ne dépassent guère 15 mètres ; parfois elles se réduisent à 9. A l'Est de Wenduyne, les bancs disparaissent, remplacés par un grand plateau sableux, het Zand, qui descend lentement vers les fonds du large, et n'a guère que 6 mìtres de profondeur devant Blankenberghe. Mais lorsqu'on arrive à la hauteur de Heyst, de nonveaux bancs et de nouvelles fosses apparaissent. Cette fois l'orientation n'est plus la même: le manche de l'éventail est engage dans l'Escaut occidental. C'est au jeu des courants entrant dans l'estuaire et en sortant qu'est dì ce nouveau groupe : le Paardemarkt, qui n'a guère plus de 2 mètros d'eau à marée basse, et que la fosse de l'Appelzak, profonde de 7 à 9 mètres, sépare de la côte; les bancs de Heyst, Knocke, et du Hompel, dont lo point lo plus élevé est à 3 mètres sous marée basse, et que longe au Sud la belle passe de Wielingen, dont les profondeurs varient de 9 à 23 mètres: c'est la vèritable entrée du fleuve. Puis se succèdent vers le Nord la passe du Spleet, qui n'atteint parfois que $5^{\mathrm{m}}, 50$, le grand plateau du Raan, la mauvaise passe du Deurloo, les banes du Rassen et de Caloo, la rainure de l'Oostgat. Enfin au large quelques

1 Gf. Van Mierlo, Carte lithologique, p. 228. - Cet effet n'est pas modifié par le courant de jusant, qui à son début porte pourtant vers le large; car le jusant à son début n'a pas autant de force que le flot, la masse d'eau qui porte de la còte vers les bancs étant beaucoup moins considérable que celle qui porte du large vers les bancs et la côte. 
médiocres plateaux continuent en face des côtes de Zélande l'alignement des bancs de Flandre.

L'édification d'une pareille rangée d'arêtes et de plateaux sablenx au milieu de la mer flamande est une ouvre considérable, dont l'ampleur s'accorde mal avec ce que nous savons de la puissance actuelle du gain de flot, qui parait être assez pou imporlante. l)'ailleur's, les bancs ont peu changé depuis qu'on a pu en relever exactement l'emplacement et la hauteur. En 1776, l'abbé Mann rapporte qu'au dire de tous les marins, et contrairement à ce qu'il pensait lui-même, les orages et tempêtes, si violents qu'ils soient, ne font aucua effet sensible sur les baucs, et qu'on ne remarque aucun changement sensible ni dans leur forme, ni dans la profondeur d'eau qui les couvre ${ }^{1}$. On comprend l'étonnement de l'abbé Mann, car l'aspect jaunâtre de la mer, toujours chargée de particules sableuses, la présence de ces rangées de bancs, d'origive évidemment alluvionnaire, lenvasement des ports dans les parties non soumises aux chasses, font croire volontiers à des transports considérables dè matériaux. Le transport existe, mais les transformations sont rares et lentes. Les cartes dressées en 1801 par Beautemps-Beaupré, celles que construi sit en 1866 le lieutenant de vaisseau Stessels, colles de M. Petit en 1882, pas plus que les cartes néerlandaises ètablies tous les dix ans depuis 182\%, ou celle de M. Van Mierlo (1897), n'accusent de changements importants ". Létude détaillée des côtes montrera que les transformations sont insignifiantes, sauf sur 3 ou 4 points déterminés; si les grands fonds s'exhaussent, très lentement d'ailleurs, les fosses de moyenne importance paraissent garder leurs profondeurs ${ }^{3}$.

Il faudrait done en conclure que l'apport des alluvions de la Manche est relativement peu considérable, et que les sables et vases dont les eaux de la mer du Nord sont si souvent chargées ne proviennent que d'èchanges faits entre les bancs et les plagés, échanges opérés si équitablement que chacun

\footnotetext{
1 Excepté pour les bancs du Traepegeer et du Stroombank, qui se rapprochent de la côte. - Abbé Mann, Mémoire sur l'histoire naturelle de la mer du Nord et sur la pêche qui s'y fait. [Anc. Mém. Ac. Brux., t. II, (1780), pry. 159)-221 (lu en 1776, publié en 1780). Cf. pp. 191-192].

2 Des échantillons de la plupart de ces cartes se trouvent dans l'Atlas annexé au livre de M. de Mey, Ports en plage de sable.

3 Ce phéromène n'est pas particulier à la mer du Nord. « Il résulte de la comparaison des cartes marines levẻes à différentes époques depuis 1689 que la masse des alluvions de la baie de la Mersey n'a pas sensiblement augmentẻ; on y constate certaines fluctuations dans la configuration des banes et dans la direction des chenaux, mais la baie, considérèe dans son ensemble, n'a pas subi de grandes modifications ". (D Mey, Ports en plage, p. 155).
} 
finit par retrouver son capital à peu près intact. Cela n'a rien de surprenant d'ailleurs, puisque ce qu'apporte le flot, le jusant le remporte. Il faut bien croire pourtant, d'après la forme allongẻe des bancs, d'après leur orientation par rapport aux courants, qu'ils sont dus aux transports de matériaux amentés de la Manche par le gain de flot; mais il faut ajouter, ou que « ces dépots ne peuvent être que le résultat d'efforts millénaires » ${ }^{\text {, }}$ ou que les conditions actuelles n'ont pas toujours existé. Les deux hypothèses sont probablement exactes. La première ébauche des bancs date de l'ére quaternaire (époque flandrienne); cela donne plusieurs millier's d'années avant notre ère. Mais les courants avaient à coup sûr plus de violence qu'aujourd'hui. Lorsque la mer y pénétra, le Pas-de-Calais était plus resserré qu'à l'heure actuelle ; l'histoire en a constaté l'élargissement, dû au recul des falaises du Gris-Nez, du Blanc-Nez et de Douvres : il continue à s'èlargir. Dans ce bras plus ótroit, les courants étaient plus rapides, le gain de flot devait donner des résultats plus appréciables. Les vagues qui amenaient de la Manche des quantités plus considérables d'alluvions, érodaient aussi avec plus de vigueur le fond de la mer du Nord, accumulant en longues files les galets et leurs dß̧bris, graviers ot sables, les dépòts quaternaires recouverts par l'invasion flandrienne, et jusqu'au soubassement tertiaire; les blocs de grès paniseliens y ont été trouvès en grand nombre ${ }^{2}$. Et l'on se rapproche ainsi de la théorie de M. Van Mierlo, qui veut que les bancs de Flandre soient dus à la violence du flot de marée de la Manche, franchissant brutalement le détroit et ravinant sur son passage le fond de la mer du Nord.

En revanche, si les dépôts alluviaux sont faibles dans les parties de la mer flamande exposées aux courants, ils sont considérables dans les anses, les bassins, les parties abritées. On a cité l'exemple du Zwin, qui s'est comblé si rapidement dés qu'il eut été fermè en arrière. Lans l'estuaire de l'Escaut, le Braakman semble destiné à disparaître d'ici un siècle; le lit de l'Escaut oriental, coupé par un barrage en 1867, est en grande partie endiguè aujourd'hui, et cultivé. Dans les ports, les anciens bassins de chasse étaient vite envasés, et à Dunkerque le bassin Becquet, creusé en 1827 et supprimé en 1882, s'était rempli dans ces 55 années d'une épaisseur de 1 à 2 mètres d'argile et de sable ${ }^{3}$. Aussi les anfractuosités ne peuvent-elles subsister sur une côte semblable, et la crique

1 De May, Ports en plage, p. 90.

2 Gilson, pp. 36-59.

3 Gosselet (J.). Géographie physique, p. 23. 
ouverte aux XVII ${ }^{\beta}$ ot $\mathrm{XVIII}^{\mathrm{e}}$ siècles à l'Est d'Ostende no tarda pas à être combléc.

Tel est, dans ses grands traits, le régime de la mer flamande. De puissants courants de marée, issus de l'onde de la Manche, la parcourent chaque jour de l'Ouest à l'Est et de l'Est à l'Ouest; cependant le premier est le plus fort, et amène peu à peu vers l'Esl les matérianx arrachés aux côtes normandes et picardes. Ainsi se sont déposées dans la mer flamand̆c, en grandes masses autrefois, en petites quantites aujourd'hui, les alluvions que labourent chaque jour le flot et le jusant, et qu'ils ont alignées en bancs longs et étroits, séparés par des fosses profondes. Malgrẻ la violence des courants, et en dépit de son aspect souille, la mer modifie à peine ces bancs et ces passes; le rythme est si bien établi que ces énormes mouvements d'alluvions, qui jaunissent les eaux, se bornent à des échanges et à des restitutions. Les courants de marée qui comblent les anses et font disparaître les golfes nettoient les chenaux et entretiennent los passes, et cette mer qui paraît si peu hospitalière a au moins le mérite de rester semblable à elle-même; elle ratisse les dépressions par lesquelles se glissent les bateanx, et va porter ce qu'elle a enlevé au fond des golfes oú elle prépare de nouveaux polders.

C'est dans ces conditions que s'est formée la plaine maritime. 


\section{CHAPITRE VIII}

\section{FORMATION DE LA PLAINE MARITIME ${ }^{1}$.}

I. La Plaine avant l'inondotion du $V^{\circ}$ siècle. Hypothèses sur l'origine de la Plaine. Structure du sol. Date de l'inondation. Nature de l'invasion marine. - II. Asseche.

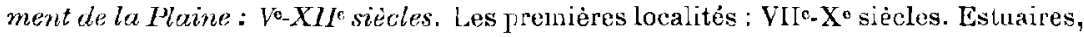
digues et dunes. Disparition des estuaires. - III. Vicissitudes de la Flandre zélerndeise. Prospérité des endiguements aux XII1 et XIV siècles. Inondations et réendiguements: $\mathrm{XIV}^{\mathrm{c}} \mathrm{XIX}{ }^{\theta}$ siècles; rôle des évènements historiques. - IV. Le Zwoirl.

I.

LA PLAINE AVANT L'INONDATION DU Ve SIEGLE.

\section{Iypothèses sur l'origine de la Plaine.}

On ne s'est jamais trompé sur l'origine marine du sol de la plaine maritime. La proximité do la mer, l'horizontalité de la plaine, la faible altitude du sol, et surtout la présence des coquilles marines, semblables à celles que rejette la mer du Nord sur ses plages, avaient éclairé les

1 Principaux travaux: Gosseles (J.), La plaine maritime du Nord de la France et de la Belgique. (Ann. Gẻog., 1892-93, pp. 306-314, 1 carte à 1.550.(0)(0); - Géographio physique du Nord de la France et de la Belgique, (I a plaine maritime), pp. 13-32 ; Belpare: Do la plaine maritime depuis Boulogne jusqu'au Danemark: 1e partie, Mémoire sur la plaine maritime depuis Anvers jusqu’à Boulogne, par Antoine Belpaire, 143 p.; $2^{2}$ partie, Fitude sur la plaine maritime depuis Boulogne jusqu'au Danemark, parAlphonse Belpaire, $242+26$ p. (Anvers, Kornicker, 1855, in-8 $)$;-Debray (A.), Etude góologique et archéologique de quelques tourbières dı littoral famand et du département de la Somme (Mém. Soc. Sc. Lille, année 1873) : Paris, Dumoulin, 1873; Rigaux (H.), Etude sur la topographie de l'arrondissement de Dunkerque antérieurement au XIIe siècle : golfes de Saugatte et de l'Yser (Bull. Com. fl. Fr., VI, 1873, $n^{o s} 5$ et $(j) ;-R u t o t(A$.$) : les opinions définitives de M. Rutot sont exprimées dans :$ Isquisse dune comparaison des conches pliocènes et quaternaires de la Belgique avec celles du Sud-list de l'Angleterre (Bull. Soc. belge Géol., XVII, 1903, Mém. Pp. 57101); - Sur les antiquités découvertes dans la partie belge de la plaine maritime, et notamment sur celles recueillies a l'occasion du creusement du nouveau canal de Bruges à la mer (Mém. Soc. Anthr. Brux., XXI, 19(03); - Jonckheere (Ed.), Lorigine de la côte de Flandre ot le Bateau de Bruges (Bruges, de Haene-Bodart, 1903, 1 vol. in-8n texte, 120 p., 1 vol. pl., 4 cartes). 
habitants. Les inondations marines, l'infiltration des eaux saumâtres dans le sous-sol, la ressemblance de la terre poldérienne avec le sol des schorres abandonnés récemment par les marées, étaient d'autres signes infaillibles. Les quelques mètres d'alluvions qui surmontent la lourbe du sous-sol étaient bien un dépôt marin. « Les gens da pays, écrit l'intendant Des Madrys, croient que la tourbe a été submergée lors du déluge, et que la mer a couvert, encore longtemps depuis, la surface de tous ces terrains bas : ce qui se vérifie par 3 on 4 pieds de sable de mer mêlés de coquillages que l'on trouve au-dessus de cette tourbe.... " ${ }^{4}$. C'est encore aujourd'hui l'avis des paysans du Furnambacht que leur pays est lo résultat du dẻluge.

Du déluge biblique, l'érudition passa, sur la foi d'un texte bien vague, au déluge cimbrique ", et s'en tint là. «Il faut, dit Buffon, que dans les siècles reculés, lorsque la Flandre n'était qu'une vaste forêt, une inondation subite de la mer ait submergé tout le pays.... Cette inondation doit avoir été bien longtemps avant la conquête que fit Jules César, puisque les ècrits des Romains, depuis cette époque, n'en ont pas fait mention $\gg^{3}$. L'argument paraissait sans réplique : puisqu'aucun historien n'avait parlé d'une inondation aussi considérable, l'óvènement devait se perdre dans la nuit des temps. D'ailleurs on n'avait jamais vu se produire de calastrophe géologique un peu importante; tous les accidents de ce genre devaient donc avoir une formidable antiquilé.

C'est l'archéologie qui permit de reconnaître ces erreurs et de préciser la date á laquelle s'était produite la dernière invasion marine. Aux XVIIe et $\mathrm{XVII}{ }^{\circ}$ siècles, on commençait à collectionner les découvertes faites dans les Pays-Bas ; au commencement du XIX ${ }^{\mathfrak{e}}$ siècle, le chanoine de Bast rassemblait en un très beau travail ces notions éparses ${ }^{5}$. Les rocherches ont continué au XIX $\mathrm{X}^{\mathrm{e}}$ sidcle, et l'on peut aujourd'hui dresser de la plaine maritime une carte archéologique ou les points d'observations sont assoz nombreux pour permettre d'en tirer des conclusions valables. Ceux des objets trouvés qui se rapportent à l'époque romaino ou aux âges anté-

1 Mémoire de Des Madrys, intendant de la Flandre maritime, (1698), dans Bull. Comm. H. N., XI, pp. 259-260.

2 Florus, Rer. Rom. Fipit., lih. III., cap. III.

3 Buffon, Euvres eomplètes, éd. Delangrle, II. p. $3: 38$.

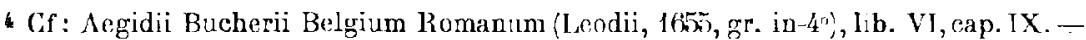
Heylen, De antiquis Romanorum monumentis in Austriaco Belgio superstitibus (Ane. Mém. Ac. Brux., VI, 1783), pp. 405-490.

5 do Bast (J. M.), Recueil d'antiquités romaines et gauloises trouvées dans la Flandre proprement dite. (Gand, 1808-1813, 2 vol. in $-4^{\circ}$ ). 
rieurs sont de diverses sortes : silex polis de provenance néolithique, vases grossiers attribués aux Gaulois (Morins et Ménapiens); surtout des potories samiennes de l'époque romaino, pots, plats de terre, urnes, vases

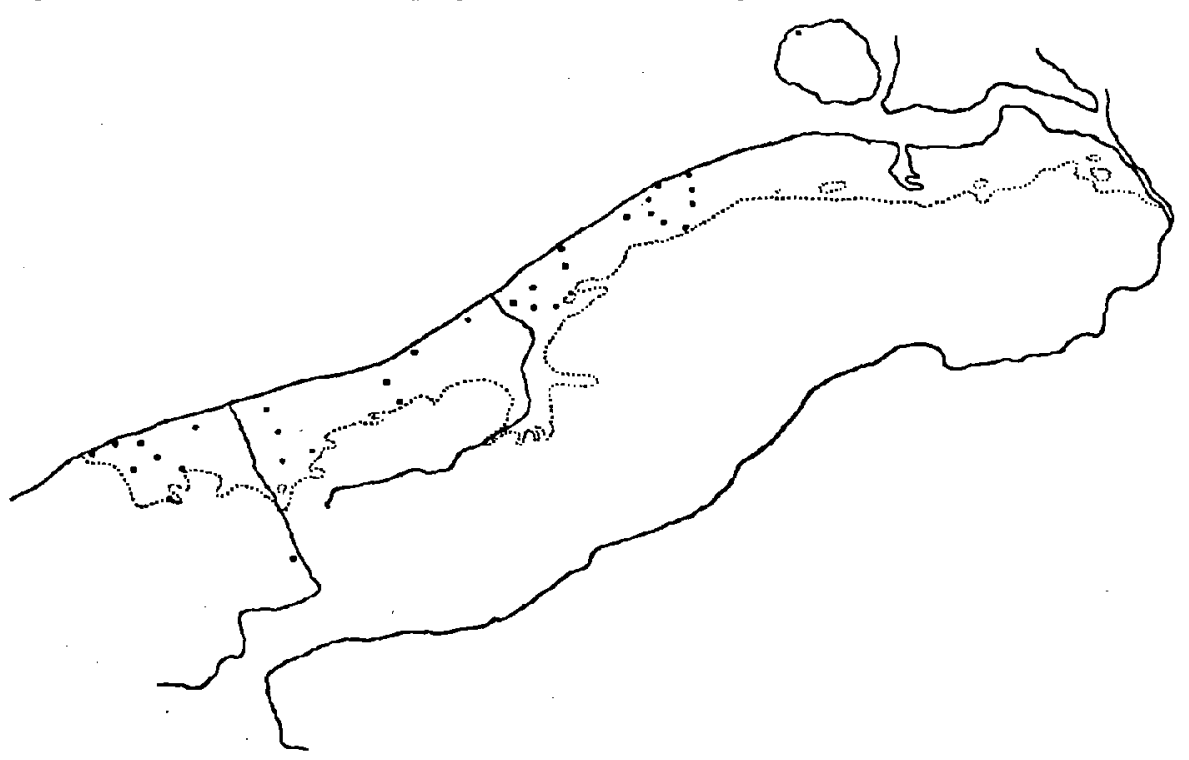

Frg. 29. - Découvertes d'objets romains et pré-romains dans la plaine.

chargés ou non de bas-reliefs, briques; des objets de métal, fibules, fers de lance. Enfin on a trouvé des monnaies, qui authentiquent et datent le reste: une monnaie gauloise à la Panne, altribuée aux Ambiani; des médailles et monnaies romaines à Calais, Sangatte, Marck, HamesBoucres, Bois-en-Ardres, Ardres, Salperwick, Drincham, Killem, Id Panne, St-Georges-lez-Vieuport, Damme, enfin Lomburg, dans l'île de Walcheren ${ }^{\prime}$.

\footnotetext{
1 Ces découvertes archéologiques sont indiqueies dans les travaux suivants: de Bast, Recueil, I, pp. 293-311; - Belpaire (Alph.), Eude, p. 30; - Fouilles de Beaumarais et de Marck dans le canton de Calais (Mém. Soc. Ant. Mor., IX, '2a partie, pp. 341-353); - de Coussemaker, in Bull. Comm. H. N., IX, pp. 25-20; - Rigaux, Topographie, pp. 213-215; - Debray, Tourbières, passim ; - Bull. Sc. Hist. Litt. Nord, V, (1873), p. 183 ; - Cousin, Un itinéraire au X'siècle. Mém. Soc. Dunk., XYI; appendice G; - Macquet (L.), Histoire de la ville de Danme (Bruges, 1856), p. 10, note 1 ; - Smallegange, Nieuwe Cronyk van Zeeland (Middellurg, Meertens, 16\%6), p. $85 ;-$ de Loë (Baron A.), La station préhistorique, belgo-romaine et franque de la Panne (Mém. Soc. Anthr. Brux., XX, 1902); - Rutot (A.), Sur les antiquités déconvertes dans la partie belge de la plaine maritime (Mém. Soc. Anthr. Brux., XXI, 1903); - enfin dans les papiers inédits de M. Debray, à la Bibliothéque communale de Lille.
} 
Or, tous ces objets ont été trouvés, non pas sur le sol ou dans les couches supérieures, d'origine marine, mais dans la tourbe qu'elles surmontent de quelques mètres. C'est en creusant le sol, et on extrayant la tourbe pour le chauffage de leurs maisons, que les paysans de la Plaine ont découvert ces antiquités; c'est ce qui explique que depuis 50 ans on n'en trouve plus guère, sauf dans les terrassements exécutés pour de grands travaux, l'exploitation de la tourbe ayant cessé. Les objets, dont certains sont lourds et les autres légers, ne sont pourtant pas enfoncés dans la tourbe, on ne les trouve que dans les $0^{\mathrm{m}}, 50$ de la partie supérieure. Ils ont donc été jetés à la surface de l'ancien sol tourboux, ou enfouis à une faible profondeur.

La conclusion ¿à tirer de leur présence on cet endroit c'est que la surface de la tourbe représente le sol que foulaient les hommes à l'époque romaine et aux èpoques précédentes, et que les 2 ou 3 mètres de sables et d'argiles qui surmontent la tourbe ont été apportés par une inondation marine postérieure à la présence de la civilisation romaine. Le sol de la plaine maritime, ce dépôt dont l'origine marine n'a jamais été discutée, serait le produit d'une invasion de la mer sur le sol flamand, survenant non dans les lointaines époques géologiques, mais tout près de nous, dans les premiers siècles de notre ère.

Cette théorie semblait si extraordinaire que l'inlelligent érudit Vredius, au XVII' siècle, n'osait pas l'admettre tout entière, et convenait seulement que les Morins et les Ménapiens avaient vécu sur le sol tourbeux ${ }^{1}$. De Bast, dont les travaux ont fait faire un si grand pas à la question, n'ose pas encore être trop affirmatif. C'est à Antoine Belpaire, dans son mémoire de 1825, que revient l'honneur d'avoir très fermement déclaré que la date' de l'invasion marino dovail être fixée au plus tòt au III ${ }^{e}$ siècle ${ }^{2}$. Depuis, l'on a apporté à cette thése des vérifications de toute sorte. On a prècisé les limites de la région inondée, les caractéres marins du sol et de la faune; on a ajouté aux arguments gćologiques de nouvelles preuves archéologiques et historiques. Aujourd'hui la structure de la plaine est connue, ot il est possible d'en esquisser l'histoire.

1 « Lbi nune aptam illam alendo igni materian, alta humo additam, rusticana scrutatur industria, fuisse tum temporis Morinorum et Menapiorum solum o (Vredius, Flandria Ethnica, p. 32).

2 « Nous pensons done que c'est pendant la domination romaine que la mer est venue pour la première fois, depuis sa retraite, se jeter sur ces terres.... Ce n'est que pendant la dernière moitié du $I J I^{\text {o }}$ siècle qu'elle somble avoir attcint ceite partie du continent qui forme maintenant l'île de Walcheren » (p. 64). 


\section{- Structure du sol.}

Les dépôts quaternaires et modernes, propres à la plaine maritime, atteignent une épaisseur de 20 à 40 mètres. Ils surmontent les couches tertiaires, que les sondages ont rencontrées dans le même ordro, et occupant respectivement les mêmes territoires que dans l'intérieur de la Flandre. Vers l'Ouest, c'est l'argile yprésienne, que la sonde atteint à la profondeur de 23 mètres sous Bourbourg, de $27^{\mathrm{m}}, 50$ sous Furnes, de $21^{\mathrm{m}}, 50$ au Petit Crocodile (Middelkerke), de $24^{\mathrm{m}}, 90$ à Leffinghe, de $33^{\mathrm{m}}, 50$ à Ostende. Puis vient le Paniselien, que M. Rutot reconnait à Blankenberghe sur une épaisseur de 24 mètres, surmonté de 36 mètres de dépòts quaternair'es et modernes. Sous la Flandre zélandaise apparaissent les derniers étages tertiaires; le Rupelien serait atteint à $19^{\mathrm{m}}, 50$ sous Schoondijke, à 22 mètres sous Watervliet, à 18 mètres sous Terneuzen. $\Lambda$ Walsoorden, il faut descendre jusqu'à $29^{\mathrm{m}}, 50$ pour trouver le Diestien. Enfin à Flessingue, lo tertiaire est apparu à 22 mètres ; à Goes, à 30 mètres ${ }^{1}$. Les résultats de ces sondages prouvent que l'épaisseur des terrains de la plaine maritime est variable, mais qu'en moyenne elle atteint à peu près 25 mètres; ils montrent aussi que la région n'est une plaine côlière, au sens prẻcis du mot, que par rapport aux conches quaternaires el modernes, puisque les terrains terliaires, sous la plaine comme dans lintérieur, plongent vers le Nord, dans une direction presque perpendiculaire à celle de la côte actuelle *

Au-dessus de ces couches tertiaires s'éléve l'épais dépôt marin des sables pissarts, que l'on s'accorde à considérer comme flandriens (quaternaire supérieur). A Calais, ils ont 20 mètres, à (Gravelines 28, à Bourbourg 23 , à Dunkerque une trentaine de mètres ". A Furnes, ils se réduisent à 18 mæ0; 30 mètres; a Coolkerko près Bruges, le sondage s'est arrêté aprìs en avoir traversé $\left.17^{\mathrm{m}}, 50\right)$. A Watervliet, les sables flandriens atteindraient 18 mètres; à Schoondijke, une dizaine de mètres ; à Sluiskil, plus de 20

1 Pour les chiffres de ces sondages, voir: Vercoustre, Sondage à Hourbourg, (Ann Soc. geol. N., VI, pp. 34-35); - Rntot, Note sur quelques points nouvealux de lit gèologie des Flandres, pp.296-313; - Les Origines du Quaternaire de la Belgique, p. 12; - De Brouwer, Le puits artésien des Aciéries de Terneuzen; - Lorie (J.), Sondages en Zèlande.

2 Cornet, Etudes évolution, p. 430.

3 Gosselet, Esquisse, Quaternaire, p. 300. 
mètres ; à Terneuzen (Aciéries) $13^{\mathrm{m}}, 50$; à Walsoorden, 15 mètres ; à Flessingue (puits artésien) 14 mètres; à Goes une trentaine de mètres ${ }^{1}$. lin dépit de quelques irrégularités, ces chiffres prouvent l'épaisseur considérable, 20 à 30 mètres, de ces sables, épaisseur d'autant plus remarquable que sauf aux environs d'Eecloo le quaternaire supérieur, dans le reste de la Flandre, ne dépasse guére quelques mètres.

Ces sables sont généralement gris, très fins, et complètement imbibẻs d'une eau qui s'ócoule dès qu'on les extrait de terre; do là le nom de sables pissarts, que leur donnent les paysans du Calaisis. Cependant ils ne sont pas, sur toute leur épaisseur, complètement homogènes. A Coolkerke, on signale en profondeur des éléments très grossiers, fragments de grès paniseliens, eclats anguleux de silex; en haut, des couches plus argilouses, et un sable très coquillier. A Bourbourg, le sable de base est plus gros, avec coquilles, sur 2 mètres d'épaisseur. A sluiskil, une des couches infẻrieures contient du sable grossier, avec cailloux de quartz et de silex; à Ostende on indique du gravier à la base; à Calais les sables reposent sur une couche de 2 mètres de gros silex. 'Tous ces éléments grossiers et roulés trouvẻs à la base du dépôt semblent indiquer une profondeur d'eau peu considerable. Au contraire à la partie supérieure le sable devient le plus souvent argileux : c'est ce qu'on observe sur $2^{\mathrm{m}}, 70$ à Ostende, $3^{\text {ma }}, 50$ à Blankenberghe, $3^{\mathrm{m}}, 40$ à Sluiskil, $3^{\mathrm{m}}, 60$ à Flessingue (Sondage des Ecluses). Un régime de lagunes se serait donc établi à la fin de la période. En tous cas, toute la masse est marine, comme l'atlestent les coquilles qu'on trouve du haut en bas, et qui appartiennent aux espéces actuelles de la mer du Nord (Curdiurn edule) et à des formes étrangères (Corbicula fluminalis).

Les sables pissarts sont presque partout surmontes d'une couche de tourbe, d'ẻpaisseur très variable, allant de quelques centimètres à 4 mètres. Parfois même le banc est remplacé par quelques linéoles noirâtres, ou do la poudre tourbeuse mêlée à une autre couche, sable ou argile. Il est très rare cependant que la tourhe fasse complétement défaut, si rare que dans ce cas on pcut supposer qu'elle a été enlevée par un ravinement. Sur 26 sondages indiqués dans la Monographie agricole de la région des Polders, 3 seulement n'ont pas rencontré de tourbe ${ }^{2}$; les autres mentionnent des épaisseurs allant de $0^{\mathrm{m}}, 10$ (Avecapelle) a $3^{\mathrm{m}}, 50$ (Cleemskerke). A Ostende on en trouve $1^{\mathrm{m}}, 3 \mathrm{o}$; a Blankenberghe, 2 mètres. Dans la partic française, la plupart des sondages l'ont atteinte et traversée sur des

1 Références indiquées, p. 138, note 1.

2 Monographie agricole de la région des Polders, pp. 6-7. 
épaisseurs analogues. Les forages zélandais l'ont trouvée sur 2 mòtres à Flessingue, $0^{\mathrm{m}}, 10$ à Sluiskil, $1^{\mathrm{m}}, 60$ entre Sluiskil et Terneuzen, $2^{\mathrm{m}}, 50$ aux Aciéries de Terneuzen, même 6 mètres à Schoondijke; à Walsoorden, ce n'étaient plus que quelques miettes. Ians l'île de SudBeveland, l'épaisseur varie de 1 mètre à $2^{m}, 50{ }^{1}$. La tourbe se retrouve en général sous la ligne des dunes, et jusque sur l'estran, au moins a l'Est do Dunkerque; parfois les tempêtes et les fortes marées la mettent à nu, on la débarrassant des sables de la plage, et il n'est pas rare de trouver dans les laisses de mer des fragments roulés, qui forment de véritables galets tourheux.

Cette tourbe semble s'être formée daris des marais plutôt que dans des eaux courantes, car les coquilles fluviales y sont rares. Ello se compose surtout de débris végétaux, fenilles de joncs, racines, mousses; les typhas et les prêles y dominent ${ }^{2}$. J)e grandes crevasses verticales, remplies d'argile on de sable, parcourent la masse. La grande curiosité, du temps où l'on pratiquait le tourbage, c'étaient les troncs d'arbres qu'on y trouvait couchés, la tête entre le Sud et l'Est: ordinairement des chênes, mais aussi d'autres essences qui indiquent un climat analogue au nôtre: frêne, noyer, sapin, sorbier, bouleau, saule, buis, noisetier. Enfin c'est là que se trouve le niveau archéologique qui a permis de fixer l'époque à laquclle la tourbe a été recouverte par la mer; et pêle-mêle avec les poteries et les monnaies, des restes d'animaux qui sont ceux que nous voyons vivre encore sur le sol flamand. L'on rencontre parfois deux couches de tourbe superposées: dans les polders qui avoisinent Anvers, les sables gris-bleuâtres du flandrien sont surmontés d'un banc appelé le « moergrond », sorte d'argile tourbeuse indiquant une période de marais, où la croissance des mousses et plantes aquatiques a été interrompue par quelque invasion du fleuve, qui a déposé une argile grise, le «duy » des paysans. Au-dessus la végétation productrice de la tourbe s'est de nouveau développée, formant un nouveau banc, épais parfois de 2 mètres, ol dans lequel on a retrouvé le niveau archéologique des monnaies et des poteries. Le tout est recouvert d'argile polderienne ${ }^{3}$. Ailleurs, la tourbe se retrouve au-dessus de la couche marine d'origine moderne, c'est-ád-dire à 1a surface du sol; c'est le cas du puits de Flessingue, où l'on a 2 mètres de tourbe à la profondeur de 6 mètres, et 1 mètre de tourbe mêlée de

1 Lorié, Sondages en Zélande, p. 204.

2 Gosselet, Géographie physique, p. 20.

3 Van Ertborn (O.), I es terrains modernes et les découvertes récentes du Kattendjjk. (Bull. Soc. Géogr. Anvers, 1884). 
sable à 1 mètre seulement au-dessous de l'orifice ${ }^{1}$ : celle-cri s'est vraisemblablement formèe dans un marais de l'époque actuelle. Le cas semble se présenter aussi dans la partic française, où les pures eaux courantes qui descendent des hauteurs crayeuses entretiennent, de l'Aa à Sangatte, une active végélation propre à la production de la tourbe. La même végélation tourbeuse moderne se retrouve en Hollande, et jusque dans les marais de Dol.

Au-dessus de la tourbe s’ètendent les couches les plus caractéristiques du littoral, less dépôts laissés par l'invasion marine contemporaine de l'époque romaine. lls ne constituent pas une roche homogène, mais un mélange ou une superposition desables et d'argiles. L'argile grisc ou bleuâtre (argile des Polders), plastique, avec Iydrobia ulvae; le sable blanc, assez grossier, contenant de nombreuses coquilles marines, se répartissent assez irrégulièrement dans la Plaine. A Frethun, $0^{\mathrm{m}}, 30$ de sable jaune fin surmontent $0^{\text {m }}, 35$ d'argile blenâtre ${ }^{2}$. $\Lambda$ Craywick, 1 mètre d'argile plus ou moins sableuse repose sur du sable jaune ou bleu, parfois sur de l'argile ${ }^{3}$. Aux Moëres, on trouve sous quelques décimètros de limon brun soit du sable marin coquillier, soit de l'argile. A Furnes, c'est une argile finement sableuse sur $1^{\mathrm{m}}, 60^{\mathrm{s}}$; à Ostende, de l'argile, puis $3^{\mathrm{m}}, 20$ d'alternances de sable el d'argile; à Slykens, de même; à Coolkerke, du sable jaunâtre (2 mètres) sur du sable gris $\left(4^{\mathrm{m}}, 75\right)$; à Schoondijke, 4 mètres d'argile; $\dot{a}$ Walsoorden $3^{\mathrm{m}}, 70$ d'argile sableuse sur $2^{\mathrm{m}}, 10$ de sable quartzeux très fin ; à Goes, $5^{\mathrm{m}}, 50$ d'argile sableuse à Cardium; à Flessingue, jusqu'à 6 couches au-dessus de la tourbe, argile, sable, et éléments intermédiaires. Ein général, c'est sur les parties élevées de la surface tourbeuse que semble s'êl'e déposée l'argile, el dans les fonds les sables ${ }^{6}$...... sauf exceptions, comme le cas signalé dans les marais d'Ardres, oú le sable ravine l'argile ', et est lui-même surmonté d'une nouvelle couche argileuse.

Ces dépôts variés sont tous d'origine marine; on y trouve exactement la même faune quesur les plages de la mer tlamande. Le Cardium edule, si commun dans la mer dı Nord, abonde dans les sables; le sable argileux

1 Rutot, Origines du Quaternaire, pp. 14-15.

2 Debray, manuserits inédits.

3 Debray, in Ann. Soc. géol. N., III, p. 88.

4 Gosselet, Géogr. physique, p. 22.

B Dewalque, Note sur le sondage de Furnes. (Ann. Soc. géol. Belg., V, 1877-78, p. (CVIII).

6 Gosselet, Esquisse, Quaternaire, p. 327.

7 Debray, Ann. Soc. géol. N., III, p. 88. 
recèle surtout 1a Scrobicularia plana; l'argile proprement dite, l'Hydrobia ulvae. On a même trouvé, dans les fondations du pont sur le MardyckGracht, blabli pour le passage de la voie ferrée de Bourbourg à Dunkerque, 3 vertébres de la baleine des Basques ${ }^{1}$. L'argile des polders, c'est-á-dire celte couche argileuse si commune dans la plaine marilime qu'elle en carectérise le sol, est assurément unéformation marine. Ia présence dans cette argile des mollusques qui vivent dans les mers yoisines en est une preuve snffisante; et les quelques formes fluviatiles qu'on y rencontre parmi les Diatomées sont si rares tant comme individus que comme espéces, que ce sont à coup sûr des animaux entraînés de l'inlérieur des terres; au contraire les Diatomées marines y sont si abondantes qu'elles constituent parfois le cinquième, voire le quart de la masse 2 . Il y a cependant une exception: les marais de St-Omer, c'est-à-dire la région basse, à l'altitude moyenne de 6 métres, qui ressemble tant à la plaine maritime par son sol plat, ses canaux, son humidité, que peu

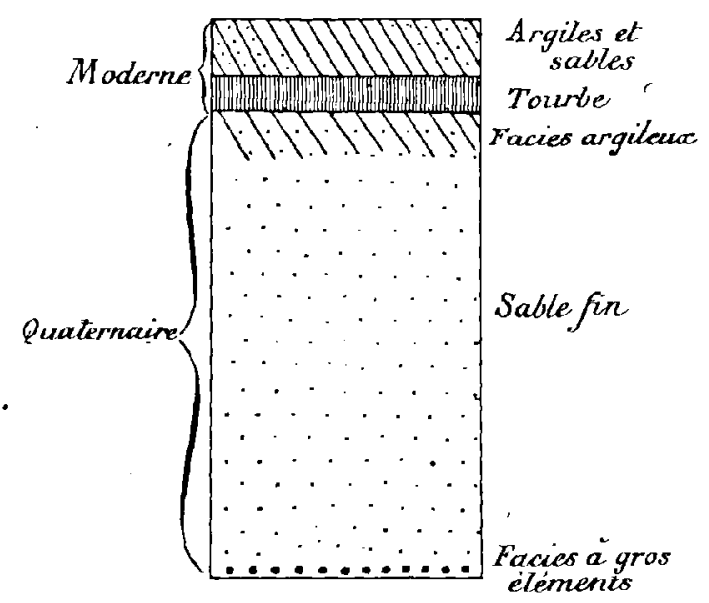

FIG. 30. - Coupe théorique des terrains propres à la plaine maritime. d'auteurs ont résistẻ à la voix populaire, qui déclare que la mer est venue jadis jusqüà SaintOmer. On a cependant montrẻ dès 1871 que si l'on $y$ trouve une couche de tourbe qui continue celle de la Plaine, le dépôt de limon rougeâtre ou noirâtre qui la recouvre n'est pas d'origine marine, puisqu'il est rempli de coquilles d'eau douce. Il est même bizarre d'y entendre appe-

ler fond de mer un gravier de grains de calcaire concrétionné, d'origine fluviatile ". La mer n'a donc jamais dépassé vers le Sud l'espèce de défilé, large de quelque 500 métres, par lequel les marais de St-Omer rejoignent la plaine maritime à Watten.

1 Debray, Ann. Soc. géol. N., III, p. 88.

2 Deby (J.), Note sur l'argile des polders, saivie d'ıne liste de fossiles qui y ont été observés dans la Flandre occidentale. (Ann. Soc. malac. Belg., t. XI, 1876, pp. 69-9)(1).

3 Gosselet, Esquisse, Quaternaire, pp. 323 et 327. 
L'argile des polders est le dernier terme de la série particulière à la plaine maritime, dont elle forme le sol. Aucun autre sédiment ne s'y est déposé depuis que la mer l'a abandonnée, sauf la tourbe des marais d'Ardres ou de quelque autre liou bas. Les inondations qui ont désolé la plaine émergée n'y ont apporté encore que des sables el surtoutde l'argile. Il est donc possible de résumer les indications précédentes en un tableau qui serait une coupe théorique du sol de la plaine, dans laquelle on peut évaluer à 25 mètres lépaisseur des sables flandriens, à 2 mètres celle de la tourbe, à 3 mètres celle des couches marines modernes.

\section{Date de l'inondation.}

Ces données géologiques permettent de reconstituer à grands traits l'histoire du pays. A la fin da quaternaire supérieur, la mer occupe l'emplacement de la Plaine maritime, el y dépose les 25 mètres de sables pissarts. Les éléments sablo-argileux qui forment la partie supérieure du dépôt indiquent un régime lagunaire ; la mer, à la fin du quaternaire, abandonne la plaine; les eaux doucos envahissent la lagune, et la végétation spécjalo des tourbières s'y établit. Le pays va devenir habitable: lorsque le marais tourbeux est mûr, des plantes arborescentes se fixent sur le sol tremblant; les arbres, chênes, hètres, sapins, noisetier's, s'y développent ; ils y forment, le long de la lisière méridionale de la Plaine, un peu abritèe des vents de mer, de véritables forêts ; ils y meurent de vieillesso, ot les vents d'Ouest font tomber leurs troncs dans la direction de l'Est. L'homme finit par y apparaître, attiré sans donte par la présence des oiseaux de marais; il y laisse quelques traces de son passage, haches polies, pointes de flèches, qui attesteront sa présence. Plus tard les populations des époques celtique el gallo-romaine s'y établissent, comme le prouvent les poteries, les ornements funéraires, les trésors qu'elles ont abandonnés sur lo sol. C'est la plaine de la tourbe que foulérent les soldats de César et de Labienus. Le général romain a été bref dans sa description : les Morins et les Ménapiens habitent un pays plein de forêts et de marais, derrière lesquels ils sabritent; deux expéditions ont été nécessaires pour parvenir au cour de ce pays inondé ${ }^{1}$. Strabon a été un peu plus explicite. « Les Ménapiens, dit-il, babitent de petites îles dans les marais.

1 «Continentes silvas ac paludes habebant" (I) Bello gallico, III, cap. XXVIII, 2). « Perpetuis paludibus silvisque muniti " (Ibid., VI, cap. V, 4). «In silvas paludesque confugiunt $D$ (Ibid.). 
Ils avaient là, dans les pluies, des refuges assurés; mais en tomps sec on les y prenait aisément »1. Forêts, marécages; la plaine restait à deminoyée, la menace d'une nouvelle invasion marine pesait sur elle.

Ia présence des sables et argiles d'origine marine, superposés a u niveau archéologique de la tourbe, prouve que cette inondation a recouvert toute la plaine vers la fin de la domination romaine. Il est possible d'en fixer la date avec quelque précision. Depuis longtemps on avait resnarqué que les plus récenles sóries monétaires trouvées dans la tourbe s'arrêtaient toutes aux empereurs gaulois, Posthumus et Tetricus. C'est le cas à Salperwick, où les dernières en date des pièces sont de Quintillus; à Ardres, à la Panne, où la série s'arrête aux monnaies de Posthumus; à Lomburg (Walcheren) où la dernière médaille est à l'effigie de Tetricus ${ }^{2}$. On a donc admis que l'invasion marine s'était produite postérieurement au règne des empereurs gaulois, dont le dornicr, Tetricus, disparaît en 273. Cependant la disparition des médailles postérieures à l'année 273 ne prouve pas que l'inondation se soil produite immédiatement aprés cette époque. Én effet l'absence de monnaies datant d'après Tetricus est un fait général en Flandre. Vredius l'avait déjà ramarqué: dans la Flaudre entière, la plupart des séries monétaires s'arrêtent à Posthumus ${ }^{3}$. A poine pent-on citer 20 localités flamandes, presque toutes situées le long de l'Escaut el de la Lys, où l'on ait trouvó des médailles romaines plus récontes que celles des empereurs gaulois ${ }^{3}$. Il semble que peu aprés la chute de cette dynastie locale, un véritable calaclysme se soit abattu sur la Flandro, quelque brusque invasion de Barbares, à l'approche desquels les habitants enfouissaient leurs trésors, et qui dévastèrent si complétement le pays que la population disparut, excopté sur les bords de la Lys et de l'Escaut. M. Kurth flace cette catastrophe dans la période de troubles qui suivit la mort d'Aurélien ${ }^{5}$. Ainsi l'absence do médailles postérieures à l'année 273 ne prouverait pas que l'inondation marine est la cause de cette lacune, puisquo cette pénurie est commune à la Flandre entière. U’ailleurs on a

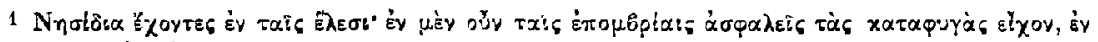

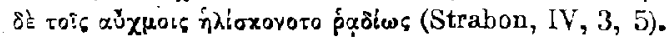

2 Cf: Rigaux, Etude sur la topographie, p. 30 ; - De 13ast, Recueil, I, p. 301; de Loë, Fouilles à la Panne, p. 6.

3 Vredius, Flandria Ethnica, pp. 642-643.

1. Le Recueil de de Bast, (I, pp. 490-494) en indique 10: Meerlebeke, Segelsem, Melden, Velsicque, Gassel, Gand, Lokeren, St-Nicolas, St-Denis-Westrem, Audenarde. - M. Van Dessel ajoute à la liste : Belcele, Melle, Waesmunster, Killem (Statistique archéologique, passim).

$\because$ Kurth (G.), Clovis, I, pp. $23-260$. 
déconvert çà et là dans la plaine maritime des médailles postẻrieures à l'osthumus, dont la trouvaille a échappé à la plupart des érudits: à Sangatte une médaille de Constantin le Grand ${ }^{1}$; à Calais, une pièce à l'effigie de Maximien " ; dans les tourbières de Iames des monnaies de Dioclétien, Maximien et Constantin ${ }^{3}$; à Damme, des effigies de Totricus, Victorinus, Constantin et Maxence * La date de l'invasion marine se trouve donc reculée jusqu'après la mort de Constantin le Grand, c'est-àdire après 337 . On pouvait déjà se rapprocher de cette date rien qu'à lire le panégyrique adressé vers 300 au césar Constance Chlore à l'occasion de sa lutte contre Carausius par un rhéteur que l'on croit être le Gaulois Eumène. Ce pays des Ménapiens " qui mérite peu le nom de terre, mais est tellement imbibé par les eaux que non seulement dans les parties marécageuses il cède aux efforts et se dérobe sous nos pieds, mais, dans les endroils même oủ il parât le plus lerme, il frémit sous les pas et semble flotter sur les abimes... $\rrbracket^{5}$, c'est bien la plaine de la tourbe, que la mer ne recouvrait donc pas au début du IVe siècle. Enfin la Notice des dignités permet de reculer jusqu'au Ve siècle la date de l'inondation. Flle mentionne en effet la présence d'un escadron de cavalerie dalmate sur la côte flamande : «quites Dalma ta Saxonicum, c'est la côte défendue contre les Saxons; Marcis a été identifié avec Marck, près Calais; et il se trouve ainsi que vers l'an 100, époque à laquelle on rédigeait ce vaste almanach officiel qu'est la Notice des dignités, la mer n'avait pas encore envahi la plaine au delà de Marck ${ }^{7}$. Il est vrai que l'inondation n'a pas dû tarder à se produire. C'estl'époque où les peuples germaniques envahissent la Flandre et s'y établissent: or ils n'ont pas laissé trace de leur présence sur la tourbe, ce qui donne à croire qu'ils ont trouvé la plaine inondée. L’invasion marine se serait donc

1 Debray, Tourbières, p. 459.

2 Mém. Soc. Ant. Mor., IX, $2^{e}$ partie, p. 341.

3 Notes manuscrites de H. Debray, à la bibliothèque communale de Lille, Catalogue manuscrit, No 138.

4 Macquet (L.), Histoire de la ville de Damme, de ses institutions civiles et politiques

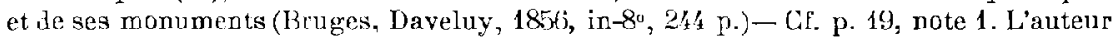
déclare avoir acheté lui-même les pièces, au nombre de 37 .

з XII Panegyrici Latini, (éd. Behrens), VILI, p. 137.

6 Notitia dign. imp. rom., Ed. Börking, II, p. 108.

7 On peut objecter que l'emplacement de Marck, situé sur le banc des Pierrettes, n'a pas étẻ inondé par l'invasion marine. Mais çaurait été pour un corps do cavalerié une garnison bizarre que ce banc isolé par la mer, et élevẻ de 2 à 3 mètres au-dessus des flots. 
avancée sur la plaine au cours des premières années du Ve siècle, en même temps que l'invasion germanique prenait possession des valleses do la Lys et de l'Escaut; le désarroi était complet, et l'on s'explique que personne n'en ail parlét.

\section{Nature de l'invasion marine.}

Ce ful bien une véritable invasion marine qui se produisit. Le dópôt de sables et d'argiles n'est pas le fait d'une simple inondation; il est trop epais et trop continu pour cela; d'ailleurs les mollusques lamellibranches découverts dans ces alluvions marines s'y trouvent avec leurs deux valves, dans la position oú ils ont vécu, verticaux, le crochet en bas, le siphon en haut ". La mer a done séjourné quelque temps dans la plaine, tout au moins dans les dépressions. Il ne semble pourtant pas que son entrée sur cette terre ait été une effroyable catastrophe, comme on le croirait en songeant à la submersion d'un territoire si étendu. L'invasion a dû être lente et continue, car le ravinement de la tourbe ne fut nulle part bien considérable, étant donné le peu de solidité de cette couche. On a même observé que la parlie inférienre des sédiments déposés par l'inondation est parfois formée de petits lits argilo-sableux bien stratifies traversés par des trous où lon trouve encore une tige presque charbonnée, ce qui prouve la lenteur de l'envahissement, pendant lequel la végétation a essayé de lutter en traversant les sédiments marins ${ }^{3}$. Les choses, comme le dit Laveleye, se passérent avec calme ${ }^{4}$; c'était encore une raison pour qu'on n'en parlât pas. Même phénomène, d'après Chèvremont, dans la baie du Mont-St-Michel ; commencée sous l'époque romaine, linvasion marine fut extrêmement lente et n'atteignit son maximum qu'au $V^{\text {e }}$ siècle. Ces inondations navaient rien d'un cataclysme.

1 L'inoffensive phraséologie de St-Paulin de Nole dans une lettre à St-Victrice (Migne, Patrologia latina, vol. 61, p. 239), invoquée parfois pour fixer la date de l'invasion narine, il'apporte aucun renseignement: au pays des Morins, " les chours vénérables et angéliques des fidèles s'élèvent pacifiquement des églises et des monastères, dans les villes et dans los bourgs, an milien des âles et des bois. D Discussion sur cette date de l'invasion marine dans Blanchard (R.), Sur la dato de linvasion marine dans la plaine maritime de Flandre à l'ćpoque historique. (Ann. E. N., I, 1005, pp. 534-541).

2 Gosselet, Gég. physique, p. 23.

3 Gosselet, Esquisse, Quaternaire, p. 328.

4 Laveleye, Géologie (Paris, Lacroix, 1859, 44 p.), p. 18. 
D'ailleurs, étent donnó l'altitude actuelle du niveau de la tourbe, on s'aperçoit que la mer ne devait s'étendre sur toute la plaine qu'à marée haute. Encore faut-il tenir compte de l'affaissement que les couches tourbeuses ont certainement subi sous le poids des nouveaux dépôts marins, et qui en ont abaissé le niveau. Le banc des Pierrettes, près de Calais, offre un autre point do repère. La mer ne l'a pas recouvert, il est resté émergé de 2 à 3 mètres, et cependant les marées de la côte calaisienne atteignent ordinairement 5 m, 30 d'amplitude; or on trouve partout, autour du banc, la surface de la tourbe à moins de 8 mètres au-dessous du niveau des Pierrettes ; à marćo basse, il n'y avait donc plus d'eau sur le sol tourbcux. D'ailleurs la faible épaisseur des couches indique la faible profondeur de la tranche d'eau. Deux fois par jour, la mer venait donc recouvrir la plaine maritime, et s'y décantait; deux fois par jour, la plus grande partie du territoire se retrourait à sec. Alph. Belpaire avait même calculé, d'après le rapport entre l'épaisseur des sédiments déposés et le temps que la mer avait dû occuper la plaine, que les eaux salées ne visitaient guère leur conquête que 2 a 5 fois par an, probablement dans les grandes marées d'équinoxe ${ }^{1}$. Belpaire se trompait sur l'un des termes du rapport, car il évaluait à 12 siècles le séjour de la mer dans la plaine, tandis que les documents historiques publiés depuis 50 ans permettent de réduire à 4 siècles environ la durèe de l'inondation ; mais il est vrai que la mer ne recouvrait pas constamment la plaine, et qu'elle ne pénétrait peut-être dans tous ses recoins que lors des marées de vive eau. Il faut faire exception pour les chenaux que la mer s'était creusés au milieu de la plaine tourbeuse, ot qui gardaient probablement de l'eau à marée basse, de même que dans un polder qu'elle vient d'envahir, la mer approfondit une crique sinueuse par laquelle la marée pénètre et sort.

Au milieu de l'inondation, il est resté dans la Plaine quelques parties émergées. Il exisle dans le Calaisis, dépassant de quelques mètres le niveau des alluvions modernes, quelques ondulations formées de galets que l'invasion marine a respectées. L'uno d'elles, qui porte le nom significatif łes Pierrettes, sétend de Nieulay à Marck, ses éléments devonant de plus en plus fins vers l'Est; les galets disparaissent après Marck, de même que sur la côte actuelle ils ne dépassent guère Calais, mais les hautes terres continuent vers Oye, dans la direction de l'Aa, et derriére Gravelines on en retrouve d'autres qui se dirigent vers Dunkerque par Loon et Synthe. An Sud de cette première ligne s'en

1 Belpaire (Alph.), La plaine maritime de Boulogne au Danemark, pp. 130-131. 
amorce une seconde au pont de Coulogne; c'est encore un banc de galets formant un monticule d'environ 4 mètres, très visible du canal et du chemin de fer de St-Omer à Calais; on l'appelait jadis l'île de Colne ${ }^{1}$. Sa direction est un peu diffèrente de celle du premier : il s'oriente à l'E.-S.E.; mais sa pointe, comme celle des Pierrettes, regarde vers Sangatte, vers le détroit. Après le village de Coulogne, où le banc porte le nom des

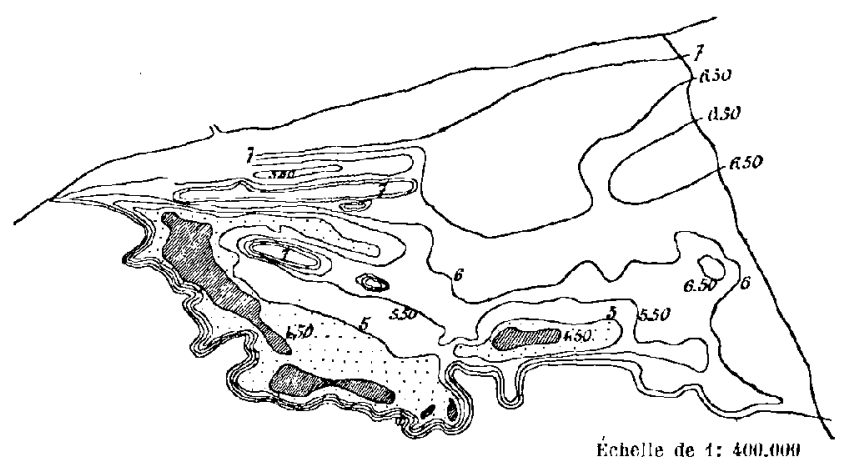

Frax. 31. - Altitudes dans le Calaisis calculées d'apres le zéro des cartes marines.

Bancs des Pierrettes et dé Coulogie.

Hauts - Champs,

le sol s'abaisse légèrement puis se redresse près des Attaques en un deuxième tertre qui vient se terminer aux hautes terres de Guemps. Entin, à l'Est de Dunkerque, levillage de Ghyvelde se trouve sur une éminence sableuse, plus élevée que la plaine d'environ deux mètres, qui commence au Meulhouck de Zuydcoote et se continue jusqu'au village d'Adinkerke. C'est encore là un de ces bancs formés probablement dans la mer flandricnne, et qui ressemblent aux levées de galets des Bas-Champs de Picardie; respectés par l'invasion du Ve siècle, ils ont offert aux habitants revenus dans la plaine les premiers emplacements favorables à un établissoment humain.

I'autre part, il a existé sur l'emplacement actuel de la côte un autre territoire émergé, dont il est difficile de définir l'étendue, mais qui comprenait en tous cas un petit rayon de pays autour de la frontièro franco-belge, dans les dunes entre la Panne et Bray-Dunes. On a trouvé là, à 200 mètres à l'Fst de la frontière, une station archéologique contenant des objets qui se rapportent à toutes les époques entre l'âge de la pierre polie et le VIII siècle de notre ère: silex, poteries du premier âge du fer, monnaic gauloise, poteries romaines, médailles d'Hadrien, Faustine jeune et Posthumus, fibule barbare, denier mérovingien en

1 Au XVo siècle, d’après Landrin (G.), Essais historiques sur le Calaisis depuis les temps les plus reculés jusqu'à la fin du XVIe siccle (Calais, Ve Gontier, 1889, in-8ª 128 p.), p. 80. 
argent, sceattas anglo-saxons ${ }^{1}$. Ainsi ce point parait avoir étẻ habité d'une façon constante jusqu'au VIII siècle au moins; il faisait donc partie d'une terre émergèe au $V^{\text {e }}$ siècle. Peut-être était-il un tronçon d'une ligne de dunes qui protégeait la plaine de la tourbe et que la mer aura rompue à la fin du IVe siècle. Au delà vors l'Est, on ignore s'il y avait encore des bancs hors de l'eau, et quelle était leur position, quoiqu'il paraisse infiniment probable que d'autres fragments fussent étendus dans cette direction, jusqu'à l'estuaire de l'Escaut: il n'y a guère à faire fonds sur une tradition populaire qui veut que le plateau sous-marin de Schooneveld, au large de l'estuaire, ait été une terre habitée qui possédait encore un château à l'époque de Guy de Dampierre ${ }^{2}$. Vers l'intérieur des terres, l'inondation marine entourait quelques îles, cernait des presqu'îles. La petite élévation qui porte le village d'Holque, à la tête du delta de l'Aa, était préservée des flots; le mont St-Winoc, devenu Bergues, tenait par un isthme au continent. Ia mer pénétrait largement dans le golfe de l'Yser, où elle ne respectait qu'un îlot à l'Est de Loo. Vers Ghistelles, elle dessinait une baie assez profonde, à l'entrée de laquelle s'élendait l'île de Zevecote. Enfin tout à l'Kst elle détachait du continent les lambeaux de St-Kruis, Zuiddorpe, Kieldrecht et Meerdonek. Aujourd'hui encore on reconnaît ces anciennes îles au premier coup d'ocil. Au milieu de la plaine poldérienne nue, champs immenses sans arbres et presque sans maisons, on voil apparaître un îlot de verdure, des haies autour de chaque champ, des rangées de saules et de peupliers entourant de nombreuses petiles maisons qui contrastent par leur nombre, leurs dimensions restreintes, leur aspect pittoresque et pauvre, avec les rares grandes fermes du polder.

Dans ces conditions, la plaine flamande inondée devait singulièrement ressembler à une rẻgion encore aujourd'hui submergéc, les Wadden de la Frise. Mêrnes îles de sable allongées vers le large, même étendue vaseuse tour à tour asséchẻe et noyée, découpée par d'innombrables criques et chenanx. 1 marce basse, une vaste plaine grise, couleur sale, avec des paquets d'herbes marines jetés çà et lá ; une surface inégale, parsemée d'une quantité de petites bosses, pareilles à des vagues figées; des nuées d'oiseaux s'abattant sur les flaques, goëlands, barges, hirondelles

1 De Loë, La Station de la Panne, passim.

" Van Vaernewijck (Historie van Belgie, ẻ. 1619, IV, p. 34), rapporte qu'il a vu (XVIo siècle) à Sluis des pierres tombales apportées de lîle de Schoonoveld, laquelle existait encore au temps de Guy de Dampierre. Cependant aucun document historique n'attesto l'oxistence de cette île an XIIle siçcle. 
de mer. Puis le flot reparaîl, l'eau remplit les chenaux, pénètre par toutes les rainures, déborde rapidement sur la plaine; d'un désert grisâtre et aride elle fait en peu d'instants un vaste détroit aux eaux vaseuses, séparant la côte des îles basses qui semblent des vaisseaux à l'anci'e; et pour quelques heures, la plaine est redevenue une mer. ${ }^{2}$.

Alors pendant quelques siècles, lhistoire dn pays reste comme suspendue; la plaine est livrée à la mer, qui y prépare les magnifiques terres fortes dont le sol est aujourd'hui formé. Les documents qui permettent désormais d'évoquer les vicissitudes du pays changent de caractère: jusqu'au Ve siécle on ne pouvait guère s'appuyer que sur des données géologiques et archéologiques; à partir du VII', il s'agit surtout de commenter des texles historiques. A coup sûr un grand nombro restent encore cachés dans les dépôts d'archives; à leur défaut on ne peut qu'essayer, à l'aide des documents publiés, de dessiner les grands traits de cette lutte entre la terre el l'eau, d'ou sortit la plaine maritime ${ }^{2}$.

1 Gr. Winkler, Considérations géologiques (Arch. Musée Teyler, V, 1880, pp. 10-72, 1 carte).

2 C'esi sur les documents écrits qu'il faut s'appuyer, et non sur les cartes de l'état du pays aux différents siècles. Les fameuses cartes de la Flandre au XIII siècle, conservées aux Archives de la Flandre Orientale à Gand, et qui procèdent toutes d'un même type, ne méritent aucune confiance. Naïvement, elles tracent les cours deau du Franc suivant lour direction actuelle, mais n'osent pas les pousser plus loin que l'endroit ou ils rencontrent aujourd'hui la mer, tandis qu'elles dessinent la côte beaucoup plus loin au large. On no pent guère accorder quelque confiance qu'aux cartes dı pays dopuis le XVI ${ }^{\beta}$ siècle. Excellent catalogue dans : I)ejardin (A.), Cartes de la Flandre ancienne et moderne, plans de la ville de Gand (Gand, Hebbelynck, 1867, in-80, 220 p.). Pour les cartes de Flandre depuis le XVIe siecle, on pent y joindre les figures de louvrage de Sanderus (Flandria Illustrata), et de Smallegange (Cronyk van Zeeland), la carte de Mercator, celle de Pourbus, les atlas de de Wit (Nieut kaerte-boeck ran de XVII Nederlands Provincie, Amsterdam, bij Fred. de Widt, s. d.), Sanson (Atlas nouveau du voyageur pour les 17 provinces des Pays-Bas, Amsterdam, Mortier, s. d.), Fricx (Table des cartes des Pays-Bas et des frontières de France, Bruxelles, Fricx, 1712, 79 c.), la belle carte topographique de Ferraris, etc.

Les principaux travaux à consulter sont: Gućrard (B.), Cartulaire de l'abbaye de St-Bertin [Cartulaires de Folcuin et de Simon]. (Paris, 1840, in-4"); - Haigneré et Bled, les Chartes de St-Berlin d'apres les cartulaires de dom de Witte (St-Omer, 1886-89, 4 vol. in-4 ${ }^{\circ}$; - Pruvost (A.), Chronique et Cartulaire de l'ablaye de Bergues St-Winoc, de l'ordre de St-Benoit (Bruges, 1875-1878, Soc. d'Em., 2 vol. in $-4^{\circ}, 883$ p.) ; - Van Lokeren, Chartes et documents de labbaye de St-Pierre au mont Blandin (Gand, 1871, 2 vol. in $4^{\circ}$ ); - Van de Putte (F.), Arnales abbatiae S. Fetri Blandiniensis (Gand, Anuoot-Braeckman, 1842, in-4\%, 208 p.); - Cronica et Cartularium monasterii do Inunis (Bruges, Soc. d'Em., 1864, in-40, XIX + 1054 + 23 p.); Aussely et Molitor, Cartulaire de l'ancienne églie collégiale de Notre-Dame de Courtrai 
II.

\section{ASSECHEMENT DE LA PLAINE : Vo-XII SIHCLES.}

Du V॰au milieu du VII siècles, depuis l'apparition de la Notice des dignités (vers 400) jusqu'à l'année 648, soit pendant 250 ans, c'est la nuit complète. La mer travaille silencieusement dans les Wadden flamands. Il semble que le desert se soit fait jusque sur les bords de la plaine inondeo. Pas de mention de villages sur cette côte : les habitants ont peut-être fui, craignant que la mer ne continuât son lent mouvement d'invasion. Derrière le rideau de forêts qui va d'Anvers à Dixmude, par le pays de Waes, le Meetjesland, les bois et bruyères de Thourout et .d'Houthulst, Jes Francs s'établissent dans les vallées de la Lys et de

(Gand, Annoot-Braeckman, 1880, in-4º, 434 p.) ; - de Coussemaker (1.), Cartulaire do labbaye de N.-D. de Bourbourg (Lille, Ducoulombier, 1882-91, 3 vol. in-8a); - Hautcour (E.), Cartulaire de l'église collégiale de St-Piere de Lille (Lille, Quarré, 18Y), 2 vol. in-80); - Gilliodts van Severen (L.), Inventaire des archives de la ville de Bruges (Bruges, 1876, in-10, 1 vol. Introduction, 6 vol. texte, 1 vol, table); - Delopierre (O.) et Priem (F.), Précis analytique des documents que renferme le dépôt des archives de la Flandre Occideritale (Brugos, 1840-1819, 2 séries de 3 et 6 vol. in- $8^{\circ}$ ); - Coutumes des Pays et Comté de Flandre: Quartier de Bruges: Coutumes de la ville de Bruges (Bruxelles, 1874-75, 2 vol. in-4 ${ }^{\circ}$ ); Coutumes du Franc de Bruges (Bruxelles, 1879-80,

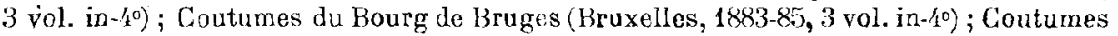
de lił Prévôté de Bruges (Bruxelles, 1887, 2 vol. in-100); Coutumes des Petices villes et seigneuries enclavées (Bruxelles, 1890-92,6 vol. in-40); - Quartier de Furnes : Coutumes - (lo la ville et chatellenie de Furnes (Bruselles, 1897-98, 4 vol. in-4" ) C Coutumes de la ville ef du port de Nieuport (Bruxelles, 1901, 1 vol. in-40); Coutumes de Lombarside, Loo et Poperinghe (Bruxelles, 1902, 1 vol. in-4ㅇ); - Kluit, Historia critica comitatus Hollandiae et Zoelandiae ab antiquissimis inde deducta temporibus (Medioburgi, Gillissen, 1777-82, 2 vol. in- $4^{\circ}$ ); - Dresselhuis (J. ab Ltrecht), De Provincie Zeeland, in hare aloudo gesteldheid en geregelle vorming beschouwd (Middelburg, Abrahams, $1836,1 \mathrm{~V}+151 \mathrm{p}, 1$ carte) ; - Roos ((x. P.), Beknopt geschied-en aardrijks-kundig w oordenboek van Zeeuwsch-Vlaanderens weestelijk deel (Oogtburg, Bronswijk, 1874, in-8०, 224 p.); - Haigneré (D.), Dictionnaire topographique de la France comprenánt les noms de lieu anciens et modernes : Arrondissement de Boulogne- s/mer (Mém. Soc. Ac. Boul., XI, 1882, CXLI + 392 p.); - Courtois (A.), Dictionnaire gẻographique de l'arrondissement de St-Omer avant 1789 (Mém. Soc. Ant. Mor., XIII, 1869); Mannier, Etudes étymologiques historiques et comparatives sur les noms des villes, bourgs et villages du département du Nord (Paris, Aubry, 1861, in-8 $8^{\circ}, 355$ p.); Chotin (A.-G.), Etudes étymologiques sur les noms de lieu de la Flandre occidentale (Ann. S. H. Ypres, VII, 1876, pp. 185-328 et VIII, 1878, pp. 1-59); - De Sinct, Essai sirr l'étymologie des noms do villes et communes des deux Flandres (Mém. Acad. Brux. XXVI, 1851, 41 p.). 
l'Escaut; ils ne se risquent pas plus à travers cette solitude boisée que dans les fourrés de la Charbonnière. Ce n'est qu'au VII' siècle que des établissements humains sont indiqués le long de la côte: Sithiu, le futur St-Omer, est occupé en 648 par St Bertin ${ }^{1}$; Oudenbourg, la « vieille forteresse », reçoit la visite de St Eloi ${ }^{2}$; Bruges s'élève peut-être déjà au fond de l'estuaire du $Z$ win. On ne pouvait espérer trouver des habitants dans la partie ẻmergée de la plaine tantque l'homme ne serait pas revenu sur ses bords. Il ne reste guère de cette époque qu'un témoin archéologique: un bateau trouvé près de Bruges, sous trois mètres de sédiments, et dont on fait un bateau saxon du $\mathrm{VI}^{\bullet}$ siècle, échoué dans une crique des Wadden ${ }^{3}$.

Pendant ces 250) années, la marée poussait aclivement le comblement de la région inondée. Elle dóposait ces petits lits argilo-sableux bien stratifiés que MM. Gosselet et Rutol ont reconnus à la base des depôts modernes. Etant donné la faible épaisseur de la tranche d'eau et les conditions spéciales de l'inondation, le comblement devait se faire rapidement, à l'abri des îles qui constituaient des brise-lames derrière lesquels les flots pouvaient se décanter tranquillement. Pour que des localités pussent apparaître, comme on le verra, dès le début du IX ${ }^{\ominus}$ siècle au beau milieu de la plaine, il faut que l'envasement ait été rapide, car il dut s'écouler encoro bien des années avant que des habitants osassent se risquer sur un sol tout neuf, qui restait à la merci des hautes marées. Aussi, tandis que le sable continuait à se déposer dans les chenaux, des sédiments de plus en plus fins s'accumulaient sur les parties élevées, formant cette argile grise romplie d'Hydrobia ulvae que l'on trouve à la partie supérieure des couches de la plaine, et qui constitue la plus grande partie de son sol. Bientôt ces dépôts argileux, que les paysans zélandais appellent blikken parce qu'on voit luire au soleil la grève laissée á sec, furent assez èlevés pour que les plantes marines pussent commencer à y croître; à leur suite l'herbe paraît lorsque l'eau salée n'inonde plus le sol que pendant un quart du temps de la marée, et l'on oblient ces prés marins que l'on appelle des schorres, vastes laisses de mer couvertes d'une végétation épaisse, aux couleurs gris et vert sombre, coupées d'un lacis de criques tortueuses. Ainsi le bras de mer s'envase de lui-même, et finit par accumuler ses alluvions jusqu'au-dessus du niveau des bautes marées; la plaine a donc pu sortir do la mer sans qu'il y ait besoin

1 Iaigneré, St-Bertin, I, p. 1, no 1.

2 Act. SS. Belg., III, p. 229.

3 Jonckheere, L'Origine de la còte, $2^{*}$ partie. Surtout pp. 8-11 et 14-15. 
d'expliquer l'assèchement par une oscillation du sol. Aujourd'hui encore, la plus grande partio de ce sol n'est guère qu'à la hauteur des hautes mers; sans les digues et les dunes, elle pourrait être inondée par quelques grandes marées.

Aussi, par crainte de ces retours offensifs, les premiers hommes qui s'aventurèrent à mener leurs moutons sur les pâturages des schorres prirent-ils la précaution d'élever çà et là des tertres de refuge, buttes qui atleignent de 7 à 10 mètres de hauteur' en Zélande, et où l'on peut s'établir pour laisser passer la marée; ce sont les Terpen ${ }^{1}$. La mer est revenue visiter la base des terpen, puisqu'on ne voit plus trace à leur pied des excavations où on a pris les matériaux de la butte, ce qui indique que la marće les a comblées. Un de ces monticules de refuge se voit encore prés de Steene (Belgique), et porte le nom do de Stelle ${ }^{2}$; on en a fait explorer un autre à Vlisseghem ${ }^{3}$.

\section{Les premieres localités : VII $-\mathbf{X}^{\mathrm{e}}$ siècles.}

A partir du milieu du VII siécle, des noms de localités commencent à apparaître dans la plaine maritime, fournis par les cartulaires des grands monastères, St-Bertin, St-Pierre, St-Bavon, ou par les vies des saints. Ces données sont d'un maniement délicat. I a présence d'un nom de lieu à telle date prouve seulement que la localité existait à cette date, mais n’indique pas à quelle époque elle a commencé d'apparaître. En général, on peut cependant tenir pour certain que les données fournies par ces cartulaires sur l'époque approximative où apparaissent les localités ont de la valeur; on peut s'en assurer en comparant les dates données pour les villages des bords de l'Escaut et pour ceux de la plaine maritime ; entre 700 et 1050 le cartulaire de St-Pierre de Gand mentionne environ 80 paroisses de la Flandre intérieure, contre 15 de la région

1 G. Mathieu, Sur les buttes de terre de la Zélande (Mém. Soc. antiq. France, II, 1820, pp. 143-154); - Cumont (G.). Les tertres de refuge de la Zélande (Ann. Soc. Arch. Brux., XII, 1899, pp. 219-229); résune un bon article de loe Man, paru dans les Archives de la Société zélandaise des Sciences, sur les collines ou tertres de refuge de Schouwen, Beveland et 'Tholen (Middelburg, Altorffer, 1897, in-8 $8^{\circ}, 142$ p., 1 carte).

2 De Loë (A.), Rapport sur les fouilles exécutées par la Soc. d'Arch. do Bruxelles pendant l'exercice 1900 (Bruxelles, Vromant, 1901, 23 p.), p. 15.

3 De Loë (A.), Rapport sur les fouilles de 1894, pp. 9-10. 
poldérienne, tandis que la proportion se renverse après le IX siècle ${ }^{1}$. Il reste, il est vaai, la crainte que la découverte d'une pièce nouvelle ne vienne bnuleverser des résultats qu'on croyait acquis ; il faut donc tenir ces données pour provisoires, et s'attacher surtout aux ensembles.

A l'année 648 apparaissent donc à la fois I.oon et Synthe, réunies clans le vocable Losantanas ", que tous les érudits identifient avec «Loon ad Sontenas ${ }^{3}$; d'ailleurs l'abbaye de St-Bertin possédait en effet drs hiens à Loon, qui reparaît en 877 sous la forme Loom ad Sentinas ', en 1040 et 1075 (Lho et Lon ) ${ }^{5}$, et est encore indiqué dans des chartes do 1211 et $1212^{6}$. Les parties élevées qui bordent aujourd'hui la mer auraient donc óté peuplées les promières. Constatation confirmée par d'autres textes qui font apparaître aussitôt après Loon les îles de Wulpen ${ }^{\top}$ et de Walcheren. C'est vers 695 que d'après Alcuin, quir écrivait un siècle plus tard la vie du saint, le hienheureux Willibrord fondait une église à Wulpen et abordait dans une île du nom de Walcheren ${ }^{8}$. De même que pour Loon, on retrouve au IX ${ }^{e}$ sic̀cle Walcheren, mentionnée comme une île dans laquelle débarquent les Normands en $837^{\circ}$. Si l'on songe qu'à la mème époque (VII siècle) la station de la Panıe était habitée, et que

1 De même dans les listes que donne le travail de Vlaminck (A. de), La Ménapie et

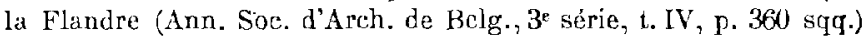

2 Haigneré, St-Bertin, I, p. 1, no 1 .

3 Haigneré, St-Bertin, ibid.; - de Coussemaker (E.), Documents historiques sur la

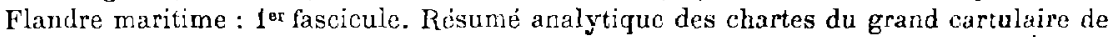
St-Bertin relatives à la Flandre maritime (Bull. Com. fl. Fr., V); - Mannier, Études étymologiques, p. 25; - Rigaux (1l.), Topographie, pp. 196-197;-Rigaux (E.), Quelques noms de lieu du Cartulaire de Folquin (Bull. Soc. Ac. Boul., V, 1891-99, pp. 534-535).

4 Guérard, St-Bertin, p. 124.

s Ibid., pp. 2ty et 32, $\mathrm{II}^{\text {os }} 70$ et 83.

6 Ibid., pp. 226 et 229, nos 516 et 523. Remarquer que jusqu'au XII siecle il n'est pas question de Mardick, situé entre Loon et Synthe, et dont on a voulu quelquefois faire un grand port de lépoque romaine, qui se serail maintenu jusqu'on 1530.

i Il s'agit ici de l'île de Wulpen, disparue aujourd'hui, et dont le banc du Paardemarkt, le long de la cote de Kadzand, semble indiquer l'omplacement. Il n'est nullement question, comme l'a cru Heiuderickx (Jaerboeken van Veurne en Venruam bacht, Ie Deel, p. 34), du village de Wulpen près Furnes, qui paraît sculement au XII' siècle. Cf. Gilliodts van Severen, Coutumes de Furnes, I, p. 25.

8 "Venit ad quamdam insulam Walachrum nonine». (Nigne, Patrologia, Ci, p. T(12). la forme insulam est de Mabillon. Migne érerit « villam ».

9 Annales Bertiniani, anno 837 (M. (G. SS, I, p. 430). La $1^{\text {re }}$ mention des îles de Zélande serait de 6:8, dans le testament de Gertrude, fille de Pépin de Landen (Miraeus, Opera diplomatica et historica, ed. Foppens, I, 1723, p. 654). 
Marck, dont le nom reparaît en $877^{1}$, n'avait peut-être pas cessé de l'être depuis l'an 400, on s'aperçoit que les premières parties habitces furent bien cette ligne de terres hautes que la mer avait fractionnée en un long archipel semblable aux îles frisonnes. Face au large, des dunes avec leur végétation particulière d'argousiers et d'oyats; vers la plaine inondée, des schorres asséchés, coupés d'anciennes criques zigzaguant dans tous les sens, tantôt larges, tantôt étroites et profondes; entre les dunes et les schorres, le village aux maisons jetées comme au hasard, séparées par des pistes de sable et des clôtures de bois, entourées de peupliers et de saules penchés sous l'effort du vent; l'aspect fruste et pauvre d'un hameau de montagne. Ainsi se présentent aujourd'hui les iles frisonnes, Ameland, Schiermonnikoog ; il est probable qu'il en fut de mêne pour les anciennos îles flamandes; et le village actuel de Loon, avec ses petites maisons exiguës, ses jardins enclos de haies et bordès de saules, dominés par des peupliers tordus, son air de bocage poussé dans le sable, ressemble encore à Nos ou Ballum, les villages de l'île d'Ameland ${ }^{2}$ (phot. 18).

Après les îles, de nouvelles terres émergent définitivement verś le Sud, contre le bord de la plaine. Aardenburg est mentionné en $707^{3}$; une tradition vout mème que St Eloi y ait prêchẻ l'Evangile en $649^{*}$; un peu plus loin, la ville d'Oostburg aurait été visitée, entre 700 et 713, par St Ursmar, qui y trouve 400 milites de mours rudes et de passions sauvages ${ }^{5}$. Le territoire entre ces deux villes semble d’ailleurs complètement émergé à la fin du VIII ${ }^{\mathrm{e}}$ siècle : en 793, donation à l'abbaye de St-Pierre du schorre de Cumbescura près d'Oostburg ${ }^{6}$; entre 811 et 870, lo Pagus Rodensis, ou région d'Aardenburg, nous parâ̂t entièrement constitué, avec ses schorres de Vaeke, Locwirde, Greveninge, sur lesquels paissent des troupeaux de moulons, sa rivière de l'Absentia (Eede?), et

\footnotetext{
1 Guérard, St-Bertin, p. 12't.

z I Tapres Chèremont (Les Mourements du sol, etc., pp. 2fi2-268), un ancien bourrelet littoral aurait subsisté dans le golfe du Couesnon inondé an vo siècle, et la s'établit dès le $\mathrm{X}^{\mathrm{a}}$ siècle le village de St-Benoit des Ondes. - Fn Hollande, Je peuplement a commencé également par la région des dunes: ligmont est de 694 , Aikmaar de 878, Haarlem de $97 \%$, avec Nordwijk, Heilo, Sassenheim. (Cf. Kluit, Historia critica, pp. 6-30).

a Van Lokeren, St-Pierre, I, p. 7, no 3.

4 Warnkonig, Flandrische Staats- und Rechts-Geschichio, bis zum Jahre 1305 (Tübingen, 182\%-42, 3 vol. in- $-8^{\circ}$ ), III, p. 25.

¿Vita S. Ursmari, Acta SS. Boll., Aprilis, II, p. 576.

6 Van de Putte, Annales S. Petri BJandiniensis, Chronicon, p.
} 
le bras de mer qui en 840 s'avance encore jusque vers Adegem ${ }^{1}$, à la limile Sud de la plaine.

Mais en même temps, dans tous les coins du pays inondé, et jusqu'au milieu des Wadden, surgissent des villages. $\Lambda u$ Nord de Bruges, Dudzeele existe en $839^{2}$. Dans le golfe de l'Yser, Lampernisse est indiquée en $857^{3}$; plus loin Furnes groupe, vers 860 , quelques habitations autour d'un château destiné à repousser les Normands . Guemps, derrière Coulogne, est signale en $826^{\circ}$; sur son banc de galets, Coulogne paraît en $891^{6}$; il est question de Marck en $877^{7}$; Holque, sur son îlot, est probablement de la même date ${ }^{8}$. Chose intéressante: parmi ces localités, il y en a qui sont établies sur des endroits élevés, asséchés de honne heure ou à l'abri de l'inondation, Holque, Marck, Coulogne, Guemps ; mais les autres sont situces à des altitudes moyennes ou basses (Lampernisse), ce qui semble indiquer que l'assèchement ótait déjà très avancé. D'ailleurs c'est le moment où les bords de la plaine se couvrent de villes et de villages, dont les habitants trouvent évidemment des ressources sur les nouvelles terres émergées: Guînes, Ruminghem, Millam, Drinchaim, Steene, Bergues, Vinckem, Oudenbourg ${ }^{9}$; Bruges est déjà une ville commerçante, où l'on frappe des monnaies à l'effigio de Charles le Chauve.

Il est donc à peu près certain que l'ensemble de la plaine était asséché à la fin du IX siècle. Sans s'arrêter à cette date brutale de 840 que l'on fixe parfois comme la fin de la période de submersion ${ }^{10}$, on peut dire que la région poldérienne est à ce moment sinon habitée, du moins

1 « Res suas supra mare in Addingahim " (Van de Putte, Chronicon, p. 5). Pour les autres noms de liew, voir Chronicon aux pages 76, 78, 79, 80, 81, 82.

2 Van Lokeren, St-Pierre, I, p. 11, n 6.

3 Haignerỏ, St-Bertin, I, p. 13, n 30.

\$ Giliodts, Coutumes de Furnes, 1, p. 25. Cf. dans Guérard, St-Bertin, p. 124: « in Furnis 1, dipl. de 877 .

s Haigneré, St-Bertin, I, p. 10, n 30.

6 Haigneré, Quelques chartes de l'abbaye de Samer. - Mém. Soc. Ac. Boul., XII, p. 98 , note 2 .

7 Guérard, St-Bertin, p. 12h.

8 Ibid.

9 Pour les références, ef. Guérard, St-Bertin, pp. 80-124; Nalou (J.-B.), Chronique du monastère d'Oudenbourg (Bruges, Soc. d'Em., 1840, 2 vol. in-40), I, p. 34.

10 Rutot, Antiquilés découvertes, p. 6 ; Esquisse d'une comparaison, p. 88. 
abandonnée par les eaux. Il n'y en a pas de meilleure preuve que l'apparition, pendant le $\mathrm{X}^{e}$ siècle, d'un grand nombre de localités ${ }^{1}$.

$\mathbf{X}^{\mathrm{a}}$ et $\mathbf{X Y}^{\mathrm{\theta}}$ siècles: Estuaires, digues, dunes.

De l'Ouest à l'Est, on voit surgir en 961 Petresse, le futur St-Pierre-lèsCalais; Oye en 944; Bourbourg entre 987 et 995 ; Teteghem en 964 et Uxem en 981; Loo en 944; Leffinghe en 988, et Testereph, à peu de distance de l'emplacement d'Ostende, en 992. Le groupe du Nord de Bruges prend de l'importince: Meetkerke, Houttave, Vlisseghem, Lisseweghe, Uytkerke, Oostkerke, Lapscheure, apparaissent entre 961 et 988. Le Pagus Rodensis étend au delà d'Oostburg ses prés salés vers ljzendijke et Gaternisse (981) ; l’̂le de Wulpen reparaît. Enfin pour la première fois on soupçonne des terres habitẻes á l'Est d'Aardenburg: au milieu du siecle on mentionne les Quatre-Métiers ; les environs de Watervliet sont signalés en 972; Boterzand, au N.-E. du Braakman, est de 990, Axol de 991, s'il n'est pas de 821 comme l'indiquerait une charte citée par Sanderus. Mais il est probable que beaucoup de ces terres élevées au-dessus des hautes mers n'étaient pas encore habitables. Les eaux douces, s'attardant dans les dépressions, cherchant leur voie sur ce sol sans pente, formaient de nombreux marais. Les mots marisci, prata, pastoralia, bientôt le terme moer, indiquant la présence de prés bas et de marécages, sont nombreux dans les chartes. Enfin il y a encore sur Ia plaine des bras de mer, qui sont pour la plupart des estuaires.

Nous possédons deux moyens de connaître ces estuaires du $\mathrm{X}^{\mathrm{e}}$ siècle. Le premier est de s'en tenir à l'altitude, et de chercher les parties basses où la mer s'est évidemment maintenue le plus longtemps; le second est

1 Petresse: Haigneré, St-Bertin, I, p. 19, $\mathrm{n}^{\circ} 62$; - Oye : Vie de St Wandrogisilus, Acta SS. Boll., Julii, V, pp. 248-300; - Bourbourg : Van Lokeren, St-Pierre, I, p. 56, n० 63; - Tetoghem: Ibid., I, p. 38, n' 35 ; - Uxom: Ibid., I, p. 50, no 53; - Leffinghe ot Vlisseghem: Le Vasseur, Annales de lEglise de Noyon (Paris, 1633, in-4 ${ }^{\circ}$ ), p. 734 ; -- Testereph: Van Lokeren, St-Pierre, I, p. 60, n 71 ; - Loo, Meetkerke, Houttave, Lisseweghe, Lytkerke, Oostkerke, Wulpen : dans la charte d'Arnoul le Grand érigeant la Prévôté de St-Donat, reproduite dans Gilliodts, Coutumes de la Prévôté de St-Donat à Bruges, II, pp. 3-8; - Oostburg : Van Lokeren, St-Pierre, I, p. 25, n० 18 ; - Ijzendijke et Gaternisse: acte inconnu cité par Sanderus, Flandria illustrata, II, p. 207 ; - les Quatre-Métiers: Vanderkindero, Formation territoriale des principautés belges, I, p. 77; - Osthold près Watervliet: Vaul Lokeren, St-Pierre, I, p. 46, $\mathrm{n}^{\circ} 47$; Boterzand : lbid., I, p. $60, n^{\circ} 69$; - Axel : Ibid., 1, p. $60, n^{\circ} 70$; cité en 821 dans une charte de Louis le Pieux, reproduite dans Sanderus, Flandria illustrata, II, p. 226. 
de s'adresser aux textes. Les plus basses terres s'étendent de la Rredenarde à Calais, le long des còtes crayeuses; au Sud de Dunkerque, de Bergues jusqu'an fond des Moëres; dans le golfe de Loo, oi certaines parties ne sont guère qu'au niveau moyen de la mer; dans les moeres de Ghistelles, et le long du Houtland entre Oudenbourg et Bruges; enfin vers Damme, Moerkerke et Westcapelle ${ }^{1}$. Or ce sont bien là les emplacements que les documents historiques assignent aux anciens golfes. Dans l'Ouest, le cortège qui transporte de Boulogne a Bruges les reliques des saints Ausbert, Wulfran et Wandrille (944) trouve à Frethun un golfe; « villa Weretha secus mare sita est »: et la mer, dans une furieuse tempête, menace d'envahir le rivage, ce qui indique qu'il était encore fort bas ${ }^{2}$. Ce golfe (alveus) qu'on appelle la Neuna, le cortège lo traverse le lendemain, à marée basse évidemment, pour gagner Oye où l'on fait étape ${ }^{3}$. Aprés Oye, on va jusqu'à Bergues sans qu'il soit question d'un estuaire aux houches de l'Aa; c'est que cotte baie, qui existait pourtant encore au XIII siècle, était déjà de dimensions assez restreintes pour qu'on pût, entre Oye et Bergues, l'eviter sans faire un trop grand détour vers lo Sud. Au contraire la mer vient jusqu'à Bergues, comme l'indique un texte de 1107, confirmant la possession d'une bergerie de cent têtes à Bergues au bord de la mer (juxta mare) ", et un autre de 981, ou Bergues est encore indiquée comme située dans la Gersta (?) sur la mer ${ }^{5}$. Or cette Gersta, où l'on trouve un bras de mor, s'étend vers Lxem, comme en témoignent des documents de 981 et $1037^{\circ}$; il est donc probable que celte crique, par' les terres basses qu'assèchent aujourd'hui les canaux des Chats et des Ġlaises, joignait à la mer, vers Synthe, la dépression des Moëres. Au delá s'étendait le golfe de l'Yser, qui remontait encore dans les terres au moins jusqu'à la hauteur de Loo; la procession de 944 le traversa à un endroit nommé Driulit, " les trois branches ", vraisemblablement celui

1 Vers l'Est, les changements ont étẻ si considérables qu'il est difficile de retrouver dans l'état actuel des traces authentiques d'un passé lointain.

2 Celte rainure profonde au pied des terres hautes rappelle un peu lit fosse pir oi la marée sort du Zuiderzée, à Nieuwdiep. Cf. fig. 31.

3 "Mare funditus eversum ita se mole fluctuum subrigebat in altum, acsi divino mox imperio terminos proprios egressurum, et superficiem terrae occupaturum " (p. 298). "Alveum, quem dicunt Neunam, Sanctorum suorum obsequio transvecti..." (p. 2Y9). (Acta SS. Boll., Julii, V).

- Bulle du pape Pascal II, donnée par Pruvost, Bergues, p. 87.

s Van de Putte, St-Pierre, p. 121. "Juxta castrum Berga in Gersta supra mare*.

6 Van Lokeren, Si-Pierre, I, p. 50, n० 53 et I, p. 84, n० 119. 
où la crique recevait, par des chenaux secondaires, les eaux de l'Yser, du Kemmelbeek et de l'Yperlée. Ia baie existait au IX ${ }^{\text {e }}$ siècle sous le nom d' «Isere portus " ", ce qui indique que le pays environnant était déjà à sec; la relation du $\mathrm{X}^{e}$ siècle précise que la marée avait l'habitude d'y pénétrer, et que la cavalerie du comte eut grand mal à la franchir ${ }^{2}$.

A l'Est de lixmude, la carte est beaucoup plus imprécise. Il y eut, semble-t-il, un bras de mer devant Oudenbourg au $\mathrm{IX}^{\mathrm{e}}$ siecle ${ }^{3}$; mais

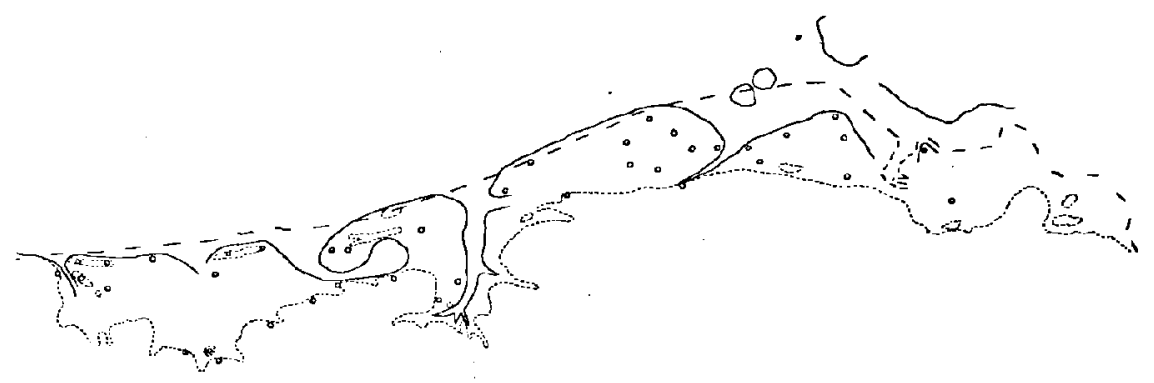

Echelie de $1: 1600.000$

F'ag. 32. - Essai de reconstitation de la Plaine à la fin du $\mathrm{X}^{8}$ siècle.

ーーーー Hivage actuel.

Extension maximn de l'inondation du vo siècle.

gagnait-il la côte par'le Zwin, ou par l'Yser? L'incertitude est complète, car le cours d'eau qui remplaça cetle crique, l'Yperlech, allait, presque sans pente, de Dixmude à Bruges. Au delà, le vaste estuaire du Zwin sépare Wulpen du continent, et vient longer les terres du Pagus Rodensis; Cumbescura, localité toute voisine d'Oostburg ", est en 951 au bord d'une mer qui pourrait bien être un bras du 7 win ${ }^{5}$. Pent-être faut-il lui ratlacher la bras de mer signalé en 840 près d'Adegem? Enfin après le $Z$ win, les textes ne laissent plus rien paraître. On en est réduit

\footnotetext{
1 « In sinum qui vocatur Isere portus $\gg(840)$. (Guerard, St-Bertin, pp. 107-108).

2 " Ad alveum venere, cognomine Driulit, quod nos latine trinum fuentum dicere possumus. Cui scilicet alveo, quia ex more mare exaestuans jam inundare cœpit, marchisus cum omni exercitu, magno equorum et labore et sudore vix transmeabilem habuit ». (Acta SS. Boll., Julii, V, p. 299). Gf. un commentaire, déjà vieilli, de ce texte dans: Cousin (L.), Un itinéraire an $X^{\circ}$ siècle (Mém. Soc. Dunk., XVI, p. 220 sqq).

3 Oudenbourg: « civitatem munitam et fortem, quum juxta litus maris sita a barbaris (Normands) crebro impetebatur » (Malou, Chronique du monastère d'Oudenbourg. p. 34).

4 "In loco nuncupante Ciumbescura in Ostborch... ». Van de Putte, St-Pierre, p. 81.

b a In loco mari proximo, vocabulo Cumbescura..." ". Van de Putto, p. 90 . - Sur les origines du Zwin, ef. ci-dessous p. 191.
} 
aux conjectures. Le diplôme d'Otton II à l'abbaye de St-Bavon (976), en mentionnant Walcheren et Beveland ${ }^{1}$ laisse entendre que le Hont existe bien, puisque ces îles sont séparées de la Flandre. Il faut même croire qu'il avait déjà une certaine imporlance, puisque la keure (loi) des Quatro-Métiers prévoit à l'article XXIV lo cas des réparations à faire au littoral de la mer ${ }^{2}$, et que la mer qui borde les Quatre-Métiers ne peut être que le Braakman ou le Hont. De même il faut bien croire que le Braakman existe, puisque le territoire des Quatre-Métiers, distinct du reste de la Flandre, appartient à l'évêché d'Utrecht dès la fondation de celui-ci (696) ${ }^{3}$, ot quau IX siècle il fait partie de l'Empire, tandis que les villages de Biervliet, Piete *, situés de l'autre côté du bras de mer, sont compris dans le Franc de Bruges.

Ces données sont encore bien imparfaites; néanmoius elles permettent do se faire une idée de ce qu'était, aux environs de l'an 1000, la plaine maritime a l'Ouesl du Pagus Rodensis. En dehors des estuaires, assez étroits pour qu'on puisse les franchir, presque tout le pays est émergè. Lne partie du sol est encore inhabitable, coupée de marais où s'abattent pendant l'hiver des bandes criardes d'oiseaux du Nord ${ }^{\mathbf{5}}$; ailleurs sont des schorres oú l'on méne paître des troupeaux de 130 et 190 têtes de moutons ${ }^{6}$. Cependant l'horme, attiré par la fertilité de ce sol vierge, essayait de prévenir le retour des hautes marées sur les territoires où il s'établissait: les premières digues nous apparaissent au $\mathrm{X}^{\mathrm{e}}$ siécle; le premier, le nom «Isendic» (984) en fait mention; mais elles sont probablement beaucoup plus anciennes. Ver's la côte, le rivage est déjà fixé dans ses grands traits, et ressemble singulièrement au rivage actuel; St-Pierre, Marck, Oye, Loon, Synthe, la Panne, Testereph, Wulpen, en jalonnent la direction. Elle est bordée de dunes : lo norn de Dunkerque, cité en 1067 dans la grande charte de Baudouin de Lille en faveur de St-Winoc ${ }^{7}$, atteste leur existence au milieu du XI ${ }^{\mathrm{e}}$ siècle, à l'endroit où

1 Serrure, St-Bavon, p. 10, $\mathrm{n}^{\circ} 8$.

2 Warnkönig, Flandrische Geschichte, III, pp. 196-197: * De reparatione littoris maris ".

3 Cf. Vanderkindere, Formation territoriale, I, p. 14.

- Piete, bourgade au S. de Biervliet, disparue au XVe siècle.

5 Harold, fils de Godwin et futur roi d'Angleterre, veut venir chasser vers 1063 sur les côtes marécageuses de la Flandre les oiseaux qui y abordaient en grand nombre des contrées du Nord. Cf. Kervyn de Lettenhove, Histoire de Flandre, I, p. 260; nombreusos réfẻrences indiquées.

6 Van de Putte, St-Pierre, p. 81.

7 Pruvost, Bergues, p. 59 : Dunkerka. 
elles sont encore aujourd'hui ; d'où la probabilité qu'elles existaient dẻjà au moins à la fin du IX siècle. Les «sablières» des salines de Synthe sont citées pour $1097^{1}$. Enfin Lambert d’Ardres, au XIL ${ }^{\text {s }}$ siécle, parle des dunes de Sangatte commo existant depuis longtemps, "ab antiquo»". Lorsque l'abbaye des Dunes est fondée en 1107, on l'établit dans les dunes, dans une solitude de sable ${ }^{3}$, oú son emplacement se trouve encore aujourd'hui, ce qui pronve que les dunes n'ont guère changé depuis cette époque. A coup sûr elles existent en l'an 1000, et ne sont pas éloignées de leur emplacement actuel. Les déplacements qu'elles subiront depuis cette époque, et dont nous connaissons quelques dètails, montrent qu'elles n'ont pu faire depris le $\mathrm{X}^{\mathrm{e}}$ siècle des progrès assez sensibles pour que le rivage actuel fût sensiblement différent de celui de l'an 1000.

A l'abri des dunes, la plaine se peuple rapidement. Dans cotte région de la Gersta par où la mer s'arançait jusqu'au pied du mont St-Winoc, huit noms de villages sortent de terre: Bierne el Steone en $1022^{\circ}$; Armbouts-Cappel, Coudekerque, Dunkerque, Ghyvelde, Hoymille, Spycker

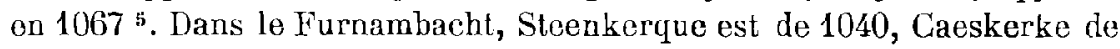
1066; Pervyse et Eggewacrtscapelle indiqués comme existant au $\mathrm{XI}^{*}$ siècle ${ }^{6}$. A l'Est du golfe de l'Yser paraissent Slype, Snaeskerke, Breedene, Clemskerke, Ter Doest ${ }^{7}$. Les derniers villages se montrent au XII ${ }^{\mathrm{e}}$ siècle, quelques attardés au XIII ${ }^{\mathrm{e}}$. Les anciennes paroisses se démembrent; des chapelles sont élevẻes sur leur territoire, qui devien-

1 Coussemaker (E. de), Documents relatifs à la Flandre maritime extraits du cartulaire de l'ubbaye de Watten. (Ann. Com. fl. Fr., V, 1859-60, p. 334).

* Lambert d'Ardres, éd. Godefroy-Ménilglaise (Paris, Renouard, 1855, in-8\%), p. 179.

3 Meyer, Annales, ad aunum.

- Pruvost, Bergues, p. 31.

5 Ibid. p. 59.

B Steenkerque: Haigneré, St-Berin, I, p. 24, no 70 ;- Caeskerke: Miraeus, Op. diplom., I, p. 65; - Pervyse: Van de Putte et Carton, Chronicon et Cartularium abbatiae S. Nicolai Furnensis, 1120-1354 (Bruges, Soc. d'Émulation, 1849, in-4 ${ }^{\circ}$ ), p. 36 ; - Eggewaertscapelle: Haigneré, St-Bertin, I, p. 41, no 115.

7 Slype: Spic. d'Achery, II, p. 919 ; - Snaoskerke : Pruvost, Bergues, p. 59 ; Breedene: lettre de Radbod, évêque de Tournai, dans Duvivier(C.), Actes et documents anciens intéressant la Belgique (Acad. roy. de Belgique, Comm. roy. d'histoire, 1818), p. 153 ; cf. Opdedrinck (J.), Notice concernant certains centres d'évangélisation et de civilisation au N. de la Flandre au VII et au VIII siécles. (Congrès archéologique de Bruges, 1902, C.-Rendu, pp. 359-364);-Clemskerke: Van Jokeren, St-Pierre, I, p. 71, no 91; - Ter Doest: Van de l'utte et Carton: Chronique de l'abbaye de Ter Doest (Bruges, soc. d'Ém., 1845, 82 p.), p. 5. 
dront paroisses à leur tour: Capelle-Bronck est formée de Bourbourg, Dixmude de Eessen, Zoetenaye d'Alveringhem. Dans lo Calaisis, toutes les paroisses actuclles (sauf les Attaques, créée au XIX' siècle), existent au début du XIII' siècle ${ }^{1}$. A l'Est de l'Aa, dans la partie française, la seule église de Leffrinckoucke n'est pas encore apparue en $1200^{2}$. En

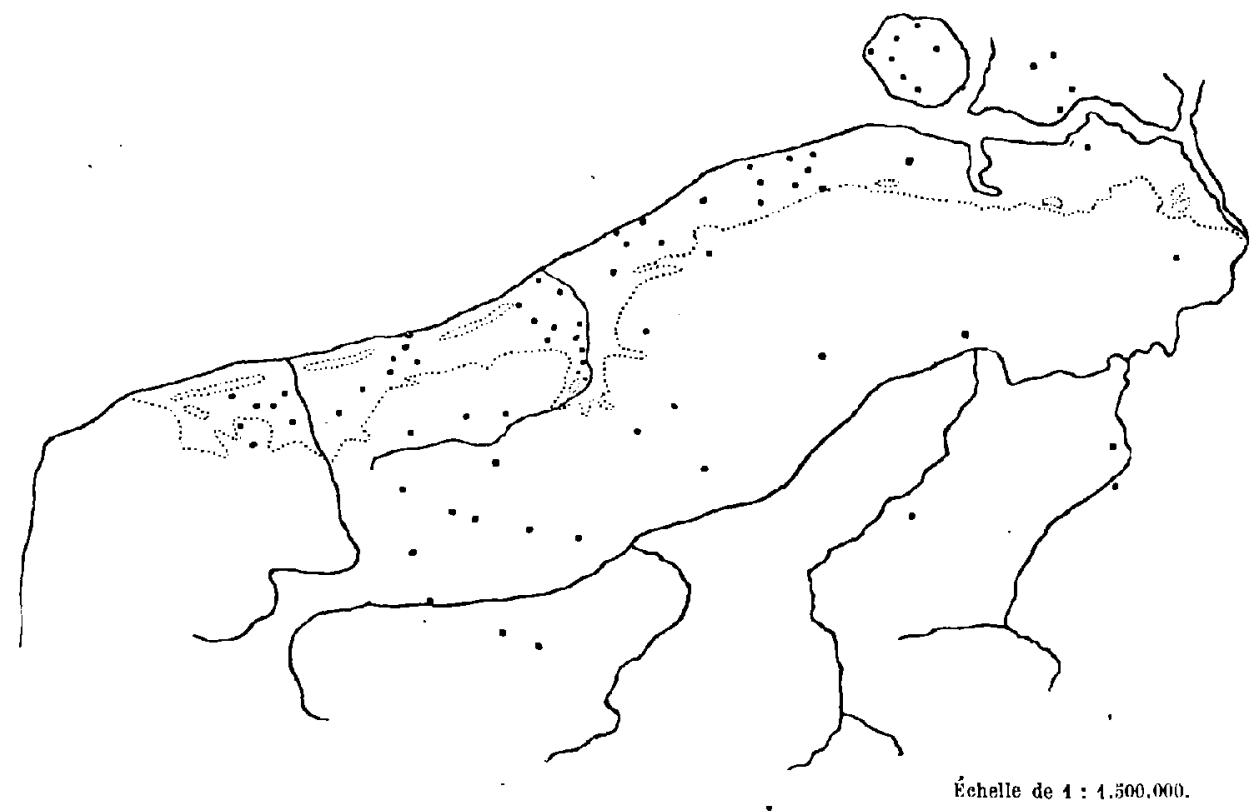

F1a. 33. - Répartition des noms de paroisses en Kerke, Église, Capelle, dans toute la Flandre.

Rares dans l'intérieur, ils forment des groupes compacts dans la plaine maritime et l'ile de Walcheren.

1 Sangatte an XI siècle: $d$ d. Chronique de Lambert d'Ardres, Godefroy, p. 177 ; -Calais en 1180: Haigneré, St-Bertin, I, p. 136, no 308 ; - Offekerque et Nello Fglise en 1100 : Courtois, Dictionnaire, pp. 171 et 174 ; - St-Folquin en 1040 : Haigneré, St-Bertin, I, p. 24, $\mathrm{n}^{\mathrm{n}} 70$ : - Vieille-Eglise en 1119 : Haigneré, St-Bertin, I, P. 52, n 135 ; St-Omer-Capelle en 1216: Courtois, Dictionnaire, p. 240; - S$^{\mathrm{a}}$-Marie-Kerque en 1224: Haigneré, St-Bertin, I, p. 286, n' 656 .

2 Mardick en $110 \tau$ (Pruvost, Bergues, p. 86); - St-Pierrebrouck en 1113 (Coussemaker, Bourbourg, I, p. 13, no XVII); - Craywick et St-Georges en 1119 (Coussemaker, Bourbourg, I, p. 21, $n^{0}$ XXV et Ilaigneré, St-Bertin, I, p. 52, no 135); Zuydcoote en 1121 (Pruyost, Bergues, p. 90); - Brouckerque en 1162 (Coussemaker, Bourbourg, I, p. 50, ñ LIII);- Capellebrouck en 1181 (Haigneré, St-Bertin, I, pp. 139$\left.140, \mathrm{n}^{\circ 5} 314-317\right)$. 
Belgique le peuplement se fait moins rapidement, peut-être à cause de la persistance des estuaires; Wulpen près Furnes, Adinkerke, Ramscapelle, Houthem, Oost-Dunkerke, Mannekensvere, Boitshoucke, sont du XII ${ }^{\mathrm{e}}$ siècle; Bulscamp, S'Heerwillemscapelle, Schoore, Nieucapelle, Zoetenaye, Oostkerke près Furnes, Oudecapelle, Coxyde, Heyst, Knocke, Nieuwmunster, du XIII ${ }^{\circ}$ siècle ${ }^{1}$. On voit apparaitre en foule ces noms en kerke ou capelle, qui caracterisent la toponymio de la plaino maritime, et dont la répartition, due à leur origine chrétienne et récente, suffirait presque pour tracer les limites du golfe, à défaut d'une carte géologique ". Les conquêtes de l'homme se font maintenant aux dépens des marais; la mise en culture des «terres neuves» emplit les chartes. On fait une rude guerre aux palus de l'Aa, entre Watten et Bourbourg, et Philippe d'Alsace célèbre en termes pompeux son triomphe sur les eaux ${ }^{3}$. Enfin on s'attaque aux estuaires.

\section{Disparition des estuaires.}

Les premiers disparurent ceux de Frethun ot de Bergues. Au XIe siẻcle, pour qu'on pût habiter dans le marais d'Ardres le château de Seluesse, il fallait que la mer se fût retirẻe assez loin déjà vers le Nord ^. Lorsqu'est fondeo en 1090, vers l'emplacement actuel des Attaques, l'abbaye do la Capelle, il est encore question de terres à gagner vers l'endroit ou le Merckled (rivière de Marck) se jette dans la mer; mais il est fort possible que cette embouchure fût située au Nord des Pierrettes, et que dejà le golfe

1 Wulpen, 1114 (Haignere, St-Bortin, I, p. 47, $\mathbf{n}^{\circ}$ 123); - Adinkerke, entro 1155 et 1167 (Van de Putte, Dunes, p. 29); - Ramscapelle, 1130 (Van de Putte et Carton, Cart. de St Nicolas de Furnes, p. 56); - Honthem, 1121 (Pruvost, Bergues, p. 101); - Oost-Dunkerke, 1135 (Van de Putte et Carton, Cart. de St Nicolas de Furnes, p. 4); - Mannekensvere, 1170 (Duvivier, Actes et documents anciens, p. 250);- Boitshoucke, 1190 (Van de Putte et Carton, Cart. de St Nicolas de Furnes, p. 228); - Bulscamp, 1205 (Guillaume le Breton, Philippide, vers 358); - SHeer-Willenscapelle, 1218 (Van de Putte et Carton, Curt. de St Nicolas de Furnes, p. 59); - Schoore, 1281 (Van I tokeren, St-Pierre, I, p. 401, no 896); - Nieucapelle, 1202 (Miraeus, Op. dipl., III, p. 674); Zoetenaye, 1204 (Van de Putte et Carton, Cart. de St Nicolas de Furnes, p. 84); Oostkerke, 1244 (Ibid., p. 225); - Oudecapelle, 1212 (Ann. Soc. Em. Br., 2e série, t. IX, p. 206) ; - Coxyde, 1295 (Van de Putte, Dunes, p. 156);-Heyst, 1221 (Haigneré, St-Bertin, I, p. 266, n 610); - Knocke, 1253 (lbid., II, p. 58, n० 1007); - Nieuwmunster, 1214 (Van Lokeren, St-Pierre, I, p. 235, n 437).

2 Rigaux (II.), Topographie, p. 226.

3 Lambert d'Ardres, éd. Godefroy, p. 168.

4 Ibid., pp. 226-227. 
ne dépassât guére Nieulay ${ }^{1}$. En 1112 on trouve dans cet ancien estuaire de la Nouna que rencontrait la procession de 944 une pâture à moutons « Bercariam de Nivenna ${ }^{2}$; la crique du $\mathrm{X}^{0}$ siècle était remplacée par une "saline". Au début du XIII siecle, une controverse au sujet de la pêche des cours d'eau nous montre, entre Guînes et les Pierrettes, un pays marécageux, avec de nombreux watergands, où l'écoulement des eaux est arrêté fréquemment, "necessilatibus patrie », probablement par le jeu des écluses qui gardent la contrée ${ }^{3}$. Mais il n'y a pas trace d'un golfe, pas plus qu'en 1210 ou en 1280 où la région est toijours qualifiée de «marais »". Cependant cette disparition du golfe ne dut pas aller sans à-coups. Iambert d'Ardres, qui vivait au XII ${ }^{\natural}$ siècle, raconte qu'un jour (quondam) la mer fit irruption a travers les dunes de Sangatte et, inonda la terre ferme (solida terra) ${ }^{5}$. La date riest pas précisée: mais l'événement lui paraît ancien, peut-être du début du XI' siècle. Enfin M. Gosselet indique qu'entre Ardres et Guemps, on a trouvé au-dessus de la tourbe et sous nne petite couche de sablo marin des vases et poteries du XIII siècle, ce qui indiquerait, à la fin de ce siècle, un retour et un court séjour de la mer en cel endroit ${ }^{6}$. L'événement a de quoi étonner, car" personne n'en parle; et ce silence n'est pas aussi explicable que celui qui accompagna de son indifférence l'invasion du $\mathrm{V}^{\mathrm{e}}$ siecle. Ce no pourrait ètre que le résultat d'uno inondation rapide, dont aucun chroniqueur n'aurait parlé, à laquelle aucune charte n'aurait fait allusion. Mais est-on bien sûr que les poteries trouvées sous le sable soient du XIII' ${ }^{\theta}$ siècle?

Le golfe que l'on a cru apercevoir au $\mathrm{X}^{*}$ siècle, entre les Moëres, Bergues, et la mer, n'est pas disparu moins rapidement que celui de Frethun. En 1107 cependant, Bergues est encore qualifiée de « juxta mare » " ; mais la Gersta s'assecche; on y trouve fréquemment des schorres

1 Desplanque, Labbaye de la Capelle. (Ann. Com. Al. Fr., IX, pp. 6-7 et 39). Il est question d'une terre neuve situee entre les bergeries du Merckled et la dune chauve $(1110)$.

2 Miraeus, Op. diplom., III, p. 87.

3aigneré, St-Bertin, I, p. 215, n० 493.

4 Duchesne (Andrẻ), Maisons de Gand et de Guines. Preuves (Paris, 1631, 1 vol. in- $\mathrm{f}^{\circ}$, p. 295 . - Voir également la description donnée par Godefroy-Ménilglaise des cours d'eau du comté de Guines au XIII siècle, dans son édition de Lambert d'Ardres, pp. 514-516.

5 Lambert d'Ardres, éd. Godefroy, p. 179.

b Fsquisse, Quaternaire, p. 329.

7 Pruvost, Bergues, p. 87. 
pour moutons ${ }^{1}$. Les Moëres sont désormais distinctes du golfe; elles portent déjà le nom qui leur est resté: c'est « la solitıde qu'on appelle Moere » $(1144)^{2}$; c'est « un territoire situé à Houthem et que les habitants appellent Moor $\gg^{3}$ (1183). Cependant une crique devait subsister entre Dunkerque el Synthe. Labbaye des Dunes possédait là un domaine sur l'emplacement actuel de la ferme Groote-Meunycken; au Sud de PetiteSynthe ${ }^{4}$, qui pouvait vers 1171 s'uccroître par conquête sur la mer, ou craindre une inondation ${ }^{5}$. C'étaient là les restes du golfe qui allait peu à peu se rétrécir jusqu'à devonir le port de Dunkerque, comme celui do Frethun est devenu le port de Calais, et comme ceux de l'Aa et de l'Yser ont formé les ports de Gravelines et de Nieuport. Vers 1183, on ne considère plus comme paroisses maritimes (maris contiguae) dans la châtellenie de Bergues que Mardick, Synthe, Dunkerque, Tetoghem, Zuydcoote et Ghyvelde ${ }^{6}$. La côte serait donc arrivée à peu prés au mêrme ètat qu'aujourd'hui.

L'estuaire de l'Aa était déjá peu de chose au $\mathrm{X}^{\ominus}$ siècle; aucun texte n'y fait allusion, et la Translation do St Wandrille parait l'éviter sans peine. $\mathrm{Au} \mathrm{XI}^{\mathrm{e}}$ siècle, la rivière gagnait la mer, nous dit la chronique de Watten, par de nombreuses et petites embouchures ${ }^{7}$; ce qui laisse supposer une plaine basse et marécageuse, qu'allaient envahir peu à peu les endiguements du XIIe sièclo ${ }^{8}$. Cependant la mer n'a pas encore quitté complélement, au milieu du $\mathrm{XI}^{\mathrm{e}}$ siècle, le pays au N.-W. de Bourbourg ${ }^{9}$. C'est en 1040 qu'on voit apparaître le village de St-Folquin, « in Gravenenga sita ${ }^{10}$. Cette Gravenenga ou Greveninga n'était pas une ville, mais toute une région de schorres où se trouvaient éparses les habitations de

11120 : Bercarias in Gersta (Van Lokeren, St-Pierre, I, p. 123, I10 197).

2 Van de Putte et Carton, Cart. de St-Nicolas de Furnes, p. 67.

3 Pruvost, Bergues, p. 146.

- Sur l'identification du domaine des Dunes avec la ferme Groote-Memycken, cf. Archives dép. du Nord, série C. Fle maritime, liasse 13.

5 « Si quid ex fratrum dunensium labore, aut ex maris adjectione eidem terrae accrovorit.... Siquid vero ex C. mensuris vi maris imminutum fuerit... (Van de Putte, Dunes, p. $459, \mathrm{n}^{\circ}$ 461).

6 Charte de I'hilippe d'Alsace (Pruvost, Bergues, p. 146).

7 «.... Ab Oceano, cui multis ostiolis infusus excipitur ». (Chronica Watinensis, M. G. SS., XIV, p. 164).

Cf. Coussemaker, Bourbourg, I, p. 6, n० VII; I, p. 11, u $^{\circ}$ XV ; I, p. 13, no XVII; I, p. 16, $n^{\circ}$ XIX ; I, p. 17, $n^{\circ}$ XXI ; I, p. 28, n० XXXII, etc.; endigruements dans les marais de Millum, St-Pierre-brouck, Capelle-hrouck et Bourbourg au dóbut du $\mathrm{XIl}{ }^{\circ}$ siècle.

9 Guérard, St-Bertin, pp. 186-187.

10 Haigneré, St-Bertin, I, p. 24, no 70. 
St-Folquin et plus tard celles de St-Willebrord et de St-Grorges ${ }^{1}$. Le même terme se retrouve d'ailleurs le long du Zwin, où un schorre de Greveninga est indiqué au IX siècle ${ }^{2}$. En 1095 on établit sur celte Greveninga une seconde église qui forme la paroisse de St-Willobrord ${ }^{3}$; en 1114 une ecclesiola de St-Nicolas, au bord de la Greveninge (juxta Greveningam) `; en 1119 on fonde la paroisse de St-Georges ${ }^{5}$. La mer est refoulée vers l'emplacement actuel de Gravolines; mais ello se maintient longtemps à cet endroit. Il y a là, devant St-Folquin, un schorre ou « hemme », comme on dit dans le Calaisis, appelé Bonhem lans les textos du XII siècle, et qu'on espère dès 1106 agrandir aux dépens de la mer ${ }^{B}$; mais en 1183 les choses, de ce côté, paraissent être restées on l'etat ' ; ot en 1211 on craint qu'avec les tompêtes de l'hiver Bonhem no soit envabi par la mer ${ }^{8}$. Si la terre ferme gagnait sur la rive Est, puisqu'on y édifiait en 1160 une ville que son fondateur, le comte Thierry, appelait « Novus portus de Greveninge » ${ }^{9}$, il restait à l'Ouest de cette nouvelle ville, le futur Gravelines, une large crique s'étendant vers St-Folquin, car en 1218 les paroisses de St-Folquin, St-Nicolas de Bage, St-Georges, sont au même titre que Gravelines et St-Willebrord considérées comme riveraines de la mer, et doivent payer la dime des harengs que pêchent leurs habitants ${ }^{10}$. Entre 1250 et 1300, la mer est encore au large de Bonhem ${ }^{11}$, n'abandonnant que peu à peu de nouveaux schorres qualifiés Hernisses ${ }^{12}$. Ce qui reste du golfe subsistera longtemps encoro; au $X V^{\theta}$ siècle il ne dépasse plus Gravelines au Sud, rais ce n'est guére qu'au XVIle qu'on voit émerger les terres des Hems St-Pol ${ }^{13}$, et c'est au XVIII ${ }^{8}$ seulement que disparaît ce qui reste de l'estuaire (p. 203).

1 D'après M. Finot (J.), Inventaire des archives de la ville de Gravelines (Lille, Danel, $15(00)$, p. VII, Gravenenga signifierait région des greves ou des dunes.

2 Van de P'utte, St-Pierre, p. 81.

3 Haigneré, St-Bertin, I, p. 47, n 124.

4 Ibid. I, p. $48, n^{\circ} 126$.

5 Ibid. I, p. $52, \mathrm{n}^{\circ} 135$.

6 Coussemaker, Bourbourg, I, p. 33, ño III.

7 Ibid. I, p. 79, n $^{\circ}$ LXXVI.

8 Ihid. I, p. 104, n० CVI.

9 Ln vidimus de l'acte de fondation existe aux Archives du Nord, 13. 1561, 19r cartulaire de Flandre, pièce 44. - Gravelines, comme devait bientôt s'appeler le Novus portus, resta distinct de St-Willebrord, paroisse rurale s'étendant à l'Est de la ville, vers I,oon.

10 Haigneré, St-Bertin, I, p. 136, n 308 ; p. 146, n 329 ; p. $247, n^{\circ} 565$.

11 Coussemaker, Bourbourg, I, p. 218, n CCXX.

12 Ibid. I, p. 114, no CXIX; p. 123, n० CXXXII; p. 126, no CXXXVI, etc.

13 Coussemaker (E.), Documents historiques, 1er fascicule, pp. 40-40. 
Le golfe de l'Yser, le plus vaste des estraires du $\mathrm{X}^{\theta}$ siècle, diminue aussi rapidement que les autres et se réduit au XIII siècle à une petite crique. En 944, il s'étend jusqu'à I oo; au milieu du XI' siècle, c'est encore une baie imposante où pénètre la flotle de Godwin ${ }^{1}$. Cependant la partie mèridionale 's'assèche; en 1066 l'emplacomont des communes de St-Jacques-Capelle, Ouducapelle, Caeskerke, Stuyvckenskerke, formo un grand schorre, une bergerie appelée Bircla, et dépendant de la paroisse d'Eessen 2. Une longue digue, l'Oudenzeedyck, protège les parties émergées les premières, Lampernisse, Furnes, Eggewaertscapelle, contre un retour offensif des eaux; la levée part des dunes vers Oost-Dunkerke, passe par Avecapelle et Zoetenaey, et aboutit à la rivière vers le fort de Knocke ${ }^{3}$. Au Nord, la côte forme une échancrure assez prononcée, car la ligne de dunes, à partir d'Oost-Dunkerke, va droit à l'Est ; c'est la vieille ligne qui borde encore aujourd'hui le Sud du polder Lens, passe sous la ville de Nieuport et continue jusque vers St-Georges, contrastant par la nature de son sol et par son élévation avec les hasses terres qui l'entourent au Nord et au Sud. C'est là qu'entre 1083 et 1093 apparaît la terre de Sandeshoved ${ }^{4}$, sur laquelle Philippe d'Alsace étahlira un siècle après la ville de Nieuport. Sur la rive Est, le bord de la baie est constitué par les vieilles dunes de Iombartzyde et de Westende; peut-être même un bras sépare-t-il Lombartzyde de Westende, si l'on en croit le dicton qui veut que le premier de ces villages ait jadis fait partie du Furnambacht ". P'ar les tempêtes du N.-W., la mer pénètro largement daus le golle, et fait encore sentir l'effet du flux jusqu'au delà de Loo, puisque les moines d'Eversham ne sont pas quittes des dégâts de l'inondation de $1105^{6}$.

Mais le recul défnitif du golfe s'accuse au XII siecle. Au Sud, on s'empare des terres neuves de Dixmude (1104) ${ }^{7}$, et en 1166 l'Yser devant

1 Kervyn de Lettenhove, Histoire de Flandre, I, p. 249.

2 Hautcour, St-Pierre de Lille, I, pp. 5-6.

3 Van de Velde (H.), Dissertation historique et topographique sur l'état ancien du Furnambacht, (Ann. Soc. Em. Br., IV, 1846, pp. 137-16\%), p. 142. - Cette digue est indiquée, entre Avecapelle et lampernisse, sur la feuille Lampernisse de la carte topographique belge à $1: 20.000$.

1 Cf. Pruvost, Bergues, p. 86.

5 I)après Van den Bussche, le Veurnambacht (la Fl., t. II, pp. 5-6).

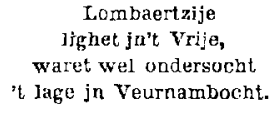

6 Chronicon monasterii Evershamensis (Bruges, Soc. d'Em., 1852, 79 p.), pp. 10-11.

7 Coussemaker, Bourbourg, 1, p. $1, n^{\circ} 1$. 
cette ville paraît bien n'être plus qu'une rivière '. Iu Nord, la langue do terre de Sandeshoved s'accroît aux dépens de l'estuaire, ot le monastère de Bourbourg se partage les terres neuves avec le chapitre de Ste-Walburge (1111-1112) 2. Il semble qu'un bras existe encore vers l'Wst, rejoignant

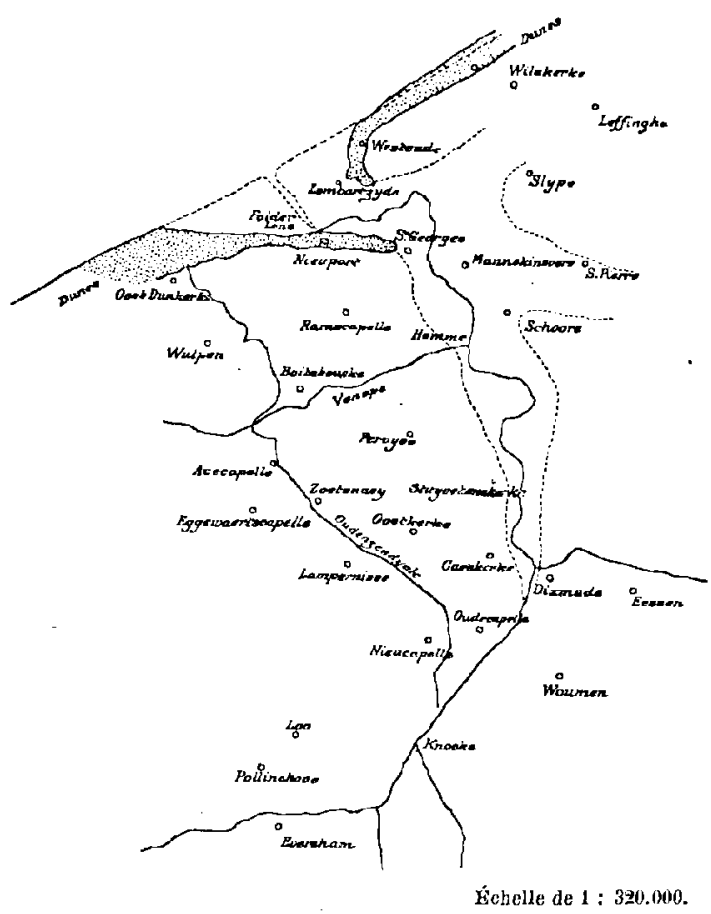

FIG. 34. - Reconstitution de l'estuaire de l'Yser au début du XIIe siècle.

les terres basses des moeres de Ghistelles ${ }^{3}$; il est encore question en 1171 de terres que le flot avait abandonnées jadis dans les paroisses de Slype, Leffinghe et Steeno *, ce qui ferait songer d̀ une communication entre le golfe do l'Yser et les terres basses d'Oudenbourg par une crique, qui serait devenue plus tard l'Yperleet.

A son tour on 1138, l'abbaye des Dunes acquiert des terres neuves dans l'estuaire 5 . On s'empare des grèves situées devant Ramscapelle, devant Pervyse (1139) ${ }^{6}$; à l'embouchure de la Venepe, qui amène les eaux de Furnes, les schorros ont tendance à s'accroître, et on peut préroir qu'ils seront un jour mis en culture ?. De l'antre côté, les terres

1 Coussemaker, Bourbourg, I, p. 55, n० LVII et p. 57, n LIX.

2 Ibid. I, p. 9, no XII; p. 10, n XIII.

3 « Terram quam in loco qui Gistelamor vocatur juste possidetis, et quidquid ipsi terre deinceps mare adjecerit ". Bulle d'Honorius II, vers 1127, in P'ruvost, Bergues, p. 101.

4 Miraeus, Op. diplom., II, p. 1316.

B Van de Putte, Dunes (Chronica), p. 138.

6 Coussemaker, Bourbourg, T, p. 40, no XI.V; Van de Putte, Dunes, pp. 440-441, $\mathrm{n}^{\circ} 435$.

7 Van de Putte, Dunes, p. 443, n$^{\circ} 440$. 
s'augmentent vers Schoore $(1176)^{1}$; enfin à Westende Philippe d'Alsace donne à l'abbaye d'Oudenbourg les terres neuves où s'élévera la ferme de Bamburg, « entre les dunes et l'Yser », resserrant ainsi les passes de l'estuaire (1173) ${ }^{2}$. Les schorres continuent de s'accroître en 1205 à l'embouchure de la Venepe ${ }^{3}$; l'apparition des paroisses de Mannekensvere $(1239)^{4}$ et St-Georges ${ }^{5}(1240)$ indique un nouveau rétrécissement de la crique, quoiqu'il soit encore question, dans ces nouveaux terriloires, d'inondations de la mer à empêcher. Pendant toute la fin du XIII siècle on continue à endiguer, à délimiter les terres neuves, du côté des Hermmes de l'abbaye des Dunes, à Westende, à St-Goorges ${ }^{6}$. Enfin en 1294 le comte Guy de Dampierre accorde l'octroi de faire une écluse qui barre la crique de Nieuwendam ${ }^{7}$; c'est la fin du golfe intérieur; en 1309 on peut construire un pont entre Lombartzyde et Nieuport ${ }^{8}$. Les atterrissements se forment dès lors ontre la nouvelle ville de Nieuport et la mer; en 1271 le Hemmekin « ke li mers a jetée et ki onques ne fut dikée » ${ }^{\mathbf{9}}$; en 1280 un « jet de mer $\gg$ entre Nieuport el les dunes ${ }^{10}$ : c'est le futur polder Lens, que viendra protéger bientôt la digue du comte Jean.

Désormais, tout l'intérêt abandonne cette partie occidentale de la plaine. Lo pays est délivrè de la mor ; il ne reste plus qu’à organiser le . mieux possible l'évacuation des eaux intérieures. $\Lambda$ XIV X siècle les inarais disparaissent à leur tour; les terres cultivées l'emportent. Les deux étangs des Moëres, entre Furnes et Bergues, restent les derp̣iers témoins de l'invasion marine: on ne les dessèchera qu'au XVII siècle. La mer róussit parfois à rompre les digues, ou à faire des brèches aux dunes: mais l'inondation n'est l'affaire que de quelques marées, et les dégàts sont promptement réparés. En 1393, la ville d'Ostende est obligée de reculer l'emplacement de ses maisons, et de les abriter derrière la digue

1 Van de Hutte et Carton, Cart. St-Nic. de Furnes, p. 70.

2 Feys et Van de Casteele, Histoire d'Ouderbourg (Bruges, Soc. d'Em., 1873.76 , 2 vol. in $\left.-4^{\circ}\right)$, II, p. 39.

3 Van de Putte, Dunes, p. 352.

* Ibid., p. $571, n^{\circ} 721$.

5 Van de Putte et Carton, Cart. St-Nicolas de Furnes, p. XII:

6 Cf. Coussemaker, Bourbourg, p. 137, no GLXXXV; pp. 182-83, n CXCI; pp. 218-19, $n^{\circ}$ CCXX; - Feys, Oudenbourg, I, p. 374.

7 Gilliodts, Coutumes de Nieuport, p. 174.

8 Feys, Oudenbourg, II, pp. 102-103.

9 Coussemaker, Bourbourg, I, p. 173, no CLXXXII.

10 Gilliodts, Coutumes de Nieuport, p. 166. 
dı Franc ${ }^{1}$; on 1409 c'est le tour de la châtellenie de Bergues ${ }^{2}$ à souffrir des eaux; en 1508, du pays de Langle ${ }^{9}$; en 1530 , de toute la cóte; en 1552, de Nieuport". La monotone liste continue jusqu'au XIX' siècle, ou l'inondation de 1808 fait des dégâts sur toute la côte, jusque dans le Calaisis. On sonnait le tocsin, la population valide accourait; on jetait dans la brèche, à marée basse, des fascines, des sacs de terre; on consolidait en toute hâte avec des liens de paille; le danger était conjuré ${ }^{5}$. Mais à l'Est de Brugres, la lutte de la terre et de" l'eau continue, violente. De terribles inondations se succèdent, ot ce n'est guère que depuis la fin du XVII' siècle que l'homme reprend définitivement l'avantage.

III.

VICISSITUDES DE LA FlANDRE ZÉLANDAISE.

Apparue la dernière dans les cartulaires, la Flandre zélandaise semble se développer rapidement au XII" siècle. Vers 1200 , toules les parties du pays paraissent habitées: à l'Est Calloo, Hulsterloo, Graauw, Hulst, Verrebroeck, Hengstdijk, Hontenisse, Ossenisse; au centre Tramsblide près d'Axel, Zaamslag, Vronendicko; à l'Ouest, Biervliet, Hamere, Elmare, Roeslaere, Henekinswerve, Kadzand, viennent s'ajouter aux localités dont nous connaissons déjà le nom au début du XI ${ }^{\mathrm{e}}$ siècle. Le pays d'Oostburg est particulièrement florissant: Ijzendijke devient paroisse; Vulendik, Oostmanskapelle, Gaternisse, Groede, Hughevliet, Beiderwan, sont fondés de 1150 à $1200^{6}$. Wulpen et Kadzand sont à l'état

1 Delepierre, Précis analytique, III, p. 191.

2 P'ruvost, Bergues, p. 291.

3 Arch. Pas-de-Calais, série C., 305, piece 64.

Gilliodts, Coutumes de Nieuport, p. 320.

5 Pour des dótails sur ces inondations partielles: cf. Feys, Oudenbourg, I, p. 323 (1609) ; r, p. $273(1530)$; etc. Les hahitants de la région còtière n'étaient jamais suirs de ne pas se réveiller dans l'eau. Le 18 fúvier 1609, une forte marée inonda et noya Moerkerke et la banlieue de Damme, recouvrant tout au point que la population dut se réfugier dans les arbres et sur le haut des maisons; on alla les chercher, tous presiue gelés, le lendemain de Damme en bateau par dessus l'inonlation, abandonnant l's bestiaux qu'on n'avait pas pu sauver aussi subitement en fleine nuit (Extrait d'un registre en flamand de la cure de Damme, publié dans F.-V., L'ancien port de Damme, Ann. Soc. Kum. Br., 2e série, I, p. 86).

6 Calloo, 1159 (Van Lokeren, St-lierre, I, p. 155, $\left.n^{\circ} 204\right)$; - Hulsterloo, 113i; Verrebroeck, 1147; Hengstdijk, 1167 (De Smet, Chronique de l'abbaye de Tronchiennes, [Recueil des Chroniques de Flandre, I (1837), pp. 5(31-731], pp. (1)6), 70(;, 712); Hulst, 1199 (Mussely et Molitor, Courtrai, p. 4) ; - Graaw, 1170 (Serrure, Nt-Bavon, p. 53, $\left.\mathrm{n}^{0} 50\right)$; - Ossenisse et Tramsblide, 11(j4 (Van Lokeren, St-Pierre, I, pp. 1150-170, I1 296 ); - Hontenisse, 1183 (Ibid. I, p. 189, n³42); - Zaanslag, 11 li3 (Ibid. I, p. 
d'îles, entourées par des bras du Zwin ; le Hont sépare toujours Walcheren du continent ${ }^{1}$; il borde les terres d'Ossenisse ot Hontenisse ${ }^{2}$; et déjả l'aspect général du pays ne paraît pas si différent qu'on pourrait le croire de celui qu'il avait au début du XIX ${ }^{\circ}$ siècle. Des terribles inondations de 1170 que citent avec épouvante les chroniqueurs, il n'est pas question.

\section{Prospérité des endiguements aux XII et XIV" siècles.}

I’ailleurs la prospérité du pays continue au XIII sieccle. Partout on assèche, on endigue, on réendigue. les particuliors; de riches bourgeois, s'y mettent; mais rion n'égale l'activilé monastique. Les Cisterciens des Dunes, daus leurs domaines éloignès d'Ossenisse ot Iontenisse, donnent l'exemple; en $1246 \mathrm{ils}$ possèdent dans cette senle région 5.600 mesures de terres endiguées et 2.400 de schorres, soit 8.000 mesures ${ }^{3}$. Ies vieilles abhayes bénédictines suivent cot exemple; St-Pierre de Gand a des domaines partout, et posséde presque la totalité des territoires

160, $\mathrm{n}^{\circ} 277$ ) ; - Vronendicke, 1114 (lbid. I, p. 118, n"187); - Biervliet, 1183 (Gilliodts, Petites villes, I, p. 515); - Hamere, 1193 (Ibid. I, p. 516) ; - Elmare, 1128 (Van Lokeren, St-Pierre, I, p. 128, $n^{\circ}$ 206); - Roeslaere, 1036 (Ihid. p. 82) ; - Henekinswerve, 1169 (Ibid. p. 49, no 45); - Kadzand, 1112 (Ibid. p. 25, n० 18) ; - Vulendik, Oostmanskapolle, Gaterrisse, 1150 (Ibid., I, p. 145, n"244);-Hughevliet, 1174 (Ibid. I, p. 182 , $\mathrm{n}^{\circ}$ 325); - Beiderwan, 1196 (Ihid. I, p. 202, no 371).

1 On a prétendu, d’après le récit de la Translation des reliques de Ste Lidwinne (Drogonis Translatio S. Lewinnae, M. G. SS. XV, pp. 788-789), opórée en 1058, que le Hont n'existait pas à cette époque, ou du moins n'a vait aucune importance. Cependant le texte dit bion « Walacra insula », ce qui implique l'existence du Hont. Ft rien dans le texte n"indique qu'on y soit allé a piod. Il est puéril de dire que la procession no ponvait so rendre dans Walcheren si lo Hont avait été déjà aussi étendu qu'aujourd'hui ; il ne faut guère que trois quarts d'houre à un bateau à voile pour gagner l'ile, en partaut de Breskens. Fn ráalité, le Hont était plus largo encore que do nos jours, puisqua Groede, ni Breskens n'existaient a cette époque; Groede, en 1133, est une terre nouvelle, qui s'est jointe peu à peu à la terre ferme (Van Lokeren, St-Pierre, I, p. 132, $\mathrm{I1}^{\circ}$ 21/4). Quant au Zwin, qui existe dès le VIIle sic̀cle sous le nom de Sincfal, d'après les lois du peuple frison, il entoure de ses bras Wulpen dès 1096 (Serrure, St-Bavon, p. 22, $\left.n^{\circ} 15\right)$; et Kadzand est depuis longtemps une ile, puisqu'en 1231 l'abbé de St-Bavon déclare que l'ỉle a toujours été entourée par la mer, " praedicta insula semper, ut nunc, fuit cincta mari » (Serrure, St-Bavon, p. 171, n 175). D'ailleurs en 1190 la Keure du Franc, donnée par Philippe d'Alsace, reconnaît au paragraphe 15 que Wulpen et Kadzand sont des iles. Cf. Gilliodts, Coutumes du Franc de Bruges, II, p. 23.

2 "Totam illam terram maris inter Hossenesse et Hontenesse ", (Van de Putte, Dunes, p. 426), 1196 .

3 Van de Putte, Iunes, pp. 201-202. Soit près de 4.000 hectares. 
d'Oostburg, Groede et ljzendijke; St-Bavon étend son autorité sur Wulpen et Kadzand. H'autres plus récentes, Cambron, Courtrai, Ter Joest, se taillent leur part dans les terres neuves. A la fin du siècle, presque toutes les localités sont apparues, et parmi elles, quelques-unes qui disparaîtront plus tard ${ }^{1}$. La carte se précise. La plaine n'est pas continue: on y voit quelques bras de mer, le long desquels on endigue sans relàche. I)éjà on devinait leur préscnce au XII ${ }^{\circ}$ siècle: Kadzand et Wulpen séparés de la còte; la mer entourant vers le Nord et l'Est les torres de l'ambacht d'Oostburg, et y découvrant les schorres sur lesquels s'établissent Groode

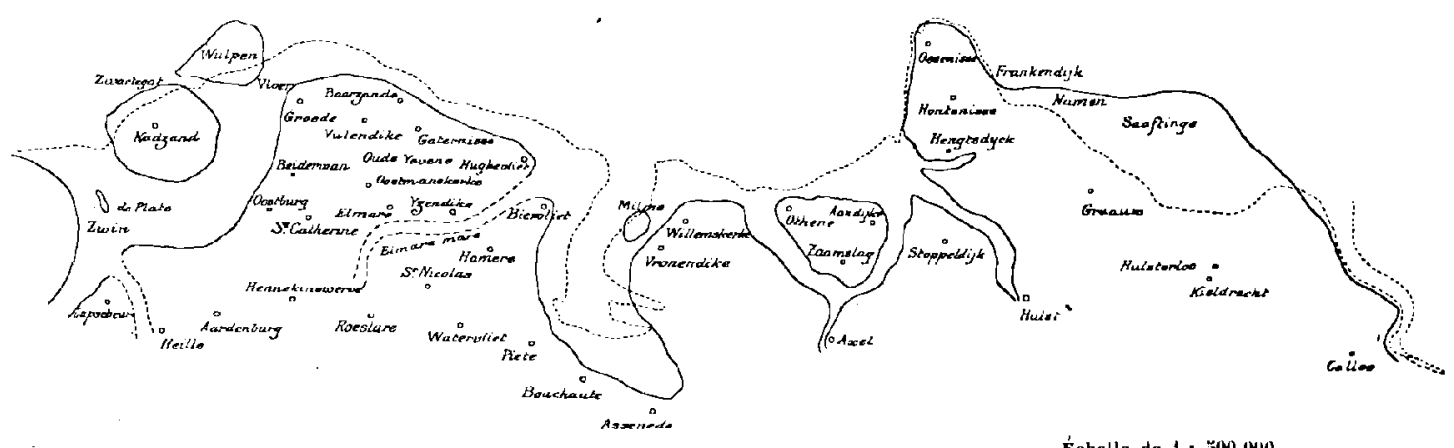

Échelle de 1: : $9(10.040$.

FIG. 3). - Essai de reconstitution de la Flandre zélandaise au début du XIII' sièle.

Rivage actuel.

et Biervliet; le «fluviolum " appelé Helmara vers 1128, devenu * Elmariam mare" en 1188. indique qu'un bras de mer se trouve dans la

1 Baarzande près Breskens, 1212 (Van Lokeren, St-Pierre, I, p. 234, n० 433); Schoondijke, 1248 (Ibid. I, p. 285, n० 598); - Heille, 12(14 (Van de Putte, I)unes, p. 483, $\mathrm{n}^{\circ} 50 \mathrm{j}$ ) ; - Monkewerve et Steenlant, 1193 (Limburg-Stirum, Cartulairo de

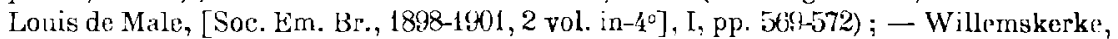
1221 (Van Lokeren, St-Pierre, I, p. 245, no 4(3); - Wevelswale, 1227 (Serrure, StBavon, p. 141, no 158); - Koudekeque, 1287 (St-Genois, Inventaire analytique des chartes des comtes de Flandre [Gand, Vanryckeghem, 1843-16, in-40, XLIV + 679 p. 1 , p. 135, no 445); - Piete, 1242 (Van Lokeren, St-Pierre, I, p. 271, n 554); - Pelchem, 1248 (Ihid. I, p. 287, n० (0)4); - Zuiddorpe, 1288 (Ibid. I, p. 436;, no 932); - Westdorpe, 1276 (Van de Putte, Dunes, p. 413); - Adendijk, 1220 (Ibid. p. i505, no 550); Copwijk, 1228 (lbid. p. 346); - Stoppeldijli, 1226 (Ibid. p. 52(1, n०506); - Beoostenblij, 1246 (Van Lokeren, St-Pierre, I, p. 278, n584) ; - Lamswaarde, 1233 (Mussely ot Molitor, Courtrai, p. 379); - Paulus Polder, 1212 (Kluit, Historia critica, II,

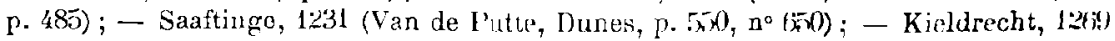
(De Smet, Tronchiennes, p. 612); - le Joel, 1267? (Kümner, Notice historique sur les Polders du Bas-Escaut. [Anu. Tr. p. Belg., II, 1844, pp. 5-69, (i cartes], pp. 12-22).

2 Van Lokeren, St-Pierre, I, p. 128, n०206; I, p. 196, n 357. 
région de Watervliet, probablement un bras du Braakman, dont l'existence est pleinement confirmée au XIII siècle. Les criques du pays d'Axel ne so montrent pas encore, mais la mer est indiquée a Hulst en $1199{ }^{2}$. Après 1200, la fréquence des endiguements resserre et précise les chenaux. Kadzand et Wulpen sont de grandes îles, toules coupées d'auciennes criques, deš « Vliet», et agrandies peu à peu par l'adjonction de nouveaux polders, comme une cellule qui pousse tout autour d'elle des prolongements ${ }^{2}$. Les détroits se resserrent entre les îles et le continent: en 1257 on voit émerger sur la côte du pays d'Oostburg, en face Wulpen, un schorre qui forme le nouveau polder d'Yzondorp, et en 1261 on endigue entre Yzendorp et Groede ${ }^{3}$; aussi organise-t-on mieux le service de passage entre la terre et les îles; Arnould de Maldegem lègue par testament de 1275 deux grosses sommes pour que la traversée soit gratuite ", et un acto de 1280 nous apprend qu'en effet au bac de Veere (passage) on passe sans payer daus l'ille de Kadzand ${ }^{5}$. Enfin une nouvelle île s'est formée sur la côte orientale de Wulpen ; cest Koesant, qualifiée en 1237 de jet de mer, dont les accroissements sont signalés en $1276^{6}$, et qui dès le XIV siècle se joindra à Wulpen, agrandie d'autant ${ }^{7}$. En face, sur la côte, il n'existe pas do bras de mer joignant le Zwin au Braakman. De Heille à Aardenburg et Oostburg, rien que dies terres cultivées et endiguées; aucune allusion à une crique ${ }^{8}$. Aardenburg est déjíz aussi äloigné de la mer qu'il l'était au XVIII' siècle, pnisque les échevins obtiensent en 1244 l'antorisation de creuser un canal entre leur ville et la ner, à Slependamme ${ }^{9}$. I'évêque de Tournai Walter de Marvis

1 Kluit, Historia Grítica, II, p. 241.

A Kadzand en 1171 et 1189 , on voit le Sudpolre, le Doudelinsvliet, le Grotvliet, le Tarwedic, le Wertvliet, le Kerpolre, le Dumbinsvliet; un «Utdic, id est incrementum $\triangleright$ (Serrure, St-Bavon, p. 58, $n^{\circ} 57$, et p. 67, $n^{\circ} 71$ ). Dans un dénombrement de 1227 , on n'y compte pas moirs de 15 polders (Ibid. pp. $159-160, \mathbf{n}^{\circ} 161$ ).

3 Var Lokeren, St-Pierre, I, pp. 314-315, no 672, et p. 331, n 728.

- Ibid. I, p. 377, n० 859. - Cf. Voisin, Le Testament d'Arnould de Maldeghem, Ann. Soc. Wm. Br., $2^{\circ}$ série, VII (1849), pp. 363 sqq.

5 Delepierre, Précis analytique, $1^{\text {ro }}$ série, I, p. LXXV.

6 Inventaire analytique et chronologique des archives hospitalières de la ville de

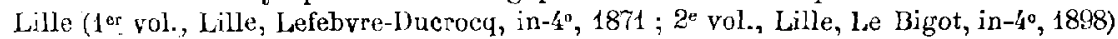
I, p. 1 , et I, p. 10 .

7 Cf. le texte de 1510 dans Arch. hosp. Lille, I, p. 86.

8 Cf. Serrure, St-Bayon, pp. 233-234, no 241 (1244).

9 Charte publiée dans Gilliodts, Petites villes, I, pp. 83-85. - C'est déjà, en 1279 comme aujourd'hui, la rivière de l'Hee (Eede) qui coule d'Aardenburg à Slependamme (St-Geuois, Inventaire, p. 78, $\left.n^{\circ} 250\right)$. 
délimite en 1243 les paroisses de St-Nicolas de Varne, Oostmanskerke, Ste-Catherine et St-Bavon d'Oostburg, Roeslaere, Aarienburg et Maldegem ${ }^{1}$, ce qui prouve la disparition des criques qui auraient pu servir de limiles naturelles. Mais au N.-E. des ambachten d'Oostburg ot d'Ijzendijke, nous retrouvons la mer. La wateringue de l'Oude-Yevene, dont on entend parler en 1239, mais qui existe probablement depuis la fin du $\mathrm{X}^{\circ}$ siècle, écoule ses eaux par Bararzande ${ }^{2}$, vers le N.-E. : ce qui indique que la côte du Hont se trouve à peu près à la hauteur de Baarzande, c'est-à-dire à la même place qu'aujourd'hui. Plus loin, Biervliet est également terre ferme 3. Mais en face de Biervliet s'étend un large bras de mer, le Braakmian, séparant la petite ville et le métier de Bruges de l'île de Milme, et des terres du inélier d'Assenede, Willemskerke, Vronendic, sur l'emplacement actuel de la commune de Hoek . Ce bras de mer pénètre profondémont au Sud. Roeslaere, à còté de Watervliet, est près de la mer en $1218^{\sharp}$, probablement l'ancienne crique d'Elmare; la paroisse de Watervliet, à la même date, comprend des parties qui touchent à la mer ${ }^{6}$; on prévoit en 1260 que dans un de ses hameaux des

1 Descamps (A.-P.), Notice sur Walter de Marvis, évêque de Tournay (Mím. Soc. hist., Tournai, I, [1853], pp. 135-300), pp. 272-273.

2 Van Lokeren, St-Pierre, I., pp. 268-269, n० 542. Charte de wateringue extrèmement intéressante. Situẻe entre Oostburg el Tjzendijke, l'Oude-Yevene correspond exactement al Pagus Gasterna apparu á la fin du $X^{\ominus}$ siècle (cf. p. 157, note 1); cest sur son flanc occidental que s'est formé le schorre de Groede, sur sa côte N. la terre de Baarzande. La charte prévoit les cas ou la mer, attaquant la côte de Baarande, obligerait à reculer la digue vers l'intérieur, et celui oi l'accroissement des schorres nécessiterait la construction diune nouvelle digue plus loin en mer. - Publié également dans Wolters, Recueil de lois, II, pp. 1-2. - Pour Barzande: Van Lokeren, St-Pierre, I, p. $173, n^{\circ} 303$.

3 1281: « si le fermier de St-Pierre dans l'Abbekinspolre ne paie pas le montant de son fermage, l'abbé peut envoyer un homme à cheval à Biervliet demander assistance... ", etc. (Van Lokeren, St-Pierre, I, p. 413, $\mathrm{n}^{\circ} 896$ ). L'Abbekinspolre était à Piete, ontre Watervliet et Bouchaute (lbid. I, p. 271, no 254 ).

4 Les textes sont formels : 1240): Cession a l'abbaye de Groeninghe des dîmes de la terre "vi marini fluctus jacte, vel post modum jaciende inter Milmen ot hierviettermuden ". (Van de Putte, Chronique et Cartulaire de l'abbaye de Gronninghe [Bruges, Soc. d'Em., 1872, in-4 $4^{\circ}$, p. 3); - 1241: terra inter insulam quile vocatur Wilme, quxe est in officio de Hassenede, et Saternessoort, quae est in officio de IBrugis; ... et medietatem totius terre que per jactum maris terris predictis accrevit, vel futuris temporibus accrescet, seu quocumque modo mare jacet contra terras predictas (Ibid. p. 12). - Plus loin est indiqué que ces terres de Milme sont situées sur les paroisses de Willenskerke et Vronendicke (Ibid. p. 74).

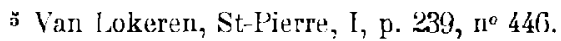

6 Girca maritima (Ibid. I, p. 240, no 448). 
schorres pourront continuer à se former ${ }^{1}$. Bouchaute, Assenede, doivent être encore au bord de la mer, puisque la keure des Quatre-Métiers de 1242 leur prescrit de foumir chacune un bateau ponté de guerre (hereogghen) ${ }^{2}$, et que la sentence de 1281 pour l'évacuation des eaux de Caprycke et Iembeke indique que les écluses sont is Bouchaute ${ }^{3}$. Ver's Axel, les données du, XIII' siècle sont moins précises, ot on pourrait hésiter sur la direction de la crique qui s'étondait certainement jusqu'à Axel *, si un texte très précis du XIV ${ }^{\theta}$ siècle ne venait donner tous les éclaircissements désirables, en indiquant qu'łutrefois les paroisses de Zaamslag, Othene et Aandijke formaient une île entourée par les eaux de la mer ${ }^{\breve{a}}$, et qu’á ces bras se joignait le « havene d'Axele exstendant en la meer ${ }^{6}$. Aucune cornmunication n'est indiquée avec le Braakman, et le métior d'Assenede s'étendait vers le Nord sans solution de continuité. Au contraire le bras de mer qui contournait l'île de'Zaamslag rejoignait en face d'Aandijke la crique d'Hulst. Celle-ci, dont les traces s'aperçoivent encore fort bien sur la carte néerlandaise à 1:50.000, suivait au N. d'Hulst le bord Ouest du Dullaart-polder ${ }^{7}$, le bord Est des terres do l'abbaye de Cambron ${ }^{8}$, passait devant Stoppeldijk ${ }^{9}$; c'est dans cette crique pompeusement qualifiée en 12:1 par l'évêque de Tournai de * Neptuni mare ${ }^{10}$ que se

1 Van Lokeren, St-Pierre, I, p. 328, $n^{0} 708$. Des textes de 1279 et 1282 confirment. la présence de la mer à Watervliet (lbid. I, p. 386, nn 884 et I, p. 427, nn 909 ).

Warnkönig, Flandrische Geschichte, III, p. 187.

3 Wolters, Recueil de Lois, II, pp. $4-5$.

4 En 1257, endiguements à Oostenblij de terres qui doivent être mises à l'abri des inondations de la mer (Van Lokeren, St-Pierre, I, p. 309, no 65\%). En 1262, endiguement de terres inonḋes par la mer entre Axel et Peerboom (Ibid. I, p. 331, na 733); Peerboom est situé vers l'emplacement actuel du Sas-de-Gand. (Van de Putte, Dunes, p. 337). En 1263, défenses contre les inondations de la mer dans le Canisvliet, au Sud d'Axel (Ibid. p. 343).

s Réponse de la contesse de Namur à une supplique, vers 1354 (Van Lokeren, II, p. 67, no 1205, note 1). Cf : Ab Utrecht Dresselhuis, De Provincie Zeeland, pp. 86-87. - Des schorres sont indiqués à Zaamslag en 1281 (Van Lokeren, St-Hierre, I, p. 401, $\left.\mathrm{n}^{\circ} 89 \mathbf{3}^{3}\right)$.

6 Ibid. II, p. 78, no 1245 (1363).

7 Terres dans le Dullaart polder, près du bord de la mer, en 1297 (Archives du Séminaire épiscopal de Bruges, $n^{\circ} 379$; citè dans Van Holleveke, Lisseweghe, son église

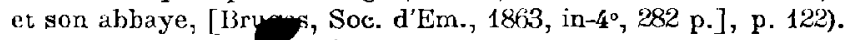

8 Charte de la colitesse Marguerite, 1269 (Kluit, Historia Critica, II, pp. 778-784).

9 Mussely et Molitor, Courtrai, p. 92 (1240).

10 Ibid. p. 533. - L'Oude haven actuel, eutre Stoppeldijk et Rummersdijk, est le dernier reste de la vieille crique de Hulst. 
jetait à ITengstdijk la crique de Vogel, endiguée en $1276^{1}$. Enfin tout est endiguè à l'Lst d'Ossenisse ; les polders de Saaftinge, de Namen, existent cn 1280 au bord du Hont ${ }^{2}$ et se relient par des schorres nouveaux (1267) aux polders de Kieldrecht, Calloo et le Doel ${ }^{3}$.

Ce tableau un peu minutieux, mais qui ne peut avoir d'intérêt que par lo nombre el l'exactitudo des détails, n'évoille pas l'idée d'un pays qui s'affaisse. L'homme y est en progrès continuel, et. ses conquètes se font avec une rapidite qui inspire le respect pour cette ouvre des particuliers et des moines. Le gain de la terre est constant; la mer ne parait dans l'action que pour préparer de nouveaux schorres. A peine signale-t-on une inondation, qui s'est accomplie ver's 1214 sur les terres de Graauw et de Frankendijk, et dont les dégâts sont réparés par un rẻendiguement on 1232 el $1233^{4}$. C'est la monnaie courante dans une région de polders. Les bras de mer entrevus depuis le $\mathrm{X}^{\mathrm{e}}$ siècle sont toujours là, mais ils vont sans cesse se resserrant, avec rapidité. Cette région zélandaise est sortie plus tard des eaux que le reste de la plaine parce que la présence d'un grand estuaire augmentait a cet endroit la force et la hauteur dos marées ${ }^{3}$; mais avec un ou deux siècles de retard elle s'est asséchée et peuplée aussi rapidement que le pays a l'Ouest de Bruges. On n'y trouve, pas plus qu'à Iunkerque, Calais ou Nieuport, trace d'une oscillation négative qui eût précipité la mer à travers ses polders. Au contraire à la fin du siècle, en 1282 et 1286 , le gain de la terre s'annonce comme plus fort que jamais. Guy de Dampierre, pauvre d'argent, est riche de schorres : et pour doter son fils Jean de Namur, il lui octroie toutes los terres neuves formées aux replis des estuaires et au front des digues. La liste en est longue: la mer a perdu du terrain partout, depuis le fond du hâvre du Zwin jusqu'aux lointains polders de Saaftinge ${ }^{6}$. L'envasement a marché si vite qu'on

\footnotetext{
1 Mussely et Molitor, Courtrai. p. 159.

2 Irautcour, Cartilaire de l'abbaye de Flines (Lille, Quaré, 1873, 2 vol. in-40\%, I, pp. 239-240.

3 Van Lokeren, St-Pierre, I, p. $353, \pi^{0} 787$.

4 . Mussely et Molitor, Courtrai, pp. 61-62, 67, 73, 83 .

5 Ia marée à Anvers a une amplitude sensiblement plus forte qu'à WVestkappel: $4^{\mathrm{n}}, 31$ contre $3^{\mathrm{w}}, 92$ (syzygies). (Wolters, Mémoire sur les marées, pp. 11-1 $\boldsymbol{i}$ ).

${ }^{6}$ les deux chartos sont publiées dans Gilliodts, Coutumes, Petites villes, t. III, p. 3,1 et VI, p. 331. Pour la premic̀re, M. Gilliodts accepte la lecture Assenede au lieu d'Alkems, inintelligible: il faut donc lire: "tous les utdis (hors des digues) entre Damıme, Biervliet et Assenede m. Cette lecture est conforme à l'ẻtat du pays à cette date; Jean de Namur reçoit les schorres formés dans le $Z$ win et dans le Braakmun. La charte de 1286 lui donne ceux qui se sont formés dans les criques d'Axel et
} 
dispute à Groede dès 1267 sur les alluvions formées depuis que l'évêque Walter de Marvis est venu (1243) partager entre les paroisses riveraines les nouveaux schorres ${ }^{1}$.

\section{Inondations et réendiguements : $\mathbf{X I V}^{\circ}-\mathbf{X I X}^{\circ}$ siècles. Róle des évènements historiques.}

On était peut-être allé un peu trop vite. Ia spéculation sur les endiguements faisait oublier les précautions nécessaires; on s"emparait des schorres avant qu'ils fussent mûrs. Les eriques restaient profondes ; la marée prenait plus de force dans les chenaux resserrés, et la mer commença à jeter bas les nouvelles digues ${ }^{2}$. Aussi les inondations commencent-elles à devenir graves depuis la fin du XIII ${ }^{\mathrm{B}}$ siccle. Il s'en produit une en $1277^{3}$ : ses effets durent être négligeables, car les chartes laissent aux chroniques le soin d'en parler. Celle de 1288, que Meyer donne pour prodigieuse ${ }^{4}$, mit sous l'eau la terre d'Ossenisse, qui fut réendiguée quatre ans après ${ }^{\circ}$.

C'étaient là des avertissements, qu'on négligea. On continua d'endiguer. Wulpen s'agrandit encore; l'île comprend 5 paroisses à la fin du $\mathrm{XIV}^{\mathrm{e}}$ siècle ${ }^{6}$. A Oostburg et Ijzendijke, l'énumération est longue, dès 1357, des terres endiguées depuis 1348 ". Au Nord d'Axel, on s'empare des schorres de l'île de Zaamslag, et en 1350 on voit apparaitre le polder de Terneuzen ${ }^{8}$. Devant ces entreprises nouvelles, la mer se cabre. Les inondations partielles deviennent fréquentes. Dans la liste dressėe en 1357 des terres nouvelles d'Oostburg, on découvre plusieurs petits polders

Hulst, ainsi que devant Frankendijk et Saaftinge. - Sur la question voir : Chartes au sujet des alluvions et schorres ou jets de la mer dans les Quatre-Mótiers (1285-13618), Mess. Sc. Hist., t. 56,1888, pp. 242-248.

1 Van Lokeren, St-Pierre, I, p. 353, no 787.

2 De même en 1809, les ingénieurs remarquent que les marées depuis quelques mois s'élèvent plus haut dans le Braakman, et qu'il y a plus souvent des marées extraordinaires; que cela répond à la fréquence des endiguements. - Arch. Nat. F* 1122.

3 Meyer, Annales, ad annum.

- Ibid.

5 Van de Putte, Dunes, p. 219.

6 Cf. Voisin, Testament d'Arnould de Maldeghem, p. 382.

7 Van Lokeren, St-Pierre, II, pp. 69-70, n 1216.

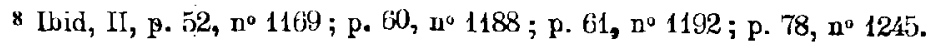


submergés, dont l'un endigué dans le courant de l'année et inondé aussitôt ${ }^{1}$. Le Westpolre de Saaftinge est sous l'eau en $1338^{1}$; le détroit de Biervliet s'agrandit, réduisant les terres endiguées à Milme au siècle précédent ${ }^{3}$. On finit par s'inquiéter et par réparer les digues; en 1353 on rétablit celles de Kieldrecht et de Calloo "; en 1376, on en hausse, slargit et renforce une qui protége le Nord du pays d'Oostburg ${ }^{3}$; on allait commencer des travaux analogues du côté d'Ijzendijke ${ }^{b}$, Iorsqu'unc grande inondation survint.

Cette catastrophe de 1377, qui ne paraît pas avoir frappé les conternporains, a épouvanté les historiens. Meyer, Gabbema, Smallegange, Van Waernewyck, en parlent avec terreur : c'est la mer s'introduisant par les écluses mal fermées (?) d'Hughevliet et noyant 22 villages dans le pays de Biervliet, Ijzendijke et Watervliet ${ }^{7}$; le Hont est élargi, le Braakman est formé. C'est beaucoup de dégâts pour une seule inondation. On a vu que lo Braakman existait avant 1377, sur lo même emplacement qu'aujourd'hui, au moins entre Assenede et Biervliet; quant au Hont, les textes du XIV ${ }^{\circ}$ siècle nous le présentent comme aussi important que de nos jours ${ }^{8}$. Enfin un

1 Cf. p. $17 \%$, note 7.

2 Mussely et Molitor, Courtrai, p. 244.

3 (1341) Van de Putte, Groeninghe, p. 74.

- Limburg-Stirum, Cartulaire de Louis de Male, II, p. 126.

5 Van Lokeren, St-Pierre, II, p. 88, n० 1297.

631 août 137 (Ibid. II. p. $\left.94, n^{\circ} 1306\right)$ ).

7 Meyer, Annales, ad annum; - Gabbema (S.-A.), Nederlandsche Watervloeden, of naukeurige beschrijvinge van alle Watervloeden voorgevallen in Holland, Zeeland, Flaandren, eng. (Gouda, Cloppenburg, 1703, in-80, 368 p.), pp. 137-138; - Smallegange, Cronyk van Zeeland, V, p. 225; - Van Waernewyck, Historie van Belgie, I, p. 174.

8 L'opinion qui fait du Hont, avant la fin du XVo siècle, un bras insignifiant, peutètre discontinu, date de loin; Kluit la formule (I, 2 partie, pp. 13 (140 et 164), et tous les historiens et géographes l'ont reprise après lui. Elle repose uniquement sur une charte de Jacqueline de Hollande ( $\mathrm{XV}^{\mathrm{e}}$ siècle), rappelée à la cour de Malines en 1504 (Kluit, I, p. 164) qui déclare que « par les grandes inondations qui advincent en son temps et aussi auparavant, la rivière de la Honte qui avait été petite, étroite et peu profonde, était devenue si large et grande et profonde, que les marchands ètrangers commençaient à prendre leur chemin par icelle Honte, etc. ". Cependant la cote flamande du Ifont n'était pas située plus au N. qu'aujourd'hui: Saaftinge, Ossenisse, Terneuzen, Hughevliet près Biervliet, Baarzand, la jalonnaient. A Ossenisse, à Saaftinge, le Hont est qualifiẻ de mer en 1183, en 1280, ce qui ne laisse guère supposer un bras étroit et sans profondeur (Van Lokeren, St-Pierre, I, p. 189, n० 342 ; Hautcour, Cartulaire de Flines, I, pp. 239-240). Cet estuaire était navigable; Kluit cite des tonlieux, coté zélandais, à Rieland, à Yalkenisse, en 1276 et 1283 (pp. 139-140); l'abbaye des Dunes de fait exempier en 1261 des droits de tonlieu 
certain nombre des villages donnés comme inondés ne paraissent pas en avoir beaucoup pâti. Willemskerke existe toujours en $1402^{1}$; Gaternisse en 1395 et $1398^{2}$; Nieuwerkerke près d'Oostburg en $1410^{3}$. Il est probable que l'inondation ne recouvrait les parties envahies que d'une tranche de 1 à 2 mètres d'eau à marée haute, el quittait les terres á marće basse : aussi essaie-t-on de réendiguer aussitôt. En 1388, on projette une digue pour assécher le métier d'Ijzendijke, et en attendant on en fait une pour protéger l'Oude Yevene 4. Ce n'est qu'en 1399 que l'on s'informe du nom des locataires qui ont l'intention d'abandonner les terres inondées ${ }^{5}$. L'on n'avait malheurousement pas accompli les traraux nécessaires avec la célérité désirable. C'est l'époque des troubles qui agitent la Flandre sous Louis de Nevers; occupés au Beverhoutsveld et à Roosebeke, les gens du Franc négligèrent leurs digues ${ }^{0}$; par passion politique, on les eut plutôt crevées, sill l'eut fallu ${ }^{7}$. Et l'on découvre là la principale cause des désastres de la Flandre zélandaise. Si l’inondation pénètre dans les

sur tout le parcours du Hont (Van de Putte, Dunes, p. 218). Enfin la largeur de l'estuairé est démontrée par la position des villages placés sur les bords ; on a énuméré ceux du côté flamand; du côté zélandais, Rieland, Valkenisse, sont aujourd'hui un peu dans les terres; Melis Stoke (Rijmkroniek van Holland en Zeeland, VII, v. 1117) qualifie le Hont de «mer s'ëtendant d'Arnemuiden (Walcheren) jusqu'en Flandre ». Un précieux point de repère est fourni par le procès-verbal de délinitation d'un schorre a Hontenisse en 1368 ; on prend comme point de mire la tour zélandaise de Kruiningen (Van de Putte, Dunes, p. 756). Cela indique que la largeur du Hont n'a guère variè à cet endroit. S'il y a eu un changement depuis la fin du XIIIe siècle, il faut le chercher dans un rétrécissement lent, mais continu, de l'estuaire.

1 Mussely et Molitor, Courtrai, p. 288.

2 Van Lokeren, St-Pierre, II, p. 123, n 1421 et II, p. 139, $\mathbf{n}^{\circ} 1449$.

Ibid. II, p. 165, no 1554. -- Oosemanskerke est citée en 1495, mais peut-être après réendiguement; St-Nicolas de Varne est indiqué comme inondé en 1/24 seulement (Ibid. II, p. 402, no 2221). Enfin daus les Comptes du Franc, on indique au 24 avril 1404 qu'un messager fait en 3 jours la tournée de Bruges à Moerkerke, Coxyde, ljzendijke, Hulst, avec retour par Ursel et Sysseele (Delepierre, Précis analytique, $2^{\ominus}$ série, I, p. 70). Pour que cette course pût se faire en 3 jours, il fallait que le pays fut à sec.

- Van Lokeren, St-Pierre, II, p. 107, n॰ 1350.

5 Ibid. II, p. 141, n 1459.

6 En 1387, les digues de l'Oude-Yevene sont en trés mauvais état, à cause des troubles de Flandre qui ont empêché de les réparer (Van Lokeren, St-Pierre, II, p. 101, no 1341). En 1395, nomination d'inspecteurs de digues dans le métier d'Oostburg, ou l'entretien des digues a été négligé depuis longtemps, par suite des troubles (Ibid. Il, pp. 123 et 125, nos $1421,1422,1424$ ).

7 C'est ce qui se produit en 1384 à Hontenisse, ou Arnould Janssoone rompt les digues, au cours de la lutte de Gand et' du comte. (Meyer, Annales, ad annum); cf.

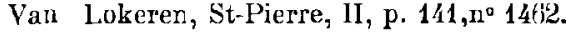


terres et s'y maintient, c'est que l'homme, occupé à la guerre civile ou étrangère, néglige l'entretion des digues et ne répare pas aussitôt les dégâts de l'inondation; le vent du N.-W., qui pousse les flots dans l'estuaire et dans le Braakman, est moins coupable que le spéculateur pressé qui a endigué trop tôt et que le dykgraaf de la wateringue, dont les préoccupations vont à Yoens et Van Artevelde plutôt qu'à l'entretien de ses digues.

Aussi le pays d'Oostburg et d'Ijzendijke, où les dégâts de 1377 avaient été mal réparès, restait à la merci d'une nouvelle inondation. Elle se produisit en 1404, et eut des effets beaucoup plus considèrables que la première. A Damme, la marée reste 24 heures sans descendre 1. Cette fois, les chartes en parlent ${ }^{2}$. Le Transport de 1408, qui est un véritable dénombrement de la Flandre pour cette date, énumère les paroisses disparues : à l'Est du Braakman, Wevelswale, Koudekerke, Boterzande, Visschersdorp ; à l'Ouest, Watervliet, Elmare, Hamere, Roeslaere, Ijzendijke ; Biervliet est fortement diıninué; lo pays d'Aardenburg perd Coxyde et Iang-Aal'denburg ${ }^{3}$. I a mer s'avance jusqu'au Houtland de Caprycke et Lembeke ", elle joint le Zwin au Braakman par le CoxijscheGat, qui s'ouvre entre Slependamme et Oostburg ${ }^{5}$. Tout le pays entre l'Oude-Yevene, qui reste intacte, et la ligne des terres hautes, par St-Kruis, Bentille et Bouchaute, est sous les eaux. Biervliet, avec les deux Zoute-polders, forme uneîle; le Braakman s'allonge vers Peerboom, dans la direction d'Axel ${ }^{6}$.

Ainsi le domaine de la mer paraît démesurément accru; le Braakman

1 Comptes de Damme, 1403-4, fo 36, n 1 . Cité dans Gilliodts, Inventaire, Introduction, p. 467.

2 Charte de la duchesse Marguerite de Male, de fëvrier 1405 (datè à faux de 1404 par Van Lokeren, St-Pierre, II, p. 154, n 15013); - attestation de 1411 que les terres do l'albaye à Watervliet sont couvertes par les flots de la mer (Ibid. II, p. $16\left(6, n^{\circ} 15{ }^{\circ}(9)\right.$; - eharte de 1416 pour l'abbaye des Dunes (Van de Putte, Dunes, p. T73); - charte de Maximilien de 1493, rappelant l'inondation de 1404 (Gilliodts, Inventaire des Archives de Bruges, VI, pp. 436-437) ; - octroi de Philippe le Beau, de 1497 (Wolters, Recueil de lois, II, pp. 38-39); - «Payé 40 sch, par jour à Nicolas Tolnin pour aller examiner, le long des çôtes, oi la mer a rompu les digues " (Comptes du Franc, 1403-4, dans Delepierre, Précis analytique, $z^{3}$ série, I, p. 70).

3 Cf. Gilliodts, Inventaire des Archives de Bruges, IV, pp. 23-25; - Priem, Précis analytique, $2^{\mathrm{e}}$ série, VI, pp. 151-1\%5.

- Van Lokeren, St-Pierre, II, p. 15/, n 1503.

5 Cif. Charte de Jean sans Peur, de 1410, dans Wolters, Recueil de lois, II, p. 13, et Gilliudts, Coutumes, Petites villes, I, p. 90.

6 Van de Putte, Dunes, p. 248. 
devient énorme. Mais en réalité, ces terres inondées restent à l'état de schorres, d'oì pointent des débris d'édifices, tours, églises. En 1557, quand on retrouve le cimetière de St-Christophe d'Ijzendijke, on constate que les ossements humains sont éparpillés à la surface du schorre: ${ }^{\mathbf{1}}$, ce qui prouve que les courants ont été bien faibles à cet endroit, et le dépót d'alluvions très restreint; d'ou l'on conclut que le territoire inondé n'était recouvert que par les très grandes marées. L'cau s'était établie seulenent dans trois chenaux principaux : le Passegeule, qui faisait suite au CoxijscheGat, et occupait l'emplacement de l'ancienne crique d'Elmare ; le Drooch te et le Zuiddiep, qui prolongeaient le Passegeule au Nord et au Sud do l'île de Biervliet, et rejoignaient le Braakman².

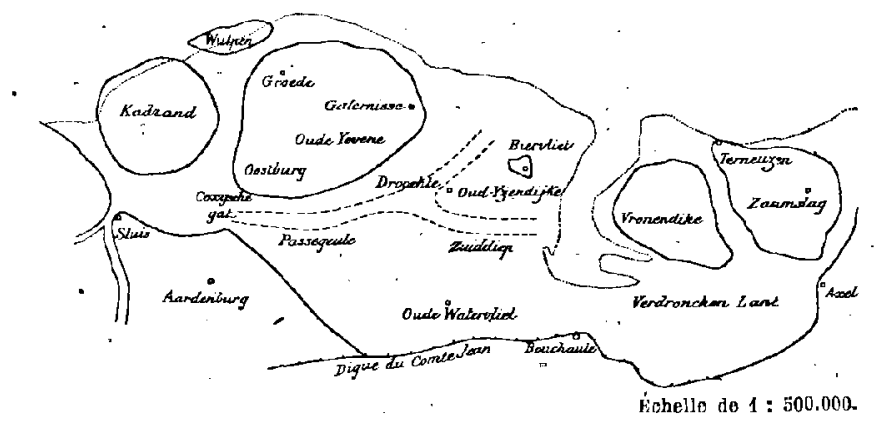

Fig. 36. - Partie occidentale de la Flandre zélandaise après les inondations' du XVe siècle.

Aussi recommence-t-on aussitôt à réendiguer ${ }^{3}$. On prend cette fois des

1. Procès-verbal de la visite dans Van Lokeren, St-Pierre, II, p. 410, n० 2255.

2 Détails tirés des chartes accordant des ondiguements au cours du XVo siècle, et citées par la suite. On peut hẻsiter sur la question de savoir si c'est bien après 1404 que le Brakman entre définitivement en communication avec le Zwin. Il s'est produit au XVo siècle d'autres inondations, celle de 1440 notamment, à laquelle des historiens zélandais attachent une grande importance (Hunnius [B.], Het Staatische Vlaanderen of de Zeeuwsche buize, met de veranderinge, die.'t zeewater an de Zeeuwsche eylunden heeft gegeven, eng. [Middelburg, Clement, 1718, in-8 ${ }^{\circ}, 388$ p. , p. 239 ; - Drosselhuis [ah Utrecht], Het distrikt van Sluis in Vlaanderen [Middelburg, Yan Beuthem, 1819, in-8\%, 162 p.], p. 25). La communication n'est pas indiquée sur la carte du pays au début du XVo siècle, à d'autres égards satisfaisante, par Willems (Historisch Onderzoek, etc. Antwerpen, Van der Hey, 1828, in-8, 293 p.). Mais M. Roos, dans son travail, la croit même antérieure (Woordenboek van Zeeuwsch-Vlaanderen, pp. 40-41).

3 Dès dẻcembre 1404, on travaille dans toute l'étendue des ambachten d'Oostburg et Aardenburg: Cf. Van Lokeren, St-Pierre, II, p. 156, nº 1515. 
précautions: c'est alors que s'élève, tout le long du Houtland, de St-Laurent jusqu'au delà d'Assenede, cette * digue du comte Jean $\gg$ que l'on attribue à Jean de Namur, fils de Guy de Dampierre, et dont on doit reporter l'honneur à Jean sans Peur, dont le règne est contemporain de l'inondation et de la reconquête du sol ${ }^{4}$. On protége ainsi les paroisses de Bentille, Caprycke, Bassevelde, Bouchaute, effrayées par la catastrophe, et on constitue une base solide sur laquelle vont s'appuyer les endiguements. Puis on se met à l'œuvre avec prudence. En 1409 lo Hellonpolder, en 1410 le Kokhuijtpolder, en 1412 le Fazierspolder sont conquis ${ }^{2}$; la région qu'on appellera désormais « Waterlanden $n$, le pays des eaux, commence à redevenir une terre habitée. En 1416, on se dispute déjà les dîmes des schorres de Watervliet et do Varne ${ }^{3}$. Après un temps d'arrêt, dû peut-être à l'inondation do 1440, les endiguements recommencent: en 1448 , on songe à s'attaquer aux schorres d'Ijzendijke ; en 1467, il existe un polder St-Georges « au lieu appelé jadis Watervliet», et à còté un Mariapoldre ". La marche en avant est lente et sûre. De l'autre côté du Braakman, on reprend, à partir de 1431, les terres inondéos de Wevelswale, Koudekerque, Vronendijk ${ }^{\boldsymbol{b}}$; de ce côté le Braakman commence à retrouver ses anciennes limites. Partout ailleurs, où les inondations du début du siècle avaient envahi des territoires, on réendigue activement: à Othene en $14644^{7}$, à Saaftinge où on a repris en 1421 les terres perdues par « les grandes tempêtes et inondations des eaux de la mer ${ }^{8}$, qui sonl celles de $1404^{9}$; à Ossenisse où on répare en 1467 les dégâts causós par Arnould Janssoone ${ }^{10}$; dans les polders du pays de Waes, où on reconquiert les terres de Calloo, Kieldrecht, Verrebroeck,

1 Jean devient comte on avril 1404. On a vu qu'à l'époque de Guy de Dampiorre ot de son fils Jean de Namur, la mer est retirée au delá de Groede, Biervliet et Assenede; pourquoi serait-on allé construire à ce moment une digue à 15 kilomètres dans l'intérieur?

2 Roos, Woordenboek, pp. 113-115.

3 Van Lokeren, St-Pierre, II, p. 180, no 1596.

Ihid. II, p. 234, no 1753.

s Ibid. II, p. 273, n० 1872.

6 Placcaetboek van Vlaanderen, III, p. 434.

7 Van Lokeren, St-Pierre, II, p. 270, no 1858.

8 Hautcone, Flines, II, pp. 746 et $752-754$.

9 Van de Putte, Dunes, p. 764. - Do mèrne : Van do Putte et Carton, Ter Doest, pp. $79-81$.

10 Van Lokeren, St-Pierre, II, p. 273, n० 1870. 
Melsele ${ }^{1}$. Malheureusement le pays est de nouveau agité, après la mort de Charles le Téméraire, par la guerre civile et la guerre étrangère. Dẹ 1477 à 1500, sous le règne de Marie de Bourgogne et la régence de Maximilien, se déroule un des plus tristes moments de l'histoire de Flandre. La mer en profite; l'inondation de 1477 ravage toute la côte, de Nieuport à l'Escaut "; le métier d'Aardenburg est endommagé, et l'on voit bientôt se reformer entre Aardenburg et Damme l'énorme crique du Lapschuursche-Gat.

Mais lorsque l'archiduc Philippe et son fils Charles-Quint eurent rendu la paix au pays, l'éternelle lutte reprit contre la mer, avec un plein succès. De 1495 à 1560, l'homme gagne sans cesse sur les flots ${ }^{3}$, et cette continuité de succès marque bien qu'il ne faut pas chercher dans des oscillations du sol la cause des retours offensifs de la mer en Flandre zélandaise; quand l'homme sait se défendre, la mer n'avance plus; quand on l'attaque, elle recule. Les inondations de détail qui se produisent, et elles sont nombreuses, n'y font rien; une population active et bien diriǵée veille*. Il est à peu près certain qu'il ne se passait guère d'années sans que, çà el là, une digue ne fût rompue, un polder inondé, un village submergẻ. Huit jours après, le dommage était réparé. On obstruait la brèche avec des toiles à voile et des sacs de sable; on réparait la digue avec la terre grasse du schorre, et il ne restait guère de traces qu'un peu d'eau saumâtre dans une crique. A l'automne suivant, il $y$ avait un peu plus de fièrres, mais les moissons ne s'on portaient pas plus mal.

L'activité des endiguements se porte de deux côtés; on reprend les territoires perdus en 1404, et on en conquiert de nouveaux entre Kadzand et la côte. La tâche était considérable. Une partie des polders rétablis

1 Wolters, Recueil de Iois, II, pp. 16-26, 27-38; - Van Lokeren, St-Pierre, II, p. $250, n^{\circ} 1780$.

2 Comptes du Franc, $1477-78$ (Priem, I'récis analytique, $2^{e}$ série, II, `pp. 138-139). - Dans une charte de 1493, Maximilien constate qu'à la suite des guerres les digues et écluses de mer abandonnèes sont près de se rompre.... (Gilliodts, Inventaire, VI, pp. $436-437$ )

3 Dates d'octroi pour endiguement d'un grand nombre de polders indiquées dans do Wulf, Generuelen Index van de vyf Placcaertboecken van Vlaenderen (Gendt, de Goesin, 1776 , in-4 $4^{\circ}, 690$ p.) d̀ l'article Dycken-Dyckage, p p. 164-105.

- Les Comptes du Franc indiquent des inondations pour 1502 (Wulpen), 1509, 1511, $1513,1514,1516,1517$, 1521 (d'Ostendo à I3iervliet). Celle du 5 novembre 1530 fut particulièrement considérable : cependant on réendigua aussitôt. C. : Delepierre et Priem, Irécis analytique, 1'se série, II, p. 40; $2^{8}$ série, II, pp. 246-47, 263-64, 268-69, $274,277,285,288$; III, pp. 4, 49, 54; IV, pp. 34, 44, etc. 
avant 1477 avait succombé pendant les troubles de Flandre ${ }^{1}$. Ruinées par les guerres et les inondations, les grandes abbayes étaient hors d'état de reconquérir leurs anciens territoires. Ce furent des sociétés capitalistes qui en assumèrent l'entreprise. La famille de Baenst, en 1497, reçoit la concession de tous les schorres entre Assenede of Kadzand 2; c'était vraiment trop, et les do Baenst passèrent bientôt à Jórôme Laureyns la besogne et le profit d'endiguer les Waterlanden. Alors sous l'impulsion de ce hardi homme d'affaires, en 50 ans le pays est transformé. Aux polders de la lisière méridionale, St-Joris de l'Est, St-Jean in Eremo, StLiévin, St-Joris de l'Ouest, déjà reconstitués en $1497^{3}$, viennont s'ajoutor en 1501 le Christoffels, en 1503 le Jeronemus, en 1504 les Maria, Laureinen et Helle-polders, en 1506 le Philippus ${ }^{4}$, dans lequel Jérôme I aureyns bâtit la même année, en l'honneur de son souverain, la ville de Philippine ${ }^{5}$. Ainsi do ce côté, où le Kapol-Polder existe déjà en $1503^{\circ}$, la côte est d̀ peu près au même point qu'aujourd'hui. Après un si beau début, la famille Laureyns continue les traditions de son chef; Mathias Laureyns, fils aîné de Jẻrôme, annexe à ses domaines l'Oudemans-polder (1521), l'Oosemans (1523) ${ }^{7}$; on était arrivé ainsi au bord de l'ancienne crique du Passegeule, qui faisait communiquer le Zwin et le Braakman, mais qui s'était si bien comblée d'elle-même qu'en 1516 les Brugeois, désireux de rétablir cette communication, avaient dû creuser entre Coxyde et Ste-Catherine d'Oostburg un canal maritime qui prit leur nom (Brugsche Vaart) ${ }^{8}$. En 1528, le Passegeule polder existe; la crique est terre ferme; vers 1530

1 Le polder St-Jacques, ondiguẻ en 1472 (Van Lukeren, St-Pierre, II, p. 278, no 18(7), est indiqué comme inondó ensuite, puisqu'on accorde l'octroi de réendiguement en 1505 (Gilliodts, Coutumes, Petites villes, V; pp. 332-333). Et on lit dans cet octroi a que durant les guerres et divisions de Flandres, la digue principale a été rompue ", etc. Mêmes indications dans Gilliodts, Ibid. IT, pp. 665-666.

2 Charte doctroi dans Gilliodts, Potites villes, V, pp. 280-281.

3 Van Lokeren, St-Pierre, II, p. 307, n 1964 . Les polders actuels de St-Anna ot Barbara y compris.

1 Dates dans Gilliodts, Coutumes, Petites villes, V, p. 154, note 3 ; - Roos, Woordenboek, pp. 113-115 et passim.

s Gilliodts, Ibidem, V, pp. $356-360$.

6 Van Lokeren, St-Pierre, II, p. 330, no 2005.

7 Roos, Woordenboek, pp. 113-115.

8 Le canal est ouvert en 1516 dans le Dierkenstenpolder. G. Gilliodts van Severen, Bruges Port de mer (Ann. Soc. Em. Br., $5^{\mathrm{e}}$ série, t. VII, 1894, 540 p., 3 cartes), pp. 170-186, et la suite, p. 66. 
s'y ajoute le Vrijen polder ${ }^{4}$. Bientôt l'île de Biervliet s'agrandit par l'endiguement de nouveaux schorres $(1538)^{2}$. Le Zuiddiep se réduit; on le diminue encore en 1542 du Gouden-polder, en 1546, du vaste Jonkvrouwpolder ${ }^{3}$. Entre la digue du comte Jean et les derniers schorres du Droochte, toute une petite province est sortie de l'eau; on y élève maisons et églises, les vieux noms d'Oosemanskerke, St-Nicolas de Varne, Watervliet reparaissent; on y plante la garance et le colza ; on y dispute âprement sur les ancionnes dîmes".

Pendant qu'on regagnait le terrain perdu à l'Est, on faisait de nouvelles conquêtes à l'Ouest. Les chenaux entre le continent et les îles de Wulpen et Kadzand avaient continué à s'atterrir pendant le XV' siècle. Le Vloet, entro Wulpen et la côte, existait encore en $1548^{\circ}$, mais à peu près comblé, comme en temoigne la carte du Franc, dresseje en 1562 par Pourbus ${ }^{6}$. Un schorre s'était formé devant la côte de Groede, comblant peu à peu l'ancien bras du Lemmer; dès 1500, il paraissait mûr. Entre Kadzand et Wulpen, le gros bras du Zwartegat, le «trou noir» aux violentes tempêtes, était encore ouvert en $1435^{7}$; mais il devait s'être fermé au milieu du siècle, puisque les Brugeois, pour ramener l'eau dans le Zwin, projettent de le rouvrir en $1470^{\circ}$. La réouverture a lieu dès 1471, sans que le Zwin y trouve l'approfondissement désiré ; si bien qu'on travaille, dès 1485, à refermer la crique, sans succès d'ailleurs ${ }^{9}$. Il resta donc, derrière Kadzand, une sorte de canal que la mer remplissait à marée haute. Mais de chaque côté de cette crique, l'activité des endiguements est intense. Les de Baenst accomplissent sur ce terrain l'œuvre qu'ils avaient abandonnée à Watervliet à l'activité do Jérôme Laureyns: le

1 C. Van den Bussche, Irventaire des archives du Franc, p. 233; Gililiodts, Coutumes, Petites villes, V, pp. 397 et 180 .

2 Van Lokoren, St-Pierre, II, p. 368, no 2154.

3 Hid. II, p. 371, ॥ $^{\circ} 2178$.

4 Cf. nombreux actes dans Van Lokeren, II, pp. 3677 a 410, $1^{25} 2145,2164,2178,221 \overline{3}$, $2219,221,2222,2230,2243,2455$.

5 Comptes du Franc, 1547-48 (Priern, Précis analyique, 2o série, II, p. 100).

6 Pourbus, Carte du Frano de Bruges. (Ann. Soc. Em. Br., ze série, VIII, 1850), p. 291).

7 Etat des fiefs de l'ille de Kadzand, 1435 (Gilliodts, Coutumes, Petites villes, II, p. 25).

8 Texte du projet dans Diegerick, Inventaire analytique etchronologique des chartes et documents appartenant aux archives de la ville d'Ypres (Rruges, 1853-68, 7 vol. in $\left.-8{ }^{\circ}\right)$, III, pp. 287-88.

9 Gilliodts, Bruges Port de mor, pp. 47-49 et 78. 
Baenstpolder est de 1510 , le St-Jans de 1502 ', appuyé à l'Antwerper, qui est créé en 1417 el réendigué en $1506^{\circ}$; l'Adornis est établi en 1535 , le Mettenijo en 1540, le Nieuwenhoven on $15 \overline{5} 4^{3}$, le Iijsbet en 1556, et après une inondation, en 1562 . La lutte avait été dure, mais la victoire

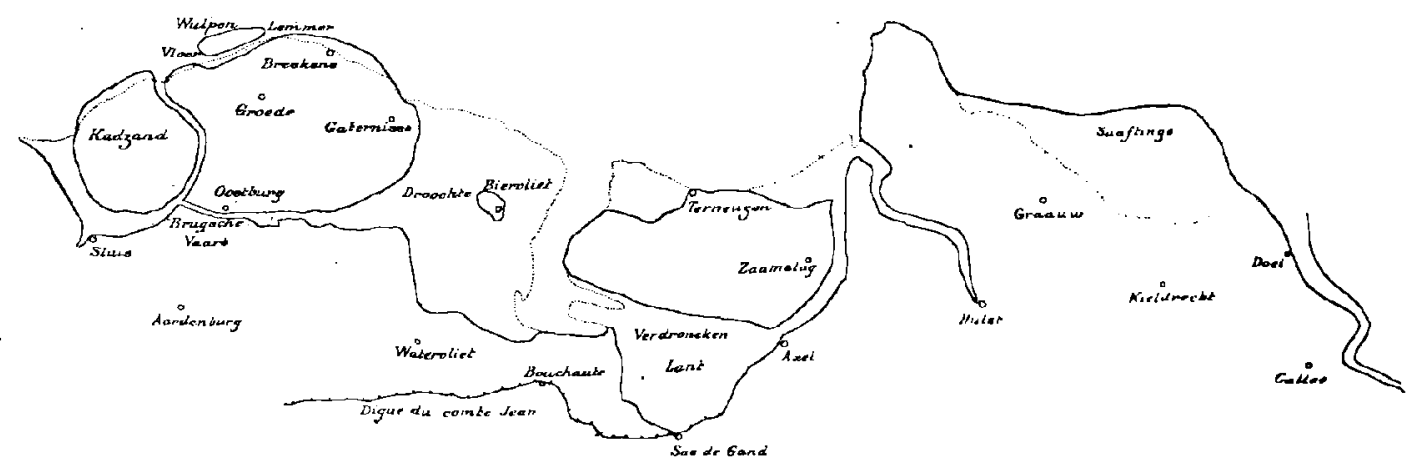

Échelle do $1: 500.000$

Fig. 37. - La Flandre zélandaise vers 1570. Rivage actuel.

restait a la terre, et il n'y avait plus en 1570 qu'un étroit chenal occupé aujourd'hui par le Groote St-Anna polder. Au Nord de Groede, les schorres qu'on appelle déjà Breskinszant au $\mathrm{XV}^{\mathrm{B}}$ siècle sont concédés en 1510 à Philippe de Clèves ${ }^{5}$, qui y établit entre 1511 et 1550 les polders OudBreskens, Jong-Breskens, Kleefschen, Barbara et Grunters, en partie disparus aujourd'hui ${ }^{6}$. Ainsi au milieu du XVI" siècle, il semble que la Flandre zélandaise soit près de prendre sa forme définitive. Wulpen et Kadzand se joignent à la terre ferme ${ }^{7}$; le comblement du Braakman

1 Endiguẻ en 1502, englouti en 1512, réendiguẻ en 1527, englouti en 1547, réendigué ensuite (Roos, Woordenboek, p. 7/).

2 Roos, Woordenboek, p. 18.

3 Dates dans Gilliodts, Coutumes, Petites villes, VI, pp. 601-605.

Ibid. III, pp. 367-369. Il faut y joindre le St-Joris (1513), l'Eiken (1543), le loodijk (1556), (Roos, Woordenboek, pp. 76, 48, 100).

5 Van Lokeren, St-Pierre, II, p. 333, n० 2024.

6 Gilliodts, Coutumes, Petites villes, III, p. 369.

7 Cependant les deux îles commençaient à courir de sérieux dangers du côté de la pleine mer. Líle de Wulpen, qui compte encore au rooins 5 paroisses au milieu du XVo sieclo (Gilliodts, Coutumes, Petites villes, II, p. 5) est extrèmement menacéo au XVIo; les Brugeois déclarent en 1513, avec une exagération calculée, qu'elle a perdu 4 villages (Gilliodts, Bruges Port de mer, p. 145); l'inondation de 1530, cello de 
s'accomplit lentement et sûrement; pendant que la famille Laureyns pousse ses digues vers Biervliet et Philippino, on établit sur l'autro rive les Kouden et Lovenpolders $(1511-12)^{1}$; de grands schorres prèts à l'endiguement s'étendent de Philippine à Axel. Hulst a toujours une communication avec le Ilont par l'étroit chenal de l'Oude-Haven "; Saaftinge, Ossenisse, Frankendijk, Namen-polder résistent aux inondations qui les assiègent ${ }^{3}$, el l'on reconquiert en 1567 les schorres du Doel, abandonnés depuis plus de 200 ans ${ }^{4}$.

Quarante ans après, la Flandre zélandaise est presque complètement sous l'eau. Depuis le XII siècle, jamais le pays n'avait été aussi largement inondé. La mer a reconquis le Zwartegat, agrandi le canal de Nieuwerhaven ouvert entro le Hont et le $Z$ win vers 1515, de Gaternisse a Oostburg ${ }^{5}$. Wulpen n'existe plus ${ }^{6}$. A la place du Brugsche Vaart comblé,

1512 ou elle fut submergée "par les grans vens et glaces qui rompirent les dicques" (Arch. hosp. de lille, I, p. 429, $\mathbf{n}^{\circ} 4521$ ), compromettent jusqu'à son existence. L'ile est singulièrement réduite en 1562 , d'après la carte de Pourbus. Kadzand souffre des mêmes catastrophes; mais l'île est plus grande, et moins exposée à l'attaque des courants yui vout et vienneut dans l'estuaire. Flle perd pourtant 500 mesures en 1531 , et Charles-Quint, en-1537, pour rendre plus énergiquo la résistance, fusionne les innombrables petits polders qu'indique lo dénombrement de 1435 (Aruhives de la ville do Bruges, Reg. do dón. de 1435, fol. 47 à 53) on une seule association do wateringue (Charte dans Gilliodts, Coutumes, Petites villes, Il, pp. 13-22); en même temps il fait abandonner à la mer une partie du polder des Mille Mesures, « à cause des passes profondes et des hrisants de la mer qui se trouvent à proximité de la digue du dit polder (Ihid:). Ainsi la passe de Wielingen semble se rapprocher de la côte ${ }_{q}$ dont elle dévore des lambeaux

1 Scharp (J.), Geschiedenis en costumen van Axel (Middelburg, Abrahams, 1787, in -8 , 3 vol.), I, p. 300. - I a carte de P. Verbist, pour 1565, montre que le Braakman rejoint toujours, derrièrc Zaamslag, la erique d'Axel (Arch. Flandre Orientale, earte $\mathrm{n}^{\circ}$ 434).

2 Gf. Gheldolf (A.-E.), Notes sur la carte des pays inondés en 1583 au Nord de Hulst, St-Gilles, Vracene, Boveren, Melsele et Zwyndresht. Mess. Sc. Hist., X (1842), pp. $3 / 8-358$, carte.

3 Par exemple celle de 1530. - Cf. Hautcour, Flinos, I, p. 488; - Schoutete de Tervarent, Inventaire gónéral analytique des archives de la ville et de l'église de St-Nicolas (Bruxelles, Muquardt, 1872, in $-4^{\circ}, \mathrm{X}+.556 \mathrm{p}$ ), pp. $46-47$ et $56, \mathrm{n}^{\circ \mathrm{0s}} 93,94$, 109.

4 Van Lokeren, St-Pierre, II, pp. 420 et 421 , nos 2200 et 2298 .

s CF. Diegerick, Arch. d'Ypres, III, pp. 287-88; - Delepierre, Précis analytique, $1^{\text {re }}$ série, III, p. 227 ; - Van Dale (J.), De Heerlijkheid Breskens (Bijdragen tot de Oudhcidkunde, etc., Il, pp. 115-177), p. 134.

6 Le deruier indice que l'on possède de l'existence de Wulpen est un bail, daté de 1593, de diverses pièces de terre en la paroisse St-Lambert (Arch. hosp. de Lille, I, p. 138). Les inondations de la grande guerre sont donc la cause de la disparition complète de l'île. 
la mer s'est ouvert entre Zwin et Braakman un nouveau Passegeule, subdivisé en plusieurs bras, Haentjesgat, Brandkreek, entourant des schorres dévastés. Toute l'œuvro des Laureyns est à refaire. Du pays d'Axel, il ne reste que deux îles; la petite ville voit les marées battre ses remparts. Un énorme bras se dirige d'Axel vers Hulst, et de lá au Hont, entre Zaamslag ot Stoppeldijk. Tout le pays à l'Est d'Hulst, les polders de Saaftinge, Graauw, Kieldrecht, Calloo, Zwyndrecht, sont sous l'eau. Des bancs d'alluvious grises on voit érnerger des décombres, comme la tour de Zaamslag, qu'indiquent toutes les cartes. Sur les terres restées sauves, il n'y a plus d'habitants; les uns se sont enfuis en Zelande, les autres en Flandre.

Tout cela est l'ouvre de l'homme. La lutte des Pays-Bas contre Philippe II a fait de nouveau négliger les défenses de la côte. La mer en profite : dès 1570, une formidable inondation envahit le pays. Mais cela ne serait rien, et on réparcrait les dégâts, comme on l'a fait à Saantinge ${ }^{1}$, si les belligérants ne provoquaient eux-mêmes l'envahissement du pays par la mer. En 1584, les Zélandais qui craignent un débarquement dans Zuid-Beveland brisent les digues à Saaftinge, et le pays disparait sous l'eau ${ }^{2}$. En 1583, la garnison de Sluis inonde le Beoostereede ${ }^{3}$; en 1586, c'est le tour du pays d'Axel ". Ceux de Groede, en 1583, mettent leur village sous les eaux plutôt que de le laisser prendre par l'armée d'Alexandre Farnèse ${ }^{5}$. La Flandre zélandaise devient la province sacrifiée qu'elle est encore aujourd'hui. Désireux d'assurer la sécurité de Walcheren et de Zuid-Beveland, les Etats-Généraux devenus possesseurs du pays ne se pressent pas de réendiguer. Quand on s'y met, on commence par les schorres du Nord, oì viennent s'établir des Zélandais protestants; c'est un bastion que l'on établit au delà du vaste fossé du Hont; en avant, la ligne d'inondations reste un excellent moyen de défense. Groede, Breskens, Kadzand, Ijzendijke d'une part, le pays entre Axel et Torneuzen de l'autre, réapparaissent ainsi après la trêve de 1609 ; mais le reste n'a la permission de vivre qu'après la pais de Westphalie. Alors les endiguements se précipitent, comblant.le $Z$ wartegat, le Passegeule et ses criques, le chenal d'Axel à Hulst. Le pays se reconstitue avec une rapidité inouie, soit que l'art des endiguements ait progressé, soit que la mer pendant son séjour ait

1 Van Lokeren, St-Pierre, II, p. 423, n० 2302.

2 Hunnius, Staatische Vlaanderen, p. 204.

3 Roos, Woordonboek, pp. 46-47.

1 Hunnius, Staatische Vlaanderen, pp. 328-29.

5 Roos, Woordenboek: pp. 58-59. 
haussé les schorres du dépôt de nouvelles alluvions. Parfois les EtatsGénéraux font mettre sous l'eau, à l'approche de l'ennerni, quelques polflers du Sud: la guerre de Hollande, la guerre de la ligue d'Augsbourg, la Succession d'Espagne et la Succession d'Autriche, la lutte de Joseph II contre la Hollande et la cámpagne de 1794 voient inonder les environs d'Hulst, d'Axel, du Sas-de-Gand, de Sluis. Lorsque les criques se comblent et qu'en dépit des efforts pour la retenir, la mer s'éloigne et abandonne le pays, les Etats-Généraux lui ouvrent et lui approfondissent un nouveau

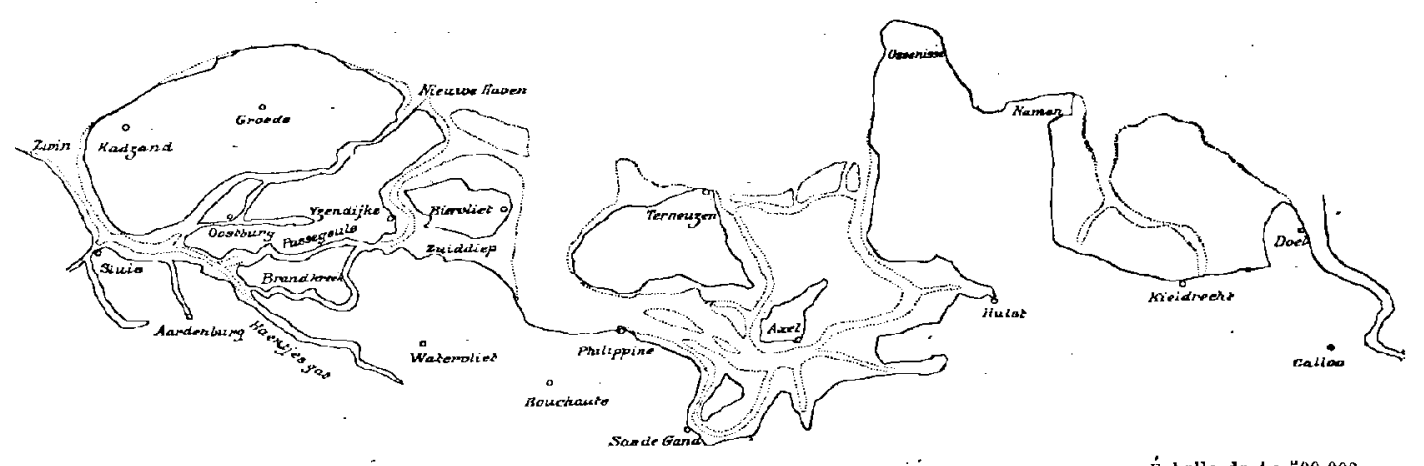

FIG. 38. - Flandío xélandaise à la fin du XVII siècle.

Échelle de 1: 500.000 ,

.......... Limite des terres découvertes a marce basse.

lit; quand le Passegeule est disparu, l'ingénieur Wildschut en 1735 creuse entre le Zwin et le Brakkman un nouveau lit baptisé Nienw Passegeule, qui renforce la «Linie », cette ligne de redoutes et de bastions dont la Zélande se protège contre une aggression venue du Sud ${ }^{1}$.

Ce ne fut guère qu'au milieu du XVIII ${ }^{\sharp}$ siècle que le pays eut vraiment retrouvé sa forme, et qu'on pul conquérir prudemment les bras de mer qui restaient au milieu des terres comme des menaces d'inondation. Le Oude-haven de Hulst, déplacé vers l'Ouest, était remplacé par la crique du Hellegat, qui passait entre Zaamslag et Stoppeldijk : en 1789 on en supprime le fond en créant les Riet-en-Wulfdijk et Absdale polders; en 1795 on isole la Hulster Vlakte par la digue de Luntershoeck 2. Au $\mathrm{XIX}^{\circ}$ siècle, on a refoulé le Ilellegat jusqu’à Campen, à l'endroit où

1 On trouvera les dates de réendiguement dans Roos, Woordenboek, pour lo Pays do Kadzand, e'est-à-dire la région à l'W. de Philippine; Wolters, Recueil de Lois, II, pp. 136-259; Dresselhuis, De Provincie Zeeland, pp. 80-90; Hunnius, Staatische Vlaanderen, pp, 268-269; Kümmer, les Polders du Bas-Escaut, pp. 34-54, etc.

2 Dresselhuis, De Provincie Zeeland, p. 89; - de Potter (J.-C.), Beschrijving van de stad en het ambacht van Hulst (Gorinchem, Noorduyn, 1844 , in-8, 68 p.), p. 16. 
aboutissait à la mer cet Oude haven qui fut si longtemps le port de Hulst; il n'en reste plus qu'un misérable tronçon d'un à deux kilomètres, que guette le service des endiguements (fig. 56, p. 329). Le Braakman, au milieu du XVIII siècle, poussait encore deux criques, séparées par des schorres, vers ces parages d'Axel et de Zuiddorpe où il s'était avancé au $X V^{e}$. La crique du Sud, ou Canisvliet, fut réduite la première; le polder St-François date de 1709, le Moerspuij de 1767; en 1787, on annexait à la terre les deux grands polders de Canisvliet; le golfe sarrêtait au Sasde-Gand. Au Nord, le Beoosten-on-bowesten-Blij était conquis en 1780; et los parties émergées entre les deux bras s'accroissaient en $1807 \mathrm{du}$ Nieuw-Vogelschor. Cependant de 1800 à 1810 on voit encore des frégates françaises poursuivies par les vaisseaux britanniques s'avancer à pleine voile vers Philippine, et y mouiller à marée basse ${ }^{1}$. Mais en 1827 on barre les deux criques entre le Sas et Sluiskil par une forte digue derrière laquelle on creuse le canal de Gand aı Sas et à Terneuzen. Alors la décadence du Brakman se précipite. Les barques ne peuvent plus passer où stationnaient les frégates. De nouveaux polders sont établis au milieu du golfe, Ie Kleine Stelle (1866), que deux nonveaux, Kanal et Mosselpolders, sont venus en 1900 rejoindre à la côte. Philippine, que Jérôme Iaureyns établissait hardiment en 1506 au bord du golfe, est maintenant entourée de terres cultivées; il a fallu ménager un canal pour que ses pêcheurs de moules pussent gagner ce qui reste du Braakman. A l'Ouest, il y a longtemps que Biervliet l'insulaire, où Beukels inventa le procédé de la caque, est devenue un village agricole; l'Elisabeth polder lui a fermẻ la mer en 1866, et récemment le Koningin polder a rejoint á la côte le polder Angelina. Ce qui n'est pas endigué n'en vaut guère nieux. La crique de Philippine, entre l'Angelina polder et le Kleine Stelle, n'est qu'un graud schorre tout couvert de végétation, oủ il faut creuser des chenaux pour l'écoulement des eaux intérieures vers la mer. La crique de Mauritsfort est dans le même état; le schorre n'y est plus couvert qu'aux hautes mers de vives eaux; la marée ne pénétre que dans quelques chenaux tortueux. D'ici dix ans, une digue joindra le Kleine-Stelle aux polders de Hoek, et Mauritsfort demande déjà un canal comme l'a obtenu Philippine. Le Waterstaat procède avec prudence, car la mer a le recul capricieux; en 1887 elle a rompu la digue du Pierssens polder. Néanmoins il semble que dans un sićcle, il ne restera guère du Braakman que les canaux par où s'écoulera vers la mer le trop plein des eaux des wateringues.

1 Vifquaiı, Des voies navigables en Belgique, p. 211. 
IV.

LE ZWIN.

L'histoire de l'agonie du Braakman de 1750 á nos jours montre bien que la prolongation de l'état de paix dans le pays, la science des ingénieurs et la vigilance des dijkgraafen, ont un rôle plus important que d'hypothétiques oscillations du sol. La mort du Zwin est un exemple plus remarquable encore de la stabilité du sol depuis le $X^{e}$ siècle dans la plaine maritime. Dès qu'on parle de lui, c'est porr signaler les diminutions qu'll subit. Lihistoire du $Z$ win, c'est l'histoire de sa disparition.

Lorientation du bras de mer, de Bruges vers Sluis (l'Ecluse), indique (Tlu'il fut à l'origine l'estuaire commun de l'Yperleet, venu de Dixmude par' Oudenbourg, et de la Waerdamme, qui traverse Bruges sous le nom de

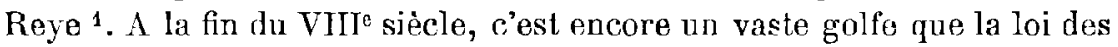
Frisons appelle le Sincfal, et qui forme la limite de ce peuple ${ }^{2}$ vers le S.-W. On l'a vu an $\mathrm{X}^{\mathrm{e}}$ siècle étrbbli le long des pays d'Aardenburg et Oostburg, au XI entourant de sos bras Wulpen et Kadzand. Mais l'envasement se produisit vite. Les eaux intérieures, trop peu abondantes, ne pouvaient suffire a entretenir l'estuaire. Le Hont avait au moins l'appoint de l'Escaut: le Zwin n'avait que les quelques ruisseaux descendus du plateau de Wynendaele. Tant qu'il put aux grandes marées s'épancher à travers les schorres, il conserva ses dimensions de bras de mer, entretenu par la forte quantité d'eau qui circulait a travers ses passes. Mais quand le grand commerce s'établit le long de l'estuaire, il fallut en fixer les bords et coindre le $/$ win de digues, qui restreignirent le champ de débordement des hautes marcos. Ainsi la masse d'eau qui parcourait le golfe fut diminuée, et les alluvions se déposérent rapidement à l'abri des digues, dans les replis où l'eau tranquille pouvait se décanter facilement. Les chasses insuffisantes d'amont n'y pouvaient rien. Le Zwin s'ost ainsi rétréci et atterri dés sa première utilisation. Les riverains ont peut-être hâté l'envasement, dans la fièvre des endiguements du XIII' siècle: mais

1 Le nom de Zwin est un ancien vocable signifiant cours deau. M. Gilliodts en donne quelques exemples, tels que le Swin de Zuyenkerke (Gilliodts, Inventaire, Introduction, p. 386, note 1).

2 Mon. Germ. Legum III, Lex Frisionum, éd. Richthofen, pp. 631-711. Le texto porte Sincfal et Sincfalam fluvium (tit. XIV), ce qui indique bien un estuairo. Discussion sur l'identité du Sincfal et du 7 win dans la préface, pp. 632-635. Deux chartes de 1241 et 1275 déclarent que le $Z$ win est l'ancien Sincfal; de même le poèto Maerlant (XlII siècle), dans son Spiegel Historiael (Leyden, Clignett, 1784), I, p. 51. 
il était inévitable, par l'absence d'un grand cours d'eau en arrière. Le $Z$ win ne fut guère qu'un hasard heureux, dont on a tiré tout le parti possible.

Le premier disparut le tronçon de Bruges à Damme. Au XI' siècle, la mer venait encore jusqu'd Brugges, et sur ses rives s'elevaient de vastes chantiers dont l'existence est attestée par les noms du quai « Houtbrekersdam $\gg$ et de Rombautswerf ${ }^{1}$. Or ce bras n'existe plus au début du $\mathrm{XIII}{ }^{\circ}$ siècle, et l'on creuse pour le remplacer un canal de navigation

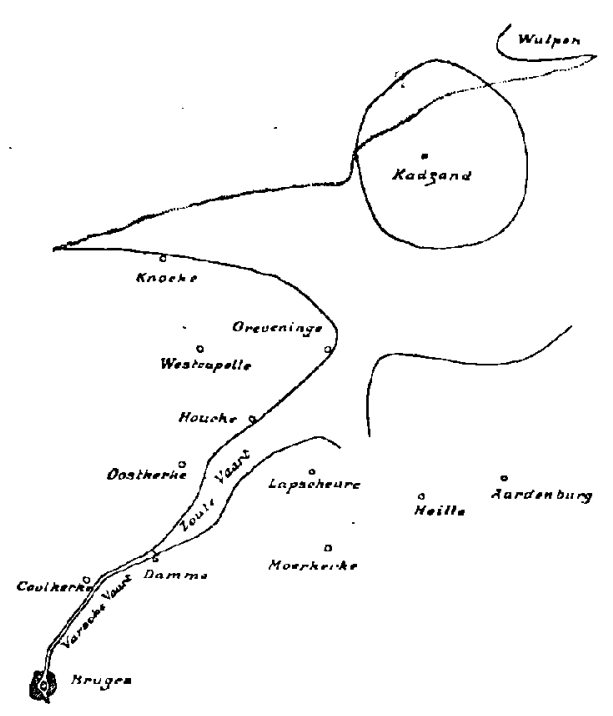

Échelle de $1: 320.000$.

Flg. 39. - Essai de reconstitution du Zwin au début du XIITe sic̀cle.

............ Rivage actuel.

prolongeant la Reye jusqu'd Damme: le Varssche raart, canal d'eau douce, par opposition au Zoute viart, canal salé, qui désigne la partio restée marine en aval de Damme. C'est alors que cette ville, terminus de la navigation maritime, prend de l'importance. Philippe d'Alsace y fait élever en 1180 de grandes digues par des ouvriers zélandais. Une écluse à sas, probablement la première construite en Europe, y fait communiquer le nouveau canal avec le Zwin ${ }^{2}$.

La deuxième période, du $\mathrm{XIII}^{\mathrm{e}}$ au $\mathrm{XV}^{\circ}$ siècles, voit la décadence du Zwin entre

Damme et Sluis. La description de Guillaume le Breton nous montre, vers 1204, un golfe marin qui se resserre brusquemenl à Damme, et forme devant la ville une vaste rade soumise à l'action des marées ${ }^{3}$.

1 Gilliodts van Severen, Bruges ancienne et moderne; notice historique et topographique sur cette ville (Bruxelles, 1890 , in $-4^{\circ}, 81$ p., pl.), p. 11.

2 Gilliodts, Inventairs, Introduction, p. 470. Le nouveau canal s'attorrit lui-même, et on est obligé de le recrenser en 1333 ot 1399 . (Bruges ancienne et moderne, p. 80).

Qui tam latus erat, tantaeque quietis, ut omnes In se sufficiat nostras concludere naves (v. 375). Retracto

Quippe mari siccum naves navale tenebant (v. 508).

Philippide, M. G. SS. XXVI, pp. 346-349. 
Lo lit se fixe et se rétrécit au delà de Damme; des bourgades s'établissent sur les bords: Monikerede, apparue en 1243 « super rivum maris » ${ }^{1}$; Houcke, indiquée dans la charte de Guy de Dampierre de 1282; Mude (St-Anna ter Muiden) et Sluis, qui datent du début du XIII ${ }^{e}$ siècle ${ }^{2}$. C'est l'époque de la grande prospérité de Damne, et cependant le Zwin n'est déjà pas sûr. Des atterrissements se forment. Lu 1246 il y a à Monikerede un terrain « extra dicum » ${ }^{3}$, un schorre. En 1274 la comtesse Marguerite vend 200 mesures dans un nouvcau polder entre Lapscheure et Moerkerke ${ }^{4}$. En 1282, Guy de Dampierre donne à son fils Jean de Namur « un scor à la Moenkerede entre deux havenes, encore un scor encoste Lapscure, encore un scor entre Moenkerede et le Houke, et tous les uldis gisans entre Dam et Bierulet $\gg$. Le besoigneux comte s'empressait de faire argent des terres neuves, encore toutes fraîches du passage des marées; au moins sa hâte à en profiter indique-t-elle les rapides progrès de l'envasement. Il est probablo qu'on se réjouit d'abord de voir sortir des eaux ces terres fertiles : mais bientôt on comprit l'imminence du danger, et la lulte s'organisa au XIV siecle. Les Brugeois portèrent leurs efforts de deux côtés. A l'amont, on creusa des rigoles pour recueillir et amener rapidement au Zwin toutes les eaux des plateaux: on les poussa jusqu'à Ursel, Bellem et Hansbeke, à trois lieues de Gand ${ }^{6}$. Si près de la Lys, il était naturel de songer à pratiquer vers Damme une dérivation de cette rivière: c'était débarrasser sa vallée d'inondations incessantes, produire dans le Zwin des chasses efficaces, et créer vers lamme une magnifique voie de communication. Bruges s'y employa dès 1330, puis en 1361 ; mais ce n'est qu'en 1378 que lo canal, débouchant d'Aeltre, parut devoir atteindre bientôt la Lys par Poucques et Deynze. Mais Gand ne voulut pas laisser détourner vers sa rivale la rivière qui faisait sa fortune; les chaperons blancs de Yoens massacrèrent les terrassiers de Bruges, et le projet du canal disparut dans la tourmente de Roosebeke. On ne devait le reprendre qu'en 1604 lorsque le $Z$ win de Damme était depuis longtemps disparu ${ }^{7}$.

En même temps on luttait dans le chenal même. On fait venir des

1 Van de Putte, Dunes, p. 577, no 755 et p. 206, n 335.

2 Gilliodts, Coutumes, Petites villes, IV, pp. 447-450, III, p. 235.

3 Van de Putte, Dunes, p. 206, n ${ }^{\circ} 335$.

* Schaeyes, Les Pays-Bas, II, p. 178, note.

5 Charte dans Gilliodts, Coutumes, Potites villes, III, p. 351.

6 Gilliodts, Inventaire, Introduction, p. 468. Compte de Bruges pour 1306, fo 11.

7 lbid. pp. 408-470. 
ingénieurs étrangers, des Hollandais experts aux chasses et aux dicages ${ }^{1}$; on s'inspire de leurs conseils. Une drague fonctionne dans les passes ${ }^{2}$; on se préoccupe d'empêcher de nouveaux endiguements ${ }^{3}$. En 1375 et 1384, on recreuse l'Yperleet et on augmente la section de tous les cours d'eau qui convergent vers Damme ${ }^{4}$. Après 1395, il ne se passe pas d'annees sans sondages, inspections; on ne peut imaginer plus grande sollicitude. Deja approfondi deux fois, le canal Bruges-Damme est abandonne en 1402, et on en creuse à l'Est du premier un nouveau, à grande section, dont le jeu put augmenter les chasses ${ }^{3}$. Pour ces chasses, il faut de l'eau : on va en chercher jusqu'à Heyst; on endigue l'Eede pour ne pas perdre une goutte de ce qu'elle fournit; on pratique dans les digues des débouchés pour laisser passer le trop plein des wateringues; les Brugeois redemandent du renfort à l'Yperleet, aux ruisseaux du plateau ; ils élargissent les fossés de leur ville pour en faire des réservoirs ${ }^{6}$ : on ne perdrait pas un hectolitre. On sacrifie un polder sous les remparts de Damme pour en faire un bassin de chasses 7. Quand un schorre se formo en dépit de la drague et des chasses, la ville de Bruges le loue, pour qu'on ne l'enligue pas ${ }^{8}$. El sans trêve on continue à sonder, draguer, consolider les digues, rectifier et baliser le chenal.

Rien n'y fit. Le Zwin de Damme s'envasait avec une efrayante rapidité. En 1421, le lit entre l)amme et Mude n'est plas qu'un canal sinueux entre deux digues, tantòt large, tantôt étroit, passant de 10 à 50 verges (30 à 150 mètres), frangé au long des digues d'atterrissements couverts de végétation, et décourrant à marée basse des « plaaten » jaunâtres et allongés. Les bancs de moules viennent encore rétrécir la passe ${ }^{2}$. La navigation souffre; déjà en 1350) les grosses nef's espagnoles ne dépassent pas Sluis, et en 1367 los lettres patentes accordéos par Louis de Male considèrent

1 En 1331, Michel de Calo est appelẻ et remet au magistrat un mémoire sur les moyens d'améliorer le régime du Zwin entre Damme et Sluis. En 13\%3, l'ingénieur Jan Vlucghen de Delft est prié de venir donner son avis. En 1412 on envoie des ingenieurs à Middelburg examiner le chonal d'Arnemuiden, et on fait venir des praticiens zélandais. (Gilliodts, Inventaire, Introduction, pp. 470-71, et IV, pp. 21(1-214).

2 Dragages incessants de 1380 à 1390 (Ibid. IH, pp. 341-344).

3 Limburg-Stirum, Cartulaire de Louis de Male, II, p. 128.

1 Gilliodts, Inventaire, III, pp. 341-344.

5 Ibid. $111, \mathrm{pp}$. $464-465$.

Ibid. IV, pp. 215-216, pp. 368-363.

$i$ Ibid. IV, pp. 317-318.

8 En 1417 et 1421 (Ihid. IV, pp. 344-345, p. 308).

9 Ibid- IY. p. 368. 
Damme comme le port où passent les barques, mais où le \& défaut de marée » empêcherait l'accès des navires ${ }^{1}$. En 1403 à leur tour, les Osterlings de la Hanse se plaignent que le $Z$ win est trop étroit et présente de grands dangers pour leur'svaisseaux ${ }^{2}$. Les Brugeois songent dêjà en 1415 à s'ouvrir vers Ostende, par l'Yperleet, la communication avec la mer que Ie Zwin ne leur procure plus ${ }^{3}$. Damme, le grand eutrepôt du XII siècle, est déchue dès 1400. La ville so débat entre ses créanciers; au XVII ${ }^{e}$ siécle, une description du pays déclare que son unique importance vient d'une grande foire aux chevaux ${ }^{4}$. Le $Z$ win de Damme existeencore en $1488^{5}$, rnais on 1567, son rôle se borne à celui d'émissaire prin-

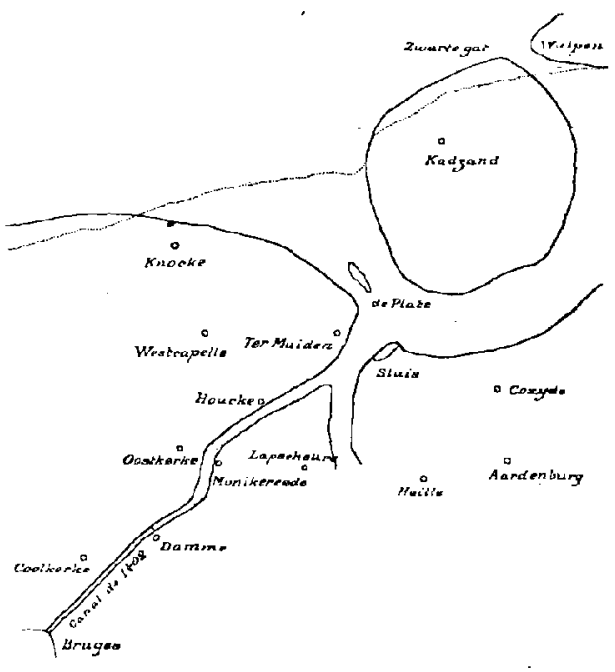

Échelle de $1,: 320.000$.

Frg. 40. - Essai de reconstitution du Zwin au milieu du XIVo siècle.

Rivage actuel.

cipal des wateringues de la région ${ }^{6}$; le bras de mer est devenu un fossé.

Sluis hérite dès le XIV ${ }^{\text {e }}$ siècle de la prospérité de Damme. Philippe Ie Bon en 1436 la qualifie de « plus principal port de mer de nostre païs de Flandres " $\gg$. Mais la décadence fut aussi rapide que pour Damme, car ce

1 Finot (J.), Lo commerce entre la France et la Flandre au moyen-âge (Ann. Com. f. Fr., XXI, pp. 1-392), pp. 66 et 77.

2 Delepierre, Précis analytique, 2 série, I, p. 63 (Comptes du Franc, 1403-04).

3 Gilliodts, Irventaire, IV, pp. 338-339.

4 Nouvelle description des Pays-Bas et de toutes les villes des dix-sept provinces (Cologne, Vau den Boon., 1669; in-12॰, 290 p.), p. 155. - Pour l'agonie de Damme, voir: Van den Bussche, Inventaire des archives de l'Wiat à Bruges, Frauc de Bruges, I, pp. 227, 231, 273, 278, 301, 337. Pour la décadence de Mudo, Houcke, Monikeredo, voir Gilliodts, Coutumes, Petites villes, III, pp. 235-256, pp. 51-67, pp. 337-348.

5 Comptes du Frane, 1487-88, dans Priem, Précis analytique, $2^{e}$ série, II, pp. 191192.

0 Gilliodts, Coutumes du Franc de Bruges, II, p. 771 .

7 Gilliodis, Luventaire, V, p. 116. 
qui restait de l'estuaire, entre Sluis el la mer, se trouva bientòt dans une fâchouse situation. Ce beau golfe qu'une charte de 1243 qualifiait de "corpus maris ${ }^{1} »$, se rétrécissait sur les bords et s'envasiat au milieu. Le Vieux Polder du Hazegras existe dès $1304^{2}$; la région des grèves, la Greveninge de Mude, était endiguée en 1282 jusqu'au Maneschijn polder inclus ${ }^{3}$. De l'autre côté de l'estuaire, Ter Hofstede, dans Kadzand, était déjà indiquée en 1303 par Melis Stoke ${ }^{4}$. En 1450, l'endiguement de Robbemoreel restreint des deux tiers la largeur du chenal entro Mude et Sluis ${ }^{5}$. Il est grand temps de faire des travaux en aval do Sluis; la charte de Philippe-le-Bon de 1463 constate que les marchands n'osent plus hanter le port, qui s'amoindrit de jour en jour ${ }^{8}$. Il fallait faire grand, car ce n'est pas une mince besogne que de ressusciter un bras de mer. Les projets proposés en 1470 se réduisent à deux : rétablir par un canal partant de Gaternisse ou d'Oostmans-Capelle la communication entre Zwin et Braakman; ouvrir le Zwartegat, le détroit entre Kadzand et Wulpen, qui s'était comblé au cours du siècle ${ }^{7}$. On espérait que le flot de marée, passant violemment par ces ouvertures, nettoierait le chenal et ferait l'office de ces chasses que les eaux donces étaient impuissantes à fournir. On se décida pour le $Z$ wartegat. Mais à peine était-il ouvert (1471) que l'on s'apercevait que le flot de marée qui entrait par le redoutable «Trou noir », loin de débarrasser le $Z$ win, venait accumuler les dépòts au Sud de Kadzand et faisait augmenter l'envasement avec une effrayante rapidité ${ }^{8}$. Dès 1485 , on essayait, sans succès d'ailleurs, de refermer la passe ${ }^{9}$.

Cette fàcheuse expérience avait angmentó le danger. Ordonnances sur le pilotage, création de stations de piloles s'engageant à ne conduire aucun navire ailleurs que dans le $Z$ win ${ }^{10}$, amélioration des balises et

1 Charte du comte Thomas, dans Kluit, II, p. 487.

\ Comptes de Briges, 1304, fo 36 (Gilliodts, Inventaire, Introduction, p. 445).

3 Roos, Woordenboek, pp. 56-57.

4 (Rijmkroniek, VII).

"Gilliodts, Inventaire, V, p. 322.

6 Delepierre, P'ècis analytique, $1^{\text {re }}$ série, I, p. 102.

7 Diegrerick, Inventaire des archives d'Ypres, III, pp. 287-288.

8 Lettre de Maximilien, dı 24 avril 1480. On y constate après 9 ans dexpérience que la marie qui entre par le Zwartegat sort par lo mème trou, ot « ainsi sont les dits bancs et sablous de plus en plus accrus et augmentés et l'entrée du havre do l'Ecluse diminuée et devenue plus étroite 》. (Gilliodis, Inventaire, VI, p. 258).

9 Dètil des travaux daus Gilliodts, Ibid. p. 261 et Bruges Port de mer, pp. 10 -78.

10 Ordonnances de 1484 et 1486 , dans Gilliodts, Inventaire, VI, pp. 235 et 276. 
bouées ${ }^{1}$, consultation des pêcheurs de Coxyde et des Zélandais , création de commissions ${ }^{3}$, voyages d'études, enquêtes, rapports, n'empêchaient pas le hâvvre d'être « tellement diminué, appovri et destruit...., que la ville de l'Écluse est taillée de tomber en totale ruyne, perdition ot désolation $\gg(1500)$. Les étrangers partent. Les Portugais dont les grosses nefs, bâties pour les grandes traversées des mers tropicales, avaient un tonnage trop considérable pour les passes atterries du 'Zwin, transfèrent officiollement en 1503 leur résidence à Anvers. Les Italiens les imitent en 1516. Les Hanséates, ces fidèles clients de Bruges, s'éloignent définitivement en 1544" En 1509, « le dit havre, ensemble lanthise d'icellui et de la dicte ville de l'Écluse, est comme du tont délaissée et habandonnée ${ }^{6}$. Pourtant Bruges s'ohstine. Le projet du Zwartegat n'a pas réussi : on essaye do la communication avec le Braakman. Elaborć en 1499, lo projet de canal Coxyde-Oostburg est mis à exécution dès 1502, et le Brugsche-Vaart ouvert en $1515^{7}$. Peut-être empêcha-t-i] le Zwin d'être complétement comblé à Ia fin du XVI siècle; mais l'envasement était rapide dans le Braakman lui-même; les endiguements des Laureyns gènaient l'entrée du canal; il fallail percer en 1547 le schorre de Vlaeke qui s'était formé devant la passe, et on finissait par délaisser la crique, au moment ou allait commencer la guerre do 80 ans. Celle-ci, par les inondations qu'elle causa, dut rendre quelque profondeur an $Z$ win, puisqu'en 1548 les Brugeois, infatigables, commençaient à creuser de Damme à Sluis un canal d'eau douce pour remplacer leur vieux Zoutevaert

1 Gilliodts, Inventaire, VI, p. 237.

2 Comptes du Franc, 1498-99-1500, dans Priem, Précis analytique, $2^{\text {ne }}$ série, II, pp. $235-6,239$.

3 Gilliodts, Inventairo, VI, p. 451.

4 Charte de Philippe le Beau, dans Gilliodts, Coutumes, Petites villes, IV, p. 589.

5 Finot, Commerce entre la Flandre et la France, pp. 242-244.

6 Gilliodts, Coutumos, Petites villes, IV, p. 603.

7 Gilliodts, Bruges Port de mer, pp. 90-91, 170-186. La charte de I'hilippe le 13eau, de 1502 , constato que le Zwin est « tellement rempli de terre et autres choses que les navires qui y souloient arriver en grande quantité... n'y povoient of encore n'y pouent entrer ne yssir, sinon en grant danger et peril de jnunder b. Le canal fera entrer «Ieaue de ladicte mer dedans lodiet $Z$ win, affin do par ce moien dehouter et regecter les bancs ot sablons, pour nectoyor, parfonder et amender icelluy Zwin ". (Gilliodts, Coutumes, Petites villes, IV, pp. 593-595). I e Brusgehe Vaart, dont il reste une crique profonde à l'Est d'Oustburg, n'a donc jamais été un canal de navigation, raais une passe permettant au flot de marée de circuler du Zwin dans le Braakman et de nettoyer l'estuaire. 
envase ${ }^{1}$, et que ce travail terminé en 1564 , ils se mettent à on stablir un autre entro Damme ot Bruges, au Nord de la voie creusée au XII' siecle ${ }^{*}$. Tout était terminé en 1572, lorsqu'intervinrent les Hollandais: maitres de Sluis, ils ne songèrent qu'à combler le nouveau canal, et cette dernièrc tentative, le Nieuwo Gedelf des Brugeois, avorta miśr rablement.

Le $Z$ win do Sluis languit encore trois siècles. Les inondations de $15 \times 3$, en rouvrant le Passegeule, rendaient à la marée la force d'entretenir l'estuaire. Maîtres de la Flandre zélandaise, les Hollandais avaient intérêt à maintenir ce large fossé de défense devant Kadzand ${ }^{3}$. Il fallut attendre le XVIII ${ }^{\mathrm{e}}$ siécle et le comblement des passes de l'Est pour reprendre les endiguements. Le Godefroi-en-Burkel, le Gouverneurs polder à gauche (1716-1718), le Casteel à droite (1737), rétrécissent de moitió l'estuaire. La fermeture du Nieuwe Haven en 1742, et surtout la disparition définitive du Passegeule en 1788 par la construction de la digue de Bakkergdam, furent la vóritable cause de la mort du $Z$ win. Le Crane polder est ótabli en 1799 ; le grand Hazegras est de 1789 ; le Kleine Pas, qui prend encore une moitié, est endigué en 1793. C'était un peu tòt : le Zwin l'inonda aussitôt, et le reprit encore en 1808. Mais en arrière, les conquêtes śtaient définitives. Napoléon concède au général Vandamme le fond du golfe, et celui-ci endigue l'Olieslager en 1803, l'Austerlitz en 1805, le Sophia en 1807, l'Aardenburgsche Haven en 1813, le Diomede en 1827. Le Zwin do 1830 n'a plus que 8 kilométres de long, et on le traverse a marée basse devant le Hazegras . Cependant on y navigue encore et en 1830 une canonnière hollandaise vient s'y embosser pour bombarder l'écluse belge du Hazegras; le Sluissche Haven ne disparaît qu'en 1860: à cette date le Zwin polder comble $5 \mathrm{~km}$. de l'estuaire. Il restait deux pelits bras entourant un schorre, l'île Vandamme; on les absorbe on 1873 dans lo

\footnotetext{
1 Comptes du Franc, 1547-48, dans Priem, Précis analytique, 2me série, III, pp. (X)-
} 100.

2 Gilliodts, Bruges Port de mer, pp. 188-234.

3 En 1748, «il part toutes les semaines de Sluis plusieurs bâtiments pour la Iollande et la Zẻlande ». (Description abrẻgée géographique et historique du Brabant hollandais et de la Flandre hollandaise [Paris, Bauche, 1748, in-12, 314 p.], p. 25i). - En 1783, d'après Derival, le port de l'Ficluse, négligé par les Hollandais, ne contient que quelques petits bâtiments (Derival, Le Voyageur dans les Pays-Bas autrichiens, ou lettres sur l'état actuel de ce pays, [Amsterdam, chez Changuion, 1782-83, 6 vol. in-120] vol.V, p.22). Encore n'est-il pas ensablé complètement, ce qui prouve que le $Z$ win s'était à peu près maintenu depuis deux siècles.

4 Andries (J-0.), Recherches historiques sur les voies d'écoulement des oaux des Flandres (Briges, de Pachtero, 1838, in-8 102 p., carte) p. 32. 
Willem-Leopold polder ${ }^{1}$. Anjourd'hni il n'y a plus du Zwin qu'une petite crique d'un kilomètre, perdue dans un vaste schorre grisâtre où paissent des moutons, et il ne s'y aventure guère que de rares barquettes de pêcheà marée haute. IBientôt cette crique disparaîtra: au long de la mer une ligne de dunes s'avance avoc rapidité,qui finira paratteindre Kadzand. Le Zwin ne sera plus alors qu'un souvenir ${ }^{2}$.

Ainsi le Zwin n'a pas cessé de diminuer depuis qu'jl apparait dans l'histoire. En général, on le fait mourir trop tôt ou trop tard ; trop tôt puisqu'il en existe oncore un débris ; trop tard puisqu'il était à pen près impraticable des la fin du XV

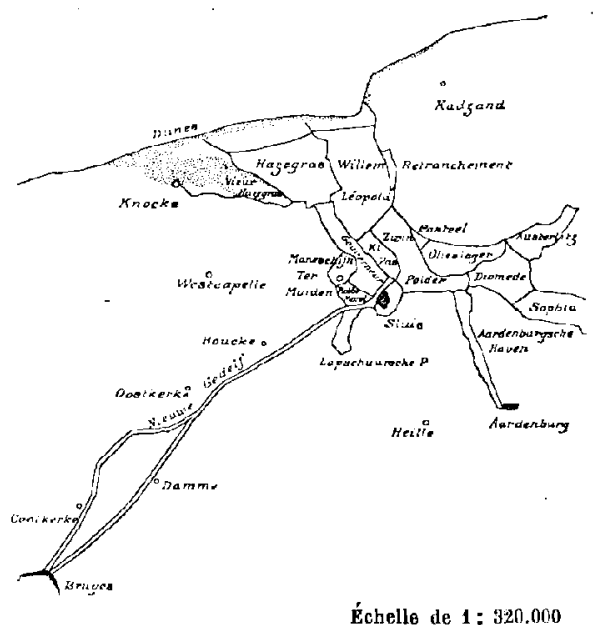

FIG. 41. - Endiguements du Zwirl aux XVIII et $\mathrm{XIX}^{\mathrm{e}}$ aic̀cles.

siècle. L'envasement a été plus rapide en amont de Sluis, ou l'action do la marée n'était pas aidée par un afflux puissant d'eaux intérieures; plus lent entre Sluis et la mer, grâce à la communication avec le Braakman. Mais le comblement a été continu; il s'est poursuivi sans arrêt du $V^{\theta}$ au $\mathrm{XX}^{\mathrm{e}}$ siècle. Et cette étude permet de préciser l'histoire des vicissitudes de la plaine après l'invasion du $V^{e}$ siècle; il paraît bien probable qu'il ne s'y est produit depuis celto époque aucune oscillation du sol, et que le comblement des estuaires s'y serait tranquillement et rẻgulièrement poursuivi, si l'homme s'y était prêté ${ }^{3}$.

1 On trouvera los dates des ondiguements dans Roos, Wuordenboek, et Andrios, Recherches historiques, pp. 45-47.

2 Le Zwin disparu, le Brakkman en voie de disparaitre, on s'oceupe maintenant de reconquérir le territoire que la guerre de 80 ans a fait perdre au pays du côté de Saaftinge. Le Nieuwen-Arenberg est do 1784; le Saftingen polder, do 1805; les polders Louisa, Van Alstein, Prosper, du XIXe siècle. Il y a dix ans, on a ondigué le vaste Koningin-Emma polder, ot en 1904 un nouveau polder au N. du Prosper. Ces travaux, exécutés pour le compte de la famille d'Arenberg, rappellent ceux des Laureyns à Watervliet.

3 Voir dans (alouzot, Jes Marais de la Sèvre Niortaiso et du Iay du Xe siècle à la fin du XVIo siècle (F'aris, Ghampion, 1904, in-8\%, 282 p., pl., carte à $1: 200.000)$, pp. 47-48, 53-54, 69-71, les desastres que la guerre de Cent ans et les guerre de Religior ont fait subir à l'cuvre du dessèchement, entreprise et achevée dès les XII $\mathrm{X} 1 \mathrm{~J}^{\circ}$ siècles par les moines. 
Il n'y a pas de catastrophes dans l'histoire du Zwin, et il n'y en a guère dans toute l'histoire de la Flandre zélandaise. Dépouillées de l'aspect terrifiant que leur prêtaient les chroniqueurs, les inondations n'apparaissent plus que comme des accidents dont les hommes sont plus responsables que la nature, et dont les effets sont temporaires et rapidement réparés. Rien n'a beaucoup changé à l'Est de Bruges, du $\mathrm{X}^{\mathrm{e}}$ au XX $\mathrm{XX}^{\ominus}$ siècle. Le Braakman existait avant le XIVe siècle; le Hellegat a remplacé le vieux chenal de Iulst; le Passegeule est toujours reparu sur l'emplacoment de l'ancienne crique d'Elmare. Le Hont existait, et au lieu d'être plus étroit, il étail probablement plus large qu'aujourd'hui. S'il y a eu changement, c'est toujours dans le même sens: los criques se sont combleses lentement depuis dix siècles, et continuent de se combler alujourd'hui ${ }^{1}$.

1 La différence de niveau que l'on remarque dans toute la Plaine entre deux polders endigués à des dates différentes, et qui fait que le plus récent domino parfois de 2 mètres le plus ancien, s'explique autroment que par un affaissement grénéral : il s'opère évidemment un tassement important dans ces matériaux, d’ailleurs compressibles (tourbe), lorsqu'on en assure convenablement le dessèchement. Certains polders des Fens et de Vénétie sont descendus à un riveau si bas après l'asséchement que l"écoulement des eaux pluviales.ne pouvait plus s'y effectuer. De là vient que les parties de la plaino d'ou la mer s'était jadis retirée d'elle-même sont descendus aujourd'hui à un niveau un peu infériour à celui des grandes marées. 


\section{CHAPITRE IX}

\section{LA COTE. - LES DUNES ${ }^{1}$}

I. Aspect et mouvements de la côte. Recul de la mer à l'Ouest. Recul de la terre à l'Est. Causes des mouvements de la côte. - II. Les Dunes : caractères physiques. Largeur des dunes. Formes. Mouvenents et fixation. - III. La vie dans les dunes. L'agriculture. L'homme et l'habitation.

\section{I.}

\section{ASPECT ET MOUVEMENTS DE LA COTE.}

Pays bas, côte basse; tout le long de la mer du Nord, la plaine maritime de l'Allemagne, de la Hollande, de la Flandre, aligne un rivage plat et triste. Du large, sur le bateau qui se faufile entre les bancs, le voyageur qui cherche la Flandre ne découvre d'abord que des tours lointaines et embrumées, les grands phares blancs, les clochers et les beffrois, la rude silhouette de St-Éloi de Dunkerque, la flèche de Notre-Dame de Bruges, mềme la vieille tour carrée de Watten, à cinq lieues de la côtét. Puis l'on voit sortir des eaux des rangéos de maisons étranges, des villes de rêve, le « front de mer » des stations balnéaires avec leurs villas où s'entrechoquent tous les styles. Entin apparaît la côte véritable, le mur bas des dunes blanchâtres dont parle Guillaume le Breton ${ }^{3}$, précédées de l'estran de sable fauve, large parfois de deux kilométres. Il a fallu jalonner de

1 Principaux travaux à consulter pour ce chapitre et le chapitre suivant: Ministere des Travaux Publics, Ports maritimes de la France : tome ${ }^{\text {er }}$, de Dunkerque a Ftretat (Paris. Imyr. nat., 1874) : Plocq, Dunkerque, pp. 1-107; Plocq, Gravelines, pp. 1(1)-193; Aron, Calais, pp. 195-252; - de Mey (P.), Ports en plage de sable ; - Les Installations maritimes belges (Exposition universelle de 1900 ; Notices sur les l'lans at Modeles exposés dans lo salon des Ponts-et-Chaussies; Bruxelles, Strickaert, 1900, in- $8 \circ, 107$ p., phot., graph., plans, cartes); - Monographie agricole de la Région des I)unes (Minist. de I'Agriculture, Bruxelles, 1901, in -8 87 p.).

2 En 1812, la marine à Dunkerque soppose énergiquement à la démolition de la tour de Watten, parce qu'ello sert d'amer pour reconnaitre le bane d'Out-Ruytingen. (Arch. Nat. Fa 894).

3 Caudentia littora (Philippide, M.G. SS. XXVI, p. 345, v. 358). 
feux les bords de celte côte incertaine; les phares sont nombreux au long de la Flandre, et leur usage y est ancien ${ }^{1}$.

Cette côte basse est rectiligne. De Sangatte à Kadzand, il n'y a guère de pointes que les jetées des ports, de golfes quo leurs chonaux. Sous l'effort des courants de marée, les alluvions amenées par le gain de flot ont comble toutes les échancrures, et presque efface les dernieres traces des estuaires. Il n'y a plus guère que deux angles, très arrondis : la pointe de Gravolines et la côte de Kadzand, pour rappeler que devant elles les golfes de l'Aa et du Zwin gagnaient jadis la mer. On a vu le Zwin se combler au XIX ${ }^{\circ}$ siècle, le golfe de Nieuport au XIV ${ }^{e}$. Ce qui restait des estuaires de Calais et de Gravelines mit plus de temps à disparaître. De bonne heure, ils n'étaient plus guère que des lagunes, enserrées entre la côte et un cordon littoral de sable, une Nehrung, que le gain de flot poussait peu à peu vers l'Est, ne laissant plus aux eaux de l'intérieur qu'un étroit passage vers la haute mer. Ces lagunes furent réduites peu à peu. Il semble que ce fut au début de la domination anglaise que fut établie, de Sangatte à Nieulay, Ia digue Royale appuyée sur l'extrémité du banc des Pierrettes ${ }^{2}$; mais l'espace entre Nieulay et le cordon littoral resta une crique jusqu'en 1770 (fig.45). Au Nord de Gravelines, il s'était formè aussi une lagune entre la ville et une rangée de dunes appuyées a l'Ouest; mais cette lagune était vite devenue un schorre, appelé les Hems-St-Pol, à travers lequel serpentait l'Aa, qualifié en 1440 de havre «tout atterry et de petite valcur » ${ }^{3}$. Rojetó peu à peu vers l'Est par les progrès de la Nehrung, le courant venait ronger les dunes qui formaient la cote de la châtellenie de Bourbourg, finissait par on « abattre, caver et emporter la greigneure partie $\gg^{k}$, et il fallait $y$ organiser au XVI ${ }^{\mathrm{e}}$ siècle de sérieux travaux de défense ${ }^{5}$. Le comblement du havre continua aux XVII et XVIII ${ }^{\ominus}$ siécles; les dunes de l'Ouest, poussées par les vents dominants, obstruaient de plus en plus le chenal, causant de graves inondations dans

1 Octroi de I'hilippe le IIardi : Que pour le sauvement des diz marchans, leurs biens et neifs, il soient ordenez encontre les costieres de Flandres sur le mer, à Dunkerke, Neufport, Ostende, Blanckenberghe, nouvelles lumières et vierboetes si comme soloient estre en vieux temps ". (Arch. Nord, B. 1599, $4^{\mathrm{e}}$ reg. des Chartes, fo 33, verso; B. $1566,6^{\circ}$ cartulaire de Flandre, fo 34 , verso).

2 Aron, Calais, p. 202.

3 Octroi de Jean de Luxermbourg à la ville de St-Omer. (Copie aux Arch. Nat. Q1 829).

1 Haignoré, St-Bertin, IIT, p. 385i, no 2368.

5 Plusieurs chartes de Charles-Quint, aux Arch. du Nord, Série C (Flandre maritime), liasses $44,46,60$. 
l'intéricur des terres. On se décida enfin en 1742 à creuser à l'.la un nouveau chenal vors le Nord-Ouost, à travers les Hems-St-Pol. Dés lors ce qui restait de l'ancien estuaire devait disparaître rupidement; les demandes de concession affluèrent ${ }^{1}$, on barra ce qui restait du golfo

Basse mer

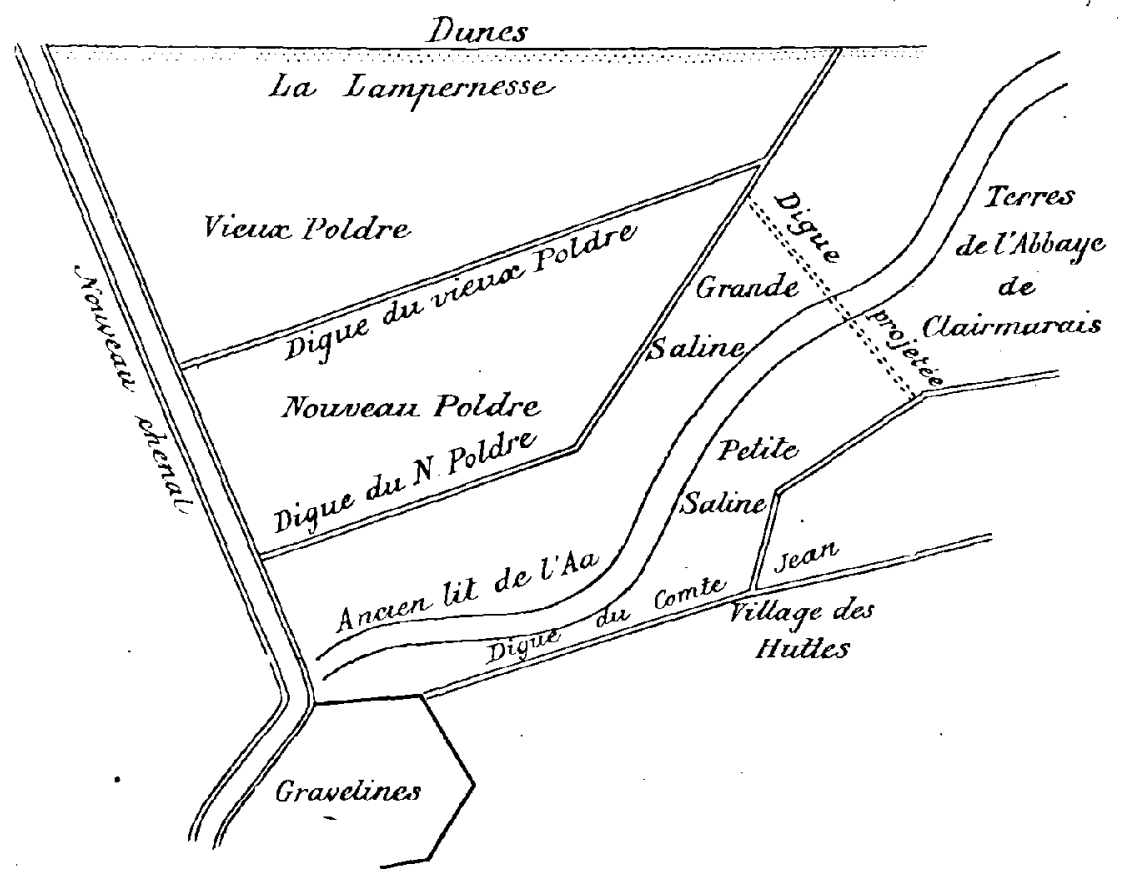

Fig. 42. - Les Hems-St-Pol en 1747,

d'après deux plans aux Arch. Nat., Q1 8:9, pièces 93 et $95 \%$

par' une digue recouverte aujourd'hui d'un amas de sable qui joint les

1 Détails sur ces demandes de concessions aux Arch. Nat., $\mathrm{Q}^{1}$ 829, et aux Arch. du Nord, G (Fl. mar.), liasse 38.

2 Commo dans l'ensemble de la plaine maritime, les parties asséchées Ies premières se trouvent au Nord, le long des dunes: d'abord la Lampernesse, qu'jl n'a pas été nécessaire d'endiguer, puis le Vieux et le Nouveau Poldre. 
LA COTE. - LES DUNES.

dunes de Calais à celles de Dunkerque. Ainsi cette côte, laissée à ellemême, se fait forcément rectiligno; elle allonge des levées littorales derant les estuaires, et les comble ensuite à loisir.

On pourrait croire que cette tendance à raccordor par une ligne droito les anciennes sinuosités indique que l'emplacement de la côte n'a pas varié depuis l'invasion marine du $\mathrm{V}^{\mathrm{e}}$ siècle, et que la mer s'est contentée de réparer les brèches que l'inondation avait faites a l'ancien cordon littoral. Pourtant la côte a subi, entre Calais et Kadzand, un double mouvement d'avance et de recul. De Calais à Dunkerque, la terre a gagné, et parfois une largeur de $1500^{\mathrm{m}}$. A l'Est de Nicuport, la mer avance, et la cote a reculè d'une quantité difficile à évaluer, mais qui atteint peut-être un ou deux kilomètres.

Recul de la mer à l'Ouest.

Le gain sur la mer, à l'Ouest de Dunkerque, n'a guère besoin d'être prouvé par les textes: l'examen des lieux suffit. A la hauteur de Mardick, on ne compte pas moins de sept témoins, sepl étapes du recul de la mer. C'est d'abord, au S.-W. du village, les vieilles dunes sur lesquelles est bâti le village de Loon; là était vraisemblablement le rivage des $\mathrm{V}^{\circ}$ ot $\mathrm{VI}^{\circ}$ siècles. Mardick lui-même est sur une légère éminence sableuse, que l'on suit à l'Est jusqu'au canal envasẻ de Louis XIV. Digue ou dune? Il est difficile de le dire, car les sables s'accumulaient si bien sur les digues qu'elles prenaient bientôt l'apparence d'une ligne de dunes naturelles. Peut-être * est-ce là ces dunes de Synthe dont parle un acte de 1097 ? Devant vient une saline, c'est-à-dire un ancien schorre cultivé, drainé par un watergand. Celte fois c'est bien là la terre indiquée par l'acte de 1067, "Salinas in Sintonis quas grevas vocant ${ }^{\prime}$ ', qui ne tarda pas à être endiguée, car elle est borncée au Nord par la digue du Comte Jean(phot.11). Elle est bien décrépite aujourd'hui, la célébro digue que fit faire le comte, disent les paysans, pour ne pas passer sur les terres d'autrui; les schorres qui se sont formés devant elle ont fini par égaler sa hauteur, et on ne la distingue flus guère qu'à la ligne de maisons qui se cramponne à son tracé : non que ce léger renflement sableux constitue encore une sauvegarde contre les attaques d'une mer refoulée à plus d'un kilomètre, (car dès 1774 l'intendant la

1 Pruyost, Bergues, p. 60. Ces salines partagées entre les abbayes de Bergues et de Watten dépendaient de la ferme du Prédembourg (Arch. Nord, C, F'l. Mar., liasse 41). 
donnait comme percée et même effacéc en plus de 30 endroits) ${ }^{1}$; mais parce que la digue, jadis propriété de l'Etat, est devenue sans bruit la

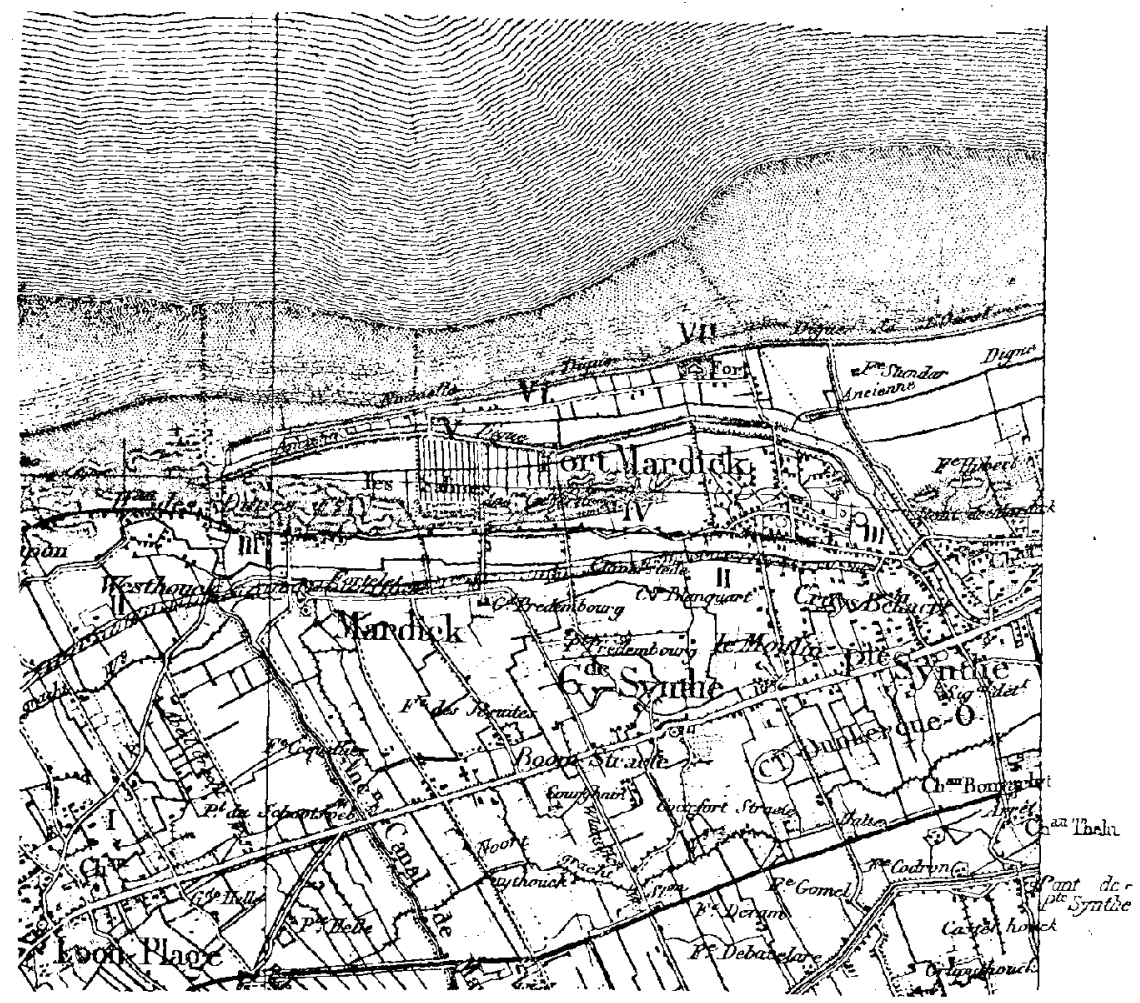

Fig. 13. - Gains de la terre sur la mer à l'Ouest de Dunkerque.

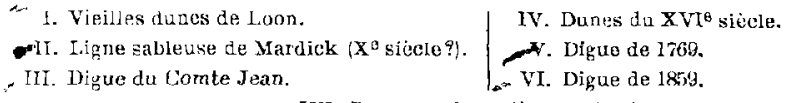

VII. Dunes on formation sur l'estran.

possession de tous ceux qui en ont bicn voulu s'emparer ${ }^{2}$. Devant la digue s'étend une nouvelle ligne de dunes, la plus importante de la série; cellesci existaient dès la fin du XVI ${ }^{\mathbf{e}}$ siècle, puisqu'un bail do 1603 parle des terres situées entre le bane de Grave-Jean et les Iunes, jusqu'à l'eau de la

1 A ech. Nat. $Q^{1} 28 \pi$.

2 C'est pourquoi l'on voit des familles, simples locataires de maisons situées au long de la digue; être les tranquilles proprićtaires des enclos contigus à leur maisorı, mais situés sur la digue, sur le bane du comte Jean. 
mer ${ }^{1}$. Puis viennent les grandes salines, mûres au milieu du XVIII ${ }^{\mathrm{e}}$ siècle, endiguées à partir de 1769 par le comte de La Morlière; et devant, une nouvelle conquête, une saline conquise en 1850. Mais les progrès de la terre ne s'arrêtent pas lá, et devant la digue de mer se sont établies, en 50 ans, de nouvelles dunes déjà couvertes de végétation. Ainsi 3 ou 4 lignes de digues, alternant avec 3 ou 4 rangẻes de dunes, indiquent les étapes du recul de la mer, presque chaque siècle. Une conséquence intéressante de ce progrès de la côte a été le comblement d'une fosse qui séparait un banc de la terre ferme, et l'annexion de ce banc au rivage. Jusqu'au XVII ${ }^{\mathrm{e}}$ siècle sélendait devant Dunkerque parallèlement à la côte et aux autres bancs de Flandre le Scheurken, découvert à marée basse, ot dont il faudrait aujourd'hui chercher l'emplacement vers l'ancien Sanatorium de St-Pol et le grand phare. Une passe, profonde au minimum de 4 pieds aux basses caux, appelée la fosse de Mardick, séparait le banc de la còte, et servait de rade au port de Dunkerque, qui y débouchait ${ }^{2}$. Déjà en 1587 s'allongeaient entre la principale ligne de dunes et la fosse de Mardick des schorres à peu près secs, servant de pâtures et appelés los Hems ${ }^{3}$. Au début du XVII siècle, et probablement à la suite de travaux de fortification oxécutés afin d'iuterdire aux vaisseaux ennemis l'accès de la fosse de Mardick vers l'Ouest, (construction sur les hemmes de la batterie dépendant du Fort de Mardick), on vit la partie centrale de la passe s'atterrir avec une rapidité singulière, et le Schourken s'allonger vers l'Est en se rapprochant de la côte. En 1624, on avait devant la ville 3 à 4 brasses d'eau (de 1'm62) à marẻe basse ; en 1639 on n'y trouvait plus que 3 à 4 pieds, et il avait fallu creuser, entre le banc et la còte, un chenal bordé de fascinages. En 1645, la fosse de Mardick n'existail plus que dans sa partie occidentale, dont l'amorce s'est conservée jusqu'à présent; à marée basse le Scheurken était réuni à la côte, et le port de Dunkerque réduit à une misérable crique qui gagnait la mer vers l'Est. L'ensablement de la passe fut si complet qu'un navire espagnol sabordé vers la fin du $\mathrm{XVI}$ siècle dans la fosse, devant l'entrée du port, a été retrouvè en 1900

1 Série de baux pour les terres de l'abbaye de Watten au Grand P'rédembourg, de 1603 à 1766 (Arch. Nat., Q1 287).

2 Les phases de la jonction du Scheurken à la còte au XVII siècle nous sont connues grâce au précieux rapport de Florent Van Langren, ingénieur au service du roi d'Espagne, qui proposait on 1033 de creuser entre Dunkerque et Fort Mardick lo canal qui fut exécuté, en 1713 , par ordie de Louis XIV. Ce rapport est publié dans : de Rive, Precis historique et statistique des canaux et rivièros navigables de la Belyique et d'uno partie de la France (Bruxelles, in-40, 1835), pp. 605-608.

3 Arch. Nat., Q1 287. 


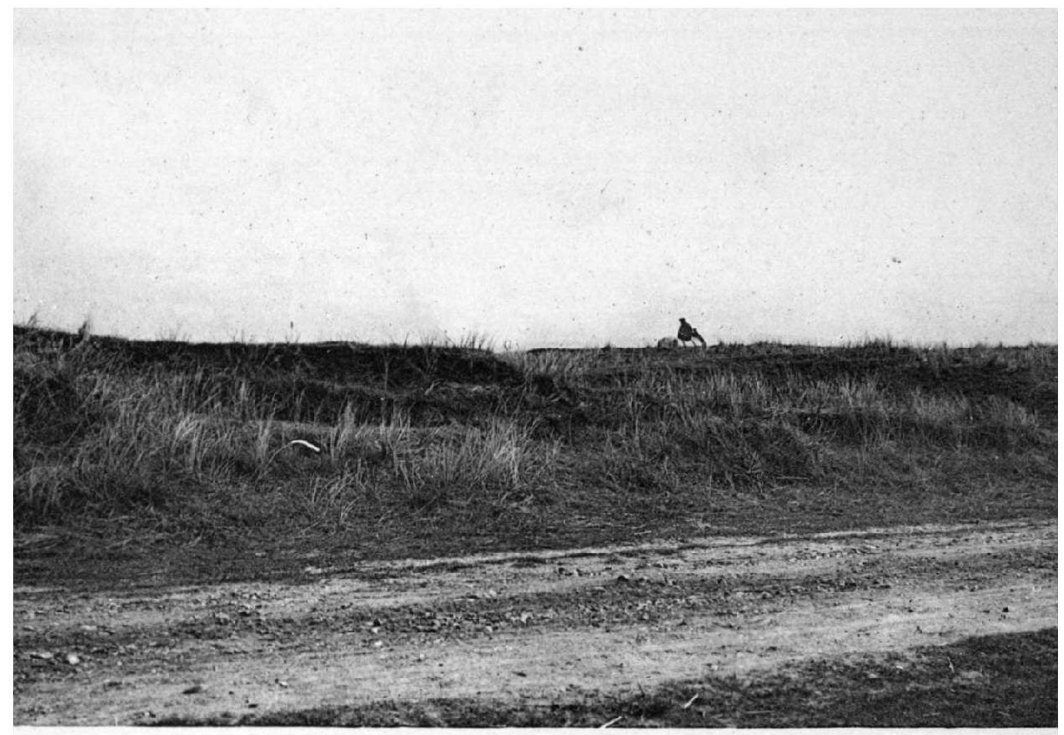

11. - La Digue du Comte Jean, près Mardick.

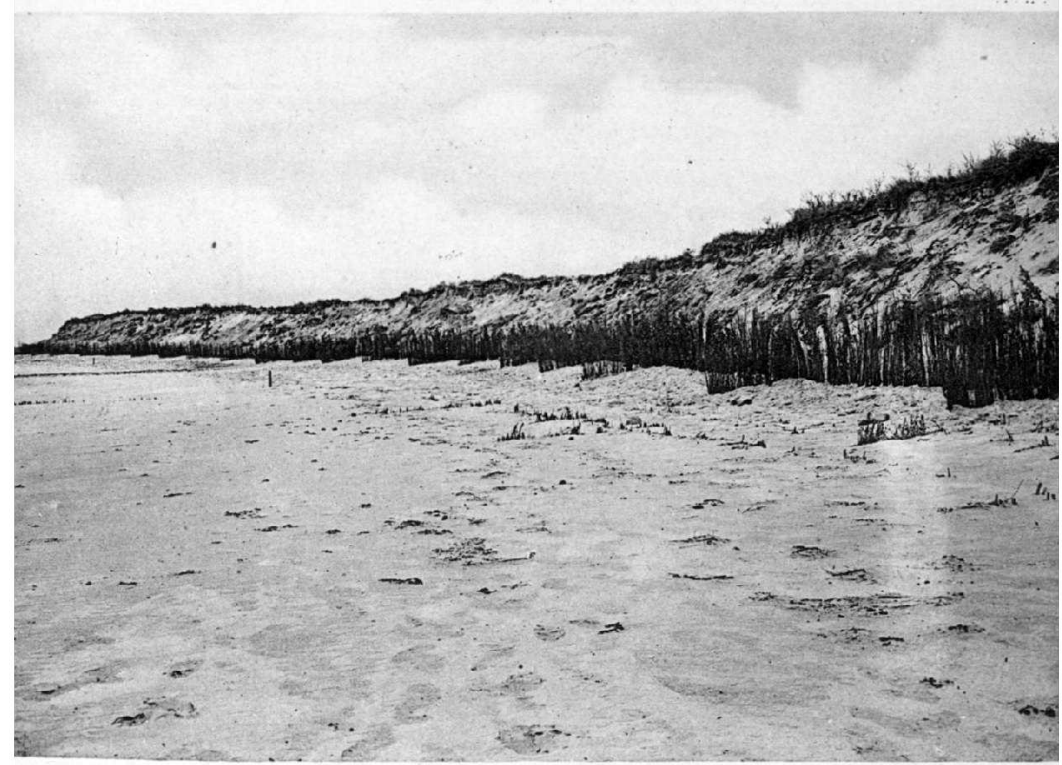

12. - Défense d'une Dune attaquée: fascinages (Breskers). 
IRIS - LILLIAD - Université Lille 1 
recouvert de 7 mètres de sédiments ${ }^{1}$. Vauban consacra la disparition de la fosse et l'annexion du banc à la cote, en lançant vers le N.-W., a travers leur ancien emplacement, le nouveau chenal de I)unkerque. Ce qui restait de la fosse en face de Fort-Mardick disparut à son tour : en 16 ans le terrain s'élevait de 5 pieds au droit des ecluses du canal de Louis XIV, entre 1763 et 1779 ; en 1778 on constatait que les schorres établis en face la partie Ouest de l'ancien Scheurken s'étaient accrus en 23 ans de 38 toises dans la direction du Nord ${ }^{2}$. Aussi en 1784 accorde-t-on au vicomte de Gand la concession des « terres salines délaissées par la mer ${ }^{3} \gg$ depuis Fort-Mardick jusqu’à Dunkerque. La plage actuolle semble continuer à s'accroître ; les courants passant par la dépression qui reste de l'ancienne fosse apportaient vers l'Est des quantilès d'alluvions si considérables qu'il a fallu prendre des mesures spéciales pour les écarter de la jetée Ouest du port ${ }^{4}$. Les dunes formées devant la Digue de l'Ouest, crevée pourtant en 1875, s'accroissent avec rapidité.

Les mêmes phénomènes se reproduisent à l'Ouest de Dunkerque ot de Mardick, jusqu'a Calais. A Loon, on retrouve au N.-W. du village, au dela d'une ancienne ligue de dunes trés effacée, la digue du comte Jean, toujours bordée de nombreuses maisons, et au dela de la saline d'Enna, possédée depuis le début du XIVe siècle par les dames de Clairmarais, une épaisse ligne de dunes qui borde les Hems-St-Pol ${ }^{5}$. A Oye, on rencontre en marchant au N.-L. une ligne trés continue de hautes terres sableuses, parcourue tout au long par la vieille route de Calais à Gravelines, et qui paraît plutôt une ancienne digue augmentée par les apports de sable qu'une véritable dune: c'est probablement, entre Gravelines et Calais, le prolongement de la digue du comte Jean. Puis vient Ie Bane à Groseilles, dont lo nom (banc) et la forme no laissent aucun donte sur l'origine; c'est une digue, qui limite au sud une large bande de terres fortes, les Hemmes de Fort-Philippe et d'Oye, où une ferme porte le nom significatif de Terre-neuve. Ces anciennes salines aboutissent vers le Nord aux

1 Voir à ce sijet la noto de M. Gosselet, Noto sur los sables de la plage de Dunkerque, ct l'intéressant travail do MM. Lancry, Glecnewerck et Debacker, Découverte d'un navire profondémont enseveli dans les sables de Duakerque, publiés dans Ann. Soc. gćol. N., XXIX (1900), pp. 128-159, 2 pl.

2 Arch. Nord, G (Fl. Mar.), 4', nus 66 et $6 \%$.

3 Arch. Nat. Q1 287.

* Eyriaud des Vergnes, Etude sur l'établissement et l'entretieu des ports en plage de sable, (Amn. P.-C., $6^{8}$ séric, ge annẻe [1889)], pp. 18j-406, 6 pl.), pp. 328-332.

5 Copie d'un diplòme de Charles-Quint de 1532, aux Arch. Nat., Q 267. 
dunes d'Oye, accumulées le long d'une digue qu'éleva en 1630 le marquis de Valençay ; mais ces dunes sont encore précédées, du côtè de la mer, par une nouvelle digue, celle-ci par une dernière ligne de dunes couvertes de végétation, le Gros-Banc, en avant duquel on trouve enfin un estran de près d'un kilométre. De Marck à la côte, même accumulation de dunes et de digues: après cette large et triste bande de sables jaunes qui s’étend du village aux remparts de Calais, c'est le banc de la vieille route de Gravelines, assez élevé à cet endroit pour que la différence de niveau avec la saline situéo au Nord soit rachetée dans un champ par un rideau. Jerrière, la ligne de dunes où se suivent les nombreuses maisonnettes des Petites-Hemmes; dunes déja hien aplaties, couvertes d'herbe, ayant l'air de grandes vagues vertes; puis la vaste dépression d'argile grise gagnée aux XVII ${ }^{\mathrm{B}}$ et XVIII ${ }^{\mathrm{e}}$ siècles par les digues Robelin et Taaf. IJes dunes en formation, hautes de 3 à 4 mètres, s'adossent à ces dernières ; sur l'estran s'ètendent quelques monticules, couverts de végètation, ou paissent des troupeaux de moutons; çà et là circulent des chenaux remplis de vase argileuse, où la mer pénètre par les très fortes marés. On pourrait s'y croire revenu au IX ${ }^{\mathrm{e}}$ siècle, au temps oì l'abluayo de St-Pierre de Gand commençait à faire paître ses brebis sur les terres que « jetait » la mer autour d'Aardenburg et Oostburg. Enfin devant cette saline bientôt mûre pour les endiguements, 1600 mètres d'un estran jaunâtre, qui paraît s'étendre à l'infini. A marée basse, on ne soupçonnerait pas la présence de la mer sans l'apparition au-dessus des sables de quelques voiles et du phare de Waldam, marquant de ce côté la limite provisoire des conquêtes de la terre sur les eaux.

Linsi la mer a reculé tout au long de la côte, de Innkerque à Calais, depuis le $\mathrm{X}^{\mathrm{e}}$ siècle, peut-être même d'une manière continue depuis le VII'. Ce progrès de la terre a changé légèrement la forme primitive du rivage; la ligno qui prolonge vers l'Ouest la direction de la côte belge passe par la ville de Dunkerque, au Nord de Loon, par Gravelines, Oye et Marck.Au contraire il est probable que de Dunkerque à l'Yser, et particulièrement entre la frontière française et Nieuport, la côte n'a guère bougé. Zuydcoote était dójà une paroisse maritime au XII ${ }^{\mathrm{e}}$ siècle ${ }^{1}$, et entro la mer et l'ancien emplacement du village, il n'y a toujour's qu'une ligne de dunes, dont l'épaisseur indique l'àge avancé. L'emplacement de l'abbaye des Iunes, établie à la fin du XII ${ }^{\ominus}$ siècle dans une dépression

1 Pruvost, Bergues, p. 140. 
ou panne des dunes de Coxyde 1 , est toujour's environné de sables ; la largeur des dunes à cet endroit, qui était en 1236 de 632 verges ${ }^{2}$, soit $1.900^{\mathrm{m}}$, est aujourd'hui d'environ deux kilowètres. A Westende, la situation n'a guère changé depuis 1241, où il est question d'un chemin allant de l'église de Westende à la mer à travers les hautes dunes ${ }^{3}$. Il y a là comme un point mort, autour duquel la mer et la terre ont gardé leurs positions. La terre y a du moins gagné l'ancien estuaire de l'Yser, devant lequel la mer a accumulé une si grande épaissenr de sable, que la digue du comte Jean est maintenant séparée de l'estran par 1.400 métres de dunes, et que Lombartzyde est éloignée d'autant de la mer, qui la touchait au XIII' siècle .

\section{Recul de la terre à l'Est.}

Mais passé Westende, on se trouve en présence d'un recul indéniable de la côte. On a trouvé sur la plage de Raversijde, entre Middelkerke et Ostende, des débris archéologiques attribués au haut moyen-âge ${ }^{5}$. Ostende a reculé à plusieurs reprises devant la mer; sa vieille église d'Onze-Lieve-Vrouw-ter-Streep fut détruite en 1334 par les flots, en même temps que l'église do Blankenberghe ${ }^{6}$, et en 1395, la ville dul se rófugier, après avoir beaucoup souffert par les « fortunes, orrages, et jnundations des eaues de la mer », à l'abri de la digue que ceux du Franc avaient élevée un peu en arrière ${ }^{7}$; ce qui restait de l'ancienne ville était complètement disparu en $1502^{\circ}$. Wenduyne a émigré vers le Sud depuis le XVİ siècle, et la grande marée du 2 février 1791, qui dévora

1 Voir la charte de la comtesse Jeanne, 1219, dans Van de Putte, Dunes, p. 362.

2 Charte de la comtesse Jeanne, dans Van de Putte, Dunes, pp. 194-95.

3 Charte de Thomas et Jeanne, dans Feys et Van de Casteele, Histoire doudenbourg, II, pp. 100-101.

4 Aucun texte ne vient d'ailleurs corroborer la légende de Lombartzyde grand port aux XI' $\mathrm{X}^{\mathrm{e}} \mathrm{XII^{ \circ }}$ siècles, si souvent rapportée dans les travaux des ancions érudits.

5 Rutot (A.), Sur les antiquités découvertes dans la partio belge de la plaine maritime.

6 Cf. Carton (C.), Notice sur Blankenberghe (Ann. Soc. Em. Br., III, pp. 53-144), pp. $72-79$.

7 Charte d'extension d'échevinage accordée à Ostende par Philippe le Hardi, dans Van den Bussche, Inventairo Arch. Franc de Bruges, I, p. 102.

8 Bons détails dans Belpaire (Ani.), Notice historique sur la ville et le port d'Ostende', (27 p.), imprimée à la suite de son travail sur la Plaine maritime. 
une largeur de 35 pjeds de dunes, mit au jour les murailles et les puits de l'ancien village ${ }^{1}$. Le même phénomène de recul est constaté à Blankenberghe, à Heyst, à Knocke: mêrne l'ampleur du mouvement augmente vers l'Est. Sur la plage de Heyst existerait l'emplacement d'un village du haut moyen-âge. Le Transport ou cadastre général de 1408, enregistrant les pertes faites depuis un siècle exactement, énumère: un grand village nommé Harendyke, peu habité, entre Wenduyne et Blankenberghe; devant Heyst, le hameau « de Panne » et 80 mesures ; sur les wateringues de Ileyst et Rheingarsvliete, 100 mesures et un village de pêcheurs; à l'Est de Knocke, 8 mesures et un hameau important 2. La digue du comte Jean, à l'Est de Heyst, se trouve entre les epis 27 et 41 en retrait sur l'ancienne direction, el cette courbure indique qu'il y eut là un tronçon rompu, dont les vestiges se voyaient sur la plage aux environs de l'épi 37 (aujourd'hui port de Zeebrugge) ${ }^{3}$. Au XVII siècle, pour prévenir de nouveaux progrès de la mer, il fallut hérisser d'épis toute la côte entre Wonduyne et Heyst . Cela n'a pas empêchẻ qu'au XIXe, la mer a fait encore aux dépens des dunes quelques progrès; la plus haute cime du littoral, le « Mont Blanc»de Heyst, a été dévoré en 1886; les dunes devant le phare de Knocke ont fondu de 2 mètres en moyenne par an entre 1870 et 1880, et les ingénieurs avouent pour certaines dunes de Knocke, propriétés particulières moins bien défendues que les dunes de l'Etat, une perte de 25 mètres en 10 ans. A Heyst la prospérité de la plage semble menacée: les grandes marées attaquent la digue et la mer haute couvre si bien tout l'estran qu’a son approche toutes les cabines roulantes doivent être remontées sur le promenoir. Mais c'est surtout à l'Est du Zwin que lá retraite de la côte a été rapide et désastreuse. On a vu Kadzand diminuer au Nord pendant qu'elle s'annexait au Sud les schorres du Zwin et du Zwartegat; Wulpen et ses cinq paroisses s'émiettęr peu à peu dans les eaux, et disparaître sous les coups de la mer ${ }^{5}$.

1 Belpaire (Ant.), Mémoire sur la Plaine maritime, p. 56, note 1. Cf. également Roche, Histoire de Wonduyno-sur-mer, suivie d'uno note sur l'ancienne topographie de Wenduyne, par L. Gilliodts van Soveren (Bruges, Daveluy, 1892, in-8', 74 p.).

2 Texte dans Gilliodts, Inventaire Arch. Bruges, IV, p. 24.

3 'De Mey, Ports en plage de sable, p. 159.

4 Baron de Serret, Mémoire sur les empiétements de la uner tels qu'ils ont lieu sur un point particulier des côtes de la Flandre Occidentale. (Bruges, Bogaert, 18IT, br., $\mathfrak{p}-8^{\circ}, 43$ p.).

Cf. p. 186 , note $7 ;$ p. 187 , note 6 . 
L'aspect des deux parties de la côte se ressent de cette situation. A l'Ouest de Dunkerque, lo rivage est imprécis et fuyant; les digues basses que l'homme plante pour abriter ses faciles conquêtes et fixer aux eaux leur limite sont bieutôt dans l'intérieur des terres, masquées par les petites dunes que la mer et le vent accumulent. Oú chercher la vraie cote, sur cet estrau si large que l'eau s'aporçoit à poine au bout de la frange de sable jaune, et si plat que la vive eau s'avance un bon kilomètre plus loin que la morte eau ? Au lieu d'accimuler des défenses contre une mer si peu agressive et dont les caprices sont rares, il faut aller a sa rencontre; et l'on voit les ports allonger désespérément leurs hautes jetées de bois à travers l'estran, vers les fosses profondes, vers une eau qui ne recule plus : 800 mètres à Dunkerque, 1.500 mètres à Gravelines. Peine perdue : l'estran s'allonge à mesure; à Dunkerque, il s'étend encore à 500 mètres plus loin que le musoir de la jetée Onest. A chaque tentative pour s'approcher d'elle, la mer fuit; le prolongement sur 300 mètres des jetées de Dunkerque, en 1836, a provoqué presque aussitôt un gain égal de l'estran vers le large; et la même opération faite à Calais (sur 250 mètres) a également reporté la laisse de basse mer de la même largeur vers le Nord. En revanche, que l'on enlève, comme à Gravelines, une pelite portion de jetée, et la laisse de basse mer se rapproche d'autant vers la côte ${ }^{1}$. Rien de pareil à l'Est do Nieuport ; lo prolongement des jetées d'Ostende, entre 1837 et 1843, n'a donné lieu à aucun mouvement de l'estran, et la ligne de basse mer se tiont aujourd'hui à plus de 75 mètres en arrière des musoirs ${ }^{2}$. C'est que là, la mer ne recule pas: elle attaque. L'estran est rétréci à 300 mètres, 200 mètres, parfois moins ; à l'Est de Kadzand il est des points où il n'existe plus, et où la mer basse continue à battre le pied des digues. La côte se défend; le pied dos dunes est protégé par des plantations de branchages; des épis formés de gros blocs assujettis entre des pieux projettent dans la mer leurs têtes verdies par les plantes marines. Entre chacune de ces petites jetées, la mer dépose des sables fins, plus abondants vers la partie Est de chaque compartiment (phot. 13). Il y en a devant Middelkerke, devant Ostende, et tout au long de Wenduyne à Heyst : 50 pour moins de 20 kilomètres. Les Hollandais en ont bardé la côte de Kadzand. Pourtant l'estran ne «s'engraisse » pas; c'est tout juste si on maintient en bon ètat les plages de l'Est, comme Heyst. Il a fallu de bonne heure construire des digues aux endroits où les dunes étaient trop minces" pour résister longtemps. Les

1 Plocq, Courants, pp. 143-144.

2 De Mey, Ports en plage, p. 298. 
ingénieurs du moyen-àge les avaient élevées en arrière des dunes, pour donner à ces collines mouvantes un point d'appui solide qui leur permît de s'accumuler, de se renforcer. C'est la fameuse digue du comte Jean, que nous retrouvons ainsi par tronçons tout le long de la côte et dans l'intérieur, entre Gravelines et le Sas-de-Gand ${ }^{1}$; de Wenduyne à Knocke elle aligne derrière la dune son faible rempart, sonvent forcé, mais qui empêche l'anéantissement de la barrière des sables. Aujourd'hui c'est au bord de l'estran que s'est installée la défense; on établit sur les dunes, face à la mer, des digues magnifiques, à la fois remparts et promenades, véritable boulevard de la Flandre belge vers la mer. Déja il étend d'Ostende à Westende, tout le long de l'ancien Streep, ses perrés de briques fortifiés de beaux blocs calcaires de Soignies, et ses promenoirs de carreaux céramiques. L'œuvre est superbe, et l'on se propose de faire plus grand encore : relier par une digue unique les promenoirs de Knocke, Heyst, Blankenberghe et Wenduyne, pousser la digne du Streep jusqu'à Nieuport-Bains et Dunkerque et joindre les deux tronçons entre Wenduyne et Ostende. Ce jour-là, la côte belge ne sera plus qu'une belle muraille de pierres et de briques, qui défiera la mer de continuer ses progrès : il suffira d'entretenir les épis submersibles et les bermos en fascinages qui défendent le pied de la digue pour que la côte soit désormais fixée ${ }^{2}$.

\section{Causes des mouvements de la cóte.}

D'où vient ce double mouvement de la côte? Là théorie courante a été longtemps et est peut-être encore que la côte subit une double oscillation

1 La situation de ces tronçons indique, en l'absence de chartes, que la digue n'a pas été construite, comme on l'a vu, d'un seul coup, et tout au long de la côte. Celui des Waterlanden (St-Kruis à Sus-de-Gand) est postérieur aux inondations de 1377 et 1404 ; celui de Wenduyne-Knocke est cité pour la première fois en 1288 (Carton, Blankenberghe, pp. 65-66). Le tronçon Oost-Dunkerke Nieuport n'a dû être établi qu'après 1280 (cf. p. 189). Aucune indication n'a été donnée jusqu'ici sur la date exacte de la construction entre Dunkerque et Gravelines. Il n'y en a jamais eu dans les parages oi le rivage était protégé par une forte ligne de dunes: La Panne, Westende, Breedene. Il est probable que ces digues, construites à des époques différentes, auront été restaurées par ordre de Jean sans Peur, sous l'empire de la crainte causée par les inondations de l'Est; et elles auront pris le nom de ce prince aux dépens de celui qu'elles portaient auparavant, “Zeedyck » par exemple à Blankenberghe.

2 Il u'y a pas à craindre que des accumulations de sable vienuent se produire devant la digue, comme cela arriverait infailliblement sur la côte française; on a vu que la eôte bolgo n'avait ancune tendance à s'engraisser, et que la prolongation verg le large des jetées d'Ostende n'avait produit aucun déplacement de la laisse des basses mers. 
autour d'un axe qui passerait par Nieuport; tout ce qui est á l'Ouest s'élève, tandis que la partie orientale s'affaisse. Cette explication est très simple, mais ne tient pas compte de dcux anomalies: il y a tout à l'Ouest un fragment de côte qui ne s'élève pas, et on en trouve un autre à l'Est qui n'a pas du tout l'apparence de s'affaisser. Sans s'étendre sur les retours offensifs dont la mer est encore capable entre Dunkerque et Calais ${ }^{1}$, et qui ne paraissent pas indiquer un soulèvement du sol en cet endroit, comment concilier la théorie d'une oscillation positive avec la présence d'un point aussi faißle que la côte de Sangatte? C'est pout-ctre, avec certains polders de la Flandre zélandaise, l'endroit le plus menacé de la côte flamande. Là aussi le rivage paraît avoir reculé, puisqu'on croit que les puits creusés dans la tourbe qui affleure sur la plage sont ceux d'une ancienne partie du village de Sungatte qui existait encore au XIII ${ }^{e}$ siècle ${ }^{2}$. Ces progrès do la mer ètaient dangereux, car Sangatte commandait l'entrée du bas pays d'Ardres et de Guînes, cinq lieues de terres marécageuses au pied de l'Artois, à peine situées au niveau moyen de la mer. Il fallait que la côte fût fixée á cet endroit : do là la fameuse digue de Sangatte, qui apparât à la fin du XVI ${ }^{e}$ siècle, et dont l'entretien dispendieux rappelle celui de la grande digue de Westkapelle, en Walcheren.

L'homme et la mer ont mis un ógal acharnement à la résistance et à l'attaque: la lutte dure encore. On travaille déjà à la digue en 1589 ; on la répare en 1591, $1594^{3}$; pourtant en 1614 la mer fait brèche, court d'un trait jusqu'à Guînes; pendant 6 ans, tous les marais en restent improductifs ${ }^{*}$. On crut que la faute en était à cette maudite terre grasse, pas assez résistante : à un bastion si important, qui protége « plus de 15 lieues de pays de circonférence ${ }^{5}$, ce n'est pas faire trop d'honneur quo de mettre bonnes pierres boulonnaises, bons grès compacts descendus par

1 Inondations de 1508 et 1520 dans les pays de Bergues, Bourhourg, Gravelines et Langle (Arch. Pas-de-Calais, C. 305, pièce 64); rupture de la digue de mer, en 1612, entre Mardick et Gravelines (Archives de Bergues, DD 53); ruptures de digues et. inondations en 1736 et 1737, entre Dunkerque et Calais (Fourcroy de Ramecourt, Observations sur les marées de la cote de Flandre, Mémoires de Math. et Phys. présentés à l'Acad. des Sciences, t. VIII, Paris, 1780, pp. 577-600 et Arch. Nat. H1647, pièce 85); inondation de 1808 (Arch. Nat. F14 572); rupture de la digue de FortMardick en 1875, près de la ferme Standart.

2 Rigaux (H.), Remarques archéologiques à propos d'ıne communication sur Sangatte (Ann. Soc. Géol. N., VII, 1879-80, p. 121).

3 Arch. Pas-de-Calais, C. 142.

4 Bernard, Annales de Calais, pp. 15-16.

5 Mómoire de l'intendant Chauvelin, Arch. Pas-de-Calais, C. 143, pièce 1. 
Guînes ; après 1624, on la reconstruit en pierres de taille ${ }^{1}$. Apparemment la pierre de taille ne suffisait pas, puisque la mer y fait brèche on 1641 , on 1691, en 1694. On s'ingénie à consolider; l'adjudication de 1691 comporte la fourniture de grosse charpenterie, ferrures, pierres de Boulogne, glaise, fascinages, tunages et nattages 2 . La mer répond par la terrible marée du 31 décembre 1720: quatre brèches à la digue; déjà lo flot a renversé une partie de l'ouvrage à corne du Fort-Nieulay; « encore une marée semblable, et le plat pays était mis sous l'eau jusqu'à St-Omer » ${ }^{3}$. Grande alarme dans le Calaisis; la corvée est commandée au tocsin dans les 24 paroisses; tous les hommes valides accourent en désordre, chacun avec un louchet ou une brouette; on répare les brèches avec une activité désordonnée *. Il faudra recommencer en 1727 , en 1736 , en $1749^{5}$. On perd confiance aux pierres de taille; n'est-ce pas là un obstacle trop rigide, que la mer démolit à coups de bélier ? Puisqu'il faut tout refaire après 1749 , on se décide pour une digue en bois, défense plus b́lastique. Il en coûte 69.000 livres, et dés 1754 les ingénieurs déclarent que la digue de charpente donne moins de sécurité que jamais ; on 1760, on constate qu'elle ne tient plus; le 2 janvier 1767 , tout le bas de Sangatte est submergé ${ }^{6}$. Force est de revenir aux vieux errements; et depuis c'est contre une digue en revêtement de pierres que la mer brise ses fureurs. Il est rare qu'on soit dix ans tranquille; il faut réparer des brèches en 1790, 1791; en 1795, la mer emporte 137 toises; en 1802 la digue est presque détruite; les marées l'endommagent en $1808,1812,1813$, et la bouleversent entièrement dans la grande inondation de 1825, qui fit sentir ses effets jusque dans l'Escaut. Les ingénieurs procèdent alors à une reconstruction totale: c'est la digue de Péliélope. Pendant 30 ans lo pays fut tranquille: mais en 1860, la mer déchaussa le pied sur 30 métres de long; elle faillit envahir le pays en 1862 ; la dune à l'Est de la digue fut réduite à 12 mètres de large; il fallut prolonger l'ouvrage dans cette direction; on y travailla de 1865 a 1867. Le coup de mer de 1882 nécessita de nouveaux efforts ${ }^{7}$ et un dernier

1 [Vétillart]. Conseil général du Pas-de-Calais. Diguo de Sangatte. Renseignements historiques. Rapport de l'Ingénieur en chef des Ports et Phares du Pas-de-Calais (Arras, Scoutheer-Dubois, 1886, br. 61 p.).

2 Arch. Pas-de-Calais, G. 142, pièce 9.

3 Ibid. pièce 21; C. 143, pièce 1.

4 Ibid.

6 Ibid., C. 142 , pièces 96 et 108 ; Arch. Nat. $\mathrm{H}^{1} 647$, pièces 46 et 85.

6 Ibid., C. 143, pièces 11, 104 ; C. 144, pièces $10,16$.

7 A partir do 1790 , les détails sont empruntés au rapport Vétillart, pp. 2858. 
dèsastre faillit se produire le 7 janvier $1905^{1}$. Il en coûte 2.000 francs environ par an au Syndicat des Dignes et Dunes du Pas-de-Calais, chargé de l'entretien de la digue; et il lui faut tous les 20 ans onviron solliciter du département et de l'Ftat un secours de 45 à 50.000 francs pour les grosses réparations. Rien que les' dégâts du 7 janvier 1905 auront nécessité une dépense d'environ 60.000 francs ${ }^{2}$. Il faudra se résondre à continuer la lutte, et à accumuler sur ce coin de la côte, devant la mer envahissante, des obstacles sans cesse renouvelés.

L'histoire de la digue de Sangatte contredit l'hypothèse d'un exhaussement de la côte française; il est superfiu de démontrer longuement que l'histoire du Zwin indique que la côte belge ne s'affaisse pas. Si elle s'enfonçait lentement sous les eaux, comment la mer se serait-clle retiréc du golfe qu'elle occupait encore en 1860 jusqu'à Sluis? comment achèverait-elle à l'heure qu'il est de faire disparaître la dernière anse respectée par l'endiguement de 1873? Si la côte belge n'est pas nourrie, ne s'engraisse pas à l'Est de Nieuport, il faut en chercher les raisons ailleurs. C'est d'abord la proximité de l'embouchure de l'Escaut; la profonde passe de Wielingen, où l'on sondo jusqu'à 23 mètres en face de Groede, se raccorde avec la côte par un talus sous marin qui est trop raide pour former un estran un pen large; il s'ensuit que les apports de sable dans la belle saison y sont peu considérables, et qu'ils sont vite repris par les tempêtes. D'autre part les banes de Flandre cessent d'étendre à l'Est d'Ostende leur écran protecteur devant la còte ; aussi les grosses vagues qui viennent librement du large buter contre le rivage ont beau jeu pour corroder en quelques instants les sables apportés pendant les temps calmes sur l'estran. Par les grandes tempêtes du N.-W., les lames viennent attaquer avec violence cette côte mal abritêe; c'est alors que sont minées les digues, et dévorées les dunes; en novembre 1897 la digue d'Albertus à l'Ouest d'Ostende a été entamée, celle de Middelkerke très menacée !

Proximite des passes de l'Escrut, et jadis des passes du Zwin, absence du rideau de banes, sont les deux grandes causes de l'amaigrissement de

1 Journal Officiel du 17 février 1905. Comptes rondus dess séances de la Chambre des députés, Session ordinaire de 1905, pp. 359-360.

2 Renseignements de M. l'ingénieur des Ponts-et-Chaussées à Calais, et du Président du Syndicat des Digues et Dunes. Les comptes du XVIII siècle indiquent des dépenses équivalentes; en moyenno 1.000 livres par an, sans compter les grosses sommes dẻpensẻes dans les grands travaux, 1720, 1750. (Arch. Pas-de-Galais, C. 145). - A consulter: Blanchard (R.), La digue de Sangatte, Mèm. Soc. Dunk., 1905. 
la côte belge. Ainsi s'explique que les effets s'en fassent sentir de plus en plus fortement vers l'Est, où la passe de Wielingen se rapproche de la côte à la toucher; de là viennent le recul de Kadzand et la disparition de Wulpen. Du côté français, rien de tel; les cinq rangées de bancs constituent un véritable brise-lames, qui rompt la violence des grosses lames de tempête. Débouchant dans les parages calmes qu'abrite cette précieuse muraille, les eaux intérieures chargées d'alluvions qui s'écoulent à marée basse par les écluses de Nieuport, Dunkerque et Gravelines sont entraînées par le jusant dans la direction de l'Ouest, puis portées tout doucement vers la plage par les premiers efforts du flot. Les matières en suspension viennent ainsi se déposer sur l'estran, à l'Ouest des ports français, surtout dans les parties abritées par les jetées ${ }^{1}$, sans que les grosses lames du large, arrêtées par les bancs, puissent venir corroder et entrainer au loin les matériaux. Finalement c'est donc à la présence des bancs qu'il faut attribuer surtout les différences du régime de la côte. L'exception de Sangatte vient confirmer la règle: les bancs ne dépassent guère Calais à l'Ouest, laissant la cốte deSangatte exposée à toutes les violences des vents et des courants du détroit ${ }^{2}$.

Cette explication est plus rassurante. La Flandre belge ne sombre pas dans la mer. Elle a perdu en 8 siècles, dans la partie la plus exposée, quelques kilometres (?) (Wulpen); mais on peut espèrer que de ce côté-là, la mer a fini ses conquêtes. Il est peu probable que la côte flamande continue son mouvement de recul à l'Est, de progrès à l'Ouest. Au delà de Nieuport, l'établissement des épis empêchera l'amaigrissement de la plage, et la jonction des grandes digues de mer fixera définitivement le rivage. Vers Dunkerque et Calais, en s'abstenant de nouveaux endiguements et en n'allongeant plus les jetées, on verra la côte garder son stat actuel ; déjà la comparaison avec les cartes de 1801 montre que l'estran n'a varié que sous l'influence des travaux d'art, et aux endroits où ils ont été exécutés. Pour ne pas obstruer les rades, et no pas éloigner encore la mor de l'entrée des ports, on paraît décidé de ce côté à ne plus faire de conquêtes sur les flots. Ainsi la côte flamande semble avoir atteint aujourd'hui un

1 De là vient qu'un allongoment des jetées, constituant un nouvel abri, augmente régulièrement la largeur des estrans.

2 Les bancs du Riden de Calais ne protègent pas la digue: on sonde devant Sangatte 11 mètres, puis 23 mètres, à une distance de 6 kilomètres de la côte. Le recul continu de la falaise du Blanc-Nez augmente encore le péril, en laissant les courants du détroit so rapprocher de plus en plus de la côte. 
état d'équilibre; elle restera à peu près semblable ả elle-même si l'homme sail se défendre à l'Est, et cosse d'atlaquer à l'Ouest. La destinéo du rivage est entre les mains de ses habitauts.

II.

LES DUNES : CaRACTÉRES PHYSIQUes.

Derrière la côte s'étend le mur gris des dunes, de hauteur variable : 6 à 8 mètres vers Calais, moins encore jusqu'à Dunkerque; atteignant 39 mètres entre Zuydcoote et Oost-Dunkerke, 27 mètres á l'Est d'Ostende, 23 mètres à Knocke. On a vu combien l'existence de cette ligne de dunes est ancienne ; leur présence au $\mathrm{X}^{\mathrm{e}}$ siècle est attestée par des documents écrits, el il est probable qu'il en a toujours existé sur ce rivage bas, même pendant que la mer avait envahi la plaine de la tourbe. Les conditions n'étaient-elles pas les mêmes? une plage peu inclinée faisant suite à un sol très bas, une mor fortement chargée de dépôts où la violence des courants amenait plus d'alluvions encore qu'à présent, un régime de vents dominants semblable au nôtre, et qui couchait les arbres do la plaine tourbeuse dans le même sens où les inclinent aujourd'hui les vents d'Ouest.

\section{Largeur des dunes.}

Les dunes se forment de l'accumulation des grains de sable déposés sur l'estran par la mer. Il existe done forcément uno relation entre la nature de l'estran et celle des dunes. On a vu que l'estran de la côte flamande présentait des différences considórables. Entre Calais et Gravelines, sa largeur varie entre 1.000 et 1.800 métres, et comprend trois tranches : une zone inférieure, large de 350 à 500 mètres, couverte on tous temps par la haute mer de morte eau; une $2^{\circ}$ zone qui atteint 800 et 1.000 mètres aux abords des ports, sur. laquelle ne s'étendent que les hautes mers de vive eau; une dernière de largeur très variable (quelques centaines de mètres), mouillée seulement par les hautes mers extraordinaires, et sur laquelle la végétation est déjà établie. Après Dunkerque, l'estran se rétrécit à 500 , puis à 350 mètres, et les hautes mers de vive cau ordinaires s'approchent à une trentaine de mètres du pied des dunes; déjá la plage est sillonnée jusqu'à cette distance de petites dépressions parallèles à la côte, et creusées par les courants, qui sont caractéristiques des stations 
balnéaires flamandes. Après Wenduyne, l'estran se rétrécit a 230 mètres en moyenne, sauf à l'ancienne embouchure du $Z$ win ; la haute mer de vive cau vient battre le pied des dunes; avec elle se rapprochent les dépressions de la plage. Enfin l'ostran disparaît presque après Kadzand, au droit du Zwarte Polder, aujourd'hui inondé; et la dune disparaît avec lui. On s'attendrait a voir la largeur des dunes en rapport avec celle de l'estran et à trouver la plus forte épaisseur de monticules aux endroits où le vent trouve à sa disposition de vastes champs d'un sable qui resto sec pendant des périodes très étendues. $\mathrm{Or}^{\prime}$ la largeur des dunes flamandes ne varie pas en fonction de l'étendue de l'estran. Par trois fois leur ligne s'étend et se rétrécil. Après la muraille haute et étroite, vrai rempart de 12 a 15 mètres qui protège Kadzand contre la mer, les dunes s'êplanouissent à Knocke; derrière le phare, elles couvrent 1.500 mètres jusqu'au village. Puis elles s'amincissent à Heyst, se réduisent à une cinquantaine de mèlres avant Blankenberghe, à la largeur d'une forte digue jusqu'à Wenduyne. Là elles s'élargissent brusquement, et atteignent 900 mètres a vant Ostende. Rasées entre cette ville et Mariakerke, elles retrouvent 120 à 150 mètres vers Middelkerke, 1.000 mètres après Westende, enfin jusqu'à 2.300 mètres avant la frontière française, vers Oost-Dunkerke. Elles diminuent ensuite vers Dunkerque jusqu'd 1 kilomètre, et so partagent à l'Ouest de cette ville en plusieurs tronçons, nouveaux et anciens, dont la largeur totale reste assez faible, et n'atteint jamais les 1.000 métres.

Ces bizarreries montrent que le rôle de l'estran dans la formation des dunes peut être contrarié par d'autres phénoménes. Si les dunes ne sont pas phus larges tout le long de la plage démesurée Calais-Dunkerque, c’est que les dépôts fins, assez argileux, que cette partio de l'estran doit à l'apport des eaux intérieures, sont relativement compacts et moins facilement entraînés par le vent que les sables purs. A Knocke, l'épanouissement de la dune a une cause historique; il y a là en réalité deux lignes de dunes, très nettement séparées par la dépression-appelée Zoute-Panne; celle du Sud, la plus ancienne, s'est formée le long de l'estuaire de l'ancien Zwin, dans le prolongement du vieux polder du Hazegras; c'est celle dont parle le texte de 1408 qui indique les progrès des sables à Knocke ${ }^{1}$. Celle qui s'étend au Nord du Zoute est récente; elle ne s'est formée qu'au XIX ${ }^{\beta}$ siècle, après l'endiguement du Hazegras-Polder (1789); et précisément cette secondo ligne, formée derrière une plage étroite, est beaucoup moins largo que l'ancienne, établie aux dépens des vastes laisses

1 Cf. page 222. 


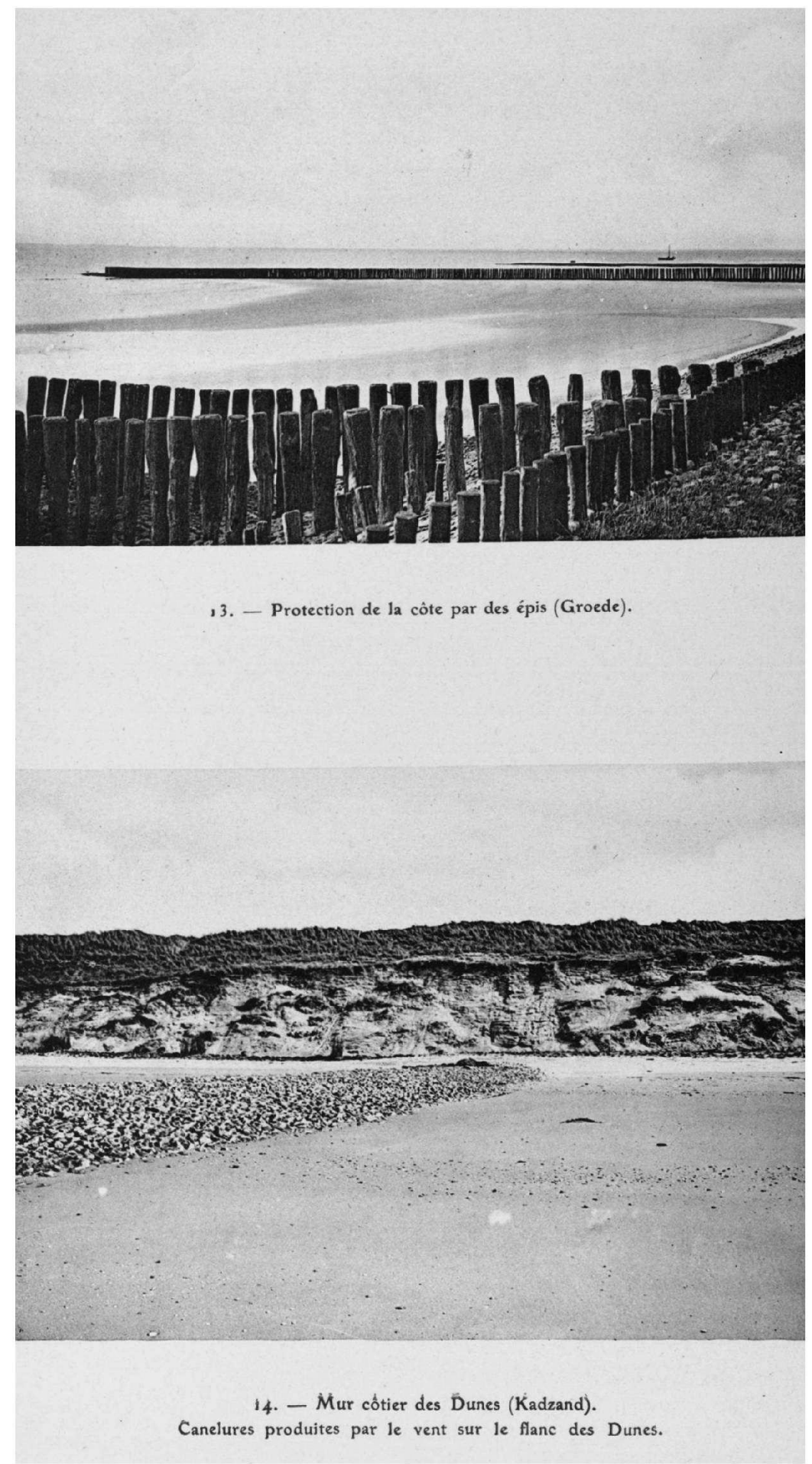


IRIS - LILLIAD - Université Lille 1 
de l'estuaire. Enfin pour les zones si étendues d'Ostende-Wenduyne et de Dunkerque-Nieuport, il existe une coïncidence qui pourrait bien indiquer la solution : ces partios élargies des dunos se trouvent juste à l'endroit oú deux bancs, le Traepegeer et le Stroom, viennent se joindre à la côte. Or la présence d'un banc contigu à la plage anène à coup sûr une augmentation de dépôts sableux sur l'estran; car le flot arrache au banc et transporte à la côle de grandes quantités de sable que le jusant, contrarié par la proximité du banc, et sans force au début de son mourement, c'està-dire lorsqu'il porte vers la pleine mer, est impuissant à ramener en totalité. Avec l'excés de ces dépôts sableux, le vent a poussé vers la terre les masses de sable qui forment aujourd'bui les épaisses bandes de dunes de Nieuport et de Breedene ${ }^{1}$. C'est là une nouvelle preuve de limportance des bancs pour tout cé qui concerne la côte flamande. Déjà c'est en s'appuyant sur d'anciens bancs que semble s'être formé le rivage actuel, et c'est la présence des bancs qui en détermine le progrès ou le recul. On verra quo le rôle qu'ils jouent dans la formation des dunes n'est rien encore à côté de l'influence qu'ils exercent sur l'établissement et la prospérité des ports.

\section{Formes des dunes.}

Mème daus les parties larges, ces dunes flamandes présentent rarement la forme classique, faiblo pente du côté d'où vient le vent dominant, flanc raide du côté opposé. Elles commencent toujours du côté de l'estran par un vrai mur côtier, continu sauf d'étroites brèches, qu'on retrouve jusqu'en Hollande (le strandreep); la pente vers la mer est parfois de 45 degrés, vers l'intérieur d'une trentaine. Derrière cette bordure peu épaisse (50 à 100 mètres) s'étendent, dans un désordre extraordinaire, monticules et dépressions, jusqu'à une nouvelle ligne à.peu près régulière qui limite la rangée vers la plaine maritime, et où le flanc raide, cette fois, so trouve être colui du Sud. C'est donc, entro ces deux. murailles extérieures, une étendue d'un à deux kilomètres de sables. Là sout mélangées toutes les formes, toutes les orientations. On finit pourtant par s'apercevoir que ces dunes intérieures semblent s'aligner grossièrement en chaînes obliques au rivage, orientées du S.-W. au N.-E.; ces chaînes, tronçonnées, rompues par des cols, sont loin d'ailleurs d'être en

1 Cette théorie est également celle de M. C.-J. Van Mierlo, dans le texte annexé à sa Carte lithologique de la partie méridionale de la Mer du Nord (Bull. Soc. belge Géol. XIL, 1899, Mém. pp. 219-265). 
ligne droite, et présentent des convexités tantôt ver's l'Ouest, le plus souvent vers l'Est '. D'un côté elles vont se rattacher au mur côtier, de l'autre elles viennent former la bordure intérieure; et l'on peut voir ainsi, entre Bray-Dunes et Adinkerke, deux alignements qui sont arrivés

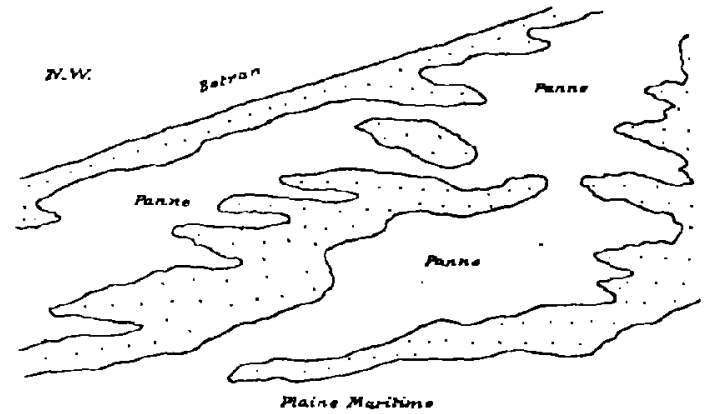

FIG, 44. - Allure théorique des chaînes de dunes. on contact avec la plaine, et s'y sunt fixés. Cetto direction est à peu près conforme à ce que nous pouvons attendre de l'action des vonts dominants. A Iunkerque comme sur toute la côte, cest du Sud-Ouest, puis de l'Ouest que le vent souffle le plus souvent ; le NordOuest ne vient qu'en troisième ou quatrième ligne, après le Nord-Est. Mais les vents du NordOuest sont parmi les plus violents et les plus mauvais ; leur vitesse horaire moyenne, calculée pour les 8 années $1878-1885$, est de $25 \mathrm{~km} .61$, contre $20 \mathrm{~km}$. 11 pour les vents Sud-Ouest; seuls les vents d'Ouest ont une vitesse supérieure ${ }^{2}$. C'est l'action de ces deux vents combinés qui oriente, face à l'E.-S.-E., les rangées irréggulières de dunes.

Non moins irrégulières sont les formes de ces dunes. Tantôt ce sont bien, en effet, de longs alignements, do vraies crêtes, parfois surmontées de monticules bizarres, en dents de scie, qui sont de petits amas de sable fixés par la végétation. Ailleurs, les chaînons sont tronçonnés par des cols profonds, orientés W.-E. ou N.-W.-S.-E. D'autres dunes sont isolées, parfois bizarrement plantées au milieu d'une dépression. La plupart des dunes isolées sont, chose étrange, en pente douce vers l'Est, et présentent vers l'Ouest un flanc raide, dénudé, que le vent creuse en son milieu jusqu’à lui donner une forme concave. Toutes ces hizarreries indiquent bien qu'il intervient dans la formation des dunes flamandes d'autres éléments que l'action des venls dominants Ouest et Nord-Ouest. La principale cause d'irrégularités est sans doute l'extrême variabilité des vents. Ceux du Nord-Est soufflent même plus souvent que ceux du Nord-

1 Mème observation dans le travail de M.M. Delépine et Labeau, Le littoral français de la mer du Nord (Feuille des Jeunes naturalistes, IVo série, 340 année, 1904, pp. $161-166$ et $189-197)$.

2 Chiffres empruntés à Eyriaud des Vergnes, Ports en plage de sable, pp. 288-280. 


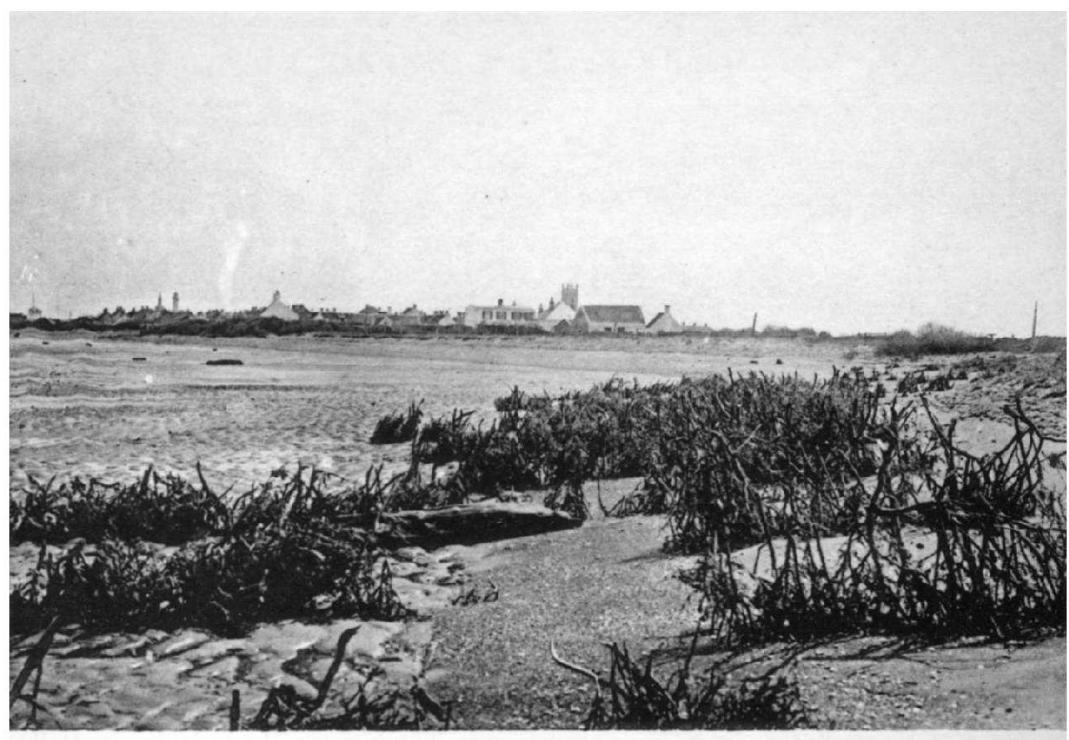

15. - La còte Ouest : vue de Grand-Fort-Philippe.

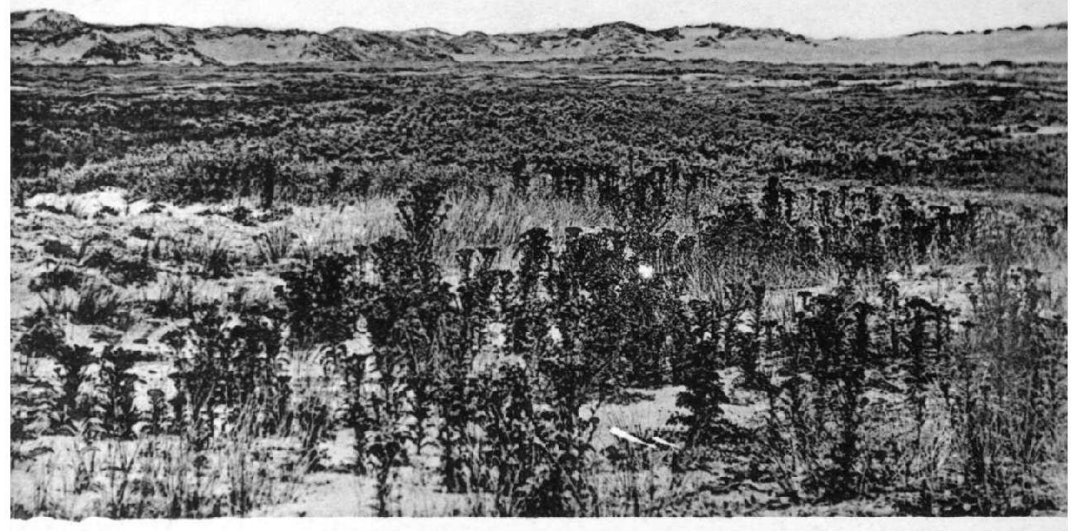

16. - Une panne dans les dunes (Zuydcoote). A droite, monticules en dent de scie. 
IRIS - LILLIAD - Université Lille 1 
Ouest, et leur vitesse horaire moyenne est presque aussi considerable. On n'a pas là un régime uniforme comme celui qui éditie les dunes règulières de Gascogne. Lhumiditê extrême du climat doit également intervenir; elle rend le sable plus cohérent et permet aux vents d'y découper ces formes bizarres, en contradiction avec les conditions générales de formation des dunes. Les vents sculptent la dune, et les érosions qu'ils y pratiquent, particulièrement du côté exposé à l'Ouest, contrebalancent les effets de l'accumulation, suppriment les pentes douces qu'on devrait trouver de ce côté. Rien n'est plus commun que de voir les flancs des dunes tout striés de cannelures qu'on prendrait aisément pour des plans de stratification, et qui témoignent de l'action érosive du vent (phot. 14). Enfin la végétation contribue à différencier les formes, en maintenant en saillie los partios qu'elle a fixées: de là les dents de scie dont se hérissent les dunes chauves.

Cette variété de formes u'empêche pas le paysage des dunes d'être uniformément triste et désolé. Ce chaos de pentes douces et de flancs raides, cet enchevêtrement de crêtes pelées et de cratères à demi effondrés sont mélancoliques sous le ciel gris. On songe à un paysage lunaire. Les dépressions sont à peine plus attrayantes. La végétation épineuse qui s'y développe au printemps donne à leur sol une teinte noire; on croirait un champ d'herbes brûlées. Parfois on trouve dans les parties profondes des plus grandes Pannes, (c'est le nom que l'on donne à ces dépressions), quelques saules, l'argousier, le sureau. Une petite mare d'eau douce occupe sonvent le fond; un tapis de mousse s'établit sur les premières pentes qui entourent la panne. Cette végétation pauvre repose un peu des tristesses du paysage; mais la vue est bornée: bientôt la panne s'efface derrière une colline qui l'envahit, et va serpenter plus loin à traver's les rangées incertaines et menaçantes de dunes grises.

\section{Mouvements et fixation des dunes.}

Les dunes flamaudes se déplacent en effet; leurs mouvements, moins réguliers et moins vastes que ceux des dunes gasconnes et hollandaises, n'en sont pas moins constatés. La faible largeur de ces dunes, la variabilité du vent, l'orientation de la côte, qui fait que les vents dominants ne prennent les dunes qu'en biais, empêchent la marche des sables d'être continue et vraiment menaçante. Cependant les exemples de déplacement de dunes abondent. En 1159, les « sables volants » ont recouvert un torritoire voisin de Gravelines, donné au début du siècle par le comte 
Robert \& l'abbaye de St-Bertin '. L'abbaye des Dunes, qui est allée s'établir au milieu de ces collines changeantes, est sans cesse en lutte avec le « sablon » qui menace de l'ensevelir ". Le Transport de 1408 fait rayer de la liste des terres imposables 80 mesures a l'Ouest de Wenduyne, recouvertes par le sable; 1.500 mesures d Tolmzant, avec de beaux hameaux qui sont disparus, sur les territoires de Vlisseghem et Clemskerke; enfin 600 mesures à l'Est d'Ostende. Blankonberghe sollicite une réduction parce qu'ello est réduite à rien par le sable des dunes; enfin du Furnambacht on signale plusieurs terres perdues ${ }^{3}$. En 1415, le métier de Breedene a tant souffert «par le vol des sables » que plusieurs babitants ont quitté le pays ". En 1623 on répare les dunes d'Ostende qui submergeaient rapidement les terres fortes situées derriere ". La destruction par les sables du village de Zuydcoote, la nuit du 31 décembre 1777, est restée célèbre dans la contrée; on réalité il n'y eut probablement de recouverles que l'eglise et quelques maisons: Zuydcoote qui avait 160 habitants en 1716, en comptait 185 en 1804, après la catastrophe. Le récit de la tempête, écrit au milieu du XIX siècle en s'inspirant des souvenirs de vieillards. témoins oculaires, montre bien ce que fut ce coup de vent du Nord-Ouest qui fit descendre les dunes sur quelques chaumières ${ }^{6}$. Les progrès des dunes ont continué au XIX ${ }^{\mathrm{e}}$ siecle autour de Dunkerque, * couvrant des terres déjà fertilisées, encombrant des habitations, des hameaux entiers " T. Plus récemment la grande tempête des 10-11 septembre 1203, qui a déraciné tant d'arbres en Flandre, a comblé des pannes, enterrant argousiers et saules; et on a pu observer une panne mesurant 80 à 100 mètres

1 Haigneré, St-Bertin, I, p. 103, no 230.

2 Charte de la comtesse Marguerite, 1246, dans Van de Putte, Dunes, p. 202.

3 Priem, Précis analytique, $2^{\mathrm{a}}$ série, VI, pp. 157-172.

4 Comptes du Franc, 1415-16, dans Delepierre, Précis analytique, 2• sèrie, I, p. 143.

5 Gilliodts, Coutumes du Franc de Bruges, III, pp. 230 sqq.

6 De Bertrand (R.), Notice historique sur Zuydcoote. (Mem. Soc. Dunk., 185354, pp. 215-342). En ouvrant, pendant l'année 1904, une chaussée à travers les dunes, de Zuydcoote a la mer, on a mis au jour des fondations d'une maison en briques blanches, et rotrouvé deux couches végétales superposées, noirutres, cohérentes, parfois plastiques, toutes deux criblées de débris de briques, poteries, charbons de boir. Les poteries de la couche inférieure ont été attribuées par M. Rigaux au XV'a siècle. Donc cet emplacement, occupé par l'homme avant le XV• siecle, aurait été recouvert de quelques mètres de sables, à la surface desquels se seraient établies de nouvelles cultures; et ce nouveau sol serait celui que vint recouvrir la tempete de 17\%7. Zuydcoote aurait donc été submergé par les sables à doux reprises.

7 Arch. Nord, C. Fl. Mar., 38bis (pièces de 1824). 
de large en 1900 , réduite en 1904 d̀ $40-50$ metres, parfois à 20 mètres ${ }^{1}$. Il n'est pas rare, en parcourant les grandes dunes, de voir des arbrisseaux d'une panne émerger de la couche de sable pur qui vient de s'amonceler dans la dépression. Sur la voie ferrée de Furnes à Dunkerque, les maisonnettes de garde-barrière sout à demi entourées, et s'abritent derrière des palissades que l'on est obligé de surélever sans cesse. Evidemment ce n'est qu'à force de soins et d'attention laboriense que les dunes sont retenues au Nord de la ligne de cultures et d'habitations qui les borde le long de la plaine marilime.

De bonne heure on a songé à utiliser la végétation spéciale des dunes pour fixer ce sol mouvant 2 . Outre les quelques arbres et arbrisseaux qui croissent dans les pannes, les dunes possèdent des plantes caractéristiques, des graminées pourvues de longues racines rampantes qui consolident le sable, comme l'oyat, la plus utile et la plus répandue. Avec ses tiges vert sombre, tout en pointe et en piquant, l'oyat n'est agréable ni à voir ni à toucher; mais il retient si bien les sables les plus arides que non seulement on le tolère, mais qu'on le propage par des plantations en alignement. L'usage en est ancien, et les moines des Dunes savaient déjà se défendre contre la montée du sablon en utilisant ces rudes végétaux ${ }^{3}$; des réglements défendaient, dans les paroisses de dunes, Adinkerke, Coxyde, Oost-Dunkerke, d'arracher les oyats et épines, sous peine d'ameade ${ }^{4}$. Les ordonnances du Franc de Bruges aux XVII et XVIII siècles insistent à maintes reprises sur la nécessité de consolider la dune en y plantant ou replantant de l'oyat ${ }^{\mathrm{s}}$. En même temps on s'attaque à l'agent le plus actif de la destruction de la dune, le lapin, qui pullule dans ces sables, et qui en creusant des terriers, en détruisant la végétation, rend au sable une mobilité qui donne prise au vent. Leurs dẻgâts sont si grands qu'à plusieurs reprises les comtes, à qui appartenaient les dunes et qui s'y réservaient jalousement le droit de chasse, permirent temporairement aux riverains de détruire ces malfaisants animaux. Il est vrai que

1 Delépine et Labeau, Le littoral français, p. 196.

2 Sur la flore des dunes de Flandre : Masclef, Étude sur la géographie botanique du Nord de la France (Journal de Botanique, II, 1888, pp. 234-237); - Durnortier, Bouquet du littoral belge (Bull. Soc. roy. de Botanique de Belgique, 186i5); - I abeau (A.), Note sur la flore maritime du littoral français de la mer du Nord (Feuille des Jeunes Naturalistes, IV série, $35^{8}$ année, 1905, pp. 141-156).

3 Van de Putte, Dunes, p. 202.

- Gilliodts, Goutumes de Furnos, II, p. 273.

Gilliodts, Coutumes du Franc de Bruges, III, pp. 230-241. 
les dommages élaient grands, et le danger parfois sérieux: les conins, comme on les appelle, détruisent les dunes de Blankenberghe à Heyst à tel point que la mer pénètre au travers (1403) ${ }^{1}$; en 1634 ils ont fait tant de dégâts aux dunes de la Wateringue d'Eyensluis qu'ils on ruiné jusqu'à son écluse 2. L'abbaye des Dunes est menacée de ruine par les conins qui creusent par dessous ses murs et sont près de la faire choir (1411) ${ }^{3}$. En 1877 l'eau de mer' a pénétré pendant une dizaine d'heures dans un polder à Lombartzyde par un trou que ces animaux avaient creusé dans la digue de l'Yser. Il suffit aujourd'hui encore de voir l'etat de certaines dunes réservées aux chasses, et où les lapins sont chez eux, pour comprendre les dégâts dont est capable cette engeance; le sol est troué de terriers comme une-écumoirc, et on risque de le voir céder sous les pas.

Enfin l'on a songé au XIX ${ }^{e}$ siècle à fixer et protéger les dunos par le boisement. Les difficultés étaient grandes, à cause du vent qui racornit les arbres, du lapin qui dévore les jeunes pousses. Les essais n'ont pas donné grands résultats. Le pin sylvestre, qui a réussi au Hazegras, n’a rien donné à Blankenberghe. Les peupliers du Canada qui ont grandi avec succès à la Panne, sont restés médiocres à Nieuport-Bains. C'est encore le saule qui réussit le mieux. En vèrité, jusqu'ici, rien n’a pu remplacer l'oyat. Des plantations d'arbres auraient l'avantage de constituer quelques revenus à une bande de territoire qui n'en a pas trop; reste à savoir si les conditions météorologiques ne s'opposeront pas toujours à ce que le boisement s'étende, au delà des dépressions, sur les pentes et le sommet des dunes".

1 Delepierre, Précis analytique, 2e série, I, p. 62. Cf. également pp. 16, 23, 30, 38, 56 , etc.

2 Gilliodts, Coutumes du Franc de Bruges, III, pp. 230-2/1.

3 Van de Putte, Iunes, p. 247. - Les dommages causés par les lapins et les réclamations auxquelles ils donnent lieu sont exposés dans la charte imposée en 1477 à Marie de Bourgogne (Gilliodts, Coutumes du Franc, II, p. 22), et la a Requête des Dunkerquois à la dame de Vendôme », éditée par Derode (Mém. Soc. Dunk., 1856-57, pp. 230-244).

- Sur le boisement des Dunes, consulter: Bulletin de l'Association maritime et agricole d'Ostende, nos de décembre 1886 et novembre 1887 ; - Van der Swaelmen (L.), Le boisement du littoral maritime belge (Bruxelles, Muquardt, 1888, 87 p., 1 pl.); -Baraban (L.), Les Dunes de Belgique (Revue des Eaux et Forèts, t. 29, 1890, 20 série, 4"vol., pp. 145-157); - Berger (L.), La flore forestière maritime de la Belgique (Bull. Soc. centrale forestière de Belgique, III, 1896, pp. 863-883). 
III.

LA VIE DANS LES DUNES.

Cette inhospitalière bande de sables, battue par des vents froids et violen Is, hérissée de plantes rares et rudes, abrite pourtant une population particulièrement dense. Sans parler des ports qui étendent leur banlieue sur les dunes voisines, on peut dire qu'il existe, de Calais à Kadzand, une ligne ininterrompue de maisons le long du bord intérieur des dunes. D'autres se sont glissées dans les pannes. Enfin les stations balnéaires s”installent tout le long du mur côtier. Ces sables infertiles et mouvants ont-ils donc des qualités qui attirent et retiennent les hommes? Pourquoi aller s'établir sur les dunes, quand la riche plaine des polders étend en arrière ses terres fortiles?

La raison de ce choix, c'est que la petite zone des dunes possède précisómont les qualités qui manquent aux Polders. Co sol infertile a l'avantage d'être élevé, de dominer de quelques mètres les riches terres fortes ; cela lui valut jadis d'être indemne des inondations marines, cela le met aujourd'hui à l'abri des débordements d'eau douce. On a vu qu'il fut le premier dans la plaine maritime à recevoir de nouveaux habitants ; ce sont là ces « Barbari circa maris littora degentes » dont parle le biographe de St Eloi, marins et pêcheurs, qui se glissent le long des dunes ot s'établissent sur les sables que l'invasion marine a respectés. Plus tard, quand la plaine fut émergée, et que des villages commencèrent à s'y disséminer autour do leur «Kerke », la zone des dunes resta un des rares points des Polders où l'on pouvait circuler en toute saison. Cela peut sembler paradoxal, et pourtant il est parfaitement exact que cette bande de sables á peine fixés a toujours servi do passage. Les dunes sont un lieu de routes. Routes peu agréables, avec de profondes orniéres de sable, mais qui valaient par la comparaison avec la plaine, où les rivières, les canaux, "vliet », " graecht», " watergand », sans compter l'argile tenace où les attelages restent enlisés, empêchaient la circulation. Les vieilles routes de Calais à Gravolines, de Gravolines à Dunkerque, de Nieuport à Ostende, suivent fidèlement le bord des dunes. Quand une armée s'aventurait dans la plaine maritime, ce n'est pas dans les vastes champs découverts qu'elle livrait bataille; c'est sur les sables qu'elle rencontrait l'adversaire. Les rares combats qu'on ait livrés dans la plaine ont eu pour thêâtre les sables : bataille des Dunes de Dunkerque, 
bataille des Dunes de Nieuport. C'est par les dunes que le duc de Guise met la main sur Calais; par les dunes que Condé, Turenne, prennent Dunkerque, que le duc d'York s'en approche en 1793, que l'archiduc Albert se cramponne à l'attaque d'Ostende. A côté de l'argile, plastique, coupée de canaux, le sable est lo chemin naturel, la route des armées et des échanges 1 .

Les Dunes, qui possédaient les routes les moins impraticables de la plaine, avaient cucore l'avantage de recẻler les eaux les moins mauvaises pour l'alimentation. Il existe dans les dunes une nappe aquifère continue, bombée dans la partie centrale, parce qu'elle se déverse par filtration vers la plage et vers l'intérieur; de là les sources comme celle de la Samaritaine, à l'Ounst de Dunkerque. Elle arrive parfois au niveau des pannes, et produit alors les petites mares d'eau douce qui en garnissent le fond. Le niveau varie suivant les saisons, mais d'une quantité assez faible, $0^{\mathrm{m}}, 50$ environ; l'évaporation des eaux pluviales étant plus considérable l'óté, la nappo, moins alimentée, s'abaisse légèrement. Mais elle no subil pas l'action de la marèe, même tout an bord de la mer. La présence de ce précieux réservoir d'eau douce dans une région où les eaux sont presque toujours saumâtres est une des grandes raisons du peuplement de la zono des Dunes. Lo modeste puits profond de $1^{\mathrm{m}}, 50$ à 2 mètres, que le maraîcher des dunes a creusé à la bêche, et où l'eau potable ne manque jamais, triomphe de la répulsion qu'on éprouverait pour un sol ingrat et mobilo. Ainsi la plaine marilime n'est que paradoxes: c'est au bord de la mer qu'on y trouve les parties les moins basses, les plus sèches, et les mieux pourvues d'eau potable ${ }^{2}$.

1 Cela est si vrai que les vieilles lignes de dunes intérieures servaient également de chemins. Un procès-verbal de visite aux dunes de Ghyvelde, en 1766, constate que « cette partic étant exposée au passago pour aller à Furnes, était remplie do voies et de carrières de chemiris 》(Arch. Nat., Qt 829).

2 L'existence de la nappe aquifère des dunes, indiquée déjà par Daubrèe, (Les eaux souterraines à l'époque actuelle, Paris, 1887 , in-8 $8^{\circ}, \mathrm{I}$, pp. 53-55), a été étudiẻe récemment par MM. Van Mierlo (Distribution d'eau potable à Ostende, Bull. Soc. belge Géol., II, 1888 , Mém. pp. 249-259, 2 pl.); - Van Ertborn (La question des eaux alimentaires dans les régions dunale et poldérienne du littoral belge, Bull. Soc. belge Géol., XVII, 1903, Mém. pp.297-315); - d'Andrimont (Notes sur l'hydrologie du littoral belge, Ann. Soc. Géol. Belğ., XXIX, 1902, Mém. pp. 129-144; Contribution à l'étude de l'hydrologio du littoral bulge, ibid. XXX, 1903, Mém. pp. 1-43; Note complémentaire à l'étude hydrologique du littoral belge, ibid. XXXI, 1904, Mém. pp. 167-183; L'allure des nappes aquifères contenues dans les terrains perméables en petit, baignés par la mer, Bull. Soc. belge Géol., XIX, 1905, Pr.-V. pp. 47-58). M. d'Andrimont estime que la nappo des dunes est la partie supúrieure d'une grande nappe aquifère 
La zone des dunos a d'autres avantages encore. Sa pauvreté même la favorise : la terre y coûte bien moins chor que dans les Polders ; c'est une raison pour aller y bâtir, et y louer bon marché un petit champ. La foule des pauvres, des journaliers, au service des gros fermiers du Sud, vient donc habiter les dunes. On s'y établissait parfois sans payer le terrain. Les I)unes appartenaient au comtc, à l'Etat. Mais l'Etal, ce n'est personne, surtout aux époques troublees; et on profitait des défaillances du pouvoir pour s'établir sur la digue du Comte Jean ou sur les sables. Pas deloyer à payer, et des petits profits accessoires: quelque bois de chauffage ramassé dans les pannes, la nourrilure de la vache assurée dans les « communes », pannes ou salines; à l'occasion, le braconnage de quelques lapins. Laautorité reparue respectait cette prise de possession ". Ainsi se sont établies les lignes si denses de maisonnettes qui suivent les digues et les dunes entre Dunkerquo et Calais, « huttes » de journaliers et de pêcheurs.

\section{L'Agriculture des dunes.}

C'est là, pour la zone des dunes, un ensemble de conditions physiques et économiques très avantageuses. Pourtant, si ce petit territoire possède assez de qualités pour attirer l'homme, a-t-il assez de ressources pour lui permettro d'y vivre? Le sol est vraiment peu favorable à l'agriculture. Son analyse physique indique d'énormes proportions de sable fin, un peu do calcaire, mais peu ou pas d'argile; dans la pineraie de Knocke, 950,7 pour 1.000 de sable fin, 18 de sable poussiéreux, 10,7 de sable grossier, 5,5 de matières organiques, 1,9 de débris organiques, 0,3 de débris minéraux, le reste, 12,3, considéré comme calcaire. Pour l'argile, l'analyse indique: traces. A Wenduyne, la terre arable comporte 959,4 de sable fin, pas d'argile. A Westende, 943,7 de sable fin, 35,5 de sable poussiéreux, 3,5 d'argile ${ }^{2}$. Les défauts d'un pareil sol sautent aux yeux.

superposée à l'argile yprésienne, et que l'eau de mer, plus dense, refoule vers le haut. Voir à ce sujet: Dubois (E.), Etudes sur les eaux souterraines des Pays-Bas. Lieau douce du sous-sol des dunes et des polders (Arch. Musée Teyler, série II, volume

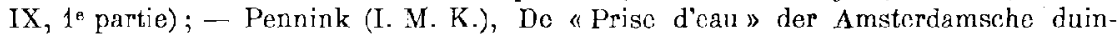
waterleiding (Communication faite à la séance du 10 nov. 1903 de l'Institut royal des Ingénieurs, La Haye).

1 Nombreux documents d'archives sur cette prise de possession des dunes par les populations pauves : Arch. Nat. Q1 827 (Mémoiro de la Ch. de Commerce de Dunkerque, 1770) ; Arch. Nord, C. Fl. Mar., 44 ; Arch. Pas-de-Calais, C. 106, 137, 198.

2 Monographic agricole Dunes, pp. 12-13. 
Aucune cohésion : faute de protection, les semences peuvent être mises à nu ou enterrées sous une couche épaisse de sable meuble. Perméabilitè complète; aussi les sécheresses de l'été peuvont-elles être très nuisibles sur ce sol qui s'échauffe facilement. Les matières organiques s'y décomposent très rapidement; il y faut des quantités d'engrais considérables. l'analyse chimique n'est pas moins défavorable: manque d'azote, d'acide phosphorique, de potasse; seule la chaux se présente en quantités relativoment élevées ${ }^{1}$, grâce aux débris de coquillages calcaires mélangés au sable. Parfois ces débris de coquilles agglutinés avec les grains de sable forment une sorte de tuf calcaire, coucho imperméable peu profonde au-dessous des pannes, et qui nuit aux plantations d'arbres. C'ost lá un bien pauvre sol. Même entre les mains du cultivateur flamand, il ne peut porter que des récoltes insuffisantes. L'orge, le blé, n’y poussent pas. Le seigle, la seule céréale dont la culture soit possible, donne de faibles rendements : 800 à $1.000 \mathrm{kgs}$ de grain à l'hectare, et 12 à $1.500 \mathrm{kgs}$ de paille ${ }^{2}$, contre environ 2.500 à 3.000 et $6.500 \mathrm{~d} 7.000 \mathrm{kgs}$ dans la Flandre intérieure. Un paysan qui voudrait vivre dans les dunes en pratiquant la culture ordinaire ne le pourrait pas.

Il faut donc que l'homme des dunes, pour assurer sa subsistance el celle des siens, ajoute à la culture de ses sables une ressource extraordinaire. Ou plutôt, on peut dire que pour les habitants de cette zone, l'exploitation du sol des dunes n'est qu'un appoint. Avant tout, ils sont journaliers pour les fermes des polders, maraîchers pour les villes voisines, ou pêcheurs. Tous pratiquent d'aillours la même culture patiente et opiniâtre. Il faut d'abord protéger le champ contre ses grands ennemis, le vent et le lapin. Dans ce but, l' « akker * est souvent creusé d'un mètre daus lo sable, co qui a lavantage de fournir aux plantes un sol moins meuble; avec ce qu'on a enlevé, on édifie autour du champ une vérilable diguette de sable (barm), que l'on plante d'oyats, d'argousiers, ou de branches sèches fichées en terre. Ce sont de vrais champs enterrés. Ailleurs on établit, autour des carrés, des haies taillis épaisses d'aulnes, de saules, de peupliers du Canada: parfois des claies do paille renforceses de branches d'arbrisseaux. Ces précautions prises, on peut essayer de cultiver ce sol jaunâtre el peu engageant. I ce labour se fait à la bêche, le vieil outil de prédilection du

1 Monographie agricole Dunes, pp. 14-17. - A ce sujet, voir : Retgers (J.-W.), Sur la conposition minéralogique et chimique du sable des dunes nécrlandaises (Recueil des Travaux chimiques des Pays-Bas, XI, 1892, pp. 169-257). S'attache surtout à la composition minéralogique des grains de quartz, dont il altribue l'origine à des granites ou à des schistes cristallins.

2 Monographie agricole Dunes, pp. 39-40. 


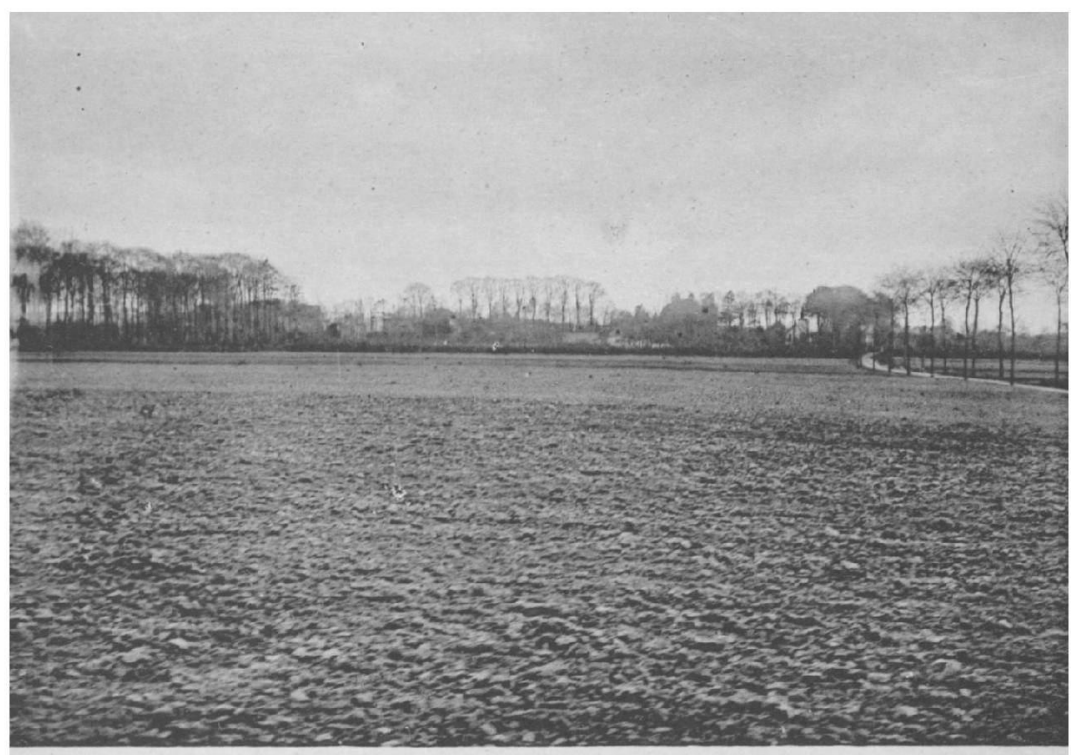

17. - Contraste entre l'argile (pays découvert) et le sable (boisé), à Loon.

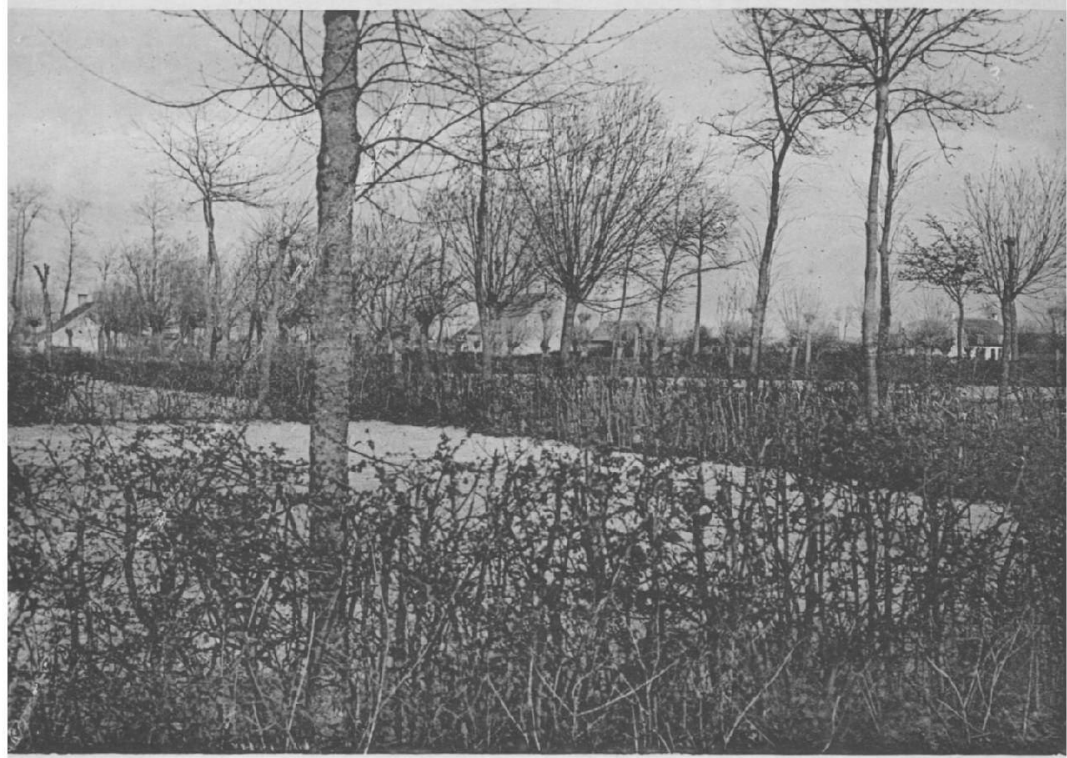

\section{8. - Un village du sable (Loon).}


IRIS - LILLIAD - Université Lille 1 
Flamand, avec lequel il retourne la terre plus profondément que ne le fait la charrue. Puis c'est la mise en place de l'engrais, opération longue et coûteuse, parce qu'il faut en faire venir de loin, le bétail des dunes n'étant pas assez abondant pour satisfaire à la consommation; or il en faut beaucoup sur un sol aussi léger. On s'adresse aux villes voisines : Ostende a un service de bateaux qui amène à Nieuport les déchets de la grande station balnéaire; Dunkerque, Calais, Blankenberghe, en envoient par voitıres ${ }^{1}$. Les pêcheurs y joignent un fumier d'algues, de mollusques et de petits poissons. Sur la limite des terres fortes; on y ajoute un peu d'argile compacte enlevée au sol sous-jacent. C'est ainsi qu'on peut faire pousser, à force de soins, du seigle, de la pomme de terre, et des légumes. On a vu que le saigle donne des résultats médiocres; aussi tout est-il consommé sur place, dans l'exploitation. Au contraire, la pomme do terre et les cultures maraîchères donnent lieu à un commerce assez important, en même temps qu'elles contribuent largement ả la nourriture de l'habitant des dunes. Dans certaines parties où l'on a pu amender le sol en y mèlant de la terre forte, on produit des variétés do tubercules hâtives qui sont expédiées en France; dans les petits champs de Rosendacl, de Middelkerke et de Westende, cette lisière des dunes peut évoquer le souvenir des fameuses terres à oignons de jacinthes, tulipes, anémones, le « bloembollenland » qui s'étend derrière les dunes de Hollande, do Leyde à Alkmaar. I.es pommes de terre hâtives une fois disparues, récoltées péniblement dans ce sable où elles roulent et vont s'enterrer, on plante à force de nouveaux engrais les petits pois, les haricots, les salades, toutes les variètés de choux ${ }^{2}$.

Ces cultures demandent trop de travail pour qu'on puisse les pratiquer sur de grandes étendues. Aussi les exploitations de la zone des Dunes sont-elles très potites, les plus potites de Flandro, où la grande oxploilation est si rare. A Fort-Mardick, chaque famille met en valeur 22 ares de terrain. Les pêcheurs, eutre Dunkerque ol Niemport, n'ont guère que $25 \dot{a}$ 30 ares. Les maraîchers ont des jardins de 50 ares à 1 hectare. A Knocke, le plus grand nombre des habitants exploite une étendue inférieure à

1 Monographie agricole Dunes, p. 37.

2 Les jardins maraîchers de Rosendael valent jusqu'à 15,000 francs l'hectare. La banlieue de Dunkerque a expédié en 19032.000 tonnes de légumes en France, 3.300 en Angleterre et 4.500 en Belgique ; Dunkerque et l'agglomération en ont consommé 3.800 . (Dufour du Breuille, L'exportation des légumes dans l'arrondissement de Dunkerque, C. Rendu du IV Congrès national des Syndicats agricoles de France, Arras, 1904, pp. 215-218). 
50 ares. Dans toute cette zone, la mise en valeur de 10 hectares de terrains constitue une exception. Ainsi c'est en fragments minuscules que se découpe toute cetle lisière des dunes. Car ce n'est guère qu'une lisière qui est ainsi patiemment occupée et mise en valeur. Dans les grandes dunes de Dunkerque à Nieuport, on trouve encore quelques groupes d'habitations dans les pannes, tel le village prospère qui porte précisément lo nom de La Panne. Mais la plus grande partie des dunes reste une vaste solitude, dont l'herbe grêle sert de pâture aux animaux domestiques ou aux lapins. On n'en tire qu'une ressource: la location pour des chasses. On y traquait encore le loup au milieu du XVII siecle $^{1}$; aujourd'hui on n'y massacre plus que les lapins, que l'on peut exterminer à loisir derrière les grillages qui enclosent bon nombre de chasses.

\section{L'homme et l'habitation.}

Le peuple laborieux qui pratique une culture si pénible est particulièroment solide et florissant. La région des dunes est celle où la phtisie et la scrofule sont les plus rares de toute la Flandre; au temps où la fièvre intermittente éprouvait la plaine maritime, elle épargnait les habitants des sables 2. Grands, forts, la figure large et pleine, colorée, hâlée, les pêcheurs sont assurément, avec les gens de la Flandre zélandaise, les plus beaux hommes du pays flamand. A les voir marcher avec le dandinement des marins, à regarder leur visage ouvert, encadré d'une barbo qui rappelle les algues des plages, à écouter leur trançais zézayant ou leur flamand archaíque, on se demande s'ils sont de même race que le paysan maigre, à la physionomie fermée, au visage glabre, qui se courbe sur Ies terres du Houtland. On songe plutôt à les rapprocher des pêcheurs de la côte normande, ou des peuples maritimes du Nord, Zélandais et Frisons. Les femmes elles-mêmes, malgré leur travail écrasant, restent plus dégagées, plus délurées que les Flamandes du Sud. La race se conserve pure, car les pêcheurs se marient toujours entre eux. Cela n'empêche pas les unions d'être fécondes. Les

1 Comptes du Franc, 1618-49: Payé pour la chasse aux loups dans les dunes du Camerlinckx-Ambacht (entre Nieuport et Ostende) 1138 livres 2 sous (Priem, Précis analytique, 2 série, $V$, p. 28).

2 Cf. Meynne, Géographie médicale, dans Patria Belgica, t. II, pp. 106-107; - de Keuwer (V.), Topographie médicale de l'arrondissement administratif de Furnes (Annales de la Soc. médico-chirurgicale de Bruges, 1847, pp. 233-264). 


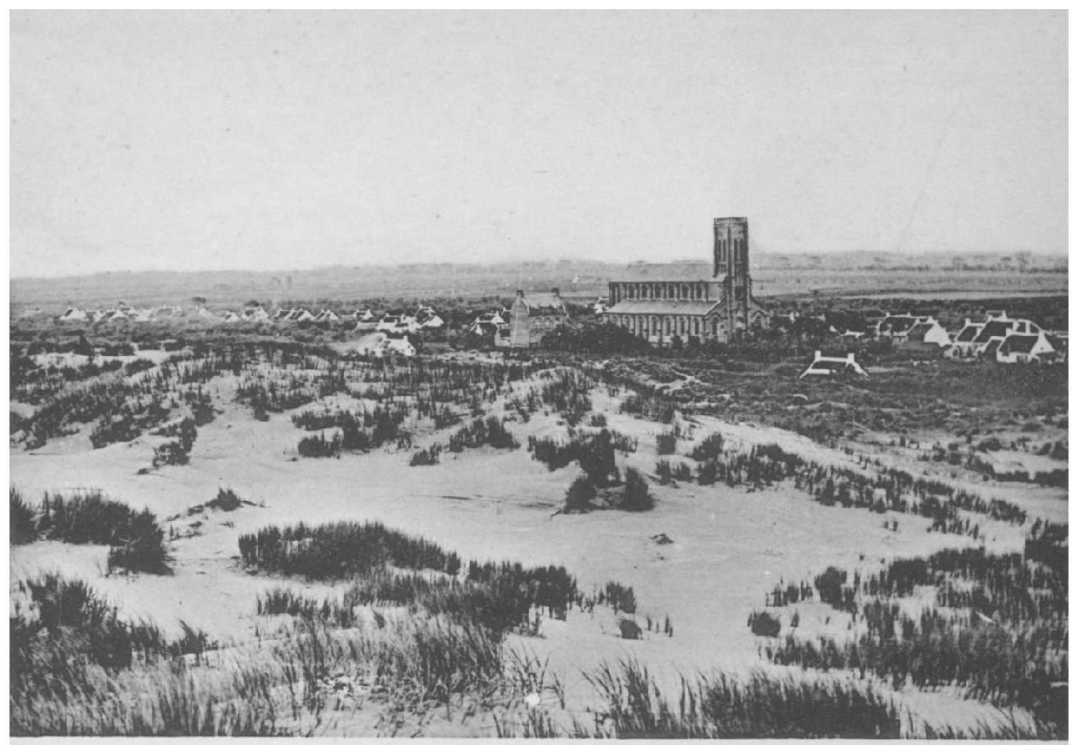

19. - Ligne de maisons au long du mur intérieur des dunes (Bray-Dunes).

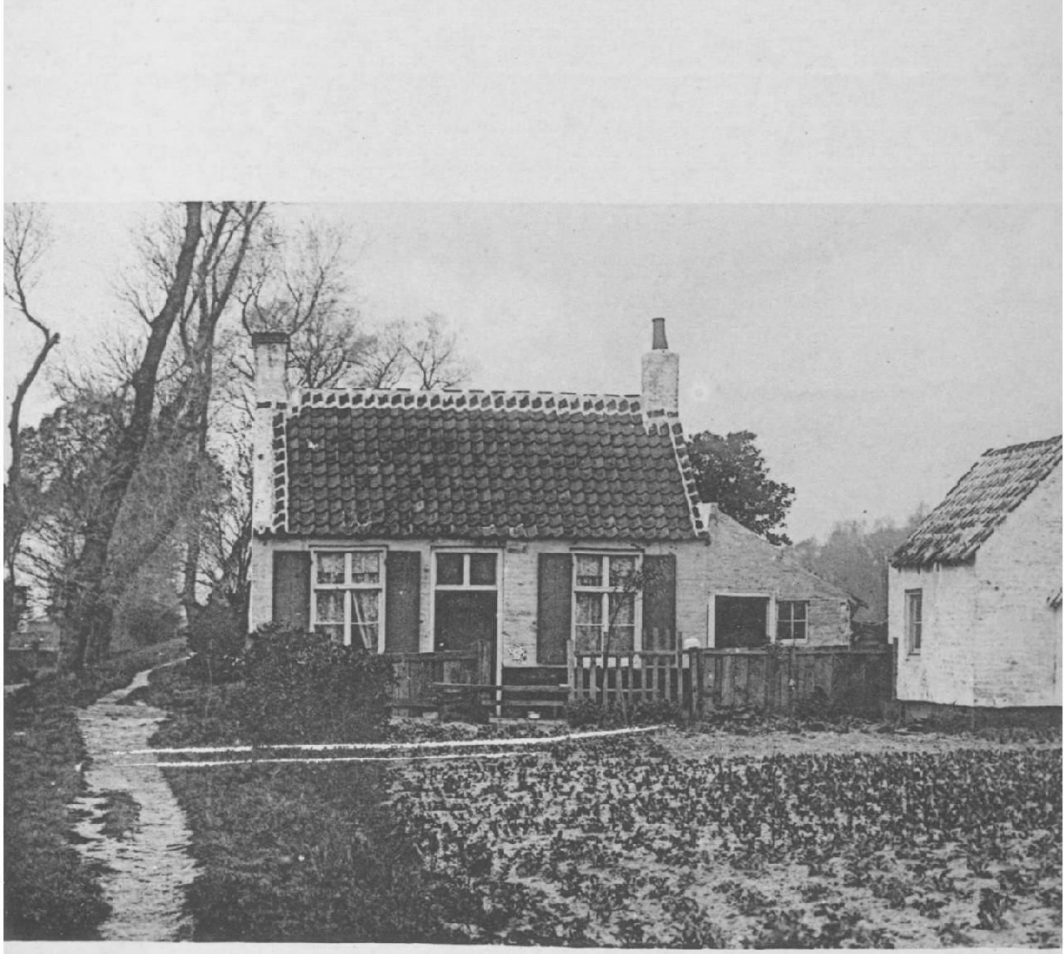

20 - La maison des dunes (Fort-Mardick). 
IRIS - LILLIAD - Université Lille 1 
villages de marins présentent les plus beaux exemples d'accroissement de toute la Flandre. La communo de Ghyvelde, qui comprenait jadis les deux communes distinctes aujourd'hui de Ghyvelde et de Bray-Dunes, comptait en 18041.086 habitants ; on 1856, 1.884 ; en 1876, 2.366. Aujourd'hui (1901), en additionnant les chiffres des deux communes, on arrive a 3.100 habitants ; la population a donc triplé en un siècle. A Gravelines, même progression pour les trois bourgades de pêcheurs, les Huttes, Grand et Petit-Fort-Philippe. I a population s'élève de 2.784 habitants en 1804 , à 5.819 en 1859 , à 7.833 en 1876 , a 9.461 en 1901, dont 3.259 pour Grand-Fort-Philippe, hahité en 1804 par quelques familles de contrebandiers. Mais Fort-Mardick est pout-être l'exemple le plus remarquable. Fondee en 1670 par Louis XIV qui y installa quatre familles de matelots picards, cette paroisse se développa rapidement, grâce a la clause qui en faisait une petite colonie communiste, el attribuait à chaque nouveau chef de famille une concession de 22 ares de sable, en usufruit, sans vente possible. Les terres non encore partagees, et les salines qui en dépendent, louées à des particuliers, servirent et servent encore à payer les impôts. Ainsi constituée, celte heurcuse Arcadie de pêcheur's se développa d'elle-même, sans alliance avec les Flamands du voisinage, souvent hostiles. Les quatre familles picardes étaient devenues $432 \mathrm{habi}$ tants en 1841,615 en 1851, 1.481 en 1886, 1.678 en 1901; la population doublait en 30 ans ${ }^{1}$. A défaut de statistiques, la vue des villages de pêcheurs, où des hordes d'enfants traînent dans les ornières de sable, suffit à indiquer l'abondance de la natalité.

Cette belle et saine population est très attachée à ses dunes. Co paysage à la fois uniforme et heurté, aux feuillages sombres, noirâtres, ontre les deux grands horizons de la plaine et de la mer, lui est aussi cher qu'au Breton ses récifs; il n'y a pas d'émigration, même parmi les maraîchers et les journaliers. Ceux qui quittent le pays ne vont pas loin: on les retrouve dans les briqueteries derrièro les stations balnéaires, ou sur les chantiers d'Ostende et de Dunkerque. Les maigres ressources de leur méticr leur suffisent. Leur alimentation de poisson bouilli, de pommes de terre, de pain, de harengs en saumure, leur infusion de cafẻ à la chicorèe, leur font oublier qu'ils n'ont guère de la viande que le dimanche. Le soin qu'ils prennent de l'entretien de leurs maisonnettes témoigne assez de leur attachement à leur petilo patrie.

La maison est la grande, presque la seule parure de la région des dunes.

1 Dr Lancry, La Commune de Fort-Mardick près Dunkerque. Fitude historique, dẻmographique et médicale (Paris, 1890). 
Lorsqu'on arrive de la plaine, l'œil fatigué de l'uniformité plate des terres fortes s'arrête plus volontiers sur leur ligne rouge et blanche que sur les formes sévères des collines de sable. Et cette parure ne manque nulle part: une vraie cointure aux couleurs éclatantes ot gaies autour de ce paysage morose. Nulle part en Flandre, même dans le pays de Waes, la ligne des maisons ne se poursuit ainsi, d'un seul tenant. Cela commence à Calais, aussitôt passé les fortifications, par les maisons du Petit-Courgain, qui tournent du côté des dunes leurs toits bas et leurs appentis, réservant pour le Sud leurs façades blanches. De l'autre côté du canal de Marck, sur les vieilles dunes du banc des Pierrettes, d'autres maisons toujours blanches se dispersent lo long de la grand'route, au milieu des landes d'ajoncs. Mais tandis que cette rangée s'arrête brusquement après Marck à l'endroit où disparaissent les sables, la premiére continue sans interruption par le Fort-Vert, les Petites-Hemmes, les Grandes-Hemmes, les Huttes, Dunes et Hemmes d'Oye, jusqu'au Grand-Fort-Philippe. Entourées au Nord et au Sud de salines vieilles ou neuves, ces rangées do maisons font admirablement ressortir le contraste entre la faible densité de population des terres fortes, réduites à quelques vastes fermes, et celle des sables, couverts d'habitations. Après Gravelines, la rangée recommence au hameau des Ifuttes, qu'on aperçoit des remparts de la petite ville comme un tas de rouge et de blanc; puis gagne Dunkerque par la vieille digue du Comte Jean; elle s'étire parfois en laissant entre les maisons des intervalles d'une centaine de mètres, el se resserre ailleurs en hameaux, en villages, en villes, Dunes de Loon, Dunes de Mardick, Fort-Mardick, St-Pol-sur-mer. Aussitôt a l'Est de la ville commence la grosse agglomération de Rosendael, longue de 3 kilomètres, et si dense que le flot des constructions a fait disparaître les dunes. Puis Zuydcoote, Bray-Dunes; encore 5 kilomètres de petites maisons blanches jusqu'à la frontière belge. Pour un moment, les habitations sont moins serrées, jusqu'à Nieuport; une partie des maisons a déserté la lisière pour les pannes de l'intérieur. Mais elles reparaissent aussi denses à l'Est de l'Yser; à Westende, Middelkerke, Mariakerke, jusqu'aux élégants faubourgs d'Ostende, et désormais la file s'allonge, ininterrompue, jusquà Wenduyne. Enfin on la retrouve à Heyst, lorsqu'on revoit de véritables dunes, et elle gagne par Knocke le Ilazegras, le vieil estuaire du Zwin.

Ce qui frappe autant que la continuité de cette ligne de population, c'est l'uniformité des maisons qui la composent. L'habitation est bien exiguë, car l'homme des dunes n'est pas riche; les dépendances sont réduites à peu de chose, puisque les récoltes sont insignifiantes, et ne suffisent même pas à l'alimentation du ménage. Parfois le marin se contente d'une seule 
pièce, à la fois cuisine, salle à manger et chambre à coucher, où la famille s'entasse dans des lits alcôves à deux ou trois étages. D'ailleur's, les hommes ve sont-ils pas absents plus de la moitié de l'année? Sur le côté un petit appentis sert de dépendance; on y enferme la chèvre, on y dépose le combustible, bois des dunes autrefois, charbon aujourd'hui. Mais bientôt la maison s'agrandit. Derrière, du côté du Nord, elle s'adjoint une cuisine, longue et étroite, sur laquelle descend le toit bas qui protège des vents de mer; de ce côté les ouvertures sont rares et petites: ur simple œil-de-bœuf. Enfin quand la prospérité est venue, la maison so double d'une autre moitié toute semblable, une chambre à coucher avec une pièce basse derrière, et sur le côté un nouvel appentis où se logent les lapins, les poules, le porc, et où l'on range les instruments de culture. C'est la maison complète de l'habitant des dunes ${ }^{1}$.

Le caractère commun à toutes ces maisons des dunes, c'est l'aspect intérieur et extérieur. Elles sont basses, pour ne pas donner prise an vent, et le toit, du côté du large, descend presque jusqu'à terre. Solidement construit en tuiles rouges, ce toit est visité chaque annce avec soin, et on en profite pour rejointoyer au mortier blanc toutes les tuiles, que l'on passe par la même occasion au rouge. De la ces couleurs éclatantes qui sont la parure de la maison des dunes. La façade à son tour est peinte chaque année en blanc ou jaune, et les volets en vert. Autour de la maison, le petit jardin de sable gris où poussent les légurnes, séparé du chemin de sable aux vastes ornières par des haies épaisses et des diguettes. Enfin l'intérieur est d'une propreté zélandaise, grand carrelage peint en rouge, dont l"entretien est aidé par la nature sablonneuse du sol, où la boue est inconnue; murs tapissés, rideaux aux fenêtres, meubles cirés, faïences aux couleurs voyantes, et devant la cheminée le grand poële belge en fonte de toute maison flamande. Tout au long de la mer du Nord, le même type de maisonnelte basse et clairo égaie le bord des dunes; il se retrouve au delà des détroits et des estuaires, après le Zuiderzẻe, après le Dollart et l'Elbe jusqu'aux îles lointaines de Sylt, Amrum et Föhr, expression de la vie pauvre et libre de l'habitant des dunes, peut-être aussi indice de l'expansion de la race frisonne.

$1 \mathrm{D}^{\mathbf{r}}$ Lancry, La maison populaire de la Flandre maritime. (Mérn. Soc. Dunk., XXXI, pp. 1-27). 


\section{CHAPITRE $\mathrm{X}$}

\section{LA COTE (Suite). — LES PORTS}

I. Origine des ports. Ports naturels : leurs transformations. Ports artificiels. II. Caractères des ports. Les ports de l'Ouest mieux abrités. Les ports de l'Est moins encombrés. - III. Les installations maritimes. Ports de voyageurs : Calais, Ostende. Port de marchandises : Dunkerque. Port d'escale : Zeebrugge. - IV. Les villes; les playes. Aspect el évolution des villes. Les plages.

Calais, Gravelines, Dunkerque, Nieuport, Ostende, Blankenberghe, demain Zecbrugge, cela fait sept ports pour 130 kilomètres de côtes, sans compter les havres du Hont, Breskens, Terneuzen, et en arrière Gand. C'est beaucoup pour l'importance commerciale de chacun; mais surtout cela peut paraître extraordinaire qu'une côte aussi basse et rectiligno, bordée de dunes, ait pu se laisser percer de sept ouvertures par ou se font les échanges entre la Flandre et les pays maritimes. Ia côte de IIollande, de Hoek van Holland au Helder, sur 120 kilomètros, n'a qu'un port, complètement artificiel (Ymuiden), un vrai défi à la nature, et qu'il faut maintenir laborieusement en bon état; la côte de Gascogne n'a qu'une échancrure bonne pour des bateaux de pêche. I a Flandre, elle, en a un tous les 18 kilomètres. Cette abondance de havres est due en partie à des causes physiques; la côte, orientée presque W.-E., parallèlement aux vents dominants, se prêtait mal à l'établissement d'une ligno de dunes épaisse, comme en Ilollande; par suite les petites rivières de la plaine gardaient la force de traverser ces dunes restées étroites, et chaque estuaire pouvait donner naissance à un port. Mais l'homme a aussi sa grande part dans la création des ports flamands, et tout en améliorant les havres qui existaient dójà, il créait de toutes pièces d'autres pertuis. Les ports flamands sont d'origine naturelle, comme Calais, Gravelines, Dunkerque, Nieuport, ou artificielle, comme Ostende, Blankenberghe, Zeebrugge.

I.

ORIGINE DES PORTS.

Parler de ports naturels en Flandre peut sembler paradoxal. A voir leur état actuel, darses, bassins, écluses, chasses, chenal, jetées ; à saisir le 
contraste entre ces solides installations aux formes géométriques et la côte vaseuse dans laquelle on les a enfoncées, on se persuade que rien n'est plus artificiel que ces ports naturels. Cependant on peut retrouver les étapes de la transformation qui a fait des anciens refuges des pêcheurs flamands de grands ports modernes.

\section{Transformations des Ports naturels.}

Les estuaires sont la première ébauche de ces ports. En se rẻtrécissant peu à peu après le $\mathrm{X}^{\bullet}$ siècle, les golfes de Fréthun, de l'Aa, de la Gersta et de l'Yser devenaient des cuiques où s'abritaient les barques des pêcheurs des dunes. Sur leurs bords s'élevèrent des bourgades devant lesquelles s'amarraient les sloops chargés de harengs, et où se tenait le receveur des grandes abbayes du roisinage, pour y prélever la dîme des poissons. Leur apparition presque simultanée au XII ${ }^{\mathrm{B}}$ siècle indique bien la transformation accomplie dans les estuaires; les bords se sont fixés, et on a pu aménager la crique pour en faire un refuge de bateaux. Calais est mentionné en 1172 à propos d'une rente de 10.000 harengs ${ }^{1}$; et son développement est rapide puisqu'en 1'02 il reçoit une église distincte de cello de St-Pierre, et qu'on y voit déjà une léproserie ${ }^{2}$. Gravelines existe comme port en $1160^{3}$, et on débarquait le hareng sur son territoire dès 1107 d'une façon régulière *. Dunkerque, sous Philippe d'Alsace, est également un port de pêche pourvu de murailles ". Nieuport est fondé au XII ${ }^{\ominus}$ siècle, et sa keure ou charto de 1163 parle déjà de la dìme des harengs, sans compter les autres poissons ${ }^{6}$.

Cependant le fond des criques s'envase. Les golfes deviennent schorres; les monastères y établissent des bergeries, puis les endiguent. Pour ne pas laisser la haute mer revenir sur les terres qu'elle a quittées, on

1 Haigneré (D.), Quelques chartes inédites.concernant les abbayes, les prieurés, ou les paroisses de l'ancien Boulonnais. (Mém. Soc. Ac. Boul., XIII, p. 421).

2 Haigneré, St-Bertin, I, p. 203, n० 464.

3 Gf. charte de Thierry d'Alsace, reproduite dans un vidimus de 1266 (Arch. Nord, B. 1561, ${ }^{\text {or }}$ Cartulaire de Flandre, pièce 4h).

- Coussemaker, Bourbourg, I, p. 4, no V.

s «Burgenses de novo oppido de Dunkerca " (1188). - Gf. Derode, Histoire de Dunkerque, (Dunkerque, 1856, in- $8^{\circ}$ ), p. 106.

6 Van de Putte (F.), Pêche du hareng sur les côtes de Flandre au moyen-âge (Ann. Soc. Em. Br., $2^{\circledR}$ série, III, 1845, pp. 339-343). La keure mentionne comme vendus sur le marché: saumons, maquereaux, cabillands, aiglef.ns, plies, dorades, turbots. 
construit à l'extrémité de la crique, à l'endroit où se déversent les eanx de l'intérieur, une écluse a portes de flot. Pendant la marẻe haute, les eaux douces s'accumulont en arrière; à mer baissante, les portes s'ouvrent, les eaux douces s'écoulentdans la crique, et leur courant chasse vers le large les alluvions accumulées dans le port. A Nieuport, c'est en $1294^{1}$ qu'on établit, dans ces conditions, l'écluse de Nieuwendamme; à Gravelines, les travaux du port datent probablement des premières années du X Ve sièclè. Les chasses d'eau douce obtenues par ce procédé étaient d'autant plus nécessaires que la crique, qui se comblait au fond, s'obstruait du cóté du large. Là, sous l'action du gain de flot, la rive occidentale croissail constamment vers l'Est, transformant la crique en lagune. Ies dunes de Sangatte marchaient vers Calais, si bien qu'en 1407 on pouvait déjà y établir le Risban ${ }^{2}$; les dunes d'Oye s'avançaient vers Loon, et derrière elles s'asséchait la Lampernesse; les dunes de Synthe vers Dunkerque, tandis que celles de Nieuport-hains se formaient devant la digue du Comto

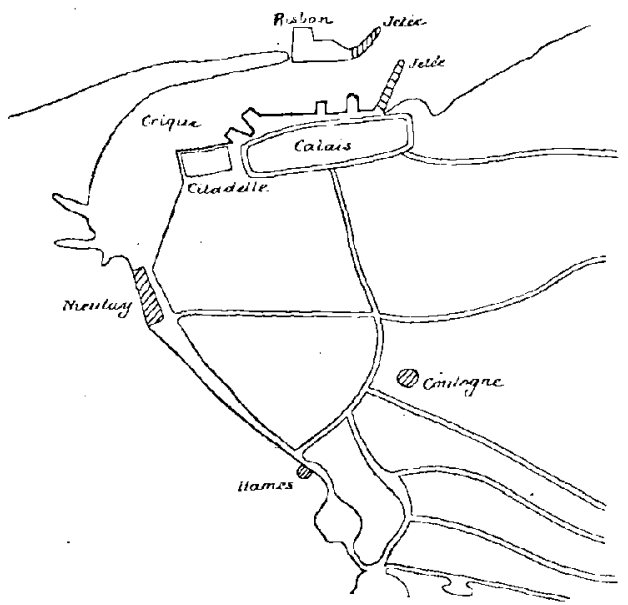

Fig. 45. - Port de Calais d'après la carto de Thomas P'ettyt, Octobre de la $37^{\circ}$ année du règne de Henri VIIL (15:3).

(Bibliothènue de Calnis, 11, 16).
Jean. Pour garantir l'entrèe, il fallut ètablir des palissades de bois qui empêchèrent tant bien que mal l'envahissement des sables, et délimitèrcnt le chenal. Plus tard, ces palissades devinrent les jetées. Leur présence ètait particulièrement nécessaire à Calais et à I)unkerque, où la crique n'était pas suffisamment nettoyée par les chasses que fournissaient les .eaux interieures, tandis que Gravelinos et Nieuport disposaient du débit, plus abondant, d'une rivière. Ce sont ces palissades qu'on aperçoit sur les anciens plans représentant Calais sous le règne de Henri VIII ${ }^{3}$, et Dunkerque au XV ${ }^{\theta}$ siècle ${ }^{4}$. Ces amorces de jetées

1 Cf. p. 169.

2 Aron, Port de Calais, p. 202.

3 Plans copiés au British Muscum; les reproductions conservées à la Bibliothèque municipale de Calais. - Voir également pour Calais l'excellent travail de I.ennel (F.), Calais par l'image, (Calais, Peumery, 1905); 2 fascicules parus.

4 C.f. Ilerode, Histoire de Dunkerque, p. 136. 
orientent l'ouverture du chenal vers le N.-E. En effet, sous l'effort des sables en marche vers l'Est, l'ouverture des criques avait dévié do plus en plus dans cette direction ; à Calais elle s'insinuait dans la mer derrière le Rishan; à Gravelines, le long des dunes de Ioon; à Dunkerque, au delà du Scheurken. C'est cette direction que l'on retrouve encore dans les anciens bassins de Calais, au Nord de la ville, dans le port de Gravelines, et dans les vieux bassins de Dunkerque, perpendiculaires au chenal actuel. Ia crique intérieure avait fini par prendre la forme d'une vaste poche, communiquant avec la mer par une étroite ouverture on biais, semblable à un grau des lagunes languedocieunes.

Enfin la crique finit par s'envaser. Ĺes chasses d'eau douce étaient insuffisantes. Mais pourquoi n'utiliserait-on pas, en même temps que les eaux de l'intérieur, la puissance de chute que représentait l'amplitude de la marée? On n'avail qu'à établir au débouché de la crique vers la mer de nouvelles portes d'écluse; à mer haute, on laissait les eaux entrer dans l'espace compris entre les deux paires de portes, puis on refermait les pertuis. Quand la mer était près d'être basse, on rouvrait et on laissait échapper la masse d'eau accumulée, qui balayait les alluvions du chenal. Grâce à la hauteur de la marẻe dans les ports flamands, on obtenait ainsi une chute considérable qui creusait, particulièrement aux abords de l'écluse nouvelle, une souille profonde ou prirent l'habitude de venir mouiller les grands bateaux. Le bassin de chasses était créé. Inapplicable sur les côtes de Hollande, où l'amplitude de la marée était trop faible, le procédẻ sauva les ports flamands de l'envasement, et leur permit d'attendre les procédés plus perfectionnés de la fin du XIX ${ }^{\ominus}$ siècle. Gravelines et Nieuport, où les chasses d'eau douce paraissaient suffisantes, ne l'appliquèrent pas ; mais il fut le salut de Calais et de Dunkerque. A Calais, ce fut la grande crique de Nieulay qui servit de bassin de chassos ; à Dunkerque, où la crique était complètement oblitérée, on se servit du canal de Bergues, dans lequel les eaux salées furent introduites à chaque marée.

On gagna ainsi le XVII ${ }^{\mathrm{e}}$ siècle. Le tonnage des navires grandissait; de nouvelles améliorations étaient nécessaires. L'un des plus gros défauts de ces ports, c'était la direction N.-E. du chenal d'entrée. En effet, obligés pour y pénétrer d'attendre la marée, les bateaux se présentaient devant le chenal lor'sque le courant de flot portait vers l'Est, c'est-à-dire à l'opposé de la direction à prendre. La fréquence des vents d'Ouest, qui entraînaient les embarcations dans la même direction contraire à leur but, venait ajouter aux difficultés. Ainsi l'orientation du chenal vers le N.-F., produit naturel du régime de la côte, ètait la plus mauvaise possible, d'autant que la plupart des navires venaient de l'Ouest, à cause des bancs qui barrent le 
chemin à l'Est. Las de voir les bâtiments obligés, pour attaquer le chenal, de manœuvrer contre vent et marée, on se résolut à changer la direction de l'entrée. Ce fut Vauban qui donna l'exemple en lançant hardiment à travers le Schourken les jetées de Ijunkerque; on dévia dans le même sens l'entrée du port de Calais, et en 1742 on perça entre Gravelines et la mer le canal du Fort-Philippe. Ainsi les chenaux des ports furent désormais à peu près orientés dans la direction des vents dominants: «attention bien essentielle à avoir quand il sagit d'orienter ces sortes de canaux, dit Belidor, quand on a la liberté de les disposer heureusement $\gg 1$.

Cette nouvelle disposition avait un défaut. La passe ainsi orientée s'obstruait rapidement. Déviés devant les jetées qui leur barraient ainsi la route, les courants de marée produisaient des mouvements tourbillonnaires qui amenaient les sables et les vases devant les musoirs. Par les forts coups de vent d'Ouest, les sables enlevés de la plage et des dunes s'envolaient par-dessus les jetées et venaient tomber dans le chenal. Enfin les alluvions accumulées à l'Ouest devant l'obstacle des jetées élargissaient l'estran de ce côté, et venaient dépasser l'entrée. De nou veau se formait à l'exlrómité des jetèes une passe extérieure, elle aussi déviée vers l'Est, dont la présence semblait reudre inıtile le travail considérable qu'on venait d'accomplir. Différents remèdes furent tentés au cour's du XIX ${ }^{\mathrm{e}}$ siècle. On perfectionna Ies chasses. A Gravelines, on utilisa, pour la remplir d'eau de mer, la vaste capacité des fossés de la place. A Dunkerque, on crousa en 1827 un bassin de chasses spécial (bassin Becquet) au Nord du port, juste à l'extrémité du chenal. A Calais, il fallut songer à en faire autant: la grande crique de Nieulay s'était complètement atterrie en quatre siècles; les salines Mouron avaient été endiguées en 1770; ce qui restait fut réduit d'un tiers en 1811 par la mise en culture du polder Bodart, malgré les protestations des Calaisiens, qui jugeaient insuffisantes les chasses fournies par l'eau des fossés de la place et par ce qui subsistait de la crique. Cependant on retarda jusqu'en 1880 la construction du grand bassin de chasses de $90 \mathrm{Ha}$ situé à l'Est du port; on s'était avisé d'un autre procédé : allonger les jetées vers les grandes profondeurs des rades.

On avait compté sans le régime particulicr de la plage. Tandis que le prolongement des jetées d'Ostende amenait avec succès l'entrée du chenal jusqu'aux profondeurs désirées, les estacades de I)unkerque, de Gravelines et de Calais voyaient l'estran accompagner leur marche, et les profondeurs fuir leur approche. D'autres tentatives intéressantes avaient lieu; : Calais,

1 Belidor, Architecture hydraulique, I (1788, in-4\%). 
on labourait la barre avec de grandes herses, pour offrir à l'action des chasses un dépot plus meuble. A Dunkerque, pendant une dizaine d'années, on halait dans le prolongement de la jetée de l'Est 300 mètres de guideaux que l'on échouait à marée basse; l'eau des chasses, rejetée ainsi vers l'Ouest, attaquait les sables dans cette direction èt, pour quelques semaines, redressait la passe ${ }^{1}$. A Nieuport, on a expérimenté une herse sur laquelle étaient fixés des tuyaux émettant des jets d'air comprimé, capables de mettre les sables en suspension et de préparer ainsi l'action des courants ${ }^{2}$.

Tous ces efforts restèrent à peu près vains. Les chasses, bonnes pour dégager les parties des ports susceptibles de s'envaser, restaient inutiles pour l'attaque de la barre formée à l'extrémité du chenal par des sables très cohérents et fortement agglomérés. Cependant il fallait une solution, car les installations intérieures s'étaient développées pendant qu'on tâtonnait autour du chend. A Calais et à Dunkerque, de vastes bassins à flot se creusaient, reliés à l'avant-port par de gigantesques écluses. Gravelines et Nieuport tentrient de suivre cet exemple. Cette solution fut l'utilisation de la drague à aspiration, familièrement appelée la suceuse. Mise en service à Dunkerque en 1877, elle donnait bientôt des résultats tels que l'on se gardait, au cours des travaux neufs du port, de reconstruire un bassin de chasses. A Calais, les suceuses employées depuis 1880 rendaient inutile le grand réservoir de l'Est, achevé en 1889 ot qui n'a jamais servi. On verra qu'à Ostende leur œuvre a été plus remarquable encore.

L'emploi des dragages est la dernière transformation subie par les vieux ports flamands. Il fait disparaître le bassin de chasses, dernier vestige de la crique primitive. Que reste-t-il aujourd'hui qui puisse rappeler les antiques lagunes du $\mathrm{X}^{\mathrm{e}}$ siècle, où pénétraient les barques des pêcheurs de harengs? Peu de chose: à Calais les débris de la crique de Nieulay; à Dunkerque et à Gravelines l'orientation des vieux bassins, à Nieuport le cours tortueux du canal de Nieuwendamme. De transformations en transformations, les havres naturels de la côte flamande ont fini par ressembler aux ports artificiels; il est bien difficile de les en distinguer aujourd'hui.

\section{Ports artiflciels.}

L'histoire de ces ports artificiels est diverse. L'un, Zeebrugge, construit tout d'une pièce à l'extrémité d'un canal de grande navigation qui mẻne à

1 Do Mey, Ports en plage, pp. 206-207.

2 Lbid. p. 210. 
Bruges, n'est pas encore complètement terminé. Le second, Blankenberghe, réclamé dès 1763 à Marie-Thérèse, a été construit de 1862 a 1872 ; c'est un petit bassin qui ne sert qu'à abriter les barques des pêcheurs. Au contraire Ostende a eu une destinée compliquée dont l'évolution est aussi curieuse à étudier que celle des ports naturels ${ }^{1}$. Aucune crique n'aboutissait à Ostende. Les pêcheurs de harengs qui furent ses promier's marins échouaient d'abord leurs barques sur la plage, comme le font encore aujourd'hui ceux de la Panne et de Heyst. Ce fut en 1445 que les Ostendais obtinrent de Philippe lo Bon l'autorisation de creuser un havro en arrière de la digue du Franc à l'abri de laquelle la ville avait commencé de se refugier en 1394 ; ce port, qui ressemblait probablement à celui que nous voyons à Blankenberghe, fut établi à l'Ouest de la ville, à peu près au droit du Kursaal actuel. 'Très exigu, ouvert au N.-E., il n'était ni commode ni profond. Il fallut les malheurs du grand siège de 1601 pour doter Ostende d'un port plus vaste. Afin d'enlever aux Espagnols la seule voie d'accès dont ils pussent disposer pour atlaquer la ville, les Hollandais firent raser les dunes de l'Est. La mer se précipita par l'ouverture, inonda la plaine aux fortes marées jusqu'à Oudenbourg, Snaeskerke et Leffinghe, et forma une vaste crique intérieure dont les chasses approfondissaient l'ouverture. Et ainsi, lorsque le siège fut terminé, on abandonna l'ancien havre et la crique de l'Fst devint le nonveau port d'Ostende. Le chenal avait dejà 28 pieds de profondeur.

Alors pendant deux siècles, l'histoire du port est celle de ses chasses. Le chenal est d'abord si profond qu'en 1612 on croit pouvoir endiguer une partie de la crique; à l'Est on construit la Groenendyk pour préserver Breedene 2 , à l'Ouest la digue de Fort-Albertus à Oudenbourg; entre les deux, la digue de Zandvoorde (1626). On réduit ainsi le volume d'eau qui pénètre à chaque marée dans la crique. Les résultats en sont déplorables pour le chenal, au point qu'on rouvre aussitôt (1627) le polder de Zandvoorde. On le referme en 1631, et l'on constate en 1662 qu'on ne trouve à marée basse que deux pieds d'eau $\left(0^{\mathrm{m}}, 55\right)$ dans la passe. On ouvrit donc pour la seconde fois le polder de Zandvoorde, et en 1698 on avait jusqu'à $13^{\mathrm{m}}, 75$ de profondeur dans le port, à marêe basse. C'était trop, et l'on pouvait craindre des accidents : que cette fosse se rapprochât

1 Urie grande partie des détails sont empruntẻs a Belpaire, Notico historique sur la ville et le port d'Ostende), et vérifiés dans Priem, P'récis analytique. Voir également: Pasquini, Histoire de la ville d'Ostende et du port. (Bruxelles, Lacroix, $2^{*}$ éd., 1863; in $-80,375$ p., 2 cartes).

2 Gilliodts, Goutumes du Franc de Bruges, III, pp. 235-236. 
de la ville, et elle en aurait fait tomber les murs. I.e polder refermé en 1700 , on vit l'envasement reprendre, si bien qu'en 1721 on se décidait à remettre sous l'eau des terres nouvelles, moins colmatées que celles de Zandvoorde: 839 mesures sur Snaeskerke, 181 sur Steene, quelques-unes sur Leffinghe ${ }^{1}$ : ce fut la crique de Steone, qui subsista jusqu'au XIX siècle.

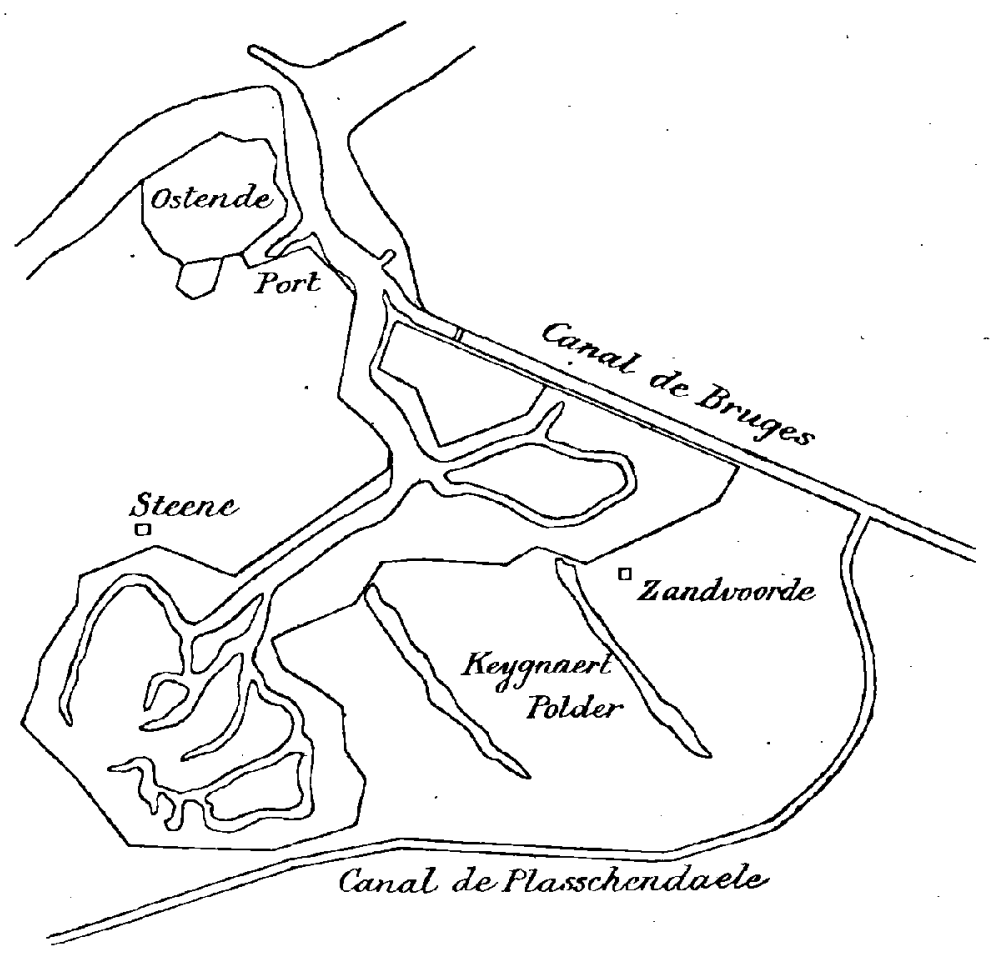

FIG. 46. - Port d'Ostende. La crique de Steene au XVIII' siècle, d'apres la carte de Ferraris.

Elle rendit d'abord au port les profondeurs de 1698 ; mais elle s'envasa elle-même peu à peu. En 1744 on endiguait le polder Sainte-Catherine. Sous la Révolution, le comblement de la crique était à peu près achevé ${ }^{2}$; en 1796 , il n'y avait plus que $0^{\mathrm{m}}, 30$ d'eau à marée basse sur la barre, et les sables comblaient le chenal. En 1803, on constatait que la crique de

1 Priem, Précis analytique, $2^{\circ}$ série, V, pp. 163-164.

a les détails sont empruntés, à partir de cette date, à Vifquain, Des Voies navigables en Belgique (Bruxelles, Devroye, 1842 , in-4으. 494 p.). 
Steene n'était plus couverte qu'aux équinoxes. Ie premier Consul, en messidor an XI (juillet 1803), la faisait barrer, et l'endiguement en était achevẻ au début do l'an XII ${ }^{1}$. Les grands horizons nus, complètoment dépourvus d'arbres, des polders de Snaeskerke et de Keygnaert, en occupent aujourd'hui l'emplacement; des digues basses, quelques criques encombrées de roseaux, sont les dernières traces de l'invasion marine; mais cet ancien golfe a conservé, de son état maritime, la largeur des horizons. De Snaeskerke aux anciens remparts d'Ostende, rien que la terre grise, quelques toits rouges et des meules; c'est un des plus vastes horizons de la plaine. La crique disparue, on ne garde qu'un bassin de chasses, dont le jen est assuré par l'écluse de l'Empereur, et dont l'efficacitè est encore insuffisante. On y adjoint en 1820-21 une nouvelle écluse de chasses, l'écluse Militaire, enfin on prolonge en mer les jetées de 1834 à 1839. Ainsi, tout artificiel qu'il est, le port d'Ostende est passé par les mêmes phases que les ports naturels de l'Ouest; mais ayant conservé plus longtemps qu'eux une vaste crique en arrière, il s'est toujours trouvé sur eux en retard d'une période; il possède encore des bassins de chasse, disparus ou inutilisés à Calais et Dunkerque, et le nouveau port, achevé en ce moment même, en est pourvu.

II.

\section{CARACTĖRES DES PORTS.}

Naturels ou artificiels, anciens ou récents, tous ces ports flamands ont un grand ennemi, l'envasement. Avec ses eaux jaunâtres chargées d'alluvions, la mer flamande a vite fait de combler les parties des ports où l'ean est tranquille. Le bassin à flot de Nieuport, creusé à la cote $-2^{\mathrm{m}}, 90$, s'envasait de $0^{\mathrm{m}}, 37$ par mois dans le premier trimestre de sa mise en service, de $0^{\mathrm{m}}, 25$ en moyenne dans le reste de l'année; au bout d'un an, le plafond était à la cote 0 . A Ostende, le petit chenal de l'écluse de la Marine, creusé en 1887 jusqu'à la cote -4 mètres, était envasé en 1888 jusqu'à 0 mètre; l'exhaussement était de 4 mètres en un an. A Blankenberghe, l'épaisseur des dépôts à enlever du petit bassin s'élève chaque

- année à 1 mètre environ ². Rien que dans l'année 1899, on a extrait de l'intérieur du port, à Ostende, 250.000 mètres cubes de déblais ${ }^{3}$. Quel est

1 Arch. Nat. Fi4 1112.

2 De Mey, Ports en plage, pp. 293, 303, 305.

3 Installations maritimes belges, p. 87. 
lo remède? Chasses ou dragages? Les ingénieurs sont divisès sur ce point. Les Belges estiment que les chasses restent lo moyen le plus efficace de combattre l'envasement à l'intérieur des ports; et ils ont construit à Ostende un nouveau bassin de retenue de 80 hectares. Les Français, pourtant favorisés par une ańplitude de marée considérable, emploient la drague à godets à nettoyer leurs bassins; et la modicité du prix actuel des dragages est en effet un argument sérieux, qui peut faire négliger l'encombrement apporté par les dragues dans le mouvement du port.

Cet inconvénient mis à part, les ports flamands, quelle que soit leur origine, ont des qualités très différentes. En réalité, il n'y en a pas deux qui se ressemblent complètement. Ce qui favorise l'un désavantage l'autr'e. Indépendamment des avantages que peut présenter pour tels d'entre eux la présence d'un beau réseau de communications avec l'intérieur, la proximité d'un vaste foyer industriel, la facilité du passage vers un grand pays voisin, la nature leur a donné à chacun des qualités et des défauts particuliers.

\section{Les Ports de l'Ouest mieux abrités.}

Les ports de l'Ouest, de Calais à Nieuport, ont le très grand avantage d'être abritós de la houle du largo par les banes de Flandre. Les vagues, qui ont passé sur des hauts-fonds très élevés, et s'y sont écrasées en déferlant, voient leurs ondulations s'amortir encore dans les fosses profondes qui se creusent entre les bancs; leur violence est fortement apaisće quand elles atteignent la côte. La dornière de cos fosses, entre le rivage et le banc qui en est le plus rapproche, constitue donc une rade qui formo un véritable avant-port, où les flots sont relativement tranquilles ; excellente condition pour les navires qui attendent que la marée leur permette d'altaquer le chenal. Calais n'est défondu que par les Ridens de Calais et de la Rade, sur lesquels il reste, en basse mer d'èquinoxe, $6^{\text {m }}, 30$ d'eau ; et si la rade est profonde, et conserve à marée basse plus de 10 mètres d'eau, la protection n'est peut-ĉtre pas suffisante. Gravelines est déjà mieux gardó par la double rangée de l'Out-Ruytingen et du West-IDyck. Mais la situation la meilleure est celle de Nieuport et de Dunkerque. La rade de Nieuport, ou West-Diep, protégée vers le N.-W. par le Smal-Bank, le Buiten-Ratel et le Dyck, vers le Nord par le banc de Nieuport et le Kwinte-Bank, est la meilleure du littoral belge. Elle présente tout au long des profondeurs de 10 mètres; elle est large; les fonds y sont d'une bonne tenue. Trois passes la mettent en communication 
avec la haute mer: une à l'Ouest, vers Dunkerque, qui est la passe de Zuydcoote; une au Nord, entre le Smal-Bank et le banc de Nieuport, et dont les profondeurs sont de 8 a 9 mètres; une au N.-E., entre ce dernier banc et le Stroom, et oú l'on sonde au moins $7^{\mathrm{m}}, 50$. Cependant elle ne vaut pas encore la rade de Dunkerque. La passo la mieux orientée, celle de Zuydcoote, avec sa profondeur minima de 6 mètres, n'est accessible pour les gros bateaux qu'à marée haute; et les deux autres passes, qui sont plus profondes, sont plus difficilement praticables à cause de la direction des vents dominants.

La fosse de Dunkerque est la rade privilégiée du littoral flamand. Si elle rossemble en gros à celles de Nieuport, de Gravelines, d'Ostende, elle possède des caractères beaucoup plus accentués. Située juste à l'endroit oủ le flot de la Manche, gèné par les courants contraires de la mer du Nord, dépose ses plus grandes quantitẻs de matériaux, elle est protégée des vagues du large par les banes qui forment devant elle comme une sextuple rangée de murailles. Large de plus d'un kilomètre, longue d'une vingtaine, elle présente sur toute son étendue une profondeur de 12 à 15 mètres. Aussi les plus gros navires peuvent-ils y séjourner tranquillement, presque par tous les temps, et peuvent même y procéder aux opérations d'embarquement et de débarquement des marchandises, sans avoir hesoin d'entrer dans le port. C'est ainsi que pendant la guerre de 1870-71 les plus gros cuirassés français $y$ ont séjourné tout l'hiver sans aucun inconvénient, et qu'on y a embarqué en quelques jours 20.000 hommes de l'armée du Nord, 1.780 chevaux, 60 pièces de canon, 226 voitures militaires ${ }^{1}$. La rade n'a que deux entrées, dont l'une, la passe de Zuydcoote, a une assez faible profondeur; mais l'autre, la passe de l'Ouest, a l'avantage d'être profonde de plus de 10 mètres sur tout son parcours, et admirablement orientée. Ce sont là des qualités précieuses pour la navigation, et depuis quarante ans on s'est altaché à les développer en organisant au long des passes et de la rade un remarquable service de balisage : à l'Est, six bouées jalonnent la passe de Zuydcoole; à l'Ouest, les deux feux flottants du Dyck et du Snouw, à éclats espacés ou fixes, 14 bouées en tôle, les unes rouges, les autres noires, dont 8 munies de feux, le grand phare hant de 57 mètres avec éclairage électrique d'une portée de 20 milles, les feux fixes des musoirs et celui de la tour du Leughenaer ${ }^{2}$ font de la rade une

1 Plocq, Dunkerque, pp. 75-76.

2 Dunkerque. Son port, son commerce (Notico publiée par la Chumbre de Commerce; Exposition universelle de $1900 ; 89$ p., pl., cartes) pp. 28-30. 
vraie rue bordée de poteaux indicateurs ot de réverbères, ou l'on peut, même sans pilote, retrouver son chemin jusqu'au fond du port. Ces qualités de rade bien férmée avaient fait de Dunkerque un vrai nid de corsaires. Ostende et Calais ont eu les leurs, parce que la situation en face de l'Angleterre, sur lo grand passage de la navigation européenne, invitait à la guerre de course ; mais nulle part les corsaires n'étaient aussi favorisés qu’à Dunkerque. Abritée derrière ses bancs aux passages compliqués, tortueux, encombrés de culs-de-sac, la rade n'avait réellement que deux entrées, faciles à surveiller, par où on voyait venir les gêneurs, gros vaisscaux de ligne d'Angleterre ou de Hollande, dont so jouaient les capres, bâtiments légers des pirates dunkerquois, qui forçaient le blocus on bondissant par-dessus les banes à marée haute, au milieu de l'écume ${ }^{1}$.

Ostende est loin d'avoir les mêmes avantages. Les abords en sont mal défendus: il n'y a guère devant le port qu'un banc, le Stroom, où l'on ne sonde que 2 à 3 mètres. Or la présence de ce banc est plus nuisible qu'utile. Soudé du côté de l'Est à la plage, il ne laisse entre le rivage d'Ostende et son rebord méridional qu'une rade cul-de-sac, étroite et peu profonde : $5^{\mathrm{m}}, \tilde{5} 0$ a $6^{\mathrm{m}}, 50$ devant la ville, avec un fond de vase d'une tenue médiocre. Les gros naviles qui ne peuvent songer à séjourner dans cette impasse mal abritéc et d'une profondeur insuffisante, ne trouvent encore qu'un mouillage provisoire dans la Grande Rade, où l'on sonde 10 à 12 mètres, mais oủ la protection des bancs fait défaut, si bien que lorsqu'ils y sont surpris par un gros temps du S.-W., ils s'empressent de prendre le large ${ }^{2}$. Pour améliorer ces fâcheuses conditions d'accès, les ingénieurs belges ont eu l'audacieuse idée de percer le banc malencontreux qui forçait les bateaux à un immense détour et qui provoquait l'envasement de la petite rade. On creusa à travers lo Stroom, pendant l'année 1890, la passe de l'Ouest, large de 500 mètres et profonde de $5^{\mathrm{m}}, 50$ à 6 métres, balisée par les deux feux de Raversijde. Le résultat a été si satisfaisant, et la profondeur do la passe a èté si aisément entretenue, qu'on entreprit en 1896 les travaux d'une nouvelle voie d'accès, la Passe directe, qui coupe le Stroombank au N.-W. d'Ostende, et permet aux navires d'attaquer facilement le port par les grands vents du large; en 1900 on y sondait au moins $5^{\mathrm{m}}, 50$ sous marée hasse de vive eau sur 350 mètres de largeur. Enfin ce double succès a fait entreprendre la passe Est, destiuée

1 Voir les extraordinaires exploits des corsaires dunkerquois aux XVII et XVIII siecles dans Saint-Iéger ( $A$. de), Ia Flandre maritime et Dunkerque sous la domination française, 1659-1789 (Lille, Tallandier, 1900 , in-8 $8^{\circ} 471$ p.), pp. 380-398.

2 De Mey, Ports en plage, p. 112. 
à empêcher l'envasement complet de là petite rade, en ouvrant une nouvelle issue aux courants de marée. Les monceaux de sable aspirés sur le Stroombank, transportés sur le banc de Wenduyne, paraissent l'avoir élargi sans provoquer un notable exhaussement ${ }^{1}$. Ces intéressants travaux ont sauvé le port d'Ostende qui, s'il reste toujours mal abrité, au moins ne deviendra pas impraticable.

Le manque d'abri, déjà sensible à Ostende, se fait encore plus sentir à l'Est. La rade de Blankenberghe, profonde de a à 7 mètres sur des fonds de vase, n'est guère protégée des vents du large par l'unique banc de Wenduyne, dont la hauteur n'est pas assez considérable pour constituer un obstacle sérieux. Au delà, il ṇ'y a plus de bancs devant Zeebrugge, et la rainure de l'Appelzak, qui étend jusqu'au nouveau porl ses profondeurs de 7 à 8 mètres, n'est plus qu'une rade foraine. D'autre part le plateau du Zand, qui sépare cette fosse de la passe des Wielingen, n'a guère que 5 à 7 mètres de profondeur, et des dragages seront nécessaires. Ce sont là pour le nouveau port des inconvénients assez graves, et les tempêtes violentes qui ont endommagé et retardé les travaux peuvent faire craindre pour la sécuritẻ des navires abrités derrière le môle.

Une question se pose a propos de ces rades : ne sont-elles pas susceptibles d'être modifiées par les courants? Ne peut-on pas craindre de voir la belle rade de Dunkerque se combler peu à peu, et le Braeck se joindre à la côte comme jadis le Scheurken? On y a souvent songé, et on a qualifié parfois de « rades de l'avenir " les autres fosses situées au Nord de la rade actuelle. Cependant il ne semble pas que cette crainte soit de si tôt réalisée. Le passé nous est ici garant do l'avonir. Les pêcheurs de Nieuport avaient déjà fait remarquer en 1776 à l'abbé Mann que les bancs et les fosses ne subissaicut aucun changement appréciable ?. Les relevés de précision dressés depuis 1801 donnent les mêmes résultats. Pas de bancs nouveaux, pas de fosses nouvelles; et les fonds de 20 mètres en particulier ne paraissent pas avoir bougé. Le cri d'alarme poussé en 1864 par M. Jonglez de Ligne n'a pas eu d'écho ${ }^{3}$. Cet ingénieur craignait de voir la rade de Dunkerque s'ensabler par l'Est, et le flot creuser entre le Snouw et le Braeck une nouvelle passe par où les

1 Van der Schueren, Travaux exécutés récemment et en cours d'exẻcution à l'atterrage et au port d'Ostende (VIII' Congrès international de Navigation, Paris, 1900 , 28 p., 5 pl.).

Z Abbć Mann, Ilistoire naturelle de la mer du Nord, pp. 191-192.

3 Jonglez de Ligne, La Rade de Dunkerque (Revue maritime et coloniale, 1864, 20 p., 1 carte). 
courants déserteraient la rade. Il n'en a rien èté. Mêmes constatations pour la rade de Nieuport, dont les passes septentrionales se seraient plutôt améliorées ; tout au plus le Traepegeer s'est-il rapproché légèrement de la côte. Los transports d'alluvions sont pourtant fréquents, constants même, dans la mer flamande, mais ils se réduisent à des échanges qui aboutissent à un véritable équilibre : les courants giratoires, qui se produisent deux fois par jour devant le littoral, entretiennent d'une manière continue la furmation des bancs aux dépens des plages, et l'ensablement des plages aux dépens des bancs ${ }^{1}$. On n'a pu constater de changements que dans l'Est. Devant Ostende, le Stroombank laissait encore en 1801 une passe de 8 mètres environ do profondeur, par où l'on pouvait sortir de la petite rade; en 1866, le banc s'est allongé vers l'Est, et a réduit la passe à $5^{\mathrm{m}}, 30$ de profondeur; la petite rade s'onvase. En 1882, le Stroombank touche à la côte, la passe de l'Est est disparue, et la profondeur de la rade diminue jusqu’à $5^{\mathrm{m}}, 70$ devant Ostende ${ }^{2}$. C'est là le grand danger que l'on essaie de conjurer en rouvrant artificiellement une passe de l'Est à travers le banc. A l'embouchure de l'Escaut, les variations ont été plus favorables; la grande passe des Wielingen s'est approfondie, en absorbant les petits bancs de Kadzand et de Buiten-Paardemarkt qui l'encombraient; le Binnen-Paardemarkt s'est serré plus près de la côte, s'allongeant légèrement vers l'Ouest, ainsi que la fosso de l'Appelzak. M. de Mey ne voit là qu'un mouvement oscillatoire, tandis que M.Van Mierlo conclut à un transport vers l'Ouest ${ }^{3}$, et prédit pour le nouveau port de Zeebrugge les pires ennuis : sous l'influence de ce transport vers l'Ouest, le banc du Hompel sera peu à peu rongé par le jusant et transporté sur lo banc du Zand, qui va s'exhausser; le Paardemarkt va s'allonger vers l'Ouest et venir joindre le banc de Wenduyne ; l'Appelzak va se combler lentement. C'est peut-être beaucoup, et les changements survenus depuis un siècle dans l'estuaire ne paraissent pas autoriser des craintes aussi sórieuses. Cependant c'est là, d'Ostende à Breskens, la seule partie de la côte flamande où l'on ne peut être complètement sûr du lendemain.

\footnotetext{
1 Plocq, Courants, pp. 123-124. - Cf. chapitre VII, p. 122.

2 Dejjà l'on proposait do construire sur lo Stroom une diguo analogue à celle de Cherbourg, un breakwater, pour augmenter dans Ia petite rade la force des courants. Voir à ce sujet de Mey, Ports en plage, pp. 318-32\%.

3 De Mey, Ports en plage, p. 157 ; - Van Mierlo (C.-J.), Etude sur le rẻgime de la côte devant le nouveau port de Heyst (Ann. Assoc. Ingénieurs Gand, XX, 1896-97, pp. 5-64, 6 pl.).
} 


\section{Les Ports de l'Est moins encombrés}

Mais si los ports de l'Est sont desservis par le manque d'abri du côté du large et par l'inconstance des fonds, en revanche ils sont beaucoup moins exposés que les ports de l'Ouest à d'aboudants transports do sable, et par suite beaucoup moins encombrés. Le vaste estran qui s'élargit, de Calais à Nieuport, à l'abri de la ligne des bancs de Flandre, est une perpetuelle menace pour les chenaux. Moins fortes que celles d'Ostende, les lames de Dunkerque obstruent beaucoup plus rapidement l'entrée du port. Aussi les chasses, qui donnent des résultats convenables à Ostende pour la tenue du chenal, étaient-elles insulfisantes à Dunkerque ou à Calais, et les dragages y sont beaucoup plus considérables et plus coûteux. Avec un dragage annuel d'environ 100.000 mètres cubes, on conserve à l'entrée du port d'Ostende une profondeur de 6 mètres sous basses eaux; a Dunkerque, il faut arracher à la passe 500.000 métres cubes de déblais chaque année, pour y maintenir une profondeur de $3^{\mathrm{m}}, 50^{1}$. Heureusement les gros navires peuvent attendre en sécurité dans la rade que l'état de la marẻe leur permette d'attaquer le chenal. Les dragages sont plus faciles à Calais qu'à Dunkerque; le sable plus pur, grâce aux courants qui entraînent rapidement les matières vasouses, est aspiré plus facilement par l'sllinde de la suceuse, et il suffit d'enlever 300.000 mètres cubes par an pour entretenir le chenal et la passe à 6 mètres sous le zéro des basses mers; il est vrai que les flots y sont plus agités, et rendent le travail de dragage plus difficile. La position la moins favorable est celle de Gravelines. I'estran y est plus large que partont ailleurs, et il est encore précédé d'un talus sous-marin presque sans pente, qui recule jusqu'à 2 kilom. au large la ligne des fonds de 10 mètres. Ces circonstances provoquent, vers l'entrée du port, un si grand apport d'alluvions, quo la passe extérieure finit par avoir une profondeur insignifiante sous le zéro des hasses mers. Les chasses n'y peuvent rien, à cause de l'insuffisance du bassin de retenue et de la longueur du chenal ; il faudrait, pour ameliorer le port, des dragages si coûteux qu'on hésite devant la dẻpense. Nieuport serait d'un entretien beaucoup plus facile; les chasses y sont alimentées par un afflux important d'eaux douces, dues à l'Ýser et aux wateringues, et les dragages de 80 à 100.000 mètres cubes qui y sont faits annuellement permettent d'entretenir dans la passe 2 mètres à $2^{m}, 50$ de profondeur au-des-

1 Je Mey. Ports en plage, p. 310. 
sous du zéro. Mais la situation un peu excentriquo du port par rapport all grand commerce belge en détourne les travaux et les amóliorations.

Il existe donc entre les ports flamands des diffẻrences naturelles assez considérables. Diverses sont les qualités, et aux qualités correspondent, des défauts. Blankenberghe, Zeebrugge, manquent d'abri, et l'inconstance des fonds leur réserve peut-être des surprises; en revanche les dragages y sont faciles, et permettront de lutter contre ces dangers. Le cas cst le même pour Ostende, que l'emploi judicieux des dragues a tiré d'une situation qui devenait monaçante. Plus exposé à la houle que Dunkerque, Calais se déharrasse plus facilement des ensablements qui obstruent la passe. Mieux abrité des lames du large, Gravelines végète derrière son estran trop étendu. Nieuport a beaucoup d'avantages naturels: une rade spadieuse et bien protégée, des chasses abondantes, et la possibilité de maintenir en bon état son chenal tortueux. Enfin Dunkerque a sa rade, dont les qualités de tenue, de profondeur et d'orientation sont telles qu'elle suffit à on faire le plus favorisé des ports flamands, puisqu'elle permet de négliger l'inconvénient d'une barre difficile à percer.

III.

\section{LES INSTALLATIONS MARITIMES.}

A ces caractères naturels s'ajoutent les qualités artificielles, c'est-à-dire l'ètat des installations maritimes qui sont l'œuvre de l'homme. Lá encore, Gravelines et Nieuport sont sacrifiés. A Gravelinos, le chenal extérieur de 1.500 mètres de long, large de 75 mètres, se continue au delà de FortPhilippe par un chenal intérieur de 1.800 mètres, qui conduit à un port d'échouage de 1 Ha 1/2, pourvu de 325 mètres de quais. Derrière, un bassin à flot de $2 \mathrm{Ha} 1 / 2$, communiquant avec l'Aa par des écluses de navigation intẻrieure, et c'est toul. Nieuport n'est guère mieux partagé : au bout d'un chenal de 3.600 mètres de long, dont 600 mètres sur l'estran, avec une largeur de 20 a 30 mètres à marée basse, se trouvent un port d'échouage profond do 1 mètre à mer basse, pourvu de 332 mètres de quais, et un bassin à flot de 1 Ha $1 / 2$, auquel donne accès une écluse de 15 mètres de largeur, avec buse à $2 \mathrm{~m}, 50$ sous le niveau des basses mers. Cest peu de chose, surtout pour Nieuport, dont les qualités naturclles permettraient un développement commercial considérable. Blankenberghe n'a qu'un bassin d'échouage de 120 mètres de long sur 100 mètres de large, et un bassin de chasses; c'est un simple port de pèche. 


\section{Ports de voyageurs : Calaig, Ostende.}

Au contraire Calais, Dunkerque et Ostende ont été largement pourvus dans la distribution des grands travaux. Réduit jusque vers 1880 au bassin d'échouage de l'Ouest, au bassin à flot qui lui fait suite, et à la pittoresque et vaseuse enceinte du Petit-Paradis, où s'abritent les barques de pêche, Calais rossemblait encore un peu au port que nous représentent les vues du temps de Henri VIII. C'est alors qu'on creusa pour les grands navires

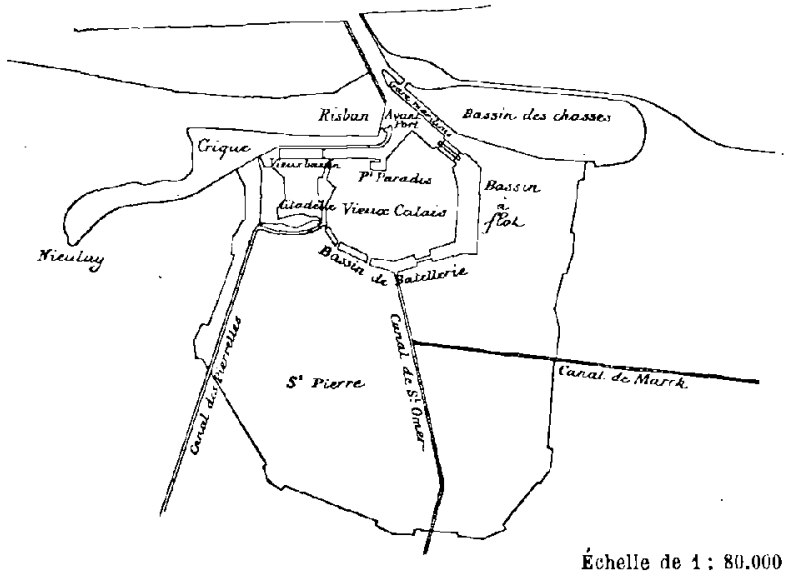

Fig. 47. - Port de Calais. Etat actuel. un nouveau port à l'Est de la ville, sur l'emplacement des fossés qui entouraient le vieux Calais : à l'extrêmité du chenal, un avant-port de 160 mètres de large, profond de 4 mètres sous le zéro des basses mers, et pourvu de 800 mètres de quais pour l'accostage des paquebots qui font le service de Douvres; un bassin à flot de $11 \mathrm{Ha}$, creusè à 3 mètres sous le zéro, relié d'un côté à l'avant-port par deux grandes écluses de $137^{\mathrm{m}}, 50$ de longueur utile, de l'autre à un bassin de navigation intérieure de 900 mètres de long, dans lequel débouche le canal de Calais à St-Omer. Ostende termine en ce rnoment même de vastes travaux. Ses installations comprenaient jusqu'en 1900 un avant-port où accostaient los paquebots de Douvres, un bassin d'echouage pour les pêcheurs, une petite darse pour les chantiers de la Marine, et trois petits bassins à flot, dits bassins du Commerce, avec une superficie totale de 5 Ha. Au fond de l'avant-port le canal de Bruges, élargi, constituait un arrièreport qui s'étendait jusqu'à l'écluse de Slykens. Presque tout est transformó aujourd'hui. On va combler un des trois bassins du Commerce, d'un accés trop difficile. En revanche le port s'est agrandi de moitié vers l'Est. L'ancien arrière-port est devenu un nouvel avant-port, pourvi sur sa rive Ouest d'un mur de quai à marée le long duquel les vaisseaux trouveront un 
mouillage de 8 mètres au-dessous du niveau moyen des basses mers de vive eau. L'écluse de chasse d'un bassin de retenne de $80 \mathrm{Ha}$, qui débouche en face de ce quai, suffira à entretenir la profondeur de cette souille. Au Sud

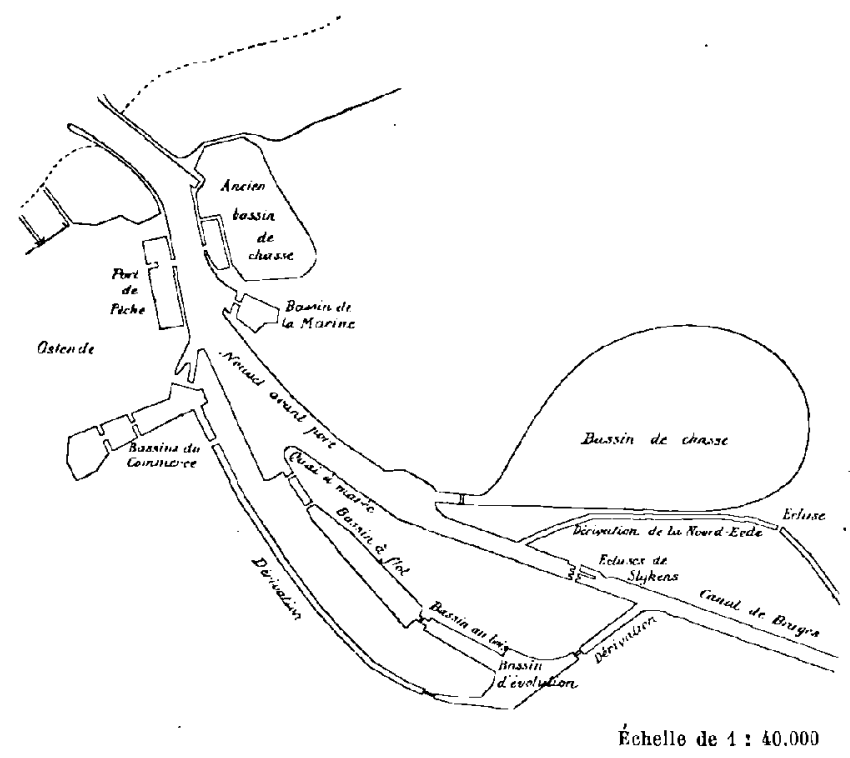

FIG. 48. - Port d'Ostende. Fitat actuel.

est creusé un nouveau bassin à flot de $6 \mathrm{Ha}$, auquel fait suite un bassin canal destiné au commerce des bois, el communiquant avec une dérivation du canal de Bruges. Les émissaires des wateringues, Noord-Eede et Camerlinckx, débouchent dans l'avant-port, et ainsi contribuent par leurs chasses à son approfondissement. L'écluse du bassin à flot a 120 métres de longueur utile, 18 mètres de large, et son busc est à $\left.4^{\mathrm{m}}, 5\right)$ sous mer basse do vive eau. Des cales sèches, un grand bassin de la Marine, sont prévus sur la rive Est du nouvel avant-port ${ }^{1}$.

\section{Port de marchandises : Dunkerque.}

A Ostende et à Calais, c'est l'avant-port qui a surtont préoccupé les ingénieurs, et c'est l'organe le plus soigné de toutes les installations ; car on $s^{2} y$ propose avant tout de faciliter l'accostage de paquebots a grande

1 Cf. Van der Schueren, Travaux exécutés récomment, pp. 8-11. 
vitesso, qui ne pénètrent pas dans les bassins. Dunkerque, port de marchandises, a surtout soigné ses docks. Jusqu'au milieu du siècle, le port ne comprenait que les deux vieux bassins à flot de l'Arrière-Port et de la Marine, aujourd'hui isolés au fond des nouvelles darses ; une loi de 1845 transforma le port d'échouage en un bassin qui est devenu lo bassin du Commerce. Enfin depuis 1861, les transformations se sont accomplies sans relache, elargissement de l'avant-port et du chenal, reconstruction des jetées, creusement de quatre nouvelles darses au Nord des anciennes, qui prirent le nom de bassins Freycinet par opposition aux trois vieux bassins ; creation de cales de radoub. Les bassins présentent aujourd'hui une surface de $43 \mathrm{Ha}$, dont 31 pour les quatre nouveaux; plus do 7 kilomètres de quais les entourent, et les terre-pleins de ces quais, couverts de hangars, d'entrepots, d'engins de manutention, offrent une surface de $55 \mathrm{Ha}$. Trois écluses relient les bassins à l'avant-port, dont la plus vaste, large de 25 métres, présentant 177 mètres de longueur utile et $209^{\mathrm{m}}, 50$ de tête on tête, ayant son busc à 5 mètres sous le niveau des plus basses mers, a coûté 9.500.000 francs ; c'nst l'écluse Trystram, ainsi nommée en l'honneur du créateur véritable du nouveau port. Il faut ajouler à cet organisme remarquable les quais de l'avant-port, utilisables sur 1.075 mètres; les chantiers et le bassin d'armement de l'Est; les bassins de batellerie, avec 5.150 mètres de quais, qui mettent en relation les canaux de Furnes, de Bergues et de Bourbourg avec les darses, et par où les grosses bélandres de 300 tonnes viennent accoster le flane des navires. Ainsi les Dunkerquois ont dignement ajouté aux qualités naturelles de Ieur port une série d'ouvrages uniquues sur la côte flamande ${ }^{1}$.

Cependant, malgré ses belles dimensions, le nouveau port étouffe. Cette ville de hangars, d'entrepôts, de magasins, qui est dójà plus étendue que le vrai Dunkerque, s'est trouvée dès son achèvement insuffisante; avant que les travaux du programme Freycinot no fussent terminés,on réclamait à grands cris de nouveaux agrandissements. Cette prétention étonne le visiteur qui parcourt les môles, el qui voit les vastes bassins où la placo ne manque pas: pourquoi donc en créer d'autres? Rien n'est plus nécessaire cependant; ce ne sout pas les bassins qui sont insulfisants, mais les quais constamment encombrés de marchandises que l'on ne peut évacuer assez vite ver's l'intéricur. Or de nouveaux quais supposent de nouveaux bassins. Voilà pourquoi la Chambre de Commerce va appliquer incessammont à la prolongation des darses 3 et 4 les crédits votés par le Parlement

1 Sur les transformations du port, consulter: Bouchet (E.), Le port de Dunkerque (Dunkerque, Chéroutre, 1896, in-8 194 p., 1 plan). 
IRIS - LILLIAD - Université Lille 1 


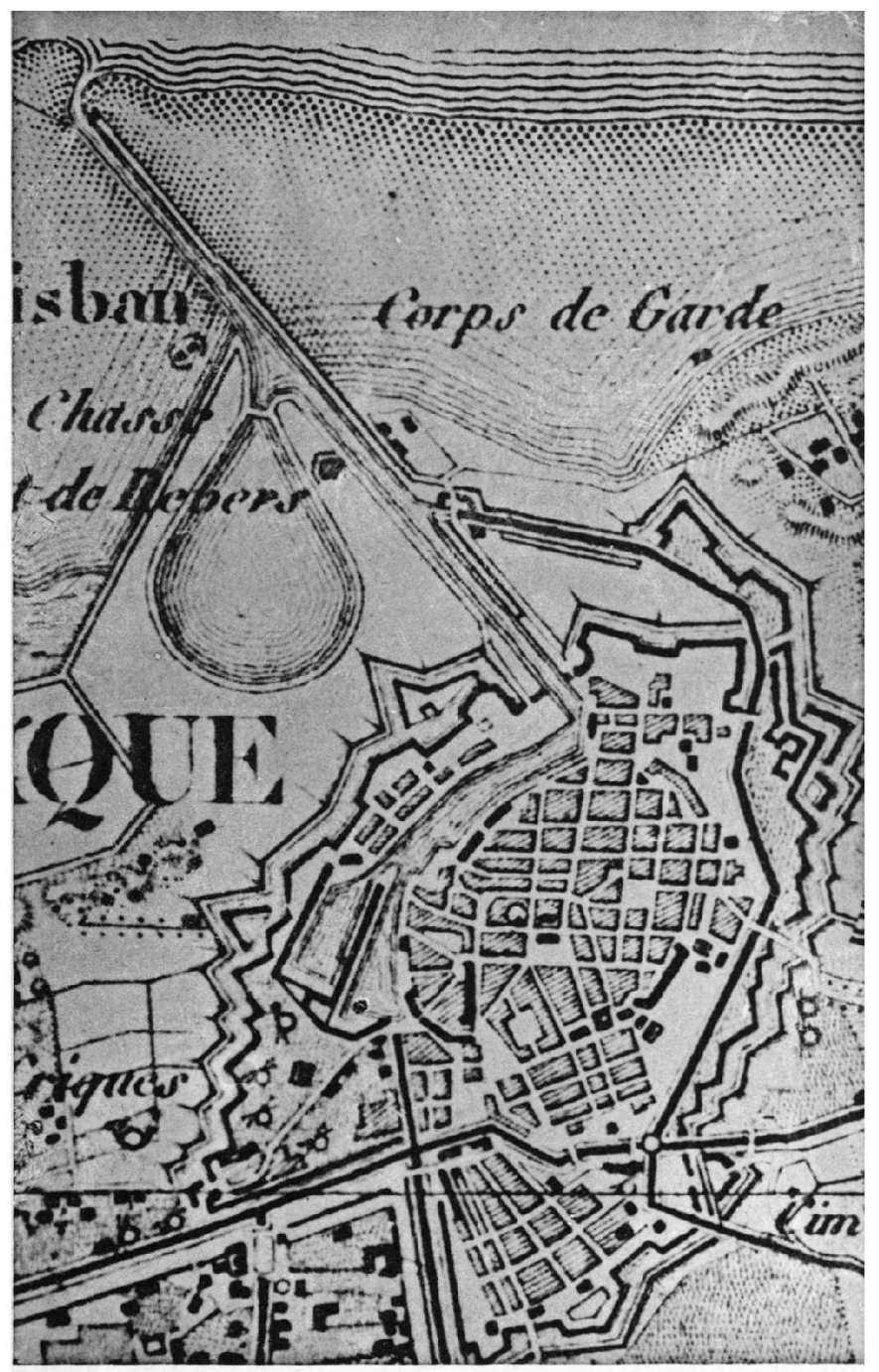

FIG. 49. - DUNKERQUE VERS 1840

d'après la Carte d'État-Major, 1re édition. 


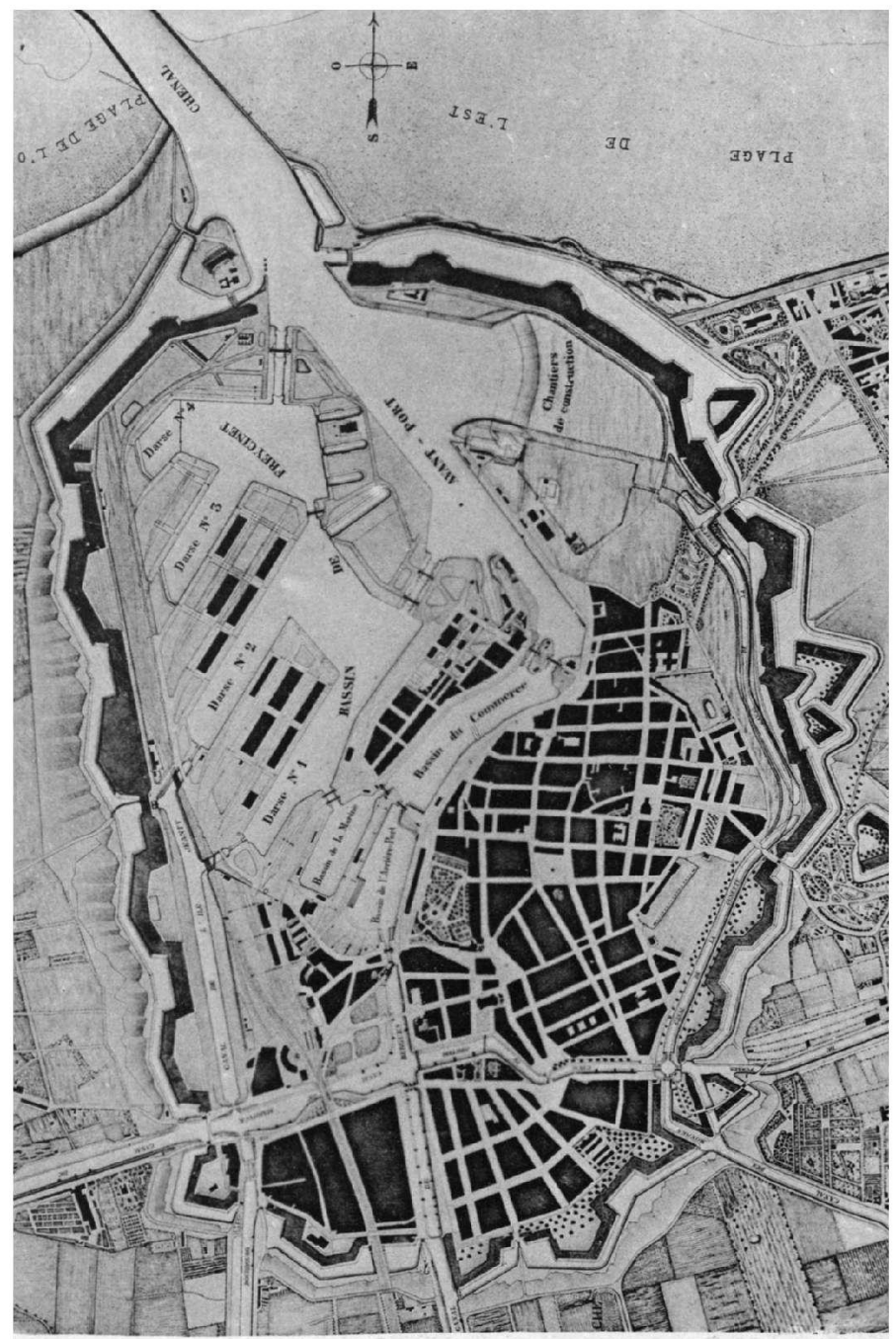

FIG. 50. - DUNKERQUE EN 1900

d'après un plan en relief, à la Chambre de Commerce. 
IRIS - LILLIAD - Université Lille 1 
et reculer à l'Ouest les fortifications à une distance telle que le port aura de quoi tripler dans l'espace devenu libre. Un programme grandiose est

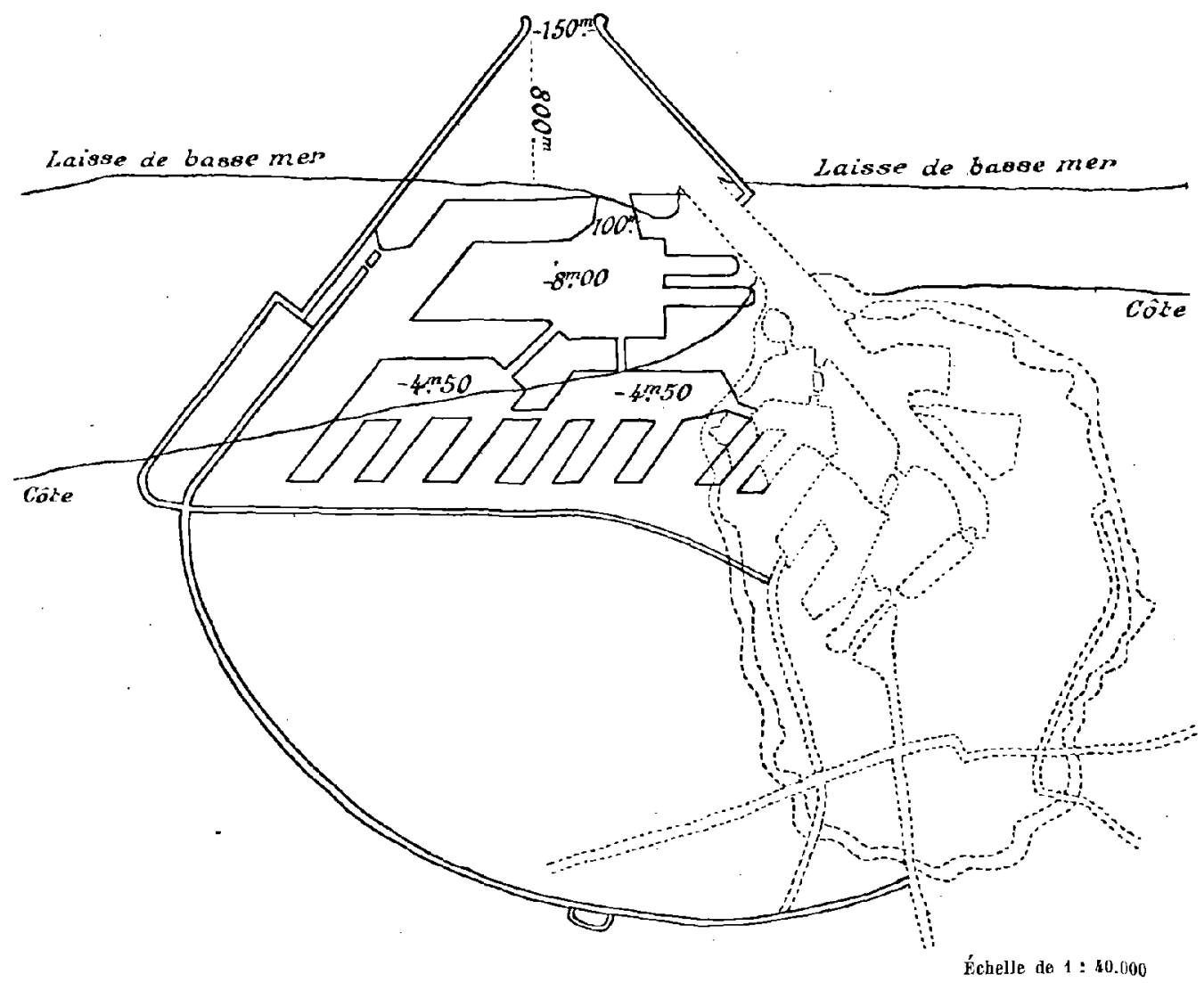

FIG. 51. - Fort de Dunkerque. - Projets d"agrandissement.

(Le pointillé représente le tracé actuel).

tout prêt pour l'avenir; le jour où la construction du canal du Nord-Est étendra jusquu’à Nancy l'hinterland du port flamand, Dunkerque sera prêt à exécuter les travaux d'agrandissement qui seront plus nécessaires que jamais ${ }^{1}$.

1 Pour les agrandissements en cours, voir: Chambre des députés, 1001, Annexe au Procès-verbal de la séance du 4 juillet 1901, Rapport de M. Guillain, 33 p. ; Sénat, 1902, Annexe au Procès-verbal de la séance du 2 décembre 1902, Rapport de M. Barbey, $26 \mathrm{p}$. 


\section{Port d'escale : Zeebrugge.}

Cependant les transformations subies par les ports flamands n'out pas altérẻ complètement leur caractère ancien : los chenanx sont agrandis, les avant-ports élargis et creusés, les bassins à flot multipliés; mais le système reste le même. A Zeebrugge, créé de toutes pièces, on a pu faire quelque chose de neuf. Il y a deux conceptions à l'origine de ce port : on a voulu d'abord en faire une sorte d'avant-port de Bruges, relié à la ville par un canal de navigation maritime; et sur ce projet on a greffẻ celui d'un port d'escale, propro à assurer avec le maximum de rapidité le transbordement des voyageurs et des colis de vitesse. De lá deux ports distincts ${ }^{1}$. Le premier est un élargissement du canal qui va à Bruges: il comprend un chenal entre deux estacades, et un avant-port, le tout long de 750 mètres, large de 106, et approfondi à 6 mètres sous Ies marées basses de vive eau; puis l'écluse, 20 mètres de large, 158 de longueur utile; enfin l'arrière-port, long de 660 mètres et large de 98 . Ln arrière le canal maritime, large de 70 mètres, profond de 8 , s'allonge droit vers Bruges, dont les hautes tours semblent regarder vers la mer qui revient au devant d'elles ${ }^{2}$. Tout cela ressemble au port d'Ostende, formé lui aussi d'un épanouissement du canal de Bruges à Ostende. Ce qui est nouveau, c'est le port d'escale. Il est formé uniquement d'un immense môle courbe, long de 2.237 métres. Cet ouvrage s'enracine dans la dune par une partie pleine de 232 mètres qui va jusqu’à la laisse de basse mer et a laquelle succède une partie à claire-voie, longue de 400 mètres, destinée à laisser circuler les courants côtiers qui doivent empêcher l'envasement. La troisiẻme partie, pleine, longue de 1.605 métres, vient se recourber devanl le chenal du port intérieur jusqu'aux profondeurs de 8 mètres, à 950 mètres de la laisse de basses

1 Voir une description très exacte des ouvrages dans: Visart (A.), Le Port de Bruges (Ia Belgique contemporaine; I, 190\%, pp. 252-271); - Nyssens-Hart J.), Ie port d'eseale et le port intérieur de Bruges (Bruxelles, lesigne, 1898, 45 p., pl.); - Nyssens-Hart et Piens (Ch.), Construction du nôle et du port d'escale de Zeebrugge (VIII Congrés international de navigation, Paris, 1900); - Nyssens-Hart et Zone, Le port de vitesse de Heyst (Rruxellos, Lesigne, 1894, in-80, 121 p., 3 pl.).

A A Bruges même, le canal aboutit à deux bassins : celui de louest avec une profondeur de $6^{\mathrm{n}}, 50$, celui de l'Est avec 8 métres; séparés par un môle de 120 mètres de large, avec des entrepôts. Le bassin de l'Ouest communique avec le canal de Bruges à Ostende, et par là avec toutes les voies navigables de l'intéricur, au moyen d'une écluse large de 20 mètres, avec une longueur utile de 97 mètres. 
mers ; l'aire protégóe est de $110 \mathrm{Ha}$. Ainsi cette jetée hardie abrite des vents de l'Ouest et du Nord l'entréo du chenal, précaution utile sur cette partio de la côte que los bancs de Flandre ne protègent pas contro les lames du large; elle fait ici l'office d'une digue de Cherbourg reliée à la terre. Mais son rôle principal est de servir elle-mêrne de quai d'accostage. La partie pleine est pourvue de 1.271 mètres de quais d'accostage, au pied dosquels on entretiendra 8 mètres de profondeur sous mer basse: ces quais sont défendus du côté de la haute mer par un parapet en béton de 6 mètres de haut; et comme le mole se trouve déjá à la cote +7 , la partie supérieure du parapet atteint la cote +13 . $A$ l'abri de ce rempart s'alignent les hangars, los engins de manutention, les voies ferrées qui amèneront les trains au long des steamers. Ainsi les grands paquebots rapides pourront, avec le maximum de rapidité, toucher $\dot{a}$ Zeebrugge et reprendre aussitôt la mer.

Cette conception hardie a souleve bien des critiques. M. de Mey estime que le môle courbe donnera des mécomptes : l'entrée est mal orientée, les bateaux auront á tourner un angle de $90^{\circ}$ pour pénétrer dans la zone protégée; par les grands vents d'Ouest au Nord, cette manœuvre risque de les jeter à la côte ou sur le Paardemarkt ; il sera difficile aux voiliers d'y entrer autrement que derrière des remorqueurs. Un envasement est à prévoir au droit des musoirs du port intérieur ; le jusant pénètrant largement el ne trouvant que l'issue resserrée de la claire-voie sera entravé et précipitera des alluvions. Le môle protègera mal l'entrée du chenal, surtout par les vents du N.-E., qui sont assez fréquents en Flandre; même il sera un obstacle pour lo port intérieur; an moment du flot, les navires devront venir attaquer de l'Ouest le chenal, manœuvre qui sera difficile dans l'espace resserré compris entre le môle et les musoirs ; par le jusant, le vent d'Est jettera les bateaux sur l'estacade. On verra à l'usage si ces craintes sont fondées. Mais on peut aussi se demander si l'absence de vieilles institutions commerciales, de négociants rompus aux affaires maritimes, d'une population de marins, le manque d'industrie et de commerce dans la région n'entraveront pas pendant quelque temps l'acliviié économique du nouveau port. Il ne manque pas de gens en Flandre pour remarquer qu'au moment où Anvers va pratiquer la « coupure » de l'Escaut et établir de nouveaux docks, où Gand double ses installations et approfondit le canal de Terneuzen, où Ostende a reconstitué complélement son port, il était peut-être superflu de jeter tant de millions sur la plage de Heyst. 
IV.

\section{I.FS VILLES; LFS PLAGFS.}

Le développement qu'ont pris les ports flamands an XIX ${ }^{\mathrm{e}}$ siécle ${ }^{1}$, n'a guère modifiẻ la physionomie des villes. Elles n'ont pas l'air animé, vivant, que présentent d'ordinaire leur's paroilles, même les plus tristes d'aspect. La différence est grande avec Anvers, ètendue en façade sur l'Escaut, et où la vie du port se mêle à colle de la ville. En Flandre, les bassins s'éloignent des anciennes cités, souvent enserrées dans leurs remparts; les installations nouvelles de Dunkerque, d'Ostende, sont loin du cœur de la ville. A Dunkerque, dès qu'on quitte les quais pour pénétrer dans les rues, rien ne rappelle le port, c'est une calme souspréfecture de province. A part quelques rues de matelots comme le quartier du Courgain à Calais, le Quai des Pêcheurs à Ostende avec ses façades bariolées et ses cabarets aux enseignes en anglais, les villes de la côte ont une physionomie assez banale.

\section{Aspect et évolution des villes.}

Cependant aucune d'elles ne ressemble aux autres. Les deux bourgades endormies de Nieupori et Gravelines sont déjà très différentes. Complètement reconstruit au $\mathrm{XVII}^{\mathrm{e}}$ siècle, Nieuport est pourtant gris et triste ; la brique hlanche de la plaine maritime y a pris une couleur sombre, presque noire; le nombre relativement considérable de pignons flamands à escalier, construits au XVII ${ }^{\mathrm{e}}$ siècle,. et de maisonnettes basses à mausarde de pierre comme on en voit dans les rues pauves de Bruges et d'Ypres, accentue son air de vétusté. La misère n'a rien pour se cacher dans ses larges rues droites et désertes, où le passant se sent épié par les vieilles dentellières qui travaillent derrière leurs petites vitres sombres. La pauvreté ici date de loin, car une charte de Maximilien la constato au $X V^{e}$ siècle, et l'Allemand Forster, en plein midi, n'y rencontre personne dans les rues Jorsqu'il y passe en $1790^{2}{ }^{2}$. Gravelines est une petite ville

\footnotetext{
1 Sur le commerce des ports, voir chapitre XVI.

2 Charte de 1495 imprimée dans Gilliodts, Coutumes de Nieuport, p. 257. - Voir Forster, Voyage philosophique et piltoresque... fait en 1790 (P’aris, Buisson, an III, 2 vol. in $\left.-8^{\circ}\right)$, II, p. 184.
} 
proprette et banale, de ces vieilles cités flamandes où les couvents et les casernes tiennent tant de terrain: d'énormes et savantes fortifications la couvrent, qui tionnent plus de place que la ville même. La partie vivante de la population, marins ot pécheurs, n'habite pas la ville, mais les gros hameaux du Petit-Fort-Philippe et des Huttes. Mais ce qui rapproche les deux petites villes, c'est l'identité du paysage environnant: l'immense étendue des plaines, polder Lens ou Hems-St-Pol; les chenaux de l'Aa et de l'Yser, les bassins d'échouage où la marée basse laisse sortir de l'eau des bancs jaunatres et gluants; la ligne blanche des dunes; un ensemble calme et mélancolique. Malgré quelques tentatives industrielles, la vie reste comme ralentie autour des deux ports que fit naître, à la même époque, l'intelligente activité des princes de la maison d'Alsace.

Au moins Calais, Dunkerque, Ostende, sont de vraies villes, bientôt de grandes villes. Calais offre le curieux spectacle de trois cités distinctes groupées dans le même organisme municipal. Tout contre le port, le Courgain des marins, d'un pittoresque de ville méditerranéenne, hautes maisons enserrant des ruelles étroites encombrées en bas de bandes d'enfants, barrées en haut de vêtements qui sèchent. Puis vient le vieux Calais, déjà a moitiẻ flamand d'aspect; les toits se hérissent de tours de guet, les monuments sont rudes comme ceux d'une ville de corsaires, surtout cette robuste et pauvre tour d’èglise, « usée par le vent salé de la Manche », et que Ruskin compare à un vieux rocher. C'est la ville des armateurs, des commerçants, des petits bourgeois. Que l'on franchisse les bassins qui ont remplacé les fortifications de François de Guise et de Richelieu, et l'on trouve un spectacle bien diffẻrent: plus rien d'un port ; une grande ville industrielle neuve et banale, déjá salie par les fumées des usines, larges rues aux maisons inégales, fabriques, terrains vagues, corons, le tout renfermé dans une enceinte moderne oú pourraient tenir 150.000 habitants, et où la ville nouvelle, malgré son rapide développement, est a l'aise. C'est St-Pierre, la capitale du tulle, qui prend sur Calais la revanche de l'antique Pétresse, dépossédée jadis au profit du port florissant. Fixée d'abord dans le vieux Calais, l'industrie érnigra définitivement en 1827 à St-Pierre, chassée par les réclamations des habitants et par le manque d'espace; elle trouvait lá, sur les espaces libres des Pierrettes, la place et les tolérances qu'il lui fallait. Bientôt le faubonrg dépassa la ville, et finit par l'annexer on 1885. Le vieux Calais a quelque rancune de cette croissance; les deux villes sont plus que diffẻrentes; elles sont un peu rivales. La population sédentaire et posée de l'ancienne considère sans bienveillance les éléments mêlés, changeants et turbulents de St-Pierre, déracinés des campagnes voisines, Flamands de 
Dunkerque et d'Hazebrouck, Belges des deux Flandres. Les Flamands sont nombreux dans la nouvelle ville, où ils exercent les professions pénibles et se louent comme domestiques; dans certaines églises il y a un prêche en flamand le dimanche. Cette population neuve, exploitant une industrie sujette à de brusques variations, traverse périodiquement des crises violentes au xquelles elle est mal préparée, et qui font grand tort à la ville. De 38.156 habitants en 1876 , Calais a bondi en 1886 au chiffre de 58.969 ; en 1901, elle reste à 59.743. Augmenter de 20.000 habitants en 10 ans, puis de 800 dans les 15 années qui suivent, c'est bien là que se caractérise l'activité économique de Calais.

Dunkerque est plus posè. Sa croissance, au cours du siècle, s'est poursuivio régulièrement, sans à-coups. Ici les statistiques n'indiquent pas exactement la réalité : à s'en tenir aux chiffres des recensements, l'accroissement serait lent, et la population à peu près stationnaire. La commune avait 23.815 habitants en 1804, 32.113 en 1861; en 1876 elle atteignait 35.071, 38.025 en 1886,38.925 en 1901. Et l'on s'étonne qu'un port qui est dovenu le troisième de France ait si peu d'habitants et présente une si faible augmentation. Simple apparence. Depuis 30 ans, Dunkerque, complètement rempli dans son enceinte, s'est répandu au dehors, dans les communes suburbaines. Aux 39.000 Dunker'quois intr'a-muros qu'on joigne les 32.000 personnes qui vivent à Rosendael, St-Pol, Coudekerque-Branche, Malo et Petite-Synthe, et l'on obtient 71.000 habitants, le v'ai chiffre de la population de Dunkerque. L'accroissement se continuera dans la banlieue, mais il a atteint son maximum dans la ville; celle-ci est pleine. On y compte par maison 11,2 habitants; or le vieux Lille lui-même, qui paraît si entassé. n'en a que 10, et les autres villes du Nord un peu plus de 5: 5,05 à Tourcoing, 5,25 à Roubaix, 5,40 à Armentières. Ici, il est difficile d'habiter une maison, comme c'est l'usage dans toute la Flandre; on en est réduit aux appartements. Faute de place dans le logement, le Dunkerquois, surtout enfant, vit dans la rue; de lá peut-être son amour des fêtes bruyantes de la voie publique, au Carnaval, à la Kermesse ${ }^{1}$. Toutes les maisons ont au moins un étage, le plus souvent deux ; encore beaucoup d'habitants continuent-ils à vivre dans les caves. Ces maisons sont pour la plupart de banales bâtisses élevées ou refaites au XIX ${ }^{\mathrm{e}}$ siécle, construites en briques jaunes, ce qui, remarque Barbault- Boyer en 1799, « distingue specialement Dunkerque de toutes les villes rouges de Flandre ». Au moins la ville est-elle propre, malgr'é l'avis de ce voyageur', qui lui trouve « l'aspect fort sale et

\footnotetext{
1 Marguerit, A travers la Flandre maritime. (Mém. Soe. Dunk., XXVIII, pp. 2566 $270)$.
} 
d'autant plus sale qu'elle fourmille de matelots " ${ }^{1}$; en réalité, la nature sablonneuse du sol, les instincts de nettoyage des habitants, la régularité et la largeur des rues, donnent à Dunkerque l'air d'une ville bien tenue, même un peu trop correcte et froide. Pas de maisons curieuses, peu de monuments : l'hôtel de ville, la grosse tour de St-Eloi, beau donjon noirâtre aux lignes sobres; le reste est utilitaire: tours de guet, phare, et l'édifice commun à toutes ces villes de la côte, la tour-réservoir en briques. En effet, trouver de l'eau potable en quantité suffisante a toujours été un des graves problémes à Dunkerque et dans les villes voisines. Il ne fallait pas songer à utiliser l'eau du sol, «l'eau braque », saumâtre, boune tout au plus au lavage des maisons. Les citernes à eau de pluie ont èté longtemps l'unique ressource; ressource assez précaire, car cette eau peu engageante manquait parfois, et l'autorité devait rationner les habitants ${ }^{2}$. En se développant, il fallait que Dunkerque trouvât autre chose. Les puits artésiens creusés á grands frais n'ayant donné aucun résultat, pas plus qu'à Ostende et Blankenberghe, la ville essaya des eaux impures du canal de Bourbourg, el finit, à l'exemple de Calais, par aller capter les sources pures de la craie qui jaillissent à la base de l'Artois. Calais, plus rapproché des hauteurs, s'alimente à Guînes; .Dunkerque dut établir une canalisation de $40 \mathrm{Km}$. et deux réservoirs pour utiliser les eaux de Houlle ". Moins bien partagée, Ostende en est encore réduite aux citernes el à l'eau de canal filtrée, très peu utilisée parce qu'elle est souvent contaminée; fâcheuse condition pour une ville de plaisance que l'emploi de ces eaux grisâtres et douteuses. Mais il faut aller si loin pour trouver l'eau pure en abondance, aux coteaux de Wynendaele, peut-être jusqu'à l'Ardenne calcaire, qu'on hésite à l'aller chercher à ce prix.

Ostende ne pourra cependant pas se passer longtemps encore de cet élément de prospérité. C'est une des villes de Flandre qui se sont le plus rapidement développées à la fin du XIX ${ }^{\mathrm{e}}$ siècle: elle végétait au XVIII $\mathrm{e}^{\mathrm{e}}$,

1 Barbault-Royer, Voyage dans les départements du Nord, de la Lys, de l'Escaut, etc. (Paris, Lepetit, messidor an VIII, in-80, 200 p.), pp. 187-188.

2 «L'eau de citerne a un gotht de vase très prononcé; en été et en automne elle est chargèe de quantité de petits insectes transparents. On y trouve des vers plats et rouges de la longueur d'un pouce najgeant presque toujours... \ (Tully, Essai sur les maladies de Dunkerque, Dunkerque, de Boubers, 1760, in-18 , 266 p.). - A Calais, l'instruction de 1734 pour les garde-citernes prescrit de fournir l'eau d'abord aux soldats chaque jour à $7 \mathrm{~h}$. $1 / 2$ du matin, puis aux bourgeois une fois le jour de 8 à 9 , pendant une beure, sur le vu des billets délivrés par les mäeur et éclevins, dans une cruche seulement. (Arch. Pas-de-Cialais, C. 110).

a Sur l'eau potable à Dunkerque, voir : Duriau (G.), L'hygiène publique à Dunkerque. (Mém. Soc. Dunk., 1898, 69 p.). 
après la chute de la compagnie austro-belge qui portait son nom, et n'avait guére en 1770 que 5.300 habitants : c'était un autre Nieuport, une bourgade de pêcheurs et de marins. Le recensement de l'an IX en indique 10.200; il r'y en a encor'e que 19.897 en 1880, 24.688 on 1890. Or lo recensement du 31 décembre 1900 fournit le chiffre de 39.484, en gros 40.000. Ainsi la population a doublé en 20 ans. Ce développenent si rapide n'est pas dû, comme à Calais, à la présence d'une grande industrie, ni même, comme à Dunkerque, à la prospérité du port ; il est le résultat de la vogue prise par Ostende comme station balnéaire. La vieille forteresse de l'archiduc Albert est devenue là « Reine du littoral ». 130 à 140.000 visiteurs y passent chaque année; 40 à 50.000 étrangers y séjournent, Belges, Anglais, Français, Allemands ${ }^{1}$. Or ces baigneurs n'êtaient guère que 10.000 en 1860, 22.000 en 1875, et c'est surtout depuis 1880 que leur nombre a augmenté: 38.000 en 1890, 42.600 en 1902, jusqu'à passé 50.000 en 1899. Pour recevoir dignement ces visiteurs et en attirer d'autres, Ostende a fait sa toilette. Ce n'est pas seulement sur la digue de mer qu'on a fait disparaître «ces petites maisons tenues fort basses pour être moins exposées aux terribles effets de certains vents de mer ${ }^{2} \gg$ qu'on y voyait au début du siècle, pour les remplacer par les splendides constructions actuelles; toute la ville s'endimanche, et prend peu à peu, surtout dans l'Ouest, l'air distingué des villes de villégiature.

\section{Les Plages.}

Ainsi le port commence à n'être qu'un accessoire dans la vie d'Ostende ; avant tout elle est uno des plus fréquentées de ces Plages qui sont la forme la plus récente des rapports entre l'homme et la côte flamande, et en ont modifié si curieusement la physionomie. La nature de la côte s'y prête, avec son estran en pente douce; la clientéle était assurée: la populeuse et riche région de l'hinterland a fait de la côte son séjour d'été: Français du Nord, Belges, Allemands, lui sont fidèles; les Anglais même y viennent en nombre. Les profits sont tels, que chaque village des dunes veut avoir sa part. Dès le Zwin commence la rangée des plages belges. Les conditions $\dot{y}$ sont peut-être moins favorables que dans l'Ouest: les lames sont plus fortes, la mer plus houleuse; copendant le succès est venu.

1 Bulletin de la Chambre de Commerce d'Ostende, 1902, n 13, pp. 315-317.

2 Paquet-Syphorien, Voyage historique et pittoresque fait dans les Pays-Bas et dans quelques départements voisins en 1811, 12 et 13 (Paris, Firmin Didot, 1816, 2 vol. in $\left.-8^{\circ}\right)$, II, p. 134. 


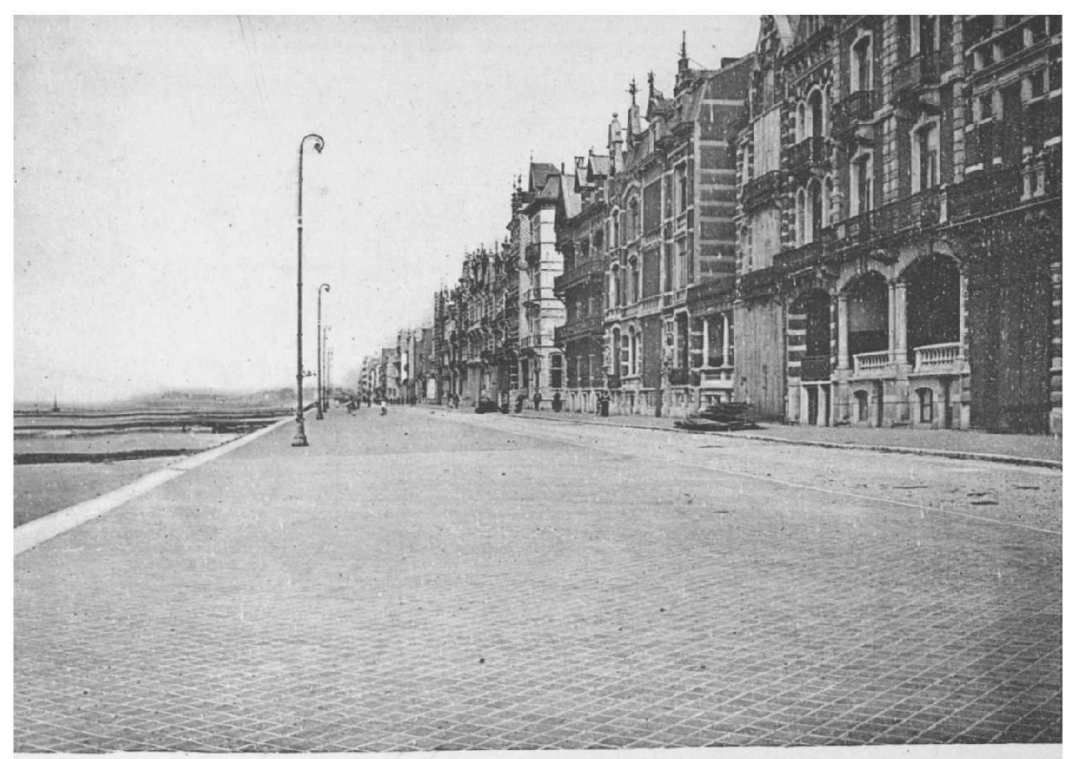

21. - La Digue de Heyst.

Villas garnies du revêtement de planches pour l'hiver.

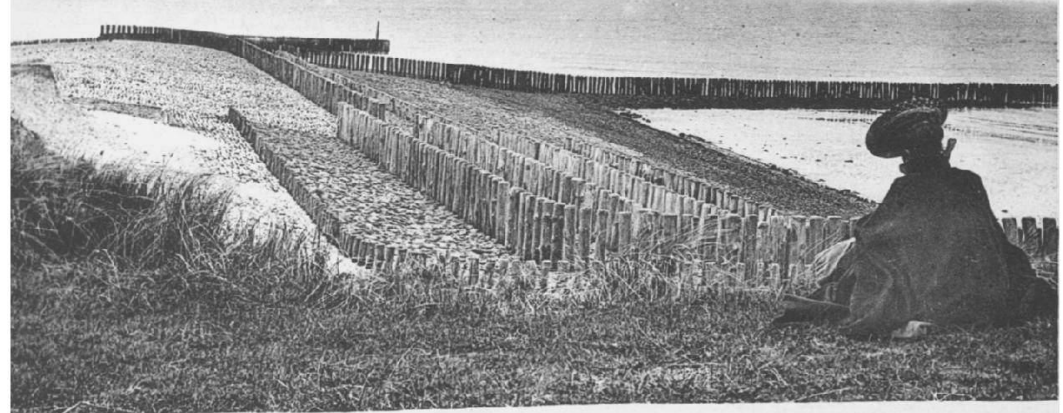

22. - Digue de mer et épis à Nieuwe Sluis (côte de Kadzand). 
IRIS - LILLIAD - Université Lille 1 
Knocke, Heyst, Blankenberghe, Wenduyne, le Coq, groupent sur les dunes, dominant la mer, de longues rangées de villas rutilantes et d'hôtels gigantesques, qui s'abritent l'hiver derrière d'immenses volets de bois et secouent leur chrysalide au printemps, pour la venue des étrangers : 15 a 18.000 à Heyst, 200.000 à Blankenherghe, dont 34.000 y séjournent 1. L'énorme développement d'Ostenden'a pourtant pas arrêlé l'essor des constructions dans la direction de l'Ouest: Mariakerke, Middelkerke, Westende, Nieuport, même Coxyde, Oost-Dunkerke, La Panne et Bray-Dunes, isolées derrière leurs sables, ont leur plage; Malo-les-Hains toucho à Dunkerque. Do Nicuport à Dunkerque, c'est la bonne côte, bien abritée des lames, avec un estran qui n'est pas démesuré, et derrière, le pittoresque des hautes dunes.

La juxtaposition de ces villes neuves aux anciens villages des dunes

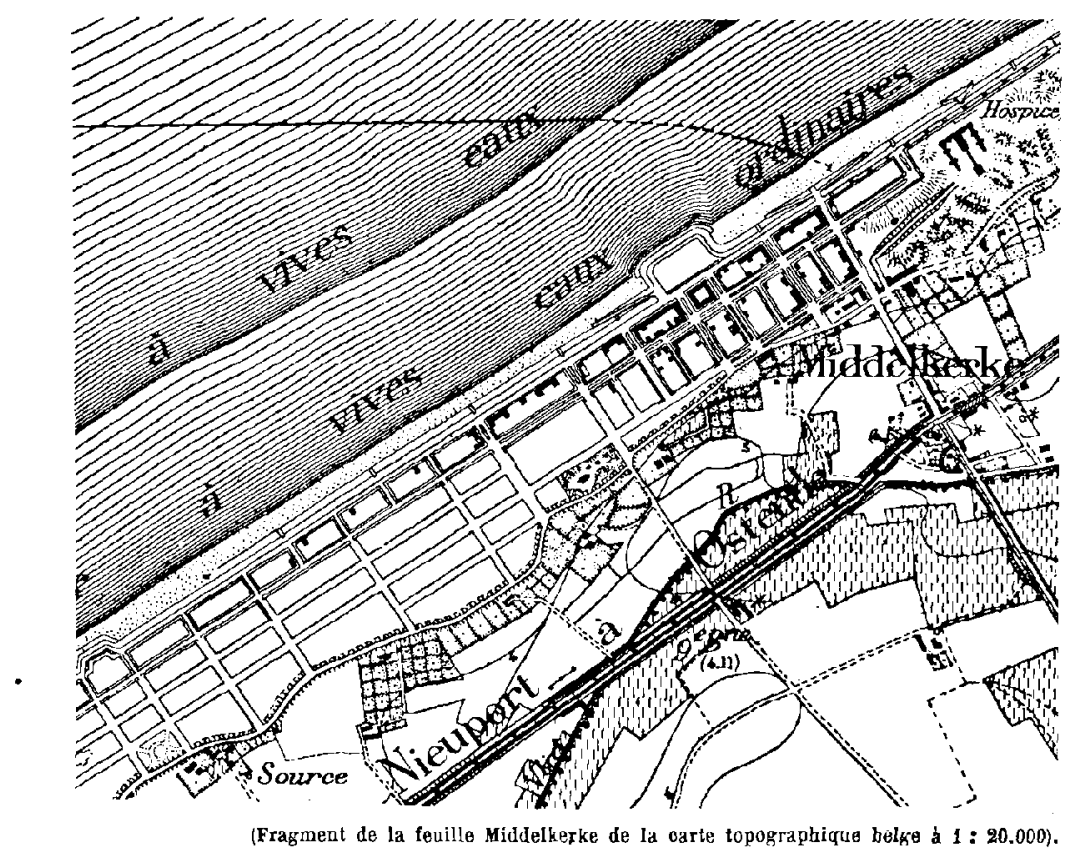

FIg. 52. - Une ville balnéaire: Middelkerke.

produit parfois des agglomérations de forme curieuse, oủ l'on retrouve les éléments anciens. La bourgade de Middelkerke comprend en réalité trois

\footnotetext{
1 Renseignements des administrations communales. - Sur Blankenberghe, voir les articles de Van den Bussche (E.) dans « la Flandre ", vol. VI, VII, VIII et IX.
} 
parties : sur les dunes, la digue de mer avec les hôtels, les villas élégantes ou biscornues, le promenoir et ses lampadaires électriques, et derrière, des embryons de rues sableuses, où les maisons alternent avec les terrains vagues. Celte partie neuve touche aux vieilles maisons de la lisière des dunes, habitées par les maraîchers, et qui forment le long des sables une ligne de chaumières pittoresques, d'aspect caractéristique. Enfin plus bas, dans la plaine mềme, s'étend l'agglomération née sur la route d'Ostende à Nieuport, habitée par les commerçants et les ouvriers agricoles; c'est un village de la plaine maritime. Ainsi dans cette simple commune de 2.040 personnes, on trouve trois types d'habitat particulier, presque trois pelites villes distinctes.

Cette floraison de villes neuves a transformé la côte; les stations balnéaires l'ont embellie et enrichie. T'outes ces bourgades des dunes, jadis les hameaux les plus misérables et les plus inconnus de la Flandre, célèbres surtout par les désastres que leur infligeaient la mer ou les sables, sont devenues prospères, presque illustres. Devant les anciennes cités, qui risquaient juste leur beffroi ou leur tour d'église par-dessus les dunes, des files de maisons se sont établies au bord même de la mer, sur le dos des monticules: hôtels énormes, aussi vastes que les grands hôtels de ville flamands: villas de tous styles, hautes et brillantes, véritable défi aux vents et aux vagues. La côte déserté, inhospitalière, s'est peuplée; elle devient une rue luxueuse et animéo. Celte transformation achève le contraste entre l'aspect peu engageant de cette côte, la tristesse de ses dunes et de ses estrans, et l'activité économique qui s'y est établie. L'âpre région côtière s'est humanisée ; elle est riche et penplée; la Flandre a maintenant sur la mer une façade digne d'elle-même. 


\section{GHAPITRE XI.}

\section{L'EAU DANS LA PLAINE: POLDERS ET WATERINGUES'.}

I. Lutte contre la mer. - II. Lutte contre les eaux interieures. Objet des Wateringues. Organisation. - III. L'œuvre des Wateringues. Les rivières: Aa, Yser. Canaux d'assèchement. - IV. Résultats de l'assèchement. Calaisis. Marais de St-Omer. Moëres. Terres basses de l'Est. Progrès accomplis et à accomplir.

Du haut des grandes dunes de la Panne, la plaine maritime apparaît sous un de ses aspects caractéristiques. De grandes étendues de guérets noirâtres ou gris, sur lesquels tranche la couleur jaune des sables côtiers; çà et là des pâtures, dans la proportion d'un tiers. Pas la moindre óminence à laquelle puisse s'accrocher le regard. Des lignes de saules bas, qui suivent les fossés; quelques massifs de peupliers fortement inclinés au S.-E. ; et derrière ce mince écran, les constructions basses de grandes fermes. Les maisons sont rares, surtout les petites. On aperçoit peu d'habitants, parfois une « bande $\gg, 30$ à 40 personnes de front, occupées à un sarclage ou à un binage. Ce qui anime le plus le paysage, ce sont les mouvements lents des bêtes sur les pâtures. Le soleil fait briller la ligne blanche d'un watergand, et sortir de lointains brumeux des clochers sévères.

Watergands, pâtures et terre grise, fermes, arbres rares et penchés, sont les notes uniformes de ce grand paysage vide. Les proportions peuvent changer, mais les éléments restent les mêmes. Aux environs de Nieuport, l'absence d'arbres dans l'ancien golfe de l'Yser est plus sensible encore qu'ailleurs: pas un tronc sur 5 kilomètres, entre l'église de Middelkerke et celle de Slype: à peine derrière une ferme quelques malheureux pommiers, tordus, leurs branches horizontales, violemuent lancées vers l'Est. Ailleurs, de Bergues à Dixmude, ce sont les pâtures qui envahissent le paysage, et l'egaient de leur immuable teinte verte, sur laquelle tranchent les petits ponceaux de briques, blanchis à la chaux, qui franchissent les watergands. Autour d'Ostende, tout est gris ; la terre forte de la crique a

1 A consulter: Schramme (J.), Des Wateringues. (Bruges, Maertens, 1899, in-8, 200 p.) ; - Schramme (J.), Limbourg (H.) et Van de Wattyno (F.), Des Polders. (Bruxelles, Larcier, 1904, in-8 312 p.). 
gardé la couleur des alluvions marines. Par endroits, les watergands deviennent plus nombreux; le sol est coupé de grandes flaques où se creusaient jadis les exploitalions de tourbe ; c'esí le marais, tantôt sauvage, tantôt cultivẻ, oủ les saules se font nombreux. Mais l'impression dominante, surtout lorsqu'on arrive de l'intérieur, est celle de nu et de vidle. Fuchanté du pays de Waes, Forster débouche sur les polders de Zwyndrecht. «Aussitôt les arbres, les buissons, disparaissent. Le pays se change en une vaste lande. On ne voit plus qu'une plaine chauve bornée par des pâturages et des prairies $\gg{ }^{1}$. Ce que l'enthousiaste Allemand appelait une lande, dans un mouvement do mauvaise humour que calmait à peine «l'imposante grandeur» du panorama d'Anvers à l'horizon, c'est la terre la plus fertile de Flandre; mais elle est bien vaste et chauve d souhait.

Ce pays plat et nu est aussi le pays bas. Sur presque toute son étendue la plaine serait recouverte par les marées hautes de vive eau, sans l'obstacle des digues et des dunes. Il n'y a guère que la lisière côtière et le dos des anciennes îles qui pourraient émerger. Certaines parties sont si basses qu'elles sont au-dessons du niveau moyen de la mer. Dans les Moëres franco-belges, le sol s'élève à peine à 1 mètre au-dessus des marées basses de vive eau. Tout au long de la limite du Houtland, la plaine s'affaisse en une rainure ou le sol se trouve, par rapport au niveau moyen des basses mers de vive eau : $\dot{a}+2^{\mathrm{m}}, 50$ entre Calais et Audruicq, $\dot{a}+3$ mètres au Nord de Bergues, $\grave{a}+2$ mètres en certains points du golfe de Loo et dans les moeres de Ghistellos, à +2 mètres et même +1 mètre entre Oudenbourg et Meetkerke, à +1 mètre dans certains polders zélandais à la limite de la Belgique, et le long du Bas-Escaut. Ainsi aucune partie de la plaine ne resterait inondée à marée basso, mais à maréo haute on verrait par exemple les grandes Moëres recouvertes d'une tranche d'eau de $3^{\mathrm{m}}, 50$. C'est a cét état amphibie que tient dans la plaine maritime le grave problème de l'eau.

Par sa situation de plaine basse étendue tout au long de la Flandre et la séparant de la mer, la région maritime reçoit toutes les eaux flamandes, sans compter celles que l'Aa et l'Escaut lui aménent des pays voisins. L'aftlux est général; il faut que tout passe là, s'écoule à la surface de ce sol sans pente. Il ne faut pas compter sur l'infiltration : cette terre est déjà saturée d'eau. L'épaisseur des sables pissarts, sous laquelle l'argile yprésienne étend son imperméable masse bleuâtre, est aussi liquide que solide; l'ean douce qui y pénètre par les lacunes de l'argile poldérienne y est mêlés à l'eau de mer dont aucune cloison imperméable n'empêche la lente inva-

1 Forster, Voyage philosophique, II, p. 222. 
sion. Tout ce qui tombe des nuages, tout ce qui descend de l'intérieur doit donc couler à la surface de la plaine. Mais la mer, de son côté, tend à pénétrer sur ce territoire moins élevé que le niveau de ses marées, et à refouler les eaux douces qui y cherchent péniblement leur route. Abandonnée à elle-même, la plaine redeviendrait aussitòt unè vaste lagiune d'eau saumâtre.

La lutte contre l'eau est donc la première tâche qui s'impose à là plaine maritime; il y va de sa richesse, de sa vie même. Sans elle, la plaine n'existerait pas. Ie combat revêt plusieurs formes. La nécessité la plus pressante semble être la défense contre l'invasion marine, qui monte deux fois par jour à l'assaut. Cependant c'est là une tâche relativement facile. La mer est terrifiante; elle frappe, mugit, écume, et pourtant fait rarement du mal. On est vite venu à bout de l'arrêter. Les eaux douces ont été un obstacle bien plus sérieux au développement de la plaine; la mer cesse d'être dangereuse deux fois par jour; les eanx intérieures ne s'arrêtent pas. Enfin après l'eau salée et l'eau douce, l'eau saumâtre. Celle-ci s'infiltre à travers les sables pissarts, passe sous les dunes et vient remonter à la surface, faisant périr les récoltes et les arbres. L'homme doit faire front de toutes parts, arrêter la marée, expulser l'eau douce, refouler en profondeur l'eau saumâtre. Pas assez d'eau dans la mer, trop d'eau sur la terre et dans la terre, c'est la formule de la région; le Flamand a fort à fairo pour rétablir l'équilibre. Encore lui faut-il, dans cette lutte ininterrompue, garder de la mesure. Pour enlever à la plaine les eaux surabondantes, il ne faut pas lui retrancher les eaux nécessaires, sans lesquelles ses habitants souffriraient de la soif, et ses terres fortes de la sécheresse. Ainsi la lutte doit être à la fois âpre et judicieuse, et l'organisme utilisé aussi délicat quo solide.

\section{I.}

\section{LUTTE CONTRE LA MER.}

Contre la mer, la lutte est relativement facile. La protection de la plaine est assurée sur une bonne partie de la côte par la nature. Les dunes sont la meilleure des défenses, et il suffit, lorsqu'elles s'amaigrissent, de les préserver' par des fascinages ou des épis. A l'Ouest, ce n'est guère que dans les anciens estuaires de l'Aa, de l'Yser, du Zwin, ou en des points particuliérement menacés que l'on trouve des digues. Mais à partir de Breskens, toute la côte en est constituée. 
Ces digues de mer, qui n'existent guère que dans la Flandre zélandaise, sont loin d'avoir l'aspect imposant des magnifiques perrés que les Belges ont établis sur les dunes de leurs stations balnéaires. Ce sont des ouvrages trés simples et très pratiques, et si nous en croyons les archives, assez semblables à ceux qu'edifièrent les moines de St-Pierre on des Dunes. L'emplacement de la digue à construire sur le schorre suffisamment mûr ${ }^{1}$ est fixe un peu en arrière de la laisse des basses mers; il faut garder en avant de la future digue une bande de schorre, où l'on prendra l'argile nécessaire à la construction, et qui servira d'avant-berme. Il y a tout avantage à ne pas prendre de la terre en arrière de la digue; on évite ainsi de gâter le sol agricole de la partie à endiguer, et de créer de véritables marais difficiles à combler, comme ceux que l'on voit encore entre Blankenherghe et Wenduyne, derrière la digue du Comte Jean. Devant l'emplacement choisi pour la digue, où l'on tient compte encore de la situation par rapport aux vents dominants, et de la direction des criques à combler ${ }^{2}$, on établit une diguette de mottes d'argile liées avec des roseaux ; et c'est à l'abri de cet obstacle, cntro la diguetto et l'ouvrage on construction, que l'on enlève les matériaux, en ayant soin de ne pas approcher l'excavation trop près de la digue, et en laissant de place en place des parties intactes qui forment des espèces d'épis. La digue s'élève jusqu'au moins $0^{\mathrm{m}}, 50$ au-dessus des plus hautes eaux connues : de sorte qu'à la suite d'une marée extraordinaire on s'astreint à rehausser tous les ouvrages; après la grande marée de février 1825, on releva de $0^{\mathrm{m}}, 75$ a 1 mètre toutes les digues du Bas-Escaut. Elle comprend une plate-forme de largeur variable dominant deux talus de pente inégale; celui qui fait face à l'intéricur très raide, tandis que celui qui reçoit le choc des vagues est en pente beaucoup plus douce, pour donnor moins de prise à l'attaque. C'est ainsi que la fameuse digue de Westkapelle, dont on aperçuit de Kadzand le profil régulier tout au bout de l'île de Walcheren, est peu imposante d'aspect, tant elle est large, et tant son talus extérieur, planté d'une forêt de pieux, descend d'une pente insensible. Même le plus sonvent ce talus comprend deux parties, toujours en pente douce, séparées par une plate-forme intermédiaire, élevée à la hauteur des marées de vive eau ordinaires. Enfin le pied de chaque talus

1 Au moins () 70 an-dossus des bassos mers ordinaires des syzygies.

2 Le tracé évite les angles brusques; et quand il rencontre une crique profonde, parfois il la contourne; la partie contournée peut servir de port d’échouage; on y place l'écluse d'évacuation. Voir la phot. 23 (Un canal d'évacuation de Wateringue à Groeds). 
est fortifié par une berme en fascinages : la berme extérieure empêche la mer de déchausser la digue par le bas, et préserve lo talus en amortissant déjà la violence des flots; la berme intérieure soutient le talus qui y correspond, et sert généralement de chomin ${ }^{1 .}$

C'est là la digue ordinaire. Lorsqu'on la voit s'allonger en courbes douces, toule recouverte d'herbe comme une pâture, on a l'impression qu'elle constitue une piètre défense contre lo redoutable élément. Pourtant il est bien rare que cet élastique rempart de terre soit brisé. Le grand danger vient plutôt d'en bas : un trou qui permeltrait à l'eau de déchausser la digue. Aussi la construction et l'entretien des bermes sont ils l'objet de soins particuliers. D'ailleurs, aux endroits exposés, on augmente les défenses. La digue est revêtue de gros blocs assujettis par des branchages, comme à Sangatte. Sur la côte zélandaise, il est rare que le talus inférieur ne soit pas formé de gros prismes de basalte solidement plantès, au-dessus desquels on dresse de une d cinq lignes de pieux, plus ou moins serrés, plus ou moins

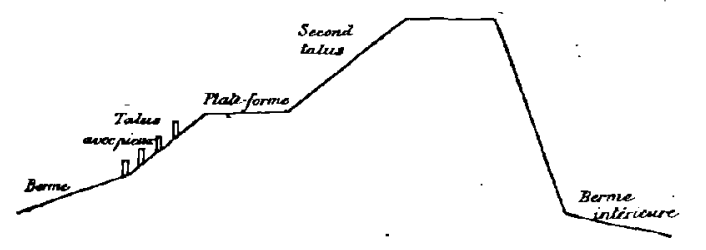

FIa. 53. - Profil d'une digue de Fländre zélandaise. élevés. I a plate-forme intermédiaire est alors pavée elle-même de ces blocs, ou soigneusement tapissée par un nattage. Enfin des epis font l'avant-garde de l'cuvre de défense et protègent la berme. Tranchées par ces pointes, les lames viennent s’émietter sur les pieux du talus inférieur, et expirer sur la première plate-forme. Avec leurs basaltes noirs, leurs pieux noirs auxquels s'accrochent les plantes marines, la côte ainsi défondue n'a plus l'aspect indécis et fuyant qu'on lui voit vers Gravelines ; elle est hérissée et rébarbative.

L'entretien de ces ouvrages revient naturellement à ceux qui en profitent, c'est-å-dire aux propriétaires des terres qu'ils protègent contre la mer, en proportion du danger qu'elles peuvent courir ; les exploitations situées à la lisière du Houtland payant moins que celles qui se trouvent au long do la côte. Dans le Pas-de-Calais, par exemple, la défense do la côte entre le Blanc-Nez et Gravelines est confiée au Syndicat des Digues et Dunes, commission de sept membres pris dans les comités des six associations de wateringues, et chargée d'assurer la conservation et l'entretien

1 Voir l'excellent article de Kümmer (U.N.), Essai sur les travaux do fascinages et la construction des digues. (Ann. Tr. p. Belg., $2^{\text {me }}$ série, IV, 1899, pp. 21-83, 163-224). 
des ouvrages au moyen d'une cotisation levée sur les différentes sections, proportionnellement à leurs risques d'inondation. C'est ainsi qu'est conservée la digue de Sangatte. L'Etat, dans la personne de ses ingénieurs des Ponts-et-Chaussées ou du Waterstaat, se cortente d'exercer un droit de surveillance et de contrôle sur les travaux ; il peut, lorsque les associations intèressées négligent leur tâche, faire exécuter lui-même les réparations, qu'il fait payer ensuite par les syndicats ${ }^{1}$. De plus, à toutes les époques, de nombreuses prescriptions ont assuré le bon entretien des dígues, et prévu la réquisition pour les cas de danger pressant. Depuis la keure du Franc de Bruges de 1190, où Philippe d'Alsace sanctionne que «quiconque aura rompu une digue de mer, perdra la main droite, el tout son bien sera à la disposition du comte » ${ }^{2}$, innombrables sont les ordonnances punissant les dégradations, el écartant des digues les animaux et les voitures ${ }^{3}$. L'obligation de venir au secours de la digue menacée est absolue; la réquisition atteint « tous les habitants au-dessus de 18 ans, avertis par le son du tocsin », sous peine d'amende et de prison; et en cas de manque de matériaux, l'autorité compétente peut «s'emparer de tout co qui existera en piquets, fascines et paille dans les environs de là digue, dût-elle même faire enlever le chaume des maisons et les chevrons de leur toiture " La nécessité explique ces mesures rigoureuses; l'entretien de la digue est la grande affaire des gens de la côte. « Celui qui ne sait pas diguer peut s'en aller », dit un adage flamand, qui so retrouve dans les Marschen de Brếme ".

Ces travaux soigneux, cette surveillance incessante ont produit de bons résultats. La plaine, derrière ses dunes et ses digues, jouit d'une sécurité complète. Cette quiétude surprend un peu l'étranger qui songe que la

1 Il en a toujours étẻ ainsi. Au milieu du XV^ siècle, le polder de Milme (Ouest de Terneuzen) ayant ses digues en muvais état, Philippe le Bon ordonne au watergrave de Flandre de prendre des nesures pour les faire réparer, et de faire supporter les frais au propriétaire, qui a négligẻ de les entretenir (Van de l'utte, Groeninghe, p. 80).

2 Paragraphe 19 de la keure, reproduit a l'article 40 de la keuro de 1330 (Gilliodts, Coutumes du Franc, II, p. 23).

3 Les amendes pour le passage des voitures, chevaux et autres bestiaux sur la digue sont encore fixées dans l'ordonnance royale du 15 juillet 1818, Digues et Dunes du Pas-de-Calais, titre 8 , article 38.

4 Articles 35 et 38 du décret du 16 décembre 1811, règlement de police des polders dans les départements de l'Escaut, etc. Les mêmes prescriptions se retrouvent dans la Keure de la Wateringue de Kadzand, de 1538 (Gilliodts, Coutumes du Franc, II, p. 606); dans l'Ordonnance de 1625 (Ibid. III, pp. 75-76), etc. 
mer, qu'on entend parfois gronder derrière un mur de terre, est plus haute que le sol oì la vie s'écoule tranquilloment. Mais l'habitant des polders est si habitué à cette anormale situation qu'il n'y pense plus; peut-être même ignore-t-il qu'elle existe. Cetto sécurité date surtout du

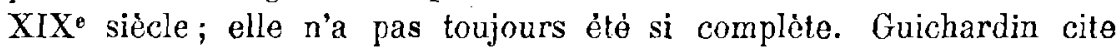
l'ancienne clause de location qui décide que si dans les dix ans la mer vient inonder, couvrir et noyer les étendues louées, le contrat serait tenu pour rompu ${ }^{1}$. Le temps n'est pas si bloigné où les habitants du Frane fuyaient à l'annonce de la terrible marée du 2 février 1791, et où les portes de Bruges restaient ouvertes toute la nuit, pour laisser passer lo flot des paysans affolés poussant devant eux leurs bestiaux. Les derniéres inondations sérieuses, si l'on en excepte les évènements de 1830-31, où les Hollandais mirent volontairement sous l'eau 3.300 hectares de polders situés en faco d'Anvers, datent de 1808 et de 1825. Celle du 14-15 janvier 1808 fit surtout des dégâts le long de la Flandre zélandaise; certains polders autour de Philippine ne furent réendigués qu'en $1811^{2}$. Cello de fèvrier 1825 fut moins grave : cependant on vit trois polders submergés près d'Axel, les communes de Bornhem, Hingene et Weert, riveraines de l'Escaut, englouties, la ville d'Ostende envahie. Depuis, ce ne sont plus que des accidents sans gravité, affectant un territoire restreint: lo Thomaespolder, sur la côte d'Hoofdplaat, inondé il y a 11 ans, et reconquis seulement en partie; les lames bondissant, par gros vents du Nord-Ouest, jusque dans les rues basses de Nieuport, ou envoyant quelques paquets d'eau de mer par-dessus la digue de Sangatte. La sécurité actuelle semble donc bien justifiée. Que l'on continue à entretenir soigneusement les beaux ouvrages qui défondent la côte, et les habitants de la plaine pourront légitimement rèserver toute leur attention à la lutte contre les caux intéricures, ennemi moins brutal mais plus dangereux de la prospéritè de leur sol.

1 Guichardin, Traduction française de 1625 (Amsterdam, Jansson, 1625), p. 326.

2 Sur l'inondation de 1808, voir : Arch. Nat. A F IV 1052, rapport du ministre d'Etat Crétet et des préfets de la Lys et de l'Escaut; F14 1122 et 1123; les dégâts pour le département de l'Escaut sont évalués à 1.455 .500 franes; - De Kauter (J.), Natuur-en Geschied-kundige beschrijving van den watervloed tusschen den 14 en 15 Januarij 1808 (Middelburg, Abrahams, 1808, in-8 118 p.). 
II.

LUTTE CONTRE LES EAUX INTÉRIEURES.

Comment se débarrasser de ces eaux qui descendent des hauteurs vers la plaine, et s'y mêlent à celles que des pluies fréquentes dérersent sur le pays? Le sol est plat, il n'y a pas de vallées où elles puissent so concentrer, toute la plaine n'est qu'une immense vallée. Ia première tâche était de canaliser le fléau, creuser d'innombrables fossés d'écoulement, frayer un lit endigué aux rivières, et prolonger toutes ces artères jusqu'aux endroits où s'interrompt la ligne de dunes, c'est-à-dire aux anciens estuaires, naturels ou artificiels. Mais là se rencontrait une grave difficulié: par ces ouvertures, la mer allait envahir le pays bas à marée haute. Il fallait donc établir là des portes qui empêcheraient la haute mer d'entrer dans la plaine, et s'ouvriraient à marée descendante pour laisser passer le trop-plein amassé derrière elles. Canaux de dessèchement et écluses de mer, c'est là le principe de l'évacuation des eaux intérieures.

La plupart des fossés étaient à l'urigine des rigoles naturelles, qui s'étaient creusées et allongées à mesure que la plaine s'asséchait, et que la mer se retirait daus des estuaires saus cesse rétrécis. Co n'est que lorsqu'on voulut mettre le sol en culture, et passer de l'élevage des moutons sur les schorres à l'agriculture sédentaire, que les hommes commencèrent à perfectionner le dessèchement, à creuser des watergands artificiels et à approfondir les anciens « kreeks ». Mais aucun propriétaire, sauf ceux dont les terres touchaient à l'écluse, ne pouvait évacuer sans l'assistance ou l'agrément d'autrui les eaux surabondantes de son exploitation. Il lui fallait les faire passer par les domaines de ses voisins, qui pouvaient refuser de laisser pénétrer sur leurs terres ce nouvel afflux, lorsqu'ils avaient déjà de la peine à assécher leur propre sol. Impossible donc d'aller aboulir à la lointaine écluse du rivage. Et d"ailleurs, ne fallait-il pas à l'écluse, en permanence, quelqu'un qui jugeât s'il fallait l'ouvrir ou la fermer, si les terres étaient ou non trop humectées ? Livré à lui-mêrne, le paysan de la plaine était donc impuissant à se débarrasser do ses eaux. Mais associé à ceux qui l'entourent, participant à l'entretien de fossés de grande ouverture où aboutiraient ses watergands, aidant à la construction de l'écluse par laquelle l'eau de ses terres gagnera la mer, contribuant au salaire de l'éclusier chargé de la delicate manouvre, il peut assécher son sol. L'association est la seule forme possible de la lutte contre les eaux dans la plaine. Cette association, c'est la Wateringue. 
Aussi les Wateringues sont-elles aussi vieilles quo l'émersion de la plaine maritime. Ce sont probablement à l'origine des associations privées sur lesquelles ne s'étend pas le contrôle de l'Etat. Le nom même du dyckgruaf, l'administrateur ẻlu par les associés, pour dirigor l'assèchement, indique l'antiquité de l'institution ${ }^{1}$. Mais au XII ${ }^{\mathrm{e}}$ siècle, elles apparaissent déjà comme constituées sous l'autorité du comte, qui surveille leurs travaux; la vénérable charte de Philippe d'Alsace de 1181 établit les moines des Dunes gardiens (custodia) de la grande écluse du métier de Furnes et décide qu'en cas d'accident elle sera reconstruite à frais communs ${ }^{2}$. Au siècle suivant apparaît lo nom de wateringue; mais la charte accordée en 1239 au syndicat de l'Oude Yevene prouve que l'institution existait depuis longtemps déjà. A la mêıe époque d'autres textes nous parlent de la wateringue des Quatre digues du métier de Bergues, de celle du Brouck à Capelle-brouck, de celle de Furnes ${ }^{3}$.

\section{Organisation des Wateringues.}

L'administration de ces syndicats s'inspirait des mêmes principes. Ello comportait l'Assemblée, corps délibẻrant formé de grands propriétaires, et une commission exécutive qui dirigeait les travaux. La composition de l'Assemblée variait suivant les circonscriptions. Dans la grande wateringue de Blankenberghe étaient membres les propriétaires d'au moins 50 mesures; il en faut 36 seulement dans la wateringue de Terneuzen. Ia wateringue du Nord de Furnes n'a en réalité comme assemblée délibérante que les quatre abbés du Furnambacht, représentant les quatre grands membres de l'association. La commission exéculive est formée des échevins et bailli de chaque localité ; à Bergues, d Bourbourg, quelques membres du Magistrat de ces villes ; dans l'Oude Yevene, les échevins d'Oostbing; dans la Blankenberghe-Watering, quatre sluysmeesters, dont un chanoine de St-Donat, un membre du Magistrat de Bruges, deux propriétaires du Franc. C'est cette commission qui nomme les fonctionnaires techniques, watergraves ou dijkgraves, chargés de la

1 M. Pirenne fait remarquer (Histoire de Belgique, I, p. 137, note 1) que tous les magistrats auxquels le mot graaf a été appliqué dams les Pays-Bas, hansgraaf, watergraaf, sont d'origine fort ancienne.

2 Van de Putte, Dunes, p. 166, n० 227.

3 Ci. Van Lokeren, St-Pierre, I, pp. 268-69, n 542;-But, Chronica abbatum de Dunis, pp. 114-115;-Coussemaker, Documents extraits du cartulaire de l'abbaye de Watten, Ann. Com. fi. Fr., V, pp. 310-311;- Coussemaker, Bourbourg, I, p. 136, n CXLVII. 
police ou de la visite journalière des ouvrages ; receveurs, chargés de recueillir les cotisations. Mais la commission, pour engager des travaux nouveaux ou faire modifier les taxes, doit en référer à l'assemblée délihérante, qui sẹ réunit d'ailleurs régulièrement chaque année. Enfin pour assurer l'unité de vues et d'exécution, le comte délègue ses pouvoirs à un haut fonctionnaire, le Watergrave de Flandre, qui resta du XIII ${ }^{\circ}$ au XVIII ${ }^{\circ}$ siècles chargé de l'inspection des digues et des canaux, de l'administration des moeres of des terrains vagues ${ }^{1}$. Ainsi la commission exécutive dirige les fonctionnaires, lève ot emploie les fonds, entretient les ouvrages; l'assemblée délibérante contrôle au moins une fois l'an, dócide des transformations, défend auprès des fonctionnaires les droits de chaque partie du pays wateringué, et répartit la taxe au prorata des difficultés de l'assèchement; le Watergrave règle les conflits entre syndicats, éveille l'attention des intéressẻs sur les travaux à effectuer, el au besoin fait procéder lui-même à ces travaux aux frais des associations nègligentes.

L'excellence du systéme n'avait pas besoin d'être démontrée; les faits suffisaient à indiquer quels beureux résultats avaient donnés pour la mise en valeur de la plaine ces associations travaillant chacune pour elle-même sous les conseils et la surveillance de l'Etat. Cependant la Révolution, dans son désir de faire disparaitre les anciennes exceptions, supprima ces utiles organismes. Dans le district de Bergues, devenu arrondissement de Dunkerque, une décision de l'administration départementale, de décembre 1790, et une délibération du Conseil général en date du 28 février 1793 établirent que les « wateringues étant dépendances du domaine public seront comprises pour les entretiens, réparations et reconstructions 'qui les concernent, dans les objets à la charge du département et de la Républiquo »; leurs dettes étaient incorporées à celles de la nation. Cette centralisation avait de graves défauls: l'impôt-wateringue allait peser désormais sur des gens qui n'en tireraient aucun bénéfice; en revanche les travaux à exécuter seraient entrepris sans l'avis des intéressés ${ }^{2}$. Les résultats furent en effet si pitoyables que dés 1801

1 Voir à ce sujet: la charte de 1282, purtant règlement de la wateringue d'Eyensluis, dans le Frane de Bruges (Van de Putte, Dunes, pp. 628-629); - Sanders (E.), La grande Wateringue de Blankenberghe (la Fl., XV, 1884, pp. 71-76); - Dalloz, article Wattringues, p. 1354; - Proost (J.), Le Watergrave de Flandre (Ann. Soc. Eu. Br., $3^{\circ}$ série, VII, 1872, pp. 217-2̌i6).

2 Desgraviers, Administration des Wateringues; caractères généraux et historiques. (1900, 19 pages manuscrites communiquées par M. le Président de la $2^{\text {a section des }}$ Wateringues du Nord). 
le préfet Dieudonné entreprenait la réorganisation du régime des Wateringues, en déclurant qu'il se rapprocherait autant que possible du règlement d'avant la Révolution, dont le bon état où se trouvait alors le dessèchement justifiait l'efficacitó ${ }^{1}$. Bientôt lo gouvernement impérial s'occupait à son tour à consacrer la réapparition des Wateringues; les décrets du 12 juillet 1806 pour le Nord, du 28 mai 1809 pour lo Pas-deCalais, complétés par les ordonnances et décrets de 1833, 1837, 1852 et 1890 ont définitivement réglẻ l'état de ces associations. Comme ił fallait s'y attendre dans la France du XIX siècle, le régime d'avant 1789 n'est reparu que modifié par un contrôle plus rigoureux de l'Etat et par quelques concessions aux idées démocratiques. Les anciennes divisions ont été refondues en dix sections, dont le territoire est plus homogène. Chaque section comprend une assemblée générale des propriétaires de la wateringue, qui, sous la présidence du sous-préfet, élit une commission administrative, comprenant cinq membres dans chacune des quatre sections du Nord, huit dans les six sections du Pas-de-Calais ${ }^{2}$. C'est cette Commission, choisie parmi les membres les plus imposés, qui administre la Wateringue, dresse des projets de travaux, passe les adjudications, vote le budget, répartil les taxes, choisit et surveille les agents. Ce sont là dos pouvoirs très étendus; mais ici intervient le contrôle de l'Etat. Les délibérations ne sont exécutoires qu'après approbation du préfet, sur avis du sous-préfet; les travaux sont placés sous la haute surveillance des ingénieurs d'arrondissement et de département; et le Conseil de Préfecture vérifie les budgets des exercices écoulés. C'est encore après avis du prefet que la Commission peut nommer ses agents, lo Conducleur qui rédige les plans des travaux et en assure l'exẻcution, le Recevenr qui recouvre les taxes et paie les dépenses, les agents infóricurs qui surveillent les ouvrages et constatent les contraventions. Le système fonctionne d'ailleur's fort convenablement, comme le prouvent l'absence de réclamations et les améliorations immenses que les Syndicats français ont pu réaliser dans la slaine au XIX ${ }^{\mathrm{e}}$ siècle.

Les Wateringues du territoire belge n'ont pas subi aussi fortement que leurs voisines de l'Ouest le contre-coup de la Révolution française. Le décret du 22 septembre 1792, rendu par la Convention, et ordonnant l'exécution provisoire des lois non abrogées et le maintien provisoire des

1 Dieudonné, Statistique du département du Nord (Douai, an XII, 3 vol. in $-8^{\circ}$ ), I, p. 326 .

2 Le département du Pas-de-Calais comprend en réalité 8 sections, dont deux en dehors de la plaine maritime flamande. 
autorités, publié de nouveau par le Directoire en pluviôse an V, laissa les organisations antérieures continuer leurs travaux. Aussi le territoire est-jl resté divisẻ comme autrefois entre un très grand nombre de syndicảts, quî se chargent d'assécher des étendues très diverses; on n'a pas crób, comme en France, de nouvelles circonscriptions de superficie à peu prés équivalente. Tandis que la Wateringue du Nord de Furnes s'étend sur 23.437 hectares, celle de Blankenberghe sur 17.069, on trouve des associations dont le ressort s'étend, comme colle de Stampershoucke, sur 316 hectares, et celle deVolkaerts-Gote sur 333. La province de Flandre Occidentale à elle seule possède dans la plaine maritime 30 wateringues. Les règlements sont aussi variés que l'étendue. Les unes ont gardé la forme d'avant 1789, approuvée sous le régime français par des arrêtés préfectoraux: on y retrouve donc l'assemblée délibérante, les administrateurs élus qui ont gardè les vieux titres de dycscepenen ou de dykgraven, enfin les échevins locaux qui assurent l'unité d'action entre les diverses wateringues. Les autres, et en particulier les plus grandes, sont sous le régime de l'arrêté royal de 1847, qui a modifié la loi hollandaise do 1815 dans un sens plus libêral. L'assemblée générale se réunit en présence d'un délégué du gouverneur de la province; les bourgmestres, nommés par le Roi, en sont membres de droit. Ciest aussi le Roi qui nomme les membres de la direction, sur une liste triple présentée par l'assemblée. La députation permanente du Conseil provincial approuve chaque année le budget de la wateringue; son avis, et dans les cas importants l'autorisation royale, est. nécessaire pour l'exécution des travaux, sur lesquels l'ingénieur en chef exerce une haute surveillance. C'est le régime français, avec un peu moins de liberté pour le choix de la direction, un peu plus pour l'administration intérieure de la wateringue. Plusieurs arrêts, en particulier celui de la cour de Cassation du 8 mai 1891, étendent à toutes les wateringues le règlement de 1817; cependant la plupart s'en tiennent à l'ancien étal de choses. Peut-être cette diversité de réglements, et surtout l'émiettement du territoire en petites associations trop pauvres pour exécuter des travaux importants; sont-ils la cause de l'infériorité que l'on constate actuellement à l'égard des résultats obtenus en France, où les wateringues, non contentes de dessécher le micux possible leur territoire, ont encore largement contribué à la création d'un beau réseau de chemins vicinaux. On remarque d'ailleurs que c'est le territoire des plus grandes, Nord de Furnes, Blankenberghe, qui est aujourd'hui le mieux assaini de la partie belge de la plaine.

Le caractère des associations se modifie au delà du Zwin. C'est la partie du territoire où la lutte a étè le plus rude contre la mer; c'est encore là 
que les travaux de défense sont le plus considérables. I.a plaine y est divisée en polders enclos de digues; et ces digues peuvent encore être utiles, même celles qui sont situées en arrière, en cas de rupture des ouvrages de première ligne. A côté des intérêts particuliers de chaque polder, l'association locale a done encore à defendre de grands intérêts généraux. De là une intervention beaucoup plus active des pouvoirs publics, chargés de veiller à ces intérêts généraux. C'est pourquoi Napoléon avait nommé, en 1811, un maître des requêtes du Conseil d'Etat Directeur des Polders, en résidence à Anvers, pour assurer l'unité de vues dans les travaux de défense des départements de l'Escaut, de la Lys, des DeuxNèthes. Ce fonctionnaire disparut en 1814; mais l'Etat belge continue à surveiller de très près la gestion de ses polders, qui sont restés d'ailleur's sous le régime du décret de 1811. Dans la partie zélandaise, le rôle de surveillance est dévolu aux Etats provinciaux. Les rôles changent ; l'assemblée générale, dont l'importance est minime dans les wateringues belgos, devient ici le véritable pouvoir; cela tient à ce que la faible étendue de chaque polder restreint le nombre des membres, et que l'assemblée n'est guère qu'un comilé, parfois une seule persomne. La Direction n'a qu'un pouvoir exécutif, c'est un ministère devant une Chambre; elle comprend un dijkgraaf et deux jurés, nommés par le Roi quand le polder comprend des travaux de défense; ce sont de véritables fonctionnaires, rémunérés, ce qui s'explique par l'importance et le caractère absorbant de leurs fonctions. Les Ftats provinciaux se réservent le droit d'annuler toutes les décisions de l'Assemblée ou de la Direction, de connaître de toutes contestations, de surveiller les travaux de dëfense, de faire exécuter les règlements inobservés, sauf recours au Roi dans un délai de 15 jours. Enfin, en raison de leur situation qui les rend tous solidaires les uns des autres, ot fait dépendre le sort d'une vaste étendue de terres du bon entretien d'un petit nombre d'ouvrages, les polders sont tenus d'aider ceux d'entre eux qui succombent sous les dépenses nécessitées par certains travaux de défense. Le polder reconnu pour avoir, pendant plus de deux ans, consacré le revenu tolal de ses terres à l'entretien de ces travaux, est déclaré calamiteux; un subside est alors décrété et levé sur les autres polders de la circonscription, au prorata de la distance qui les sépare du polder en détresse. Les Etats provinciaux de Zélande et de Flandre Orientale ont, bien entendu, la haute main sur cette opération, expression la plus complète de la nécessité de l'association pour la lutte contre l'eau dans la plaine. 
III.

CELVRE DES WATERINGUES.

L'œuvre accomplie par les associations dans la plaine maritime est immense. Elle ne s'est pas faite en un jour; depuis dix siècles les Wateringues y travaillent, et il reste encore à faire. Les guerres qui ont si cruellement frappé le pays, une fois au moins par siècle, avaient pour l'assèchement des résultats désastreux ; après chaque invasion, une bonne partie du travail était à recommencer. C'est pourquoi l'œuvre du $\mathrm{XlX}^{\theta}$ siècle, où la Flandr'e depuis 1815 n’a connu que la paix, a été si favorable au pays.

\section{Les rivières, Aa, Yser.}

La nécessité la plus pressante, c'était de se débarrasser des eaux que la Flandre intérieure, l'Artois, le Cambrésis et le Brabant envoyaient à la plaine. Tant qu'on ne les aurait pas conduites à la mer derrière une solide muraille de digues, il ne fallait pas songer à dessécher le pays. On a vu que l'Escaut fut de bonne heure enfer'mé dans son estuaire par les endiguements de la Flandre zélandaise. Le $Z$ win, de son côté, disparaissait plus vite qu'on n'aurait voulu. Restaient l'Yser et l'Aa. Ces petits fleuves, à leur entrée dans la plaine maritime, épanchaient leurs eaux en un delta. Outre son cours actuel entre Dixmude et Nieuwendamme, etabli sur l'emplacement de l'ancien estuaire, l'Yser envoyait vers l'Est un bras disparu aujourd'hui, mais dont l'existence n'est pas douteuse. Cet Yperleet, qui se détachait du fleuve en aval de Dixmude, devait snivre à peu près le même chemin que le canal actuel de Plasschendaele, car le nom d'Yperlect, plus ou moins défiguré, est encore attaché à un tortucux watergand qui s'allonge sur la rive Nord du canal entre Nieuwendamme et Snaeskerke. De là celte rivière gagnait Oudenbourg, où son existence est attestée par les nombreux textes réunis dans l'histoire d'Oudenbourg ${ }^{1}$, et rejoignait l'ancien Zwin à Bruges. De bonne heure des digues furent construites au long des deux rivières.

1 Feys, Oudenbourg, passim. C'est également l'opinion de Merchantius (Jacobi Marchantii Flandria descripta, p. 133); de Gramaye (Ipretum, p. 10), qui déclure que l'Yperleet apparticnt aux Yprois jusqu'à Bruges oi perdant son nom elle se jette dans la Reye; de Oudegherst (II, p. 515), etc. 


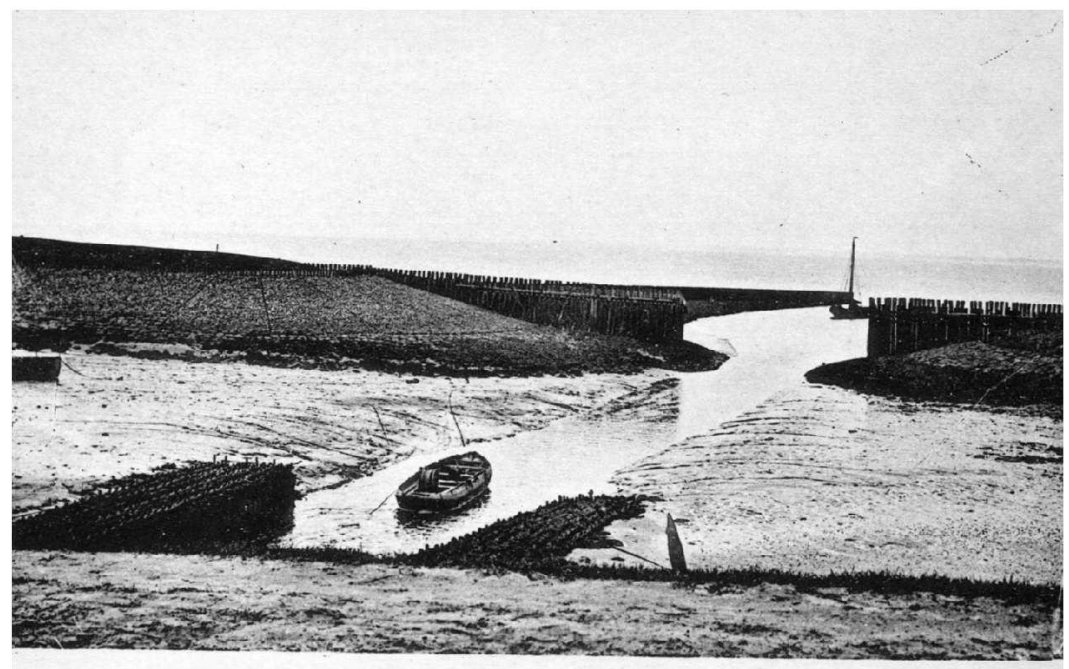

23. - Une écluse d'évacuation de Wateringue (Suatie-geul), à Groede.

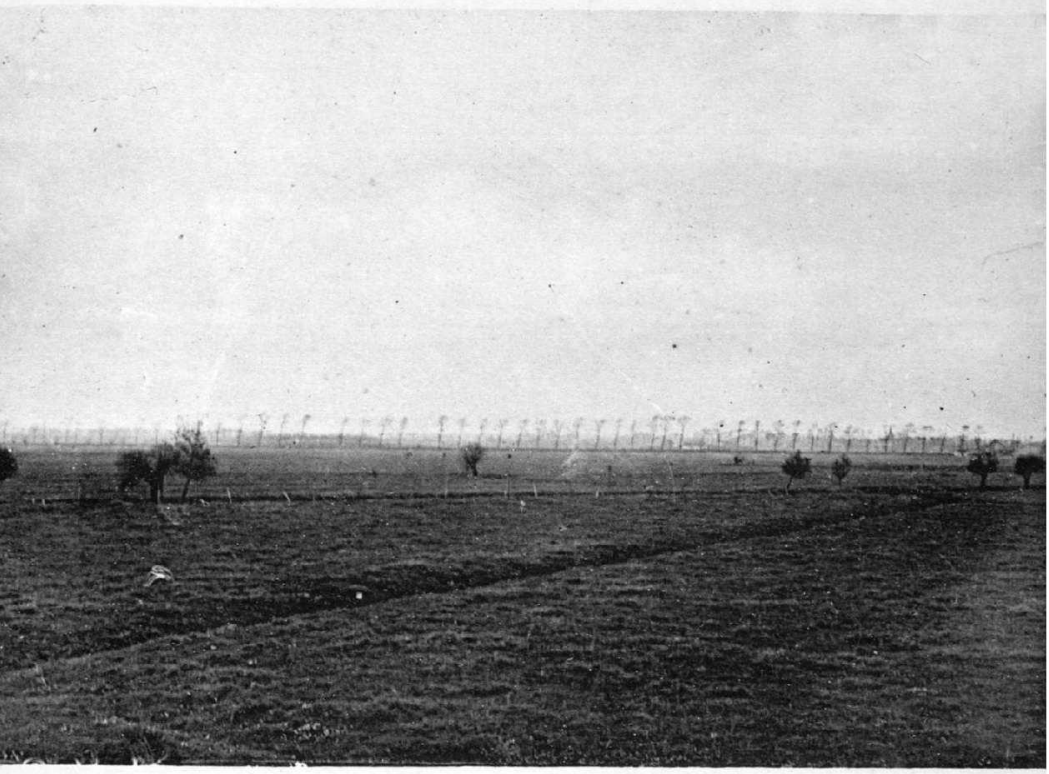

24. - Les terres basses de l'Yser: pàtures d'Eessen. 
IRIS - LILLIAD - Université Lille 1 
Plus abondant que l'Yser, l'Aa avait un delta plus compliqué. Dès l'endroit où la rivière pénètre dans la plaine par l'ouverture creusée entre les hauteurs de Watten, ses eaux se divisaient entre plusieurs branches. C'est, dít la chronique de Watten an $\mathrm{XI}^{\mathbf{e}}$ siècle, une eau profonde et navigable, qui gagne l'océan par nombre de petites embouchures ${ }^{1}$; et en 1172 une charte de Philippe d'Alsace désigne deux de ces cours d'eau sous les noms de «Columa » et de «Monsterleht » ${ }^{2}$. Le cours de ces branches du delta est encore visiblo aujourd'hui ; l'une, la Haute-Colme, est devenue un canal navigable; l'autre, ou Vieille-Colme, se détache de l'Aa après Holque, et gagne Dunkerque; sa partie inférieure est devenue le canal de Bourbourg au-delà de Coppenaxfort. Quant au cour's principal acluel, c'est un canal artificiel creusé au début du $\mathrm{XV}^{\mathrm{e}}$ siècle entre le Wetz près de Holque et les Hauts-Arbres, près de Gravelines. Jusque là, la rivière après Holque coulait vers Bourbourg par le lit actıel du Denna, et de Bourbourg gagnait Gravelines par St-Georges. De nombreux textes le prouvent, qui parlent, comme en 1347, de a l'eaue et ryvière qui va d'Arques à St-Omer, à Bourbourg et à Gravelingues » ${ }^{3}$; un acte de Louis de Luxembourg aux échevins do Bourbourg (1445) atteste l'importance qu'avait la ville avant les derniers troubles de Flandre, lorsque les navires y venaient « par la grande rivière qui descent de St-Omer àWaltenes et qui lors flonoit et prenoit chemin du dit wattenes en nostre ville de Bourbourcq... Et depuis icelles commotions la dite rivière ayt este empechée a venir comme elle solloit du dit wattenes en icelle nostre ville de Bourbourcq et a pris et prend a présent voye et cours par autre marche» Une note pour le magistrat de Gravelines indique que le changement est de $1402^{5}$, et que c'est le comte Philippe qui fit creuser le nouveau lit entre Holque et les Hauts-Arbres, d'où les eaux gagnaiont la mer en empruntant le cours inferieur de la Hem. D'ailleurs les paroisses du pays de Langle, commo $\mathrm{S}^{\mathrm{e}}$-Marie-Kerque, que la nouvelle rivière vinl séparer de la châtellenie de Bourbourg, en faisaient encore partie au XIH ${ }^{e}$ siècle ${ }^{6}$. Une carte de Picardie et Artois par Samson d'Abbeville (1651) indique

1 M.G.S.S. XIV, p. 164.

2 Coussemaker, Documents sur Watten, p. 18.

3 Textes dans Haigneré, St-Bertin : do 1163 (I, p. 108, $\mathbf{n}^{\circ}$ 238); de 1200 (I, p. 188, $\mathrm{n}^{\circ}$ 434); de 1202 (I, p. 201, n० 458); de 1347 (II, p. 325, n 1619).

4 Copie aux $\Lambda$ rchives du Nord, C. (Fl. Mar.), liasse 46.

s Arch. Nord, C. (Fl. Mar.), 60.

61224 : S. Mariæ ecclesia in terra Broburgensi (Haigneré, St-Bertin, I, p. 286, n 656). 
encore le vieux cours de l'Aa par Bourbourg, et de nos jours un watergand à Quathove près Bourbourg garde le nom de Oude Aa. Ainsi il n'y a pas de doute que le cours de l'Aa ait été artificiellement déplacé vers l'Ouest.

Les crues de ces petites rivières peuvent être un fléau pour la plaine que leurs bras parcourent dans toutes les directions. En effet elles ont exhaussé leur lit par le dépôt d'alluvions, et ont le niveau habituel de leurs eaux au-dessus du niveau de la plaine. LAa en particulier coule à l'endroit le plus élevé du sol. De là, aux siècles précédents, des inondations incessantes par-dessus les digues insuffisantes. Le pays de Langle, comprenant les quatre paroisses de $\mathrm{S}^{\mathrm{e}}$-Marie-Kerque, StNicolas, St-Folquin, St-Omer-Capelle, situées sur la rive gauche do la rivière, souffrit particulièrement de ces dẻsastres. Lorsque le débit de l'Aa, renforcé des eaux de la Hem, atteignait comme en novembre 1894 une somme de $100^{m_{3}}$ par seconde, tout le pays de Langle était sous l'eau. De 1640 a 1680 , ce canton reste à peu près constamment inondé, faute d'entretien de l'Aa maritime, délaissé par les gens de St-Omer qui avaient charge jusque là de le curer et se souciaient peu de la sécurité d'un pays devenu français ${ }^{1}$. Abrités derrière une bonne digue, les gens de Bourbourg ćvitaient le désastre et refusaient à chaque inondation de laisser écouler une goutte par la Colme ou le sas du Guindal 2. Aussi tous les hivers le pays de Langle disparaissait-il sous l'eau, et ceux de Bourbourg devaient monter la garde à leurs écluses pour empêcher leurs voisins, désespérés, de venir les ouvrir. En 173̄, l'inondation dure jusqu'en mai et coûte 32.000 livres aux quatre paroisses ${ }^{3}$. En janvier 1737, « les habitants du pays de Langle ne peuvent même sortir de chez eux qu'en bateau, et pendant ce temps les habilants de la Flandre qui ne sont séparés que par la rivière de l'Aa sont à sec et voient leurs terres annoncer une riche récolte » ". Il en fut ainsi jusqu’à la fin du XVIII" siècle, où l'on refit là digue de l'Aa et où l'on améliora ses débouchés à la mer. Sur l'Yser, la situation était là même; là rive gauche, protégée par une forte digue, restant indemne pendant que la rive droite était inondée aux moindres crues.

1 Arch. Pas-de-Calais, G. 305, piece 20.

2 Arch. Pas-de-Calais, C. 305, pièce 69. En 1678, 1698, 1703, 1726, 1735, le Magistrat de Bourhourg rofuse énergiquement d'ouvrir ses écluses pour soulager le pays de Langle.

3 Inondations de 1730 et 1735 : Arch. Pas-de-Calais, G. 282 et 305 ; Arch. Nord. C. (kl. Mar.), 1 et 16.

* Arch. Pas-de-Galais, C. 421, pièce 12 (lettre du maieur de St-Omer). 
Cependant ces eaux étrangères, si nuisibles l'hiver, sont pendant l'ótó un bienfait pour le pays. Lorsque les pluies deviennent rares, les eaux baissent dans les watergands, dont la multiplicité offre une surface d'évaporation considérable. Il en résulte de graves inconvénients. Les eaux douces, qui ne s'écoulent plus vers la mer', se corronpent au contact de la tourbe du sous-sol ; parfois même, elles viennent à manquer pour l'alimentation des bestiaux et des hommes. Enfin si la couche d'eau douce entretenue par les infiltrations des watergands dans la partio supérieure du sol vient à diminuer, les eaux saumâtres qui imprègnent les sables pissarts remontent vers la surface, et viennent frapper le sol végétal de stérilité. C'est alors qu'on a recours aux eaux des rivières, pour alimenter les fossés et y maintenir un léger courant. On saigne l'Aa et l'Yser. L'Aa surtout, à cause du niveau élevè où coulent ses eaux, est bien placé pour être mis à contribution. « Cette bonne rivière de l'Aa, dit avec enthousiasme l'auteur d'un consciencieux travail sur les eaux de l'arrondissement de Dunkerque, est un trésor pour le pays qu'elle traverse; toutes les populations le réclament à l'envi; il fertilise les campagnes, donne la santé aux habitants, et produit le bonheur et l'abondance chez l'agriculteur $\gg$. Cependant l'Aa lui-même est bien pauvre pendant l'été et son étiage peut descendre à 1.800 litres par seconde ; son niveau s'abaisse alors, et on est obligé de rationner les wateringues, en ne leur fournissant plus de l'eau douce que certains jours de la semaine. Aujourd'hui où les débouchés à la mer sont suffisants, où les lits des rivières sont soigneusement approfondis et entretenus, les inondations par les eaux intérieuros sont devenues rares, et peu dàngereuses; l'Aa et l'Yser ont cessé de faire du tort à la plaine maritime, et n'ont conservé à son égard que le rôle de bienfaiteurs.

\section{Canaux d'assèchement.}

Débarrassée des eaux étrangères, menées en droite ligne à la mor derrière leur rempart de digues, la plaine pouvait s'occuper des eaux de son propre sol, et c'élait déjá assez pour absorber l'activité de ses syndicats. Tandis que chaque particulier s'occupait d'aménager son propre champ en y creusant des fossés, à la Wateringue revenait la tâche d'établir des watergands larges ot profonds, d'en consolider les bords et d'en entretenir

1 Durand, Mémoirc pour faire connaitre le règime des eaux de Dunkerque (Uunkerque, Maillard, 1860 , in- $\left.8^{\circ}\right)$, p. 3. 
Ies dimensions; de placer des vannes et des éclusettes a la jonction des canaux secondaires avec les artères principales ; de construire des écluses de mer; enfin de veiller à la manœuvre de cet outillage. On utilisa d'abord pour le dessèchement les anciennes rivières, bras secondaires de l'Yser ou de l'Aa, dont quelques-uns sont encore reconnaissables à leurs sinuosités, caractère qui n'existe pas dans les rigoles artificielles. Il suffisait d’établir des vannes au débouché des watergands secondaires pour avoir un système complet d'assèchement. Mais ces canaux tortueux ne laissaient écouler l'eau qu'avec une lenteur désespérante; l'entretien de leurs sinuosités était inutile et coûtenx. On s'arrangea alors pour faire aboutir les canaux de wateringues dans les quelques grandes artères du pays, qui étaiont on même temps des voies navigables: canal de Watten à Calais, Aa, canaux de Bourbourg, de Bergues et de la Colme, de Dunkerque à Nieuport, de Loo, Yser, canaux de Plasschendaele, d'Ostende à Bruges. Cette transformation s'accomplit au XVII é siècle et fut d'abord favorable au dessèchement, qui disposa ainsi de voies plus directes, plus larges, régulièrement entretenues.

Cependant, à mesure que la navigation se développait, et que le tirant d'eau des bateaux devenait plus considérable, des conflits se produisaient entre le service des voies navigables et celui des Wateringues. Qu'une crue se produisît, et il fallait ouvrir toutes grandes les écluses à la mer, opérer des tirages á pleine voie dans les canaux principaux pour pouvoir abaisser le plan d'eau de tous les watergands. Il en résultait, dans ces grands canaux, des courants violents et une diminution de profondeur qui arrêtaient la navigation ef causaient même aux bateaux de graves dégâts. Faire cesser ces inconvénients devint la règle des grands travaux accomplis par l'Etat et les Wateringues aux XVIII ${ }^{e}$ et XIX ${ }^{e}$ siecles. Le but est de rendre indépendants l'un de l'autre les systèmes de navigation et de dessèchement. Ce sont donc des kilomètres de nouveaux watergands à creuser ou à approprier, avec lesquels les riviéres et les canaux ne communiquent plus que par des vannes, qu'on ouvre l'été pour se procurer de l'eau douce. Les grandes artères de dessèchement ont pu être établies ainsi au milieu du canton qu'elles sont chargées de drainer, le Langhe-gracht dans l'axe de la $2^{\mathrm{e}}$ section des Wateringues du Nord, le Schelvliet à l'endroit le. plus favorable de la $1^{\mathrm{re}}$, la Noord-Eede an milieu de la Wateringue de Blankenberghe. La plupart des régions ont maintenant lour canal d'évacuation, distinct des voies navigahles: généralement un watergand sans ombrage, large de 5 d 10 métres, et où coule une eau brune sur laquelle flottent des débris de plantes. Le Calaisis a le canal des Pierrettes, la rivière d'Oye et le canal de Marck; les sections du.département du Nord 
ont le Schelvliet, le Langhe-gracht et le canal des Moëres, Furnes lo Koolhofvaart, Ostende le Camerlinckx et la Noord-Eede, Blankenberghe son canal et Heyst le canal Léopold, Sluis la rigole d'évacuation dı Zwin, Calloo le Melkader. Lorsqu'ils rencontrent un grand canal navigable, ces watergands passent dessous, en siphon, ou à travers, par une ćcluse carrée: c'est par une écluse carrée que le Vinfil traverse le canal de Guînes, et par un siphon que le canal Léopold et le grand canal de dérivation de la Lys franchissent la voie navigable qui va de Sluis à Bruges. Ce double réseau, délicat et compliqué, fait songer á l'appareil circulataire du corps humain; des rivières el des canaux de navigation l'eau pure s'écoule, vannes levées, dans l'innombrable réseau capillaire des watergands, qui la ramenent, utilisẻe et impure, aux grosses veines des canaux de dessèchement; et coux-ci vont gagner la mer eu se glissant à travers les mailles du réseau navigable, de même que dans le corps de l'homme les vaisseaux artériels ot veineux vont parfois se che-

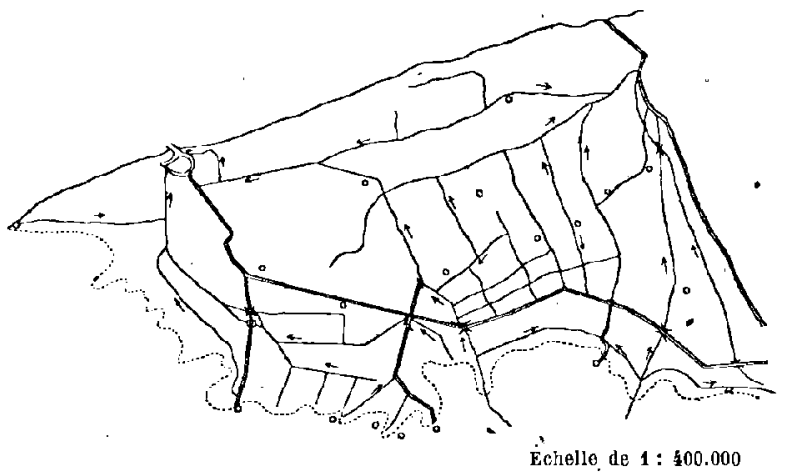

FIǴ. 54. - Réseau d'éyacuation du Calaisis.

\begin{tabular}{l|l}
$=$ Canal navigable. & $\Varangle$ Siphon. \\
- Watergand d'évacuation & $1=$ Barrage.
\end{tabular} 由 Écluse carré.

vauchant l'un l'autre. Mais le plus singulier est l'étonnante facilité avec laquelle on fait changer la pente d'un watergand, et comment de son extrémité on fait sa tête. La rivière d'Oye a eu son écoulement jusqu'en 1680 vers Gravelines; à cette dato on en dirige' les eaux vers Calais ; à la fin du XVIII ${ }^{\mathrm{e}}$ siècle, on en ramène la moitié vers Gravelines, et aujourd'hui l'ancienne pente est sur le poinl d'être roconstituée. Les canaux coulent indifféremment vers l'Lst ou vers l'Ouest; il suffit d'un bâtardeau bien placé et d'un faucardement bien fait pour déplacer la pente, tant celle-ci est peu considérable.

Enfin l'établissement de canaux de wateringues distincts des voies navigables entrainait la construction d'ècluses spécialos dans les ports. Cette transformation a coïncide, dans les ports français, avec la disparition des bassins de chasse, et c'est aux eaux de dessèchement qu'on a confié l'ancien rôle des chasses devenu secondaire grâce aux dragues. Pour 
désencombrer le port, c'est en utilisant les fossés des fortifications qu'on a résolu, à Calais et à Dunkerque, la question de l'évacuation. De même à Terneuzen. A Blankenberghe, c'est dans le petit bassin de retenue que débouche le canal de la Wateringue. A Ostende, lo Camerlinckx a les honneur's d'un tunnel voûté qui l'amène à travers les installations dans la souille de l'avant-port. Mais c'est à Nicuport que le jeu d'écluses est le plus compliqué et le plus curieux. Six pertuis sont rangés en demi-cercle an fond du bassin d'échouage; trois écluses de wateringues alternent avec trois écluses de navigation. Les vannes des écluses de wateringues dominées par un haut tablier de manouvre, les sas, à réservoir accolé, des écluses de navigation, l'appareil des crics, des leviers, du réseau tẻlégraphique aboutissant au bureau des écluses, donnent une singulière impression de complexité savante, qui s'accrô̂t lorsqu'on s'aperçoit que les niveaux de tous ces canaux sont tenus à des altitudes différentes audessus du zéro: $4^{\mathrm{m}}$, 05 pour le canal de Plasschendaele, $3^{\mathrm{m}}, 25$ pour l'Yser, $2^{\mathrm{m}}, 54$ pour le Koolhofvaart, $2^{\mathrm{m}}, 39$ pour la crique de Nieuwendamme, hauteurs correspondant an niveau du sol desservi par ces artères, et dont les diffërences sont d'une importance capitale pour le bon fonctionnement de l'ensemble. Nulle part on ne voit aussi bien quelles précautions il faut prendre pour que l'œuvre du desséchement soit efficace.

\section{IV.}

\section{RÉSULTATS DE LASSÉGHEMENT.}

Les difficultés du dessèchement sont très variables dans la plaine. Il y a des parties hautes et d'autres basses; l'éloignement de la mer, la proximité des collines du Houtland d'où ruissellent des quantités d'eau considerables, sont des facteurs importants. Aussi la cotisation perçue par le Syndicat pour établir son budget, l'impôt-wateringue, comme on l'appelle, varie-t-elle avec le terrain : la Wateringue do Mocre in Mcetkerke percevait en 18985 fr. 50 par hectare, étant donné la situation et l'altitude du territoire asséché, dont il faut élever les eaux au moyen d'une machine à vapeur et d'un moulin à vent; au contraire les terres à l'Est du canal Léopold (Oost-Waterschap van Leopoldsvaart), dont les terres sontélevées et proches de la mer, ne paient que 0 fr. 10 par hectare, et les terres de l'ancienne crique d'Ostende, Keygnaert, Polder Ste-Catherine, ne doivent aucune cotisation, la location des marais pour la pêche et la chasse aux oiseaux couvrant, et au-delá, tous les frais. Les terres situées au long de 
la côte sont les plus favorisées, car elles sont plus rapprochées de l'écluse d'évacuation, et sont toujours plus élevées. C'est le cas tout le long du rivage depuis Sangatte jusqu'd Breskens; tous les watergands s'y dirigent de la côte vers l'intéricur, où les recueille un canal paralléle aux dunes: tels le canal de Marck et la riviére d'Oye, le Schelvliet et le canal de Bourbourg, le Langelis de Coxyde et l'Yper de Middelkerke.

\section{Le Calaisis.}

Au contraire, les ter'res basses se trouvent être en même temps les plus eloignées de la mer, par suite les plus proches des terres hautes du Houtland; elles reçoivent donc de l'eau en abondance, et ont les plus grandes difficultés à s'en débarrasser. Aussi nulle part le desséchement ne fut plus pénible et plus lent que le long de celte bordure du haut pays, ot particulierement dans le Calaisis, Ies marais de St-Omer et les Moëres franco-belges. Le Calaisis, de Ruminghem à Sangatte, resta longtemps après la disparition de l'estuaire une terre basse et noyée: une Wastine où les pâtres menaient l'été leurs troupeaux, d'après la chronique d'Andres; un marais, dit Lambert d'Ar'dres, rempli de grenouilles, crapauds, lézards et autres vermines immondes ${ }^{1}$. Les cartes de l'époque de IIenri VIII (au British Museum) montrent une ligne de marais ayant de l'eau en toute saison, qui se succèdent d'Audruicq à Nieulay, et un registre de la mairie de Calais indique qu'au milieu du XVII ${ }^{\mathrm{e}}$ siècle les terres basses sont couvertes d'eau pendant 9 mois de l'année ${ }^{2}$. Le terrain était si bas, et les canaux tellement de niveau avec le sol, que par vent d'Ouest et pluie légère les eaux du canal d'Hennuin, refoulées par la brise, inondaient les terres de Guemps, Offekerque, Vieille et Nouvelle-Eglise, tandis que par vent d'Est et grosse pluie il n'y avait pas de submersion à craindre. Ainsi le Calaisis n'avait rien à envier à son voisin le pays de Langle; tous deux étaient inondés à peu près régulièrement tous les hivers ${ }^{3}$, même au XVIII siècle. En décembre 1755 par exemple, toutes les terres sont submergées d'Hennuin à Coulogne, et a plutôt un lac qu'une campagne; sur la rive du côtẻ de Bredenarde, la terre et la rivière ne sont plus qu'une mer, sans apparence de digues » ${ }^{4}$. La faute en est, celte fois, à la rivière

1 Lambert d'Ardres, éd. Godefroy, p. 241.

2 Registre aux enregistrements, 9 décembre 1667.

3 Voir Arch. Pas-de-Calais, C. liasses 150 à 160 .

- Ibid, C. 145, pièce 21 ; mémoire du maire do Calais à M. d'Argenson. 
de la Hem; d'autres fois c'est l'Aa dont les eaux se déversent par l'écluse d'Hennuin. Certaines terres sont si basses et pour les assócher l'été il faut ouvrir si fréquemment les écluses à la mer que les autres parties finissent par manquer d'eau ${ }^{1}$. Il n'y avait, au début du XVIII' siècle, que deux voies d'écoulement: le Vinfil, artère centrale du dessèchement, coulant de Vieille-Église à Nieulay, et le canal d'Hennuin à Calais. Un programme de travaux fut dressé en 1737, pour donner aux terres du Nord un écoulement par le canal de Marck; dans la seule année 1738 il en coûta, 292.000 liv. au Calaisis ${ }^{2}$; un programme plus vaste encore fut élaboré en 1745 ; mais ni l'un ni l'autre ne furent terminés. Le Calaisis traîna encore plus de 30 ans une misérable existence, jusqu'à ce que fussent ébauchés, en 1778, de grands travaux qui commencèrent à rendre le système d'asséchement indépendant des voies navigables ${ }^{3}$. Cependant il a fallu encore un siècle d'efforts pour mettre hors d'affaire tout le pays bas. Il n'y a guère qu'une douzaine d'années que les grands márais ont disparu, et il reste encore des parties noyées, celles où se creusaient jadis des tourbières. L'hiver, de novembre à janvier, on pouvait encore au début du $\mathrm{XIX}^{\circ}$ siècle voir tout le pays sous l'ear, de Coquelles à Guines, et les voyageurs qui prenaient la route de Paris s'embarquaient à Nieulay sur des bateaux plats qui venaient les déposer près de Fréthun, à la Tourelle; là commençait la vraie ronte de terre, s'élevant sur les flancs gris du Pays haut. Aujourd'hui les Wateringues projettent d'autres améliorations: approfondir la riviere d'Oye pour envoyer toutes les eaux du N.-E. vers Gravelines ; faire passer les eaux de la Bredenarde sous le canal de Calais pour les rejeter dans le canal de Marck. On a beaucoup travaillé dans le Calaisis, et il reste à faire encore. Les marais d'Ardres, de Guînes, avec les nappes blanches de leurs « clairs » qui brillent entre les rangées de saules, leurs carrés de terre noirâtre, leurs pâtures hérissées de roseaux et leurs petites maisons de paurres gens, représentent un grand progrès sur le pauvre pays noyé que vit Lambert d'Ardres, et les améliorations continuent: depuis 5 ans, le plan d'eau dos marais do Guines a été abaissé de $0^{\mathrm{m}}, 50$ et la plupart des terres s'en sont trouvées asséchées. Mais à cette tâche, les Wateringues s'épuisent et s'endettent. La $1^{\mathrm{e}}$ section du Pas-deCalais a déjà emprunté 100.000 franes; il lui en faut 50.000 autres. Les $2^{\circ}$,

1 Arch. Pas-de-Calais, C. 147, p. 108.

$z$ Pour los travaux de 1738 et 1745-16, voir Arch. Nat., $\mathrm{H}^{1} 48$ et $\mathrm{H}^{1} 647$.

3 Sur les grands travaux 1778-1788, voir Cordier de la Houssaye, Essai sur le mouvement des eaux dans le Calaisis, manuscrit de 1788 dans: Arch. Pas-de-Calais, C. 154 ; pièces dans C. 90 , C. 151 , etc. 


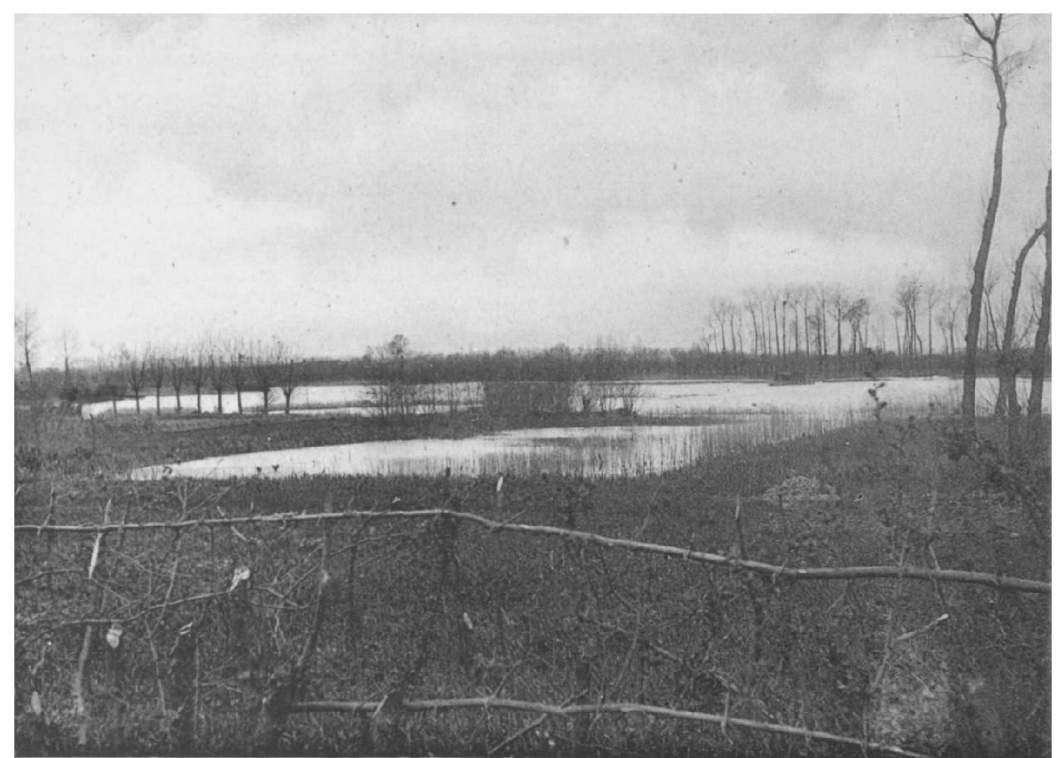

25. - Un clair (ancienne tourbière) dans les Marais d'Ardres.

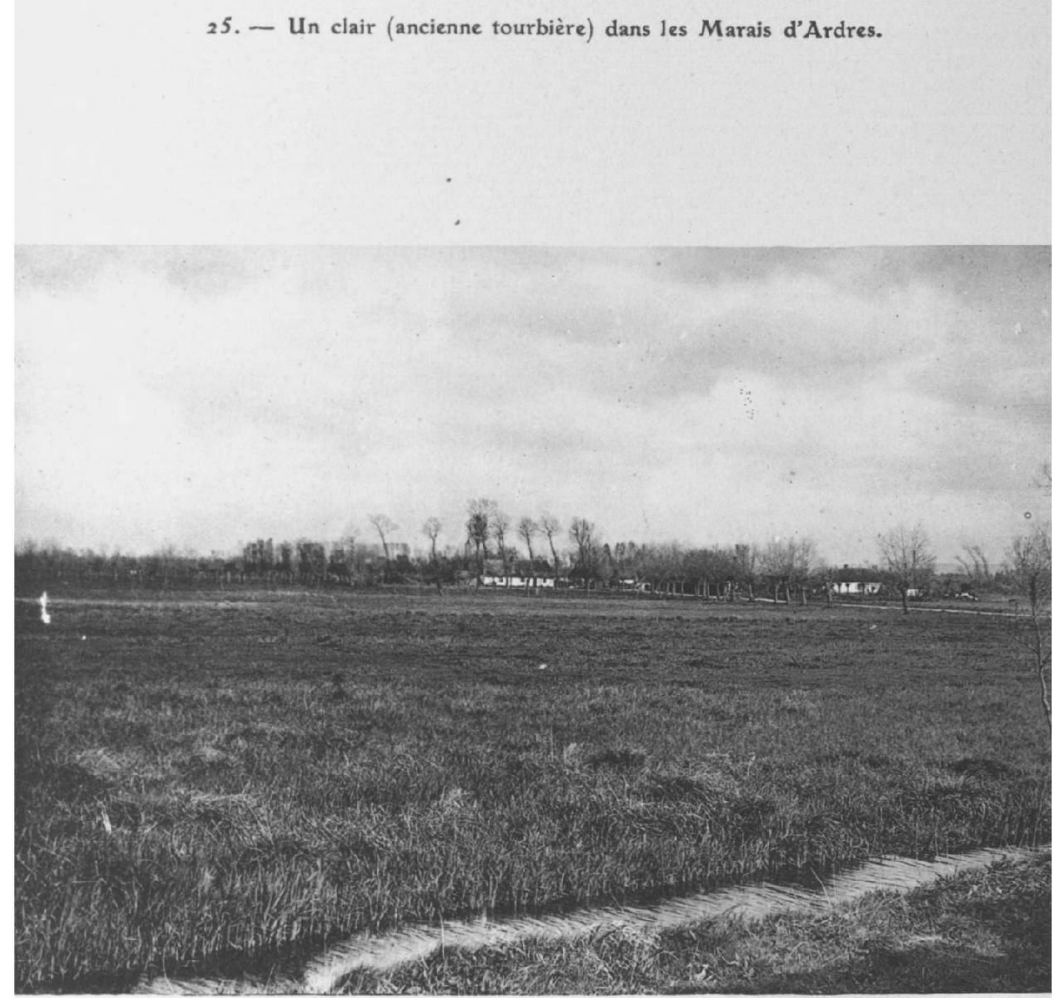

26. - Les terres basses: le Marais de Guînes. 
IRIS - LILLIAD - Université Lille 1 
$3^{\mathrm{e}}$ et $4^{\mathrm{\theta}}$ s'apprêtent den faire autant. Le dessèchement complet n'est pas encore termine dans cette partie de la plaine: peut-être même les amateurs de chasse voudront-ils conserver dans ce coin quelques marais autour d'une hutte.

\section{Marais de Saint-Omer.}

La nature arait fait des marais de St-Omer une région particulièrement difficile d dessécher. Ce territoire dont l'altitude, supérioure au niveau des hautes mers de morte eau, n'attoint pas celui des vives eaux, est entouré d'une ceinture de collines élevées qui lui envoient leurs eaux; de l'Artois sortent de grosses sources dont l'une, la Houlle, est une véritable rivière; l'Aa y débouche au Sud, et le brusque changement de pente qu'il y subit rend les inondations presque inévitables: enfin à toutes les eaux accumulées sur ces terres basses ne so présente qu'une ouverture large de 500 mètres, le passage de Watten, encore éloigné de la mer d'une vingtaine de kilométres. Le canton devint donc, lors de l'invasion marine, un vaste marais d'eau douce, «spatiosum stagnum » ${ }^{1}$, sur lequel St Bertin au VII ${ }^{\mathrm{e}}$ siècle abandonne sa nacelle, que les flots incertains poussèrent de St-Momelin vers St-Omer, c'est-à-dire vers l'amont. Cette étendue d'eau stagnante est devenue au XII siècle une terre basse, " palus $*$ ou «terra palustris ${ }^{\mathbf{2}}$; une charte de 1211 donne à la grande abbaye voisine les terres gagnèes sur l'Aa par le dessèchement, et celles qu'on pourra acquérir.par la suite ${ }^{3}$, ce qui supp̧ose une rivière très large et peu profonde. Ce u'est qu'au XVIII ${ }^{\mathrm{e}}$ siècle, par l'amélioration de l'Aa marilime, que l'on put dẻfinitivement assécher et livrer à la culture un sol jusque là réservé à la pêche et à la chasse. Les propriétaires de leur côté se mirent à exhausser leur sol par des remblais, et à creuser partout des fossés pour augmenter les facilités d'écoulement. Il en résulta, il est vrai, que les eaux descendirent beaucoup plus vite à la rivière, et que les imoudations s'en trouvèrent accrues. On n'osait pas, dans le Marais, faire de semailles d'hiver, une crue étant toujours possible, et ne pouvant être détournéo. Il a fallu, de 1875 à 1880 , exćcuter sur l'Aa inférieur des travaux qui, en doublant la section de son lit, permettent l'évacuation rapide des eaux supérieures; ce qui n'a pas empêché l'inondation de 1894 de recouvrir les marais d'un mètre d'eau. L'inconvénient de l'état actuel, e'est que l'émissaire des eaux surabondantes est en même

\footnotetext{
1 S. Audomari vita in Acta. SS. Boll. Sept. III, p. 409.

2 Haigneré, St-Bertin, I, pp. 117 à 216, passim.

3 Ibid., I, p. 225, n० 515.
} 
temps une grande voie navigable, et que des intérêts opposés se trouvent ainsi exposés à des conflits. Enfin l'été, la $\mathbf{7}^{\mathbf{B}}$ sectión des Wateringues du Pas-de-Calais, qui veille sur les marais de St-Omer, se trouve"en discussion avec les autres sections, qui saignent l'Aa à leur profit pour alimenter leur territoire ${ }^{1 .}$

\section{Les Moëres.}

L'asscèchement des Mö̈res est une ocuvre plus curicuse encore. Situés entre Bergues et Furnes, ces marais étaient le point le plus bas de la plaine maritime, puisque leur sol ne s'élève guère qu'à un mètre au-dessus des basses mers de vive eau. Aussi, lorsque toute la plaine était déjà cultivée, il restait lá une sorte de grand lac encombré de roseanx, étendu sur 4 à 5.000 hectares suivant les saisons, et accompagné à l'Ouest d'un plus petit. On y envoyait toutes les eaux d'alentour ; en revanche les Moëres causaient des fièvres à phusieurs lieues à la ronde. Fnfin en 1617 le hardi Cobergher, ingénieur des Archiducs, entreprit le dessèchement; il établit autour de la Moëre un canal de ceinture, (Ringsloot), beancoup plus élevé que le niveau du marais, et dont les digues arrêtèrent les eaux extérieures ; il mit ce canal en relation avec un bean watergand qui alla gagner la mer à Dunkerque, et disposa 20 moulins à vent, munis de vis d'Archiméde, à l'attaque des Moëres. Les eanx pompées par les moulins furent déversées dans le Ringsloot et de lá vers la mer; en quelques mois le sol était asséché (1624), coupé en reclangles égaux (cavols) par des canaux perpendiculaires, et cette terre vierge mise en exploitation. L'enthousiasme fut général.

Vingt-deux ans plus tard, toul élait à recommencer. Près d'être assiégé dans Dunkerque, le gouverneur espagnol marquis de Leyde voulut se défendre par des inondations : il fit ouvrir l'écluse de la Cunette, par où se vidait le canal des Moëres, et la haute mer, se précipitant par le passage, engloutit en quelques jours l'œuvre de Cobergher. Les deux lacs se reformèrent; il n'émergeait de l'eau que les débris de l'église, où des brigands ne tardèrent pas à s'établir comme sur un roc inaccessible. Pendant plus d'un siècle les Moëres continuèrent d’infester les contrées voisines. Ce fut un officier de la garnison de Bergues, le comte d'Hérouville, qui tenta de

1 Cf. Pas-de-Calais au XIX' siècle, IV, pp. 135-140, et II, pp. 629-637;- Bertin, Navigation intérieure, pp. 7-8; - [Deschamps de Pas] Septième section des Wateringues. Rapport de l'ingénieur ordinaire sur les diverses questions concernant le dessèchement du bassin de la 7 e section, et sa position relativement à la navigation (St-Omer, Guermonprez, 1868 , br. 46 p.). 
reprendre l'ouvre de Cobergher : en 1752, il obtint la concession royale, reconstruisit les canaux et moulins, assécha la Petite Moëre: il s'y ruina. De compagnie en concessionnaires, inondée en 1793 à propos de la guerre, la grande Moëre était encore en fort piteux état au début du XIX ${ }^{\theta}$ siècle: les anciens du pays de Bergues se rappelaient encore en 1840 le temps où dans la saison des pluies on pouvait monter en bateau à une demi-lieue de Bergues et voguer droit sur Furnes, à une distance de plus de 3 lieues et demie, sans être obligé de s'arrêter' ou de se détourner une senle fois ${ }^{1}$. Ce ne fut qu'après 1821 que les Moëres, jusque là entre les mains d'un Syndicat, furent mises en vente, partagées entre de nombreux propriótaires, el en 1826 que le dessèchement fut rendu définitif.

Depuis cette date, les Moëres sont restées hors des eaux, et les grandes pluies ne parviennent pas à en inonder le sol plus de 24 heures de suite. Celte terre, la plus basse de toute la plaine, en est peut-etre la mieux assẻchẻe. Aux grands moulins à vent installẻs par d'Hẻrouville, et qui portent les noms illustres des grands fleuves d'Europe, Rhin, Pô, 'Tage, Elbe, on a joint une machine à vapeur destinèe à supplèer les moulins en cas d'urgence et surtout au cas où le vent serait trop faible. Derrière la digue qui supporte le Ringsloot s'étendent les champs de terre grise, mêlés de quelques rares pâtures. Ce qui caractérise le paysage, ce sont les canaux intérieurs, avec leur bordure de saules en lignes inexorablement droites, tous perpendiculaires, le lriomphe du paysage géométrique. De loin en Ioin, quelques grosses fermes avec lcurs meules; au centre, un village très propre, où les maisons, entretenues avec un soin digne de la Hollande, sont peintes de toutes les couleurs de l'arc-en-ciel. Dans ce polder en pleine terre, tout pousse bien ; le fumier n'est pas nécessaire; la betterave y a plus de densité qu'ailleurs. Aussi la population augmente, et l'émigration vers les villes est inconnue.

Cette prospérité n'a pas été sans éveiller quelque jalousie chez des voisins que la nature avait mieux pourvus que les Moëres, et qui cependant sont moins avantagés aujourd'hui. Les Moëres sont constituées, pour le dessèchement, en une association spéciale indépendante de toute intervention administrative; cependant leurs eaux, pour gagner la mer, doivent traverser lo territoire de la $4^{\mathrm{e}}$ section des Wateringues, qui a fait du Canal des Moëres son artére principale de dessèchement. De bonne heure, la

1 Van de Wynckel, Précis historique et critique de l'administration des wateringues (Bergues, 1840, br. 35 p.), p. 17. - Sur les Moëres, consulter : Quarrẻ-Reybourbon (L.), Dessèchement des wateringues et des moëres dans l'arrondissement de Dunkerque (Lille, Quarré, 1893 , in $-8^{\circ}, 108$ p.) ; et aux Archives Nationales, cartons $\mathrm{N}^{13} 18$; T 256 ; $\mathrm{T} 120^{1} ; \mathrm{T} 182^{2} ; \mathrm{Q}^{1} 829$. 
$4^{\circ}$ section s'est plainte d'être encombrée des eaux des Moëres, qui empêchent ses propres eaux de s'écouler vers Dunkerque. Les Moëres excipent de la nécessitó de se débarrasser de leurs eaux, ce qui est pour elles une question de vie ou de mort. De là est né un procès, caractéristique de l'importance que la question de l'eau a encore dans la plaine maritime. Après des escarmouches en 1817 et 1834, la $4^{\mathrm{e}}$ section a pris résolument l'offensive depuis que la machine à vapeur, qui débite 40 mètres cubes à la minute, permet aux Moëres de se dẻbarrasser avec une grande rapiditê de leurs eaux surabondantes pour les envoyer passer chez les voisins. Le conflit a commencé en 1879, par une demande des Wateringues d'établir dans les canaux aboutissant au Ringsloot des repères que les eaux évacuées des Moëres ne devront jamais dépasser: il dure encore à l'heure qu'il est. Nous ne sommes plus au temps oú, pour débarrasser le pays de Langle de l'inondation, la maréchaussée d'Artois venait elle-même détruire le bâtardeau du Houlet, ou faire ouvrir de force l'ècluse d'Hennuin, sans se soucier de noyer le Calaisis ${ }^{1}$; mais pour être strictement légale, la lutte n'en est pas moins âpre: tribunal civil de Dunkerque, cour d'appel de Douai, conseil de Préfecture, conseil d'Etat, tribunal des Conflits, el de nouveau la cour de Douai, se sont vus saisir de l'affaire par deux parties qui montrent un égal acharnement, et n'ont pas désarmé encore ${ }^{2}$.

\section{Terres basses de l'Est.}

Il existe encore en Flandre d'autres parties basses oủ les eaux n'ont été vaincues qu'au prix de travaux particulièrement longs et coûteux. Les Moëres de Ghistelles, ce golfe de terres fortes que la plaine dessine entre les sables de Ghistelles et ceux de Couckelaere, et qui forme, sans maisons, sans pâtures el sans arbres, tout en guérets, un coin si étrange entre les deux bords du Houtland qui l'enserrent, n'est débarrassé que depuis peu des graves inondations annuelles qui l'accablaient. Elles étaient aussi subites que redoutables : parfois il fallait sonner le tocsin pour prévenir les habitants du danger. Il y a 32 ans, le 15 août, l'inondation arriva pendant les vêpres, et les formiers du Nord ne purent regagner leurs habitations. Plusá

1 Arch. Pas-de-Calais, C. 152, pièces 13-14, 76-89; (1774 et 1776).

2 Voir: Ovigneur, Mémoire pour l'administration des Moëres françaises contre la IV' section des Wateringues (Lille, Danel, 1891, br. 68 p.), et: Mémoire en réplique (Lille, Danel, 1892,15 p.). Le dernier arrêt de la Cour de Donai se trouve dans le Nord Judiciaire, $13^{\circ}$ année, Nus 89 , pp. 229-234. 
l'Est, ce fut pour les communes belges de Watervliet, Waterland-Oudeman, Ste-Marguerite, St-Laurent, Middelbourg et Lapscheure, une inquiétante situation, lorsque les Hollandais devinrent maîtres en 1648 des écluses par. où leurs eaux s'écoulaient à la mer, et que pour comble de malheur l'évacuation devint de plus en plus difficilo par les estuaires en voie de comblement du Braakman et du Z win. Résolu à éviter cette dépendance à l'egard de la Hollande, Joseph II avait fait commencer par le colonel de Brou un grand canal longeant la frontière et s'ouvrant dans le \%win a l'eccluse du Hazegras. Il fallut revenir à ce projot après 1830, lor'sque la Hollande eut fermé jusqu'en $18 \not 0$ tous les débouchés, et infligé aux communos belges des inondations annuelles qui leur causaient, de 1831 à 1833, 4.595.000 francs de dégâts ${ }^{1}$. En juin 1842 intervint une loi décrétant la construction « d'un canal pour l'écoulement des eaux des Flandres » 2. C'est la belle voie d'écoulement dite canal Léopold, ou de Selzaete, qui part de Bouchaute, vient longer la frontière hollandaise vers Eede, rejoint le canal de Schipdonck, franchit en sa compagnie le canal de Bruges à Sluis et gagne la mer à Hoyst. Non seulement elle amène sans encombre à Hoyst, après 38 kilomètres de chemin, les eaux de Watervliet qui ne sont qu'à une lieue du Braakman, mais elle a fait faire au dessèchement de tout le Nord de Bruges les plus grands progrès.

Enfin la situation la plus critique à l'heure actuelle est celle des terres basses du pays de Waes. Ces beaux polders de Vracene, Calloo, Kieldrecht sont sous le coup d'inondations continuelles; leur niveau est si bas que l'écoulement dans l'Escaut par l'écluse de la Perle est très intermittent, tandis que du plateau de Waes qui les domine d'une vingtaine de mètres leur arrive avec une rapidité extraordinaire l'eau des moindres averses. Il ne se passe pas d'année sans plusieurs inondations ; celle de 1880 a couvert 2.800 Ha. Trois projets sont à l'étude: une machine à vapeur pour écouler l'eau à marée haute, une rigole spéciale pour l'évacuation des eaux du haut pays, entin un grand canal analogue au canal Léopold, qui serait en même temps une voie navigable, et mènerait du canal de Terneuzen à l'Escaut ${ }^{3}$.

1 Andries, Recherches sur les voies d'écoulement, pp. 84-85.

- Texte dans Wolters, Recueil de lois, I, pp. 784-786.

3 Mertens (A.), Bijdrage tot de studio ovor de droogmaking der Polders in hot land van Waas (St-Niklaas, Sleybol, 1904, 17 p., carte à 1 : $100.000,1 \mathrm{fig.}$ ). 


\section{Progrès accomplis et à accomplir.}

Ainsi va se perfectionnant sans cesse l'écoulement des eaux de la plaine. Les progrès réalisés au XIX ${ }^{\circ}$ siècle ont été immenses. La paix en a été la première cause. On n'a plus revu de ces inondations tendues autour des places fortes, comme celles qui remirent sous l'eau les Moëres en 1646 et 1793, et celles qui sous prétexte de défendre Nieuport, cette bicoque, noyaient tout le Furnambacht jusqu'à Pollinchove et Eversham, gâtaient los terres pour 7 ou 8 ans $^{1}$, au point que les 13.000 Ha recouverts en 1794 par l'eau salée n'avaient pu encore être fertilisés en 1804. Les Wateringues, rẻorganisóes, stimulées par l'Etat, ont réalisé de grandes améliorations, ot cela non seulement dans les parties faibies comme le Calaisis, mais dans toute la plaine. Il n'y a qu'une voix chez les habitants pour constater les bienfaits de leurs syndicats. A St-Pierre-Brouck, à Holque, on est obligé de constater la disparition des inondations depuis la mise en service du watergand neuf que la malignité publique avait désigné dés l'abord sous le nom de « Panama ». A Cappelle, l'eau ne ś́journe plus qu'un jour ou deux sur les terres, en cas de grande pluie. A Teteghem, les terres du Sud qui restaient inondées jusqu'à 5 mois par an sont desséchées en quelques jours par la machine à vapeur que la 4 e section des Wateringues du Nord a établic à Steendam; même cas pour les terres basses de Warhem. Les gens de Bulseamp constatent que l'inondation qui durait, il y a 25 ans, ă à 6 semaines par an, pent être disparue en trois jours. Woumen n'a plus de l'eau sur ses terres pendant 12 et 15 jours de suite, comme cela se passait avant qu'on eût, on 1880, amélioré les débouchés à la mer, à Nieuport. Slype n'a pas vu une inondation sérieuse depuis 50 ans, et ses voisines St-Pierre-Capelle et Zevecole, quoique moins bien partagées, n'ont qu'à se louer des changements survenus. Vlisseghem et Clecmskerke sont lranquilles depuis 25 ans. Groede, Oostburg, Ijzendijke, Axol, paraissent ignorer que des inondations soient encore possibles. On pourrait multiplier ces exemples; mais la meilleure preuve du progrés accompli, c'est le recul de la fièvre paludéenne.

La fièvre paludéenne, avec ses accès féguliers, a été jadis la maladie caractéristique de la plaine, celle à laquelle personne n'échappait; à force

1 G. Lettre de l'intendant de Bernières au Contròleur gènéral (1707) dans Boilisle, Correspondance des Contrôleurs généraux avec les intendants des provinces, II, p. 379, $\mathrm{n}^{\circ} 1179$; - de Viry, Mémoire statistique du département de la Lys, adressé au Ministre de l'Interieur (Paris, Impr. impériale, an XII, in-4 $4^{\circ} 180$ p.), p. 125. 
d'en constater la régularité, on avait fini par la croire nécessaire, et on disait aux enfants de 7 a 15 ans, qui l'avaient pendant des scmaines, que c'ètait une fièvre de croissance (grooikoorts), et que ça faisait grandir, Les vastes étendues d'eau stagnante que présentait la plaine en élaient la cause; et St Arnulf trouve cinq fiévreux couchés dans la même cabane, lorsqu'il traverse les moeres de Ghistelles '. Un dictorn de garnison mettait sur le même rang que la peste et la famine l'obligation d'aller sêjourner à Gravelines ou à Bergues z, l'une à cause des Moëros, l'autre à cause des schorres des Hems St-Pol; « dès que la chaleur se fait sentir à Gravelines, on y voit régner des fièvres putrides ou bilieuses, dont la convalescence est fort pénible et dure souvent jusqu'à l'hiver ${ }^{3}$. La Flandre zélandaise en particulier avait un fâcheux renom : le préfet Faipoult y constate que tous les habitants y sont tourmentés de fièvres en fructidor el vendémiaire; aussi parviennent-ils rarement à une grande vieillesse; les troupes $\mathrm{y}$ souffrent infiniment, et les Hollandais avaient l'attention de ne jamais y changer les garnisons ${ }^{5}$. Les malheureux gardes nationaux envoyẻs en 1809 à la défense de l'Escaut s'en aperçurent, car en 1839 on trouvait encore à Lille plusieurs d'entre eux qui n'avaient pu se débarrasser de cette tenace fièvre de Kadzand 6 . Jusquo passé le milieu du siècle, la fièvre resta la maladie dominante; à l'hôpital de Furnes, en 19 ans, elle donne un cas sur cinq; même proportion à Ostende ${ }^{7}$; Laveleye parcourant « cette maremme de la Belgique * après les chaleurs de juillet 1859 trouve dans chaque forme deux ou trois personnes épuisées par la fièvre, et dans chaque village entend lo glas de la cloche des morts ${ }^{8}$. Or ce fléau commence à n'être qu'un souvenir. Par toute la plaine on entend célébrer la disparition des fièvres. A Iamme, on en comptait 150 cas par an a vant la construction du canal Léopold: 3 ans après, le nombre était

1 Ex vita Arnulfi episcopi Suessionensis auct. Hariulfo, I. II (M. G. SS., XV, p. 889).

2

Seigneur, délivrez-nous de la peste, de la famine,

De la grarnison de Bergues et de Gravelines.

3 Tully, Essai, pp. 49-51. - Cf. Arch. Pas-de-Calais C. 305, pièce 20.

4 Dresselhuis (Ab Utreclit), Het distrikt van Sluis in Vlaanderen, pp. 44-59.

5 Faipoult, Mémoire statistique du département de l'Fscaut, adressé au Ministre de - l'Intériour (Paris, Impr. impér., an XIII, in $-4^{\circ}, 160$ p.), p. 21.

${ }^{6}$ Derode, Histoire de Lille, III, p. 326.

7 De Keuwer, Topographie médicale de l'arrondissement de Furues (Annales de la Société médico-chirurgicale de Bruges, 1847, pp. 233-264), p. 248; -- Janssens, Topographie médicale de l'arrondissement d'Ostonde (Thid., 1848, pp. 17-66, 117-166), pp. 55-56. - De même: Waldack, Topographie médicale du canton d'Eecloo (Annales Soc. médecine de Gand, XX, 1847, pp. 69-140), fp. 8486 .

8 Laveleye, Economie rurale, pp. 23-24. 
tombé à 50, et aujourd'hui il n'y en a plus. Jusqu'd une date assez rapprochée, le nombre des décès dans l'arrondissement de Dunkerque ètait presque l'équivalent de celui des naissances; le changement est complet de nos jours ${ }^{1}$, et suffit a illustrer l'œuvre accomplie par les Wateringues dans les 25 dernières années.

Cependant la malaria n'est pas complètement vaincue. Les causes du Héau sont très atténuées, mais elles subsistent. Il y a encore des étendues d'eau stagnante, on particulier los anciennes tourbières. L'extraction de la tourbe fut jadis la principale industrie de la plaine, et probablement la plus ancienne: témoin l'inscription de Rimini qui garde le souvenir des sauniers ménapiens ${ }^{2}$. L'extraction a cessé aujourd'hui, car le charbon a chassé de tous les foyers flamands ce combustible odorant, qui imprégnait les habits et empestait les maisons au point qu'aujourd'hui encore, par les temps humides, les vieilles demeures ou l'on en a brûlé jadis exhalent encore l'odeur de tourbe ${ }^{3}$. Mais les excavations restent, les vastes clairs de Balinghem et Ardres, les mares de Jabbeke et de Stalhille. On remblaie peu à peu; le travail va lentement, car la terre disponible est rure. Le manque d'eau potable est une autre cause d'insalubrité. Tous les puits sont mauvais, ou doivent être considérés comme tels : près de la surface, l'eau est chargée d'impuretés de toute sorte; en profondeur, elle est saumâtre. Il faut s'alimenter à des citernes, dont l'appoint est souvent insuffisant l'été ; aux canaux, aux watergands, à des mares. Furnes a $\mathbf{9 0 0}$ citernes, dont une de $\mathbf{3 0 0}$ mètres cubes, pour 1.214 maisons. Les ressources fournies par ces eaux peu appétissantes n'empêchent pas que 13 communes belges de la plaine, sur une cinquantaine, soient exposées à manquer d'eau donce l'êté : à Calloo, les habitants de 200 maisons doivent faire en cette saison 3 kilomètres pour en trouver; au Doel, pour 130 maisons la distance est de 1 kilomètre . A Guemps, un brasseur est obligè d'avoir un bateau à soupape pour aller chercher de l'eau douce au pied de l'Artois, dans la rivière de Balinghem. L'armée anglaise a éprouvé, pendant l'été de 1809 qu'elle a

1 Voir les Annuaires du département du Nord, depuis l'an XI.

2 C'est des cendres de la tourbe que l'on extrayait le sel. - Sur les tourbières du Calaisis, voir: de Bonnard, Notice sur les tourbières du département du Pas-de-Calais (Journal des Mines, 2 vol. de 1809, pn. 121-155).

3 Tl existe encore dans le Sud de la commune des Attaques, en plein marais, quelques maisons dont les propriétaires tirent de la tourbe et s'en servent pour la cuisson des aliments, effectuée dans une pièce à part. C'est probablement le dernier vestige qu'on puisse en trouver dans toute la plaine.

* André, Enquete sur les eaux alimentaires, I, pp. 402-409. 
passé dans l'île de Walcheren, les inconvénients de ce manque d'cau potable. Il y a donc encore des fièvres paludéennes dans la plaine, et poutêtre plus dans la partie belge, où l'organisation des Wateringues est restée par endroits un peu archaïque. D'ailleurs ce sont moins les habitants qui sont atteints que les etrangers, les ouvriers pauvres du Houtland qui viennent faire la moisson ou la campagne des betteraves ${ }^{1}$.

Ainsi tout n'est pas parfait encore dans la plaine maritime. Il faut que les Wateringues continuent leur ceuvre d'amélioration. Les inondations peuvent encore se produire: celle de novembre 1894 s'est fait sentir sur une bonne partie de l'arrondissement de Dunkerque. Par les très grosses mers, l'écoulement peut être momentanément arrêté, et les terres submergéos si les fossés ne sont pas assez profonds. Les syndicats ne doivent pas se borner à entretenir en bon état les ouvrages existants, curer les fossès, réparer les vannes et les écluses; leur cuvre est à complèter. L'indépendance du dessèchement n'est pas encoro complète à l'égard de la navigation, et chaque grande Wateringue n'a pas encore son canal particulier d'écoulement. Enfin une autre tâche s'offre aux habitants de la plaine. Lorsque l'évacuation des eaux à la mer sera devenue irréprochable, ce qui en beaucoup de points ne saurait tarder, on pourra se mettre hardiment à combler les petits fossès qui sillonnent les champs, et à les remplacer par des drains creusés à une faible profondeur. Quand l'écoulement était très imparfait, il fallait des fossés partout, pour évacuer plus vite; c'est encore le cas dans les réģions mal desservies, comme les moeres de Ghistelles; aujourd'hui, dans presque toute la plaine, ces petits fossés peuvent disparaître. On y gagne une étendue appréciable de terre cultivable; les travaux sont plus faciles, et on évite les mauvaises herbes qui croissent toujours le long des fossés. Déjà appliqué autour d'Ostende et à Ste-Marie-Kerque, ce système a donnć d'excèllents résultats ${ }^{2}$; nul doute qu'il ne s'étende. L'homme a beancoup fait dans la plaine pour asservir l'eau; aujourd'hui il peut se croire vainqueur, il lui reste à savoir profiter de sa victoire.

1 Au fort de Cruybeke, dans les polders de l'Escaut, les officiers reçoivent une solde supplémentaire pour compenser les inconvénionts du sejour, particulièrement la fièvre. De même à Ste-Anne, en face d'Anvers.

2 C. Monographie agricole de la région des Polders, pp. 72-73; le Pas-de-Calais al XIX siècle, IV, pp. 125-131. 


\section{CHAPITRE XII}

\section{LA VIE DANS LA PLAINE}

I. L'Agriculture. Qualités du sol. Anciennes cultures. La betterave. Pátures et bétail. I'océdés et exploitations. - II. L'habitat rural. La grande ferme. Les agglonérations. - III. Les villes. Marchés agricoles de la plaine et de lia lisière. Bruges. L'absence d'industrie. - IV. La population. - V. La Flandre Zélandaise. Etat actuel de la lutte contre la mer. Agriculture, habitat, population. Isolement économique.

I.

\section{L'AGRIGULTURE.}

Avant de commencer à exploiter leur terre, les habitants de la plaine ont dû se mettre à la débarrasser des eaux. Ailleurs l'homme se contente de labourer, de tirer parti de son sol : ici il est le sauveur du champ qu'il exploite; il le protège contre la mer, contre les rivières, contre l'eau d'en dessus et d'en dessous. Aujourd'hui s'il no le préserve pas héroüquement en allant « porter de la terre à la digue », il contribue à son salut en payant, en plus de toutes les contributions ordinaires, la taxe de la Wateringue.

\section{Qualités du sol.}

Il faut que ce sol soit bien riche pour mériter de pareils sacrifices. N'est-ce pas celui qu'un moine d'Oudenbourg appelait dès le XI' siècle la meilleure terre de Flandre, et dont Meyer au XVIe célébrait la fertilité, qui ne connaît pas les engrais et dédaigno les assolemonts ${ }^{1}$ ? Cela est vrai en général, et le seul aspect de la plaine en juillet suffit à l'indiquer. Cependant ce sol des polders comporte des variétés. A la surface on trouve parfois de la tourbe ; et la terre noire des marais d'Ardres, celle qu'on aperçoit dans les prairies de Bierno ou dans les jardins maraîcher's

1 Malou, Histoire d'Oudenbourg, I, p. 35. - Meyer, Rerum Flandricarum tomi X. (Bruges, Soc. d'Him., 18'3), vol. IX, p. 77. 
d'Hoymille rappelle les hortillonages des vallées de la craie. Cette tourbe de la surfacè ne se rencontre guère que le long de la lisière Sud : tandis que le sable est répandu un peu partout; il est peu de communes qui n'en possèdent pas quelque veine. Enfin l'argile grise occupe la plus grande partie de la plaine.

L'argile est, à l'état vierge, d'une fertilité extrême; des analyses lui donnent dix fois plus de principes fertilisants, matières phosphatées, organiques, salines, que les meilleures terres alluviales de Belgique ${ }^{1}$; et cola grâce anx débris organiques, plantes, animaux, qui s'y accumulent quand elle se forme en schorre. Pendant quelques annèes, cette fertilité se maintient, le sol du nouveau polder n'a pas besoin d'engrais ; puis vient l'épuisement. La plaine tout entière en est venue depuis longtemps à cet ctat de fatigue, ou des restitutions d'azote et d'acide phosphorique sont nécessaires. Les analyses indiquent une quantité considérable de calcaire, probablement due aux apports de la Manche; une teneur suffisante de potasse, enfin une légère insuffisance d'acide phosphorique. Ainsi les engrais comme les scories et les superphosphates sont nécessaires. D’autre part l'imperméabilité est un des grands inconvẻnients du sol de la plaine. Là où l'argile n'est pas mélangée au sable, c'est la terre forte, le « blek », sur lequel l'eau de pluie séjourne et ne disparaît que par évaporation; oú une averse survenant avant la levée provoque la formation d'une croûte dure qui nécessite un nouvel ensemencement. Aussi cette terre, pour être cultivée, demande à être saisie juste à point: pas trop sèche, parce qu'elle devient dure comme une pierre; pas trop mouillée, parce que le cultivateur et son attelage s'y embourberont. La terre argilo-sableuse, * opene grond $»$, est une terre franche plus facile à travailler, où la róussite des semis est assurée, et où l'on n'est pas obligẻ comme dans le blek de recommencer les semailles deux ou trois fois, ou de retarder celles d'automne jusqu'en janvier et même février ${ }^{2}$.

Mais en revanche, les terres fortes donnent un rendement supérieur. S'il y faut plus de travail, et si l'on n'est jamais sûr de pouvoir faire ce travail a temps, il y faut moins d'engrais, ot le rendement est parfois plus élevé d'un tiers. Ce résultat fait beaucoup pardonner; et malgré ses défauts, la plaine maritime n'en reste pas moins, comme le disait Hariulf d'Oudenbourg, la meilleure glèbe de Flandre. Dans les terres moyennes, le rendement du blé à l'hectare y est de 20 hectolitres; dans les bonnes

1 Monographie agricole de la région des Polders, p. 6.

2 Monographie rég. Polders, p. 14; - Leplae, Esquisse agronomique de la Flandre, Occidentalo (Rev. gén. agr. L., 1899, pp. 38-44, 78-91), p. 44. 
terres, de 33; celui de l'orge, de 28 à 48 ; celui de l'avoine, de 33 à 75 ; dans les bonnes terres, la pomme de terre donne 35 tonnes à l'hectare, la betterave à sucre $40^{\circ}$. Et ce sont là des résultats moyens. De bonnes terres traitées par de bons agriculteurs donnent des quantités bien plus considérables: jusqu'à 60 hectolitres de blé à l'hectare, 95 d'avoine, 60 tonnes de betteraves riches à plus de $7^{\circ}$, dans une grande exploitation de Ste-MarieKerque; ailleurs jusqu'à 100 hectolitres d'avoine dans une grande ferme d'Offekerque ${ }^{2}$. C'est bien là la terre dont Meyer disait qu'elle était grasse à souhait, et sur la fertilité de laquelle se sont souvent extasiés les agronomes.

La fertilitẻde ce sol, l'humidité due au climat et à l'imperméabilité du sous-sol, entretiennent à la surface de la plaine une vigoureuse végétationi. Nulle part en Flandre les marvaises herbes ne poussent avec une telle rapidité; aussi le sarclage y est-il devenu une des operations indispensables de la culture. Si les arbres sont rares et grêles, ce n'est pas au sol, mais au climat qu'il faut s'en prendre; car dans la partie de la plaine qui s'éloigne de la côte pour longer l'Escaut, les arbres reparaissent en longues rangées le long des digues, ou en massifs épais autour des fermes: de Bruges à Hulst, peupliers, saules, vergers, encadrent ou garnissent les polders. Si le vent de mer ne s'y oppose pas, tout peut pousser dans la plaine et donner de beaux fruits. La terre en est accueillante, elle n'a pas de próférences, et la flore est sans caractère; à peine y distingue-t-on certaines plantes halophiles qui ont survécu à la disparition de la mer. L'homme a profité de ces heureuses dispositions, et partout où l'humidité ne réclamait pas trop impérieusement le maintien des prairies, il a peuplśs le sol de plantes exigeantes et productives, céréales riches, cultures industrielles.

\section{Anciennes cultures.}

Pâtures et cêréales ont été d'abord la base de l'agriculture dans la plaine. C'est parce qu'ils sont « fondés sur labouraige et nourrissement de bétail » que les hommes du Franc de Bruges refusent sous Charles le Tóméraire de participer au salut du Zwin. Les vienx textes où il est question des redevances à payer par les hommes de la plaine nous parlent de céréales et de produits d'élevage: les vassaux de St-Bertin autour de Gravelines acquittent à l'abbaye, au XII siècle, leur fermage en fromage,

1 Le Pas-de-Calais au XIX' siècle. IV, pp. 124-125.

2 Ibid., IV, pp. 125-135. 
beurre, brebis, cultivent le blé, les pois et les fèves ${ }^{1}$; à la même date l'orge, l'avoine, les agneaux, le beurre ot le fromage, figurent en tête des revenus du châtelain de Bourbourg 2 . Le terroir de Bourbourg, dit Des Madrys en 1698, est fertile en bleds, et les prairies sont pleines de bestiaux; et le prófet Dieudonné indique qu'en $18(14$ dans les formes de l'arrondissement de Bergues, les pâtures occupent 8/20 du sol, les céréales 7/20 et les autres cultures le reste, $\mathrm{y}$ compris la jachère ${ }^{3}$. Ainsi les céréales sont la culture traditionnelle; celle qui s’imposait sur ce sol riche et profond. L'orge et le froment s'y disputent le premier rang; l'un est plus en honneur à l'Est, dans la partie belge, l'autre dans la partie française. Il y a peu de temps qu'on ne les cullive plus après jachère, c'est-à-dire après un repos d'un an laissé à la terre que l'on préparait par un nettoyage, trois a quatre labours profonds et une fumure énergique; aujourd'hui c'est plutôt après demi-jachère, c'est-à-dire après que la terre, débarrassée de bonne heure d'une récolte de pois, de lin ou de trèfle, a eu quelques mois de repos et de préparation, que l'on sème le froment ou l'orge.

De bonne heure cependant, à côté des céréales, on vit prospérer d'autres récoltes qui trouvaientlà des conditions favorables, difficilement réalisées ailleurs. Le sol argileux et profond de la plaine donnait aux fèves la terre qui leur convient; son climat, tempéré l'hiver, permettait d'en opérer la semence de bonne heure (février ou mars), condition nécessaire à leur complet dévoloppement. Aussi féves et pois ont-ils toujour's fait partie des assolements; avec leurs grosses tiges, leurs cosses dures, et au printemps leurs bouquets de fleurs blanches et noires, les fèves sont unc des plantes les plus caractéristiques de la plaine. I.es Ordonnances de 1341 dans le pays de Guînes défendent d'arracher ou d'esplucher poiz, feves, ne aultres grains " ${ }^{3}$ et la statistique de Dieudonné réserve aux fèves 3/20 du sol, sur los 5/20 que laissent disponibles céréales et pâtures. A côté d'elles, le lin s'était établi ; lui aussi trouvait dans la plaine des conditions clima-

1 Haigneré, St-Bèrtin, I, p. 51, no 133 ; p. 131, n²89.

2 De Baecker, Histoire de la ville de Bourbourg jusqu'en 1789 (Dunkerque, 1879, in- $\left.8^{\circ}\right)$, p. 26. - Casuel du curé de la nouvelle paroisse de Leffrinckoucke (1176) : 350 gerbes de froment et avoine, 2 vaches, 1 fromage, une pelisse de mouton (Feys et Nélis, Cartulaire de St-Martin d'Ypres, I, p. 16).

3 Mémoire de l'intendant Des Madrys, dans Bull. Comm. H. Nord, XI, p. 288 ; Statistique du Nord, I, p. 485.

- Recensement agricole de 1895, vol. Introduction, p. 69.

5 Tailliar, Le Livre des Usaiges et anciennos coustumes de la conté de Guysnes (St-Omor, Chauvin, 1856), p. 48. 
tériques assez favorables pour faire négliger l'influence, plutôt fâcheuse, des terres fortes sur son développement; la région poldérienne, qui ne connaît pas les extrêmes de températur'e, permet de semer de bonne heure la délicate plante qui doit être vite arrivée à maturité. Certaines parties de la plaino vivaiont du lin : les fermiers y trouvaient des ressources considérables, les pauvres étaient occupés un bon mois au sarclage, et le filage utilisait toute l'année le travail des femmes. Le Calaisis, si pauve au XVIII ${ }^{\mathrm{e}}$ siécle, se serait dépeuplé sans lo lin ; ce textile faisait vivre la campagne, et formait le plus clair du commerce de la ville ; jusque dans les premières années du XIX siécle, orge et surtout lin sont la plus grando part des transactions de Calais $\mathbf{1}$. On le rouissait dans les marais d'où l'on voyait sortir en novernbre d'epais brouillards jaunes. Le chanvre accompagnait souvent le lin; les marais de St-Omer, les alentours des Moëres alimentaient les fabriques de cordagres de Dunkerque; année moyenne, le Calaisis à la fin du XVIII siecle en tirait pour 10.000 livres des marais de Guemps, de Coulogne et des Attaques ². Telles étaient les vraies cultures de la région maritime, celles que l'on retronve dans les autres terres basses qui frangent ẹá et là les bords de l'Océan ou de la mer du Nord, polders hollandais, marschen allemandes; dans le marais poitevin, du XII au XVI ${ }^{-}$siècle les champs de blé et de fèves se partagent le sol avec les pâtures ${ }^{3}$; au début du $\mathrm{XIX}^{\mathrm{e}}$ siècle, la répartition $\mathrm{y}$ est exactement la même qu'autour de Bergues: moitié pour la nourriture du betail, le reste pour le froment et la féve des marais, le lin au long des fossés . Pâtures d'une part, orge et froment, lin, pois et fèves, un peu d'avoine el de tr'éfle de l'autre, tel était l'état d'équilibre qu'avait adoptẻ l'agriculture dans la plaine, et auquel elle se tenait encore en 1870.

\section{La Betterave}

C'est alors que se produisil la révolution qui bouleversa tous ces anciens assolements, et brusquement fit faire place au milieu d'eux à la betterave. Variétés sucrières, fourragères, botteraves de distillerie, trouvaient un

1 Arch. Pas-de-Calais, C. 101, C. 132.

2 Ibid., C. 194.

3 Clouzot, Les Marais de la Sèvre Niortaise et du Lay du X'à la fin du XVI $\mathrm{X}^{\mathbf{a}}$ sièclo (Paris, Champion, 1904, in-8 282 p.), pp. 112-113.

4. Gaudincau, Topographie médicale des marais orientaux du département de la Vendée (Paris, Didot, 1810, in-4ㅁ, 23 p.), p. 12. 
excellent terrain sur ce sol riche et humide. La conquête fut rapide; elle se fit aux dépens des fòves et du lin, qu'elle pouvaìt remplacer dans les rotations. On vit les premières diminuer rapidement; leur culture avait un caractère aléatoire que no présentaient pas au même degré les plantes industrielles, et les profits étaient beaucoup moins considérables : de $\mathbf{1 8 1 6}$ à 1895, l'êtendue cultivée en fèves dans la partie belge passa de $18.951 \mathrm{Ha}$ à 10.275 , et la diminution continue. Quañt an lin, sa décadence dans la plaine maritime ne fut qu'un épisode de celle qui se poursuivait à travers loute la Flandre. Pondant ce temps la betterave s'accrut avec une incroyable rapidité, surtout dans les années qui s'ètendent de 1880 à 1900. Rien que pour la betterave sucrière, on mettait en cuvre au cours de la campagne 1887-88 dans les trois usines de l'Ouest de la plaine (Ardres, Ste-Marie-Kerque et St-Martin-au-Laert), 53.000 tonnes de racines; en 1891-92, la quantité s'éleva à 100.874 tonnes, et en 1899-1900, à $288.000^{1}$. Il $\mathbf{y}$ eut des communes où la betterave occupa autant de place que le blé. Ce fut une véritable révolution agricole ${ }^{2}$, dont les effets bienfaisants se firent sentir jusque sur les autres cultures; en forçant les paysans qui la cultivaient à employer des engrais puissants, à ameublir profondément lo sol et à le débarrasser soigneusement des mauvaises herbes, la bettorave a fait l'èducation professionnelle des cultivateurs tout en ameliorant la terre ; les rendements ont généralement augmentẻ d'un tiers depuis qu'elle prend place dans les assolements. Mais nulle part la transformation ne fut plus complète que dans le Calaisis. C'était assurément, jusqu'en 1860, la partie la plus pauvre de la plaine maritime. Les témoignages sont nombreux à ce sujet; le sénateur Depère dáns sa tournée d'inspection de 1805 découvre en passant l'Aa « la ligne de séparation entre la pauvre culture de l'ancienne France et la culture flamande $»^{3}$; un autre voyageur « habitue au coup d'ceil ravissant de la Flandre », se trouve après Gravelines « comme transporté dans un dósert, tant le manque de population et le triste aspect des villages clairsemés et composés de misérables chaumières y offrent un contraste affligeant avec la florissante contrée que nous venions de parcourir ». En 1844, on constate encore

1 Le Pas-de-Calais au XIX' siècle, III, p. 99.

2 A Guemps, en 1889, dans un prêche lo curé « espère que Dieu arrètera l'engouement pour cotte maudite denrée qui fait beaucoup profaner le saint jour du dimanche ».

${ }^{3}$ Depère, Coup d'oil sur l'agriculture de la Belgique comparée avec celle de la Picardie (An XIII, 1805), pp. 111-112.

1 Paquet-Syphorien, II, pp. 150-151. 
que malgrẻ l'identité du sol, « les procédés de l'admirable agriculture de Flandre n'ont presque pas passé sur la rive gauche de l'Aa », et que la culture du Calaisis est " la plus misérable qui se puisse voir» ${ }^{1}$. Cette infériorité, qui venait sans doute de la situation du pays, où l'évacuation des eaux intérieures est particulièrement difficile, et des charges énormes qu'on lui imposa pour perfectionner le système de ses canaux, des routes royales, et des digues comme celle de Sangatte ${ }^{2}$, a cessé brusquement depuis 30 ans; aujourd'hui le Calaisis ressemble au reste de la plaine; peut-être même a-t-il plus que la rive droite de l'Aa l'aspect d'une région de culture scientifique, où tont est sacrifié à la production intensive, les arbres y étant plus rares que partout ailleurs; ou les fermes, avec leurs grands hangars neufs converts en zine, ont déjà un air industriel, et où la vue des cheminées des sucreries et des touraillons des séchoirs à chicorée semble indiquer qu'ici le champ n'est qu'une dépendance de l'usine.

Cependant on était allé un peu loin. La surproduction est venue pour l'industrie sucrière, et depuis 1900 la betterave a arrêté son mouvement ascensionnel, puis a brusquement reculé devant la menace de la conférence de Bruselles. Chose curieuse: une partie de la place qu'elle abandonnait a étẻ reprise par le lin, au moins dans la partie française, où cette culture est stimulée par une prime. Puis un autre occupant est apparu, dont les progrès ont été considérables : la chicorée, qui trouvait dans les sols légèrement sablonneux un excellent terrain; aussi s'est-elle établie surtout au Nord, le long des vieilles lignes de dunes; et là elle fait une rude coucurrence a la betterave. A Ghyvelde, Teteghem, Bourbourg, Mardick, Loon et Craywick, dans les Hems-St-Pol, a Oye, Vieille-Eglise, Marck, la nouvelle culture se développe, et les soins qu'elle réclame étant aussi délicats et fréquents que ceux qu'on prodigue à la betterave, les sarcleuses de la zone des Dunes y trouvient leur compte. Un peu partout on voit s’élever le séchoir à chicorée, gros bâtiment de briques sans fenêtres, surmontée de deux à trois touraillons en zinc, qui s'anime à la fin de l'été ; c'est déjà une des constructions familiéres de la plaine. Dans la partie belge, où la betterave s'était moins furieusement développée, le changement n'a pas étẻ si grand: là l'aug-

1 Baude (J.-J.), Le Pas-de-Calais (Rey. des Deux-Mondes, tome 8, $13^{e}$ année, nonvolle séric, 1844, pp. 765-815), p. 769.

2 En 1738, on prévoit une dépense de 232.266 livres pour le Calaisis (Arch. Nat. $\mathrm{H}^{1}$ 647, pièce 9); en 1778, pour les pays de Langle t de Bredenarde, 720.000 livres en 4 ans (Ibid., pièce 2); en 1777, pour le Calaisis seul, 208.955 livres, etc. Sur les désastres de la corvée de Sangatte (1721) voir Arch. Pas-de-Calais, C. 142, pièce 118. 
mentation porte surtout sur les pommes de terre, et aussi sur l'avoine, favorisée par un tarif douanier assez récent.

Ainsi ces cultures qui ne se partagent que le tiers laissé libre par les pâtures et les céréales, mais dont l'importance économique a été et est encore considérable, semblent se tenir actuellement dans un certain équilibre. Les fèves seules paraissent en diminution constante; mais la betterave sucrière, après son éclipse de 1903, paraît devoir maintenir ses positions; la betterare de distillerie et la variété fourragère seraient plutôt en augmentation. Le lin, pourtant bien déchu, se refuse à disparaître ; la chicorée prend une place honorable; la pomme de terre augmente, ainsi que le treffle, qui présente l'avantage d'ètre une culture peu compliquée, ne réclamant pas de ces coûteux engrais azotés qui chargent les budgets agricoles, et au contraire enrichissant le sol en azote. La variété des cultures s'accroît chaque jour, garantissant le cultivateur contre les crises qui frappent périodiquement telle ou telle production, et causaient des désustres lorsque la plaine ne pratiquait que deux ou trois cultures très développées, córéales, lin ou betteraves. L'agriculture de la plaine voit s'effacer dans celte transformation ses caractères particuliers ; elle devient semblable à celle de toutes les grandes régions limoneuses, Hesbaye, Picardie; mais si loriginalité s'efface, la prospérité augmente.

\section{Les Pâtures.}

L'évolution qui s'est accomplie depuis 30 ans autour du lin, des fèves et de la betterave se poursuivait à la même époque, plus discrètement, autour des céréales; le résultat en apparaît clairement aujourd'hui. La concurrence des grands pays à blé s'est fait cruellement sentir daus la plaine, et a ébranlé une des colonnes sur lesquelles s'étayait la prospérité de ses habitants. L'abaissement du prix du blé depuis 20 ans a causé bien des ruines, surtout dans l'Est; à l'Ouest, la grande extension prise par la culture rémunératrice de la betteravo atténuait les désastres qu'infligeait la vente des céréales à perte. Alors, ne pouvant plus fonder lour fortune sur labourage, ceux du Franc s'appuyèrent plus que jamais sur pâturage, et la spéculation animale prit un essor qu'elle n'avait pas encore connu jusque lá. C'est là le second trait de la transformation opérée depuis 30 ans dans l'agriculture de la plaine: l'extension des pâtures aux dépens des champs de céréales. Seuls réussissent à se maintenir', comme l'avoine, les grains qui servent à l'alimentation des animaux ; ceux qui sont destinés à l'homme sont restreints peu à peu aux besoins de 
la consommation locale, particulièrement en Belgique où la défense douaniére est moins âpre contre les produits du dehors. Dés qu'on a dépassé Bergues à l'Est, on voit l'ćlevage et l'engraissernent du bétail prendre le premier rang dans la vie économique.

Dans la période qui suivit l'émersion du pays, ce fut l'élevage du mouton qui commença la prospérité de la plaine, et les pâtures actuelles succédent directement aux prés salés, aux « hernisses » sur lesquelles on installait des bergeries au $\mathrm{XI}^{\mathrm{e}}$ siècle. Mais bientôt la concurrence des moutons anglais, et la possibilité d'établir sur les pâturages complètement dessalés du gros bétail, peuplèrent de bœufs et de chevaux toute la plaine maritime. L'Ouest, peut-être plus sec, ou plus facile à assécher, garda toujours une préférence pour la culture; l'Est fut par excellence le pays d'élevage, et les lettres patentes données par l'archiduc Philippe à ceux du Franc, en 1504, constatent que la nourriture et l'élevage des chevaux forment la principale occupation des habitants ${ }^{1}$. En génceral, et malgré d'assez nombreuses exceptions, c'est dans les parties les plus basses et les plus humides que l'on rencontre surtout les pâtures; par suite, c'est au long de la limile méridionale de la plaine que l'on trouve les plus beaux herbages de Flandrc. Cependant, même dans cette région oủ l'élevage forme la principale occupation des habitants, il est rare que l'étendue des pâtures soit supérieure à celle des terres labourables. Certes cotte étendue est encore bien plus considẻrable que celle qui est réservée aux herbages dans le reste de la Flandre, et dans l'arrondissement de Dixmude elle occupe encore 36,5 pour cent de l'étendue cultivée, contre 12,5 dans celui de Termonde et 13, ̌̆ dans celui de Courtrai ; de même les arrondissements maritimes d'Ostende, Furnes et Bruges possédent jusqu'à 30 et '26 pour cent de pâtures contre 14 et 15 dans les arrondissements d'Fecloo et StNicolas ${ }^{2}$. Rares sont pourtant les communes où les herbages tiennent plus de place que les champs: à peine les denx villages de Lampernisse et de Zoetenaye au milieu du F'urnambacht; en France les belles prairies de la commune de Bierne, au beai milien du vert pays de Bergues, ne garnissent que $452 \mathrm{H}^{*}$ sur les 1.089 d'étendue cultivée. Aussi malgré le mouvement qui porte les paysans de la plaine à réduire leurs champs de céréales au profit de Icurs pâtures, celles-ci ne forment guère encore qu'un tiers de la surface en exploitation.

Il est vrai que cette disproportion entre l'étendue des pâtures el l'impor-

1 Delepierre, Précis, $1^{\text {「æ }}$ série, II, p. 7.

2 Recensement agricole 1895, Introduction, p. 162. 
tance qu'elles occupent aujourd'hui dans la vie de la plaine est 'rachetée par l'amélioration des méthodes d'entretien. Quand on vent établir une pâture nouvelle, on ne laisse plus à la nature le soin de la former; on prépare soigneusement le terrain, et on l'ensemence d'espèces choisies; une fois créee, on la soigne comme un champ, on y creuse des rigoles, on $\mathrm{y}$ enfouit des drains, on y répand de l'engrais. Aussi le nombre de têtes de gros bétail que pouvaient entretenir 2 hectares de pâture s'est-il élevé de 4 à $5{ }^{1}$. De même, on a améliorè les animaux. Ç'a été d'ailleurs de tout temps une magnifique ráce que colle des bêtes de la plaine. Végétaux, animaux, tout y pousse dru. Les chevaux sont ces animaux puissants, énormes et lourds, qui n'ont pas leur pareil pour enlever sur le sol bououx de la plaine les lourds charrois, capables de traîner à deux, sur un chariot de 2 tonnes, 5.500 kilos de blé, et de ramener dans le même voyage 6.000 kilos d'engrais ${ }^{2}$. Quoi qu'on ait dit de leur nature lymphatique, de lour corps «spongieux, souffée et mou », c'est bien là l'animal adaplé aux besoins de la plaine, aux lourds transports de grains et de betteraves, aux rudes labours dans l'argile compacte ${ }^{3}$. Aujourd'hui que les Wateringues ont amélioré le sol, on commence à croiser cette forte race dite de Bourbourg avec les Boulonnais moins hauts, moins lourds. L'espèce bovine, large de dos et de poitrail, forte de membres, particulièrement apte ì l'engraissement, porte bien, comme le cheval, la trace de l'influence du. sol: tous deux sont les produits d'une terre humide et fertile, produisant en abondance des végétaux épais et nourrissants. Il n'est pas jusqu'aux porcs, avec leurs dos et leurs membres longs, leur poids considérable, et aux moutons, de grande taille, tête forte, corps long, santé rustique, fournissant une longue laine, belle et de bonne qualité "qui no soient une preuve de l'influence du sol de la plaine sur le développement des animaux. Aussi a-t-on tiré partie de bonne heure de ces heureuses qualités du pays, en amenant dans la plaine des bêtes maigres à engraisser. Le Franc de Bruges au début du XVI ${ }^{\mathrm{e}}$ siècle s'enrichit en « mettant ès prairies selon la nature du quartier pour les engraisser des vaches qu'ils achètent maigres et âpres ${ }^{5}$; Sanderus voit amener dans le Furnambacht

1 Monographie agricole Polders, pp. 42-45.

2 Ardouin-Dumazet, Voyage en France, $19^{\text {ra }}$ série, pp. 425-426.

3 Cf: Telliez (R.), De la production chevaline dans le département du Nord (Bull. Soc. Agriculteurs du Nord, 1879, p. 82); - La production chevaline en Belgique (Ibid. p. 79).

4 Monographie agricole Polders, p. 47.

5 Charte de 1515, Delepierre, Prècis, 1 ro série, III, p. 222. 
des poulains venus du dehors, et Derival constate que les fermiers des polders « tirent de l'Artois et de la Picardie du bétail maigre qu'ils paient à bas prix et qu'ils vendent fort cher lorsqu'ils l'ont engraissé ${ }^{1} \gg$. Ce trafic continue: beaucoup des fermiers de l'Ouest font encore le voyage de la Mayenne pour aller chercher les bêtes efflanquées qu'ils confieront å leurs pâtures. Fn Belgique, il est fréquent de voir les plus belles des pâtures grasses occupées, non par des animaux du pays, mais par des bestiaux achetés maigres en Condroz, en Insembourg, jusqu'en France et en IIollande. De même on améne souvent dans les herbages de la plaine des jeunes chevaux de la rẻgion sablonneuse.

Ainsi les pâtures de la plaine servent à deux fins. On y pratique l'engraissement du bétail, pour la production de la viande de boucherie; aussi un grand nombre de bouchers, de marchands de bétail, ont-ils acquis dans le pays des pâtures grasses, sur lesquelles ils amènent chaque année des hêtes maigres. Parvenu à 6 ou 700 kilos, l'animal est expédié dans les grandes villes de l'intérieur. L'autre spéculation est l'ẻlevage: après un ou deux ans de séjour dans la plaine, les jeunes animaux sont vendus sur place ou dans les grands marchés de Thourout et de Bruges : Ies plus beaux chovaux généralement pour l'Allemagne. Le lait donne lieu à la fabrication d'un beurre renommé(beurre de Dixmude), vendu pendant l'été aux grandes villes et surtout aux grandes agglomérations françaises *. On fabrique même, aux environs de Bergues, une variété de fromage de Hollande.

Ce sont là, pour la plaine maritime, des sources de profit considérables. La consommation de la viande augmente sans cesse, surtout dans les grandes villes; Lille et le groupe Roubaix-Tourcoing, Anvers, Bruxelles, Charleroi sont des clients de plus en plus exigeants. D'aulre part, le paysan constate que jamais les chevaux ne se sont mieux vendus que depuis dix ans. Et l'élevage augmente. Aussi les pâtures atteignent-elles des prix considérables. A Bierne, près Bergues, les bonnes pâtures valent 9.000 franes l'Ha, contre 6.000 les terres labourables ${ }^{3}$; a Westcapelle près de Bruges, à Loo, à Dixmude, la valeur moyenne des herbages de toute la commune s'élóve à 7.000 francs, of l'on peul en voir alteindre 13.000

\footnotetext{
1 Sanderus, I, p. 9; - Derival, IV, pp. 237-238.

2 Nombreuses mentions de redovances en bourro et fromage dans les actes anciens concernant la plaine. Au moyen-âge, l'abbaye de St-Martin de Tournai achète son beurre à Oudenbourg, ct prête sur ce gage de grosses sommes à l'abbayo doundenbourg (Archives de l'Etat ì Bruges, Chartes du couvent d'Ouderbourg, no 215 ).

3 Deleporte et Ryngaert, Excursion agronomique dans Ie canton de Bergues (Bull. Soc. Agriculteurs Nord; 1889, pp. 305-369, carte).
} 


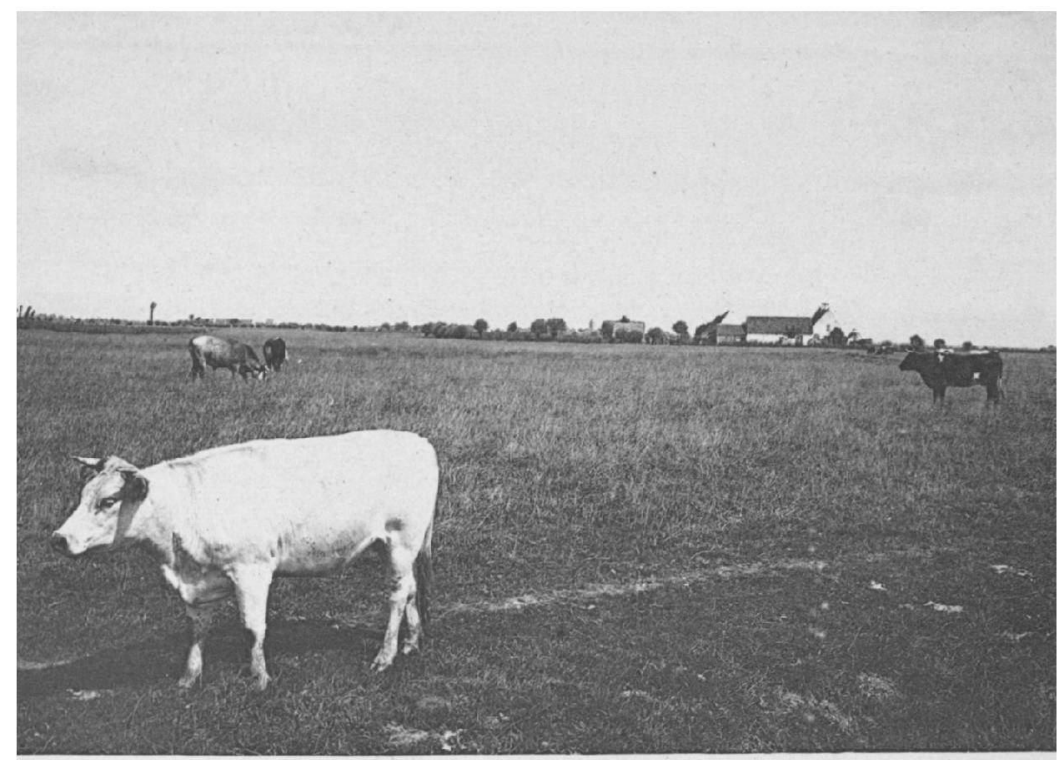

27. - Vue en Furnambacht (Lampernisse).

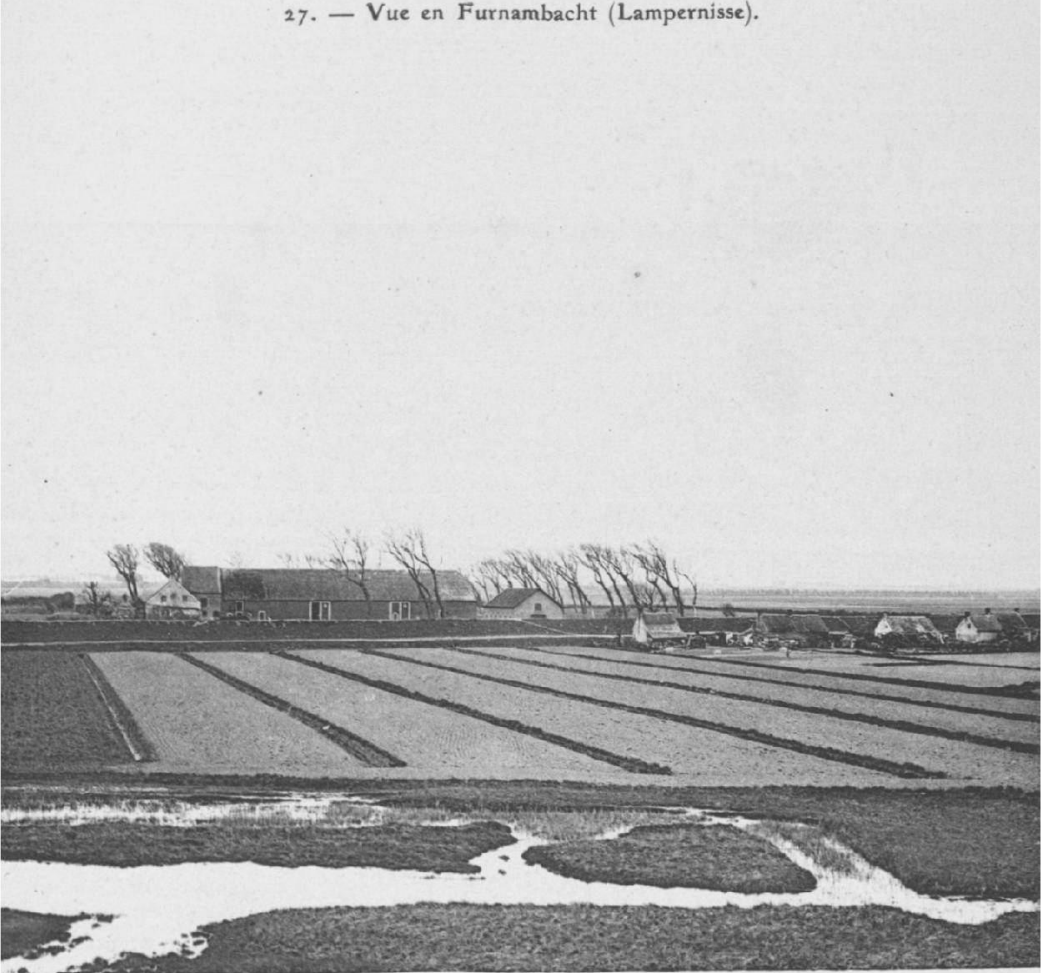

28. - Vue en Flandre zélandaise (Groede). 
IRIS - LILLIAD - Université Lille 1 
franes l'hectare à Lampernisse. Sauf dans l'Ouest, où la betterave, pour satisfaire à la demande de grandes sucreries, reste la principale ressource, l'exploitation des pâtures est devenue la grande affaire de la Plaine, celle qui fait vivre son homme et lui procure même l'aisance. Nulle part plus que dans le Furnambacht, la contrée qui va de Furnes à Dixmude et à Loo, type du pays des pâtures. C'est une grande étendue verte, complètement privée d'arbres et de clôtures ; même pas un arbre pour accrocher à l'entrée des pâtures la petite niche qui contient la madone; il faut la placer au bout d'une poutre fichée en terre. Rien que quelques grosses fermes à toits surmontés de paratonnerres, et les ponceaux de briques, blanchis à la chaux, qui franchissent les watergands. Peu ou pas d'êtres humains ; les villages sont petits et espacés, comme ce bourg de Lampernisse, formé d'une vingtaine de maisons propres dominées par une église énorme, ou le village d'Oostkerke, aux rues houeuses salies par le passage du bétail qu'on vient charger là chaque jour en wagons pour Bruxelles. En revanche les bêtes animent le désert verdoyant: quelques chevaux; bœufs et vaches à robe noire, blanche, et surtout brun-rouge avec taches blanches, se déplaçant lentement dans les pâtures ou venant boire aux fossés qui les séparent. Le calme est complet ; on n'entendque le bruit lent des mâchoires qui tranchent l'herbe, et quelques beuglements dans le grand silence.

\section{Procédés et exploitations.}

Les pâtures ont rendu à la plaine la prospe̊rité agricole si vantée autrefois, que la baisse des céréales menaçait de lui faire perdre. La leçon du moins n'a pas été perdue : l'agriculture des polders s'est ressaisie, et modernisée. Avant 1880, les fermiers vivaient tranquilles, confiants dans la fertilité de leur sol; habitués à la prospérité, ils s'en tenaient aux vieux errements et se laissaient dépasser par leurs laborieux voisins du Houtland. \& Là où la nature a le plus fait pour l'homme, celui-ci fait le moins pour lui-même »; et Van Aelbroeck ajoutait que ce n'était pas aux polders qu'il fallait chercher la perfection de l'art de cultiver ${ }^{1}$. La jachère y élait couramment employée, comme elle l'était à la même époque dans le marais poitevin. Elle n'a même pas complétement disparu des rotations de la plaine. Il est vrai que les habitants y ont quelque

1 Van Aelbroeck, L'Agriculture pratique de la Flandre (Paris, 1830, in-8 $-^{\circ}$, p. 25 et p. 131 . 
excuse. C'est souvent faute do temps propice à l'arrière-saison pour pouvoir préparer et nettoyer le sol qu'une pièce est laissée en jachère nue jusqu'à l'année suivante. Les caprices du temps sont si imprêvus, et le travail des terres, tantôt trop sèches, tantôt trop mouillées, y est si aléatoire, qu'il n'est pas étonnant que-le cultivateur se laisse surprendre. De même les progrès du machinisme agricole ne sont pas toujours applicables dans la plaine, car les appareils nouveaux ne s'adaptent pas aisément à ses terres fortes. Il y faut des instruments spéciaux, comme ce * mollebart», sorte d'immense pelle traînée par un cheval, pour transporter la terre et égaliser le sol de certains polders, et qui n'a pas de roues pour pouvoir circuler sur l'argile grasse ${ }^{1}$; ou ces traîneauxnacelles destinés à charrier les betteraves en temps humides, qu'on emploie dans une ferme d'Offekerque ${ }^{2}$. Néanmoins il est certain que les terres sableuses du Sud sont exploitẻes avec un soin et une science agricole qu'on ne trouve pas au même degré dans la Plaine. De là vient souvent que les produits, malgré la fertilité du sol, soient moins rémunérateurs, el que les magnifiques terres de la plaine se vendent moins cher que les sables de l'intérieur. La moyenne du prix des terres labourables, dans l'arrondissement de Furnes, est de 2.980 francs l'hectare; elle est de 3.958 dans celui de Thielt ${ }^{3}$. Les bons travailleurs du Houtland ont pensé qu'entre leurs mains habiles et actives, les fermes du bas pays pourraient augmenter leur rendement; et depuis 20 ans on assiste a l'invasion lente de la plaine par les gens de l'intérieur. Moins exigeants, ils enlèvent plus aisément la location des fermes, et c'est par eux que la terre des polders sera régênérée. Déjà on signale au delà de l'Aa la marche des «Flamands »; ils s'installent dans les bonnes exploitations betteravières autour de Calais: voici que l'avant-garde escalade même les croupes de la craie, s'établit à Bonningues, Fiennes, Marquiso, et entreprend la conquête du haut Boulonnais.

Une autre raison qui fait que les terres sont moins chères dans la Plaine, c'est que les exploitations y sont beaucoup moins divisẻes que dans l'intérieur; or plus les exploitations sont petites, plus le prix moyen de la terre augmente. Par exemple les exploitations dépassant 50 hectares représentent encore $2,36 \%$ des terres cultivées dans l'arrondissoment d'Ostende, tandis qu'il n’en existe pas dans celui de Roulers; celles

1 Van Aelbroeck, p. 104.

2 Pas-de-Galais au XIX' siècle, IV, pp. 131-135.

s Recensement agricole 1895, III, pp. 151-153. 
qui ont de 20 à 50 Ha forment $13,55 \%$ de la surface cultivée dans larrondissement de Furnes, et $0,94 \%$ dans celui d'Alost, 0,12\% dans celui de Termonde ${ }^{1}$. La Plaine est la seule partio de la Flandre où l'on puisse rencontrer de très grandes fermes : heaucoup de communes en possèdent qui ont plus de 100 hectares; la plus belle, au Hazegras, dans les nouveaux polders du Zwin, s'étend sur 648 hectares. En général, les grandes fermes de la plaine ont de 50 à $70 \mathrm{Ha}$, les moyennes 30 à 40 ; enfin un grand nombre de journaliers exploitent quelques lopins do 50 ares à $2 \mathrm{Ha}$. Cette différence d'étendue entre les fermes de la Plaine et celles de l'intérieur vient surtout de la différence de population. Tandis que le Houtland est une des régions les plus habitées du monde, la Plaine possède une assez faible densité de population; il n'y a pas besoin d'habitants pour exploiter les pâtures; el quant aux gros travaux de sarclage, de binage, de moisson, d'arrachage de betteraves, les Dunes et le Houtland fournissent au moment désiré une main-d'œuvre inépuisable. D'autre part la compacité du sol, en exigeant, surtout autrefois, de forts attelages, jusqu'à 5 chevaux avec l'énorme charrue dont on se servait encore au XVII ${ }^{\theta}$ siècle, empêchait l'établissement de petites exploitations à un cheval ou mulet, selon le typo du Houtland. Los exploitations devaient donc être plus considérables dans la Plaine qu'ailleurs. Cependant au XIX ${ }^{\circ}$ siècle l'augmentation du nombre d'habitants, due à la perfection du dessèchement, et l'enrichissement produit par la culture de la betterave et l'amélioration de l'élevage, tendent au morcellement des fermes. Retardé dans l'Est par la crise de 1880, ce monvement est plus accusé dans l'Ouest, ef particulièrement dans le Calaisis, où la grande culture, qui occupait $30 \%$ des terres en 1859, tombait à 25 en 1898 , en faveur de la moyenne qui passait de $60 \dot{a} 63 \%$ et de la petite $(10 \text { à } 12 \%)^{2}$.

II.

LHABITAT RURAL.

La grande F'erme.

Etant donné l'étendue considérable des exploitations, la grande ferme

1 Recensement agricole 1895, Introduction, p. 454.

a Pas-de-Calais au XIX ${ }^{\text {e }}$ siècle, IV, p. 329. 
est le type ordinaire des constructions rurales dans la plaine. Les domaines ne sont pas rares; qui comme celui de Tempelhof, sur la commune de Slype, comprennent 100 hectares de terres, entretiennent 9 chevaux do labour, 60 vaches laitières, autant de jeunes bêtes d'élevage, et occupent une quinzaine de personnes; il faut de vastes bâtiments pour loger ces gens, abriter ce cheptel, engranger les récoltes. Aussi la grande ferme estelle une des caractéristiques de la plaine. De tous côtés on aperçoit ses nombreux bâtiments aux toits rouges. La ferme en effet ne cherche pas le bord des chemins ou des canaux. Assurée d'avoir n'importe où quelque watergand qui fournira l'ean nécessaire aux animaux, elle s'établit an centre de l'exploitation, sans s'inquiéter des villages ni des autres fermes. La nature du sol lui en fait une nécessité; par temps humide il so prête si peu aux charrois que les bâtiments doivent etre le plus près possible des champs qui on dépendent. La ferme de la Plaino est donc isolée ; c'est un organisme complet, qui se suffit à lui-même:

Derrière le rideau de grands peupliers penchós qui souvent la protègent contre le vent d'Ouest, la ferme aligne ses bâtiments autour d'une cour carrée ou rectangulaire. Mais il est rare que deux bâtiments se rejoignent ; presque partout, il y a entre chaque construction un espace libre, que l'on ferme d'une palissade en bois. L'habitation forme un des côtés ; sa façade donne ordinairement vers le Sud, ou vers l'Est. L'intérieur en est simple: d'abord une vaste chambre où l'on se tient, et quj est la maison (huis); là est le long poöle flamand à charbon, arrondi en boule à l'extrémité, et brillant comme de l'acier poli. La grande cheminée où l'on brûlait la tourbe est encore là, mais vide, proprement peinte, et supportant l'arrangement des objets de piẻté et des vieux étains astiqués. De la «maison *, deux ou trois marches donnent accès à la « voûte», qui est la pièce d'honneur, le salon, servant en même temps de chambre à coucher ; elle est surélevée au-dessus de la cave, que l'on creuse dans le sol à 1 mètre au plus de profondeur, car les suintements n'y sont déjà que trop abondants. Une troisième pièce, de plein-pied avec la «maison *, peut encor'e se trouver en façade. Derrière ces chambres, dautres, plus petites, encombrées de lits, ou servant de magasin à provisions, de relaverie (wasschkamer). A l'habilation est souvent attenante l'écurie; le fermier est ainsi tout près de ses animaux les plus précieux; quelques pas sur le trottoir de briques qui longe le bâtiment, et il est à la porte de ses bêtes, avec lesquelles un valet loge la nuit.

Le reste des bâtiments, qui entourent la cour defoncêe par le trou à fumier, se partage entre les produits de la culture et ceux de l'élevage. Etables et grange sont à peu près équivalentes: de longs bâtiments peu 


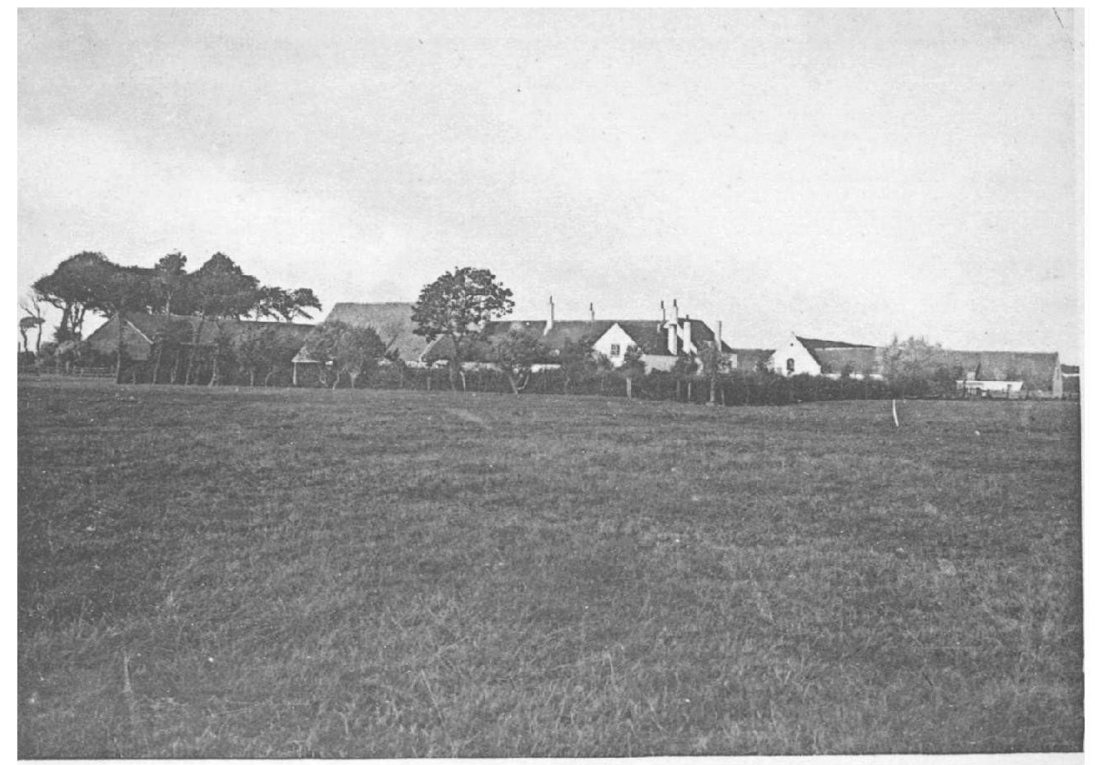

29. - Type de grande ferme de la Plaine (Cappelle).

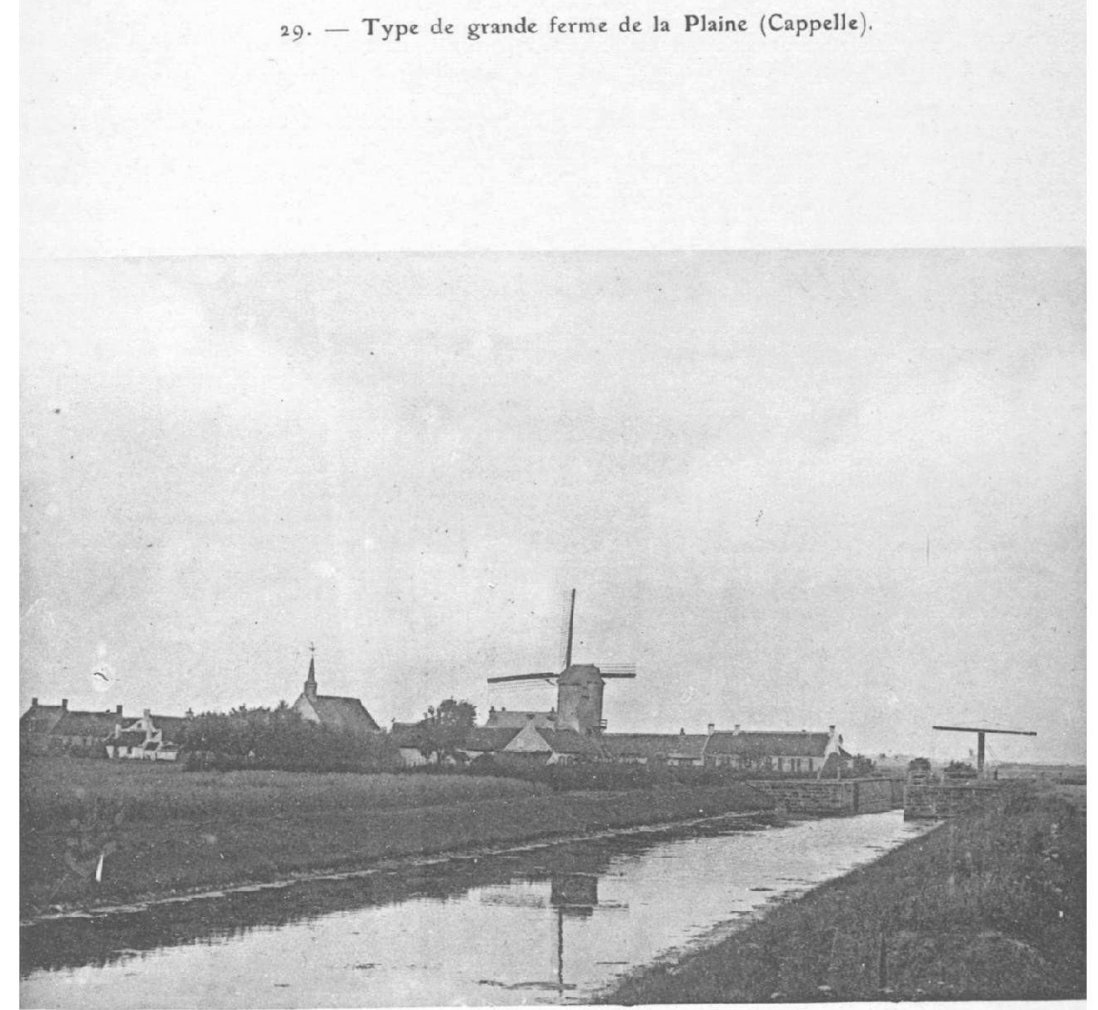

3o. - Type d'agglomération au bord d'un canal (Pont-de-Zuydcoote). 
IRIS - LILLIAD - Université Lille 1 
élevés, qui laissent libre un côté de la cour, ou l'entourent complètement. Dans les cantons de patures, région de Bergues, Furnambacht, l'étable s'étend, restreignant la grange; les animaux sont logés dans tous les locaux disponibles, et souvent il faut leur construire encore, derriére la ferme, des baraquements en bois dont on soigne peu la construction puisque les bêtes ne sortent pas de la pâture de fin-avril à novembre et n'habitent leur ótable que l'hiver. Où domine la culture, le nombre des hangars augmente; et dans le Calaisis beaucoup de formes so complètent, un peu à l'écart des bâtiments, d'uno de ces constructions caractéristiques, haute charpente de poutres recouverte d'un toit en tole, sous lequel s'abritent les bottes de paille, et qui donnent à la ferme une apparence industrielle. Chaque ferme possède à l'extrémité d'un des bâtiments sa charretterie, où sont rangés côte à côte trois ou quatre grands chariots à quatre roues, peints en vert avec filets rouges, et les instruments agricoles. Enfin près de l'habitation se tient le petit bâtiment de l' «ovekot », l'ancien fournil, où l'on prépare la nourriture des bêtes et où mangent l'êté les ouvriers. C'est un véritable amas de constructions, jusqu'à 7 ou 8 hâtiments, toute une petite ville dont la surveillance occupe assez le fermier pour l'empêcher de mettro lui-mème la main à la besogne et fait de lui un «monsieur», un directeur, bien diffórent du petit exploitant du IIoutland, qui peine avec ses ouvriers.

Ces bâtiments sont généralement d'un aspect avenant, murs de briques blanchis à la chaux, toits de pannes bien rouges, volets verts, rideaux aux fenêtres. Les materiaux sont fournis par la plaine même: l'argile des polders est exploitée par d'innombrables briqueteries, qui alimentent en même temps la région côtière, où la bâtisse se développe chaque jour. II existe çà et là quelques fabriques de pannes, dont les produits, apportés par des petits bateaux, pénètrent partout. Il en est de même pour les maisons des villages ou pour celles qui sont éparses le long des chemins ou des canaux; les murs de terre ne se retrouvent que dans quelques rares bâtiments d'exploitation, dont le soubassement d'ailleurs est de briques; le chaume n'est guère plus frẻquemment employé malgré ses qualités; on se contente de placer sous les tuiles une doublure de grosse paille de soigle, ou de roseaux (glui). Même, cette généralisation de la construction «en dur» et de la couverture de pannes est une des caractéristiques de la Plaine, et c'est l'un des traits qui sautent aux yeux lorsqu'on sort du Houtland, où sont fréquentes les maisons atxx murs de torchis jaunes et aux toits de chaume bruns. Les habitants expliquent cetto différence en faisant observer que dans leur pays découvert, murs et toits doivent être particulièrement solides pour pouvoir résister à la violence 
des vents de mer ${ }^{1}$. La remarque est juste; cependant l'extension des luilos et de la briquo est récente. Jusqu'au XIX siècle, les constructions ressemblaient à celles de l'intérieur, même dans les villes. Dunkerque est brûlé en 1558 parce que beaucoup de maisons sont en bois et couvertes en chaume ${ }^{2}$. Les hahitations bâties et couvertes on dur sont signalées comme une rareté, et les ordonnances qui dèfendent de couvrir en paille, celles qui empêchent les habitants dos villes de garder choz eux de la paille, du chanvre et du lin ${ }^{3}$ par crainte d'incendie, qui accordent des primes aux propriétaires qui mettent des pannos ${ }^{4}$, indiquent que le Houtland n'avait rien à envier à la Plaine. En 1804, le préfet du Nord note que $1 / 5$ seulement des maisons dans l'arrondissement de Bergues ont des couvertures en dur ${ }^{\circ}$, et que $1 / 3$ sont construites en briques, le reste en pisé. Mais comme l'état atmosphérique readait particulièrement impérieuse dans la Plaine la nécessité d'avoir des habitations plus solides, c'est par elle qu'a commencé au XIX ${ }^{\ominus}$ siècle le mouvernent, favorisé par l'extension des voies do communication et le développernent de la richesse, qui remplace dans toute la Flandre les cabanes de terre et de chaume par de bonnes constructions en dur.

\section{Les agglomerations.}

Le village de la Plaine ne fait guère plus d'effet qu'une grande ferme. Quelques rues de petiles maisons basses, presque toutes sans étage; les murs blancs, les toits ronges; un rideau d'arbres autour de l'ensemble; seule l'église, haute flèche barbclce ou grosse tour massive, donne un peu d'allure. On y trouve quelques magasins, des dépôts de charbon et d'engrais, quelques maisons de rentiers et surtout les demeures des journaliers. La vie n'est pas dans ces maigres agglomerations, et les grosses fermes qu'on aperçoit de tous côtés en sont vraiment indépendantes;

1 En 1722, on décide de couvrir en ardoises l'église de Guemps, " comme l'expérience fait connaître qu'une couverture de paille n'est pas de longue durée dans un pays auvert de tous côtés et exposé aux vents impétueux qui y règnent la plus grosse partie de l'annèe ». (Arch. Pas-de-Calais, C. 118, pièce 1).

2 Faulconnier, Description historique de Dunkerque, I, p. 61.

3 Recueil des ordonnances de police de I)unkerque (1741 et 177/4), pp. 11 et 78. Règlement semblable à Bourbourg (1691 et 1728).

4 Oudenbourg, fin du XVo siècle (Feys, Oudenbourg, I, p. 5f6); Furnes, 15/4 (Gilliodts, Coutumes de Furnes, III, pp. 365-368), etc.

s Dieudonne, I, p. 506 . 
ce n'est que le dimanche, après les offices, que la « pláce» s'anime, et que les estaminets s'emplissent des valets de ferme et tâcherons venus de tous les points de la commune. Cependant ces villages sont les plus anciens lieux de peuplement de la plaine. Presque tous représentent les points les plus anciennement occupés, sur les parties élevées des anciens schorres. Mais lorsque toute la plaine fut asséchée, il n'y eut plus aucun intérêt à habiter dans le village, où le terrain coûtait plus cher, et la plaine s'est parsemée de petites maisons isolées, établies le long des chemins, à proximité des fermes où vont travailler leurs habitants. Enfin au XIX ${ }^{e}$ siècle les anciens villages ont trouvé de rudes concurrents dans les agglomérations qui se sont formées le long des grandes voies navigables. La proximité d'un moyen de transport plus praticable que les mauvaises routes de la plaine a attiré çà et là, aux abords d'un pont, quelques commerçants et industriels; les marinier's s'y approvisionnent; une bourgade se crée de chaque côté du canal; et généralement chaque rive

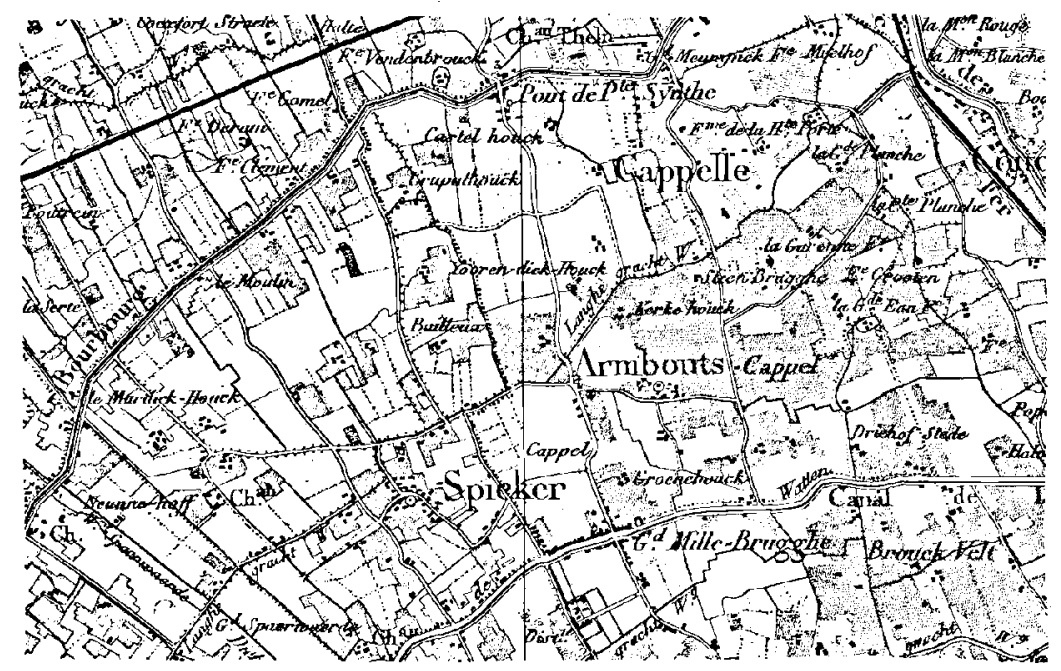

FIG. 55. - L'habitation dans la Plaine (entre Bergues et Dunkerque). Villages non agglomérés au centre. Grosses fermes èparses.

Hameaux au long des canaux.

appartient à une commune distincte. Ce sont les parties vivantes do la plaine: des estaminets, un séchoir à chicorée, un moulin à vent, quelque briqueterie ou tuilerie, dont on charge immédiatement les produits sur bateaux. Les exemples abondent: Hennuin sur le canal de Calais, Pontd'Oye sur la rivière d'Oye, le Pont-de-Zuydcoote sur le canal de Furnes, Lynck sur la Haute-Colme, Zwaentje sur la Basse, Slypebrug et Schoor- 
bakke sur le canal de Plasschendaele et l'Yser en sont d'excellents types. Il n'est pas rare de voir cette agglomération nouvelle plus considérable que les vieux villages dont elle dépend. Lynck, avec ses 250 habitants, esł aussi peuple que le village de Looberghe. A Capelle, près Dunkerque, il n'existe même aucune agglomération municipale, tandis que le long du canal se pressent les maisons du Kroemenhoek. Enfin lorsque c'est une usine considérable qui a déterminé la création d'un de ces centres, il finit par se former là une petite ville: Pont-d'Ardres, autour de l'énorme sucrerie; Coppenaxfort, à côté d'une distillerie, avec 600 habitants groupés, chiffre rarement atteint dans la plaine; le Grand Millebrugghe, près de la grande distillerie de Steene, qui en a bien 1.000. On voit ainsi des communes comme celle de Steene (France) où les 1.072 habitants sont réparlis en : 443 dans les fermes et habitations éparses, 368 au Grand Millebrugghe, 218 au village et 13 dans une cité ouvrière. De l'autre côté de la Colme, le village d'Armbouts-Cappel compte à peine 100 habitants agglomérés sur 1.164. Il est à prévoir que ces agglomérations neuves continueront à s'agrandir aux dépens des anciens villages.

Il existe enfin, dans certaines parties de la plaine, un autre mode de répartition des habitations. Dans les cantons où le sol était particulièrement bas, ou dans ceux que la proximité d'un fleuve exposait à des inondations fréquentes, les maisons se sont accrochées aux digues qui servent à défendre le pays. Le long de l'Yser, de petites maisons accompagnent la grande digue du Furnambacht. De Watten à la mer, les deux digues de l'Aa servent d'appui à deux rangées d'habilations ; de même celles du Mardick, par où s'écoulent les eaux redoutées de la Hem. Les maisons ne sont pas situées sur la digue mềme, généralement trop étroite, et qu'il faut éviter de détériorer ; mais elles s'appuient sur son flanc extérieur; ainsi elles sont un peu plus élevées que le reste de la plaine, et jouissent de la voie de communication qu'offre le talus. De même pour les terres basses d'Ardres, de Cuines, peuplées depuis une soixantaine d'années sculement, et pour l'intéressante région des marais de St-Omer. La population n'y est établie que sur les digues aux abords des cours d'eau, et forme ainsi de longues rues de maisons accompagnant l'Aa ou quelque rameau de la rivière: tels les hameaux de l'Overstel, et ceux du Haut-Pont et de Lyzel qui sont des faubourgs de St-Omer. Il n'y a cependant pas d'industrie à cet endroit, mais des hortillonages aussi riches et aussi célèbres que ceux de la Somme. Le sol noir, découpé par d'innombrables fossés en petits rectangles appelés lègres, est fertile à souhait; l'acide phosphorique y abonde, grâce à la craie marneuse dans laquelle l'Aa creuse son lit supérieur; la contenance en azoto est consi- 
dérable, grâce à l'état vierge où l'inondation a forcé de laisser longtemps ce riche terroir. Aussi la proximité d une ville importante $y$ a fait naître depuis longtemps la culture des légumes; of dès le XVIII ${ }^{e}$ siècle, les marais de St-Omer exportaienl des choux pour Lille et toutes les villes à dix lieues à la ronde ${ }^{1}$. Aujourd'hui, lo sol de cet ancien lac produit par an deux ou trois récoltes de pommes de terre, choux pommés et chouxfleurs, sans compter les pois, chicorées, fraises, artichauts. Le trafic, qui consistait au milieu du siecle en un départ hebdomadaire par bateaux pour le marché du lundi de Bergues, s'est transformé depuis qu'on l'a confié au chemin de fer; il atteignait 3.200 tonnes par an en 1883, et 13.171 tonnes en 1903, dont 6/10 de choux-fleurs ". Dans la seule journée du 3 octobre 1900, les chargements de légumes à la gare de St-Omer se sont élevés à plus de cent wagons contenant environ 200.000 choux-fleurs et autres légumes ${ }^{3}$. Avec une production pareille, il n'est pas étonnant qu'une population dense se soit établie le long des digues du marais: race laborieuse, qui a consorvé jusqu'à la fin du XIX siècle grâce à l'isolement dans les terres basses un costume spécial, et a cessé à peine de parler flamand au milieu de populations françaises, qui regardent ces hommes comme des êtres d'une autre race, et font de ces «maraischers » ou « brouckaillers » soit des Sarrasins, soit des Saxons transplantés jadis par Charlemagne .

III.

LES VILLES.

Marchés agricoles de la plaine et de la lisière.

Si les agglomérations sont rares, plus rares encore sont les villes dans la Plaine. Car il ne faut pas compter comme dépendant de la plaine les groupements urbains de la région côtière. Calais, Dunkerque, Ostende, vivent de la mer. Même Nieuport et Gravolines, ports déchus, presque

1 Lettre du subdélégué Decauchy (1775), aux Arch. Pas-de-Calais, C. 562.

2 Cf. : Pas-de-Calais au XIX' siecle, IV, pp. 135-140 ; - Migneaux, La culture maraîchère à St-Omer (C. Rendus du IVo Congrès National des Syndicats agricoles de France, Arras, Rohard, 1904, in -8 , 487 p.), pp. 426-429.

3 Exposé succinct des travaux de la Chambre de Commerce de St-Omer, 1900 (p. 87).

4 Cf. Piers, Histoire des Flamands de Haut-l'ont et de Lyzel. (St-Omer, Lemaire, 1836 , in $-8^{\circ}, 200$ p.). 
abandonnẻs par le flot qui les a laissés isolés dans les terres, continuent à regarder vers la mer et à n'avoir que peu de rapports avec l'intérieur. Bourbourg ignore Gravelines, et n'en parle que pour attribuer aux Gravelinois un caractère cassant, désagréable, et les traiter de pirates. Les marchés agricoles y sont peu fréquentés; Loon, St-Georges, même St-Folquin fréquentent la grand'place de Bourbourg plutôt que celle de Gravelines; Wulpen va à Furnes plutôt qu'à Nieuport. Dès lors, les villes de la côte écartées, que reste-t-il dans la plaino? Deux humbles cités, si l'on met à part les bourgades de la Flandre zélandaise, qui ne sont plus que de gros villages. Furnes et Bourbourg sont seules à représenter l'élément urbain: or l'une a 5.800 habitants, l'autre avec son faubourg Bourbourg-Campagne, 5.500. Leur unique rôle est celui de marchés agricoles; Bourbourg expédie chaque semaine vers le groupe de Iille un train de bestiaux, volailles, beurre, et envoie en Angleterre des œufs. Furnes a toujour's été une bourgade agricole; dès lo XIV ${ }^{\theta}$ siècle elle est habitèe par une majorité de propriétaires fonciers, et de nombreuses granges sont mentionnées dans l'intérieur de la ville ${ }^{1}$; une ordonnance de 1/73 la déclare pauvrement et petitement peuplée ${ }^{2}$. Toutes deux ont le même caractère de villes aquatiques, entourées d'eau, ou coupées de canaux, calmes et propres; si Furnes a pour parure quelques beaux édifices, Bourbourg est animé par l'incessant mouvement de batellerie qui traverse la petite ville, en suivant le canal qui relie Dunkerque au reste de la France.

Cependant les agglomérations urbaines deviennent nombreuses sur la lisière méridionale, au contact de la plaine et de l'intérieur. Grosses ou petites, elles sont les points d'échange entre deux régions différentes, et le mouvement des transactions y fut considérable. Guînos avait une navigation active sur sa Riviére, alimentée par les eaux abondantes de la craio; c'est là que se faisait le commerce entre Boulonnais et Flandre; bois, vin, chaux, et pierres, fer, charbon, descendant du haut pays, s'y échangeaient contre cervoise, blé, orge, avoine, pois, sel, produits par la plaine ${ }^{3}$; au XVIII ${ }^{\mathrm{e}}$ siècle, c'est le point d'embarquement des pierres de Ferques et de Landrethun ${ }^{*}$. Ardres est resté Ie plus grand marché du Calaisis. Audruicq, Watten, ne sont que des bourgades; mais Bergues est une vraie ville, le

1 Pironno (H.), Le sonlèvement de la Flandro maritimo on 1323-1328 (Acad. roy. do Belgique, Comm. roy. d'histoire, 1900, LXX + 241 p.), p. LXV1I.

2 Gilliodts, Coutumes de Furnes, I, p. 48.

3 Tailliar, Livro des Usaiges ( $\mathrm{XV}^{\mathrm{\beta}}$ siècle), pp. 83-84.

4 Cf. Arch. Pas-de-Calais, C. 87, 90. 


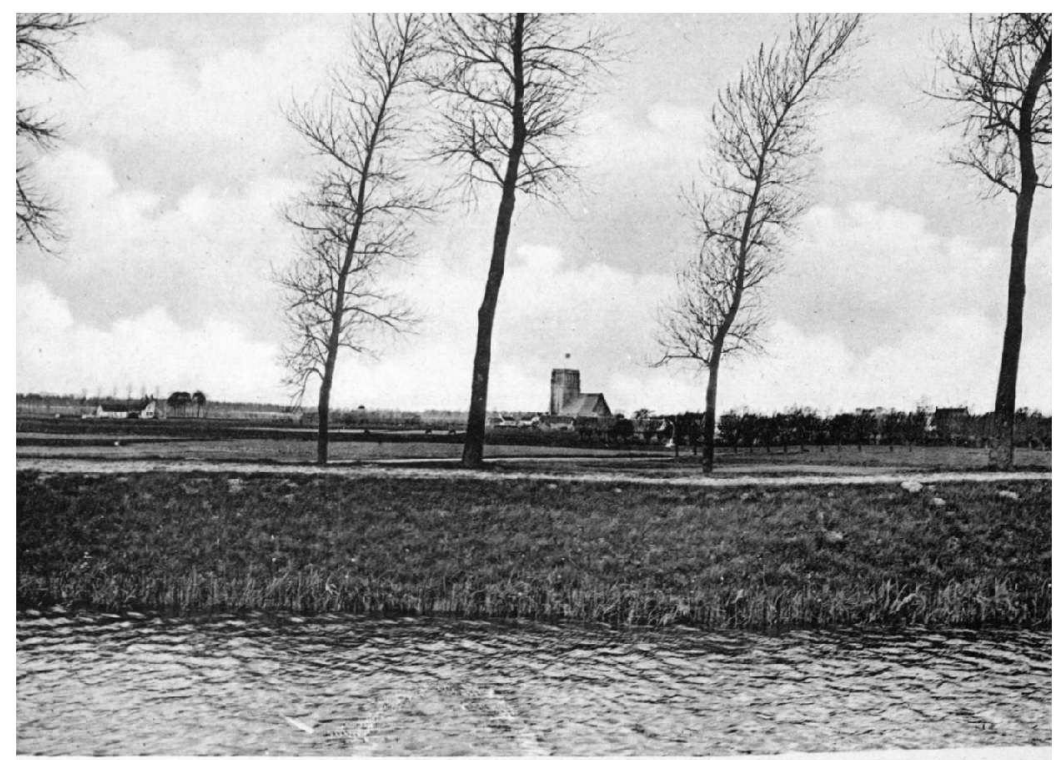

31. - Type de village de la Plaine (Oostkerke, près Bruges).

La tour, ancien phare $d u Z_{\text {win. }}$.

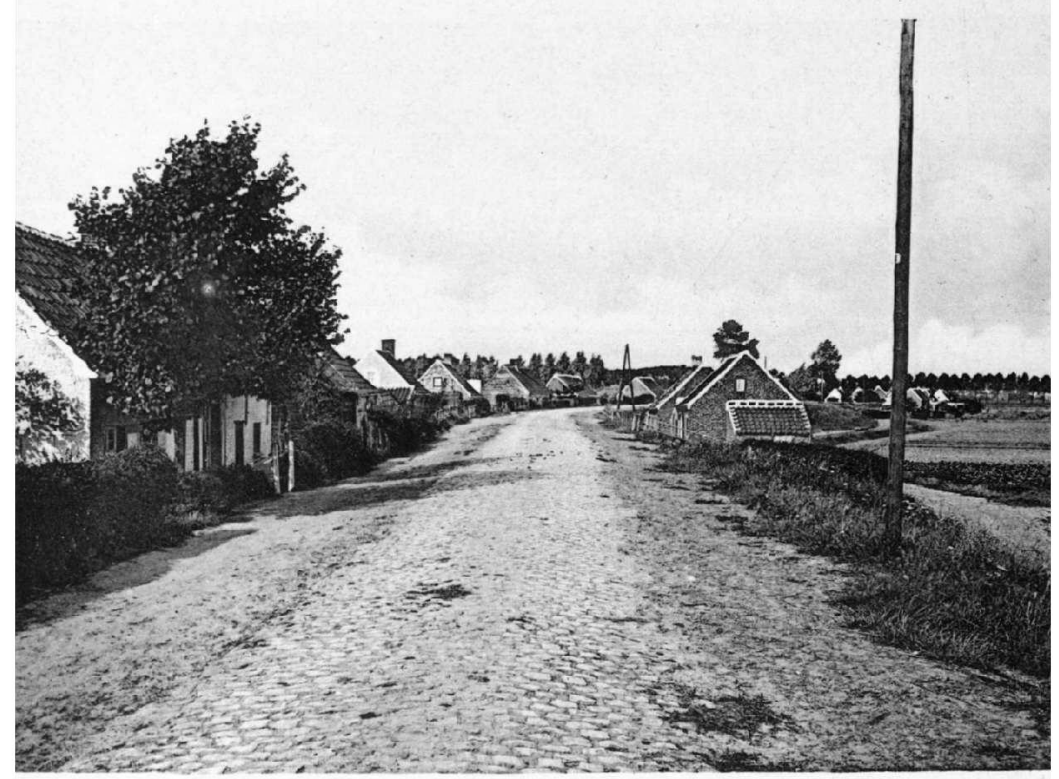

32. - Type de village accroché à une digue (Westdorpe). 
IRIS - LILLIAD - Université Lille 1 
type de ces marchés, intermédiaires entre deux régions : le mouvement du froment en 1804 y était de 111.709 hectolitres ${ }^{1}$, contre 18.472 à Bourbourg, et la place élait désignée en 1819 comme un des grands marchés régulatours des cérbales, avec Arras, Paris, Rouen, Royo, Soissons. Dixmude dispute d Furnes la prépondérance sur le Furnambacht, et l'emporte sur sa rivale. Hondschoote, Ghistelles, Oudenbourg, jouent un rôle analogue, et il n'est pas jusqu'à la lointaine ville de Hulst qui ne serve d'intermédiaire entre les sables du Sud et les argiles du Nord. Toutes ces bourgades se ressemblent; elles ont également l'air assoupi. Bergues est le type de la ville morte; les couleurs qui décorent ses maisons sont passées et pâlies; les rues sont silencieuses et tortueuses; on dirait un quartier de Bruges, et les belles tours qui la dominent contribuent à fixer cette impression. Jadis l'industrie les animait; Hondschoote était la ville des serges ${ }^{2}$; Oudenbourg avait la spécialité des sayettes, et ses habitants étaient les «strypgarenmakers» (fabricants d'étoffes rayées); les anciens noms de marché au fil, coin des teinturiers, foulerie, et de marché au beurre, marché aux œufs, rappellent les éléments de l'ancienne prospéritẻ ${ }^{3}$. Aujourd'hui que les céréales se vendent par échantillons, que le bétail même est souvent acheté sur place, l'importance agricole de cos villes diminue encore. Celles que l'industrie ne vient pas sauver ne vivent plus que par la force acquise : leur population décroît. De 1880 à 1900, Dixmude descend de 4.106 à 3.829 habitants ; Bergues en perd 400 entre 1860 et 1901 ; Guînes de 4.618 en 1846, descend a 4.157; Hondschoote, de 3.700 à 3.365. Au contraire Watten devenue industrielle passe de 1.260 habitants en 1860 à 2.113 en 1901.

\section{Bruges.}

Bruges est la plus belle et la plus célèbre de ces villes endormios qui bordent la plaine au sud. De tout temps, la ville qui se fonda vers le VIIIe siècle autour d'un château qui gardait le fond de l'estuaire du Zwin s'est tournẻe vers la plaine nue que dominent ses hautes tours, et non vers le Sud aride, bois et bruyères à peine colonisés entièrement au XIX ${ }^{\mathbf{e}}$ siècle. Bruges fut d'abord une ville commerçante, un port du Zwin, port dont l'importance ancienne est attestée par l'existence à cet endroit d'un atelicr

1 Dieudonnè, II, p. 486.

2 Sur Iondschoote, voir de Bertrand (R.), L'industrie manufacturière à IJondschoote du XII' au XVIII' siècle (Ann. Gom. fl. Fr. IV, 1858-1859, pp. 343-389).

3 Feys, Oudonbourg, I, p. 66 ot p. 71. 
monótaire au IX $\mathrm{X}^{\theta}$ sidele $^{1}$; ce sont des marchands que Jean d'Ypres nous montre, à la fin de ce siècle ${ }^{2}$, établissant leurs maisons autour du Bourg que vient de fortifier Beaudouin Bras de fer, et encore des marchands qui peuplent le suburbium au XII", lors des graves évènements qui suivent la mort de Charles le Bon ${ }^{3}$. Lo sol marécageux, bordant des buttes de sable et une forêt de chênes, dont les vieux noms de rues nous conservent le souvenir ", se couvrit d'entrepôts où l'on amenait, \& pour être réexpédiés dans toutes les parties du monde », l'argent, le cuivre, les tissus de Phénicie, de Chine, des Cyclades, les pelleteries de Hongrie, les vins de Gascogne et de la Rochelle, le fer et les métaux, les draps et autres marchandises d'Angleterre et de Flandre ${ }^{5}$. Pourtant, tout en devenant un grand port de transit et une ville industrielle de premier ordre, Bruges restait le marché des produits de la plaine, et Guillaume le Breton dans la revue rapide qu'il passe des ressources de chaque ville flamande, voit les èlẻments de la richesse de Bruges à la fois dans ses grains, ses prairies, et le port qui l'avoisine ". Aussi lorsque la mer s'éloigna lentement de la ville, et que, le grand commerce international disparu, l'industrie brugeoise à son tour se mit à décliner lentement, Bruges vécut en restant une capitale agricole. C'est le rôle qu'elle a gardé jusqu'à présent. Contrairement à ce qui s'est passé pour Bergues, le marché de Bruges prend une importance croissante pour la vente du bétail, et surtout pour le commerce des beaux chevaux du Franc. C'est à Bruges, d'ailleurs, qu'habitent la plupart des propriétaires des terres de la plaine situées entre l'Yser et le Braakman. Chaq́ue semaine le jour du marché, les paysans du Franc, avec leur figure pleine et rasée, envahissent la ville de leur foule calme et lente; ils ont remplacé, à travers les rues archaïques, les marins et les commerçants d'Espagne, de Portugal, Gascons, Italiens, Hanséates, Anglais qui peuplaient la Bruges du $X V^{e}$ siècle de leur cohue bigarrée.

1 De Schodt, Résumé historique de la numismatique brugeoise. (C. Rendu Congrès hist. et archéol. Bruges, 1887, pp. 237-238).

2 Chronicon S. Bertini (M. G. SS. XXV, p. 768).

3 Galbert de Bruges, Passio Karoli boni comitis Flandriae (éd. Pirenne, Paris, 1891, in- $8^{\circ}$ ). Cf. sur les origines de Briges : Gilliodts, Bruges ancienne et moderne (Bruxelles, 1890, in-4", 81 p.); - Des Marez (G.), Etudo sur la propriété foncière dans les villes du moyen-âge et spécialement en Flandro (20) fascicule du Recucil des travaux publiẻs par la faculté de philosophie et lettres de l'Université de Gand, 1898).

4 Verschelde (Ch.), Etude sur les noms des rues et des maisons de la ville de Bruges (Ann. Soc. Em. Br., $3^{e}$ série, X, 1875, pp. 283-437).

5 Guillaume le Breton, M. G. SS. XXVI, vers 380-390, p. 346.

6

Frugibus et pratis dives, portuque propinquo

Dam quoque.... (Ibid. vers 104, p. 321). 
Aussi le contraste est vif entre le rôle économique actuel de la ville et le décor magnifique qu'clle a conservé intact, restée une ville du XVI ${ }^{\mathrm{c}}$ siècle, (avec des monuments du XIV ${ }^{8}$ ), parce qu'elle a été trop pauvre pour se transformer ${ }^{1}$. C'est la misère qui nous a garde, dans toute sa splendeur, la Bruges industrielle et commerçante. Ses principaux monuments jurent avec son rôle et son activité actuels: ils portent l'empreinte d'un génie impérieux et pratique, où l'ensemble est plus remarquable que les détails, où le grandiose et la hardiesse des constructions frappent plus que leur élégance. Les grandes églises sont les «clochers militaires » dont parle le poète de Bruges la Morte: Notre-Dame avec sa tour incroyable d'énormité, toule bardée de contreforts $\otimes^{2}$; St-Sauveur avec « ses grands murs aveugles, sa tour altière qui ressemble plus à un chevalier surveillant l'ennemi, qu'à un prélat voulant bénir ses ouailles ${ }^{3}$. Le beffroi des Halles, qui symbolise l'ancienne activité brugeoise, étonne avant d'inspirer l'admiration. Peut-être les matériaux employés sont-ils pour quelque chose dans cet aspect un peu sévère; la brique ne se prête pas aux mêmes combinaisons gracieuses que la pierre; elle oblige les architectes à donner à leur cuvre plus de simplicité. A Ypres, on pouvail construire en pierre; les grès de Bèthune n'étaient pas loin; à Bruges, il fallait se contenter des briques de la Plaine, ou des coûtenx matériaux venus de Guînes par le dédale des canaux. Tout fut donc de brique, sauf quelques édifices de la Renaissance; et ce sont des maisons de briques aux pignons en marches d'escalier qui bordent la plupart des rues. On en trouve de semblables dans presque toutes les villes flamandes, mais nulle part autant qu'à Bruges; de même qu'aucune autre ville du pays ne posséde à un pareil degré le charme mélancolique des canaux, bras de la Reye entourant l'antique Bourg, ou anciens fossés des fortifications du XIII ${ }^{\mathrm{e}}$ siècle. Tout paraît noble à Bruges, même la tristesse des quartiers les plus déserts, comme ce coin N.-E. qui futjadis, à proximité du canal de Sluis, l'entrepôt, et le point le plus animé de la ville; les quartiers ouvriers même ont moins de banalité qu'aillours, la plupart des petites maisons basses étant surmontées d'une fenêtre mansarde encadrée de deux montants en briques, qui suffit à orner ces pauvres masures.

Cet air de grandeur et de noblesse inscrit jusque dans les plus humblẹs

1 Fierens-Gevaert(H.), Psychologie d'une ville. Essai sur Bruges (Paris, Alcan, $2^{\circ}$ éd., 1902, in-12, 191 p.), pp. 174-75.

Taine, Notes de voyage, p. 302.

3 Havard (H.), La Terre des Gueux. Voyage dans la Flandre flamingante (Paris, Quentin, 1879, in-12), p. 293. 
édifices de briques devait inspirer aux Brugeois le désir de rétablir l'harmonie entre la beauté de leur ville et sa prospérité économique. Mais comment ressusciter cette ville pauvre, où sur une population de 50.000 habitants en 1896, on comptait 9.000 indigents secourus? On pensa que puisque le port avait fait jadis sa fortune, c'était le port qu'il fallait rétablir. De là les tentatives faites depuis trois siècles: le grand canal creusé jusqu'à Ostende au $\mathrm{XVII}^{\mathrm{e}}$ siècle; puis l'essai de reprendre la voie du $Z$ win en ouvrant, au début du XIX ${ }^{\mathrm{e}}$ siècle, un canal de Bruges à Sluis. Achevé de 1810 à 1818, on devait le prolonger jusqüà Breskens, quand la révolution de 1830 vint tout empêcher de ce côté. On exhuma alors un projet proposé dès le XVI siécle par le peiutre Lancelot Blondeel, creuser un canal de Hruges à la rade de Heyst. M. de Maere demandait, dés 1866, un canal maritime Gand-Br'uges à Heyst; en 1877 il restreignait son plan à une grande voie d'eau Bruges-Heyst, et ce projet a fini par donner le port de Zeebrugge, le canal maritime et les bassins établis sur le bord Nord de l'ancienne enceinte. Les désirs des Brugeois sont accomplis; reste à savoir si leur cité va redevenir un grand port, ou rester assoupie dans ce demi-sommeil qui convient si bien a son air de ville sainte de la Flandre.

\section{L'absence d'industrie.}

Ce qui manque à toutes ces villes de la plaine pour échapper à la décadence of faire quelque figure, c'est l'industrie. Il n'y en a pas dans tout ce bas pays: c'est la partie de la Flandre qui en possède le moins. Et comment l'industrie pourrait-elle y naître? Il n'y a déjà pas assez. d'hommes pour cultiver la terre, et il faut, dans les cas pressants, faire appol aux bandes enrôlées dans les Dunes ou le Houtland. A quoi bon d'ailleurs s'occuper de transformations industrielles? La terre polderienne suffit à nourrir' ses habitants ; l'agriculture, à leur procurer des r'essources. On néglige done tout ce qui n'est pas le travail des champs; et la fabrication de la dentelle, par exemple, si répandue dans les parties pauvres de l'intẻrieur, s'arrête à la limite de la plaine: Keyem, Leke, Jabbeke, Bruges, Moerkerke sont à la frontière Nord de la région dentellière(fig. 61). Ainsi l'industrie ne s'acclimate pas dans les polders; les habitants y sont trop peu nombreux et trop aisés. Hors des ports, où l'abondance de main d'œuvre et les facilités de transport l'ont toujours favorisée, elle se bornait jusqu'au milieu du XIXe sièclo à quelques malhoureux métiers manuels : la briqueterie; le tourbage qui occupait en 1811 en Flandre Occidentale 
750 ouvriers pendant 6 semaines ${ }^{1}$, et dans l'arrondissement de I) unkerque 125 hommes environ en 1850 ; le curage des canaux, pour lequel les habitants de Damme ont la réputation d'être passés maîtres. L'apparition - de la betterave et de la chicorée a provoqué la création de quelques usines, sucreries, distilleries, séchoirs ; dans la partie française deux seulement sont considérables: la sucrerie de Pont-d'Ardres, qui centralise les produits du Calaisis, et a écrasé en 1902160.000 tonnes de betteraves ${ }^{2}$, et la distillerie de Steene qui produit chaque annèe 45 à 50.000 hectolitres d'alcool el a occupé jusqu'à 300 ouvriers. La partie belge a deux sucreries, l'une à Selzaete, approvisionnée par les betteraves de la Flandre zélandaise ; l'autre à Snaeskerke près d'Ostende. Bruges a des distilleries. A peine trouve-ton d'autres industries: à Watten une filature de jute et d'étoupes de lin, une grande tannerie et des chantiers de construction de bélandres, occupant en tout près d'un millier de personnes; à Bergues une malterie, a Dixmude une minoterie, à Bruges une usine métallurgique, des malteries et des fabriques de brosses: encore toutes ces fabriques sontelles construites à la limite de la plaine et occupent-elles des ouvriers de l'intérieur. De même pour les usines établies au milieu du pays bas ; ce sont des hommes de Beveren-lès-Roulers et des communes voisines qui font brûler les cosseltes dans les tourailles des séchoir's à chicorée ; des ouvriers venus de tous les points du Houtland qui travaillent aux sucreries pendant les trois mois de la fabrication, ou confectionnent les briques destinees aux villes de la côte. Les gens de la plaine qui s'occupent dans une usine sont rares.

\section{IV.}

\section{LA POPUlation.}

I'homme de la plaine se détourne donc de l'industrie. Il est et reste un cultivateur. De mêrne il n'a jamais été un marin; les belles terres des polders rapportaient bien assez pour dispenser leurs habitants d'aller chercher dans les dangers de la mer un supplément de ressources: cela n'était bon que pour les populations pauvres des dunes. La Plaine tourne le dos à la mer, qui ne lui a apporté que des malheurs; elle ne la connaît

1 Arch. Nat. F12 1592. Surtout dans le Franc de Bruges, dont les habitants étaient surnommés les brûleurs de tourbe (daryncharners).

2 Fxposé sommaire des travaux de la Chambre de Commerce de Calais, 1902, p. 229. 
que pour la craindre, et lutter contre elle. Les ports et leurs habitants étaient à part du pays, ne comptaient pas avec les châtellenies : Dunkerque hor's de l'ambacht do Bergues, Nieuport et Ostende à part du Furnambacht et du Franc. Ia population de la plaine est bien terrienne ; c'est une classe de paysans aisés.

Ces paysans n'ont pas toujours été les hommes froids et calmes qui peuplent aujourd'hui le pays. $\mathrm{Du} \mathrm{VI}^{\ominus}$ au $\mathrm{XI}^{\mathrm{\beta}}$ siècle, la colonisation de la plaine avait amené sur ce sol des éléments mêlés, d'une turbulence et d'une énergie extraordinaires. Ces rudes habitants des terres nouves, exposés sans cesse à des retours offensif's de la mer: pirates normands restés eu route, Saxons venus par les côtes, Frisons descendus du Nord en suivant dans leurs barques le tracé des-estuaires, Francs aventurés au delà des forêts et des marécages, formèrent un peuple violent et libre, ignorant le servage, et groupé de bonne heure en associations de défense contre les éléments et contre les hommes. Ce peuple jeune avait d'incroyables mouvements de violence: St Arnulf qui vient les apaiser au $\mathrm{XI}^{\mathrm{e}}$ siècle trouve tout le pays, d'Aardenburg à Furnes, en état de guerre perpétuelle; en un an on constate officilement 1.200 meurtres autour do Bruges, et certains s'estiment déshonorés s'ils n'ont pas tué leur homme dans la journée ${ }^{1}$.

Aussi ces indomptables hommes libres ne supportèrent-ils pas aisément la main-mise de l'autorité comtale, qui s'appesantit sur eux à partir du XII ${ }^{e}$ siècle. Leur terre était à eux; ils l'avaient conquise sur les eaux et la gardaient; que leur voulaient les nobles, l'abbé et le comte ? lls s’insurgent donc contre l'autorité qui pénètre chez eux; ce sont des hommes de la plaine qui font la conjuration contre Charles le Bon, le comte justicier; et après la mort du comte, les meurtriers sont en relation avec « les gens de Furnes et les Flamands qui sont au bord de la mer ${ }^{2}$. $\Lambda$ u XII ${ }^{\mathrm{e}}$ siècle revient, tous les trois ou quatre ans, comme une litanie, l'annonce d'une sédition dans le territoire de Furnes. Les premiers de toute la Flandre, ces hommes de la plaine se font octroyer des chartes, qui leur assurent, dans leurs circonscriptions rurales, une large autonomie; ce sont de vraies communes rurales, avec les mêmes priviléges que les organismes urbains ${ }^{3}$. Aussi de 1323 à 13228 se lèvent-ils tous pour défendre leur liberté contre les empiétements des nobles et des prêtres, soutenus par le comte; ce fut une vraie guerre sociale. Les

1 Ix vita Arnulfi episcopi Suessionensis, auct. Hariulfo (M. G. SS., XV, pp. 872-904).

2 C.f. Galbert, éd. Pirenne.

3 Pirenne, Soulèvement de la Flandre maritime, pp. III-X. 
chefs étaient de la plaine: Bouwin, d'Aardenburg, Janssoone de Ghistelles; le principal, Nicolas Zannequin, était propriétaire do 38 mesures à Lampernisse; et ce fut bien l'independance des hommes du bas pays qui périt à Cassel ${ }^{1}$.

Mais aujourd'hui la transformation est complète. Sauf pour la fierté, personne ne reconnaîtrait les descendants de ces terribles «Kerles» dans les gros fermiers du Furnambacht. Ces hommes, avant tout, sont calmes. Des gens froids, qui s'émeuvent difficilement, assure-t-on. C'est aussi lo caractére qu'on attribuait, au début du XIX ${ }^{e}$ siècle, au peuple du marais poitevin ${ }^{2}$. On n'agit guére par sentiment; on dirait dejà le caractère hollandais; la plaine est peuplée d'hommes du Nord. En même temps on les décrit plus orgueilleux, plus fiers que leurs compatriotes du Houtland. Rare dans les polders est le fermier qui mange à la même table que ses ouvriers.

Ces caractères s'expliquent en partie par l'aisance à laquelle sont habitués les gens de la Plaine. Le fermier d'une exploitation de 40 à 50 hectares est déjà un gros personnage en Flandre; les ouvrier's même dans la Plaine gagnent des salaires plus élevés qu'ailleurs. A Lampernisse, le gain moyen d'un journalier (sans nourriture) est de 2 francs par jour ; à Vladsloo, commune du Houlland éloignée de 10 kilomètres, il est de 1 fr. 40. A Boitshoucke, près de Nieuport, il s'élève à $2 \mathrm{fr} .50$; à Hoogstaede, situé à 13 kilomètres au Sud, il tombe à 1 fr. 35, prosque moitié moins ${ }^{3}$. La meilleure preuve de la richesse de la contrée, c'est l'abondance des dépôts effectués aux Caisses d'épargne de la Plaine. Celle de Furnes comprenant 8 communes poldériennes, est la première de la Belgique entière pour le total des sommes versées par habitant: 287 francs par tête; à côté, la caisse d'Eessen-Vladsloo, hors de la plaine, ne compte que 18 francs par tête, et les communes des dunes, comme Adinkerke, 25 francs ${ }^{4}$. Plus riches, ils sont plus orgueilleux. Peut-être aussi

1 Un rapprochement paraît possible entre ces fermiers libres des polders et les hommes des Fens d'Angleterre, puritains démocrates et égalitaires, au milieu desquels so leva Cromwell. Au Nord de la Hollande, la Frise a toujours óté par excellence un pays do liberté, et les Frisons luttainnt sauvagement contre la domination hollandaise pendant que lours frères de Flandre s'insurgeaient contre lour comte.

2 «Caractère froid, tranquille, apathique ». (Gaudinoan, Topographie, p. 15).

3 Recensement agricole de 18\%5, III, pp. 30-32. Les chiffres se rapportent à l'année 1895.

1 Burny et Hamande, Les Caisses d'Fpargne en Belgique (Mémoires couronnés et autres mémoires Acad. roy. Belgique, collection in-8 $8^{\circ}$ t. I.VI, 1896-1902, 677 p., 2 cartes à $1: 320.000$ ) planche $B$. 
l'isolement dû à la situation des fermes, écartées les unes des autres et reliées par de mauvais chemins impraticables par.la pluie, contribue-t-il a donner a leur caractère cette froideur et cette absence de sociabilité qu'on est unanime à leur reconnaître.

Colte richesse se traduit par une vie plus large. L'homme de la plaine vit bien, dépense largement, connaît la toilette. Ia nourriture y est beaucoup plus substantielle que dans le Sud ; on y mange de la viande (du lard) tous les jours; et c'est là, en Flandre, un signe indiscutable d'aisance. En général, dans les fermes, les domestiques en reçoivent même deux fois par jour, et trois fois dans los communes riches comme Lampernisse, accompagnant le café au lait, le pain, les pommes de terre et le lait baltu. Déjà Dieudonné en 1804 remarquait que l'arrondissement de Bergues était celui où l'habitant se nourrissait le mieux ${ }^{1}$. Et c'est peut-être une des raisons pour lesquelles les gens de la plaine maritime ont une vigueur, une santé qui les distingue encore une fois de leurs voisins du Sud. Grands, forts, hauts en couleur, c'est, dit un rapport médical, « une population forte et robuste, chez laquelle l'élément sanguin domine ${ }^{2} \gg$. Il y a peutêtre ld aussi une question de race, et les hommes de la Plaine pourraient bien, en majorité, êtro descondants des Frisons, peuple dont le type se retrouve tout le long des pays bas de la mer du Nord, et rappelle l'aspect des Flamands maritimes. En tous cas, on ne peut s'empêcher, à propos de cette population des terres basses, de retrouver dans leur physique ce caractère d'ampleur et de puissance qui accompagne dans la Plaine toutes les manifestations de la vie. Sauf les arbres, rien n'est étriqué sur cette terre nourricière; tout est gros, luisant, végétaux, animaux, hommes. C'est bien lả cette bonne et forte Flandre dont parle Michelet, ces « grasses et plantureuses campagnes, où tout pousse à l'envi, grossit à plaisir », où vit cette race puissante illustrée par les tableaux de Rubens; le bon pays que regarde de travers l'homme du Houtland, habitant d'une terre plus maigre, plus rude, où l'on sent l'effort.

\section{V.}

\section{FLANDRE ZÉLANDAISE.}

Il y a dans la Plaine une région, séparée du reste de la Flandre par une

\footnotetext{
1 Dieudonné, Statistique, I. p. 76.

2 Enquête sur la condition des classes ouvrières et sur le travail des enfants (Bruxelles, Lesigne, 1846, 3 vol. in- ${ }^{\circ}$ ), III, pp. 298-299, Rapport de la Commission médicale de la Flandre Occidentale.
} 
frontière politique et religieuse, isolée de la Hollande derrière le bras de mer du Hont, qui a conservé presque tous les anciens caractères de la Plaine, en leur gardant une fraîcheur et une netteté qui s'est un peu atténuée en France et en Belgique : c'est la Flandre zélandaise. Elle forme comme un résumé de la plaine maritime; un résumé où les traits sont plus accentués.

Etat actuel de la lutte contre la mer.

C'est dans cette partie que la lutte contre les eaux, et surtout contre la mer, a pris des proportions particulièrement vastes. On a vu qu'd plusieurs reprises, profitant des distractions dos défenseurs, l'ennemi avait fait de brusques invasions, et que c'est au XVIII siècle seulement qu'on avait reconquis les limites attointes déjà au XIVe. La bataille continue; la Flandre zélandaise s'accroît patiemment aux dépens de la mer; tous les quatre ou cinq ans vient s'ajou ter à son territoire, aux dépens du Braakman ou des bancs de Saaftinge, quelque nouveau polder au sol grisâtre et crevassé, sur lequel se levent bientôt des moissons merveilleuses. Mais il y a aussi quelques retours de fortune. Lo Z warte Polder n'a pu être réendigué depuis un siècle; un épi jeté au milieu n'a provoqué que la formation locale d'une petite dune; le Thomaes Polder n'est qu'en partie reconquis ; constamment on rencontre sur la côte les équipes du Waterstaat, vérifiant, consolidant, enfonçant des pieux ou plantant des fascinages. C'est que la côte est constamment menacée par lo déplacement des chenaux de l'Fscaut occidental. L'estuaire, en effet, subit fréquemment des modifications de détail. Il ne semble pas qu'il se soit, dans l'ensemble, envasé ou approfondi depuis un siècle, car les banes de l'embouchure n'ont guère bougé, ce qui prouve qu'ils n'envoient pas de matériaux dans le fleuve, et le débit solide amont, composé à peu près uniquement de matières vaseuses en suspension, finit par être expulsé de l'estuaire grâce a la prédominance du jusant: les anfractuosités seules, comme le Braakman, se comblent peu a peu. Mais les chenaux profonds subissent des modifications fréquentes. Les courants de marée qui les parcourent obéissent à la loi sinusoïdale des cours d'eau et s'appuient sur les rives concaves en s'éloignant des rives convexes: il y a ainsi creusement et affouillement très rapides, et parfois abandon d'anciens chenaux au profit de nouveaux ${ }^{1}$. C'est ainsi que du côté du Nord, le banc

1 Sur l'Escaut maritime, voir: de Mey, Por ts en plage, pp. 105-182; - de Mey, l'kscaut maritime (Ve congrès international de navigation intérieure, Paris, 18y2, $10^{\mathrm{E}}$ question, 20 p., 3 pl.); - Rochot, Description hydrographique de l'Escaut depuis son embouchure jusqu'à Anvers (Bruxelles, Lesigne, 1894, in-fo, 120 p., 176 pl.). 
du Kaloot diminue sans interruption depuis 1800, tandis que la passe de Borsele s'approfondit jusqu’à 40 mòtres; qu'au Sud la passe de Hoofdplaat menace la rive, et qu'en revanche les bancs de Hooge Springer s'élargissent, et s'allongent devant Breskens. Plus loin, c'est la passe de Terneuzen qui se creuse et se rapproche de la côte, avec des profondeurs de 33 mètres, tandis que le Suiker-plaat s'exhausse et s’étend. Au delá d'Ossenisse, l'ancienne fosse de Waarde est devenue impraticable: c'est une impasse (schaar), et le courant s'est reporté vers le Zuidergat, qui se rapproche du rivage de Walsoorden, et ronge le bord des schorres de Saaftinge. Ces mouvements des fonds ne compromettent en rien la navigabilité de l'estuaire: il suffit d'un peu d'attention pour reconnaître les passes el de quelques travaux de détail, dragages ou fixations, pour les accommoder; mais les côtes peuvent se trouver menacées. Le village de Hoofdplaat, fondé après l'endiguement du schorre en 1778, a été inondé presque aussitôt, et réendigué en 1795; il a fallu hórisser les digues de pieux et d'épis ${ }^{1}$. La fortification de la côte, entre Terneuzen et Ossenisse, rappelle les défenses du pays de Kadzand; la digue porte la trace des remaniements que les inondations lui ont fait subir; son dessin est tourmenté; il y a des pointes noirâtres ot des rentrants, des épis sont projetẻs dans toutes les directions, et cependant à mor basse les thots viennent encore battre son pied, fortifie de six rangs de pieux serrés. En revanche, au fond du Braakman, la marée haute elle-même parvient péniblement au pied des digues, et la mer s'éloigne tant que l'évacuation des eaux intérieures devient difficile; à l'écluse Isabelle, on a dû pratiquer à travers les vases grises du schorre un canal artificiel par où l'eau d'Assenede et Bouchaute gagne pénihlement la mer.

Le pays conserve des traces des séjours que la mer y a faits à plusieurs reprises, et des travaux entrepris pour l'en expulser. Le sol est encore sillonné de larges criques tortueuses, trop profondes pour pouvoir être comblées de main d'homme, et qu'on laisse au temps le soin de colmater; en attendant elles servent de viviers, et la location de ces étendues poissonneuses fournit de sérieuses ressources aux polders qui les possèdent ${ }^{2}$. Surtout, les terres sont tout enserrées de digues. La Flandre

1 Il a mème été un moment question d'abandonner le village, et l'on dit que l'entretien des 3 kilomètres de digues du polder a couté 3 millions de trancs. Cif. Lacroix (J.), Mémoire sur l'histoire hydraulique de la Néerlande(Ann. P.-G., 1846, pp. 193-194).

2 Cette ressource ẹst une des plus anciennes de la Plaine, et les locations de droit de pêcho, en particulier de " poises d'anguilles ", sont extrêmement fréquentes dans les chartes des abbayes. 
zélandaise est un vaste échiquier aux cases irrégulières, enfermées de lignes gazonnées qui sont le trait dóminant du paysage. Il y en a de hautes et de basses ; des vieilles comme la Langendamsche-dijk, près d'Hulst, que l'on peut voir complètement plantée de betteraves ; d'autres plus récentes qui ont encore le profil raide d'un côté, adouci de l'autre, avec la plateforme intermédiaire, qui caractérisent les modernes digues de mer. Mais presque toutes sont aujourd'hui couvertes do maguifiques rangées d'arbres, qui en font de heaux chemins verdoyants et ombrenx. Cette présence des arbres est une des grandes diflérences d'aspect entre la Flandre zélandaise et le reste de la Plaine. Sauf autour du Braakman, où la vue porte pour ainsi dire à l'infini, il est rare de retrouver là les immenses horizons du Furnambacht. Le paysage est plus intime. Les arbres envahissent même les polders, forment des massifs épais autour des fermes, abritent des vergers, qui ne semblent pas craindre la morsure des vents de mer déjà affaiblis. Autour d'Ijzendijke, dans les Waterlanden, on a parfois l'impression d'un pays boisé, d'un bocage. Les vieux polders, ceux qu'a épargnés l'inondation de la guerre de 80 ans, se reconnaissent rien qu'à leur magnifique végétation. Le Paulus-Polder, les abords de Hengstdijk et de Kloosterzande, au Nord de Hulst, dans l'heureuse presqu'île d'Ossenisse, avec leurs digues ombragées de cinq à six rangẻes d'ormes superbes, leurs pâtures coupées de lignes de saules et de peupliers, leur crique du Groot-Vogel, vrai fleuve déroulant ses vagues claires entre des rives gazonnées, ont l'air d'un beau parc où tout est disposé pour le plaisir des yeux (fig. 56).

\section{Agriculture, habitat, population.}

Les calamités des inondations ont eu au moins d'heureuses conséquences pour la bonté du sol ${ }^{1}$. La Flandre zélandaise, recouverte à différentes reprises du manteau gris des alluvions marines, a vu la fertilité de son sol renouvelée à chaque désastre. Les petits-neveux ont profité des malheurs qui ont frappé les ancêtres; son sol est le plus riche de la Plaine, particulièrement dans les polders qui sont plus proches de la mer ; la différenco est sensible entre les belles terres de Kadzand, Groede, Schoondijke, et les polders aigres et humides de Heille ou de St-Kruis. Les propriétaires d'un polder neuf, obligés de le laisser la première année sans culture pour

1 Sur l'agriculture, voir: de Hoon, Mémoire sur les polders de la rive gauche de l'Escaut et du littoral belge. (Mèm. couronnẻs par l'Acad. roy. Belg., sẻrie in-8 ${ }^{0}, \mathrm{~V}$, 1852, 144 p., 7 cartes, 2 pl.) 
pouvoir combler les creux et égaliser le sol, n'y perdent rien; les années suivantes, cette argile grise compacte aux crevasses innombrables donnera sans engrais des récoltes plis abondantes que toutes les terres voisines. Seul l'emplacernent de quelques anciennes criques fait tache ; le sol en est blanchâtre, garni de roseaux; de chaque côté le blé ne pousse pas, et on voit les épis devenir plus forts en proportion de la distance ou ils sont de cette terre restée salée.

L'extension de la culture des céréales s'accompagne, comme dans le reste de la plaine, de la présence de grandes exploitations, plus vastes encore qu'à l'Ouest du Zwin. La Flandre zélandaise est le pays des grandes fermes, et aussi des grandes propriélés. La famille d'Aremberg, après être restée en procès jusqu'à la Róvolution avec l'abbaye de Tronchiennes à propos des terres englouties de Saaflinge ${ }^{1}$, reçoit aujourd'hui la récompense de son obstination; rien qu'au Sud de la frontière hollandaise, elle possède 1.400 hectares de terres magnifiques ", et ses polders hollandais, agrandis en 1904, sont peut-être plus étendus encore. Les bâtiments d'exploitation répondent à l'étendue des terres; cependant la grande ferme de la Flandre zélandaise ne ressemble pas à celle du Calaisis ou du Furnambacht. Au lieu des bâtiments disposés autour d'une cour, elle ne comprend guère que deux constructions. L'une est l'habitation, toujours à l'ècart, quelquefois à 50 ou 100 mètres du reste; bâtie en briques. couverte en tuiles, entourće d'un trottoir en briquettes, ornce d'une platebande de fleurs, elle regarde d'ordinaire non vers la ferme, mais vers le jardin ou le verger ; c'est la maison d'un hornme à l'aise, qui, rentré chez lui, veut trouver un cadre agrẻable, propre à lui faire oublier ses occupations ordinaires. Certaines ont l'air de véritables maisons de plaisance, a vec leur peinture gaie des volets et des portes, et à l'intẻrieur leurs chambres revêtues de carreaux de faience chargés de scènes bibliques. L'autre construction comprend tous les services de la forme. C'est une sorte d'immense grange, parfois longue de 25 mètres et large de 10; les murs sont en bois, d'immenses poutres mal équarries que l'on goudronne, ou que l'on badigeonne en ronge; le toit, très haut, est de chaume; il se relève et s'échancre au droit des grandes portes, généralement deux de chaque côté. Tout tient dans ce vaste édifice, séparé à l'intérieur par des cloisons: d'un côté les écuries, qui contiennent dans les grandes fermes, outre les poulains, 14 à 16 chevaux de trait; d'un autre l'étable; à une

1 Cif. Arch. Nat., Fis 1121.

2 Vandervelde (E.), La propriété foncière en Belgique (Paris, Schleicher, 1900), pp. 93-103. 


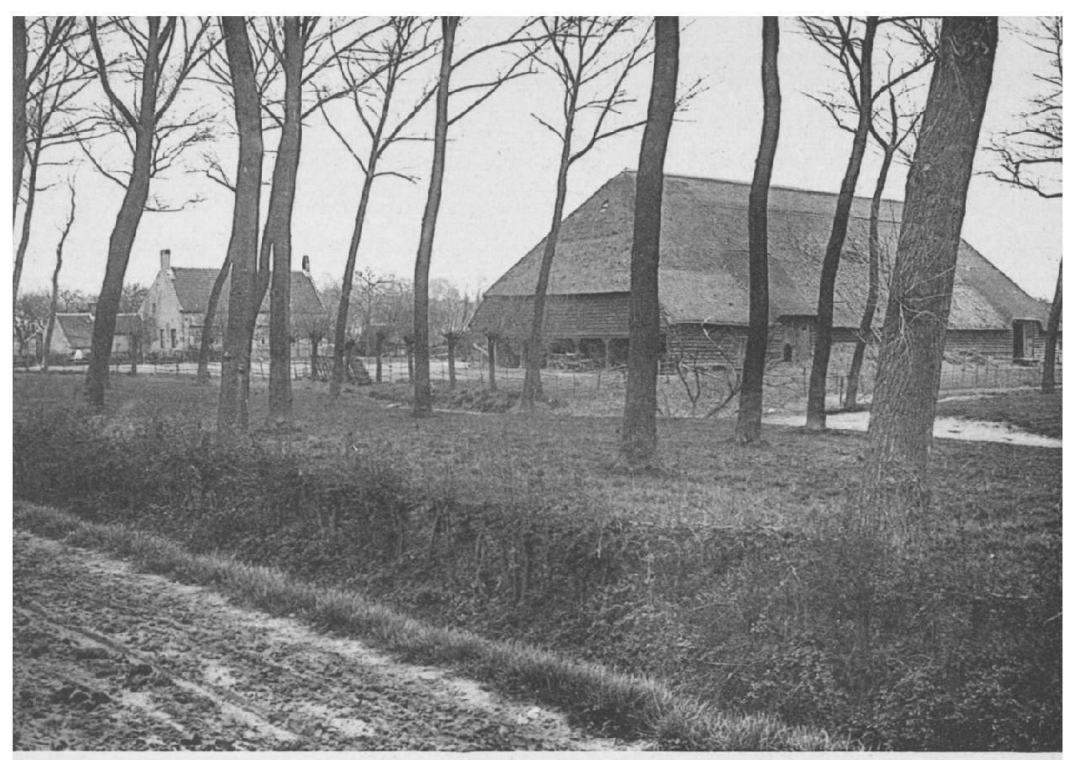

33. - Ferme de la Flandre zélandaise (Schoondijke).

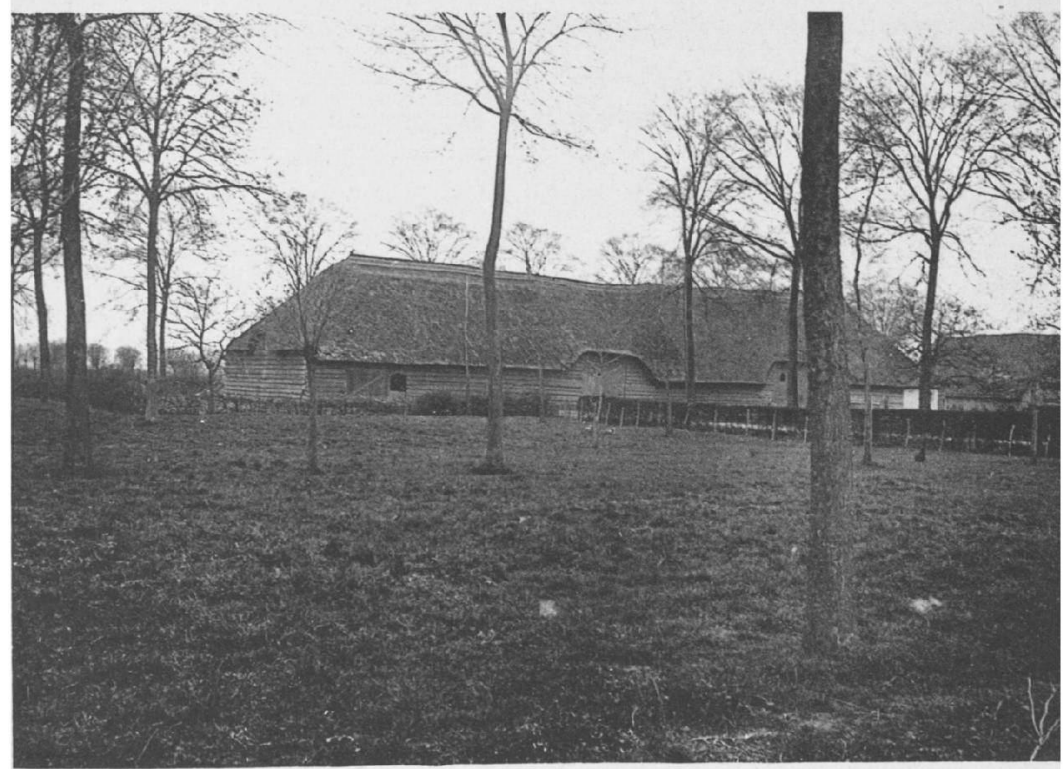

34. - Le Bàtiment d'exploitation en Flandre zélardaise (S̈ choondijke). 
IRIS - LILLIAD - Université Lille 1 
extrémité la charretterie, généralement disposéo pour abriter quatre grands chariots a quatre roues, peints en vert et en rouge, plus larges que ceux du reste de la Plaine, afin de ne pas verser sur les digues où les inégalités sont fréquentes; par dessus le tout, le grenier à foin et à blé. C'est bien ainsi que devaient être les « Grangiae » possédées par les abbayes cisterciennes dans leurs domaines de l'Est. Les progrès de l'elevage depuis 20 ans ont fait b́lever dans quelques formes des constructions annexes; mais c'est toujours l'immense grange qui reste le trait dominant. La même disposition se retrouve en Zélande; plus loin, en Frise, la ferme se réduit à un seul bâtiment, qui ressemble à la grange des Polders, et dont l'habitation se dégage légèrement. Ainsi cette ferme du Nord de la Flandre serait une transition entre la maison frisonne et la maison flamande. De la ferme frisonne à un bâtiment, on passe à la ferme zélandaise, qui en a deux; dans le Houtland, la vaste grange d'exploitation se dédouble, la ferme comprend trois bâtiments séparés autour d'une cour ; dans Ie Sud ces bâtiments se rapprochent, se rejoignent, et l'on a la ferme wallonne de Lille, carrée, fermée de tous côtés, qui annonce la ferme picarde. Il y a là à coup sûr des différences ethnographiques; mais le changement qu'on observe de chaque côté du Zwin peut avoir une explication géographique; la culture des céréales a toujours été plus importante en Flandre zélandaise que dans le Frane de Bruges; de là, dans les polders zélandais, la prédominance du type « grange », que les récents progrès de l'élevage ne sont pas venus encore modifier ${ }^{1}$.

Avec son verger et son massif de grands arbres, la ferme zólandaise est vraiment un ensemble imposant. Bien petite paraît à côté d'elle la maison de l'ouvrier agricole. Il est vrai que son exiguité frappe moins, parce qu'elle est rarement isolée; les habitations vont toujours par hameau. C'est au croisement de trois ou de quatro digues qu'elles s'établissent; il le faut bien, car les digues sont le seul moyen de communication dans un pays impraticable l'hiver; et l'on est ainsi à proximité de plusieurs polders. La ferme est généralement placée dans les mêmes conditions; mais tandis que ses bâtiments sont assis dans le polder, les petites maisons ne s'écartent pas de la digue; les unes, les plus anciennes, accrochées à la partie inférieure, les plus récentes établies tout en haut, de sorte qu'il y a parfois ainsi deux rangées de maisons l'une au-dessus de l'autre. Quelquefois le hameau s'allonge, devient village; Westdorpe se déroule tout au long d'une digue de 4 kilométres ; au centre, on compte quatre rangées de maisons, deux en

1 Quelquefois on élève deux de ces grauges face à face; l'une reste réservée aux récoltes; daus l'autre on établit les animaux. 
contre-bas, deux en haut sur la digue. Il était défendu jadis de bâtir sur une digue, crainte de la détériorer; aujourd'hui la défense ne s'étend plus guère qu'aux digues de mer, et les petits hameaux de maisons claires, dominées par la haute silhouette du grand moulin en briques, escaladent de plus en plus les tertres pour venir se placer au nivean du chemin.

Ies principaux groupements, cependant, ne se trouvent pas dans cette situation pittoresque. Ce sont, ou bien de gros bourgs comme Schoondijke, Zaamslag, Boschkapelle, que l'on a fondés tout d'une pièce après la reconquête, au croisement de quatre routes, bien au centre d'un grand polder, ou bien les « villes * de la plaine, assises sur une faible éminence qui les préservait des inondations. Ces villes ne sont que des bourgades, à peine de gros villages. Sluis n'est qu'une nécropole: Ie quai, une rue avec quelques magasins, quelques maisons et des fermes; les terrains bâtis ne garnissent guère qu'un cinquième de l'enceinte; le reste forme des champs et des pâtures garnies d'arbres superbes; c'est plus une forêt qu'une ville. Sas-de-Gand n'est qu'un quai, Philippine ne fait illusion qu'à cause de ses remparts. Il ne reste guère que deux villes: Hulst et Terneuzen. La première, qui n'a pas 4.000 habitants, est une pauvre bourgade de rentiers, d'ouvriers agricoles et de petits artisans. Terneuzen n'est urbaine que dans la partie Est, autour de la motte qui porte deux hauts moulins à plateforme; elle vit du canal qui mène a Gand. Le terrain y étant moins cher que dans la grande ville, on y a établi d'immenses entrepots de bois, et quelques navires y débarquent leur chargement, ce qui leur vaut un fret moins élevé et leur évite au moins un jour de navigation. Mais villages ou villes ont lo même air de propreté minulieuse auquel se reconnaît n'importe quelle localité hollandaise. Ce sont toujours les petites maisons sans étage, aux murs crépis irréprochables, el où tout ce qui est bois est peint, montants des portes et dos fenêtres, poutres depassant le toit, balustrades courant devant les maisons, si nombreuses que les rues ont l'air de boxes. De Westcapelle à Cassandria, do Maldegem à Aardenburg, on sent la différence entre l'honnête propreté belge et les raffinements hollandais. Il y a une nuance cependant; le pays d'Hulst est déjà plus flamand, les maisons sont plus basses, les fenêtres plus enfoncées, moins larges, pourvues de contrevents extérieurs; au contraire le pays de Kadzand, avec ses grandes larges fenêtres au ras du mur, sans controvents, ses contrastes heureux de couleur, la fraîcheur des teintes renouvelées chaque année, ses fleurs, ses arbres, évoque déjà les paysages gracieux et calmes de Zélande et de IIollande.

Un contraste analogue s'accuse dans la population, et contribue efficacement à faire diviser la Flandre zélandaise en deux parties dont l'une est 
$60.000 \mathrm{~W}$

L2.

46.

-2 .

1.7.

1)

3 (2)

cols

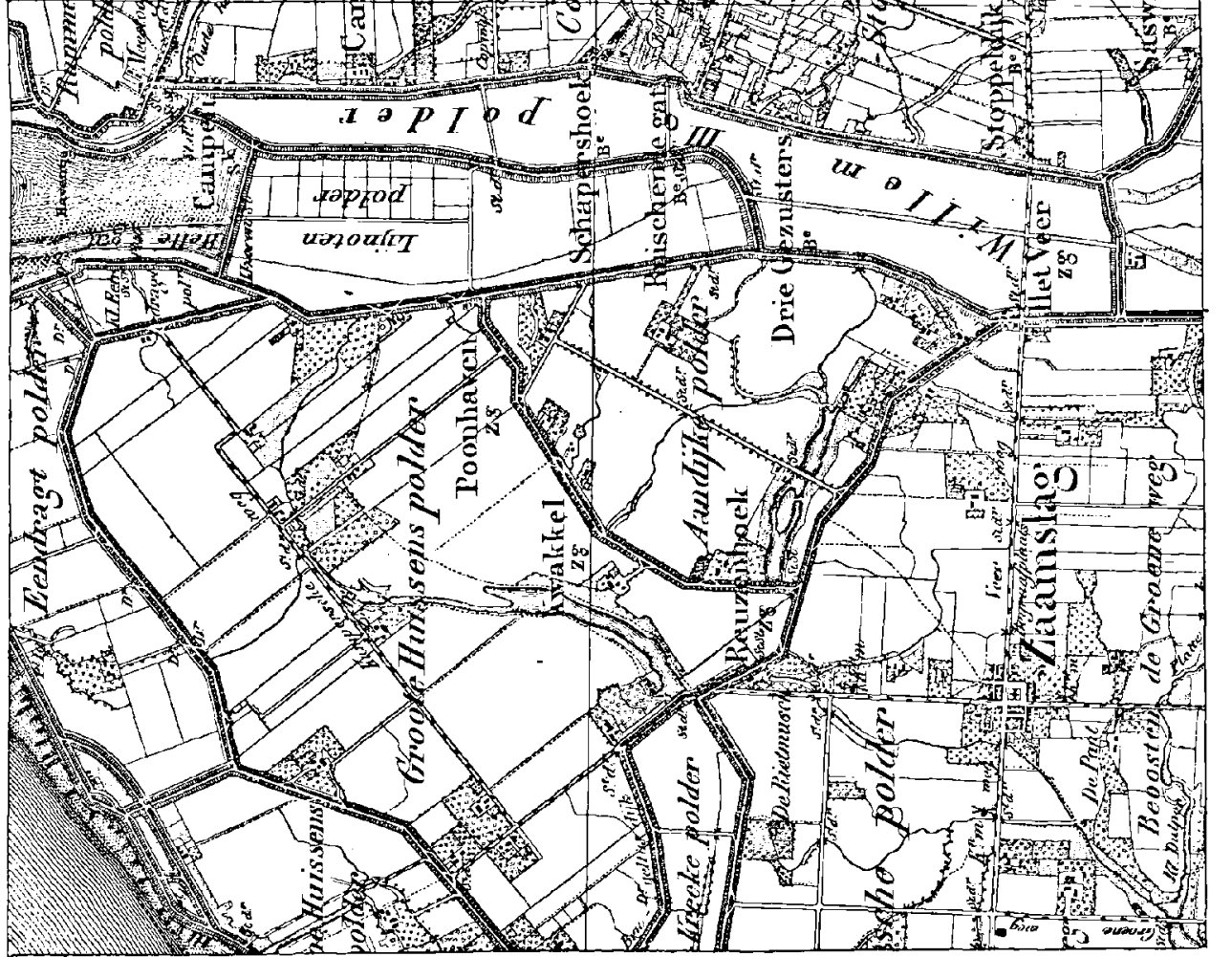


le pays de Kadzand, et l'autre le pays d'Axel, (il vaudrait mieux dire pays de Hulst). Si l'habitant de ces polders, depuis la disparition des fievres, est en général grand, robuste, flegmatique, les différences sont sensibles entre les hommes de l'Est et ceux de l'Ouest; et ces différences viennent de leur origine distincte. Lorsque le pays se repeupla aprés la guerre de 80 ans, ce furent des Flamands du Sud qua s'établirent a Hulst et aux environs, jusqu'à Ossenisse, Zaamslag, Axel et le Sas-de-Gand. Aussi parle-t-on dans cette partie la même langue qu'à Gand ${ }^{1}$; les catholiques y sont en grande majorité : dès 1730 , ils étaient déjà les $7 / 8$ de la population du district ${ }^{2}$; à Hulst, ils sont 2.500 contre 600 réformés ; leur prédominance est attestée par les hautes flèches qui couronnent leurs églises, tandis que les temples protestants de l'Ouest se contentent d'un clocher très simple et très bas. Au contraire, ce furent des Zẻlandais qui vinrent habiter les nouveaux polders de l'Ouest, que les chenaux du Zwin, du Passegeule et du Braakman isolèrent de la Flandre jusqu'à la fin du XVIII ${ }^{\theta}$ siécle, et avec eux bien d'autres élèments ; réfugiés français après $1685^{3}$, Salzbourgeois chassés par leur archevêque, Wallons et Allemands des garnisons qui y furent maintenues jusquà la Révolution. Tous sont protestants, de caractère plus grave et plus calme que les catholiques du Sud ; peut-être plus instruits. Plus isolés des Flamands, ils ont mieux conservé leurs anciennes coutumes; il n'y a plus guère que chez eux, et surtoul vers Hoek et Terneuzen, que l'on ait gardé les anciens costumes. Les catholiques d'ailleurs augmentent de nombre même daus l'Ouesl, grâce à l'immigration des ouvriers du Houtland, qui viennent chaque année de temps immémorial sarcler et arracher le lin, biner et récolter les betteraves, et dont quelques-uns, attirẻs par le prix élevé des salaires, finissent par se fixer dans le pays.

Tous ces habitants vivont de l'agriculture: nulle part il n'y a moins d'industrie. A peine quelques brasseries, des briqueteries; les fours à garance ont disparu. Le vaste établissement des Aciéries construit á Terneuzen n'a jamais fonctionné; il va disparaître. Seul le Sas-de-Caand, grâce au canal et à la proximité de la frontière belge, posséde quatre usines, deux sucreries, une glacerie, une fabrique de couleurs; ainsi cette bourgade dont le rôle a été longtemps celui d'une petite place de frontière est devenue le seul centre industriel de la Flandre zélandaise. La pêche est

1 Gf. Winkler (J.), Algemeen Nederduitsch en Friesch Dialecticon (S'Gravonhage, Martinus Nijhoff, 1874, in-8º, II, pp. 176-229.

2 de Potter, Beschrijuing van Hulst, p. 67.

3 Les noms français sont nombroux à Groede: tels Bécu, Freuillet, Frémiot, do Hullu, Lucier, Rousseau, Tellier, Toussaint, etc. 
nulle: Breskens arme 21 barques, Terneuzen deux ou trois; ce sont les chaloupes zélandaises qui peuplent l'Escaut. Il n'y a plus rien de marin ḋ Biervliet, patrie de la caque, ni à Kadzand, dont les marins en 1270 transportèrent Guy de Dampierre à la croisade de Tunis ; les anciens havres sont comblés. Seule Philippine grâce à son port artificiel maintient sa florissante pêche de moules. La Flandre zélandaise, comme le Franc de jadis, est fondée sur labourage et pâturage ; elle ne s'occupe que de vendre son lin et ses betteraves, élever ses chevaux et son bétail. L'hiver, lorsque la culture chôme, la plaine semble abandonnée, le mouvement est nul sur les chemins impraticablos.

\section{L'isolement économique.}

L'agriculture au moins fait-elle prospérer ce pays? On pourrait le croire, tant cette race courageuse et soigneuse donne à la région qu'elle habite un air d'aisance qui peut faire illusion. Pourtant l'agriculture zélandaise so débat dans une crise qui dure depuis 1830. Co n'est pas qu'elle soit aussi routinière qu'on le lui reprochait en $1850^{1}$; la culture y a fait de grands progrès, et il y a, dans le Koningin-Emma polder, telle ferme neuve, avec installations électriques, qui peut servir de modèle à toute la Flandre. Mais le développement de celte province est entravé par la frontière politique et douanière qui depuis trois sieccles l'isolo du pays dont elle fait naturellement partie. Tout incline la Flandre zélandaise à regarder vers le Sud. Les communications avec les autres provinces des Pays-Bas sont difficiles à cause des bras de mer, et d'ailleurs, la matière d'un commerce fait défaut; si les petits bateaux'hollandais, avec leurs nageoires caractéristiques, peuvent apporter tous les 8 ou 15 jours a Terneuzen, Breskens, Mauritsfort, Walsoorden, quelques caisses de denrées coloniales et quelques chargements de matériaux pour les digues, en revanche ils ne trouvent à peu près rien à remporter; la Zélande, la Hollande, la Frise produisent dans leurs polders ce que pourrait leur offrir la lointaine région flamande. Au contraire, tout favorisorait les échanges avec la Belgique. Chemins de for et canaux y aboutissent. C'est à Courtrai que l'on envoie la plus grande quantité du lin, et le reste dans le pays de Waes. Les betteraves du pays vont alimenter les usines de Selzaete et de Snaeskerke. C'est vers les centres populeux de Gand, Anvers, Bruxelles et du pays wallon, que doivent

\footnotetext{
1 De Hoon, Polders, p. 88.
} 
se diriger les bestiaux de la province. Enfin beaucoup de propriétaires sont Belges ou Français, et un nombre déjà respectable de fermiers est formé d'hommes du Houtland, aux dépens des fermiers protestants que leur éducation plus avancée rend peut-être moins souples à l'égard de leur propriétaire. Bref, les gens du pays évaluent à $9 / 10$ du total les affaires qu'ils font avec leurs voisins du Sud, contre 1/10 avec leurs compatriotes du Nord. Or la frontière est là, qui vient arrèter cet irrésistible mouvement. L'avoine zélandaise est taxće au passage; l'entrée des bestiaux est depuis quelque temps interdite, sous le prétexte d'épizooties. Or l'élevage ćlant devenu depuis une dizaine d'années la ressource principale du pays, la Flandre zélandaise doit exporter à tout prix; de là une contrebande effrénée, qui s'exerce surtout à l'Est de Philippine, là où les fraudeurs ne rencontrent pas sur leur route l'obstacle des canaux léopold et de Schipdonck. C'est là que l'on voit, sur ces vastes étendues plates, des troupeaux ontiers de bœufs lancés au galop franchir la frontière dans un clan furieux dont les douaniers sont obliges de se garer. Ft la fraude s'ètend aux cigares, au fromage, aux poules; tous les miséreux de la lisière sablonneuse se font controbandiers; de véritables agglomérations de fraudeurs s'établissent sur la frontière.

Malgré ce remède hasardeux, la Flandre zélandaise souffre de ce manque de débouchés. Ia population diminue; on émigre en Amérique; on démolit les fermes inoccupées. Ainsi ce sympathique pays continue à être sacrifié. Il l'est depuis le jour où les Provinces-Lnies en ont fait un boulevard de la Zélande, et s'en sont servies pour ruiner, dans les provinces du Sud qui refusaient d'adhórer à l'acte d'union, l'agriculture et le commerce. Le Zwin, Ie Braakman, l'Escaut, furent fermés à la navigation; lc jays environnant noyẻ sous les inondations militaires, et séparé de la Flandre par les forteresses de la Ligne. A l'abri de cette zone sacrifiée, la Zélande pêchait et moissonnait en paix. Ligno, inondations, prohibitions, péages, ont disparu ; l'Escaut est libre, le canal de Terneuzen remplace le Braakman, et Bruges a son débouché sur la mer; mais la Hollande on 1830 a gardé les provinces conquises par Maurice de Nassau; elles resteront gênées dans leur développement tant qu'une union douanière ne les aura pas rattachées à la Belgique, dont elles dépendent. Leur exemple montro que, livrée à elle-même, la plaine maritime ne peut prospérer; qu'elle a besoin du Houtland auquel elle envoie ses produits, et qui lui fournit sa main-d'ouvre; en un mot, que les deux grandes régions flamandes sont solidaires. 


\section{CHAPITRE XIII.}

\section{FLANDRE INTÉRIEURE. - L'AGRICULTURE FLAMANDE'}

I. Le pays aux arbres. Les forêts. Zone des bois et des bruyères. Les arbres. II. Caractères généraux de l'agriculture. Défauts du sol. Les explaitations. Les procédés. - III. Variétés régionales. Lo pays du sable. Le pays do Waes. Le pays d'Alost. Le peys de Courtrai. Houtland de I'Ouest. Le pays de Lille. La plaine de la Lys. - IV. L'évolution actuelle ; les spéculations animales.

I.

LE PAYS AUX ARBRES.

De la Plaine à l'intérieur, la transition est brusque. On quitte les terres nues pour les ombrages; la région découverte pour le pays des arbres. C'est comme un bois continuel, dit l'intendant Dugué de Bagnols; un immense jardin percé d'avenues, ajoute le préfet Dieudonné ". L'ingénieur Cordier le décrit comme * une forêt de haute futaie qui forme de toutes parts l'horizon; à mesure qu'on s'avance, la forêt semble s'éloigner, et au lieu d'entrer dans un bois épais et sombre, on continue à voir des arbres magnifiques, isolés et fort espacés... »3. La guerre acharnée faite aux arbres depuis 30 ans n'a pas encore fait disparaître cet aspect, resté particulièrement accentué dans le pays de Waes. En venant des Polders, celte contrée fait l'effet d'une belle forêt d'ar'bres fins ; de plus près, cette sylvo s'anime, on aperçoit des toits bas de tuiles rouges, et on distingue les premières lignes de peupliers du Canada dressés autour

1 A consulter: Van Aelbroeck, LA Agriculture pratique de la Flandro (Paris, 1830); De Laveleye (E.), Essai sur l'économie rurale de la Belgique, (2o éd., Bruxelles, Lacroix, 1863, in-12\%); - Statistique de la Belgique, Agriculture, Recensement général de 1895 (Bruxelles, 1900, 5 vol. dont un d'Introduction; un atlas); - Monographie agricole de la Région sablonneuse des Flandres (Bruxelles, 1900) ; - Monographie agricole de la Région limoneuse et sablo-limoneuse (Bruxelles, 1901).

2 Mẻmoire de l'intendant Dugué de Bagnols, Bull. Comm. H. N., X, p. 462. Dieudonné, Statistique, I, p. 269.

3 Cordier, Mémoire sur l'agriculture de la Flandre française et sur l'áconomie rurale (Paris, Didot, 18:3, 553 p.), p. 388. 
de chaque pièce de terre, qui forment cette prétendue forêt ; on s'avance, et l'aspect boisé persiste; à travers tout le pays de Waes on se croirait dans une clairière dont le bord reculerait toujours. Aulrefois, par toute la Flandre intérieure, chaque pièce de terre, pâture ou champ, était entourée d'arbres et de haies comme les « akkers » du pays de Waes; c'était la parure et l'originalité du pays ; et aujourd'hui encore, en venant des plateaux de Picardie ou de Brabant, c'est comme le pays aux arbres que se présente la Flandre ${ }^{1}$.

\section{Les forêts.}

Cette abondance des arbres a de bonne heure fait croire que la Flandre in térieure a été jadis une vaste solitude boisée. La première, la chronique de Lambert, moine de St-Bertin, écrite en 1120, atteste qu'an VIII ${ }^{\theta}$ siècle la Flandre était «inculta, vacua, ac nemorosa "; bien d'autres on suivi. I es textes cependant sont moins formels que les chroniqueurs. Sans doute César indique les «continentes silvas» qui garnissent la contrée des Ménapiens et des Morins ${ }^{3}$, et Strabon, Dion Cassius parlent à la dérobée des bois qui servaient d'asile aux habitants ; mais le nombre et l'importance des trouvailles romaines faites a travers la Flandre intérieure semblent indiquer que dès le $I V^{\mathrm{e}}$ siècle le pays était déjà largement érodé et peuplé. Il n'y avait en Flandre rien qui ressemblât à la Charbonnière; mais des forêts séparées, entre lesquelles s'établit la colonisation franque probablement aux mêmes emplacements que la colonisation gallo-romaine. Un capitulaire de 877 nomme la Lisga et le Sceldeholt, qui bordaient les rives de l'Escaut et de la Lys ; et à l'époque de St-Bavon (VII'e siècle) s'étendait, entre Thourout et Gand, « une vaste solitude d'arbres serrés $\gg$. Ie fait que l'on distingue des forêts semble bien indiquer qu'elles ne couvraient qu'une partie de la contrée. $\mathrm{Au} \mathrm{XI}^{\mathrm{\theta}}$

1 Les roms des communes flamandes sont fréquemment empruntés à des noms de végétaux. Eecloo est le bois des chêries; Eecke, le chêrne; Zeveneecken, sept chênes; Alost (Aalst) signifie aulne; Bouchaute est le bois de hêtres; Lootenhulle, le bois près de la colline; Houtkerque, l'églice du bois ; Lynde, le tilleul ; Abeele, le tremble ; Quaedypre, l'orme tordu; Eschen, le frêne, etc.

2 M. G. SS. IX, p. 309 .

3 De Bello Gallico, lib. III, cap. XX VILI.

4 Baluze, Gapitulaires, II, p. 268.

s Acta SS. Belg., II, pp. 508-509. 
siecle, on mentionne la forêt d'Houthulst ${ }^{1}$, ce qui signifie que le pays qui l'entoure n'est plus boisé. Le bois du Ham, entre Watten et StMomelin, est juste aussi étendu au XIII siècle qu'aujourd'hui . Quant au «Nemus sine misericordia » des chroniqueurs, qui courait à travers toute la Flandre, aucun texte positif ne vient en affirmer l'existence.

D'ailleurs la plupart des paroisses de la Flandre intérieure apparaissent de bonne houre dans les documents écrits. Le cartulaire de St-Pierre de Gand mentionne, du VII ${ }^{\mathrm{e}}$ an XI' $\mathrm{XI}^{\mathrm{e}}$ siècles, presque toutes les localités situées sur l'Escaut et la Lys. Dans la région même qui est restée la plus boisée, des villages sont établis de bonne houre: Roxem apparaît en 745, Adegem, Somergem, vers 840 , Couckelaere. Wynghene, Beernem en 847 , A ertrycke en 902, Aeltre en $974^{3}$. A la fin du XI ${ }^{\ominus}$ siècle figurent déjà, dans le cartulaire de l'abbaye de Voormezeele, tous les villages des environs d'Ypres ${ }^{4}$. Enfin l'on vit se produire au XII ${ }^{\text {e }}$ siècle un irrésistible mouvement de défrichement. $95 \%$ des villages actuels existent en 1200 , et tout autour d'eux disparaissent les forêts et les bruyères. Les abbayes nées de la réforme de Gérard de Brogne, et celles qui apparaissent au $X I I^{\theta}$ siècle par l'effort des Cisterciens, joignent leurs efforts à ceux des vieux monastères: tous s'empressent au dẻfrichement. Le pays de Waes est déboisé à cette époque, et lo «Forestum Wasda》 dont parle le roi Lothaire en $969^{\text {s }}$ est róduit au XIII ${ }^{\mathrm{e}}$ siècle à des wastines sans cesse rétrécies.

Dès lors la Flandre devient, comme le dit avant 1/250 l'Anglais Glanville, un pays qui possède beaucoup d'arbres, el pou de forêts ${ }^{6}$; et c'est exac-' tement l'avis de son contemporain Guillaume le Breton, qui trouve que " peu de forêts Iui donnent de l'ombre " 7. Peu de forêts, mais beaucoup de petits bois, il n'y avait guère de paroisse qui n'en eut quelques

1 Limburg-Stirum, Cartulaire de Louis de Male, I, p. 506.

2 Haigneré, St-Bertin, 1I, p. 159, no 1240.

3 Roxem : Guérard, St-Bertin, p. 53 ; Adegem et Somergem : Van Lokeren, St-Pierre, I, pp. 10-14; Couckelaere, Wynghene, Beernem: charte de Charles le Chauve dans Duvivier, Hainaut, pp. $297-299$; Aertrycke : charte de Charles le Simple dans Duvivier, Hainaut, p. 325; Aeltre: Van Lokeren, St-Pierre, I, p. 46.

4 Van de Putte et Garton, Ghronicon Vormeselense (Bruges, Soc. d'Em., 1847, 63 p. in- $8^{\circ}$ ).

s Texte dans Kluit, II, pp. 30-31.

- Multas quidem habens arbores, non tamen multas silvas. (Bartholomei Anglici, Tractatus de Proprietatibus rerum, Coloniae, 1481, in-fo), traduit dans Histoire littéraire de la France, XXX, p. 39.

7 Raris sylva locis facit umbram (M. G. SS. XXVI, p. 322, v. 146). 
hectares. Ils se sont maintenus à peu près intacts jusque dans la première moitié du XIX ${ }^{\theta}$ siècle et n'ont disparu que devant l'afflux de population en quête de nouveaux territoires. Mais depuis cinquante ans, le changement est radical. A Nazareth, la moitió de la communo était en bois avant 1850 ; il n'en reste en 1895 que 279 hectares sur un total de 2.572. A Staden, la forêt d'Houtbulst s'duançait, il y a 100 ans, jusqu'au village ; elle en est aujourd"hui à $4 \mathrm{~km}$. Le territoire de Moorsleede, d'après un terrier de 1660, était pour moitié couvert de bois: on n'y trouve plus en 1895 que 39 hectares boisés sur 2.951 de superficie totale, et le nombre est tombé à 30 en 1904; le déboisement a tari les ruisseaux, et la roue du moulin à eau sur le Passchendaelebeek ne tourne plus. A Gulleghem, en 30 ans, la surface boisée est passée de 30 à 6 hectares. De Cuerne à Lendelede, le pays en 1800 n'était qu'un bois; il en reste '13 hectares. De Poperinghe à Watou et à la frontière française s'étendait il y a 50 ans une forêt continue, la Warande; elle est réduite à 27 hectares. A Sercus, les derniers bois sont disparus il y a 30 ans. Partout on signale le mêrne phénomène.

Il ne reste plus aujourd'hui que de rares débris des forêts flamandes. Au contact de l'Artois et do la Flandre se sont maintenus les bois d'Eperlecques, de Clairmarais et de Nieppe; sur les clyttes des environs d'Ypres, les habitants ont renoncé à déboiser, et laissé debout les taillis de SaintSixte, de Zillebeke et d'Ilouthulst. La partie qui reste la plus boisée, c'est la zone sablonneuse qui commence au N.-E. de Dixmude, et par Thourout, Aeltre, Crsel, s'avance jusqu'au delá d'Eecloo, à la rencontre des sapinières qui garnissont la frontière hollandaise de Wachtebeke à I a Clinge. C'est la Campine flamande; le paysage rappelle aussi la Sologne, avec ses bois de conifères, ses genêts et bruyères, ses champs de seigle maigre; lorsque la nappe d'un étang (poel) apparaît. entre les arbres, et que l'on aperçoit au bout d'une allée la silhouette d'un château de briques, l'illusion est complète.

\section{La zone des bois et des bruyeres.}

Cette écharpe de forêts établies sur de mauvaises terres fut en Flandre la dernière région à être exploitée. Le défrichement s'y porta surtout au XIII siècle; mais trop fréquemment les bois ne furent convertis qu'en hruyères, ou wastines; la couche de tuf qui s'étend souvent à uno faible profondeur, et dont le défoncement exige un travail difficile, condamnait le sol à rester inculte; à la place de la forêt s'étendit le Veld, c'est-à-dire 
Ia terre en friche, par opposition à l'akker ou au kauter qui sont les terres cultivées. Ainsi se formèrent ce Bulscampvelt, ce Beverhoutsveld, qui ont survécu jusqu'au XIX ${ }^{\mathrm{e}}$ siècle, et qui étaient les parties les plus pauvres et les plus sauvages de la Flandre. Bruyères et bois étaient le refuge des maraudeurs et des bêtes sauvages. A Beernem, jusqu'au XVHI ${ }^{\mathrm{e}}$ siècle, les sangliers ravageaient les champs cultivés, les renards dévoraient les volailles, les loups rendaient la campagne peu sûre ; le nom même de la commune rappelle les ours du voisinage ${ }^{1} . \mathrm{Du} X \mathrm{X}^{\circ}$ au XVIII siècle, les loups sortis des bois d'Houthulst, de Wynendaele et de Thourout courent le pays ; de grosses primes sont payées chaque année pour leur destruc- tion 2. De curieuses formes d'exploitation s'étaient établies sur les bruyères. Les Velden devinrent la propriété des habitants dont les domaines entouraient l'espace ossarté ; cette zone privilégiée autour do la bruyère, le vrydom, ne se confondait pas avec une paroisse, et pouvait dépendre de plusicurs. C'est ainsi quo le Beverhoutsveld (Bruyère du bois des Castors) était commun à des habitants d'Oedelem, Beernem et Oostcamp; que le Vry-Geweid se partageait entre gens de Swevezcele et de Ruddervoorde; que le Gemeene Weide avait son vrydom sur Oedelem et Assebrouck. Les exploitants (amborgers) élisaient des administrateurs spéciaux (veldheeren) qui réglaient l'admission des bestiaux sur la pâture commune. Il fallut le XIX ${ }^{\text {e }}$ siècle pour amener des modifications. A une époque où l'on défrichait de tous côlés, il paraissait scandaleux de laisser sans culture ces vastes espaces : l'insalubrité des bruyères, où s'amassaient des eaux stagnantes arrêtées par le tuf, fournit un prétexte au gouvernement, d'intervenir. Le Beverhoutsveld fut déclaré en 1847 bien communal des trois paroisses attenantes, et mis en culture. Le Gemeene Weide d'Assebrouck, au cours d'un long procès entre les exploitants et l'Etat, fut confié en 1862 à une commission qui l'administra jusqu'en 1881, et en profita pour le convertir en terre arable, y tracer des chemins, y creuser des fossés ; ce fut dans cẹt état qu'on le rendit aux 37 amborgers qui depuis en ont gardé la gestion. Le Vry-Geweid, le Sysselsche Veld sont devenus bien communaux ${ }^{3}$. Ainsi sont disparues les grandes bruyères communes do Flandre; il n'en reste plus guère que des lam-

1 Andries (J. O.), Notice sur la grande bruyère flamande de Bulscamp. (Bull. Soc. hist. et litt. Tournay, t. XI, 1886, pp. 48-95).

2 Delepierre et Priem, Précis analytique, Comptes du Franc, passim.

3 Sur les Velden flamands, voir: Errera (P.), Les Masuirs. Recherches sur quelques vestiges des formes anciennes de la propriété en Belgique (Bruxelles, 1891, 2 vol. - in-8 ${ }^{\circ}$, I, pp. 237-311 et pp. 433-440. 
beaux, comme le Maeleveld, débris de l'ancienne wastine où chassaient les comtes.

Cette zone des bois et des bruyères garde cependant quelques traits caractéristiques. Nulle part les communes ne sont plus étendues que sur son parcours; le contraste saute aux yeux entre leur vaste superficie et l'étendue restreinte de celles qui sont situées au Nord et au Sud, dans la plaine maritime ou sur les bords de la Lys et de I'Escaut ${ }^{1}$. Là sont aussi les grandes cotes foncières de la Flandro intérieure, dont les propriétés sont, partout ailleurs, si morcelées: les 339 hoctares de la famille d'Ursel, à Oostcamp, d'origino féodale; les biens des descendants de M. de Naeyer, répartis dans les communes d'Ursel, Aeltre, Bellem et Wynghene; la propriété de Wynendaele, reste du grand domaine des comtes ${ }^{2}$. Enfin les habitants de la zone boisée ont conservé quelques particularités qui les distinguent du reste de leurs compatriotes. Réfugiées à l'abri des bois, les races primitives qui peuplaient la Flandre avant l'arrivée des Francs on des Celtes y ont gardé quelques traits de leur type elhnique. C'est aux néolithiques que semblent remonter directement les habitants de Ter Heest, hameau sur la lisière Nord de la foreêt d'Houthulst; leurs cheveux noirs et hérissés, leur crâne arrondi, leurs yeux bruns, leur teint olivâtre, les distinguent des Flamands aux yeux blcus et cheveux clairs qui les entourent ${ }^{3}$. Le même type a été signalé aux haméaux Ryvers, de Somergem, Cleite, de Maldegem, Aelterhoeksken, d'Aeltre, tous situés dans des clairiéres, et au faubourg du Nieuwe Markt, à Roulers. Aujourd'hui, si le type primitif se métisse par le contact avec la population germanique, les moeurs restent spéciales. Les gens de Ter Heest et du hamean voisin d'Houthulst forment, au milieu des populations agricoles qui les entourent, une curieuse colonie de marchands, née sous l'influence de la forêt. Le bois et la bruyère leur fournissaient jadis les éléments de la fabrication de brosses et de balais, qu'ils allaient vendre dans le voisinage; ils ont étendu cette industrie, reçoivent aujourd'hui leur matière première de l'Amérique par Anvers, leur bois de l'Ardenne ou de France, el vont vendre leur marchandise à travers toute l'Europe, jadis en France, aujourd'hui dans le fond de l'Allemagne. Leurs voisins, qui les craignent, leur attribuent un caractère

1 Maldegem, 6271 hectares; Aeltre, 46333; Wynghene, 4613; Thourout, 4415; Oostcamp, 4119.

2 Vandervelde, Propriété foncière en Belgique, pp. 106-108.

- 3 Cf. Ciaerhout (J.), lges Labitants de la station néolithique de Ter Heest (Bill. Soc. Anthr. Brux., XX, 1901-02). 
rusé, défiant, plein de duplicité, les tiennent pour malins et menteur's; au demeurant, braconniers impénitents, et batailleurs acharnés. La prospérité leur est venue, qui leur a fait remplacer par do confortables maisons de briques les curieuses huttes en terre entremêlée de branchages, percées d'une seule fenêtre opposée à la porte, qui rappelaient peut-être les habitations de leurs lointains ancêtres; il ne reste plus guère sur le coteau de Ter IIeest qu'une dizaine de ces invraisemblables demeures. Ailleurs la présence des bois avait influé d'une aulre maniére sur la santé, les mours, les occupations des habitants. Les topographies médicalos insistent sur le tempérament défectueux des gens qui habitaient auprès des forêts ou des anciennes bruyères; la Cornmission médicale de 1846 attribue à l'infertilité de leur' sol et à la misère qui en résulte la scrofule et une sorte de lépre dont ils étaient fréquemment atteints. A la meme époque, on signalait dans les collines de Renaix, encor's complètement boisées, la présence d'une population spéciale, hostile a la fois aux Wallons et aux Flamands, vivant de rapines et de crimes. Ce ne sont plus guère là que des souvenirs; la diminution des bois a fait disparaitre les tares physiques et atténué la rudesse des mœurs; l'habitant de Schoorisse ne jone pas du couteau plus souvent que ses compatriotes du pays d'Alost, et les « boschkerles » de la Flandre Occidentale se portent aussi bien que leurs voisins des terres découvertes ${ }^{1}$.

\section{Les arbres.}

Il somble que le mouvement qui depuis le début du XIX ${ }^{\mathrm{e}}$ siècle a jeté le peuple flamand à l'assaut des bois soit a la veille de s'arrêter. Aussi bien ne reste-t-il plus grand chose à fairo. Les forêts, résineux compris, ne tiennent plus guère que $5 \%$ de l'étendue exploitée ; 4,19 en Flandre Occidentale, 5,35 en Flandre Orientale. Si les arrondissements de Bruges et de Gand, qui possèdent la zone boisée, en ont encore 7,28 et $7,53 \%$, et celui d'Ypres 6,56, l'arrondissoment de Courtrai n'en a plus que 1,09²,

1 Cf. : Huyttens, Études sur les moeurs, les superstitions at le langage de nos ancètres (les Ménapiens). Gand, 1861, in-120; - Rapport de la Commission médicale de la Flandre Oecidentale, dans l'enquète sur la condition des classes ouvrieres, III, pp. 298-300; - Woets, Topographie médicale de l'arrondissement de Dixmude, pp. 64-68; - Ducpétiaux (Ed.), Statistique des tribunuux ei des prisons de la Belgique (Mess. Se. Hist., II, 1834, pp. 164-188); - Nelvaux, Notice explicative de la feuille de Flobecq (Bull. Soc. Anthr. Brux., VIII, 1888-89), pp. 147-148.

2 Recensement agricole de $18 \% 5$. 
représentant une surface de $\mathbf{4 3 3}$ hectares. Il n'y a plus on bois que les terres complètement stériles. Aussi faudrait-il s'attendre à ne plus voir leur étendue diminuer de nouveau; dejà dans certaines communes on signale des reboisements, sur des clyttes ou des sables meubles ${ }^{1}$. En revanche, les arbres isolés, ou établis en lignes autour des champs et des pâtures, continuent à disparaître. Il était naturel, dans un pays où l'humiditẻ favorisait la croissance des arbres, d'en garnir tous les champs et de conserver ainsi du bois, en dépit du recul des forêts ; ormes, chênes, frênes, peupliers, saules têtards rapportaient aux própriétaires de beaux bónéfices et payaient le fonds de la terre une fois chaque demisiècle. Pour la même raison on maintenait, autour des pâtures et de nombre de champs, des haies d'épines ou d'aulnos, qui fournissaient du bois de chauffage et empêchaient les bestiaux de passer. Mais la culture intensive leur a déclaré la guerre; désireux de conserver d leur's récoltes les matières fertilisantes absorbées par les arbres, et de leur épargner l'ombre nefaste projetée sur les partios en bordure, les paysans depuis une trentaine d'années poursuivent leurs propriétaires de réclamations contre les arbres et les haies. Le résultat est déjà considérable; dans toute la région limoneuse du S.-W., les beaux ormes, parure de la Flandre, sont tombés en masse; les habitants accordent que le pays est devenu méconnaissable. Bientôt il ne restera, dans certains districts, de plantations que le long des routes : tel le pays autour de Courtrai, qui ne tardera pas à ressembler à la plaine marilime. Ailleurs, vers Thielt, on conserve les arbres, mais on remplace les chênes ou les ormes par des essences plus hâtives, peuplier's blancs, Canadas. Enfin dans l'Ést, on s'obstine à garder les arbres, qui alimentent l'industrie sabotière du pays de Waes ${ }^{2}$, ou les haies d'aulnes, dont les branches, coupres a a peu près chaque annèe, servent de bois à brûler. Là s'est réfugièe la flore originelle du pays. Il est peu de contrées au monde, en effet, où les plantes sauvages subissent plus de vicissitudes que dans ces champs de la Flandre orientale: allant de sarclages en binages, de binages en labourages, de labourages en hersages, se faufilant au milieu des cultures dérobées, profitant du riche engrais destiné aux pommes de terre, évilant les linières trop choyées du paysan, sans cesse brûlées, tranchées, arra-

1 A Couckelaere, on a reboisé dans le Sud de la commune. A Zele, on a reconstitué depuis dix ans une trentaine d'hectares vers l'Ouest.

2 A Stekene, on estime qu’un « Canada » rapporte environ 1 franc piar an; $\dot{a}$ BeverenWaes, on évalue le produit à 1 fr. 50 ou 2 francs. 
chées, et même, véritable ironie, transformées en engrais: ce sont bien Ies «akkerproletariërs » de M. Mac-I_eod, auxquels les haies seules peuvent donner asile ${ }^{1}$.

II.

GARACTÉRFIS GÉNĖRAUX DE LAGRICULTLRE.

L'âpreté de la lutte du paysan contre la nature, indiquẻe par celte chasse acharnce faite aux plantes sauvages dans l'Est, et par la campagne contre les arbres et les haies dans l'Ouest, est en effet le trait principal de l'agriculture en Flandre intérieure. C'est bien à propos d'elle qu'il faut répéter qu'ici « la terre fut créée par l'homme ${ }^{2}$ ». Abusés par la grandeur du résultut obtenu, les étrangers parlent volontiers du « riche pays » ou des « grasses plaines » de Flandre, sans savoir que la plus grande partie de ce sol est composé de sable meuble ou de glaise. Ce n'est pas un paradoxe de soutenir que la Flandre intérieure est un pays plutôt peu fertile que riche. Desobservateurs pénétrants l'ont remarqué depuis longtemps. « Le pays (de Flandres) de soy est poure pays et peu de labour, pour ce qu'il est en eauës et en sablons », dit le héraut Berry, en mettant d'ailleurs hors de causo la région lilloise; et il ajoule que «n'est ce pays riche que des grans marchandises qui descendent en iceluy pays $\star^{3}$. Commynes, qui voit clair, jüge que le pays de Lombardie est «bien meilleur et plus fertille » et les quatre membres de Flandre, en 1476, tiennent un langage analogue, déclarant « qu'il est assez connu que la Flandre n'est pas très fertile, et que sa prospérité repose uniquement sur son commerce et son industric $\gg$.

\section{Défauts du sol.}

L'on s'explique ces appréciations lorsque l'on examine les qualités du

1 Cf. Mac-Leod (J.), Proeve van een botanische besclurijving van het Kempisch gedeelte van Vlaanderen. (Botanisch Jaarboek, VIe Jaurgang, 1894, pp. 381-119).

I Michelet, éd. de 1841, V, p. 321.

3 Géographie attribuée à Gilles Bouvier, dit Berry, héraut de Charles VII, imprinée dans Labbe, L'abrégé royal de l'alliance chronologique de l'histoire sacrée et profane (Paris, Gaspar Meturas, 1651), pp. 703-704.

4 Commynes, VIII, 8 (p. 602 de l'éd. Chantelauze).

: Charte du 11 fúvrier 1476, publiée dans: Verzameling van XXIV origineele charters (Gand, 1787). 
soi flamand. Dans l'Est, d'Anvers à Thourout et à Deynze, le sable domine, plus ou moins meuble, plus ou moins épais ; vers Maldegem, ou au Nord de Wachtebeke, il constitue même de petites dunes. C'est un sol trop perméable, qui souffre de la sécheresse ; une terre trop peu consistante, dont le vent s'empare, decouvrant les semis, ou enterrant les jeunes pousses; et c'est une des raisons pour lesquelles on garde les haies d'aulnes dans les parties où le sol est particulièrement meuble. Souvent le sable s'agglutine à une faible profondeur en tuf (rokke ou rotse) qui empêche les labours profonds, et arrête les racines. Ces terres légères sont èxposées à se refroidir rapidement, ot le rayonnement y cause souvent des gelées désastreuses. Au point de vue chimique, elles ne sont guère plus favorisées: pauvres en chaux, en magnésie, en potasse, en acide phosphorique, et surtout en azote, elles ne peuvent prodnire qu'à force d'engrais ct de fumures ${ }^{1}$. Parfois lo sable est remplacé par une argile tenace et froide, comme celle des collines d'Crsel, où les labours sont presque impraticables, et sur lesquelles on ne peut guère établir que des essences forestières. L'Ouest est mieux partagé, ot le sol s'amóliore á mesure qu'on avance vers le Sud-Ouest. Le sable passe insensiblement au limun argileux, terre franche parfois suffisamment perméable, mais de composition chimique défectueuse, manquant de chaux, d'acide phosphoriquect de matière azotée ${ }^{2}$. D'autre part la présence à une faible profondeur de la couche d'argile yprésienne vient retenir l'humidité à la surface, et le. drainage est souvent nécessaire. Enfin on voit affleurer çà et là l'argile elle-même, trouant le manteau de limon; ce sont les clyttes, les pacauts, impossibles à travailler quand il a plu, et qu'on ne peut ameublir qu'à l'époque des gelées: telle cette glaise du Sud d'Hazebrouck où il faut parfois trois hommes pour labourer, un pour verser de l'eau sur la charrue, et deux pour peser sur le manche, et où il faut aller pieds-nus, ancune chaussure n'y résistant. Ailleurs ce sont des sabjes yprésiens compacts, ou des étendues pierreuses de psammites paniseliens, on des sables plus ou moins meubles garnissant les pentes des collines. Rien de tout cela n'est Irès satisfaisant.

\section{Les exploitations.}

Pourtant ce sol médiocre esl devenu un des premiers pays agricoles du

\footnotetext{
1 Voir analyses physiques et chimiques de sols dans la Monographie agricole de la rugion sablomense des Flandres, pp. 18-22.

2 Cf. Risler, Géologie agricole, II, p. 272 et IV, pp. 152-153.
} 
monde. Il l'a bien fallu, pour nourrir les foules qui s'y pressent depuis le moyen-âge ; mais cette transformation n'a pu s'accomplir que par des procédés particuliers. Il n'y a guère lieu d'insister sur le courage et l'opiniâtreté du cultivateur flamand; tout a été dit sur ce sujet; mais il faut retenir qu'une bonne partie du sol est travaillée par le paysan Iui-même, sans le secours d'un animal. Pour retourner plus profondément sá terre et aller chercher le plus has possible un sable moins infertile que celui de la surface, pour ne laisser aucune place sans labour, le paysan du pays de Waes ou du Meetjesland travaille son champ à la bêche; ce n'est plus de la culture, c'est du jardinage, et le champ ressemble à un jardin, avec ses longues planches ótroites séparóes par des rigoles et soigneusement bombées au milieu. C'est à l'émploi de sa lourde bêche que le cultivateur de l'Est a longtemps attribué son succès, et le proverbe « de spa is de goude mijn », - la bêche est la mine d'or du paysan —, est encore en faveur. Dans ce pays d'opiniâtre travail personucl, les machines agricoles restent rares; les terres sont trop morcelées, car la population agricole est énorme; de plus la main-d'œuvre est à bon marché, tandis que les appareils sont chers. Nulle part les exploitations agricoles ne sont plus petites. La Flandre Orientale n'en complait, en 1895, que 74 de plus de $50 \mathrm{Ha}$; il n'y en avait que 4.579 qui comprissent de 10 a $50 \mathrm{Ha}$; en revanche, 57.315 possédaient de 50 ares à $10 \mathrm{Ha}$, et 51.706 moins de 50 ares. On peut dire que l'exploitation comprenant plus de $50 \mathrm{Ha}$ n'existe pas. En Flandre Occidentale, où la présence d'une vaste étendue de polders fait augmenter le nombre des grandes fermes, on comple encore sur 108.088 exploitations 34.465 allant de 50 ares à $10 \mathrm{Ha}$, et $65.943 \mathrm{de}$ moins do 50 ares ${ }^{1}$. Co morcelloment extrême des terres, dú à la surpopulation du pays, à la nécessité d'accumuler les efforts sur des parcelles très petites de ce sol stérile, et à co fait que l'exploitation des très petits champs n'est souvent que l'appoint d'un salaire industriel, est très ancien; les vieilles keures veillent à ce que les fermes ne soient pas réunies, ni les maisons abattues ${ }^{2}$; les cahiers des paroisses en 1789 s'élèvent vivement contre l'incorporation des petites fermes aux grandes et contre la démolition des maisons ${ }^{3}$. L'émiettement a continué de plus belle au $\mathrm{XIX}^{\mathrm{e}}$ siècle ; dans la plaine de la Lys, les grandes exploitations n'occupent

1 Recensement de 1895, Introduction, p. 463.

2 Keure de Poperinghe, homologue en 1620. G. Gilliodts, Coutumes de Poperinghe, p. 177.

a St-Léger, Dinkerque et la Flandre maritime sous la domination française, p. 427. 
plus en 1898 que $3 \%$ du sol, contre $25 \%$ en 1789 , tandis que les petites passaient de 45 à $66 \%$; en Flandre Orientale, celles de 50 ares à $10 \mathrm{Ha}$ passaient de 43.463 en 1846 à 57.315 en 1895 ; les mêmes s'elevaient, en Flandre Occidentale, de 25.766 à 34.465. Les renseignements sur l’évolution qui se poursuit a lheure actuelle sont contradictoires; cependant la tendance au morcellement paraît prépondérante, grâce à la prospérité que connaît depuis 15 ans l'agriculture flamande, et qui permet aux ouvriers agricolos d'essayer à leur tour de louer des terres. Chose curieuse: la plupart de ces courageux exploitants ne sont pas propriétaires de la terre qu'ils fertilisent. La Flandre ne connaît guẻre le petil fermier possesseur de soll exploitation; ce type, si fréquent en France, constitue ici l'exception, ot le nombre de ces petits propriétaires paysans va diminuant. Il était de $15 \%$ en 1840 dans la Flandre Occidentale; il n'est plus que de $12 \%$ en 1895; la proportion est descendue a $8 \%$ dans l'arrondissement d'Ypres. Les propriétaires n'habitent pas la campagne; ils forment l'aristocratie urbaine des petites villes, Bergues, Bailleul, Ypres; enfin beaucoup de terres sont passées, depuis 20 ans, aux mains des grands fabricants de Gand, de Lille, Roubaix, Armentières ; la prospérité industrielle qui a coïncidé après 1870 avec la crise agricole leur a permis de se constituer à peu de frais une fortune terrienne, un capital immobilier qui commence à payer largement l'intèrêt des sommes qu'on y a consacrées.

\section{Les procédés.}

Ce morcellement extraordinaire de la torre flamande, qui entrave l'emploi des machines, peut être un obstacle au progrès agricole; le petit fermier absorbé par un travail écrasant, animé d'un esprit d'économie excessive, hésite devant les innovations et les dépenses. Il est vrai que ces dẻsavantages sont compensés par ailleurs. La coopération pénètre en Flandre, surtout darıs l'Est, où elle est stimuléo par des préoccupations politiques et religieuses; des associations se forment pour l'achat et l'exploitation de machines, pour la constitution de caisses de cródit agricole ${ }^{1}$. Le cultivateur flamand lit des journaux et des revues pratiques, suit avec soin les conférences organisées par les professeurs de

1 Cf. Max Turmann, Les associations agricoles en Belgique (Paris, Lecoffre, 1903, in-8n, VII +432 p.);-Goret (J.), Les associations agricoles dans les pays de langue flamande de France et rle Belgique (Paris, Roussean, 1902, in-80). 
l'Etat. D'autre part, l'énorme somme de travail et de soins prodigués à chaque lambeau de terre suffit pour rétablir l'équilibre. Surtout, le paysan est depuis longtemps passé inaître dans l'art de gaver sa terre d'engr'ais. Il en faut beaucoup à ce sol sableux, léger, pour lui faire porter une culture intensive; le Flamand en trouve partout. D'abord, une harmonieuse combinaison entre la culture et l'élève du bétail lui en fournit dos quantités considérables. « La prospérité de l'agriculture, s'écrie Van Aelbroeck, dépend de la quantité de bétail que les cultivateurs entretiennent dans leurs étables. En effet le bétail procure le fumier, qui fait pousser les fruits de la lerre, et sans fumier la terre ne peut produire do bonnes récoltes »1. Mais lo « dieu de l'agriculture » comporte encore bien dautres produits que le fumier de ferme. On y joint les plantes extraites des fossés el des ruisseaux, les boues draguées dans les canaux, les déchels des fabriques et des tanneries, le noir animal, les cendres, les boues des rues, les os broyés, les déblais écrasés de vieux bâliments, la suie, les épluchures, les tourteaux de lin et de colza, enfin tous les engrais chimiques. Des individus gagnaient jadis leur vie à ramasser des fumiers qu'ils revendaient aux fermiers. Les vidanges, dédaignées partont ailleurs, sont recueillies, épandues avec soin; c'est «l'engrais Hamand» par excellence ; au printemps et à l'automne, des files de chariols chargés de petits tonneaux d'épandage parcourent la campagne; les fermiers vont on quêter dans les villes. Les cultivateurs sont de véritables connaisseurs en engrais; les déchets de Gand sont jugés inférieurs à ceux de Bruges, parce que les boues de celte ville, apportées par les pieds ou les chariots des paysans poldóriens, gardent quelque chose de la fertilité de la plaine maritime ${ }^{3}$. Ce sont là de vieilles habitudes; les coutumes, surtout celles de l'Est, prescrivent avec minutie quels engrais le fermier sortant aura dû donner aux terres qu'il quitte; la précision et le détail de ces règlements témoignent d'une agriculture déjà très complexe, très diversifiée, très savaute ${ }^{4}$. En 1764, le chef-collège de Termonde établit quo la seule paroisse de Zele achète annuellement au dehors pour 30.000 florins d'engrais. Less procédés modernes ont élé bientôt accueillis avec lo mêre

\footnotetext{
1 Van Aelbroeck, p. 113.

Corenwinder (B.), Recherches sur l'engrais flamand. Son emploi dans la culture des terres. (Lille, Blocquel-Castiaux, 1872, 40 p.).

3 Dietionnaire gẻographique de la Flandre Orientale (Bruxelles, Vandermaelen, 1836, in $-8^{\circ}, 237$ p.), pp. $146-147$.

- Voir en particulier: Berten, Coutumes du Quartier de Gand, t. VIII, Vieux-Bourg de Gand, pp. 110-422.
} 
enthousiasme; les nitrates et phosphates sont.devonus un des principaux articles du commerce de Dunkerque, d'Ostende, de Gand ; et la vieille voie romaine de Walten à Cassel, qui élait la plus fŕćquentée du canton lorsque les cultivateurs s'en servaient pour aller chercher à Watlen les boues et vidanges do Dunkerque et de St-Omer, est devenue déserte depuis que les engrais chimiques ont pénétré dans le pays.

Ce travail acharné du paysan a forcẻ la terre; il n'y a pas de sol stérile qui puisse résister à un pareil effort. De même que l'horticulture réussit à prospérer aux environs des villes sur n’importe quel terrain, de même la Flandre fut comme un immonse jardin dont tous les voyageurs ont admiré la vigucur et l'éclat. « Je commence par déclarer, disait l'Anglais Colman ${ }^{1}$, que l'agriculture des Flandres est supérieure à celle de tous les autres pays que jai visités ». Cette supériorité est moins éclatante, aujourd'hui que le progrès agricole est général, et favorise des terres fertiles jusque lá négligées; mais il est certain que jusque vers la fin du XIX ${ }^{\circ}$ siècle, la Flandre a montré l'exemple à l'Europe. Dès le XII ${ }^{e}$ siécle, elle commence à employer comme engrais le fumier animal au lieu du jonc séché, et malgré la disparition des bois et des bruyères, dévoloppe largement l'élıvage du hétail ". Au XIV siècle, elle supprime l'assolement triennal avec un an de jachère, qui s'est maintenu en Angleterre jusqu'au XVII' siècle, en Picardie jusqu'au XVIII', en Hesbayejusqu'au début du XIX ${ }^{\mathbf{e}}$; la jachère est remplacée par la culture des prairies artificielles et du navet, qui permettent de développer l'élevage, et par suite d'augmenter les quantités d'engrais ${ }^{3}$. Enfin dès le XVIIe siècle s'introduit l'usage des cultures dérobées, qui force la terre à produire chaque année deux récoltes, la première de céréales ou lins coupés fin juin ou fin juillet, et la seconde de racines, navels, carotles, destinées au bétail, semées après la moisson et récoltées en automne ${ }^{4}$. Il faul pour cela des terres lögères, s’échauffant vite, où la première récolte doivo être précoce, et où

1 Golman (H.), De l'agriculture et de l'économie rurale en France, en Belgique, en Hollande, en Suisse, (traduit de l'anglais par Le Bailly de Tilleghem, Bruxelles, Janssens, 1850 , in-80, 308 p.), p. 211.

2 Pirenne, Histoire de Belgique, I, p. 284.

3 Cf. Brants (V.), Histoire des classes rurales aux l'nys-Bus jusquä la fin du XVIII siècle (Mémoircs couronnés publiés par l'Acad. roy. de Belgique, t. XXXII, 1881,263 p.).

- Usige indiqué en 1671 dans la coutume du Vieux-Bourg de Gand : A Après la dépouille de deux fruits sur la même terre, on ne paiera rien pour l'estination de l'arriele-graisse.." (ce qui reste de fumier) (Berten, Coutumes du Vioux-Bourg do Gand, p. 417). 
l'on puisse s'aventurer même en automne, à la saison pluvieuse, pour arracher la seconde; ce sont lá précisément les quálités dos torres sablonneuses, elles rachètent ainsi, par lindustrie des habitants, une partie de $\theta^{\circ}$ leurs défauts. Cette ingénieuse coutume permit presque de doubler le nombre des têtes de bétail dans l'Est de la Flandre; elle donna le moyen de les tenir constamment à l'élable, par là d'augmenter forlement la production du fumier, et par suite d'accroître en proportion la valour et le rendement des terres.

Ainsi s'est formèe l'agriculture de la Flandre intérieure, si différente de celle de la plaine maritime, où le paysan, confiant dans la fertilité do son sol, s'est laissé dépasser par le Houtlander, moins favorisé. On le constate avec satisfaction dans le Sud : le Noordland de Bruges, si florissant il y a 80 ans, est endetté aujourd'hui, tandis que les Zuyderlingen des bois et des bruyères se trouvent dans l'aisance. Le Houtland tout entier prospère. Cependant il y a là de notables différences de sol; mais si les cultures ne sont pas les mêmes, les résultats sont partout satisfaisants. L'agriculture flamande est si bonne que là où la terre est ingrale, on réussit à faire toutes les cultures ordinaires, et lá oú elle est passable, les cultures industrielles, les cultures savantes.

\section{III.}

\section{VARIÉTÉS RÉGIONALES.}

La division génórale du Houtland est très simple: à l'Est les sables, occupant la plus grande partie de la Fland re Orientale; à l'Ouest le limon argileux, étendu sur le Nord français, la Flandre Occidentale, les arrondissements d'Audenarde et d'Alost. C'est un peu l'Ost-Flandre et la WestFlandre d'autrefois. Mais la variété du sol est presque infinio dans chacune des deux régions. Les sables meubles d'Eecloo ne ressemblent pas au limon sableux du pays de Waes; le limon de Courtrai est moins fort que celui d'Ypres; enfin les deux régions passent l'une à l'aulre par une bande où la transition est insensible. Ainsi se sont constitués, malgré l'identité des procódés généraux, des territoires agricoles dont les productions sont différentes.

\section{Le pays du sable.}

La vraie terre du sable comprend tout le pays entre la Durme, qui la sépare du Waes, la plaine maritime, et une ligne allant de Dixmude à 
Termonde par Thourout, Ruysselede, Deynze, Nazareth et Wetteren. C'est lá que l'on trouve les cxemples les plus caractérisliques de celle agriculture qui obtient d'excellents résultats dans un sol maigre, faisant produire en moyenne à l'hectare 3.127 kilos do froment dans le canton de Waerschoot, et 2.982 de seigle; 212 quintaux de pommes de terre dans le canton de Ledeberg, et jusqu'à 500 quintaux de navets dans celui de Lokeren ${ }^{1}$. C'est, avec le pays de Waes, la région par excellence des cultures dérobées, qui pour 100 hectares d'étendue cultivée garnissaient on 1895 38,86 hectares dans le canton de T'ermonde, 33,13 dans celui de Gand et 30,23 dans celui de St-Nicolas; soit environ le tiers des terres. Il y a longtemps qu'on a donné aux paysans de Waes lo surnom de « raepeters ", mangeurs de navets, et que la bannière du pays est

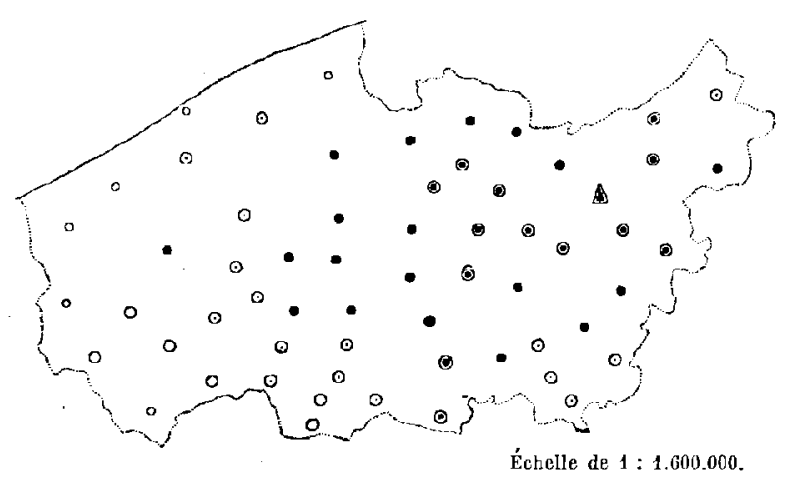

Fig. 57. - Répartition des cultures dérobés en Flandre

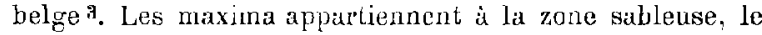
canton de Lokeren en tête : los minima à la plaine maritime et aux terres fortes du Sud-Ouest.

Proportion par cent hectares d'étendue exploitée :

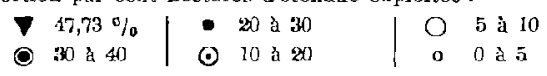

« armoyée d'azur à la rape (navet) dargent en naturel $»^{2}$. Nulle part. enfin on ne trouve unepareille moyenne de petites exploilations. Trois domaines seulement, dans toute la Flandre Orientale, dépassent 100 hectares; sur 22 cantons appartenant à la région sablonneuse, 11 n'ont aucune ferme

ayant plus de 30 hectares de lerre; ceux de Lokeren et de Hamme, sur 4.301 et 4.366 exploitations, n'en ont aucune qui atteigne 20 hectares *

Le seigle est le principal produit du pays; c'est une plante peu exigeante, qui s'accommode bien de ces terres légères; elle a l'avantage de mûrir vite, et de permettre les secondes cultures; enfin elle seule

1 Statistique de la Belgique. Recensement agricole de 1902 , publiẻ par le Ministre de l'Agriculture (Bruxelles, 1903 , in-8, 261 p.) pp. 38-40.

2 Laveleye, p. 48.

${ }_{3}$ D'après l'atias du Recensement agricole belge de $1815, \mathrm{pl}$. XXI.

- Recensement agricole de 1902, pp. 238-241. 
peut fournir la quantité de paille nécessaire à l'entretien d'un bétail nombreux. Le froment à côté de lui tient bien peu do place, et il diminue encore; la plupart des terres ne lui convienneul pas, et son prix de vente est trop peu élevé. L'avoine occupe une place honorable; le sarrasin diminue. C'était la céréale caractéristique des sables ; on Ia plantait dans les terres les plus pauvres. Mais aujourd'hui des que lo sol a acquis par labours et engrais quelque fertilité, on laisse le sarrasin pour lo seigle; aussi ne le trouve-t-on plus guère que dans les nouveaux défri-

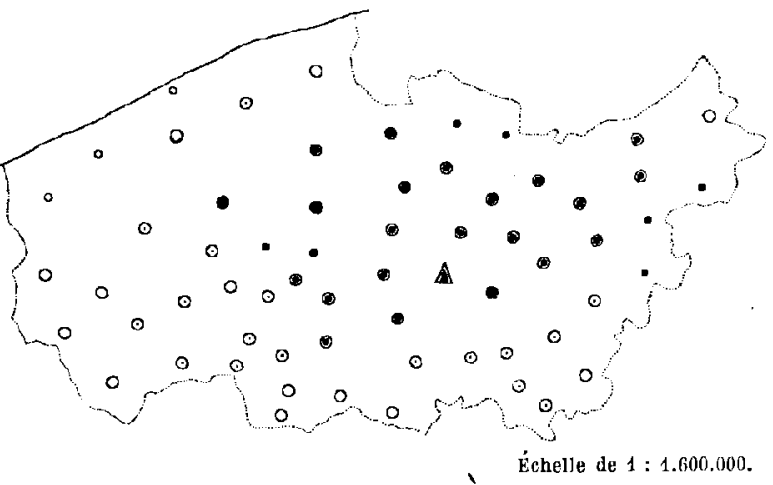

Fia. 58. - Répartition de la culture du seigle en Flandre belge 1. Le maximum dans la zone sableuse de l'Gat ; le minimım dans la plaine maritime et sur les terres fortes du SudOnest.

Proportion par cent hectares d'ćtendue exploitée:

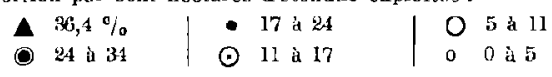

chements du pays d'Eecloo. Avec lui disparaît l'apiculture flamande, déjà fort éprouvée par la chute du colza. Enfin la pomme de terre tient dans les assolements une grande place; son importance tend a augmenter encore, elle se classe généralement après le seigle.

Outre ces cultures alimentaires, le pays du sable possédait autrefois des cultures industrielles. Le prefet Faipoult constatail en 1802 dans le département de l'Escaut la présence de 14.759 hectares de lin, 2.577 de chanvre, 9.584 de colza ${ }^{2}$. Une certaine part dans ces totaux doit être accordée à la Flandre zólandaise, qui dépendait alors de l'Escaut ; cependant la diminution est visible, puisque la Flandre Orientale n'a plus en 1902 que 6.574 hectares de lin, 433 hectares de colza, et 319 hectares de chanvre (en 1895). Ce sont là, pour ces terres pauvres, des cultures trop coûteuses, qui réclament beaucoup de frais pour un résultat incertain. De même pour la chicorée, qui n'occupe plus qu'une superficie insignifiante,

1 D'après l'atlas du Recensement agricole belge de 1895, pl. V.

2 Faipoult, Mémoire, p. 77. 
une trentaine d'hectares: On lits a délaissées lorsque la crise agricole est venue montrer aux. cultivateurs que leur salut ótait dans l'éleyage, et qu'il fallait orienter leurs efforts vers l'accroissement de leur bétail, de leurs chevaux, de lours porcs. Or il y a peu de pâtures sur les sables. On essain d'en créer, d'en augmenter le nombre et la valeur; en attendant il n'y a guère pour fournir de l'herbe que les vergers, les bandes de gazon d'un mètre de large que l'on a l'habitude de laisser autour des champs, et les mauvaises prairies des bords de la Durme, de l'Escaut et du. Moersaart. Ponr pouvoir nourrir le bétail dont on augmentait le nombre, on a remplacẻ les plantes industrielles par des cultures fourragères: le trèfle, la betterave. Le lin s'est réfugié sur les terres plus fertiles du pays de Waes; il est presque disparu dans les arrondissements de Gand et d'Eecloo. Le chanvre n'ẻlève plus ses hautes tiges qu'autour de Zele et de Termonde, à proximité des corderies de Hamme.

EXEMPIES DASSOLEMENTS 1.

\begin{tabular}{|c|c|c|c|}
\hline & $\begin{array}{l}\text { TELUFS MÉDTOCKLS } \\
\text { (NEVFLE) }\end{array}$ & $\begin{array}{c}\text { ASSEZ BONNES TERHES } \\
\text { (N GVFLE) }\end{array}$ & $\begin{array}{l}\text { BUNNES THHHES } \\
\text { (SLFYMNaR) }\end{array}$ \\
\hline 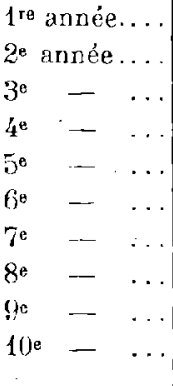 & $\begin{array}{l}\text { Pommes de terre. } \\
\text { Seigle (navets). } \\
1 / 2 \text { Avoine } 1 / 2 \text { P. d. tre. } \\
\text { Seigle (navets). } \\
\text { Avoine. } \\
2 / 3 \text { Trefle } 1 / 3 \text { Better.fes. } \\
\text { Seigle. } \\
\text { Seigle (navets). } \\
\text { l.in (carottes). } \\
\text { Seigle (navets). }\end{array}$ & $\begin{array}{l}\text { Seigle. } \\
\text { Seigle (navets). } \\
\text { Chicoré. } \\
\text { Lin. } \\
\text { Seigle (navets). } \\
\text { Pommes de terre. } \\
\text { Seigle (navets). } \\
\text { Ayoine. } \\
\text { Trèfle. }\end{array}$ & $\begin{array}{l}\text { Pommes de terre. } \\
\text { Seigle (navets). } \\
\text { Betteravos fes. } \\
\text { Froment. } \\
\text { Avoine avec trifle. } \\
\text { Tréfle. } \\
\text { Orge (navets) } \\
\text { Seigle (navets). }\end{array}$ \\
\hline
\end{tabular}

Ainsi l'agriculture du pays des sables a pris, depuis une vingtaine d'années, une unité qu'elle n'avait pas auparavant. Tout est destiné à la nourriture des animaux. Seuls les pommes de terre et le seigle serrent en partie à l'alimentation de l'homme; mais l'usage du pain noir, du pain de seigle, s'affaiblit, et l'on ne se nourrit plus qu'avec du blé importé. Tout ce qui pousse, à grand renfort d'engrais, est destiné à ce bétail

1 Monographie région sablonnense, pp. 46-50. 
enfermé dans les étables, dont on n'aperçoit que quelques rares individus qu'un enfant mène paître sur les bordures, autour des champs. Ainsi le pays qui a le moins de pâtures est celui qui peut nourrir la plus grande quantité de bétail (fig. 60); il s'y consacre tout entier.

Il n'y a guère dans la région sablonneuse que les onvirons de Gand pour se livrer à une culturo dont le but ne soit pas de nourrir les bêtes. C'est même un des exemples les plus remarquables de l'industrieuse activité du paysan de l'Ost-Flandre, que cetle floraison de l'horticulture autour de Gand. Elle y est établie depuis longtemps, puisqu'on cite un témoignage de 1550 sur la présence des serres chaudes en Flandre à cette époque ${ }^{1}$, et que de Candolle déclare que Gand lui semble la ville privilégiée de la botanique. Aujourd'hui, les serres, pépinières et jardins horticoles se dispersent dans un rayon étendu autour de la ville : à l'Ouest jusqu'à Landegem, au Sud jusqu'à la Pinte et Meirelbeke, à l'Est et au Nord surtout, jusqu’à Wetteren, Overmeire, Exaerde, Moerbeke, Wachtebeke et Evergem, $20 \mathrm{~km}$. autour de Gand. L'accroissement est rapide: il y a 15 ans, Evergem n'avait que deux établissements; il on compto aujourd'hui près de 50 ; on ne voit plus que les cheminées de briques des serres. De Meirelbeke à Gand, les toits vitrés se succèdent sans interruption. A Saffelaere, les horticulteurs bordent toute la rue du Sud de leurs parterres de fleurs, d'un heureux effet; on se croirait en Hollande. Dans la commune suburbaine de Gentbrugge, les établissements Van Houtte comprennent 20 hectares de serres, dont 10 d'un seul tenant. L'on retrouve l'horticulture sur les sables autour des remparts de Bruges, tandis que Bailleul possède de grandes serres où l'on « force » lo raisin. Ce paradoxe de faire produire à cette terre les plantes dont la nature $\mathrm{du}$ climat el du sol semblaient interdire la croissance, ètait digne de tenter le cultivateur flamand.

Cette région sablcuse, où le travail agricole esl si intense, n'en garde pas moins un aspect agréable de bocage. Les taillis d'aulnes qui garnissent les fossés et les bordures de gazon qui entourent chaque champ, les vergers, nombreux dans la région de Caprycke, Sleydinge, Somergem, donnent à ce pays de sable un aspect de fraîcheưr assez inattendu. Les champs étroits, perpendiculaires au chemin, ont l'air parfois d'une allée cultivée, prolongée par ur autre champ tout semblable, qui va aboutir à un chemin parallèle au premier. La vue est bornée, mais agréable. L'activité est grande dans les champs où la couleur gris-sale du

1 Van Hulthem, Discours sur l'état ancien et moderne de l'agriculture et de la botanique dans les Pays-Bas (Gand, 1837, br. 70 p.), p. 37. 
sable meuble contraste avec le vert des navets ou des betteraves; elle est grande aussi sur les chaussées ou les pistes défoncées d'énormes ornières ; peu de chevaux, car les exploitations sont trop petites; les vaches tirent la charrue et la herse, traînent les chariots à trois roues; le chien lui-mème s'évertue dans les roues qui actionnent les barattes, ou court par les chemins, donnant de Ia voix, attclé à des brouettes ou à de petites charrettes dans lesquelles les gens trop pauvres pour avoir une vache transportent leur fumier, rentrent leurs récoltes.

\section{Le Pays de Waes.}

Lo pays de Waes fait tort à la répulation que devrait avoir l'agriculture de la vraie région sableuse. C'est à lui que vont tous les éloges ; c'est lui que l'on cite comme exemple du tour de force accompli par les cultivateurs flamands, qui ont fait d'une terre stérile un sol riche, dont « la fertilité est le triomphe de l'industrie humaine»1. Le charme de cette petite région, qui semble être une forêt merveilleusement cultivée, a aidé à la création de cette légende. On a cru que le sol en était aussi aride que celui d'Eecloo ou de Maldegem, et on s'est extasié sur les résultats. Or le limon sableux qui forme presque tout le sol du pays de Waes est beaucoup moins rebelle à la culture que les sables meubles de l'Ouest. Il suffit pour s'en convaincre de voir la difference entre les communes voisines de St-Gilles, où le sol est limoneux, et La Clinge, où il est formé d'un sable aussi blanc et aussi meuble que celui des dunes; ou mieux encore de visiter, au centre du pays de Waes, le pelit territoire sablonneux qui s'ètend entre Haasdonck et Nieuwkerken; c'est presque un désert : les maisons disparaissent, les champs de pommes de terre se font rares; de petits bois de sapins se montrent, et bientôt des landes, des bruyères, que lon commence à reboiser. Ainsi la seule partie sableuse du pays de Waes est presque aussi désolée que les landes de Maele. Pourtant les cultivateurs de ce district sont aussi intelligents et laborieux que ceux du resle de la contrée ${ }^{2}$.

Cette fertilité plus grande a permis aux plantes industrielles, particulièrement au lin, de résister plus énergiquement qu'ailleurs à l'invasion des plantes fourragères. Quoiqu'en diminution, le lin est encore une des cultures importantes du pays de Waes, où il occupe 2.238 hectares en 1902, sur les 6.574 que possède la Flandre Orientale; on le rouit dans les

\footnotetext{
1 Derival, VI, p. 89.

2 CA. Van Ertborn, Texte explicatif de la planehette de Tamise, p. 12.
} 


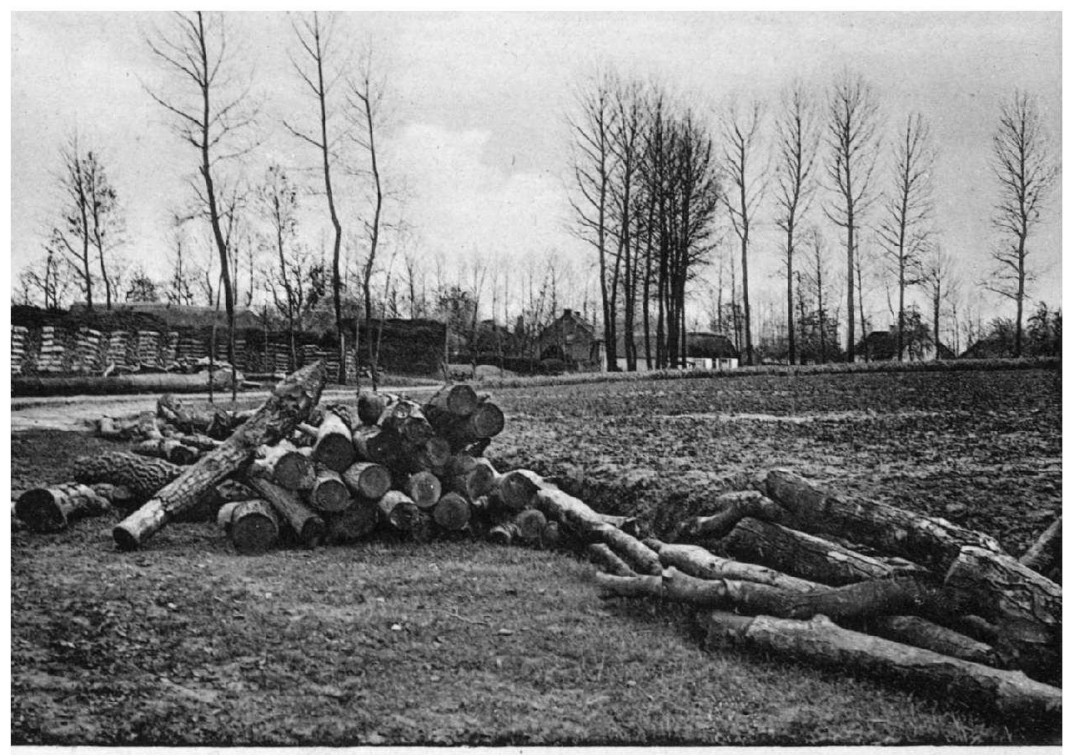

35. - Vue en pays de Waes (Nieuwkerken).

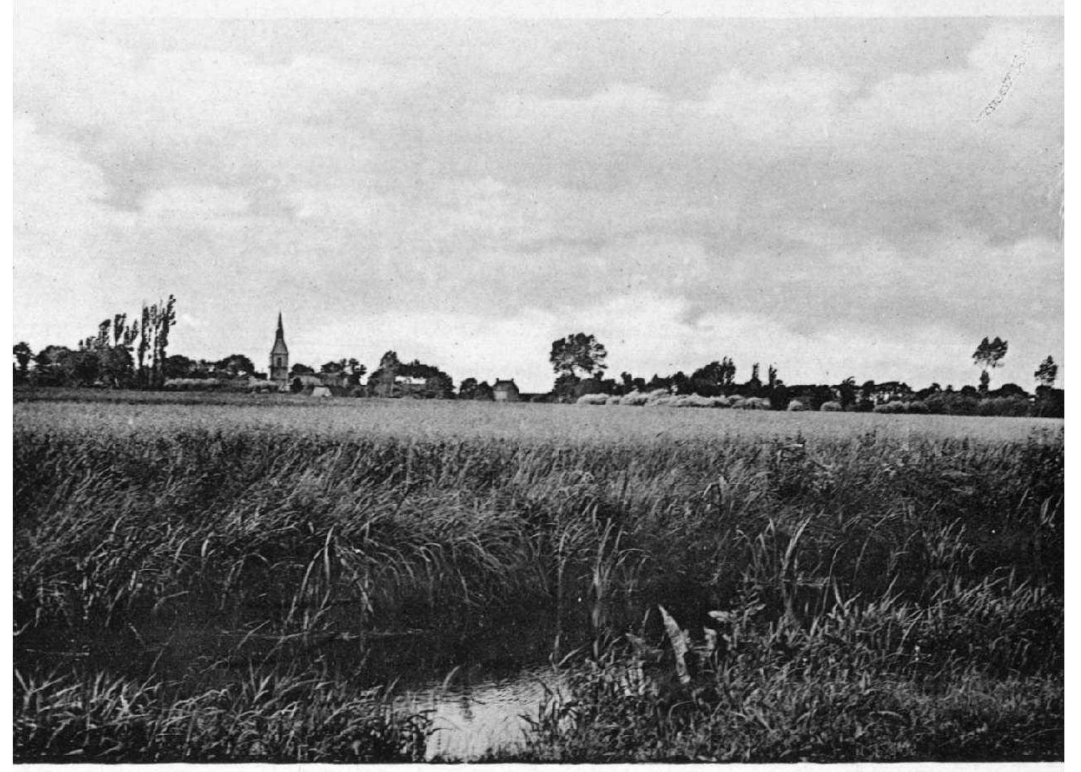

36. - Vue dans la Plaine de la Lys (Vieille-Chapelle). 
IRIS - LILLIAD - Université Lille 1 
fossés d'eau stagnante creusès le long des routes, ou dans les anciens bras de l'Escaut. La vallee du fleuve, fertile et basse, contient aussi des oseraies, dont les produits s'exportent par Anvers vers l'Angleterre, ou des cultures de légumes comme les curieuses plantations de choux rouges autour de Termonde. De là le prix élevé atteint par ces terres pourtant exposès aux inondations, et payant l'impôt-wateringue: $6.000 \mathrm{fr}$. l'hectare à Berlaere, 9.000 à Tamise, 10.000 à Zele.

\section{Le Pays d'Alost.}

Vers l'Ouest et le Sud, la transition se fait, insensible, du sable au limon. Le sol est plus varié : au Nord de Thourout s'étend un sable aride et sec; au Sud, un sable plus compact que la présence de l'argile yprésienne à faible profondeur rend humide; sur le flanc des coteaux le sable et l'argilite paniseliens mêlés donnent une terre franche assez fertilo; enfin vers Roulers, Iseghem, le sable commence à devenir limoneux. Le paysage change et s'éclaircit: moins d'arbres, moins de haies; les bordures de gazon disparaissent. A Deynze, c'est encore l'Est; a Vive-StEloy, c'est l'Ouest. Le froment se retrouve plus régulièrement dans les assolements. A Nevele, il n'occupe encore (1903) que 50 hectares, contre 336 au seigle, 128 aux pommes de terre, 115 à l'avoine, 53 aux betteraves fourragères ; à Wynghene, 98 contre $1.120 \mathrm{de}$ seigle, 595 de pommes de terre, 194 de lin (1895). Puis la proportion s'élève; à Thielt, elle est de moitiè (347 contre 635); a Coolscamp, les chiffres s'égalisent: 102 contre 135 ; d Iseghem, Beveren - lès Roulers, Hooglede, le froment

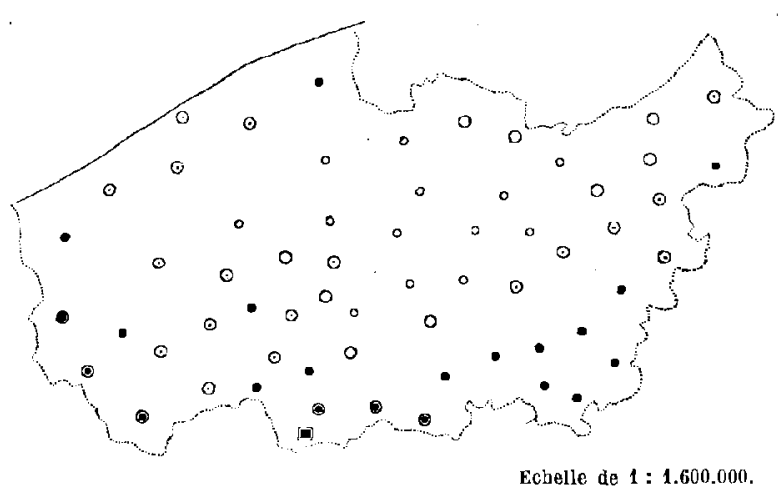

Fig. 59. - Répartition de la culture du froment en Flandre belge 1 . La proportion la plus faible dans la zone sableuse de l'Est, productrice de seigle; la plus forte dans les terres limoneuses du Sud, antour d'Alost, Courtrai, Poperinghe; le maximun dans le canton de Mouscron.

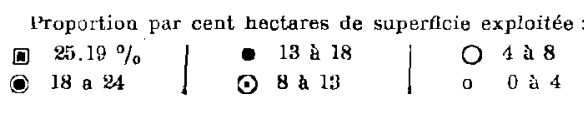

I D'après l'allas du Recensement agricole belge de 1895; pl. IV. 
l'emporte. La culture d̀ la bêche disparaît; les exploitations s'agrandissent ; tous les cantons en possèdent d'au moins $30 \mathrm{Ha}$; on en trouve de plus de 40 . Les chevaux se font plus nombreux, les vaches ne traînent plus la charrue ni les véhicules. On arrive ainsi aux régions d'Alost, de Courtrai, d'Ypres.

Le territoire situé à l'Est de l'Escaut, et auquel on donne le nom, d'ailleurs peu satisfaisant, de pays d'Alost, est une des parties les plus variees de la Flandre. Au Nord, vers Wetteren et Meirelbeke, c'est encore la région sablonneuse. Puis le plateau s'éléve vers Ie Sud, les vallées s'y dessinent, et si le haut reste sableux, des terres fortes se montrent au flanc des vallons, une végétation spéciale y indique la présence des argiles. Dès qu'on franchit l'Escaut à Eecke, Gavere ou Audenarde, il faut escalader un flanc raide (fig. 11); en haut se découvre un grand plateau très nu, où les moulins à vent sont encore nombreux ; quelques têtes d'arbres émergeant d'un creux invisible indiquent la tête d'un vallon. Tel est l'aspect du champ de bataille de Semmerzaeke, ou Philippe le Bon écrasa les Gantois; on le retrouve tout au long du pays, le plateau toujours monotone, à peine ondulé, déserté par la verdure et par les habitations, les ravins et vallons riants et frais, profonds, remplis d'arbres, de prairies et de sources. Pour qui suivrait les grandes routes, le pays d'Alost paraîtrait singulièrement découvert et triste, car pour éviter des côles trop brusques et trop fréquentes, les chaussées principales se tiennent le plus souvent sur le plateau, suivent les arêtes entre les vallons; aussi ne touchent-elles pas les villages, qui sont établis a mi-côte, et n'ont-elles guère fait naîlre sur leur passage que des hameaux de forges et d'estaminets. Quant aux chemins des vallées, ils sont souvent impraticables, enfouis qu'ils sont derrière d'épaisses haies qui retardent l'assèchement du sol humide.

La variété de sol engendre la variété des cultures. Sur le plateau s'élendent les céréales: le Nord, plus sableux, produit plus de seigle;

EXEMPLE D'ASSOLEMENT 1

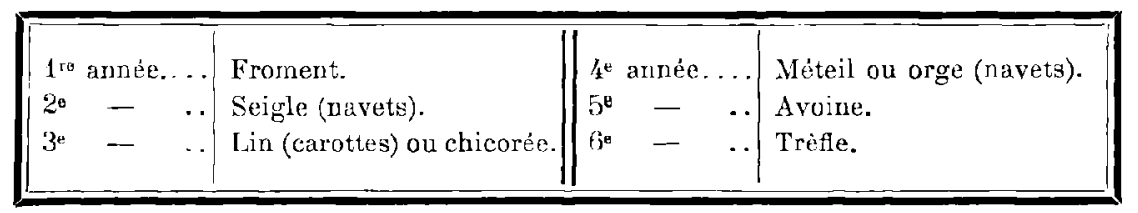

1 Munographie région limoneuse, p. 94. 
c'est le cas des cantons d'Alost, Oosterzeele et Sottegem; mais le Sud, plus limoneux, est déjà un pays de froment : 1.060 hectares dans le canton d'Hoorebeke-Ste-Marie contre 820 de seigle (1902); à côté d'eux, l'avoine, les betteraves fourragères, les pommes de terre, les prairies artificielles. Le lin, la chicorée, se retrouvent dans les terres plus fertiles du Sud-Ouest. Dans les vallées, des prairies fanchées et des pâtures; quelques bouquets de bois sur les argiles tenaces; autour d'Alost les oignons, les choux-fleurs, les cultures maraîchères de la vallée de la Dendre; enfin le houblon qui s'accommode bien de ces pentes où des terres légères sont superposées à des couches imperméables. Tout cela soigné par une ónorme population rurale; le pays d'Alost est la région agricole la plus peupléo de la Flandre; en 1895, pour 100 hectares d'étendue la population agricole, comprenant les personnes au-dessus de 12 ans, s'élevait à 121 habitants dans l'arrondissement d'Alost, et à 118 dans celui de Termonde, contre 41 dans celui de Furnes ${ }^{1}$. Aussi tout le sol disponible a-t-il été soigneusement exploité ; la proportion des terrains incultes y est infime; pour 100 hectares d'étendue exploitée, elle est de 0,34 hectare dans l'arrondissement d'Alost, de 0, 41 dans celui d'Audenarde, tandis qu'elle s'èlève encore à 5,89 dans les bruyères de l'arrondissement d'Eecloo ${ }^{2}$. Il en résulte que les terres y sont plus chéres que partout ailleurs. Les terres labourables, dont le prix s'élevait en 1895 à 2.989 franes l'hectare dans le canton de Furnes, valaient à la même époque 4.980 francs dans celni d'Alost, 4.878 dans celui d'Audenarde ; la moyenne pour l'ar'rondissement d'Alost montait à 4.882 francs. Même constatation pour les pâtures. A Sottegem, terres et pâtures valent 6.000 francs, el sont louées 250 francs; à Erembodegem, à AudenhoveSt-Géry, $6.500^{3}$. Cependant en Hesbaye, les riches terres de l'arrondissement de Waremme n'atteignent qu'à la moyenne de 4.245 francs. Ainsi, grâce à la variété du sol qu'elle exploite, l'agriculture du pays d'Alost reste prospère. N'étant pas adonnée exclusivement à la culture des céréales riches ou des plantes industrielles, elle a pu résister sans trop de dommage à la crise agricole ; mais elle s'oriente résolument vers l'augmentation du cheptel vivant, accroît les cultures destinées aux animaux et restreint l'étendue des autres. De 1895 à 1902, I'étendue cultivée en froment est tombée, dans les deux arrondissements, de

1 Recensement 1895, Introduction, p. 426.

2 Ibid., p. 495.

3 Ibid., IHl, pp. 15\%-16:. 
12.000 hectares a 10.300 ; de 733 hectares, le lin est descendu dans celui d'Alost à 199; la chicorée, dans celui d'Audenarde, de 865 à 289 ; enfin le houblon a diminué de moitié (257 contre 562). Ainsi l'érolution qui s'opère dans l'agriculture de la région sableuse est plus caractérisée encore ici.

\section{Le pays de Courtrai.}

Au contraire le pays qui s'étend de Roulers et d'Audenarde à Wervicq . et Mouscron, et dont Courtrai est le centre, reste voú aux vieilles cultures industrielles. Le lin, la chicor'ee, le tabac, le colza lui-même, y occupent une place honorable ${ }^{1}$; en tous cas ce sont ces plantes qui gardent le premier rang dans les occupations des agriculteurs. Aux environs de Courtrai, le lin est l'âme de la contréo; les nappes vert tendre des linières sont un élément du paysage; les bottes couleur jaune pâle emplissent les voitures qu'on rencontre ; on en aperçoit empilées dans des magasins ; on croise des ouvriers teilleurs, la figure et les vêtements couverts de poussière jaune.

\section{EXEMPLES D'ASSOLEMENT'}

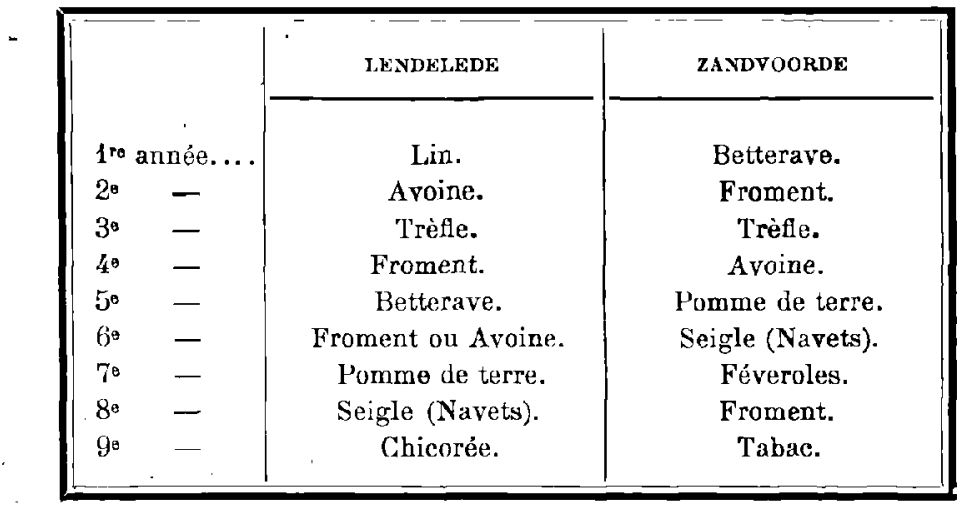

Si la chicorée a traversé une crise récente, qui a fait restreindre les étendues consacrées à cette culture, le lin et le tabac se main-

1 En 1902, environ un dixième des terres exploitées dans l'arrondissement de Courtrai.

z Monographie région limoneuse, p. 93. 
tiennent, et le colza lui-même, qu'on avait pu croire frappé à mort, a retrouvé quelque faveur. Il est vrai que le terroir est particulièrement favorable. * L'arrondissement de Courtrai, dit le préfet de Viry, est l'enfant gâté de la nature» '. Le sol est formé d'un limon sableux qui rappollo celui du pays de Waes; la présence de la couche d'argile imperméable d une faible profondeur assure une certaine humidité. Il y a bien des parties plus ou moins sableuses, surtout au Nord-Est; mais qu'importe; par les temps humides, les sables valent peut-être mieux que les terres argileuses, et d'ailleurs, de l'aveu du paysan flamand, toutes les terres avec des engrais ne finissent-elles pas par se valoir? D'ailleurs la chicorée et le lin n'aiment pas les terres trop fortes. Ils trouvent là d'autres conditions tavorables : pour le lin, la présence de la Lys, dont les eaux sont les meilleures possibles pour le rouissage; pour tous deux, une main-d'œuvre abondante due à la forte densité de lạ population : condition essentielle pour ces plantes qui exigent des soins minutieux et délicats. Voilà pourquoi ces intéressantes cultures diminuent moins autour de Courtrai que dans le reste de la Flandre; la chicorée malgré les tarifs dont s'est fortifiée la frontière française; le lin en dépit du caractère aléatoire de sa culture, où il faut compter comme nulle une année sur huit, et comme bonne une au plus sur trois. En dépit de la terrible concurrence russe, qui enlève aux lins belges lo marché français et les poursuit jusque chez eux, les cultivaleurs de Roulers el Courtrai conservent cette plante, qui en une bonne année peut rapporter le prix de la terre où elle pousse 2.

Les cultures industrielles ont un autre avantage. La quantite énorme d'engrais qui leur sont nécessaires, la façon soignée qu'il faut donner au sol ne sont pas perdus pour les plantes qui les suivent dans l'assolement. Le tabac de la région de Wervicq est apprécié des cultivateurs non seulement pour les profits que leur donne sa vente, mais parce que la terre qui l'a porté n'a plus besoin d'engrais pendant deux ans. Aussi l'agriculture du pays de Courtrai n'hésite pas à confier à sori sol des quantités formidables d'amendements; un hectare de lin reçoit en moyenne 195 francs d'engrais, un hectare do tabac, 751 franes. En revanche, le rendement de toules les récoltes s'éléve; les cantons de Mouscron, de Roulers et d'Avelghem sont, de toute là Flandre Occidentale, ceux où l'on récolte les plus grandes quantités de fromont et d'avoine a

1 De Viry, Mẻmoire, p. 110.

2 Lichtervelde, Mémoire sur les fonds ruranx du département de l'Escant (Gand, Goesin, 1815, in-80, 179 p., pl.) p. 114. 
l'hectare; ceux d'Ardoye et de Menin tiennent la tête pour les pommes de torre. Le soin que réclament les plantes industrielles s'étend d̀ toute l'agriculture; le pays de Courtrai-Roulers est la région la plus remarquable de la province au point de vue agricole; le bétail y est aussi soigné que les cultures : un agronome distingué l'estime le plus beau de Flandre; l'instruction technique du cultivateur est poussée plus loin que partout ailleurs; aussi la crise agricole y a-t-elle été moins pénible que dans le reste du pays ${ }^{1}$. L'agricullnre $\mathbf{y}$ est devenue scientifique; les engrais savants, peu employés dans l'Est, y sont en honneur. Par hectare d'étendue cultivée, les arrondissernents de Roulers et de Thielt emploieut 43 et 33 kilos d'engrais azotés, contre 4 et 3 kilos dans ceux de Termonde et d'Alust; en particulier le nitrate de soude, dont on use par hectare 162 kilos à Roulers et à Thielt, voit sa consommation réduite à 4 kilos autour de Termonde. Les tourteaux, le sulfate d'ammoniaque, les engrais phosphatés, sont employés dans des proportions semblables .

Laspect de la région porte l'empreinte de cette prédominance des cultures industrielles. L'agriculture scientifique a pourchassé les arbres; le pays est nu et monotone; rien que des champs et des maisons, à peine quelques bouquets d'ormes auprès des fermes. Les ouvriers agricoles habitent des files de corons aux constructions peu soignées; la couleur de la brique $y$ est crue; les rideaux manquent parfois anx fenêtres. On dirait des morceaux détachés d'un faubourg industriel. D'ailleurs leurs habitants sont déjá à moitié des ouvriers d'industrie, faisant rouir en automne, teillant en hiver le lin qu'ils ont cultivé et récolté dans la première partie de l'année.

\section{Foutland de l'Ouest.}

Bien plus pittoresque est le pays flamand de l'Ouest, la partie du Houtland qui s'étend de Roulers et Wervicq jusqu'à St-Omer et Ardres, la riante région d'Ypres et de Cassel. Collines, bois, haies, pâtures, lignes d'ormes et de chênes s'y succédent; les arbres et les plantes donnent l'impression d'une nature riche, presque exubérante. Guichardin estime que le pays d'Ypres est le meilleur qui soit en Flandre flamingante, et la chronique de Watten (XIe siècle) déclare que l'agriculteur peut négliger

1 Leplae, Esquisse, pp. 89-91.

2 Recensement 1895, Introduction, pp. 200-260. 
son travail : le sol produira encore malgré lui ${ }^{1}$. C'est beaucoup dire : car si le limon brun qui garnit les parties basses constitue une terre arable suffisante, il reste sur les hauteurs bien des sables et des clyttes. Les sables qui forment la rangée de collines à l'Est d'Ypres portent encore des bois; on y cultive le seigle en quantités plus grandes que le froment. L'abbaye de Nonnenbosche léve des redevances en seigle à Reninghelst au XIII' siècle ${ }^{2}$; la prévôté de St-Martin d'Ypres en 1443 n'exige pas de froment à Zonnebeke, n'étant pas sûre qu'on en cultive ${ }^{3}$. De 1895 à 1902, le seigle a même gagné plus de 200 hectares dans l'arrondissement d'Ypres, tandis que le froment en perdait 1.200.

Mais sitòt la frontière passée, la proportion change. Le seigle, encore abondant autour de Poperinghe, disparaît sur le territoire français; il n'en est plus question dans les rotations. Aucune commune n'en tient plus de 10 hectares ; il faut aller aux confins de l'Artois pour en retrouver sur les mauvaises terres. Le blé règne dans l'assolement; il occupe invariablement la moitié des terres labourables, parfois plus. A Caestre, c'est 270 hectares sur 473 ; à Ledringhem, 240 sur 468 ; à West-Cappel, 290 sur 557. Nulle part il ne descend au-dessous du tiers. C'est le premier miracle dì à la présence d'une frontière. Protégé par les tarifs de 1892, le froment se tient à un prix moins bas qu'en Belgique. Aussi, landis qu'il garnit environ un cinquième des terres labourables dans le canton belge de Rousbrugge, étendu au long de la frontière, il en occupe la moitié en France dans le canton voisin de Wormhoudt.

Cependant là aussi on constate l'augmentation des récoltes destinées, en tout ou en partie, à la nourriture des animaux. L'avoine prend de l'extension; elle est moins exigeante que le froment, et se vend aussi bien. Les vieilles cultures du trêfle, des féves, des haricots, sont en croissance. Un peu partoul, on signale le développement de la pomme de terro; parfois elle prend la promière place aprés le blé. Ici encore, c'est aux dépens des cultures industrielles que le mouvement s'opère. Le houblon, rien que dans la partie belge, a perdu en sept ans un tiers de son étendue cultivê : de 1.497 hectares en 1895, il descend à 1.021 on 1902 ; parfois, comme à Elverdinghe, on l'a remplacé par la chicorée, qui

1 Guichardin, Trad. française de 1625 (Amsterdam, Jansson), p. 349; - M. G. SS, XIV, pp. 164-165.

2 Van Hollebeke (L.), Cartulaire de l'abbaye de Nonnenbosche (Bruges, Soc. d'Em., 1865 , in $\left.-4^{\circ}\right)$, p. 96.

3 Feys et Nélia, Les trois cartulaires de la Próvôté de St-Martin à Ypres (Bruges, Soc. d'Em., 2 vol. in- $4^{\circ}, 1880-81$ ), II, p. 758. 
périclite à son tour. Des prix de vente un peu plus élevés, en 1903 et 1904, ont provisoirement enrayé le mouvement; mais ce ne peut être là qu'un arrêt momentané dans la décadence. Pourtant cette plante est bien à sa place autour des collines; il lui faut un sol assez léger, mais beaucoup d'humidité ; elle trouve l'un et l'autre dans les terres sableuses de la base des collines, qui surmontent l'argile yprésienne. Mais c'est une culture délicate et coûteuse, qui demande beaucoup de soins, d'engrais, une main-d'ceuvre abondante que le pays ne fournit pas, et nécessile des opérations compliquées, cueillette, séchage, pressag $\theta$, qui font monter le prix de revient à plus de $1.000 \mathrm{fr}$. l'hectare. D'une année à l'autre, lo houblon peut rapporter plus que le prix du terrain, ou mettre le cultivateur en déficit.

Le lin a été, il y a 35 ans, la culture la plus importante du pays, sinon pour l'étendue occupée, du moins pour l'intérêt qu'y attachaient les cultivateurs; sa présence dans le pays est d'ailleurs fort ancienne; Pline le signale chez les Morins, et la loi salique le mentionne à côté du blè, des pois et des fèves ${ }^{1}$. Mais à partir de 1870 apparaît la concurrence $\mathrm{du}$ lin russe et d'antres plantes industrielles en vogue, comme la betterave; les difficultés avec lesquelles est aux prises l'industric linière l'obligent d'employer de préférence la matiòre premiére de qualité inférieure, mais moins chère, que lui offrent les lins russes ${ }^{2}$; la culluro décline rapidement. En 1871, le département du Nord possédait 15.782 hectares de lin; dès 1877, il n'en restait que 9.648; en 1887, 6.854; en meme temps on voyait l'importation des lins russes bondir de 18.200 .000 kilos en 1872 a 58.800 .000 en $1882^{3}$. Pour arrêter la chute, on accorda en 1892 une prime de $60 \mathrm{fr}$. environ par hectare à tout planteur de lin qui ferait sa déclaration de culture; le département ne eultivait plus à cette date que 1.862 hectares. En 1893, la prime faisait atteindre 3.168 hectares, et 4.674 en 1894 ; mais les causes de décadence étaient trop puissantes, et la chute recommença; il n'y avait plus que 1.367 hectares en 1898, dont 422 pour l'arrondissement de Lille, 419 pour celui de Iunkerque, 188 pour celui d'Hazebrouck ". Lne légère reprise a eu lieu depuis, à la faveur

1 Pline, XIX, II, 1-2; Vanderkindere, Introduction, p. 118.

\$ Aftalion (A.), ta dócadence de l'industrie linière et lá concurrence victoriense de lindustrie cotonniere (Revue d'Economie politique, 190:3, pp. 420-447, 6166036, 721784), p. 7f5i). Ajouter la décalence du lin comme plante oléagineuse devant le sésame, l'anachide, le pétrole.

3 Merchier (L.), Monographie du lin et de l'industrie linière dans lo département du Nord, (Lille, Danel, 19(12), p. 154.

I Ibid. pp. 161-161. 
de la baisse de la betterave; mais ce ne sont guère que les derniers soubresauts d'une culture agonisante ${ }^{1}$. Enfin la betterave, après une fortune rapide, a vite connu le déclin; en 1901 la gare de Steenvoorde en expédiait chaque jour, pendant la campagne, plusieurs trains supplémentaires ; en 1902, il n'y en avait plus un seul. Seule la betterave fourragère est capable de se maintenir ; quant à celles de sucrerie et de distillerie, l'étendue des terres qu'on leur consacre peut varier do moitié d'une année à l'autre, selon l'ètat do l'industrie.

\section{Le Pays de Lille.}

Le pays de Lille participe à cette situation un peu instable ; le blé y fait toujours le fond de la culture, mais les autres produits augmentent ou diminuent dans des proportions déconcertantes, le cultivateur, aujourd'hui informé, étant toujours prêt à fournir la denrée qui se vendra le mieux. Sous Charlemagne, les missi de l'empereur constataient dans les villas d'Annapes et de Gruson la prósence de 5.522 muids d'épeautre, 4.000 muids d'orge, 630 d'avoine, 250 de seigle, et 100 do froment pur; en plus, quantité de fèves et de pois, et 750 muids de vin provenant des vignes du domaine 2. Ainsi les céréales riches étaient, de beaucoup, la culture principale. Bousbecque au $\mathrm{XV}^{\mathrm{e}}$ siècle produit «bleds, lain, colsat et légumes » ${ }^{3}$; c'est l'apparition des cultures industrielles. Aujourd'hui, ce territoire, siège d'une industrie florissante, n’est plus qu'à demi agricole; les cultures y sont dẻjà unc dépendance de la ville et de l'usine. Si les céréales, moitié par habitude, moitié par nècessité d"équilibrer les assolements, continuent de tenir une grande place, les autres plantes sont en évolution constante. La betlerave de distillerie y remplace la pomme de terre, qui avait profité de la decadence du lin; les prairies artificielles augmentent, car il faut nourrir un bétail sans cesse plus nombreux, destiné à alimenter de viande, de lait et

1 Voir: Brame (J.), Rapport sur la question des lins au Conseil général du Nord, session de 1852; - Ladureau, Etudes sur les causes de la diminution de la culture du lin en Flandre (Bull. Soc. Agricult. Nord, juillet 1883); - Fauchenr, Rapports (annuels) sur les concours liniers dans le Nord; etc. - En 1903, larrondissement de Dunkerque retrouve 1.720 hectares; celui d'Hazebrouck 430 ; celui de Lille 896 ; en 1904 , les chilfres sont de $2.148,621$ et 1.050 ; c'est la plus forte quantité constatée depuis $189^{\prime}$.

2 Leuridan (Th.), Statistique féodale du département du Nord: le Mélantois (Bull. Comm. H. N., XXIV), p. 5.

3 Dalle (J.), Histoire de Bousbecque (Wervieq, 1880), p. 165). 
de beurre une énorme population urbaine. A Bousbecque, sur 416 hectares labourables, les céréales occupent 220 hectares; mais la pomme de terre qui s'étendait sur 95 hectares en 1880, est réduite (1904) à 26 ; le lin est descendu de 41 à 15 ; en revanche la betterave est montée de 42 a 100, dont 67 pour la distillerie, et ses progrès semblent devoir continuer. A Bondues, sur 993 hectares, le blé en tient le liers, 326; l'avoine, 237 ; et pendant que le lin est réduit à 26 , la pomme de terre à 62 , les betteraves de distillerio tiennent 147 hectares (1903); enfin la proximité des grandes villes fait prospérer les cultures maraîchères (60 hectares). Ainsi cette agriculture du pays de Lille dépend étroitement des puissantes agglomérations qui font de ce coin un des plus peuplés du monde; jadis elle fournissait surtout le lin mis on ouvre dans ses usines; aujourd'hui sa spécialité, après les légumes et l'élevage, c'est la production de la betterave utilisée dans les distilleries de Bousbecque, de Wambrechies, de Mouvcaux, de Roubaix, de Lille.

\section{La Plaine de la Lys.}

Plus on s'ivance vers le S.-W., plus la terre devient bonne et forte. La plaine de la Lys, à ce point de vue, est la partie du Houtland qui ressemble le plus à la Plaine maritime. Le sol y est en général un limon argilo-sableux, épais de 2 a $3^{\mathrm{m}}$, interrompu parfois par des affleurements d'argile yprésienne qui constituent les terres glaiseuses tenaces des Pacauts. Ce sont donc des terres fortes; il leur arrive de brûler les plantes; on sème plus tard le blé à Steenwerck qu’à Bailleul : il viendrait trop tôt, ei d'ailleurs la moisson est encore en avance sur Bailleul et Strazeele (fig. 3). La terre doit être préparée avant la fin d'octobre, où les grandes pluies rendent les champs impraticables; et souvent on ne séme qu'à la fin de janvier, quand il a gelé. L'horizontalité du sol est une autre point commun avec la région poldérienne; les altitudes varient entre 14 et 24 métres. La plaine est donc sans cesse menacée d'inondation, et il a fallı y creuser un système do watergands presque aussi compliqué que celui des Wateringues. De plus les rivières, la Lys et ses affluents, sont toujours près de déverser sur la plaine leurs eaux de crues; jusqu’à la fin du XVIII siècle, lesinondations étaient annuelles; chaque hiver encore il y a des inondations partielles, qui empêchent quelques jours ou quelques heures la circulation; en 1894, tous les habitants étaient dans les greniers. Le sol est si plat que l'eau de la Lys remonte dans les becques jusqu'à Steenwerck et Vieux-Berquin. Il faut donc curer avec soin 
fossés et ruisseaux ; les Ponts-et-Chaussées en surveillent chaque année le détail. Depuis un siècle, c'est par le drainage qu'on remplace les fossés ${ }^{1}$; on gagne ainsi un espace appréciable; dans leur cahier de 1789, les habifants de Fleurbaix, déclarant que leur pays est aquatique et n'a puêtre défriché qu'au moyen d'un grand nombre de fossés larges et profonds, avouent qu'ils « absorbent avec les chemins la sixième parlie du terroir ${ }^{2}$. La besogne. s'est poursuivio par toute la plaine; partout on constate que les fossés diminuent de nombre, que les vieux chemins de terre, larges parfois de 15 mètres, disparaissent; avec eux on voit diminuer les haies d'aulnes ou d'epines, et les arbres, ces grands bouquets d'ormes qui sont la parure du pays; on constate à Vieux-Berquin qu'il n'en reste pas le dixième de ce qu'il y avait, il y a 60 ans.

Comme dans la Plaine maritime, les céréales et les pâtures se sont partagées ces terres fortes et humides. Les premiêres y ont gardẻ une situation importante et le rendement en est considérable; à Richebourg on arrive assez aisément à 50 hectolitres à l'hectare. Les pâtures, groupées près des fermes, occupent entre un quart et un sixième du sol. Cependant d'autres cultures sont venues : le lin, important au XVIII siècle, et qu'on faisait rouir dans les fossés, au grand détriment de la santé publique ${ }^{3}$; le colza et l'œillette, dont on trouvait en 1814, 2.950 et 2.245 heclares dans l'arrondissement de Béthune, contre 129 et 217 en 1898. La betterave a pris leur place; mais elle est aujourd'hui fortement menacée par la pomme de terre. On s'est mis à en planter en grand, puur l'exportation; et chez beaucoup de paysans, c'est le remède qui a permis de sortir de la crise. A Steenwerck, à Estaires, à Merville, Hazebrouck, la pomme do terre vient aussitôt après le blé pour l'étendue cultivée; à Vieux-Berquin, elle l'égale, et occupe un tiers du sol arable. La gare de Strazeele en expédie parfois 900 lonnes par semaine pour Paris et les villes du Nord, tandis que des quantités énormes de plants sont envoyès en Algérie, d'où ils reviennent comme primeurs en février. Enfin les pois et les haricots, exportẻs d'Estaires et Merville vers Marseille et l'Allemagne, les plantes fourragéres, le tabac dont l'importance va diminuant, se partagent le reste de l'assolement.

La prospérité de la betterave autrefois, colle de la pomme de terre à

1 La fiòre paludéenne, qui frappait surtout les moissonneurs, n'a disparu que depuis 1870 à Vieux-Berquin, c'est-à-dire depuis qu'on a comblé les trous et les fossés.

2 Loriquet, Cahiers de 1789 dans le Pas-de-Calais, (Arras, Répessé-Crépel, 1891 , in $\left.8^{\circ}\right)$, p. 389.

3 Arch. Pas-de-Galais, C. 440. 
l'heure actuelle, contribuent à diviser dans la plaine de la Lys les exploitations déjà très peu étendues. La densité de la population et l'habitude des plantes industrielles en avaient fait un pays de petite culture; dans les communes de La Couture, Locon, Richebourg-l'Avoué, $90 \%$ des exploitations ont de 1 à 5 hectares; à Estaires, 500 sur 561 sont dans le même cass; à Steenbecque, 340 sur 389. Merville, sur 692 exploitations, n'en a que deux qui dépassent 40 hectares. Aussi cette potite culture est-elle particulièrement soignée; les engrais, surtout ceux qui remédient au défaut d'acide phosphorique, sont d'un emploi courant; les marchands d'engrais sont nombreux dans chaque agglomération; pour leurs produits, on délaisse le fumier, et la paille amenée de partout, à $20 \mathrm{~km}$. à la ronde, est pressée d̀ la gare de Strazeele, et expédiée vers Io bassin houiller et l'Angleterre.

V.

L'ÉVOLLTION ACTLELLE : LES SPEGULATIONS ANMMLES.

L'agriculture flamande a donc èvolué au XIX ${ }^{\mathrm{e}}$ siècle. Conservant ses traditions de labeur excessif, lo paysan du Houtland a fait l'apprentissage des nouvelles conditions économiques; il s'est résigné à délaisser les cultures traditionnelles que des pays plus favorisés ou mieux outillés pouvaient produire à meilleur corpte ; il senquiert des dessirs des consommateurs ; il suit la demande, et parfois même la précéde. L'agriculture flamande y perd en originalité, mais y gagne la prospérité.

Cependant malgrés sa science el son courage, le cultivaleur flamand, resserré sur sa petite exploitation, ne pourrait pas vivre si les spéculations animales ne venaieut fournir leur appoint. Il en a toujours été ainsi ; d'ailleurs le sol humide so prêtait à la production de l'herbe, et il falliat fournir de la viande aux grandes agglomérations industrielles. De bonne heure, la Flandre fut donc un pays de bétail. Aux $\mathrm{IX}^{e}$ et $\mathrm{X}^{e}$ siecles, on retrouve assez fréquemment indiquée dans les cartulaires l'existence de ce bétail, et les grandes fermes en ont à peu près la proportion indiquée pour une manse de St-Bertin, sur laquelle vivaient, 4 boufs, 10 vaches, 15 porcs et 50 brebis ${ }^{1}$. En 1462, la ferme de l'abbaye de CTroeninghe posséde 4 juments de labour, 15 vaches a lait et 3 génisses, 3 taureaux;

1 Guérard, st-Bertin, p. 158. 
c'est la proportion d'une grande ferme actuelle de 30 à 40 hectares ${ }^{1}$. Au XV siècle. le territoire de Bousbecque a beauconp de moutons, et en 1592, on constate que sur 125 feux, 83 ont des bêtes à cornes, une ou deux chacun ${ }^{2}$. La loi salique elle-même énumère déjà tous les animaux domestiques que l'on trouve aujourd'hui en Flandre.

Mais la nécessité de s'aider des profits tirés des animaux pour boucler le budget de l'exploitation est devenue bien plus pressante depuis 30 ans. Les céréales ne se vendent plus à des prix rémunérateurs, sauf de rares exceptions. Les cultures industrielles, dont la Flandre, grâce à son abondante main-d'œurre et à son savoir agricole, s'était fait une spécialité, périclitent ou disparaissent. L'œillette, le colza, ne comptent plus; le lin recule ; la chicorée et le houblon languissent; la betlerave n'est pas sûre. Seuls les animaux sont demandés, et rapportent. D'un bout à l'autre de la Flandre, l'élevage, l'engraissement ont pris le pas sur toutes les autres besognes de l'agriculteur. On constate à Cruybeke que le hétail est « l'appoint essentiel »; à Bellem: que * c'est la vraie ressource du pays ; on ne vend plus que cela el des porcs »; a Poperinghe, « bẻtail et houblon font tout »; à Wervicq «c'est une ressource plus importante encore que le tabac »; à Neuve-Église, « la prospérité actuelle vient de la vente des veaux et des porcs; un fermier qui cherche à placer un fils, essaie d'abord de lui louer beaucoup de pâturages ». Fait significatif : à Thielt, l'ancien marché au lin est devenu le marché au beurre. La comparaison avec l'Artois est intéressante ; le pays de la rive gauche de l'Aa entre Arques et Eperlecques, qui avait mis sa confiance dans le blé et la betterave et négligé les animaux, avoue sa gêne, tandis que la Flandre est prospère.

On a vu que cette préoccupation générale d'étendre les spéculations animales a occasionné à travers toutes les régions agricoles une révolution dans les assolements. Le temps n'est plus où "un tiers des récoltes était consacré a la nourriture de l'homme, un tiers à celle des troupeaux, un tiers à la culture des plantes précieuses qui paient le loyer de la ferme et l'achat des engrais ${ }^{3}$. On préfère acheter du grain au dehors pour étendre la surface destinée aux plantes fourragères; on ne vend plus le grain, sauf en France; on le consomme à la ferme. Quant aux cultures industrielles, on a réduit leur étendue en proportion de l'aléa

1 Van de Putte, Groeninghe, p. 82.

2 Dalle (J.), Histoire de Bousbecque, p. 165.

3 Cordier, Agriculture, p. 278. 
que présente leur production. En même temps, on a développé les herbages; à Moorsleede le nombre des pâtures a triplé depuis 30 ans ; même mouvement à Harlebeke, Ardoye, Beveren-Roulers, et dans cent autres communes. Enfin, on en améliorait la valeur, de façon a augmenter d'un tiers, parfois d'une moitie, leur rendement. Aussi arrive-t-on à des quantités considérables d'animaux par exploitation. Le cheptel vivant de telle ferme de 45 hectares en Flandre Occidentale atteint la valeur de 19.505 francs; une autre, de 26 hectares, en a pour 13.835. Dans la partie sablonneuse, une ferme de 49 heclares a un cheptel vivant de 20.635 francs; une de 13 hectares 30 ares, de 13.562 francs; une petite de 4 hectares 90 , un de 2.695 franes ${ }^{1}$.

Le porc. - Le porc a toujours été l'animal le plus utile et le plus répandu en Flandre. Ia loi salique en mentionne des troupeaux de plus de 50 têtes ${ }^{2}$; beancoup de coutumes s'occupent d'eux : la Keure d'Hazebrouck de 1336 leur consacre sept articles ${ }^{3}$; Martial même célébre les jambons de Ménapie . C'est l'animal qui convient le mieux á un pays pauvre, où les très petites exploitations sont si nombreuses; aussi n'est-il guère de petit paysan qui n'engraisse un porc, qui lui fournira de la nourriture pendant des mois ou qui, vendu, payera le loyer. On en trouve donc partout, en quantités considèrables. A Blaringhem, il y a jusqu'à 80 têtes par ferme, et 4 à ó coches; à Neuve-Eglise des fermes possèdent 10 truies. La commune d'Eecke (1903) sur 1.029 hectares a 180 truies et 1.700 porcelets, vendus dans le Cambrésis; à Moorsleede, il naît 3.000 animaux pendant l'été, qu'on expédie à Bruxelles et à Lille. Mais en tête vient la région pauvre des bois et des bruyères. Là le porc est la grande ressource. $\Lambda$ Couckelaere, c'est une spécialité ; 10 bouchers en abattent 5 à 6.000 par an; ils alimentent Ostende. Aeltro en a 300 à chaque marché hebdomadaire; Beernem, tout l'hiver, en expédie chaque lundi 7 à 10 wagons à

1 Monngraphies Région limoneuse, pp. 213-215; Région sablonneuse, pp. 118-119. Ces animaux sont surtout des porcs, des chevaux et des bêtes bovines. Cependant il ne faut pas tenir pour négligeable le commerce des volailles. Chaque ferme en possède, qui lui procurent d'appréciables bénéfices; ce sont de petits profits, mais sûrs. Au marché d'Aeltre, chaque mercredi, viennent passer au moins 125.000 œufs, sins compter les volailles. De même les lapins, élevés par les pauvres, et dont on vend 2.000 par semaine à Maldegem, pendant l'hiver. Quant aux moutons, ils sont à peu près disparus, depuis qu'il n'y a plus de jachères.

2 Vanderkindere, Iniroduction, p. 116.

3 Ann. Com. fl. Fr., XXIIr, pp. 3-128.

- Martial, XIII, épigr. LIV. 
Bruxelles ; Maldegem, dans ses cinq abattoirs, en débite, d'août en avril, 400 par semaine. Caprycke, en 1903 , a 4.100 naissancos de porcelets. Enfin Eecloo est lo grand marché aux porcs de toute la Belgique; chaque jeudi matin il en part onviron un millier de petits porces, expédiós les uns au pays wallon, les autres en Angleterre. En 1895, l'arrondissement d'Eecloo possédait 132 porcs pour 100 hectares d'étendue cultivée, et la proportion serait probablement plus forte encore à l'heure actuelle.

Le cheval. - Sauf dans la région d'Alost, le cheval n'est pas, comme le porc, un animal né et élevé dans le pays. Én général, on va acheter, à l'àge de $1 \breve{a}$ à 18 mois, les poulains dans le Brabant ou le Boulonnais. Ceux de l'Ouest vont aux foires de Fruges, d'Hucqueliers, de Wittes, de Thérouanne; ceux de l'Est, aux foires d'Eename, de Mont-St-Amand, de Hauthem St-Liévin, où viennent jusqu’à 1.000 et 1.200 chevaux; ceux de la plaine maritime amènent leurs bêtes à Thourout et Bruges. L'animal acheté est gardé à la ferme, employé aux travaux de la culture, bien nourri d'avoine, de féveroles, de foin et do trèfle, enfin vendu vers l'àge de 4 ou 5 ans. Ce sont des courtiers allemands qui los achètent alors, et les dirigent sur les pays rhénans; ils sont les rois des marchés; de plus une dizaine de ces commerçants, appelés dans le pays « les Juifs », parcourent la contrée de ferme on ferme et achètent sur place ${ }^{1}$. La région entre Dixmude et Roulers, et celle de Courtrai, sont parmi les plus actives pour l'élevage du cheval; dans chaque village, des affiches annoncent des courses; des carrousels font partie de toutes les fetes; on sent que l'attention des habitants se porte principalement de ce côté.

Le gros bétail. - Mais la spéculation sur les animaux de l'espéce bovine est celle qui s'est le plus développée en Flandre depuis 30 ans. Partout on a entrepris l'engraissement et l'ólevage, pour fournir aux villes de la viande, du lait, du beurre. Dans l'Ouest, on a augmenté et amélioré les pâtures, dans lesquelles les bêtes restent environ 6 mois, de mai à novembre; mais bientòt il a fallu trouver d'autres ressources, l'étendue des pâtures ne suffisant plus à nourrir les betes dont le nombre croissait sans cesse. L'intendant Dugué de Bagnols signale déjà en 1698, outre les navets et les fèves donnés l'hiver, le « drac qui est le marc du grain dont on a tiré la bière $>$ (drèche), les tourteaux de colza, « nourriture très profitable », enfin le tròfle, « une herbe qui profite

1 Leplae, Lisquisse, p. 91. 
beaucoup aux bestiaux ${ }^{1} \gg$. Ces produits sont toujours cmployes, el avec eux les betteraves fourragères, les tourtcaux américains, les fèves, les pois bleus. On est arrivé ainsi à posséder beaucoup plus de bétail qu'autrefois. Dans la partie française, chaque ferme de 30 a 40 hectares possède de 15 à 20 vaches; la commune de Quaedypre, qui contient de bons herbages, comptait 2.300 têtes en 1903. L'arrondissement d'Ypres, de 1895 à 1902, a gagné 12.100 têtes, passant de 39.600 à 51.700 ; Courtrai, de 30.200 a 38.300 , en gagne 8.000 . Le seul canton de Thourout passe de 12.575 à 16.029 animaux et l'accroissement continue de plus belle à l'heure qu'il est.

L'Ost-Flandre, dont le sol ne peut produire de céréales riches, ni soutenir la concurrence des autres contrées pour les cultures industrielles, avait plus grand besoin encore que l'Ouest de l'élevage. «Misère dans l'étable, misère partout », rappelle Van Aelbroeck ${ }^{2}$; ot le sage Lichtervelde déclare en 1815 que « c'est le bétail qui décide des produits les plus

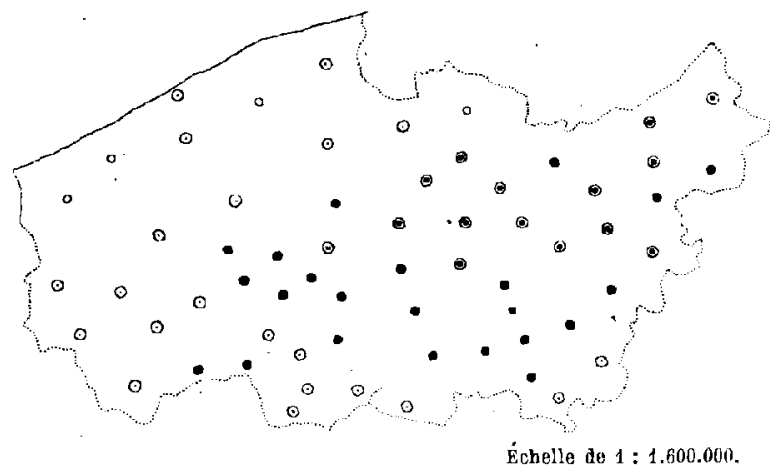

Fig. 60. - Rẻpartition des bôtes bovines en Flandre belge 4. La proportion est beaucaup plus forte dans les pays du sable, pourtant prives de pâtures, que dans la plaine maritime ou le Sud-Onest.

Nombre de bêtes bovines par cent hectares d’ótendue exploitée: O 100 a 125 - 89 à 100 $\odot 60$ मे 80 o 40 is 60 avantageux de lagriculture ${ }^{3} »$. Mais comme les pâtures sont rares sur le sol sablonneux, c'est à l'ótable qu'il faut tenir les bestiaux toute l'année. Tout ce que produitlesol est donc réservé pour les nourrir. Au printemps, c'est. l'herbe des bordures de gazon et des prairies, puis le trèfle coupeen vert, additionné de pain et de farine de seigle. En août, les feuilles de betterave et de chicorée, un peu de maïs fourrage, remplacent le trèfle, et permettent d'attendre l'arrivée des navets, base de l'alimentation pendant l'hiver, avec les carottes, le foin, les balles de céréales. Enfin les betteraves, sorties

1 Bull. Comm. H. N., X, pp. 460-461.

2 Van Aelbroeck, p. 44.

3 Lichtervelde, Fonds ruraux, p. 87.

- D'après l'atlas du Recensement agricole belge de 1895, pl. XXIV. 
des silos, succédent aux navets; on est arrivé au printemps. La farine de lin, les pommes de terre, les drèches, s’ajoutent aux autres produits. Gràce à ces procédés, dès 1902, l'arrondissement de St-Nicolas posséduait 108 têtes de gros bétail pour 100 hectares, celui de Termonde 118, et celui de Gand 121. L'arrondissement de, Gand à cette date comptait 87.576 têtes, et la province entière de Flandre Orientale 267.185, en augmentation de 42.000 sur le chiffre de 1895.

On devine, après la lecture de ces chiffres, qui doivent être en 1906 fortement dépassés, quelle quantité de lait, de beurre, de viande, est ainsi produite dans toute la Flandre intéricure, et dirigée sur les villes, le groupe lillois, Bruxelles, le pays wallon. Les races de Cassél et du Furnambacht, qui peuplent l'Ouest, celle de Hollande croisée avec le bétail indigène dans l'Est, sont bonnes laitières ; on table en moyennesur une production annuelle de 3 a 3.500 litres de lait par animal, donnant 111 à 122 kilos de beurre. De nombreuses sociétés s'occupent spécialement de bétail; presque toutes les communes de la Flandre Orientale ont des assurances contre la mortalité des bêtes bovines ; 158 syndicats d'élevage fonctionnaient, au 31 décembre 1901 , dans la province ${ }^{1}$; des laiteries coopératives se sont fondées, sur le modèle de la célćbre usine d'Oostcamp ${ }^{2}$. Le mouvement s'étend vers l'Ouest; des laiteries à vapeur s'organisent; des écrémeuses centrifuges remplacent les primitives barattes. Il reste à assurer la santé de ce bétail, que l'on a un peu négligée en poussant surtout à la quantité, à l'accroissement; dans l'Est, les vaches hollandaises, habituées au grand air des polders, et parquées sans en jamais sortir dans les étables mal construites et devenues insuffisantes, prennent fréquemment la tuberculose; dans l'Ouest, l'abus des drèches, des tourteaux falsifiés, des pulpes, conduit au même résultat; la production du lait augmente, mais au détriment de l'animal.

Grâce au bẻtail, l'agriculture flamande est aujourd'hui prospère. La crise n'ost plus qu'un souvenir, que les cultivateurs aiment à rappeler, parce qu'il leur permet de mesurer les progrès accomplis depuis 30 ans. Cette prospérité semble durable; l'agriculture flamande est assez souple, asscz avertie aujourd'hui, pour s'adapter à n'importe quelle circonstance. Elle sait prévoir maintenant, et ne redoute plus les nouveautés ; elle est prête à faire pousser sur sa terre indifférente n'importe quoi, qui rapporte. Élle donne ainsi le spectacle curieux d'une culture morcelée à l'extrême, où le travail et la patience n'impliquent pourtant pas la routine.

1 Turmann, Associations agricoles, pp. 192-196.

2 G. Journal de l'Agriculture, No 1937, 2 Janvier 1904. 


\section{CHAPITRE XIV \\ FLANDRE INTÉRIEURE: L'INDUSTRIE}

I. Nêcessité de l'industrie: son ancienneté. Industrie drapière. Industrie de la toile. La crise de 1846. - II. Persistance d'anciennes formes: industrie à domicile. Tissage. Autres industries : la dentelle. - III. La grande industrie. Caractères génẻraux. Région gantoise. Groupe de Courtrai-Renaix-Roulers. - IV. Groupe de Lille. La main-d'œuvre étrangère. La protection douanière. Lin, laine, coton; confection.

I.

\section{NÉCESSITÉ DE L'INDUSTRIE; SON ANGIENNETÉ.}

Ponr prospère que soit l'agriculture flamande, elle ne suffit pas encore à faire vivre l'énorme population qui se presse dans la Flandre intérieure. D'autres ressources sont nécessaires. Les 65.943 exploitants que le Recensement agricole signale en 1895 comme cultivant moins de 50 ares dans la Flandre Occidentale, les 51.706 qui occupent la même étendue dans la Flandre Orientale, ne peuvent considerer leur culture que comme un appoint. D'autre part, les ouvriers agricoles qui vont travailler chez

1 A consulter : Briavoinno (N.), Sur l'état de la population, des manufactures et du commerce dans les provinces des Pays-Bas depuis Albert et Isabelle jusqu'a la fiu du siècle dernier (Mém. Ac. R. Belg., 1841, in-4º, 217 p.); - Ducpétiaux (Ed.), Mémoire sur le paupérisme dans les Flandres (Mém. C. Ac. R. Belg., 1850, in-80, 340 p.); Merchier (L.), Monographie du lin et de l'industrie linière dans le département du Nord (Lille, Danel, 1902, in-8 $)$; - Houdoy (J.), La filature de coton dans le Nord de la France (Paris, Rousseau, 1903, in $-8^{\circ}, 453$ p.); - Royaume de Belgique, Ministère de l'Industrie et du Travail. Office du Travail, Les Industries à domicile en Belgique : II, Dubois, L'industrie du tissage du lin dans Ies Flandres; Gillès de Pélichy, L'industrie de la cordonneric en pays flamand $(1899)$; - III, Beatse, L'industrie de la ganterie (1900); - IV et V, Verhaegen, Ia dentelle ot la broderio sur tulle (1902); VI, Beatse, L'industrie du tissage du coton en Flandre et dans Ie Brabant, (1904); Ihid., Varlez (I..), Les salaires dans l'industrie gantoise: I, Industrie cotonnière, 1901, in-80, 214-506 p.); - Ibid., Recensement général des Industries et des Métiers, 31 octobre 1896 (18 vol. in $\left.4^{\mathrm{a}}, 1902\right)$; - Ibid., Salaires et duréc du travail dans les industries textiles au 31 octobre 1901, (in-40, 1905, 689 p.);-Résultats statistiques du Recensement général de la Population effectué le 24 mars 1901 (Ministère du Commerce), tome I (Paris, 1905), pp. 576-517. 
les fermiers y gagnent un salaire trop peu élevé pour qu'une famille puisse subsister : d'après le Recensement de 189ă, l'ouvrier non nourri à la ferme gagne par jour en moyenne, dans le canton de Lokeren, 1 fr. 48 les hommes, 0 fr. 83 les femmes; à Bellem, 1 fr. 25 et 0 fr. 63 ; à Aeltre, 1 fr. 25 et $0 \mathrm{fr} .72$; à Sysseele, $1 \mathrm{fr} .15$ èt $0 \mathrm{fr}$. 72 ; à Waerbeke près Grammont, $1 \mathrm{fr} .09$ et $0 \mathrm{fr}$. 85. Ce n'est que dans l'Ouest, tout près de la frontière, at au delà, sur le territoire français, que les journaliers arrivent à dépasser, les hommes 2 francs, les femmes $1 \mathrm{fr} .50$; à Luingne près Mouscron, 2 fr. 50 et 2 francs; à Reckem, 2 fr. 50 et 1 fr. $50{ }^{1}$; les mêmes salaires moyens sont payés en France. Ce sont, là des gains insuffisants, pour des journées de travail très ètendues, commençant à 5 heures du matin pour finir après 8 heures du soir; l'ouvrier habitant loin quitte donc sa maison a $4 \mathrm{~h} .1 / 2, \mathrm{y}$ rentre a 9 heures et doit prendre sur son repos pour entretenir le lopin de terre qu'il a pu prendre en location ${ }^{2}$. La vie est par trop difficile dans ces conditions; il faut qu'un membre au moins de la famille s'ingénie à trouver d'autres ressources. L'industrie s'offre naturellement pour les fournir. « Trop nombreux, dit une supplique de 1733, pour s'appliquer tous à l'agriculture, trois quarts des habitants du pays s'occupent actuellement à la fabrique des manufactures permises, avec quoi ils paient leurs charges et entretiennent leurs familles, lesquelles, sans ce secours, seraient réduites à la mendicité.... ${ }^{3} \gg$.

\section{Industrie drapière.}

Aussi l'industrie est-elle très ancienne en Flandre intérieure. Les jambons dont se délectait Martial n'étaient pas les seuls produits que la Ménapie envoyait à Rome; olle expédiait encore des laines façonnées, sorte de manteaux appelés « birri », dont un édit de Dioclétien fixe le prix ${ }^{4}$. Ce sont les toisons des moutons de l'Artois qui semblent avoir fourni les éléments de cette primitive industrie drapière, à laquelle succede sous les Mérovingiens et Carolingiens la fabrication des draps frisons où l'on mettait en ouvre la laine des moutons qui paissaient sur les schorres de la

1 Recensement 1895, t. III, pp. 28-55.

2 Monographie Région sablonneuse, p. 38.

3 Supplique des habitants de Wasquehal, dans : Leuridan (Th.), Notes pour servir à l'histoire de Wasquehal (Móm. Soc. Emul. Roubaix, 2o série, t. I, 1885, Pp. 117185), p. 165.

4 Corpus Inscript. lat., III, 801. 
plaine maritime '. Un diplôme de 800 nous apprend que les serfs de St-Omer fabriquent « des draps ou chemises de laine qu'ils appelaient bernicrist $\%$. Ce sont là les lointaines origines de l'industrie drapière.

L'abondance de la laine, la renommée des draps frisons, développèrent l'industrie qui commonça à s'organiser, et à venir s'établir autour des comptoirs fondés parles marchands, à l'abri d'un château, Ypres, Bruges, Gand, Lillè. Bientôt, les progrès du commerce aidant, on fit appel aux laines anglaises. Le Yorkshire, le Lincolnshire, devinrent les principaux fournisseurs; les grandes foires aux laines de Northampton, Winchester, Buston, St-Yves, Stamfurd, n'eurent pas de meilleurs clients que les marchands flamands ${ }^{3}$. Ia glaise yprésienne, onctueuse et délayable, servait a merveille pour le foulage. Les XIII e et XIV e siècles virent un essor inouï de cette industrie urbaine. Mais c'était l'époque ou sévissait déjà la surpopulation des campagnes. Pour échapper à la misère, celles-ci se mirent á exercer la lucrative industrie dont le monopole avait eté jusque là réservé aux villes. Travaillant à moins de frais, elles purent faire aux mẻtiers urbains une concurrence victorieuse. Les villes résistent, font rendre anx comtes arrêt sur arrêt défendant de fabriquer des draps hors de leurs murs "; quand l'arrêt est inefficace, la ville se charge de le mettre à exécution; en 1337, Y pres marche sur Poperinghe; en 1344, elle détruit, après une terrible bataille, les métiers de Poperinghe, Langemarck, Reninghelst. Peine perdue; dès le XIV'e siècle, l'industrie est partout, à La Gorgue, à Bousbecque, à Ghistelles, Deynze, Caprycke, Hulst. Au XV siècle, malgré la concurrence anglaise, les métiers battent dans tous les villages; en 1427, les plus insignifiantes paroisses des environs d'Ypres, Dranoutre, Kemmel, Strazeele, Eecke, Meteren, Merris, s'occupent à draper, et l'édit de Philippe-le-Bon constate une telle fièvre industrielle que des terres restent sans labour ou sont cultivées par des étrangers 5 .

1 Pirenne, Hist. Belgique, I, pp. 30-31.

2 Guẻrard, St-Bertin, p. 66.

3 Arch. de Douai, Registre L, fol. 4/ ; registre MM, fol. 43

4 1314: défense de fabriquer du drap dans un rayon de 5 lieues antour de Gand; 1322, défense d'en fahriquer dans la châtellenie de Bruges; 1322, défense d'en fabriquer dans un rayon de 3 lieues autour d'Ypres, etc. (Diegerick, Inventaire Arch. Yprea, I, pp. 245, 289, 291).

5 De Coussemaker (I.), Documents inédits relatifs à la ville de Bailleul (3 vol. in- $8^{\circ}$, Lille, 1887), I, pp. 208-213. 


\section{Industrie de la toile.}

L'industrie lainière s’étiole á la fin du $X V^{\mathbf{e}}$ siècle. I a matière première n'arrive plus: l'Angleterre garde ses toisons pour elle; l'Espagne n'en envoie pas assez. Les draps anglais envahissent le marché des Pays-Bas. Cependant, habituées à l'industrie, les campagnes ne pouvaient plus s'en passer pour vivre: ce fut donc au travail du lin qu'elles eurent recours. Émployé dès l'époque franque, le lin était resté jusqu'alors la matière première d'une industrie domestique, qui ne fabriquait que pour le compte des membres de la famille. Seules, quelques villes le travaillaient en grand; les tisserands de toile sont cités à Gand en 1280 ', à Bruges en $1297^{2}$; on renouvelle is St-Omer en 1327 une keure qui les concerne ${ }^{3}$, et la keure d'Hazebrouck, de 1336, consacre à cette industrie sept articles, qui règlent avec soin le blanchiment, la vente, le mesurage *. Ce fut dans la région où le lin est encore aujourd'hui le principal produit agricole, que l'industrie de la toile commença sa fortune; une charte de 1471 indique qu’à Swevezeele « la plupart des habitants vivaient de la marchandise des draps de lin ${ }^{5}$; et la plupart des villages situés entre la région des bruyères et la Lys sont cités au XVI ${ }^{\mathrm{e}}$ siècle comme apportant de la toile à Bruges ${ }^{8}$. De lá, elle gagna toute la Flandre. Appliquant au lin les procédés techniques acquis en travaillant la laine, les Flamands eurent bientôt créé une vaste industrie d'exportation. Véritable industrie à domicile que celle-là ; la famille entière participait d'abord à la culture, puis a la manipulation de la plante; les femmes filaient, les hommes. tissaient, a leur temps, lorsque l'état de la culture le leur permettait. Les laboureurs prennent la navette lorsqu'ils n'ont r'ien á faire aux champs, dit des Madrys ${ }^{7}$; et I)ugué de Bagnols explique la prospérité de Roubaix ef Tourcoing en 1693 par «la commodité que les habitants y ont de joindre quelque labeur avec le travail de leurs maisons ${ }^{8}$ ». $\Lambda$ la même époque, la

4 Van Lokeren, St-Pierre, , , p. 388.

2 Gilliodts, Inventaire, I, p. 54.

3 Mém. Soc. Ant. Mor., XVI, p. 560.

4 Aun. Com. fl. Fr., XXII, pp. 3-128.

5 Charve de Charles le Téméraire, dans Ann. Soc. Ein. Br., 20 série, II, 1844, p. 291.

6 "Lamentations * de Siger van Maele (Ann. Soc. Em. Br., 2ø série, III, 1845), p. 293.

${ }^{7}$ Bull. Comm. H. N., XI, pp. 316-320.

8 Ibid., X, p. 480. 
dentelle prend son essor, donnant du travail aux femmes; la tapisserie, pendant deux siècles, occupe 20.000 personnes autour d'Audenarde ${ }^{1}$; l'industrie de la laine persiste dans quelques localités, à Gand et à Courtrai où la trouve Guichardin, à Ypres, dans la région de Lille, à St-Omer où elle existe encore on 1803, à Nenve-Eglise où \& la plupart des fabricants sont en même temps laboureurs ${ }^{2}$. Le coton lui-même, qui doit détrôner le lin, apparaît au XVI $\mathrm{X}^{\text {e }}$ siècle; en le mélangeant au lin et à la laine, on obtient des siamoises que l'on fabrique à Bruges, à Courtrai, à St-Nicolas ${ }^{3}$; et les fabricants du pays de Waes, demandant qu'on autorise l'entrée libre du coton turc, affirment que l'existence de plusieurs milliers d'ouvriers en dépend 4 . En 1811, le coton emploie, dans le département de la Lys, 732 fileurs, dont 310 à Bruges, et 1.765 tisseurs, dont 813 à Thielt, lo resto à Moorseele et Mouscron; plus 359 ouvriers en siamoises ${ }^{5}$.

Malgré cette concurrence nouvelle, la production de la toile augmente au cours du XVIII ${ }^{\circ}$ siècle. La Flandre produit en 1765200.000 pièces, estimées 8 millions ${ }^{6}$; Courtrai retrouve sa supériorité dans le blanchiment, qu'elle avait perdue au XVIe siècle, par l'émigration de ses artisans à Haarlem. Fn 179?, la seule circonscription du Vieux-Bourg de Gand possède 8.868 métiers à tisser la toile, ce qui donne de l'ouvrage à 57.642 personnes, fileuses, tisserands, épeuleurs ${ }^{7}$. Dans le département de l'Escaut en 1805, 101.033 individus * d'un âge fait * s'occupent à la filature du lin, 21.871 au tissage ; et il faut y ajouter les enfants pour les travaux préparatoires; c'est presque 200.000 personnes ${ }^{8}$. I.e département de la Lys n'en possède pas moins : il a 23.133 tisserands en $1804{ }^{9}$; au début de 1812, malgré la guerre d'Espagne qui faisait grand tort au commerce de la toile, les ouvriers des textiles du département étaient encore 49.650 , soit 50.000 personnes ${ }^{10}$.

1 Voir l'étude de Van der Meersch, Histoire de l'origine, du progrès, de la splondeur et de la décadence des manufactures de tapisserie de la ville d'Audenarde (la Flandre, XV, 1884, pp. 5, 77, 180, 300).

2 Ann. Soc. Em. Br., $2^{8}$ série, VIII, 18;0, p. 273.

3 Briavoinue, p. 148.

- Arch. Nat. F12 607 .

5 Tableau dressé par lo préfet, Arch. Nat. F 1592.

6 Briavoinne, p. 133.

7 Tableau dressé par le bailli du Vioux-Bourg (Berten, Coutumes, Quartier do Gand, VII, pp. 97-98).

8 Faipoult, Mémoire, p. 128.

9 De Viry, Mémoire, p. 155.

10 Elat dressé par le préfet, Arch. Nat., F2 1585. 
Presque toute cette population ouvrière vivait dans les campagnes. Meulebeke, en 1811, avait 3.125 fileuses et 985 tisserands ; Lichtervelde, 2.200 personnes occupées au lin; Waereghem, 1.800 '. Tandis que Gand, en 1795 , avait tout juste 976 ouvriers en tex tiles pour ses 54.000 habitants ${ }^{2}$, Thourout, en l'an XIII, avait « autant à peu près de fabriques de toiles qu'il y a de ménages; et l'agriculture n'y est pas moins florissante, quoique le sol soit des plus ingrats »". En France, l'industrie roubaisienne, en 1771, donne du travail à 40.500 personnes, dont 30.000 fileuses répandues jusqu'en Artois "; et dans la châtellenie de Lille, la dentelle fait encore vivre 14.000 femmes, et 2.000 apprenties ${ }^{5}$. Ainsi l'union de l'agriculture et de l'industrie produisait les plus heureux effets; littéralement, elle faisait vivre la Flandre; elle apparaissait comme l'exprossion d'un système qui était próposé en modéle aux autres nations. Appuyées l'une sur l'autre, l'agriculture et l'industrie prospéraient: « Ce sont, dit l'intelligent préfet de l'Escaut, les manufactures et l'industrie qui ont créé dans ce pays le genre d'agriculture qui en fait la gloire et la richesse » ${ }^{6}$. Et tout ccla, grâce au lin, une plante, écrit Van Aelbroeck, qu'il faut mettre au premier rang dans l'agriculture flamande, puisqu'elle procure ä 100.000 ouvriers peu aisés un travail continuel, et que sans cela ils seraient tous réduits à l'aumône `. En 1840, on peut estimer à 220.000 le nombre des fileuses dans les deux provinces belges, à 57.000 celui des tisserands, soit 277.000 individus travaillant le lin, sans compter les enfants qui vivent du labeur de leurs parents ${ }^{8}$. En y ajoutant, pour la partio française, le chiffre très modéré de 50.000 personnes, on arrive à 330.000 travailleurs. * Je ne crains rien pour les Flandres, disait Charles-Quint, tant qu'il y aura des champs pour cultiver le lin, des doigts pour le filer, des bras pour le tisser; les Flamands seront toujours riches, tant que l'on ne coupera pas les pouces à leurs fileuses ». Le moment approchait où cette prospérité allait brusquement sombrer.

1 Arch. Nat. F12 1592 (état dressé par le prêfet).

2 Varlez, Industrie cotonnière, I, pp. 5-10.

3 Annuaire du département de la Lys pour l'an XIII (Bruges, de Busscher, in-8*, 411 p.), p. 220.

4 Leuridan (Th.), Histoire communale de Roubaix, V, p. 88.

5 Vau Hende (E.), Etat de la ville et de la châtellenie de Lille en 1789 (Bull. Comm. H. N., XIX, pp. 251-366).

6 Faipoult, Mémoire, p. 76.

7 Van Aelbroeck, p. 173.

У Ducpétiaux, Paupérisme, pp. 75-76. 


\section{La crise de 1846.}

La crise de l'industrie linière à domicile, qui éclata en 1846, avait des causes multiples. C'est d'abord l'insuffisance des dîbourhés, les marchés français et espagnol fermés par des droits sans cesse plus élevés à mesure que l'industrie s'organisait dans ces pays; c'est la concurrence terrible de la Grande-Bretagne, qui représente les progrès de la grande industrie, et qui inonde de ses produits l'Europe, $y$ compris la Brlgique; c'est l'avènement du coton, qui détrône, par son bon marché et les facilités de sá mise en ouvre, les beaux et coûteux tissus de lin; eufin c'est l'apparition de la filature et du tissage mécaniques. Il y faut joindre l'insuffisance de l'instruction, de l'éducation morale et professionnelle de l'ouvrier flamind, due à ses habitudes, à son caractére, à sa langue qui l'isole du reste de l'Europe 1. En quelques années, l'arrêt du travail est presque complet. En 1816, 200 métiers sur 800 sont en activitẻ à Evergem, 170 sur 1.250 à Waerschoot, 124 sur 500 a Tronchiennes, 80 sur 550 à Cruyshautem 2. Tout l'édifice de la prospérité flamande était fondé sur cette union de l'industric linière et de l'agriculture ${ }^{3}$; la chute fut lourde. Des causes accidentelles, la maladie des pommes de terre en 1845 , l'insuffisance de la récolte en 1846, vinrent augmenter le désastre. Le Nord français fut le moins éprouvé; pourtant à Hondschoote, les 1.500 ouvriers agricoles que lo travail du lin faisait vivre dans le canton se trouvent dans la misère; autour d'Hazebrouck, les bureaux de bienfaisance ont grand peine à faire vivre pendant l'hiver la population ouvrière privée de ses occupations ordinaires ${ }^{4}$; c'est de cette époque que date l'omigration de toute la WestFlandre vers les villes, oủ prospérait déjá la grande industrie ; et la crise qui priva de travail, au profit de la mécanique, les $\$ 00.000$ femmes qui

1 Ducpétiaux, Paupérisme, p. 49.

2 Van der Meersch, De l’ètat do la mendicité et de la bienfaisance dans la province de Flandre Orientale depuis le règne de Marie-Thérèse jusqu'à nos jours (Bull. C. C. St., V, 1853, pp. 25-268), pp. 232-233.

3 Cette idée est exprimée partout avant 1840. "C'est des travalux productifs que la manufacture de toiles procure aux cultivateurs, aux femmes et aux enfants de la campagne que naît le supplément de subsistance que la senle culture de la terre ne donnerait pas aux familles rurales. Voilà donc ici l'art de la culture et une grande fabrique associés depuis des siècles, et dont l'existence et la prospérité sont mutuellement dans une telle dépendance, que le tort fait à l'un est toujours une circonstance funeste a l'autre " (Dictionnaire de la Flandre Orientale, 1834, p. 193).

4 Gossez, Le département du Nord sous la deuxième République (Lille, Leleu, 1904, in-8o, 448 p.), pp. $191-192$. 
filaient le chanvre et le lin ${ }^{1}$, sans compter les tisserands et les épeuleurs, ne fut pas une des moindres causes du succès de la Révolution de 1848. La crise fut bientôt plus grave encore en Belgique. Le nombre des indigents enfle brusquement : en Flandre Orientale, il passe de $13 \%$ en 1840 à $28 \%$ en 1847, soit221.000 personnes à cette date dans la provinee, dont 171.000 pour les campagnes; l'arrondisscment d'Audenarde a $36 \%$ d'indigents, 31.222 personnes 2. Liagriculture et l'industrie linière étaient si bien associées dans les habitudes de la population, que les gens du pays d'Alost se refusent pendant plusieurs années a accepter le fait accompli, et restent dans une misère complète. Termonde et Wetteren, en 1810, « fourmillent de mendiants», qui sont des hommes et des femmes adultes : c'est «la grande misère ${ }^{3}$. En Flandre Occidentale, to pays linier de CourtraiRoulers est particulièrement éprouvé; la province compte $37 \%$ d'indigents, 232.000 personnes; il y en a $39 \%$ dans l'arrondissement de Courtrai, 42 et $43 \%$ dans ceux de Thielt et Roulers; au $1^{\text {er }}$ mai 18.47 , celui-ci a 1 indigent sur 2,37 habitants. La famine régne; les vieillards d'aujourd'hui se rappellent ce temps où on se jetait sur les aliments, même avariés, où on ne parlait plus que de nourriture, ot ou les gens mouraient comme des

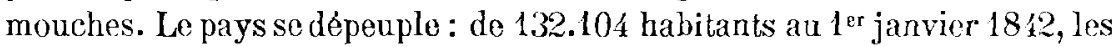
deux arrondissements de Roulers el Thielt tombent à 117.772 au $1^{\mathrm{er}}$ janvier 1849, soit 14.332 de moins, en 7 ans. Ias naissances diminuent: en Flandre Occidentale, elles étaient 22.485 en 1840 : elles ne sont plus que $19.079 \mathrm{en}$ moyenne entre 1841 et 1850 . Les decès augmentent: pour 18 亿, l'arrondissement de Roulers a 1.356 naissances, 3.099 décés ; celui de Thielt, 1.101 naissances et 3.218 décès; la proportion est de 1 à 3.1 )e 4.497 en 1810 , les mariages même descendent à 4.025 entro 1811 et 1850. La criminalité augmente brusquement: de 8.766 individus arrêtés en 184h, on passo à 25.584 en 1817 dans les deux Flandres; sur les 24.604 détenus ecroućs à Bruxelles en 1846-48, 19.456 étaient de Flandre. Ostende est envahi de nuées de jeunes vagabonds venus à pied do Meulebeke, Wynghene, Thielt, Thourout ". C'est alors que de tous les points de la Flandre des bandes èmigrèrent vers le Nord de la France, et firent enfler brusquement les chiffres de population de Lille, Roubaix-Tourcoing,

1 Blanqui, Des classes ouvrières en France pendant l'année 1818 (1 vol. in-120, 1849), p. 95.

2 Ducpétiaux, Paupérisme, pp. 19-22.

3 Réponse de la Chambre de Commerce de Termonde à I'Enquête sur la condition des classes ouvrières, II, pp. 68-70.

* Ducpétiaux, Paupériame, pp. 23-46. 
Armentières. D'autres; n'ayant plus pendant l'hiver le travail du lin qui les occupait et les faisait vivre, gagnèrent Bruxelles, Anvers, et les mines du pays wallon. Ce fut une des plus rudes crises que la Flandre ait connues.

II.

PERSISTANGE D'ANCIENNES FORMES : INDUSTRIE A DOMICILE.

\section{Tissage à domicile.}

La persistance de l'industrie textile à domicile après un pareil désastre montre bien à quel point cette combinaison d'activités industrielles et agricoles était nécessaire à la Flandre. Le paysan flamand se cramponne à ce genre de travail, parce qu'il sent que l'agriculture ne lui suffit pas, et quo lorsqu'il aura cessé de lancer la navette, il lui faudra aller travailler dans une usine, ou partir louer ses bras en France. Mais la mécanique fait une rude concurrence, et le travail à la main se trouve peu à peu resserré soit dans la fabrication des tissus les plus fins, des articles de grand luxe, devant lesquels la machine, un peu brutale, hésite encore, soit dans la production des étoffes les plus grossières. Les produits de consommation courante sont monopolisés par l'usine; le tisserand à la main ne s'y risque plus. Les 57.000 tisserands de lin de 1840 sont réduits à 10.000, répartis surtout dans les arrondissements de Courtrai (4.500), Roulers (2.152) et Thielt (1.861); le nombre en est d'ailleurs variable, et ils sont plus nombreux l'hiver, Iorsque chôment les travaux des champs. Certaines communes ont énergiquement maintenu leurs positions : Meulebeke, qui avait 985 tisserands en 1811, en garde 683; Lendelede, de 260, ne descend qu'à 233, et a en plus 39 tisserands de jute: il existe encore, dans cette commune, un atelier d'apprentissage pour le tissage à la main. On trouve mềme encore çà et là, à Wynghene, à Caprycke, à Knesselaere, à Nevele, à Beveren-Roulers, même en France à Bollezeele, quelquos demi-douzaines de vieilles fileuses, qui luttent avec leur antique rovet contre la victoriouse filaturo mécanique. Le jute, la laine, le coton, la soie, sont également tissés, çà et la, par des travailleurs isolés. Il existe encore 1.100 tisserands de laine (article tapis et moquettes) dans lo Sud de l'arrondissement de Courtrai, à proximité de Roubaix ; plas de 800 à StNicolas et Lokeren, 220 à Eecloo, et 2.600 dans l'arrondissement d'Audonarde, groupés autour de Renaix qui, à lui seul, en a 1.175. Le coton donne du travail à 700 tisserands de la régivn de Courtrai, ef à 2.230 en Flandre Orientale, pour le compte de fabricants de Renaix, Gand et 


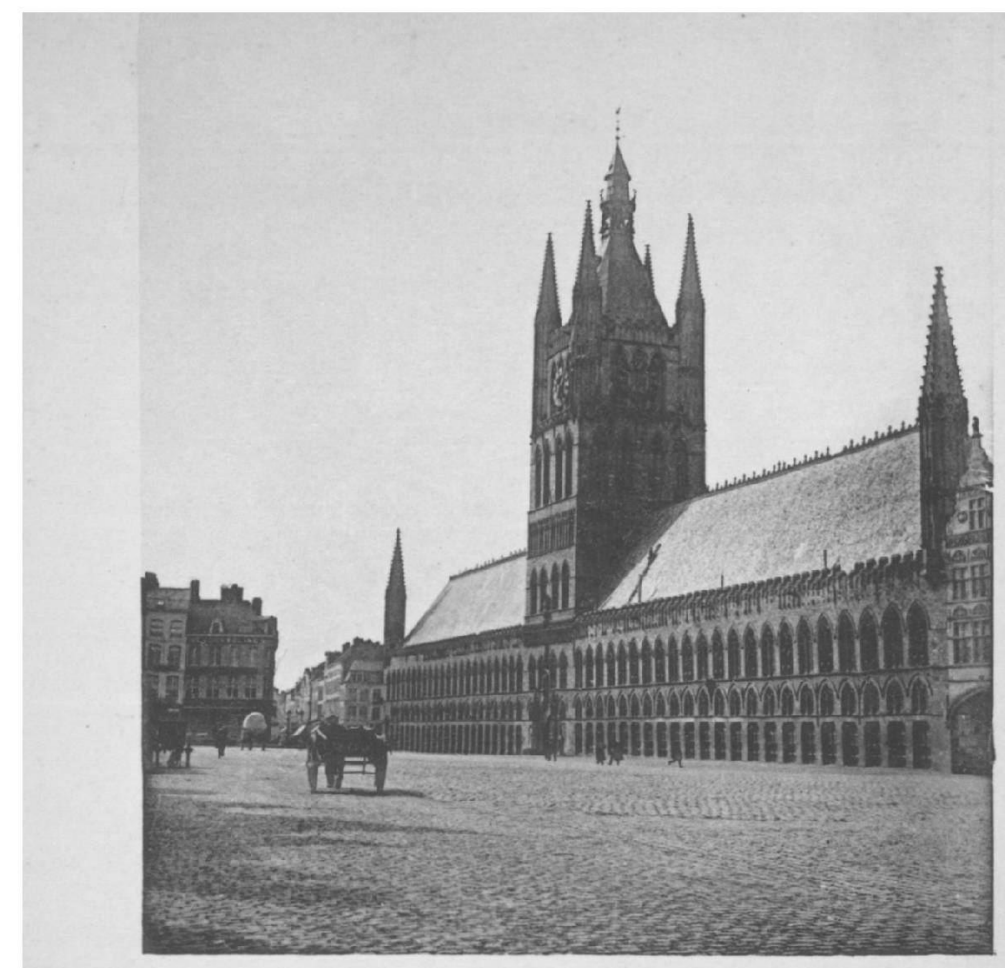

37. - L'ancienne industrie flamande: la halle aux draps d'Ypres.

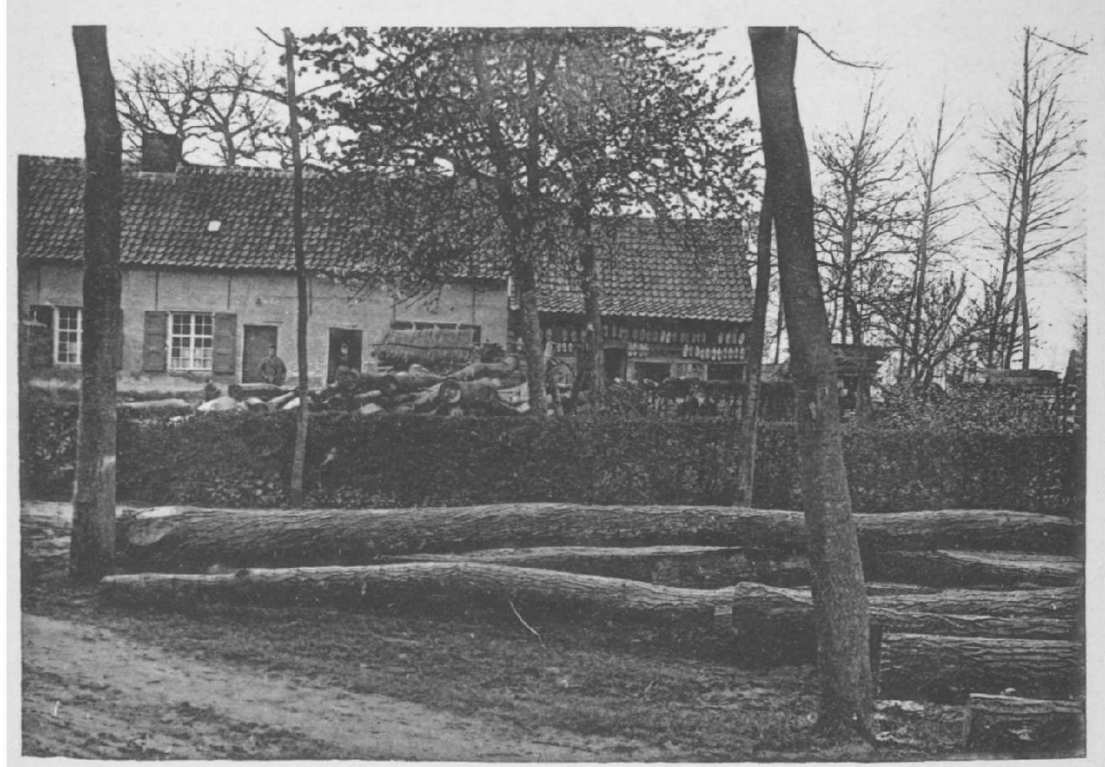

38. - Industrie à domicile: sabotiers du pays de Waes (Haasdonck). 
IRIS - LILLIAD - Université Lille 1 
Lokeren. La soie est mise en cuvre par 200 personnes autour de Deynze et d'Alost; le jute même, qui ne connaît guère que la grande usine, est tissé par une centaine d'ouvriers entre Courtrai et Rouler's, et par une aułre centaine d'ouvriers de Zele, fabriquant des tissus très grossiers qui servent à l'emballage des machines, à des prix si bas que la mécanique ne peut pas encore faire mieux 1. En France, on en trouve encore quelques milliers dans la région qui s'étend de Roubaix à Bailleul, et de 20 à 50 dans les grosses communes de la plaine de la Lys: une cinquantaine id Vieux-Berquin, au lieu de 500 vers 1860; uno trentaine à Hazebrouck contre 300 en 1875 ; une cinquantaine à Steenbecque l'hiver ; 5 à Sercus, う pour les deux Richebourg; quelques vieux çà et là dans les autres communes.

Mais les jours du tissage à domicile sont comptés. Le machinisme est en progrès continuel : il s'attaque peu à peu aux spécialités que le travail à la main avait gardées. D’autre part, le tisserand est un ouvrier trop irrégulier ; il s'évade dès que le travail presse aux champs, et le patron ne pent pas compter sur la pièce au jour dit. Enfin le salaire est par trop insuffisant; il ne faut pas espérer un gain de plus do $2 \mathrm{fr}$. pour un travail de douze heures au moins; la moyenne ne dépasse guère $1 \mathrm{fr} .50$ pour une journée qui commence à 6 heures du matin et se termine à 8 heures du soir. Écrasé par la grande industric, le tisserand est si misérable qu'on en arrive à souhaiter la disparition rapide de cette intéressante forme de travail, si bien adaptée aux nécessités de la vie en Flandre. Vivant dans une chambre obscure, souvent enfoncée dans le sol, sans plancher, pour entretenir l'humidite nécessaire aux fils, un vrai chenil, dit l'Enquête de $1846^{2}$; mal nourri de lait battu, de pain et de légumes, ignorant les nécessités de l'hygiéne, prédisposé à la tuberculose, l'ouvrier en textile passe à l'état d'organe atrophié dans l'activité flamande. Le nombre des vieux ouvriers est considérable ${ }^{3}$ : en 1896 les tisserands à domicile de plus de 55 ans formaient $39,90 \%$ du total dans l'arrondissement de St-Nicolas, 27,73\% dans celui de Gand, 22,20\% dans

1 Tous les chiffres sont empruntés au tome I du Recensement de 1896. - Remarquer que l'introduction de la mécanique a surtout modifié les conditions du filage : la machine produit 20 fois plus que la fileuse, tandis que le métier mécanique, qui bat ses 140 coups à la minute, ne dépasse que médiocrement le métier à bras qui parvient à en battre 80. Aussi le tissage à la main résiste, tandis que les fileuses sont à peu près complètement disparues.

2 Enquête, III, pp. 302-304.

3 Recensement 1896, XVIII, p. $39 \%$. 
celui de Roulers ; le tissage à la main deviont une occupation de vieillards qui s'obstinent au travail de lour jeunesse ${ }^{1}$.

\section{Autres industries à domicile: la dentelle.}

Cependant l'industrie à domicile répond si bien aux besoins de cette abondante population en quête de ressources, qu'elle se survit sous d'autres formes que celle du tissage. Le pays de Waes est peuplé de sabotiers, qui utilisent les arbres des haies, canadas, saules; les produits sont vendus en Allemagne et en Hollande; il y a là prés de 4.000 travailleurs confectionnant les sabots à domicile ou dans de petits ateliers : 373 à St-Nicolas, 365 à Beveren, 257 à Tamise. Le teillage du lin est une des ressources les plus appréciées du paysan flamand pendant l'hiver; à Stekene, Beveren-Waes, Caprycke, Maldegem, Ćruybeke, le lin des polders zélandais, roui dans les criques ou les fossés, est ainsi travaillé l'hiver ; a Swevezeele, 300 personnes s'y consacraient jadis uniquement; et la station compte encore chaque semaine un mouvement de deux ou trois wagons de lin, de 10 tonnes chacun. Il n'est pas rare, même dans la West-Flandre française, d'entendre sortir des maisons d'ouvriers agricoles le sifflement de la roue, et d'apercevoir par la porte ouverte l'ouvrier faisant tourner son instrument, au milieu d'un nuage de poussière. Ia commune de Beveren-lés-Roulers conserve cot étrange spectacle d'uno industrie à domicile encore complète, qui ramène à soixante ans en arrière: le lin du pays, roui à la I,ys, et teillé sur place, est encore filè par des vieilles femmes, puis tissé d la main pour le compte d'un fabricant qui ne craint pas d'affronter pour ses produits l'épreuve des expositions. C'est là un curieux exemple de la résistance désespérée que fait l'industrie à domicile, Iuttant contre des conditions économiques défavorables. Elle se maintient encore dans la fabrication des cordages, où l'on trouve en 1896 un millier d'ouvriers à la main, dont 514 à Hamme, les « buitenspinners » marchant lentement à reculons sur les banen (chemins) des corderies, tandis qu'un enfant tourne la roue qui opère la torsion du fil ; elle domine dans l'industrie neuve des coupeurs de poils pour la chapellerie, qui utilise les peaux des lapins bleus du pays de Waes dans tous les villages autour de Lokeren; elle l'emporte également dans la fabrica-

1 Sur cetie disparition du tissage à domicile, voir Beatse, Tissage de coton en Flandre ; - Dubois, L'Industrie du tissage ; - les Rapports annuels de l'Inspection du Travail. 
tion de Ia chaussure, qui occupe en Flandre Occidentale plus de 2.000 oú́riers à domicile, dont 1.200 dans la seule ville d'Iseghem, 280 à Thielt, 215 à Thourout, 200 à Poperinghe ${ }^{1}$.

D'autre part les femmes sont restées plus fidèles encore que les hommes à l'industrie familiale. Les nécessités économiques qui obligeaient les paysans flamands à chercher hors de la culture un supplément de ressources agissaient aussi sur les femmes; de bonne heure la Flamande consacra au filage les instants qu'clle pouvait dérober aux soins du ménage ou au travail des champs. La fabrication do la dentelle apparut au $X V^{\theta}$ siècle; sa présence élait toute naturelle dans un pays qui travaillait le lin, et ou los femmes a vaient l'habitude de manipuler les textiles. Charles-Quint aidait à l'extension de cette industrie, en faisant enseigner les meilleurs procédés dans les couvents, et la dentelle prenait au XVII ${ }^{e}$ siècle une importance justifiee par l'usage universel qu'en faisait la mode à l'époque de Louis XIV. L'apogée fut atteinte au XVIII siècle; Bruxelles et Malines occupaient autour d'elles 100.000 femmes à la confection du point à l'aiguille; 5.000 personnes dans les seuls béguinages de Gand fabriquaient de la Valenciennes au fuseau, et le point de Lille occupait dans la Flandre wallonne 16.000 ouvrières en 1789. L'apparition de la grande industrie menaça un moment de faire partager a la dentelle le sort de la filature à la main; la concurrence du tulle mécanique provoqua vers 1840 une disparition presque complète de l'industrie dentellièro, disparition qui contribua à rendre plus pénible la crise de 1816.

Cependant l'excès du mal contribua à ressusciter la dentelle. On cherchait de tous côtés des ressources; il parut que cette industrie, allégée de certains frais généraux, pourrait encore foumir une carrière dans la lutte contre la mécanique, et être utile à des populations besogneuses. On abandonna le fil de lin qui atteignait, Iorsqu'il réalisait les conditions de finesse nécessaires, des prix fabuleux : jusqu’à 6.000 francs la livre pour les meilleures qualités; à la place on adopta l'économique « fil d'Écosse», c'est-à-dire le coton, qui se trouva à l'usage plus commode ; on fit la part du feu en abandonnant à la machine la fabrication des bandes de tulle. I.es couvents prirent une part active à la résurrection de l'industrie, en fondant des écoles où s'instruisent aujourd'hui la plupart des ouvrières. Ia dentelle reprit un essor qui lui a permis de garder jusqu'à nos jours

1 Voir Gillès de Pélichy (Ch.), Lindustrie de la Cordonnerie (Industries à domicile, II, 1900). 
un rôle important parmi les industries flamandes ${ }^{1}$. 45.000 dentellières environ sont disséminées à travers la Flandre, presque uniquement dans la partie belge, car la région française ne possède guère qu'une centaine d'ouvrières dans la ville de Bailleul'2. Mais l'arrondissement de Thielt en avait en 18966.397 , soit $18 \%$ de la population féminine; le Sud de celui de Dixmude, 3.253 , soit $12 \%$; celui de Roulers, $4.122(8 \%)$; celui d'Alost 8.552 (12,9\%).

Le chiffre élevé du nombre des dentellières indique l'importance qu'occupe encore cette industrio dans la vie économique de la Flandre. La dentelle remplace véritablement la filalure du lin à domicile; elle permet à la femme des champs de gagner quelque argent lorsque sa présence n'est pas indispensable aux travaux de la ferme. Dans les villes, l'ouvrière peut s'occuper dans la grande industrie, dont les salaires sont plus élevés et qui ne demande pas l'apprentissage; aussi la dentelle en est-elle à peu près disparue, sauf de Bruges, qui n'a guère d'industrie, et ou elle est acclimatée depuis longtemps ${ }^{3}$. Mais dans les campagnes, elle constitue une des rares ressources supplémentaires que peuvent se procurer les femmes. Dans les populeuses communes rurales autour de Rouler's, Thielt, Courtrai, c'est la dentelle qui permet aux paysans de vivre pendant l'hiver. A Wynghene, ou le Recensement de 1896 accuse 1.321 dentellières, le nombre des petites exploitations augmente, grâce aux ressources fournies par cette industrie, qui permet aux journaliers de louer des terres à leur tour. A Lootenhulle, on constate que la dentelle n'a jamais tant rapporté qu'aujourd'hui ; c'est olle, et l'émigration saisonnière en France, qui font vivre le pays; elle nourrit le ménage pendant l'hiver. A Bellem, la broderio qui occupe 200 ouvrières est une ressource des plus sérieuses. L'été, beaucoup de dentellières sont aux champs; c'est en hiver que l'on entend dans chaque maison claquer les petits fuseaux de bois; a Moorsleede, le nombre d'ouvrières passe d'une centaine l'été à 600 l'hiver.

Cependant cette utile industrie est en crise ; elle diminue malgrè l'active campagne menée en sa faveur par le parti conservateur belge, désireux de retenir la femme chez elle, et de l'empêcher d'aller se perdre dans les foules des grandes fabriques. Les salaires sont trop bas: l'enquête de 1902 en cite de $0 \mathrm{fr} .95$ pour 15 heures de travail, à Tamise; de $0 \mathrm{fr} .52$ pour

1 Sur la dentelle, voir Industries à domicile, t. IV et $\mathrm{V}$.

2 Sur l'industrie dentellière à Bailleul, voir : Cortyl (E.), La dentelle à Bailleul (Bull. Com. fl. Fr., 1903, pp. 225-237).

3 En 1896, Bruges avait 3.394 dentellières. 


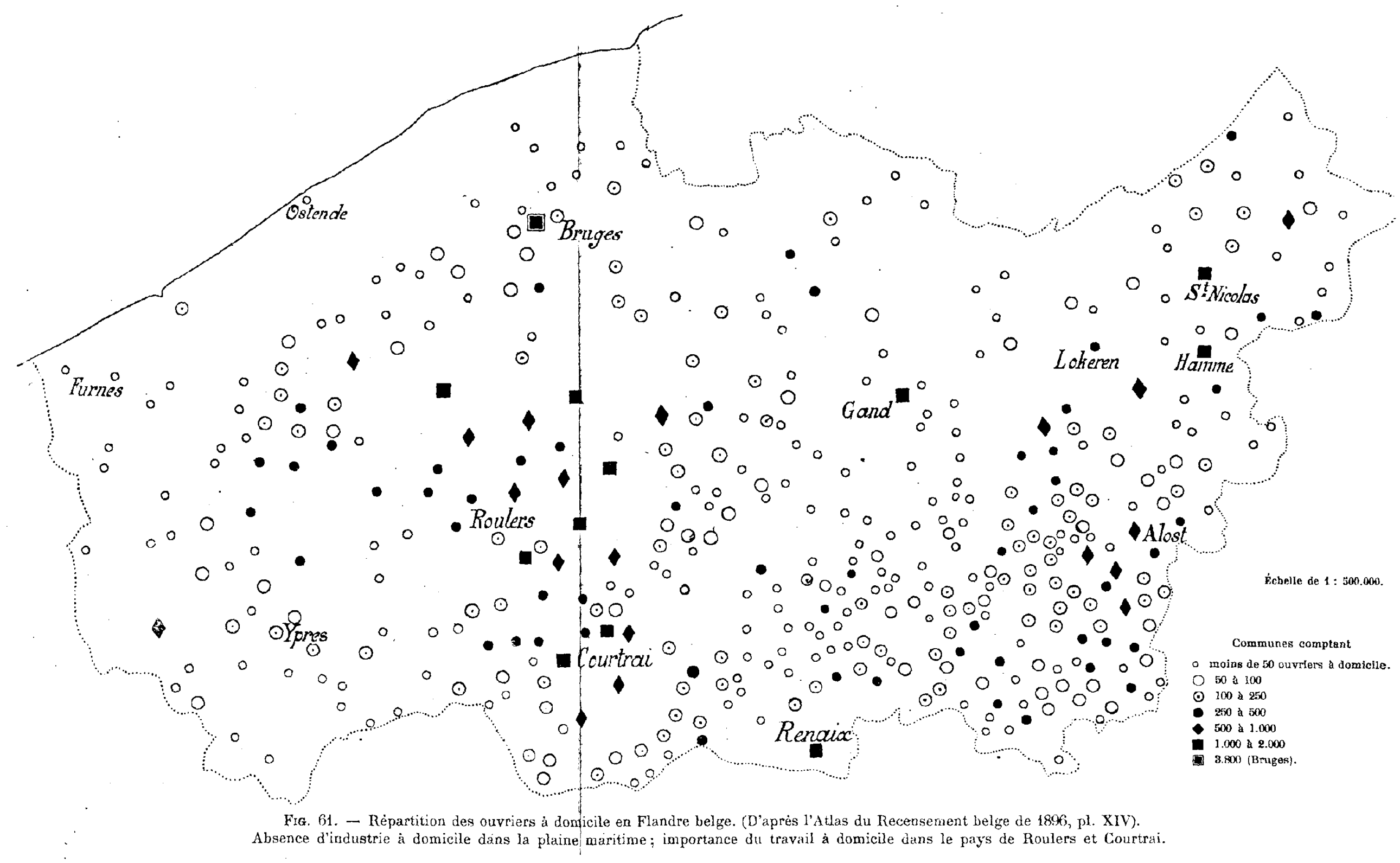


IRIS - LILLIAD - Université Lille 1 
14 heures, a Courtrai ; de 0 fr. 40 pour 12 heures, a Beveren-Waes; de 0 fr. 27 pour 10 heures, d Deynze. Pour dépasser ce gain de famine, la dentellière veut produire beaucoup, et abandonne les points fins pour la dentelle commune, appelée ordinairement le torchon; la réputation de l'industrie en souffre. La mécanique augmente sans cesse sa concurrence: le tulle de Calais et de Caudry, perfectionné chaque jour, chasse la dentelle flamande du marché français. Aussi l'industrie dentellière manque-t-elle de solidité. Qu'une usine vienne à s'établir à la campagne, qu'un autre mode de travail à domicile se présente, et la femme abandonne le fuseau. La fabrique de brosses établie en 1890 à St-André-lésBruges a fait tomber dans cette commune de 5.128 habitants le nombre des dentellières à 55 ; de même a Lede la fabrique de lingerie. Les industries de la broderie sur linge à Bellem et Sweveghem ont recruté leur personnel travaillant à domicile parmi les dentellières ; de même dans le pays d'Alost la couture des gants pour les maisons de Bruxelles et pour l'Allemagne, introduite par hasard en 1850, et qui groupe autour de Ninove et d'Audenhove 3.350 ouvrières à domicile, gagnant au maximum 1 franc à 1 fr. 25 par jour en travaillant de 6 heures du matin a 7 heures du soir ${ }^{1}$.

Malgré sa lente décadence, l'industrie à domicile reste un des caractères les plus curieux de l'activité économique en Flandre intérieure. Sans compter les petits métiers de l’alimentation et du vêtement, qui restent disséminès en ateliers minuscules, on peut encore évaluer à 80.000 , pour toute la klandre belge, le nombre des personnes (la plupart à la campagne), qui travaillent chez elles pour le compte de patrons, dont 45.000 dentellières. Ce chiffre élevé montre à quel point cette ancienne forme d'industric, appoint du travail agricole, est nécessaire à ce pays. Pourtant la Flandre n'a pas pu échapper à la transformation qui a créé au XIX ${ }^{\theta}$ siècle la grande usine, et qui s'accentue encore, irrésistible. La grande industrie, qui n'a pas pu tuer brusquement la petite vers 1846 , s'est pourtant solideunent installée en Flandre, et y fait des progrès lents et sûrs.

III.

\section{LA GRANDE INDUSTRIF.}

\section{Caractères généraux.}

Cependant cette grande industrie tient encore de près au passé. L'utili-

1 C. Industrios a domicile, III, L'Industrio do la gánterio. 
sation des textiles, qui a fait le renom et la furtune de la Flandre au moyen-âge, est toujours l'objet de l'activité de ses ouvriers. Les autres industries y ont relativement peu d'importance. La métallurgie s'est à peine installée sur les frontières: aciéries d'Isbergues, établies au bord de la plaine de la Lys, à proximité du bassin houiller et de la grande voie d'eau qui le relic à Dunkerque; usines de Lille et Fives-Lille, bien placées pour disposer d'une main-d'cuvre abondante et pour se procurer facilement le combustible; ce sont plutót là des dépendances du bassin houiller rapprochées do lia Flandre pour utiliser sa nombreuse population ${ }^{1}$. La fabrication des briques et des pannes est eparse a travers tout to pays; elle ne se concentre un peu que sur le limon de la Basse-Ieûle, l'alluvion de l'Escaut moyen (pour les briques), et sur quelques affleurements d'argile yprésienne (StMomelin) ou rupelienne (Steendorp, Stekene), pour les briques, pannes, tuiles et tuyaux 2. Les huileries sont encore nombreuses, souvenir du temps où l'on récoltait en Flandre le lin et le colza en abondance; mais ce ne sont plus guère que de petits établissements, travaillant une saison par an, sauf autour de Lille, dans les fabriques de Quesnoy-sur-Dê̂le, Marcq-en-Barcul, Comines, et dans la grande usine de Termonde, qui reçoit par l'Escaut les graines de Russie et des pays tropicaux, et peut produire 300 tonnes par semaine. La distillerie est surtout concentrée autour de Lille. Le bois, travaillé dans les ports du littoral, est egalement ouvré à Gand et aux environs, à St-Georges, à Evergem dans une grande usine occupant 700 ouvriers. Le tabac, les allumettes, occupent quelques centaines de personnes à Gand, Grammont, St-Nicolas. La meunerie à Landegem et Deynze, la vannerie à Maldegern, Halluin, Tamise, l'industrie des coupeurs de poil à Lokeren, Maldegem, Zele, Nevele, garnissent quelques usines. Eufin le groupe de Lille possède des fabriques attirées là

1 En plus, les ateliers de constructions mécaniques dans les grands centres industriels, Lille, Roubaix, Gand, pour la fabrication ou la réparation des machines de l'industrie textile.

2 Cette industrie occupe 600 ouvriers à Stekene; au X VI siècle, les gens de Stekene étaient dejjù los "Teghelbackers », les fabricants de tuilos (St-Genois, Surnoms ot Sobriquets donnés aux villes et villages de Flandre; Mess. Sc. Hist., VI, 1838, pp. 13-24). De môme l'argile de Steendorp aurait déjà été exploitée à l'époque romaine (Van Raemdonck, Le Pays de Waas préhistorique [St-Nicolas, Edom, 1878, in-80, 153 p.), pp. 134-135). Le village vit complètement do l'exploitation de l'argile: au bord du fleuve, des pontons de planches couverts de briques; puis les fours, généralement couverts d'une toiture; derrière, les longs hangars de séchage, et enfin la carrière, avee un escarpement d'une dizaine de mètres. Au fond, les hommes extraient l'argile; les femmes brouettent vers les bateaux de lourdes charges de briques, ou les transportent aux sechoirs; des vieillards tournent dos ventilateurs pour actionner les fours. L'animation est intense. 
par l'abondance et le bon marché de la main-d'œuvre, papeterie de Bousbecque (600 ouvriers), fabriques de caoutchouc, de produits chimiques, de ciment, d'appareils électriques, usines de cerruse, qui n'occupent qu'un nombre restreint de personnes au milieu des gros bataillons de l'industrie textile. Ainsi cette dernière reste de beaucoup la plus importante. Armentières, Roubaix, Tourcoing, Courtrai, Roulers, en vivent. A Gand, sur 42.400 personnes occupées à l'industrie en 1896, et parmi lesquelles il faut compter maçons, couvreurs, tailleurs, modistes, blanchisseurs, boulangers, en un mot tous les corps de métier, les seuls ouvriers du lin et du coton sont au nombre de plus de 20.000. Si le travail mécanique y devient de jour en jour plus important, la Flandre est toujours le pays de la laine et du lin.

Cependant une nouvelle évolution se manifeste. Le lin recule, même dans cette Flandre qui est son pays d'élection, devant le roi coton. $A$ une époque où l'on veut surtout du bon marché, la toile de lin est souvent trop chère ; et elle est trop chère parce que la matière première coûte plus, et que la transformation industrielle est plus difficile, plus onéreuse que pour le coton. Tandis que celui-ci est d'un travail aisé, qu'un ouvrier peul conduire 8 ou 10 cardes, un fileur avec trois aides suffire à un métier renvideur de 2.800 broches, long de 37 mètres, un tisseur commander à la fois plusieurs métiers, le lin réclame un personnol nombreux, un outillage compliqué, une manipulation parfois malsaine: au tissage il y a un ouvrier par métier; à la filature, quatre personnes pour 220 broches, et une femme par carde à étoupes. La différence saute aux yeux entre l'absence presque complète de personnel dans les grandes salles des filatures de coton, et l'encombrement d'ouvriers et d'ouvrières qui se pressent au milieu des poussières ou des vapeurs dont est saturée l'atmosphère des établissements liniers. Les conditions hygiéniques y sont moins favorables: les poussières, la température élevée jointe à un étal hygrométrique voisin de la saturation, peuvent produire chez les fileuses l'anémie, les affections rhumatismales, et chez les cardeuses la tuberculose ${ }^{1}$; pourtant les salaires sont moins considérables que ceux de l'ouvrier du coton. Aussi le personnel est-il souvent de qualité inférieure. Malgré tout, la fabrication d'un tissu type revient encore trois fois plus cher pour le lin que pour le coton ;

1 Gf. Dr Glibert, Les filatures de lin: Etude d'hygiène professionnelle. Rapport d'Enquête (Ministère Industrie et Travail: Bruxelles, Schepens, 1902, in-8 $8^{\circ} \mathrm{X}+$ 462 p.). - A Lille, la mortalité des enfants en bas-âge dont les mères sont ourrières dans les filatures de lin est plus considérable que celle des enfants nés d'ouvrières du coton: il est mort en $189942,72 \%$ et en $190038,7 \%$ des enfants d'ouvrières en lin, contre 30,63 et $27,19 \%$ d'enfants d'ouvrières en coion ( $D^{r}$ Oui, La mortalité des enfants du premier âge à Lille. Causes et remèdes. Lille,'Danel, 1901, 48 p.; cf. pp. 9-11). 
d'où la redoutable concurrence contre laquelle lutte l'industrie linière ${ }^{\text {. }}$ Ainsi cette vieille fibre, née dans le pays, utilisée par tous ses possesseurs, Ménapiens ou Francs, passẻe au premier rang au $\mathrm{XV}^{\ominus}$ siècle, devenue la matière d'une grande industrie d'exportation remplaçant tant bien que mal celle de la laine, s'est vue attaquée par un nouveau venu, un exotique, qui voudrail la reléguer au deuxième rang. Grave transformation, qui enlèverait à l'industrie flamande une de ses plus anciennes caractéristiques.

La grande industrie d'aujourd'hui se groupe autour de trois centres. Gand est la capitale d'une région qui englobo les pays do Waes et d'Alost, pousse jusqu'à Selzaete, Eecloo et Deynze ; c'est l'ancien foyer de l'industrie gantoise tolle qu'elle existait au temps d'Artevelde. Au contraire, Ypres est morte au travail industriel, et l'activité s'est déplacée à l'Est, vers la région de Courtrai-Roulers, dont dépend Renaix. Enfin le pays de Lille-Roubaix-'Tourcoing-Armentieres forme le groupe le plus compact, celui où la vie industrielle est la plus intense.

\section{Région gantoise.}

Gand est à coup sûr la ville de Flandre restée la plus fidèle à l'industrie. Le marasme où se débat le pays aux XVII et XVIII sièclès pèse lourdement sur elle; cependant elle se débat et s'ingénie. La fabrication des toiles est devenue à la fin du XVI ${ }^{e}$ siecle la principale occupation de ses ouvriers ${ }^{2}$; cependant elle conserve obstinément la draperie, essayant en 1631 le bouracan qui périclito après 1700 , la tapisserie qui a le mòme sort, se mettant au XVIII ${ }^{e}$ siècle au bombasin, puis aux ligatures, dont la fabrication occupe jusqu'à 600 ouvriers, pour finir ensuite misérablement; en 1789 il n'y avait plus à Gand que 18 tisserands de laine; le dernier métier n'a pourtant dispar'u que vers $1880^{3}$. Heureusement le coton sauva la ville, et à sa suite le lin retrouva, dans l'application du machinisme, une nouvelle prospérité.

Aujourd'hui Gand, avec ses 42.100 personnes occupẻes à l'industrie (1896), représente la plus forte agglomération industrielle de la Belgique *

1 Renseignements empruntés à Aftalion, Décadence de l'industrio linière.

2 Guichardin, p. 333.

3 Varlez, Industrie cotomnière, I, pp. 5-10.

- Recensement 1896, t. XVIII, p. 148. Suivent Anvers, avec 40.500 , Liège, avec 38.100 , Bruxelles, avec 36.900 . Bien entendu, dans cette évaluation, les faubourgs de Bruxellẹs sont comptés à part. 
De vastes usines s'ellèvent aux endroits où les bras de la Lys et de l'Escaut pénètrent en ville. La filature belge du lin, du chanvre ot du jute y est en grande partie concentrée; sur 292.000 broches existant en 1898 dans tout le royaume, Gand en possédait 197.635, n'en laissant que 95.000 en dehors d'elle. Pour le lin en particulier, sur 13.366 ouvriers qu'employaient toutes les filatures belges, Gand en comptait 8.915, dont 6.000 femmes; en y ajoulant le chanvre et le jute, on arrive à 10.500 personnes occupées dans les filatures gantoises en 1900, parmi lesquelles les fermmes occupent une place de plus en plus própondérante, au point de monopoliser bientôt cette industrie comme leurs aïeules avaient monopolisé jadis le travail du filage. I'immenses établissements abritent cette industrie, comme cette usine de la société « la Lys », véritable ville d'énormes bâtiments aux formes géométriques, hauts de cinq étages, ontourée de deux bras de la riviêre, et contenant 60.172 broches; la Linière Gantoise, qui en actionne 50.000 , la société « la lieve», 24.000 ${ }^{1}$. Le tissage de ces toxtiles y est beaucoup moins considérable; en y joignant ses faubourgs de Ledeberg et de Gentbrugge, Gand n'avait en 1896 que 6 établissements, occupant 1.155 ouvriers, ce qui porte à 11.600 environ le nombre des personnes occupées dans la vieille capitale flamande à la grande industrie du lin. du chanvre et du jute.

Le coton a plus d’importance encore, quoique le nombre d'ouvriers employés à sa préparation soit moins considérable que celui que nécessite la transformation du lin en filés et en tơiles. Cetle industrie existait à Gand au XVI ${ }^{\mathrm{e}}$ siècle, mais s'était moins développée qu’à Bruges óu dans le pays de Waes; Gand se bornait à la spécialité de la blanchisserio et de la teinturerie, el opérail sur des tissus exportés. Plusieurs tentatives avaient échoué pour acclimater dans la ville du lin la grande industrie cotonnière ", et Gand n'avait encore en 1789 que 414 ouvriers en coton, lorsque Liévin Bauwens introduisit en 1801 les machines à filer et à tisser dont il avait dérobé le secret à l'Angleterre. Le succès fut énorme: la maind'ceuvre linière était lá, abondante, prêtè à se ruer dans lés filatures et les tissages ; le blocus continental favorisait l'industrie nouvelle ; l'empereur sontenait Bauwens de tout son pouvoir, le décorait, l'élevait a la mairie de Gand. En 1802, on avait 220 ouvriers fileurs et quelques tisserands; en

1 Dubois, Industrie du tissage, pp. 41-45.

2 Fn 1700, Jean l'Kint demande à ouvrir une fabrique de coton à Gand, qui doit employer 470 personnes (de Potter, Petit Cartulaire de Gand, [Gand, Leliaert, 1885, in $-8^{\circ}, 411$ p.], pp. 372-375). En 1753, permission au sieur Verhegghen d'établir une filature de coton à Gand (Ibid. pp. 378-380). 
1810, Bauwens et ses émules employaient 10.000 ouvriers cotonniers. Ce fut une r'évolution dans Gand. Malgré l'abondance de la main-d'œuvre, malgré des salaires de 7 à 8 franes par jour aux fileurs, on manquait encore d'ouvriers, et il fallait monter des succursales à Audenarde, à Dinant, à Paris, faire tisser à St-Quentin et dans le Nord ${ }^{1}$. Gand était devenue la capitale du coton en France.

Cependant, après ce formidable boom, vinrent les crises. La séparation d'avec la France en 1814, privant l'industrie gantoise de son marché, faillit la ruiner" ; pourtant elle s'adapta aux circonstances et se découvrit un nouveau champ d'action dans les colonies hollandaises. En 1829, Gand avait 67 filatures et 14 fabriques d'indiennes; les premières possédaient 297.500 broches et produisaient 4.500 .000 kilos de coton filé, donnant au tissage 1.200.000 pièces, tandis que les secondes fournissaient 300.000 pièces imprimées par an. Une nouvelle transformation politique, celle de 1830, ruina cet édifice. Le marché de Java se ferma: ce fut la misère; beancoup d'onvriers émigrèrent. Déjà après 1814 ils avaient appris le chemin du Nord de la France, où se levait la jeune industrie roubaisienne; l'exode vers la région de Lille recommença après 1830, il partit en 1831 2.300 Gantois. Aussi Gand demeura-t-elle quelques années Orangiste, et bouda le nouvean gouvernement. Malgré une reprise en 1839, il n'existait alors que 247.000 broches dans 53 filatures, et la production d'indiennes ne s'élevait guère par an qu'à 117.000 pièces . Enfin la crise du coton de 1860, sortie de la guerre de Sécession, amena de nouvelles misères et jeta de nouvean les ouvriers gantois sur la route de France, à la recherche d'un travail industriel plus stable et mieux rémunéré.

Malgré les crises, Gand est resté le grand centre pour la filature et le tissage du coton en Belgique. Débarqué sans transbordement, grâce au canal de Terneuzen, le coton est travaillé dans 18 établissements, occupant en 1900573.000 broches à filer (870.000 en Belgique) et 83.000 à retordre (161.000); 4.500 ouvriers forment le personnel de ces usines. De plus, Gand possède environ 7.000 métiers à tisser, occupant également 4.500 personnes sur les 7.500 qui s'y consacrent dans la Belgique entière ${ }^{3}$. Population curieuse, très attachée à sa ville: quatre cinquiẻmes des ouvriers cotonniers sont originaires de Gand, et le reste, pour moitié, d'une commune limitrophe; les fileurs en particulier sont Gantois dans la

1 Varlez, Industrie cotonnière, I, pp. 17-sqq.

a Chiffres emprintés a l'Fnquête sur la condition des classes ouvrières, III, p. 312.

3 Smeesters (C.), L'essor industriel et commercial du peuple belge (Bruxelles, Schepens, 1902, in-8 $8^{\circ} 287$ p.), p. 167. 
proportion de $89 \%$. Presque tous sont nés de parents occupés dfans l'industrie cotonnière. C'est pour cette branche du travail gantois un sérieux avantage que ce recrulement opéré dans une population spéciale, possédant ainsi de véritables aptitudes professionnelles.

Cependant malgré cet avantage, les chefs de l'industrie gantoise, pour se dérober aux revendications dont se font l'organe les syndicats ouvriers, groupés dans les puissantes associations du *Vooruit ${ }^{1}$, préfèrent employer, hors de Gand, des ouvriers moins entrainès, mais plus maniables. L'industrie gantoise a essaimé hors de la grande cité; toutes les petites villes de la Flandre Orientale se sont peuplèes de manufactures, qui ont fait augmenter rapidement leur population. Alost est un petit Gand, avec des produits plus variés peut-être que ceux de la capitale: filature et lissages de jute, filatures, tissages et retorderie de coton, filature, filterie et tissages de lin, tissages de laine et de soie, corderies, bonneteries, fabriques de rubans et tresses, ateliers d'apprêt, teintureries, blanchisseries qui étalent sur la Dendre de longues trainées éclatantes, y occupent 1.500 ouvriers, sur les 7.500 personnes qui se consacrent dans la ville au travail industriel. En comptant les ouvrier's à domicile, St-Nicolas contient 8.000 individus occupés à l'industrie, dans les filatures de laine, dans la fabrication de la bonneterie, des tapis, des tissus d'ameublement, dans la teinturerie, sans compter les scieries et les fabriques de sabots. A Lokeren, les filatures et tissages de chanvre, de jute, de lin ; a Ilamme, les corderies mécaniques, la fabrication des nattes, des rubans, des tajis et carpettes, occupent 3.800 et 3.200 personnes. Termonde, bien desservie par l'Escaut et la Dendre, a ajouté à son role de forteresse celui de ville industrielle; elle a la spécialité de la couverture de coton, qu'un millier d'ouvriers y fabriquent; et son usine de câbles occupe plus de 300 personnes. Enfin les petites villes de la Dendre moyenne, Ninove et Grammont, possèdent des fabriques importantes de fil à coudre et d'espadrilles, des tissages de laine.

Mais c'est surtout à la campagne, dans les grosses communes à moitié rurales, peuplées de 5 a 15.000 habitants, que l'industric ganloise est venue s'établir depuis 20 ans. Elle trouve là une main-d'œuvre abondante, plus souple, plus maniable; la naissance d'une usine dans cettc région surpeuplée est un bienfait pour tous ces petits paysans que l'agriculture ne suffit pas à nourrir, et qui trouvent là le supplément de ressources que ne fournit plus l'industrie à domicile; les salaires d'un tiers moins élevés que ceux dont se contente à peine l'ouvrier gantois font le bonheur de ces

1 Sur le Vooruit, voir Lauzel, Le Vooruit de Gand (Revue de Paris, 1905, pp. 638-668). 
nouveaux venus à l'industrie. Pour le coton en particulier, le déplacement est sensible; en 1900 on comptait déjà que 5.000 métiers à tisser battaient dans les campagnes, contre 6 à 7.000 à (Xand, et de nouvelles usines se sont créées depuis. Eecloo possède des tissages de laine, coton, lin et jute, des teillages mécaniques de lin, ce qui avec l'industrie chapelière constitue une agglomération ouvrière d'environ 1.600 personnes, sans compter les individus qui travaillent à domicile. Wetteren occupe près de 2.000 per'sonnes dans denx immenses tissages de coton et lin. Zele tisse le coton, le chanvre et le jute; Deynze a la spécialité de la soie ; Tamise travaille jute, coton et lin; Stekene vient d'ouvrir une fabrique de draps ; Moerboke possède un tissage de toiles. Le mouvement s'accuse surtout vers le NordOuest. Waerschoot, Evergem, Sleydinge, Somergem ont des tissages de coton, occupant près de 2.000 personnes, dont le salaire moyen ne dépasse pas deux francs par jour; Thielt tisse le lin et le coton mélangés, et l'industrie gantoise pousse ses dornières conquêtes jusqu'à Ardoye, à une lieue de Roulers, où elle a fondé successivement deux tissages de coton et lin, l'un de 40 , l'autre de 500 métiers, qui groupent sous la direction de contremaîtres gantois 400 jeunes paysans d'Ardoye et des villages voisins, Lichtervelde, Moulebeke, Denterghem, Ingelmunster, Cachtern, Emolghem, Coolscamp, Eeghem, même Thourout, qui s'empressent chaque jour à pied ou en chemin de fer vers l'usine nouvelle. Ainsi la Flandre Orientale redevient peu à peu ce qu'elle a toujour's été avant 1846 , un pays oủ se combinent l'industric et l'agriculture, ot où celte combinaison seule empêche une partie des habitants de mourir de faim. C'est en effet dans les villages qui contendient jadis les nombres les plus élevés de tisserands a domicile que se sont ètablies les usines : á Waerschoot où l'on comptait en 1792821 métiers, ot 1.250 en 1846; à Evergem, qui en possédait aux mêmes dates 651 et 800 ; à Sleydinge qui en avait 724 et 675 ; à Somergem où l'on en trouvait 400 ol $700^{1}$. Ainsi sous l'empire des mêmes conditions économiques, c'est à la même place qu'autrefois qu'est revenue se fixer l'industrie, sans laquelle ce pays agricole ne peut vivre.

\section{Groupe de Courtrai-Renaix-Roulers.}

La région industrielle dont Courtrai est le centre voit se produire les mêmes phénomènes économiques que celle de Gand. Lả aussi, Ie lin fut

1 Chiffres empruntés aux tableaux dressés en 1792 par le bailli du Vieux-Bourg (cf. p. 374, note 7) et pour 1846 par Van der Meersch (cf. p. 376, note 2). 
tout jadis; c'était le roi du pays; dans tout le département de la Lys, en 1811, il y avait juste 473 ouvriers occupés à filer la laine, et 104à la tisser: à peine une vague dans la marée linière qui montait sans cesse; quant au coton, il occupait en tout 2.500 personnes 1. Le premier, Renaix, après 1850, suivit l'exemple donné par Gand, et remplaça le lin par le coton, mélangea plus tard coton et laine, et attaque aujourd'hui l'article laine pure: deux filatures de coton, une vingtaine de tissages de coton et de laine, 19 teintureries, 5 ateliers d'apprêts, $\mathbf{y}$ constituent un groupe important, qui rassemble au moins 3.000 ouvriers dans les usines, sans compter les 2.500 à 3.000 travailleur's à domicile qui dépendent de cette industrie. Cette fabrication des tartans, des contils, cotonnettes, molletons, draps pour dames, qui alimente le marché belge et depuis trois ou quatre ans s'essaie avec succès à l'exportation (Congo), est malheureusement entravée dans son essor par la situation de la ville; 'isolée derrière sa colline, au fond d'une vallée pittoresque qu'elle enfume, Renaix réclame un canal, des voies ferrées mienx desservies; son mouvement d'affaires, qui monte à 20 millions environ par an, légitime ces doléances. Ce qui manque surtout, c'est l'ean nécessaire à l'industrie, que des forages nombreux n'ont pas encore trouvée en quantité suffisante dans la craie ni dans les roches primaires.

C'est surtout à Renaix que le coton a réussi à dótrôner le lin. Aillenrs, la fibre flamande a gardé l'avantage. Sauf une retorderie a Courtrai, et un tissage mócanique à Moen pour le coton, des petits tissages de laine à Courtrai et Mouscron, le lin règne en maître; il caractérise l'industrie du pays, comme il en fait de l'agriculture. On s'occupe d'abord du rouissage, pour lequel les eaux de la Lys sont particulierement favorables. Une fois arraché et seché, le lin doit rester plongé longtemps dans l'eau, qui est chargéo de dissocier de la fibre une sorte de petite écorce appelée la chònevolte: c'est le rouissage. Cette opération peut se faire en étendant simplement le lin sur un pré, oú il est soumis à l'action de la pluie et de lá rosée (rorage); ou en le plongeant dans l'eau stagnante, comme on fait dans les routoirs du pays de Waes; mais le rouissage à l'eau courante dlans la Lys, par les qualités qu'il donne à la fibre, est universellement préfẻré: des lins provenant de toute la Flandre, française, belge et hollandaise, même de Normandie, de Bretagne, des provinces de Zćlande et de Groningue, sont apportés à la Lys pour acquérir dans les eaux de la « Rivière d'or » lo brillant, la souplesse qui en font des matériaux de première qualité. Aussi, en dépit des innombrables ordonnances qui ont proscrit, comme insalubre,

1 Arch. Nat. F12 1592. 
le rouissage en rivière ${ }^{1}$, cette opération constitue une industrie des plus prospères. Jadis établie sur la Deûle et la Lys moyenne, à Warneton, Comines et Wambrechies, elle s'est déplacée an XIX ${ }^{\theta}$ siècle et se déplace encore vers l'aval, abandonnant Warneton, gagnant Vive-St-Eloi, Deynze, concentrée surtout entre Boushecque et Courtrai, pentêtre pour éviter le contact direct des eaux impures de la Deûle. Le long des 75 kilomètres de rivière s'agitent dans la belle saison (avril-octobre) 12.000 ouvriers environ, manipulant 110 millions de kilos de lin, et gagnant 9 à 10 millions de francs. Les rives sont couvertes de bottes jaunes, de meules, de files de javelles, au point que la teinte verte des prés disparaît sous l'uniforme couleur jaune-gris du lin séché; des hommes s'empressent dans ce dédale, chargeant et déchargeant les lourdes caisses de bois (ballons) qui contiennent le lin et qu'on enfonce dans la rivière en les alourdissant de grosses pierres. L'automne venu, on sèche et on engrange le lin; on procède alors au teillage, qui sépare la fibre de la chènevotte. L'ouvrier de la Lys se transforme alors en teilleur, et va travailler dans les teillages mécaniques de Wevelghem, de Gulleghem, de Courtrai : industrie souvent insalubrè̀ cause des poussières, qui occasionnent fréquemment chez les teilleurs des affections de poitrine; elle augmente cependant, et est passée de 1896 à 1901, dans le district de Courtrai, de 98 teillages mécaniques occupant 2.640 moulins à 121 établissements et 3.419 moulins ${ }^{2}$.

Une fois teillé, le lin est mis en cuvre par les filatures et les tissages. Courtrai jouit, dans la fabrication des toiles, d'une vieille renommée justifiée encore par l'existence d'une dizaine d'usines. Roulers se développe avec rapidité : le coton a été récemment entrepris, s’ajoutant aux teintureries, blanchisseries, filatures de lin, et surtout aux tissages qui produisent la spécialité de la vilfe, les toiles d'emballage en lin et jute. Tout autour de ces deux agglomérations, les tisserands à domicile sont restés nombreux, qui travaillent pour les fabricants de Courtrai et de Roulers. Cependant ici comme à Gand on voit l'industrie s'établir à la campagne. Autour de Roulers, des tissages de lin et de jute sont venus s'installer à Fmelghem, Iseghem, Meulebeke, Ingelmunster, faisant de cette partie de la vallée de la Mandel un pays complètement industriel

1 Ordonnances de 1512 (Wolters, Recueil de lois, I, p. 82); de 1627, 1702, 1713, 1725, 1732, 1756, 1815, 1825, ete. (Delesalle, Lindustrie linière, Mém. Soc. Dunk., XI, pp. 97-144).

2 Office du Travail de Belgique; Rapport annuel de l'Inspection du Travail (1901), p. 159. - Sur l'insalubrité des travaux du lin, voir Enqquète Condit. classes ouvrières, III, p. 300, 
joignant a la fabrication des brosses et de la chaussure celle des toiles, des tapis, des tissus d'ameublement; c'est là que l'on trouve, pendant les heures d'usine, des villages de briques complètement silencieux, - hommes et femmes étant partis pour la fabrique - , qui s'animent matin et soir au passage des ouvriers pâles et maigres, pieds nus ou en sabots, qui portent chacun quelque boisson dans un petit bidon peint en bleu. Au Sud de Roulers, un tissage de sacs d'emballage s'est établi à Lendelede, un autre à Rolleghem-Cappelle. Enfin à l'Est de Courtrai, les tisserands à la main viennent peupler les nouvelles fabriques, le tissage de coton de Moen, les tissages de lin et élastiques de Sweveghem, qui occupent bien un millier de personnes, les petits tissages de Waereghem. Ainsi l'extension de l'industrie à la campagne, où elle trouve l'abondante main-d'ouvre des tisserands à domicile, n'est pas moins accusée qu'à Gand; elle serait plus forteencore, à Gand comme à Courtrai, sans la crise qu'a amenée de 1901 à 190 ) la surproduction générale, qui a fait passer de 1896 à 19102 dans le district industriel de Courtrai le nombre des broches pour lin et jute de 22.360 à 29.796, et celui des métiers à tisser de 3.905 à 5.896 .

IV.

LE GROUI'E DE LILLE.

Le groupe de Courtrai est limitrophe au Sud-Ouest de celui de Lille, le plus grand de tous, un des plus importants foyers industriels du monde. Des hauteurs qui entourent Ypres au Sud, et qui portent les villages de Zandvoorde et de Gheluvelt, on voit les files de maisons couronner les buttes du Ferrain, les clochers, les cheminées d'usine sortir des arbres, el les fumées industrielles épaissir la brume bleuâtre. I'Halluin à Lille par Boncq, Linselles, Mareq, d'Armentières à Roubaix par Pérenchies et Croix, l'industrie est partout; et ce groupe compact pousse encore des prolongements vers Seclin au Sud, a l'Ouest vers Estaires et Merville, vers Bailleul et Hazebrouck.

Cottè industrie lilloise, dont le développemont date surtout du $\mathrm{XIX}^{\theta}$ siècle, est cependant beaucoup plus ancienne. Au début du XIII ${ }^{\bullet}$ siècle, Lille est cólèbre à l'étranger « par les draps qu'elle a teints ${ }^{1}$ "; et le travail de la laine reste jusqu'à la Révolution une des principales formes de son activité. De bonne heure les villages qui l'entourent, surtout

1 Guillanme lo Breton, M. G. SS, XXVI, p. 322, y. 112. 
les gros bourgs des campagnes du Nord, se mettent d lui faire une concurronce redoutable, attestée dès 1534 par l'acte de Charles-Quint défendant la fabrication des sayettes dans la châtellenie, hors de la ville de Lille, où cette industrie occupait la plus grande partie de la population ${ }^{1}$. La draperie existait avant 1352 à Bousbecque ${ }^{z}$, avant 1363 a Linselles ${ }^{3}$; l'octroi de Charles le Téméraire aux Roubaisiens, leur permettant de draper, est de 1469 *. En 1609, la fabrication des bourrats, futaines et tripes se fiit dans toutes les paroisses entre Lille, Menin et Lannoy ${ }^{\mathbf{3}}$; Tourcoing a reçu à son tour l'autorisation de faire battre 25 , puis 50 méliers. Les guerres des $\mathrm{XVI}^{\mathrm{e}}$ et $\mathrm{XVII}^{\mathrm{e}}$ siècles ralentissent cette activité industrielle, mais ne la font pas disparaître.

L'annexion dı pays à la France après la paix d'Aix-la-Chapelle (1668) fut un bienfait pour le pays de Lille, et surtout pour son industrie. Détaché de la Flandre qui languissait depuis que les Hollandais l'avaient isolée de la mer, incorporé à un grand pays où ses produits allaient trouver un marché illimité, le groupe lillois se remit au travail avec ardeur. I a concurrence devint plus forte que jamais entre Lille et les villages de la châtellenie, dont quelques-uns s'enflaient jusqu'd devenir des villes. En 1683, l'intendant atteste quo «l'industrie du plat pays a próvalu sur celle des ouvriers de la ville et que Roubaix, Tourcoing, Wattrelos font des étoffes plus fines et plus belles que Lille ${ }^{6} \gg$; Roubaix a 500 inétiers en 1693 ; et lautorisation définitive de travailler toute matière industrielle, accordbe en 1762 aux paroisses, ne fait que consacrer une situation de fait; en 1771 , le groupe de Roubaix occupe ou fait vivre 8.400 personnes, sans compter les fileuses dispersées en Artois ?. Le groupe d'Armentières, abandonnant la laine, s'est spécialisé au XVIII siècle dans le travail des toiles fines; en 1698 , on constate que la draperie est fort diminuée dans la ville ${ }^{8}$; de mème à Houplines où le lin ot le coton prennent définitivement l'avantage après $1715^{9}$. Estaires, La (Korgue, Merville, suivent le mouvement, el les

1 Diegerick, Archives d'Ypres, V, pp. 216-217.

2 Dalle, Bousbecque, p. 157.

:Inventaire des archives de Linselles, p. 1 (série AA.).

4 Leuridan, Roubaix, V, pp. 16-17.

5 Ibid. $\mathrm{V}, \mathrm{p} .51$.

6 Instructions de Le Peletier de Souzy (Bull. Comm. H. N., X, p. 395),

7 Leuridan, Roubaix, V, p. 88. - Sur la lutte de Lille et des campagnes, voir Flammermont, Histoire de l'industrie à Lille (Lille, 1897).

8 Mémoire de Dugué de Bagnols (Bull. Comm. H. N., X, p. 478).

9 Inventaire Arch. Houplines, p. XXXVIII. 


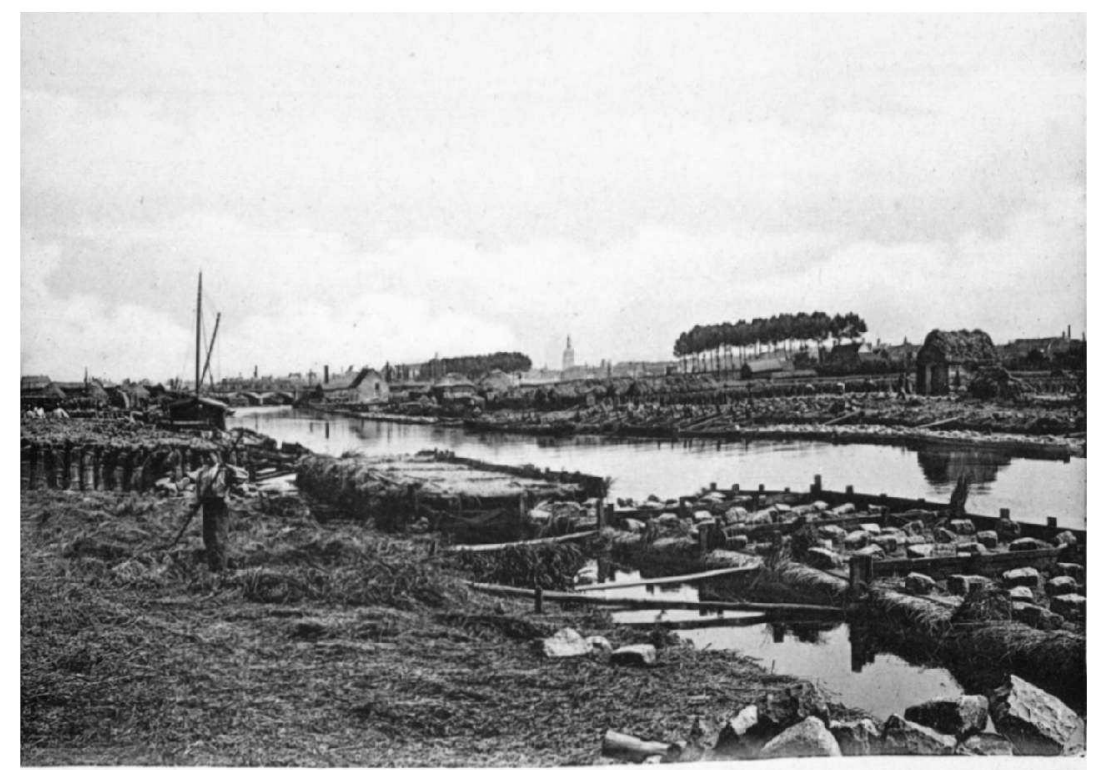

39. - Le rouissage à la Lys (Courtrai).

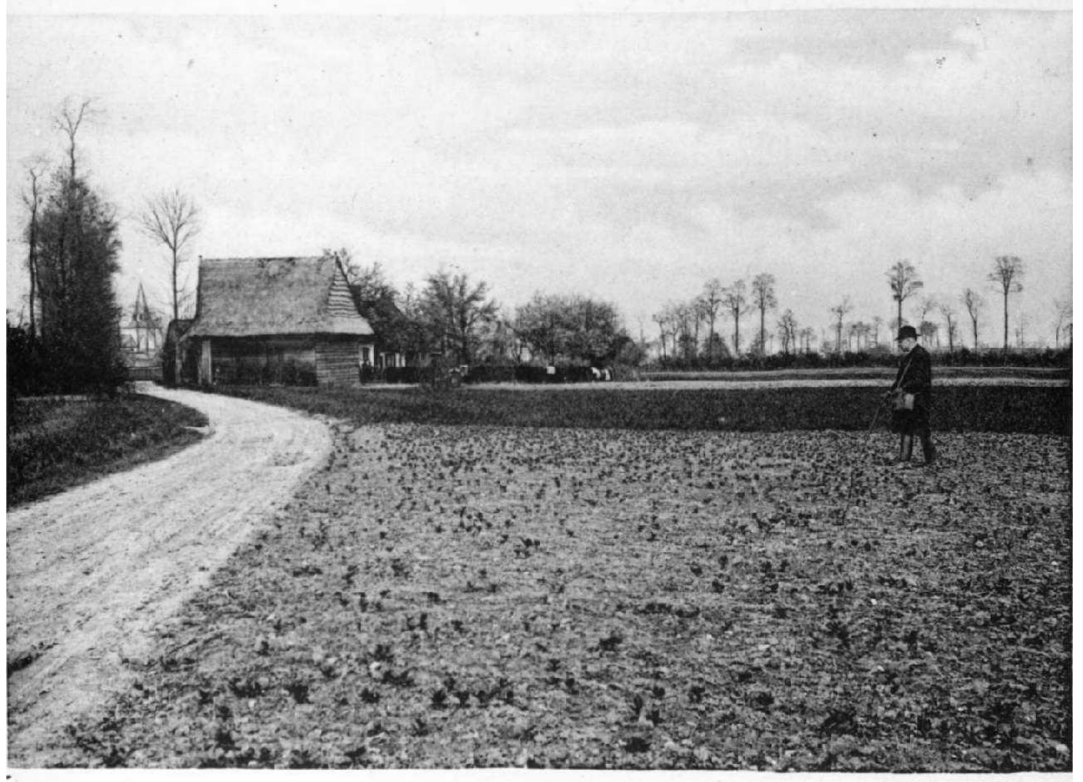

40. - Un village de West-Flandre (Volkerinckhove). 
IRIS - LILLIAD - Université Lille 1 
gens du pays de l'Alleu offrent à St-Simon, qui les a défendus au conseil en 1717 , « deux mannes prodigieuses du plus beau linge de table que j'aie jamais vu ». En 1789, malgré les effets désastreux du traité de commerce de 1786, la région lilloise était déjà un des principaux centres industriels de France: Armentières avec ses toiles fines, Halluin avec ses toiles grossières, Roubaix et Tourcoing avec leurs draps, Comines avec ses fils, Lille avec toutes ces productions réunies, auxquelles s'ajoutaient encore le travail du coton et du tabac, la production de l'huile, de la poterie, de la porcelaine, du sel raffiné ${ }^{1}$. La machine trouve là, au début du XIXe siècle, une main-d'œuvre abondante et exercée, qui forme d'abord le gros, puis les cadres de l'armée industrielle démesurément accrue depuis cent ans autour de Lille.

Cette rapide histoire de l'industrie lilloise permet de retrouver les causes de la formation de ce grand centre. La première, attestée par l'anciennetè de cette industrie, est évidemment comme dans tout le reste de la Flandre la présence d'une population très nombreuse, à laquelle l'agriculture ne pouvait suffire et qui s'est mise de bonne heure à travailler les textiles qu'elle avait sous la main, laine et lin. De là une vieille tradition industrielle, qui a permis le vaste développement du XIX ${ }^{\mathrm{e}}$ siècle. I a proximité d'un grand bassin honiller est venue aider le mouvement : de la banlieue Sud de Lille; on aperçoit les fumées des fosses; on quelques heures les trains de charbon arrivent de Lens ou d'Anzin à Roubaix, amenant le combustible à des prix modiques, gràce à la concurrence des canaux. La mer non plus n'est pas loin, et les balles de laine et de coton, les lins russes, le jute, la ramie débarqués dans les darses de Dunkerque peuvent être rapidement amenés à pied d'œuvre. Mais la vraie cause de la prospérité de l'industrie lilloise, celle qui l'a fait s'élever au-dessus de Gand el de Courtrai, c'est la proximitè de la frontière.

\section{La main-d'ouvre étrangère.}

De Bailleul à Baisioux, la limite de la France et de la Belgique s'étend, sinueuse, sur 70 kilomètres, formant un angle dont le sommet est à Halluin. Rien de plus artificiel que cette ligne; la Lys, qui sert de limite entre Armentières et Bousbecque, est d'une largeur insignifiante ; ailleurs, le tracé enprunte un fossé, un chernin, court à traver's champs. Des rues sont belges d'un côté, françaises de l'autre; des maisons ont une porte en

1 Van Hende, État de Lille et de la châtellenie en 1789. 
France, une autre en Belgique. Ciest pourtant cette ligne conventionnelle, gardee par une armée de douaniers, qui constitue le puissant rempart derrièrelequel s'est élevé l'édifice de l'industrie lilloise. D'une part, en effet, à l'abri des tarifs protecteurs qui empêchent les produits étrangers, malgré leur' prix peu élevé, d'entrer en France, la région de lille peut garder le marché français, et même exporter lorsque les cour's de l'étr'anger sont plus élevés que les siens. Mais d'autre part cette muraille de Chine, qui arrête l'invasion des produits manufacturés du dehors, ouvre ses portes toutes grandes pour laisser passer le flot d'ouvriers belges qui viennent travailler à bon compte dans les usines du pays. Les conditions générales de la vie économique en France sont telles que les bas salaires eux-mêmes sont encore supérieurs au gain des ouvriers belges. Dans l'industrie cotonnière, les hommes qui gagnent a Gand 2 fr. 58 en moyenne par jour, les femmes 1 fr. 91, peuvent trouver en France pour un travail équivalent des gains de 3 fr. 30 et 2 fr. 40. Une pareille différence peut dejà donner à réfléchir ; cependant les salaires de Gand sont encore parmi les plus élevés. En considérant l'ensemble des salaires dans l'industrie tex tile de Belgique, on voit que $77 \%$ des fileurs, et $76 \%$ des tisseurs de jute, $51 \%$ des fileurs, et $56 \%$ des tisscurs de lin, gagnent moins de 2 fr. 50 par jour ${ }^{1}$; parmi eux, $2 \%$ gagnent moins de $1 \mathrm{fr}$. 75 dans le travail du jute, et moins de $2 \mathrm{fr}$. dans le travail du lin. Jans les bourgs industriels de l'arrondissement de Roulers, 6อั\% des tisseurs de lin, dans les entreprises de plus de 100 ouvriers, 90\% dans les cntreprises occupant moins de 100 personnes, gagnent un salaire inférieur à $2 \mathrm{fr} .50 ; 75 \%$ des tisseurs de coton, dans les grandes usines rurales de l'arrondissement de Gand, ne dépassent pas ce chiffre; $1 \%$ alteint $3 \mathrm{fr}$. 50 . Il y a à Ninove des filteries où le salaire moyen ne dépasse pas 2 francs par jour pour 11 heures de travail, et l'on trouve des conditions analogues à Zele, Lokeren, St-Nicolas, Humme. Pour les femmes, on estime à $\$$ \% le nombre de celles qui n'atteignent pas un salaire de $1 \mathrm{fr}$. 75 dans l'ensemble des industries textiles de Bolgique. Au contraire en France lo tisseur de coton se fait $3 \mathrm{fr}$. 30 à Roubaix, $3 \mathrm{fr} .50 \dot{a}$ Lille; le fileur atteint en moyenne 3 fr. 90; le tisscur de lin lui-même, le moins payé de tous, gagne de 3 à 5 francs à Armentières, de 2 fr. 50 à 5 francs à Lille. Dans la laine, cette aristocratie des textiles, les salaires moyens de Roubaix-Tourcoing s'èlévent : dans le peignage, à 4 fr. ว0 pour les ouvriers de la partic industrielle, a 6 fr. pour les tricurs; dans la filature, à 6 fr. et 6 fr. 25 pour les fileurs, 3 fr. 50 pour les rattacheurs, 3 fr. pour les femmes; dans le tissage, les ouvriers conduisant un métier

1 Il s'agit lì uniquement dẹs ouvriers mâles de la fabrication âgés de plus de 16 ans. 
gagnent $4 \mathrm{fr}$. 50 à $5 \mathrm{fr}$; ; coux qui en conduisent deux, de travail plus facile, se tiennent à $\mathbf{4} \mathrm{fr}$. et $\mathbf{4} \mathrm{fr}$. 25 ; les femmes à $3 \mathrm{fr}$. Ainsi les femmes de Roubaix gagnent plus quo les ouvrier's les mieux payés de l'industrie du jute en Belgique. De l'autre côté de la frontière, on ne trouve plus que $12 \%$ à Renaix parmi les tisserands de laine et $7 \%$ à St-Nicolas, qui gagnent 3 fr. 50 ; le plus grand nombre (67\% a St-Nicolas) reste à moins de 2 fr. 50. La tentation est grande pour l'ouvrier belge de franchir la frontière, et d'aller gagner en France des salaires que le Français estime trop faibles, mais qui lui paraissent, à lui Belge, largement rémunérateurs; et cela d'autant que la journée de travail est moins longue d'1/6 environ en France qu'en Belgique. Tandis qu'en France tous les ateliers mixtes (c'est-à-dire presque tous les services de l'industrie textile) ont la journée de 10 heures, celle de $11 \mathrm{~h} .1 / 2$ est la règle dans la plupart des filatures, et dans le plus grand nombre des tissages de Belgique ; on voit même dans l'industrie des corderies à la main $67 \%$ des ouvriers travailler 12 heures et plus, $55 \%$ dans les blanchisseries, $42 \%$ dans les Cilteries, $41 \%$ dans les filatures de chanvre, $36 \%$ dans les fabriques de couvertures de coton. A tous ces hommes la région lilloise apparaît comme le pays béni, celui où l'on travaille moins, et où l'on gagne gros ${ }^{1}$.

Aussi est-ce la main-d'œuvre belge qui depuis l'essor de la grande industrie a alimenté les usines d'Armentières, de Roubaix, de Tourcoing, même de Lille. Le flot des ouvriers flamands s'est précipité aprés la débâcle de 1846 ; mais il avait dẻjà coulé avant, en 1831 ; il n'a pas tari depuis. Une bonne partie de la population, dans la région lilloise, est d'origine belge: dans la commune de Lille, on évaluait au cours du $1^{\text {er }}$ semestre de 1901 à 40.827 le nombre des Belges, la plupart ouvrier's d'usine, habitant dans le quartier de Wazemmes quelques rues et ruelles que les Français appellent « la Petite Belgique », et où l'on entend couramment parler flamand". Dans l'arrondissement, on estimait en 1901 à 162.723 le nombre des étrangers, contre 648.936 Français ; c'est exactement le quart de la population française. Roubaix a 35.577 Belges contre 88.788 Français; Tourcoing, 17.773 contre 61.470. IIors des grandes villes, la proportion est plus forte encore: Lys-lez-Lannoy a 2.027 Belges, 4.198 Français; Croix, 5.451 contre 10.512 ; La Madeleine, 3.008 contre 9.351 ; Roncq, 2.625 contre 4.053 ;

1 Pour les salaires, voir : Varlez, Industrie cotonnière, I, pp. 144-145; - Salaires et durée du travail en France, IV, pp. 308-314 et pp. 352-366; - De Winne (A.), A travers les Flandres (Gand, Volksdrukkerij, 1902, in-80, VIII + 130 p.); - Merchier, Monographie, pp. 257-259; - Houdoy, Filature, pp. 357-361; - Salaires et durée du travail dans les industries textiles, etc.

2 Renseignementa du Commissariat central do police de Lille. 
Wattrelos, 10.482 contre 15.402. Enfin deux communes ont plus d'étrangers que de nationaux: Neuville-en-Ferrain, avec 2.147 Belges et 2.127 Français, Halluin où les Belges sont 9.058, les Français 7.541 1.

Ce n'est pas tout: car si beaucoup de Belges sont venus en France chercher des salaires plus élevés que ceux de leur pays, et grâce à leur esprit d'économie réussissent à vivre en France avec leur famille, d'autres so sont avisés que le mieux serait d'habiter en Belgique, où la vie està bon marché, tout en allant gagner gros en France. Jussi un grand nombre sont-ils venus habiter à proximité de la frontière, et partent tous les matins pour l'usine située en territoire étranger. Ploegsteert déverse ses habitants sur Armentières et IIouplines, Comines-Belgique sur Comines-France, Wervicq sur Wervicq-Sud, Menin sur Halluin, Reckem, Mouscron, Luingne, Herseaux sur le groupe de Roubaix-Tourcoing. De grosses agglomérations se sont ainsi formées tout le long de la frontière, tristes lignes de corons rougeâtres, recélant d'innombrables estaminets ; on cherche en vain au-dessus des maisons basses la silhouette familière de la haute cheminée d'usine; les fabriques sont groupées à quelque distance, sur territoire français. Ainsi s'explique la croissance de ces bourgades frontières, pourtant à peu près dépourvnes d'industrie: Mouscron passant de 11.042 habitants en 1880, à 18.909 en 1900); Menin de 11.749 à 18.611 . Menin vit d'Halluin, comme Mouscron vit de Roubaix-Tourcoing; chaque jour vers 6 heures du matin leurs rues s'emplissent de la foule d'ouvrier's en sabots qui descendent aux usines françaises: 3.500 travailleurs pénètrent ainsi chaque jour à Ilalluin, autant à Tourcoing, un plus grand nombre encore à Roubaix et Wattrelos, d'autres à Bousbecque, Wervicq-Sud, Comines et dans le groupe d'Armentières : en tout plus de 15.000 par jour. Mais il en vient de bien plus loin encore: anciens tisserands restés locataires d'un lopin de terre, ils préfèrent continuer à habiter leur village où la vie est bon marché et où leur champ les aide à se nourrir. Ils prennent done le train tous les matins, grâce aux abonnements ouvriers à prix réduits, et débarquent aux gares frontières de Menin, de Comines, de Wervicq, d'Herseaux; il en vient ainsi chaque jour de Roulers, de Thourout même : ceux-lá quittent leur maison à 3 heures du matin, et ne sont guère rentrés chez eux avant 10 heures du soir; n'importe: le dimanche ils se reposent et cultivent leur champ. Des environs d'Audenarde, de

1 Chiffres communiqués par la Préfecture du Nord. Ils sont d'ailleurs probablement trop peu élevés. La mairie de Roubaix évaluait en 1901 le chiffre des Belges à 48.000 sur 124.000 habitants. Dans toutes ces villes industrielles, un tiers environ de la population est belge. 
Deynze, de Thourout part ainsi chaque matin le misérable bélail humain, parqué dans les wagons ouvriers où ces hommes dorment entassés, allant chercher au loin le salaire qu'ils ne peuvent trouver chez eux ${ }^{1}$. Il en est qui demeurent trop loin pour aller et revenir chaque jour: ils partent done le lundi matin et ne rentrent au village que le samedi soir. Ceux-ci n'apportent pas leur nourriture avec eux, tandis que les autres, surnommés les « Pots de beurre $\gg$, ont sur le dos la gamelle qui contient le pairn, la graisse, la petite tranche de lard qui serviront au repas de midi, pris dans un estaminet à proximité de l'usine. Ainsi ils protitent des salaires français, et de la vie belge à bon marché.

Ainsi s'explique la présence de tant de grandes villes industrielles à proximité de la frontière, le plus près d'elle possible. Les agglomérations, à la lettre, bordent la limite: Armentières étend ses faubourgs de Nieppe et d'Houplines, en croissant, pour serrer de plus près la terro belge ; Comines, Wervicq-Sud, Bousbecque, se tassent tout contre le territoire étranger ; Halluin forme un triangle dont la frontière forme la base, Tourcoing et Roubaix poussent leurs faubourgs de Risquons-Tout, la Marlière, Mont-äLeux, Wattrelos, vers la limite. Les usines, avec leurs toits en dents de scie, s'ètablissent en pleins champs, faisant une partie du chemin à la rencontre de cette précieuse main-d'œuvre, de ces ouvriers énergiques et résignés, que là misère rend faciles à contenter. Ce n'est pas, comme on se l'imagine parfois, que les ouvriers belges reçoivent des salaires moins élevés que leurs camarades français. Tous les ouvriers de la même spécialite gagnent autant les uns que les autros; mais il est vrai que les Belges, plus faciles à contenter, acceptent volontiers les besognes pénibles et moins rétribuées, et que cet afflux d'hommes habitués à gagner peu contribue à entraver la montée générale des salaires. L'offre de bras étant considérable, lá inain-d'ouvre ne peut guère augmenter de prix.

\section{La protection douanière.}

Ainsi sa situation de région-frontière, enfoncée comme un coin en territoire belge, assure au groupe lillois une main-d'ceuvre économique et

i A la gare d'Herseaux, on compte que 450 à 500 ouvriers débarquent tous les matins, venant d'Avelghem, St-Genois, Bossuyt, Dottignies, Espierres, Courtrai, Aelbeke, Marcke, Lauwe; 950 arrivent le lundi et repartent le samedi, venant d'Audenarde, Harlebeke, et jusque de Doynze. (Renseignements du chef de station). A Menin, le nombre des abonnés quotidiens est de 200 environ, celui des hebdomadaires d'une cinquantaine. 
inépuisable. C'est là une cause décisive de prospérité. Mais la frontière a un autre rôle. Si elle s'ouvre pour les hommes, elle se ferme devant les choses, et protège contre la concurrence étrangère les produits que fabrique cette main-d'œuvre en grande partie étrangère. Pour se procurer des ouvriers a bon comple, le groupe lillois profite de sa situation et consent à être à moitié belge ; mais c'est une autre affaire quand il s'agit de vendre les files et les toiles. On se souvient alors qu'il y a une frontière hérissée de tarifs qui permet aux toiles d'Armentières, aux filés de Tourcoing et de Lille, de se réserver le marché français el de tenter la chance à l'étranger.

Il estcurieux à ce titre d'examiner l'influence qu'on tex rcée sur l'industrie lilloise les transformations du régime douanier. Dès 1789, les députés de la Flandre wallonine et de la Flandre maritime se déclarent, dans leurs cahiers, protectionnistes ; le tiers de la seconde province demande instammont que le traité de commerce avec l'Angleterre soit annulé, et que les toiles étrangères no puissent être introduites en France qu'en payant un droit considérable ${ }^{1}$. L'annexion des Pays-Bas autrichiens, en ouvrant le marché français aux fabricants belges qui produisent à bon compte, porto un rudo coup aux industries lilloises ; en l'an X, les manufacturiers de drap do Lille déclarent $\dot{a}$ Fourcroy "que leur fabrique a beaucoup perdu, surtout depuis deux ans, par le défaut de consommation attribué à la préférence que l'on donne aux draps de Verviers et autres fabricants de la Belgique, à cause du bas prix qui séduit los acheteurs ${ }^{2} »$. Les fluctuations de la population de Roubaix à celte époque indiquent bien l'influence néfasto de cette disparition de la frontière: de 12.000 habitants au moins en 1789, Roubaix est tombé en l'an VIII à 8.302. Il est vrai que celte chule pourrait être attribuée en partie aux campagnes de 1793 et 1791 dans le Nord; mais ensuite, tandis que Gand jrogresse, Roubaix reste stationnaire, s'arrête à 8.704 habitants en l'an XI, à 8.998 en 1806 ; il ne retrouve ses 12.000 âmes qu'en 182\%, et atteint enfin 18.000 habitants en 1831; un auteur d'alors constate que « depuis 1814, la séparation de la Belgique d'avec la France y a amené un nombre considérable de familles », et qu'on y compte 4 à 5.000 ouvriers étrangers ${ }^{3}$. Ainsi la réapparition de l'ancienne frontière ot de ses prohibitions a ramené dans la région lilloise la prospérité. Aussi le pays ne veut-il pas entendre parler de trailés de

1 De Coussemaker (E.), Les Cahiers d'Gtats-Généraux en 1789 (Ann. Com. A. Fr., VII, pp. 182-318).

2 Rapport du conseiller d'Etat Fourcroy, Arch. Nat. AF IV, 1019.

3 Dupont (J.-B.), Topographie historique, statistique et médicale de l'arrondissement de Lille (Paris, Delarue, 1833, in-12, 367 p.), p. 235. 
commerce; et lorsque le Second Empire pose discrètement la question, Roubaix déclare repousser en masse toute espèce de tarifs, et ne pouvoir accepter pour son industrie que le régime de la prohibition absolue, sous peine de voir ses ouvriers réduits à la misère et à la mendicité 1 . Toutes les Chambres de Commerce protestent pareillement, et ce n'était pas sans raison, car la période inaugurée par les traités de 1860 marqua d'abord un léger embarras dans la croissance de l'industrie lilloise. Aussi les industriels ne se lassèrent pas de réclamer le retour au protectionnisme, en dépit des réserves faites par les Roubaisiens, devenus libre-échangistes depuis qu'ils avaient créé vers l'Amérique une remarquable exportation; et les tarifs de 1892 vinrent donner à la région un essor extraordinaire. Sous l'effet de ce «coup de fouet protectionniste», on vit accourir les foules belges, les usines et les corons sortir de terre.

\section{Lin, Laine, Coton, Confection.}

Toutes les industries textiles sont représentées dans la région lilloise. On y file la ramie; on y utilise le jute et le chanvre. Mais les trois grands articles sont le travail du lin, ceux de la laine et du coton. Le domaine du lin, c'est la rive droite de la Lys, d'Armentières à Halluin, puis Lille et sa banlieue ; la laine règne à Roułaix et à 'Tourcoing ; le coton est filé surtout à Lille; mais la grande ville, en vraie capitale, concentre dans ses murs et sa banlicue, sauf la laine, la plupart des autres spécialités iudustrielles de la régrion ${ }^{2}$.

Lө Lin. - Le lin employé dans les filatures de la rẻgion lilloise n'est plus la fibre indigène. On a vu comment la culture de cetle plante étail peu à peu disparue du sol français, où cependant il serait peut-être plus facile qu'on ne pense de la ressusciter, aujourd'hui que l'extension de la culture en lignes contribue à tenir le sol propre, et où l'emploi des engrais nécessaires à la croissance du lin est singulièrement facilité ${ }^{3}$. Ce sont aujourd'hui les lins russes de Riga et d'Arkhangel, et dans une faible mesure les

\footnotetext{
1 Réponse de la Chambre de Commerce (1856), dans Merchier, Monographie, p. 70.

a On trouvera les chiffres globaux concernant l'activité industrielle du département du Nord (1901) dans les Résultats statistiques du Recensement de 1901, tome I, pp. 576-617.

3 Renseignements de M. A. Potié, Sénateur du Nord. Le véritable obsiacle à la résurrection de la culture du lin serait l'absence des intermédiaires d'autrefois, les marchands de lin, qui faisaient passser la plante du cultivateur au filateur ou au teilleur.
} 
lins belges de la Lys," qui alimentent l'industrie '. Presque tout ce lin étranger qui pénètre en France est dirigé sur le pays de Lille. C'est là en effet que s'est concentrée l'industrie linière, surtout celle de la filature. Lorsque le . lin se vit serré de près par le coton, il se réfugia peu à peu dans la région où l'on continuait à cultiver quelques milliers d'hectares de la plante, où l'on employait des procédés de rouissage perfectionnẻs, et où l'industrie linière, antique spécialité, possédait déjà un personnel exercé, et pouvait disposer des gros capitaux d'un pays riche. Aussi sur 485.572 broches que comptait la filature de lin en France (1899), le département du Ford en avail 434.351, et l'arrondissement de Lille à lui seul $424.181^{2}$; c'est un véritable monopole. Même c’est presque uniquement dans la ville de Lille et sa banlieue immédiate, à Lomme, à La Madeleine, ou dans un rayon de quelques kilomètres, à Seclin et Pérenchies, que sont concentrées les filatures : la ville compte 14 b́tablissements, les faubourgs dix, la ville de Seclin six ${ }^{3}$. Quelques autres, d'importance moindre, existent à Armentières et dans sa banlieue; à Halluin et Bousbecque, à Quesnoy, à Lannoy, à Linselles * Ainsi Gand et Lille, les deux grandes villes manufacturières de la Flandre, ont fidélement conservé la vieille industrie du pays, signe que l'industrie flamande, dans son essor actuel, tient encore de près au passé. C'est encore à Lille et dans la ville de Comines qu'est restée établie depuis des siècles la fabrication des fils à coudre en lin, appelée la filterie de lin; hors des 16 etablissements qui dans ces deux centres produisent par an 20 à 25 millions de francs de fil à coudre, il n'y a pas d'industrie filtière en France 8 .

Le monopole du Nord est moins caractérisé en matière de tissage, quoique la région lilloise comprenne déjà les deux tiers des métiers mécaniques existant en France. Dans cette branche de la fabrication, Lille et ses faubourgs comptent encore 26 établissements, mettant en marche 3.765 métiers, dont la production comprend surtout des tissus mélis, contenant deux tiers de lin contre un tiers de coton. Mais la prépon-

1 D'après la Chambre de Commerce russe do Paris, les importations de lin en France (1899) ont atteint 74.986 .769 kilos, dont 70.464 .670 kilos de lins russes, 3.294 .559 belges, 1.227 .540 dautres pays. (Enquêtes industrielles et commerciales, fascicule 1, 1905, p. 8). D'appès Merchier (Monographie, p. 154) l'importation de 1897 porterait sur 74.200 .000 kilos de lins russes, et 10.500 .000 kilos de lins belges.

2 Merchier, Monographie, p. 187.

3 Chiffres de 1901.

4 La filature du lin, chanvre, jute, oceupe dans le département du Nord (1901) 24.983 personnes (Recensement, p. 597).

5 Merchier, Monographie, p. 213. 
dérance appartient à Armentières et à ses environs. La circonscription de la Chambre de Commerce, qui comprend le canton d'Armentières, Bailleul, et les villes de la Haute-Lys, comptait en 189953 tissages mócaniques où battaient 8.550 métiers, occupant plus de 12.000 ouvriers ; cela saus compter les 2.500 métier's à la main, dont 1.000 environ à Bailleul, qui sont actionnés à domicile ou dans de petits ateliers réunissant au plus 10 métiers ${ }^{1}$. $\Lambda$ lui seul, le canton d'Armentières comprenait les $9 / 10$ des métiers mécaniques, et la gare d'Armentières expédiait en 1902 la somme de 19.664.000 kilos de toiles ${ }^{2}$; or les envois par voitures étant évalués à la moitié environ des expéditions par voie ferrée, c'est à bien près de 30 millions de kilos de toiles que s'èlevait la production. Ainsi c'est à peu près uniquement à la fabrication de la toile que se livre cette ville d'usines créée đu XIX siècle autour de la vieille forteresse de la Lys, ainsi que ses faubourgs d'Houplines, de Nieppe, de Ia Chapelle. Vers l'Ouest, deux tissages sont installés à Bailleul, deux à Sailly-sur-Lys, six à La Gorgue, un à Merville; et l'industrie armentiéroise pousse ses ramifications jusqu'à Hazebrouck, où 1.000 ouvriers travaillent dans trois usines de toiles, et à Richebourg-l'Avoué, dans la région tonte rurale de la plaine de la Lys, utilisant à l'exemple des industriels gantois la main-d'œuvre à bon marché des paysans.

Enfin Halluin est le troisième centre du tissage du lin. Ses 14 tissages mócaniques, avec 2.500 métier's, produisant des coutils, du linge de table, produits mètissés où le coton se glisse pour un quart, écrasent de plus en plus les 11 établissements de travail à la main, qui avec leurs 700 métiers ne fournissent guère qu'un dixième de la production totale ${ }^{3}$. Halluin possède encore des établissements pour les dernières opérations que subit la toile avant d'être livrée au consommateur; des blanchisseries bordent la Lys jusqu'à l'extrêno limite de la frontière, semblables aux grandes usines établies au Sud de Lille, a Haubourdin et Don * Au total, filature, tissage, hlanchiment réunis, c'est un peuple de 50.000 ouvriers que le lin

1 Merchier, Monographie, pp. 200-201.

2 Recueil trimestriel des Procés-verbaux des séances de la Chambre de Commerce d'Armentières, $1^{\text {er }}$ fascicule 1903, p. 81.

3 Merchier, Monographie, p. 204. Aux centres de tissage déji mentionnés, ajonter Lannoy, avec sa fabrication de toile à sacs, Wervicq avec celle des lacets. - Lo nombre d'ouvriers occupés dans le Nord (1901) à la fabrication des toiles s'élève à 31.321 (Recensement, p. 597).

4 Les industries de teinture et apprêts pour l'ensemble du travail des textiles occupent en 1901 dans le Nord 13.461 personnes (Recensement, p. 598). 
occupe encore, tout déchu qu'on le proclame, à Lille et le long de cette Lys qui est bien en Flandre comme l'axe géographique de la région linière.

La laine. - Il semblerait que le travail de la laine à Roubaix, comme celui du lin à Lille, fût une survivance directe de la plus ancienne des industries flamandes. Or la fabrication actuelle est d'origine récente. Roubaix, après avoir fait à Lille pendant des siècles une concurrence heureuse dans la confection des étoffes de laine, abandonna après la Révolution cette industrie pour celle du coton. Ce changement s'opéra au milieu des troubles politiques et des guerres, et le succès de l'opération montre à quel point était déjà développé l'esprit industrieux et actif des Roubaisiens, abandonnant une industrie delaissée par la mode pour en adopter une autre, à laquelle souriait la fortune. En 1804, Roubaix fabriquait donc le nankin avec « une activité toujours croissante, et les coups répétés du tisserand qui bat sa toile, le murmure des rouets, des déviduirs et de la navette, donnaient aux voyageurs qui entraient dans la commune l'idée d'une unique et immense manufacture ${ }^{1}$. Puis la frontière rétablie à ses portes la protégeant de la concurrence de Verviers, les lainages reprenant faveur, Roubaix à partir de 1830 revint à son ancienne industrie avec la même aisance qu'elle avait mise à la quitter. Dès 1844, il n'y a plus qu'une dizaine de filatures de coton dans la ville, contre 52 en $1833^{2}$. Depuis, Roubaix est restee la ville de la laine.

Ce n'est pas, comme pour le lin à Lille, un monopole, el le groupe champenois, le Berry, le Bas-Languedoc, Fourmies, soutiennent la lutte ; mais Roubaix, Tourcoing el leur banlieue forment le centre le plus important de France, et l'un des plus considèrables du monde, pour le peignage, la filature et le tissage de la laine. La ville de Roubaix et ses faubourgs, Wattrelos, Croix possédaient, au début de 1903, 8 peignages de laine, 18 filatures de laine peignée avec 305.000 broches, 7 filalures de laine cardée avec 86.830 broches, 12 retorderies avec 50.000 broches; pour le tissage, 80 établissements á métiers mécaniques, et 38 maisons ayant des tissages mécaniques au dehors ou faisant tisser à la main ; enfin 41 teintureries ${ }^{3}$. 'l'ourcoing est plutôt la ville des filatures, tandis que Roubaix se spécialise dans les tissages; enfin elle est restée le siège du grand commerce des laines, et la ville comprend beaucoup d'entrepôts où s'entassent les toisons arrivées d'Australie et d'Argentine.

1 Dieudonné, Statistique, II, p. 322.

2 Leuridan, Roubaix, V, pp. 142 et 161.

3 Archives de la Chambre de Commerce de Roubaix (XXVIII, 1902), p. 236. 
A côté de cette grande industrie lainière, le groupe comprend des spécialités; Roubaix possède huit fabriques de bonneterie, deux de broderie, dix tissages pour tissus d'ameublement; Tourcoing est la capitale de cette industrie, ainsi que le grand centre de la fabrication des tapis. C'est surtout dans la banlieue quo sont établies ces industries annexes: Halluin fabrique des lapis du genre Tourcoing; le canton de Lannoy possède 22 établissements de courtepointes, couvertures, tapis, tissus d'ameublement, établis non seulement au chef-lieu et dans son faubourg de Lys, mais dans les communes rurales de Chéreng, Flers, Annappes, Anstaing, Ascq, Leers, Forest, Tressin, Willems, avec les teintureries, les blanchisseries, les tissages de toile et de jute. Aussi cette région frontière qui va de Baisieux à Ialluin est-elle la partie la ṕlus peuplée du pays lillois : l'agriculture n'y est plus qu'une occupation accessoire ; la plupart des habitants des campagnes travaillent dans les fabriques des villes, à moins qu'ils ne se consacrent chez eux à l'industrie à domicile ${ }^{1}$.

Le coton. - Le domaine du coton est moins nettement délimité que celui de la laine et du lin ; c'est que cet envahissant textile s'impose de plus en plus à ses concurrents, et que les centres qui tissent le lin et la laine ont hesoin de fils de coton qu'ils incorporent à leurs tissus. C'est ainsi que Roubaix possédait en 190311 filatures de coton avec 365.604 broches, et Tourcoing une quantité à peu près équivalente; qu'Armentières en mettait en marche 53.800 dans quelques établissements. Cependant c'est surtout d Lille qu'est concentrée l'industrie cotomière, sous forme de filatures, le tissage étant peu pratiqué dans le Nord, où on ne comptait à la fin de 1902 que 2.951 métier's mécaniques, avec 1.200 ouvriers, sur les 102.000 métiers français; mais il ne faut pas oublier que le coton se tisse en mètis, mélangé au lin et à la laine, dans les usines d'Armentières et de Roubaix. La croissance a été rapide: en 1849, l'arrondissement de Lille possédait 552.157 broches; en 1902, la quantité s'élève à 2.186 .720 broches à filer dont 1.200 .000 pour Lille et sa banlieue ${ }^{2}$, et à 5 à 600.000 broches á retordre, dont 37\%.000 pour Lille; 15.000 personnes y sont occupées. Lá ençore, la région lilloise vient en tête des pays français qui pratiquerit cette industrie, Normandie, Lorraine, et fabrique les 3/5 des filés produits par toute la France. Il y a là des établissements formidables, comme cette Cotonnière d'Hellemmes, qui possède 180.000 broches ; ct cette branche du

1 Le travail de la laine occupe en 1901 dans le Nord 82.605 personnes (Recensement, p. 598).

2 Houdoy, Filature, pp. 60 et 179. 
travail lillois est une des plus vivantes, une de celles où l'accroissement a été le plus soutenu, le plus régulier ${ }^{1}$.

La confection. - A fabriquer tant de tissus, draperies, lainages, cotonnades et métis, il était naturel que naquît l'idée de les transformer sur place en vêtements. L'industrie de la confection trouvait à Lille la matière première, si l'on peut dire, sur place; clle profitait, commeles autres, de l'abondante main-d'œuvre du pays. Restée jusqu'à ce jour tributaire du travail à domicile, elle était adaptée d'avance aux habitudes d'une population dans laquelle la disparition du tissage a la main avait laissê un malaise. La confection s'est donc établie dans tous les villages que la grande industrie n'a pas occupés encore; aussi son domaine s'est il étendu surtout au Sud de Lille; dans toute la Pévèle, les pays crayeux de Seclin et Carvin, jusqu'à Courrières et Lens, la machine à coudre est devenue le meuble indispensable de chaque habitation rurale; elle r'emplace le carreau des dentellières de 1'789. C'est de Lille que partent les ordres, que viennent les étoffes, c'est là que retournent les produits du travail à domicile. De grands ateliers se sont fondés dans la ville; les plus vastes maisons de confection de Paris y établissent leurs fabriques. Peu à peu cette industrie nouvelle tend à se concentrer en quelques grandes entreprises, où la mécanique fait son apparition. L'essor considérable de la confection lilloise depuis quelques années en fait déjà une des branches les plus importantes de l'activité industrielle dans la ville et dans sa grande banlieue du Sud; c'est à 60 millions de francs qu'on évalue (1905) son chiffre d'affaires; a 14 millions le total des salaires qu'elle verse aux 23.000 personnes qu'ello emploie.

C'est à coup sûr un formidable organismo que ce groupe industriel de l'arrondissement de Lille, où plus de 150.000 ouvriers se pressent dans les usines, constituant une agglomération que la France oppose avec fierté aux grandes régions manufacturières de Grande-Bretagne et d'Allernagne. Nulle part en France on ne manifeste autant d'activité, on rle fait preuve de plus de sens pratique. Pourtant toutes ces grandes industries ne sont pas également souples, également armées pour la concurrence internationale. Menacés par les filés et les toiles d'Angleterre et de Belgique, les tisseurs et les filateurs de lin sont résolument protectionnistes, et ce sont

1 Ia filature et le tissage du coton occupent en 190120.390 personnes dans le Nord (Recensement, p. $5 \% 7$ ). 
les industriels liniers qui ont eu la plus grande part à l'élaboration des tarifs protecteurs de 1892. Ce n'est guère que pour se débarrasser de ses stocks, et souvent à perte, que la filature exporte, en Belgique et en Angleterre; et si le tissage réussit à écouler normalement dans ces pays des toiles spéciales en grosses étoupes pour bâches et sacs, c'est surtout sur le marché français (France et Colonies), réservè par les tarifs, que s'enlève leur production. Déjà la filature de coton, girâce à une spécialisation plus avancée de quelques grandes usines, réussit mieux dans l'exportation que l'industrie linière; enfin la laine s'est créé hors de France une clientéle si considérable, que là plupart des industriels de Roubaix-Tourcoing ne craignent pas, désirent même le libre-échange. Seule la filature de laine, moins spécialisée, exploitèe à peu près uniquement par des façonniers qui travaillent pour les tissages, tient à voir fermer la frontière aux filés allemands. Au contraire le peignage, contralisé par de grandes maisons dont chacune se spécialise dans la production d'un très petit nombre de peignés, l'emporte si bien sur les produits étrangers que l'Allemagne est devenue, après la France, son meilleul client; de même, le tissage alimente, outre le marché national, l'Orient (Grèce et Turquie), l'Italie, la Belgique, l'Amérique du Sud, et surtout l'Angleterre, qui lui achète par an pour 80 millions de franes de drap, et lui permet ainsi de supporter les effets du terrible coup quo lui a porté l'adoption par les Etats-Unis du bill Mac-Kinley. Ainsi quelques industries du groupe de Lille se révèlent singulièrement vivaces et actives, maís la plupart ont besoin d'être aidées dans la lutte contre l'étranger ; une partie de la prospérité actuelle est à la merci des tarifs protecteurs; que les droits de 1892 soient abaissés, et certaines industries connaîtront des heures plus difficiles. Déjà quelques branches de production donnent des signes de malaise ; le travail du lin a souffert particulièrement de la crise de surproduction qui s'est déclarée de 1901 a 1905 dans toute l'Europe: à Armontières, il a fallu diriger sur le bassin houiller un certain nombre de travailleurs inoccupés, que les trains emménent chaque jour aux mines de Lens, oú ils s'emploient tout en continuant à hahiter leur ville. Les ouvriers, micux organisés, réclament des salaires plus élevès, et certains patrons trouvent avantage à étahlir des usines en lerritoire belge: une maison d'Halluin possède un tissage à Moen, Roubaix essaime à Mouscron; la main-d'wuvre belge leur permet d'y fabriquer à si bas prix que leurs produits peuvent affronter les droits de douane qui les isolent du marché français ${ }^{1 .}$

1 I $\dot{a}$ chose n'est pas nouvelle; en 1762, Roubaiix, d'après los Iillois, ótait alló établir des métiers à Mouscron, Herseaux et Luingne (Leuridan, Roubaix, Y, p. 86). 
Ces réserves faites, il n'en reste pas moins que l'industrie flamande tout entière, au milieu de la lutte économique moderne, fait preuve d'une remarquable vitalitè. C'est un spectacle imposant que la continuité du labeur industriel dans cette province, qui depuis dix siècles se maintient au rang des premières régions manufacturières de l'Europe, tout en restant un des plus riches pays agricoles. C'est que ces deux branches du travail humain lui sont également nécessaires; l'industrie n'est pas un luxe en Flandre, elle en est la moitié de la vie; et ainsi se vérifie ce mot de Michelet, que « l'industrie, ayant fait ce pays de rien, méritait bien d'en être souveraine ${ }^{1}$.

1 Michelet, Hist. de France, èd. 1841, V, p. 321. 


\section{CHAPITRE XV.}

\section{FLANDRE INTÉRIEURE. - LE MILIEU HUMAIN.}

I. La Vie et les Mours, - II. L'habitation rurale. L'Hofstede. La Cense. Les matériaux. - IIl. Dispersion des habitations. Dans l'Ougst : les maisons isolées. Dans l'kst : les maisons groupées en rues. - IV. Les villes. I es villes avant le XIXe siècle. Les villes au XIX' siècle : influence de l'industrie. Vicilles villes et villes neuves. Le groupe de Lille.

I.

\section{LA VIE ET LES MGEURS.}

Beaucoup de travail et peu de profit: telle pourrait être la devise de la Flandre intérieure. Le Flamand a beau pratiquer l'agriculture la plus savante du monde, se livrer à l'industrie: c'est tout juste s'il peut vivre. On a vu les salaires agricoles de la Flandre belge; ceux de l'industrie ne valent guère mieux; comment nourrir, avec une paie qui va de 1 à 3 francs par jour, l'nne de ces familles de $6 \dot{a} 8$ enfants que l'on rencontre si fréquemment dans le pays ? C'est à peine de quoi ne pas mourir de faim ${ }^{1}$.

La Flandre intérien re est done une des régions de l'Europe occidentale où le train de vie des habitants est le plus modeste. Le journalier agricole, le tisserand de Zele, le petit fermier même de la Flandre Orientale sont loin de connaître l'aisance du paysan normand ou hollandais, ou de l'agriculteur de la Plaine maritime. Tandis que la caisse d'épargne de Furnes est à la tête d'une somme de 287 francs par habitant, celle d'Anseghem n'a que 21 francs, celle de Gavere 16, celle d'Oosterzeele 14, et celle de Burst $13^{2}$. Aussi la nourriture en souffre. I a description faite de l'alimen-

1 A Pitthem, l'ouvrier agricole nourri à la ferme rapporte, pour tout salaire, $0 \mathrm{fr}$. 63 chez lui. A Steenbecque, on cite un chef de famille qui doit faice vivre ses dix enfants avec $1 \mathrm{fr}$. 25 par jour. A St-Floris on a dressé le budget d'un ouvrier agricole (Pas-deCalais au XIX ${ }^{\circ}$ siècle, IV, p. 357): veuf avec cinq jeunes enfants, il gagne 8 fr. 10 par semaine, en dépense 6 fr. 95 : d'ou un excédent annuel de recettes de $59 \mathrm{fr}$. 80, avec lequel il doit achoter 54 francs de chaussures, puis du linge, des vêtements, de la literie, etc.

- Burny el Hamande, Les Caisses d'Epargne, carte planche B. 
tation des ouvriers par l'Enquâte de 1846 accuse une nourriture presque exclusivement végétale, pain de seigle, pommes de terre, légumes; la Chambre de Commerce de Courtrar avoue que la plupart des ouvriers, faute d'un salaire suffisant, ne peuvent se procurer même du lait battu ${ }^{1}$. Ducpétianx en 1855 ne découvre du lard que dans le menu des « gens aisẻs » de l'arrondissement de Gánd *. Il y a, à coup sûr, amélioration depuis cette date. Cependant la chère de louvrier flamand est encore maigre. Pain de froment (lo seigle n'est phus que l'exception), pommes de terre et lait battu, forment le fonds de tous les repas. En général, les tartines au saindoux se mangent cinq fois par jour, le potage an lait hattu, trois ou quatre fois; les pommes de terre, deux ou trois. Le matin vers 5 heures, les tartines s'accompagnent, dans la partic belge, du breuvage appelé café, el qui n'est qu'une décoction, très étendue d'eau, de chicorée; dans la partie française, d'une boisson faite d'une infusion de tilleul et de réglisse, baptisée « le thé ». La bière, inconnue dans les mènages ouvriers où l'eau seule est employée, n'est même pas en usage dans la moitié des - formes, pour l'alimentation du personnel. Quant à la viande, on ne la trouve consommée régulièrement que dans les régions favorisées. La partie française comprend bien pen de communes oi les ouvriers agricoles ne mangent pas, au repas de midi, un peu de lard, et une tranche de bouf le . dimanche; dans la plaine de la Lys, le lard apparaît presque à tous les repas. Passé la frontière, il en est de même dans beaucoup de communes du pays d'Ypres, a Poperinghe, à Messines ; mais à l'Est, la consommation du lard diminue; autour de Roulers on n'en voit plus apparaitre à table que deux ou trois fois la semaine; plus loin, il $y$ a bien des villages où l'ouvrier n'en mange qu'aux jours de fêtes.

La race d'hommes qui peine si fort sur le travail et cependant se nourrit si mal porte la trace des fatigues qu'elle s'impose et des privations qu'elle subit. 'Tandis que l'homme de la classe moyenne est généralement grand et large, le visage coloré, grand mangeur et grand buveur, l'ouvrier agricole ou industriel a triste mine, maigre, souvent voûté; la croissance des enfants est lente, leur développement paraît fréquemment incomplet. La légende du F'lamand grand, gros et fort, s'est créée à propos de l'homme de la Plaine maritime, qui mérite ces épithètes; c'est parmi eux que l'on trouve ces exemples de robustesse restés fameux au moyen-âge: le comte Charles le Bon haut de neuf pieds; Baudouin à la Hache, bâti en colosse,

1 Enquête, II, p. 218; III, pp. 304-305.

2. Ducpétialux (E.), Budgets économiques des classes ouvrières en Belgique (Bull. C. C. St., VI, 1855, pp. $295-2(6)$. 
qui d'un seul bras et sans fatigue, pend dix chevaliers pillards aux poutres de sa salle d'armes, dans le château de Wynendaele. Moins robuste, le Flamand de l'intérieur remplace souvent la force par la ruse, la vigueur par la brutalité.

Les étrangers ont fait au Flamand, pour le caractére, une réputation détestable. «Ivrognes, paresseux, fanatiques, hypocrites et dissolus, bas et rampants », les juge un lieutenant de gendarmerie d'Hazebrouck dans un rapport à Fourcroy ${ }^{1}$. Leurs frères de la Plaine maritime les tiennent pour arriérés, inintelligents, et ridiculement avares. Des écrivains flamands eux-mêmes les jugent méfiants, superstitieux, brutaux, vindicatifs ${ }^{2}$. Il est certain que l'homme de l'intérieur est moins fier, plus soumis et aussi plus sournois que celui des Polders; ces différences sont signalées parfois dans la même commune, dont le territoire appartient moitiè au pays bas et moitié au Houtland. Il est infiniment probable que c'est à la différence d'aisance que sont ducs ces nuances de caractère; l'homme des Polders est plus indépendant parce qu'il est moins pauvre. C'est à la même cause qu'est dû probablement le retard où se trouve encore pour l'instruction la Flandre intérieure, par rapport aux autres parties de l'Europe occidentale. Il fatut mettre à part la région française, où l'application des lois sur l'enseignement obligatoire a fait sentir ses effets comme dans toute la France; peut-être les instituteurs trouvent-ils leurs élèves un peu indiffèrents à l'instruction; en revanche, ils les estiment dociles et soumis. En Belgique, où l'obligation n'existe pas, les résultats sont moins beaux. En 1881, la Flandre Orientale était la province la plus illettrée de Belgique, les trois arrondissements les plus retardataires de tout le pays étant ceux d'Eecloo, Termonde et Alost, tandis que l'arrondissement de Furnes, en majeure partie composé de terres basses, et celui d'Y pres, moins paurre que ses voisins de l'Est, étaient les plus instruits des deux Flandres ${ }^{3}$. En 1900, la Flandre Occidentale contient 391.760 personnes àgées de plus de 15 ans sachant lire et écrire, et 138.790 illettróes : c'est une proportion de plus d'un tiers. A Bruges, il y a 9.821 illettrès de plus de 15 ans, contre 26.137 sachant lire et écrire; on trouvail mème près d'un tiers d'illettrés parmi les enfants de 10 ans : 256 sur un total de 912. A Menin, les illettrés de plus de 15 ans font presque la moitié des persomes sachant lire et

\footnotetext{
1 Arch. Nat. A F IV, 1019.

Huyttens, Etude sur les mours, les superstitions et le langage de nos ancêtres les Mẻnapiens (Gand, 1861, in-12), pp. 220-221.

3 Sauveur (J.), Statistique génẻrale de l'Instruction publique en Belgique, dressée d'après les documents officiels (Bull. C. C. St., XIY, 1881, pp. 1-85i).
} 
écrire: 3.976 contre $8.215^{1}$. C'est bien pis en Flandre Orientale, où l'on peut meltre en regard des 497.256 personnes de plus de 15 ans sachant lire et écrire le total de 185.721 illettrés de même âge: soit 1 illettré pour $21 / 2$ personnes sachant lire et écrire. Dans l'arrondissement pauvre d'Eecloo, la proportion n'est même plus de 1 à $2: 15.033$ illettrés contre 29.662. Dans la plupart des villes, Alost, Renaix, Eecloo, Lokeren, St-Nicolas, on n'arrive pas à la proportion de 1 à 3 ; a Tamise, on n'a même pas 1 à 2: 2.823 illettrés pour 5.135 ; à Grammont, on compte 3.044 illettrés et 4.761 sachant lire et écrire ; enfin à Hamme, $3.8 \overline{3}$ illettrés contre 5.106 ; dans cette commune, en défalquant les enfants au-dessous de six ans, on trouve à peu près autant d'illettrés que d'individus sachant lire et écrire ${ }^{2}$.

C'est encore à la misére qu'il faut attribuer vraisemblablement l'ivrognerie, et à la suite la brutalité du Flamand. L'ouvrier qui a peiné toute la semaine et r'a bu quo de l'eau, profite du dinanche pour absorber de la bière; il se venge alors de son abstinence; un « homme » doit pouvoir avaler dans sa journóe $\mathbf{4 0}$ chopes. Chaque dimanche soir, à la suite de ces sceines d'ivrognerie, des bagarres éclatent, les couteaux sortent des poches. « Rixantur nomunquam inter pocula, dit Meyer, ac caedes invicem faciunt ${ }^{3}$. Le spectacle n'a guère changé. A Cortemarck, du $1^{\text {er janvier }}$ au 1er juillet 1904, on comptait déjả 3 meurtres, plusieurs attentats, et 60 procès-verbaux avaient été dressés. A La Clinge, de 1897 à 1904, pour une population de 2.400 habitants, on comptait 396 condamnations, pour coups, blessures, vols et contrebande. C'est surtoul au retour des ouvriers qui sont allés travailler l'été en France que se produisent les rixes et les méfaits ; c'est la détente après plusieurs mois de privations ef de labeurs écrasants. Il y a progrès d'ailleurs; la disproportion cntre la criminalité de la Flandre et celle des pays voisins s'atténue. Au début du siècle, de 1826 à 1833, sur 77 condamnations capitales prononcées en Belgique, on en comptait 35 pour la Flandre Orientale, et 10 pour la Flandre Occidentale,

1 Au contraire l'arrondissement de Furnes donnait, contre 20.215 personnes de plus de 15 ans sachant lire et écrire, 3.527 illettrés seulemeut, dont 2.096 ayant plus do 55 ans.

2 Recensement de la population, dı 31 décombre 1900, t. II. Des considèrations sur l'état d'ignorance des provinces flamandes de la Belgique sont déveluppées dans le chapitre a La carte de l'ignorance en Belgique », pp. 137-149 et dans les chapitres suivants du livre de Huysmans (C.), de Brouckere (L.) et Bertrand (L.): 75 années de domination bourgeoise (Gand, Volksdrukkerij, 1905, in-80, 327 p.).

3 Meyer, Rerum Flandriae, t. X, pp. 77-78). 
soit plus de la moitié pour elles deux ${ }^{1}$. Dans le tableau indiquant le nombre d'individus condamnés par les tribunaux correctionnels à plus d'un an d'emprisonnement (1826-1829), six des sept arrondissements judiciaires flamands venaient en tête, celui d'Audenarde avec 101 condammós (5̆51 pour toute la Belgique), celui de (xand avec 93; le premier comptait 1 condamné sur 1.700 habitants, le second 1 sur 3.400 \%. On voyait des villages entiers se ruer sur la commune voisine, le dimanche, Vinderhaute sur Tronchiennes, Poesele sur Vosselaere, Millam sur Pitgam. Aujourd'hui encore, si les arrondissements flamands sont assez Ioin en arrière des autres pour les articles « Rébellion » et « Outrages à un agent de l'autorité », ils viennent en tête de toute la Belgique pour les rubriques «Coups et blessures simples », où Termonde dépasse largement Bruxelles; pour « Ivresse publique », où Bruges, Gand, Termonde, Courtrai, ne sont dépassés que par la capitale; pour «Destruction de clôtures », «Viols» et «Attentats à la pudeur $\gg$. D’ailleurs dans la proportion de condamnés par 10.000 habitants, l'arrondissement de Bruges égale sensiblement celui de Charleroi ; ceux de Courtrai et de Gand dẻpassent Bruxelles et Anvers ${ }^{3}$.

Cette rudesse de mœurs, ce retard intellectuel, tiennent cependant aussi à une autre cause qu'à la pauvreté. La Flandre est comme isolèe, dans l'Europe occidentale, par la langue qu'elle emploie. L'usage d'un dialecte que les Flamands eux-mêmes consideraient naguère comme inférieur les a empêchés de suivre d'un pas aussi rapide que leurs voisins les progrès intellectuels accomplis au XIX ${ }^{\mathbf{e}}$ siècle. De là leur défiance contre l'étranger, accrue aussi par le souvenir des maux que lour ont apportés les invasions. be là aussi cette fidélité à la religion qui est un des traits les plus caractéristiques de la mentalité flamande, et sur laquelle ne tarissent pas les administrateurs étrangers, intendants, gouverneurs et préfets. Ainsi s'est formé ce caractère fermé, à la fois soumis et brutal, d'hommes pacifiques, obstinés et rudes, dont on a pu dire sagement qu'ils étaient laborieux, mais pas actifs, qu'ils avaient les mours douces et les manières rudes ${ }^{4}$.

1 Ducpétiaux (E.), Statistique des tribunaux et des prisons de la Belgique (Mess. Sc. Hist., II, 1834, pp. 164-188), p. 188.

2 Ibid., p. 181. - L'arrondissement poldérien de Furnes etait au contraire le dernier de la Belgique, avec un condamné seulement, sur $66.000^{\circ}$ habitants.

3 Voir: Ministère de la Justice. Statistique judiciaire de la Belgique (1901). $4^{0}$ année (Bruxelles, Larcier, 1903, in-4 ${ }^{\circ}$ LXVII + 350 p.).

- Derival, Le Voyageur dans les Pays-Bas, IV, pp. 248 ot 252. 
II.

\section{L'HABITATION RURALE.}

Le genre de vie du Flamand n'atténue pas ce qu'il y a, dans son carnctère, de fermé, d'hostile à l'étranger. L'habitant de la Flandre intérieure vit autant qu'il le peut chez lui, dans sa maison, souvent isolée des autres demeures; il apporte tous ses soins à la rendre gaie et propre : il la préfère au monde extêrieur, où sévit un climat désagréable.

La ferme est le type principal de la maison flamande, celui où s'expriment le mieux les influences du sol et de la race. Il en existe, dans la Flandre intérieure, deux variétés: dans la région sablonneuse, et dans la West-Flandre d'Ypres, Cassel et Hazebrouck, c'est l'hofstede, aux bâtiments séparés; dans la plaine de la Lys, dans la région lilloise, au Sud de Courtrai, d'Audenarde et d'Alost, c'est la cense wallonne, complètement close.

\section{L'Hofstede.}

L'hofstede rappelle, avec moins de complications, la ferme de la plaine maritime. Flle comprend généralement trois bâtiments, entourant de trois côtés une cour carrée, occupée en grande partie par le trou à fumier. Au centre, l'habitation, généralement orientée vers le Sud ou l'Est. C'est une petite construction assez basse et allongée, contenant de chaque côté d'un corridor, d'une part deux salles qui se suivent, de l'autre une pièce isolée. Des deux premières, l'une est « het huis 》 (la maison), l'autre la « voûte». La Maison est, comme dans la Plaine maritime, la salle commune, où l'on fait du feu dans le grand poële (stube), ou l'on fait la cuisine, od l'on mange, où l'on se tient d'ordinaire. La * voûte », surélevée au-dessus de la cave, est la pièce d'apparat, le salon, réservé pour les repas de kermesse, de baptême, de noce, d'enterrement. La troisième pièce est une chambre à couchor ; mais il est rare que les deux premières ne contiennent pas egalement chacune un lit. Enfin le toit bas qui descend par derriẻre jusqu'à un ou deux mètres du sol abrite souvent des salles basses, parfois des appentis, où l'on établit une relaverie, des chambres à coucher, et aussi, dans l'Ouest, la petite pièce où l'on fait le beurre. Cet ensemble est simple; ce qui en fait le charme, c'est la propreté : propreté des murs tapissés de papier peint ou badigeonnés de couleurs à l'huile, des meubles cirés, horloge, armoire, du poële brillant, des objets de piété, bleus, blancs et or, 


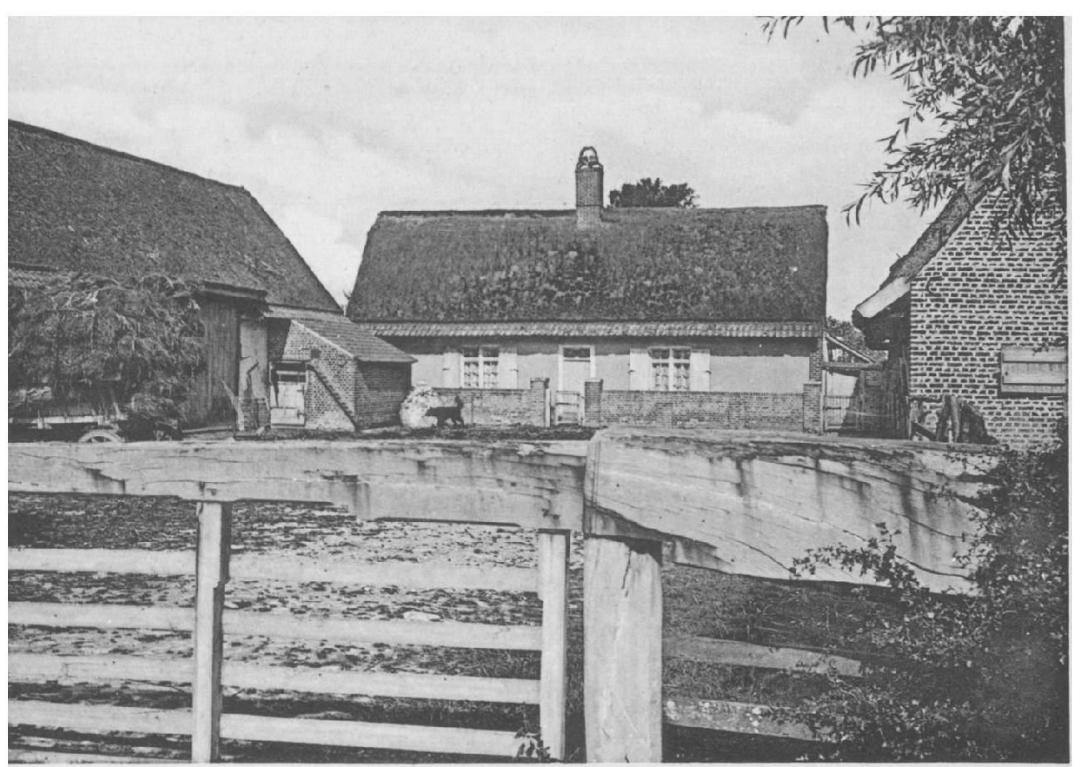

41. - Type de l'Hofstede (Esquelbecq).

Au premier plan, la barrière avec contre-poids.

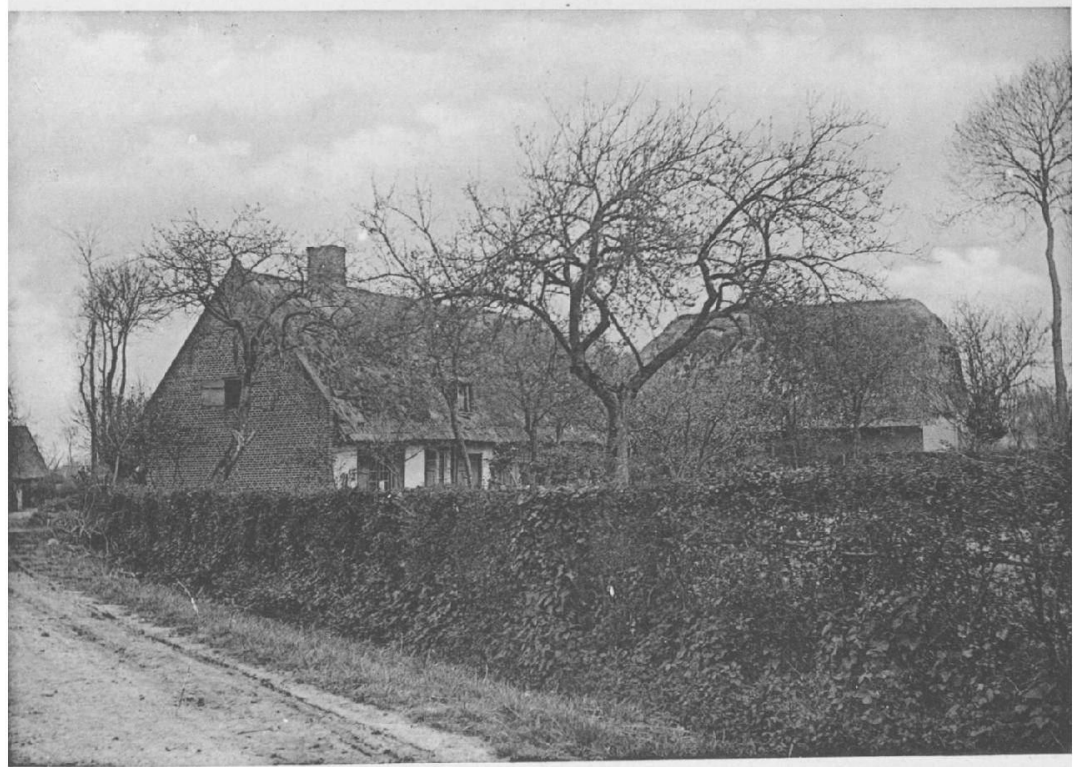

42. - Type de petite exploitation (Lederzeele). 
IRIS - LILLIAD - Université Lille 1 
qui garnissent la cheminéo. Des fleurs égaient les fenêtres qui sont souvent quadrillées de menus carreaux, toujours garnies de rideaux et flanquées de volets vert et blanc; d'autres fleurs forment le plus souvent une plate-bande d'hortensias, de dahlias et de giroflées devant l'habitation qu'une grille et un trottoir de briques séparent du reste de l'exploitation. Ainsi le fermier vit à part, avec plus de propreté et d'hygiène.

De chaque côté de l'habitation s'alignent les bâtiments d'exploitation. D'une part, les écuries et étables, l'écurie toujours plus rapprochée de la maison; ce sont des bâtiments a plafond bas, chargé de. paille en hiver ; une demi-obscurité y règne; l'augmentation de l'èlevage y rend l'espace insuffisant, surtout dans l'Est, où les bêtes restenl en stabulation toute l'anne. Un trottoir de briques permet de circuler le long du bâtiment. De l'autre côté, c'est la grange, et à l'extrémité, la charretterie. Lne haie d'aubépine, ou une clôture en bois, enferme souvent l'ensemble; mais les trois bâtiments restent toujours séparés, ce qui diminue les dangers d'incendie. C'est là le trait caractéristique de l'hofistede. Les autres dispositions peuvent changer: la voûte devient plus rare dans l'Est, où on la trouve surtout dans les bâtiments un peu anciens; les grandes fermes ont quatre corps de logis an lieu de trois, et enferment complètement la cour ; les petites en ont deux seulement, orientés normalement l'un à l'autre: l'habilation d'une part, les dépendances de l'autre, on bien bout à bout la demeure des hommes jointe à la demeure des bêtes en un long bâtiment; tandis que la grange reste à part. Mais toujours les diverses constructions sont isolées; il y a là une parenté évidente avec la ferme de la Plaine, particulièrement avec celle de la Flandre zélandaise, dont la vaste grange reparaît encore çà et là dans le Pays de Waes, avec ses murs de bois et son tuil de chaume, pour ne disparaître que vers Gand et Termonde.

\section{La Cense.}

L'hofstede cependant n'occupe pas toute la Flandre. A l'Ouest, sur la lisière de la Plaine maritime, la ferme close apparaît: elle accompagne, jusque vers Aire, la limite do l'Artois et de la Flandre. Après Aire, elle pénètre dans le pays flamand et occupe presque toute la plaine de la Lys: tandis que l'hofstede se maintient sur les hauteurs argileuses, à Sercus, Steenbecque, Morbecque, Hazebrouck, Caestre, Merris, Bailleul, la cense wallonne domine à Merville, Neuf-Berquin, Steenwerck, Nieppe ; à VieuxBerquin, les vieilles fermes sont du type hofstede, les neuves sont closes. Au delà de Bailleul, la limite suit la Lys jusqu'à Menin, et de là se dirige a travers le pays de Courtrai vers Avelghem et Audenarde. Dans le pays . 
d'Alost, les deux types sont mélangés: sur le plateau d'Edelaere, une grande ferme close domine des hofsteden établies dans la vallée; même à Lede, au Nord d'Alost, on retrouve encore le type cense, ainsi que sur le plateau brabancon entre la Dendre et Bruxelles. Cependant les productions, la vie agricole sont les mèmes de chaque côté de cette ligne de démarcation. Il faut bien croire qu'il y a là une influence ethnique, et cette hypothèse est renforcèe lorsque l'on considère que de Calais à Avelghem, la limite des deux types suit à peu près l'ancienne frontière linguistique du flamand et du français. Vers la limite, la cense présente d'ailleurs fréquemment un aspect où l'on reconnaît des traits de l'hofstede, un air de parenté avec le type purement flamand. C'est un assemblage confus de bâtiments de hauteur différente, reliés comme artificiellement les uns aux autres par tout un rapię̧age de toits. On dirait une véritable hofstede dont on a bouché les ouvertures entre bâliments. Ailleurs, et par exemple dans la partie Sud de la plaine de la Lys, les bâtiments s'égalisent, deviennent homogènes et se raccordent naturellement les uns aux autres; c'est le type que l'on retronve au Sud vers Douai, Valenciennes, et qui, sur les plateaux de craie, devient la ferme picarde.

A l'intérieur, la conse wallonne présente une disposition semblable à celle de l'hofstede. Tout autour d'une cour carrée, les bâtiments; l'habitation généralement au milieu, face à la grande porte, et comprenant comme dans l'hofstede la Maison, le Salon sur vô̂te, des chambres à coucher, des appentis ; d'un côté, l'écurie, qui tient à l'habitation, puis l'étable; de l'autre, la grange, et parfois des étables supplémentaires, la porcherie, le poulailler, le fournil. La cour est en partie pavée; le trottoir de briques l'entoure. En général, un bâtiment est établi en dehors de l'ensemble: c'est un hangar à voitures, abritant chariots et tombereaux. Derrière l'habitation, collèe au mur, apparâit la grande roue de bois abritée sous un auvent, et qu'un chien met en mouvement pour faire tourner la baratte.

\section{Les matériaux.}

Hofstede flamande on cense wallonne sont construites avec des matériaux identiques. La pierre est absente: il n'y a pas dans toute la Flandre dix fermes bâties en grès ou en craie. Dans l'Est, la brique domine; dans l'Ouest, le torchis reste fréquent. On pourrait s'étonner de rencontrer ainsi les maisons de terre dans les riches régions à limon, tandis que dans les pays pauvres du Nord-Est elles sont construites en dur; la raison est bien simple: on emploie la brique dans la partie sableuse parce qu'obligés 


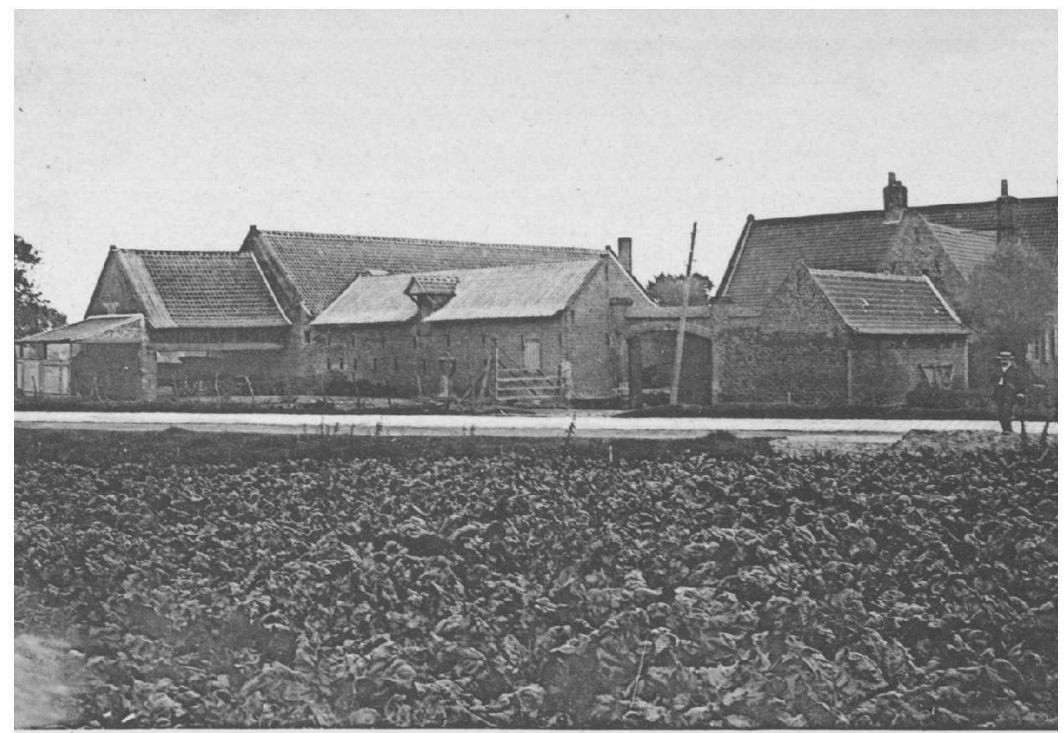

43. - Cense wallonne à bâtiments disparates (Capinghem, près Lille).

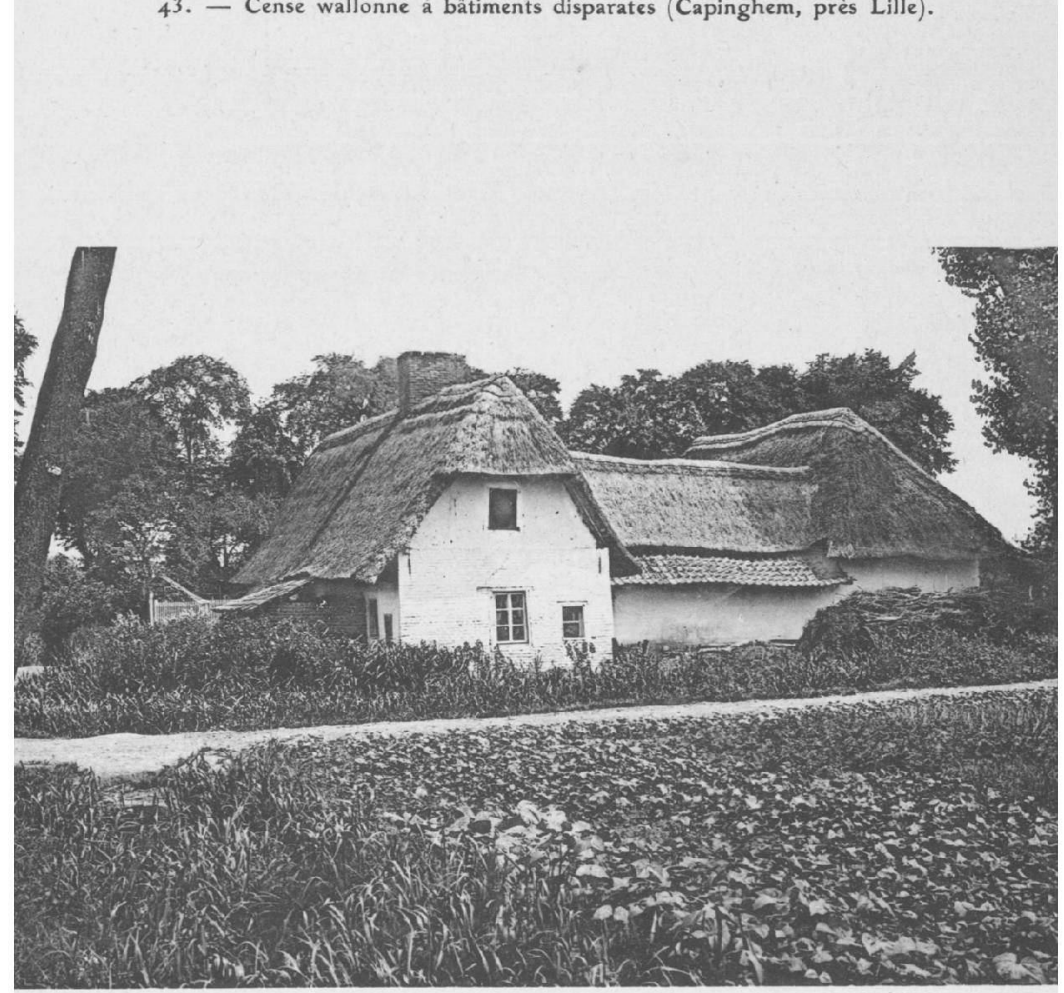

44. - Cense wallonne à bâtiments homogènes (Richebourg-l'Avoué). 
IRIS - LILLIAD - Université Lille 1 
d'importer des matériaux de construction que lo sol ne fournit pas, les habitants préfèrent choisir la brique, plus solide et moins exposẻe à l'incendie. Toute la région sableuse est ainsi couverte de maisons de briques, dont les murs sont passés à la chaux. Au contraire dans le pays d'Alost, la région de Courtrai, dans toute la West-Flandre où le limon, plus ou moins sableux, garnit le sol, on peut construire la ferme en briques poussiéreuses, mais il est plus économique de prendre tout bonnement le limon auquel on mêle un peu de chaux et de la balle de grain. Dans la plaine de la Lys, les trois quarts des fermes sont ainsi bâties; ailleurs, la proportion dos murs en terre est encore de deux tiers environ dans le pays d'Alost, d'un bon liers autour de Lille et dans le Houtland de Cassel. Seulement il y a contraste entre la vétusté (souvent apparente) de ces maisons, penchées, déjetées, affaissẻes sous le poids du toit, et la richesse du sol limoneux. Il faudra toutefois longtemps encore pour que la construction de briques prenne possession de toute la Flandre. La bâtisse en dur gagne du terrain ; elle s'adjuge nouf dixièmes des constructions neuves, et la brique se glisse dans les murs en torchis, dont elle constitue souvent le soubassement solide. Mais la construction en terre n'est pas près d'être abandonnée pour les dépendances, étables, et surtout granges; rien de plus frequent qu'une ferme où l'habitation est en dur, et les antres batiments en torchis. De même le chaume, encore plus employé pour couvrir les maisons que la terre pour les bâtir: l'on peut estimer qu'une moitié peut-être des bâtiments, dans les campagnes flamandes, porte encore cette couverture grise, rapiécée ģà et là de jaune clair, sur le faîte de laquelle s'alignent les joubarbes, comme une rangée de pots de fleur. Malgré les risques d'incendie, beaucoup de cultivateurs préfèrent aux pannes le chaume, qui convient mieux aux récoltes enlassées sous le toit; seulement presque partout le toit de paille se termine par une rangée de 4 à 5 tuiles formant auvent qui protège le trottoir de briques. Dans les villes, l'ardoise fait aux pannes une timide concurrence; la pierre ellemême apparâit, amenée à grands frais de l'Artois, du Tournaisis on de l'Ardenne, et servant à décorer les façades ${ }^{1}$.

1 Sur la ferme de la Flandre interieure, voir: Meitzen $(\Lambda)$, Siedelung und Agrarwesen der West- und Ost-Germanen (Berlin, 1895, 4 vol. in-8 ${ }^{\circ}$ ), III, pp. 200-240; Winkler (J.). Oud Nederland (S'Gravenhage, Ewings, 1888, in $8^{\circ}, 367$ p.), Pp. 112-113; - de Foville (A.), Enquête sur les conditions de l'hahitation en France, les maisonstypes; I, pp. 15-19 (étude do M. Bachelı); - I emire (abbé), L'lıabitat dans la Flandre française (Ann. Com. fl. Fr., XX, pp. 1-18); - Marguerit, A travers la Flandre maritime (Mém. Soc. Dunk. XXVII, pp. 213-215); - Claerbout, Nos origines (Ann. Soc. Em. Br., LII, 1902). 
Les mêmes matériaux, dans les mêmes proportions, se retrouvent pour l'édification des maisons d'ouvrier. Mais qu'elles soient do briques ou de terre, couvertes de chaume ou de pannes, celles-ci sont toujours longues et basses, presque enterrées. Ce double caractère vient de leur ancienne destination. Chaque maisonnette devait autrefois contenir un ou plusieurs métiers, qu'il fallait abriter dans une grande pièce à part, qui s'ajoutait aux deux chambres réservées à la vie de la famille; et pour obtenir l'humiditẻ nécessaire au fil, on ètablissait légèrement au-dessous du sol le plancher de terre battue. A l'extrémité de la maison se trouve l'étable de l'animal, vache, chèvre ou porc. L'intérieur est sombre, mal éclairé par des fenêtres souvent étroites el garnies de petits carreaux, mal aéré par' le système de la guillotine; le mobilier rudimentaire comprend surtoul la commode sur laquelle reposent sous globe les objets de piété; la literie de balle de céréales, d'herbe séchée, ou simplement de paille, est défectueuse; les couvertures de coton trop souvent remplacees par des sacs ou des vêtements, le nombre do lits insuffisant. Mais l'extérieur reste agréable et pittoresque: les maisons les plus pauvres sont passées à la chaux; les vieilles sont peintes en bleu pâle, et sur toutes tranche joyeusement lo bariolement des volets, sur lesquels les peintres ont épuisé toutes los gammes du vert, du bleu et du jaune. Pour mieux apprécier la propreté et l'aspect avenant de ces maisonnettes, il suffit d'escalader les pentes du pays haut d'Artois ou de pénétrer dans une des vallées qui en descendent vers la Flandre: à dix kilomètres du bas pays, les maisons se font moins bien entretenues; les rideaux disparaissent des fenêtres ; le badigeon est tombé par écailles, et on voit sortir du torchis les pointes noirâtres du soubassement de silex.

III.

DISPERSTON DES HABITATIONS.

Maisons et fermes sont comme jetées au hasard sur le sol. La dispersion des habitations est la règle en Flandre; et si l'un des traits essentiels du pays est d'être la région des ar'br'es, un autre, non moins caractéristique, est d'être la terre des maisons éparses. Cela saute aux yeux d'autant plus nettement que le cas n'est pas le même en Brabant, où les maisons tendent à s'aligner en rues, ni dans les régions crayeuses du Sud, où le groupement en gros villages est la règle. Le changement est brusque; dès qu'on a dépassé Lille au Sud, les habitations isolées disparaissent; toutes les maisons rallient les villages étendus le long des vallées tourbeuses ou 
groupés sur une bosse du plateau. Les habitants se rendent parfaitement compte de la différence, et les gens de Steenwerck demandent dans leur cahier de doléances de 1789 le retrait de l'ordonnance défendant de garder des fusils, « attendu qu'en Flandre les habitations sont dispersées çà et là dans la campagne, tandis qu'en France les maisons sont toutes amassées près de l'église $\gg 1$.

La présence de l'eau à une faible profondeur dans le sol est la cause de cette dispersion générale des habitations flamandes. Dans quelque partie que ce soit du pays, on est assuré de trouver une nappe en creusant, dans un sol meuble, un puits de moins de dix mètres de profondeur. Le plus souvent, c'est à 4 ou 5 mètres que va s'alimenter la rustique pompe en bois. $\Lambda u$ Nord-Est, l'eau est à 3 mètres, 5 ou 6 mètres au plus, dans le sable limoneux qui surmonte l'argile rupelienne: Beveren-Waes a 1.700 puits privés, 6 publics; St-Yicolas plus de 5.000, sans compter 80 puits artésiens qui vont chercher dans le sable asschien le supplément d'eau réclamé par l'industrie. Vers Gand, les linéoles argileuses qui traversent les sables quaternaires ou tertiaires alimentent à Ertvelde 630 puits pour les 674 maisons de la commune, à Mendonck 67 pour 77 maisons, à Oostacker 801, à Zele 1.918, à Tamise 1.640, tous à 3, 4, 5 mètres de profondeur. L'argile paniselienne, le sable argileux yprésien, enfin l'argile yprésienne, se chargent de retenir à fleur de sol la nappe phréatique do la West-Flandre et du pays d'Alost; Waereghem a 1.400 puits, Ruysselede 1.350, Menin 2.467 privés, 4 publics ${ }^{2}$. Sans doute cette imperméabilité du sol, qui permet la dispersion des habitations, a de graves inconvénients: les nappes phréatiques s'épuisent vite, et chaque élé il y a des puits à sec; surtout la faible profondeur du réservoir permet la contamination de l'eau par les produits des latrines et les engrais libéralement versés à la terre: il n'y a pas un village flamand dont certains puits ne soient empoisonnés. Le paysan paraît s'en soucier peu, et continue à boire cette eau impure, de même qu'il va s'alimenter à une mare, au ruisseau, au canal lorsque la nappe devient insuffisante. Même les citernes qu'on trouve presque dans chaque village ne servent qu'à fournir l'eau nécessaire à la lessive. Les villes, plus soucieuses de l'hygiène, sont plus embarrassées; la question de l'eau potable y est un des problèmes les plus épineux des programmes municipaux. Gand pratique une distribution par galeries de drainage qui donne une eau brune peu engageante; Bruges n a

1 Seigneurie de Steenwerck-Dampierre, Cahier du 26 mars 1789, article II.

2 André, Enquête sur les eaux alimentaires, I, pp. 355-401. 
rien trouvé de moins mauvais que l'eau du canal de Gand. Lille, Roubaix et Tourcoing sont allées chercher dans les fissures de la craie, comme Calais et Dunkerque, une eau plus pure et plus abondante que celle de leur propre sol ${ }^{2}$.

Mais au moins, sûr de trouver partout sans difficultés l'eau nécessaire à sa consommation et à celle de ses bêtes, le Flamand est allé établir son exploitation à l'endroit qui lui paraissait le plus commode. Cependant la dispersion qui en est résultée ne s'est pas opérée de la même façon á l'Est qu'à l'Ouest. On retrouve lá, dans la disposition de cette poussière de maisons et de fermes, la différence entre l'Ost et la West-Flandre.

\section{Dans l'Ouest : les maisons isolées.}

Le sol de l'Ouest est beaucoup plus compact que celui de l'Est. Le limon argileux, l'argile elle-même, les sables gras de l'Yprésien et du Paniselien forment une terre lourde et tenace dans laquelle le paysan embourbe ses attelages et enlise ses chaussures. A l'époqne oì il n'existait pas de chemins régulièrement entretenus, c'est-à-dire jusqu'au début du $\mathrm{XIX}^{\mathrm{e}}$ siècle, la circulation restait impossible en West-Flandre, pendant toute la mauvaise saison. Détrempé par les fines pluies persistantes de l'automne, le sol eût empêché le cultivateur d'aller à quelque distance faire ses labours, ses semailles, ses hersages. Il n'y avait qu'un reméde: élablir l'exploitation au milieu même des terres à cultiver. L'hofstede ou la cense groupaient là autour d'elles, aussi étroitement que le désirait l'exploilant, les pâtures où le bẻtail paissait sous la surveillance du maître, et à proximité les champs de lin, de colza et de céréales ${ }^{2}$. Lorsqu'une pâture se trouvail trop éloignée de l'habitation pour qu'on pût veiller sur les bêtes, on y établissait une maison d'ouvrier, où un journalier habitait à prix réduit sous condition de s'occuper du troupeau. C'est ainsi que se repeupla le pays après l'occupation franque; l'établissement des fermes éparses et des maisonnettes disséminées y précéda l’apparition

1 Sur un projet d'alimentation de toute la Flandre en eau potable pompée dans les sables pliocènes de la Campine, voir: Putzeys (E.), Alimentation en eau potable de la Basse-Belgique. (Bull. Soc. belge Géol. XVIII, 1904, Pr.-V., pp. 61-64).

2 Cette forme de dispersion (hof system) serait, d"après Meitzen, une survivance du système celtique, dû aux Ménapiens qui habitèrent le pays avant les Francs (Meitzen, Siedelung, III, pp. 239-240). Il serait étrange, dans ce cas, que la coutume celtique se fût imposée aux Francs de la VVestflandre, et n'eût laissé aucune trace dans la région sableuse, qui fut cependant, au même titre que l:Ouest, un territoire ménapien. 
des villages groupés plus tard autour de l'église. Les Flamands, dit Meyer, n'habitent pas comme les autres peuples autour des églises, mais eparpillent leurs maisons par les champs et les bois; et chacun possède là ses

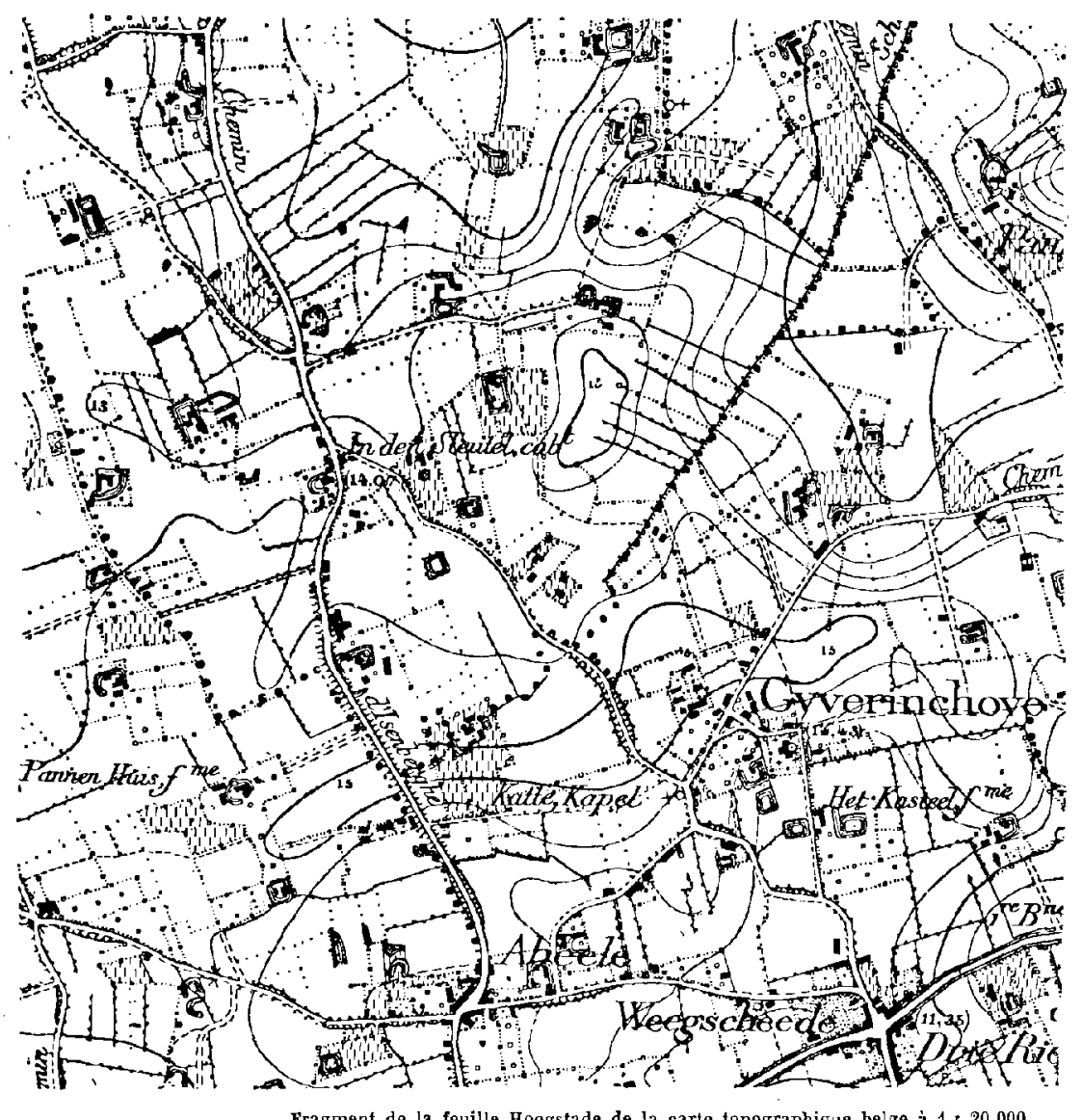

Frg. 62. - Dispersion des habitations dans l'Ouest de la Flandre (environs d'Hondschoote).

Fermes entourées d'eau; petite agglomération communale (Gyverinchove); maisons groupées aux carrefours.

terres arables, ses pâtures, ses vergers ${ }^{1}$. Cette disposition des habitations subsiste encore. Dans toute la West-Flandre, les formes restent isolées, sans souci des villages ni des chemins, à travers la campagne. On dirait qu'on

1 Meyer, Rerum Flandriac, p. 89. 
les a jetées au hasard. Pour remédier à cet isolement qui pouvait être dangereux aux époques troublées, elles s'entouraient presque toujours d'un fossé, qui enfermait tous les bâtiments, et au moins l'habitation. La belle carte du Franc, cxécutée au XVI siècle par Pourbus, indique par exemple dans la paroisse de St-Andró-lez-Bruges 22 «manoirs » entourés d'eau ${ }^{1}$. Ces manoirs fortifiés sont encore nombreux dans lo pays d'Ypres, dans la plaine do la Lys et la région lilloise (Fig. 62).

Dans ces conditions, le village proprement dit, le chef-lieu de la paroisse, était forcément peu de chose. Le «Platz», comme on l'appelle, ne comprenait guère, autour de l'église, que quelques maisons de commerçants, avec une majorité d'estaminets. L'emplacement importait peu; cependant on remarque que beaucoup de villages sont établis sur de petites hauteurs. A l'Est d'Ypres, West-Rooseheke, Passchendaele, Moorslcede, Beceldere, Gheluwelt, Zandvoorde sont placés au sommet de tertres; même disposition pour beaucoup de villages à l'Est de Courtrai, pour la plupart de ceux qui entourent Cassel, et surtout pour les villes et bourgades situées ał Nord de Lille: Bondues, Linselles, Roncq, Neuville-en-Ferrain, Mouveaux, Mouscron et Tourcoing couronnent des collines, et cetle disposition donne du pittoresque à ce paysage industriel. Cette particularité, que les habitants nes'expliquent pas, doit tenir à des préoccupations de défense; l'église était établie sur un lieu élevé pour pouvoir surveiller le pays, et prévenir au son du tocsin les habitants épars du danger qui les menaçait. Un autre lieu de villages, c'est le bord des vallées, à l'endroit où se termine la bande de terres basses inondables; on compte 15 villages le long de l'Escaut entre IIelchin et Audenarde, sur 20 kilomètres à vol d'oiseau ; et 16 le long de la Lys pour Ios 25 kilomètres qui séparent Courtrai de Deynze.

La situation s'est modifiee au XIX ${ }^{\ominus}$ siècle, avec la création des chemins. Les fermes neuves viennent se placer au bord des routes, assuré qu'est désormais le fermier d'avoir accès dans toutes les parties du domaine exploité; les vieilles au contraire sont restées à l'écart, et principalement dans les creux, où on les bâtissait jadis de, préférence, pour trouver plus facilement l'eau nécessaire à la défense et à l'alimentation; il arrivait même qu'avant de construire on enlevait de la terre pour que la dépression fût plus prononcée. Pour faire cesser leur isolement, elles se sont reliées aux routes par de belles dréves, avenues d'ormes qui s'allongent parfois sur un kilométre. Le Platz a beaucoup grandi avec le développement des chemins,

1 Voir Van Speybrouck (A.), St-André. (Ann. Soc. Km. Br., 38 volume, 1888, pp. 1-172). 


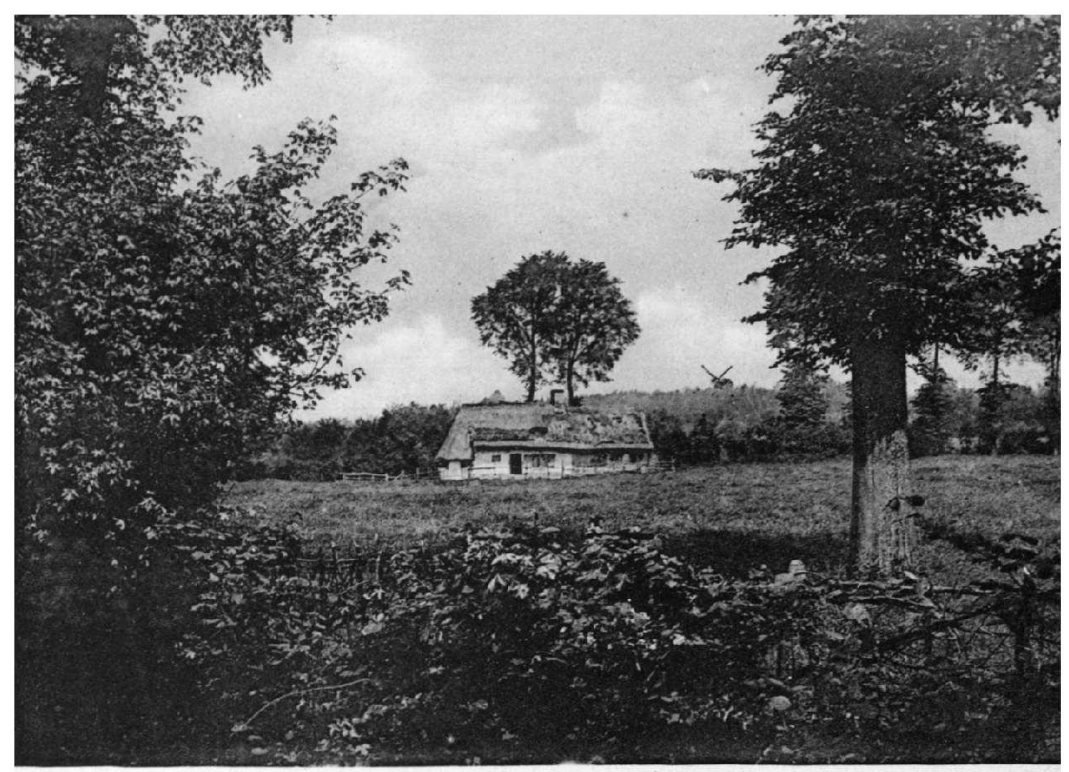

45. - La maison d'ouvrier dans une pâture (Saint-Jans-Cappel).

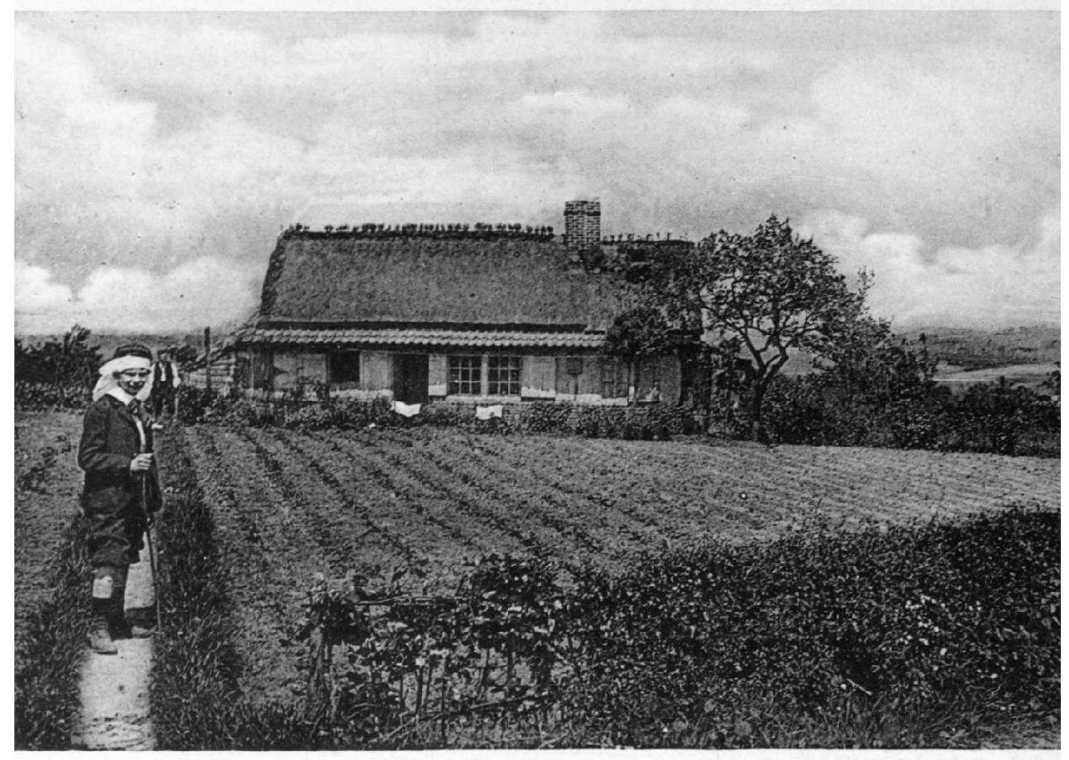

46. - Type de maison d'ouvrier agricole (Westoutre). 
IRIS - LILLIAD - Université Lille 1 
qui viennent s'y croiser; les rentiers sont venus s'y fixer; avec eux sont venus s'établir les ouvriers agricoles, quittant peu à peu les maisonnettes éparses dans les pâtures. Maintenant que l'accès des champs est facile, et qu'il n'est pas nécessaire que la ferme soit placée au centre de l'exploitation, beaucoup de petites fermes ont disparu, dont les terres ont été partagées entre d'autres domaines, les propriétaires y trouvant l'avantage d'être débarrassés du souci d'entretenir les bâtiments. Pour la même raison, on a démoli la plupart des maisonnettes ísolées, « ces cabanes éparses dans la campagne, asiles de l'innocence » ${ }^{1}$, sur lesquelles s'attendrissait Forster, et on a offert à leurs occupants un logement dans des corons construits à bon marché et d'entretien facile, situés aux abords du village. Le mouvement de concentration est particulièrement prononcé en France, où la diminution de la population rurale contribue à faire disparaître les habitations isolées. La comparaison d'une carte de 1737 conservée à la mairie de Steenbecque avec l'état actuel montre que les deux tiers des maisons éparses n'existent plus. Dans la plupart des communes, on signale que cette concentration s'opère: $\dot{a}$ Rexpoede, à Bollezeele, à Quaedypre, à Boeschèpe on voit disparaitre les petites formes; à Ste-Marie-Cappel, on en a démoli dix en 25 ans. On s'aperçoit en parcourant le pays que la plupart des maisonnettes isolées sont vieilles et délabréos, qu'on ne les entretient plus; d'autres sont en ruine. Ainsi la dispersion, jadis poussée à l'extrême dans l'Ouest, tend a s'utténuer el la plupart des villages forment des bourgades assez compactes, avec une population beaucoup plus aggloméré que dans la plupart des communes de Basse-Normandie ou de Bretagne.

\section{Dans l'Est : les maisons groupées en rues.}

Lorsqu'on a dépassé à l'Est la ligne Thourout-Thielt-Deynze, l'aspect du pays change. Tandis que les pâtures se font rares, que les champs s'entourent d'une bande de gazon et d'une haie d'aulnes, on voit les maisons dispersées rallier le chemin, et disparaître peu à peu du milieu des champs; au delà du canal de Bruges à Gand, la transformation est accomplie, toutes les maisons sont dorénavant au bord des routes, qui se transforment en longues rues hordỏes de bàtiments. Hors des villagos il est rare que les maisons se touchent : elles restent à 10,20,50, parfois 100 mètres l'une de l'autre; mais aucune ne s'écarte du chemin, vers lequel elle tourne sa façade ou son pignon. Entre Exaerde et Oostacker (N.-E.

1 Forster, Voyage philosophique, II, p. 167. 
de Gand) s'allonge ainsi une route de 16 kilomètres, toute bordée de maisons dont aucune n'est à plus de 100 mètres d'une autre, petites fermes dont l'habitation regarde la route, tandis que les bâtiments d'exploitation lui sont perpendiculaires. Au delà, au Nord et au Sud, s'étend un désert cultivé, sans une cabane jusqu'aux maisons de la prochaine route dont on aperçoit parfois les toits rouges entre les arbres. Entre Gand et Lokeren, le voyageur qui suit lo chemin de fer voit le pays se dérouler de chaque

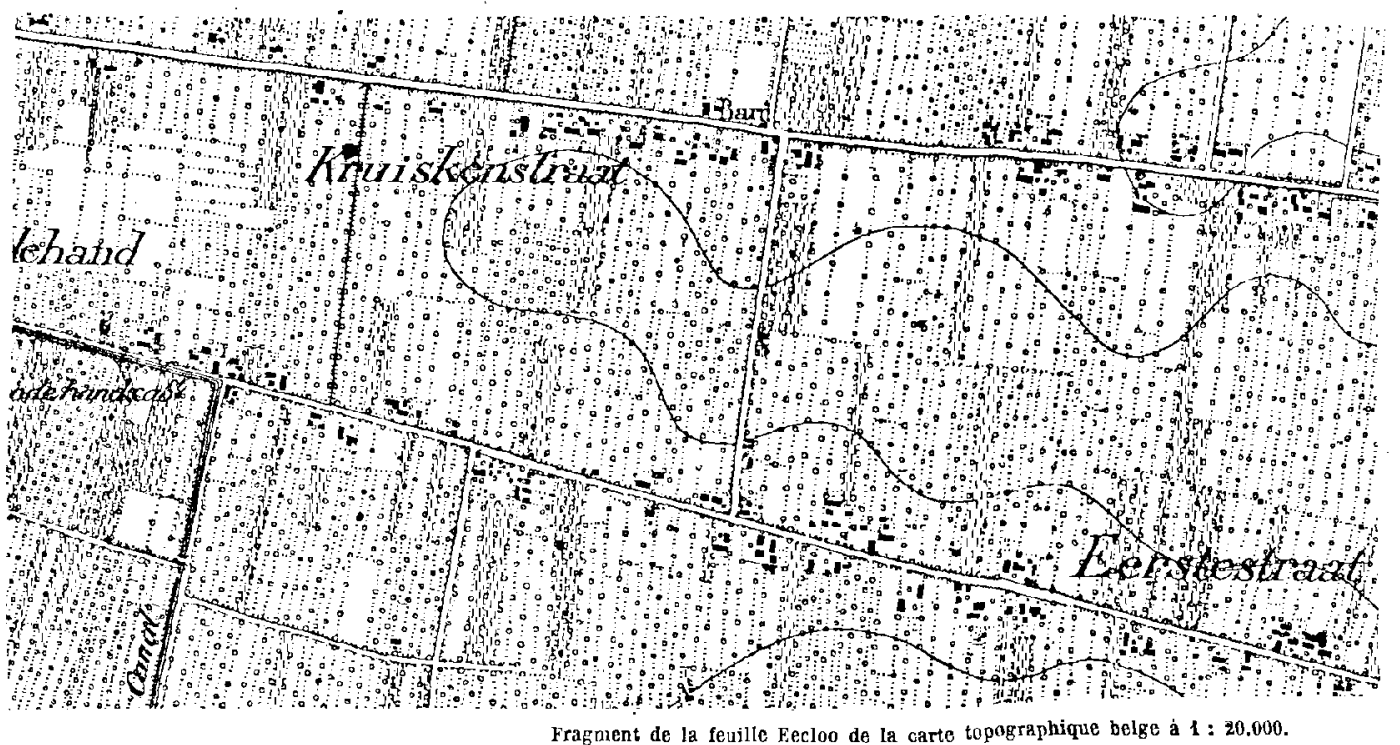

Fig. 63. - Maisons groupées en rues lans l'Est de la Flandre.

Maisons et jardins au long des chemins; champs enclos de haies s'étendant d'un chemin à l'autre.

côté de la voie comme une vraie solitude boisée, quoique la densité de la jopulation soit supérieure à 200 habitants au Kmq. C'est que les routes étant parallèles à la voie ferrée, et les maisons n'étant construites que le long des routes, on n'aperçoit qu'à de longs intervalles quelques toits cachés par les peupliers et les saules.

C'est encore à la nature du sol qu'est due la raison de cette curieuse disposition. Le sable et le limon sableux qui recouvrent toute cette région sont des terrains toujours secs. L'eau de pluie est rapidement absorhée par cette surface poreuse, et jamais le sol n'est impraticable pour le passage du paysan et de son outillage agricole. De même que dans la Plaine maritime la ligne des dunes, en dépit de son sol mouvant, a toujours tenu lieu de route, de mềme les sables de l'Ost-Flandre, dans lesquels le pied 
enfonce parfois jusqu'à la cheville, n’ont jamais empêché la circulation que les pluies rendent impossible dans les terres fortes de l'Ouest. Sùr de pouvoir a toute époque de l'année avoir accès à ses champs, le paysan préférait établir sa maison au long des voies de communication, chaussées ou pistes de sable, rchappant ainsi à un isolement qui pouvait être dangereux : ses instincts d'indépendance restant d'ailleurs sauvegardès par Ia possibilité où il était de se tenir à bonne distance de la maison voisine, l'eau ne faisant défaut nulle part, à quelques métres de profondeur.

Dès lors, dans tout l'Est, on passe de la pleine campagne aux villages par d'insensibles transitions. Les maisons se rapprochent, leurs jardins se touchent, puis disparaissent; les habitations finissent par se rejoindre, la route est devenue rue. Aussi est-il difficile de dire où commence l'agglomération. Villes et hourgades se prolongent dans la campagne par d'interminables faubourgs: St-Nicolas a l'air d'une pieuvre dont les maigres bras s'allongent sur le pays de Waes. La plupart des communes sont complètement désarticulées en gros hameaux qui courent le long des routes. Waerschoot, qui compte 6.100 habitants, en groupe à peine 1.371 . autour des trois rues qui se rejoignent devant l'église; les hameaux se partagent le reste: $41 \mathrm{j}$ à Leest, 300 à Kerre, 779 à Arisdonck, 601 à Oostmoer, 361 à Hoeksken, 411 à Weststraat, etc. ; chacun d'eux est dejjà un village. Zele compte 21 hameaux, contenant plus de la moitié de la population totale.

Ces villages, ces bourgades mi-rurales mi-industrielles, ont un aspect

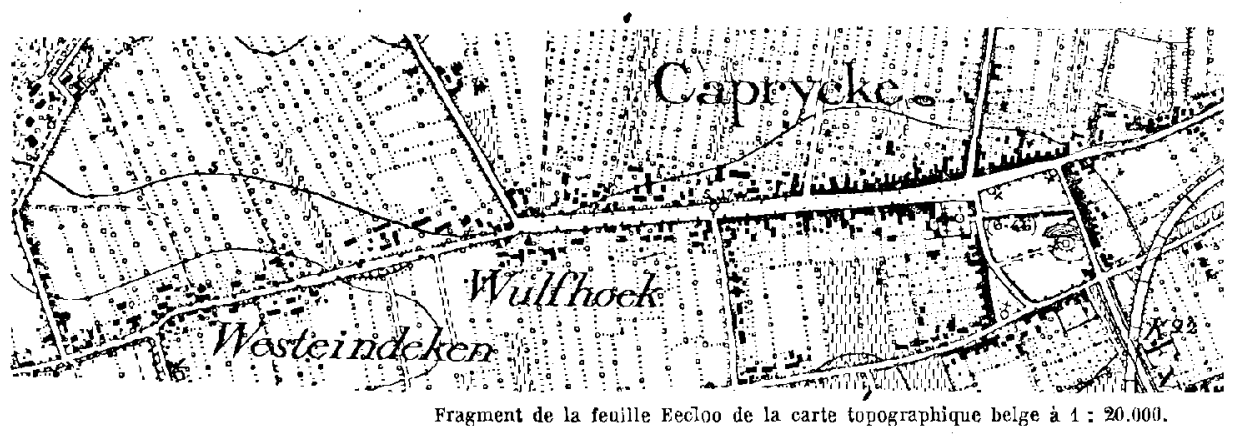

Fı. 64. - Un village de l'Est: Caprycke. Disposition en rue.

Largeur de la rue principale, due à la disparition des jardins devant les maisons. Vastes dimensions de la place.

singulier. L'entrée est charmante: des jardins et des vergers bordent la route, derrière une haie; au fond, dans ce cadre heureux, apparaît la propre maison de briques. Mais vers le centre, les jardins disparaissent, 
sans que les maisons se rapprochent du chemin, de sorte que la rue devient une énorme voie de 20 à 30 mètres do large, comprenant une chaussée pavée au milieu, et des pistes de sable, vrais champs d'ornières, de chaque côté. Telle se présente la ville d'Eecloo, où les jardins qui s'ètendaient devant les maisons sont disparus depuis une soixantaine d'années. La place-carrefour est vaste en proportion des chemins; d̀ Caprycke elle atteint la superficie de 5 hectares; la plupart servaient ou servent encore de pâtures, et à l'époque de la prospérité du lin, on y mettait sécher

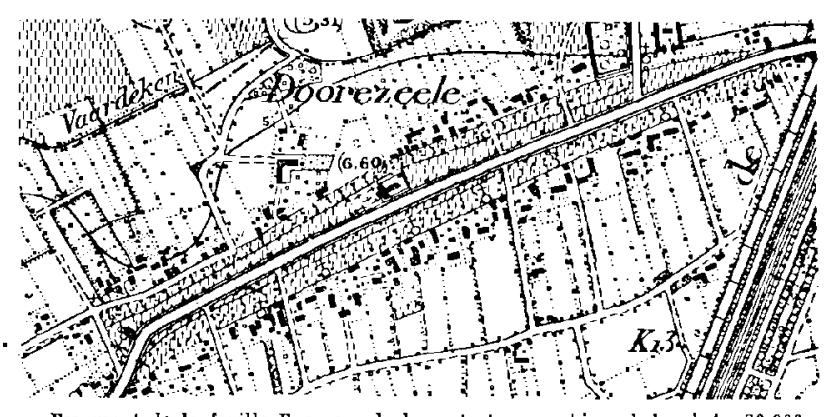

Fragment de la feuille Evergem de la carte topographique belge a $1: 20.000$.

Fıa. 65. - Un village de l'Est: Doorezeele. Exagération du type ordinaire; largeur énorme de la rue, plantée d'arbres et: servant de pâture.

les fibres rouies dans les mares. Il existe encore destypescurieux do l'ancienne disposition des villages. Le hameau de Doorezeele (commune d'Evergern ) comprend, d'une ligne de maisons à la ligne située en face, d'abord les vergers bordés d'une haie, puis une pâture communale avec cinq rangées d'arbres, une chaussée pavée, une autre pâture avec six rangs d'arbres, les haies et de nouveau les vergers: environ 160 mètres de distance d'une maison à celle qui Iui fait vis-à-vis. Avec un pareil systeme de groupement, les habitations finissent par être aussi isolées que celles de la West-Flandre.

Les noms de lieu expriment nettement cette dispersion des habitations qui caractérise la Flandre. I.e nom de Hoek (coin) est très fréquent, particulièrement dans les lieux-dits ; autour d'Hondschoote, presque tous les hameaux sont ainsi le coin des tilleuls (Lindenhoek), le coin de Beveren (Boverenhoek), le coin de la chapelle (Cappelhoek), le coin de l'Ouest (Westhoek), le coin du puits (Puthoek), etc. Mais les noms les plus fréquents sont ceux qui désignent l'habitation germanique. Le suffix « heim », traduit en hem, em, ghem, gem, ghen, ghien, ain, et signifiant: séjour, demeure, remplit la Flandre intérieure, déborde sur le I3rabant, la Campino, depuis les Valdegem et les Landegem de l'Est jusqu'aux Pitgam, Frelinghien, Radinghem et Sainghin français. « Sele», désignant la maison du chef franc, s'étend sur les mêmes territoires, en Belgique 
(Zele, Oosterzeele, Dadizeele), en France et en pays wallon (Horzecle, Strazeele, Linselles, Herseaux). Le plus ancien de ces termes employés pour indiquer l'habitation, « Laer », est resté cantonné dans l'Est : Vosselaere, Knesselaere, et ne fait dans l'Ouest que de rares apparitions : Rousselaere (Roulers), Becelaere; Oxelaere. La maison isolće (huis) apparaît dans une multitude de lieux-dits. De même pour la ferme (hove), qui a également donné son nom à de nombreux villages, Etichove, Kerkhove, et dans la partie française Bavinchove, Volkerinckhove, Polincove, jusqu'å 46 dans le seul département du Pas-de-Calais. La disposition des habitations dans l'Ost-Flandre rend particulièrement fréquent dans cette région l'emploi du terme Dorp (village), désignant les hameaux en rues:Opdorp, Steendorp, West-et Zuyd-dorpe; de même pour le vocable Straat(rue), qui s'applique á une quantité considérable de lieux-dits autour de Zele, Hamme, et dans tout le pays de Waes.

Enfin d'antres termes traduisent l'abondance de l'eau, la nature humide du pays. Broeck, Briel (marais) se rencontrent même hors de la plaine maritime ; beaucoup de villages, de hameaux, ont pris le nom de ruisseau: Beke, déformé en becque et baix: Roosebeke, Harlebeke, Steenbecque, Roubaix, Fleurbaix. On rencontre fréquemment des termes augmentès du suffixe Voorde (passage sur l'ean): Steenvoorde, Zand voorde, Hardifort, ou du suffixe Brugge (pont): Langerbrugge, Gentbrugge. Les champs (Veld, Akker, Kauter), les bois (Busch, Hont, Loo), les noms d'arbres, entrent fréquemment en composition, ainsi que les termes qui expriment les hauteurs et les dópressions (Berg, Dacle) ${ }^{1}$.

\section{IV.}

\section{LES VILLES ?.}

Etant donnó l'ébat de dispersion de la population, il ne faut pas s'attend re à trouver en Flandre un grand nombre de groupes urbains bien constitués, de vraies villes qui tranchent sur les agglomérations rurales. Beaucoup de communes flamandes ont des populations supérieures à celles de

1 Sur les noms de lieu, voir l'excellent travail de Kurth, La frontiére Iinguistique en Belgique et dans le Yord de la France (Mém. C. Ac. R. Belg., XLVIII, 1896-1898, 2 vol.). On trouvera une bibliographie complèce de la question dans: Adriaens ((X.), Orthographe des noms de commune (BulI. C. C. St., XVI, 1890, pp. 1-99), pp. 93-98.

2 Sur les villes, voir: Deventer, Atlas des villes de la Belgique au XVle siècle (publié par Ch. Ruelens et L. Gilliodts van Severen). 
villes françaises, tout en restant de simples agglomérations rurales. Wynghene avec ses 8.132 habitants, Stekene avec 7.949, Moorslede avec 7.304 , Aeltre avec 7.240 ne sont que de gros villages. Mais faut-il considérer comme villes des communes telles que Zele, où sur les 12.932 habitants 6.000 sculement habitent lo centre ? De même à Iseghem : sur 12.172 habitants, plus de la moitié se trouvent hors de l'agglomération. Thourout, contre 3.000 habitants dans la ville, en a 7.100 dans la campagne; Thielt se partage entre 3.500 habitints et 700 maisons sur sa colline, 7.000 et 1.400 maisons dans la plaine d'alentour. Beaucoup de villes, même parmi celles qui sont en pleine croissance, restent donc à demi-rurales.

\section{Les villes avant le $\mathbf{X I X}^{\circ}$ siècle.}

Les premières villes apparaissent à l'ópoque romaine. Ce sont des forteresses qui succèdent peut-êtro aux oppida gaulois. Cassel (Castellum Menapiorum), de sá butte, commande la West-Flandre sur laquelle il étend - son réseau de chaussées étoilées autour de la colline; sur le mont de Watten, dominant le gué de l'Aa, existe un établissement dont les ruines sont décrites au IX siècle par l'auteur de la Chronique ${ }^{1}$. D'antres villes sont établies au bord de la Lys, marchés et têtes de pont: Minariacus (Pontd'Estaires), sur la route de Cassel à Arras; Viroviacus (Wervicq), sur la route de Cassel à Tournai; Cortoriacus (Courtrai), bâti à un ondroit oủ se rétrécit la vallée. Cependant Gand existe probablement déjà sur la pente du Sablon, devant laquelle s'unissent les bras de l'Escaut et de la Lys; au VII ${ }^{\circ}$ siècle, avant qu'un monastère y fût fondé, St Amand se rend au "pagus qui vocabulum est Gandavum " 2, que le biographe de St Bavon appelle un castrum, et celui de St Eloi un municipium ${ }^{3}$.

Les villes somnolent après l'invasion franque. Les nouveaux venus sont une population rurale, qui se disperse en fermes et en hameaux. Quelques grands marchés suffisent aux échanges. Mossines reste pendant longtemps, grâce a sa situation sur la frontiere linguistique, une des foires les plus animẻes de la Flandre. Thourout, vrai centre du pays, est déjà en relation avec le Nord de l'Europe ; on forme dans son monastère des missionnaires pour l'évangélisation de l'Allemagne septentrionale. Mais ces foires

1 M. G. SS. XIV, p. 163.

2 Vita S. Amandi (Mabillon, Acta Sanctorum, II, p. 683).

3 Vita S. Bavouis (Mabillon, II, p. 337); vita S. Fligii dans Don Bouquot, III, p. 557 . 
fréquentées ne donnent pas naissance à des villes. C'est la renaissance du commerce régulier et permanent, à la fin de l'époque carolingienne, qui va fixer des populations plus denses « aux nouds du transit régional » ${ }^{1}$.

I.es cours d'eau sont à cette époque les seules voies commerciales de la Flandre. Ce sont donc des villes de rivière qui s’établissent aux endroits les plus favorables pour le transit. St-Omer s'étend à l'endroit où l'Aa, descendu rapidement de l'Artois, se calme en pénétrant dans les marais et devient navigable. Ypres se place au point extrème où peuvent alleindre les bateaux de l'Yperlée, et d'où l'on peut facilement gagner la Iys ${ }^{2}$. Cette dernière devient une rue de villes. Depuis Aire, où elle peut porter des barques, jusqu'à Gand où elle atteint l'Escaut, les cités commerçantes se succèdent à intervalles presque égaux : Merville, Estaires, Armentières ${ }^{3}$, Warneton, Comines, Wervicq, Menin, Courtrai, Deynze. D'Armentières à Menin, les villes sont placées successivement à droite et à gauche de la rivière; c'est qu'elles choisissent pour s'établir l'endroit où la Lys, promenant ses courbes de gauche à droite, vient frôler le bord du lit majeur; ainsi placées sur cette rive blevée, elles ne craignent pas les inondations qui s’étendent chaque hiver sur la vallée. Lille ${ }^{4}$ canalise déjá la Deûle, Alost la Dendre; Termonde profite de la jonction de cette dernière et de l'Escaut. Mais la position de Gand est favorable entre toutes. Non seulement sa situation au confluent des deux grands cours d'eau flamands lui assure un trafic important, mais elle est à l'endroit où les denx riviéres sont assez rapprochées de la mer pour que les marchandises puissent gagner directement la côte en évitant le long détour par Anvers. La Lieve jadis,

1 Pirenne (H.), Les villeg flamandes ayant le XIIe siècle (Ann. E. N., I, 1905, pp. 9-32), p. 23. - Sur le nène sujet: Pirenue, Lorigine des constitutions urbaines au moyen-âge (Revue Historique, LVII, 1895, pp. 57-38 et 293-327); - 11., Villes, marchés et marchands all noyen-âge (Ibid. LXVII, 1898, pp. 59-70); - Des Marez (G.), Les villes flamandes (Bruxelles, Moreau, 1900, 24 p.); - Id., Etude sur la propriété foncière dans les villes du Moyen-Age et spécialement en Flandre (20 fascieule du Recueil des travaux publiés par la Faculté de philosophie et lettres de l'Université de Gand, 1898).

2 Sur Ypres, voir bibliographie très complète dans: Diegerick (A.), Liste des ouvrages et notices concernant l'histoire de la ville d'Ypres publiés depuis 1830 (Aun. S. H. Ypres, VIII, 1878, pp. 78-125).

3 Jean sans Peur accorde une foire à Armentières en considération de sa situation sur la Lys. Voir Inventaire Arch. Armentieres, sẻrie HH. p. 2.

s Sur les origines de Lille voir: Hautecur (E.). Cartulaire de l'église collégiale de St-Pierre de Lille (lille, Quarré, 189/4, 2 vol. in-80); - Id., Histoire de l'église collégiale et du chapitre de St-Pierre de Lille (Lille, Quarró, 1896, 3 vol. in-8\%). La première charte originale ou soit mentionné le nom de Lille est de 1066. 
puis le canal de Bruges, aujourd'hui le canal de Terneuzen, ont ainsi fait de Gand un port maritime en même temps qu'il était le principal port fluvial de la Flandre. L'existence de deux abbayes autour desquelles ne sont nés que des faubourgs agricoles, of d'un castrum resté longtemps à part, n'était donc pas nécessaire à l'établissement et au développement de la ville commerçante (Portus), élendue au confluent véritable, autour des marchés aux l'oissons et du Vendredi.

Le magnifique développement de l'industrie drapière aux XIII ${ }^{e}$ et XIV siècles acheva ce que le commerce avait commencé. Les villes prirent un essor inouī. Lille, qui apparaît an $\mathrm{XI}^{\mathrm{a}}$ siècle, est déjà comptée an XIII ${ }^{\mathrm{e}}$ comme une des cinq grandes cités flamandes. La prospérité, restée attachée jusque là aux villes de rivières, déborde hors des vallées, roule à travers le plat pays; les villages deviennent bourgs, et les bourgs, villes. Hazebrouck ${ }^{1}$, Bailleul, Poperinghe, Roulers, Thielt, deviennent des cités actives pourvues d'institutions municipales. Les grandes villes voient leur population s'accroître dans des proportions inconnues jusqu'alors, sans atteindre cependant aux chiffres fabuleux qu'on leur attribue généralement: 300.000 habitants à Bruges, 250.000 à Ypres; il est probable qu'aucune ville de cette époque ne dépassait 60.000 habitants, peut-être 80.000 ; leur' croissance ne pouvait être indéfinie, chacune ne pouvant guère se nourrir que de ce que produisait sa châtellenie ${ }^{2}$. Pour Ypres en particulier le chiffre de 200.000 âmes donné en 1247 par une bulle d'Innocent IV est corrigé dès 1257 par une bulle d'Alexandre IV, disant que d'après le prévôt et le chapitre de St-Martin, la population de la ville dépasse 40.000 habitants ${ }^{3}$. Bruges et Gand étaient d'ailleurs plus importantes qu'Ypres, si l'on s'en rapporte an T'ransport de $1309^{4}$. A celte date, sur 100 livres à fournir par le comté tout entier, Bruges était taxée à 15 livres, Gand à 13, Y pres à 10.

La décadence de l'industrie drapière causa naturellement la décadence des villes, que sa prospérité avait enrichies et peuplées. Ypres en souffre particulièrement; ses faubourgs sont détruits en 1382 par l'armée anglaise de l'évêque de Norwich; ses artisans émigrent. Dès le début du XV $V^{e}$ siècle

1 Pour le développement d'Hazebrouck, voir Finot, Inventaire des Arch. d'Hazebrouck, Introduction ; -- Taverne de Tersud, Ilazebrouck depuis son origine jusqu'à nos jours (Hazebrouck, Venclle, 1890, in-4\%, 454 p.).

2 Des Marez, Les villes flamandes, p. 14.

3 Diegerick, Arch. d'Ypres, I, pp. 64 et 82.

4 Pilblic dans Gilliodts, Inventaire, IV, pp. 279-280; de Limburg-Stirum (Th.), Codex diplomaticus Flandriae, inde ab anno 1296 ad usque 1327 (Bruges, de Plancke, 1889, 2 vol.) II, pp. 141-143. 
on réduit de 10 à 8 livres sa contribution au Transport; sa population tombe à 12.000 habitants en 1412, à 10.000 en 1470 ; en 1486, le tiers d'entre eux mendie 1. L'industrie linière, vers laquelle se retourne l'activité flamande, s'exerce à la campagne, les villes n'en profitent pas, sauf quelques rares exceptions. Au Transport de $1517^{2}$, Ypres est taxée à 7 livres, qu'elle est d'ailleurs incapable de payer; Courtrai, assignée pour 30 sous en 1309 , est tombée a 22 ; Poperinghe, de 24 sous à 14 ; Thourout, de 3 sous a 12 deniers. Les grandes villes commerçantes résistent mieux : Gand s’est élevé de 13 à 14 livres; Bruges est taxée à 14. Mais les guerres surviennent: lutte contre la France, révolte des Pays-Bas, guerre de 80 ans. Au Transport de $1631^{3}$, la décadence des villes est définitive. Gand est tombé à 6 livres 14 sous; Bruges à 5 livres; Ypres à 2 . On a dû reporter sur les campagnes et sur les petites villes les charges que les grandes ne peuvent plus payer. On a transformé en forteresses les anciennes capitales de l'industrie; en forts d'arrèt les petites villes. A Gand, on rase un quartier et une abbaye pour dresser une citadelle espagnole. Audenarde, où la fabrication des tapisseries réunissait 20.000 travailleurs dans la ville et la banlieue, voit ses ouvriers émigrer vers la Hollande et la France; elle est réduite à son rôle stratégique de forteresse défendant l'entrée de la Flandre; la situation était belle à l'endroit où la colline d'Edelaere se dresse au-dessus de la vallée resserrée, facilitant le passage et la défense; les sièges du XVII siècle et la bataille du XVIII en ont prouvé l'importance. Termonde, marché du lin do l'Est, devient le fort contre lequel se brise l'élan de l'armée française en 1667. Menin, Wervicq, Armentières, Warneton, St-Venant, sont des fortins qui hérissent la ligne de la Lys. Encore ces villes fortifíes, qui languissent derrière leurs murailles, sontelles protégées contre les attentions que les belligérants, dans la seconde moitié du XVII siècle, prodiguent au plat pays et aux villes ouvertes: pillages, incendies, contributions. Aussi Poperinghe tombe à 1.592 habitants en 1698; Roulers à 699 ; Estaires à 1.027; Bailleul à 2.302 4 . Même la paix qui règne en Flandre de 1748 à 1789 ne ramène pas la prospérité dans les villes. C'est la campagne, ce sont les bourgades à moitié rurales qui

1 Pirenne, Hist. de Belgique, II, p. 388 ; -Id., Les dénombrements de la population d'Ypres au XV' siècle (Vierteljahrschrift für Social-und Wirtschaftsgeschichte, I, 19(03, pp. 1-sqq.)

2 Publié dans : Eerste bouck der Ordonnancien, Statuten, Edicten en Placcaerten.... van Vlaenderen (Ghendt, bij Anna van den Steene, 1639 , in-4 ${ }^{\circ}, 820$ p.), pl. $549-551$.

a Publié dans Priem, Précis, $2^{e}$ sério, VII, pp. 110-119.

* Daprès le mémoire de des Madrys (Bull. Comm. H. N., X, pp. 251-328). 
profitent du réveil de l'industrie à domicile. En 1784, Gand végéte à 50:000 habitants, Ypres, à 12.000, Audenarde à 3.000, Termonde à 5.000 1', faibles chiffres que la conquête française contribua encore à rẻduire.

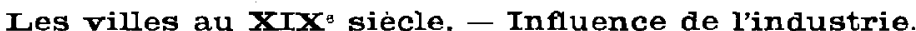

Mais lorsqu'au début du XIX siècle apparut la grande industrie, les villes retrouvèrent leur supériorité, et les campagnes commencèrent à se dépeupler en leur faveur. Co fut un long et irrésistible mouvement qui se prolongea toute la durée du siècle et continue de plus belle aujourd'hui. Sous l'influence du développement industriel, et sous cette influence seule, les anciennes villes reprirent leur croissance interrompue, et de nouvelles naquirent, qui firent une fortune prodigieuse.

IIors de l'industrie, point de salut. Les villes qui ne voient pas dressẻes dans leurs faubourgs les hautes cheminćes de briques sont restées petites ou médiocres, quand elles n'ont pas décru. L'intluence des voies de commu-

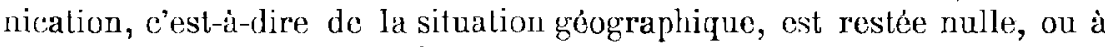
peu près. St-Omer est établie au bord de la grande voie fluviale qui relie Dunkerque au Nord et à Paris; c'est une étape toute désignée sur une ligne dont le tonnage dépasse 2 millions de tonnes en 1901 ; enfin c'est l'intermédiaire entre le haut pays d'Artois et le bas pays de Flandre; pourtant l'industrie ne s'y étant pas acclimatẻe, et s'y réduisant à quelques ateliers de lingerie, á quelques fabriques de pipes, la ville reste comme morte; de 20.109 habitants en 1803, olle est passée à 20.867 en 1901. Lire, míeux placée encore, au carrefour du canal de Neuffossé, du canal d'Aire à La lassée et de la Iys navigable, a gagnè 872 habitants en un siècle, de 7.586 à 8.458 ; sur ce nombre, 1.060 personnes indigentes étaient admises, pour 1903, à l'assistance médicale gratuite ${ }^{2}$. Qu'on les compare à leurs voisines du Sud : Lillers, à l'écart de la grande voie navigahle, a pourtant gagné de moitié grâce à l'industrie de la chaussure et au voisinage des houillères (de 4.094 à 7.747); Bethune, pour la momeraison, est montéede6.165à 12.404habitants. Il y a bien d'autres exemples. Termonde est dans une situation commerciale remarquable, au confluent do l'Escaut et de la Dendre, à mi-chemin de Gand et d'Anvers; cependant gênée par les servitudes militaires dans son développement industriel, elle n'a pas connu l'essor rapide de sa voisine Wotteren,pourtant moins bien placée. IRenaix, aussi mal située que possible,

1 Kervyn de Lettenhove, La Flandre dans les trois derniers siècles, pp. 292-293.

2 Journal l'Écho de la Lys da 13 novembre 1902. 
à l'extrémité de la Flandre dont dépend son industrie, isolée au fond d'une vallée qui est une impasse, privée d'un canal et desservie par des voies ferrées incommodes, est en pleine prospérité pendant qu'Audenarde végéte. Il est clair qu'Hazebrouck s'est heureusement ressentie de la création dos grandes voies ferrées qui s'y croisent et que les 400 ouvriers et employés de la gare contribuent à sa prospérité; cependant en 1876 la ville n'atteignait pas encore 10.000 habitants, et c'est depuis la création des tissages mécaniques et de la filature, avec leur personnel de 1.200 individus, que la ville, en 25 ans, est passée de 9.857 à 13.261 habitants.

Aussi les villes qui ne se sont pas créé une industrie déclinent, fussent-

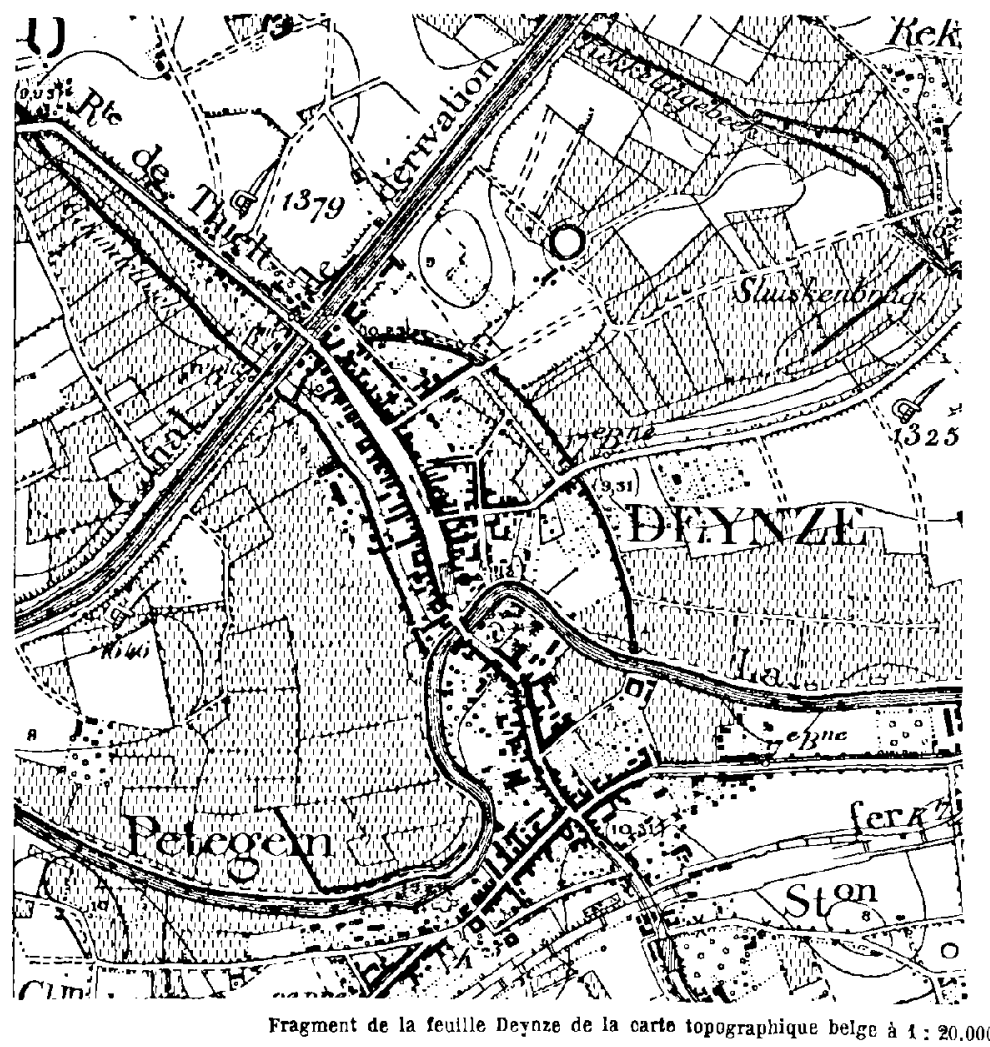

Fig. 66. - Deynae. Type de ville formée d'une chaussée à travers une vallé marécageuse.

Emplacements de batailles aux environs.

elles des centres agricoles de premier ordre. Cassel possède tous les quinze jours un imporlant marché de bestiaux, où l'on vient de toute la West- 
Flandre française; ses foires sont fróquentées; sa butte pittoresque se couronne d'un grand hôtel et de villas; elle fait figure de ville de plaisance : cependant sa population, de 3.785 habitants en 1804 , apres avoir atteint 4.200 au milieu du siècle, est tombéo à 3.222. Poperinghe, après avoir dépassé 11.000 habitants, est descendue au-dessous de ce chiffre. Audenarde est un type de la vieille ville flamande, avec les murs jaunâtres des grandes casernes du XVII ${ }^{e}$ siècle qui rappellent le rôle militaire de la ville, les toits à pignons en escalier, les églises, et l'hôtel de ville si finement ajouré qu'il ressemble à une châsse d'orfèvrerie; mais l'industrie n'est pas venue, et la ville s'est tout honnement élevée en un siècle de 4.200 à 6.200 habitants. Ypres est une autre ville du passé ; ses 16.500 habitants tiennent peu de place dans les rues, et ses immenses Halles étonnent d'autant plus le visiteur qu'elles sont disproportionnées avec l'activité actuelle de la cité. Les autres vieilles villes, qu'avait rudement atteintes la crise du travail à domicile, ne se maintiennent qu'en introduisant chez elles la grande industrie. Thielt, devenue l'avant-garde de la région gantoise vers l'Est, Thourout, vrai village aux rues étroites et tortuenses, bordées de maisons basses, sans étage, qui s'cmplit du tapage des marteaux de cordonniers sur le cuir, se tiennent a 10.000 habitants, la plus grande partie dans la campagne. Enfin l'important marché de Deynze, jadis chaussée traversant les prés mouillés de la Lys; dont l'importance stratégique est attestèe par' les nombreux combats que mentionne la carte autour d'elle, ne se maintient que gràce à la fabrication des soieries et au travail des blés dans ses usines et celles de son faubourg de Petegem.

\section{Vieilles villes et villes neuves.}

Mais lorsque la grande industrie est venue s’établir à leurs portes, sur les glacis des anciens remparts, ou au milieu des grands jardins qui couvraient une bonne partie de leur territoire urbain, les vieilles villes flamandes se sont réveillées, rágaillardies, ouvertes à la foule des paysans vaincus par la concurrence des métiers mécaniques. Grammont et Ninove ont doublé; Alost et Courtrai ont triplé ${ }^{1}$. Au centre, ces derniéres villes sont restées propres, correctes et froides, d'une baralité que vient corriger parfois l'aspect heureux d'un hôtel de ville Renaissance, d'un beffroi, d'une tour d'eglise; mais autour de ces quartiers bourgeois, des

1 Population de Grammont en $1801: 5.948$ h.; $1900: 11.855$. Ninove : 3.021 et 7.714 . Alost : 10.927 et 29.203. Courtrai : 11.641 et 33.143 . 
lignes de maisons ouvrières aux murs de briques rouges, de couleur crue, s'étendent aux abords des usines ou s'alignent en faubourgs interminables. Gand est le meilleur exemple de ces anciennes cites auxquelles l'industrie moderne a donné une seconde jeunesse. La ville avait 55.000 habitants en 1801, et les citadins etaient à l'aise dans l'enceinte. Mais lorsque les « mécaniques »e Liévin Bauwens eurent amené des foules, il fallut se serrer, s'entasser. On parqua les nouveaux venus dans des « enclos 》, impasses bordées de maisons, qui dépassaient en horreur les quartiers ouvriers de Lille et de Paris. L'enclos Batavia, long de 100 mètres, contenait 117 habitations des deux côtés d'un passage de $2^{\mathrm{m}}, 70$ de large, et logeait 585 habitants dont chacun disposait d'une superficie de $3^{\mathrm{m} 2}, 24$; sur 1.000 ouvriers interrogés par la Commission d'Enquête, 430 habitaient dans des enclos sermblables, 314 dans des ruelles qui ne valaient guère mieux, sans compter ceux qui vivaient dans les caves ${ }^{1}$. Depuis, Gand s'est étendu en d'immenses faubourgs qui doublent l'ancienne superficie de la cité ; cependant elle avait conservé. jusqu'à la fin du XIX ${ }^{\circ}$ siècle cet aspect de ville étriquée, pousséo trop vite, aux rues étroites, animées, d'où se dressent tout à coup des monumonts «qu'on ne peut apercevoir qu'en renversant la tête ${ }^{2}$. C'ette nuance d'antiquité que les beffrois, clochers, châteaux, vieilles maisons, laissent planer sur la ville, mêlée à l'aspect moderne que présente un grand centre de commerce et d'industrie, fait que Gand symbolise mieux que Bruges, la ville du passé, la vraie Flandre, robuste et vivante, avec ses souvenirs et ses espoirs. L'accroissement continue; au delà du faubourg ouvrier de Muide, on creuse d'immenses bassins qui doivent faire de Gand un véritable port de mer; avec ses grands faubourgs de Mont-St-Amand, Gentbrugge et Ledeberg, qui s'allongent jusqu'à quatre kilomètres Ioin du beffroi, la ville comptait en 1900 198.000 habitants; depuis, elle a largement depassé les 200.000 .

A côté des vieilles villes qu'elle a rajeunies, l'industrie a créé çà et là en Flandre des agglomérations neuves qui ne sont pas moins curieuses à étudier. Ce sont pour la plupart d'anciens villages, que l'industrie à domicile avait élevés, dès le XVIII siècle, au rang de bourgades. St-Nicolas, jusqu'au $\mathrm{XVI}^{\mathrm{e}}$ siècle, paraît purement agricole; on y institue un marché en 1513; la place, qui s'étendait sur 12 hectares avant 1811, avait été d'abord un bois, puis une prairie (Driesch) sur laquelle ọn mettait sécher les lins ${ }^{3}$; la

1 Enquête de 1840, III, pp. 387-389.

2 Tennent, Notes sur la Belgique (Bruxelles, Hauman, 2 vol. in-120), I, pp. 58-60.

3 Van Raemdonck (J.), Topographie de St-Nicolas (Ann. C. A. P. Waes, X, 1885, pp. 23-39). 
paroisse, avec ses 15 hameaux, avait 10.890 habitants en 1801 . Lokeren était alors une grosse commune de 12.000 habitants ; Renaix en comptait 9.500 . EIles ont eu cette bonne fortune de voir s'élever autour d'elles des usines sans que cette arrivée de la grande industrie fit disparaître les métiers à la main; mais les travailleurs à domicile s'embrigadèrent sous l'autorité des chefs d'industrie, et exécutèrent pour eux les travaux que la machine dédaignait ou n'osait pas entreprendre. Ainsi, elles ont gardé en partie l'aspect du passé : elles sont restées à demi-rurales. La plupart sont de grands villages ; jusqu'au centro les maisons basses d'ouvriers agricoles se sont conservées à côté des bâtisses modernes. Lokeren a l'air d'une ville qui ne serait formée que de faubourgs, faubourgs interminables et sales, où s'ouvrent de pauvres ruelles de corons; Zele, Hamme, sont aussi tristes. La banlicue est habite par des paysans qui s'industrialisent: tisserands travaillant chez eux pour les fabriques, ouvriers d'usine qui gardent leur maison à la campagne et leur lopin de terre; ot cette qualité de villes miurbaines mi-rurales est un gros avantage pour l'industrie, à laquelle elle assure une main-d'œuvre patiente et économique, moins chère et plus soumise qu'un prolétariat urbain. De là leur développement: Renaix, Tamise, Hamme, Zele, Eecloo, Lokeren, Iseghem, ont doublé en un siècle; Roulers et St-Nicolas ont triplé. Roulers est devenue une vraie capitale, plus active que Bruges et que Courtrai : à 25 kilomètres à la ronde on ne rencontre que les voitures de ses négociants qui vont fournir les campagnes de denrées coloniales, de riz, de pétrole, de maïs, en refoulant devant eux la concurrence de Courtrai et de Gand; elle demande avec énergie le prolongement du conal de la Mandel jusqu’à Jixmude. En revanche, si les agglomérations augmentent, nulle part on ne rencontre en Flandre plus de pauvreté, car la concurrence des ouvriers à domicile et des ouvriers de fabrique tient à un taux très faible les salaires des uns et des autres; ce sont les villes de la misère, omplies régulièrement quatre fois par jour du passage eles ouvriers hâves, pieds-nus ou chaussés de sabots grossiers.

\section{Le groupe de Lille.}

Cependant nulle part l'industrie n'a autant bouleversẻ le pays flamand que dans la région de Lille, oì elle a dressé l'un à côté de l'autre deux groupes urbains dont chacun dépasse, 250.000 ầmes, sans compter ceux qui comptent quinze, trente, quarante mille habitants, jusqu'à faire de l'arrondissement une fourmilière humaine de 811.000 personnes. C'est de cette région qu'est vrai le mot de Guichardin, que * la Flandre n'est 
qu'une ville »; là les villages sont déjà des bourgs, et les bourgs des villes. Cependant on peut distinguer trois groupes où la population est plus particulierement urbaine: Lille et ses faubourgs, Roubaix-Tourcoing et leur banlieue, enfin la ligne de la Lys.

Lille était déjà, au début du XIX ${ }^{e}$ siécle, la plus grosse ville de Flandre. Pour être moins ancienne que Gand et Bruges, son territoire n'en a pas moins été habité aux époques romaine et franque ${ }^{1}$. La ville qui apparaît au $\mathrm{XI}^{e}$ siècle dans un îlot de la vallée tourbeuse oủ coule la Deûle ćlait dans une heureuse situation commerciale : terminus méridional de la navigation sur la petite rivière, elle était une étape naturelle entre la Flandre et les plateaux de craie, qui poussent une avant-garde jusqu'aux abords de la cité; ainsi elle est un de ces entrepôts, nés au contact de la plaine flamande et du haut-pays crayeux, qui se succèdent depuis l'Aa jusqu'à l'Escaut. Mais celui-ci était un des mieux placés, sur la route de la Flandre vers Paris par Bapaume ${ }^{2}$; Lille se trouvait donc être la porte française du pays flamand. La prospérité vint vite, malgré les défauts de l'emplacement, qui obligeait la ville à s'étendre dans un marais tourbeux, sillonné de bras de rivière, et dont les noms des rues Basse, Marais, des Molfonds, rappellent l'existence. Au moment de l'annexion à la France, Lille était dójà tenue pour la première ville de Flandre, tant par son industrie drapière que par son commerce. Après l'occupation française, Vauban l'agrandit en bâtissant vers le Nord tout un quartier régulier dont la rue Royale forme l'axe. En 1698, l'intendant Dugué de Bagnols lui attribuait 55.000 habitants; mais la crise qui sévit sur les villes flamandes au XVIII ${ }^{\mathrm{e}}$ siècle entrava la croissance de Lille, dont la population n'atteignait encore, en 1804; que 59.000 personnes.

L'essor' commença après 1815 . Lille profita brusquement de l'installation des machines nouvelles dont de hardis industriels étaient allés dérober le secret en Angleterre. Comme à Gand, la population s'entassa entre les remparts ; pourtant Lille était déjà, avec Dunkerque, la ville du département où les habitants se trouvaient le plus les uns sur les autres ${ }^{3}$. Aussi devint-elle la plus malsaine de la région, cello dont le renom d'insalubrité et de tristesse fut le plus répandu ; et cette fâcheuse réputation la suit encore. Le médecin Brault, qui y tenait garnison en 1820, note « l'infection

1 Rigaux (H.), Fouilles dans l'arrondissement de Lille. (Bull. Soc. nat. des Antiquaires de France, 1872, pp. 89-95).

2 Cf. Finot (J.), Le commerce entre la France et la Flandre au moyen-äge. (Ann. Com. fl. Fr. XXI, pp. 1-392).

3 Dieudonné, Statistique, pp. 127-133. 
des tanneries, boucheries, triperies placées au centre de la ville, celle des tonneaux des gadouards, les immondices qui remplissent les canaux $\gg{ }^{1}$. L'entassement et l'insalubrité atteignaient leur maximum à l'Est, dans le quartier St-Sauveur, devenu tristement célébre à ce titre. C'était dẹjà au XVIII siècle un quartier ouvrier, peuplé * d'un monde de petits artisans allachés à leur domicile, peu policés et très rebelles ${ }^{2}$; c'est lui qui supporta vaillamment les coups du bombardement en 1792. Ia population y vivait dans des caves et des courettes, dont l'horreur rappelait celle des enclos de Gand. Villermé y trouvail les habitants plus entassés encore que dans les deux quartiers les plus populeux de Paris, les uns logés dans des caves ne recevant le jour que par un escalier servant de porte et de fenêtre, les autres dans des cités ouvrières (courettes) plus malsaines encore; la seule rue des Etaques avec les courettes qui y aboutissaient abritait, en 1826, 3.000 habitants. La misère, la mortalité, y étaient effroyables, et la classe ouvrière lilloise semble encore sous le coup des tristes conditions dans lesquelles récurent ses ancêtres jusqu'au milieu du $\mathrm{XIX}^{\mathrm{e}}$ siècle $^{3}$.

Cette situation ne pouvait durer ; la ville éclatait dans son enceinte. Le second Empire se décida à l'agrandir en reculant le mur d'enceinte au Sud, jusqu'à englober les communes suburbaines d'Esquermes, Wazemmes et Moulins-Lille; la surface de la ville fut près d'en être triplée. Cependant l'accroissement se pour'suivit si rapide, que l'étendue annex éo s'est presque tout entière couverte de maisons, et qu'il ne reste plus guère de vide que le coinS.-W., où pénètre dansun décor agreste d'ormes et desaules un tortueux bras de la Deûle. Mais les nouveaux quartiers ne ressemblent pas aux anciens. Il y a dans Lille, depuis l'annexion de la banlieue Sud, trois villes qui se touchent et ne se confondent pas. Le vieux Lille, au Nord-Est, a gardé en grande partie son caractẻre de cité compacte, aux rues étroites *

1 Brault (J. A.), Essai sur la topographie physique et médicale de la ville de Lillo (Rocueil de Mémoires de Médecino, Chirurgie ot Pharmacie militaires, t. VII, 1820, pp. 1-113), p. 106.

2 Flammermont (J.), Ilistoire de l'industrie à Lille (Lille, 1897), p. 94.

3 Voir à ce sujet: Dupont (J.-B.), Topographie historique, statistique et médicale de l'arrondissement de Lille (t'aris, Delarue, 1833, in-12, 367 p.), pp. 112-116; - Villermé, Tableau de l'état physique et moral des ouvriers employés dans les manufactures de coton, de laine et de soie (Paris, Renouard, 1840, 2 vol. in-8 ${ }^{\circ}$ ) I, pp. 80-90 ; - Cazeneuve $\left(\mathrm{U}^{\mathrm{r}}\right)$, Rapport sur les opérations du conseil de rẻvision dans le département du Nord pendant l'annéc 1841 (Lille, Danel, 1842, in-8 ${ }^{\circ}$; - Gosselet (Dr), De la création d'un hôpital pour les enfants dans la ville de Lille (Bulletin médical du Nord, 1847, $\mathrm{n}^{\circ} 5$, p. $129, \mathrm{n}^{\circ} 6$, p. 161); - et les vers de Victor Hugo dans les Châtiments, III, IX, II. 
bordees de hautes maisons blanchies à la chaux, dont les fenêtres sont souvent ornées de festons et de guirlandes de pierre que le citoyen Barbault-Royer jugeait d'une architecture pesante et surchargée $\gg^{1}$; c'est la ville du grand et du petit commerce. En bordure du vieux Iille, sur l'emplacement des remparts disparus et de leurs glacis, s'est bấtie une ville neuve, grands hôtels des riches commerçants et industriels, maisons bourgeoises, édifices publies; c'est le type de toutes les grandes villes modernes. Enfin tout le Sud s'est formé de la réunion des anciens faubourgs, rues ouvrières aux petites maisons de brique rouge, grandes usines, corons, ruelles; c'est là que grouille la population flamande émigrée à Lille; c'est la partie industrielle et pauvre.

En dépit de cet agrandissement qui lui a permis de respirer, Lille est restéo une cité où la salubrité n'est pas encore aussi complète qu'on pourrait le désirer. Ia mortalité infantile y est considérable; un quart des petits enfants y meurent avant un an: la proportion est de $21,24 \%$, contre $20,48 \%$ à Roubaix, 13,24 á Bordeaux et 13,19 à St-Etienne ${ }^{2}$. Aussi, pour trouver au dehors l'air pur qui fait défaut dans la grande ville souillée par les fumées industrielles, comme pour échapper à la cherté de la vie, les habilants vont s'étalolir en grand nombre dans les faubourgs. Lille présente un curicux exemple de ce « retour aux champs », si prononcé déjà dans beaucoup de grandes villes de Belgique ot d'Anglrterre ; grâce à la facilité qu'offrent les voies de communication, les Lillois vont habiter les communes suburbaines. Aussi la population de Lille a-t-elle légèrement diminué de 1895 à 1901, tandis que celle des faubourgs a fortement progressé. Il est donc juste d'ajouter leur chiftre d'habitants à celui de la ville pour se rendre compte du nombre d'individus que groupe l'organisme lillois : 290.000 âmes en 1901, dont 210.000 pour la ville, presque la population d'un département moyen du centre de la France ${ }^{3}$.

Le même développement industriel, qui faisait passer la population de Lille et faubourgs de 75.000 a 290.000 âmes au cours du siècle, quintuplait celle des villes de la Lys. Armentières était une petite ville d'étape sur la rivière; avant la création de la route de Dunkerque á Lille par Cassel (XVIII siècle), elle avait moins d'importance que Comines ou Warneton, par où passait la vieille route Lille-Ypres-Poperinghe-Bergues. Devenue grand centre industriel, elle a submergé le petit noyau urbain qui se serre

1 Barbault-Royer, Voyage, pp. 60 ot 62.

Oui (Dr), La mortalité, p. 5.

3 Hellemmes, Mons-en-Baroul, La Madeleine, Marquette, St-André, Lambersart, Lomme, Haubourdin, Loos, Faches, Ronchin, Lezennes. 
autour de la grand' place dans un enchevêtrement do rues banales et droites; les 7.485 habitants qui formaient en 1804 la population de la ville et de sa grande banlieue rurale sont derenus $29.40 \mathrm{l}$ en $190 \mathrm{l}$, et même $52.000 \mathrm{si}$ l'on y ajoute les faubourgs d'Houplines, Nieppe, La Chapelle, en partie découpés dans l'ancienne commune d'Armentières, et l'agglomération belge de Ploegsteert, massée derrière la frontière. En effet chacune de ces villes de la Lys est double: la population ouvrière se tenant de préférence sur la rive gauche, - helge -, les usines et les commerçanls sur la rive droite, -française - Warneton se double de deux communes françaises. Comines ajoute aux 8.129 habitants de la rive française les 5.927 de CominesBelgique, soit 14.000 âmes; Wervicq et Wervicq-Sud forment une agglomération de 11.000 personnes; enfin Halluin et Menin ne sont qu'un seul groupe de 35.000 habitants. Halluin rappelle Zele, Lokeren, Hamme, Ies tristes villes ouvrières de la Flandre Orientale; la mortalité infantile y atteignait naguère l'effroyable chiffre de $50 \%$, tombé en un an (1904) à $39 \%$ grâce à l'installation d'une Goutte de lait. En revanche, la natalité y est plus forte que partout en France; la misère de l'ouvrier halluinois le détourne do la prévoyance. Tandis que la natalité ne s'élève, à Cambrai, qu'à 18,4́ pour 1.000 habitants, qu'elle atteint 27,96 à Roubaix, 28,74 à Tourcoing, 28,84 à Iille, elle est de 41,74 a Halluin, St-Pol-surmer ne venant qu'en seconde ligne avec 40,35 ${ }^{1}$.

Derrière la ligne de la Lys, la mer de maisons roule à travers les campagnes pittoresques ; les villages s'entourent de corons, « les courrées», qui gagnent de proche en proche. A partir de Bondues, la route de Paris à Menin n'est qu'une r'ue où les vieilles censes, les auberges massives du $\mathrm{XVIII}{ }^{e}$ siècle voisinent avec les petites maisons ouvrières de brique rouge. A Linselles, on distingue jusqu'au centre du bourg d'anciennes fermes transformées peu à peu en habitations, en magasins, en dépendances d'usines. A Roncq, l'agglomération est formée de corons qui escaladent de tous côtés la colline. Enfin à l'Est la campagne disparait derrière la couleur rousse des toits et des murailles; c'est le groupe de RoubaixTourcoing ${ }^{2}$.

On juge souvent le développement des deux villes au XIX ${ }^{e}$ siècle comme un prodige industriel comparable à la croissance des grandes cités américaines. Cependant il faut en rabattre ; l'essor de Roubaix est même infórieur à celui de la plupart des grandes villes industriclles allemandes,

1 Chiffres se rapportant à la période 1898-1902.

2 Voir Gayet, La Maison des environs de Tourcoing, dans l'enquête de de Foville, I, p. 20 . 
Barmen, Elberfeld, Essen passé de 6.000 à 119.000 habitants en un demisiècle, ou Lodz qui, hameau de 200 personnes en 1820 , avait 350.000 habitants en 1900. Roubaix ni Tourcoing ne sont brusquement sorties de terre au XIX ${ }^{\circ}$ siècle. Dess 1697, on déclarait que Roubaix n'était pas un village, et que ce serait leur faire injure que d'appeler ses habitants des villageois ; que c'était un lieu fort considérable, peuplé d'un grand nombre d'habitants ${ }^{1}$ : probablement 12.000 en 1786 . Tourcoing était plus considérable encore, et sa population atteignait 15.000 âmes en $1750^{*}$. Il est vrai que la crise révolntionnaire et la disparition de la frontière firent diminuer ces chiffres, et que le recensement de 1804 trouva seulement 8.703 habitants à Roubaix, et 11.889 a Tourcoing; les deux villes n'en possédaient pas moins 20.600 habitants à l'aurore du $\mathrm{XIX}^{\circ}$ siècle. C'ètait là une entrée de jeu déjà respectable.

Le développement n'en a pas moins été fort remarquable. Les 20.600 habilants sont devenus 203.000 en 1901 ; la population a décuplé. Tout cela est l'ouvre de l'industrie; seule la contrebande, á côté du travail de la laine et du coton, contribue à faire vivre quelques milliers d'individus. Aussi l'aspect est-il celui d'une ville ouvrière banale, sauf les quelques quartiers cossus où sont établis les hotels des fabricants. Les deux villes d'ailleur's ne sont pas toute l'agglomération. Sur ce sol où l'expansion n’était pas gênée par des servitudes militaires, les faubourgs se sont allongés, englobant peu à peu les communes voisines. Croix, Wattrelos, I annoy, tiennent à Roubaix ; Neuville, Mouveaux, Mouscron, à Tourcoing. En ajoutant à la population de ces deux villes celle de leur banlieue immediate, française et belgo ${ }^{3}$, on trouve que 293.000 personnes vivent sur ce coin de terre, dans les maisonnettes de briques qui dévalent des coteaux ou s'entassent dans les vallons. Iéjá l'avant-garde du groupe. roubaisien ver's le Sud n'est qu'à trois kilomètres des faubourgs de Lille, et une grande voie monumentale doit être bientôt jetèe d'une agglomération à l'autre, consacrant la jonction de ces deux puissants foyers industriels en une immense ville de 560.000 habitants.

Pourtant, en dépit de cette proximité, chacune de ces villes garde jalousement son autonomie, son originalité. Ces cités neuves ont chacume leur caractère, tant est forte la personnalité de cette race d'industriels qui a

1 Leuridan, Roubaix, V, p. $(j 5$.

2 Roussel-Defontaine (C.), Histoire de Tourcoing (Lille, Vanackère, 1855, in-8", 452 p.), p. 66.

3 Wattrelos, Lannoy, Lys-lès-Lannoy, Croix, Wasquehal, Mouveaux, Neuville, Mouscron, Herseaux, Roubaix a 124.000 habitants en 1901, Tourcoing 79.000 . 
fondé la prospérité actuelle. Il existe un esprit roubaisien, et un esprit Lourquennois, aussi éloignés l'un de l'autre que possible. Roubaix est hardi, entreprenant; lo Roubaisien se dit volontiers Américain; comme l'Anglo-saxon, il se livre avec autant d'ardeur aux récréations qu'aux

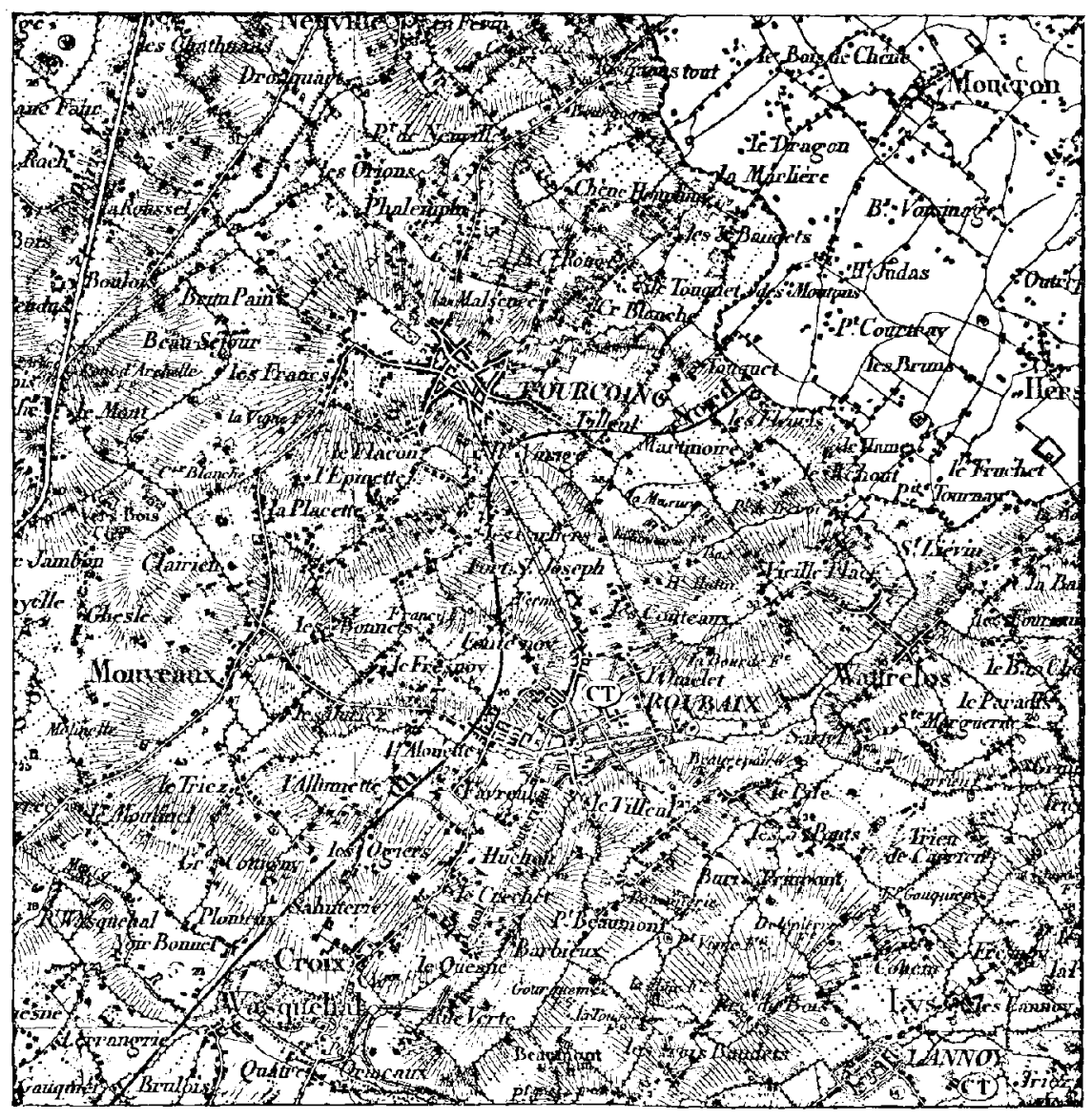

$\left(1^{\text {re }}\right.$ édition de la carte topographique à $\left.1: 80.000\right)$.

Fig. 6it. - Roubaix-Tourcoing vers 1840.

affaires, et cultive les sports plus qu'on ne fait dans n'importe quelle ville française. Le Tourquennois, habitant d'une ville qui tient à Roubaix par des lignes ininterrompues de constructions, est aussi réfléchi, aussi ponctuel que son voisin est vif et primesautier. Ainsi une vic municipale intense existe jusque dans ces agglomérations neuves. C'est là d'ailleurs un des traits les plus caractéristiques de la vie urbaine en Flandre, que cette persistance de 
l'esprit local. Ia prospérité des villes au moyen-âge, en obligeant les comtes à accorder des libertés aux citoyens, a habitué ceux-ci depuis six siècles à prendre conscience des intérêts et de la vie de leur cité; de là cette persistance de sentiments locaux, et cet ardent patriotisme municipal,

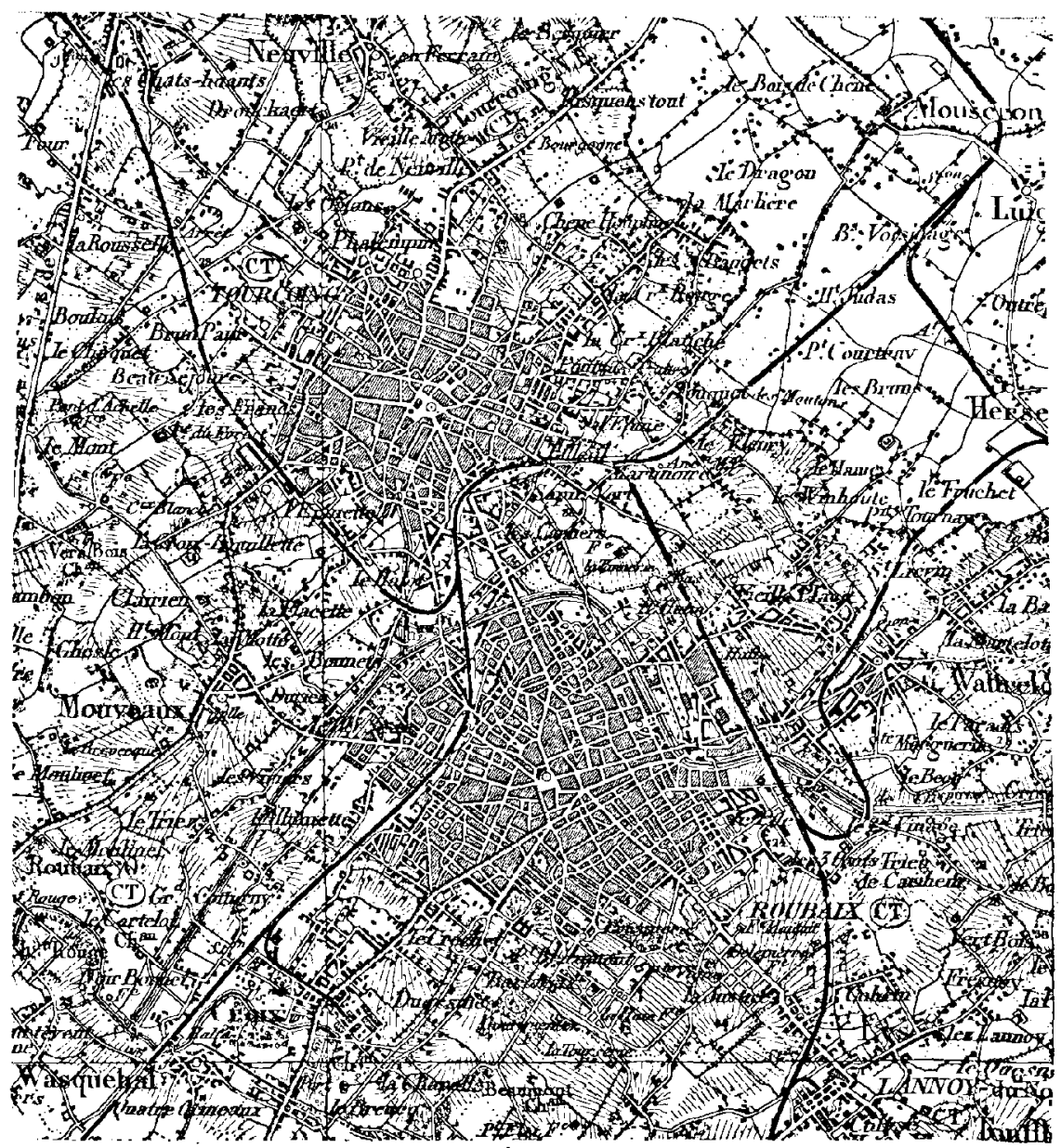

〈Édition de 1898 de la earte topographique a $1: 80.000 \%$.

FIG. 68. - Roubaix-Tourcoing vers 1900.

qui s'affirment encore par des fêtes vivaces, des plaisanteries traditionnelles, une rivalité devenue courtoise mais restée ardente avec les villes voisines. 


\section{CHAPITRE XVI.}

\section{LES VOIES DE COMMUNICATION. - LE COMMERCE}

I. Communications par terre: les routes. Voies romaines. Mauvais état des chemins dans l'Ouest. - II. La voie d'eau. Le rèseau navigable avant le X VIo siècle. Transformations des XVI et XVII siècles. Litablissement du réseau français. Les voies navigables au XIX $\mathrm{XI}^{8}$ siècle. - III. Les voies ferrées. - IV. Le Commerce. Trafic intérieur. Trafic extérieur : échanges avec l'Artois et l'Angleterre. Mouvement commercial des ports. Le transit.

Pour distinctes que soient les deux régions flamandes, l'unité de la Flindre nes'en est pas trouvée compromise; jamais une domination politique nes'est ètablic dans l'une sans être maitresse de l'autre, etsi les hommes de la Plaine ont deux fois assuré le pouvoir du comte de leur choix sur le IIoulland, ça été sans grandes difficultés ${ }^{1}$. Le climat a beau présenter dans chacune des deux parlies des différences appréciables, le sol, les productions agricoles, l'activité économique, le caractère même et l'aspect extérieur des hommes changer de chaque côtó de la ligne de démarcation: la facilité des communications a lié de tous temps à l'Intérieur la Plaine, bande de terre d'aillewrs trop étroite et trop allongée pour pouvoir se ramasser en une province compacte et vivante, comme l'a fait la Hollande.

I.

COMMUNIGATIONS PAR TERRE : IAFS ROUTES.

Le sol de la Flandre semble se prêter admirablement à l"établissement des routes. Pas d'accidents de terrain: les « monts » ne sont pas des obstacles. Pas de grands fleuves à traverser: la Lys, l'Escaut, étaient partout guéables. Pourtant la nature du terrain constituait un gros obstacle. A l'Est le sable, un sol fuyant et meuble, dans lequel les roues des chariots enfoncent de vastes ornières. $\Lambda$ l'Ouest, l'argile, bien plus

1 Sous Robert le Frison et Thierry d'Alsace. 
funeste encore, avec sa boue tenace qui enlise bêtes et gens; au Nord, une terre gluante coupée de canaux. L'humidité du climat dégrade les chemins que les lourds charrois mettent à une rude épreuve.

\section{Voies romaines.}

Cependant l'administration romaine, dont la construction des routes constituait une des grandes préoccupations, s'était mise hardiment à l'œuvre. Même, c'est dans l'Ouest, où les difficullés étaient pourtant plus grandes, que s'est porté son principal effort. De la forteresse érigée sur le mont Cassel, sept grandes routes s'elloignaient vers tous les points de l'horizon: les unes reliant la place forte aux villes romaines de l'Ouest et du Sud, Arras, Térouanne, Boulogne, les autres s'enfonçant vers l'inconnu du Nord et de l'Est: deux viennent s'arrêter, à Steene et Hoymille, à la limite de la Plaine maritime, oì l'invasion marine a fait disparâ̂tre leur prolongement avec les lointaines bourgades vers lesquelles elles se dirigeaient; une autre, par Poperinghe, pénètre dans les fourrés de l'Est. Du haut de la colline, on les voit toujours s'éloigner inflexiblement droites, escaladant les pentes, disparaissant dans los creux; tout le long de leur parcours, elles servent de limite anx communes, ce qui est une preuve de leur haute antiquité. Les sondages pratiqués çà et lá ont montré qu'elles étaient faites de grès de Cassel (grès diestiens) surmontés d'une couche de gravier pris dans les exploitations les plus proches; de lả les noms de Steenstraete (route empierrée) ou Rue des Pierres que leur ont gardés les habitants ${ }^{1}$.

La présence de voies romaines devient beaucoup moins sûre vers l'Est ${ }^{2}$. La route Cassel-Poperinghe se suit sans grande hésitation par Elverdinghe, Merckem, Zarren, jusqu’à Wynendaele: mais là s’arrête son tracé. Sur les cartes, on en a indiqué bien d'autres : de Courtrai à Oudenbourg, de Thielt

1 Yoir Pigault de Beaupré, Reconnaissance des voies locales existantes au Va siècle (Mém. Soc. Dunk., VI, 1858-59, pp. 75-91); - Rigaux (H.), Topographie, pp. 198-202.

2 Sur les voies romaines de la Flandre belge: Van der Rit, Etude théorique et pratique sur les anciennes chaussées romaines traversant le royaume de Belgique (Journal de l'Architecture, $4^{6}$ année, Bruxelles, 1851, pp. 60-97, 1 carte); - Van Dessel (C.), Topographie des voies romaines de la Belgique (Bruxelles, 1877, $4^{\mathrm{e}}$ volume de Schaeyes); - Verschelde, Notice sur la route romaine do Gassel à Poperinghe et Winendale (Ann. Soc. Em. Br., $4^{\text {s }}$ série, I, 1876-77, pp. 245-249); - Gauchez (V.), Topographie des voies romaines de la Belgique (Amn. Ac. Arch. Belg., XXXVIII, 1882, 432 pp., 3 cartes); - Van den Bussche (E.), Les chaussées romaines en WestFlandre (la Fl., XV, 1884, pp. 51-70, carte). 
à Bruges, de Furnes à Gand, de Cassel à Anvers, de Bavai à Bouchaute, de Bavai à Wenduyne, de Boulogne à Utrecht, sans compter des tracés plus extraordinaires encore. Ces hypothèses reposent sur de faibles indices: découverte de monnaies, persistance en un point du nom Steenstraete, existence de vieux chemins encore appelés Heirweg (chemin militaire) ou Heidenweg (chemin des païens). Il y eut bien là des routes antérieures au XI' siècle, et par où se faisait le trafic: plusieurs d'entre clles s'ètoilent au Sud de Bruges, le Dixmuidschen heirweg, par Aertrycke, rectiligne par les bois et les clairières; l'Aerdenburgschen heirweg, le Gendschenheirweg, le Curtrycwech; une autre, le Looweg, longe de Drincham a Loo le hord de la plaine maritime. Peu importe qu'elles soient d'origine franque, romaine, ou antér-romaine : au moins ces pistes de sable déroulant leur's ornières à travers la Flandre orientale continuèrentelles jusqu'à notre époque à assurer le trafic, tandis que les belles et authentiques voies romaines de l'Ouest ne suffisaient plus, faute d'entretien, à faire communiquer entro elles les régions de la West-Flandre.

Mauvais état des chemins dans l'Ouest.

La West-Flandre souffrit jusqu'au XIX' siècle de ce mauvais état des voies de communication. Avec ses fossés, ses haibs, ses arbres, ses chemins défectueux, c'était le pays impraticable. Philippe-Auguste en sut quelque chose, lorsqu'il mena son armée s'engluer autour de Steenvoorde, malgré les conseils de ses familiers qui lui avaient représenté les difficultés que causeraient à son armée « l'abondance des fossés et l'étroitesse des chemins $\gg^{1}$. Il en était encore de même au XVII siècle; en 163̌ Bailleul ne pouvait guère se procurer le nécessaire pendant l'hivor que grâce á la navigation sur la becque, les chemins étant trop mauvais 2. L'intendant Barentin constate en 1699 que la riche châtellenie de Cassel, faute de chemins praticables, ne peut débiter les denrées qu'elle produit, ni assister les châtellenies voisines en cas de disette ${ }^{3}$. Un projet de défense du pays après 1715 déclare qu'entre Armentiéres et Cassel, les grands chemins sont impraticables quasi toute l'annẻe, parce qu'ils sont trop bas et bordés d'une si grande quantité d'arbres que le soleil n'y peut être jamais et ne

1 Radulf de Coggeshale, M. G. SS. XXVII, p. 352.

2 De Coussemaker (I.), Documents inédits, I, p. 424.

3 Mémoire concernant la Flandre française occidentale, ou Flandro du côté de la mer, par M. Barentin (Bibl. comm. de Lille, mas. $n^{\circ} 577$ ). 
peut les sécher ". Au début du XVIII ${ }^{\theta}$ siécle, tout le commerce de Lille avec Dunkerque se faisait soit par la chaussée d'Y Yres, soil par la Deûle et la Lys jusqu'à Aire, d'Aire à St-Omer par terre, et de St-Omer à I unkerque par eau ; de lá l'opposition violente que l'Artois, qui profitait de.ce transit, fait en 1732 au projet de chaussée de Bergues à Armentières et Lille ${ }^{2}$. Le préfet Dieudonné constatait encore avec tristesse, en 1804, le mauvais état des routes, «qui ont, dans la nature du sol, une cause perpétuelle de dégradation, le terrain bas, humide, et souvent tourbeux, n'ayant aucune solidité ${ }^{3}$.

L'état des routes était pis encoro dans la plaine de la Lys. Ia nature du sol, plus gras et plus hurnide qu'autour de Cassel et d'Ypres, les rendait impraticables en toute saison. En 1761, la ville de St-Venant se plaint d'être « inaccessible par le mauvais état des chemins » ${ }^{4}$; en 1766 les échevins expliquent que par temps humide c'est la boue qui empêche d'approcher de la ville, et par temps sec les ornières qui sont si effioyables, « qu'il est impossible d'y aborder soit à cheval soit en voiture sans s'exposer à tout briser ${ }^{5}$. Pendant plusieurs années, la vieille voio romaine Cassel-Arras est impraticable entre Estaires et La Bassée à un endroit. appelé le Trou Gallot, « où s'est creusé un abîme qui devra coûter la vie à tous ceux qui y passeront ${ }^{6}$. Le seul moyen pour les piétons de circuler en hiver dans le pays (car pour les voitures il n'y fallait guère compter), c'était de sauter de pas en pas sur les blocs de grès de Béthune que la prévoyance de l'autorité avait fait placer sur un côté de chaque chemin, et qu'on appelait «pierres de Marche-pied » ou " pierres de pas »; chaussés de souliers fortement ferrés pour ne pas glisser sur les grès et disparaître dans le bourbier jusqu'à la ceinture, armés de longues perches pour sauter d'un bloc à l'autre, les gens du pays étaient habitués à cette manière de voyager, et les accidents étaient rares ${ }^{7}$. Tout au centre de la plaine, le petit pays de l'Alleu restait, une grande partie de l'année, isolé du reste du

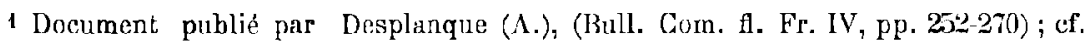
p. 265.

2 Arch. Pas-de-Calais. Fonds Etats d'Artois, no 12:3.

3 Dieudonné, Statistique, III, p. 2.

- Requête des échevins aux Etats d'Artois ; Arch. Pas-de-Galáis, C.. 583, pièce 46.

5 Ibid., pièce 50 .

6 Ibid., pièces 95 et 97 .

7 Sur l'existence des pierres de Marche-pied, voir: Arch. Nord, C. (Fl. Mar.), 54;Dieudonné, Statistique, I, p. 231 ; - Feville hebdomadaire de l'arrondissement de StOmer, $\mathrm{I}^{\circ} \mathrm{du} 20$ juin $180 \%$. 
monde, sauf par les cours d'eau; et ses habitants réclament dans les cahiers de 1789 « que comme le pays n'a point de sortis, il soit accordé un pavé »1. Cette difficulté de pénétrer dans le pays créait dạns ces qualre paroisses de l'Alleu un état d'esprit particulierr; l'autorité comtale ou royale ne s'y faisant que difficilement sentir, les habitants avaient contracté de singuliêres habitudes d'indépendance et de violence, qui mppollent celles des gens de Furnes au XII ${ }^{\circ}$ siècle; la guerre privée des d'Englos et des Neuve-Eglise y ensanglante 25 années du XIV' siècle; en 1388 coux de l'Allen viennent provoquer les « Flamands » à Ia Gorgue ; en quelques années on compte trente homicides à Laventie. Au XVI siècle ce sont les protestants qui s'y établissent et résistent longtemps à l'Espagne; au XVIII siècle, des contrebandiers y ont leur quartier général. Sous l'Émpire, les réfractaires s'y protègent dans le dédale des fossés, des haies, des arbres, des marais, ayant à leur tête l'aventurier Fruchard, surnommé Louis XVIII ; de là ils narguent en 1812 la division Boyer de Ribeval qui n'ose pas quitter Béthune tant que dure l'automne, mais qui, la gelée arrivèe, pénètre dans l'Alleu, pousse les réfractaires vers le pont d'Estaires, et les y enveloppe pour les incorporer à Béthune d'où ils s'échappèrent au premier dégel ${ }^{2}$.

Bien entendu, la situation était la même dans la Plaine maritime. On n'y trouve pour ainsi dire pas de routes jusqu'à l'èpoque moderne; toutes les communications se font par voie d'eau. C'est en 1502 seulement qu'on parle de construire une chaussẻe de Bruges à Nieuport ${ }^{3}$; et en 1787 le Calaisis et l'Ardrésis n'avaient cncore que trois grandes routes et trois chemins ${ }^{4}$. On s'explique la popularité du Pont-Sans-Pareil(Pont-d'Ardres), qui permet de franchir d'un seul coup quatre larges cours d'eau, réunit quatre routes, huit chemins de halage, soit en tout douze voies de communication; dans un pays si impraticable, c'était un résultat merveilleux. Il est vrai que jusqu'aux travaux effectués après la loi sur les chemins vicinaux, la plupart des voies étaient encore impraticables par les hiver's pluvieux sans des pierres ou des planches disposées sur le côté; et en 1828 lo maire de Guemps se plaint qu'une personne ayant négligé de mettre des

1 Loriquet, Cahiers, p. 387, article 17 du cahier de Lalleu.

2 Desplanque (A.), Batailles et guerres privées dans le pays de Lalleu au XIVe siècle, 1382-1395 (Bull. Com. fl. Fr. IV, pp. 209-230); - Dictionnaire historique et archéologique du Pas-de-Calais, arrondissement de Béthume, I, pp. 258-262; II, pp. 228-29, $247-258$.

3 Feys, Oudenbourg, I, p. 255.

- Arch. Pas-de-Calais, C. 92, piece 3. 
planches le long du chemin, a compromis la vie des étrangers, empêché le curé d'aller célébrer le service dịin, le médecin d'aller secourir les malades ${ }^{1}$. Encore aujourd'hui, certaines fermes de la Flandre zélandaise restent comme isolees tout l'hiver.

Ainsi la Flandre, celle de l'Ouest surtout, a souffert.jusqu'au XIXe siècle du manque de routes. Le fermier restait cloîtré une partie de l'année dans son hofstede, son horizon restant borné au petit coin de terres qui entouraient son habitation; peut-être cette difficulté de communications a-t-elle eu quelque influence sur le caractère un peu fermé du paysan flamand. Car les routes praticables en toute saison ne datent que du $\mathrm{XIX}^{e}$ siècle. Le XVIII ${ }^{\theta}$ vit oúvrir quelques grandes chaussées, utilisables pour le trafic général : la route de Lille à Dunkerque par Warneton et Ypres est achevée en 1700, celle d'Armentières à Dunkerque en 1759; on commençait en 1773 celles de St-Oner et d'Aire à Cassel; celle de Dunkerque à Calais n'était ouverte en 1789 que jusqu'à Loon. Mais les chemins ruraux, qui font sortir de l'isolement les villages et les fermes, sont du XIX ${ }^{e}$ siècle; les Wateringues, dans le bas-pays, contribuérent largement à leur extension. D'ailleurs la plupart de ces routes et chemins sont pavés, tant l'établissement de voies macadamisées est jugé coûteux sur ce sol mou, détrempé par l'humidité incessante.

II.

LA VOIE D'EAU.

Heureusement la Flandre disposait d'un autre moyen de communications, qui venait, dans une large mesure, atténuer l'inconvénient du mauvais état de ses routes. L'humidité de l'atmosphère et du sol, funeste aux chemins, permettait en revanche d'utiliser largement le système des voies d'eau. La navigation fut jusqu'au XIX ${ }^{\circ}$ siècle le mode de communication le plus apprécié, et il est peu de pays où elle ait conservé autant d'importance.

C'est par la commodité des rivières, disait en 1632 Philippe IV dans ses instructions au Cardinal-Infant, que le commerce fut autrefois introduit en Flandre 2. C'est en effet par les rivières, Lys, Escaut, Dendre, Deûle, Aa, fleuves lents et commodes, que pénétrèrent en Flandre les marchands;

1 Registre des délibérations de la commune, 6 janvier 1828.

2 Briayoinne, Etat de la population, p. 30. 
c'est sur leurs bords que s'établirent les grandes villes. Mais le réseau serré des petits affluents, becques qui coulent à la Lys, fossés du pays de l'Alleu, watergands de la plaine maritime, ne laissait pas de porter bateau, et de venir déposer jusqu'à la « place » des villages les denrées agricoles, les matériaux de construction et de chauffage. C'est par bateau que les gens du Franc amènent les grains au marché des bonnes villes, puisque * le pays est de telle nature qu'en temps d'hiver on n'en peut sortir à cheval ni à chariot $\gg 1$, et qu'on transporte la tourbe exploitée dans la plaine maritime 2. Aussi les échevins de Calais en 1777 déclarent-ils inutile la construction de la route de Dunkerque, « puisque le transport des marchandises pour Dunkerque ne se fait jamais par charrois, mais par bateaux, les canaux étant à proximité et moins frayeux »; à peine servira-t-elle pendant les quelques jours oủ les cours d'eau sont gelés ${ }^{3}$. C'est en grande partie pour être à portée des matérianx de construction qui lour arrivent par les wà tergands que les villages s'établissent nombreux à la lisière du Houtland et de la Plaine; et c'est pourquoi un certain nombre de vieilles églises de cette lisière, à Steene, Bulscamp, Noordschoote, sont bâties pour moitié en grès de Cassel. Dans l'intérieur, d'insignifiantes becques sont utilisées de la même façon; il oxiste à Steenwerck au XVII" siècle un « martschep » ou bateau du marché, qui va porter les denrées par le ruisseau, une fois par semaine, à Armentières *. Malgré l'établissement des routes, le trafic existe encore; il y a 25 ans, on chargeait des bateaux de grain à Steenwerck; il y a peu de temps qu'on n'utilise plus, à Vieux-Berquin, la Platebecque pour les transports, et il y a encore une petite navigation sur le Kemmelbeek. Par les watergands, les bateaux de briques, de fumier, de denrées agricoles continuent à se glisser dans tous les coins de la plaine maritime, et il y a des petites régions, les marais de Guînes et ceux de St-Omer, ou les barques sont utilisces seules pour le transport: barqueltes effilées aux extrémités, qui se faufilent dans le dédale du marais.

\section{Le réseau navigable avant le XVI' siècle.}

A mesure que s'augmentait le mouvement commercial, la nécessité d'user des voies d'eau devint si grande qu'on dut songer à les améliorer.

1 Charte de 1515, Delepierre, Précis, $1^{\text {ro }}$ séric, III, p. 223.

2 Van de Putte, Dunes, p. 633.

3 Arch. Pas-de-Calais, C. 151, pièce 168.

4 Arch. Nord, C. (Fl. Mar.) 54. 
La pente naturelle était peu considérable; cependant pour la rendre moins sensible encore, on barra les rivières; et comme l'écluse á sas n'existait pas encore, on s'avisa de faire passer les bateaux d'un bief à l'autre au moyen d'un overdrach, plan incliné sur lequel on faisait glisser les embarcations au moyen d'un treuil actionné par des hommes ou des animaux ${ }^{1}$. Il en existait dès le XIII ${ }^{\mathrm{B}}$ siècle à Watten, à Bergues, à Lynck " ; un autre est mentionné en 1351 à Slype sur l'Yperleet, un à Snaeskerke en $1633^{3}$; celui de Fintelle, sur le canal de Loo, n'est disparu qu'en 1828. Non seulement on r'end navigables, au XIII siècle, la Dendre jusqu'à Grammont, la Haute-Deûle de Lille à La Bassée, mais on creuse des canaux. La plupart ne sont que des tronçons de rivière que l'on rectifie et approfondil: la Lieve, qui joint l'Escaut au $Z$ win, ouverte par les Gantois de 1228 à 12\%1, est dans ce cas ; le canal de Poperinghe, dont le creusement est autorise par une charte de 1187, ulilise avec l'aide de plusieurs overdrachs le cours du ruisseau qui coule de Poperinghe à Elsendamme ${ }^{4}$. Le canal d'Ostende à Oudenbourg remonte à 1284 ; la Colme est recreusée en 1293 ; le canal de Loo existe au XIII ${ }^{\natural}$ siècle ${ }^{5}$. Enfin l'Yperleet est canalisé dès le XII siècle entre l'Yser et Bruges. Aboutissant d'un côté au Zwin, se prolongeant de l'autre par la Venepe et la Colme jusqu'à l'Aa, et par la « rivière de Calais » jusqu'à Ardres, Guînes et Calais, au Sud permettant d'atteindre Ypres, à quelques lieues de la Lys, c'était la plus magnifique voie d'eau de toute la Flandre, «profitant non seulement à ceux d'Ypres, mais à ceux de St-Omer et de tout le Westquartier, qui viennent importer leurs marchandises en toute saison au lieu de les amener comme autrefois par mer, avec grand danger el grosse avènture, et à plus grands frais ${ }^{\mathbf{6}}$. C'est par là qu'arrivaient les laines anglaises, lorsque l'étape eut été translërée à Calais; et la charte de 1432 énumère parmi les denrées transportées les blés et graines, laines, chaux, vin, fruits, fers, etc. ${ }^{1}$. Aussi veillait-on avec grand soin à son entretien :

1 Deschamps de Pas (L.), Ge que c'était qu'un overdrach (Añn. Com. fl. Fr. VI, 1861-62; pp. 210-222).

2 Lynck, 1234 ; Bergues, 1244 ; Watten, 1254 (Van de Putte, Dunes, pp. 192, 199, 380).

3 Limburg-Stirum, Cartulaire, II, p. 16; - Van den Bussche, Inventaire, I, p. 289.

- D'Hoop, Recueil des chartes di prieuré de St-Bertin à Poperinghe (Bruges, Soc. d'Em., 1870), p. 25.

5 Sur ces canaux, voir: Van Ortroy (F.), Carte de Flandre de 1538 par Pierre Van der Beke (Gand, Van Doosselaere, 1897, in-8, 145 p.), pp. 114, 120, 126-128.

6 Charte de 1417, dans Gilliodts, Coutumes du Franc, II, p. 209.

7 Diegerick, Arch. d'Ypres, III, p. 161. 
des envoyés d'Ypres visitaient fréquemment le eours, examinaient la profondeur du lit, l'état des ponts, des écluses, dès overdrachs ${ }^{1}$; en 1311 les Yprois ouvrent un canal latéral à la rivière entre leur ville et l'Yser; en 1416 ils etablissent à Nieuwendamme un nouveau canal et un overdrach pour éviter aux bateaux allant d'Ypres ou de St-Omer à Bruges de passer par Nieuport; en 1423 ils approfondissent l'Yperleet tout entier pour le rendre navigable à des bateaux d'un fort tonnage 2. L'Aa, de St-Omer a Gravelines, n'était pas moins utilisé ; enfin on a vu la fortune du Zwin.

\section{Transformations des $\mathrm{XVI}^{*}$ et $\mathrm{XVII}{ }^{*}$ siecles.}

Ce réseau navigable se modifia au $X V I^{\mathrm{e}}$ siècle. La disparition du $\mathrm{Zwin}$ en fut la première cause : elle ruina la prospéritẻ de l'Yperleet, qui devenait un cul-de-sac; d'autre part Ypres déchue n'avait plus la force ni les moyens d'entretenir la rivière dont elle avait jalousement assumé la garde. La Lieve s'envase à son tour ; en 1513 dejà, elle ne sert plus guère qu'aux transport des tourbes ${ }^{3}$. Pour se rouvrir vers la mer une issue directe, Gand fait recreuser à partir de 1551 un vieux canal mentionné en 1323 entre l'Escaut et Selzaete ${ }^{4}$, et qui dès 1552 atteint le Braakman au Sas. En même temps Philippe II octroie (1556) la concession d'un canal entre Stekene, Hulst et l'Escaut ${ }^{5}$. Bruges, de son côté, creusait son « Nieuwe Gedelf » jusqu'à Sluis. Mais la grande guerre survient. En 1572, les écluses du Sas sont détruites; Sluis et Hulst deviennent hollandais. Le traité de Westphalie empêche toute navigation de la Flandre vers le Hont; les grands estuaires sont condamnés à mort, et les voies qui y aboutissaient désertées par le commerce.

Pour retrouver des débouchés vers la mer, la Flandre dut faire volteface. Malgré leur's efforts, les Hollandais n'avaient pas pris Dunkerque, ni gardé Ostende; on se retourna vers ces ports. Gand donnait encore l'exemple en commençant, vers 1613, les travaux d'un canal qui dovait le relier à Brugges; mais ces travaux traînèrent, et ce n'est qu'en 1724 que les batcaux purent aller d'une.ville à l'autre: c'est le canal actuel de Gand à

1 Feys, Oudenbourg, I, p. 571.

2 Diegerick, Arch. d'Ypres, I, pp. 232 et 264, III, p. 72.

3 I) ubois et de Hondt, Coutumes de Gard, II, p. 87.

4 Van Duyse et de Busscher, Inventaire analytique des chartes et documents appartenant aux archives de la ville de Gand (Gand, Annoot-Braeckman, 1867, in-4\%, 720 p.), $n^{\circ} 318$.

Wolters, Recueil, I, p. 106. 
Bruges par Vinderhaute et St-Georges. De son côté, Bruges essaie de retrouver à l'Ouest son débouché à la mer. Pour cela on recommence à utiliser l'Yperleet, mais cette fois à rebours de son ancien cours. On le recreuse, en 1622, en un canal qui va de Bruges à Plasschendacle, où il atteint la crique d'Ostende, étendue à cette date vers Zandvoorde. Mais ce débouché à la mer par nne crique vaseuse fut bientôt jugé incommode et insuffisant; dès 1639, on allait chercher plus loin à l'Ouest l'estuaire qui serait le port définitif de toute la Flandre; on utilisait le lit de l'Yperleet à partir d'Oudenbourg pour creuser, jusqu’à Nieuport, un canal qui s'appela Canal de Plasschendaele. Enfin Nieuport étant envasé, la Flandre, avec une belle ténacité, alla plus loin encore conduire ses canaux vers l'Ouest: en 1648 on établissait la voie d'eau Nieuport-Furnes, qui se reliait à Furnes avec le canal creusé en 1638 jusqu'à Dunkerque. En 1648 donc, la ligne Bruges-Dunkerque était achevée, 90 kilomètres de canaux ressuscitant à travers la plaine maritime la voie de l'Yperleot, complétée à l'Ouest par la remise en état du canal de Bergues en 1634, de la HauteColme à la même date, et de la Basse-Colme en 1662; de nouveau on pouvait, de Bruges et bientôt de Gand, gagner Gravelines, St-Omer, Calais, mettre en relation les différentes parties de la Flandre. La grandeur de l'cuvre surprendrait, étant donné l'état précaire du pays à cette date, si l'on ne songeait que la plupart de ces travaux n'étaient que dos rectifications, approfondissement, élargissement de voies d'eau déjà existantes : l'Yperleet de Bruges à Nieuport, et de là à Furnes un canal existant déjà au $\mathrm{XIV}^{\mathrm{e}}$ siècle, et qu'on recreusait en 1413; comme le dit l'acte d'octroi de 1638, il s'agil « deslargir, approfondir, ot en aulcuns endroits, par nouveaux fossoyements, accourir les canaulx se trouvant depuis le Sas du diet Plasschendacle... jusques à Iuncquerque ${ }^{1}$. Enfin on se préoccupe de joindre directement la Lys à ce système de canaux; il est question en 1611 d'un canal de Roulers à Dixmude, et en 1664 on exhausse tous les ponts de la Mandel pour livrer passage à la navigation ; on 1667 nait un projet de canal Warneton-Ypres ${ }^{2}$. Le réseau est reconstitué, orienté vers la mer du Nord, avec Dunkerque comme débouché.

Mais en 1662, Dunkerque tombe définitivement entre les mains des Français. Il faut se rabattre sur Ostende : en 1666 on trace un canal de quelques kilomètres de Plasschendaele à Slykens, où une ócluse à sas permet aux bateaux l'entrée dans la crique et le port. Ostende devient l'emporium flamand, et connait la prospèrité au début du XVII ${ }^{\ominus}$ siècle.

1 Delepierre, Précis, $1^{\circ}$ série, III, p. 62.

2 Vifquain, pp. 39-49. 
Cependant la France continue ses conquêtes: la Haute-Lys, la Deûle, passent sous la domination de Louis XIV; plus tard les Anglais et les Hollandais obtiennent la disparition de la Compagnie d'Ostende. Bâillonnée au Nord, diminuée à l'Ouest, la Flandre végète au XVIII ${ }^{\ominus}$ siècle; on se contente d'entretenir le réseau navigable devenu presque inutile, sans chercher' à l'améliorer ni à l'étendre.

\section{Établissement du réseau français.}

Au contraire dans la partie devenue française, les $X V I^{\mathrm{e}}$ et $\mathrm{XVIII}{ }^{\mathrm{\theta}}$ siècles sont la grande période de canalisation. Il s'agit de relier au $x$ anciens cours d'eau français ceux des nouveaux territoires. Dunkerque ètait à peu près isolé de l'Ouest depuis que le canal de Bergues, d'où on pouvait passer dans la Colme et l'Aax, servait de bassin de chasses ; aussi dès 1670 Louis XIV octroie la création d'un canal de l'Aa à Bourbourg et Coppenaxfort, continué jusqu'à Dunkerque par l'approfondissement du walergand Vliet Gracht; on communique ainsi de Dunkerque avec Gravelines, avec St-Omer d'où les marchandises gagnaient Aire par yoie de terre, avec Calais enfin par le canal de l'Aa à Calais qui fut rétabli de 1681 à 1682, en même temps qu'on canalisait les rivières de Guînes et d'Ardres. Ainsi le réseau de la plaine maritime française était complet, et tel qu'il se présente aujourd'hui. Restait à le relier au reste de la Flandre française, en joignant l'Aa à la Lys, que l'ouverture du canal de la Haute-I)ếle rénnissait à ce moment (1693) à la Scarpe, et par suite à l'Escaut. Vauban, que l'on retrouve à l'origine de tout ce qu'il y a de grand dans le pays en matière de travaux publics, suggéra à Louvois le projel d'un canal á écluses ulilisant d'Aire à St-Omer' la dépression où un comte de Flandre avait, suivant la tradition, établi au $\mathrm{XI}^{\mathrm{e}}$ siècle un parapet el un fossé de défense qu'on appelait le Neuffossé. Les plans en furent dressés dès 1686, et pourtant ce ne fut qu'en 1753 qu'on entreprit les travaux, et en 1786 que tout fut terminé: le nouveau canal de Neuffossé utilisait en un seul palier la vallée de la Melde par ó̀ l'Aa rejoignaitjadis la Lys, puis plongeait par cinq écluses superposées dans la vallée de l'Aa sur Arques, rachetant ainsi 13 mètres de dénivellation brusque. En même temps, de Deulémont à Aire, on améliorait la Lys, dont le nouveau canal allait augmenter le trafic, en y opérant d'importants travaux de redressement; on créait à Lille le canal de l'Esplanade qui permettait pour la premiére fois de passer de la haute dans la basse Deùle. On pouvait désormais, par bateau, aller de Dunkerque ou Calais à Valenciennes et Cambrai. 
Cependant cette voie navigable n'était pas irréprochable. Elle s'attardait en trop nombreux zigzags, entrainant les bateaux de Valenciennes vers Condé et Maulde, les ramenant brusquement vers Dokai et Pont-à-Vendir, les renvoyant vers le Nord-Est jusqu'à Lille et Deulémont, pour les expédier de là sur Aire et St-Omer; il y avait trop d'écluses, sur la Haute-Lys en particulier; enfin la Scarpe et la Lys n'avaient pas toujour's la profondeur nécessuire. Les défectuosités élaient telles que jusqu'en 1825 les bateaux charbonniers qui se rendaient de Mons à Dunkerque préféraient passer par Gand, Bruges, Nieuport et Furnes que par Lille et Aire. Il fallait trouver une combinaison pour rejoindre phus directement l'Aa à la Scarpe et à l'Escaut. Dès 1774, un projet était apparu, préconisant un canal de StVenant à Béthune et La Bassée ${ }^{1}$; puis ce fut un projet La Bassée-La Gorgue, par Lacouture et Vieille-Chapelle ${ }^{2}$. Ce ne fut cependant qu'au début de 1826 que fut ouvert le canal d'Aire à La Bassée, joignant par le Neuffossé l'Aa à la Deûle, et permettant d'éviter le détour de la Haute-Lys et ses dangers. 1)êjà depuis 1820 le canal de la Sensée joignait la Haute-Scarpe au Haut-Escaut; ainsi se complétait au début du XIX ${ }^{e}$ siècle la chaîne des voies navigables qui desservent la plaine flamande en longeant les dépressions dont les hautes terres crayeuses sont précédées tout le long de leur lisière, de Calais à l'Escaut.

Ainsi développé, le rćseau navigable flamand faisa it tête à la concurrence que la création des grandes chaussées commonçait à faire à la batellerie. Toutes les marchandises lourdes continuaient à être transportées par eau, grains, arbres, bois scié, pierres, charbons, engrais, chaux, tuiles, briques ${ }^{3}$. Canaux et rivières gardaient même une fidèle clientèle de voyageurs. Au XVII ${ }^{\mathrm{B}}$ siècle, Furnes a des transports réguliers pour passagers vers Dixmude, Loo, Ypres, Hondschoote et Bergues ". En 1804, les services publics des « coches d'eau » sont nombreux ; la harque de Lille à Douai a un départ quotidien; de Dunkerque, on va à Furnes, Bergues, Calais et St-Omer ; de Hondschoote, à Dunkerque; de Gravelines, à St-Omer ; de Merville, à Armentières, Hazebrouck, Aire, St-Omer ; d'Estaires, à Armentiéres 5. De Gand, une barque se rend à Bruges tous les jours, et vice-versa ;

1 Arch. Nord, G (Fl. Mar.) 18.

2 Arch. Nat. $\mathrm{H}^{1}$ 37, pièce 150 (plan), 1786.

3 Ordonnance de 1769, réglementant les transports par eau entre Eecloo et Gand (Gilliodts, Coutumes peiites villes, Eeeloo, II, p. 711).

Ann. Com. fl. Fr. XV, p. 430.

s Dieudonné, Statistique, III, pp. 72-73. 
c'est le moyen de transport le plus apprécié jusqu'à l'apparition des chemins de fer, et Paquet-Syphorien en fait, dans son voyage de 1812, un éloge enthousiaste ${ }^{1}$.

\section{Les voies navigables au $\mathbf{x I X}^{\circ}$ siècle.}

La naissance des chemins de fer surprit donc le réseau navigable dans une époque de pleine prospérité. En France, on construisait des canaux ; la Belgique, dans l'essor économique qui suivit 1815, reconstituait les siens. De 1820 à 1830, on procède au dévasement des voies d'eau, à la suppression d'ecluses devenues inutiles, des overdrachs archaïques: sur le canal de Plasschendacle, sur le canal d'Ostende qu'on relie aux bassins du port par une dérivation, sur la Lys où l'on fait disparaître des bancs dangereux. On continue le creusement du canal de Bruges à Sluis commencé en 1810, et qui atteint le Zwin en 1818 ; enfiu on travaille á la grande cuvre du canal Gand-Terneuzen. Profitant de l'union de la Flandre zélandaise à son ancienne patrie, les Gantois ćlaborent dès 1817 le projet de la voie d'eau qui doit amener les bateaux de mer dans leurs bassins : cette fois, il faudra aller au delà du Sas-de-Gand, dépasser le Braakman condamné à l'envasement, pour atteindre les eaux profondes sur le IIont, à Terneuzen. De $182 \tilde{i}$ à 1827 , on restaure les débris de l'ancienne voie entre Gand et le Sas ; au delà, on barre un golfe du Braakman, la crique d'Axel, travail pénible qui retint sur place pendant deux ans 800 terrassiers ot 200 embarcations ${ }^{z}$; cependant l'activité fut telle que le canal était ouvert en novembre 1827, et quo le bassin du Commerce, à Gand, était prêt en 1829. On projetail de nouveau, en 1840, un canal de Roulers et un canal d'Ypres à la Lys ; en France, on entreprenait en 1824 le canal de Roubaix, destiné à rejoindre la Deûle à l'Escaut; la section Marquette-Croix était inaugurẻe en 1831 ; les Belges terminaient en 1813 la section de l'Espierre (Roubaix-Escaut); on continuait de travailler à la partie intermédiaire.

L'engouement qui se prononça pour les chemins de fer à partir de 1840 amena un ralentissement dans le travail de création ou de perfectionnement des voies navigables. Il fallut attendre 30 ans pour que l'on rendît justice aux cours d'eau. C'est en 1870 que l'on se mit à réparer' et à approfondir le canal de Gand à Ternenzen, que l'hostilité de la Hollande avait longtemps tenu fermé après 1830; les travaux se terminaient en 1885. Le canal de

1 Voyage, II, pp. 119-122.

2 Vifquain, pp. 139-145. 
Roubaix, dévié de son tracé primitif et établi entre Tourcoing et sa voisine, fut inauguré le 31 décembre 1876 ; à la même date on ouvrait le canal de Courtrai a Bossuyt, qui joint la Lys à l'Escaut et permet aux houilles belges d'alimenter les fabriques de la Lys ; la Mandel était canalisée jusqu'à Roulers; enfin les Yprois, réalisant leur rêve, se mettaient au canal de Comines, qui devait joindre l'Yperlée à la Lys, et dont les difficultés de percement dans la traversée des collines ont fait jusqu'ici retarder l'achévement. Sous l'impulsion du programme Freycinet, on perfectionna dans la partie française les artères existantes ; on poursuivit l'approfondissement à $2^{\mathrm{m}}, 50$ de toutes les voies, le redressement des courbes, l'établissement de garages; on doubla les cinq écluses des Fontincttes par un ascenseur hydraulique.

Les résultats sont magnifiques. Si on laisse de côté les voies secondaires, canaux d'Ardres, de Guînes, d'Audruicq, qui ne transportent chaquo année que quelques mille tonnes de betteraves, de charbon et de briques; canaux de Furnes et de la Basse-Colme, dont la frontière fait de véritables impasses ; canaux d'Hazebrouck, qui ne servent guère qu'à évacuer les bois de la forêt de Nieppe et à approvisionner Hazebrouck ; rivière de la Lawe qui, par défaut d'entretien et d'amélioration, ne porte par an que 30 d 40.000 tonnes au lieu des $\mathbf{4 0 0 . 0 0 0 ~ q u ' e l l e ~ d e v r a i t ~ c h a r r i e r , ~ l e ~ r e ́ s e a u ~ f r a n c ̧ a i s ~}$ se présente comme un tronc vigoureux détachant à droite et à gauche de puissants rameaux. De Dunkerque à l'Aa, le canal de Bourbourg transportait en 1901 1.469.000 tonnes; l'Aa, qui lui fait suite entre le Guindal et Arques, en portait 2.035.000, le canal de Neuffosse, 1.988.000; les affluents de ce grand courant commercial, canaux de Bergues et de la Haute-Colme, qui doublent la voie vers Dunkerque, et cantl de Calais, avaient un trafic de $227.848,362.412$, et 474.000 tonnes. Sur toutes ces voies, les produits agricoles constituaient de 30 a $\mathbf{4 0 \%}$ des marchandises transportées, la houille française $30 \%$ environ ; les bois, Ies matériaux de construction, les engrais, les produits de l'industrie métallurgique le reste. A partir d'Aire, et surtout à la hauteur de Béthune, le canal de La Bassée fait un trafic bien plus considérable encore : 3.679 .000 tonnes en 1901, qui deviennent 5.186.000 tonnes sur la Haute-Dê̂le; mais l'honneur n'en revient plus à la Flandre; c'est le bassin houiller du Pas-de-Calais qui, de ses « rivages » de Vendin, Béthune, Harnes, Beuvry, y déverse plus de 2.000.000 de tonnes de charbon, qui forment $64 \%$ du total, tandis que les produits agricoles ne contribuent plus à l'ensemble que pour $16 \%$. De même sur la Lys française, où sur 720.898 tonnes, $43 \%$ représentent la houille française, $25 \%$ les matériaux de construction, et $18 \%$ les produits agricoles. Enfin la Deûle on aval de Don et le canal de Roubaix transpor- 
taient en 19011.537 .234 et 609.844 tonnes, parmi lesquelles le trafic des houilles françaises représente encore plus de la moitié du total. Les grands ports établis le long de ces canaux ont une importance exceptionnelle: celui de Dunkerque en 1898 avait un tonnage de 1.470.000 tonnes; celui de Lille, 710.000, celui de Roubaix 470.000, celui d'Isbergues 232.000 , sans parler de cenx du canal d'Aire ou s'effectue l'embarquement de la houille ${ }^{1}$.

Le réseau belge préscnte la mème activité. Là, c'est l'Escaut qui accapare

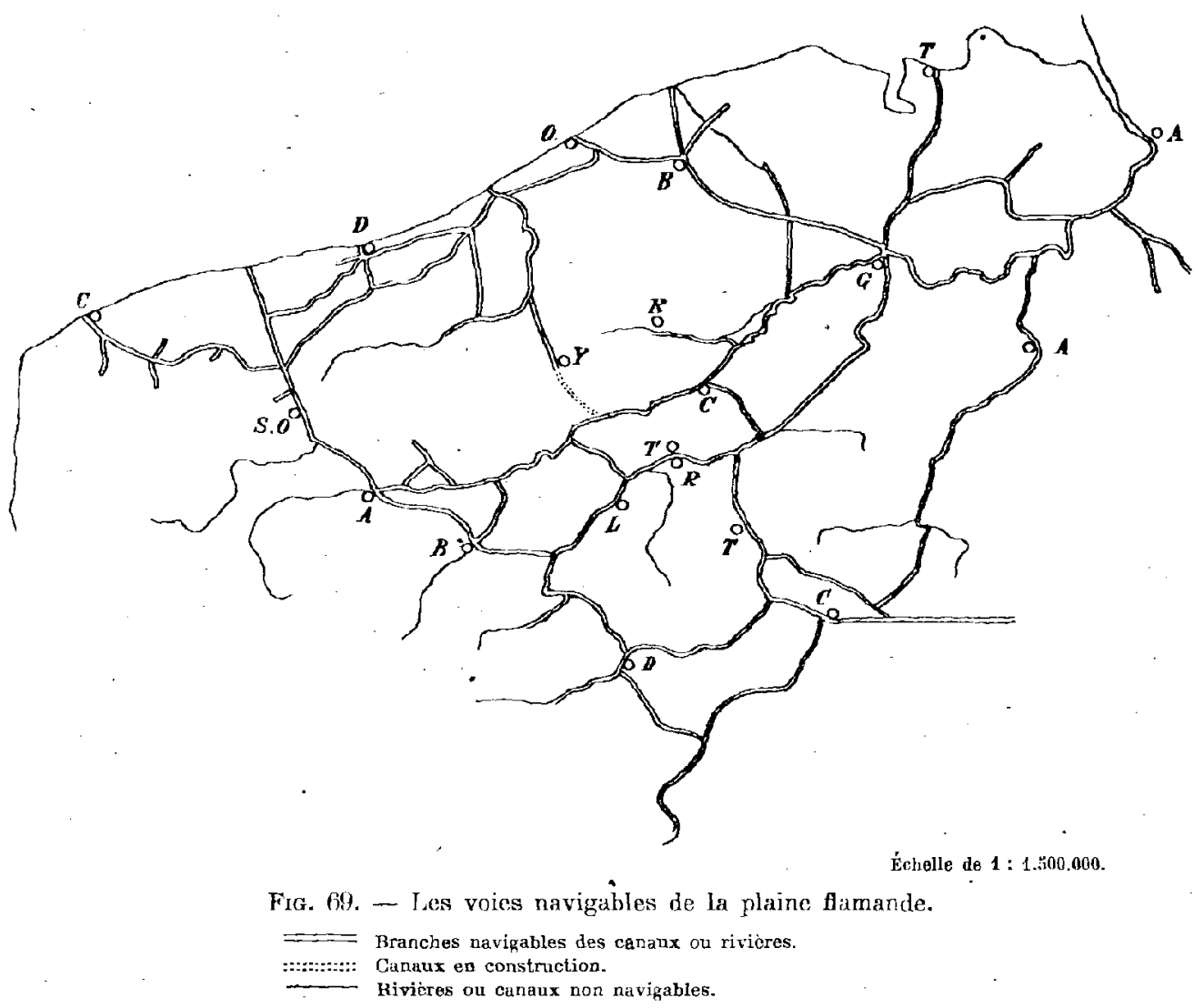

la plus grande partie du trafic; la houille descend, charriée par d'innom-

1 Renseignements dans La Rivière, et dans: Guillain, Canaux du Nord, Rapport. (Chambre des députés, Session extraordinaire de 1901, annexe, $\left[1^{\circ} 2.773\right.$, pp. 154-156); - Conseil Général du Nord, Session d’août 1902, Rapports des chefs de service, p. $79 ;$ - enfin lẹs travaux des Chambres de Commerce de Calais, Dunkerque, Lille. 
brables flottilles, du bassin du Borinage vers Courtrai, ver's Gand et de là vers Bruges; par le canal de Blaton d'autres péniches de charbon gagnent la Dendre, Termonde et le Bas-Escaut. Les briques, pavés el pierrailles, les engrais, les bois, les produits agricoles font le reste. La Lys est moins fréquentée, sauf par les bateaux amenant le lin de Waes et de Hollande; les voies d'eau de la plaine maritime sont désertes depuis qu'elles ne sont plus la route de Dunkerque vers l'intérieur. Lè canal de Gand Bruges a retrouvé de l'activité dans les travaux de Bruges-Port de mer et dans l'alimentation de l'usine Solvay, qui traite à.Zeebrugge les sous-produits de la houille. C'est Gand qui reste le grand carrefour. Le Haut-Escaut lui a amené en 19032.980 bateaux, d'une contenance de 640.000 tonnes; le canal de Bruges 2.301, avec 299.000 tonnes; le BasEscaut 5.998, avec 884.693 tonnes; enfin la Lys 131 seulement, avec 12.000 tonnes. De toute cette flotte, une partie ne fait que passer à travers la ville; cependant le mouvement du port s'est élevé en 1904 à 899.000 tonnes, soit en gros 900.000 , portant sur 4.687 embarcations. Gand, port fluvial, est donc supérieur à Lille, et se range, après Dunkerque, au second rang parmi les entrepôts flamands ${ }^{1}$.

Ainsi la navigation a gardé, dans la vie économique de la Flandre, une grande importance. On peut dire que ce mode de transport est resté familier au pays. Il y a encore, en bien des endroits, rivalité avec la voie ferrée: le canal est employé à des fonctions que les chemins de fer ont monopolisées ailleurs. Autour de Gand, des bateaux font encore des services de messageries. De Bellem part chaque vendredi, pour le marché de Gand, une barque d'oufs et de beurre. La voie d'eau a gardé des transports de voyageurs: il existe un service Gand-Selzaete; à Tamise, on compte six départs quotidiens pour Anvers; lBruges en a pour Ostende, pour Sluis; à Rupelmonde, presque tout le trafic, marchandises et voyageurs, se fait par le fleuve.

\section{III.}

\section{VOIES FERRĖES.}

Cependant cette persistance de la navigation fluviale, dont l'imporlance s'accroît sans cesse, ne paraît pas avoir cntravé-le dévcloppement d'un des réseaux ferrés les plus denses qui soient au monde. L'établissement, il est vrai, en était facile: pas d'ouvrages d'art, sauf les ponts, qui sont nombreux ; les ingénieurs, en construisant leurs lignes, n'avaient à tenir comple

1 Chambre de Commerce de Gand, Rapport de 1904, pp. 80-81, 

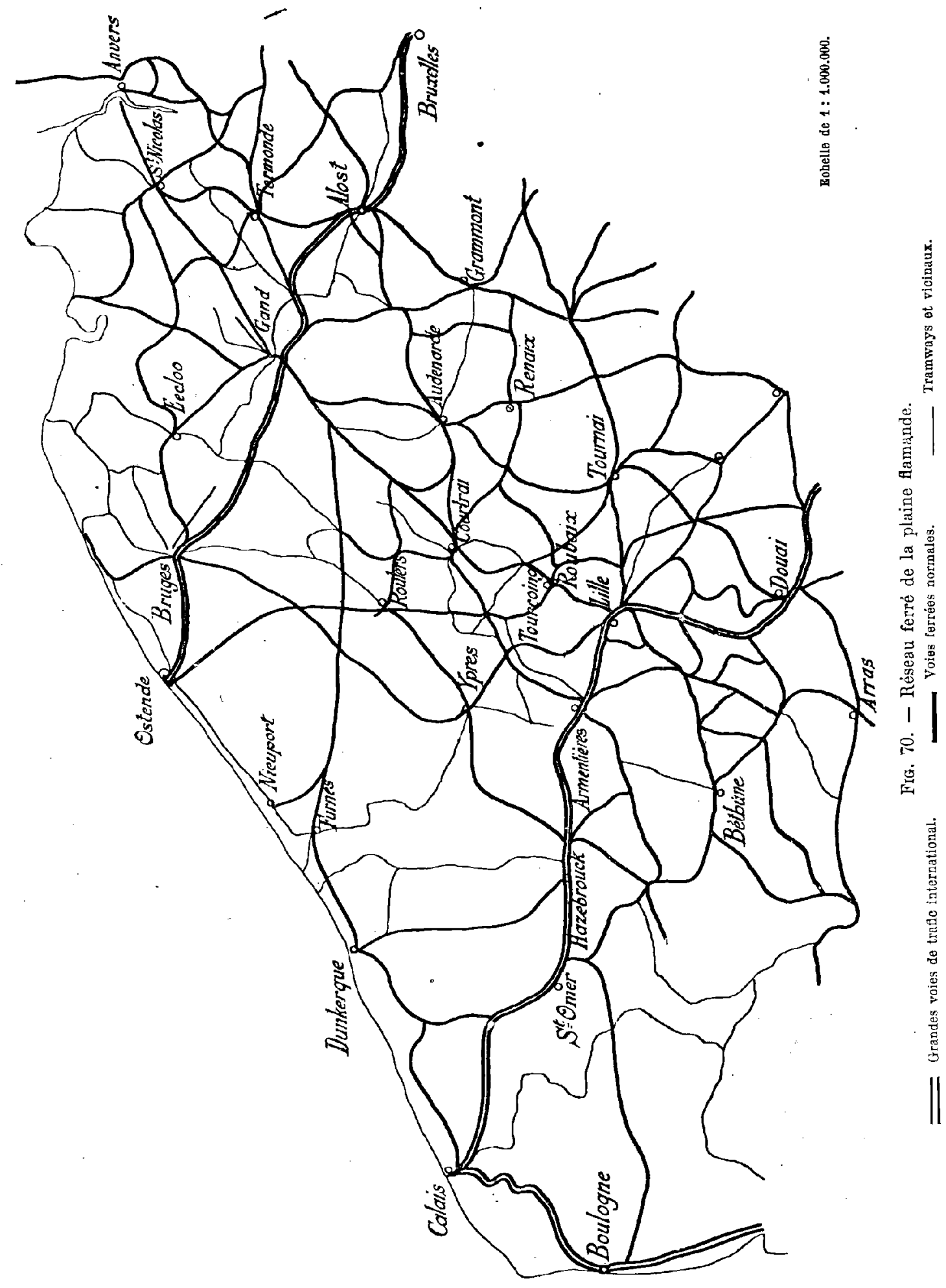
que des courants commerciaux; pas de vallée à laquelle le chemin de fer dut s'attacher pour pouvoir passer, car tout est vallée en Flandre. Seule la ligne de Renaix à Gand a dû être pourvue d'un petit tunnel. Aussi le réseau des grandes voies a-t-il ćté rapidement constitué, et l'on a pu se mettre a la construction des lignes secondaires à une époque où d'autres régions en étaient encore à établir leurs grandes artères. Dix voies ferrées partent de Lille, dont la gare a vu en 1904 un mouvement de 4.332.467 voyageurs ${ }^{1}$; et bientôt un réseau plus considérable encore de tramways va garnir toutes les routes de l'arrondissement. La partie belge, où les chemins de fer vicinaux sont en honneur, ne comptera bientôt plus un village situé à 8 kilomètres d'une station. Cependant toutes ces lignes font leurs affaires ; le bas prix que les abonnements ouvriers accordent aux voyageurs, au lieu d'ameper le déficit, contribue à la prospérité. La concurrence de la batellerie, en obligeant les chemins de fer à abaisser leurs tarifs, contribue en réalité à l'activité des transactions par voie ferrée: e'est ainsi que la houille, la matière prélérée des transports par eạu, est l'objet d'une circulation plus active encore par chemin de fer que par bateau. La coopération est d'ailleurs fréquente entre les deux modes de transport: le vicinal, et même la grande ligne, pousse ses voies entro les bassins des ports maritimes ou fluviaux; la richesse circule aisèment d'un réseau à l'autre.

IV.

\section{LE COMMERCE.}

\section{Trafio intérieur.}

Le nombre et l'importance de ces voies de communication atteste l'ampleur du trafic qui passe à travers la Flandre. Une région si peuplée et si active est évidemment le siège d'un commerce intérieur florissant. Matériaux de construction pour les villes-champignons, denrées agricoles et produits de boucherie pour les agglomérations, betteraves pour les sucreries de la plaine maritime, alimentent une bonne part du trafic. Cette circulation intérieure, on en retrouve un exemple dans la liste des fournisseurs de Bruges au XVI' siècle. Le blé lui vient du quartior Sud-Ouest du pays, et de l'Artois ; le beurre, le fromage, los coufs, les poulets, les boefs gras et les vaches, de Dixmude, Furnes, Bergues-St-Winoc et Lampernisse;

1 Voyageurs ayant pris leur billet à ou pour Lille; ceux qui transitent par Lille ne, sont pas compris dans ce chiffre. 
les fruits, de Courtrai et du pays de l'Alleu; les moutons et veaux gras de la région gantoise ${ }^{1}$. La présence d'une frontière depuis le XVII siècle gêne, il est vrai, ce trafic intérieur, ou plutôt le coupe en deux. Mais la frontière, à son tour, a fait naitre tout un commerce, qui pour être interlope n'on est pas moins florissant. La contrebande s'exerce en grand sur cette ligne tracée comme au hasard, et qu'aucun ubstacle naturel ne défend ; c'est une vraie ressource pour toute une catégorie d'individus, et on connaît des fortunes qui s'y sont faites. Rien qu'à Roubaix, la justice a constaté l'existence d'environ 15.000 freudeurs de profession, et le préfet de Viry s'apercevait dans la Lys en 1804 que la population des villes frontières avait diminué depuis la réunion à la France : « la fraude dans ces villes nourrissait un grand nombre d'individus, qui ont dû aller chercher fortune allleurs »?. Les communes rurales de la frontière sont sillonnées de mystérieux sentiers qui se dirigent tous vers la Belgique. La Lys même n'est pas un obstacle; des harques se faufilent la nuit d'un bord à l'autre, sous prétexte d'inspecter les ballons du rouissage ${ }^{3}$. $A$ côté du fraudeur isolé, il y a de vastes entreprises qui sont des modéles d'organisation et d'ingéniositó. An Nord de la I ys, il existe des relais de contrebande, l'un sur la butte argileuse du Ryveld, près Steenvoorde, l'autre sur la colline caillonteuse de la Belle-Ilôtesse, derrière Morbecque; et les denrées que les fraudeurs ont péniblement amenées au premier relais, transportées par ballots au second, sont chargées là sur des voitures qui les répandent dans l'intérieur, à-travers l'Artois et la Picardie. Ainsi il y a là tout un commerce très actif qui, né d'un élément artificiel, doit une partie de son développement aux circoustances géographiques: facilité de la circulation dans un pays sans obstacles, abondance d'une population pauvre quï assure un recrutement aisé pour ce trafic dangereux et lucratif.

\section{Trafic extérieur : échanges avec l'Artois et l'Angleterre.}

Les échanges intérieurs n’ont jamais suffi à la Flandre. I a population y est trop dense pour que le pays pût la nourrir ; d'autre part l'industrie, presque dès son origine, a dû faire appel aux matières premières du dehors. La Flandre intérieure, avec son sol médiocre, n'a pu sulfire de bonne heure

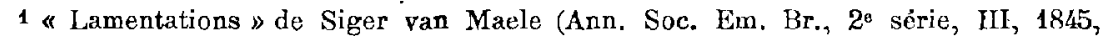
pp. 298-299).

2 De Viry, Mémoire, p. 27.

3 Sur les procédés des fraudeurs et l'activitó de la douane, voir série d'articles darı « l'Echo du Nord », janvicr et février 1905. 
à fournir ses habitants de grains; il lui a fallu s'adresser aux riches terres du Sud, où le blé croît en abondance sur le limon qui revêt les plaleaux de craie.' Le transport des grains par l'Escaut, la Deûle et la Lys a été un des premiers éléments de la circulation sur ces rivières, et l'une des causes de la fortune de Gand, qui centralisait dans ses 220 entrepôts (beerien) les cargaisons amenées par eau: monopole qu'elle gardait jalousement ${ }^{1}$. Au XVIo siècle, Meyer constate que la Flandre, ne peut se suffire en blé, et qu'il lui faut en demander à ses voisins du Vermandois, de l'Artois, de l'Amiénois, du Cambrésis, bien plus favorisẻs que les Flamands pour la fertilité de leur sol ². Guichardin témoigne dn même fait ${ }^{3}$. De là l'importance ancienne d'Aire et de Bóthune: ce sont les fournisseurs de pain pour la Flandre; aussi leur rôle est-il d'être des marchés à blée. « Le commerce de grains est le seul que les supplians connaissent dans leur ville » écrivent en 1749 les habitants d'Aire * et ceux de Béthune en 1730 déclarent que le commerce de leur ville ne consiste que dans les marchés publics des grains et des lins que l'on apporte des environs ${ }^{5}$. Tous les documents contemporains insistent sur ces traits: ce qui fait vivre l'Artois, c'est l'exportation des blés, le passage des voyageurs et des marchandises. Ainsi l'Artois se trouvait lié de très près à la Flandre par des relations économiques. Le blé était le principal objet d'échange: mais jadis il lui avait envoyé ses laines, et jusqu'à la fin du XVII ${ }^{\circ}$ siècle il lui expédia ses grès ${ }^{6}$; aujourd'hui, il lui vend son charbon. Les fileuses de l'Artois travaillaient pour Roubaix et pour le groupe de la Lys. De pareilles relations d'affaires devaient nouer entre l'acheteur el le fournisseur de solides liens politiques; l'Artois et la Flandre apparaissent à peu près inséparables dans l'histoire. La Civitas Morinorum s'étend-sur les deux pays: plus tard, jusqu'an XII ${ }^{\mathrm{e}}$ siècle, Arras est la capitale des comtes de Flandre. Séparés par la politique habile de Philippe-Auguste, les deux pays tendent à se rejoindre; l'Artois devient vite distinct du _domaine royal, et l'union avec la Flandre recommence sous la maison de Bourgogne. Esca-

1 Pirenne, Hist. Belgique, II, p. 334.

2 Rerum Flandriae, p. 77.

3 Guichardin, p. 382.

- Arch. Pas-de-Calais, C. 263, pièce 161.

5 Ibid., C. 376, pièce 94.

6 En 1757, achat pour le pavage du chemin d'Ypres à Menin (Árch. Pas-de-Calais, G. 657); la même année, pour la route de Bailleul à Meteren (ibid.); en 1778, pour le pavage des rues de Dunkerque (C. 140 et 140 bis), pour le pavage des rues de Gand (C. 584), etc. 
moté par Louis XI, il est rendu par Charles VIII. Aussi les souverains du XVII siècle, en annexant l'Artois au royaume, y joignirent-ils un gros morceau de Flandre, et l'ensemble fit comme une nouvelle province complète, qui entra facilement dans l'unité française.

Les mêmes circonstances donnent leur caractère mixte aux villes de l'Artois qui bordent le pays flamand. Aire et St-Omer, se détachant de l'Artois annexé par la France au traité des Pyrénées, suivirent le sort de la Flandre et ne furent absorbées qu'avec elle en 1678. Pour l'aspect extérieur, ce sont des villes artésiennes, où la pierre tient une bonne place dans les constructions et apparait dans de belles églises soigneusement fonillées, chose si rare en Flandre; mais leurs relations sont avec la plaine qui s'ètend devant elles; St-Omer ne connaît pas Arras: Lille est sa vraie métropole; de même pour Aire, Lillers, Bélhune, au delà seulement de laquelle la présence du bassin houiller oriente ver's une autre direction, vers Lens et Douai, les préeccupations et les relations des habitants.

I'Artois fournissait le blé, mais l'Angleterre avait la laine. «Il est vrai que de France nous viennent blés, auraient dit en 1329 les députés des villes a Philippe de Valois; mais pour acheter faut-il avoir de quoi payer. Or d'Angleterre nous viennent laines, qui nous donnent grand profit et nous permettent de vivre à l'aise et joyeusement ${ }^{1}$. I a réplique était juste: privẻe des prés salés de la plaine maritime qu'étaient venues remplacer des cullures, la Flandre ne pouvait approvisionner son industrie drapière qu'en achetant de la laine en Angleterre. De bonne heure les relations s'établissent avec la grande île. St-Omer achète dès 800 des étoffes de l'autre côté du détroit ${ }^{2}$; au X $\mathrm{X}^{\mathrm{e}}$ et au $\mathrm{XI}^{\mathrm{e}}$ șiècle, ses rapports commerciaux sont fréquents avec la Grande-Bretagne ${ }^{3}$. Les lois du roi Ethelred, au début du XI" siècle font mention des marchands de Flandre "; et dès la fin du XIIe, l'association commercialo de la hanse de Londres s'étend à tous les Pays-Bas ${ }^{5}$. Jusqu'à la fin du XV $\mathrm{X}^{\mathbf{e}}$ siécle, ce commerce de laines fut pour la Flandre le problème vital, et l'on a fait remarquer depuis longtemps la solidité des liens politiques que ces relations économiques avaient noués entre les deux pays. «La laine était d'un côté du détroit,

1 Gité dans Le Glay (Ed.), Histoiro des Comtes de Flandre, (2e éd., Tournai, Castermann, 1867, in- $\left.8^{\circ}\right)$, II, p. 415.

2 Guérard, St-Bertin, p. 66.

3 Giry, St-Omer, p. 276.

4 Gité dans Koryyn de Lettenhove, Hist. de Flandre, I, p. 212.

5 Van der Linden (H.), Les gildes marchandes dans les Pays-Bas au moyen-âge (Recueil travaux fac. lettres Gand, 15 fascieule, 18\%6, 126 p.), p. 28. 
l'ouvrier de l'autre. Le boucher anglais, le drapier flamand, étaient unis au milieu des querelles des princes, par une alliance indissoluble ${ }^{1}$. Ces liens se relâchèrent au $X V^{\theta}$ siècle, lorsque l'Angleterre garda sa laine pour fabriquer elle-même. Dès lors ce furent des produits manufacturés que la Grande-Bretagne essaya de faire pénétrer en Flandre, tandis que celle-ci expédiait aux Anglais les produits agricoles de la plaine maritime. En 1781 , le Calaisis « vend fort cher aux Anglais tout ce qu'il ne consomme pas de ses denrées », et recoit les nombreux produits que lui apportent les bateaux des fraudeurs (smoggleurs) ${ }^{2}$. De nos jours, il existe des services réguliers vers les ports anglais pour le transport des fruits et des produits de l'élevage. Des paquebots rapides embarquent pour Douvres les denrées alimentaires amenées par trains directs sur les quais de Calais; la Belgique a organisé une ligne Ostende-Tilbury par laquelle les produits partis à 3 heures du soir d'Ostende peuvent être le lendemain matin à 4 heures sur les marchés de Londres.

\section{Mouvement commercial des ports.}

Cependant l'importation flamande, au moyen-âge, ne se bornait pas à la laine et au blé. Le pays, aux époques de prospérité, consommait beaucoup. L'Espagne, le Portugal, les ports français de l'Atlantique, étaient les grands fournisseurs. Au début du XIVe siècle, le vin, amené des ports de Biscaye, Bayonne, Guéthary, Fontarabie, el surtout du Poitou par La Rochelle, tient dans les entrepôts de Calais autant de place que la laine. Les harengs viennent ensuite, puis une liste de denrées d'une variété incroyable, biére d'Angleterre, fruits en boîtes, dattes, figues, sol du Poitou, grains, lard, suif, cuirs, cire, poix, goudron, vinaigre, métzux ${ }^{3}$. En revanche la Flandre exporte ses draps dans le monde entier, et jusque dans les pays qui lui font la guerre mais ne peuvent se passer des produits de son industrie. Un tonlieu de Perpignan du XIVe siécle cite les draps verts de Gand et d'Y pres, ceux de St-Omer et de Bruges, les draps rayés d'Ypres et les draps blancs de Tamise ". Plus tard, les toiles de Courtrai approvisionment la France, conquièrent le marché espagnol. Tandis que

1 Michelet, Histoire de France, èd. de 1837, III, p. 277.

2 Arch. Nat. H1 647, pièce 2.

3 Chavanon (J.), Etudes ot documents sur Calais avant la domination anglaise, 1180-1346 (Paris, Picard, 1901, in-8 $35+32$ p.).

4 Finot, Commerce, passim. 
les marchandises importées arrivent généralement par mer, en raison de leur nature lourde et encombrante, ce que la Flandre exporte, produits de fabrique légers et précieux, prend déjà la route de terre, comme le font aujourd'hui les tissus et les filés sortis des usines de Gand ou de Lille.

Il s'ensuit que le mouvement des marchandises a été toujours plus important, ou si l'on veut plus bruyant, par les ports de Flandre que par les bureaux de douane de l'intérieur. Aussi les ports ont-ils joué de bonne heure un rôle considérable. Ce fut d'abord le règne des entrepôts établis au fond des estuaires: St-Omer, Damme. Les golfes maintenus jusqu'au $\mathrm{XII}^{\mathrm{e}}$ siècle dans la plaine maritime semblaient inviter le commerce à s'établir sur leurs bords; la mer s'offrait aux bateaux flamands; elle avait fait elle-même la moitié du chemin. Tandis que prospéraient ces villes aux rades bien abritées, les havres du littoral n'êtaient guère que des refuges de pêccheurs. Devenus grands, ils ont gardé cette industrie : mais l'oljet et le lieu de la pêche ont souvent changé depuis le moyen-âge ; on ne pourchasse plus la baleine que les contemporains de St Bavon, et même ceux de St Arnulf (XIIe siècle) harponnaient encore dans la mer du Nord ${ }^{1}$. Ln petit nombre seulement des pêcheurs reste en vue des côtes; beaucoup sortent de la mer flamande, à la recherche du maquereau ou du hareng. Ostende, où se répand la pratique des chalutiers à vapeur, a vu vendre en 1902 pour 4.802.000 francs de poisson ${ }^{2}$; Calais, dans la même période, pour 1.059.000 ${ }^{3}$. Enfin Dunkerque et Gravelines arment pour la grande pêche en Islande ou sur les côtes de Norvège, tandis que les autres villes ou bourgades de la côte, la Panne, Nieuport, Blankenberghe, Breskens, envoient des barques chaque jour pour croiser dans les parages des bancs".

Lorsque les grands ports d'estuaire furent dẻchus, enlisés dans les alluvions ou isolés de la mer par la disparition des golfes, on vit passer au premier rang les havres de pêche de la côte. La fermeture de l'Escaut augmenta leur prospérité, malgré les efforts de leurs rivaux maritimes, Anglais et Hollandais, pour ruiner Dunkerque et museler Ostende; dès

1 Cif. M. G. SS., XV, pp. 596 et 901.

2 Bull. Ch. Commerce, Janvier 1903, p. 10.

3 Exposé sommaire Gh. Conmerce, 1902, p. 234.

4 Sur la pêche, voir : Patria Belgica, I, pp. 331-333; - Van den Bussche (E.), La pêche et les pêcheurs de Blankenberghe (La Fl.,VlII, 1876, pp. 347-464);- Capdeville (E.), La pêche maritime à Ostende en 1897 (Revue maritime, Paris, Beaudouin, mai 1898, pp. 401-409); -- Delbeeq (Dr), Le matelot de Grand-Fort-Philippe (Mém. Soc. Dunk., XXXVI, 1902, pp, 459-480). 


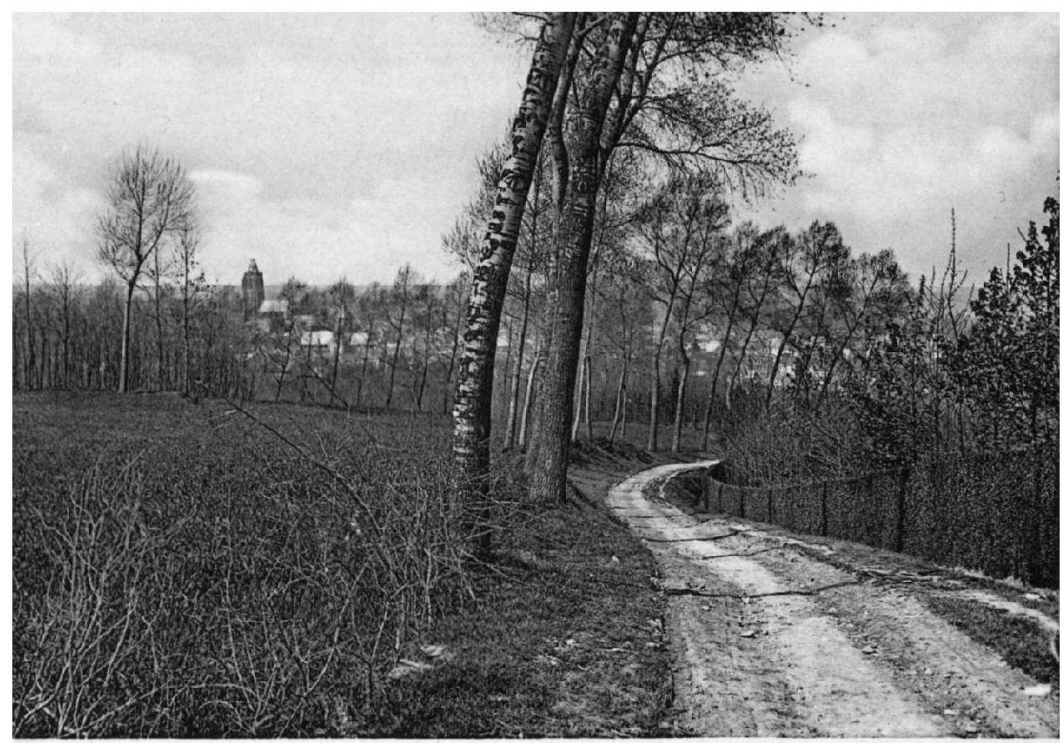

47. - Audenarde, vu de la colline d'Edelaere.

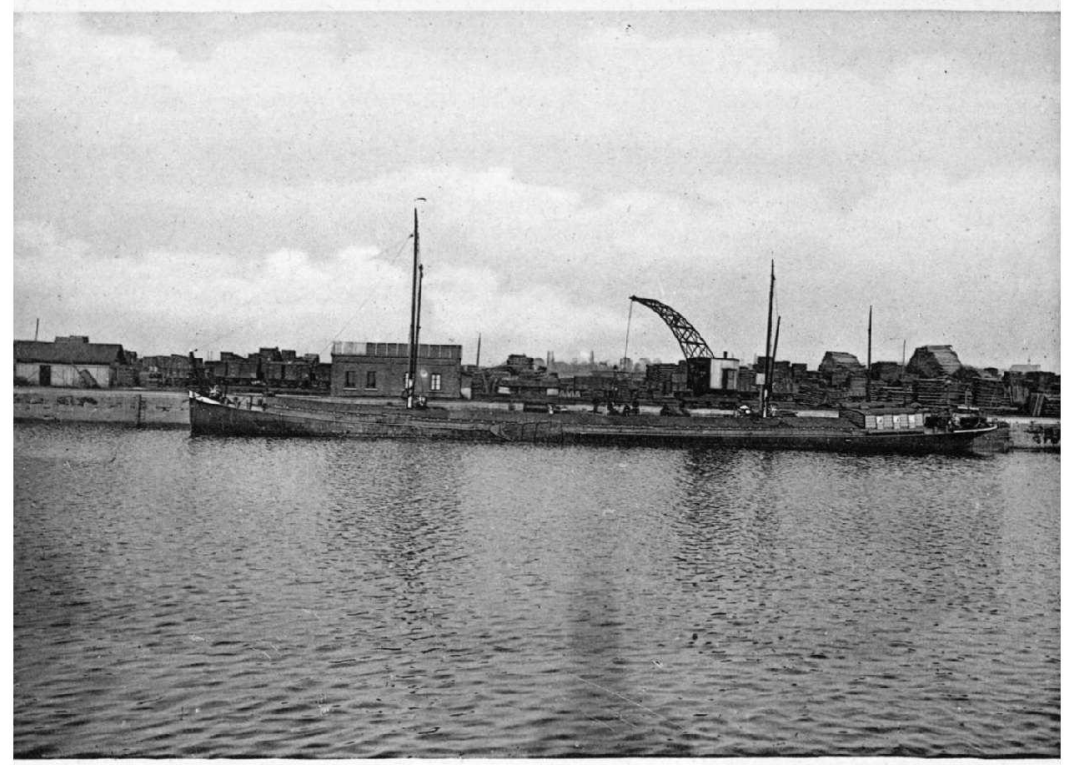

48. - Vue dans le port de Gand (Quai aux Bois). 
IRIS - LILLIAD - Université Lille 1 
que la pression etrangère faiblissait, on voyait grandir a vue d'œil le mouvement des affaires: Dunkerque prend une importance énorme de 1763 à 1789, et Ostende pendant la guerre d'Amérique: indice de la nécessité absolue où se trouve la Flandre d'avoir des débouchés sur la mer. Au XIX siècle, malgré la résurrection triomphante d'Anvers, dont l'hinterland s'enchevêtre dans le leur, les ports flamands ont accepté la lutte et l'ont glorieusement soutenue.

Dans cette prospérité actuelle des ports, Dunkerque a la plus belle part ${ }^{1 . *}$ Les débuts du XIX ${ }^{\text {e }}$ siècle avaient été durs; on tâtonnait. Ce fut le perfectionnement du réseau navigable entre 1815 et 1830 , puis la création des chemins de fer, puis de nouveau les améliorations apportées à la voie d'eau après 1875, qui ont donné et soutenu l'élan. Dunkerque est redevenu ce qu'il était déjả à la fin du XVIII siècle, le port régional de la Flandre française et de la France du Nord. Déjà, vers 1789, la Norvège y expédiait ses bois, l'Angleterre son charbon, ses métaux, sa quincaillerie, Riga la graine de lin, le chanvre, les céréales 2. Des 1.904.113 tonnes reçues en 1901, dont 1.800.000 venant de l'étranger, c'est en grande partie vers les foules de la région lilłoise que I)unkerque expédie les 363.000 tonnes de farineux alimentaires, les 191.000 tonnes de graines et fruits; c'est sur les campagnes flamandes que doivent être répandues pour la plus grande part les 182.000 tonnes de nitrates du Chili, dont il a presque le monopole d'importation en France $(83 \%$ du total); de même les 42.000 tonnes de tourteanx oléagineux destinés aux exploitations de l'intérieur. C'est à Roubaix-Tourcoing que sont réservées les 130.000 tonnes de laine arrivées d'Australie et de la Plata, et à Lille les 35.000 tonnes de lins russes. Lille et sa banlieue réclament encore pour leurs usines de produits chimiques les 86.000 tonnes de pyrites. Enfin des 243.000 tonnes de minerais, tout se dirige vers Denain, Donai et Isbergues ; des 137.000 tonnes de houille, la plus grande partie est expédiée vers Paris. Par les canaux, par les voies ferrées, par les routes même, ce trafic de marchandises s'achemine vers le Sud; Armentières est traversée chaque nuit de lourdes voitures qui roulent de Dunkerque vers Lille, utilisant encore la route, plus rapide que le canal, moins chère que le rail.

1 Sur Dunkerque, voir l'excellente étude de: de Rousiers (P.), Ports de France. Dunkerque (Revue de Paris, 1903, I, pp. 65-96). Les chiffres cités s'y rapportent à 1901 ; ceux de 1903 se trouveni dans le Tableau général du Commerce et de la Navigation, année 1903 (Direction des Douanes, Paris, 1904), I, pp. 116-117, II, pp. 39-58.

2 I) Bertrand (R.), Le port el le commerce maritime de Dunkerque au XVIII"siècle, '2e partie (Mŕm. Soc. Dunk., X, pp. 69-sq4.). 
Ainsi Dunkerque est la porte d'entrée du Nord français, de l'Escaut à la mer, et son rayon d'action, par les canaux picards et champenois, gagne vers le Sud. Il en est aussi la porte de sortie. Sur les 549.000 tonnes exportées en 1901, le sucre des fabriques picardes et flamandes n'est pas loin de fournir la moitié, 253.000 tonnes, soit $52 \%$ de l'exportation tatale des sucres français à cette date ; les produits métallurgiques de Lille et du bassin houiller, 86.000 tonnes; Ies charbons du Pas-de-Calais, 50.000; enfin les denrées agricoles de la Flandre, 30.000. L'énorme différence entre les exportations et les importations (presque le rapport de 1 à 4) ne paraît pas faire du tort au port de Dunkerque en augmentant le fret des navires abligés de reprendre la mer sur lest après avoir débarqué la cargaison. C'est qu'il y a, à proximité, d'autres grands ports où le long courrier, arrivé d'Australie, du Chili ou de l'Argentine, va chercher le fret de retour qui lui manque à Dunkerque ; et ce nouveau parcours de quelques cent kilomètres vers Anvers, Iull ou les ports charbonniers du Durham lui importe peu, comparé á l'immense trajet qu'il a déjà fourni. Ainsi cette infériorité est compensée par la situation du port; de là le grand avantage que prẻsente Dunkerque sur le Havre. La Manche n'est guère qu'une rue, très animée, très fréquentée, mais òi on s'arrête peu, tandis que la mer du Nord est la grand'place de l'Europe, bordèe des façades de ces gigantesques maisons de commerce qui s'appellent Londres, Newcastle, Hlambourg, Rotterdam, Anvers. Dunkerque doit beaucoup à ce voisinage, et avec lui la région du Nord, desservie par un port qui peut presque impunẻment importer sans rendre aux visiteurs l'équivalent de ce qu'ils lui ont amené ${ }^{1}$.

Les autres ports, en plus petit, ont un rôle analogue: grands importateurs, exportant peu, et desservant la région ou ils se trouvent. Mais tandis que les uns, Calais, Gravelines, sont gênés par I)unkorque, qui alssorbe la plus grande part du trafic, les autres, Ostende, Gand, sont dejà trop près d'Anvers. C'est Gand qui réussit le mieux, grâce à sa situation au centre d'une région agricole et industrielle surpeuplée. Le mouvement du port, entrées et sorties réunies, a porté en 1904 sur 2.307 navires, d'un tonnage de 1.546.000 tonneaux; il n'était, en 1894, que de 1 million de tonneaux, et de 500.000 seulement en 1884; le mouvement a done triplé en 20 ans. Aussi l'accroissement du trafic a-t-il déterminé la ville de Gand et l'État belge à faire exécuter de nouvelles améliorations au canal de

1 En 1903, Dunkerque (2.243.000 tonnes) est le $3^{3}$ port français, entre Le Havre (2.587.000 tonnes) et Bordeaux (2.213.000). - Le mouvement du port s'est élevẻ la même anaée à 4.936 navires entrés et sortis, d'un tonnage net de 3.647.225 tonnes. 
Terneuzen, par lequel s’effectuo la totalité de ce trafic maritime. La convention de 1879 avec la Hollande prévoyait un mouillage de $6^{\mathrm{m}}, 05$; les nouvelles stipulations de 1895 et de 1902 vont faire porter le mouillage minimum à $7^{\mathrm{m}}, 80$, élargir à 24 mètres le plafond du canal et à 420 mètres carrés la section. La voie n'aura plus qu'un seul bief, de Gand à Terneuzen, l'écluse nouvelle du Sas-de-Gand devant être ouverte en temps normal; une nouvelle écluse de mer, atteignant 18 mètres de largeur utile, et 140 mètres de longueur, est en achèvement à Terneuzen 1 . D'immenses darsos se construisent à l'Est des anciens bassins de Gand. C'est un effort considérable, que la croissance rapide du port depuis 20 ans semble justifier. Les bassins présentent déjà une animation, une variété remarquables. A côté du grand vapeur anglais apportant du coton ou chargeant des denrées agricoles, du steamer russe ou scandinave chargé de bois, on aperçoit toute sorte de bateaux qu'on ne voit pas à Dunkerque. Là, c'est la péniche flamande, avec ses couleurs vives, qui est seule à naviguer dans les darses et les canaux de jonction. A Gand, on la retrouve encore, mais à côté d'elle s'alignent les longs chalands du Rhin, aux teintes sombres, puis des hateaux hollandais larges et courts, avec une paire d'ailerons à leur flanc, enfin la barque du pêcheur de Philippine amenant des moules et des poissons au marché du vendredi.

Comme à Dunkerque, les importations de matières premières pour l'industrie flamande, lin (27.000 tonnes), jute (14.000), minerais (19.000), d'engrais pour l'agriculture, tourteaux (14.000), nitrates (7.000), enfin de houille anglaise (213.000 tonnes), forment les principaux éléments du commerce gantois, tandis qu'à l'exportation les pommes de terre, les sucres, les matériaux de construction, les fruits, les fils de lin et les ciments sont les articles essentiels. Mais avant tout, et de loin, viennent les bois; ils forment en 1904 plus de la moitié de l'importation : 448.000 tonnes sur $884.000^{2}$. Cette proportion se retrouve dans les autres ports flamands. A Ostende (1902), les bois viennent en tête, précédant les charbons et les nitrates ${ }^{3}$. A Calais (1903), le bois constitue plus de la moitié des arrivages; loin en arrière viennent la houille, les fers, les laines, tandis que les denrées agricoles (fourrages, pommes de terre) prennent le premier rang à l'exportation . Gravelines, Nieuport, hors du mouvement de leurs

1 Gf. Bruneel et Braun, Le Canal de Terneuzen; Gand et ses installations maritimes (Gand, Annoot-Braeckman, 1881, in-4ㅇ, 60 p., $10 \mathrm{pl}$. et cartes); - baron Guillaume, L'Escaut depuis 1830 (Bruxelles, Castaigne, 1903, 2 vol. in $-8^{\circ}, 4$ pl.), II, pp. $450-463$.

2 Rapport Ch. Commerce, 1904, pp. 62-67.

3 Bull. Ch. Gommerce, 1902 , p. 310.

- Tableau Commerce-Navigation, 1903, I, pp. 122-123. 
pêcheurs, n'ont d'activité que par l'arrivée des batraux de bois du Nord ; sur 138 bâtiments entrés en 1903 à Gravelines, 57 revenaient de pêcher la morue, 43 arrivaient de Suède, 21 de Norvège, 8 de Russie ${ }^{1}$. Le bois encombre les quais ; on circule entre des montagnes de planches ; les ports flamands sont réellement des ports à bois. La présence de ces amas a même donné lieu, dans chacune des villes de la côte, à des industries asséz actives. Calais a 6 scieries et des fabriques de moulures (pour bâtiment et canalisation electrique) qui sont prospères et occupent 500 ouvriers. A Gravelines s'est crée au bord de l'Aa un petit quartier industriel contrastant avec la ville vieillotte, et où l'on trouve entre autres deux scieries, une cartonnerie, une grande papeterie utilisant les bois et pâte de bois amenés du Nord. Ostende, Nieuport, ont quelques scieries; de même Dunkerque qui recevait en 1903113.000 tonnes de bois, et en utilise la plus grande partie.

Ainsi ces ports destinés à desservir une grande région industrielle finissent par s'industrialiser eux-memes. A voir passer sur ses quais tant de graines, d'huiles minérales, de balles de jute ou de coton, Dunkerque s'est mis, lui aussi, à fabriquer. Dans la ville et ses faubourgs se sont établies des filatures de lin, de coton et surtout de jute, des fabriques d'huile végétale, des raffineries de pétrole et de soufre, des usines de constructions métalliques, des fonderies, minoteries, rizerie, savonneries, sans compter les grands chantiers de construction des navires où travaillent 1.800 ouvriers. Gravelines s'est dotée d'une filature de chanvre. A Calais même, on pent dire que c'est à la situation maritime de la ville qu'est due la grande industrie du tnlle. Les fabricants anglitis qui acclimatèrent en 1816 le tulle à St-Pierre s"ètablissaient tout naturellement à l'endroit le plus rapproché de l'Angleterre, d'où devaient leur parvenir les machines, ot aussi les filés de lin et de coton, que l'industrie française fut longtemps hors d'état de fournir. Ainsi c'est à sa position de port le plus rapproché de la Grande-Bretagne que Calais doit la présence de cette belle industrio, avec ses 400 fabricants, ses 20.000 personnes employées, sans compter le travail du cartonnage et la construction des métiers à tulle. Créé par les besoins de l'industrie, le commerce a créé l'industrie à son tour.

\section{Le transit.}

Le trafic important qui se fait entre la Flandre et les pays étrangers,

1 Tableau Commerce-Navigation, 1903, II, p. 116. 
amenant les grains, les engrais, les bois et charbons, les laines et les lins, rénvoyant au dehors les produits agricoles et industriels, ne constitue pas encore la totalité du mouvement d'ecchanges qui s'accomplit à travers le pays. La Flandre est une région de transit. Tenant largement à la France, dont aucun obstacle ne la sépare et à laquelle la joignent un réseau serré de routes, canaux et chemins de fer; aux pays de la Meuse et du Rhin par les plateaux brabançons; à la Hollande par les îles et les canaux; établie bien en face de la mer du Nord, route de l'Ecosse, du Danemark, de la Scandinavie et de la Russie, enfin aussi proche que possible de l'Angleterre, la Flandre occupe peut-être la plus belle situation internationale qui soit en Europe. Ce rôle de pays-carrefour, que toute la Belgique partage avec elle, lui a valu bien des désagréments. «Il semble que Dieu ait fait cette bonne Flandre, qu'il l'ait placée entre tous pour être mangée des uns et des autres ${ }^{1} \gg$. Mais la ruée des peuples vers ses campagnes, qui ruinait la Flandre à chaque guerre, l'enrichissait dès qu'on proclamait la paix. La Flandre fut pendant tout le moyen-âge le point de contact du Nord et du Midi de l'Europe. Vénitiens, Génois, Espagnols, Gascons et Poitevins, Danois, Scandinaves, Lithuaniens, Allemands de la hanse, désireux de s'épargner les dangers d'une trop Iongue navigation, ayaient fait des bords du Zwin leur foire permanente, où les produits du Nord s'échangeaient contre ceux de la Méditerranée. A Thourout se prépare l'évangélisation des Danois; les monnaies des comtes du $\mathrm{X}^{\boldsymbol{\theta}}$ siècle, Arnould II, Baudouin IV, retrouvées en Danemark, en Russie, en Prusse, atlestent l'importance des relations commerciales de la Flandre à cette époque ${ }^{2}$. Les denrées de l'Europe entière affluent à Bruges, les unes par mer, les autres par terre, par la Champagne, Bapaume, et la ligne des foires flamandes, allongée de la Scarpe au Zwin, Douai, Lille, Messines, Ypres, Thourout ${ }^{3}$. Par les canaux et la Leulene s'acheminent vers Calais et Wissant les marchandises destinées à l'Angleterre, les tonneaux de vin, les draps de Flandre et ceux de Brabant, croisant en route les sacs de laine, les chevaux et bestiaux, les peaux de mouton ${ }^{4}$. C'est un incessant va-et-vient à travers le comlé, qui enrichit le comte et ses sujets, et ne contribue pas moins que l'industrie à faire de la Flandre du XV $\mathrm{XV}^{\mathbf{B}}$ siècle le plus beau comtó de l'Europe.

Depuis, cette situation s'est modifiée. Lorsque la nature eut tué Bruges

1 Michelet, Hist. France (1837), III, p. 45.

2 Pirenne, Hist. Belgique, I, p. 159.

3 Sur la variété des marchandises vendues à la foire de Thourout, voir le réglement du tonlieu de 1270 dans: Gilliodts, Coutumes, Petites villes, V, pp. 104-106.

* Tailliar, Livre des Usaiges, art. 176, p. 73. 
au profit d'Anvers, le trafic international adopta sans peine ce deplacement de quelques kilomètres: mais il suffisait à tuer la Flandre. Servi par un admirable réseau de voies thuviales, qui s'enfoncent dans toutes les directions comme les branches d'un éventail, Anver's a gardé sa qualité de grand port de transit. Dunkerque seul peut prétendre à lutter, expédie des marchandises ver's le Sud hors de la Flandre et du pays houiller vers la Picardie et la Champagne; et l'on peut espérer que le jour où il possédera ver's la Meuse et la Moselle la voie d'eau directe qui lui manque, il étendra jusqu'en Iorraine le rayon d'action de son port. En attendant, le rôle international de la Flandre s'est réduit au transport des voyageurs. De ce côté au moins, elle a gardé tous les avantages que lui donne sa situation. Aucun progrès n'empêchera Calais d'être le point du continent le plus rapprochè d'Angleterre, si bien qu'une heure de navigation suffit d'une terre à l'autre. Plus de 300.000 voyageurs s'embarquent ou débarquent chaque année dans son avant-port; 301.677 en $1902^{1}$; 306.062 en $1903^{2}$. Ostende de son côté en voit passer 120.000 environ par an, 113.827 en 1900, 129.(149 en $1902{ }^{3}$. Boulogne et Dieppe en 1902 avaient un mouvement de 158.000 et de 195.000 ; l'avantage reste donc aux ports flamands. De 1888 a 1902 , les lignes de Calais et d'Ostende ont transbordé 5.630.000 voyageurs, soit 375.000 par an; aujourd'hui le mouvement atteint 130.000 . Ces foules s'embarquent, au sortir des steamers, dans les grands trains rapides qui traversent la Flandre à toute vapeur; si la ligne Calais-Paris quitte aussitôt la plaine pour les hauteurs crayeuses du Boulonnais, la ligne Calais-Bâle,par St-Omer et Hazebrouck, dessert Lille et Douai qui Iui assurent d'ailleurs une bonne partie de son trafic ; et les trains Calais-Bruxelles emportent par Lille et Tournai les voyageurs ver's l'Europe centrale. Pour lutter contre l'admirable situation de Calais, Ostende possède des services vers toutes les régions de l'Furope du centre et de I'Est: Ostende-Milan par le Gothard, circulant trois fois par jour, Ostende-Vienne, vers Constantza ot Constantinople, OstendeBerlin et Eydtkühnen. Ainsi la Flandre est encore un des pays de grand transit international ; elle voit passer à toute vitesse les gens affairés qui s'empressent de l'Angleterre vers la Méditerranée, la mer Noire, la Russie, les pays du Danube, ou refluent de ces directions vers le Nord. C'est quelque chose encore que de posséder ces grandes voies; pourtant il y a

1 Exposẻ sommaire Ch. Commerce, 1902, p. 238.

2 Tableau Commerce-Navigation, 1903, II, p. 62.

3 Bull. Ch. Commerce, 1902, p. 312. 
décadence sur l'époque où les marchandises suivaient, elles aussi, ces mêmes routes. L'activité commerciale reste un facteur important dans la vie économique de la Flandre; mais plle n'occupe plus le premier rôle comme au temps où le hérault Berry disait que * n'est ce pays riche que des grans marchandises qui descendent en iceluy pays $\gg{ }^{1}$. Cette sentence a cessé d'être exacte, mais elle a été profondóment juste, et l'on verra l'importance de ce commerce international dans l'explication d'une des particularités géographiques les plus curieuses de la Flandre, le grave problème de la surpopulation.

1 Hérault Berry, in Labbe, p. 704. 


\section{CHAPITRE XVII.}

\section{LE PROBLĖmE DE LA SURPOPULATION.}

I. Origines de la population flomande. Les anciennes populations. Invasions germaniques. La frontière linguistique. - II. La Surpopulation. la surpopulation précoce. Mouvements do population au XIX siècle. Causes des transformations. Densité actuclle de la population ; ses conséquences. - III. L'Emigration. Nécessité de I'énigration. Déplacements quotidiens et hebdomadaires. Migrations saisonnières. l'émigration définitivo.

La Flandre est. très peuplée : 249 habilants au kilomètre carré dans la province de Flandre Occidentale, 343 dans celle de Flandre Orientale, 494 dans la partie flamande du départemont du Nord. En ajoutant la Flandre zélandaise et la partie du Pas-do-Calais qui s'ètend dans la plaine flamande, on obtient la forte densité de 312 habitants au kilomètre carré : 3.119.000 personnes se pressaient en 1901 sur les 9.979 (en gros 10.000) kilomètres carrés du territoire flamand ${ }^{1}$. Ainsi la Flandre contient presque le douzième de la population française. C'est une des régions les plus habitées de la terre.

On pourrait dire qu'olle est trop peuplée. Ia Flandre, on l'a vu, n'est pas par elle-même un pays riche. Le sol, dans une grande partie du torritoire, est pauvre, ou médiocre. Les métaux et les combustibles minéraux, dunt l'exploitation attire les foules, ne s'y trouvent pas : ni houille, ni fer. Les matières premières nécessaires à l'industrio sont toujours venues du dehors: la laine d'Angleterre, le lin, au XIX' siècle, de Russie, le coton d'Amérique. Sans doute l'agriculture y est admirablement développée, et l'industrie y est prospère: mais on a vu que c'ètait la présence d'une

1 On trouvera les chiffres do population et de superficie: pour le début du siècie, dans les Mémoires s'atistiques de La Chaise (F'as-de-Calais), Dieudonné (Nord), de Viry (Lys), Faipoult (Escaut); pour le milieu du siècle, dans les Annuaires statistiques des départements du Nord et du Pas-de-Calais, et dans le Recensement de la population belge de 1846; pour 1901 dans la Situation financière des communes de France en 1903, et le Recensement géséral de la I'opulation belge au 31 décembre 1900 (tome I). Les chiffres de la Flandre zélandaise pour 1816 et 1900 ont êté communiqués par M. de Man, à Middelbourg, par l'obligeant intermédiaire de M. Ach. Ledieu-Dupaix, consul des Pays-Bas à Lille. 
population surabondante qui avait déterminé la naissance d'une agriculture savante, et y avait, de force, associé l'industrie. Ainsi la surpopulation en Flandre ne procède pas de la prospérité agricole et industrielle: elle la précède. Agriculture savante, industrio nécessaire, tout vient de là. Le problème de la surpopulation est donc le plus important, et le plus difficile à résoudre, de tous ceux que soulève l'étude de la rógion flamande; il domine tous les autres. Ia meilleure manière de l'aborder semble êtro de suivre à travers les siècles le développement de la population flamande, pour voir à quel moment, ot sous l'influence de quelles causes le pays se trouve surpeuplé.

I.

ORIGINES DE LA POPULATION FLAMANDE.

Anciennes populations.

La Flandre a été peuplée à l'époque préhistorique. Les hauteurs qui derrière Ypres rejoignent aux collines du Sud les monticules de Staden et d'Hooglede recèlent parmi les traînées de cailloux dont elles sont couvertes des silex sur lesquels on a cru distinguer des traces d'utilisation; les auteurs de ces retouches involontaires seraient des hommes palóolithiques, vivant au début de l'époque qualernaire ${ }^{1}$. Du moins, si la présence de ces populations est encore discutée, il n'y a pas de doutc sur le séjour que firent en Flandre les néolithiques. Les collines continuaient à offrir à ces pemples des refuges et des observatoires : aux Monts des Cats et des Récollets, sur le Mont Noir, le Mont Kemmel, le Mont Rouge et le Mont Aigu, sur les collines de Tieghem ot de Lendelede, les tertres de Lichtervelde, Pithem, Ardoye, Gits, enfin à Ter Heest les archéologues ont récolté en abondance grattoirs, haches polies, pointes de flèche, lames ${ }^{2}$. D'autres populations ont abandonné des instruments sur los bords des rivières du pays de Waes, á Rupelmonde, Lokeren,

1 Voir: Rutot (A.), Note sur la découverte d'importants gisements de silex taillés (Bull. Soc. Anthr. Brux., XVIII, 1900). - Discussion dans Claerhout (J.), Nos origines; Le Préhistorique de la Flandre occidentale (Ann. Soc. Ens. Br., t. LII, 1902).

2 Gillós de Pólichy (Ch.), Les stations préhistoriques de la Flandre occidentule (11. Congrès arch. et histor. de Belgique, Gand, 1896, II, pp. 28-37); - Rapports sur les fouilles de 1900 et 1001 , rédigés par le baron de Lö̈ pour la Soe. d'A rchéologie de Bruxelles; - Claerhout (J.), Les stations ncolithiques de Pitthem (Bull. Soc. Anthr. Brux., XXI, 1902-03). 
Exacrde, Iacknam 1. Enfin les vallées marécageuses semblent avoir été des points d'établissement appréciés des néolithiques. Sur les pienx enfoncés dans la tourbe s'élevait une palafitte: on en trouve des débris dans la vallée de la Caele à Meerendré; sur le bord de la Deûle à Houplin; le long de la Mandel à Roulers, Emelghem et Denterghem, dans les tourbières de l'Escaut à Audonarde ${ }^{2}$. Ces populations ont d'ailleurs laissé d'autres traces que les débris de leurs habitations et de leurs instruments; elles ont contribué à former la race flamande actuelle. Il suffit d'avoir voyagé quelques jours en Flandre, et d'avoir interrogé les habitants, pour s'apercevoir qu'à côté des Germains blonds ou roux, aux yeux bleus, existent des types bruns aux yeux foncés, que d'innombrables métissages relient aux blonds par une foule d'inlermédiaires où se distinguent tous les tons châtains. Les bruns, moins nombreux, semblent représenter les anciennes populations, repoussées dans les forêts par les onvahisseurs, comme il est arrivé à Ter Heest et à Maldegem. L'examen des résultats de l'enquête anthropologique faite en 1879 sur la couleur des yeux et des cheveux semblo indiquer que le type brun se retrouve surtout vers la frontićre française, vers le pays resté plus pur d'infiltrations germaniques : $32,7 \%$ dans le canton de Messines, 31,7 dans celui du Sud d'Ypres, 29,5 dans celui de Wervicq, tandis que le type blond garde une majorité considérable dans les cantons de la Flandre orientale: St-Nicolas et Zele, $(56,2 \%$ contre 17,5 et 16,8 de bruns), Hamme, I cokeren, St-Gilles-Waes, Somergem, Thourout, Ardoye et Thielt, où la proportion des blonds dépasse $50 \%$ sans que celle des bruns atteigne le chiffre de $23^{3}$.

- Van Raemdonck (J.), Ic pays de Wacs nólithique (Congrès arch. et histor. Namur, 1886; pp. 241-293). In même autenr: Io pays de Waes à l'époque du mammouth (Ann. C. A. P. Waes, XII, 1889-90), pp. 79-122 et 185-194); - Le pays de Waes préhistorique (St-Nicolas, Edom, 1878, in-8 ${ }^{\circ}, 153$ p., pl.).

2 Voir: Gosselet, Esquisse, Quaternaire, pp. 315-319; - Schaeyes, Notice cur plusieurs découvertes d'antiquités (Bull. Ac. R. Belg., XIV, 2 partie, 1847, p. 260); - Claerhout (J.), Objets provenant de la station palustre de Ienterghom (Ann. Soc. Arch. Brux., XVI, 1902, $1^{\text {re }}$ et $2^{\circledR}$ livraisons, et XVII, 1903, $3^{\star}$ et $4^{\mathrm{e}}$ livraisons); - de Loë (A.), Découverte de palafittes on Belgique (C.-R. Congrès international d'Anthropologie, XII' session, Paris, 1900); - Delvaux (E.), Les alluvions de l'Escaut et les tourbières aux environs d'Audenarde (Ann. Soc. géol. Belg., XII, 1885, Mém. pp. 140-170).

3 Vanderkindere (L.), Inquête anthropologique sur la couleur des yeux et des cheveux en Belgique (Bull. Soc. belge Géog. $3^{\circ}$ année, 1879, pp. 409-449, 4 cartes). - Consulter : Houzé (Dr), Les indices céphaliques des Flamands et des Wallons (Bull. Soc. Anthr. Brux. I, 1882-83, pp. 20-26) ; Cartes de la taille en Belgique (Ibid., VI, 1887-88, p. 304); 
Les populations celtiques qui possédèrent la Flandre sous le nom de Ménapiens et de Morins ont laissé peu de traces datant de l'époque où elles étaient indépendantes. Au contraire on peut se fairo une idée de l'élat du pays sous l'administration romaine. Ce n'est pas la région désolée, tout en bois et marais, que l'on s'imagine sur la foi des textes mal interprétés de Cósar et de Strabon. Les monnaies et les vases qu'on y a trouvés en grand nombre, les fragments de voies romaines, attestent le peuplement et la civilisation. Si on ne trouve guere trace de maisons, c'est qu'on les bâtissait, faute de pierres, en torchis, ou en bois, comme l'étaient encore nombre de maisons de la ville d'Ypres au début du XIX ${ }^{\mathrm{e}}$ siècle, et que ces domeures fragiles sont disparues sans laisser de vestiges. Cependant tout le pays ne semble pas avoir été également peuplé. Les cartes archéologiques montrent les antiquités romaines réparties en deux groupes: celui de la plaine maritime, auquel so rattachent les découvertes faites sur le bord Sud, a Bruges, St-Michel, Zedelghem, Aertrycke, Merckem, Bixschoote, Poperinghe; d'autre part le groupe, beaucoup plus compact, des vallées de l'Escaut et de la Lys, qui so poursuit par le pays de Waes jusqu'd Anvers. Entre les deux, un vide, qui n'est comblé que dans la Flandre française. On y a bien dessiné quelques routes romaines assez sinueuses. Mais d'antiquités, on n'en a découvert qu'd Thourout, Gits, Roulers, Rumbeke, c'est-d-dire le long d'une route allant de Courtrai vers le Nord. Ce pays intermédiaire, si vide de traces romaines, était donc assurément peu habité, peut-être désert; c'était la rẻgion boisée ${ }^{1}$.

\section{Invasions germaniques.}

Cette population si inégalement répartie dut subir, après la mort d'Aurélien, une catastrophe à laquelle nous devons l'enfouissement d'un grand nombre de séries monétaires s'arrêtant aux empereurs gaulois ${ }^{\text {z }}$. Le pays ne dut se repeupler que faiblement, car les trésors postérieurs à

Enquête anthropologique sur lo village de Mendonck (Tbid., XV, 1896-97, pp. 244-270, 8 pl.); - Delvaux, Notice sur la feuille de Flobecq. - Enfin les connaissances sur le préhistorique belgo sont résumées dans: Fraipont (J.), La Belgique préhistorique et protohistorique (Bull. Ac. R. Belg., Sciences, 1901, pp. 823-877); - Engerrand (G.), Six leçons de prẻhistoire (Bruxelles, Larcier, 1905 , in-12, VII +263 p.).

1 Voir les listes d'antiquités romaines dans de Bast, et la carte archéologique de Van Dessel.

2 Cf. p. 144. 
cette date n'ont ćtó trouvés qu'en petite quantité, et à peu près uniquement sur les bords de l'Escaut et de la Lys. C'est dans ce pays vidé que pénètrent peu à peu de nouveaux envahisseurs. Installes dans la Toxandrie (Campine) dès $358^{1}$, les Francs touchaient ainsi à l'Escaut; mul doute qu'une partie de ce peuple n'ait déjà pénétré par infiltration lente dans les vallées flamandes, plus fertiles que les sables et les marícages où ils étaient campès. Au dẻbut du Ve siècle, l'invasion de la Flandre par les Saliens est chose faite. Il n'est pas nécessaire de penser que ce fut là une marché d'ensemble d'un peuple s'avançant d'un seul bloc dans un pays nouveau. La désorganisation do l'Empire les laissant libres de chercher vers le Sud une torre plus fertile que la Toxandrie où Rome s'était efforcée de les maintenir, les Francs, arrêtés en Brabant par les ouvrages de défense qui flanquaient en avant la grande voie BavayCologne, et par le monde boisé de la Charbonnière, s'écoulèrent au long de la forêt et se transportèrent, à quelques lieues de leur ancien séjour, le long des rives de l'Escaut et de la Lys. Certaines familles ne firent peutctre pas trente kilometres pour trouver en terre plus fertile, sur les limons sableux d'entre Lys et Escaut, ou le long des ruisseaux du pays d'Alost, l'emplacement d'un nouvel « heim », d'une « sala » définitive. Ce qui restait des Ménapiens et des Nerviens dépossédés se retira dans les fourrés de Thourout et d'Houthulst, dans les solitudes de la Charbonnière, où bientôt ils furent si bien absorbés par les envahisseurs, que le christianisme disparut complètement de la région. Mais au Sud de Courtrai, de Wervicq, d'Estaires, où la population gallo-romaine était restée considérable, les Francs s'établirent en nombre moindre, et finirent par se fondre au milieu de leurs nouveaux sujets ; enfin ce ne furent guère, à la génération suivante, que des enfants perdus d'avant-garde, établis vers Tournai au contact des pays restés romains, qui partirent avec Clovis et firent la conquête politique de la Gaule ${ }^{z}$.

Il y eut cependant en Flandre une région que respecta l'invasion franque. La Plaine maritime, isolée d'ailleurs, par la ligne des bois, des pays saliens de la Lys, était sous les eaux deux fois par jour au moment où les Francs s'établissaient le long des rives des deux fleuves. Il était difficile de pénétrer par terre dans cette région noyée; au contraire des peuples marins pouvaient facilement aborder dans la rangée d’îles de sable

1 Ammien Marcellin, X XIII, 8, 3.

^Voir Kurth (G.), La frontière linguistique, I, pp. 543-550. - Sur l'évangélisation du pays flamand: de Bertrand (R.), Dévotions populaires chez les Flamands de l'arrond. d'Hazebrouck (Ann. Com. fl. Fr., II, 1854-55, pp. 105-186). 
qui limitaient au Nord les wadden de Flandre. Ce sont les Saxons, "peuple vivant dans les boues dos rivages ${ }^{1}$, et les Frisons, que les auteurs de l'époque confondent souvent avec les précédents, qui prennent pied sur cette côte tronçonnée qui était dojà au IVe siècle le Littus Saxonicum. Lorsque St Eloi se risque au VII ${ }^{\mathfrak{e}}$ siècle sur cette terre à peine émergée, il y trouve des peuples marins, "Flandrenses, Andoverpenses, Frisiones quoque et Suevi ${ }^{2}$, différents des Francs de l'intérieur auxquels s'attaquent les prédications de St Amand. On retrouve encore aujourd'hui dans la plaine maritime des traces de l'origine frisonne de la population. La Iangue, Ie droit ancien de la Plaine, ressemblent aux dialectes et aux coutumes frisons; la toponymie de la région côtière, avec ses « ham », ses « tun, ton, thun », si fréquents dans le Boulonnais, ses « wick », « muyde », « mude », « drecht », « donck », se rapproche beaucoup plus des formes qu'on retrouve sur les côtes de Hollande et d'Angleterre, que de celles du pays salien, caractêrisé par le «heim ». On a vu la ressemblanco des fermes de la Flandre zélandaise avec celles du reste de la Zélande, et comment co type d'habitation se rattachait à la maison frisonne. Les mceurs même do la Plaine rappellent celles des habitants de la Frise, et on trouve encore au Nord de Bruges des vieilles femmes qui porlent autour de la tète l'ornement frison appelè « oorijzer ${ }^{3}$; la physionomie même des gens de Leeuwarden ou de Dokkum a été entrevue par M. Winkler chez les gens du pays bas, et particulièrement parmi Jes pêcheurs de la côte. Celte origine frisonne explique en partie les différences qu'on ne peut manquer d'apercevoir en Flandre entre des gens aussi rapprochés les uns des autres que le sont les habitants de la Plaine et ceux de l'intérieur ‘.

Linvasion de la F'landre par ces peuples germaniques refoula vers le

1 Orose, 1. VIII ; cf. Kervyn de Lettenhove, Hist. de Flandre, I, p. 32.

2 Act. SS. Belg. III, p. 231.

3 Claerhout (J.), Sur un ornement frison trouvé à Dudzeele (Bull. Soc. Anthr. Brux. XX, 1901-1902, 4 p.).

- Sur lorigine frisonne des hommes de la Plaine, voir en particulier les travaux de Winkler (J.): Algemeen Nederduitsch en Friesch Dialecticon (S'Gravenhage, Nijhoff, 1874,2 vol. in $-88^{\circ}, 500$ et 449 p.) ; - Oud Nederland (S'Gravenhage, Ewings, 1888 , in-80, 367 p.); - In ons zeventiende gewest (Tijdspiegel, 1895, pp.121-266) [I'Artois revendiqué comne pays néerlandais]; - Studien in Nederlandsche Namenkunde (Haarlem, Tjeenk Willink, 1900, in-80, 328 p.). - Bon article de Vanderkindere (L.), Les origines de la population flamande; la question des Suèves et des Saxons (Bull. Ac. R. Belg. $3^{e}$ série, X, 1885, pp. 431-458, carte, et XI, 1886, pp 211-241); du même : Sur l'établissement des Francs on Belgique, spécialement d'apròs la toponomastique (Bull. Soc. Anthr. Brux., II, 1884-85, pp. 39-48, carte). 
Sud-Ouest la langue latine au profit du dialecte néerlandais que l'on appelle le flamand (Vlaamsch). Le flamand n'est pas une langue homogène, et l'on $y$ distingue des différences assez fortes entre les sousdialectes: l'Ost-flamand, limité à l'Ouest par une ligne très droite passant à Lapscheure, St-Georges, Ruysselede, Aerseele, Wacken, Harlebeke ; Courtrai ${ }^{1}$, et qui est plus proche du brabançon que des idiomes de l'Oues!; le West-flamand, mélangé d'éléments frisons, qui s'étend à l'Ouest du premier jusqu'au contact avec Ia Iangue française; des philologues estiment que celui-ci, dans la prononciation, rappelle le français, tandis que la rudesse de l'Ost-flamand fait déjä songer au hautallemand ". Mais les nuances sont infinies dans chacun d'entre eux. En France, on a pu distinguer un flamand de Bailleul, un autre d'Hazebrouck, de Cassel, de Dunkerquo; et de village à village les differences sont fortes. Un homme de Courtrai, qui ne comprend pas un Anversois, converse sans difficulté avec un citoyen de Leouwarden ${ }^{3}$. Hauthem St-I iévin ne parle pas la langue d'Alost, et comprend à peine ce qu'on dit à Frembodegem, à Burst même, dont 4 kilomètres le séparent. Eecloo possède un idiome différent de celui de Maldegem. Aussi pour faire l'unité et résister aux empiètements du français, les flamingants ontils dû adopter une langue presque étrangère, le néerlandais littéraire, qui est devenu sans modifications le flamand officiel, enseigné dans toutes les écoles de Belgique.

\section{La frontière linguistique.}

Cette langue sans unité avait for't à faire pour se maintenir devant l’invasion lente de sa rivale, lo français, idiome des maîtres du pays, fort de la puissance matérielle et intellectuelle d'un grand royaume. La résistance a été inégale. A l'Ouest, où le tudesque avait jeté une avant-garde qui occupait, dans une position très aventurée, en flèche, le Calaisis et le Boulonnais, les progrès du français ont été considérables. Partant de Boulogne, que le Hamand n'avait pu enlever, la langue romane gagna vers l'Est. Les noms Hamands dominent dans les chartes de l'abbaye de Licques au début du XIII siècle ${ }^{4}$, et les affaires se plaident en tudesque

1 De Bo (L.), Westvlaamsch Idioticon (Brigge, Gailliard, 1873, in-8 , 1488 p.), p. V.

₹ De Bo, p. VII ; - Winkler, Dialocticon, II, pp. 306-388.

3 Winkler, Oud Nederland, p. 139.

4 Haigneré, Chartes de Licques, Mém. Soc. Ac. Boul., XV, p. 13. 
devant la cour de l'abbaye d'Andres en 1229 ; un curé du pays de Langle, appelant d'une sentence, s'exprime en flamand en 1454; les baillis et écherins d'Ardres peuvent tenir leur plaid en flamand (1507) en la mainere accoustumée »; même on 1674 I ouis XIV rend encore en langue germanique une ordonnance pour le pays de Bredenarde. Mais dès le XIe siècle la cour de Guînes emploie le français; des actes dans cette langue sont publiès au XII siècle à St-Omer, et le cueilloir de l'abbaye de Beaulieu (1286) est rédigé de la même manière; en 1586, Philippe II ordonne que toutes procédures dans le pays de Langle se feront en langue française et le magistrat de St-Omer cesse en 1593 de publier ses sentences dans les deux idiomes ${ }^{1}$. Il y a 120 ans, le flamand était encore parlé à Audruicq; le dernier curé flamand y est mort en 1728, mais ses successeurs, jusqu'à la Révolution, étaient encore obligés de connaître les deux langues ${ }^{2}$. Depuis, sous les coups des ordonnances royales en interdisant l'emploi, corsées par le décret de la Convention du 2 thermidor an II, le flamand a repassé l'Aa, et le français le poursuit au delà de la rivière.

Mais aux endroits où la langue germanique opposait à l'envahissement du français un bloc compact, appuyé sur d'immenses réserves, la situation n'a guère changé depuis le haut moyen-âge. De honne heure, les éléments flamands qui avaient franchi la Lys pour s'aventurer autour de Lille, de Valenciennes, de Douai, d'Arras, s'étaient vus absorber par le gros de la population romane; seuls les noms de lieu d'origine germanique, tout défigurés qu'ils sont, restent pour attester la venue des envahisseurs. Lille, Armentières, le pays de l'Alleu, n'ont aucune trace du flamand dans les plus anciennes pièces d'archives qui les concernent, et dès le XII ${ }^{\mathrm{e}}$ siècle on peut admettre que la limite linguistique, entre St-Omer et Courtrai, doit être fixée au Nenffossé et à la Lys ${ }^{3}$. C'est à Courtrai que Guillaume le Breton, revenant du Nord, se réjouit d'entendre de nouveau la langue française ${ }^{4}$; et c'est la Iys que l'Italien Villani indique comme frontière

1 Détails empruntés à : Courtois (A.), Le roman et le thẻotisque belge (Mém. Soc.

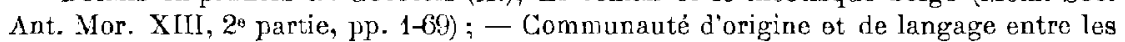
habitants de l'ancienne Morinie flamingante et wallonne (Ann. Com. fl. Fr., IV, 185859, pp. 390-412).

z Dictionnaire hist. et arch. du Pas-de-Calais, arr. de St-Omer, canton d'Audruica, pp. 315-316.

3 Voir les arguments réunis par Dehaisnes (C.), I)élimitations du Français et du Flamand dans le Nord de la France (Bull. Comm. H. Nord, XX, 1897, pp. 277-318), Pp. 202-301.

4 M. G. SS. XXVI, p. 350, vers 580-584. 
linguistique ${ }^{1}$. Or jusqu'au début du XIX ${ }^{e}$ siècle, le français ne fit que de minces conquêtes le long de la rivière. La ligne des communes de la lisière, Reckem, Halluin, Bousbecque, Wervicq-Sur, Comines, Warneton ${ }^{2}$, Ploegsteert, devint romane; une pointe fut poussée vers Ypres, où Zandvoorde, Houthem, Hollebeke même, se francisèrent. Plus loin Nieppe, Steenwerck, Neuf-Berquin, Haverskerque, Thiennes, Boeseghem, Blaringhem et Renescure furent perdues pour le flamand. Ainsi la langue prépondérante, en dix siècles, n'avait pu enlever qu'une lisière.

Il est intéressant de voir ce qu'est devenue la frontière linguistique au cours du XIX ${ }^{\mathrm{e}}$ siècle, où un double mouvement de pression s'est exercé de chaque côté pour la faire reculer, oú pour la première fois on a lulté pour propager l'idiome. En France, l'enseignement obligatoire en français, l'établissement de voies de communication mettant les centres flamands en contact incessant avec les pays de langue romane, la conscience chaque jour plus nette de l'unité nationale, étaient assurément de puissants moyens d'action. Pourtant, la plus grande partie de l'ancien pays flamingant a gardé l'usage de sa langue.

La limite des deux idiomes ${ }^{3}$ part de la còte à l'Est de Dunkerque, à Leffrinckoucke. La ville neuve de Malo est toute française, et Rosendael de même jusqu'au centre; le flamand ne se conserve que chez les maraîchers de la périphérie. Dunkerque est devenu complétement français, et le flamand n'est plus connu que des petits commerçants que leurs affaires mettent en relations avec les gens de la campagne. De même pour les faubourgs ouvriers de Coudekerque-Branche et de St-Pol. Par contre, la langue germanique se maintient, quoique en minorité, dans la partie rurale de Petite-Synthe ot dans la commune de Cappelle. GrandeSynthe possède quelques habitants flamands dans le sud, vers le canal de Bourbourg; Mardick et Loon sont dans le même cas. Le français a gagné sensiblement dans ce coin depuis 50 ans, grâce à la prospérité de Dunkerque et au rôle que la ville joue dans le développement de la France du Nord. De nouvelles conquètes s'annoncent: à Zuydcoote où le Sanatorium améne un élément français important; à Teteghem où la langue romane est en progrès sensible; à Bergues et à Quaedypre oủ les enfants

1 «Liscia, ove si parte la lingua Francesca dalla Fiaminga » (IIistorie Fiorentine, éd. Muratori, Scriptores rerum Italicarum, XIII, p. 502).

2 Pour les progres à Warnoton, voir: do Simpol, Lónvahissement de la langue française en Flandre (la Fl., XIV, p. 41).

3 Cette limite a été étudiée et suivie sur le terrain, avec le concours de M. J. Dewachter, de Lille. - 
dans leurs jeux commencent à délaisser l'ancienne langue pour la nouvelle.

Vers le Sud, les gains sont moins accusés. Craywick est complètement français, mais le flamand se cramponne aux bords du canal de Bourbourg, a Coppenaxfort. Bourbourg est francisé, la dernière génẻration seule sait encore le flamand; celui-ci est refoulé derrière le Vliet, sur Looberghe. A Capellebrouck, la situation est transformée depuis 1856, la prépondérance est passée du flamand au français ; celui-ci tient encore Holque, Watten, et contrebalance l'influence de la langue rivale à Wulverdinghe. A St-Momelin, le flamand n'est guère quo la langue des nouveaux venus, émigrés de Buysscheure, d'Arneke. Lederzeele reste germanique; cependant le français est la langue usuelle de 200 personnes sur 1.400 habitants, et gagne du terrain. Les faubourgs aquatiques de St-Omer sont francisés, et le flamand n'est plus parlé à Lyzel que par un nombre très restreint d'individus. Clairmarais, Renescure n'ont plus qu'une infime minorité flamande. La pénétration commence dans lintérieur, dans le bloc flamand de Cassel : à Staple plusieurs familles n'emploient que la langue nationale; à Bavinchove autour de la gare, à Cassel grâce à la villégiature, le français se taille sa part; il commence à l'emporter dans Ebblinghem.

Enfin dans la plaine de la Lys, le français a lentement pris possession de tout le pays bas, refoulant le flamand vers les hauteurs. Lynde et Sercus restent en majorité germaniques, mais à Steenbecque 150 familles sur 400 sont devenues françaises; à Morbecque le flamand a rétrogradé jusqu'à la place. Hazebrouck, depuis l'établissement de la grande industrie, se francise avec rapidité, quoiqu'elle soit la seule ville on France où dans une institution d'enseiguement secondaire on fasse un cours de néerlandais. De là jusqu’à Bailleul, la limite suit à peu près exactement la voie ferrée, englobant dans le pays roman Vieux-Berquin d'où le flamand est presque disparu. Seule, la ville de Bailleul, solidement appuyée sur la Belgique, reste la citadelle de la langue tudesque en France, abandonnant seulement au français ses faubourgs du Sud, Outtersteene et la Crèche, par où la limite linguistique atteint le territoire belge.

Depuis un siecle, et en particulier depuis 50 ans, le francais a donc gagnè sur tout le pourtour de la lisière; il gagne encore. L'enseignement obligatoire, linstruction religiouse faite en français, le service militaire font beaucoup pour le répandre. Dans toutes les communes où le flamand reste la langue usuelle, le français est compris et parlé de tous sauf quelques vieillards; on entend dans les estaminets les consommateurs 
employer successivement les deux langues, parfois dans la même phrase. Lidiome vieilli dont se sert la population ne s'adapte plus aux nécessités de la vie moderne; déjà les Flamands de France, qui en sont restés au langage de Maerlant, ne comprennent plus les ouvrages belges, écrits en Néerlandais. Pris comme dans une pince entre Lille et Dunkerque devenu un foyer de rayonnement du français, le flamand de France paraît condamné à mourir ; et l'on ne peut plus guère discuter que sur la date d laquelle finira cette agonie ${ }^{1}$.

Mais il n'en va pas de même en Belgique. La propagande flamingante, s'exerçant au nom du principe « in Vlaanderen Vlaamsch», ne s'est pas contentée d'empêcher lo français de prendre, dans la vie des communes purement flamandes, une place exagérée; elle a marché résolument à l'assaut des localités où le wallon était la langue usuelle de la population. Le mouvement d'émigration des ouvriers de la Flandre intérieure, qui descendent de leur's villages vers los villes de la Lys afin d'être à portée des usines françaises, a puissamment aidé cette marche en avant ; l'action du clergé, des institıteurs, n’a pas été moins efficace. Les résultats sont tangibles. A Ploegsteert, si le nombre des français est passé de 1.917 à 2.800 entre 1880 et 1900 , celui des bilingues est monté de 480 à 1.389. Or sous le titre de bilingues se dissimulent des Flamands qui ont appris le français, mais continuent à faire un usage constant de leur langue naturelle ; car le Wallon, le Français, dédaigne d'apprendre le flamand, tandis que le Flamand, servi d'aillenrs par une remarquable faculté de s'assimiler des idiomes étrangers, apprend vite celui qui lui sera utile, la langue du patron d'usine et du contremaître. A Warneton, en 20 ans le français perd 250 unités, les bilingues augmentent de moitié ; de même à Bas-Warneton, el surtout à Comines-Bulgique, vù le français fléchit de 2.651 à 1.910, pendant que les bilingues passent de 218 a 2.384 , le flamand se maintenant de 1.132 à 1.313. Hollebeke et Zandvoorde, de wallons sont devenus fiamands; il reste a Hollebeke 10 wallons contre 767 flamands et bilingues, à Zandvoorde 96 contre 843. Houthem est monacé, perdant 119 français en 20 ans pendant que les autres catégories gagnent. A Mouscron, les flamands purs passent de $7: 23$ à 2.523; à Luingne les bilingues el flamands dépassent les wallons. Le français recule à Dottignies, à St-Genois ; s゙il se maintient dans les petites agglomérations rurales d'Orroir, Amougies et Russeignies, il recule d Renaix, perdant 600 unités pendant que flamands

1 Pour comparer à l'état actuel la situation du flamand en 1856, voir: de Coussemaker (F.), Délimitation du flamand et du français dans le Nord de la France (Ann. Com. fl. Fr. III, 1856-57, pp. 377-397, carte ì $1: 160.000$ ). 
et bilingues en gagnent 6.500, dont plus de 2.000 aux flamands purs. Ainsi tout lo long de la limite, entre Bailleul et Renaix, la poussée du flamand semble irrésistible. Chose plus grave, le territoire français est envahi. On entend parler dans Wervicq-Sud, dans Bousbecque même, la langue germanique; à IIalluin, elle rẻsonne dans tous les corons, et refoule le français dans la campagne; dans les usines, il faut employer des interprètes. C'est un nouveau pays flamingant que l'industrie fixe sur territoire français, sans que l'on puisse craindre d'ailleurs que cette poussée flamande s'avance bien loin au Sud, où elle serait absorbée par les populations françaises comme le sont les inmigrants de Roubaix ou de Lille.

II.

LA SURPOPULATION.

\section{La surpopulation précoce.}

Cependant les Saliens se sont établis dans les vallées de la Lys et de l'Escaut, tandis que les Frisons parsèment de leurs «stellen » les schorres que la mer abandonne dans la plaine maritime. Or la population, dés cette époque, parait dẻjả nombreuse dans le Sud du pays flamand. Le nombre considérable de villages que les chartes mentionnent sur les bords des deux grandes rivières aux $\mathrm{IX}^{\mathrm{e}}$ et $\mathrm{X}^{\mathrm{Q}}$ siècles semble indiquer, non seulement que le nombre des habitants devait être déjà considérable dès cette époque, mais encore que cotte forte densité doit remonter jusqu'aux VIII e et. VII ${ }^{\mathrm{e}}$ siècles, car il est peu probable que tous ces villages aient été fondés au IX siècle, dans la terreur des invasions normandes; et les chartes des abbayes demandant frécuemment anx souverains, après le départ des barbares, la restitution ou la confirmation d"un grand nombre de biens dans ces mêmes villages, semblent être une nouvelle preuve qu'ils existaient déjà auparavant '. Le nombre considérable de petites communes très exigues que contient le pays d'Alost donne à penser que ces petits organismes ont èté de très bonne heure érigós en paroisses, tandis que beaucoup de gros hameaux du Nord et de l'Ouest ne sonl pas devenus autonomes parce qu'ils ont été créés et peuplés beaucoup plus tard, presque tous après le XII ${ }^{\mathrm{e}}$ siècle, dans la période des grands défrichements.

1 Van Lokeren, Histoire de'l'abbaye de St-Bavon (Gand, 1855, in- $-8^{\circ}$ ), p. 8. 
Ce ne sont lá encore que des déductions: au XI' siècle, des textes indiquent que la Flandre est déjà surpeuplée. Le premier, Lambert de Hersfeld l'énonce avec précision, en parlant de cette «multitudo, qua regio praegravari videhatur ${ }^{1}$ : c'esl la première fois que l'on indique que la Flandre souffre d'être trop peuplée. Le diocèse de Tournai, qui ne comprenait qu'une partie du pays flamand, aurait eu vers 1130, d'aprés un chroniqueur, plus de 900.000 habitants ${ }^{2}$; l'exagération évidente du chiffre indique au moins que le nombre devait en êlre considérable. Suger d'ailleurs tẻmoigne à la même époque que la Flandre est une terre très peuplée, «valde populosa * ${ }^{3}$. Les faits viennent corroborer ces affirmations. Si aucun peuplo du monde n'a fourni, proportionnellement à l'étendue du pays, autant de combattants pour les croisades, si les Flamands se pressent autour de Guillaume le Conquérant pendant et après sa conquête, s'ils forment déjä sous le nom de Brabançons, qui cache des Flamands de l'Est, des armèes de mercenaires au $\mathrm{XI}^{\mathrm{B}}$ siècle, c'est que le pays, dès cette époque, a trop d'hommes. Le mal est déjà si grand, la Flandre si gênée au XII ${ }^{\theta}$ siècle, qu'il lui faut à tout prix de l'espace: l'expansion commence; les Flamands colonisent à l'extérieur, ils se répandent dans toute l'Allemagne, Marscheu de Brême, Holstein, Thuringe, Misnie, Brandebourg, Lusace, Silésie, jusqu'en Hongrie et en Transylvanie; d'autres passent en Angleterre, sur les marches d'Ecosse et de Galles. On colonise aussi fiévreusement à l'intérieur: les XII et $\mathrm{XIII}{ }^{\mathrm{e}}$ siècles voient la grando poussée vers les bruyères et les hois, vers los hemmes et les jets de mer de la plaine maritime, et la chevauchée des prẻlats courant délimiter les paroisses nouvelles *

La surpopulation existe done dêjá en Flandre à la fin du XI ${ }^{\mathrm{e}}$ siècle. Il s'ensuit que c'est dans la période qui s'étend avant cette date qu'il faut chercher les causes de ce phénomène anormal. Elles n'en sont que plus difficiles à dégager. L’industrie est encore peu développée à cette époque; l'agriculture ne devient intensive que lorsque la population est surabondante.

Une promière hy pothèse, c'est que le nombre d'habitants a dû être élevé dès la fin de l'invasion franque. Une fois engagé dans les vallées do

\footnotetext{
1 Lambert de Hersfeld, Anuales, éd. Holder-Egger, 1894, p, 121.

2 Historiæ Tornacenses, partim ex Herimanni Libris excerptæ (M. G. SS. XIV, p. 344).

3 De Vita Ludovici Grossi regis (Recueil des Historiens de France, XII, p. 54, C.).

4 Cet étal de surpopulation précoce aux XI ${ }^{\circ}$ et XII siècles est remarquablement étudiè dans: Pirenne (H.), Histoire de Belgique, I, p. 134 sqq.
} 
l'Escaut et de la Lys, le peuple salien se trouva resserré entre la Charbonnière a l'Est, les bruyères et les wadden à l'Ouest, arrêté au Sud par la masse des populations gallo-romaines restées denses autour d'Arras, de Famars, de Tournai, et n'ayant à sa disposition qu'un espace assez restreint, la moitié à peine de la Flandre actuelle, qu'il partageait avec les survivants des Ménapiens et des populations préhistoriques. Qu'on y ajoute la forte natalité de cette population germanique, où les grandes familles sont la règle, et où une mortalité considérable n'empêche pas les naissances d'être toujours en excédent sur les décès, et l'on comprendra que le nombre d'habitants devait déjà être élevẻ au XI'e siècle autour de Gand, de Courtrai et de Termonde.

Mais rien ne pouvait, dès les premiers siècles, contribuer à la prospérité et au peuplement de la Flandre, autant que sa magnifique situation internationale et son beau réseau de voies de communications, ses rivières, ses canaux. Ce rôle de marché de l'Europe du Nord, que la Flandre assume dès le IX $\mathrm{X}^{\circ}$ siècle, en attirant chez elle le commerce ot les marchands, que l'on retrouve mêlés au XI siècle à tous les événements de son histoire, donna l'essor au développement des richesses et de la population. Bientôt le commerce permit l'extension de l'industrie, amoncela des foules d'artisans autour des points de transit où s'étaient fixés les marchands, et il fallut, pour les nourrir, transformer en terres productives le maigre sol de sable. L'impulsion était donnẻe; commerce, industrie, agriculture, réagissant les uns sur les autres, firent de la Flandre la contrée la plus peuplèe de l'Europe.

La première crise de surpopulation paraît se terminer à la fin du XII ${ }^{e}$ siècle. L'exode vers l'étranger, le défrichement des terres vides, assurèrent une rẻpartition plus égale des habitants; l'Est, engorgé, se dégagea vors l'Ouost. C'est alors que toute la Flandre se couvre de petits paysans libres, propriélaires d'un lopin et d'une cabane ${ }^{1}$. La prospérité du grand commerce international, par le Zwin el les routes de terre, l'essor de l'industrie drapière, le perfectionnement de l'agriculture, suffisent à assurer la subsistance d'une population pourtant considérable. Les grandes villes sont en plein développement; les campagnes ne sont pas moins habitécs. Linventaire fail en 1328 des biens appartenunt aux rebelles défaits à Cassel donne sur l'état des campagnes de la WestFlandre au début du XIV siècle des renseignements aussi précis que favorables ${ }^{2}$. Watou a envoyé au combat 272 hommes, ce qui, en comptant

1 Pirenne, Hist. Belgique, I, p. 286.

2 Pirenne, Le soulèvement de la Flandre maritime. 
les vieillards, les enfants, les femmes, et ceux des rebelles dont le norn a pu échapper aux commissaires du roi, donne à la paroisse une population d'environ 1.000 personnes. Par la même méthode, on en trouverait 250 à Elverdinghe, 265 à Reninghe, 300 à Roushrugge, 385 à Alveringhem, 400 d̀ Beveren, et ces nombres sont évidemment au-dessous de la réalité, puisque tous les habitants n'avaient pas pris part à la révolte, et que beaucoup s'étaient enfuis au début des troubles.

Vinrent les mauvais jours du XV siècle, la décadence de liruges et le déplacement du grand commerce vers Anvers; la chute de l'industrie drapière; au XVI ${ }^{e}$, la guerre contre l'Espagne, et la lutte avec la Hollande. La Flandre se dépeuple; le problème de la surpopulation est écarté. On constate en 1588 que depuis 5 ans le pays du Franc est inhabité, et les terrains en friche parce que les habitants ont dû fuir; en 1596 on est oblige de payer pour aider les habitants de Cortemarck et d'Aertrycke à remettre leurs terres en culture ${ }^{1}$. C'est pire encore au XVII sièclo. Un registre de la commune de Lampernisse indique qu'en 1643 il existe dans la paroisse 25 fermes de moins qu'en $1420^{2}$. La guerre de la ligue d'Augsbourg a fait mettre en friche 25.000 mesures dans le Franc, et une grande partie des habitants a quitté le pays ${ }^{3}$. Le Vieux-Bourg de Gand et le pays de Waes sont ravagés périodiquement par les Français, particulièrement dans les randonnées que dirige le maréchal d'Humières en 1675 et 1677, et au cours desquelles \& il brûle au nord de Gand les plus beaux villages du monde ». C'est Saffelaere incendié en 1675, en 1676, en 1677, et où il ne reste plus que 4 maisons; Destelbergen et Desteldonck anéantis en 1677, Wachtebeke brûlé en 1676, Hansbeke et Landegem pillés en 1668, Bachte-Maria-Leerne détruit en 1696, Somergem ravagé pendarit la guerre de Succession d'Espagne, et bien d'autres qui partagent leur sort * Après une pareille période de désolation, ce ne fut pas trop de tout le XVIII' siècle pour que la Flandre pût retrouver sa population normale, et ce n'est qu'au XIX $\mathrm{XI}^{\mathbf{e}}$ siécle que s'est posée de nouveau la question de la surpopulation.

\footnotetext{
1 Comptes du Franc, dans Priem, Précis, 2o série, IV, pp. 124 et 144.

2 Notice sur la commune de Lampernisse (Ann. Soc. Em. Br., 2a série, IX, 1851-54, p. 222).

3 Delepierre, Precis, 1 ro série, III, p. 112.

- De Potter et Broeckaert, Geschiedenis van den Belgischen boerenstand tot op het einde der XVIII' eeuw (Mém. C. Ac. R. Belg. XXXII, 1881, 406 p.), pp. 306-309.
} 


\section{Mouvements de population au XIX siecle.}

La densité de population indiquée pour la première fois d'une façon précise par les recensements opérés de 1801 à 1804 est dejjà considérable. La répartition est inégale d'állleurs; il y a des régions faiblement habitées: d'autres ont dès lors trop d'hommes. La plaine maritime ne présente guère que des communes où la densité n'atteint pas 50 habitants au kilomètre carré; on en trouve 27 à Nouvelle-Eglise et St-Georges (du Nord), 15 aux Moëres françaises, 7 aux Moeres belges, 17 à Coxyde, 22 à Vlisseghem et Uytkerke, 23 a Stalhille, 21 à Hock, 22 à Philippine. Au contraire l'intérieur ne contient que des communes où la densité est supérieure à 50 , et l'immense majorité dépasse 100 habilants au kilomètre carré. Autour de Cassel, presque tous les villages atteignent ce chiffre; dans la région boisée, de Dixmure à Thourout et Gand, dans le pays de Waes, onfin le long de la Lys, la densité ne descend qu'exceptionnellement au-dessous de 100. Mais il y a mieux : la riche plaine de la Lys a 9 communes pouplées do plus de 200 habitants au kilométre carré; toutes celles du pays linier de Roulers, Iseghem et Courtrai se tiennent andessus de ce chiffre. Enfin les pays d'Alost et Audenarde paraissent uno vraie fourmilière; de simples communes rurales y dépassent 250 , 300 habitants au kilomètre carré. Erondegem en a 264, Kerkxken 285, Syngem 299, Asper 315, Meire 325, Nederbrakel 361. La population y est plus entassée que dans la région industrielle française; la banlieue d'Alost est plus habitée que celle de Lille. Ainsi le vieux pays salien a gardé à travers les siécles la forte densité que révèle déjà pour le IX l'examen des cartulaires d'abbayes; c'est dans la région où s'érigèrent aux $V^{e}$ et $V I^{e}$ siecles la foule des «heim » et des « sala » que la population se retrouvait le plus étroitement pressée au début du XIX ${ }^{e}$ siécle.

Cette population si dense s'est encore accrue dans l'ensemble au cours du XIX ${ }^{e}$ siécle. L'augmentation a été inégale, mais à peu près générale. Si l'arrondissement d'Hazebrouck passait seulement d'une densité de 146 habitants par kilomètre carré à celle de 161 en 1901, celui de Lille (partie flamande), s'élevait de 344 à 1.298, et celui de Dunkerque de 118 à 202. De 600.000 âmes, la . Flandre Orientale allait an million, et la Flandre Occidentale de 500 à 800.000 . Comparée au mouvement de la population dans les autres régions françaises, l'augmentation flamande paraît extrêmement satisfaisanto.

Cependant la comparaison avec les pays voisins, avec les aulres provinces belges par exemple, est moins favorable à la Flandre. Celle-ci 
LE PROBLEME DE LA SLRPOPULATION

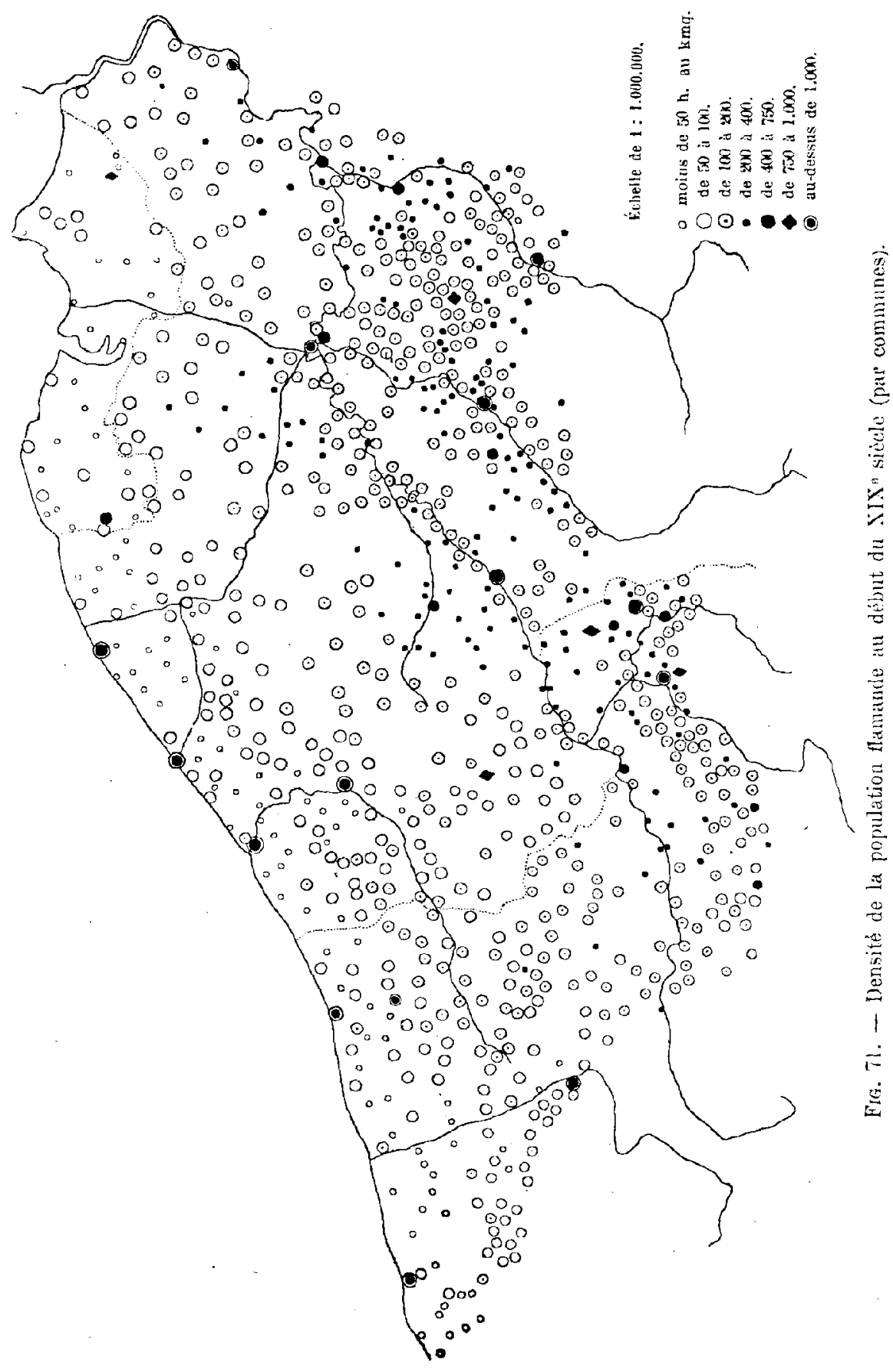


était, jusqu'au milieu du siècle, de beaucoup la région la plus peuplée de la Belgique. En 1831, sur les neuf arrondissemints belges où la densité de population s'élevait aux chiffres les plus élevés, la partie flamande en posscedait huit: Courtrai, Roulors, Alost, Gand, Audenarde venaient en tête, précédant Bruxelles; et derrière, les circonscriptions de Termonde, St-Nicolas of Thielt dépassaient encore colle de Liège. Or, dès 1865, la Flandre avait perdu les premiers rangs; Courtrai et Gand venaient bien loin derrière Bruxelles, Liègè et Charleroi ; Mons précédait de beaucoup Alost, Tormonde et Roulers. En 1895, il n'y avait plus que quatre flamands parmi les dix arrondissements belges les plus peuplés; du deuxième rang, Roulers itait passé an onzième, Audenarde du cinquième au quatorzième, Thielt du neuvième au dix-septième 1 . Et dans cette dẻchéance, il ne s'agit pas seulement de l'infériorité de régions purement rurales dont l'accroissement ne saurait être comparé à celui d'arrondissements où le développement d'une grande ville comme Bruxelles fait doubler on tripler la population. Laccroissement de la population rumle en eflet a étẻ presque aussi faible dans les circonseriptions flamandes que celui de la population urbaine. L'arrondissement le plus favorisé, celui oi les communes rurales ont atteint la plus grande augmentation (arr. de Termonde), n'est encore que lo huitième des $4 \mathrm{~L}$ arrondissements belges; celui d'Ostende est le dixième. Charleroi, Anvers, Liège les précédent là, comme lorsqu'il s'agit de l'accroissement de la population urbaine. Les autres sont loin: Gand est lo 23', Courtrai le $35^{\mathrm{e}}$; enfin celui d'Audenarde se classe $40^{\mathrm{a} z}$. Ainsi le taux d'augmentation de la Flandre belge reste inférieur à celui des autres parties du royaume. Les campagnes de Liège, de Namur, d'Anvers, du Limbourg même, se sont beaucoup plus rapidement développées.

Ce n'est pas pourtant que la nalalité flamande soit inférieure à celle des pays voisins; au contraire. En France, si le Finistère posséde la natalité la plus considérable $(31,94$ pour 1.000 h.), il est immédiatement suivi par le Pas-de-Calais $(31,18)$ et le Nord $(28,72)^{3}$; et la partie flamande du Nord donnerait un chiffre bien plus considérable encore. On a vu combien ce phénomène était caractéristique dans certaines localités, à Halluin $(41,74)$, à St-Pol-sur-mer $(10,35)$. Les départements flamands viennent oncore en tềte pour le chiffre des familles nombreuses; le Yord en comptait (1896)

1 Rutten (A.), Ia population belge depuis 1830. Tone I, Etat de la population (Louvain, Peeters, 189\%, in-8o, 123 p.), p. 48.

Rutten, p. 100. Laccroissement est calculé de 1846 à 1890.

3 Résultats statistiques du dènombrement de 1896, p. 90 . 
53.937 composées de 7 personnes et au-dessus, contre 40.236 à la Seine, 33.193 au Finistère, 27.1 45 au Pas-de-Calais ; de mème il possédait 42.517 groupes de 6 per'sonnes, la Seine 41.193, le Pas-de-Calais 22.571, lo Finislère 17.868. 1. En Flandre belge, les calculs effectués pour la période 1875-1884 montrent que les arrondissements d'Ostende et de Furnes, suivis de près par presque toutes les circonscriptions flamandes, présentent la nalalité la plus forte de loute la Belgique. De 1884 à 1893, Ostende est toujours en tête, suivi de Roulers et de St-Yicolas, les autres arrondissements, sauf Thiell, dépassant largement les arrondissements wallons, où la natalité est beaucoup moins élevée ${ }^{2}$. Mais la mortalité enléve à la Flandre ce que la natalité semblait Iui promettre. Les pays wallons, avec leur quantitẻ restreinte de naissances, n'accroissent pas moins leur population avec plus de rapidité, grâce au faible taux de la mortalité. Dans les mêmes périodes 1875-84 et 1884-93, les arrondissements flamands d'Ostende, puis de Furnes, Dixmude, Gand et St-Nicolas, présenlaient une mortalité supérieure à celle de tout le reste de la Belgique; de toutes les autres circonscriptions de Flandre, celle d'Eecloo seule était privilégiẻe, ot pouvait offrir quelque ressemblance avec les pays wallons, Namur, Luxembourg. Lo tableau de la mortalité par maladies infectieuses met encore en tête Bruges, Ostende, Courtrai, Alost, de loin les premiers de la Belgique ${ }^{3}$. La même distinction se relrouvo dans lo département du Nord, entre arrondissements wallons et flamands. Est-ce là un phénomène ethographique, el la race germanique, plus prolifique, serait-elle moins résistante à la maladie que la française? Ou bien le climat flamand serait-il le coupable, en dépit de la ressemblance qu'il prósente a vec les climats brabançon et picard, dont l'influence est loin d'être aussi néfaste? Ou plutôt les causes de cette forte mortalité ne seraient-elles pas la misère, due à l'entassement de la population dans un pays médiocrement doué, et l'ignorance du paysan flamand?

L'augmentation de la population flamande au XIX' siècle n'est donc pas aussi considérable qu'on aurait pu l'altendre. Et non seulement l'accroissement total reste assez faible, mais il y a même, en quelques endroits, des communes où la population en 1900 se trouve moins élevée qu'en 1800. Dans la Flandre Orientale, 8 communes entre Somergem et la Iys, et une vinglaine autour d'Audenarde, ont diminué de 0 à $30 \%$.

1 Résultats statistiques dı dénombrement de 1894, pp. 52-53.

2 Janssens, Bulletin de statistique démographique et médicalo (Bull. C. G. St., XVII, $1890-96$, p. 955, pl.).

3 Ibid. 


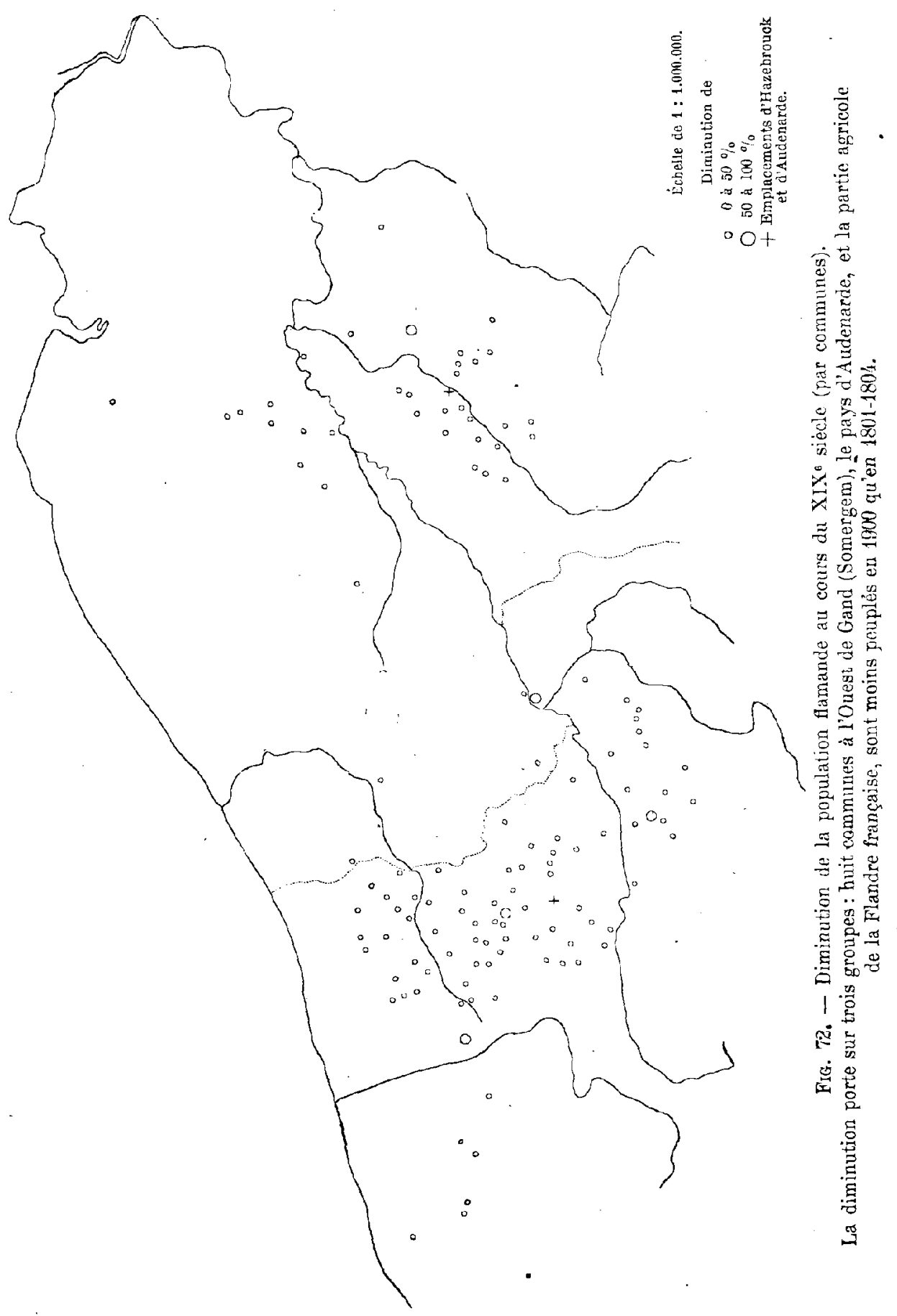


La Flandre française, sauf le pays lillois et la plaine maritime, est plus rudement frappée : 83 communes du rebord de l'Artois, de la plaine de la Iys, et surtout du Foutland de Cassel voient leur population moins nombreuse qu'au début du XIX ${ }^{*}$ siècle ; la diminulion est surtout sensible dans les petits organismes ruraux : elle atteint un quart à Sle-Marie-Cappel et Vieille-Chapelle, trois dixiènes à Wulverdinghe, quatre dixièmes à Warneton-Bas. L'influence de conditions générales, politiques ou économiques, s'annonce déjà dans l'inégalité de traitement entre la partie française of la partie belge. La diminution, générale autour de Cassel et d'Hazebrouck, s'arrête en effet à la frontière; quatre communes belges seulement sont atteintes dans la région d'Ypres, oì les productions, la manière de vivre des habitants, sont identiques à celles du pays français voisin. Quant à la région éprouvée par la dépopulation autour de Somergrem et d'Audenarde, il faut constater qu'elle ètait au XVIII siècle et jusqu'au milieu du XIX ${ }^{\text {e }}$ le centre le plus important d'industrie linière a domicile, et que la disparition des rouets, puis des métiers de Meerendré, Ardoye, Lovendegem, Nevele, Waerschoot, Somergom, Cruyshautem, Wortegem, Huysse, est à coup sûr la cause principale de la diminution constatée.

Ailleur's, l'angmentation est inégale. Le pays d'Y pres voit surtout grandir les villages des hauteurs, de la frontière française à West-Roosebeke: Westoutre gagne $90 \%$, Hollebeke 80, Zandvoorde 70, Zillebeke 90, Zonuebeke $160 \%$; Ies défrichements des collines sont la cause de cette augmentation. Le pays boisé, entre Dixmude, Thourout, Aeltre et Bruges, double ou triple sa population : c'est le resultat d'une nouvelle colonisation du pays, aussi ardente qu'au temps de Walter de Marvis. Avec la mise en valeur des Velden, on a pu voir à St-Michel la population passer de 696 à 2.402 habitants, à Ste-Croix de 1.021 à 3.300, à Eerneghem de 1.495 à 4.514, à Assebrouck de 495 à 2.733, à Bekeghem de 202 à 943, à St-André de 400 à 5.128 : l'augmentation de presque toutes les communes de cette zone est supérieure à $100 \%$. Dans les pays d'Alost et de Termonde, l'accroissement est régulier; la plupart des communes rurales ont augmenté de moitié ou des deux tiers; une trentaine ont doublé. De Menin à Deynze l'industrie du rouissage a fait croitre la population dans toutes les communes de la vallée: Bisseghem a gagné 260\%, Marcke 200 , Lauwe 280. Le pays de lille enfin, comme il fallait s'y attendre, a.commu un accroissement formidable. Le canton d'Armentières, peuplé au début du siècle de 236 habitants au kilomètre carré, en compte aujourd'hui 791 ; ceux de Tourcoing sont passés de 319 à 1.453, enfin les trois cantons de Roubaix, dont la densité au kilomètre carré était de 400 habitants en 1804, atteignaient 

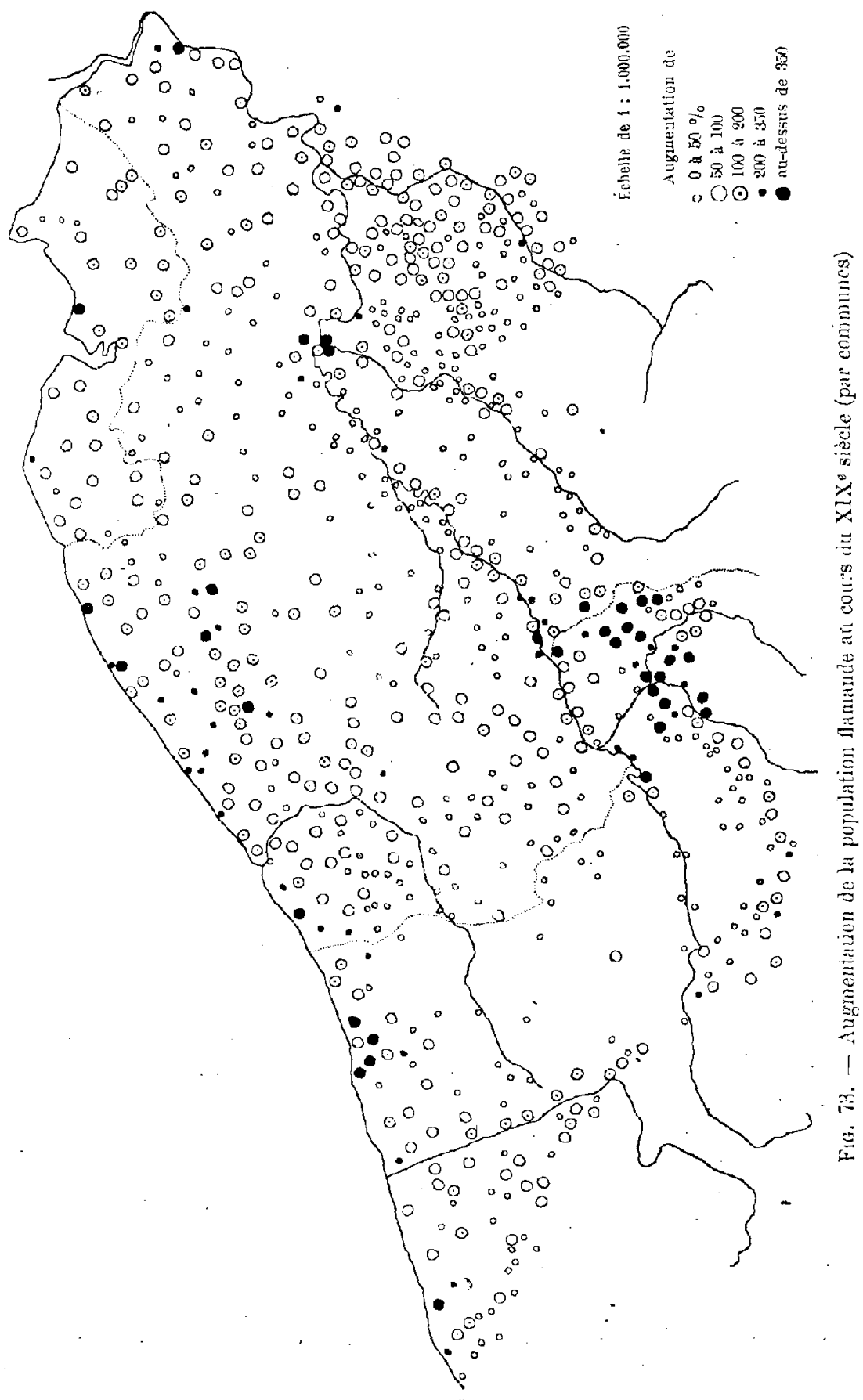
4.522 en 1901 ; la population a décuplé. De Lille à Aire, l'augmentation s'est ćtendue à toutes les communes de la lisiére entre Flandre et Artois, -grâce à la présence du bassin houiller, tout proche de La Bassée et de Béthune.

Mais aucune région flamande n'a connu un accroissement aussi régulier, aussi général, que celui de la Plaine maritime. Les ports et les villages des dunes ont les plus gros chiffres: Coxyde, Uytkerke augmentant de $360 \%$, Heyst passant de 437 a 3.662 habitants $(750 \%$, la banlieue de Dunkerque, de 3.000 à 30.000. Ia plaine elle-même, toutes les agglomérations rurales, participent à l'accroissement: de Sangatte à Calloo, il n'y a pas une défaillance. A Armbouts-Cappel, aux Moëres, entre Ostende et Bruges (Stalhille, V'lisseghem, Oudenbourg), l'augmentation dépasse $200 \%$; ailleurs il n'est pas rare qu'elle atteigne $100 \%$. C'est là le plus beau commentaire de l'ouvre accomplie au XIX $\mathrm{X}^{\ominus}$ siècle par les Wateringues ; parl'aménagement judicieux des eaux, elles ont fait doubler la population d'un pays purement rural, à une époque où la r'égion voisine de Cassel perdait $16 \%$ de ses habitants.

Les phénomènes d'augmentation et de diminution constatés pour le siècle tout entier se précisent dans la deuxième moitié du siècle, lorsqu'on compare aux chiffres de 1900-1901 ceux de $1846^{1}$. Toutes ou presque toutes les communes rurales autour d'Audenarde, ou sur les plateaux entre Audenarde et Grammont, ct d'autre part le groupe de Thielt, Nevele, Somergem et Waerschoot, perdent 10 a $20 \%$ de leur population ${ }^{2}$. A Wacrmacrde, on tombe de 1.260 à 833 habitants; à Caster, de 1.320 à 867. En France, l'abaissement de la population est général, sauf autour de Lille, sur le bord du bassin houiller, et dans la plaine maritime. De Bergues à la Lys, il n'y a pas dix communes rurales en augmentation. De 492, Bissezeele tombe à 325 habitants; Wulverdinghe de 412 a 245 ; Quaed ypre de 1.875 à 1.363 , Ledringhem de 702 à 478 . Le canton de Cassel avait, en 18:16, 127 habitants au kilométre carré : il n'en a plus que 104; colui de Bergues passe de 135 à 121, celui d'Hondschoote de 104 à 93, celui de Wormhoudt de 111 à 97 ; dans le Pas-de-Calais le canton de Laventie perd 2.000 âmes. La dépopulation a mème gagné un coin de la West-Flandre belge, où toutes les communes entre la plaine maritime

1 On $\rightarrow$ choisi le recensement français de 1846 de préférence à celui de 1851 pour plusieurs raisons: il concorde avec un recensement belye (18/6), tandis que le recensement suivant opéré on Belgique ne date que de 1856 ; d'altre part cette date précède exactement la grande crise de l'industrie à domicile, qui a si profondément modifié le pays.

2 Cf. Jacquart (C.), La dépression démographique des Flandres. Fitude sur la natalité de l'arrondissement de Thielt. (Bruxelles, Polleunis et Ceuterick, 1905, in-8, 125 p.). 

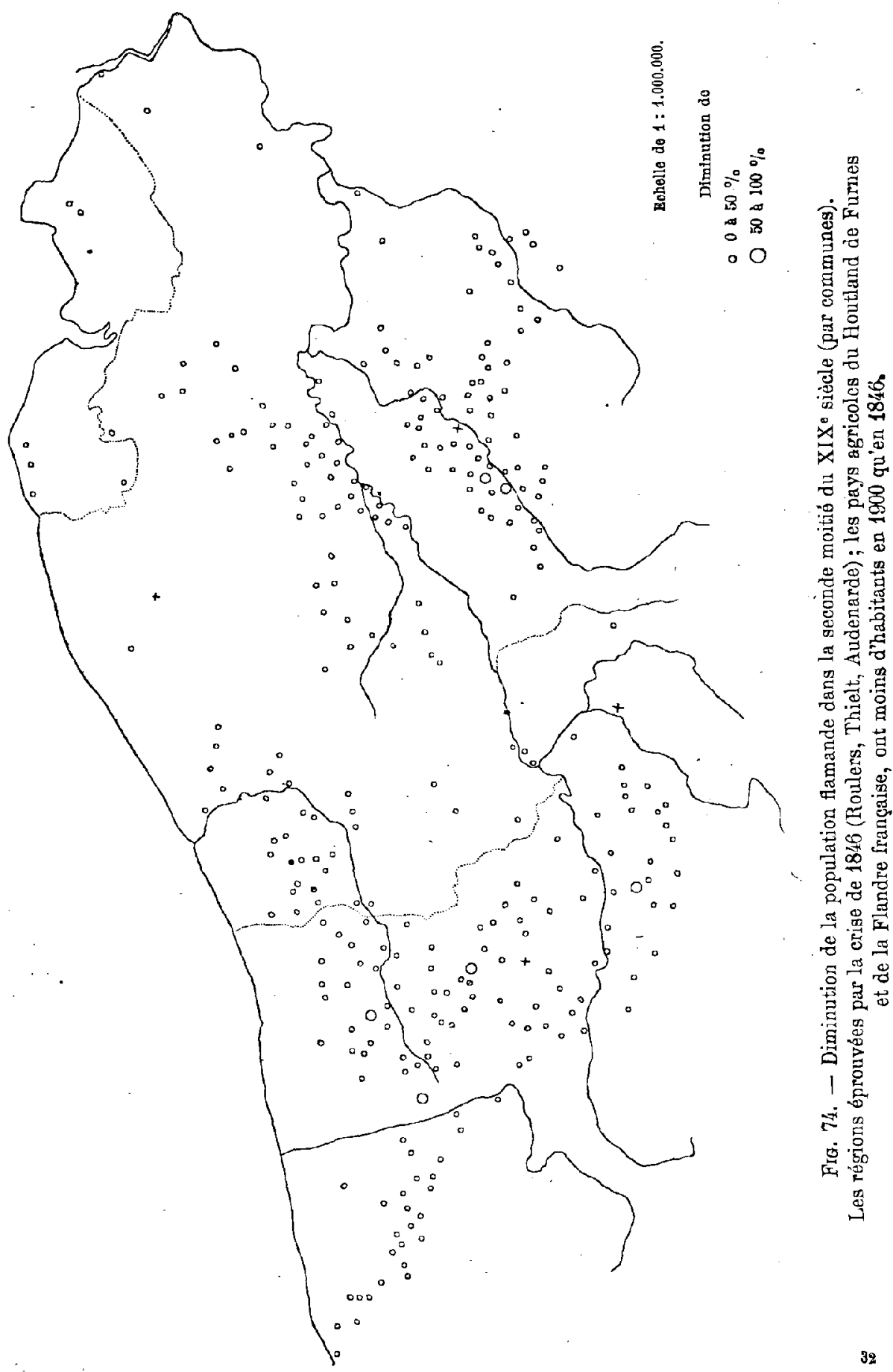


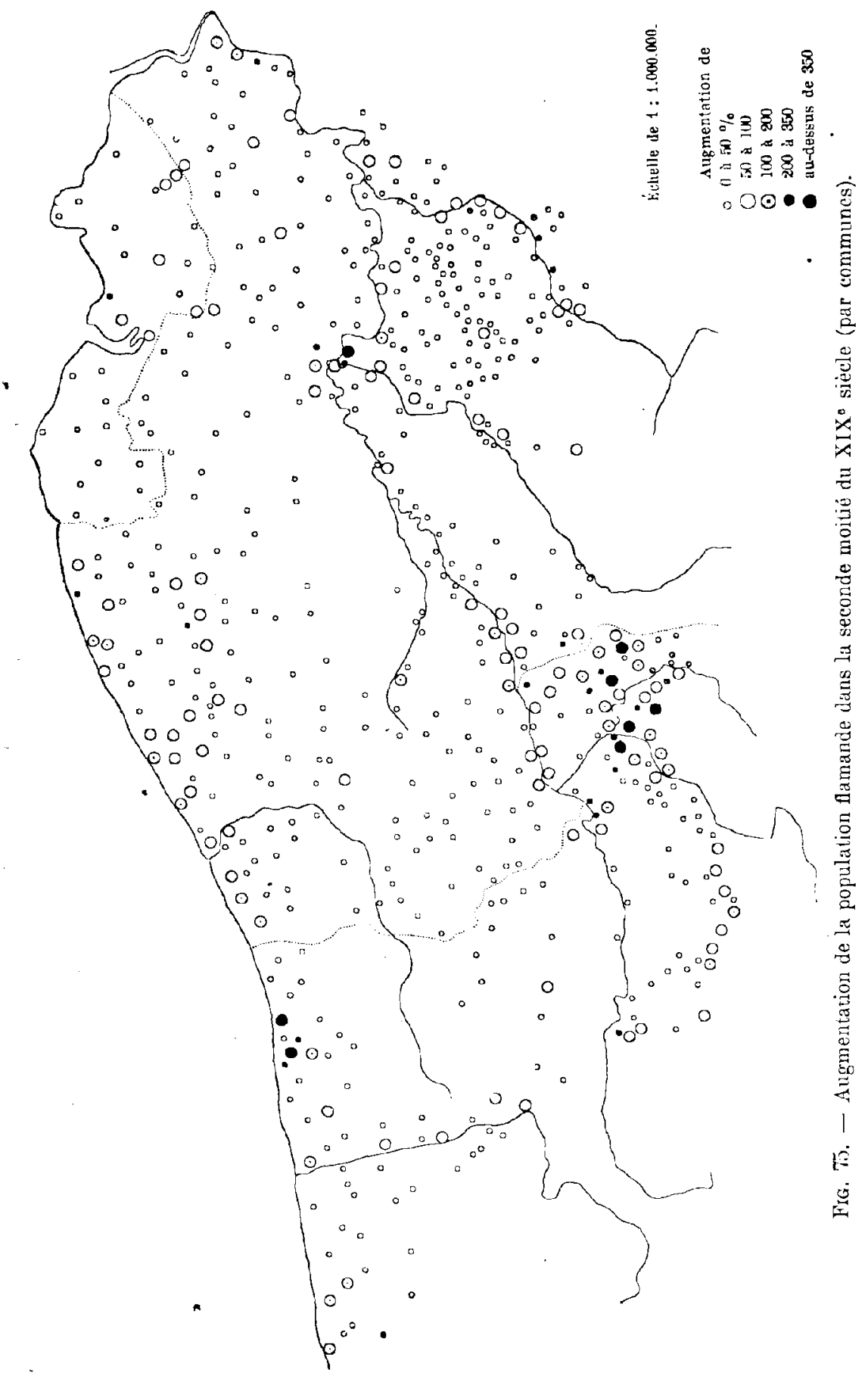


et l'Yser sont en décroissance. Cependant les augmentations se maintiennent de 1846 a 1900 dans les mêmes régions où on les découvrait lorsqu'on considérait le siècle en entier. La banlieue de 'Tille continue à présenter des accroissements de 4 a $500 \%$; le rouissage exerce toujours sur les communes riveraines de la Lys une influence heureuse. Pays d'Alost, pays de Waes, pays d'Ypres, sont en augmentation complète. De même pour la région boisée au Sud de Bruges, et enfin pour toute la plaine maritime; c'est encore là, particulièrement le long de la côte, que persistent les taux les plus élevés d'augmentation.

\section{Causes des transformations.}

Ce ne sont pas des différences de natalité ou de mortalité qui viennent dépeupler telle partie do la Flandre, et accumuler les hommes dans telle autre. Ces augmentations et diminutions sont presque partout le fait de déplacements de population. A mesure que le service des Wateringues perfectionnait le dessèchement de la plaine maritime, faisait disparaître les fièvres et permettait d'éviter les inondations, on voyait descendre dans le pays les fermiers et les journaliers du Houtland, en quête de terres plus riches et de salaires moins faibles. C'est ainsi que le Calaisis est envahi peu a peu par les hommés de Cassel et de Wormhoudt, par les Belges de Roulers : à Oye, il y en a dans toutes les fermes; d Loon, outre les Flamands du Houtland français, on compte 80 Belges établis dans le pays. Seuls les villages des dunes doivent uniquement à leur triomphante natalité laccroissement remarquable de population signalé à Gravelines, Fort-Mardick, Bray-Dunes, La Panne, Coxyde.

C'est surtout vers le Sud, vers les régions industrielles, quo se précipitèrent les émigrants. Les filles vont s'engager comme servantes dans les villes; il y a des villages où le domestique de forme est devenu un rouage introuvable. Les hommes deviennent ouvriers d'industrie, ou pratiquent dans les villes de durs métiers manuels: ils peuplent les faubourgs de Dunkerque, èt les rues tristes de St-Pierre, à Calais ; d'autres vont offrir leurs services aux compagnies minières. Depuis 50 ans; le bassin houiller du Pas-de-Calais fait l'effet d'une énorme pompe pneumatique, dont l'aspiration puissante enlève des hommes de toutes les parties du pays flamand. Il est peu de communes du Houtland français qui n'aient envoyé lour contingent à Bruay ou à Lens, et l'exode continue. En Flandre belge, il en est venu jusque de Thielt, d'Aertrycke, de Clercken, d'Oostcamp et de Maldegem, tandis que la Flandre orientale en envoie surtout vers les charbonnages de la Sambre et de la Meuse, Charleroi et Liège. Enfin les 
grandes villes ont reçu les plus fortes quantités d'immigrants flamands. La Flandre belge a contribué à l'accroissement de Gand, Bruxelles, et Anvers. Surtout le groupe do Lillo a paru longtemps la terre promise, le pays béni des hauts salaires, du travail assuré. C'est entre Armentières, Halluin, Wattrelos et Wazemmes qu'il faut chercher les anciens émigrants de Somergem, d'Ardoye, des banlieues d'Audenarde et de Roulers, mêlés à ceux de Cassel, de Quaedypre, de Vieux-Berquin. Chaque village du Houlland avait au loin sa ville, presque sa colonie, vers laquelle ses émigrants se dirigeaient de préférence: Caprycke envoyait vers Croix, Somergem vers Halluin et Lille. Vite assimilés, les nouveaux venus ont fait souche do Français: on a vu des fils d'immigrants parvenir aux dignités municipales.

Les causes du mouvement qui a vidé au profit de la plaine maritime et des grandes agglomérations industrielles les campagnes du centre de la Flandre sont faciles à apercevoir. Les pays frappés sont ceux qui vivaient de l'industrie à domicile associée à une agriculture savante et aléaloire. L'installation dos filatures et des tissages mécaniques autour de Gand et de Lille réclamait des foules d'ouvriers que la disparition du travail à la main allait fournir. Abandonnant son rouet inutile, la fileuse n'avait plus qu'à venir offrir" son travail aux cardes ou aux bancs à broches de la grande usine, et le tisserand qu'à se transformer en tisseur. Il était pénible pourtant à ces paysans d'abandonner le village, le lopin de terre, le travail familial, pour entrer dans l'inconnu de la grande ville et de l'industrie. Mais l'agriculture etait moins que jamais capable de fournirle nécessaire à ces hommes privés déjà de la moitié de leurs ressources. La mévente des céréales se prononçait à partir de 1860, et le lin, La plante nourcicière, n'était plus d'aucun rapport, écrasé sous la lourde concurrence de la Russie. Il fallut émigrer, partir pour les usines jamais remplies. Ainsi diminua la population, à partir de 1840, dans la plaine de la Lys, dans le pays français de Cassel et bientôt après dans les arrondissements d'Audenarde, houlers et Thielt, les pays du lin par éxcellence, coux qui vivaient de la culture a la fois et du travail de la précieuse plante. Au contraire le pays d'Alost, où de nouvelles industries à domicile venaient promptement remplacer celle qu'avait écrasée le travail mécanique, le pays d'Ypres et la région boisée du Sud de Bruges, où de nouvelles terres s'offraient à la culture, voyaient se continuer leur lente, mais continue augmentation de population. En même temps la plaine maritime, qui n'avait jamais connu le travail industriel à domicile, lraversait sans en souffrir la crise causée par la disparition de ce dernier; et remplaçant dans ses terres fortes le lin par la betterave, elle ne 
trouvait dans le marasme de la culture linière que l'occasion d'une nouvelle prospérité.

C'est donc bien à la disparition ou à la diminution de l'industrie à domicile que sont dues les diminutions de population signalées en plusieurs points de la Flandre intérieurc. La dépopulation a frappé là oủ les rouots et les métiers étaient jadis les plus nombreux. Cependaut il y a encore autre chose. La crise de dejpeuplement, qui semble avoir produit des résultals définitifs dans les communes rurales de la Flandre française, n'a eu que des effets temporaires en Flandre belge. Les communes même qui ont perdu le plus d'habitants depuis 1801 ou 1846, se trouvent aujourd'hui presque toutes en croissance. Dans l'arrondissement d'Audenarde, où 37 communes ont aujourdhui une population inférieure à celle de 1846, il n'y en a que 10 qui aient diminué depuis 1880 : toutes les autres sont en augmentation; et huit seulement ont légèrement diminué de 1890 à 1900 . La diminution par rapport à 1846 s'étend à 12 communes (sur 19) de l'arrondissement de Thielt: or 4 d'entre elles seulement ont moins d'habitants en 1900 qu'en 1880, et 5 out décru légèrement de 1890 à 1900. Dans l'arrondissement de Gand, mêmes constatations: 29 communes y ont un chiffre de population inférieur à celui de 1846, 16 un chiffro inférieur à 1880, 11 seulement un chiffre inférieur à 1890; ainsi la reprise s'accentue à chaque rocensement. Seules quelques très petites communes rurales perdent, chaque dizaine d'années, une douzaine de personnes. On peut prévoir le moment où sera comblé à peu près partout le déficit creusé après 1846 .

Ainsi la population augmente partout en Flandre belge, soit dans les régions où elle avait décru depuis 1801 et 1846, soit dans celles oì elle avait continué son mouvernent d'ascension. En dépit de l'émigration, de la mortalité élevée, l'excédent des naissances suffit à accroître, parfois rapidement, la population. A Wetteren, qui gagne en 10 ans 2.500 habitants, les entrées et sorties s'équilibrent à peu près; il y a en 1908 483 immigrants, et 512 émigrants; mais le nombre des naissances est doux fois plus élevẻ que celui des décès. Oostcamp avait 6.690 habitants au 31 décembre $1900 ; 3$ ans aprés (31 décembre 1903), cette commune purement rurale atteint 7.123 personnes. Rumbeke avait 6.042 habitants en 1846 ; en 1890 on n'en trouve plus que 5.866 ; mais en 1900 le total est monté à 6.116, el dès le 31 décembre 1903 il atteint 6.511. Somergem, qui possédait 7.396 habitants au $1^{\text {er }}$ janvier 1831 , est tombé à 5.000 vers 1850; mais il est bien près d'en retrouver 6.000. Dans la plaine maritime, l'augmentation continue, sauf dans quelques communes du Furnambacht où l'abondance des pâtures fail diminuer la quantité de main-d'œuvre 
nécessaire. A Vlisseghem (Est d'Ostende), l'accroissement est de 25 par an; à Adinkerke, de 60. A l'heure actuelle, il n'y a pas 80 communes en voie de diminution dans toute la Flandre belge. Ainsi la crise qui avait dépeuplé une partie du pays n'était due qu'à des causes temporaires ; c'est la grande misère de 1846-47, aggravée par le déclin du lin et des céréales, qui en était responsable. Aujourd'hui que la grande industrie s'installe dans les campagnes, qu'elle utilise même les métiers à la main qui ont résisté à la tourmeule, el que l'élevage est devenu une source de richesse, la dépopulation paraît enrayée, et l'augmentation redevient générale.

Grosse différence avec la France! Cette frontière invisible et artificielle qui court à travers les champs de la West-Flandre suffit a bouleverser les conditions économiques. Houtkerque, commune française, est mitoyenne de Walou, commune helge: or la première, de 1876 a 1901 , est passée de 1.323 à 1.095 habitants, la seconde de 2.494 à 3.632. En France, la diminution constatée après 1846 n'a pas cessé; il y a même des communes qui se dépeuplent depuis le début du XIX ${ }^{\mathrm{e}}$ siècle. Hondeghem avait 1.596 habitants en 1803, 1.375 en 1816, 1.137 en 1901. Killem passo de 1.407 à 1.348 (1846), à 1.157 (1876), à 1.086 (1901). Ainsi la dépopulation est un mal beaucoup plus profond dans les campagnes françaises; elle n'est pas enrayée comme en Belgique. De 1876 à 1901, 72 communes perdent des habitants dans les deux arrondissements de Dunkerque et d'Ilazebrouck; celles qui en gagnent sont toutes situées dans la plaine maritime, a l'exception de 12, dont quatre villes, Hazebrouck, Bailleul, Merville et La Gorgue. Les cantons de Wormhoudt et Cassel tout entiers sont en décroissance, et la ville de Cassel en cés 25 ans perd à elle seule 1.071 habitants. De même le canton de Laventie, où la diminution de toutes les communes fait tomber la population de 14.798 à 13.554 , et les communes de La Couture et Vieille-Chapelle, passant de 2.062 et 690 habitants à 1.699 et 519 , soit une perte globale de 534 habitants en 25 ans, le quart des leur population totale.

Done, si la dépopulation en Flandre française paraît due, dans la première partiè du siècle, aux mêmes causes qu'en Flandre belge, et particulièrement à la disparition des industries à domicile, d'autres causes l'ont maintenue et aggravée, qui n'agissent pas de l'autre côté de la frontière. La prospérité agricole est cependant revenue, et le bien-être; un rapide voyage de chaque côté de la frontière suffit à montrer que le pays qui se dépouple est loin d'être le moins prospère des deux. Ce n'est pas non plus l'abaissement de la natalité qui cause le déficit; les grandes familles demeurent nombreuses. C'est par l'émigration vers les villes que diminuent toutes ces communes rurales. On entend partout ce monotone refrain: les 
jeunes gens s'en vont, les hommes vers Lille, Dunkerque, Calais, les mines du Pas-de-Calais, Ies filles en particulier vers le groupe de Lille. Calais, il y a 20 ans, eut la grande vogue; aujourd'hui la prospérité des houillères attirerait plutôt vers Lens et Béthune les émigrants. Or' ce déplacement irrésistible, qui menace de vider complètement certaines petites communes comme Wulverdinghe, n'est plus dû̀̀ la misère résultant de la disparition du travail á domicile, - ce sont là vieux souvenirs, presque oubliés -, mais à des causes plus générales. Le service militaire obligatoire, qui fait virre tous les jeunes hommes plusieurs années daus les villes, scmble être le principal coupable: précisément il n'existe pas en Belgique. Ia diminution de certaines cultures délicates, qui exigent beaucoup de soins, est une autre cause: le tabac, le lin, le houblon, réclamaient une main-d'œuvre abondante, que leur disparition a faite libre et qui est allée chercher ailleurs un travail jugé plus agréable et mieux payé. Enfin les machines agricoles, venues pour remplacer los travailleurs dont le nombre se raréfiait déjà, ont précipité l'exode : effet de la dépopulation, elles en sont devenues une cause. Déjà co pays, jadis si peuplé, a besoin de la main-d'cuuve étrangère; les Flamands Belges viennent chaque année y louer leurs bras. Les cabaretiers se plaignent; il n'y a plus d'ouvriers pour achalander leurs estaminets; ceux qui rcstent au pays, bien payés, devenus une manière de bourgeois, ont chez eux de la bière; les beuveries en commun, si chêres aux Flamands d'autrefois, se font rares. Enfin la campagne se parséme de maisonnettes en ruines, désertées pour les corons de Lens, les courrées de Roubaix et de Lille.

\section{Densité actuelle de la population; ses conséquences.}

Malgré les pertes subies au XIX' siècle, malgré des diminutions dont les unes ne sont pas encore réparées, dont les autres vont s'aggravant, la Flandre n'en reste pas moins extrêmement peuplẻe. Il esi vrai que le chiffre global de 312 habitants au kilomètre carré (densité de la population en 1900-1901), ne représente pas une réalité concrète. Dans ce chiffre sont comprises les grandes villes, dont l'énorme population pèse trop lourd dans la balance. De plus, il existe des régions beaucoup moins peuplées, et d'autres dont la densité dépasse celle de la moyenne.

- La Plaine maritime est toujours la partie la moins habitée. C'est la soule région flamande où l'on trouve encore des communes possédant moins de 50) habitants au kilomètre carré, une dizaine environ; et cela en dépit de l'augmentation constante de toute la population de la Plaine au cours du 
siècle. On a vu que d'une part l'importance des exploitations ne permet qu'à un petit nombre de cultivateurs aisés d'acquérir ou de prendre à bail ces fermes dont beaucoup commandent 50 hectares ; d'autre part la grande place que tiennent les pâtures contribue à la faible densité de la population, car l'entretien de ce bétail qui reste la moitié de l'année hors do l'étable ne réclame qu'un petil nombre d'hommes. Lampernisse, la riche commune du Furnambacht, est l'exemple le plus typique de cette faible densité des polders: ses 392 habitants sont 27 par kilomètre carré. La plupart des communes de la Plaine en ont 50 a 100 , sauf les villages de pêcheurs, les stations balnéaires et les ports ; et cette densité, qui paraîtrait considérable partout ailleurs, en fait la région vide de la Flandre; c'est la seule oú l'on puisse éprouver parfois une impression de solitude.

A l'autre extrémité de l'échelle des densilés se tient le pays lillois. Le canton le moins peuplé (La Bassée) y possède déjà 257 habitants au kilomètre carré; celui de Quesnoy-sur-Deûle atteint 358; Lannoy est à 475; quant aux trois cantons de Roubaix, ils sont peupless de 4.522 habitants par unité kilométrique. De lille a Tourcoing, de Mouscron à Lannoy, la campagne n'est qu'une ville, avec quelques champs dans les intervalles des quartiers. Ia présence de l'industrie explique aisément la présence de cette agglonération d'hommes; le pays est très peuplé, mais on ne peut pas dire qu'il le soit trop, puisque ces foules trouvent aisément sur place de quoi les occuper et les faire vivre.

Surpeuplé au contraire se trouve être, quoiquo la donsitó de population y soit bien inférieure à celle de la région lilloise, tout le pays entre l'Yser et la Dendre, entre Ypres et Dixmnde à l'Ouest, Grammont, Termonde et St-Nicolas à l'Est, en un mot presque toute l'Ost-Flandre. Tandis que la West-Flandre, malgré sa fertilité, ne nourrit guère qu'une population de 100 à 200 habitants au kilomètre carré autour d'Ypres, de Cassel, d'Hazebrouck et de Merville ${ }^{1}$, les communes où la densité de population s'abaisse au-dessous de 200 habitants deviennent une exception dans l'Ost-Flandre : 235 habitants par kilométre carré dans l'arrondissement de Thielt, 266 à Audenarde, 319 a St-Nicolas, 349 à Roulers, 362 à Termonde, 388 à Alost. Dans l'arrondissement de Roulers, il n'y a qu'une seulo commune dont la densité kilométrique soil inférieure à 200; encore atteint-elle 199, et cela à cause de la présence, sur le territoire de cette commune (Staden), d'une partie de la foret d'Houthulst. Rien n'est plus remarquable, comme densité de population rurale, que celle du plateau alostois. Entre Sottegem et Alost, 11 communes rurales ont plus de

1 Arrondissement d'Hazebrouck, 161 habitants au kilomètre carré ; d'Ypres, 200. 


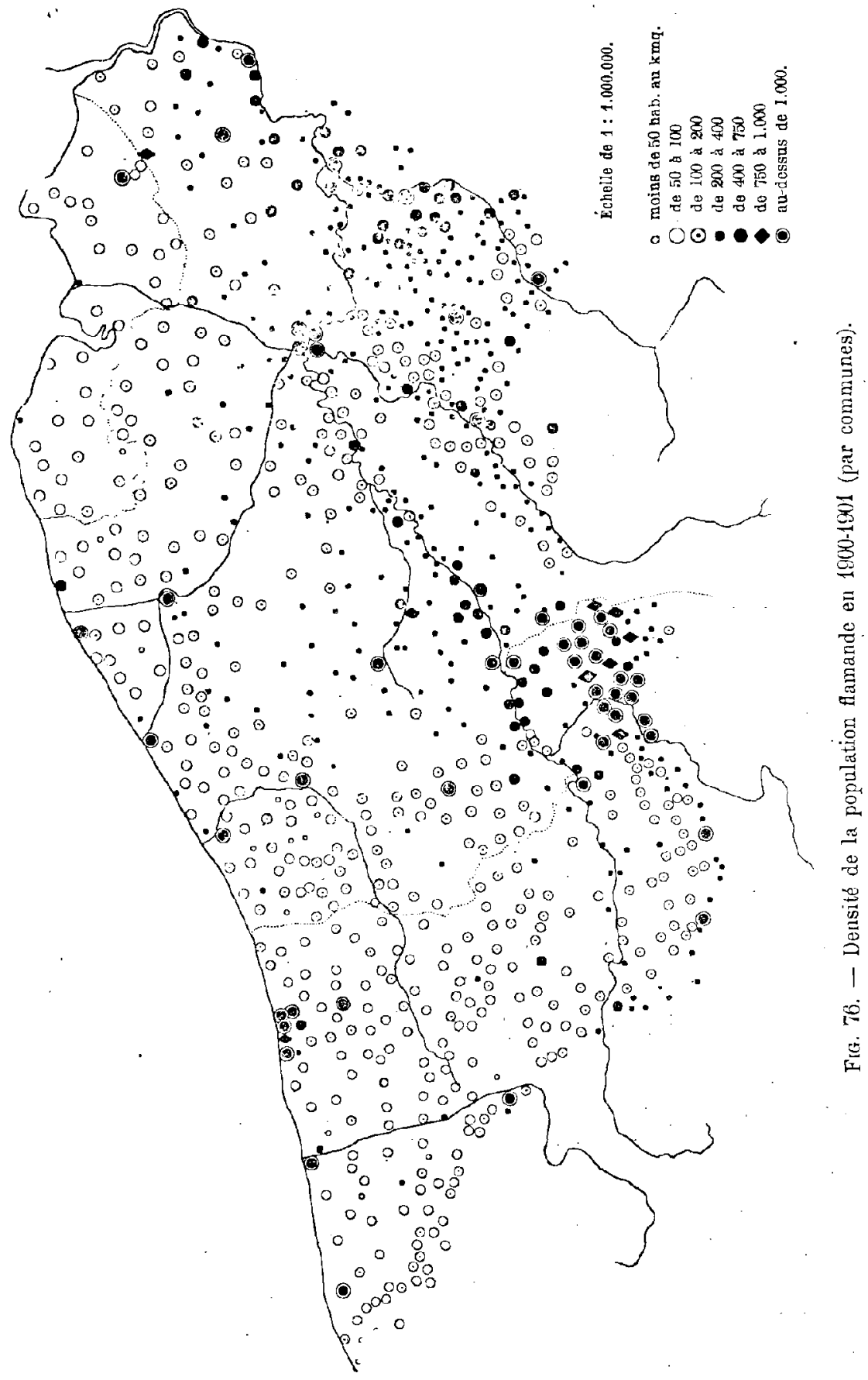


400 habitants au kilomètre carré, 13 dépassent 300 ; aucune n"en a moins de 200. Rien qu'à traverser le pays, l'impression esl forte; le voyageur éprouve qu'il y a vraiment trop de monde autour do lui. On ne peut faire cinquante pas sans voir quelqu'un dans les champs, femmes sarclant en so traînant sur les genoux, hommes labourant, poussant la rasette, grattant le sol, tirant la herse ; d'autres sortant des maisons, conduisant des chariots, montant des charrettes à chiens. On se sent coustamment surveillé, épié; il y a des gons partout, meme lorsque les hameaux sont un peu ćloignés. L'Ost-Flandre grouille de population.

De quoi vit donc cette foule? Quel miracle continu nourrit et fait prospérer ces multitudes? Le sol est pauvre, ou médiocrement riche. La grande industrie, beaucoup moins développée quautour de Lille, est surtout cantonnée dans les villes; elle no fait que commoncer à s'établir dans les campagnes. Dans ces conditions, il faut furcer la nature, faire porter au sol rebelle des moissons plus abondantes que celles des riches terroirs, et joindre aux bénéfices de la culture cenx que procure l'industrie $\dot{a}$ domicile. De là cette agr'iculture de la Flandre de l'Est, ce tour de force par lequcl une terre ingrate, la fremière en Europe, a vu supprimer la jachère, établir les cultures dérobées; ce prodige qui fait que ce pays sans pâtures possède plus de bétail que toul le reste de la Flandre (fig. 60). De lá ce travail du lin à domicile, teillage, flage, tissage, qui ètait l'appoint nécessaire à la vie de ces familles agricoles. Aujourd'hui encore les régions qui ont conservé une industrie familiale sont celles où l'augmentation de la population est la plus rapide, où l'émigration définitive est la moins importante. La West-Flandre française, qui a complétement abandonné le tissage, se dépeuple; l'Ost-Flandre, qui s'entête à garder ses métiers, et leur a adjoint la dentelle, la broderie ou la couture des gants, est en croissance.

Mais les habitants de l'Ost-Flandre ont beau forcer leur terro en la gavant de labeurs et d'engrais, peiner 12 et 14 heures par jour à lancer la navette, a faire voltiger los fuseaux ou a actionner la machine à coudre, ils n'arrivent pas encore à se suffire. Cette population acharnée au travail ne connaît pas la moitié de l'aisance ou vit l'homme de la plaine maritime, qui garde paisiblement ses bêtes ou surveille le travail des tàcherons venus de l'intèrieur; elle se fait concurrence d̀ elle-mème, et végète dans la pauvreté. Sur la carte du mouvement de l'épargne en Belgique, la Flandre apparaît comme le pays ou l'on économise le moins, à l'exception de la plaine maritime ${ }^{1}$. Cette faiblesse de l'épargne en Ost-

1 Burny et Hamaude, Les Caissos d’Epargne en Belgique, planche B. 
Flandre ne signifie pas que l'habitant d'Audenarde ou de Rouler's soit moins économe que celui de Furnes ou de Dunkerque, mais qu'ayant dejjà à peine de quoi se suffire, il ne peut songer à faire des réserves. Il est exact que la plus grande partie de la Flandre est un pays pauvre, que l'homme violente pour lui faire produire la subsistance de la lormidable population qui s'y est établie, sans réussir à faire sortir de l'état degêne cette population qui se développe plus vite que les ressources. De là les crises qui ont secoué le pays, comme celle de 1846 ; mais de lá résulte aussi la misíre qui accable de tous temps uue partie de ses habitants. C'est là un état ancien, et Van der Meerscb évalue déjả à 64.681 le nombre des indigents du seul plat pays pour l'année 1771 en Flandre autrichienne, co qui donnerait sur 100 personnes le chiffre d'une dizaine qui ne pouvaient suffire à leurs besoins ${ }^{1}$. De celte misère chronique est nẻe assurément cette antique et vaste organisation de la bienfaisance dont la Flandre donne l'exemple; mais de là procẻdent aussi cette énorme mortalité qui contrebalance les effets d'une natalité pourtant florissante, ces tares physiologiques qui font que la Flandre précède tous les pays voisins pour la proportion de mortnés, d'infirmes, d'aliénés, d'hommes impropres au service militaire ${ }^{2}$, cette ignorance dont l'Ost-Flandre donne encore l'exemple, et à lcur suite ce taux élevé de la criminalité qui fait que leurs voisins du Sud et de l'Esl considérent parfois encore les Flamands comme des demiharbares.

III.

\section{L'ÉMIGRATION.}

Nécessité de l'émigration.

La Flandre est donc trop peuplée. Il y a dans le pays trop d'hommes pour son étendue et ses ressources. Celte situation ne comporte qu'un remède : il faut aller chercher au dehors ce que le pays ne peut fournir. L’émigration devient nécessaire.

Aussi n'est-elle pas une chose nouvello. La Flandre, vaste réservoir d'hornmes, a souvent débordé; elle a fourni des habitants à toutes los parties de l'Europe. Déjá la surpopulation précoce du $\mathrm{XII}^{\mathrm{e}}$ siècle a

I Van der Meersch (P. C.), De l'état de la mendicité et de la bienfaisance dans la province de la Flandre Orientale depuis le règne de Marie-Thérése jusqu’a nos jours (Bull. C. C. St., V, 1853, pp. 25-268), p. 69.

2 Meynne, Géographie médicale (Patria Belgica, II, pp. 96-sqq.). 
précipité sur toutes les routes des Flamands en quête d'un gîte ${ }^{1}$. Ils en trouvèrent en Allemagne, où la guerre d'extermination contre les Slaves laissait beaucoup de cantons déserts. Dès 1106, ils colonisent les Marschen de Brême; en Thuringe, ils mettent en culture la Goldene Aue, établissent autour d'Erfurt la culture maraîchère au XII sieccle, fondent près de Naumbourg des villages dont l'un porte encoro le nom de Flommingen. Une charte de 1154 parle des Flamands venus par hasard (adventantes) à Meissen; un diplôme de 1200 cite des fermes flamandes dans la vallée de l'Elster noire, et un village de Flämisch-dorf rappelle le souvenir des colons établis près de Leubus (Silésie). L’Anhalt a gardé de leur venue les expressions « ein flämischer Kerl (vigoureux gaillard) et « das ist flämisch» (disproportionné); la rive droite de l'Elbe en face de Magdebourg était la « Flämische Seite ». Enfin les princes, empressés à se procurer de pareils sujets, aussi laborieax qu'habiles, les avaient appelés dans la Wagrie, où un village de Flemigstorf rappelle lour souvenir au Nord d'Eutin; en Brandebourg où Albert l'Ours les établit autour de Stendal ; ot á Jütterbog où ces industrieux émigrants, crousant des puits sur le plateau aride, élevant des digues et creusant des rigoles dans les terres basses, ont si bien transformé le pays qu'il leur a emprunté et qu'il en a gardé son nom de Fläming. Mais ils sont allés bien plus loin encore. A Vienne, des artisans sont atlirés dès 1208, et le métier des tisserands porte encore en Autriche le nom de Flemminge Hantwerk; d'autres se fixent au XII ${ }^{\mathrm{e}}$ siècle dans le Zips, et participent avec les Allemands au peuplement des montagnes de Transylvanie sous le nom général de Saxons. Nombreux autour de Guillaume le Conquérant dans sa conquête, ils pullulent en Angleterre sous Guillaume le Roux, époux d'une Flamande; Henri I ${ }^{\text {er }}$, puis Henri II les établissent sur les marchés de Galles, où le Flemingsway atteste leur activité ; ils apportent dans le Norfolk l'art de travailler la laine, et le roi Edouard, pour attirer ces affamés dans son royaume, fait rẻpandro parmi eux un allèchant prospectus, qui leur promet outremer \& du bon bœuf et du bon mouton, tant qu'ils en pourront manger »". L'industrie drapière anglaise date des denx grandes émigrations flanandes des XIII ${ }^{e}$ et $\mathrm{XVI}^{\mathrm{B}}$ siècles; à cetle dernière date, on trouve jusqu'à 4.000 Flamands établis à Norwich ; aussi

1 Sur l'émigration flamande aux XII'-XIII siècles, voir: de Borchgrave (Mém. Ac. R. Bolg., 1865, VIII + 375 p. ; 1871, VIII + 126 p. ; - Anu. Ac. Arch. Belg., 1874, pp. 744-753); - Pirenne, Hist. Belg., I, pp. 136 et 257.

2 Stocquart (E.), Les Flamands en Ecosse au moyen-àge (Ann. Soc. Arch. Brux,, XIII, 1849, pp. 5-14), p. 7. 
le Norfolk et Norwich restent-ils jusqu'à la fin du XVIII ${ }^{\mathrm{e}}$ siècle le grand centre de cette industrie de la laine ${ }^{1}$. Les tisserands flamands créent à l'étranger bien d'autres industries. Appelés à l'époque de Guy de Dampierre par un sire de Laval époux de Béatrix de Gavere, ils introduisent dans le Maine la grande fabrication des toiles ${ }^{2}$; à la fin du $\mathrm{XV} \mathrm{V}^{\mathrm{e}}$ siècle le Brugeois van Gobeleen va fonder en France la manufacture des Gobelins, dont les ouvriers se recrutaient encore au XVII siècle autour de Bruges el d'Audenarde ${ }^{3}$; d'autres, amenés par le duc d'Epernon, viennent assécher à la fin du XVI ${ }^{\mathrm{e}}$ siècle les marais autour de Bordeaux ${ }^{4}$.

L'émigration a repris de plus belle au XIX' siècle, avec l'augmentalion générale de la population; et la crise de 1846 précipita les Flamands vers les grandes villes belges et surtout vers la région industrielle du Nord français. Depuis 30 ans, les traces de la criso effacées, la population s'accroissant de nouveau, l'exode a recommencé. Aussi bien, il n'y a plus de place en Flandre. La plaine maritime est asséchée; il n'y a plus de moeres à conquérir. Les forêts et les bruyères, à l'assaut desquelles on s'est lancé depuis le début du siècle, sont réduites à leur plus simple expression; on songe plutôt à reboiser des terrains imprudemment défrichés. Plus de wastines, plus de moeres; il faut voir au dehors. Pourtant le Flamand répugne au départ; il tient à son sol ; c'est un paysan difficile à déraciner. Il faut que la nécessité soit biev pressante, qui l'oblige à partir.

Cependant les progrès de la locomotion lui ont permis, depuis 30 ans, de résourire a son gré le problème. Grâce aux voies ferrées, le Flamand est arrivé á émigrer tout en restant chez lui. Il va travailler au dehors, chercher au delà des limites de son pays pauvre un salaire rémunérateur, quitte à revenir le plus souvent possible au logis oú il a laissé sa famille, et autour duquel il cultive encore le petit champ dont le produit, joint à la paye du père et au gain réalisé par les femmes à faire des gants ou de la dentelle, permet d'équilibrer le budget. De là ces nouvelles formes d'émigration qui sont les déplacements quotidiens ou hebdomadaires, et les migrations saisonnières.

1 Cf. Dochesno (L.), L'évalution économique et sociale de l'industrie de la laine en Angleterre (Paris, Larose, 1900 , in-8, 282 p.).

z Kervyn de Lettenhove, Hist. de Flandre, IV, p. 330.

3 Van Bruyssel (k.), Histoiro du commerce et de la marino en Belgique (Bruxelles, Lacroix, 1891-65, 3 vol. in-8\%), II, p. 194.

4 Mess. Sc. Hist., t. 63, 1895, pp. 346-348. 


\section{Déplacements quotidiens et hebdomadaires.}

C'est vers les régions industrielles les plus proches, les grandes villes, les entreprises de travaux publics de longue durée, que se dirige done chaque jour l'ouvrier flamand. Solide travailleur, soumis, peu exigeant, il est recherché des ingénieur's et entrepreneurs, houreux de trouver cet alliẻ dans leurs difficultés avec le prolétariat industriel. Trop éloigné pour attirer chaque jour des Belges, le bassin houiller du Pas-de-Calais emploie au moins des Flamands de France; Steenbecque envoie chaque jour cinquante ouvriers aux charbonnages, cinquante aux aciéries d'Isbergues; Hazehrouck abrite 300 mineurs, qu'un train enlève tous les matins vers Berguette et Béthune, et qui, heureux des 4 à 5 francs de leur salaire qu'ils comparent aux 2 fr. 50 de leurs camarades tisseurs, sont très satisfaits de leur sort et ne craignent rien tant que les grèves. Estaires, La Gorgue, en envoient par le tramway, et d'autres partent à pied de toutes les communes situóes dans le Sud de la plaine de la Lys. De Coulogne et Guînes, on va à Calais; de Teteghem à Dunkerque. Oslende, Blankenberghe, Heyst, Zeebrugge ot ses grands travaux attirent des ouvriers de tout le Nord du Houtland; de Beernem, Oostcamp, Oudenbourg sur la ligne de Gand, de toules les stations depuis Gits sur la ligne de Roulers, ils s'en vont vers $4 \mathrm{~h}$. $1 / 2 \mathrm{du}$ matin, reviennent à 9 houres du soir ; lerrassiers, manouvres, paveurs, briquetiers, il en part déjà une trentaine de Cortemarck, 200 d'Werneghem, 300 de Ghistelles. Dans l'Est, on se dirige vers les travaux du canal de Terneuzen. L'industrie gantoise, en s'ótablissant. dans les campagnes de la Flandre Orientale, crée autant de centres d'attraction que de fabriques; les ouvriers viennent de plusieurs kilomètres aux usines d'Eecloo, de Mocrbeke, de Waerschoot; le nouveau tissage d'Ardoye recrute son personnel à plusieur's lieues à la ronde; de Thourout, Lichtervelde, Thielt, Pitthem, Meulebeke, Denterghem, Ingelmunster, Cachtem, Eeghem, Coolscamp, Emelghem, on se dirige vers la nouvelle usine, à pied ou en chemin de fer. Les grandes villes recrutent les ouvriers d'alentour; on vient à Gand de Maldegem, d'Aeltre, de Novele, de Wetteren et de tous les villages intermédiaires; Anvers attire les gens du pays de Waes; 20) dockers prennent chaque jour le bateau à Tamise, 80 à Rupelmonde ; Cruybeke envoie 600 ouviers travailler dans les chantiers Cockerill, à Hoboken; 700 prennent le train à Beveren-Waes; Melsele, Zwyndrecht se vident tous les matins vers la métropole de l'Escaut. Termonde, Zele, Lokeren même, expédient des trạvailleurs quotidiens vers Bruxelles, 
éloignée de 50 kilomètres; ceux-ci, maçons, terrassiers, partent avant 4 heures du matin, sont de retour à 9 heures, sans parler du trajet qu'ils ont encore à faire à pied jusqu'à leur' domicile ; d'autres viennent d'HautomSt-Lievin, de Sottegem, Herzele, Ninove, de tout le pays d'Alost; Lede envoie chaque jour 5 à 600 terrassiers et paveurs, qui vivent bien, mangent de la viande tous les jours, et vont souvent passer à Gand ou dans la capitale un joyeux dimanche terminé par une soirée au théâtre. Il en est qui ont le courage d'aller travailler, à jo ou 60 kilomètres de chez eux, dans les charbonnages de La Louvière. Enfin l'exode le plus important est celui qui entraîne chaque jour vers la France les ouvriers de Roulers, Thourout, Harlebeke, Avelghem, et de toutes les communes desservies par les lignes se dirigeant vers Herseaux, Mouscron, Menin et Wervica; d'autres à pied, à vélo, font chaque jour les 10 ou 12 kilomètres qui les séparent d'Halluin, de Tourcoing, de Roubaix. Ainsi tous les matins, de tous les points de la Flandre intérieure, des hommes se mettent en route vers les grandes villes, les usines et les mines; la circonférence qui limite l'attraction d'un foyer urbain ou industriel est tangente aux circonférences qui entourent les autres; de Lichtervelde, on va à la fois vers Ostende, Ardoye et Halluin; à Deynze les émigrants se partagent entre Gand et la France, a Lede entre Gand et Bruxelles, a Sottegem entre Bruxolles, Gand et la Wallonnie. De partout, sans souci de l'écrasante fatigue, on se hâte vers les gros salaires.

Cependant, quelles que soient l'endurance de ces hommes et la facilité des communications, il reste impossible à beaucoup d'entre eux de faire chaque jour le voyage entre leur domicile et la ville ou l'usine qui les emploie. Ceux-là se rèsignent à ne revenir chez eux qu'une fois la semaine; partant le lundi matin, ils ne retrouvent leur famille que le samedi soir, et n'ont que le dimanche à consacrer au petil champ que la femme ou les enfants entretiennent pendant leur absence. Les autres jours, réunis on groupes, ils prement ensemble les misérables repas dont les provisions apportées de chez eux font presque toujours les frais, du pain, du saindoux, parfois du lard ; la nuit ils s'entassent dans d'économiques dortoirs, dont la fatigue fait oublier l'exiguité et les conditions insalubres. C'est ainsi que des terrassiers du Sud vont travailler a Ostende ou Zeebrugge; que des maçons de Stekene, de La Clinge et des villages voisins, ont leurs occupations à Bruxelles; que de Zele, de Lokeren, même d'Aeltro (à moitié chemin de (xand à Bruges) il y a des ouvrier's pour Charleroi, et l'on voit parfois de ces malheureux, pour rentrer plus vite chez eux re samedi soir, s'entasser encore noircis de charbon dans les trains oir ils dorment les uns sur les autres. A plusieurs lieues a la ronde de la frontière du pays 
lillois, les ouvriers partent pour los usines le lundi matin, souvont a pied: de Messines pour Pérenchies, de Zandvoorde et Hollebeke pour les briqueteries de la Deûle, de Moorslede pour Halluin, tandis qu'il en vient en chemin de for jusque des environs d'Audenarde et de Deynze.

\section{Migrations saisonnières.}

D'autres partent pour plus longtemps encore, sans quitter pourtant le sol de Flandre. Il y a des régions flamandes où la main-d'cuuvre locale n'est pas assez abondante pour certaines besognes industrielles ou agricoles qui doivent êtro exẻculées rapidement, et à époques fixes. La cueilletto du houblon autour de Poperinghe et d'Alost exige un soin, une minutie, et en mème temps, pour ne pas laisser les baies se gâter, une rapidité, qui obligent les cultivateurs à faire appel à de nombreux étrangers. L'Ost-Flandre en fournit autant qu'on en désire. A Poperinghe, tandis qu'on recrute peu d'ouvriers aux alentours même de la région houblonnière, 10 à 20 par village, il en vient des troupes de l'Est : dójà 30 de Vladsloo, 50 de Becclaere, une centaine de Couckelaere et de Moorslede, 50 d'IIooglede, des centaines de Roulers, de Thielt, d'Aertrycke, de Ghistelles, jusque de Wynghene, d'Aeltre, d'Eecloo (50 en 1903); la paroisse d'Houthulst à elle seule en fournit 3 à 400 ; tous les villages des arrondissements de Roulers et de Thielt donnent. Ces gens partent à pied au début de septembre, cheminant en bandes, chantant le long de la route, au son d'un accordéon, et les paysans de l'Ouest ne les voient pas défiler sans crainte; á leur approche, on clot soigneusement les poulaillers. La commune de Poperinghe en hẻberge ainsi 3 ou 4.000; Watou un millier environ; Boeschepe en avait 2.000 en 1902, 10 à 50 par ferme. Pendant trois semaines ou un mois que dure la cueillette, le pays vit dans la terreur; les batailles sont fréquentes entre houblonniers qui vivent pêle-mêle dans les granges ; on quadruple pendant leur présence les brigades de gendarmerie. Les mêmes scènes se produisent autour d'Alost et d'Assche, oú les cueilleurs viennent du pays de Lokeren et de Termonde; Zole en a parfois envoye jusquu'à mille à la fois.

Ailleurs, c'est pour la moisson, pour le sarclage, le binage et l'arrachage des betteraves, pour la préparation des cossettes de chicorée, pour la sucrerie enfin, qu'on fait appel à l'inépuisable réserve de la Flandre intérieure. La Plaine maritime, avec sa faible population d'agriculteurs aisés, ne peut se passer pour ces multiples opérations de secours étrangers; elle s'adresse aux familles do pêcheurs et surtout aux gens du Houtland. 
En Belgique et en Hollande, toutes les communes de l'intérieur établies le long de la lisière envoient leurs bras disponibles travailler dans les polders voisins ; Stekene à elle seule fournit 4 à 500 personnes, qui restent trois mois absentes; Watervliet, Axel, en reçoivent chaque été plusieurs centaines. On les voit venir, particulièroment nombreux, dans la plaine maritime française, où la culture sur de larges espaces de la betterave et de la chicorée, où la présence de sucreries el do distilleries réclament une main-d'weuvre abondante. C'est ainsi qu'on voit à la distillerie des Moëres des gens de Maldegern; a la sucrerie de la Bistade des hommos de Roulers et d'Harlebeke, des travailleurs d'Oudenbourg et de Ghistelles à Pont-d'Ardres, ou ils se rencontrent avec les pauvres habitants des " côtes » crayeuses du haut pays d'Artois. La chicorée, avec le travail pénible des séchoirs, est une autre spécialité des Flamands belges, particulièrement des gens de Roulers. Tous les hivers, depuis une cinquantaine d'annóes, on les voil se diriger vers la Plaine, vers les tourailles du Calaisis et de Dunkerque; á Loon il en arrive 70 , el 80 se sont établis définitivement. La commune de Beveren-lés-Roulers, qui fournit spécialement les chefs de fabrication, envoie ainsi 300 hommes chaque hiver dans les séchoirs de l'Ouest. Enfin la dimiuution constante de la population daus les communes rurales du IIoutland français, due à l'èmigration vers les villes, oblige les cultivateurs à faire appel aux Belges, surtout pour la moisson; il n'est pas de village qui n'en fasse venir au moins une dizaine; une centaine à Bondues, aulanl à linselles, 50 à Quaedy pre, 40 à Strazeele. A Steenwerck, on convient qu'il n'y aurait pas de moisson sans eux; la propriẻtẻ est trop morcelée pour qu'on puisse se servir utilement de machines; il en vient donc une centaine de la région de Becelaere, génór'alement les mòmes chaque année, sous la conduite d'un chef de bande; ils travaillent une quinzaine, presque jour et nuit, et s'en retournent chez eux à pied. Les rares ouvriers français restés au pays ne voient pas sans dépit la venue de ces étrangers, plus soumis, et mieux payés qu'euxmêmes; ils se vengent par des sarcasmes, les traitant de « Casten », terme méprisant dont la signification est inconnue même de ceux qui l'emploient; ils se moquent de leur pauvre accoutrement, les appellent «Clouftjes 》 (sabots), injure où tient l'immense dédain de l'homme en souliers pour celui qui marche pieds-nus, tenant ses sabots à la main de crairte de les user; à Groede même et dans le reste de la Flandre zélandaise, des batailles éclatent, où les habitants du pays essayent de se vengor de ces * Flamands » laborieux et méprisés.

Beaucoup de ces moissonneurs sont en même temps briquetiers. Le métier est pénible: il répugne à l'ouvrier français : voilà l'affaire du Flamand. Le 
préfet Dieudonné indiquait déjà (1803) que des ouvriers d'Armentières, Frelinghien, Lompret, Pérenchies, partaient chaque année faire des briques dans les autres arrondissements du Nord, et au loin, en Bourgogne, en Bourbonnais '. Il est vrai qu'aujourd'hui ce ne sont plus guère des habitants du pays, mais surtout des gens d'Ypres et de Roulers qui viennent travailler aux briqueteries de la Basse-I)eûle. Il en part bien 300 de Moorslede, 400 d'Harlebeke; il en vient jusque de Steendorp, non loin d'Anvers. Ils quittent leur pays à Pâques, se dirigent vers les chantiers de la Basse-Dê̂le et du bassin houiller; Lens est leur capitale. Mais ils vont bien plus loin au Sud, a travers le pays picard, en Hainaut, en Hesbaye; partout où le limon argileux se prête à là fabrication des briques, on aperçoit leurs énormes tas de briques crues autour desquels circulent leurs équipes silencieuses. En juillet, heaucoup lâchent le moule à briques pour la faucille, et font la moisson, puis reviennent à la fabrication jusqu'à la fin de septembre. La plupart rentrent alors chez eux; d'autres vont s'embaucher jusquà l'hiver dans les sucreries, voire dans les usines métallurgiques et aux charbonnages, où on les emploie à la surface. lls se sont faits, de mars à septembre, 2 fr. 50 à 3 franes d'excédent par jour; la moisson leur a rapporté 100 francs environ; c'est un peu plus de 500 francs qu'ils peuvent rapporter à leur famille, pour l'aider à passer l'hiver.

Mais ces pays du Nord étaient encore trop peuplés, et trop proches de la Flandre, pour que les salaires agricoles puissent être élevés ; les Fla mands en quête de hautes payes s'avisèrent bientòt qu'il leur fallait descendre plus loin au Sud pour trouver les pays rêvés: d'immenses plaines de céréales, habitées par une population clairsemée dont le total diminue sans cesse, la Beauce et la Brie. Sans doute les fermier's de ces régions pensaient avoir avantage a employer les machines agricoles; mais il y a des opérations que ces instruments ne peuvent encore entreprendre, et des circonstances - la verse par exemple - où leur usage est impossible. L'arrivée des Flamands, s'off'rant à planter, à sarcler, à biner, à arracher les betteraves, à moissonner le blé, ful accueillie avec joik ; c'était le remède à l'émigration des campagnes. Depuis une quarantaine d'années, les Flamands vont et viennent chaque année de la Loire et de la Seine à l'Escaut; ils sont devenus un des facteurs les plus importants de la vie agricole en ces régions françaises ${ }^{2}$.

1 Statistique, I, p. 527

2 Voir Eylenbosch (G.), les ouvriers holges en France (Annuaire de la ligue démocratique belge, 1899, Gand, het Volk, 20 p.); -- de Grüune (Gh.), Les ouvriers agricoles belges en France (Rev. gén. agr. L., 1899, pp. 127-133, 145-157). 
Le Franchman, comme l'appelent ses compatriotes, part au printemps. Son bagage est simple: un bissac bleu en toile à matelas, contenant les vêtements de travail, le linge; à la main, il tient la faucille piquée dans un bouchon de liège; sur la tête, uno casquette plate. Il y en a de tous les âges, entre 15 et 60 ans. Les premiers s'en vont au milieu de mars: mais lo grand exode ne se dessine que dans les premières semaines de mai, pour les betteraves. Ils ont étẻ r'ecrutés par un chef de bande, auquel s'est adressé le cultivateur français; des agences de placement existent d'ailleurs dans les villes flamandes, et Lille en possède do nombreuses aux alentours de la gare. Ils voyagent en chemin de fer: par groupes, le gouvernement belge leur accordant un prix très réduit jusquà la frontière. De quinzaine en quinzaine, leur nombre s'accroît; en 1898, le nombre des Belges occupés ainsi en France, de 692 dans la première semaine de mars, s'était élevé à 3.846 dans la $2^{c}$ quinzaine du mois ; il montait à 27.200 dans la première quinzaine de mai et atteignait le maximum, 40.176, à l'époque de la moisson, dans les quinze derniers jours de juillet ${ }^{1}$.

A combien s'élève le nombre des Flamands qui participent à cette invasion pacifique? La statistique de 1898 , établie par le gouvernement belge pour constater quelle quantité d'électours seraiont absents dans un scrutin opéré au cours de l'été, indiquait 31.527 Flamands sur 57.262 partants ; 18.942 de Flandre Orientale, 12.582 de Flandre Occidentale ${ }^{2}$. Ce recensement des émigrants ṇ'a plus été établi depuis; cependant on peut affirmer que le chiffre actuel est buaucoup plus élevé. Cclui de 1898 était do 18.912 pour les 297 communes de Flandre Orientale; or les renseignements fournis en 1904 par les administrations de 23 communes de la province donnent déjà 4.375 parlants ; de même on a trouvé 4.235 émigrants dans 25 communes seulement de Flandre Occidentale. Si l'on ajoute. que dans ces chiffres ne sont pas compris la majeure partie des briquetiers et des moissonneurs qui viennent travailler dans le Nord de la France, on voit que c'est à 50.000, peut-être à 60.000 hommes qu'il faudrait fixer le nombre de ces émigrants temporaires. C'est une véritable armée. Les grosses communes fournissent d'èpais bataillons. Il en part 400 de Langemarck, 450 de Couckelaere, de Lede, de Nederbrakel, 500 de Zele et de Nazareth, 700 de Staden, un millier de Renaix. Certains villages sont vides d'hommes; on n'y trouve plus que les enfants, las femmes et les vieillards.

\footnotetext{
1 Lylenboseh, p. 1.

2 Ibid., pp. 1-5.
} 
Arrivé en France après un voyage lent dans des trains peu rapides, le Franchman gagne l'exploitation où il est engagé, de préférence celle où il a travaille déjà, où ont peiné ses parents ou ses amis; il y a des fermes où ils se succèdent de père en fils depuis 1870. On discute les conditions du travail, et l'on se met à l'ouvrage; payé à la tâche, l'ouvrier flamand fournit un labeur extraordinaire; en moisson, il commence parfois à 3 houres du matin et ne s'arrête qu à 9 heures du soir. Les Franchmans se nourrissent eux-mêmes, à peu de frais comme on pense; la nuit, ils s'entassent dans les granges. Parfois ils reçoivent la visite des cunsuls belges, ou des prêtres qu'envoient des patronages spéciaux; do temps à autre on célèbre à leur intention une messe en flamand dans les centres oú ils sont particulièrement nombreux. Ils vivent isolés de la population française, et supportent cet exil en pays étranger sans trop de peine, étant groupés dans chaque ferme en compagnies nombreuses, une vingtaine en Beauce, 30 à 40 on Brie, jusqu'à 50 dans les grands domaines, tous du même canton, parfois du même village.

La moisson du blé terminée, une partio des Flamands refiue vers le Nord; l'on voit en particulier remonter tous ceux qui s'étaient aventurés au Sud de la Loire, jusque vers Moulins, Châteauroux, Angoulêrme. Ceux du Sud du pays d'Alost, où la moisson est particulièrement tardive ${ }^{1}$, r'etournent chez eux au début d'août, et r'entrent leur blé ou leur seigle avant de repartir à la fin de septembre. D'autres reviennent définitivement; mais un grand nombre restent en France, employés par les fermiers à des travaux accessoires pour attendre l'arrachage des betteraves. Au dèbut d'octobre s'ouvre cette nouvelle campagne, qui occupe encore les Franchmans pendant un bon mois. C'est ver's le 1 ó novembre que la plupart reparaissent chez eux, après 6 mois d'absence. Ils rapportent de 3 à 500 franes, férocement économisés sur leur gain. Le sarclage des betteraves en Beauce leur a valu environ 150 francs, autant la moisson, autant l'arrachage ; les travaux accessoires, une conlaino de francs. En Brie, le salaire est un peu plus élevé ${ }^{2}$. C'est peu pour une pareille somme de travail, mais c'est l'appoint indispensable à la vie de la maisonnée. Dans beaucoup do communes rurales, l'existence des ouvriers serait impossible sans la France. A Hautern-St-Liévin, rien que du 15 mai au 15 août, pour la betterave et la moisson, les 250 tâcherons rapportent environ 300 francs par tête: c'est 75.000 francs de numéraire que cette saison d'été jette dans le village; à Renaix, avec les 1.000 émigrants travaillant de mai à

1 Voir la carte cle la moisson du blé en Flandre (Fig. 3).

2 Lylenbosch, pp. 12-13. 
novembre, c'est presque un demi-million. La dentelle, la couture des gants, le tissage, l'élevage des bestiaux ou du porc sont l'appoint, mais l'émigration en France est la grande ressource; sa disparition brusque provoquerait en Flandre une catastrophe semblable à celle de 1846 .

Cependant tous les Franchmans ne réintègrent pas leur domicile au mois de novembre. Certains d'entre eux, séduits par les hauts salaires de France, sollieités par les fermiers désireux de garder ces bons ouvriers, finissent par se fixer en Beauce ou en Brie; ils font venir leur famille et s'établissent définitivement. De petites colonies agricoles s'organisent ainsi dans ces plaines, $\dot{a}$ la place des paysans français partis pour les villes. La statistique des étrangers dans l'arrondissement de Melun au $1^{\mathrm{er}}$ juillet 1903 indiquait 2.365 Belges, que l'on pouvait prendre pour des ómigrants temporaires; mais le relevé effectué le $1^{\text {er }}$ janvier 1904 en indiquait encore 1.030, parmi lesquels 151 fommes et 241 enfants; ce sont là des sédentaires ${ }^{1}$. D'autres restent jusqu'à Noël occupés dans les sucreries et distilleries du pays picard. Il en est qui, ne pouvant se décider à rentrer, se font pour l'hiver ouvriers d'industrie: les établissements métallurgiques de Hautmont (la Providence) et de Montataire en recueillent un grand nombre; d'autres s'embauchent aux fours à coke des charbonnages du Pas-de-Calais. Ceux-là ne font plus à leur domicile qu'une rapide apparition, de la mi-janvier à la mi-mars; et parfois ils repartent pour Hautmont en attendant l'ouverture de la saison des betteraves. Ceux qui reviennent chez eux on novembre ne peuvent se décider à travailler la terre: les uns se mettent à tisser, quelques autres à faire de la dentelle; ceux de Couckelacre vont louer leurs bras à Ostende, ceux d'Ardoye s'emploient à l'usine, ceux du pays d'Alost vont travailler à Bruxelles. Enfin beaucoup, laissant la femme et les enfants continuer les travaux agricoles entrepris en leur absence, restent oisifs ou s'occupent des soins du ménage. Mais tous, en rentrant chez eux, connaissent la détente qui suil les longues privations et le travail excessif; leur retour s'accompagno d'interminables séances à l'estaminet, suivies de batailles, de coups et de meurtres. Ainsi ils sont devenus de véritables prolétaires agricoles, dont les liens avec leur sol se relâchent sans cesse, et qu'un rien suffit à entraîner dans l'émigration définitive ${ }^{2}$.

1 Communiqué par M. Louis Raveneau.

2 4 u Nord-Est de la Flandre, quelques ouvriers émigrent ailleurs qu'en France. I)e Hulst, on va passer l'hiver à Fssen, dans les usines métallurgiques; les gons de La Clinge vont faire des briquos en Westphalie. I"autres travaillent au canal de Charleroi, à Seneffo. 


\section{L'émigration définitive.}

L'émigration definitive ost beaucoup moins considérable aujourd'hui qu'il y a 50 ans; cependant elle subsiste. Chaque flux et reflux des Flamands abandonne au loin quelques épaves; parmi les ouvriers qui se déplacent à la journée, a la semaine; pour une saison, pour 10 mois, il en est toujours qui restent en route, se fixent dans les villes, aux alentours de la région lilloise, en Wallonnie, en France. Pour atténuer l'influence politique que le séjour en France exorce sur los émigrants, le parti catholique encourage un mouvement qui s'est dessiné depuis une trentaine d'années vers l'Amérique du Nord. C'est vers le Canada (Manitoba), la région des grands lacs (Détroit) et l'Ouost que se dirigent les émigrants, la plupart ouvriers agricoles. Il en part de Flandre zélandaise, de toute la Flandre Orientale, de quelques communes de Flandre Occidentale. La quantité des départs varie avec l'état des travaux agricoles ou industriels. Dans certaines communes, cette émigration a disparu; ailleurs, elle est en faveur. En avril 1904, West-Roosobeke voyait partir 17 de ses habitants ; à Swevezeele, il y a des départs chaque semaine, une centaine au moins par an; à Wynghere 150. T'out l'arrondissement de Thielt en fournit; le village d'Eeghem menaçait un moment de se vider. La crise de l'industrie cotonnière en 1903-1904 a précipité les départs autour de Gand; à Bellem, tout ce qui est fort va en France ou en Amérique. Groede, en Flandre zélandaise, a perdu 150 personnes dans les 6 premiers mois de 1904 ; 70 émigrants sont partis d'un seul coup de Breskens. Dans tout l'Est, les euseignos d'estaminets sont nombreuses qui portent les titres «In Amerika» et «In de stad New-York». D’ailleurs tous les émigrants ne sont pas perdus pour le pays; le Flamand se résigne difficilement à quitler son sol; beaucoup reviennent au bout de quelques années avec uno petile fortune, louent des terres et deviennent des fermiers aisés.

Ainsi l'émigration définitive en pays lointain ne plâ̂t pas au Flamand ; il n’aime pas les décisions brusques et irrévocables; pour qu’il se décide à quitter son village, il faut qu'il ait été longuement sollicité, qu'il ait essayé d'abord du déplacement quotidien, ou de la migration saisonnière. Aussi est-ce tout près de chez eux, à quelques lieues, parfois à quelques kilomèt res de leur ancienne demeure, que vont se fixcr la plupart des émigrants. Le I3rabant wallon, le Tournaisis, le Hainaut, en sont remplis ; ils forment des groupes compacts dans toutes les communes de la Flandre française. Ceux-là viennent gẻnéralement des villages belges les plus proches, oú ils sont romplacés à leur tour par des plus pauvres, venus de l'Est. Les 
communes frontières sont ainsi comme des relais d'une émigration à longue échéance, par oủ se prépare l'absorption des Flamands en route pour l'Ouest. A Neuve-Eglise, la moitié des habitants sont des étrangers, venus d'Ypres, Passchendaele, qui prennent la place des indigènes partis pour les campagnes, les villes et les charbonnages de Frąnce; à Westoutre, la liste électorale comprend $40 \%$ d'hommes non originaires de la commune, venus du Nord et de l'Est. Le mouvement est constaté dans toute la West-Flandre belge: à Messines il n'y a comme ouvriors agricoles que des gens venus d'au delá d'Ypres; Wervicq s'augmente par émigration de Gholuvelt, Becelaere, Roulers; à Gulleghem les ouvriers de forme sont originaires de Gits, IIooglede, Deynze; leurs enfants deviennent teilleurs de lin ou s'expatrient à leur tour en France; à Zandvoorde et Hollebeke, les gens de Zillebeke, Gheluvelt, Zonnebeke remplacent les anciens habitants partis pour Comines, Quesnoy, Lille; le flamand s'avance avec eux, refoulant le français vers la Lys. A Elverdinghe, tous les fermiers viennent de Lichtervelde, 'Thourout, Roulers ; ce sont eux qui ont importé la chicorée il y a trente ans. Merckem descend sur Noordschoote. Peu à peu, la Flandre roule de l'EsL vers l'Oucst, des pays pauvres vers le pays riche. C'est une nouvelle invasion des Barbares, semblable à celle qui s'est accomplie pacifiquement tout au long des quatre siècles de l'empire romain ; comme jadis leurs ancêtres des bords du Rhin, ces Germains pauvres et prolifiques viennent louer leurs bras, se font colons des riches territoires que les Latins quittent pour habiter les villes; peu à pou ils s'établissent, la naturalisation automatique les transformo en Français, et ces nouveaux citoyens ne se distinguent bientòt des autres que par lour docilité et leur endurance au travail. Aucun des 4 à 500 Belges fixés à Bousbecque, à Bondues, à Steenvoorde, à Ghyvolde, dans toutes les communes frontières, ne s'avise de revendiquer pour ses enfants son ancienne nationalitẻ ; ils deviennent Français sans esprit de retour; les traiter de Belges leur parait dejà une insulte. 


\section{GONCLUSION.}

«La Flandre s'est formée, pour ainsi dire, malgré la nature; c'est une œuvre du travail humain ${ }^{1}$. Rien n'est plus exact. Les qualités physiques de la terre flamande sont maigres et rares, ses défauts sont gros et nombreux. Climat désagréable, surtout par son humidité qu'aggrave l'imperméabilité du sol. De la terre, deux parts: l'une féconde à souhait, mais trop basse, recouverte d'eaux stagnantes, menacée en haut par les grandes marées, en bas par los infiltrations; l'autre moins humide quoiqu'imperméable, mais d'une médiocre fertilité, surtout dans l'Est. Pour les cours d'eau; des ruisseaux numbreux et indigents, des rivières trop lentes, attardées en bras morts et en marécages, noyant leur vallée de crues régulières et aussi d'inondations inattendues. Dans l'ensemble, une nature renfrognée, peu accueillante. Mais l'admirable situation géographique du pays y appelait les hommes; la Flandre devait être un lieu de passage, une contrée d'échanges. Les habitants y vinrent donc nombreux, et forcerent la nature. Il y a peu de pays où l'aspect, la valeur du sol, le tracé des cours d'eau, lour régime, en un mot les conditions géographiques, aient été pareillement transformées par l'homme. La plaine maritime a été asséchée, ses caux évacuées, ses terres « endiguẻes, purgées, raffermies 》. Los forêts̀ ont disparu, et les arbres isolés auront demain le même sort, si l'agronomie l'exige; les bruyères sont mises en culture, quitte à y rétablir des bois si l'opération paraissait profitable. Les terres maigres de l'Est portent plus de moissons que les plus riches sols arables, nourrissent plus de bétail que les grandes régions de pâturages. On a changé le cours de certaines rivières, raccourci ou allongẻ le lit des autres; on les a toutes barrées, creusées, asservies. L'empreinte de l'homme est partout; sa présence domine l'étude géographique du pays. La «plantureuse Flandre» est

1 Michelet, IIist. France, V, p. 320. 
une légende, si l'on entend par là un pays naturellement gras et fertile, la terre de l'abondance et de la bonne chére; Ia prospérité du pays est l'œuvre exclusive de sa population. Ailleurs, on n'a eu qu'à tirer parti des ressources qu'offrait la nature; ici, il a fallu les lui arracher, ot ce long effort n'a pas suffi; victime de sa population débordante, la Flandre doit continuer à peiner et à souffrir, pour rendre de plus en plus habitable colte terre peu favorisée. 
IRIS - LILLIAD - Université Lille 1 


\section{TABLE DES MATIERES}

\section{CHAPITRE I \\ LA FLANDRE, RÉGION NATURELLE.}

I. La Flandre daprès l'histoire

................. 1

II. Definition getofrophique de lo Plaine flamande ............... 6

\section{CHAPITKE II \\ LE CLIMAT.}

1. Les élémeents da climeat. Température. Anomalie de la plaine maritime. PJuie.

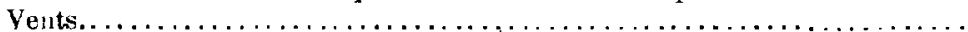

1I. Caractères du climet. Infiuences sur la nature ot sur l'homme. Prétendus

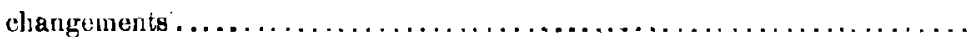

\section{CHAPITRE III \\ LE SOL.}

I. Hisloire géologique. La dèpression flamande. Primaire et crétacé. Landénien. Yprésien-Panisolien et Parisien. Oligrocène, Miocène, Pliocène. lirosion

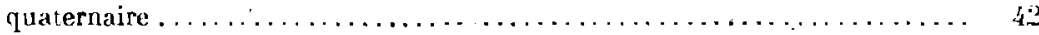

II. Le sol actuel. Imperméabilité : les ilappes aquitëres. Le sol quaternaire... . 54

\section{CHAPITLE IV \\ RELIEF. - FORMES DU TERRAIN.}

I. Aspect et origines du relief. L'ancien plan inclinẻ. Les collines. Hypothèse des Cuestas. Rôle des collines........................... G

II. Les formes du terrain. Les sables. Les argiles................. 72

\section{CHAPITRE V}

\section{LES COURS D'EAU.}

I. Hydrographie. Hypothèses sur l'origine des cours d'eau. Cours d'eau conséquents et subsecruents. Les rivières au Nord de Gand.................

If. Hydrologie. Éléments du régime. Crues régulières et inondations. Travaux de régularisation. Rivières à marẻe $\ldots \ldots \ldots \ldots \ldots \ldots \ldots \ldots \ldots \ldots$ 


\section{CIIAPITRE VI}

\section{DIVISIONS DE LA FLANDRE: LES VARIÉTÉS RÉGIONALES.}

Pages

Les noms de pays. Distinction essentielle : Plaine maritime et Intérieur.... 117

\section{GHAPITRE VII}

RÉGIME dE LA MER FLAMANDE.

La mer flamande. Régime des marées : le gain de flot. Formation des bancs.. 122

\section{CHAPITRE VIII}

\section{FORMATION DE LA PLAINE MARITIME.}

(I. La Plaine avant l'inondation du Vo siècle. Hypothèsos sur l'origine de la Plaine. Structure du sol. Date de l'inondation. Nature de l'invasion marine. 135

II. Assèchement de la Plaine : $V^{t}-X I I^{0}$ siècles. Les premières localités : VII-X ${ }^{\mathrm{e}}$ siècles. Estuaires, digues et dunes. Disparition des estuaires........... 151

III. Vicissitudes de la Fllandre zélandaise. Prospèrité des endiguements aux $\mathrm{XIII}^{\circ}$ et XIV' siècles. Inondations et réendiguements : XIVa-XIX' siècles ; rôle des évènements historiques............................. 170

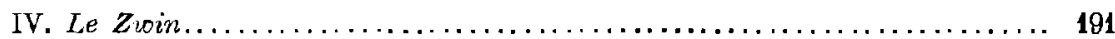

\section{CHAPITRE IX}

\section{LA COTE. - LES DUNES.}

I. Aspect et mouvements de la côte. Recul de la mer à l'Ouest. Recul de la terre à l'Est. Causes des mouvements de la cote.................. 2011

II. Les Dunes : caractères physiques. Largeur des durles. Formes. Mouvements

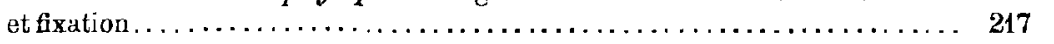

III. La vie dans les Dunes. L'agriculture. L'homme et l'habitation. ........... 225

\section{GHAPITRE X}

\section{LA COTE (suite), - LES PORTS.}

I. Origine des ports. Ports naturels : leurs transformations. Ports artificiels.. 234

II. Caractères des ports. Les ports de l'Ouest mieux abrités. Les ports de l'Kist moins encombrés..................................... 242

III. Les installations maritimes. Ports de voyageurs: Culaie, Ostende. Port de marchandises : Dunkerque. Port d'escale : Zeebrugge.............. 249

IV. Les villes; les plegges. Aspect et évolution des villes. Les plages........... 256 


\section{CHAPITRE XI}

\section{L'EAu dans la plaine. POLDERS et wateringues.}

I. Lutte contre la mer. . . . Pages

II. Tutte contre les eaux intérieures. Objet des Wateringues. Leur organisation. 270

III. L'ouvre des Wateringues. Les rivières: Aa, Yser. Canaux d'assèchement.. 276

IV. Résultats de l'assechement. Calaisis. Marais de St-Omer. Moëres. Terres basses de l'Est. Progrès accomplis et à accomplir................

\section{GHAPITRE XII}

\section{LA VIE DANS LA PLAINE.}

I. I'agriculture. Qualités du sol. Anciennes cultures. In betterave. Pâtures et bétail. Procédés et exploitations......................... 294

II. Lhabitat rural. La grande ferme. Les agglomẻrations .............. 307

III. Les villes. Marchés agricoles de la Plairle et de la lisière. Bruges. Labrence

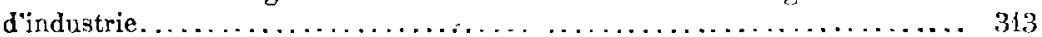

IV. La population..................................... 319

V. La Flandre zélandaise. Etat actuel de Ia lutte contre la mer. Agriculture, habitat, population. Isolement économique.................. 322

\section{CHAPITRE XIII}

\section{FLANDRE INTÉRIEURE, - L'AGRICULTURE FLAMANDE.}

I. Le pays aux arbres. Les forêts. Zone des bois et des bruyéres. Les arbres. 333

II. Caracteres généraux de l'agriculture. Défauts du sol. Les exploitations. Les procédés..........................................

III. Variétés régionales. Le pays du sable. Le pays de Waes. Le pays d'Alost. Le pays de Courtrai. Houtland de l'Ouest. Le pays de Lille. La plaine de

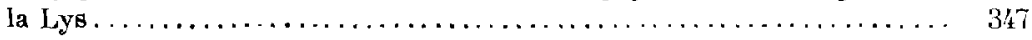

IV. L'évolution acluelle; les spéculations animales ............... 364

\section{CHAPITRE XIV \\ FLANDRE INTÉRIEURE. - L'INDUSTRIE.}

I. Nécessité de l'industrie : son ancienneté. Industrie drapière. Industrie de

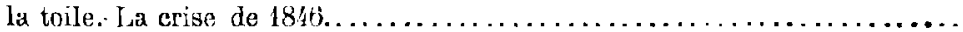

II. Persistance d'anciennes formes : industrie à domicile. Tissage à domicile. Autres industries à domicile : la dentelle. . . . . . . . . . . . . . . . ... 378

III. La grande industrie. Caractères généraux. Région gantoise. Groupe de

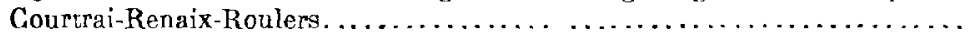

IV. Le groupe de Lille. La main-d'cuvre étrangère. La protection douanière.

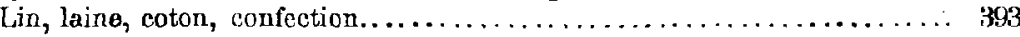




\section{CHAPITRE XY \\ FLANDRE INTÉRIEURE. - LE MILIEU hUMAIN.}

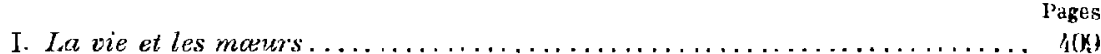

II, L'habitalion rurale. L'Hofstede. La Cense. Les matériaux............. 114

III. Jispersion des habitations. Dans l'Ouest: les maisons isolées. Daus l'ist: les maisons groupées en rues........................... 118

IV. Les villes. Ies villes avant Is XIX siòcle. Les villes an XIXo siècle: influence do l'industrie. Vieilles villes et villes neuves. Le groupe do Lille. 427

\section{CHAI'ITRE XVI}

\section{LES VOIES DE COMMUNICATION. -- LE COMMERCE.}

I. Communications par terre: les routes. Voies romaines. Mauvais état des

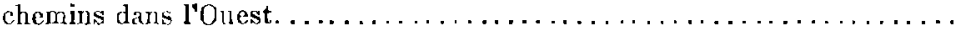

If. La voie d'ear. Le réseau navigablo avant le XVI siècle. Transformations des XVIa ot XVIIe siècles. Etablissement du rẻseau français. Les voies navigables au XIX siècle...................................

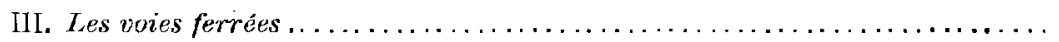

IV. Le commerce. Trafic intérieur. Trafic extérieur: échanges avec l'Artois et l'Angleterre. Mouvement commercial des ports. Le transit........... \&6it

\section{CHAPITRE XVII}

\section{LE PROBLĖME DE LA SURPOPULATION.}

I. Origines de la population flawande. Les anciennes populations. Invasions germaniques. La frontière linguistique.........................

II. La Surpopulation. La surpopulation précoce. Mouvements de population au $\mathrm{XIX}^{\circ}$ siècle. Causes des transformations. Densité actuelle de la population ;

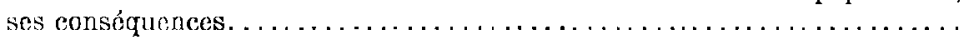

III. L'Émigrotion. Nécessité de l'émigration. Déplacements quotidiens et hebdomadaires. Migrations saisonnières. L'ómigration défnitive .............

Conelusion 


\section{TABLE DES FIGURES.}

FIr. 1. Influence de l'éloignement de la mer sur les moyennes saisonnières de température..

Tempatures moyennes à Dunkérque et à Selzaete............... 10

3. La moisson du froment en Flandre (Carte) .................... 20)

4. Courbes annuelles de quelques stations pluvionétriques........... 2t)

5. Altitude de la surface du I'rimaire sous la Flandre............... 44

6. Altitude de la surface du Grétacé sous la Flandre............... 4.5

7. Altitude de la surface du Landénien sous la Flandre............. 47

8. Coupe à travers la Flandre, de l'Artois au Brakman............ 54

9. Carte géologique de la Flardre à 1 : $1.500 .000 \ldots \ldots \ldots \ldots \ldots \ldots \ldots \ldots$.4

10. Type de vallée du pays d'Alost aux flanes dissymétriques..........

11. I'rufil de la vallée de l'Escaut a Gavere..................... 63

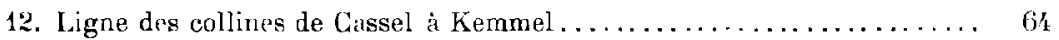

13. Hauteurs du Ferrain............................. 65

14. Rebord du pays de Waes à Thielrode..................... o

15. Profil des collines de Renaix. . . . . . . . . . . . . . . . . . . . . 6 ()

16. Allure théorique des collines de Flandre...................... (39)

17. Profil et coupe des hauteurs d'Anseghem.................... 74

18. Profil Nori-Sud et coupe du mont de l'Hotonkl. . . . . . . . . . . . . 75 ,

19). Glissement d'argile paniselienne........................ 76

20. Glissement de février 1904 an Waienherg.................. 77

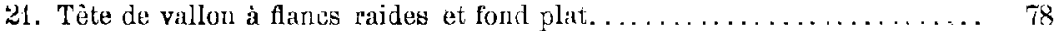

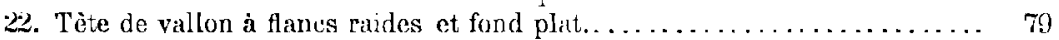

23. Tète de vallon en entonnoir........................... 7 9

2'. Direction des cours d'ean flamands....................... 88

25. Exemple de chevelu : le hassin de la Dendre................. פ6

20. L'Escaut de Melsen à Zwynaerde (régularisation)............... 110

27 . Carte de la mer flumande.......................... 128

28. Profil dı fond de la mer flamande entre North Foreland et Dunkerque... 12.

¿3). Découvertes d'objets romains et pré-romains dans la Plaine (carte) . . . . 136

30. Coupe théorique des terrains propres a la Plaine maritime. . . . . . . 1/42

31. Altitudes dans le Calaisis (carte) .......................... 118

32. Essai de reconstitution de la Plaine maritime à la fin du X siècle...... . 153)

33. Répartition des noms de paroisse en Kerke, Fylise, Capelle......... 162

34. Reconstitution de l'estuaire de l'Yser au début du XII siècle......... 168

3i). Essai de reconstitution de la Flandre zélandaise au début du XIlle siècle. 172

36. Partie occidentale de la Flandre zélandaise au XV siécle.......... 181

37. La Flandre zélandaise vers $1570 \ldots \ldots \ldots \ldots \ldots \ldots \ldots \ldots \ldots \ldots \ldots \ldots \ldots$

38. La Flindre zélandaise à $I_{1}$ fin du XVII siècle............... 189)

39. Essai de reconstitution du $Z$ win au début du XII [e siècle. . . . . . . . . . . 192

40. Essai de reconstitution du $Z$ win au milieu du XIVo siecle.......... 195 


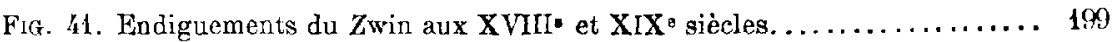

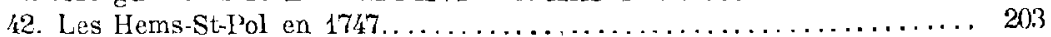

13. Gains de la terre sur la mer à louest de Dunkerque............ 205

44. Allure theorique des chaînes de dunes.................... 220

45. Port de Calais au XVI siècle........................ 236

46. Port d'Ostende an XVIII siècle........................ 241

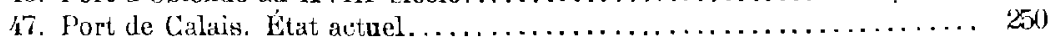

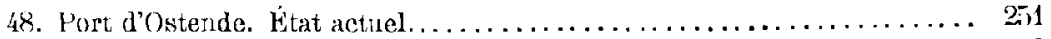

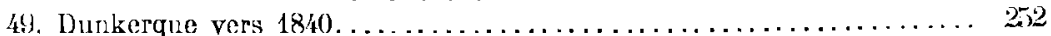

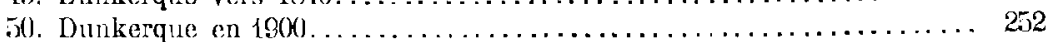

51. Port de Dunkerque. Projets d'agrandissement ................ 253

52 . Une ville balnéaire : Middelkerke....................... 261

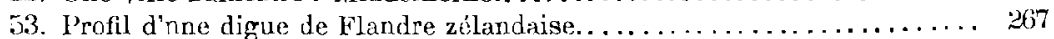

54. Le réseau d'évacuation du Calaisis........................ 281

55. L'habitation dans la Plaine maritime (carte à $1: 80.000) \ldots \ldots \ldots \ldots \ldots \ldots 311$

F(j. Type de carte de la Flandre zélandaise.................. 3\%

57. Répartition des cultures dérobées en Flandre belge............. $3: 18$

58. Répartition de la culture du seigle en Flandre belge............. 349

59. Repartition de la culture du froment en Flandre belge............ $5 \times 33$

60. Répartition des bêtes bovines en Flandre belge................. 368

61. Répartition des ouvriers a domicile en Flandre belge.. . . . . . . . . . 382

62. Dispersion des habitations dans l'Ouest de la Flandre ........... 421

63. Maisons groupées en rues dans l'Est de la Flandre............... 424

64. Un villagre de l'Est: Caprycke.......................

6 .j. Un village de l'Est: Doorezcele ...................... 426

66. Deynze, ville formée d'une chaussée à travers une vallée marécigeuse. . 4333

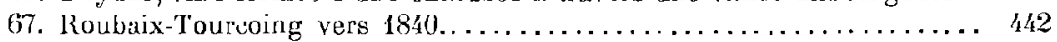

68. Roubaix-Tourcoing vers $1900 \ldots \ldots \ldots \ldots \ldots \ldots \ldots \ldots \ldots \ldots \ldots \ldots \ldots \ldots$

(j): Les voies navigables de la plaine flamande................ 458

70. Le réseau ferré de la plaine flamande................... $\quad$ ( $(x)$

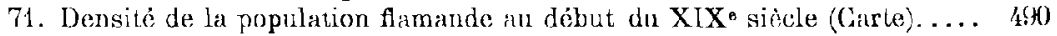

72. Dimintition de population au $\mathrm{XJX}{ }^{0}$ siècle (Carte)............... $4(13$

73. Augentation de population au XIX" siècle (Carte)............. 495)

74. Diminution de population dans la $2^{2}$ moitie du XIX siècle (Carte).... 497

75. Augmentation de population dans la 2 moitié du XIXe siecle (Carte)... 498

76. Wensité de la population flamande en $1900-1901$ (Garte) ........... 50)

\section{TABLE DES CARTES HORS TEXTE}

\section{A LA FIN DU VOLUME.}

1. Répartition des pluies en Flandre.

II. Carte de lia flamdre et des contrées voisines à l'échelle de $1: \bar{b}(0),(0) \ldots \ldots \ldots$ 


\section{TABLE DES PHOTOGRAPHIES.}

1. LArtois vu du bas pays (Landrethun-lès-Ardres)

2. Le plateau crayeux du Mélantois, vu de Lille $\ldots \ldots \ldots \ldots \ldots \ldots \ldots \ldots \ldots \ldots\}$

3. Rebord de la plicine de la Lys, derrière l'loegsteert................. (j1

4. Vue dians la région des collines : flane Sud du mont Vidaigne..............

5. Une colline fumande : le Mont-Aigu, près Locre..................

6. Une colline flamaude : le Muziek-Berg, près Renaix.................

7. Rebord Est de la vallée du Molenbeek, à Moortzeele................. ) ,

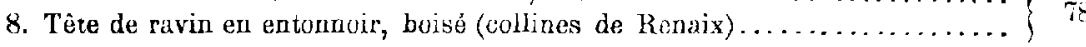

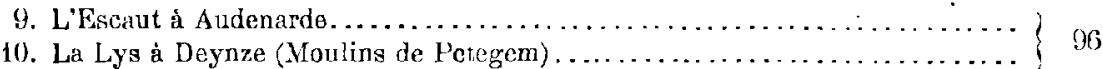

11. La digue dı Comte Jean, près Mardick:...................... 206

12. Défense d'une dune attaquée : fascinages (Breskens) $\ldots \ldots \ldots \ldots \ldots \ldots \ldots \ldots \ldots, 206$

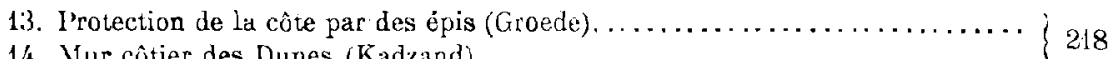

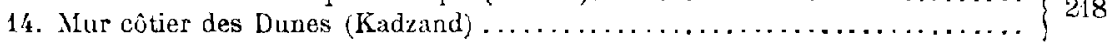

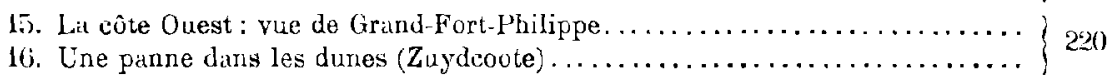

17. Contraste entre l'argile (pays découvert) et le sable (boisé) à loon.........
18. Un village du sable (Loon)

19. Jigne de maisons au long du mur intérieur des dunes (Bray-Uunes)...... 230

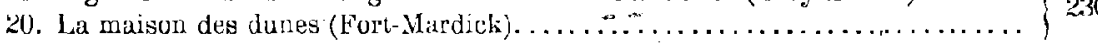

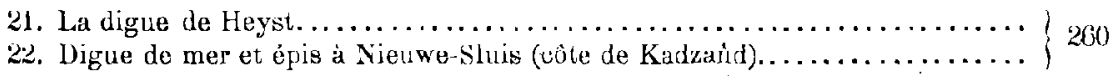

23. Lne écluse d'évacuation de Wateringue (Suatie-geul) a Groede ........ 276

24 . Les terres basses de l'Yser : pâtures d'Eessen...................

25. Un elair (ancienne tourhière) dans les Marais d'Ardres............. 284

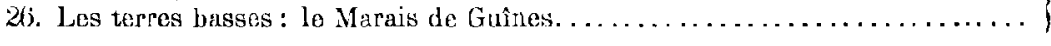

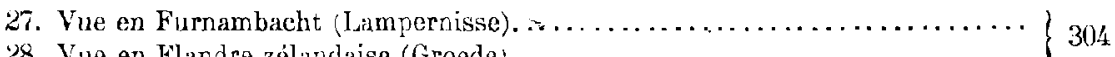

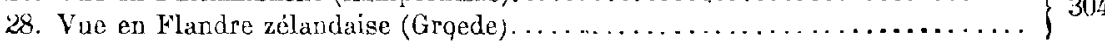

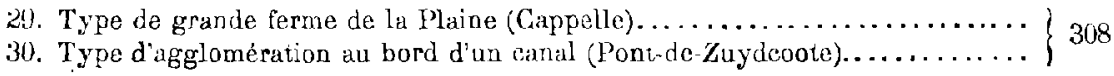

31. Type de village de la l'laine (Oostkerke, prés Bruges) $\ldots \ldots \ldots \ldots \ldots \ldots \ldots\} 314$

32. Type de village accroché à une digue (Wostdorpe) .................

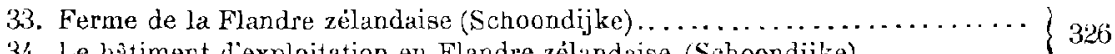

34. Le bâtiment d'exploitation en Flandre zélandaise (Schoondijke)...........

35. Vue en pays de Waes (Nieuwkerken) $\ldots \ldots \ldots \ldots \ldots \ldots \ldots \ldots \ldots \ldots \ldots \ldots \ldots \ldots \ldots \ldots \ldots \ldots \ldots \ldots$
36. Vue dans la Plaine de la Lys (Vieille-Chapelle) $\ldots \ldots \ldots \ldots \ldots \ldots$ 


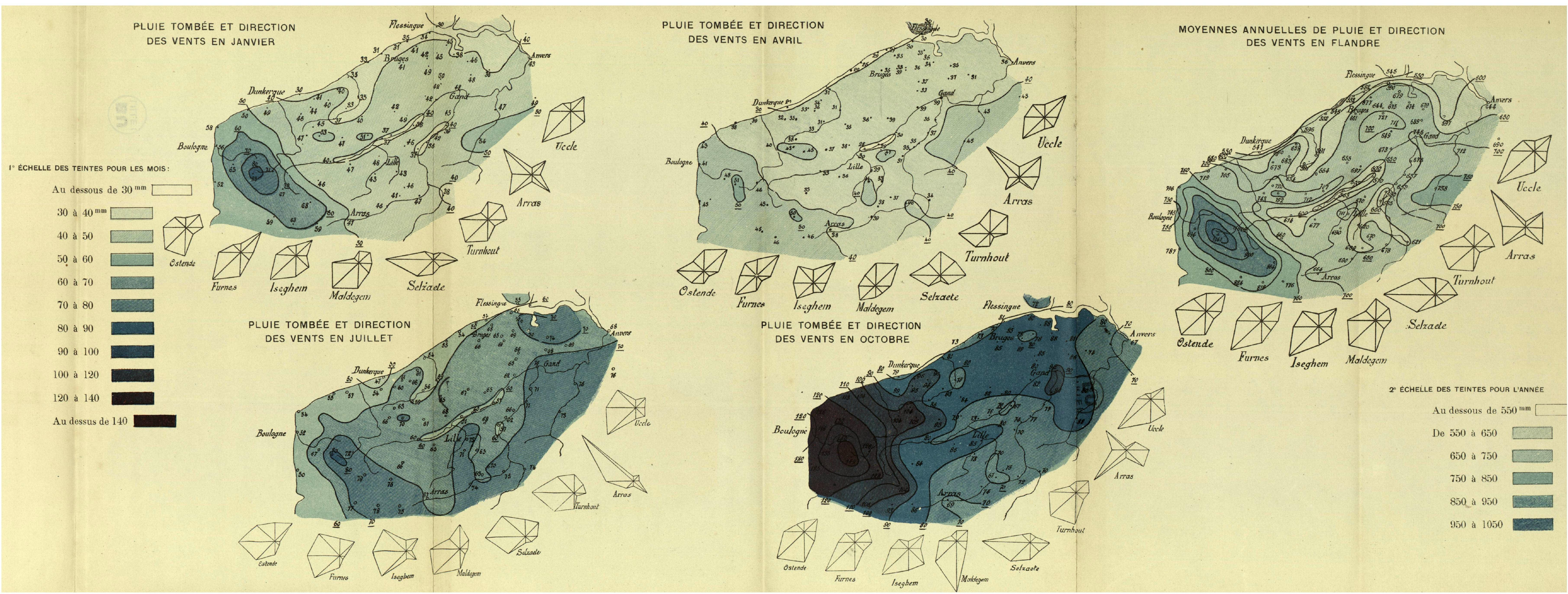


IRIS - LILLIAD - Université Lille 1 


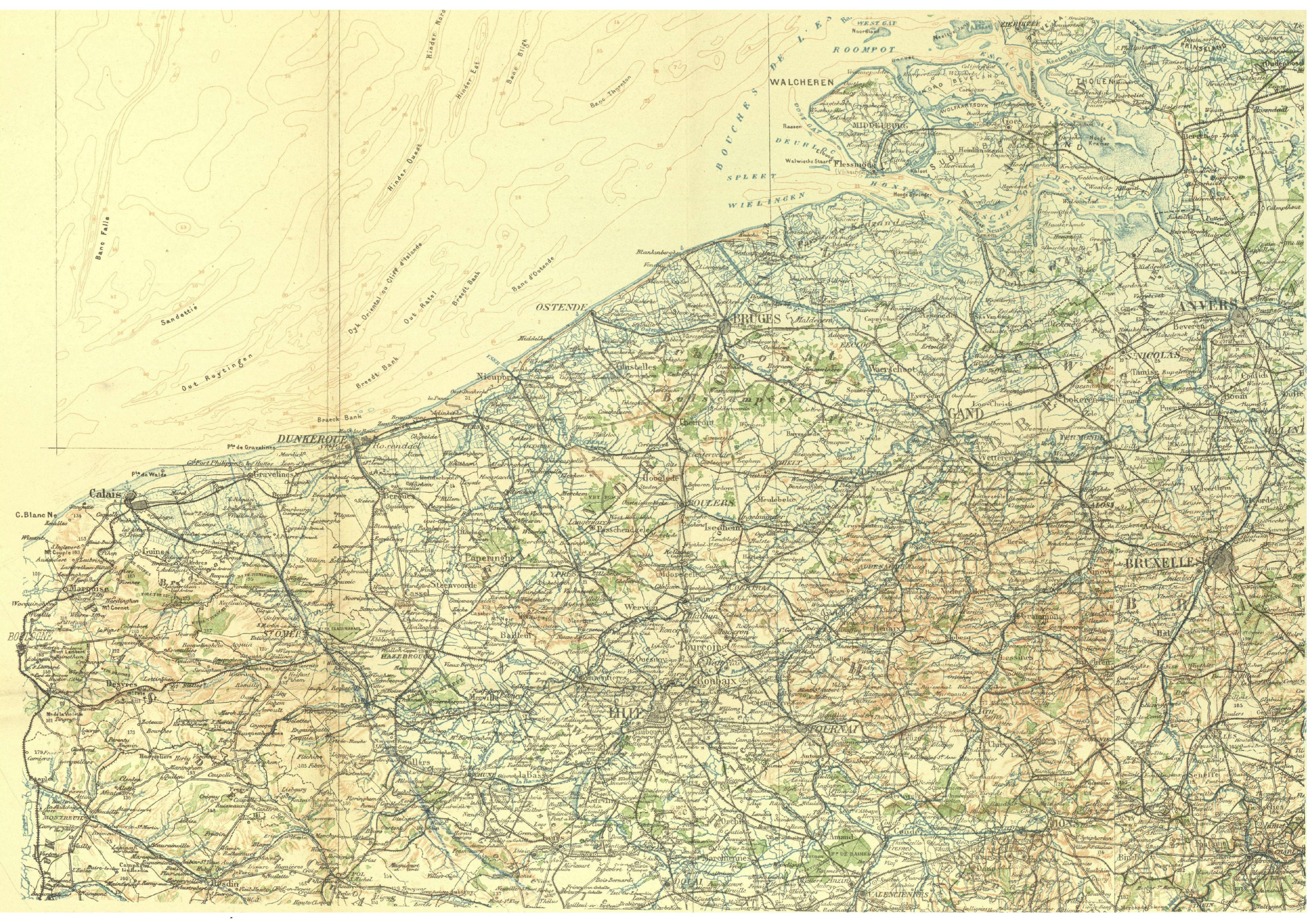

\section{CARTE GÉNÉRALE DE LA FLANDRE}

aे $1: 500.000$

Extrait de la carte de France à 1: 500.000, publiée par le Service Géographique de l'Armée 


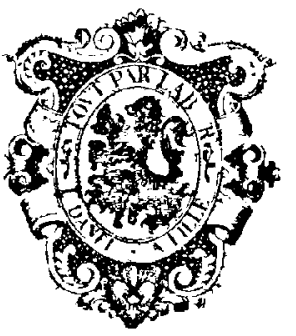

IRIS - LILLIAD - Université Lille 1 